\title{
LA RECONFIGURACIÓN CAPITALISTA DE LOS ESPACIOS URBANOS: TRANSFORMACIONES Y DESIGUALDADES
}

\author{
Juan Manuel Parreño Castellano \\ Claudio Jesús Moreno Medina
}

(Coordinadores) 



\section{LA RECONFIGURACIÓN CAPITALISTA DE LOS ESPACIOS URBANOS: \\ TRANSFORMACIONES Y DESIGUALDADES}


Los textos han sido sometidos a revisión ciega realizada por: Carme Bellet Sanfeliu (Universitat de Lleida), Josep Vicent Boira Maiques (Universidad de Valencia), Dolores Brandis García (Universidad Complutense de Madrid), Basilio Calderón Calderón (Universidad de Valladolid), Elia Canosa Zamora (Universidad Autónoma de Madrid), María del Carmen Cañizares Ruiz (Universidad de Castilla-La Mancha), Francisco Cebrián Abellán (Universidad de Castilla-La Mancha), Gerardo Delgado Aguiar (Universidad de Las Palmas de Gran Canaria), Víctor Fernández Salinas (Universidad de Sevilla), Jesús Manuel González Pérez (Universitat de les Illes Balears), José Ángel Hernández Luis (Universidad de Las Palmas de Gran Canaria), Maria Lucinda Fonseca (Universidade de Lisboa, Portugal), Claudio Moreno Medina (Universidad de Las Palmas de Gran Canaria), Antonio J. Palacios García (Universidad Autónoma de Madrid), Juan Manuel Parreño Castellano (Universidad de Las Palmas de Gran Canaria), Thomas Perrin (Université de Lille, Francia), Christy Petropoulou (University of the Aegean, Grecia), María José Piñeira Mantinán (Universidad de Santiago de Compostela), Jose Alberto Rio Fernandes (Universidade de Porto, Portugal) y Onofre Rullan Salamanca (Universitat de les Illes Balears).
El XV Coloquio de Geografía Urbana (19 y 20 de octubre, 2020) fue organizado por el Grupo de Investigación “Sociedades y Espacios Atlánticos" (SEA) del Departamento de Geografía de la Universidad de Las Palmas de Gran Canaria, bajo los auspicios del Grupo de Geografía Urbana de la Asociación Española de Geografía y los proyectos de investigación "Vivienda y movilidad internacional en las ciudades de Canarias. La aparición de nuevas formas de desigualdad urbana" (RTI2018-093296-B-C21) y “Vivienda y movilidad internacional en las ciudades de las Islas Baleares. La aparición de nuevas formas de desigualdad urbana" (RTI2018-093296-B-C22), financiados por el FEDER, la Agencia Estatal de Investigación y el Ministerio de Ciencia, Innovación y Universidades de España. 


\title{
LA RECONFIGURACIÓN CAPITALISTA DE LOS ESPACIOS URBANOS: TRANSFORMACIONES Y DESIGUALDADES
}

\author{
Juan Manuel Parreño Castellano \\ Claudio Jesús Moreno Medina
}

(Coordinadores)

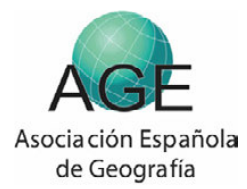




\section{COLOQUIO DE GEOGRAFÍA URBANA (15․ 2020. Las Palmas de Gran Canaria)}

La reconfiguración capitalista de los espacios urbanos : transformaciones y desigualdades / Juan Manuel Parreño Castellano, Claudio Jesús Moreno Medina (Coordinadores). -- Las Palmas de Gran Canaria : Universidad de Las Palmas de Gran Canaria, Servicio de Publicaciones y Difusión Científica ; [Madrid] : Asociación Española de Geografía, 2021

723 p. ; 1 archivo .pdf - (Congresos y homenajes. Congresos)

En preliminares: En este libro de actas se recogen 43 de las aportaciones presentadas en el Coloquio de Geografía Urbana, organizado por el Grupo de Geografía Urbana de la Asociación Española de Geografía (AGE) y el Departamento de Geografía de la Universidad de Las Palmas de Gran Canaria.

Obra patrocinada por la sociedad Municipal de Gestión Urbanística de Las Palmas de Gran Canaria, S.A. (GEURSA).

ISBN 978-84-9042-400-1

1.Geografía urbana - Congresos y conferencias 2. Urbanismo - Congresos y conferencias 3. Capitalismo - Congresos y conferencias I. Parreño Castellano, Juan Manuel, coord. II. Moreno Medina, Claudio Jesús, coord. III. Universidad de Las Palmas de Gran Canaria, ed. IV. Asociación Española de Geografía, ed. V. Título VI. Serie

911.375(063)

\section{Colección Congresos y \\ Homenajes Serie Congresos}

Este libro ha sido posible gracias al patrocinio de la sociedad municipal de Gestión Urbanística de Las Palmas de Gran Canaria, S.A. (GEURSA) y la colaboración mostrada por el Ayuntamiento de Las Palmas de Gran Canaria.

(c) de los textos: sus autores

(c) de la edición:

Universidad de Las Palmas de Gran Canaria

Servicio de Publicaciones y Difusión Científica

serpubli@ulpgc.es · http://spdc.ulpgc.es

Asociación Española de Geografía

Primera edición [versión electrónica PDF]. Las Palmas de Gran Canaria, 2021

Maquetación y diseño:

Servicio de Publicaciones y Difusión Científica de la ULPGC

ISBN (ULPGC) [edición electrónica]: 978-84-9042-400-1

ISBN (AGE) [edición electrónica]: 978-84-947787-8-0

ISBN (ULPGC) [edición impresa]: 978-84-9042-399-8

(AGE) ISBN [edición impresa]: 978-84-947787-9-7

Thema: RGCU, RPC, KCSA, GBD

https://doi.org/10.20420/1642.2021.383 


\section{ÍNDICE}

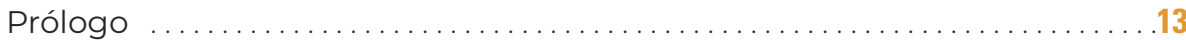

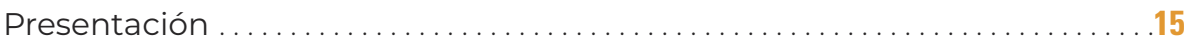

DINÁMICAS Y CAMBIOS DE USO EN EL ESPACIO URBANO ..................17

Turismo de cruceros en Las Palmas de Gran Canaria (España):

reflexiones territoriales

Ainhoa Amaro García y Silvia Battino ........... . . . . . . . . . . . . . . . . . . . 19

Multiplicidad del territorio como concepto de análisis geográfico

de las ciudades: el caso de Las Palmas de Gran Canaria

Jordi Boldú Hernández y Lorena Naranjo Almeida

Procesos de cambio en las ciudades medias y sus áreas urbanas en

la España democrática (1981-2019): evolución de la población

Luis Alfonso Escudero Gómez, José María Martínez Navarro

y Juan Antonio García González

Cambios de uso en los barrios históricos. El ejemplo de Ciudad Jardín

(Las Palmas de Gran Canaria)

Santiago Hernández Torres, Guillermo Morales Matos,

María Yazmina Lozano Mas y Vicente Benito Molina ..

Metropolización y regiones metropolitanas: dinámicas europeas

Thomas Perrin

Análisis de la dispersión urbana en Castilla-La Mancha a través

del proceso de jerarquía analítica (AHP)

Irene Sánchez Ondoño y Francisco Cebrián Abellán

Cidades pequenas: uma análise a partir das cidades de Goiás

e Itaberaí do estado de Goiás, Brasil

Camila De Souza Dantas Mota, Diogo Isao Santos Sakai, Érika Munique

De Oliveira, Rafael Martins Lisboa y Sueli Souza De Oliveira Soares 
O processo de densificação e verticalização e seus impactos no sistema de drenagem de águas pluviais: estudo de caso do Jardim Goiás em Goiânia, Goiás - Brasil

Sueli Souza De Oliveira Soares

CAMBIOS SOCIODEMOGRÁFICOS, DESIGUALDAD Y GENTRIFICACIÓN EN LA CIUDAD ...165

Propuesta metodológica para el estudio de la justicia espacial en relación con los parques urbanos. Un caso aplicado a Tarragona Joan Alberich González, María Yolanda Pérez Albert, Adrià Balart Casas y José Ignacio Muro Morales.

La segregación residencial y condiciones de vida. Un análisis de las desigualdades sociales en Catalunya a partir de cuatro perspectivas espaciales

Joan Checa y Oriol Nel.lo

Barrios turísticos y nuevos procesos de desigualdad socio-urbana en Baleares y Canarias Josefina Domínguez-Mujica, Jesús M. González-Pérez, Juan Parreño-Castellano y Dolores Sánchez-Aguilera . .

Segregación residencial y recursos municipales. El caso de los sistemas urbanos del arco metropolitano de Barcelona Carles Donat Muñoz

Patrones espaciales de la movilidad residencial de los españoles y extranjeros en Zaragoza (2003-2017)

Severino Escolano-Utrilla, Carlos López-Escolano, Ángel Pueyo-Campos y José Antonio Salvador Oliván

¿Hacia la ciudad fragmentada? Nuevas tendencias demográficas metropolitanas en el periodo de poscrisis

Fernando Gil-Alonso, Cristina López-Villanueva, Jordi Bayona-i-Carrasco e Isabel Pujadas-Rúbies

Estallido cartográfico de una crisis de modelo-país: el caso de Santiago de Chile (octubre-noviembre 2019) Víctor Jiménez Barrado

Gentrificación y turistificación en las áreas urbanas centrales de Sevilla y Cádiz Julio José Parralejo Sánchez y Ibán Díaz Parra 
El proceso de transformación de la plaza de mercado de Bello (Colombia), hacia un espacio percibido

Santiago Rojas Tavera y Elizabeth Dahiana Londoño Toro .307

VIVIENDA Y DESPOSESIÓN

Los mismos vecinos, elección de preferencia para una nueva ubicación en la reposición del barrio Las Rehoyas-Arapiles (Las Palmas de Gran Canaria)

Federico E. González-Ramírez .325

¿Integración social y territorial en ciudades fluviales, marinas y lacustres? Efectos espaciales en las viviendas subsidiadas litorales de La Serena, Valdivia y Villarrica, Chile (2000-2018) Rodrigo Hidalgo, Laura Rodríguez, Voltaire Alvarado y Federico Arenas . . . . . 339

Desposesión de vivienda y espacios comerciales en núcleos turísticos. Analizando la reconfiguración de las dinámicas desplazadoras en Los Cristianos/Las Américas (Tenerife)

Dennis Hof .... .353

Financiarización y mercado de alquiler en las ciudades españolas

Ricardo Méndez Gutiérrez del Valle .375

PLANIFICACIÓN Y PROYECTOS URBANOS .393

La planificación urbana en ciudades medias catalanas 1979-2019.

Manresa y Lleida

Carme Bellet Sanfeliu

La transformación de enclaves periféricos del centro ciudad.

La operación Mahou-Calderón, Madrid

Dolores Brandis García

La resignificación del espacio público contemporáneo: experiencias alternativas emergentes (casos de América y Europa)

Juan Manuel Bueno Carvajal

Potencialidades del paradigma de la infraestructura verde para la recuperación de sistemas fluviales periurbanos. El caso del arroyo Porzuna (Sevilla)

Daniel Fazeli Tello y Leandro Del Moral Ituarte 
Modelo Smart City: iniciativas europeas y del estado español para su implementación

Mireia Ferrer Vilanova

Urban planning and railway integration in medium-sized cities:

comparative analysis in Santander and Torrelavega

Francisco García Sánchez y Cecilia Ribalaygua

Diagnóstico, didáctica y atención a la vulnerabilidad en la planificación urbana de los barrios: el caso de Las Palmas de Gran Canaria Santiago Hernández Torres, Carmen Ginés De La Nuez y María Yazmina Lozano Mas

Non-transparent urbanism? Urban planning and stakeholders in the megaproject Santa Cruz Verde 2030 (Canary Islands, Spain) Marcus Hübscher y Johannes Ringel . .

Crisis y regeneración en áreas urbanas: el caso de Linares (Jaén)

Juan Jesús Lara Valle y Luis Miguel Sánchez Escolano. ...

De macrofestivales a megaproyectos urbanos. Dos experiencias en la Comunidad Valenciana (Cullera y Burriana)

Jaime Martínez Ruiz

Los modelos urbanísticos en la vega de La Laguna. San Cristóbal de La Laguna. Tenerife

Miguel Ángel Mejías Vera y Ma Mercedes Arranz Lozano .555

TRANSPORTE Y MOVILIDAD EN LA CIUDAD

Políticas públicas de movilidad autónoma y segura para la población escolar. Análisis de caso en Las Palmas de Gran Canaria Itahisa Chávez Santana y Carmen Ginés De La Nuez

El impacto de las nuevas movilidades eléctricas urbanas en el contexto de los planes de movilidad urbana sostenible de Las Palmas de Gran Canaria José Ángel Hernández Luis 
Diseño y caracterización espacial de escenarios futuros de desarrollo urbano y transporte mediante técnicas participativas en el corredor del Henares (Madrid) Ramón Molinero-Parejo, Amor Ariza-Álvarez, Montserrat Gómez Delgado, Francisco Aguilera-Benavente y Julio A. Soria-Lara

Tendencias recientes de la planificación del transporte y la movilidad en Hispanoamérica: el caso de los TFM de UNIBA Verónica Quiroz López

La posibilidad de rodar en una megaciudad: la Ciudad de México Alejandra Trejo Poo

PATRIMONIO URBANO

Recuperación del patrimonio industrial urbano: los silos en España M. Carmen Cañizares Ruiz

El color del patrimonio urbano edificado. Aproximación a su estudio Isolina Díaz-Ramos

Memoria histórica, territorio y patrimonio. La lectura de la Ley de Memoria Histórica de Andalucía en el municipio de Sevilla Víctor Fernández Salinas y Rocío Silva Pérez

La presencia de los hornos de cal en la configuración de los espacios urbanos de las ciudades de Canarias

Jorge L. Manzano Cabrera y Francisco M. Mireles Betancor

Los museos como elementos sociales integradores en el entramado urbano

Héctor Moreno Mendoza y Agustín Santana Talavera 



\section{PRÓLOGO}

Las ciudades españolas y canarias han experimentado su particular adaptación al escenario que nos han brindado las primeras décadas del siglo XXI. La herencia de etapas anteriores se ha ampliado con los acontecimientos políticos, económicos, geoestratégicos, sociales y medioambientales más contemporáneos. La suma se manifiesta en un sinfín de realidades urbanas que, a partir de sus rasgos territoriales, denotan sus propias fortalezas y debilidades. En esa diversidad, nos preocupa especialmente el crecimiento crónico de la vulnerabilidad y desigualdad, incluidas las de género, como consecuencia de las deficiencias de un paradigma capitalista que, lejos de solventarse, demuestran nuevos efectos o acrecientan los existentes.

Es un compendio en el que sobresale la impronta social en forma de distintas formas de exclusión, de dificultades para la sostenibilidad económica de las familias, de deterioro en la percepción de los entornos cotidianos, de acceso a los más elementales servicios, de degradación de la calidad ambiental del espacio público y, en definitiva, de obstáculos cada vez más arraigados al bienestar de la ciudadanía.

Las administraciones públicas, en especial las municipales por su mayor vínculo con la búsqueda de soluciones directas a través de la planificación, la regeneración y la gestión del espacio urbano, tienen un reto constante en responder a un problema con múltiples caras y en constante evolución.

La oportunidad que nos brinda la Asociación Española de Geografía y la Universidad de Las Palmas de Gran Canaria con este XV Coloquio de Geografía Urbana se ha valorado con mucho interés desde el Área de Urbanismo, Edificación y Sostenibilidad Ambiental del Ayuntamiento de Las Palmas de Gran Canaria.

Estamos ante la inmediatez de un foro con especialistas de varios perfiles científicos y con base en un destacado número de universidades canarias, españolas, europeas y latinoamericanas. Es una excusa perfecta para observar y reflexionar sobre la situación de la ciudad ante estos desequilibrios y, también, sobre las potencialidades y herramientas para el futuro cercano. Aprender de esta experiencia y de sus resultados es casi una obligación ante la responsabilidad que tenemos con nuestras vecinas y vecinos.

Este volumen de reflexiones, debates, resultados de investigación sobre problemas comunes a otras ciudades nos permitirá disponer de una foto fija sobre el estado actual de la investigación especializada en el espacio urbano. 
Nos interesa toda ilustración sobre la vivienda, la exclusión residencial, las distintas formas de segregación, la impronta del turismo urbano, el papel del patrimonio cultural, la calidad del entorno urbano, el nuevo escenario de la movilidad, las metodologías de diagnóstico integrado de los barrios, la adaptación del tejido comercial, el comportamiento de los centros y el de la periferia, etc.

Todos ellos son capítulos fundamentales en la actual planificación y gestión de la ciudad si nos atenemos a la experiencia que desarrollamos en Las Palmas de Gran Canaria desde nuestra función de gobierno político. Sólo podemos estar más que agradecidos por la rica aportación que se expone en este libro y esperar que el espíritu crítico y constructivo siga imponiéndose en pro de cumplir el derecho de la población a una ciudad de calidad, igualitaria, inclusiva y garante de su bienestar.

Javier E. Doreste Zamora

Concejal de Gobierno del Área de Urbanismo,

Edificación y Sostenibilidad Ambiental del Ayuntamiento de Las Palmas de Gran Canaria 


\section{PRESENTACIÓN}

Se hace complejo definir los factores que caracterizan la evolución de las ciudades en nuestros días. Tras dos décadas de intenso crecimiento inmobiliario y urbano, la parálisis constructiva y las modificaciones devenidas de la crisis financiera están dando paso a nuevos procesos de reconfiguración urbana, que obligan a fijar nuestra mirada en los cambios inherentes a la reorganización del capitalismo. Estos nuevos procesos se dan en un contexto caracterizado, entre otros factores, por el incremento de las desigualdades y los conflictos sociales, el progresivo envejecimiento de la población, el impulso a las perspectivas de género y a los feminismos reivindicativos, el aumento de la movilidad y las migraciones, la creciente presencia de los problemas ambientales y la despoblación de muchas entidades urbanas pequeñas y medias.

Un panorama tan complejo y dispar como el que se registra en la actualidad requiere de un análisis sosegado ahondando en la reflexión sobre el modelo de ciudad que se está desarrollando y en el estudio de las respuestas que emergen desde la ciudadanía y los poderes públicos. En este contexto, el XV Coloquio de Geografía Urbana, organizado por el Grupo de Geografía Urbana de la Asociación Española de Geografía (AGE) y el Departamento de Geografía de la Universidad de Las Palmas de Gran Canaria, ha pretendido ser una herramienta para entender la situación actual de la ciudad desde un enfoque en el que también caben las inquietudes y perspectivas de otras disciplinas afines.

En este libro de Actas se recogen 43 de las aportaciones presentadas en el Coloquio, procedentes de universidades y centros de investigación de casi todas las comunidades autónomas, representando las preocupaciones investigadoras y planificadoras de la Geografía Urbana española. Además, el Coloquio ha sido una oportunidad de encuentro con geógrafos urbanos de otros países. Baste decir que se han presentado comunicaciones en varios idiomas procedentes de Alemania, Brasil, Chile, Colombia, Francia y México. Todo ello da cumplida muestra del papel que la Asociación Española de Geografía (AGE) desempeña en la dinamización del debate sobre la ciudad. Esta, en continua transformación, requiere de una mirada atenta desde la Geografía.

No podemos concluir esta presentación sin dos referencias principales. Por un lado, la pandemia sanitaria motivada por la COVID-19 es la mejor prueba 
de la necesidad de volver a reinterpretar las tendencias urbanas, algo que se puede convertir en un nuevo reto para la Geografía urbana. Esta pandemia está transformando la manera de enfrentarse al estudio de la ciudad, y está recuperando antiguos debates, algunos insuficientemente cerrados, sobre lo urbano y lo rural, sobre la ciudad compacta o dispersa, sobre las altas o bajas densidades, entre muchos otros. La Geografía urbana seguirá ocupando en los próximos años espacios de debate fundamentales, debido a su demostrada capacidad en el uso de metodologías que permiten vincular los procesos urbanos a diferentes escalas con variables sociales, económicas o de vivienda.

Por otro lado, después de catorce coloquios de Geografía Urbana, la pandemia ha condicionado la dinámica del XV Coloquio y ha obligado a replantear la fórmula de realización del mismo. Se ha desestimado la presencialidad y, en consecuencia, no se han realizado las importantes salidas de campo, con las que tanto hemos aprendido en las conferencias anteriores. No obstante, el comité organizador ha intentado adaptarse a la nueva situación para lograr realizar un coloquio de calidad y de dimensión global, no sólo abierto a la comunidad académica y científica, sino también a estudiantes y colectivos ciudadanos.

Por último, no queremos concluir sin mostrar nuestro afecto, a modo de pequeño pero sincero homenaje, a dos excelentes geógrafos urbanos que nos han dejado en los primeros meses de 2020. Dos personas de gran calidad humana y de reconocido prestigio que han realizado grandes aportaciones a la Geografía Urbana en general y a nuestro grupo en particular. Con todo nuestro cariño y reconocimiento, una especial dedicatoria a los profesores Miguel Ángel Troitiño Vinuesa y Luz Marina García Herrera. 



\title{
TURISMO DE CRUCEROS EN LAS PALMAS DE GRAN CANARIA (ESPAÑA): REFLEXIONES TERRITORIALES
}

\section{CRUISE TOURISM IN LAS PALMAS DE GRAN CANARIA (SPAIN): TERRITORIAL CONSIDERATIONS}

\author{
Ainhoa Amaro García \\ Universidad de Las Palmas de Gran Canaria \\ SiLVIA Battino \\ Universidad de Sassari
}

\begin{abstract}
Resumen
El turismo es una industria global, en 20181.400 millones de personas se desplazaron con fines recreativos por todo el mundo. Como consecuencia, las ciudades han detectado en el sector turístico un motor de crecimiento y desarrollo económico. Tal es el caso de Las Palmas de Gran Canaria, una ciudad que, de manera intencionada, bien a través de intervenciones puntuales o de cambios normativos, ha terminado transformando muchos aspectos de la configuración territorial y de la vida de los residentes a raíz de la llegada de cruceros. Ante este escenario, se pone de manifiesto la importancia de estudiar la situación particular de la actividad turística de la capital como puerto base de cruceros y como ésta, al convivir con el turismo interno, suele presentar dos caras: una positiva, relacionada con los beneficios económicos; otra negativa, generada por el impacto espacial y funcional que supone la llegada puntual de un gran número de viajeros. La metodología propuesta se ha basado en un análisis cuantitativo y cualitativo, a través de la evolución cartográfica de Las Palmas de Gran Canaria.
\end{abstract}

Palabras clave: impactos, turismo de cruceros, Las Palmas de Gran Canaria.

\section{Abstract}

Tourism is a global industry, in $20181.400 \mathrm{M}$ people traveled for recreational purposes. As a consequence, cities have detected in the tourism sector an engine of economic growth and development. Such is the case of Las Palmas de Gran Canaria, a city that intentionally, either through specific interventions or regulatory changes, has ended up transforming many aspects of the territorial configuration and life of the residents following due to the arrival of cruise ships. Faced with this scenario, it is highlighted the importance of studying the particular situation of the tourist activity of the capital as a base port of cruises and how this, in confluence with internal tourism, usually presents two faces: a positive one, related to the economic benefits; another 
negative, generated by the social, spatial and functional impacts of the timely arrival of a large number of travelers. The proposed methodology has been based on a quantitative and qualitative analysis, through the cartographic evolution of the Las Palmas de Gran Canaria.

Keywords: impacts, cruise tourism, Las Palmas de Gran Canaria.

\section{INTRODUCCIÓN ${ }^{1}$}

El turismo de cruceros, tal y como se conoce actualmente, surgió en la década de 1970, pero ha sido durante los últimos veinte años cuando ha registrado un crecimiento significativo tanto en términos de número de pasajeros y buques utilizados en travesías, como en destinos afectados por este nuevo segmento turístico. Según las estadísticas, en 2019 se utilizaron 404 buques para transportar 27,8 millones de pasajeros, con un impacto económico de 41,6 millones de dólares (38,7 millones de euros), si se tienen en cuenta ingresos directos, indirectos e inducidos. Actualmente, las zonas más afectadas por el turismo de cruceros son el Caribe (38,7\%), el Mediterráneo (14,8\%) y Asia-Pacífico (12,3\%) (CIN, 2020).

Desde principio del siglo XXI, el producto de cruceros se ha diversificado para satisfacer las nuevas demandas: pasajeros más jóvenes, con diversidad de intereses turísticos y de perfiles socioeconómicos dispares, con la implementación de las nuevas tecnologías y la especialización, diversificación y mejora de los servicios en tierra que ello conlleva. De esta forma, el turismo de cruceros ofrece una experiencia completa durante las travesías al ofrecer a bordo todo tipo de facilidades tales como restaurantes, piscinas, gimnasios, teatros, centros estéticos y áreas recreativas, y en tierra, con las actividades complementarias of recidas en las ciudades portuarias donde recalan (Dowling, 2005; Chin, 2008; Pallis, 2015).

Por todo esto, los cruceros son considerados hoteles flotantes, ya que son el resultado de la suma de múltiples agentes, elementos y actores implicados. De ahí que su éxito y consolidación se basen en las relaciones e impactos generados en destino por el propio sistema turístico y por los que allí residen. Ante este hecho, se dan dos situaciones: una caracterizada por las medidas utilizadas por los destinos portuarios para atraer la actividad, entre las que

1 El artículo se divide en 5 secciones: (1) Introducción, (2) Estado del arte y metodología, (3) Las Palmas de Gran Canaria y el Turismo de Cruceros, (4), Transformaciones e impactos asociados, (5) Conclusiones. La redacción y elaboración de los capítulos 1, 2 y 3 corresponden a la doctora Silvia Battino, y los 4 y 5 a la doctora Ainhoa Amaro García. Cabe destacar que las dos autoras han colaborado de forma bidireccional en el fondo y forma de la investigación aquí presente, definiendo de forma unánime las líneas de trabajo, estructura y conclusiones del mismo. 
destacan: (a) ampliar la capacidad de amarre de sus puertos, como Santa Cruz de Tenerife, Canarias, España, (b) dragar sus fondos para recibir cruceros de mayor calado, como Olbia, Cerdeña, Italia y (c) ofrecer bajos impuestos en las tasas de atraque, como en Buenos Aires, Argentina; otra caracterizada por las desventajas y conflictos que provoca este tipo de turismo en las ciudades portuarias: (a) masificación de las áreas turísticas, donde podemos encontrar el caso de Barcelona, expuesto en el documental Bye, Bye, Barcelona², (b) el síndrome de Venecia ${ }^{3}$, en el que la población local se ha visto obligada a emigrar de sus hogares por la fuerte presión turística e inmobiliaria ${ }^{4}$ y (c) movilizaciones antiturismo y turismofobia, sobre todo en ciudades con alta ocupación turística en el que conviven varios segmentos turísticos, destacando los casos de Barcelona, Dubrovnik, Mallorca y Venecia.

Partiendo de estas consideraciones generales, en este artículo se analizan diversas vertientes de la relación turismo de cruceros, patrimonio y planificación, estudiando un caso particular: Las Palmas de Gran Canaria. Para la capital, de manera intencionada, bien a través de intervenciones puntuales o de cambios de normativas, la llegada de cruceros ha terminado transformando muchos aspectos de la configuración y la vida de los residentes capitalinos, que han sido testigos de cómo, en apenas una década, confluyen en un mismo espacio turistas convencionales, cruceristas y población flotante. En base a estas consideraciones, el objetivo principal de este artículo es analizar las transformaciones urbanas y los cambios recientes de usos del suelo que ha experimentado la capital durante los últimos diez años debido, principalmente, al manifiesto y creciente fenómeno del turismo de cruceros. Para ello, el artículo se ha dividido en cuatro secciones: (1) Estado del arte y metodología, en el que se explica la revisión bibliográfica así como la metodología utilizada para el trabajo de campo; (2) Las Palmas de Gran Canaria y el turismo de cruceros, en el que se expone la evolución de la actividad turística en la capital desde el punto de vista de la recepción de visitantes; (3) Transformaciones e impactos asociados, en el que se analizan los cambios de uso del suelo y sus respectivas transformaciones urbanas; y (4) conclusiones, las obtenidas de las secciones anteriores.

2 Documental realizado en 2014 por Eduardo Chibás en el que se denuncian los problemas que afectan a la ciudad de Barcelona a raíz de la llegada masiva de turistas.

3 Se recomienda el documental «The Venice Syndrome» de Pichler (2012). Muestra la hiperturistificación de la ciudad lacustre, el gran éxodo y la progresiva desaparición del tejido social veneciano (Milano, 2017:9).

4 El Comitato No Grandi Navi el 18/06/2017 convocó un referéndum que hacía alusión a lo siguiente: «¿Quieres que los grandes cruceros permanezcan fuera de la laguna de Venecia y que no se lleven a cabo nuevas excavaciones dentro de la laguna?». E referéndum, no vinculante, tuvo mucho éxito. Acudieron 18.105 personas y el 80\% eran venecianos, el resto extranjeros o turistas extranjeros. El 98.72\% de los votantes 


\section{ESTADO DEL ARTE Y METODOLOGÍA}

Originalmente, las investigaciones relacionadas con el turismo de cruceros centraron sus estudios en los impactos económicos que tuvo el sector de cruceros en las regiones de América del Norte y el Caribe (Lawton y Butler 1987; Hall y Braithwaite, 1990; Dwyer y Forsith, 1998). Progresivamente las líneas de trabajo ampliaron sus ámbitos territoriales y se centraron sobre las tendencias de la oferta y la demanda de las navieras, considerando también las rutas e itinerarios en tierra de los pasajeros de cruceros desembarcados (Lopes, Dredge 2017; Whyte, 2017; Sabato, 2018), sobre el impacto ecónomico (Amato, 2015; Di Cesare, 2015; BREA, 2017 y 2018; McCarthy, 2017; Paoli et al., 2017; MacNeill y Wozniak. 2018; Pino y Peluso, 2018) y sobre los impactos socioambientales causados por el atraque de los buques (Soriani et al., 2015; Strazza et al., 2015; Carić, 2016; Perić et al., 2016: Perić y Račić, 2017; Dragović et al., 2018; RosaJiménez et al., 2018;). Algunos investigadores, ante el éxito de la actividad, abrieron nuevas líneas de debate, al centrarse sobre contextos de experiencia y comportamiento de los pasajeros de cruceros en puertos de escala o de tránsito (Marti, 1992; Teye y Leclerc, 1998; Qu y Pin, 1999; Duman y Matilla, 2005; Jones, 2011; Del Chiappa y Abbate, 2016; Jordan y Vogt, 2017; Del Chiappa, Lorenzo Romero y Gallarza, 2018; Sorrentino et al., 2019).

Como se puede observar, los ejes de investigación del segmento de cruceros han estado basados en estos cuatro ejes temáticos y su correspondiente subdivisión, sobre todo en las zonas del Caribe y Mediterráneo. Ahora bien, desde un punto de vista autonómico, es importante notar aún más la escasez de estudios para el caso del Atlántico, lo que en parte tiene su explicación debido a que su despegue ha sido reciente y su peso en relación a otros destinos incipiente. Entre la bibliografía existente destacan las líneas de investigación relacionadas con el impacto económico y de satisfacción del crucerista, con los trabajos de Edei consultores $(2005,2009,2012)$ y Centro Atlántico de Pensamiento Estratégico (2016); el marketing turístico, con los trabajos de Aguiar (2014, 2016); y el impacto socio urbano con los trabajos de Hernández Luis et al. (2015) y Goycoolea y Amaro (2015).

Esta revisión bibliográfica junto con las encuestas de muestra transversal realizadas por las autoras, con 467 cuestionarios realizados a residentes en la capital ${ }^{5}$ y 432 cuestionarios realizados a cruceristas $^{6}$, han servido de base me-

correspondiente a un total de 17.874 personas se declaró en contra de los grandes cruceros. El resultado provocó la petición al Gobierno de la inmediata aplicación de la ley «Clini-Passera» de 2013 que preveía la prohibición de ingresos de cruceros de más de 40.000 toneladas en la laguna (Milano, 2017:13-14).

5 Véase Hernández Luis, J. Á., Del Chiappa, G. y Battino, S. (2015). Percepción de los residentes de las Palmas de Gran Canaria ante el turismo de cruceros. Vegueta, 15, 287-316

6 El cuestionario consta de 25 preguntas — divididas en cuatro módulos - basados algunos de ellos en la revisión metodológica de la literatura de (Chen y Tsai, 2007; Chi 
todológica de esta comunicación. Cabe destacar que la información obtenida relativa a los usos del suelo y su evolución se han basado en un análisis de la información detallada por organismos oficiales autonómicos, sistemas de información geográfica y normativas urbanísticas.

\section{LAS PALMAS DE GRAN CANARIA Y EL TURISMO DE CRUCEROS}

Las Palmas de Gran Canaria ubicada al noreste de la isla de Gran Canaria, Archipiélago Canario (España), fue fundada en 1478 y es capital de la isla de Gran Canaria y de la provincia de Las Palmas. Tiene una población de 379.925 habitantes a 1 de enero 2019 (ISTAC, 2020)7, convirtiéndose en la ciudad más poblada de Canarias y la novena de España (Enterat, 2019) con una densidad de población de 3.755 hab/ $\mathrm{km}^{2}$. Esto sin tener en cuenta la población flotante del resto de municipios que acuden a la capital por motivos laborales y el resto de visitantes que pernoctan en otros términos municipales.

Teniendo en cuentas estas consideraciones y antes de pasar al análisis pormenorizado de la actividad turística capitalina, es necesario tener en cuenta que la ciudad está dividida en cinco distritos, tres de los cuales forman parte del ámbito de influencia del turismo de cruceros: el distrito 1, Vegueta-Cono sur-Tafira; el distrito 2, Centro; y el distrito 3, Isleta-Puerto-Guanarteme (Figura $1)^{8}$.

y Qu, 2008). Los dos primeros bloques están diseñados para recopilar información demográfica y hábitos generales. Las preguntas correspondientes al bloque I (preguntas 1, 2, 3,4, 5 y 6) informan sobre datos de carácter geográfico y perfil del turista e incluyen: género, edad, nacionalidad, ciudad de residencia, profesión, viaja solo o acompañado, frecuencia de viajes al año y gasto medio. El bloque II se centra en analizar el perfil del turista como cruceristas y la información que tienen los cruceristas antes de visitar la ciudad y la región —así se puede deducir de manera indirecta cómo es la promoción de los destinos en este segmento- (preguntas 7, 8, 9, 10, 11, 12 13, 15, 17, 19, 20 y 23): cuántos viajes en crucero ha hecho, compañías, meses, itinerarios, por qué ha elegido viajar en crucero, modalidad de compra del viaje en crucero, cuánto suele gastar en un viaje, cuánto tiempo emplea en visitar la ciudad, cuál es la información que los cruceristas tienen antes de visitar la ciudad y/o la región y uso de la tecnología pre/post viaje. Los bloques III y IV han sido diseñados como un instrumento de análisis para detectar y baremar: (1) imagen del destino, (2) oferta y promoción del destino, (3) satisfacción del atributo turístico, satisfacción general y (4) lealtad que tienen los cruceristas sobre las ciudades portuarias que visitan. Para mayor información consultar la Tesis doctoral de Ainhoa Amaro García, 2019.

7 Para más informacion ver: http://www.gobiernodecanarias.org/istac/temas_estadisticos/demografia/poblacion/cifraspadronales/E30245A.html

8 Éste censo representa la información oficial por distritos vigente, ya que desde 2018 no se actualiza públicamente la población por distritos. 
Figura 1. Representación de los distritos de Las Palmas de Gran Canaria y su correspondiente censo, 2018

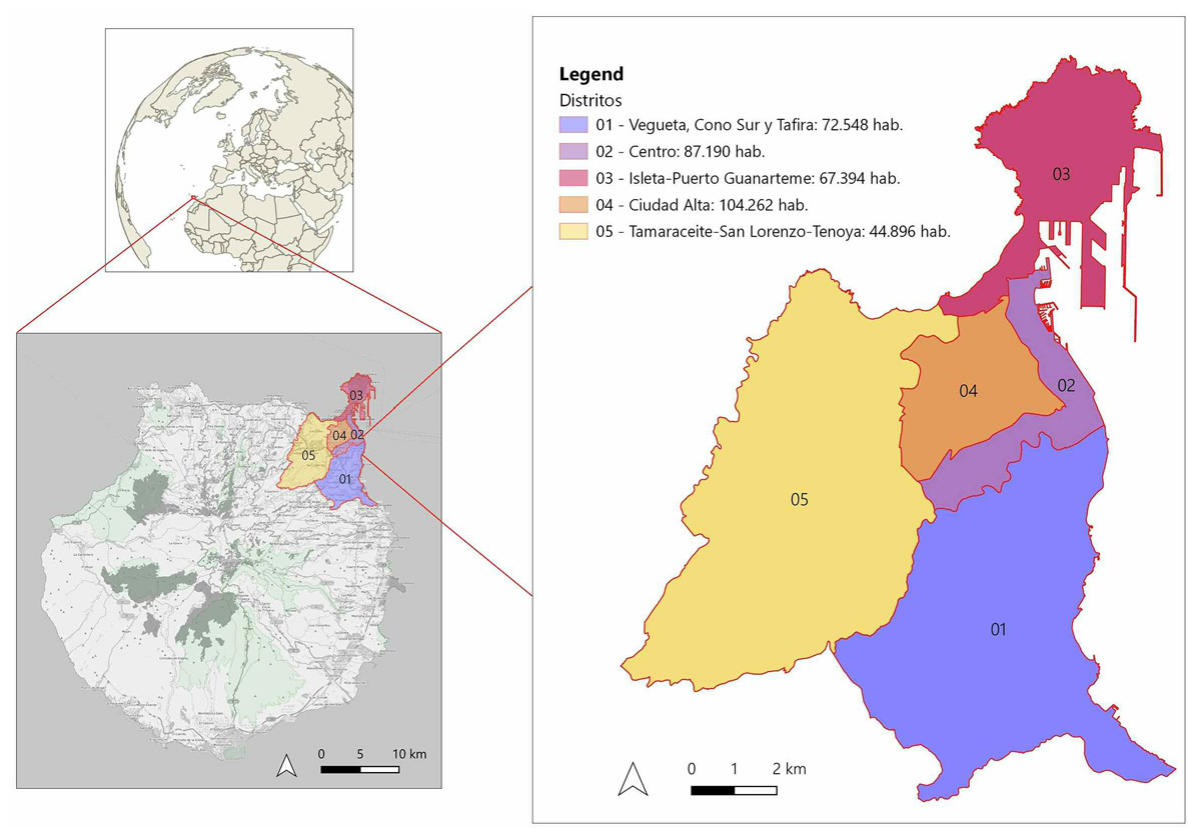

Fuente: Ayuntamiento de Las Palmas de Gran Canaria. Elaboración propia

El turismo en Gran Canaria fue promovido por ingleses mediante el establecimiento de líneas de transporte marítimo, conectando así servicios de correos, transporte de mercancias y personas entre Gran Canaria y Reino Unido. La historia del turismo en Las Palmas de Gran Canaria sigue derroteros similares a los experimentados a escala global, pero con algún desfase temporal. Hasta finales del siglo XIX, el turismo capitalino estaba relacionado con la construcción y posterior ampliación del puerto de La Luz y de Las Palmas y el desarrollo de las comunicaciones marítimas con Europa. (Donato, 2001; Hernández Luis, 2008). Sin embargo, a finales del siglo XIX y principios del XX, la Revolución Industrial impactó con fuerza en el sector marítimo. El puerto de La Luz fue testigo de la sustitución del carbón por el petróleo y, dada su posición estratégica, durante esta fase de transición se convirtió en la mayor estación carbonera del Atlántico medio gracias a los depósitos de carbón que instalaron las consignatarias inglesas en el Muelle Grande. A este hecho, hay que sumarle que los astilleros a nivel internacional empezaron a construir nuevos y más grandes buques para hacer líneas trasatlánticas, por lo que el puerto se convirtió también en taller de reparaciones navales de buques y trasatlánticos que hacían escala para repostar y/o visitar la ciudad. 
Sin embargo, la irrupción del transporte aéreo en el aeropuerto de Gran Canaria en 1954 y la posterior construcción en serie del boeing a escala global, condicionó enormemente los desplazamientos marítimos. El avión ganó progresivamente cuota de mercado y pasó a sustituir al barco en el transporte de pasajeros; las navieras, frente a la continua pérdida de ingresos y servicios, afrontaron la situación reinventando el modelo de negocio. El transporte de pasajeros fue sustituido por cruceros de placer, éstos ofrecían itinerarios por todo el mundo, entre los destinos de la época destacó la ciudad de Las Palmas de Gran Canaria cuando en 1958 y 1960, respectivamente, recibió a los dos mayores transatlánticos de la época: el «Queen Mary» y el "Queen Elizabeth».

Durante la década comprendida entre 1955 y 1965, la capital fue el principal punto turístico de la isla, pero la consolidación del transporte aéreo anteriormente mencionada, la aparición de los vuelos chárter y el desarrollo urbanístico del sur de la isla cambió el escenario. Entre 1970 y 2000 el modelo turístico de la isla se asentó en las zonas de Maspalomas y Playa del Inglés y se caracterizó por ser un turismo de masas de sol y playa, en el que se ofrecía sol, tranquilidad y, al mismo tiempo, se garantizaban servicios sanitarios, seguridad y alimentación en el propio complejo hotelero a los turistas.

A partir de entonces, Las Palmas de Gran Canaria perdió su relevancia turística, un hecho que no se solventó hasta principios de siglo XXI con la reaparición del turismo de cruceros. Concretamente en 2004, con la llegada del Queen Mary 2 a la capital. Desde entonces, el puerto de La Luz y de Las Palmas comenzó a aparecer de nuevo en los itinerarios de las navieras internacionales. De hecho, desde 1998, año en el que se comenzó a hacer estadísticas de crucerísticas en la capital hasta la actualidad, el turismo de cruceros ha experimentado un incremento de más del 1.000\% pasando de 60.508 pasajeros de cruceros en 1998 a 723.655 en 2019.

Durante el 2019, el puerto de La Luz y de Las Palmas se situó en la cuarta posición en la clasificación de los puertos de España por número de pasajeros de cruceros después de Barcelona, Palma de Mallorca y Santa Cruz de Tenerife (Tabla 1) ${ }^{9}$.

9 La alusión a los puertos canarios es referida a los puertos isleños, que a su vez están administrados por las respectivas Autoridades Portuarias. Por un lado, está la provincia de Las Palmas, cuya gestión recae sobre la Autoridad Portuaria de Las Palmas y administra el puerto de la Luzy de Las Palmas (Gran Canaria), los puertos de Arinaga y de Salinetas (Gran Canaria); Arrecife (Lanzarote); y Puerto del Rosario (Fuerteventura). Por otro está la provincia de Santa Cruz de Tenerife administrada por la Autoridad Portuaria de Santa Cruz de Tenerife, que a su vez gestiona los puertos de Santa Cruz de Tenerife y de Los Cristianos (ambos en Tenerife); Santa Cruz de La Palma (La Palma); San Sebastián de La Gomera (La Gomera); y La Estaca (El Hierro). 
Tabla 1. Evolución histórica de los 9 principales puertos de España por número de pasajeros de cruceros (en miles)

\begin{tabular}{|l|c|c|c|c|c|c|c|c|c|c|}
\hline \multicolumn{1}{|c|}{ Puertos } & $\mathbf{2 0 0 9}$ & $\mathbf{2 0 1 0}$ & $\mathbf{2 0 1 1}$ & $\mathbf{2 0 1 2}$ & $\mathbf{2 0 1 3}$ & $\mathbf{2 0 1 4}$ & $\mathbf{2 0 1 5}$ & $\mathbf{2 0 1 6}$ & $\mathbf{2 0 1 7}$ & $\mathbf{2 0 1 8}$ \\
\hline 1.Barcelona & 2.151 & 2.348 & 2.657 & 2.409 & 2.599 & 2.364 & 2.540 & 2.684 & 2.712 & 3.049 \\
\hline 2.Palma de Mallorca & 1.056 & 1.351 & 1.425 & 985 & 1.246 & 1.336 & 1.722 & 1.631 & 1.673 & 2.051 \\
\hline 3. Santa Cruz de Tenerife & 422 & 536 & 607 & 669 & 528 & 545 & 644 & 559 & 618 & 663 \\
\hline 4. Luz y de Las Palmas & 245 & 290 & 426 & 426 & 425 & 589 & 683 & 611 & 642 & 676 \\
\hline 5. Arrecife & 299 & 300 & 258 & 328 & 320 & 358 & 435 & 378 & 427 & 423 \\
\hline 6.Cádiz & 237 & 337 & 377 & 334 & 375 & 381 & 411 & 385 & 387 & 425 \\
\hline 7.Málaga & 488 & 659 & 639 & 652 & 397 & 408 & 419 & 444 & 510 & 507 \\
\hline 8.Valencia & 185 & 253 & 378 & 480 & 473 & 373 & 371 & 403 & 412 & 421 \\
\hline 9.Ibiza & 103 & 132 & 129 & 258 & 192 & 169 & 190 & 251 & 340 & 274 \\
\hline 10.Vigo & 223 & 234 & 254 & 240 & 172 & 176 & 205 & 169 & 140 & 158 \\
\hline Total - Top 10 & $\mathbf{5 . 4 0 9}$ & $\mathbf{6 . 4 4 0}$ & $\mathbf{7 . 1 5 0}$ & $\mathbf{6 . 7 8 1}$ & $\mathbf{6 . 7 2 7}$ & $\mathbf{6 . 6 9 9}$ & $\mathbf{7 . 6 2 0}$ & $\mathbf{7 . 5 1 5}$ & $\mathbf{7 . 8 6 1}$ & $\mathbf{8 . 6 4 7}$ \\
\hline
\end{tabular}

Fuente: Elaboración propia en base a Puertos del Estado

Este flujo continuado de turistas debe tener, y de hecho tiene, un impacto en los destinos. En dos trabajos de campo realizados por las autoras de este artículo, (1) un cuestionario a la población residente en la capital (467 cuestionarios gestionados) y (2) un cuestionario a los cruceristas que visitan la capital (432 cuestionarios gestionados), se detectó que gran parte de los encuestados, tanto residentes como cruceristas, ven positivamente la actividad crucerística ya que genera empleo, promueve el intercambio cultural e incentiva la oferta de los servicios complementarios: bares, restaurantes, equipamientos recreativos y hoteles. Sin embargo, este trabajo de campo también evidenció algunos aspectos negativos tales como: cambios en el uso del suelo, pérdida del espacio público e incremento del coste de la vida.

En definitiva, en apenas una década los residentes de los distritos afectados por el turismo de cruceros han visto cómo llegan durante la temporada de cruceros, de octubre a abril, una media de 8 cruceros semanales, muchos de ellos coinciden durante el viernes, sábado y domingo, con una media de 2.200 ocupantes, sin contar tripulación. Esto genera, en la mayor de las coincidencias (normalmente los sábados), un volumen de alrededor 6.000 personas desembarcando al unísono para visitar la ciudad si sólo se tienen en cuenta los cruceristas que desembarcan con tour libre.

Además de los pasajeros de cruceros y al propio movimiento portuario, estos distritos son frecuentados por unos 4.000 turistas (Gran Canaria Patronato del Turismo, 2020) y 2.000 excursionistas (ISTAC, 2019) cada día. El resultado es, consecuentemente, la transformación de la configuración urbana y oferta de la ciudad, así como su forma de habitarla. 


\section{TRANSFORMACIONES E IMPACTOS ASOCIADOS}

La oferta del destino es un factor clave dentro del sistema turístico: cuanto mayor sea el área geográfica y los recursos turísticos que sirven de apoyo al puerto base, mayor será la probabilidad de que los cruceristas prolonguen su estancia una vez finalicen su itinerario con la naviera (López, 2011).

A principios del 2000, la mirada superficial de los visitantes de crucero, debido a las escasas horas de desembarco, modificó la construcción de las ciudades portuarias. Poco a poco los destinos se han ido transformando para adaptarse a las exigencias de sus visitantes. Tal es el caso de Las Palmas de Gran Canaria que, a raíz del aumento de la llegada de turistas de cruceros y la búsqueda por parte de los turistas «convencionales» de nuevas experiencias únicas y diferenciadoras, alejadas de la sobreexplotada oferta de sol y playa, ha transformado el modo de funcionar y, por tanto, habitar la capital.

\subsection{USOS DEL SUELO}

\subsubsection{EQUIPAMIENTOS COMERCIALES}

En las últimas décadas el tejido comercial ha experimentado cambios relevantes en su organización, pero también en su proyección espacial. Fue a partir de 1992 cuando Las Palmas de Gran Canaria empezó este proceso de transformación que afectó no sólo a la estructura comercial, sino que llevó aparejado alteraciones del tejido urbano existente. (Armengol y González, 2007). Desde entonces el número de equipamientos ha ido en aumento. Tal es así que actualmente hay, como mínimo, un centro comercial en cada uno de los distritos de la capital. El distrito que nos ocupa, Puerto-Canteras, tiene dos: el centro comercial Las Arenas y el centro comercial El Muelle, ambos conectados peatonalmente con la terminal de cruceros del muelle de Santa Catalina.

Estos equipamientos se materializaron con doble orientación: 1) hacia la población y 2) con una proyección turística hacia el turismo de cruceros. Estas intenciones surgieron en 1989 con la aprobación definitiva del Plan General de Ordenación Urbana, que permitió la revisión y recalificación del uso del suelo de Las Arenas, y la concesión del suelo por parte de la Autoridad Portuaria, para la construcción del centro comercial El Muelle.

El flujo de personas que atrajeron los centros a principios del siglo XXI, así como la activación económica con tiendas y restaurantes de la zona, supusieron un cambio trascendental en la configuración y uso del litoral. Se llevaron a cabo toda una serie de iniciativas, entre ellas destacan la Operación Estratégica de Interés Insular denominada «Regeneración Turística de Las Canteras», el «Plan Director de la zona comercial Puerto-Canteras», la «Recuperación del Frente Marítimo» y el parque de «El Rincón». 
Figura 2. Conexiones peatonales entre la terminal de cruceros y los equipamientos comerciales: el centro comercial El Muelle y el centro comercial de Las Arenas

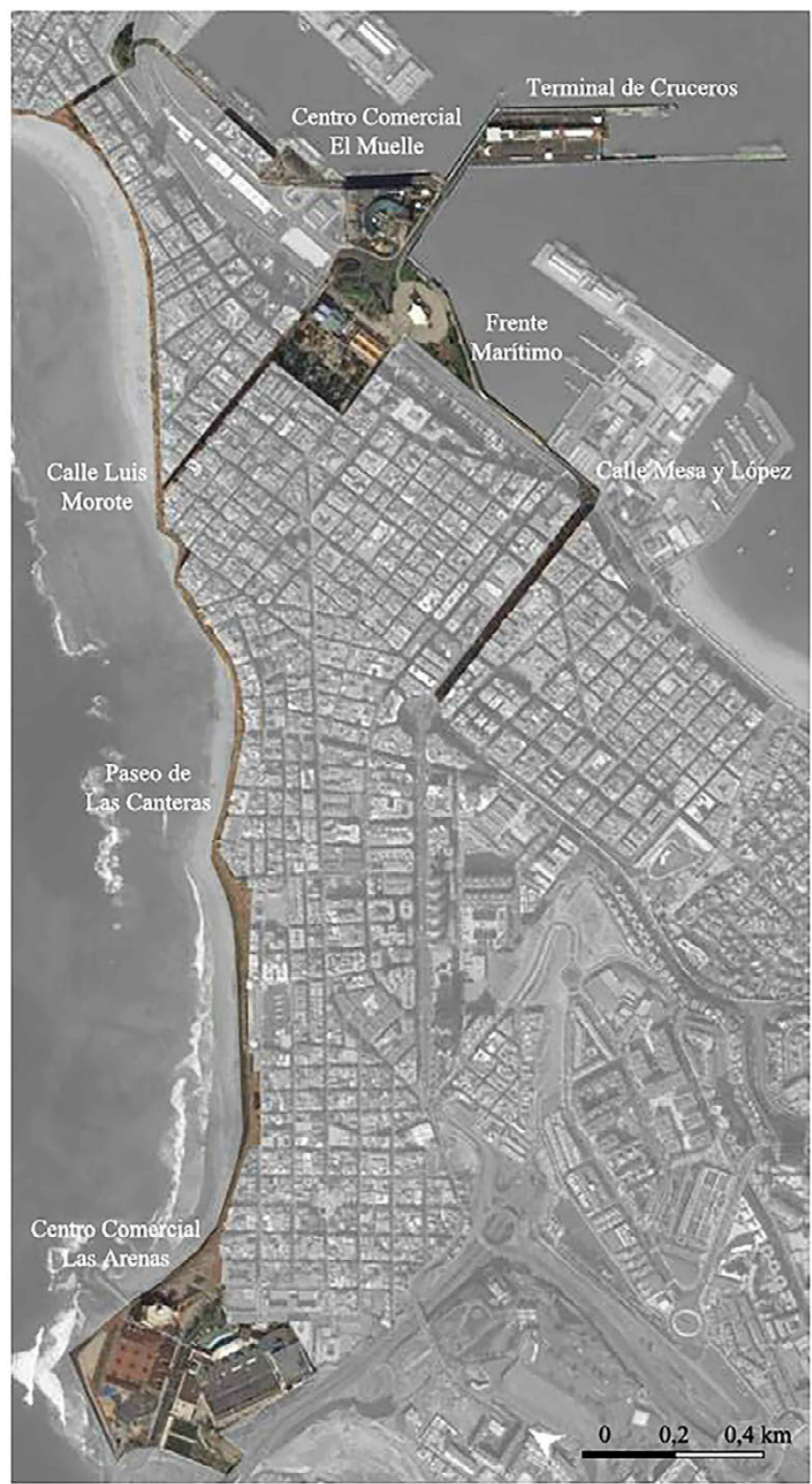

Fuente: Elaboración propia 


\subsubsection{FLEXIBILIDAD DE LAS ZONAS COMERCIALES}

A través del Decreto-Ley 20/2012, por el que se establece que se habrán de declarar Zonas de Gran Afluencia Turística los municipios con más de 200.000 habitantes que hayan registrado más de 1 millón de pernoctaciones en el año 2011 o que cuenten con puertos en los que operen cruceros turísticos que hayan recibido en ese mismo año más de 400.000 pasajeros, el Gobierno de Canarias declaró en 2014 las zonas de Triana, el centro comercial El Muelle, el Puerto y Las Canteras como zonas de Gran Afluencia Turísticas. Cuatro años más tarde, en 2018, a estas zonas se le sumaron el centro comercial Las Arenas, Vegueta y Mesa y López (Figura 3). Esto permite a los comerciantes de la zona abrir durante la temporada de cruceros, de octubre a abril, sin limitación horaria.

\subsubsection{EQUIPAMIENTOS RECREATIVOS}

Durante la última década, hemos sido testigo de cómo Las Palmas de Gran Canaria ha ido adaptándose a los requerimientos de navieras para que sigan teniendo en cuenta a Las Palmas de Gran Canaria entre sus itinerarios. El Ayuntamiento, la Autoridad Portuaria de Las Palmas y los empresarios involucrados en el sector turístico han apostado por ampliar la oferta turística de la capital, proponiendo nuevos atractivos que inviten al turista a bajarse del crucero y a conocer la ciudad. Actualmente hay más de cuatro proyectos sobre la mesa, uno inaugurado en 2015 y otros en fase de licencia y/o estudio de viabilidad. Entre estos futuros atractivos destacan los siguientes: a. Acuario Poema del Mar, b. Teleférico, c. Noria y d. Hotel Kiessling.

\section{a. Acuario}

El grupo Loro Parque, perteneciente a la familia Kiessling, inauguró en 2015 el acuario Poema del Mar. Ubicado a $150 \mathrm{~m}$ de la terminal de cruceros. El acuario ocupa alrededor de $12.000 \mathrm{~m}^{2}$ de la zona del Muelle de Sanapú. Su ubicación, junto a la terminal de cruceros y la playa de Las Canteras, surgió con la vocación de convertirse en reclamo turístico de primer orden para turoperadores y agentes turísticos (Figura 3).

\section{b. Teleférico}

El anteproyecto del teleférico en Santa Catalina, ubicado a $120 \mathrm{~m}$ de la terminal de cruceros y 20 m del muelle de Santa Catalina, se presentó ante los medios de comunicación el 9/08/2016. La idea surgió de un grupo de empresarios canarios que plantearon instalar un teleférico que uniera la zona de Santa Catalina con la Montaña del Vigía, uno de los tres volcanes desconocidos ubicados en la zona militar de La Isleta (Figura 3). 
Figura 3. Representación de todas las áreas incluidas en las Zonas de Gran Afluencia Turística en Las Palmas de Gran Canaria y los equipamientos asociados a ellas, 2018

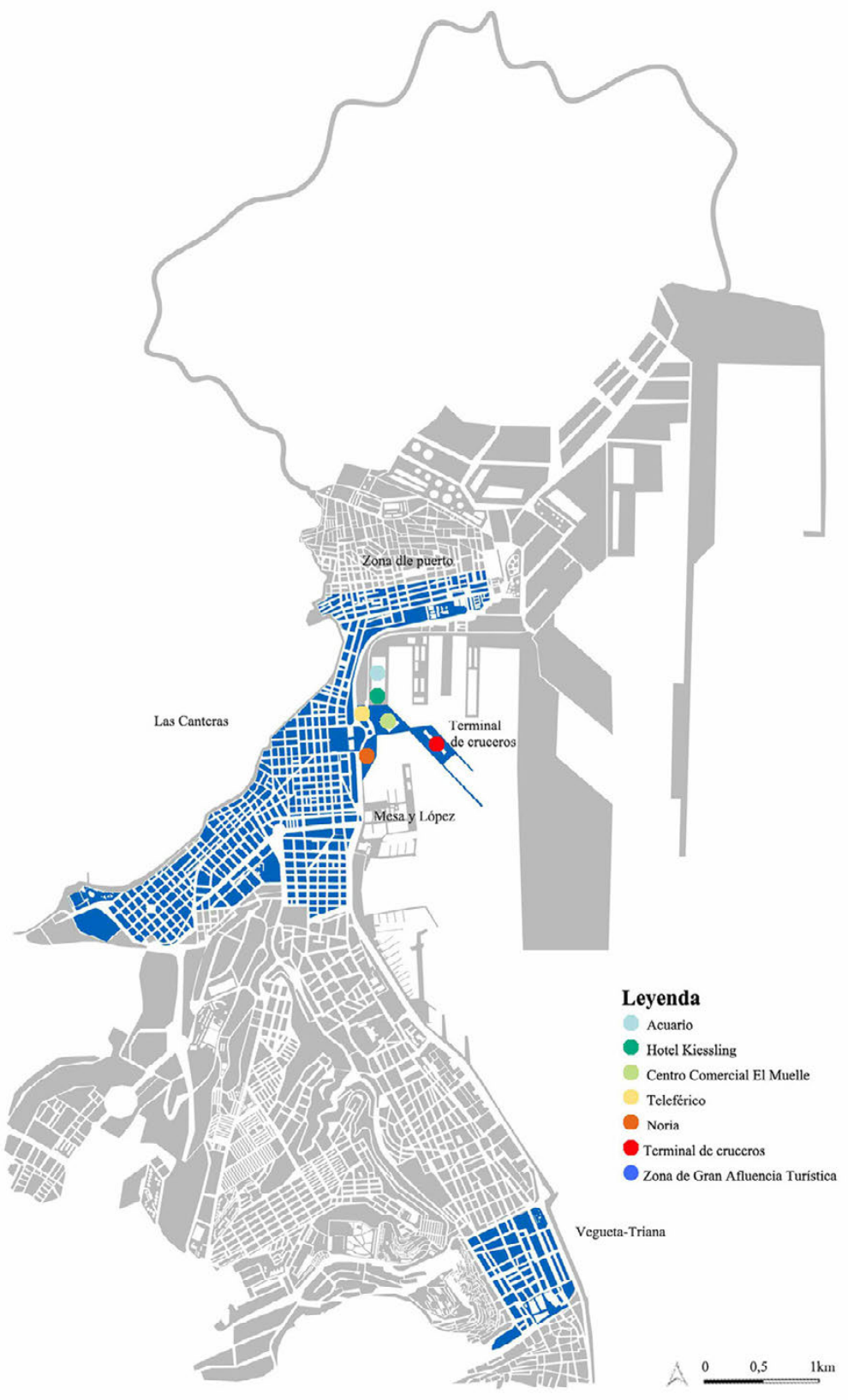

Fuente: Elaboración propia 
c. Noria

El Ayuntamiento aprobó en 2009 las bases del concurso de ideas para impulsar la «Ordenación Integral del Litoral y Frente Marítimo de Las Palmas». El Ayuntamiento de Las Palmas de Gran Canariay Cabildo de Gran Canaria barajaron la opción de implementar de manera aislada algunos proyectos. Tal fue el caso de la noria gigante, un proyecto que, con finalidad turística, pretendía erigirse como nuevo referente de la capital. Su ubicación está proyectada para la zona del parque Santa Catalina (Figura 3).

\section{d. Hotel Kiessling}

La familia Kiessling, propietaria del Acuario Poema del Mar solicitó en abril de 2017 a la Autoridad Portuaria una parcela de $1.500 \mathrm{~m}^{2}$ para construir un hotel. Este nuevo equipamiento está previsto que se ubique a $50 \mathrm{~m}$ del acuario y a unos $100 \mathrm{~m}$ de la terminal de cruceros. La idea se apoya en la estrategia diseñada por PROMOTUR de fomentar la pernoctación de los cruceristas que recalan en el puerto de La Luz y, a su vez, atraer al segmento de negocios y náutico (Figura 3).

\subsubsection{PLANTA ALOJATIVA: APARTAMENTOS Y HOTELES}

Durante los últimos seis años, entre 2012 y 2018, se han construido 12 nuevos hoteles, 3 hoteles emblemáticos, 10 casas emblemáticas y 5 apartamentos. Esto hace un total de 30 nuevos establecimientos turísticos en seis años. De la quincena de nuevos hoteles, seis pertenecen a Vegueta, sumando 94 plazas (camas). El entorno de Santa Catalina, por su parte, estrenó cuatro alojamientos, sumando 324 camas más. La zona del puerto acogió dos instalaciones hoteleras, con otras 90 camas. El entorno de Triana inauguró en 2018 un hotel urbano y otro emblemático, que aportaron 70 camas. En definitiva, la capital sumó a las 6.134 plazas hoteleras que oferta en la actualidad las 640 de los 15 establecimientos urbanos y emblemáticos que se inauguraron entre 2012 y 2018.

Esto corrobora el argumento que la mayoría de las actuaciones relacionadas con los alojamientos turísticos (planta hotelera, extrahotelera y viviendas vacacionales) se han producido en el distrito 2 Puerto-Canteras y en el distrito 1 Vegueta-Cono sur y Tafira. Coincidiendo también con las Zonas de Gran Afluencia Turística, ámbito de influencia del segmento de cruceros y centro histórico (Triana-Vegueta) (Figura 4). 
Figura 4. Representación de los hoteles, casas emblemáticas y apartamentos abiertos entre 2012 y 2018 en las zonas catalogadas como de Gran Afluencia Turística y registro de viviendas vacacionales censadas en 2018 por el Ayuntamiento de Las Palmas de Gran Canaria.

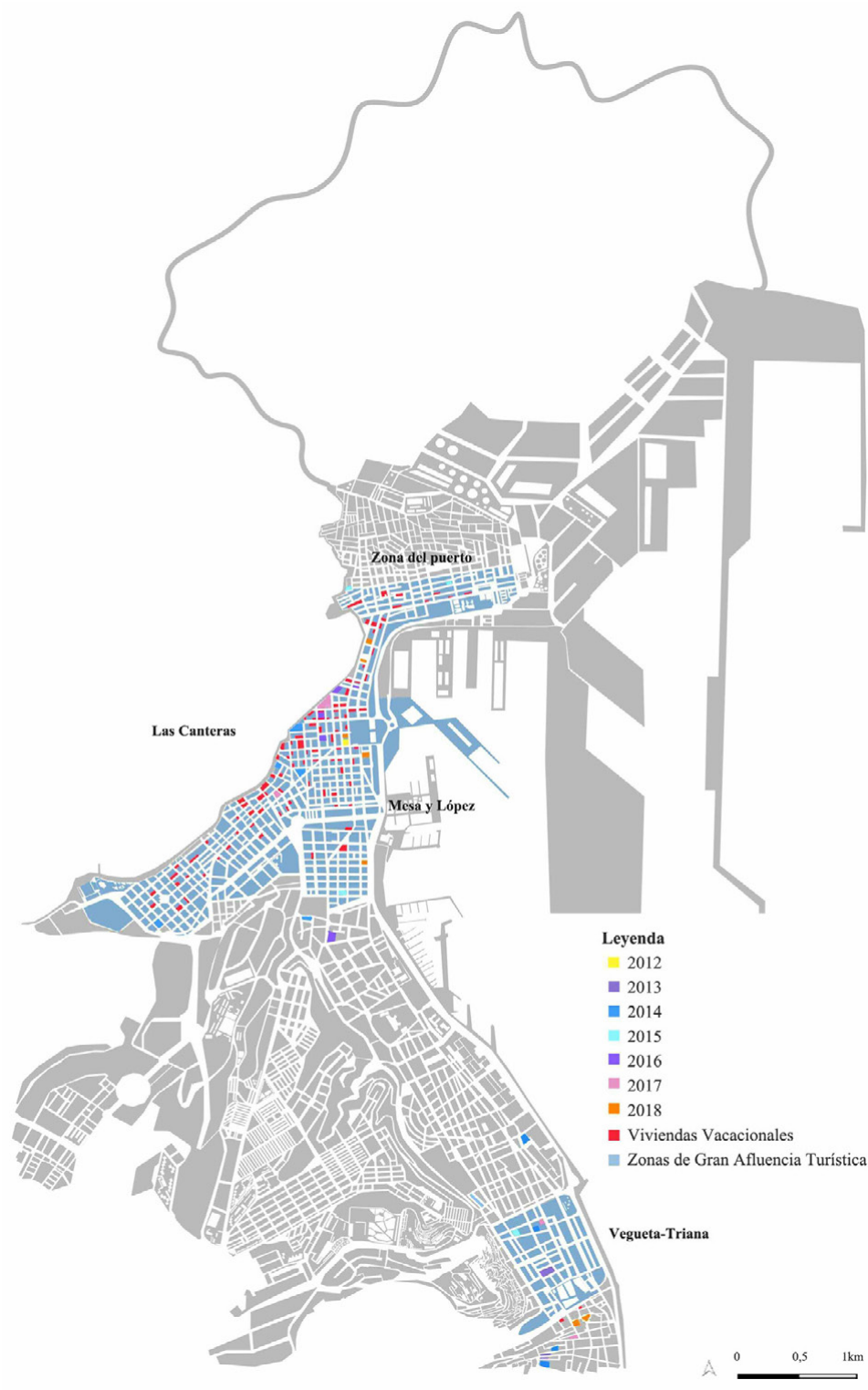

Fuente: Cabildo de Gran Canaria y Ayuntamiento de Las Palmas de Gran Canaria. Elaboración propia 


\subsection{TRANSFORMACIONES URBANAS}

\subsubsection{HOTELIZACIÓN DEL PARQUE RESIDENCIAL}

El Ayuntamiento aprobó de forma definitiva el nuevo Plan Especial de Protección para el conjunto histórico que forman Vegueta y Triana (PEP), cuyo principal objetivo fue impulsar la «protección activa» de los dos núcleos históricos, para salvaguardar el patrimonio artístico, cultural y arquitectónico de la ciudad fundacional, a la vez que se dinamiza la zona autorizando actividades comerciales y usos hoteleros a todos los inmuebles del ámbito protegido. De esta forma, cualquier vivienda del casco histórico puede convertirse ahora en hotel o casa emblemática, siempre y cuando el número de plazas de todo el conjunto no supere las 400 camas y que en un mismo inmueble no haya más de 40 unidades alojativas.

En definitiva, la modificación de esta normativa ha propiciado que, desde 2012, la ley permita abrir alojamientos turísticos en áreas catalogadas originariamente de uso residencial. A raíz de ahí, la situación observada en ciertos municipios canarios ${ }^{10}$, principalmente en los de carácter urbano como Las Palmas de Gran Canaria, refleja que se está produciendo una disminución de la planta alojativa de uso residencial en los centros urbanos, con la correspondiente progresiva pérdida de calidad de vida de la población local e impacto económico y social que ello implica, dando lugar al fenómeno que Torres (2009) denomina como «hotelización del parque residencial», expulsando a los residentes permanentes que asumen con resignación e impotencia el nuevo escenario.

Se está produciendo un proceso de turistificación de la ciudad, en el que el centro turístico o sus áreas de influencia se transforman y adaptan para satisfacer las necesidades del turista más que del residente. Esta ruptura del equilibrio de la gestión de la ciudad, al fomentar usos turísticos en terrazas, bares y cafeterías en cubiertas de edificios ubicados en zonas residenciales, puede provocar (y de hecho está provocando) rechazo en los residentes de la zona.

Este fenómeno de hotelización, transformación de vivienda residencial en alojamiento turístico ha llegado hasta tal punto que los residentes de los distritos 2 Puerto-Canteras y 1 Vegueta-Cono sur y Tafira se han organizado a través de plataformas y asociaciones vecinales. El principal motivo de la protesta fue mostrar públicamente su malestar y rechazo al modelo turístico de la capital.

10 Cabe destacar que es una problemática que afecta al territorio nacional, pero con más repercusión en aquellas ciudades consolidadas como destinos turísticos. MaIlorca, Barcelona, Benidorm, Bilbao y Alicante son otros ejemplos. 


\subsubsection{TURISTIFICACIÓN DE LA CAPITAL}

Desde principio del siglo XXI los edificios de Las Palmas de Gran Canaria han ido cambiando de uso para satisfacer la demanda turística: de residencial a hotelero, de oficina a comercial, de comercial a hostelero y de equipamiento cultural a hotelero son los casos más habituales que ha experimentado la trama urbana capitalina. De hecho, uno de los ejemplos más recientes de este tipo de transformación lo podemos encontrar en la intersección de las calles de San Bernardo con Viera y Clavijo: El edificio de El Museo Canario se convertirá en un inmueble con apartamentos turísticos de alto standing, con 18 unidades alojativas de dormitorios individuales y dobles. La superficie de cada apartamento rondará los $60 \mathrm{~m}^{2}$ la comercialización de los mismos recaerá en manos de la cadena Be Mate, del empresario Kike Sarasola (Canarias 7, 01/08/2018). Sin embargo, de entre todos ellos los casos detectados, nos parece interesante profundizar en la reconversión del «Mercado del Puerto». El mercado representa la transformación funcional que experimentan los destinos turísticos más consolidados, donde las ciudades, tras haber explotado el sistema de alojamientos (crear hoteles, apartamentos, promover la vivienda vacacional, etc.) se centran en ofrecer nuevos servicios para satisfacer al turista.

Históricamente los mercados municipales de Las Palmas de Gran Canaria han pertenecido al Ayuntamiento, teniendo cada propietario una licencia administrativa de explotación de sus espacios y negocios por 50 años. Sin embargo, en 1997, a través de una ordenanza, se reguló para privatizarlos. Los locatarios del Mercado del Puerto optaron por crear una cooperativa. En 2011, la cooperativa ideó una estrategia para seguir con su actividad tradicional, pero adaptándose a los «nuevos» tiempos. Para ello en 2012, en colaboración con el Ayuntamiento, decidieron «dinamizar» el recinto y la zona como centro de ocio y de compras tradicionales, fomentando la implantación de negocios orientados a la restauración y como centro de interés turístico (Otero, 2014). Este interés de la cooperativa del Mercado del Puerto por el sector turístico transformó absolutamente su dinámica tradicional. La mayoría de los puestos de frutas y verduras se convirtieron en tascas y bares de tapas. Poco a poco la gastronomía ha ido ganando peso en detrimento de los puestos de carnicería, pescadería y frutas y verduras.

\section{CONCLUSIONES}

El incremento del segmento ha hecho que la capital se consolide como un referente no sólo a nivel nacional, sino incluso a nivel europeo, situando a la capital entre las diez primeras ciudades del país en volumen demográfico y afluencia de turistas. Pero esta llegada continuada de cruceros no sólo ha producido efectos económicos en la capital, sino también transformaciones urbanas e cambios en el uso del suelo. De esto se deduce que conforme los 
procesos de globalización aumentan, incrementan también los desplazamientos turísticos y sus impactos sobre los destinos.

A raíz de la llegada de cruceros Las Palmas de Gran Canaria ha experimentado impactos similares a otros destinos turísticos más consolidados, pero con menor intensidad, por lo que no se puede considerar que haya llegado al colapso. Ahora bien, a raíz del trabajo de campo realizado, se deduce que la capital se enfrenta a la disyuntiva de desarrollar con criterios objetivos las estrategias a seguir y así evitar lo sucedido en otras ciudades portuarias patrimoniales.

Muchos de los proyectos diseñados para mejorar la acogida de cruceristas y que están en fase de aprobación y respectiva licitación están siendo muy cuestionados por la ciudadanía, lo cual no contribuye a la sostenibilidad del sistema. Las propuestas se basan en el crecimiento intensivo del número de visitantes más que en el desarrollo sostenible, la calidad de la oferta y la convivencia entre cruceristas y residentes. Para una mayor eficiencia de los programas de actuación, es necesario devolver el papel protagonista a la ciudadanía, reforzar el derecho de propiedad privada, reducir los intereses personales sobre los colectivos y motivar la participación ciudadana.

Por otro lado, existen algunas incompatibilidades a nivel morfológico y funcional que hacen que no se rentabilice del todo la presencia de turistas ni que se eviten los conflictos con vecinos y emprendedores locales. Se ha detectado que los destinos turísticos tiendan a la estandarización de la oferta y a favorecer a las grandes superficies/cadenas en detrimento del comercio local y artesanía. De hecho, la llegada de cruceristas atrae a inversores que quieren rentabilizar sus propiedades, provocando modificaciones en planes urbanísticos diseñados en base a unos criterios de escala, movilidad, sostenibilidad, servicios básicos, infraestructura e interacción social completamente antagónicos. Así, lo que inicialmente era uso residencial o equipamiento pasa al sector servicios, convirtiéndose en restaurantes, hoteles, comercios u oficinas turísticas. El cambio de uso de los edificios y, por ende, de los espacios públicos vinculados a ellos tiende a satisfacer las exigencias de turistas en detrimento de los usos y necesidades de la comunidad receptora, provocando procesos de turistificación de las áreas urbanas más demandadas"

11 Cabe destacar que, tal y como ha evidenciado la fuerte crisis turística internacional causada por el Covid 19, cuando se priorizan los intereses de los turistas frente al de los residentes se generan desequilibrios económicos y sociales e incluso quiebra de toda una cadena turística en el destino. Consecuentemente, los destinos se ven obligados a reformular de forma sostenible las intervenciones urbanísticas. Las Palmas de Gran Canaria, a través del Pacto Para la Reactivación Económica y Social de Canarias (Parlamento de Canarias, 2020), es un claro ejemplo de ello. En la sesión del Parlamento de Canarias celebrada el 14 de abril de 2020, el Presidente del Gobierno de Canarias, Ángel Víctor Torres, compareció para presentar, entre otras medidas, la diversificación del sector turístico y la necesidad de establecer estrategias urbanísticas teniendo en cuenta las necesidades de los residentes y no solo la de los turistas. 
Ante estos escenarios, se recomienda tener en cuenta las dinámicas sociales actuales y compatibilizarlas con las nuevas propuestas, evitando generar cualquier posible impacto en los residentes y la especulación de precios. Todo ello, estableciendo medidas sustentables a través de mecanismos de participación ciudadana que controlen y disuadan posibles problemas de corrupción y especulación.

\section{BIBLIOGRAFÍA}

Aguiar, T. (2014). Evolución del turismo de cruceros: la relación existente entre destino-crucero. Estudios Turísticos, 202, 63-98.

Amaro, A. (2019). Nuevas prácticas turísticas: turismo de cruceros en ciudades patrimoniales. Situación y coyuntura en Las Palmas de Gran Canaria. Tesis Doctoral. Universidad de Alcalá: Madrid.

Amato, V. (2015). Tra mare e terra. II crocierismo nell'economia turistica. In Cusimano, G. (a cura di). /l turismo nelle/delle destinazioni, Bologna, Pàtron editore, 54-71.

- (2016). La adaptación de un destino al turismo de cruceros: el caso del puerto de Las Palmas de Gran Canaria. Revista Electrónica CECIET, VI volumen, 1-17.

Armengol, M. y González, A. (2007). Los centros comerciales en Las Palmas de Gran Canaria. Dinámicas e impactos en el espacio urbano. Anuales de Geografía, 27(1), 9-27.

Ayuntamiento de Las Palmas de Gran Canaria. Página web oficial. Obtenido de https://www.laspalmasgc.es/es/

BREA (Business Research and Economic Advisors) (2017). Economic contribution of cruise tourism to the destination economies. Phillipsburg NJ: BREA.

BREA (Business Research and Economic Advisors) (2018). Economic contribution of cruise tourism to the destination economies. Phillipsburg NJ: BREA.

Canarias 7. (01/08/2018). De edificio de El Museo Canario a 24 apartamentos. Recuperado el 17/01/2020 de:

https://www.canarias7.es/siete-islas/gran-canaria/las-palmas-de-gran-canaria/de-edificio-de-el-museo-canario-a-24-apartamentos-DB5201317

Carić, H.(2016). Challenges and prospects of valuation e cruise ship pollution case. Journal of Cleaner Production, 111, Part. B, 487-498.

Centro Atlántico de Pensamiento Estratégico (CAPTE) (2016). Informe CATPE sobre la competitividad turística de Canarias. Propuestas para encauzar el equilibrio económico-social-medioambiental del Archipiélago Canario. Disponible en:

http://www.catpe.es/wp-content/uploads/downloads/2016/02/CATPE_ Competitividad_Turistica_A42.pdf

CIN (Cruise Industry News) (2020). 2020 Annual Report, New York. CIN.

Chen, C. y Tsai, D. (2007). How destination image and evaluative factors affect behavioral intentions. Tourism Management, 28 (4), 1.115-1.122. 
Chi, C. G. Q. y Qu, H. (2008). Examining the structural relationships of destination image, tourist satisfaction and destination loyalty: An integrated approach. Tourism Management, 29 (4), 624-636.

Chin, C. B. N. (2008). Cruising in The Global Economy: Profits, Pleasure and Work at Sea. Aldershot: Ashgate Publishing.

Del Chiappa, G.y Abbate, T. (2016). Island cruise tourism development: a resident's perspective in the context of Italy. Current Issues in Tourism, 19 (13), 1.372-1.385.

Del Chiappa, G., Lorenzo Romero, C. y Gallarza, M. (2018). Host community perceptions of cruise tourism in the homeport. A cluster analysis. Journal of destination marketing \& management, 7, 170-181.

Di Cesare, F. (2015). Le imprese crocieristiche. In Garibaldi, R. (a cura di). Economia e gestione delle imprese turistiche. Milano, Hoepli, 193-216.

Donato, C. (2001), Le Canarie e l'«industria» turistica. Osservazioni su di uno spazio che ripensa il proprio sviluppo attraverso strategie ecosostenibili. Trieste: Edizioni Goliardiche.

Dowling, R. (Ed.) (2005). Cruise ship tourism. Perth: Edith Cowan University.

Dragović, B., Tzannatos, E., Tselentis, V., Meštrović, R. y Škurić, M. (2018). Ship emissions and their externalities in cruise ports. Transportation Research Part D: Transport and Environment, 61, 289-300.

Duman, T. y Mattila, A. S. (2005). The role of affective factors on perceived cruise vacation value. Tourism Management, 26 (3): 311-323.

Dwyer, L. y Forsyth, P. (1998). Economic significance of cruise tourism. Annals of Tourism Research, 25 (2), 393-415.

EDEI Consultores

- (2005): Inteligencia Competitiva Cruises in the Atlantic Islands 2004-2005. Las Palmas de Gran Canaria (inédito).

- (2009). Estudio cuantitativo y cualitativo del turismo de cruceros en las Islas Canarias. Las Palmas de Gran Canaria (inédito).

- (2012). Estudio del mercado del turismo de cruceros en Canarias. Las Palmas de Gran Canaria (inédito).

Enterat (01/01/2018). Web oficial. Recuperado el 02/01/2020 de http://www.enterat.com/servicios/ poblacion-espana-provincias-municipios.php

Goycoolea, R. y Amaro García, A. (2015). Turismo de Cruceros y Patrimonio. Una relación compleja, bien reflejeda en Las Palmas de Gran Canaria, España. Revistas Márgenes Espacio de Arte y Sociedad, 12(16), 7-26.

Gran Canaria Patronato del Turismo (2020). Estadísticas turísticas por zonas 2019 - Gran Canaria. Página web. Recuperado el 8/05/2020 de: http://www.grancanaria.com/turismo/fileadmin/PDF/informes/zonas/ ETZ_gc_2019.pdf

Hall, J. y Braithwaite, R. (1990). Caribbean cruise tourism: A business of transnational partnerships. Tourism Management, 4(11), 339-347.

Hernández Luis, J. Á. (2008). El turismo de masas evolución y perspectivas. Madrid: Editorial Síntesis. 
Hernández Luis, J. Á., Del Chiappa, G. y Battino, S. (2015). Percepción de los residentes de las Palmas de Gran Canaria ante el turismo de cruceros. Vegueta, 15, 287-316.

ISTAC (Instituto Canario de Estadística). 2018-2019. Recuperado el 19/01/2020 de: http://www.gobiernodecanarias.org/istac/

Jones, R. (2011). Motivations to cruise: An itinerary and cruise experience study. Journal of Hospitality and Tourism Management, 18(1), 30-40.

Jordan, E. J. y Vogt, C. A. (2017). Residents' Perceptions of Stress Related to Cruise Tourism Development. Tourism Planning \& Development, 14 (4), 527-547.

Lawton, L. y Butler, R. (1987). Cruise ship industry-patterns in the Caribbean 1880-1986. Tourism Management, 4 (8), 329-343.

Lopes, M. J. y Dredge, D. (2017). Cruise Tourism Shore Excursions: Value for Destinations? Tourism Planning \& Development, 15 (6), 633-652. Doi: 10.1080/21568316.2017.1366358.

López, P. (2011). Explosión del tráfico de cruceros en el Mediterráneo y su impacto en las ciudades portuarias. PortPlus, 1, 1-10.

Martí, B. (1992). Passenger perceptions of cruise itineraries. Marine Policy, 24(5), 360-370.

McCarthy, J. (2017). Maximising cruise tourism outcomes in small-medium cruise ports: lessons from Atlantic Canada. Urban Research \& Practice, 11 (4), 289-313.

MacNeill, T. y Wozniak, D. (2018). The economic, social, and environmental impacts of cruise tourism. Tourism Management, 66, 387-404.

Milano, C. (2017). Overtourism y turismofobia: Tendencias globales y contextos locales. Barcelona: Ostelea School of Tourism \& Hospitality.

No Grandi Navi (2013). Página Web. Recuperado el 15/12/2019:

http://www.nograndinavi.it/no-grandi-navi-a-venezia-davide-contro-golianel-canale-della-giudecca/

Otero, I. (20/04/2014). Mercados Municipales para el siglo XXI. El Diario. Recuperado el 16/12/2019 de:

https://www.eldiario.es/canariasahora/premium_en_abierto/Mercados-Municipales-siglo-XXI_O_251275091.html

Pallis, T. (2015). Cruise Shipping and Urban Development: State of the Art of the Industry and Cruise Ports. International Transport Forum, Discussion Paper 2015-14, 1-67.

Paoli, C., Vassallo, P., Dapueto, G., Fanciulli, G., Massa, F., Venturini, S. y Povero, P. (2017). The economic revenues and the emergy costs of cruise tourism. Journal of Cleaner Production, 166, 1.462-1.478.

Perić, T., Komadina, P. y Račić, N. (2016). Wastewater pollution from cruise ships in the Adriatic Sea. Traffic\&Transportation, 28 (4), 425-433.

Perić, T. y Račić, N. (2017). Analysis of cruise ship traffic in the Adriatic Sea considering MARPOL Annex IV Areas of limited wastewater discharges. In 
Atti 7th International Maritime Science Conference (April 20th-21st, 2017), Solin (Croazia), 243-255.

Pichler, A. (06/12/2012). FilmAffinity. Recuperado de: https://www.filmaffinity.com/es/film 730658.html

Pino, G. y Peluso, A. M. (2018). The development of cruise tourism in emerging destinations: Evidence from Salento, Italy. Tourism and Hospitality Research, 18 (1), 15-27.

Qu, H. y Ping, E. W. Y. (1999). Service performance model of Hong Kong cruise travelers' motivation factors and satisfaction. Tourism Management, 20 (2), 237-244.

Rosa-Jiménez, C., Perea-Medina, B., Andrade, M. J. y Nebot, N. (2018). An examination of the territorial imbalance of the cruising activity in the main Mediterranean port destinations: Effects on sustainable transport. Journal of Transport Geography, 68, 94-101.

Sabato, G. (2018). Crociere e crocieristi: itinerari, immaginari e narrazioni. Torino, Giappichelli.

Soriani, S., Buono, P., Camuffo, M., Dalla Via, M. y Tonino, M. (2015). Un'indagine sull'adozione della gestione integrata della zona costiera in Alto Adriatico. Risultati e valutazioni critiche. Rivista Geografica Italiana, 122, 95-118.

Sorrentino, A., Risitano, M., Del Chiappa, G. y Abbate, T. (2019). Profiling cruise passengers in a Mediterranean port-of-call. Anatolia - Journal of Tourism and Hospitality Research, 30, 279-290.

Strazza, C., Del Borghi, A., Gallo, M. y Manariti, R. (2015). Investigating of green practices for paper use reduction onboard a cruise ship - a life cycle approach. The International Journal of Life Cycle Management, 20, 982-993.

Teye, v. B. y Leclerc, D. (1998). Product and Service Delivery Satisfaction Among North American Cruise Passengers. Tourism Management, 19 (2), 153-160.

Torres, E. J. (Noviembre de 2009). Prólogo. En E. Torres, (Presidencia), XIV Congreso de la Asociación Española de Expertos Científicos en Turismo. Gijón, 18,19 y 20 de noviembre de 2009.

Whyte, L. J. (2017). Understanding the relationship between push and pull motivational factors in cruise tourism: a canonical correlation analysis. International Journal of Tourism Research, 19 (5), 557-568. 



\title{
MULTIPLICIDAD DEL TERRITORIO COMO CONCEPTO DE ANÁLISIS GEOGRÁFICO DE LAS CIUDADES: EL CASO DE LAS PALMAS DE GRAN CANARIA
}

\section{SPATIAL MULTIPLICITY AS A CONCEPT OF GEOGRAPHICAL ANALYSIS OF CITIES: THE CASE OF LAS PALMAS DE GRAN CANARIA}

\author{
JoRdi Boldú HeRnÁNDEZ \\ Universidad de Las Palmas de Gran Canaria \\ Lorena Naranjo Almeida \\ Universidad de Las Palmas de Gran Canaria
}

Resumen

La ciudad de Las Palmas de Gran Canaria es el centro administrativo y vital de un área metropolitana de tamaño medio. Se enmarca en un estatus de dominio especializado por las relaciones funcionales de economía de servicios, ocio-comerciales, y de relaciones laborales con su entorno más inmediato. Como ciudad residencial destacan tres realidades: el espacio litoral de alta densidad caracterizado por su dimensión histórica, el carácter suburbial de alta densidad de la ciudad alta y un espacio periurbano de baja densidad de uso heterogéneo en contacto con la transición hacia áreas rururbanas. El análisis geográfico basado en el esquema metodológico del pensamiento crítico de la «trialéctica espacial», de Henri Lefebvre y Edward Soja, permite el acercamiento a su realidad metropolitana, a través de un enfoque que, sumado a nuevos conceptos como la conectividad o vialidad, optimizan los esfuerzos para encuadrar este tipo de análisis propios de la geografía regional. Son, por tanto, la multiplicidad del territorio y sus variantes dimensionales herramientas clave para el urbanismo y los estudios de las transformaciones urbanas.

Palabras clave: geografía urbana, urbanismo, transformaciones urbanas, áreas metropolitanas, nuevas centralidades, conectividad.

\section{Abstract}

The city of Las Palmas de Gran Canaria is the administrative and vital center of a medium-size metropolitan area. It is underpinned by a status of specialized domain for multiple functional relations regard to service economy, business and leisure practices, and labor relations with its immediate surrounding area. As a residential city, three realities stand out: the high-density coastal space characterized by its historical dimension, the high-density of the upper town suburbs, and a multipurpose low-density peri-urban space in transition to rururban areas. 
The geographical analysis based on the methodological scheme of the critical thinking of the trialectics of spatiality, by Henri Lefebvre and Edward Soja, allows the approach to its metropolitan reality, through an method that, added to new concepts such as connectivity or roads, optimize efforts to frame this type of analysis typical of regional geography. Therefore, the multiplicity of the territory and its dimensional variants are key tools for urban planning and studies of urban transformations.

Keywords: urban geography, urban planning, urban transformations, metropolitan areas, new centralities, connectivity.

\section{INTRODUCCIÓN}

Las Palmas de Gran Canaria, capital insular, provincial y regional _ junto a Santa Cruz de Tenerife- , es la ciudad canaria más extensa y habitada, además, se posiciona como una de las mayores áreas metropolitanas de España. Con una población residente que alcanza los $379.925^{1}$ responde a una compleja tipología de su espacio urbano cuya dimensión espacial dificulta el encaje de la ciudad en el marco de su región urbana.

Figura 1. Situación y emplazamiento del ámbito de estudio, Tamaraceite Sur

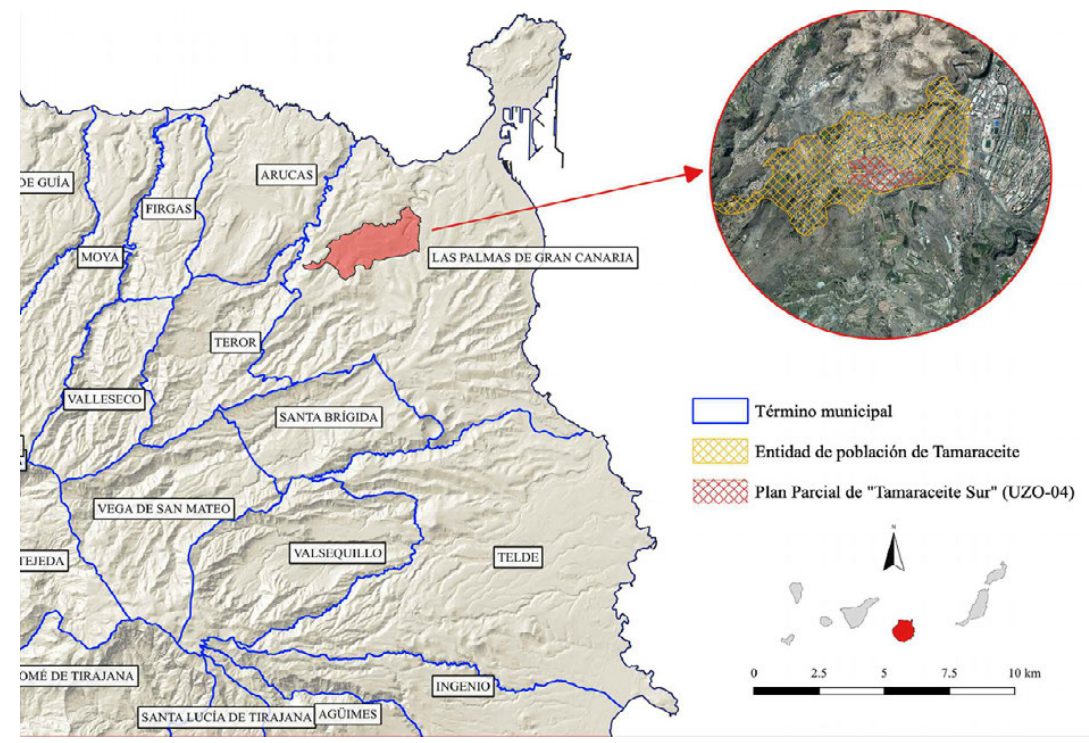

Fuente: Elaboración propia

1 A partir de datos del padrón continuo a 1 de enero de 2019 (INE, 2020). 
Esto, supone una de las premisas principales para abordar la línea de estudio de la presente comunicación, cuyos objetivos se reducen a la búsqueda del esquema urbano que configura la ciudad de Las Palmas de Gran Canaria y su área urbana, y el papel que juega la entidad de población de Tamaraceite en el segundo borde del anillo metropolitano (Figura 1 de la página anterior). Todo ello, a través de la puesta en práctica de un cuadro metodológico que rescata las tesis radicales de segunda mitad del siglo XX, la trialéctica del espacio de Henri Lefebvre, una interesante lógica de análisis de las transformaciones urbanas.

El enfoque metodológico se complementa en dos líneas de investigación, de una parte, la lectura bibliográfica se ayuda de la investigación cualitativa de interés, a partir de entrevistas semiestructuradas a actores de relevancia en el marco del urbanismo, la movilidad y la gestión y gobernanza pública de proximidad (Tabla 1). De otra parte, la segunda vertiente metodológica pretende definir el encuadre de la región urbana de la ciudad de Las Palmas de Gran Canaria desde el enfoque metodológico de la multiplicidad y la dimensionalidad a través de Sistemas de Información Geográfica.

Tabla 1. Entrevistas semiestructuradas a actores de relevancia

\begin{tabular}{|l|l|l|}
\hline \multicolumn{1}{|c|}{ NOMBRE COMPLETO } & \multicolumn{1}{|c|}{ PERFIL } & FECHA \\
\hline Jonathan Tabares Sicilia & Socio de Urbanfix & 2 de junio de 2020 \\
\hline Mónica Palacios Parada & Vicepresidenta de Las Palmas en Bici & 3 de junio de 2020 \\
\hline José Alberto Pérez López & $\begin{array}{l}\text { Monitor sociocultural de la Concejalía de } \\
\text { Distrito de Tamaraceite-San Lorenzo-Tenoya }\end{array}$ & 4 de junio de 2020 \\
\hline
\end{tabular}

Fuente. Elaboración propia

\section{MULTIPLICIDAD EN EL TERRITORIO Y DIMENSIONALIDAD COMO CONCEPTOS DE ANÁLISIS}

El interés por dotar de sentido al concepto de multiplicidad nos traslada al pensamiento filosófico y su búsqueda por dar respuesta a los interrogantes y ambigüedades que presentaba el citado término en la esfera de las ciencias más estrictas. La multiplicidad entendida como una lógica epistemológica, por tanto, rescata la corriente wittgensteineana de principios de siglo XX. El filósofo y matemático Ludwig Wittgenstein, en su afán por reemprender las implicaciones sobre el término que marcó el Movimiento Tractariano, determinó la multiplicidad como un concepto combinado de elementos (red de relaciones): caracterización de formas, por un lado, y diversificación de contenidos, por otro (Knabenschuch, 2003). 
Por tanto, la multiplicidad aplicada a las ciencias sociales que estudian lo urbano vendría a entender dichos espacios como territorios de confluencia, interconectados, dinámicos y de un imbricado conjunto de expresiones. Algunos acercamientos contemporáneos incluyen esta perspectiva: la ciudad, entendida como un lugar de encuentro de diversas realidades y flujos que terminan conformando el espacio público (Borja, 2011).

Partiendo de esta premisa de ciudad como «organismo vivo», la dimensionalidad se articula como otro concepto de interés para las ciencias urbanas. Por una parte, la dimensionalidad espacial o física, donde la escala, es el elemento protagonista para cualquier tipo de estudio o diagnóstico urbano. Por otro lado, la dimensión temporal, donde la historia se articula como la cultura de la ciudad y el futuro como el reto o las áreas de oportunidades. Las consecuencias sobre el espacio o territorio habitado son el resultado de problemáticas enmendadas según la perspectiva de estas dimensiones, es decir, las intervenciones urbanísticas tendrán consecuencia directa sobre las personas según la óptica de análisis: la escala ciudad, distrito, barrio, calle, hogar o humana. Borja et al. (2003), en su observación sobre la dimensión espacial ilustra una ciudad con tres realidades de análisis geográfico o, como bien destaca, tres dimensiones. De una parte, la dimensión administrativa que circunscribiría la ciudad a su realidad más inmediata, de componentes político-administrativas y jurídicas, esto es, el ámbito electoral y de gestión pública. Asimismo, una dimensión de componente físico-funcional y que atiende a aspectos meramente utilitarios: la ciudad de las personas o la ciudad real, aquella que desborda los límites administrativos.

Por último, añade una tercera dimensión o escala, la región urbana o la ciudad de ciudades, aquella que incluye su periferia y con vocación de construir una fuerte articulación en cuyo marco se puede dar una movilidad cotidiana significativa (Borja et al., 2003, 37).

La ciudad ha sido siempre un fenómeno cambiante, tanto en su escala como en su estructura territorial, tanto en sus formas de gobierno y organización como en las culturas y en los comportamientos urbanos.

Otra cosa es que en nuestro imaginario cada uno tenga una visión aparentemente unívoca de ciudad. Aunque menos de lo que parece. Se identifica ciudad con una realidad histórica, física y simbólica. (Borja et al., 2003, 35).

De otra parte, la dimensionalidad temporal hace referencia a su historia. La ciudad no es otra cosa sino una cronología de circunstancias e hitos historiográficos proyectados sobre su paisaje, su arquitectura, sus circuitos de movilidad, su cultura y sus sentimientos de pertenencia y arraigo a los lugares, entre muchos otros elementos que en ella confluyen. A su vez, también conforma una arquitectura trilateral: la ciudad histórica, la ciudad moderna y la ciudad futura.

Los límites urbanos son, considerablemente, difíciles de encajar o definir, esto nos lleva a articular un sistema adecuado de análisis con el objetivo funda- 
mental de prestar un servicio de respuesta, lo más adecuado posible, para con la ciudadanía y su espacio. Este condicionante ayuda a explicar el marco teórico de Henri Lefebvre en su «dialéctica de la triplicidad», alejándose de las ideas neopositivistas de segunda mitad de siglo XX que proponían generalizar el espacio y aproximar los estudios territoriales a la «Geografía de los Modelos» (Baringo, 2013). Lefebvre (1974), por el contrario, concebía la ciudad como un territorio activo, fértil y no, así, desprovisto de sentido.

En consecuencia, el filósofo francés proponía estudiar las urbes desde tres dimensiones espaciales: el territorio físico, social y mental. Una trialéctica geográfica explicada desde acercamientos conceptuales definidos como el espacio concebido (l'espace conçu), representaciones del espacio, aquel que es socialmente dominante, sujeto a las relaciones productivas de la sociedad y utilizado por los expertos del urbanismo. El espacio vivido (l'espace véçu), espacios de representaciones, estrechamente ligado a su población, interpretado, simbólico y apropiado por su ciudadanía. Y, por último, el espacio percibido (l'espace perçu), prácticas espaciales, los que integran las relaciones sociales de producción y reproducción, en especial la división del trabajo, la interacción entre gente de diferentes grupos de edad y género, la procreación biológica de la familia y la provisión de la futura fuerza de trabajo (Baringo, 2013, 124).

En esta línea, le siguieron muchos autores como Michel Foucault, François Ascher o Milton Santos, pero especialmente Edward Soja, cuya fascinación por Lefebvre y su tesis de la «trialéctica espacial» marcó un hito en su trayectoria de pensamiento, y de especial relevancia e impacto para la geografía regional, primero con The Socio-Spatial Dialectic y, posteriormente, con Thirdspace (Morente et al., 2012). Los autores citados se interesaron, principalmente, por esa tercera dimensión espacial, el espacio o el paisaje vivido, fundamental para marcar la frontera entre las teorías más estrictas como el neopositivismo y las corrientes más críticas.

En relación con las corrientes de pensamiento encontradas en el escenario revulsivo de los paradigmas radicales, entre otros aspectos, el conflicto se reducía a las posturas, diametralmente opuestas de concepción del espacio. Esencialmente, el «espacio» entendido desde su acepción más capitalista y geométrica correspondía con esa perspectiva neopositivista que lo definía como contenedor de recursos para el desarrollo y la transformación. El de un escenario único y continuo de relaciones y formas representativas como testimonio de una historia escrita por los procesos evolutivos.

En cambio, el concepto de «lugar» atendía a una respuesta más en la línea de los pensamientos críticos, dotándolo de un significado, si cabe, más impreciso y orgánico. Los lugares entendidos, por tanto, como espacios con límites más difusos al ser reconocidos e interpretados por las personas que los viven y perciben, resultado de la interacción entre un grupo social y el ambiente en el que se desarrolla. También es único y particular, pero irreproducible, al 
estar íntimamente ligado a sus usos, cotidianidad y significado simbólico (Hagget, 1994).

En la actualidad, el geógrafo catalán Jordi Borja et al. (2013) aborda, en su libro La ciudad conquistada, la tesis de Lefebvre desde una interesante óptica múltiple para definir los espacios que ocupa la ciudad. Con relación a la trialéctica del espacio, define ciudad con tres escenarios inmediatos: la ciudad real, la ciudad oficial y la ciudad ideal. Así, la primera se equipararía con el área metropolitana, diferenciándola de la ciudad oficial, (el municipio). En último lugar, la ciudad ideal la identifica con la interpretada por sus ciudadanos (la ciudad de la memoria y de la identidad) y, por ende, con arraigo cultural e histórico.

\section{LAS PALMAS DE GRAN CANARIA Y SU ENCUADRE EN LA REGIÓN URBANA}

Las relaciones funcionales son, por tanto, el primer acercamiento para entender la ciudad y definir su encuadre urbano, un análisis territorial que coliga con el concepto wittgensteineano de multiplicidad aplicado a las ciencias geográficas de análisis regional. Las Palmas de Gran Canaria y su entorno inmediato obedecen a un modelo espacial de funcionalidad mixta y fuertemente condicionada por su topografía.

Por un lado, la ciudad baja, a lo largo de su plataforma litoral, concentra las funciones principales ocio-comerciales, ocio-turísticas, laborales, de servicios y residenciales. La ciudad alta, responde a funciones, principalmente, residenciales de alta capacidad y de tipología de crecimiento urbano por lotes promocionales. Un espacio que viene definido por la lógica del mercado inmobiliario y en el que, recientemente, se han establecido grandes dotaciones comerciales (Capel, 2013).

Por último, las zonas periurbanas del municipio se configuran como espacios de usos mixtos de transición hacia áreas de tradición más rural con poblamiento disperso y caracterizado por núcleos poblacionales de baja densidad en convivencia con barrios de tipología suburbial.

El carácter histórico de ciudad sujeta a su economía de exportación de productos agrícolas ha venido marcando su crecimiento desde su núcleo fundacional, en el barrio de Vegueta, hacia el Puerto, en la Bahía de las Isletas. Una estrecha relación de dependencia con el exterior que conforma uno de los hitos principales en su primera dimensión temporal, la histórica, en la que no debe obviarse, otros enclaves tradicionales de referencia que servían de abastecimiento agrícola, como San Lorenzo, el segundo núcleo histórico de referencia de la ciudad (Figura 2). 
Figura 2. Dimensión histórica de la ciudad de Las Palmas de Gran Canaria y su área metropolitana directa

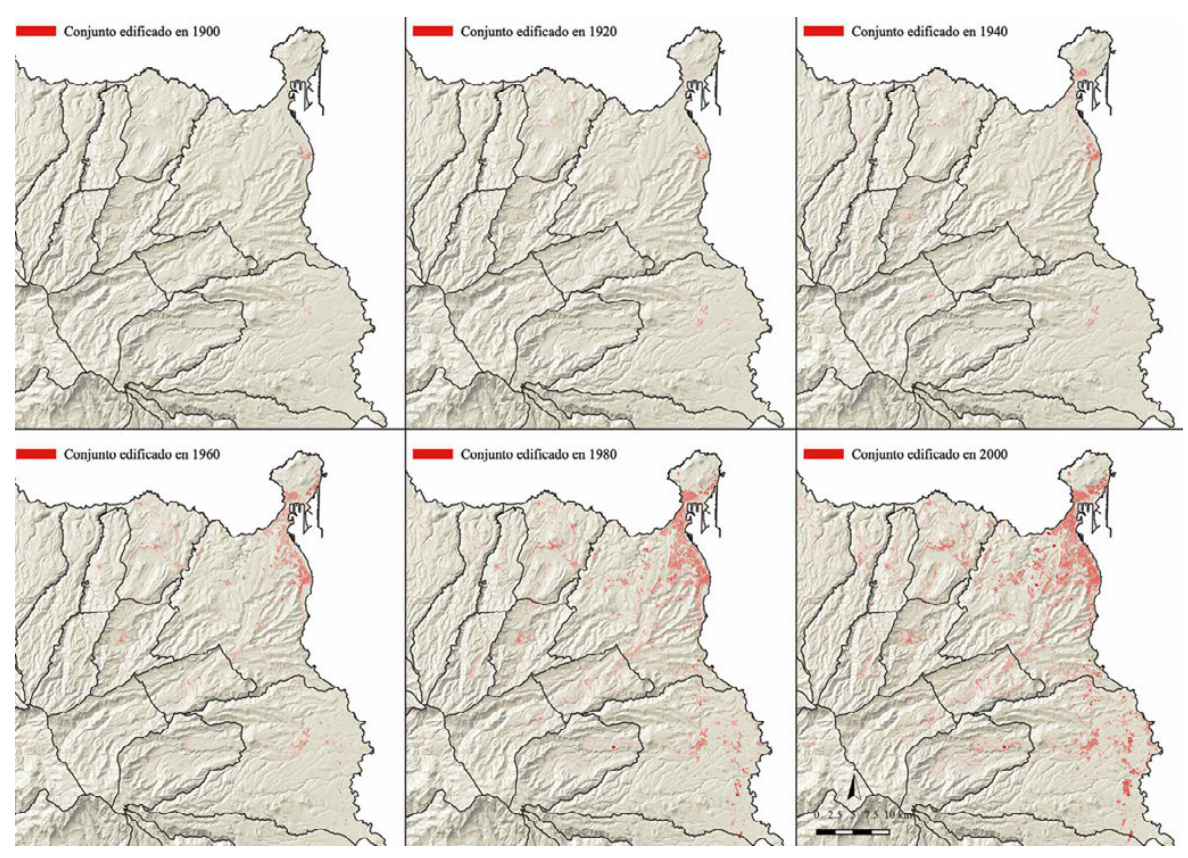

Fuente: Elaboración propia, a partir de datos de la Dirección General del Catastro. 2020

El encuadre de la región urbana es el aspecto que suscita más debate y mayores interpretaciones. Desde un punto de vista morfológico, el desplazamiento parte del eje económico tradicional del norte de la isla, desde Agaete, pasando por Gáldar hasta Telde, hacia uno ex-novo, Las Palmas de Gran Canaria-Sur, el cual dibuja un continuo urbano por toda la franja litoral oriental y de fuerte implicación estructural y estratégica.

Su relación (Las Palmas de Gran Canaria) con el resto del territorio ha estado vinculada principalmente a cuestiones suprainsulares y los nodos que las resuelven; así, podemos dibujar un arco Norte que incluye el Puerto de Agaete, su relación con Tenerife y el nodo de población que lo articula (Gáldar) [...] y Maspalomas, su relación internacional y Telde-Vecindario como núcleos de población y servicios, como el aeropuerto, para el arco Este [Jonathan Tabares, 2 de junio de 2020].

Hacia el sur de la capital, se extiende la comarca del Sureste, vertebrada por la GC-1, y que mantiene una relación bidireccional, por un lado, de bienes y servicios con la ciudad, y con el sur, por la fuerza que ejerce la industria turística de Maspalomas y Costa Mogán. 
Otra apreciación pone sobre la mesa la idea de «isla-ciudad» como región urbana, al entender que el ámbito insular está supeditado a una relación de dominación con la actividad económica de la isla y su capital. Este concepto adquirió importancia con la tercerización de la economía canaria y el desarrollo turístico del Sur. La subsecuente explosión demográfica propició una elevada proporción de concentración urbana en los municipios del eje oriental. Esta consideración del espacio metropolitano adolece de falta de rigor porque, a pesar de estar determinados por unos límites físicos ineludibles, es la misma geografía la que confina el desarrollo de otros núcleos con cierto grado de ruralidad, aislamiento y lejanía.

El concepto de isla-ciudad no es compartido por ninguno de los entrevistados, Mónica Palacios añade, además, que esa idea no se sostiene en absoluto, teniendo en cuenta el papel que juega la Reserva de la Biosfera, un importante enclave patrimonial ubicado en la vertiente suroeste de la isla. Palacios se inclina por interpretar un continuo urbano en forma de media luna que iría desde Agaete hasta la localidad de Arguineguín en el municipio de Mogán, el resto de la isla cumple la función de parque de la zona urbana [Mónica Palacios, 3 de junio de 2020].

\subsection{ESTUDIO METROPOLITANO DESDE LA TRIALÉCTICA ESPACIAL}

Desde un análisis más conceptual, y siguiendo la línea marcada por el marco lógico, el límite administrativo de Las Palmas de Gran Canaria conformaría la «ciudad oficial» o el espacio concebido de las teorías de Lefebvre y Soja, mientras que la «ciudad real» o el espacio vivido correspondería con el área metropolitana. Finalmente, la «ciudad ideal» se reduciría al espacio consolidado de Las Palmas de Gran Canaria, es decir, a los barrios que conforman la ciudad baja y la ciudad alta, hasta el límite con la circunvalación GC-3 y el Barranco de Tamaraceite por el noroeste, estructuras que actúan de frontera y cuya explicación se aborda en el siguiente epígrafe (Figura 3).

El esquema propuesto para definir un mejor encuadre del área metropolitana de Las Palmas de Gran Canaria toma partido de novedosos estudios de la ciudad, desde la óptica de la movilidad y la accesibilidad. Estos, permiten atribuir al urbanismo nuevos indicadores de referencia como la conectividad, la vialidad, la circulación y la velocidad para entender mejor la multiplicidad del territorio y sus relaciones (Santos y Rivas, de las, 2008).

De esta manera, algunos estudios de la conectividad de las ciudades con su entorno metropolitano reflejan una realidad que se asemeja a los buffers o zonas de influencia de un área de dominio. A fin de cuentas, se trata de un proceso de análisis espacial que calcula los tiempos de conexión desde un punto de partida a través de su sistema viario, teniendo en cuentan indicadores de vialidad (cualidad y calidad de los viales), hacia los núcleos de su área de influencia. 
Figura 3. Esquema conceptual de análisis de la multiplicidad y dimensionalidad espacial

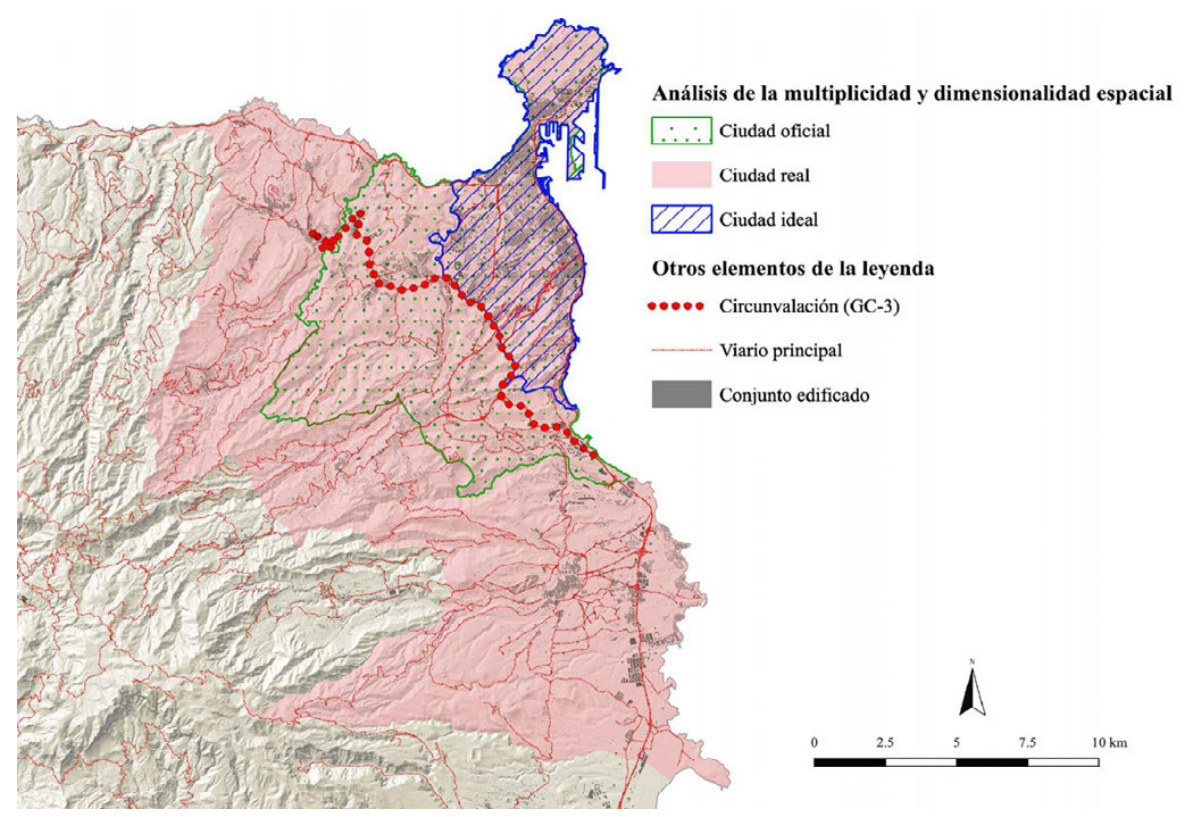

Fuente: Elaboración propia. 2020

Por tanto, considerando que la distribución modal de la movilidad en Las Palmas de Gran Canaria es, principalmente intramunicipal y está subordinada al vehículo privado (67\% del total) ${ }^{2}$ frente a otros modos de transporte; y a unas pautas de traslados donde predominan las de motivos laborales, las de asunto personal, de ocio y comerciales, la presión que ejerce esta modalidad es crítica.

Trasladado este contexto al estudio de área metropolitana y sus relaciones de funcionalidad más directa, se establece, desde su núcleo fundacional, un área de influencia de unos $5 \mathrm{~km}$ lo que, aproximadamente, se traduce en traslados cortos que rondarían entre los 15 y 20 minutos en transporte rodado. Explicado esto, el área metropolitana de primer orden se circunscribe, entonces, dentro del término municipal de Las Palmas de Gran Canaria, en lo que se ha definido como ciudad ideal y que abarcaría toda la ciudad baja y parte de la ciudad alta hasta la barrera del viario de alta capacidad (GC-3) (Figura 4).

2 Según el diagnóstico de la movilidad del Ayuntamiento de Las Palmas de Gran Canaria (2010-2011) contenido en el documento LPA_GC Movilidad en Transformación en https://www.laspalmasgc.es/export/sites/laspalmasgc/.galleries/documentos-otrassecciones/LPA-GC-Movilidad.pdf 
Figura 4. Estudio del área metropolitana de Las Palmas de Gran Canaria

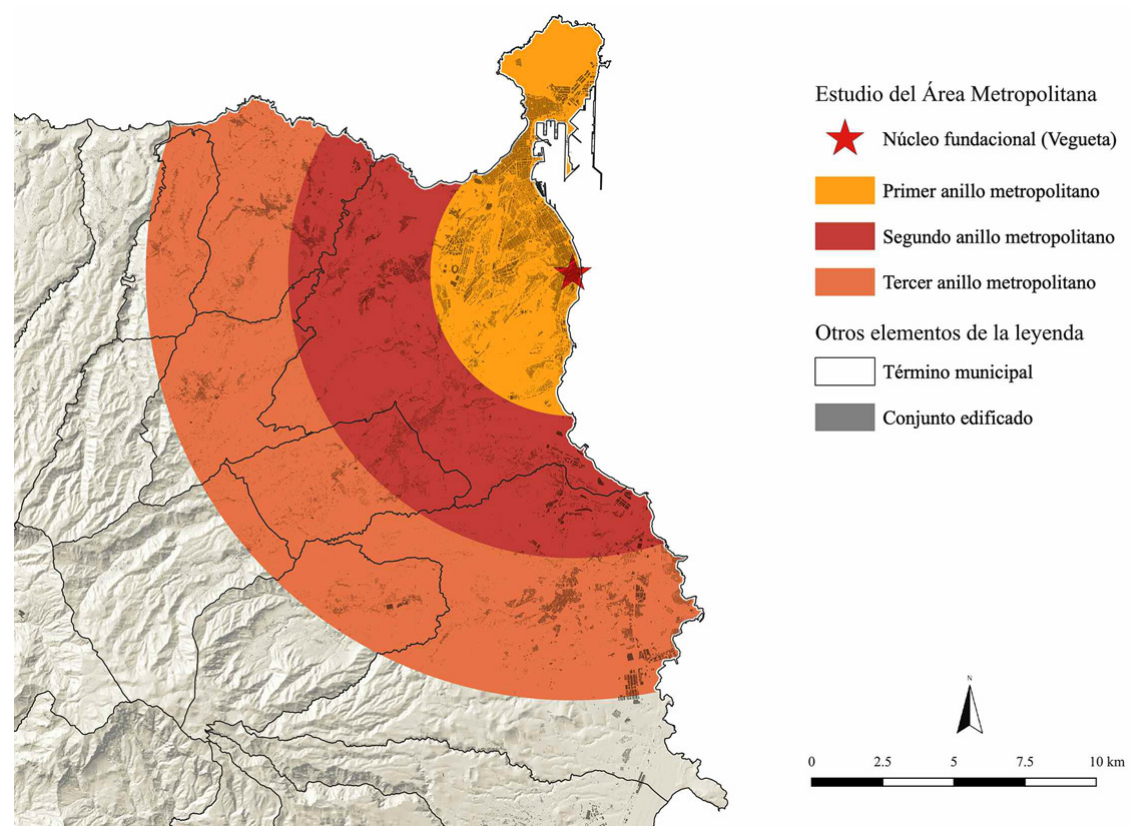

Fuente: Elaboración propia. 2020

Continuando con este modelo de análisis, el segundo anillo metropolitano correspondería con la transición hacia los espacios periurbanos del municipio en relación con las fronteras de los municipios limítrofes de Arucas, Santa Brígida y Telde. Abarcando núcleos como Almatriche, Ciudad del Campo, Los Giles, Marzagán, Las Mesas, San Lorenzo, San Francisco de Paula, Tafira, Tamaraceite o Tenoya, en Las Palmas de Gran Canaria; Cañada de los Perros, Las Goteras, Jinámar, La Majadilla o La Pardilla en Telde; La Angostura, Bandama, Monte Lentiscal, Los Olivos o El Reventón en el municipio de Santa Brígida; Cardones, Lomo Espino, San Francisco Javier, San Gregorio o Santidad en Arucas. El tercer y último borde del anillo metropolitano, esto es, $15 \mathrm{~km}$ de radio para el área de influencia desde el barrio capitalino de Vegueta abarcaría el resto del territorio municipal de Arucas y Santa Brígida y la mayor parte de Telde, salvo su extensión hacia la cumbre, y los núcleos de Cuatro Puertas, El Goro, Ojos de Garza y Piletillas hacia el extremo meridional en continuación por el corredor que vertebra la autopista (GC-1). Por otra parte, anexiona núcleos en contacto más directo con la ciudad de los municipios de Firgas, Teror, Valsequillo y la Vega de San Mateo. 


\section{ANÁLISIS DE LA TRANSFORMACIÓN URBANA DE LAS PALMAS DE GRAN CANARIA: EL PLAN PARCIAL "TAMARACEITE SUR»}

\subsection{TAMARACEITE EN EL ENCUADRE URBANO DE LAS PALMAS DE GRAN CANARIA}

Tamaraceite representa, actualmente, un paisaje convulso de diversas tipologías urbanísticas producto de una incesante historia de cambios trascendentales. Ubicado de espaldas a una vega agrícola, en una intercuenca entre los Barrancos de Guiniguada y Tenoya, su origen se remonta a un pequeño núcleo periférico perteneciente al extinto municipio de San Lorenzo y que sirvió de campo para lo que, hoy día, es la ciudad ideal.

En el presente, tal y como se viene señalando, Tamaraceite quedaría fuera de ese esquema dialéctico de dimensión lógica de la ciudad ideal por diversos factores, principalmente, de conectividad, de índole fisionómico-geográfico y de arraigo cultural.

La conectividad con el centro urbano es una tarea aún no resuelta y que dificulta el contacto y la cercanía con los enclaves neurálgicos de la ciudad ideal. Hay que tener en cuenta que la entrada más inmediata es la circunvalación (GC-3), lo que lo dota de una paradójica percepción ciudadana de estar entrando en una nueva ciudad. A este respecto, se le presenta una problemática que el sistema viario de la circunvalación ha acrecentado, principalmente, con la conexión hacia sus núcleos próximos como San Lorenzo, La Suerte o Los Giles.

Barrios semidispersos en el territorio o fragmentados por vías de alta capacidad o ejes de tráfico redado no adaptado para los peatones. Realidad aún más compleja si se tiene en cuenta que la población que reside en estos espacios, acostumbrada a andar por zonas no urbanizadas como caminos o sendas, ya no pueden hacer los recorridos habituales por los riesgos que conllevan ciertos lugares. (Ayuntamiento de Las Palmas de Gran Canaria, 2017, 32). Su alejada localización con el centro histórico de Vegueta-Triana, sumado a una enrevesada fisionomía geográfico-paisajística, lo posicionan como un espacio dividido por fronteras tanto antrópicas como naturales, el Barranco de Tamaraceite y la circunvalación (GC-3), ambas limitantes en lo que a relación positiva con dicho centro se refiere.

\subsection{TAMARACEITE ¿UNA NUEVA CENTRALIDAD?}

Es indudable, que la transformación que, hoy por hoy, sufre el borde del segundo anillo metropolitano, en conexión directa con los municipios de Santa Brígida, Teror y Arucas, se presenta como una de las áreas de oportunidad para la planificación territorial y, desde luego, de las que mayor reto asume dada su fragilidad territorial y paisajística, además de, responsabilidad estratégica (Casariego y Ley, 2005). 
Pero no cabe olvidar la paradoja de Tamaraceite en relación con su verdadero núcleo fundacional, este es, San Lorenzo. Lo que hoy se presenta como una nueva centralidad, ayer era periferia de la pequeña centralidad que pivotaba alrededor de la iglesia y plaza de San Lorenzo. Los crecimientos urbanos, como tradicionalmente han ido sucediéndose en otras áreas de Gran Canaria, se fueron vertebrando en los márgenes de las vías de comunicación [Jonathan Tabares, 2 de junio de 2020] y las lógicas del mercado han terminado por funcionar como pequeños lobbies que condicionan al urbanismo. La apuesta decidida por el modelo de grandes parques comerciales, el objetivo principal del UZO-04 y que, precisamente, se trataba del único distrito municipal que no contaba con este tipo de equipamientos, además de concentrar el reparto modal de los traslados en los vehículos privados, ejerce una presión ex nova y que se recrudece, si cabe, teniendo en cuenta el exuberante patrimonio natural y cultural que colinda en los alrededores de la parcela ocupada 3 (Armengol y González, 2007).

Es en estos territorios en colindancia donde se encuentran en un delicado equilibrio provocado por la presión de la ciudad. La estrategia comercial de Las Palmas de Gran Canaria, que coloca grandes centros y parques comerciales en todos sus puntos de acceso, aparentemente es una estrategia de descentralización, sin embargo el hecho de duplicar en Tamaraceite el parque comercial de La Estrella (Telde) compromete áreas comerciales de la franja Norte prevista por el Plan Territorial Parcial-14 al sur de Gáldar, es decir, Las Palmas de Gran Canaria tiene una dinámica independiente y arrolladora con respecto a la dinámica insular: es el único municipio con una economía diversificada, concentra prácticamente la mitad de la población insular y duplica a la otra gran capital de Canarias, lo que viabiliza cualquier estrategia de implantación de servicios [Jonathan Tabares, 2 de junio de 2020].

Atendiendo a las estrategias públicas de marco jurídico, Tamaraceite sí se posiciona como una nueva centralidad para el municipio y así queda recogido en las determinaciones del Plan General de Ordenación (Plan Parcial Tamaraceite Sur - UZO-04). Los objetivos marcados en la planificación lo prevén como área de oportunidades de especial carácter estratégico. Todo ello, a través de la ejecución de un sistema general de dotaciones y equipamientos de espacio público de esparcimiento, instalaciones deportivas, socioculturales y otras de uso terciario para comercios, oficinas y servicios públicos.

3 Hacia el sur del Plan Parcial de Tamaraceite Sur (UZO-04) se extiende una vega agrícola con un sistema tradicional de charcas terrosas catalogadas como patrimonio etnográfico y natural y que sirven de soporte para avifauna nidificante y recalante estacional, además de contar con espacios con Hábitats de Interés Comunitarios y zonas interés tanto medioambiental como etnográfico recogidas en los catálogos de protección patrimonial del Ayuntamiento. Precisamente, la parcela que ocupa el UZO-04 localizó algunos de estos sistemas acuíferos, hoy día desaparecidos. 
Este esquema de ordenación territorial se presentó acompañado de un modelo de comunicaciones reforzado que permitiría constituir un marco que trascendiese el mero localismo de accesos y circulaciones interiores del Sector, estructurando las comunicaciones de la zona con idéntica vocación de centralidad que la expresada para su relación con el área metropolitana (Ayuntamiento de Las Palmas de Gran Canaria, noviembre de 2012).

Posterior a la aprobación definitiva del PGO de Las Palmas de Gran Canaria, el sector del UZO-04 fue objeto de modificación en 2018. Entre los aspectos por los que fueron naturaleza de cambios destacan, por un lado, las mejoras sustanciales de reforzamiento del viario principal, con el objetivo de optimizar la accesibilidad y las conexiones con sistemas viarios secundarios de núcleos y barrios periféricos. De otra parte, las determinaciones de nuevo suelo reserva para dotaciones educativas y culturales, así como, la designación de determinaciones de ordenación específica para equipamiento de espacios verdes y deportivo, en detrimento de aquellos inicialmente destinados a uso industrial. Por último, una significativa reordenación del Área de Centralidad Terciaria proyectada de cara a sus núcleos periféricos, especialmente, San Lorenzo y, así, intentar responder a la transición hacia los suelos de tradición más rural en el sector hacia el sur. Tal y como especifica el documento, trata de determinaciones de reordenación que contribuirán a dinamizar los espacios frágiles de su entorno más inmediato dado su carácter rururbano y que, a buen propósito, citan como espacios de oportunidades (Ayuntamiento de Las Palmas de Gran Canaria, noviembre de 2018).

\section{CONCLUSIONES}

Los conceptos de multiplicidad y dimensionalidad aplicados como metodologías de estudio para caracterizar el grado de urbanidad se establecen como herramientas que facilitan, considerablemente, la caracterización de las áreas metropolitanas; máxime, en geografías tan complejas como la canaria. Además, si se pretende atender el urbanismo más allá de pautas, excesivamente definidas, no se debiera dejar de lado las teorías críticas que rompieron con las tendencias del urbanismo más geométrico para colocar la escala hogar o humana en el centro del análisis espacial.

El esquema metropolitano propuesto, a pesar de definir un enfoque metodológico lo más preciso posible, no deja de atender a una apreciación subjetiva y de espacio percibido tanto por los autores que lo firman, dadas sus experiencias vividas en el territorio, como la de los actores relevantes entrevistados, y que han puesto de relieve las debilidades que presenta el espacio concebido. Unos límites definidos que, aplicados a la planificación y la gestión territorial, pueden presentarse como beneficiosas o valiosas para una parte como perjudiciales para otra. 
Dicho esto, las estrategias de centralidad adoptadas por la administración local del municipio de Las Palmas de Gran Canaria son el resultado de medidas de desahogo que necesita el centro urbano de la capital y, por consiguiente, las de su población, pero no responden a las necesidades reales de la población de los entornos limítrofes sino, como bien definía Horacio Capel, a sus lógicas del mercado inmobiliario.

Las necesidades de una ciudadanía urbana demandante de «suelo reserva» para esparcimiento, ocio, deporte, etc., no van a solucionar la dicotomía del periurbanismo o la rururbanización si no se le pone remedio a la debilidad y fragilidad que vienen sufriendo enclaves como San Lorenzo, El Román o Risco Negro.

\section{BIBLIOGRAFÍA}

Armengol Martín, M. T. y González Morales, A. (2007). Los centros comerciales en Las Palmas de Gran Canaria: dinámicas e impactos en el espacio urbano. Anales de Geografía de la Universidad Complutense, 27(1), 9-27. Recuperado de:

https://accedacris.ulpgc.es/bitstream/10553/58931/1/32049-Texto\%20del\%20 art\%C3\%ADculo-32066-1-10-20110609.PDF

Ayuntamiento de Las Palmas de Gran Canaria (noviembre de 2018). Modificación del Plan General de Ordenación de Las Palmas de Gran Canaria en el sector del UZO-04 «Plan Parcial-Tamaraceite Sur». Recuperado de: https://www.laspalmasgc.es/export/sites/laspalmasgc/.galleries/documentosurbanismo/Version-Inicial-doc-tecnico-T-SUR_Nov-2018.pdf

Ayuntamiento de Las Palmas de Gran Canaria (2017). Rehabilitación y regeneración urbana del casco histórico de Tamaraceite: Memoria de Diagnóstico Participativo. Las Palmas de Gran Canaria, España. Recuperado de: https://www.laspalmasgc.es/export/sites/laspalmasgc/.galleries/documentosdistrito-Tamaraceite-San-Lorenzo-Tenoya/REHABILITACION-Y-REGENERA CION-CASCO-HISTORICO-TAMARACEITE-MEMORIA-DIAGNPART.pdf

Ayuntamiento de Las Palmas de Gran Canaria (octubre de 2012). Memoria del UZO-04. Plan General de Ordenación de Las Palmas de Gran Canaria. Recuperado de:

https://sit.laspalmasgc.es/pgo_2012/navegacion/tecnico/pormenorizada/por_ anx_nor_uzo/por_anx_nor_uzo4.pdf

Baringo Ezquerra, D. (2013). La tesis de la producción del espacio en Henri Lefebvre y sus críticos: un enfoque a tomar en consideración. Quid 16. Revista del Área de Estudios Urbanos, (3), 119-135. Recuperado de: https://dialnet.unirioja.es/servlet/articulo?codigo=5593337

Borja, J. (2011). Espacio público y derecho a la ciudad. Viento Sur, 116(1), 39-49. Recuperado de: 
https://www.sistemamid.com/panel/uploads/biblioteca/7097/7128/7129/ 83427.pdf

Borja, J., Drnda, M., Iglesias, M., Fiori, M. y Muxí, Z. (2003). La ciudad conquistada. Madrid: Alianza Editorial.

Capel, H. (2013). La morfología de las ciudades: Agentes urbanos y mercado inmobiliario. III. Barcelona: Ediciones del Serbal.

Casariego Ramírez, J. y Ley Bosch, P. (2005). La construcción de los Nuevos Sub-Centros: El caso de Tamaraceite en Las Palmas de Gran Canaria. En J. Casariego y P. Ley (Eds.), La creación de los nuevos sub-centros: El caso de Tamaraceite en Las Palmas de Gran Canaria, pp. 15-20. Las Palmas de Gran Canaria: Exploraciones EX5.

Haggett, P. (1994). Geografía: una síntesis moderna. Barcelona: Ediciones Omega.

Knabenschuch, S. (2003). Multiplicidad y conocimiento: alcances y trasfondo de un concepto wittgensteineano. Ideas y Valores, 52(121), 3-39. Recuperado de:

https://revistas.unal.edu.co/index.php/idval/article/view/14470

Lefebvre, H. (1974). La production de l'espace. París: Editions Anthropos.

Morente, F., Benach, N. y Albet, A. (2012). Edward W. Soja o la reubicación del espacio en el debate de las ciencias sociales. Biblio.W Revista Bibliográfica de Geografía y Ciencias Sociales, 17. Recuperado de:

http://www.ub.edu/geocrit/b3w-977.htm

Santos y Ganges, L. y De las Rivas Sanza, J. L. (2008). Ciudades con atributos: conectividad, accesibilidad y movilidad. Ciudades, (11), 13-32. Recuperado de: https://157.88.20.48/index.php/ciudades/article/view/1274/1083 



\title{
PROCESOS DE CAMBIO EN LAS CIUDADES MEDIAS Y SUS ÁREAS URBANAS EN LA ESPAÑA DEMOCRÁTICA (1981-2019): EVOLUCIÓN DE LA POBLACIÓN
}

\section{CHANGE PROCESSES IN THE MEDIUM-SIZED CITIES AND THEIR URBAN AREAS IN DEMOCRATIC SPAIN (1981-2019): POPULATION EVOLUTION}

\author{
Luis Alfonso Escudero Gómez \\ Universidad de Castilla-La Mancha \\ José María Martínez Navarro \\ Universidad Autónoma de Madrid \\ Juan Antonio García González \\ Universidad de Castilla-La Mancha
}

Resumen

Las dinámicas de urbanización y sus características han alterado profundamente la estructura, forma y paisaje de las ciudades medias de España y sus áreas urbanas, que han resultado en estructuras urbano-territoriales complejas, fragmentadas y dispersas. La evolución de su población absoluta es una de estas dinámicas. El presente trabajo se analiza este aspecto en un marco temporal de referencia: los 40 años de la España democrática iniciada con la constitución de 1978. Con este fin, se recurre al censo de población de 1981, el primero democrático, y al padrón municipal más reciente (2019). Se analiza la evolución de las áreas urbanas medias españolas, con la tasa de crecimiento poblacional anual como técnica de comparación. Se comprueba que el país es más urbano. En él, las áreas de las ciudades medias han crecido a un ritmo superior que el de España. Son aquellas localizadas en el litoral mediterráneo y en el exterior del área urbana de Madrid las que tienen un mayor crecimiento. Las que han conocido un proceso de desindustrialización y gran parte de las áreas urbanas de interior capitales de provincia tienen una evolución poblacional menor. La divergencia y la heterogeneidad entre los casos es muy común. El trabajo supone una aportación a la literatura académica sobre las ciudades medias de España y es de utilidad para cualquier investigador o persona que tenga interés en el tema.

Palabras clave: ciudad media, área urbana, urbanización, España democrática.

\begin{abstract}
The dynamics of urbanization and its characteristics have profoundly altered the structure, form and landscape of Spain's medium-sized cities and their urban areas, resulting in complex, fragmented and scattered urban-territorial structures. The evolution of their absolute population is one of these dynamics.
\end{abstract}


This paper analyses this aspect in a time frame of reference: the 40 years of democratic Spain that began with the constitution of 1978. To this end, we use the 1981 population census, the first democratic one, and the most recent municipal census (2019). The evolution of the Spanish average urban areas is analysed, with the annual population growth rate as a comparison technique. It is verified that the country is more urban. In it, the areas of the average cities have grown at a higher rate than that of Spain. It is those located on the Mediterranean coast and outside the urban area of Madrid that have the greatest growth. Those that have undergone a process of deindustrialization and a large part of the urban areas in the interior of provincial capitals have a lower population evolution. Divergence and heterogeneity between cases is very common. The work is a contribution to the academic literature on the average cities in Spain and is useful for any researcher or person with an interest in the subject.

Keywords: medium-sized city, urban area, urbanization, democratic Spain.

\section{INTRODUCCIÓN}

Las dinámicas de urbanización y sus características han alterado profundamente la estructura, forma y paisaje de las ciudades medias de España, que han resultado en estructuras urbano-territoriales complejas, fragmentadas y dispersas. Las ciudades medias han experimentado así intensos procesos de transformación y han pasado a ser actores claves para la interactuación entre las diferentes escalas, aunque su papel depende de sus características y posición en las redes urbanas (Bellet y Olazábal, 2017). De este modo, las diferentes dinámicas y las características de los procesos de urbanización vienen muy condicionadas por la localización y los rasgos de los territorios en los que las áreas urbanas se insertan. Por ejemplo, Vázquez y Martínez (2020a) se plantean si en el interior de España las ciudades medias han sido el motor del crecimiento regional y si conforman la estructura organizativa del territorio o, por el contrario, han contribuido a absorber la población y los recursos desmantelando los espacios rurales que organizan. Estos autores concluyen que las respuestas no son únicas ni simples y parecen depender de la distancia con respecto a la ciudad media, de la ubicación de cada ciudad en relación con las estructuras urbanas policéntricas y del nivel previo de desarrollo y cultura territorial de cada región. Por esta razón, las ciudades medias del interior se sitúan entre la vertebración de nuevas estructuras urbanoterritoriales y el despoblamiento de sus entornos provinciales (Vázquez y Martínez, 2020b).

De manera general, las áreas urbanas de las ciudades medias se han expandido mediante la producción de suelo residencial de densidad media y baja alejados del núcleo principal, sobre todo en municipios periféricos, configu- 
rando extensas áreas urbanas complejas (Olazábal y Bellet, 2019). Este proceso de transformación de las ciudades medias en España, de una forma compacta a una forma dispersa, ha sido calificado como una metástasis territorial (Cebrián 2020).

Los autores del presente trabajo vienen desarrollando una labor de investigación centrada en las ciudades medias españolas y sus áreas urbanas en los últimos años. En sus publicaciones se puede ampliar el marco teórico de esta cuestión, aquí simplemente sintetizado, con referencias bibliográficas múltiples y actualizadas a estudios previos internacionales y, fundamentalmente, de la geografía española sobre la cuestión. Igualmente, en estas investigaciones anteriores se puede acceder a diversos resultados acerca de su evolución demográfica y constructiva en la etapa expansiva del boom inmobiliario y en la fase posterior de la Gran Recensión (García, Martínez y Escudero, 2018; Escudero, García y Martínez, 2019; García, Martínez y Escudero, 2020 y Martínez, García y Escudero, en prensa). Esta comunicación forma parte del proyecto «Ciudades medias españolas: urbanización y políticas urbanísticas. 40 años de Ayuntamientos democráticos» del Ministerio de Ciencia, Investigación y Universidades, actualmente disgregado en el Ministerio de Ciencia e Innovación y en el de Universidades, y del Fondo Europeo de Desarrollo (FEDER). El objetivo principal del presente trabajo es iniciar un análisis sobre la evolución de la población entre 1981 y 2019 de las áreas urbanas medias de España definidas por el Atlas Estadístico de las Áreas Urbanas del Ministerio de Transportes, Movilidad y Agenda Urbana. Los hallazgos obtenidos aportan una comprensión de las urbes de tamaño medio en España y de sus áreas urbanas desde una perspectiva evolutiva poblacional en las cuatro décadas pasadas del país en democracia. Es una contribución para añadir a la extensa y prolífica literatura académica acerca de las ciudades medias en España y también un balance necesario tras cuatro décadas de democracia en el país.

\section{METODOLOGÍA}

Este apartado presenta el método de análisis empleado, las fuentes utilizadas, así como el área de estudio sobre el que se ha aplicado.

\section{1. ÁREA DE ESTUDIO}

El área de estudio objeto de investigación son las ciudades medias de España y sus áreas urbanas. Sin embargo, su delimitación plantea graves problemas metodológicos. En publicaciones anteriores de los autores se han abordado extensamente estas dificultades (García, et al., 2018; Escudero et al., 2019; García et al, 2020 y Martínez et al., en prensa). Esta comunicación, como se ha indicado, forma parte de un proyecto coordinado «Ciudades medias españo- 
las: urbanización y políticas urbanísticas. 40 años de Ayuntamientos democráticos» del Ministerio de Ciencia, Investigación y Universidades donde participan más de 15 expertos en la materia. Tras un seminario realizado en León en octubre de 2020 se concluyó que es imposible delimitar cuáles son las ciudades medias de España por la complejidad de la red urbana del Estado, su evolución en las últimas décadas y, fundamentalmente, la debilidad de la propia definición de «ciudad media». Sin embargo, asumiendo este problema epistemológico, se llegó a un acuerdo para delimitar el área de estudio que es el que sigue el presente trabajo. Se optó, por una solución administrativa que si bien no es científicamente perfecta si es operativa. De esta forma, se asume la selección de las áreas urbanas del Atlas Estadístico de las Áreas Urbanas del Ministerio de Transportes, Movilidad y Agenda Urbana (anteriormente Ministerio de Fomento) (2020). A partir de ahí, se fijan los siguientes tres criterios para delimitar las áreas urbanas de las ciudades medias en España:

- La ciudad media debe tener un mínimo de 50.000 habitantes y un máximo de 250.000. No obstante, se incluyen las capitales de provincia con menor número de habitantes por sus funciones urbanas especializadas.

- Se excluyen aquellas ciudades medias cuyas áreas urbanas superan los 400.000 habitantes.

- No se tienen en cuenta las ciudades insulares, Ceuta y Melilla por su particular condición.

Las áreas urbanas y ciudades medias (16 áreas urbanas solo están formadas por su municipio central) finales son un total de 55 que agrupan 231 municipios y se pueden consultar en el apartado de resultados (ver Tabla 1). Las que tienen más municipios son las Pamplona, con 18, de Tarragona-Reus, con 15, y Gandía, con 13.

\subsection{MÉTODO Y FUENTES}

La metodología establecida es el análisis cuantitativo a través del empleo del censo de población de España del año 1981 y el padrón municipal de habitantes de 2019. La comparación entre las áreas urbanas de las ciudades medias españolas se ha realizado a partir de una tasa de crecimiento entera simple que posibilita el examen entre sí de casos absolutos muy diferentes, como sucede en el objeto de estudio. Esta tasa se ha calculado a partir de la siguiente fórmula, donde A es el año final, 2019 y B el inicial, 1981:

$$
T p=\frac{\frac{\operatorname{Pob}(A)-\operatorname{Pob}(B)}{A-B}}{\frac{\operatorname{Pob}(A)+\operatorname{Pob}(B)}{2}} \times 100
$$


Se trata de un crecimiento ponderado por el número de años, lo cual permite comparar periodos distintos. Se considera que el análisis entre 1981 y 2019 es suficientemente amplio y sólido para ver tendencias consolidadas. Es evidente que el estudio segmentado en periodos más cortos, decenios o quinquenios, por ejemplo, daría lugar a dinámicas diversas. No obstante, en los indicados trabajos anteriores de los autores se ha realizado esta labor para comparar la década de crecimiento urbanístico explosivo en España (19982008) con la posterior de la Gran Recesión (2008-2018).

En función de los resultados obtenidos, se han definido tres intervalos segmentados por el 0 y el $2 \%$ de crecimiento poblacional anual. El primero de los intervalos, por debajo del $0 \%$ de tasa de incremento anual, pretende mostrar las pérdidas de población; el segundo, entre o y $2 \%$, señala unos intervalos moderados; y el tercero, por encima del $2 \%$, unos incrementos intensos. Se ha recurrido a una representación cartográfica a partir de estas secciones de la tasa.

Asimismo, el trabajo se complemente con la elección de cuatro casos ejemplo: Ferrol, Tarragona-Reus, Guadalajara y Salamanca. En los estudios de caso se ha optado por detallar también la evolución de la población absoluta de los municipios que los conforman empleando los censos de población de 1981, 1991, 2001 y 2011 y el padrón municipal de 2019. Con estos ejemplos se realiza un primer acercamiento más detallado a las diferencias en la evolución poblacional entre las áreas urbanas medias españolas y se intentan detectar pautas en esta dinámica.

\section{RESULTADOS}

Los resultados se organizan de manera multiescalar. Se parte de un análisis general para pasar a unos estudios de caso seleccionados.

\subsection{EVOLUCIÓN DE LA POBLACIÓN DE LAS CIUDADES MEDIAS DE ESPAÑA Y SU ÁREA URBANA ENTRE 1981 Y 2019}

La evolución de la población de España democrática, tomando como referencia el primer censo en democracia (1981) y hasta el 2019, se representa en la Figura 1. En ella, a partir de la escala municipal, se ha considerado tres tipologías posibles: espacios que pierden población, que la ganan moderadamente (hasta el $2 \%$ de crecimiento anual) y que la captan intensamente (por encima del 2\%). El mapa resultante expresa notorios contrastes. La primera evidencia es que la mayor parte del territorio peninsular ha perdido población. El crecimiento poblacional se ha concentrado en el corredor del Mediterráneo, la costa sur y los archipiélagos y en la gran corona interior que forma el área urbana de Madrid. Sin embargo, escapan al fenómeno de despoblación las ciudades medias que, de forma general, forman excepciones de cre- 
cimiento moderado de manera intercalada en el mapa a través de sus áreas urbanas. Además, algunos municipios que forman parte de estas áreas urbanas han ganado población de forma intensa.

Figura 1. Evolución de la población de España y de sus ciudades medias y sus áreas urbanas entre 1981 y 2019

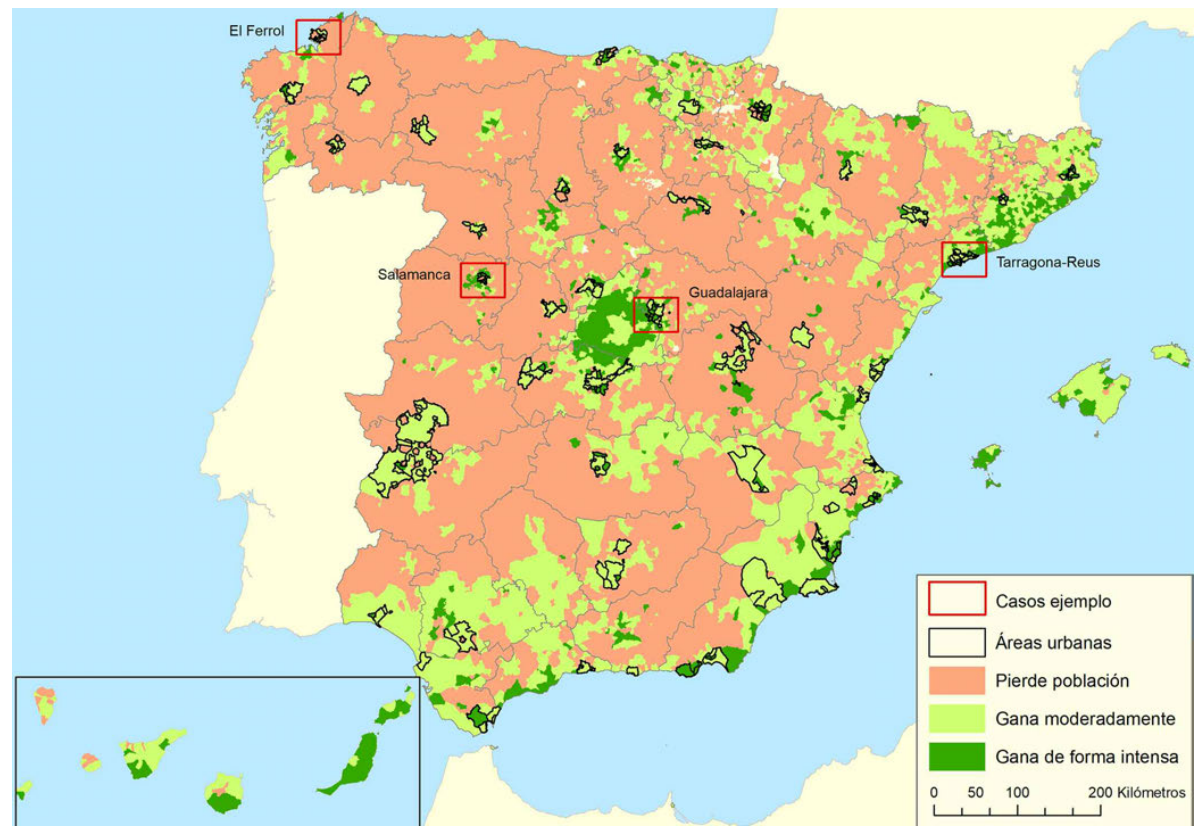

Fuente: Elaboración propia e INE (2020)

La representación cartográfica de la pérdida de población en gran parte del Estado es muy clara mostrándose no tanto la España vaciada, que tan mediática se encuentra en el momento actual, sino más bien la España que está vaciándose. Aquí no sólo se incluyen los municipios pequeños en entornos rurales, se añaden algunos de mayor tamaño y determinadas ciudades. Por otro lado, son múltiples las conclusiones que se pueden extraer del análisis cartográfico de la evolución de la población de España en los 40 años de democracia y, aunque no sean todas objeto de estudio principal de este trabajo, se destacan los siguientes:

- El dinamismo demográfico del área urbana central de Madrid con un núcleo de incremento moderados y una corona que lo rodea totalmente con un crecimiento intenso. En la periferia de esta gran área urbana, las áreas urbanas medias de Guadalajara, Toledo y Aranjuez, sobre todo las caste- 
Ilano-manchegas, también tienen un aumento poblacional destacad y forman, un tercer anillo, al menos en el aspecto analizado.

- El crecimiento de la mitad occidental de Cataluña, no solo de la gran área urbana de Barcelona sino también de áreas urbanas medias como la de Gerona o la de Tarragona-Reus.

- La división longitudinal del Levante donde, como si se tratase de una isolínea, hay una diferencia entre el incremento del litoral y de los municipios interiores más cercanos al mar frente a un decrecimiento de los siguientes municipios occidentales, ya más alejados de la costa.

- La evolución favorable de los ejes formados por la parte central de los valles del Ebro y del Guadalquivir.

- El dinamismo de la vertiente sur del mediterráneo en su litoral desde Almería hasta Cádiz.

Retornando al objeto de estudio del presente trabajo, se analizan ahora los datos cuantitativos (ver Tabla 1). En primer lugar, se observa que la población total de las áreas urbanas intermedias ha pasado de 5.187 .037 en 1981, el $13,76 \%$ de los habitantes totales de España, a 7.508 .440 en 2019, el 15,94\% del país, con una tasa de crecimiento anual del 0,96\% - 20 áreas urbanas tienen una tasa de crecimiento superior a esa media y 25, inferior- En el mismo periodo, España pasó de 37.683.362 a 47.100.396 habitantes, con una tasa del $0,58 \%$. Por lo tanto, dado que el ritmo de crecimiento poblacional de las áreas urbanas medias ha sido superior al de España en estos casi 40 años, el porcentaje que representan sobre el total de residentes en la nación ha aumentado. El peso poblacional de las áreas urbanas medias de España se ha ido incrementando.

Tabla 1. Población total de las áreas urbanas medias de España en 1981 y 2019 y tasa de crecimiento poblacional anual

\begin{tabular}{|c|c|c|c|c|}
\hline $\begin{array}{c}\text { N. } .^{\circ} \text { de } \\
\text { municipios }\end{array}$ & Área urbana & $\begin{array}{c}\text { Población } \\
1981\end{array}$ & $\begin{array}{c}\text { Población } \\
2019\end{array}$ & $\begin{array}{c}\text { Tasa de } \\
\text { crecimiento } \\
\text { Anual (\%) }\end{array}$ \\
\hline 2 & Torrevieja & 18.030 & 98.685 & 3,64 \\
\hline 1 & Roquetas de Mar & 18.891 & 96.800 & 3,54 \\
\hline 9 & La Costa Blanca & 84.366 & 227.523 & 2,42 \\
\hline 1 & El Ejido & $41.374^{*}$ & 83.594 & $2,47^{* *}$ \\
\hline 3 & La Costa del Sol & 84.990 & 219.757 & 2,33 \\
\hline 7 & Guadalajara & 68.119 & 161.683 & 2,14 \\
\hline 8 & Toledo & 65.464 & 123.509 & 1,62 \\
\hline 3 & Vélez-Málaga & 48.998 & 91.098 & 1,59 \\
\hline 9 & Gerona & 95.752 & 161.582 & 1,35 \\
\hline
\end{tabular}


Tabla 1 (Continuación). Población total de las áreas urbanas medias de España en 1981 y 2019 y tasa de crecimiento poblacional anual

\begin{tabular}{|c|c|c|c|c|}
\hline $\begin{array}{c}\mathrm{N} .^{\circ} \text { de } \\
\text { municipios }\end{array}$ & Área urbana & $\begin{array}{c}\text { Población } \\
1981\end{array}$ & $\begin{array}{l}\text { Población } \\
2019\end{array}$ & $\begin{array}{c}\text { Tasa de } \\
\text { crecimiento } \\
\text { Anual (\%) }\end{array}$ \\
\hline 1 & Aranjuez & 35.619 & 59.607 & 1,33 \\
\hline 15 & Tarragona-Reus & 234.920 & 380.707 & 1,25 \\
\hline 6 & Orihuela & 63.228 & 100.478 & 1,20 \\
\hline 2 & Ciudad Real & 57.044 & 90.114 & 1,18 \\
\hline 5 & Almería & 150.111 & 230.488 & 1,11 \\
\hline 7 & Lorca & 61.879 & 94.404 & 1,09 \\
\hline 18 & Pamplona & 237.795 & 359.892 & 1,07 \\
\hline 7 & Albacete & 116.484 & 173.329 & 1,03 \\
\hline 6 & Castellón & 207.174 & 306.215 & 1,01 \\
\hline 6 & Logroño & 119.710 & 176.883 & 1,01 \\
\hline 13 & Gandía & 85.082 & 123.545 & 0,97 \\
\hline 1 & Ávila & 40.173 & 57.744 & 0,94 \\
\hline 3 & $\begin{array}{l}\text { Santiago de } \\
\text { Compostela }\end{array}$ & 103.002 & 147.632 & 0,94 \\
\hline 1 & Motril & 40.506 & 58.020 & 0,94 \\
\hline 4 & Algeciras & 167.804 & 239.964 & 0,93 \\
\hline 4 & Cáceres & 74.667 & 106.715 & 0,93 \\
\hline 1 & $\begin{array}{l}\text { Sanlúcar de } \\
\text { Barrameda }\end{array}$ & 48.390 & 68.684 & 0,91 \\
\hline 8 & Lérida & 120.769 & 169.620 & 0,88 \\
\hline 1 & Teruel & 25.935 & 35.890 & 0,85 \\
\hline 6 & Mérida & 52.412 & 71.959 & 0,83 \\
\hline 1 & Cuenca & 40.007 & 54.690 & 0,82 \\
\hline 1 & Lugo & 72.574 & 98.276 & 0,79 \\
\hline 2 & Badajoz & 116.481 & 156.016 & 0,76 \\
\hline 1 & Utrera & 38.097 & 50.728 & 0,75 \\
\hline 7 & Vitoria & 189.533 & 251.774 & 0,74 \\
\hline 4 & Talavera de la Reina & 71.286 & 94.028 & 0,72 \\
\hline 1 & Soria & 30.326 & 39.398 & 0,68 \\
\hline 2 & Cartagena & 182.198 & 235.027 & 0,67 \\
\hline 2 & Sagunto & 56.601 & 72.837 & 0,66 \\
\hline 4 & Manresa & 81.581 & 104.907 & 0,66 \\
\hline 1 & Huesca & 41.455 & 53.132 & 0,65 \\
\hline 3 & Huelva & 137.328 & 174.223 & 0,62 \\
\hline
\end{tabular}


Tabla 1 (Continuación). Población total de las áreas urbanas medias de España en 1981 y 2019 y tasa de crecimiento poblacional anual

\begin{tabular}{|c|c|c|c|c|}
\hline $\begin{array}{c}\text { N. de } \\
\text { municipios }\end{array}$ & Área urbana & $\begin{array}{c}\text { Población } \\
1981\end{array}$ & $\begin{array}{c}\text { Población } \\
2019\end{array}$ & $\begin{array}{c}\text { Tasa de } \\
\text { crecimiento } \\
\text { Anual (\%) }\end{array}$ \\
\hline 8 & León & 155.402 & 192.082 & 0,56 \\
\hline 4 & Jaén & 112.357 & 138.271 & 0,54 \\
\hline 5 & Segovia & 56.475 & 69.273 & 0,54 \\
\hline 6 & Ponferrada & 66.423 & 80.485 & 0,50 \\
\hline 5 & Orense & 110.821 & 131.000 & 0,44 \\
\hline 2 & Elda-Petrer & 73.740 & 86.894 & 0,43 \\
\hline 2 & Burgos & 153.011 & 177.935 & 0,40 \\
\hline 6 & Salamanca & 159.416 & 183.965 & 0,38 \\
\hline 8 & Santander-Torrelavega & 286.536 & 321.695 & 0,30 \\
\hline 4 & Palencia & 83.958 & 93.853 & 0,29 \\
\hline 3 & Zamora & 60.868 & 66.174 & 0,22 \\
\hline 1 & Linares & 55.122 & 57.414 & 0,10 \\
\hline 3 & Alcoy & 82.173 & 79.829 & $-0,08$ \\
\hline 5 & Ferrol & 145.954 & 128.413 & $-0,34$ \\
\hline 231 & Total áreas urbanas & 5.187 .037 & 7.508 .440 & 0,96 \\
\hline 8.131 & estudiadas & & & 0,58 \\
\hline
\end{tabular}

*Dato de 1991. ** Tasa de 1991-2019. Fuente: Elaboración propia e INE (2020)

No hay datos de la población total de 1981 del área urbana de El Ejido porque este municipio pertenecía al municipio de Dalías, que en el año 1982 se dividió en dos (Dalías y El Ejido) (Doucet, 2016). Por esta razón, su tasa de crecimiento anual se ha obtenido a partir de la población del censo de 1991. Teniendo en cuenta esta excepción, todas las áreas urbanas que conforman el área de estudio han crecido su población entre 1981 y 2019 salvo Ferrol caso ejemplo seleccionado que se verá en el apartado siguiente-y Alcoy, núcleo industrial de relevancia en décadas pasadas (Dávila, 1990) y que viene sufriendo los impactos de la crisis desde los años 1990 (Pitarch y Albertos, 2018).

Las áreas urbanas medias de España que tienen una tasa de crecimiento poblacional anual más alto se sitúan en el litoral mediterráneo tanto en el levante alicantino -Torrevieja, con la mayor tasa, 3,64\%, y la Costa Blanca, la tercera con 2,42\% - como en el sur —Roquetas de Mar, la segunda con 3,54\%, y la Costa del Sol, la quinta con $2,33 \%$ - . La evidencia es que ha sido el impulso 
de la actividad turística en el Mediterráneo el que justifica las mayores expansiones en el número de habitantes de las áreas urbanas de carácter medio en el país. La excepción entre los cinco primeros puestos es justamente el caso de El Ejido, que con una tasa de 2,41\% se sitúa en cuarto lugar. Teniendo en cuenta que el cálculo es sobre 28 años y no sobre 38 como las demás áreas urbanas, es claro el impulso en su población relacionado, en este caso bien conocido, con el desarrollo agrario (Sánchez, 2013). La otra área urbana que supera el 2\% de crecimiento poblacional anual es Guadalajara caso-ejemplo escogido en la investigación-.

A continuación, tras estas áreas urbanas medias con tasas de crecimiento población anual superior al 2\%, aparece un conjunto heterogéneo de 13 con un índice entre el 1 y el $2 \%$. Después, más de la mitad de las áreas urbanas medias, 25, tienen una tasa de menos del 1\% y quedan por debajo de la media de las áreas urbanas de España, como se señaló. Palencia, Zamora y Linares tienen tasas inferiores al 0,30\% y los citados casos de Alcoy y Ferrol presentan un decrecimiento. En general, aparecen áreas urbanas medias repartidas por toda España con un ritmo de crecimiento poblacional menor y no se pueden extraer regularidades generales para todas ellas. No obstante, es evidente la atonía provincial en muchas áreas urbanas de las capitales de provincia del interior: las indicadas Zamora y Palencia, pero también Salamanca -casoejemplo-, Burgos, Orense, Segovia, Jaén, León, Huesca, Soria, etc.

Figura 2. Gráfico de dispersión con la población total de las áreas urbanas medias en 2019 (serie X) y la tasa de crecimiento poblacional anual entre 1981 y 2019 (serie Y)

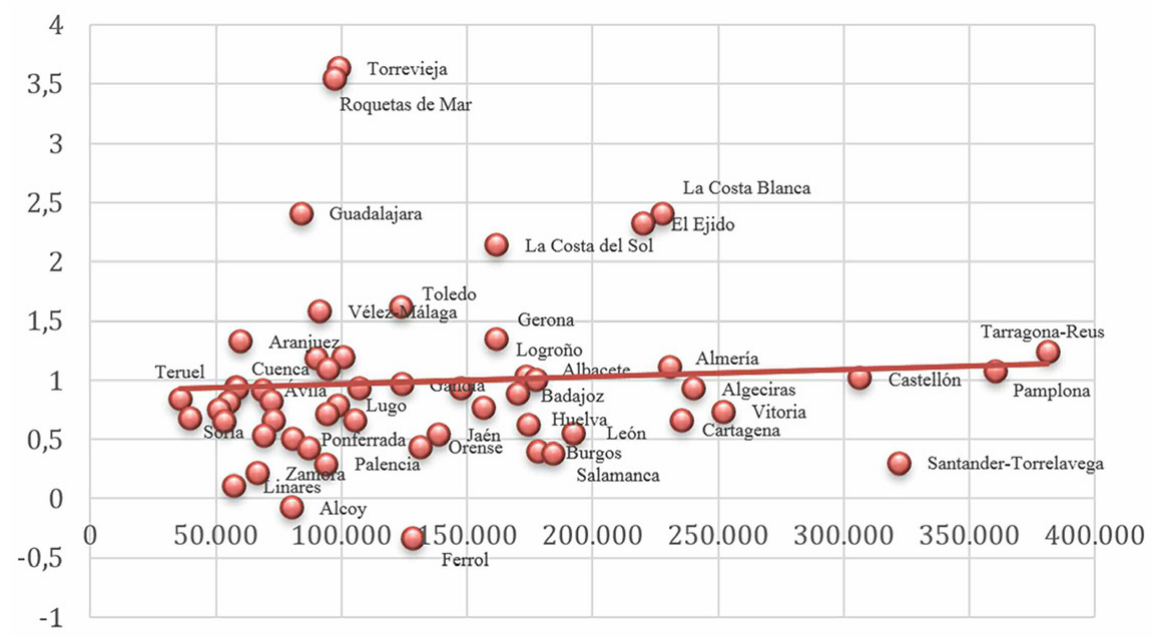

Fuente: Elaboración propia e INE (2020) 
Como ejercicio de análisis complementario se ha realizado un gráfico de dispersión entre la población total de las áreas urbanas medias analizadas al final del periodo investigado, 2019, y la tasa de crecimiento poblacional anual entre 1981 y 2019. No hay una correlación ni directa ni indirecta entre ambos indicadores. Se puede señalar que muchas áreas urbanas siguen la línea de tendencia, aunque aparecen también un gran número de irregularidades tanto superiores como inferiores. Son los casos de incrementos más explosivos, las áreas urbanas que encabezan la Tabla 1, los que más se separan de la línea de tendencia. Se puede concluir que la heterogeneidad es la norma, por esta razón, es conveniente revisar la evolución caso por caso e intentar hallar pautas comunes.

\subsection{CUATRO CASOS-EJEMPLO: LAS ÁREAS URBANAS DE FERROL, TARRAGONA, GUADA- LAJARA Y SALAMANCA}

La extensión de la comunicación no permite que se aborde el caso particular de todas las ciudades medias de España y sus áreas urbanas. Tampoco es el propósito principal de este trabajo. Sin embargo, se ha optado por escoger cuatro casos concretos y ver, a través de ellos, tipologías repetidas en la evolución poblacional de estos asentamientos urbanos en la España democrática. Se han seleccionado los casos de Ferrol, Tarragona-Reus, Guadalajara y Salamanca.

1. Una ciudad media en decrecimiento: Ferrol. El área urbana de Ferrol está formada por el municipio cabecera y los periféricos de Narón, Neda, Fene y Mugardos. Es un caso de ciudad en disminución o decrecimiento (shrinking city). Ferrol y su área urbana tienen una fase regresiva en la España democrática a causa de su desindustrialización por deslocalización y por el fracaso de cualquier otro modelo productivo alternativo planteado por su reconversión industrial. Parte de su población y de su dinamismo económico se ha trasladado al vecino municipio Narón, que hoy ya es el más poblado de Galicia después de las siete ciudades principales de esta comunidad autónoma (López y Piñeira, en prensa). De hecho, Narón es el único municipio del área urbana con una tasa de crecimiento poblacional anual positiva, un 0,76\%. Ferrol casi presenta el equivalente contrario, una tasa de -0,74\%.

2. Un área urbana media expansiva: Tarragona-Reus. El área urbana de Tarragona está formada por la capital provincial y la ciudad media cercana de Reus, así como 15 municipios periféricos a estos dos núcleos. Presenta un crecimiento moderado en sus dos núcleos principales y de manera general un incremento intenso en los municipios que los rodean. Las dinámicas de esta área urbana son complejas y han dado lugar a una creciente integración funcional (Bellet y Olazábal, 2017). Con un crecimiento excepcional está Salou, 
ayuntamiento segregado de Vila-seca en 1989. Su tasa es calculada con un periodo temporal menor en 10 años al resto de municipios, pero se dispara al 7,14\%. Es una evidencia más de la relación entre una actividad turística intensa en el Mediterráneo y crecimientos fuertes de población en la España democrática. Con tasas altas aparecen los municipios periféricos de Els $\mathrm{Pa}$ Ilaresos (4,52\%), Altafulla (3,45\%) y La Pobla de Mafumet (3,41\%). Las ciudades medias centrales tienen tasas menores: Reus (0,72\%) y Tarragona (0,55\%). Por último, dentro del área urbana, Constantí no participa de la expansión general y se queda con una tasa de 0,20\%.

3. Una ciudad media y su área urbana con un crecimiento explosivo derivado de una gran ciudad: Guadalajara. Este caso estaría formado por la capital provincial y 6 municipios periféricos. El crecimiento de esta área urbana bascula hacia la parte occidental y se traduce en incrementos poblacionales muy altos en los municipios que rodean a Guadalajara. La propia capital conoce un aumento de población moderado. El motor de este dinamismo, sin embargo, es el área urbana de Madrid y la expansión que ha conocido el corredor del Henares, del cual forma parte Guadalajara y su área urbana, sobre todo en el actual siglo (García y Pérez, 2014). Marchamalo, aunque sea un municipio nuevo segregado de Guadalajara en 1999, y su tasa se calcula sobre 18 años en vez de 38, tiene un crecimiento poblacional anual del 11,11\% y es la prueba de como la influencia madrileña puede transformar rápidamente a un municipio. Todos los otros municipios del área urbana tienen incrementos anuales mayores del 3\%. La capital provincial tiene una tasa menor, el 1,15\%, pero en número absolutos pasa de 55.137 habitantes en 1981 a 85.871 en 2019.

4. Una ciudad media central en decrecimiento con una corona expansiva: Salamanca. Esta área urbana está formada por la capital provincial y 5 municipios periféricos. En este ejemplo, la ciudad central ha perdido población, conociendo así un proceso de decrecimiento (otro caso de una shrinking city en la España democrática), pero los municipios que la rodean y conforman su área urbana han tenido incrementos muy intensos. Así, Salamanca tiene una tasa de crecimiento poblacional anual negativa del -0,17\% mientras que todos los municipios periféricos de su área urbana tienen tasas superiores al 3,70\%. Ha habido un proceso notable de suburbanización (sprawl) (Arellano y Roca, 2009).

El análisis de estos cuatro casos demuestra que, a pesar de que unos procesos generales son aceptados en la dinámica de las ciudades medias y sus áreas urbanas (su expansión y su metástasis territorial, como se indicaba en el apartado introductorio) y se repiten en la literatura académica, en realidad hay una falta de coherencia, de determinismo y homogeneidad en su evolución poblacional en estos últimos cuarenta años. Por el contrario, en función 
de la localización y de cómo las dinámicas generales —la deslocalización industrial, el desarrollo España de las Autonomías, la actividad turística litoral, el efecto gravitacional y, a la vez, expansivo de las grandes ciudades, etc.las han afectado, encontramos dinámicas muy diferentes tanto a escala interna, comparando las ciudades medias y sus áreas urbanas, como en un exactamente entre estas urbes entre sí (basta con ver qué diferentes son las dinámicas de Ferrol y de Guadalajara).

Figura 3. Evolución poblacional en las áreas urbanas de Ferrol, Tarragona-Reus, Guadalajara y Salamanca entre 1981 y 2019
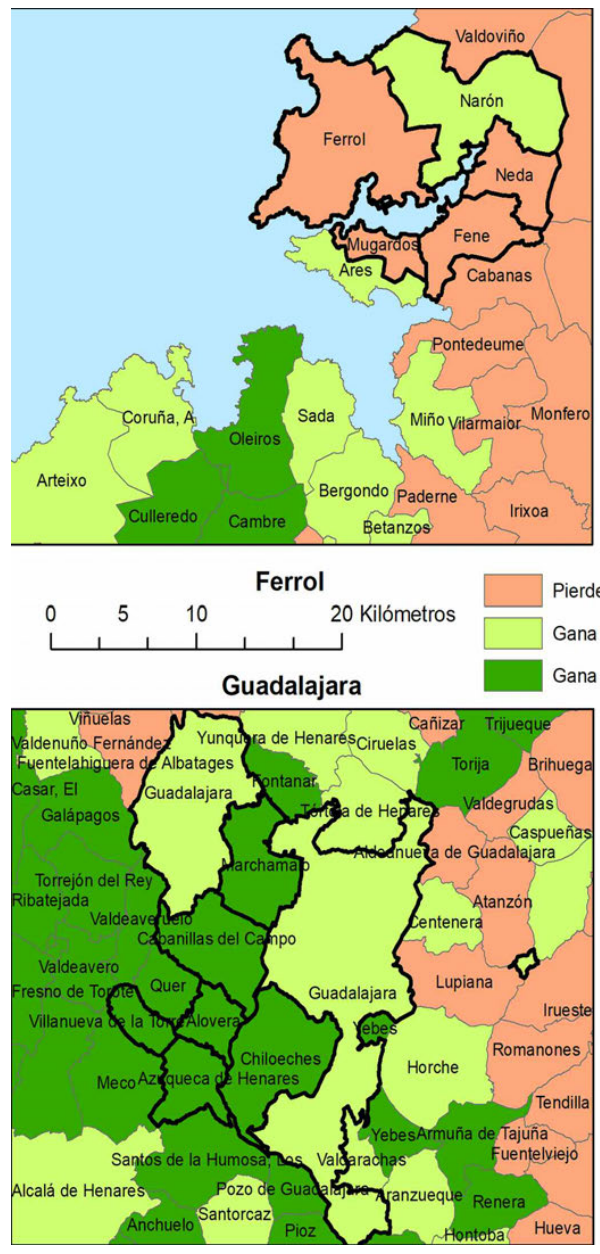

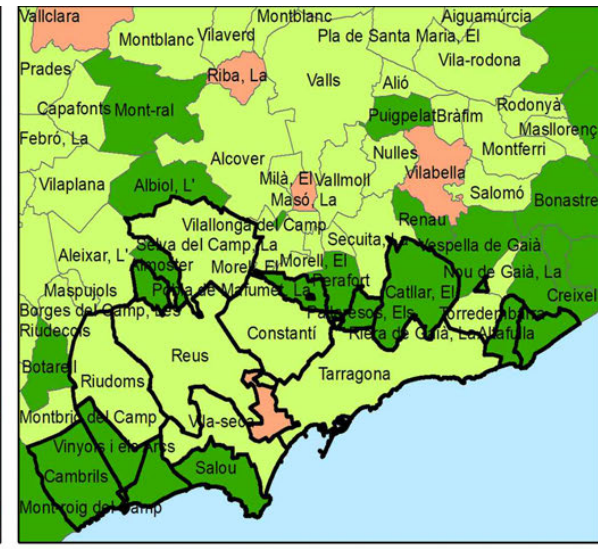

Tarragona-Reus

Salamanca

Fuente: Elaboración propia e INE (2020) 


\section{CONCLUSIONES}

Esta investigación aporta una evolución de la población de las áreas urbanas medias de España en los 40 años de democracia, desde el primer censo tras la constitución de 1978, el de 1981, hasta el padrón municipal de 2019. Se trata de un trabajo que se suma a la extensa y reciente literatura académica española sobre las ciudades de tamaño medio. Es una evidencia el importante papel que estos núcleos urbanos adquieren en la red urbana española y el interés de su dinámica en los últimos decenios. Sin embargo, y esta es la primera conclusión que se extrae, sigue siendo un imposible delimitarlas exactamente de forma clara, precisa e indiscutible. Se ha recurrido a las áreas urbanas establecidas por el Ministerio de Transportes, Movilidad y Agenda Urbana (2020) y fijando unos criterios comunes tras una reunión entre expertos. Aun así, los déficits siguen presentes. Por ejemplo, hasta 16 áreas urbanas son unimunicipales. Entre ellas, considerar a Utrera, verbigracia, con una población de 50.728 como área urbana media puede ser como mínimo objeto de debate.

Asumido el problema de su exacta delimitación, hay un segundo hecho que destaca, y es también la segunda conclusión que se extrae: las áreas urbanas medias de España tienen un ritmo de crecimiento anual superior al de España y han aumentado su peso población en el sistema urbano estatal.

Analizando las 55 áreas urbanas medias objeto de estudio, se obtiene una tercera conclusión: no hay una homogeneidad ni tan siquiera una coherencia, en su evolución poblacional, como demuestra el gráfico de dispersión, y predomina la diversidad. Esto obliga a analizarlas caso por caso y buscar tendencias y rasgos comunes en su evolución. Así se ha realizado para los ejemplos de Ferrol, Tarragona-Reus, Guadalajara y Salamanca. En futuras investigaciones, aparte de ampliar los aspectos a estudiar, sería conveniente seguir con este análisis de casos y poder concluir con una tipología, si es que fuera posible finalmente alcanzar esa clasificación.

Finalmente, sí aparecen unos hallazgos destacables:

- Las áreas urbanas medias de España de mayor crecimiento se localizan en el litoral mediterráneo.

- Las ciudades medias que forman parte de la corona periférica de Madrid, Guadalajara, Toledo, principalmente, y Aranjuez tienen tasas de crecimiento poblacional anual elevadas.

- Existe una importante relación entre el modelo productivo y el comportamiento demográfico, bien positivo, bien negativo como sucede con El Ejido o Ferrol, respectivamente.

Las limitaciones de la investigación vienen derivadas de ser una aproximación parcial al tema, a través de los datos absolutos de población de las áreas urbanas medias de España. En futuros trabajos se pretende profundizar en 
la cuestión con otros indicadores como la evolución de los inmuebles construidos o de la vivienda.

\section{AGRADECIMIENTOS}

Este trabajo ha sido financiado por el proyecto de investigación «Procesos de cambio en la urbanización de las ciudades medias y sus áreas urbanas: 19792019» (RTI2018-096435-B-C22), Agencia Estatal de Investigación, Ministerio de Ciencia, Investigación y Universidades y FEDER.

\section{BIBLIOGRAFÍA}

Arellano Ramos, B. C. y Roca Cladera, J. (2009). Algunas reflexiones sobre el proceso de sprawl en España y México En International Conference Virtual City and Territory. 5th International Conference Virtual City and Territory, Barcelona, 2, 3 and 4 June 2009, pp. 89-106. Barcelona: Centre de Política de Sòl i Valoracions.

Bellet, C. y Olazábal, E. (2017). . En F. Maturana et al. (Eds.), Sistemas urbanos y ciudades medias en Iberoamérica, pp. 146-185. Santiago de Chile: Instituto de Geografía de la Pontificia Universidad Católica de Chile.

Cebrián, F. (2020). Los procesos de transformación de las ciudades medias. De la ciudad compacta a la metástasis territorial en España. En F. Cebrián (Coord.), Ciudades medias y áreas metropolitanas. De la dispersión a la regeneración, pp. 27-66. Cuenca: Ediciones de la Universidad de CastillaLa Mancha.

Dávila Linares, J. M. (1990). Planeamiento y ordenación urbanística de la ciudad de Alcoi (estudio de geografía urbana). Universidad de Alicante: Alicante.

Doucet Plaza, M. S. (2016). El nacimiento del municipio de El Ejido, de las primeras elecciones democráticas al cambio político (1979-1991). Almería: Universidad de Almería.

Escudero Gómez, L. A., García González, J. A. y Martínez Navarro, J. M. (2019). Medium-sized cities in Spain and their urban areas within national network. Urban Science, 3(1), 5. doi:10.3390/urbansci3010005

García González, J. A., Martínez Navarro, J. M. y Escudero Gómez, L. A. (2018). La importancia de las ciudades medias en el sistema urbano de España. En F. Cebrián (Coord.), Ciudades medias y áreas metropolitanas. De la dispersión a la regeneración, pp. 25-40. Cuenca: Ediciones de la Universidad de Castilla-La Mancha.

García González, J. A., Martínez Navarro, J. M. y Escudero Gómez, L. A. (2020). Las ciudades medias españolas, nexos en la red urbana nacional: dinámicas demográficas y edificativas en el siglo XXI. En F. Cebrián (Coord.), Di- 
námicas de urbanización en ciudades medias interiores, pp. 67-94. Valencia: Tirant Humanidades.

García Rodríguez, M. P. y Pérez González, M. G. (2014). Análisis multitemporal del urbanismo expansivo em el corredor del Henares: aportación de las imágenes de satélite. Estudios Geográficos, LXXV(277), 597-318. doi: 10.3989/ estgeogr.201419.

Instituto Nacional de Estadística (2020). Censos de población de 1981, 1997, 2001 y 2011 y Padrón Municipal de Habitantes de 2019. Recuperado de https://www.ine.es/ [Consulta: 24 de febrero de 2020].

López Rodríguez, R. y Piñeira Mantiñán, M. J. (en prensa). Reestructuración espacial: cambios sociales en espacios regresivos. El caso de Ferrol. En J. Farinós (Coord.), Desafíos y oportunidades de un mundo en transición; una interpretación desde la Geografía. Valencia: Universidad de Valencia. Martínez Navarro, J. M., Escudero Gómez, L. A. y García González, J. A. (en prensa). Las ciudades medias de España y sus coronas en el siglo XXI: dinámica demográfica y desarrollo inmobiliario. Urbe. Revista Brasileira de Gestão Urbana.

Ministerio de Transportes, Movilidad y Agenda Urbana (2020). Atlas Estadístico de las Áreas Urbanas. Recuperado de:

https://www.mitma.gob.es/portal-del-suelo-y-politicas-urbanas/atlas-estadis tico-de-las-areas-urbanas [Consulta: 24 de febrero de 2020]

Olazabal, E. y Bellet, C. (2019). De la ciudad compacta a la ciudad extensa. Procesos de urbanización recientes en áreas urbanas españolas articuladas por ciudades medias. Anales de Geografía de la Universidad Complutense, 39(1), 149-175. doi: 10.5209/AGUC.64681.

Pitarch Garrido, M. D. y Albertos Puebla, J. M. (2018). El impacto de la crisis en un territorio de tradición industrial. El caso de las comarcas valencianas de L'Alcoià, El Comtat y La Vall d'Albaida. Ería: Revista cuatrimestral de Geografía, 38(2), 205-223. doi:10.17811/er.2.2018.205-223.

Sánchez Escolano, L.M. (2013). Modelo territorial innovador y articulación urbana en el poniente almeriense. Investigaciones Geográficas, 59, 57-74. doi: 10.14198/INGEO2013.59.04.

Vázquez Varela, C. y Martínez Navarro, J. M. (2020a). Medium-sized Spanish inland cities and regional development in the Iberian Peninsula. In J. Banski (Ed.), Dilemmas of Regional and Local Development [Versión eBook]. Nueva York: Routledge.

Vázquez Varela, C. y Martínez Navarro, J. M. (2020b). Ciudades medias de interior y desarrollo territorial: entre la vertebración de nuevas estructuras urbano-territoriales y el despoblamiento de sus entornos provinciales. En F. Cebrián (Coord.), Dinámicas de urbanización en ciudades medias interiores, pp. 95-146. Valencia: Tirant Humanidades. 


\title{
CAMBIOS DE USO EN LOS BARRIOS HISTÓRICOS. EL EJEMPLO DE CIUDAD JARDÍN (LAS PALMAS DE GRAN CANARIA) CHANGES OF USE IN THE HISTORIC NEIGHBORHOODS. THE CIUDAD JARDIN EXAMPLE (LAS PALMAS DE GRAN CANARIA)
}

\author{
Santiago Hernández Torres \\ Universidad de Las Palmas de Gran Canaria \\ Guillermo Morales Matos \\ Universidad de Carlos III de Madrid \\ María Yazmina Lozano Mas \\ Universidad Internacional del Atlántico Medio \\ Vicente Benito Molina \\ Virgin Media y Universidad de Alicante
}

Resumen

Los barrios históricos son formaciones urbanas con una apreciable singularidad y una variada casuística de adaptación al dinamismo del siglo XXI. Interesa inventariar los cambios en los usos del suelo y la edificación y valorar los efectos que los mismos han tenido en su valioso patrimonio cultural y ambiental. El recurso metodológico fundamental se corresponde con el inventario exhaustivo a nivel de parcela, ayudándonos de los SIG, de las fuentes históricas del desarrollo urbano y del análisis sociodemográfico y el tejido edificado. Los resultados significativos que podemos adelantar se corresponden con la producción de tensiones significativas entre las demandas y pautas urbanas del siglo XXI con la vulnerabilidad del paisaje que configura estos barrios, con un papel nada desdeñable en la dinamización turística de la ciudad como enclaves emblemáticos y singulares y una serie de retos en la eficacia de la ordenación y gestión pública. La geografía y la ordenación del territorio tiene mucho que decir en esta cuestión.

Palabras clave: barrios históricos, paisajes urbanos, patrimonio cultural, análisis geográfico, ordenación urbana.

\section{Abstract}

The historic neighborhoods are urban formations with an appreciable singularity and a varied casuistry of adaptation to the dynamism of the $27^{\text {st }}$ century. It is interesting to inventory he changes in land uses and buildings, assess cultural and environmental heritage. The fundamental methodological resource corresponds to the exhaustive inventory at the plot level, helping us with the GIS, the historical sources of urban development and the sociodemographic analysis and the built fabric. The significant results that we 
can anticipate correspond to the production of significant tensions between the demands and urban patterns of the $21^{\text {st }}$ century with the vulnerability of the landscape that configures these neighborhoods, with a not inconsiderable role in the tourist revitalization of the city as emblematic and unique enclaves and a series of challenges in the effectiveness of public planning and management. Geography and spatial planning has a lot to say on this question.

Keywords: historic neighborhoods, urban landscapes, cultural heritage, geographic analysis, urban planning.

\section{INTRODUCCIÓN}

El barrio de Ciudad Jardín constituye en 2020 una formación urbana que se localiza en la plataforma costera de Las Palmas de Gran Canaria (Canarias. España), integrándose en un espacio entre el centro histórico y el complejo neurálgico del Istmo de Guanarteme-Puerto de La Luz que ha experimentado una intensa transformación durante la $2^{a}$ mitad del siglo XX.

Estos cambios no han sido en su totalidad de carácter físico en cuanto a su configuración como zona urbanizada, sino también dinámicos en cuanto a la diversificación del carácter residencial. Los usos del suelo y de la edificación han modificado sustancialmente su distribución y proporción respecto al barrio existente a mediados del siglo XX. Ha sido una renovación que ha discutido en buena medida sus fisonomías paisajística y arquitectónica, las cuales se dotan de una destacada distribución de singularidades ambientales, históricas y de patrimonio cultural.

Es ésta una reproducción de una fenomenología extendida en el sistema urbano español que a nuestro juicio necesita de una constante actualización de los mecanismos y criterios de diagnóstico urbano y de estrategias de regeneración.

El debate que se propone en este Coloquio sobre la reconfiguración capitalista de los espacios urbanos, sus transformaciones y desigualdades es oportuno e imprescindible en una problemática como la que proponemos.

Desde la mirada del análisis geográfico y la ordenación del territorio, compendiamos en esta comunicación los resultados de una investigación que partió con los siguientes objetivos.

De una parte, interesaba hacer un diagnóstico comparativo de estos entornos urbanos, representado en el caso de Ciudad Jardín, a partir del análisis de su parcelario y de los cambios individuales en los usos y edificaciones.

Por otro, queríamos proponer una tipificación de las situaciones que se derivan de esos cambios, como indicador del proceso de adaptación de estos barrios a los avatares que se observan en estas primeras décadas del siglo $\mathrm{XXI}$. 
La metodología propuesta consiste en un exhaustivo trabajo de campo a nivel de parcela y su gestión en un sistema de información geográfica, incluyendo asimismo el inventario de la documentación histórica sobre la evolución del desarrollo físico del barrio. Se completará con el uso de técnicas comunes de síntesis estadística y de análisis del planeamiento urbano incidente en el espacio.

\section{SU EMPLAZAMIENTO Y PROCESO URBANO DE FORMACIÓN}

El barrio de Ciudad Jardín es una unidad urbana de algo más de 85,8 Ha. que se desarrolla sobre la plataforma costera y arenosa de la denominada ciudad baja, mostrándose como un espacio consolidado por la urbanización que en buena medida conserva muchos rasgos del escenario que podemos considerar histórico.

Su origen podemos situarlo en la aparición de las primeras viviendas durante los años del tránsito del siglo XIX al XX sobre la antigua Vega de Santa Catalina, ejemplificando el modelo tradicional anglosajón de formaciones residenciales en zonas periurbanas (Morales, 1995, 90). Fue una modalidad de ocupación del suelo basada en unas construcciones singulares por su calidad y forma arquitectónica (barrio de los hoteles), con una distribución aislada en parcelas de huertas con apreciable superficie y asociándose al uso del jardín y el arbolado como complemento indispensable a la función de núcleo de viviendas (Arroyo 1898 y Navarro 1911 en Tous 1999).

Aquellas pautas de residencia, fija o estacional, pusieron en valor los rasgos de calidez y reducidas precipitaciones del clima en Las Palmas de Gran Canaria. Asimismo, su desarrollo presentó una vocación por el vínculo entre el hábitat, el descanso, el ocio y el dinamismo cultural en el contexto de la ciudad del momento.

Al uso residencial se fue añadiendo durante los inicios de la anterior centuria apareció una protourbanización del litoral para acompañarse de baños y un relativo confort en la antigua playa de Santa Catalina, sumándose al emblemático Hotel Santa Catalina y el Parque Doramas (surgidos a fines del siglo XIX, y adaptados a mediados del siglo XX). También aparecieron la Capilla Anglicana (ya existía la Ermita de Santa Catalina), el precedente del actual Colegio Salesianos (Sagrado Corazón), el Beach Club, el Hotel Metropole.

Como elemento estructurante a este proceso, se acondicionó la vía costera representada en la antigua Carretera del Puerto (hoy calle León y Castillo); a la cual se fueron añadiendo una sucesión de calles o caminos que descendían desde las laderas que hoy conocemos como Altavista (Baterías de Arenales y de Guanarteme) (Arroyo, 1898, Navarro, 1911, Chías, 1914 en Tous 1999). Estos recorridos transversales fueron denominándose en función de los grandes propietarios, sirviendo de acceso a sus fincas o huertas y permaneciendo en algunos casos en esa función conectora hasta la actualidad (Camino de 
Santa Catalina -actual calle Francisco González Díaz-, Camino del Colegio — calle Beethoven-, Camino de Blandy — calle Alejandro Hidalgo-, Camino de Dempster — calle Rafael Ramírez-).

Era un atisbo de trama que se superponía con similar formato a la fisiográfica. En ésta última, a la línea costera y la antigua Playa de Santa Catalina se le «conectaban» los cauces de barranquillos que descendían desde la vertiente oriental y que hoy se sitúan bajo el espacio urbano consolidado (Barranquillo de Santa Catalina — hoy Barranquillo de Don Zoilo y Avda. Juan XXIII-, Barranquillo sin denominación — probable cauce de López Socas-, Barranquillo de Alcaravaneras —Avda de Escaleritas y calle Maestro Valle-). Fue desarrollándose un conjunto residencial que acogió a aquellos pudientes que no quisieron integrarse en la ciudad consolidada del momento, seleccionando un entorno de alta calidad ambiental en viviendas unifamiliares rodeadas de jardín (Morales, 1995, 91-92). Pese a esas características y a la denominación actual del barrio, realmente fue un modelo difícil de asimilar al conocido paradigma de las garden cities (ciudad jardín) que planteó en esta misma época Ebenezer Howard como alternativa o sustitución de la ciudad densa. También es difícil asimilarlo al concepto más colectivo y organizado del garden suburb que se nos define para varias ciudades españolas coetáneas del supuesto que analizamos (De Terán, 1999, 158) en el que subyace una componente de proceso colectivo impulsado desde esfuerzos protoinmobiliarios.

En uno u otro caso, no es de extrañar que aquel crecimiento edificatorio en la entonces Vega de Santa Catalina derivase en estrategias planificadoras con vistas a dar un relativo orden, criterio y perspectiva a lo que se atisbaba como un barrio con múltiples facetas.

Ya en 1922 y antes de convertirse en uno de los grandes protagonistas del diseño de la ciudad de primera mitad del siglo XX, el arquitecto Miguel Martín Fernández de la Torre desarrolla el Plan de Ordenación de la ciudad (aprobado en 1930).

Su modelización culminaba la urbanización de la plataforma costera convirtiéndolo en un continuo urbano de sur a norte entre el centro histórico hasta el Puerto, dando forma en gran medida a la actual ciudad baja.

Ciudad Jardín fue definido con una red estructurante más densa que se rellenaba con un tejido parcelario adaptado a unas posibilidades de crecimiento residencial y de equipamientos. Y así fue.

El mismo arquitecto fue el proyectista de la mayoría de unas viviendas que reproducían las condiciones de estilismo arquitectónico y de asociación a la zona verde, persiguiendo un paisaje atractivo y en cierto modo naturalista. Se dio rienda suelta a un protagonismo fundamental de las formas racionalistas y regionalistas, conformando hoy una representación obligada del patrimonio arquitectónico de la ciudad. 
Figura 1. Localización de Ciudad Jardín, situación previa (años 50)

al proceso de transformación de la segunda mitad el siglo XX y situación actual
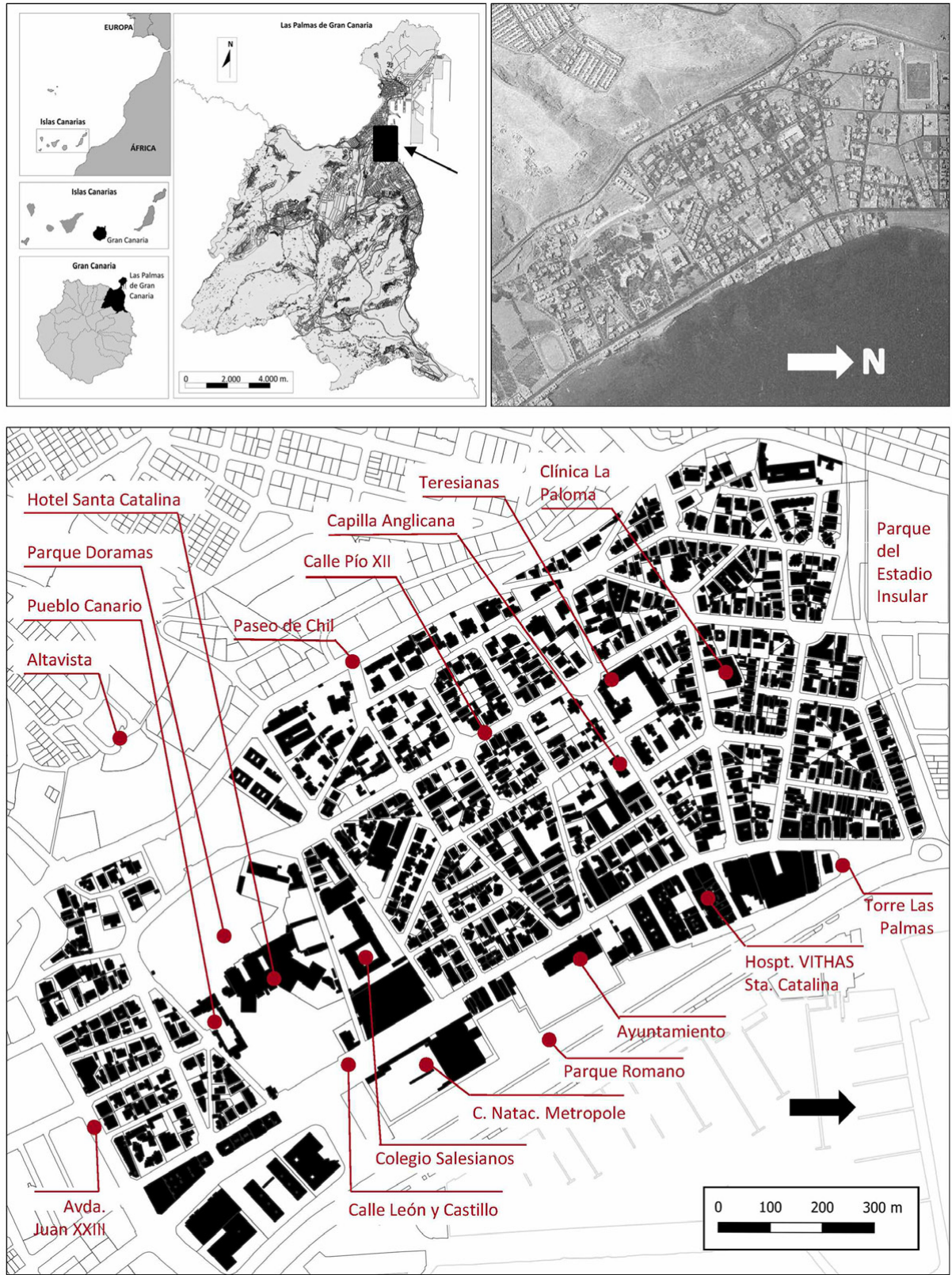

Fuente: Elaboración propia a partir de IDECanarias 
Junto a este tejido residencial, proliferaron algunos hoteles que participarían del dinamismo turístico de esas décadas.

Las pautas constructivas y de espacio colectivo reproducían los objetivos de estilismo arquitectónico, calidad ambiental del entorno, confort y tranquilidad, elitismo social de influencia y protagonismo europeo, sobre todo británico. Fue ampliándose el tejido residencial y el volumen demográfico tal como se había previsto, proceso en el que cada vez participó más la burguesía local atraída por una zona residencial más atractiva que los restantes barrios.

Estos rasgos definieron la condición de Ciudad Jardín como uno de los principales centros del patrimonio cultural y arquitectónico de Las Palmas de Gran Canaria, compitiendo en este sentido con el propio centro histórico de Vegueta y Triana (Martín, 2001, 113, y Herrera, 1978, 343). Fue en esa dinámica donde se consolida la actual condición de barrio tradicional con unas características y valores muy específicos, y con ello uno de los principales aspectos que tipifican la formación en el análisis que exponemos en este trabajo.

Su desarrollo fue poco alterado en el Plano de Secundino Zuazo (1944), excepto en la configuración de las manzanas costeras (antecedente de la edificación en bloque actualmente predominante).

A partir de los años 60s ese conjunto urbano iniciaría un proceso de adaptación a los esquemas del boom expansivo y terciarización del tejido urbano de la ciudad que se desarrollaría durante varias décadas y tendría consecuencias en la formalización singular del barrio.

La aparición del Plan General de Ordenación Urbana de Las Palmas de Gran Canaria (1962) en su relativa sencillez normativa introduce varias potencialidades que acabarían reformulando la forma urbana de Ciudad Jardín durante las siguientes décadas.

De una parte, una apreciable libertad para la configuración del tejido parcelario tuvo como resultado una atomización de la propiedad multiplicando la densidad de las fincas, reduciendo casi a la mínima expresión la superficie de las mismas y, con ello, incentivando la implantación de viviendas y otros usos edificados. El factor acelerante de este proceso fue la paralela densificación de la trama viaria y la accesibilidad interior del área, lo cual sólo tuvo que aprovechar la red estructurante prevista en el Plan de los años 30s. Es un fenómeno que ya hemos observado en otros casos españoles (Alvargonzález, 1999, 75) y de esta misma ciudad (Sobral, 1995).

De otra, los parámetros constructivos en unos casos y la falta de mecanismos de control facilitaron la diversificación de los estilos constructivos que bajo el paraguas de la modernidad sustituyó las formas prevalentes (y hoy tan valoradas) en la primera mitad del siglo. Se pasó a seleccionar formatos más pragmáticos y adaptados al confort residencial y urbano del momento. Fue una barra libre que contaminó la rica herencia regionalista, racionalista y ecléctica, proliferando nuevos materiales, gustos cromáticos, ampliaciones y añadidos constructivos o, de modo más drástico aún, la sustitución por dise- 
ños contemporáneos. La prolongación de la Ciudad del Mar con sus volumetrías en torres en el espacio entre la calle León y Castillo y la Avenida Marítima distorsionó íntegramente la relación con el mar, no sólo por el añadido estructural y la sustitución de la antigua línea marítima sino por la generación de una pantalla paisajística sólo abierta por el Hotel Metropole (ahora Oficinas Municipales), el Parque Romano y hasta cierto punto el complejo deportivo del Metropole.

Un ingrediente básico de la Ciudad Jardín (la zona verde privada), fue reducida al mero testimonio de algún arbolado y mantos de césped, prefiriendo las estancias al aire libre, los garajes exentos a la vivienda, las piscinas y demás complementos de la moda de esos momentos. Tal fue el caso que poco a poco el protagonista en la presencia natural pasó a ser el espacio público, tanto el viario como el Parque Doramas y otros rincones.

Los procesos de renovación en los barrios adyacentes (Alcaravaneras, al norte, Lugo, al sur, la Cornisa, al Oeste, y el expuesto conjunto en torres en el margen costero) fueron fieles compañeros de esta transformación.

Los inicios del siglo XXI se encontraron con un barrio en crisis de identidad morfológica y funcional en el contexto de la ciudad de Las Palmas de Gran Canaria y de tensiones entre los rasgos heredados como barrio de origen residencial y nuevas oportunidades emanadas de sus cualidades, su localización en la ciudad baja o su accesibilidad.

\section{RESULTADOS DE LA INVESTIGACIÓN. LAS TENSIONES Y ESTRATEGIAS EN LA CIUDAD JARDÍN}

\subsection{LA EXPLOSIÓN DEL TEJIDO NO RESIDENCIAL Y LAS TENSIONES DEL SISTEMA DE MOVILIDAD}

Ciudad Jardín ha observado durante los últimos años un dinamismo específico respecto a los restantes barrios residenciales de Las Palmas de Gran Canaria. Para empezar, acoge en 2019 una población de 4.988 residentes. Ha perdido efectivos respecto a 2010, pero se sitúa en cifras algo superiores a las del año 2000, cuando se contabilizaron 4.914. Es un comportamiento con muchas afinidades al conjunto de la ciudad, si bien es verdad que el retroceso en la última década es más intenso en nuestro ámbito de estudio (-5,08\% frente al -0,88\% municipal según el INE).

La misma fuente anterior refleja un crecimiento en la proporción de la población mayor a 64 años en un proceso similar al de la ciudad (20,7\% local frente al $18,3 \%$ municipal). Sin embargo, podemos considerar un rasgo definitorio la reinversión positiva de la población infantil (menos de 15 años). En 2000 era menor la proporción en el ámbito de estudio que en el conjunto de la urbe. Ésta ha demostrado una evolución negativa en ese período reciente (de 15,4\% a 12,1\%), Mientras, en Ciudad Jardín ha aumentado este colectivo (de 12,5\% a 14,7\%). 
¿A qué se debe estas diferencias poco relevantes en apariencia? ¿podemos considerar una renovación en el tejido social y residencial del barrio? Lo cierto es que estos ajustes coexisten con unos cambios significativos en la distribución de los usos del suelo y la edificación, evidenciando un nuevo mapa funcional.

Tabla 1. Distribución de las parcelas en Ciudad Jardín según su uso en 1995 y 2020

\begin{tabular}{|c|c|c|c|c|}
\hline usos & 1995 & $\%$ & 2020 & $\%$ \\
\hline Uso residencial & 597 & 88,44 & 554 & 82,07 \\
\hline Usos de dotaciones y equipamientos & 41 & 6,07 & 66 & 9,78 \\
\hline Educativo & 14 & 2,07 & 30 & 4,44 \\
\hline Sanitario y servicios de salud & 9 & 1,33 & 18 & 2,67 \\
\hline Deportivo & 4 & 0,59 & 3 & 0,44 \\
\hline Cultural & 4 & 0,59 & 4 & 0,59 \\
\hline Administración y sedes oficiales & 4 & 0,59 & 5 & 0,74 \\
\hline Religioso & 1 & 0,15 & 1 & 0,15 \\
\hline Militar, incluida residencia & 4 & 0,59 & 4 & 0,49 \\
\hline Comisaría de Las Palmas & 1 & 0,15 & 1 & 0,15 \\
\hline Usos terciarios & 19 & 2,81 & 33 & 4,89 \\
\hline Alojamiento turístico & 1 & 0,15 & 9 & 1,33 \\
\hline Comercio, restauración y superficies comerciales & 2 & 0,30 & 3 & 0,44 \\
\hline Oficinas, servicios, colegios profesionales & 15 & 2,22 & 20 & 2,96 \\
\hline Estación de servicios & 1 & 0,15 & 1 & 0,15 \\
\hline Espacios públicos abiertos & 5 & 0,74 & 7 & 1,04 \\
\hline Parques & 3 & 0,44 & 5 & 0,74 \\
\hline Otros espacios libres & 2 & 0,30 & 2 & 0,30 \\
\hline Usos mixtos & 13 & 1,78 & 15 & 2,22 \\
\hline Residencial con oficinas, servicios y similar & 12 & 1,78 & 12 & 1,78 \\
\hline Residencial con uso sanitario y servicios de salud & 1 & 0,15 & 2 & 0,30 \\
\hline $\begin{array}{r}\text { Educativo con superficie comercial en planta } \\
\text { baja parcial }\end{array}$ & 0 & 0,00 & 1 & 0,15 \\
\hline TOTAL DEL ÁMBITO & 675 & 100,00 & 675 & 100,00 \\
\hline
\end{tabular}

Fuente: Elaboración propia y Morales, 1995 
Un inventario de campo nos permite comparar la situación actual de los usos del suelo y de la edificación con respecto a un trabajo similar realizado en los años 90s (Morales, 1995), utilizando como base de análisis tanto el parcelario como la edificación. El resultado se resume en la tabla anterior (tabla 1).

Tabla 2. Distribución de la superficie parcelaria en Ciudad Jardín según su uso en 1995 y 2020

\begin{tabular}{|c|c|c|c|c|}
\hline usos & 1995 & $\%$ & 2020 & $\%$ \\
\hline Uso residencial & 305.843 & 53,17 & 276.164 & 48,01 \\
\hline Usos de dotaciones y equipamientos & 131.929 & 22,93 & 118.631 & 20,57 \\
\hline Educativo & 38.060 & 6,62 & 44.691 & 7,77 \\
\hline Sanitario y servicios de salud & 9.777 & 1,70 & 12.533 & 2,18 \\
\hline Deportivo & 41.536 & 7,22 & 21.171 & 3,68 \\
\hline Cultural & 6.715 & 1,17 & 6.204 & 1,08 \\
\hline Administración y sedes oficiales & 15.016 & 2,61 & 12.937 & 2,25 \\
\hline Religioso & 2.185 & 0,38 & 2.185 & 0,38 \\
\hline Militar, incluida residencia & 13.343 & 2,32 & 13.343 & 2,32 \\
\hline Comisaría de Las Palmas & 5.297 & 0,92 & 5.297 & 0,92 \\
\hline Usos terciarios & 27.325 & 4,75 & 40.880 & 7,10 \\
\hline Alojamiento turístico & 9.866 & 1,72 & 16.778 & 2,92 \\
\hline Comercio, restauración y superficies comerciales & 4.522 & 0,79 & 3.894 & 0,68 \\
\hline Oficinas, servicios, colegios profesionales & 11.277 & 1,96 & 18.548 & 3,22 \\
\hline Estación de servicios & 1.660 & 0,29 & 1.660 & 0,29 \\
\hline Espacios públicos abiertos & 79.173 & 13,76 & 102.525 & 17,82 \\
\hline Parques & 71.613 & 12,45 & 94.965 & 16,51 \\
\hline Otros espacios libres & 7.560 & 1,31 & 7.560 & 1,31 \\
\hline Usos mixtos & 30.977 & 5,28 & 37.317 & 6,49 \\
\hline Residencial con oficinas, servicios y similar & 29.344 & 5,10 & 29.344 & 5,10 \\
\hline Residencial con uso sanitario y servicios de salud & 1.633 & 0,28 & 1.930 & 0,34 \\
\hline $\begin{array}{r}\text { Educativo con superficie comercial en planta baja } \\
\text { parcial }\end{array}$ & $\mathrm{O}$ & 0,00 & 6.043 & 1,05 \\
\hline TOTAL DEL ÁMBITO & 575.247 & 100,00 & 575.247 & 100,00 \\
\hline
\end{tabular}

(*) El viario es el mismo en ambos años, experimentando actuaciones de mejora y reurbanización entre una fecha y otra. Fuente: Elaboración propia y Morales, 1995 
Figura 2. Distribución de los usos del suelo y de la edificación en Ciudad Jardín en 1995

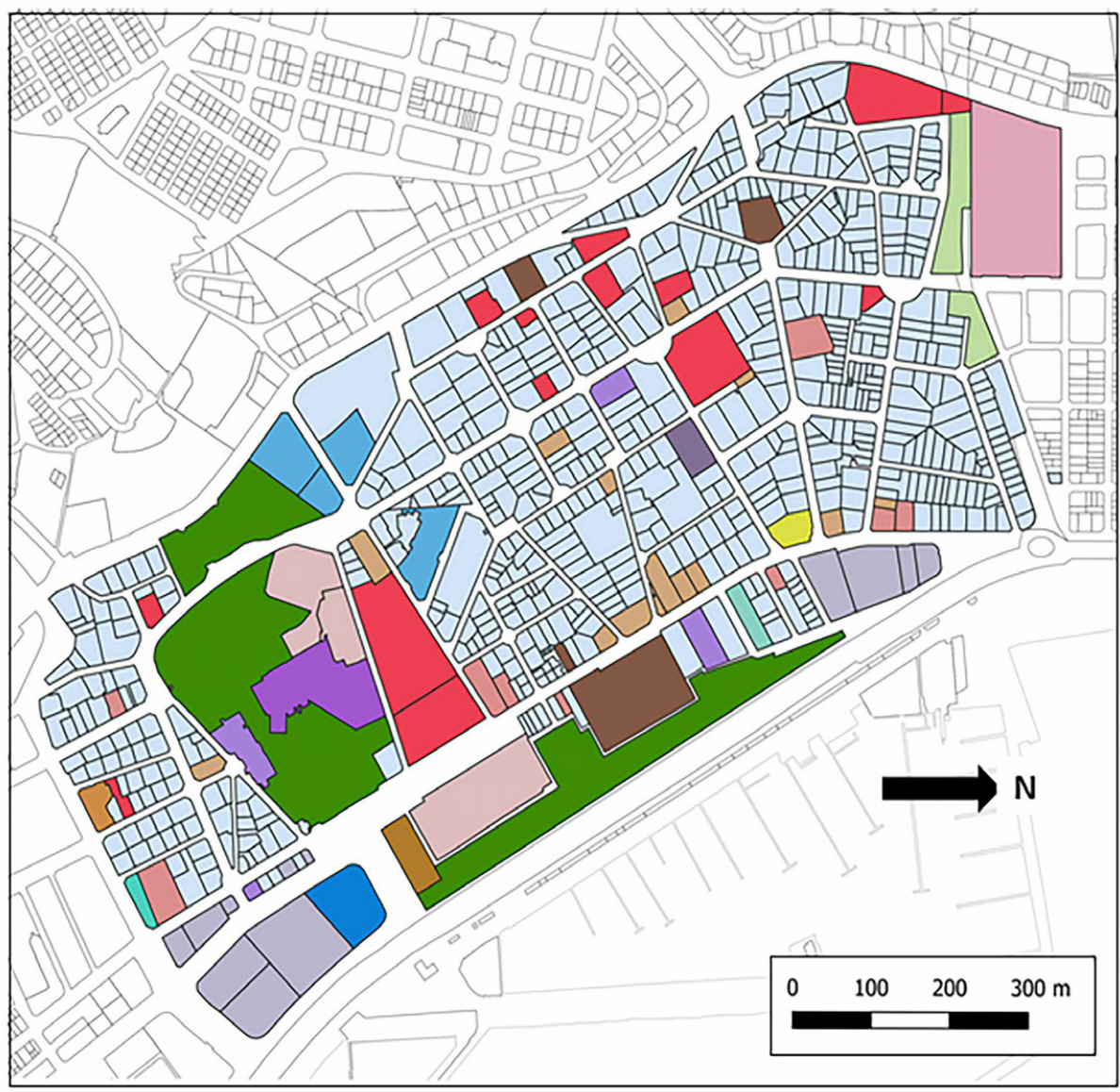

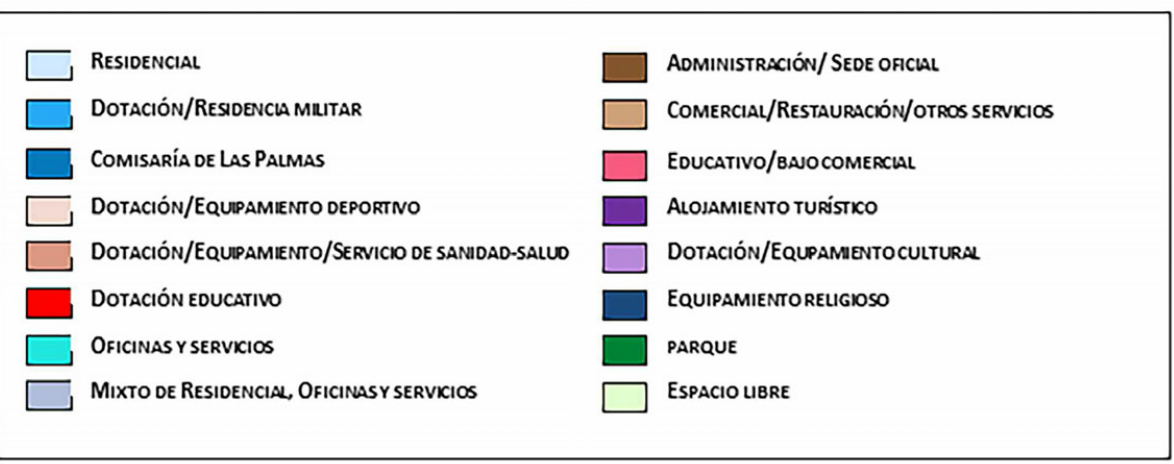

Fuente: Elaboración propia 
Figura 3. Distribución de los usos del suelo y de la edificación en Ciudad Jardín en 2020
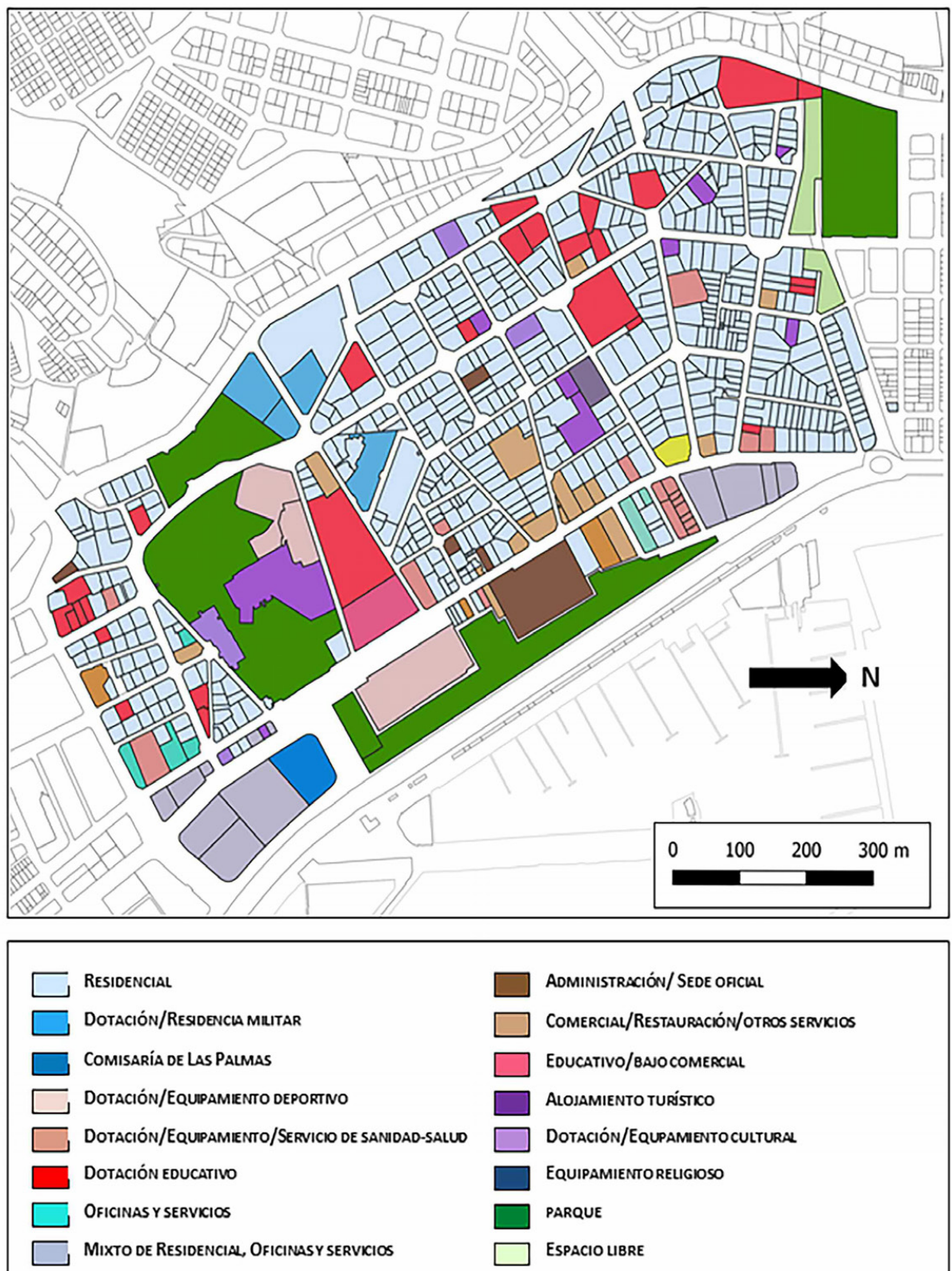

ADMINISTRACIÓN/SEDE OFCLLL

Comercial/Restauración/Otros servicios

Educativo/Banocomeaclal

Alojamiento turistico

Dotación/EquPamientocultural

EquiPAMIENTOREUGIOSO

PARQUE

ESPACIO UBRE

Fuente: Elaboración propia 
La condición de barrio residencial sigue siendo predominante. Bien es verdad que observamos un descenso proporcional en número de parcelas y superficie implicada. Entre una variable y otra estamos en una pérdida de entre un 5\% y un 6\% en 25 años que conviene contextualizar en un período supeditado a la fase de nueva planificación (culminada en 2012) y el efecto de la crisis de 2008 que ralentizaron en gran medida las nuevas implantaciones de usos y la renovación edificatoria.

Este escenario se caracteriza igualmente por la continuidad en el proceso de

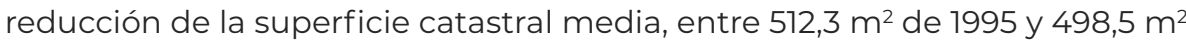
actuales. La flexibilización normativa ha sido un incentivo, que proponemos como mecanismo de freno al despoblamiento y envejecimiento experimentado en otros barrios tradicionales de la ciudad.

El comportamiento residencial coexiste con un crecimiento evidente de los usos de dotaciones y equipamientos colectivos, con un mayoritario protagonismo de la titularidad privada. Los recintos educativos, sanitarios y de servicios de salud y los usos terciarios han intensificado la ocupación en este conjunto urbano. El proceso está lejos de paralizarse.

La revitalización funcional del barrio durante las últimas décadas puede representarse en la continuidad de centros educativos y sanitarios históricos que han mantenido su localización y su actividad pese a los crecientes requerimientos de la normativa sectorial. El Colegio Salesianos, el de Las Teresianas, los centros de educación a distancia del IBAD y la UNED, la Clínica de Santa Catalina (recientemente renovada), la Clínica de La Paloma, la Clínica del Carmen (ambas también rehabilitadas) conservan su plena vitalidad. No olvidemos que el ámbito localiza los hitos de dotaciones públicas del Ayuntamiento, la Comisaría de Las Palmas y varias instalaciones-residencias militares. El antiguo Estadio Insular se ha reconvertido en un Parque, añadiéndose a los parques Doramas y Romano como enclaves neurálgicos del ocio y el esparcimiento en la ciudad baja, así como las instalaciones deportivas vinculadas a la natación (Metropole, Julio Navarro). Pese a la transformación de la ciudad, todos los anteriores siguen siendo hitos significativos del sistema urbano de dotaciones y equipamientos colectivos.

Probablemente por unas condiciones paisajísticas y de calidad arquitectónica más favorecidas que en otras zonas de aparición contemporánea, unido a los factores derivados de su localización y accesibilidad, Ciudad Jardín experimenta signos de reconversión en un subcentro neurálgico dentro de la ciudad baja. A fecha de hoy es un escenario específico y singular en la localización de inversiones, explicando que la ocupación superficial de los usos distintos al de vivienda sea superior.

Esas cualidades ambientales y de representatividad cultural están detrás de que el barrio sea el principal foco ajeno al Istmo (Playa de Las Canteras-Santa Catalina-La Isleta) y al centro histórico (Vegueta-Triana) en la localización de viviendas vacacionales (nueva modalidad de alojamiento turístico de amplio 
desarrollo en el sistema urbano nacional). Y una cadena hotelera (Barceló) es responsable de la rehabilitación del emblemático Hotel Santa Catalina y el emplazamiento reciente de otro hotel en sus inmediaciones.

La localización de «franquicias» de la educación se ha convertido en un rasgo significativo de la imagen urbana del barrio, añadiéndose a las «marcas» tradicionales (Hispano Inglés, Canterbury, Anita Conrad). Y similar efecto ha tenido la renovación de la histórica Clínica Santa Catalina (ahora Hospital VITHAS) que ha contaminado las manzanas de su entorno con un buen número de locales de servicios asociados (laboratorios, consultas, etc) y el acompañamiento de otras empresas significativas en este campo (ICOT).

Como suele ocurrir en estos casos, la difícil localización de aparcamientos en inmuebles por su limitada rentabilidad ha derivado en la ocupación del espacio público viario para esta función. A falta de nuevos viarios, esta demanda «foránea» ocupa en gran medida la oferta de los residentes (basada en las plazas en calle). Éstos ven acrecentada la dificultad impuesta por la normativa de protección del patrimonio arquitectónico para introducir garajes y la destacada demanda de espacio viario de tránsito y de estancia en estos nuevos usos.

No olvidemos que la calle León y Castillo (arteria fundamental del barrio) es un recorrido paralelo a la Autovía GC-1 del Sur en el perímetro costero y se colinda con la intersección de ésta con la GC-2 del Norte (Torre de Las Palmas), siendo una de las áreas más saturadas de tráfico de la Isla.

\subsection{LAS TENSIONES DEL PATRIMONIO AROUITECTÓNICO E HISTÓRICO}

En otra investigación hemos abordado el concepto del barrio tradicional, en el que podemos ejemplificar a Ciudad Jardín, como entidad específica en el puzle funcional, social y paisajístico de toda urbe (Hernández, Ginés y Lozano, 2016).

La concreción en la modalidad tradicional de estos barrios incorpora una noción de espacio con unas condiciones morfológicas y paisajísticas diferenciadas del resto de la ciudad; condiciones que resultan de una conciencia social conservada a lo largo del tiempo (identidad) y de una materialización histórica con arreglo a unas pautas culturales y económicas en cada momento. Son un espacio social integrado con una evidente delimitación en la trama urbana, con una herencia polifuncional y una idiosincrasia cultural que, en conjunto, participa con un papel especifico en el dinamismo contemporáneo (Solana et al., 2003, 27).

Su evolución ha perfilado la configuración del barrio de acuerdo a los criterios, pautas y estrategias de cada período temporal; evolución que ha permitido conservar su fisonomía tradicional en el contexto una ciudad muy transformada. Este tipo de características conduce a unidades urbanas bien diferenciadas en su forma, distinguiendo las que podemos considerar como 
parte del casco antiguo, de las diversas modalidades de ensanche, de la variedad de ejemplos de autoconstrucción, o del fenómeno de ciudad jardín (Capel, 2002 y Hernández, 2000).

El dinamismo que se sintetizó en el apartado anterior tiene lugar en un barrio que no olvidemos presenta un origen relativamente histórico en el contexto local (primeras décadas del siglo XX) y un proceso de consolidación que ha tenido como resultado una herencia apreciable en forma de patrimonio arquitectónico.

Pese a la continuidad de la trama en su conjunto, la constante renovación en las pautas de ocupación residenciales y restantes usos y la sucesión de cambios formales en los inmuebles y su impronta paisajística dejó en el camino un buen número de testimonios arquitectónicos de aquellas primeras décadas. Sin embargo, un volumen de 103 edificios o parcelas siguen representando en Ciudad Jardín el patrimonio arquitectónico de Las Palmas de Gran Canaria, conformando un muestrario del diseño residencial y civil de estilo racionalista, regionalista, neocanario y variedades eclécticas que definieron las pautas constructivas menos comunes en la ciudad de esa primera mitad de la centuria anterior.

Su número es relevante para un ámbito que no ha sido considerado Bien de Interés Cultural con la categoría de Conjunto Histórico, como el centro de Vegueta, Triana y Perojo. No obstante, Ilama la atención su influencia espacial en la globalidad de la zona de estudio.

Incluso, es significativa la localización puntual de los monumentos declarados con esta figura legal en el conjunto del Pueblo Canario o de la Capilla Anglicana, y, sin serlo, la referencia emblemática del Hotel Santa Catalina y el Parque Doramas.

Las tensiones del proceso transformador en este paisaje urbano de marcada componente cultural puede ejemplificar uno de los principales conflictos que experimentan los barrios tradicionales y centros históricos del sistema urbano español.

La presión de las demandas particulares, los malabarismos en el equilibrio de la administración municipal en las autorizaciones, algunas sentencias judiciales contrarias a las tesis conservacionistas, entre otros factores, convierten la gestión pública del patrimonio cultural de este espacio urbano en un constante esfuerzo con variada casuística.

El resultado formal no es siempre el deseado para el interés general del paisaje. En determinados casos, la renovación se convierte en un estímulo en la conservación, rehabilitación y puesta en valor de ese conjunto, redundando en una impronta favorable en las cualidades del entorno.

Ejemplos significativos del esfuerzo público y privado y esperanzadores para una sostenibilidad de este patrimonio urbano podemos representarlos en la reconversión del antiguo Estadio Insular en Parque y en la rehabilitación integral del conjunto de Hotel Santa Catalina, Parque Doramas y Pueblo Canario. 
Figura 4. Inmuebles en Ciudad Jardín considerados de especial interés arquitectónico

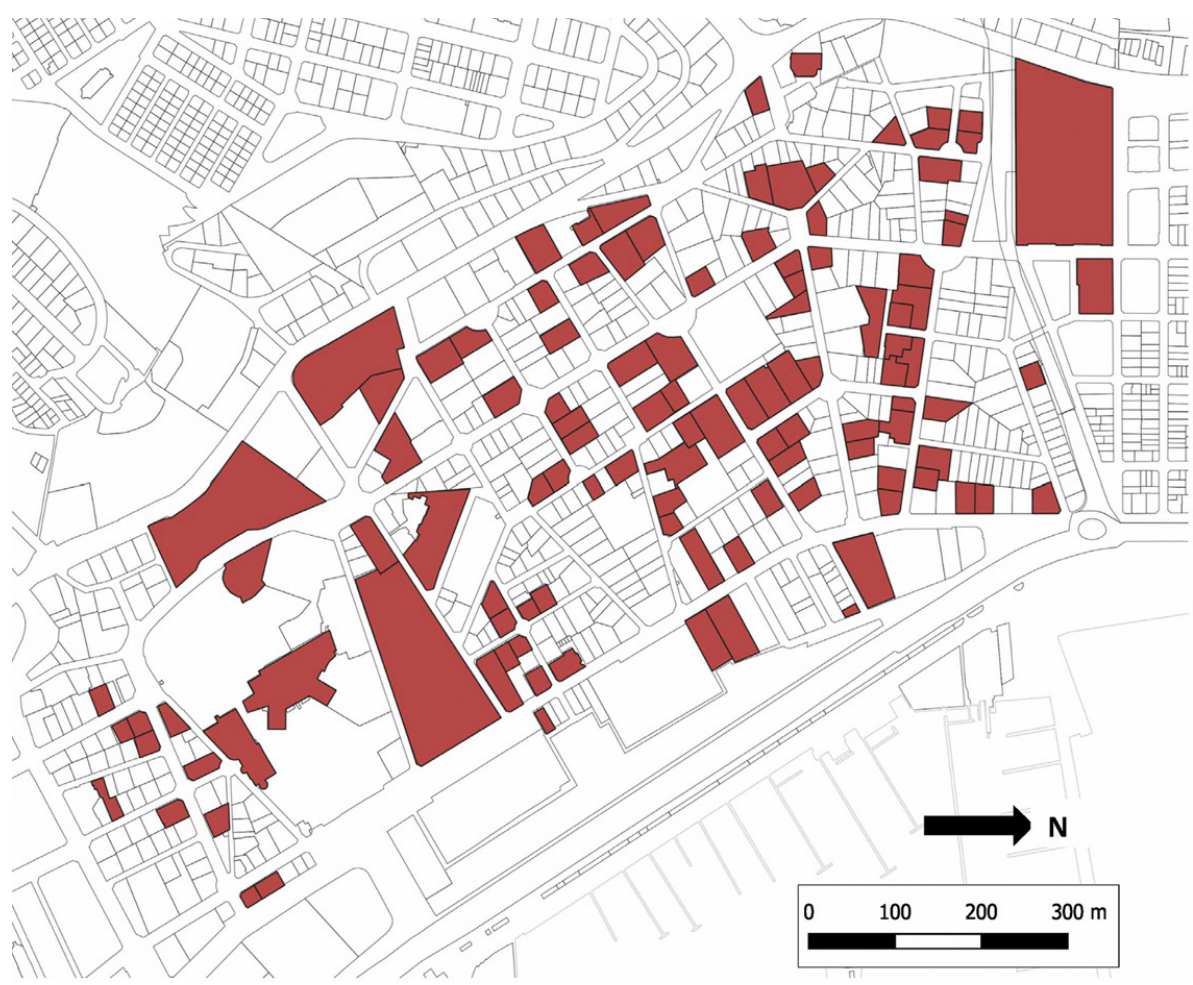

Fuente: Elaboración propia a partir del Catálogo Municipal de Protección de Las Palmas de Gran Canaria

\section{CONCLUSIONES}

Los cambios de uso en los barrios históricos o tradicionales constituyen un fenómeno cuyo análisis es oportuno y procedente. La relación entre unos rasgos sociales, de patrimonio cultural y paisajísticos puestos en valor en el conjunto de la ciudad, por una parte, y la transformación funcional en el tejido de parcelas e inmuebles y su efecto en la capacidad de acogida de la trama, por otro, se resuelven en improntas positivas y desequilibrios que discuten la eficiencia y calidad del espacio urbano.

El inventario exhaustivo basado en el trabajo de campo y el uso de los sistemas de información geográfica hacen relativamente sencillo el análisis de estas transformaciones, demostrándose como herramienta de gran interés en la geografía urbana que aplicamos a los barrios tradicionales. 
El ejemplo de Ciudad Jardín es aplicable a otras muchas formaciones afines que surgieron durante las primeras décadas del siglo XX en el sistema urbano español.

Los momentos actuales observan una adaptación parcelaria a los atractivos y oportunidades definidos en el dinamismo urbano por unas cualidades de configuración, calidad ambiental, localización y accesibilidad que coexisten en el ámbito de estudio.

En esa adaptación se reflejan rasgos muy perceptibles de la vulnerabilidad urbana de estos barrios que se corresponden con varios comportamientos abordados en la presente comunicación. De una parte, una frágil estabilidad de las características demográficas (pausado del volumen de población, relativo control del envejecimiento, satisfacción teórica de la oferta de dotaciones, equipamientos y servicios, calidad del entorno doméstico). De otra, una adaptación proporcional del uso residencial como elemento definitorio del carácter de barrio (incentivado por la flexibilidad de la normativa urbanística). Y por otro, con la acogida de una creciente implantación de los citados usos dotaciones, de equipamiento y servicios que se singulariza en la creciente implantación de alojamientos turísticos.

Es un tema que requiere nuevos aportes de investigación para completar el análisis de variables importantes que no hemos podido abordar por cuestiones de alcance del trabajo.

\section{BIBLIOGRAFÍA}

Alvargonzález, R. (1999). Somió. La ciudad jardín de Gijón. Gijón: Fundación Alvargonzález.

Arroyo, L. 1898, Navarro, F. 1911 y Chías, 1914, consultados en Tous, J. (1995). Las Palmas de Gran Canaria a través de la cartografía (1588-1899). Las Palmas de Gran Canaria: Cabildo de Gran Canaria.

Capel, H. (2002). La morfología de las ciudades. Sociedad, cultural y paisaje urbano. Barcelona: Serbal.

De Terán, F. (1999). Historia del urbanismo en España (III). Siglos XIX y XX. Madrid: Cátedra.

Hernández, A. (2000). La desigualdad urbana en España. Madrid: Ministerio de Fomento.

Hernández, S., Ginés, Mª C. y Lozano, Mํ․ (2016). Barrios tradicionales y espacio público. Usos y potencialidades en los Riscos de Las Palmas de Gran Canaria. XXII Coloquio de Historia Canario-Americana.

https://mdc.ulpgc.es/utils/getfile/collection/coloquios/id/2413/filename/ 2466.pdf.

Herrera, A. (1978). La ciudad de Las Palmas. Noticia histórica de su urbanización. Las Palmas de Gran Canaria: Ayuntamiento de Las Palmas de Gran Canaria. 
Martín, F. (2001). Las Palmas. Ciudad y Puerto. Cinco siglos de evolución. Las Palmas de Gran Canaria. Las Palmas de Gran Canaria: Fundación Puertos de Las Palmas.

Morales, G, (1995). La Ciudad Jardín de Las Palmas de Gran Canaria (18801994). ERÍA. Revista de Geografía. N³6, 89-99. Recuperado de: https://dialnet.unirioja.es/ servlet/articulo?codigo=34818.

Sobral, S. (1995). La formación suburbana de baja densidad del municipio de Las Palmas de Gran Canaria: CIES.

Solana, E., González, D., Melián, A., Olivares, A. y Pérez, Mª T. (2003): Crisis del barrio tradicional. Ruptura, mutación o continuidad. Guadalajara (México): Universidad de Guadalajara y Universidad de Las Palmas de Gran Canaria. 



\title{
METROPOLIZACIÓN Y REGIONES METROPOLITANAS: DINÁMICAS EUROPEAS
}

METROPOLISATION AND METROPOLITAN REGIONS: EUROPEAN DYNAMICS

\author{
Thomas Perrin \\ Universidad de Lille
}

\section{Resumen}

La continua metropolización de los espacios ha producido una forma urbana que se ha convertido en una cuestión recurrente para las acciones y políticas de ordenación territorial y urbana: la región metropolitana. Esta metro-región toma forma no sólo por las interdependencias territoriales y espaciales internas, sino también por la inclusión de esta región en los flujos mundiales de bienes, personas, información y servicios. Si bien la cuestión de la metro-regionalización es común a la mayoría de los países, la morfología y la extensión de las regiones metropolitanas varían mucho, desde la metrópoli (que forma) región hasta la región (formada por) metrópolis. Diferentes evoluciones conceptuales y empíricas ilustran estas evoluciones. Las autoridades públicas han intentado responder a este desafío urbano, no sólo mediante la adaptación del aparato estadístico, sino también y, sobre todo, mediante varios dispositivos institucionales. En Europa, si bien las regiones capitales se benefician en general de medidas específicas desde hace tiempo, la consideración del hecho metropolitano se ha extendido más recientemente a otras zonas, a través de diversas respuestas institucionales, como, por ejemplo, la creación de métropoles en Francia, città metropolitane en Italia, combined authorities en Inglaterra o Metropolregionen en Alemania. Este artículo presenta estas diferentes evoluciones y propone un análisis comparativo. Más allá de las grandes diferencias en las situaciones y respuestas, el enfoque comparativo proporciona una mejor comprensión de los problemas que conlleva la regionalización metropolitana y abre perspectivas, especialmente en términos de ordenación territorial, de gobernanza y de representación democrática.

Palabras claves: metrópolis, regiones, Europa, reformas, planificación urbana.

\begin{abstract}
The continuous metropolisation of spaces produced an urban form that has become a recurrent issue for regional planning actions and policies: the metropolitan region. This «metro-region» takes shape not only because of internal territorial and spatial interdependencies, but also because of the inclusion of this region in the global flows of goods, people, information and services. Although the issue of metro-regionalisation is common to most countries, the morphology and extension of metropolitan regions varies
\end{abstract}


greatly, from the «metropolis (that forms) region» to the «region (formed by) metropolises». Different conceptual and empirical developments illustrate these evolutions. Public authorities have tried to respond to this urban challenge, not only by adapting the statistical apparatus, but also and above all by installing various institutional arrangements. In Europe, while the capital regions have generally benefited from specific measures for a long time, the consideration of the «metropolitan fact» has more recently been extended to other areas, through various institutional responses, such as the creation of métropoles in France, città metropolitane in Italy, combined authorities in England or Metropolregionen in Germany. This article presents these different evolutions and proposes a comparative analysis. Beyond the great differences in situations and responses, the comparative approach provides a better understanding of the problems involved in metropolitan regionalisation and opens up perspectives, especially in terms of spatial planning, governance and democratic representation.

Keywords: metropolis, regions, Europe, reforms, urban planning.

\section{INTRODUCCIÓN}

Desde 2009, según las Naciones Unidas, más de la mitad de la población vive en zonas urbanas y esta cifra llega al 75\% en la Unión Europea (UE). La expansión de las aglomeraciones urbanas produce entidades territoriales a nuevas escalas. La ciudad central y sus suburbios forman un continuo urbano extendido, más o menos denso y a veces intercalado con discontinuidades en el entorno construido, pero cuyos diferentes polos de densidad están vinculados por interacciones e interdependencias funcionales como, por ejemplo, desplazamientos domicilio-trabajo o vínculos entre empresas en cadenas de producción. Para calificar estas aglomeraciones urbanas se ha utilizado en primer lugar el concepto de metrópoli, en referencia a la acepción griega de ciudad madre, que concentra las principales funciones, manteniendo un vínculo funcional con sus periferias.

Los conceptos de metrópoli y metropolización se han convertido en paradigmas esenciales para comprender el desarrollo urbano (Paris, 2003; GhorraGobin, 2015). Se refieren a cuatro dinámicas:

- la concentración de recursos como la población, las actividades, las finanzas, la información y el conocimiento.

- la conexión a las redes internacionales de información, comunicación, comercio, transporte y energía.

- la movilización de los agentes políticos, socioeconómicos y civiles en el desarrollo metropolitano: la gobernanza metropolitana. 
- la difusión morfológica y funcional de las dinámicas metropolitanas dentro de vastas y complejas unidades territoriales que van más allá de las ciudades madre para formar regiones metropolitanas.

El creciente número de comparaciones y clasificaciones internacionales ponen en evidencia estas evoluciones, tal como en los términos de varias comparaciones y clasificaciones internacionales ${ }^{1}$, o en la creación de la red europea de áreas y regiones metropolitanas METREX². La metropolización de las aglomeraciones urbanas parece ser emblema de una posmodernidad espacial y territorial que conduce a una renovación de los dispositivos de ordenación y desarrollo territoriales. Si bien la cuestión metropolitana es común a la mayoría de los países, la morfología y la extensión de las regiones metropolitanas varían, desde la metrópoli (que forma) región hasta la región (formada por) metrópolis.

Las autoridades públicas han intentado responder a este desafío de planificación urbana, no sólo con la adaptación del aparato estadístico, sino también, y, sobre todo, mediante varios dispositivos institucionales. Este artículo reflexiona sobre el estado de la cuestión metropolitana en diferentes países europeos, con un enfoque principalmente teórico y cualitativo, basado en un análisis documental y de la literatura científica. Los datos empíricos también proceden de trabajos e intercambios dentro de varios proyectos o grupos de investigación ${ }^{3}$, incluso una tesis de habilitación (Perrin, 2020). En primer lugar, el artículo expone unas de las principales evoluciones teóricas y empíricas que ilustran el fenómeno de metropolizacion (1). Luego presenta unos dispositivos institucionales desarrollados para ordenar les regiones metropolitanas en diferentes países europeos, en particular los estatutos específicos creados en Alemania, Francia, Inglaterra e Italia (2). Se aporta un análisis comparativo de estos casos. Más allá de las diferencias o convergencias entre las situaciones y respuestas (3), el enfoque comparativo proporciona una mejor comprensión de los problemas que conlleva la regionalización metropolitana y abre perspectivas, especialmente en términos de ordenación territorial, de gobernanza y de representación democrática (4).

1 Como por ejemplo GaWC: Globalization and World Cities Research Network ranking; MasterCard Global Destination Cities Index; Knight Frank Global Cities Index; A.T. Kearny Global Cities Index.

2 https://www.eurometrex.org

3 Proyecto Euborderscapes http://www.euborderscapes.eu, grupo de estudio sobre urbanismo británico y francés https://www.aesop-planning.eu/blogs/en_GB/frenchand-british-planning-studies, grupo del ARL-Akademie für Raumentwicklung in der Leibniz-Gemeinschaft sobre urbanismo y ordenación territorial en Alemania y Francia. 


\section{LA METROPOLIZACIÓN: MARCO TEÓRICO Y EVOLUCIONES EMPÍRICAS}

Desde hace más de un siglo, muchos conceptos y visiones han ilustrado la evolución de las aglomeraciones urbanas con el proceso de metropolización, desde la conurbación de Patrick Geddes a principios del siglo XX hasta las recientes proyecciones megarregionales de geógrafos estadounidenses (Figura 1). Algunos enfoques ponen de relieve la conexión de estas aglomeraciones tanto entre sí como con la economía mundial: las ciudades globales de Sassen (1996) (Figura 1), o bien el archipiélago megalopolitano mundial (Dollfus, 1994), formado por las metrópolis mundiales que concentran la mayoría de los flujos financieros y de los conocimientos científicos.

Figura 1. Metrópolis y regiones metropolitanas: conceptos y formas

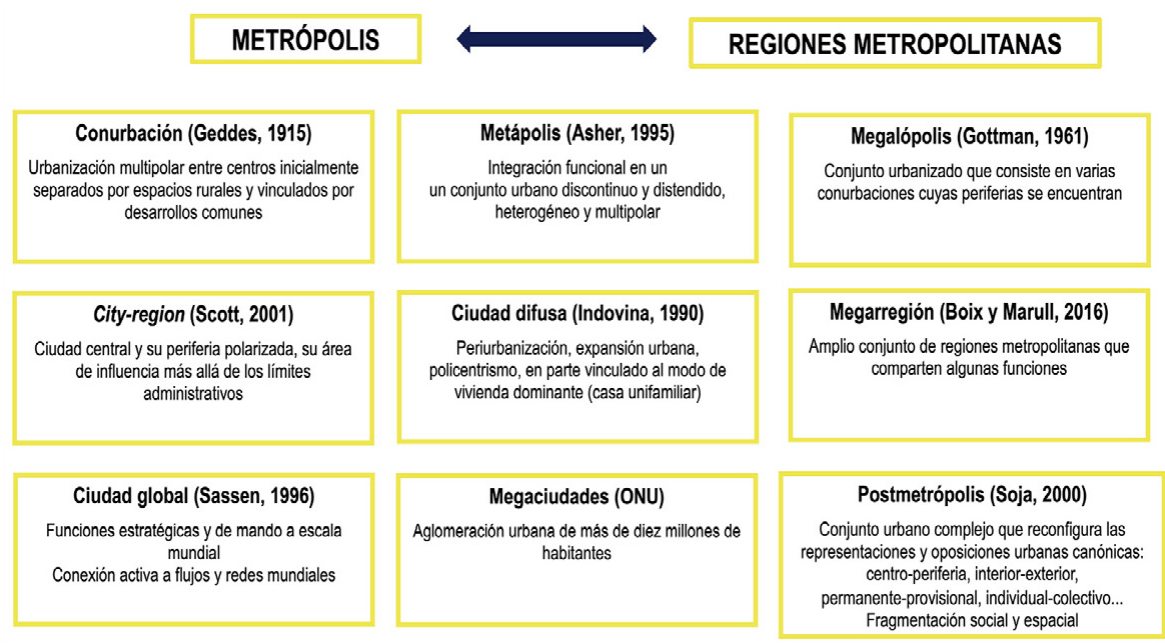

Fuente: Elaboración propia

Referencias:

Ascher, F. (1995). Métapolis ou l'avenir des villes. Paris: Odile Jacob.

Boix, R. y Marull, J. (Eds.). (2016). Megaregions i desenvolupament urbà sostenible. Factors estratègics per a l'àrea metropolitana de Barcelona en el context europeu, Papers $n^{\circ} 58$.

Geddes, P. (1915). Cities in Evolution: an introduction to the Town Planning Movement and to the Study of Civics. Londres: Williams \& Norgate.

Gottman, J. (1961). Megalopolis, The Urbanized Northeastern Seaboard of the United States. Nueva York: The Twentieth Century fund.

Indovina, F. (Ed.) (1990). La Città diffusa. Venecia: DAEST-IUAV.

Sassen, S. (1996). La Ville globale: New York, Londres, Tokyo. Paris: Descartes et Cie.

Scott, A. J. (Ed.) (2001). Global city-regions: trends, theory, policy. Oxford University Press.

Soja, E. (2000). Postmetropolis: critical studies of cities and regions. Oxford: Blackwell. 
La Conferencia Europea de Ministros responsables de ordenación del territorio (CEMAT, 2007) define una región metropolitana como, por lo general, la extensión de un área metropolitana, pero también indica que ambos conceptos pueden utilizarse como sinónimos. Ciertamente, a escala mundial, las metrópolis y regiones metropolitanas de la UE son de tamaño mediano o pequeño en comparación con las aglomeraciones mas densamente pobladas y extendidas de Asia o América. Sólo las regiones metropolitanas de Londres y París pueden parecer megalópolis, que cuentan mas de 10 millones de habitantes según los criterios de la ONU, a las cuales se puede unir Moscú y Estambul en los márgenes europeos. Sin embargo, los problemas de la metropolización no están menos presentes en Europa, como lo demuestra, por ejemplo, la adopción en 2015 de la Agenda Urbana de la UE. La evolución de los sistemas estadísticos indica estas evoluciones.

Las nomenclaturas geo-estadísticas han sido adaptadas para tener en cuenta mejor a los cambios de prácticas espaciales y territoriales vinculados con la metro-regionalización: el INSEE en Francia ha identificado 29 grandes áreas urbanas y 12 áreas urbanas metropolitanas (Brutel, 2011). En Alemania hay categorías para regiones metropolitanas [Großstadtregionen] ${ }^{4}$, y en el Reino Unido se hace una distinción entre las áreas urbanizadas [built-up areas] grandes [large] o mayores [major] $]^{5}$. Eurostat, la agencia estadística de la UE, ha formado la categoría de regiones metropolitanas o metrorregiones sobre la base de las áreas urbanas funcionales (AUF) de la UE y la OCDE (Figura 2$)^{6}$. Sin embargo, esta última categoría, basada en las unidades territoriales de nivel europeo NUTS 37 , es menos concluyente porque estas unidades son extremadamente diversas a nivel europeo y su perímetro es generalmente político-administrativo más que basado en polarizaciones funcionales (Breuer y Halleux, 2016). Por ejemplo, según Eurostat, la región metropolitana de Lille corresponde al departamento del Norte, y la región metropolitana de Toulouse al del Alto Garona: esas divisiones datan de la Revolución Francesa y ya no corresponden a las polarizaciones funcionales de estas regiones metropolitanas.

4 Bundesinstitut für Bau-, Stadt- und Raumforschung, https://www.bbsr.bund.de

5 Office for national statistics, https://www.ons.gov.uk

6 Muchos datos están disponibles en https://measuringurban.oecd.org

7 Por ejemplo, departamentos en Francia [départements], provincias españolas o italianas, arrondissements belgas. 
Figura 2. Metrorregiones de la Unión Europea

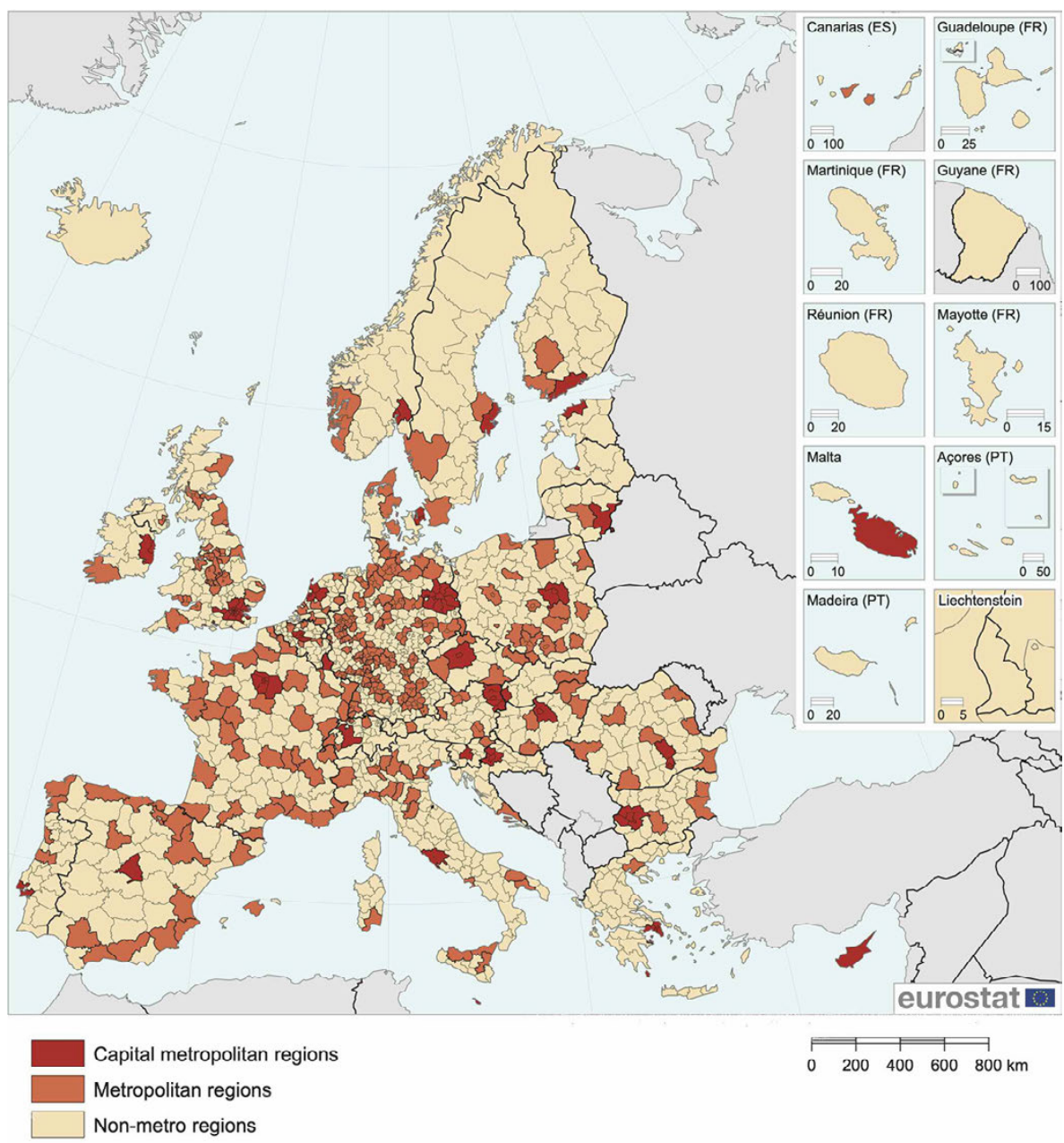

Fuente: Eurostat (https://ec.europa.eu/eurostat), basado en los índices de población 2011 y la NUTS 2013. Administrative boundaries: ๑ EuroGeographics (c) UN-FAO ㄷ Turkstat Cartography: Eurostat - GISCO, 08/2026

Paralelamente, en varios países las autoridades lanzaron nuevos instrumentos de organización y ordenación territorial para responder a estas dinámicas de metropolización. 


\section{RESPUESTAS Y DISPOSITIVOS INSTITUCIONALES: PANORAMA EUROPEO}

Muchas regiones capitales europeas tienen en general estructuras institucionales regulatorias y específicas desde hace mucho tiempo, como la Ciudad-Estado de Berlín, la comunidad autónoma de Madrid, el Gran Londres, la comunidad urbana de Copenhague. Sin embargo, mientras que la metropolización de los espacios se ha acentuado, unas recientes reformas han extendido dispositivos especiales en más aglomeraciones, que han sido objeto de un volumen importante de análisis y trabajos críticos (Lebras, Seigneuret y Talandier, 2016; Bettoni, Le Bras y Navarre, 2018; Kawka, 2016; Zimmermann, 2017; Demazière, 2018; Martí-Costa y Tomàs Fornès, 2018; Lupton et al., 2018; Purkarthofer y Humer, 2019). Podemos observar nuevas organizaciones o estatutos en Alemania, Francia, Inglaterra o Italia (Tabla 1, Figura 3 y 4). En otros países las soluciones se construyen más gradualmente (Tabla 2).

Tabla 1. Esquemas de metro-regionalización en Alemania, Francia, Inglaterra e Italia

\begin{tabular}{|c|c|c|}
\hline Dispositivo & Contexto & $\begin{array}{c}\text { Principales } \\
\text { características }\end{array}$ \\
\hline $\begin{array}{l}\text { Alemania } \\
11 \text { Europäische Metro- } \\
\text { polregionen, } 1995\end{array}$ & $\begin{array}{l}\text { - Amplia variedad de } \\
\text { regiones de planifica- } \\
\text { ción según los Länder } \\
\text { (Estado federal) } \\
\text { - Ciudades-Estados de } \\
\text { Hamburgo, Bremen y } \\
\text { Berlín: regiones metro- } \\
\text { politanas per se } \\
\text { - Otras áreas metropo- } \\
\text { litanas bastante inte- } \\
\text { gradas (transporte, } \\
\text { residuos, turismo, pla- } \\
\text { nificación urbana) en } \\
\text { perímetros más pe- } \\
\text { queños: Stuttgart, } \\
\text { Hannover, Ruhr, Frank- } \\
\text { furt... }\end{array}$ & $\begin{array}{l}\text { - Superación de las fronteras } \\
\text { tradicionales entre Länder: } \\
\text { nuevas dinámicas regionales, } \\
\text { adaptadas al contexto socio-te- } \\
\text { rritorial europeo } \\
\text { - Aplicación flexible, basada en } \\
\text { la auto-organización de las co- } \\
\text { munidades afectadas } \\
\text { - Gran diversidad de situacio- } \\
\text { nes y estructuración } \\
\text { - Grupo de Iniciativa Regiones } \\
\text { Metropolitanas Transfronteri- } \\
\text { zas (asociación entre los Län- } \\
\text { der y las asociaciones } \\
\text { regionales u otras agrupacio- } \\
\text { nes de planificación): promo- } \\
\text { ción y fortalecimiento de la } \\
\text { cooperación transfronteriza en } \\
\text { las eurorregiones del Mosa-Rin, } \\
\text { el Alto Rin, la Gran Región y el } \\
\text { Lago de Constanza. }\end{array}$ \\
\hline
\end{tabular}


Tabla 1 (continuación). Esquemas de metro-regionalización en Alemania, Francia, Inglaterra e Italia

\begin{tabular}{|c|c|c|}
\hline Dispositivo & Contexto & $\begin{array}{l}\text { Principales } \\
\text { características }\end{array}$ \\
\hline $\begin{array}{c}\text { Francia } \\
22 \text { métropoles, } 2015\end{array}$ & $\begin{array}{l}\text { - Estado tradicional- } \\
\text { mente centralizado, } \\
\text { pero proceso gradual } \\
\text { de descentralización a } \\
\text { partir de los 1980's } \\
\text { - Estatutos particulares } \\
\text { para las aglomeracio- } \\
\text { nes de Paris, Lyon, Aix- } \\
\text { Marseille } \\
\text { - Cooperación interco- } \\
\text { munal, iniciada en el } \\
\text { decenio de 1960: pri- } \\
\text { meras comunidades } \\
\text { urbanas } \\
\text { - Aceleración a partir } \\
\text { del } 2000 \text { : por ejemplo, } \\
\text { incentivos del Estado } \\
\text { para animar polos me- } \\
\text { tropolitanos (redes de } \\
\text { ciudades) } \\
\text { - Reforma territorial } \\
\text { iniciada en 2010, relan- } \\
\text { zada en 2014: ley de re- } \\
\text { forma de las } \\
\text { colectividades territo- } \\
\text { riales (2010); ley de mo- } \\
\text { dernización de la } \\
\text { acción pública territo- } \\
\text { rial y de afirmación de } \\
\text { las metrópolis (MAP- } \\
\text { TAM, 2014); ley sobre el } \\
\text { estatuto de París y la } \\
\text { planificación metropo- } \\
\text { litana (2017) }\end{array}$ & $\begin{array}{l}\text { - Intermunicipalidades integra- } \\
\text { das: evolución de los criterios } \\
\text { de formación tras el lobbying } \\
\text { de las aglomeraciones urbanas } \\
\text { mas pequeñas } \\
\text { - Capacidad avanzada en plani- } \\
\text { ficación, desarrollo económico, } \\
\text { movilidad... } \\
\text { - Posibilidad de negociación de } \\
\text { la transferencia de competen- } \\
\text { cias con otros niveles (departa- } \\
\text { mento, región) }\end{array}$ \\
\hline
\end{tabular}


Tabla 1 (continuación). Esquemas de metro-regionalización en Alemania, Francia, Inglaterra e Italia

\begin{tabular}{|c|c|c|}
\hline Dispositivo & Contexto & $\begin{array}{l}\text { Principales } \\
\text { características }\end{array}$ \\
\hline $\begin{array}{l}\text { Inglaterra } \\
10 \text { combined authorities, } \\
2011\end{array}$ & $\begin{array}{l}\text { - Centralización (Wes- } \\
\text { tminster system) pero } \\
\text { proceso de devolution a } \\
\text { partir del fin de los 1990's } \\
\text { - Londres: estatus espe- } \\
\text { cial desde } 2000 \text { Greater } \\
\text { London Authority } \\
\text { - Programa de localismo } \\
\text { (conservador) lanzado } \\
\text { en 2010: sinergia de las } \\
\text { fuerzas públicasy priva- } \\
\text { das a escala de una ciu- } \\
\text { dad-región } \\
\text { - Local Democracy, Eco- } \\
\text { nomic Development } \\
\text { and Construction Act } \\
2009, \text { Localism Act 2011, } \\
\text { Cities and Local Go- } \\
\text { vernment Devolution } \\
\text { Act } 2016 \\
\text { - Sucede al programa } \\
\text { del partido Labour de } \\
\text { las agencias de desarro- } \\
\text { llo regional (planifica- } \\
\text { ción), que fue derogado } \\
\text { en } 2010 \text { por ser dema- } \\
\text { siado tecnocrático. } \\
\text { - Debates entre el regio- } \\
\text { nalismo y el localismo } \\
\text { en la campo de la plani- } \\
\text { ficación-ordenación en } \\
\text { el Reino Unido }\end{array}$ & $\begin{array}{l}\text { - Grupos de autoridades locales } \\
\text { - Modelo flexible definido por } \\
\text { cada coalición formada } \\
\text { - Transporte, economía y transfe- } \\
\text { rencia de otras competencias } \\
\text { según acuerdos con Westminster } \\
\text { - Alcalde elegido directamente } \\
\text { en } 8 \text { autoridades combinadas } \\
\text { (2019) } \\
\text { - Diversas combinaciones con } \\
\text { incentivos para la descentraliza- } \\
\text { ción: devolution deals, city deals, } \\
\text { Local Entreprise Partnership } \\
\text { (LEP) }{ }^{8} \text {... }\end{array}$ \\
\hline
\end{tabular}

8 El LEP es una entidad creada por el gobierno en 2011 para determinar las prioridades económicas locales e impulsar el crecimiento económico. El gobierno y el LEP firman un growth deals, y el LEP no necesariamente tiene el mismo perímetro que las combined authorities. 
Tabla 1 (continuación). Esquemas de metro-regionalización en Alemania, Francia, Inglaterra e Italia

\begin{tabular}{|c|c|c|}
\hline Dispositivo & Contexto & $\begin{array}{c}\text { Principales } \\
\text { características }\end{array}$ \\
\hline $\begin{array}{l}\text { Italia } \\
14 \text { città metropolitane, } \\
2015\end{array}$ & $\begin{array}{l}\text { - Estado regionalizado: } \\
\text { descentralización avan- } \\
\text { zada y diferenciada } \\
\text { - Proceso largo, aplica- } \\
\text { ción compleja iniciada } \\
\text { en el decenio de } 1990 \\
\text { con la Ley 142/90 de re- } \\
\text { forma de la administra- } \\
\text { ción local (1990), } \\
\text { consagrada en el artí- } \\
\text { culo } 114 \text { de la Constitu- } \\
\text { ción } \\
\text { - Implementación con- } \\
\text { creta por la ley n56 del } 7 \\
\text { de abril de } 2014 \text { Disposi- } \\
\text { zioni sulle citta' metro- } \\
\text { politane, sulle province, } \\
\text { sulle unioni e fusioni di } \\
\text { comuni }\end{array}$ & $\begin{array}{l}\text { - Nueva entidad territorial que } \\
\text { sustituye a la provincia de la ciu- } \\
\text { dad central } \\
\text { - Misión principal: plan de desa- } \\
\text { rrollo estratégico de tres años y } \\
\text { la posibilidad de desarrollar pla- } \\
\text { nes territoriales más aplicados } \\
\text { - Coordinación de servicios e in- } \\
\text { fraestructuras: agua, sanea- } \\
\text { miento, equipamiento, movili- } \\
\text { dad, economía... }\end{array}$ \\
\hline
\end{tabular}

Fuente: Elaboración propia 
Figura 3. Instituciones metro-regionales en Alemania, Francia, Italia.

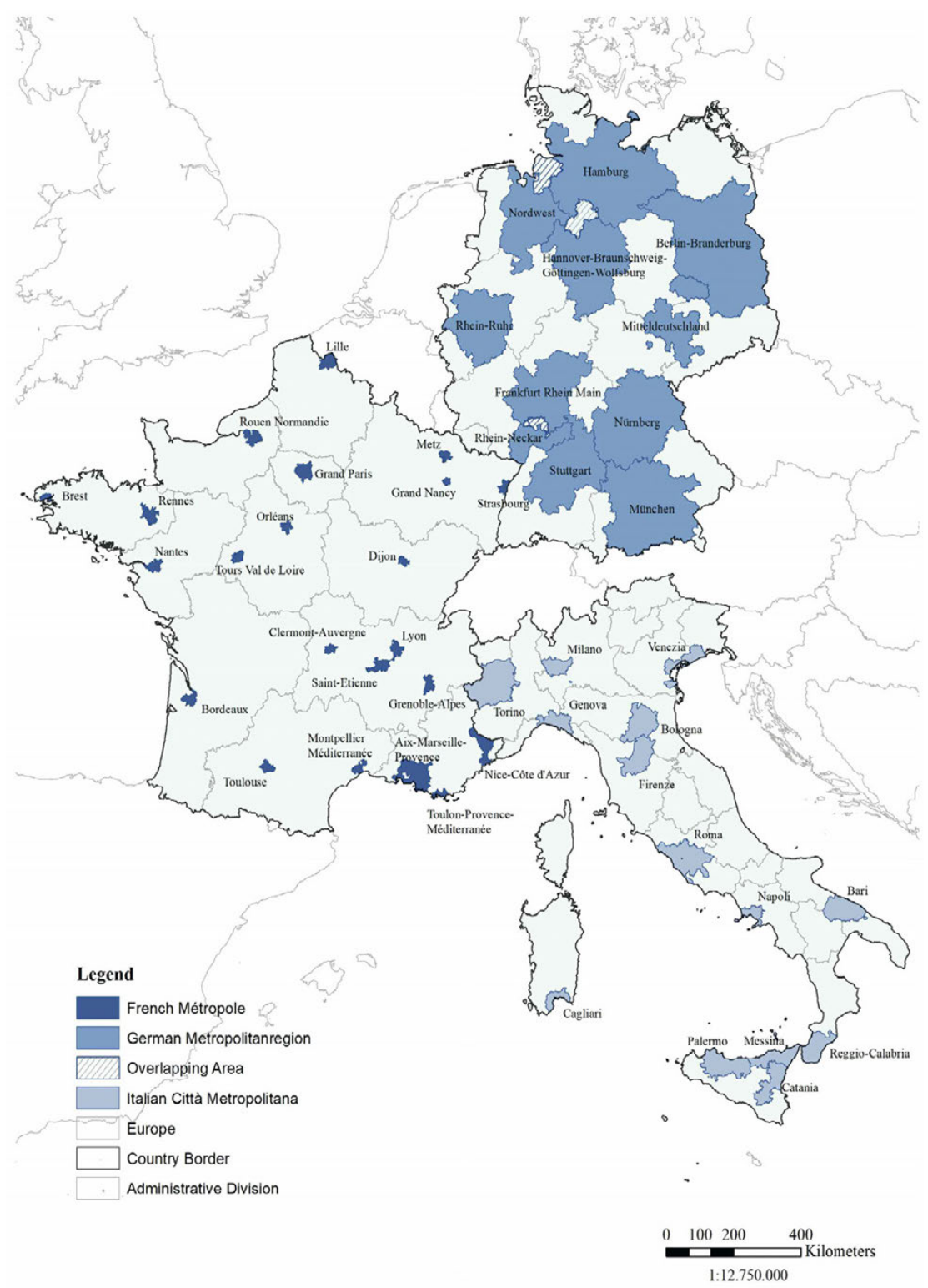

Fuente: Zimmermann \& Feiertag, 2018, 18.

Mapa base: Eurostat NUTS 2016, ๔ EuroGeographics. Sistema de Coordenadas Geográficas: GCS_WGS_1984, GCS_RGF_1993_Monte_Mario 
Figura 4. Combined authorities y dispositivos de desarrollo metropolitano en Inglaterra

Combined Authority/GLA

LAs associated with a CA

City Deal outline

LAs in City Deal but not CA

LAs in North East CA \& not the North of Tyne CA

$\mathrm{CA}$ : Combined authority

LA : Local authority

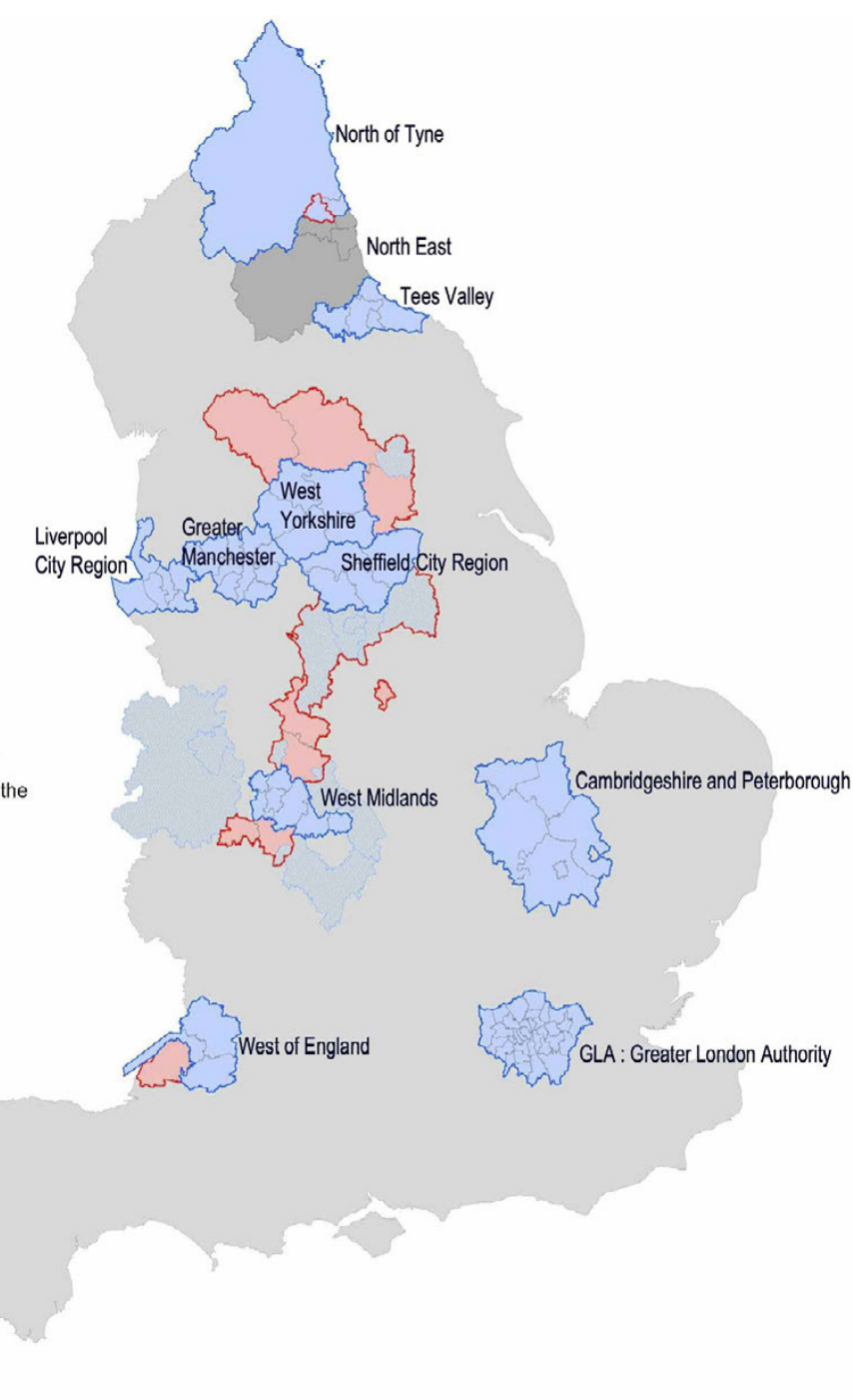

Fuente: Lupton et al., 2018, 59 
Tabla 2. Otros esquemas de metro-regionalización en la Unión Europea

\begin{tabular}{|c|c|c|}
\hline País / dispositivo & Contexto & $\begin{array}{c}\text { Principales } \\
\text { características }\end{array}$ \\
\hline $\begin{array}{l}\text { Austria } \\
\text { Agenda Stadtregionen, } \\
2015\end{array}$ & $\begin{array}{l}\text { - Reconocimiento del } \\
\text { valor de la cooperación } \\
\text { metropolitana por parte } \\
\text { de los actores: asociación } \\
\text { Städtebund (municipios } \\
\text { urbanos) y Conferencia fe- } \\
\text { deral de planificación y or- } \\
\text { denación, } \\
\text { (Österreichische Rau- } \\
\text { mordnungskonferenz, } \\
\text { ÖROK) }\end{array}$ & $\begin{array}{l}\text { - Recomendaciones en el } \\
\text { marco de la estrategia de } \\
\text { planificación decenal } \\
(O ̈ R E K) \\
\text { - Establecimiento de una } \\
\text { agenda metropolitana } \\
\text { Agenda Stadtregionen }\end{array}$ \\
\hline $\begin{array}{l}\text { Bélgica } \\
\text { Communauté métropoli- } \\
\text { taine de Bruxelles, } 2012\end{array}$ & $\begin{array}{l}\text { - Ley Especial de } 19 \text { de } \\
\text { julio de } 2012 \text { que com- } \\
\text { pleta el artículo 92bis de } \\
\text { la Ley Especial de } 8 \text { de } \\
\text { agosto de } 1980 \text { sobre las } \\
\text { reformas institucionales, } \\
\text { en lo que respecta a la Co- } \\
\text { munidad metropolitana } \\
\text { de Bruselas } \\
\text { - Región metropolitana } \\
\text { cuya influencia y alcance } \\
\text { se extiende más allá de la } \\
\text { Región de Bruselas-Capi- } \\
\text { tal }\end{array}$ & $\begin{array}{l}\text { - Órgano de consulta: mo- } \\
\text { vilidad, seguridad vial y } \\
\text { obras viarias } \\
\text { - Municipios de la Región } \\
\text { de Bruselas } \\
\text {-Capital, del Brabante } \\
\text { Valón y del Brabante Fla- } \\
\text { menco } \\
\text { - Cooperación mal inte- } \\
\text { grada: tensiones políticas } \\
\text { entre actores valones y } \\
\text { flamencos (Estado fede- } \\
\text { ral) } \\
\text { - Dificultad para organizar } \\
\text { una red de transporte ex- } \\
\text { preso que sirva eficaz- } \\
\text { mente al área } \\
\text { metropolitana- Iniciativa } \\
\text { de los actores privados } \\
\text { privés Brussels Metropoli- } \\
\text { tan }\end{array}$ \\
\hline
\end{tabular}


Tabla 2 (Continuación). Otros esquemas de metro-regionalización en la Unión Europea

\begin{tabular}{|c|c|c|}
\hline País / dispositivo & Contexto & $\begin{array}{c}\text { Principales } \\
\text { características }\end{array}$ \\
\hline Diverso & $\begin{array}{l}\text { - Estado regionalizado: } \\
\text { descentralización avan- } \\
\text { zada y diferenciada } \\
\text { - Organización u ordena- } \\
\text { ción metropolitanas bajo } \\
\text { la jurisdicción de cada co- } \\
\text { munidad autónoma }\end{array}$ & $\begin{array}{l}\text { - Organizaciones metro- } \\
\text { politanas en Barcelona, } \\
\text { Valencia o Bilbao: agua, } \\
\text { transporte, planificación...- } \\
\text { Abolición y sustitución } \\
\text { por organismos sectoria- } \\
\text { les } \\
\text { - Creación del área metro- } \\
\text { politana de Barcelona } \\
\text { (2011): agua, medio am- } \\
\text { biente, transporte, resi- } \\
\text { duos... } \\
\text { - Pero con competencias } \\
\text { limitadas } \\
\text { - Madrid y Sevilla: organis- } \\
\text { mos o planes metropolita- } \\
\text { nos que dependen más } \\
\text { directamente de las Co- } \\
\text { munidades Autónomas }\end{array}$ \\
\hline $\begin{array}{l}\text { Finlandia } \\
\text { Diverso }\end{array}$ & - Incentivos del Estado & $\begin{array}{l}\text { - Proyecto PARAS (2007- } \\
\text { 2012): incentivos para la } \\
\text { fusión voluntaria } \\
\text { - Acuerdos MAL (2011), in- } \\
\text { centivos para la coopera- } \\
\text { ción en el campo de la } \\
\text { vivienda, el transporte, la } \\
\text { ocupación territorial: prin- } \\
\text { cipalmente en las regio- } \\
\text { nes urbanas más } \\
\text { importantes (Helsinki, } \\
\text { Tampere, Turku y Oulu) }\end{array}$ \\
\hline
\end{tabular}


Tabla 2 (Continuación). Otros esquemas de metro-regionalización en la Unión Europea

\begin{tabular}{|c|c|c|}
\hline País / dispositivo & Contexto & $\begin{array}{c}\text { Principales } \\
\text { características }\end{array}$ \\
\hline $\begin{array}{l}\text { Países-Bajos } \\
8 \text { plusregio, 2006-2015Me- } \\
\text { tropoolregio, } 2015\end{array}$ & $\begin{array}{l}\text { - Órganos de cooperación } \\
\text { obligatoria entre munici- } \\
\text { pios } \\
\text { - Transferencias financie- } \\
\text { ras del Estado } \\
\text { - Ley de modificación de } \\
\text { los reglamentos comunes } \\
\text { para las autoridades loca- } \\
\text { les, } 2005 \text { (Wet gemeens- } \\
\text { chappelijke regelingen), } \\
\text { abrogada en } 2015\end{array}$ & $\begin{array}{l}\text { - Gestión conjunta de } \\
\text { ciertos servicios: planifica- } \\
\text { ción estratégica, movili- } \\
\text { dad, economía, } \\
\text { equipamiento... } \\
\text { - Abolición en } 2015 \text {, a } \\
\text { causa de falta de integra- } \\
\text { ción real de los munici- } \\
\text { pios, y la adición de una } \\
\text { capa administrativa adi- } \\
\text { cional } \\
\text { - Regreso de las compe- } \\
\text { tencias a los municipios o } \\
\text { provincias, o nuevos } \\
\text { acuerdos o entidades de } \\
\text { cooperación: por ejemplo, } \\
\text { Metropoolregio de Áms- } \\
\text { terdam, Rotterdam- } \\
\text { Hague o Eindhoven: } \\
\text { cooperación los sectores } \\
\text { de economía, transporte, } \\
\text { atractividad, turismo... }\end{array}$ \\
\hline $\begin{array}{c}\text { Polonia } \\
\text { República Checa } \\
\text { Eslovaquia }\end{array}$ & $\begin{array}{l}\text { - Política regional de la } \\
\text { UE, 2014-2020 } \\
\text { - Aplicación de Inversio- } \\
\text { nes territoriales integra- } \\
\text { das (ITI): un instrumento } \\
\text { para una estrategia terri- } \\
\text { torial integrada e intersec- } \\
\text { torial en un área } \\
\text { geográfica predefinida. }\end{array}$ & $\begin{array}{l}\text { - Creación de agrupacio- } \\
\text { nes dentro de las zonas } \\
\text { urbanas funcionales para } \\
\text { gestionar los ITI } \\
\text { - Proceso de aprendizaje } \\
\text { cooperativo a nueva es- } \\
\text { cala } \\
\text { - Posibles tensiones entre } \\
\text { nuevas y antiguas regio- } \\
\text { nes }\end{array}$ \\
\hline
\end{tabular}

Fuente: Elaboración propia 
Si bien estos elementos indican una convergencia hacia la consideración de la escala metropolitana en las cuestiones y políticas de ordenación territorial, también existe una gran variabilidad en el establecimiento de tales metroregiones (Epígrafe 4). Los dispositivos reflejan las culturas de planificación y las trayectorias dependientes específicas de cada país. Sin embargo, también es posible identificar retos comunes de estos procesos de institucionalización de la metrópoli, en particular las cuestiones de cooperación y encarnación de estas formas socio-territoriales emergentes (Epígrafe 5).

\section{LA METRO-REGIÓN: ENTRE OBJETIVO DE EFICIENCIA Y SITUACIÓN DE COMPLEJIDAD}

Las metrópolis francesas suelen ser más pequeñas que un departamento de nivel NUTS 3, con una superficie de aproximadamente 143 a 3.150 km², con una media de $750 \mathrm{~km}^{2}$, y una población media de 700.000 habitantes (excluyendo el Gran París). En Italia el tamaño de las ciudades metropolitanas varía desde perímetros ex-provinciales (NUTS 3) bastante grandes en el caso de Turín (6.830 km²) y Roma $\left(5.363 \mathrm{~km}^{2}\right)$, a otros más pequeños en la región de Milán (1.575 km²), Génova $\left(1.838 \mathrm{~km}^{2}\right)$ y Venecia $(2.472$ km²). La población media, excluyendo a Roma, es de 1,4 millones. Las combined authorities en Inglaterra tienen la misma población media, con una superficie media de $2.300 \mathrm{~km}^{2}$. Las regiones metropolitanas alemanas son una excepción entre estos procesos de metropolización: son mucho más grandes, van desde menos de 6.000 hasta más de $30.000 \mathrm{~km}^{2}$, con poblaciones que van de $2,4 \mathrm{a}$ 12,8 millones, con una media de más de 5 millones de habitantes ${ }^{9}$. En este sentido, a pesar de su nombre y de sus objetivos declarados, morfológicamente hablando están más bien ligados a una regionalización macro, de mayor escala (Perrin, 2020).

En Francia, Italia, Inglaterra o en los Países Bajos, el Estado tiene un papel relativamente importante para establecer —o suprimir - los dispositivos mediante leyes y reglamentos. La acción estatal centralizada es más débil en Alemania y España, con situaciones variables según el contexto subestatal, aunque en Alemania hay una voluntad de armonizar las acciones dentro de la Federación. En Polonia, el Estado deja un cierto margen de maniobra a los actores para organizar su cooperación. Las reformas en Italia e Inglaterra están más marcadas por una lógica de austeridad financiera. En Francia y Alemania, el argumento de la competitividad ha motivado particularmente la creación de regiones metropolitanas, no sin contradicciones con la orientación tradicionalmente fuerte, en ambos países, a favor de la igualdad o el equilibrio entre territorios. En Francia las autoridades también han invocado

9 Se pueden encontrar muchos datos en la base estadística de la asociación de regiones metropolitanas: http://deutsche-metropolregionen.webseiten.cc/monitoring 
la eficacia de la acción pública frente a la fragmentación de los niveles de administración territorial, para crear metrópolis más integradas con acciones más legibles.

También existe una variabilidad dentro de los sistemas nacionales, con una doble tendencia a la diferenciación territorial y a la superposición de sistemas. Las combined authorities inglesas tienen diferentes acuerdos de desarrollo de tipo city-deal o LEP, los cuales también se han concedido a otras autoridades territoriales. El gobierno deja un margen de maniobra a los actores locales para que apliquen sus políticas metropolitanas según esquemas a veces distintos, pero al final el sistema sigue siendo bastante centralizado y dependiente de los incentivos del gobierno de Westminster. En Francia, varias metrópolis tienen un estatuto diferenciado, que deroga al derecho común. Las metrópolis del Gran París y de Aix-Marsella se organizan en subconjuntos territoriales definidos por la ley. La metrópoli de Lyon ha absorbido directamente, dentro de su perímetro, las funciones y competencias del departamento del Ródano, a la manera de las ciudades metropolitanas italianas. Los estatutos de Lille, Niza y Estrasburgo toman en cuenta su posición específica en áreas fronterizas. Estas eurometrópolis deben establecer un Plan de cooperación transfronteriza. Por otra parte, las metrópolis deben desplegar sus políticas de planificación y ordenación en relación con los planes urbanos y otros esquemas de ordenación en su área, cuyos perímetros no se corresponden. En algunas áreas existen procesos inter-territoriales adicionales, que inducen articulaciones complementarias: cooperaciones inter-Scot entre los esquemas de planificación $\mathrm{Scot}^{10}$, o creación de un polo metropolitano o esquema de cooperación entre aglomeraciones urbanas.

En Italia, no todas las ciudades metropolitanas adoptaron un plan estratégico y prefirieron tener un plan territorial. Algunos han conservado el plan provincial preexistente. En Turín existía una tradición de planificación al nivel del área metropolitana, tras la acción de la asociación Torino Strategica que produjo el plan Torino 2025 en 2012. Con la creación de la ciudad metropolitana la asociación se disolvió y un plan estratégico fue elaborado a una escala mucho mayor, con un cierto retorno de la gestión directa por la administración. En Bolonia, la creación de la ciudad metropolitana también cambió el contexto y las escalas de cooperación que existían para la planificación, pero, a diferencia de lo que ocurrió en Turín, las nuevas acciones se basaron en la cooperación preexistente. En Alemania, las regiones metropolitanas europeas operan en contextos territoriales muy variados. Algunas son muy grandes, pero también débiles en cuanto a la capacidad de gobierno. Es posible que haya habido superposiciones, o incluso conflictos, entre esas regiones

10 Schéma de cohérence territoriale. 
metropolitanas y los sistemas y organismos de las regiones de ordenamiento y planificación dentro de cada Land. Los resultados de las combinaciones son distintos según la región y pueden ser más o menos operativos.

A pesar de estas diferencias y diversidad entre los casos, podemos identificar retos comunes para la construcción y el funcionamiento de las metro-regiones en Europa.

\section{COOPERACIÓN Y REPRESENTACIÓN: RETOS Y DILEMAS METROPOLITANOS}

Los dispositivos de ordenación metropolitana presentados indican como la cooperación territorial (la gobernanza cooperativa) es una variable clave en su funcionamiento. Esta constatación ilustra los enfoques conceptuales que ponen de relieve el carácter complejo de la ordenación y planificación territorial. En particular, los conceptos de soft space (Allmendinger et al., 2015) o de interterritorialidad (Vanier, 2008) introdujeron una visión flexible de la acción territorial. En sociedades complejas, los dispositivos y políticas de ordenación articulan varios intereses u objetivos, en función de los socios implicados, quienes dependen de diferentes ámbitos políticos y administrativos. En las regiones metropolitanas específicamente, las poblaciones cruzan, casi diariamente, varios usos territoriales, conformados por los territorios donde viven, trabajan, se divierten o se aprovechan de algunos servicios, por lo que la acción territorial a escala metropolitana necesita modalidades de cooperación entre autoridades u organizaciones, para que las decisiones políticas tomadas en territorios fijos respondan a los usos territoriales variables. La creciente complejidad de los dispositivos territoriales - a fortiori los dispositivos metropolitanos- plantea la cuestión de su operatividad en varios aspectos: tensión entre los perímetros funcionales y las divisiones político-administrativas de la región metropolitana; tamaño óptimo de una jurisdicción para prestar eficazmente los servicios públicos; estrategias de cooperación y modos de gobernanza que deben establecerse; nivel de representatividad democrática y de participación ciudadana. En estos debates, diferentes visiones se enfrentan sobre cómo organizar la región metropolitana, con dos tendencias principales: la agregación de entidades que cada vez más tienen que desarrollar acciones conjuntas, o el fortalecimiento de las estructuras de cooperación sin modificar los perímetros político-administrativos (Tabla 3). 
Tabla 3. La organización institucional de las regiones metropolitanas: visiones y debates

\begin{tabular}{|c|c|c|}
\hline \multicolumn{2}{|c|}{ Reformistas / institucionalistas } & $\begin{array}{c}\text { Liberales / elección pública e } \\
\text { individualismo racional }\end{array}$ \\
\hline Centristas & $\begin{array}{c}\text { (Neo-) } \\
\text { regionalistas }\end{array}$ & Policentristas \\
\hline Fusión / integración & $\begin{array}{c}\text { Creación de nuevas } \\
\text { estructuras de } \\
\text { gobernanza }\end{array}$ & Fragmentación \\
\hline $\begin{array}{l}\text { Mejor gobernabilidad y mejor productividad } \\
\text { por efecto de la aglomeración, en particular } \\
\text { en términos económicos }\end{array}$ & $\begin{array}{l}\text { Mejor eficiencia del servicio a través de la } \\
\text { competencia en el mercado metropolitano, } \\
\text { pluralismo de los canales de representación }\end{array}$ \\
\hline
\end{tabular}

Fuente: Elaboración propia

Christophe Breuer $(2017,101-103)$ subraya que son visiones arquetípicas y que empíricamente se encuentran muchas soluciones híbridas. Por ejemplo, en muchas regiones metropolitanas de Europa existen entidades metropolitanas integradas para ordenar servicios metropolitanos como el transporte, el agua o la gestión de desechos. Sin embargo, la creación de tales entidades integradas no significa el establecimiento de un gobierno político integrado de la región metropolitana.

En Italia, por ejemplo, las autoridades optaron por una solución integrada: el perímetro de las ciudades metropolitanas es la provincia de nivel NUTS 3 y la institución metropolitana absorbe las instituciones provinciales preexistentes. Esto dispositivo tiene defectos, especialmente en términos de morfología, como, por ejemplo, en la región metropolitana de Turín que se extiende por zonas montañosas muy rurales. Sin embargo, esta solución también puede considerarse como una respuesta para no multiplicar los actores y los niveles de intervención en las regiones metropolitanas así creadas.

Las metrópolis francesas, por su parte, padecen no solo circunscritas en sus delimitaciones institucionales que poco corresponden a dinámicas funcionales, sino que también están afectadas por el reparto de prerrogativas con las demás autoridades locales con las que comparten su espacio socioeconómico: municipios, departamentos, regiones e, incluso, los servicios territoriales del Estado. La implementación errática de las metrópolis del Gran París y de Aix-Marsella ilustra una situación de complejidad máxima. Para responder a este tipo de situación, el legislador francés ha dado la posibilidad de crear, mediante fusión y absorción, autoridades locales de estatuto especial, 
Ilamadas colectividades únicas. Estas autoridades cuentan con una sola asamblea que tiene poderes compartidos con diferentes niveles administrativos departamentales y regionales. Encontramos este estatuto para las regiones de Córcega, Martinica y Alsacia, por ejemplo. A nivel metropolitano, sólo la metrópoli de Lyon tiene este estatuto donde, en el año 2020, por primera vez en Francia, un gobierno metropolitano será elegido directamente. Sin embargo, el $27 \%$ de los empleados de la metrópoli lionesa siguen viviendo fuera de su perímetro institucional y el mapa truncado del nuevo departamento del Ródano confirma esta situación, al tiempo que indica la necesidad de establecer vínculos entre la metrópoli y el departamento en varios ámbitos. La maraña de niveles decisionales en las combined authorities del Reino Unido es también un factor de complejidad, que puede dificultar la coherencia de las acciones (Lupton et al., 2018).

Además, el re-escalamiento de la acción pública y la multiplicación de los niveles de decisión dentro de las regiones metropolitanas no anulan el peso significativo de los actores decisionales tradicionales, ya sea el Estado o los gobiernos municipales, como indican Breuer y Halleux $(2016,56)$ al final de su trabajo sobre las regiones metropolitanas: [...] la gobernanza urbana no ha sustituido al gobierno de las ciudades. Aunque fueron fuertemente transformados por la competencia internacional, por la privatización de los servicios públicos, por el auge de los agentes privados y los grupos de interés en la gestión de las ciudades, los gobiernos urbanos siguen siendo agentes clave, si no centrales, en la gobernanza urbana. Por eso, la representatividad y la elección directa de los órganos que gobiernan efectivamente la metrópolis sigue siendo una cuestión crucial para la representación y el arraigo socioculturales de esas instituciones, que se han convertido en lugares de poder, pero apenas de identificación (Ghorra-Gobin, 2015).

Así, la elección del alcalde por sufragio directo en las combined authorities inglesas intenta responder a esa problemática de representación. En las primeras elecciones de los seis alcaldes metropolitanos en 2017, la participación media fue de alrededor del 30\%, lo que parece estar en línea con la participación media en otras elecciones locales, lo que todavía no es muy alentador, ni para la participación ni para la representación democrática. La cuestión del incremento democrático de las metro-regiones no puede resolverse mediante el mantenimiento de elecciones indirectas, si el objetivo es realmente arraigar socialmente la escala metropolitana, en la cual se concentran recursos - y cada vez más competencias- para el desarrollo socioeconómico. Es necesario construir una narrativa metropolitana unificadora y la representación directa es un paso esencial en este proceso.

En el mismo sentido, un cierto grado de centralización, integración de funciones o entidades puede reforzar la eficacia de ciertos servicios o acciones y mejorar su legibilidad. Las entidades metropolitanas pueden estabilizarse tras las fusiones de municipios. Sin embargo, la reacción de las poblaciones 
durante las operaciones de fusión es una cuestión particularmente sensible, como lo enseñan las operaciones realizadas en muchos países europeos. Un estudio de las fusiones territoriales en Europa mediante la creación de entidades más grandes [up-scaling], identifica algunos efectos de estas reformas sobre la participación democrática y los votos de protesta, aunque no deben ser sobreestimados porque varían según la situación (Ebinger, Kuhlmann y Bogumil, 2019). Por ejemplo, los efectos en términos de economías presupuestarias de escala son cuestionables y difíciles de medir. Los gastos fijos suelen permanecer estáticos y los nuevos ajustes presupuestarios pueden crear nuevos cargos.

No se trata aquí de (re)abrir el debate entre las visiones centralistas o policéntricas de la organización metropolitana, sino más bien de subrayar que este debate debe ser abordado de manera adaptativa y no binaria. Cualquiera que sea su organización, la acción territorial está condicionada por los parámetros políticos, evolutivos y específicos de cada situación. Por lo tanto, la revolución metropolitana está aún pendiente, mientras que, en un contexto de crisis, las ventajas de la metropolización son cuestionadas por enfoques alternativos del desarrollo territorial, que apuntan a las capacidades de innovación, de resistencia y a la calidad de vida que también se encuentran fuera de las metrópolis (Bernié-Boissard y Perrin, 2019).

\section{CONCLUSIÓN}

Los ejemplos de metro-regionalización analizados señalan la importancia de la dimensión metropolitana en la planificación y ordenación regional de Europa, a pesar del modesto tamaño de las metrópolis europeas a escala mundial. Algunos sistemas han atribuido la etiqueta de metrópoli a territorios poco urbanizados (regiones metropolitanas alemanas) o a aglomeraciones urbanas medianas o incluso pequeñas a escala internacional, cuyo perfil metropolitano es cuestionable desde el punto de vista geográfico y socioeconómico (metrópolis francesas).

Además, esas operaciones confirman las características de la regionalización posmoderna. Los sistemas establecidos tienen como objetivo de contemporizar con la diversidad y la fluidez de las dinámicas espaciales y de los niveles de gobernanza, entre soft spaces, dispositivos ad hoc y juego interterritorial de escalas. Ilustran el papel operativo de la gobernanza cooperativa y de la cooperación territorial en la implementación y el funcionamiento de los dispositivos contemporáneos de planificación y ordenación, que combinan los perímetros fijos de decisión política con la variabilidad de los perímetros funcionales.

Por último, la cuestión metropolitana plantea el debate sobre la representatividad democrática de las instituciones territoriales. Si bien las nuevas entidades metropolitanas absorben más competencias y controlan más recursos 
importantes para la vida de sus habitantes, el nivel de toma de decisiones a veces sigue siendo multi-situado a diferentes escalas, y el gobierno metropolitano no tiene una representatividad directa. A medio plazo, tal configuración puede obstaculizar la legibilidad política y la confianza de los ciudadanos en la acción metropolitana que, sin embargo, resulta ser importante para organizar y distribuir las actividades y recursos en las aglomeraciones urbanas contemporáneas.

\section{BIBLIOGRAFÍA}

Allmendinger, P., Haughton, H., Knieling, J. y Othengrafen, F. (2015). Soft Spaces in Europe: Re-Negotiating Governance, Boundaries and Borders. Abingdon: Routledge.

Bernié-Boissard, C. y Perrin, T. (2019). Una región, dos metrópolis. La región Occitania, problemáticas e interacciones territoriales de una nueva región en construcción. III Jornadas hispano-francesas de geografía, 22-23 de Marzo de 2019, Sevilla.

Bettoni, G., Le Bras, D. y Navarre, F. (2018). Métropoles en chantiers 2. Ambitions métropolitaines, réalités territoriales. Boulogne-Billancourt : Berger-Levrault.

Breuer, C. (2017). La spatialité de la gouvernance des régions urbaines intermédiaires en Europe (Tesis de Geografía). Université de Liège.

Breuer, C. y Halleux, J. M. (2016). Spatiality of local governments in European intermediate urban regions: a methodological approach. Quaestiones Geographicae, 35(2), 39-58.

Brutel, C. (2011). Un maillage du territoire français : 12 aires métropolitaines, 29 grandes aires urbaines. Insee Première, $n^{\circ} 1333$.

CEMAT. (2007). Glossaire du développement territorial (serie Territoire et paysage $\mathrm{n}^{\circ}$ 2). Estrasburgo: Ediciones del Consejo de Europa. Recuperado de: https://www.coe.int/fr/web/conference-ministers-spatial-planning/publications [Consulta: 27 de mayo de 2020].

Demazière, C. (2018). Le sacre des métropoles ? L'institution d'un nouveau palier de gouvernement local dans trois pays européens (Angleterre, France, Italie). Bulletin de la Société de Géographie de Liège, 71(2018/2), 2746. doi: 10.25518/0770-7576.5659

Dollfus, O. (Ed.) (1994). Chapitre I. L'espace Monde, un espace géographique. En O. Dollfus (Ed.), L'Espace Monde (pp. 15-34). Paris, Economica.

Ebinger, F., Kuhlmann, S. y Bogumil, J. (2019). Territorial reforms in Europe: effects on administrative performance and democratic participation. Local Government Studies, 45(1), 1-23. doi: 10.1080/03003930.2018.1530660

Ghorra-Gobin, C. (2015). La Métropolisation en question. Paris: Presses universitaires de France. 
Kawka, D. (Ed.). (2016). Metropolregionen - Kooperation und Wettbewerb in Deutschland und Europa, Informationen zur Raumentwicklung, 5/2016. Recuperado de:

https://www.bbsr.bund.de/BBSR/DE/Veroeffentlichungen/IzR/izr_node.html Lebras, D., Seigneuret, N. y Talandier, M. (Eds.). (2016). Métropoles en chantiers. Boulogne-Billancourt: Berger-Levrault.

Lupton, R., Ceri, H., Peake-Jones, S., y Cooper K. (2018). City-region devolution in England (SPDO Research paper $n^{\circ} 2$ ). CASE/London School of Economics. Recuperado de: http://sticerd.Ise.ac.uk/case

Martí-Costa, M., y Tomàs, M. (Eds.). (2018). Governança metropolitana, Papers, $n^{\circ}$ 61. Recuperado de:

https://iermb.uab.cat/ca/revistapapers/n-61-governanca-metropolitana

Paris, D. (2003). Métropole, métropolisation: question de mots. En N. El Haggar, D. Paris y I. Shahrour (Eds.), La Ville en débat, pp. 41-60. Paris: L'Harmattan.

Perrin, T. (2020). Refaire région. Pour une reconsidétation de la région en aménagement (tesis de habilitación en ordenación territorial y urbanismo). Université de Perpignan-Via Domitia.

Purkarthofer, E. y Humer, A. (2019). City-regional policies in the planning systems of Finland and Austria: National initiatives and European opportunities. Belgeo 2-2019. doi: 10.4000/belgeo.32122

Sassen, S. (1996). La Ville globale: New York, Londres, Tokyo. Paris: Descartes et Cie.

Vanier, M. (2008). Le pouvoir des territoires. Essai sur l'interterritorialité. Paris: Economica.

Zimmermann, K. (Ed.). (2017). Metropolitan Governance in Europe, Raumforschung und Raumordnung - Spatial Research and Planning, special issue 75(3).

Zimmermann, K. y Feiertag, P. (2018). Return of the metro-model? Governance and planning in metropolitan regions under change. An international comparison of France, Italy and Germany. Papers, $n^{\circ}$ 61, 16-27. Recuperado de: https://iermb.uab.cat/ca/revistapapers/n-61-governanca-metropolitana 



\title{
ANÁLISIS DE LA DISPERSIÓN URBANA EN CASTILLA-LA MANCHA A TRAVÉS DEL PROCESO DE JERAROUÍA ANALÍTICA (AHP) \\ ANALYSIS OF URBAN SPRAWL IN CASTILLA-LA MANCHA THROUGH ANALYTIC HIERARCHY PROCESS
}

\author{
Irene Sánchez Ondoño \\ Universidad de Castilla-La Mancha \\ Francisco Cebrián Abellán \\ Universidad de Castilla-La Mancha
}

Resumen

La dispersión urbana ha venido afectando en los últimos años a las ciudades y a sus áreas próximas. Desde comienzos del siglo XXI estos procesos se han acentuado en España. La atención se ha dirigido a los efectos de estas dinámicas en los entornos de las grandes metrópolis, aunque el fenómeno se ha reproducido en las de tamaño medio. En este caso se presta atención a lo sucedido en las capitales de provincia de Castilla-La Mancha, donde se aprecian estas dinámicas en sus respectivas áreas urbanas, aunque con intensidades y alcances diferentes.

Se ha analizado lo sucedido entre 2000-2016 a partir de tres variables: evolución de la población, de la superficie urbanizada y de la vivienda. Se pretende medir la intensidad de la dispersión urbana en el entorno de las ciudades de Albacete, Ciudad Real, Cuenca, Guadalajara y Toledo. La metodología empleada para analizar el comportamiento de los municipios con dinámicas más intensas se apoya en el Proceso de Jerarquía Analítica (AHP). Permite establecer escalas de análisis utilizando datos estándar mediante operaciones aritméticas. Los resultados esperados pretenden identificar y clasificar los municipios con dinámicas más intensas a partir del alcance y peso de las diferentes variables consideradas.

Palabras clave: ciudades medias, urbanismo expansivo, dispersión urbana, AHP, Castilla-La Mancha, España.

\begin{abstract}
Urban sprawl has affected the cities and their nearby areas in recent years. Since the beginning of the 21st century, these processes have increased in Spain. Attention has been directed to the effects of these dynamics in the environments of big cities, although the phenomenon has been reproduced in medium-size cities. In this essay, the attention has been centered on what happened in the provincial capitals of Castilla-La Mancha, where these dynamics
\end{abstract}


are appreciated in their respective urban areas, although with different intensities and ranges.

We have analyzed what happened between 2000-2016 based on three variables: evolution of the population, the urbanized area and housing. The intention is to measure the intensity of urban sprawl in the surroundings of the cities of Albacete, Ciudad Real, Cuenca, Guadalajara and Toledo. The methodology used to analyze the behavior of the municipalities with the most intense dynamics is supported by the Analytical Hierarchy Process (AHP). It allows us to establish analysis scales using standard data through arithmetic operations. The expected results are intended to identify and classify the municipalities with the most intense dynamics based on the scope and weight of the different variables considered.

Keywords: medium-size cities, expansive urbanism, urban sprawl, AHP, Castilla-La Mancha, Spain.

\section{EL MARCO TEÓRICO DEL PROCESO DE DISPERSIÓN URBANA}

Las últimas tres décadas han venido marcadas por un acusado proceso de transformación morfológica de la ciudad. Posiblemente la manifestación más clara está en el protagonismo creciente de la dispersión, que complica la identificación precisa de sus límites y refuerza la idea de las áreas urbanas como parte integrante de la ciudad. De hecho, la Unión Europea no entiende la ciudad como una unidad compacta y bien definida, sino como una unidad administrativa que trasciende los límites convencionales y que integra un área funcional urbana en la que al menos el 75\% de la población vive en el centro de la ciudad, al que se añade otro porcentaje, superior al 15\% o más de población residente en las periféricas más o menos alejadas, y que trabaja en la ciudad central (Eurostat, proyecto Urban Audit). Aparece así la ciudad dispersa como una nueva modalidad complementaria de la ciudad compacta, que tiene un elevado impacto territorial y que se reproduce en las diferentes escalas del sistema urbano, aunque con mayor incidencia en las grandes y de tamaño medio.

En un intento por identificar los factores y los actores del cambio hacia la ciudad sin límites, hay que recurrir a procesos globales y a lógicas locales. En lo global hay que vincularla a las estrategias del capitalismo y del sector financiero en relación al sector inmobiliario; a la modernización de las infraestructuras de comunicaciones y la revolución en las telecomunicaciones; a las políticas públicas en favor de la vivienda en propiedad; a la presencia creciente de grandes multinacionales dedicadas a la construcción; a la densificación y mejora de la red de carreteras; a la proliferación de grandes superficies comerciales en las periferias urbanas; al deterioro de la calidad de vida en al- 
gunas áreas urbanas centrales; o a los cambios sociales (aumento de la renta, nuevas preferencias de vivienda...).

Posiblemente ninguno de ellos pueda explicar el proceso, ya que todos están estrechamente interrelacionados, y han tenido repercusiones en la mayor parte de nuestro contexto sociocultural. Lo cierto es que la génesis tiene mucho que ver con el modelo de ciudad apoyado en el capitalismo expansivo neoliberal, con sistemas de gobierno, medidas económicas e ideología estrechamente interconectados, que han derivado en un urbanismo especulativo y descontrolado (Lois, R, et al., 2016, 3; Capel, H., 2016, 233; Méndez, R., 2019), y que se ha mantenido como paradigma dominante hasta el año 2008. Las consecuencias más visibles han quedado reflejadas en las morfologías urbanas descentralizadas y dispersas en población, vivienda y actividades productivas de ocio y comercio en áreas apartadas de los tradicionales límites urbanos y que dejan importantes efectos espaciales (Ferras, C., 2000, 2), con una reterritorialización de la ciudad hacia su periferia (Arellano, B. y Roca, J., 2010). También ha habido modificaciones en las tipologías constructivas, caracterizadas ahora por formas repetitivas y estandarizadas en modalidad de baja densidad edificatoria, a base de unifamiliares exentos o hileras de casas individuales de una o dos alturas; o el decrecimiento de algunos espacios urbanos consolidados y compactos (Cebrián, F., 2019).

El modelo se ha reproducido en España, que durante el periodo 1998-2008 ha dejado la una inusitada actividad urbanizadora (Valenzuela, M., 2016). Han sido años de fuerte dinámica económica en la que el urbanismo, sobre todo el disperso, ha sido el máximo exponente del ciclo. Se ha definido como urbanismo depredador (Pezzi, C. H., 2017) expansivo (Burriel, 2008), como desgobierno territorial (Romero, J.; 2010) o como desorden territorial, urbano y constructivo (Naredo, J. M., 2017). El fenómeno se ha caracterizado por el crecimiento del suelo de uso residencial e industrial, de la superficie urbanizada y de la vivienda privada, y lo ha hecho muy por encima de las necesidades reales (Burriel, 2014, 116). Las razones del aumento hay que asociarlas al crecimiento de la población en nuestro país por la llegada masiva de inmigrantes (Según el INE en el año 2000 fueron 362.468 los inmigrantes llegados a España, y en 2008 se registraron 599.074 llegadas; por otro lado había censados 923.879 extranjeros en el año 2000 y eran 5.268 .762 los reconocidos para 2008, y 4.1618.581 en 2016) ); a la subida de las rentas de la población; a la facilidad de acceso al crédito para la compra de vivienda (Gaja, F., 2008; Romero, J., 2010, 23); a la demanda de segundas residencias para un turismo en expansión en el litoral mediterráneo e insular; a la incorporación de las entidades financieras al sector inmobiliario y de inversores privados, con afán especulativo (Herce, M., 2013, 349; Lois, R. et al., 2016, 14); a los cambios de preferencia de los consumidores. Se añade la implantación del euro en el año 2002 y la oportunidad de blanqueo de capitales en el mercado de la vivienda (Gaja, F., 2008). 
En estos años la administración, con diferentes colores políticos, ha favorecido este modelo desde la aprobación de la Ley del suelo de 7/1997 de 14 de abril y la Ley 6/1998, de 13 de abril, sobre régimen del suelo y valoraciones que facilitaban la generación de suelo urbanizable y favorecía el negocio inmobiliario. Desde su publicación y hasta comienzos de la segunda década del siglo XXI las administraciones autonómicas han consentido e impulsado este modelo, con un protagonismo especialmente reseñable de las administraciones locales, muy implicadas en el proceso a la espera de incrementar impuestos, residentes e ingresos al amparo del crecimiento inmobiliario en la modalidad de unidades residenciales de baja densidad edificatoria. Como resultado del proceso, en el año 2007, cuando se dieron los valores más altos, el precio medio de la vivienda era de $149.599 €$, para bajar a $96.266 €$ en 2013 , que alcanzó los precios más bajos en plena crisis económica (INE). Afortunadamente con la Ley 8/2013, de 26 de junio, de rehabilitación, regeneración y renovación urbanas y la publicación de las agendas urbanas (la Agenda Urbana Española ha sido aprobada en febrero de 2019) la tendencia apunta en otra dirección, pero los efectos del pasado siguen presentes y hasta la fecha no hay iniciativas para dar solución a lo ya hecho.

\section{PROPUESTA METODOLÓGICA}

En este caso se analiza lo sucedido en un conjunto de ciudades intermedias, que habitualmente quedan enmarcadas entre los umbrales demográficos de los cincuenta y los trescientos mil habitantes desde el punto de vista demográfico, y que cuentan con una gran capacidad reequilibradora, ofreciendo oportunidades de organización socioeconómica a través de las externalidades urbanas que generan (Bellet y Sposito, 2009; Precedo y Mínguez, 2014; ESPON, 2012). En Castilla-La Mancha se han elegido cinco ejemplos de caso: las capitales provinciales (Albacete, Ciudad Real, Cuenca, Guadalajara y Toledo). Se ha hecho porque cuentan con una diversificación funcional más asentada, ya que presentan la función administrativa, universitaria, sanitaria especializada, comercial, cuentan con conexión ferroviaria en AVE. La mirada se ha centrado en lo acontecido en las respectivas áreas urbanas porque a nivel general los datos apuntan a que, de manera agrupada, las áreas urbanas de las ciudades intermedias ha sido las más dinámicas desde el inicio del proceso del urbanismo expansivo (Cebrián, 2019).

Se parte de la hipótesis de que los municipios que tienen dinámicas superiores a la de las respectivas ciudades centrales lo han hecho porque están directamente diferidas desde la ciudad. Como primer paso se han identificado los municipios incluidos en un radio máximo de $30 \mathrm{~km}$ alrededor de cada una de ellas. En total son 198 (con los de las ciudades centrales suman 203) repartidos desigualmente en número por el diferente tamaño de cada uno de ellos: 13 municipios alrededor de la ciudad de Albacete, 24 en el en- 
torno de Ciudad Real, 30 en la periferia urbana de Cuenca, 71 en la de Guadalajara, y 60 alrededor de Toledo.

Para estudiar la dinámica de los municipios incluidos dentro de cada área urbana se ha analizado lo sucedido entre 2000 y 2016, porque resume lo acontecido desde el inicio de urbanismo expansivo, con los efectos subsecuentes durante los años sucesivos, marcados por la parálisis edificatoria, pero conservando la herencia en vivienda y población del periodo previo. Se asume por ello que ha habido dos subperiodos con comportamientos desiguales, pero lo que se pretende en este caso es presentar el balance final de lo sucedido desde comienzos del milenio.

Como fuentes estadísticas se ha empleado el Padrón de Población, del que se ha obtenido la población total residente en cada uno de los años (INE, 2000 y 2016) También se ha utilizado el catastro de urbana, del que se han obtenido, a partir de las estadísticas proporcionadas por el portal web, las variables de superficie de parcelas urbanas en hectáreas y el número de parcelas urbanas. De los ficheros .cat se ha obtenido el número de bienes inmuebles a partir del registro 15 (tipo 15.- registro de inmueble), al que se han aplicado dos filtros: la clase de los bienes inmuebles incluidos en la categoría «UR», es decir, de tipo Urbano y una clave de grupo residencial, codificado en los ficheros como «V». Finalmente se han empleado cuatro variables para este análisis: la población, el número de parcelas urbanas, la superficie de parcelas urbanas —en hectáreas - y el número de bienes inmuebles (viviendas) obtenido como diferencia entre el total disponible para 2016 y 2000. La escala ha sido la municipal, lo que puede distorsionar el comportamiento de aquellos municipios que cuentan con varias entidades de población, que en ocasiones presentan dinámicas desiguales.

Como primer paso en la investigación, se ha partido del obligado proceso de obtención, transformación y preparación de la información. En el caso de los datos obtenidos a partir de los ficheros cat se ha diseñado un software específico para convertir el texto plano, que es el que aporta la fuente oficial, a un formato alfanumérico para su posterior tratamiento en base de datos. Posteriormente los valores absolutos se han transformado en tasas, empleadas para elaborar el indicador sintético. La información ha sido finalmente cartografiada con ArcGis.

\subsection{METODOLOGÍA DE ANÁLISIS}

La metodología empleada para delimitar las áreas urbanas ha sido el Proceso de Jerarquía Analítica (en inglés Analytic Hierarchy Process - AHP-). Se trata de una herramienta de apoyo en la toma de decisiones que permite identificar las variables más relevantes comparando el peso en diferentes elementos. El AHP es un método de análisis multicriterio desarrollado por Saaty en la década de los 60 (Saaty, 1990), entendido como «un procedimiento de 
toma de decisiones multiobjetivo y multicriterio, el cual emplea la comparación por pares para llegar a una escala de preferencias entre un conjunto de alternativas» (Saaty, 1984, 286). Las aplicaciones de esta metodología son diversas y comprenden áreas de estudios muy variadas (Ortigoza et al., 2016; Molero et. al., 2007; Da Silva, C. J. y Cardozo, O. D., 2015). En este caso, se ha empleado con el objetivo de identificar el comportamiento de los municipios incluidos dentro de las coronas urbanas de las capitales provinciales de Castilla-La Mancha, tomando como referencia aquellos núcleos que se encuentran dentro del radio elegido.

La aplicación de la metodología permite obtener el vector promedio, como valor de referencia para jerarquizar las alternativas en los diferentes rankings. De manera resumida y muy sintética el procedimiento es el siguiente (Osorio y Orejuela, 2008).

- Selección de alternativas y criterios.

- Análisis por pares según la escala de preferencias de Saaty (Saaty, 1990): consiste en la comparación por pares de cada una de las alternativas y por cada uno de los criterios empleados.

- Normalización de las matrices: habrá tantas matrices como criterios empleados. De cada matriz resulta un vector promedio.

- Sintetización del vector promedio a partir de cada uno de los vectores obtenidos de las matrices.

- Cálculo del índice de consistencia. El valor del coeficiente derivado, para ser aceptado como válido, debe ser inferior a 0,10. Ello implica que no se han producido contradicciones en la evaluación de las alternativas?.

Los criterios empleados se corresponden con la tasa de variación 2000-2016 de población, de número de parcelas urbanas, de superficie de parcelas urbanas (en hectáreas) y de número de bienes inmuebles. La cantidad de alternativas varía en función de los municipios del área urbana de cada ciudad (Albacete 13, Ciudad Real 24, Cuenca 30, Guadalajara 71 y Toledo 60). Se han generado seis ensayos, asignando en cada uno de ellos un mayor peso a las diferentes variables empleadas (Tabla 1). De todos ellos se ha elegido el que establece la jerarquización de municipios en función del número de bienes

1 Para la realización de los cálculos pertinentes se han respetados los principios y axiomas propuestos por Saaty, (Saaty, 1990). La fórmula presentada a continuación representa una síntesis de ello:

$\mathrm{AW}=\mathrm{nW}$

Sea $A$ una matriz $n \times n$, donde $n \in Z^{\wedge++}$. A es una matriz de comparaciones pareadas de $n$ alternativas

Donde $\mathrm{W}$ es el vector columna de pesos relativos Wi

$\mathrm{N}$ número de elementos comparados. 
inmuebles (que se han entendido en este caso como viviendas) (Opción E), porque es el que mejor representa la realidad urbanizadora de todo el periodo (por encima de la población y la superficie urbanizada).

Tabla 1. Propuesta metodológica para elaboración de AHP

\begin{tabular}{|l|l|}
\hline Opción A & Pesos iguales: todos los criterios cuentan con la misma importancia. \\
\hline Opción B & Mayor peso a población. \\
\hline Opción C & Mayor importancia de la superficie parcelas urbanas. \\
\hline Opción D & Mayor relevancia del número de parcelas urbanas. \\
\hline Opción E & Mayor significado al número de bienes inmuebles. \\
\hline Opción F & $\begin{array}{l}\text { Los pesos de los criterios varían, de mayor a menor, por este orden: } \\
\text { bienes inmuebles, población, superficie de parcelas urbanas y número } \\
\text { de parcelas urbanas. }\end{array}$ \\
\hline
\end{tabular}

Fuente: Elaboración propia

\section{DESARROLLO DE LA INVESTIGACIÓN}

\subsection{CAMBIOS A ESCALA MUNICIPAL}

Los resultados obtenidos permiten, como se ha apuntado con anterioridad, establecer un ámbito territorial del área urbana para cada ciudad a partir de las dinámicas edificatorias, demográficas y de parcelas urbanas. Estas incluyen solamente los municipios cuyos indicadores de «\% de vector promedio» superan al valor obtenido por su respectiva ciudad central (Figura 1). 
Figura 1. Municipios incluidos en las áreas urbanas según método AHP

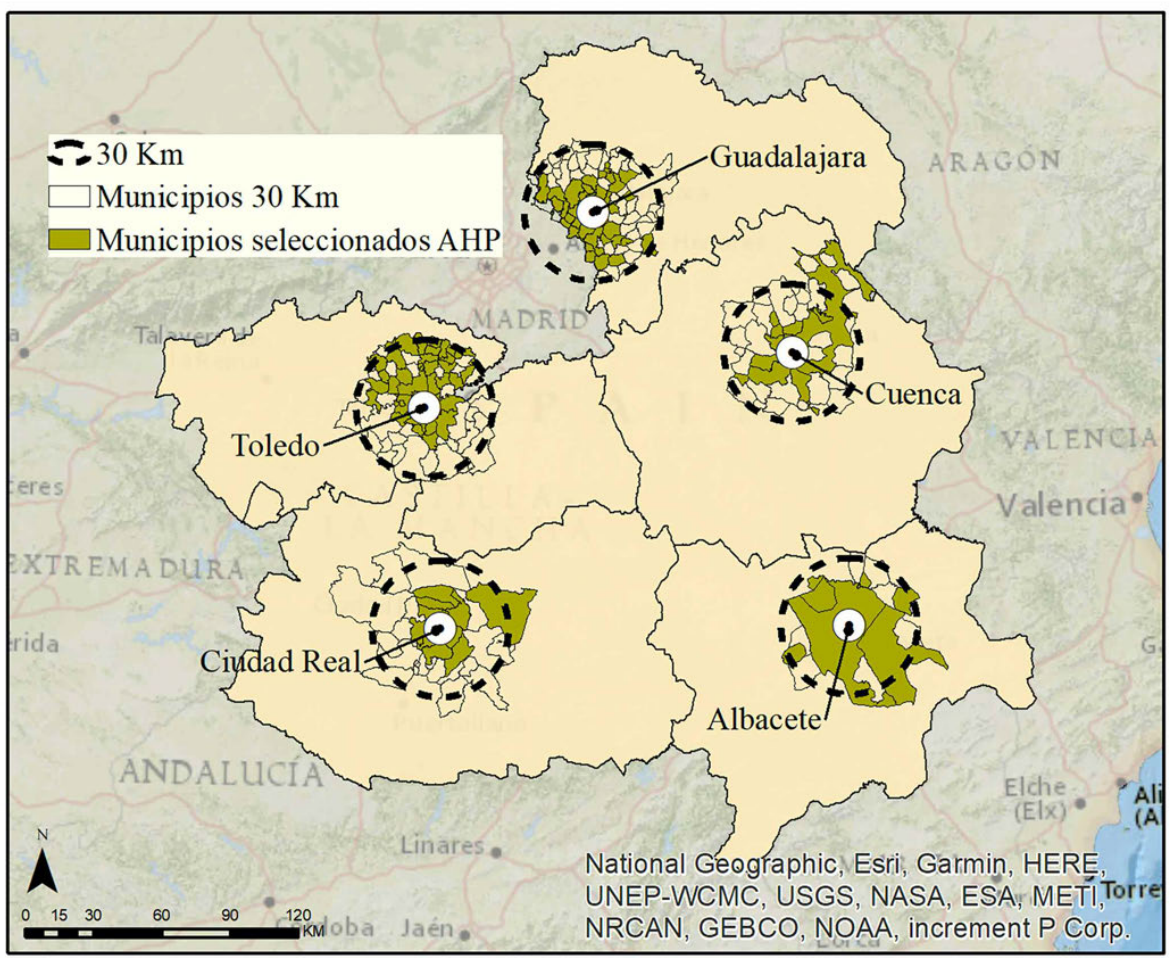

Fuente: Elaboración propia

Según el Atlas de las Áreas Urbanas Españolas publicado en 2018 por el Ministerio de Fomento, las capitales de Castilla-La Mancha articulan áreas urbanas menores a las obtenidas con uso de la metodología AHP. De hecho, las áreas urbanas de Albacete y Cuenca no incluyen más municipios que las propias capitales. Ciudad Real por su parte contiene solo a Miguelturra. Las áreas urbanas que más municipios registran son las de Toledo con 8 (Bargas, Olías del Rey, Argés, Nambroca, Cobisa, Burguillos de Toledo y Guadamur) y Guadalajara con 7 (Azuqueca de Henares, Alovera, Cabanillas del Campo, Marchamalo, Villanueva de la Torre y Chiloeches).

Una vez aplicado el AHP, desde el punto de vista territorial quedan unas áreas urbanas caracterizadas por la proximidad-continuidad, ya que en la mayor parte de los casos incluyen la primera corona de municipios, que son limítrofes con el de cada capital provincial. Hay que apuntar que el tamaño y la forma de algunos que incluyen capitales provinciales pueden inducir a cierta confusión interpretativa. Son los casos de Cuenca y de Albacete, ambos con una considerable superficie, y el primero con una forma irregular y con varios 
términos que están enclavados dentro, dejando una situación atípica. Otro elemento explicativo es la conectividad mediante vías de alta capacidad (las autovías, sobre todo), que explica el hecho de que en algunos casos aparezcan integrados municipios más alejados en distancia, pero mejor conectados en tiempo con sus respectivas ciudades centrales (es el caso de Daimiel con Ciudad Real). Se añade el hecho diferencial de que algunos municipios han apostado por realizar políticas urbanizadoras muy agresivas, lo que se refleja en la superficie de parcelas recalificadas y que han permitido un crecimiento muy fuerte de los bienes inmuebles edificados en este periodo (ejemplos relevantes son Chinchilla en Albacete; Poblete en Ciudad Real; Arcas del Villar en Cuenca; Yebes, Quer, Pozo de Guadalajara, Pioz, Alovera o Galápagos en Guadalajara; Barcience, Chozas de Canales, Burguillos de Toledo o Magán en Toledo).

Otro hecho que queda patente es la capacidad de atracción que genera el área metropolitana polinuclear de Madrid, que salta los límites provinciales y determina que municipios del norte de Toledo y del oeste de Guadalajara graviten hacia este potente polo económico y demográfico. Lo cierto es que las tasas de variación más elevadas, tanto de población como de vivienda, quedan vinculadas a los municipios cercanos al área metropolitana polinuclear de Madrid, tanto en el entorno de Guadalajara como en el de Toledo, lo que pone de manifiesto la fuerte capacidad de influencia e irradiación hacia las ciudades próximas y los ejes industriales próximos (Alcalá de Henares y el corredor del Henares entre Guadalajara y Madrid, y Valdemoro o Pinto y Parla y el Corredor de la Sagra y en dirección a la capital nacional) (Figura 2). Es ahí donde se han concentrado las mayores dinámicas. Pero también han sido elevadas en la primera corona de municipios de Toledo de Guadalajara, estrechamente vinculados con las respectivas capitales. 
Figura 2. Tasa de variación de población 2000-2016 y diferencia absoluta entre 2000 y 2016

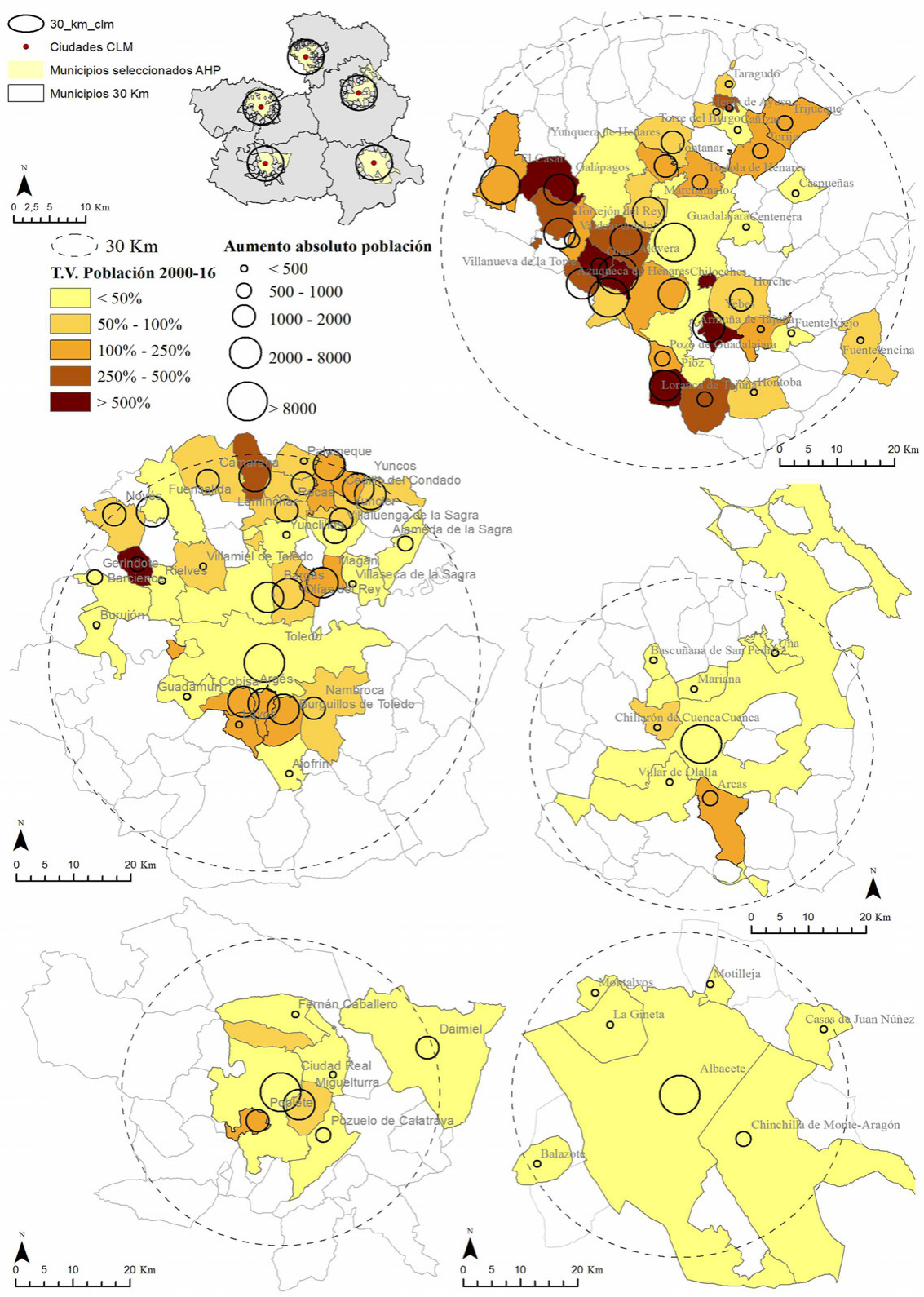

Fuente: Elaboración propia 
Figura 3. Tasa de variación de bienes inmuebles 2000-2016 y diferencia absoluta entre 2000 y 2016

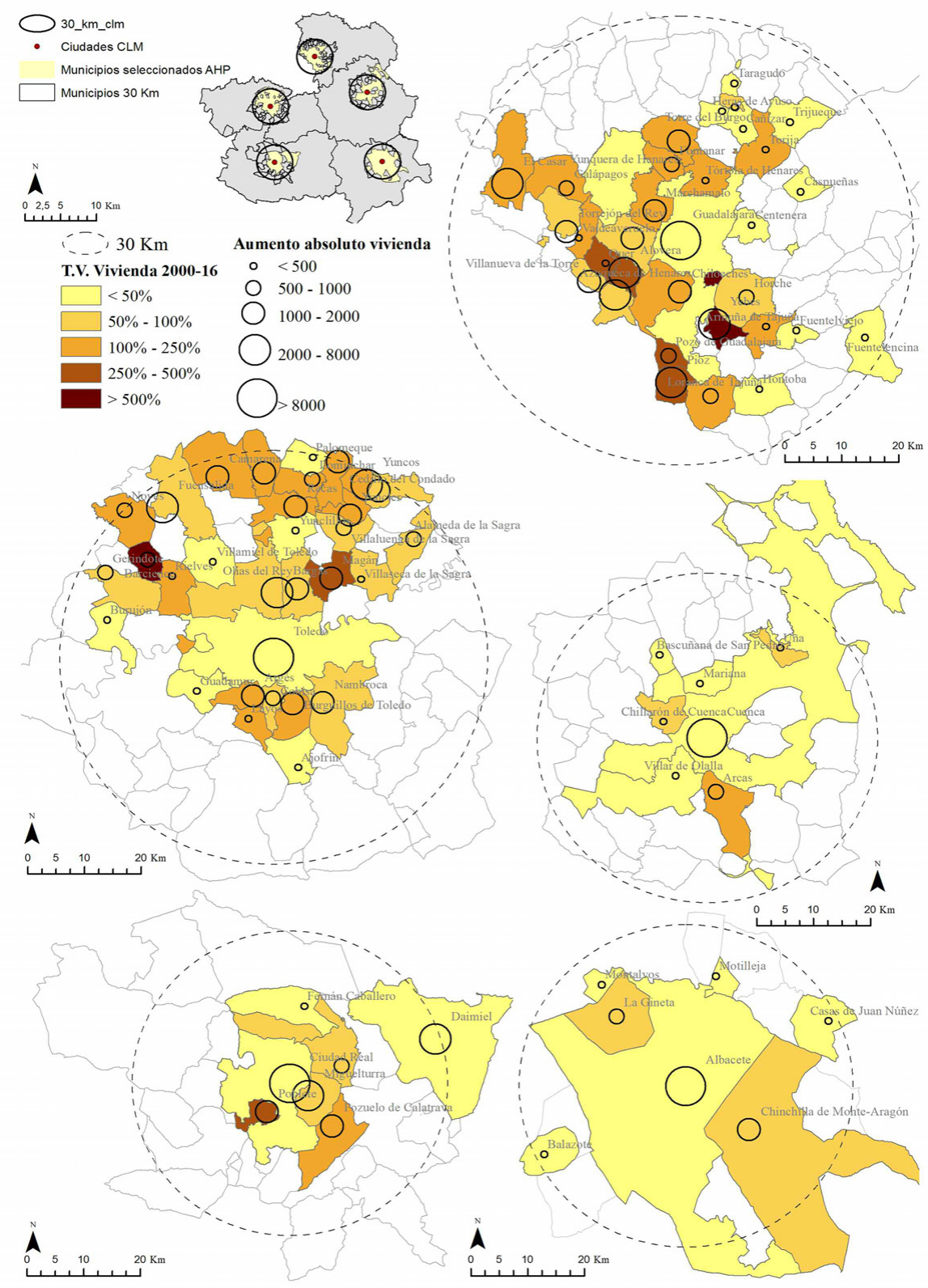

Fuente: Elaboración propia 


\subsection{LOS CAMBIOS A ESCALA DE ÁREA URBANA}

El balance resumido de lo acontecido en este periodo se observa en la Tabla 2 , que recoge los valores para el conjunto de las respectivas coronas. Los datos agregados permiten establecer una caracterización de las ciudades y de sus áreas urbanas en función de su dinámica y comportamientos desiguales. Hay que partir de la idea de que ha habido una situación diferenciada para las cinco capitales. La lectura de los valores es sumamente interesante. Por un lado, destaca el hecho de todas han dejado crecimientos positivos, aunque muy desiguales. Guadalajara, Ciudad Real y Toledo han sido las más dinámicas, mientras que Cuenca y Albacete han dejado un escenario mucho más contenido.

En segundo lugar, hay que apuntar que las coronas, en todos los casos, han crecido proporcionalmente por encima de las respectivas capitales. Se da además la circunstancia de que lo han hecho de forma muy desigual, ya que algunas han tenido comportamientos especialmente elevados, llegando a una crear un modelo claro de ciudad dispersa, como en los casos de Guadalajara y Toledo, donde las respectivas áreas urbanas han crecido más de tres veces en población y vivienda que las ciudades centrales. Es importante destacar que las dinámicas han sido desiguales entre población y crecimiento de la vivienda, en beneficio siempre de las áreas urbanas. Por lo general, el cambio ha sido muy superior en parcelas y bienes inmuebles que en población. Mientras tanto ha crecido más la población que las viviendas y las parcelas urbanas dentro de las ciudades (Tabla 2).

Llama también la atención el hecho de que en muchos municipios haya crecido la vivienda por encima de la población (Tabla 2). Esta realidad demográfica y edificatoria coincide con la propuesta de definición de ciudad de ESPON, entendida área urbana. En este sentido, es interesante considerar la población de los municipios incluidos dentro del área urbana a partir de la aplicación del AHP al área urbana. Sumando los datos de la población de las capitales (en este caso la de 2016) y la que se ha incorporado dentro de las áreas urbanas propuestas desde comienzos de milenio (diferencia entre la que había en 2016 y 2000 en cada municipio), se obtiene una propuesta jerárquica que trastoca lo que tradicionalmente nos ha planteado la estadística oficial, y que dejaría a Albacete, Guadalajara y Toledo como principales ciudades de la región (en lugar de Albacete, Talavera de la Reina y Toledo) (Tabla 3). 
Tabla 2. Evolución demográfica, de bienes inmuebles, de superficie y de parcelas en las capitales, y sus respectivas áreas urbanas (2000-2016)

\begin{tabular}{|l|c|c|c|c|c|c|c|c|}
\hline MUNICIPIO & $\begin{array}{c}\text { Aumento } \\
\text { absoluto } \\
\text { población } \\
2000-16\end{array}$ & $\begin{array}{c}\text { Tasa de } \\
\text { variación } \\
\text { población } \\
2000-16\end{array}$ & $\begin{array}{c}\text { Aumento } \\
\text { absoluto } \\
\text { bienes } \\
\text { inmuebles } \\
2000-16\end{array}$ & $\begin{array}{c}\text { Tasa de } \\
\text { variación } \\
\text { bienes } \\
\text { inmuebles } \\
2000-16\end{array}$ & $\begin{array}{c}\text { Aumento } \\
\text { absoluto } \\
\text { superficie } \\
\text { (ha) } \\
2000-16\end{array}$ & $\begin{array}{c}\text { Tasa de } \\
\text { variación } \\
\text { superficie } \\
2000-16\end{array}$ & $\begin{array}{c}\text { Aumento } \\
\text { absoluto } \\
\text { número } \\
\text { parcelas } \\
2000-16\end{array}$ & $\begin{array}{c}\text { Tasa de } \\
\text { variación } \\
\text { parcelas } \\
2000-16\end{array}$ \\
\hline Albacete & 22.759 & $15 \%$ & 20.387 & $32 \%$ & 1.130 & $62 \%$ & 2.373 & $0,13 \%$ \\
\hline A.U. Albacete & 1.516 & $16 \%$ & 2.478 & $56 \%$ & 526 & $93 \%$ & 2.354 & $38 \%$ \\
\hline $\begin{array}{l}\text { Total } \\
\text { Albacete }\end{array}$ & 24.275 & $15 \%$ & 22.865 & $33 \%$ & 1.656 & $69 \%$ & 4.727 & $20 \%$ \\
\hline Ciudad Real & 13.811 & $23 \%$ & 12.354 & $46 \%$ & 87 & $6 \%$ & 884 & $12 \%$ \\
\hline $\begin{array}{l}\text { A.U. Ciudad } \\
\text { Real }\end{array}$ & 9.136 & $27 \%$ & 9.795 & $64 \%$ & 817 & $64 \%$ & 6.973 & $56 \%$ \\
\hline $\begin{array}{l}\text { Total Ciudad } \\
\text { Real }\end{array}$ & 22.947 & $23 \%$ & 22.149 & $46 \%$ & 904 & $32 \%$ & 7.857 & $39 \%$ \\
\hline Cuenca & 9.395 & $21 \%$ & 84.07 & $38 \%$ & 289 & $64 \%$ & 1.421 & $20 \%$ \\
\hline A.U. Cuenca & 1.379 & $56 \%$ & 1.704 & $85 \%$ & 157 & $98 \%$ & 1.313 & $35 \%$ \\
\hline Total Cuenca & 10.774 & $22 \%$ & 10.111 & $42 \%$ & 446 & $72 \%$ & 2.734 & $25 \%$ \\
\hline Guadalajara & 17.530 & $27 \%$ & 12.032 & $43 \%$ & 627 & $73 \%$ & 2.970 & $43 \%$ \\
\hline $\begin{array}{l}\text { A.U. } \\
\text { Guadalajara }\end{array}$ & 73.379 & $166 \%$ & 32.358 & $113 \%$ & 4.296 & $117 \%$ & 30.715 & $84 \%$ \\
\hline $\begin{array}{l}\text { Total } \\
\text { Guadalajara }\end{array}$ & 90.909 & $82 \%$ & 44.390 & $78 \%$ & 4.923 & $108 \%$ & 33.685 & $77 \%$ \\
\hline Toledo & 14.922 & $22 \%$ & 11.604 & $43 \%$ & 1.807 & $107 \%$ & 2.070 & $27 \%$ \\
\hline A.U. Toledo & 48.547 & $78 \%$ & 32.042 & $104 \%$ & 1.930 & $48 \%$ & 33.231 & $81 \%$ \\
\hline Total Toledo & 63.469 & $51 \%$ & 43.646 & $75 \%$ & 3.737 & $65 \%$ & 35.301 & $73 \%$ \\
\hline
\end{tabular}

Fuente: Elaboración propia

Tabla 3. Población Castilla-La Mancha

\begin{tabular}{|c|c|c|c|}
\hline CIUDAD & $\begin{array}{c}\text { Población ciudad } \\
\mathbf{2 0 1 6}\end{array}$ & $\begin{array}{c}\text { Incremento } \\
\text { población área } \\
\text { urbana 2000-2016 }\end{array}$ & $\begin{array}{c}\text { Total de población } \\
\text { ciudad + área } \\
\text { urbana 2016 }\end{array}$ \\
\hline Albacete & 172.426 & 1.515 & 173.942 \\
\hline Ciudad Real & 74.054 & 9.136 & 83.190 \\
\hline Cuenca & 55.102 & 1.379 & 56.481 \\
\hline Guadalajara & 83.633 & 73.379 & 157.012 \\
\hline Toledo & 83.459 & 48.547 & 132.006 \\
\hline
\end{tabular}

Fuente: Elaboración propia 


\section{CONCLUSIONES}

A la vista de lo recogido en estas páginas, y de acuerdo con el comportamiento de las ciudades analizadas, se pueden aportar algunas ideas que ayudan a contextualizar los procesos urbanos de las ciudades intermedias reproducidos en la España interior. Por un lado, destaca la creciente realidad de la ciudad líquida, sin fronteras nítidas, apoyada en la planificación que delega parte de sus responsabilidades de actores e intereses privados. Ambas han sido resultado de las leyes y políticas liberalizadoras del suelo de finales del siglo pasado, de marcado carácter neoliberal. Por otra parte, se aprecia como se ha producido una fuerte redefinición de la relación de las grandes ciudades y sus respectivas áreas de influencia, incrementando su influencia hacia territorios cada vez más alejados, siguiendo ejes viarios y corredores industriales. Se aprecia en el efecto de Madrid sobre las ciudades de su entorno, convertidas en una segunda corona, en la que la atracción es muy nítida. Mientras tanto, las más alejadas (por encima de los $100 \mathrm{~km}$ ) quedan al margen de estos procesos, y consecuentemente dejan una menor activación demográfica y urbanística. El efecto se puede medir en forma de reordenación jerárquica de las cinco ciudades, en la que Albacete sigue estando en primera posición, aunque pierde dinámica en favor de Guadalajara y Toledo, que aparecen como las grandes beneficiarias. Mientras Ciudad Real crece de forma importante. Albacete y Cuenca apenas han tenido cambios en sus respectivas coronas.

Queda ilustrado a nivel cuantitativo que la dialéctica entre urbanismo compacto/disperso ha quedado claramente decantada en estas dos décadas en favor del segundo modelo. En estos años la población y de la vivienda se han dirigido prioritariamente a las periferias, por razones de naturaleza diversa, y se ha mantenido la tendencia hasta 2016. Se ha concentrado en los municipios colindantes y bien conectados, y lo ha hecho sobre el modelo de bajas densidades edificatorias. Hay que apuntar no obstante que hay un factor distorsionador en esta idea, y es que la vivienda ha cobrado durante algunos años la condición de bien de inversión, más que de uso, lo que ayuda a explicar que las dinámicas edificatorias hayan sido mayores que las demográficas, pasando en los años de la crisis muchas de ellas a ser propiedad de entidades financieras. Lo cierto es que la ciudad, como entidad de límites difusos y confusos ha cobrado protagonismo. En los últimos años (desde 2015) se intenta, a través de las agendas urbanas y nuevas normas planificadores, poner orden a una realidad compleja, que requiere nuevos enfoques, una mayor coordinación interadministrativa y sobre todo una apuesta clara por un modelo de ciudad más sostenible en lo social, ambiental y ecológico. 


\section{BIBLIOGRAFÍA}

Arellano, B. y Roca, J. (2010). El urban Sparwl ¿un fenómeno de alcance plantario? Los ejemplos de España y México. Arquitectura, Ciudad y Entono, (12), 115-147.

Bellet, S. y Spósito, M. E. (2009). Las ciudades medias o intermedias en un mundo globalizado. Lérida: Publicaciones de la Universidad de Lleida.

Burriel, E. (2008). La década prodigiosa del urbanismo español (1997-2006). Scripta Nova, XII, 270 (64).

Capel, H. (2016). Violencia, inequidad, contaminación y otros problemas en la ciudad actual ¿qué hacer? En N. Benach y A. F. Carlos (Eds): Horacio Capel. Pensar la ciudad en tiempos de crisis. Barcelona: Icaria, espacios críticos.

Cebrián, F. (Coord.). (2019). Dinámicas de urbanización en ciudades medias interiores ¿hacia un urbanismo más urbano? Valencia: Tirant lo Blanc.

Da Silva, C. J. y Cardozo, O. D. (2015). Evaluación multicriterio y Sistemas de Información Geográfica aplicados a la definición de espacios potenciales para uso del suelo residencial en Resistencia (Argentina), GeoFocus, (16), 23-40.

ESPON (UE) (2012). Red Europea de Observación del Desarrollo y la Cohesión Territorial.

Eurostat, proyecto Urban Audit: Disponible en: http://ec.europa.eu/eurostat/statistics-explained/index.php/Glossary: Functional_urban_area consulta 02/03/2018). [Fecha de consulta: 14 de marzo 2020].

Ferras, C. (2000). Ciudad dispersa, aldea virtual y revolución tecnológica. Reflexiones acerca de sus relaciones y significado social. Scripta Nova. Revista electrónica de Geografía y Ciencias Sociales, (69), 1-12. Disponible en http://www.ub.es/geocritic/sn-69-68.htm.

Gaja, F. (2008). El «tsunami urbanizador» en el litoral mediterráneo. El ciclo de hiperproducción inmobiliaria 1996-2006. X Coloquio Internacional de Geocrítica. Diez años de cambio en el mundo, en la Geografía y en las Ciencias Sociales, 1999-2008, Barcelona: Universidad de Barcelona.

Herce, M. (2013). El negocio del territorio. Evolución y perspectivas de la ciudad moderna. Alianza editorial. Madrid.

Instituto Nacional de Estadística: Disponible en:

https://www.ine.es/dyngs/INEbase/es/operacion.htm?c=Estadistica_C\&cid= $1254736177011 \&$ menu=resultados\&idp=1254734710990 [Fecha de consulta: 14 de marzo de2020].

Lois, R. C., Piñeira, M. J. y Vives, S. (2016). El proceso urbanizador en España (1990-2014): una interpretación desde la Geografía y la teoría de los circuitos del capital. Revista Scripta Nova, XX, (539).

Méndez, R. (2019). Ciudades en venta. Estrategias financieras y nuevo ciclo inmobiliario en España. Valencia: PUV. 
Ministerio de Fomento; DG de Arquitectura, Vivienda y Suelo; SG de Suelo, Información y Evaluación. (2018). Áreas urbanas en España 2018. Constitución, Cuarenta años de las ciudades españolas. [Fecha de consulta 14 de marzo de 2020]. Disponible en:

https://apps.fomento.gob.es/CVP/handlers/pdfhandler.ashx?idpub=BAW058.

Molero Melgarejo, E., Grindlay Moreno, A. L. y Asensio Rodríguez, J. J. (2007). Escenarios de aptitud y modelización cartográfica del crecimiento urbano mediante técnicas de evaluación multicriterio. Geofocus: Revista Internacional de Ciencia y Tecnología de la Información Geográfica (7) 120-144.

Naredo, J. M. (2017). La ciudad como mercancía o negocio ¿no es un atentado a los derechos ciudadanos y a la sostenibilidad del territorio. En J. Borja et al. (Eds), Ciudades resistentes, ciudades posibles, pp 203-207. Barcelona: UOC.

Osorio Gómez, J. C. y Orejuela Cabrera, J. P. (2008). El proceso de análisis jerárquico (AHP) y la toma de decisiones multicriterio. Ejemplo de aplicación. Scientia Et Technica, XIV (39) 247-252. [Fecha de Consulta 14 de marzo de 2020] Disponible en: https://www.redalyc.org/articulo.oa?id=849/84920503044.

Ortigoza, E., González, A., Blanco, G. y Martínez, A. (2016). Transformación estructural del sector productivo del Paraguay: un enfoque desde la perspectiva de la complejidad económica y del espacio producto. Revista Latino-Americana de Inovação e Engenharia de Produção.

Pezzi, C. H. (2017). De la ciudad caótica a la ciudad sostenible ¿hay respuestas urbanísticas para la ciudad sostenible? En J. Borja et al. (Eds), Ciudades resistentes, ciudades posibles, pp 198-202. Editorial UOC. Barcelona.

Precedo. A. y Mínguez, A. (2014). Las ciudades medias en la globalización. Madrid: Síntesis.

Romero, J. (2010). Construcción residencial y gobierno del territorio en España. De la burbuja especulativa a la recesión. Causas y consecuencias. Revista Cuadernos Geográficos (47) 17-46.

Saaty T. L. (1984). The Analytic Hierarchy Process: Decision Making in Complex Environments. En R. Avenhaus y R. K. Huber (Eds) Quantitative Assessment in Arms, pp 285-308. Boston: Control Springer.

Saaty, T. L. (1990). How to Make a Decision: The Analytic Hierarchy Process. European Journal of Operational Research 48(1), 9-26.

Sede electrónica del catastro: Disponible en:

http://www.catastro.minhap.gob.es/esp/estadisticas.asp y https://www.sede catastro.gob.es/Accesos/SECAccDescargaDatos.aspx [Fecha de consulta: 14 de marzo 2020].

Valenzuela, M. (2016). Tendencias y desafíos de la planificación urbana y del gobierno del territorio. La perspectiva de los geógrafos españoles (2005-15). Aportación española al 33er Congreso Internacional de Geografía. 


\title{
CIDADES PEQUENAS: UMA ANÁLISE A PARTIR DAS CIDADES DE GOIÁS E ITABERAÍ DO ESTADO DE GOIÁS, BRASIL
}

\author{
SMALL CITIES: AN ANALYSIS FROM THE CITIES OF \\ GOIÁS AND ITABERAÍ IN THE STATE OF GOIÁS, BRAZIL
}

\author{
Camila de Souza Dantas Mota \\ Universidade Federal de Goiás
}

Diogo Isao Santos Sakai

Universidade de Brasília

Érika Munique de Oliveira

Universidade Federal de Goiás

Rafael Martins Lisboa

Universidade Federal de Goiás

Sueli Souza de Oliveira Soares

Universidade Federal de Goiás

Resumo

Habitualmente, há um debate para superar o entendimento da cidade pequena no Brasil tendo como base apenas um critério, o de dimensão demográfica. Avançar nesta discussão é o que motiva esta investigação. O trabalho propõe compreender as cidades pequenas a partir das suas dinâmicas territoriais, considerando as centralidades apresentadas por elas e suas relações urbano-rural. Como desdobramento, partimos dos objetivos: i) apresentar as principais características de duas cidades pequenas do estado de Goiás: Itaberaí e Goiás, dentro de duas lógicas regionais; ii) identificar alguns aspectos da dinâmica socioespacial: mesorregião centro goiano-Itaberaí, e mesorregião noroeste goiano-Goiás; iii) identificar as atividades econômicas das cidades; iv) observar empiricamente as centralidades intra-urbana e relações urbano-rural. Neste âmbito, realizamos pesquisa bibliográfica acerca do contexto de formação e organização das cidades, com ênfase na espacialização das principais atividades econômicas; assim como, trabalho de campo, mapeando a localização dos comércios e serviços na atualidade. Haja vista, as cidades, em especial as pequenas, Goiás e Itaberaí são, em um universo, apenas duas representações no Estado de Goiás, mas que são únicas e específicas. Por isso, mais do que estruturar uma metodologia para categorizar cidade pequena considerando o número populacional é necessário buscar caminhos para compreendê-las.

Palavras chave: cidades pequenas, centralidade, relação urbano-rural, Goiás, Itaberaí, Brasil. 


\section{Abstract}

Usually, there is a debate to overcome the undertanding of the small city in Brazil based on only one criterion, the demographic dimension. Advancing this discussion is what motivates this investigation. The work proposes to undertand the small cities from their territorial dynamics, considering the centralities presented by them and their urban-rural relations. As a result, we start from the objectives: i) to presente the main characteristics of to small cities in the state of Goiás: Itaberaí and Goiás, within of two regional logics; ii) to identify some aspects of social-spatial dynamics: mesoregion central goiano-Itaberaí, and mesoregion northwest goiano - Goiás; iii) to identify the economic activities of cities; iv) empirically observ intra-urban centralities and urban-rural relations. In this context, we carry out bibliographic research about the contecxt of formation and organization of cities, with na emphasis of the spatialization of the main economic acitivities; as well as fieldwork, mapping the location of businesses and services today. In view, the cities specially the small ones, Goiás and Itaberaí are, in a universe, only two representations in the state of Goiás, but they are unique and specific. For this reason, more than to structuring a methodology to categorize a small city considering the population number, it is necessary to seek ways to understand them.

Keywords: small cities, centrallity, urban-rural relationship, Goiás, Itaberaí, Brasil

\section{INTRODUÇÃo}

No Brasil, para classificar a cidade quanto ao porte, é considerado o número populacional em que utiliza-se a definição do Instituto Brasileiro de Geografia e Estatística (IBGE) que conceitua como cidade pequena aquela entre 50 e 100 mil habitantes, cidade média de 100 mil até 500 mil habitantes, e cidade grande definida aquela com mais de 500 mil habitantes.

De encontro com esta definição, ao hierarquizar as cidades brasileiras em conjunto homogêneo, tendo como base apenas um critério para cidade pequena, a consequência é um agrupamento com dimensão extensa: das 5.570 cidades, 89,76\% são classificadas como cidades pequenas (IBGE, 2019). Com base nisso, parte-se do seguinte questionamento: é possível e necessário definir cidade pequena somente pelo seu aspecto demográfico?

A lógica dessa classificação formal ignora a complexidade em que a cidade é construída, planejada e habitada por pessoas, por sua vez, ambas carregam em sua gênese características heterogêneas.

Para compreender a cidade pequena, tem-se que partir da ideia que a discussão em torno da cidade cria inúmeras e inacabadas questões, devido a sua diversidade, pluralidade e dinamismo. Segundo Olanda (2019), não há 
uma definição ou conceito de cidade pequena do ponto de vista teórico que contribua para a compreensão.

Sobarzo (2006) explica que cidade e campo se diferenciam em função do trabalho, ou seja, das relações interpessoais ou conteúdos sociais produzidos por ele e descritos como «urbano» e «rural». Essas são as características que definem e constituem cada espaço, e sua articulação o que organiza o território.

Segundo Carlos (2007) essas relações sociais embora não se restringem ao espaço físico, podem se reproduzir o urbano e o rural, tanto no campo como na cidade, criando relações em ambos os espaços, assinalando novas organizações territoriais. Assim sendo, não existe a neutralização de espaços, mas a o surgimento de novas organizações territoriais. A superação entre cidade e campo está superada e ela ocorre no campo das relações de produção a partir do crescimento das forças produtivas (Carlos, 2007).

Para Limonad (1999), a urbanização é um processo de disseminação do urbano que amplia-se e generaliza-se em escala mundial enquanto expressão das relações sociais ao mesmo tempo em que incidiria sobre elas, em que chama a atenção para as escalas de expressão do processo de urbanização: Um processo onde as desigualdades geográficas, econômicas, sociais etc... conjugadas à mobilidade espacial e setorial do trabalho contribuem para alterar o território, subordinadas às necessidades de reprodução geral das relações sociais e espaciais de produção e ao desenvolvimento do meio técnico-científico. Este processo que gera fixos e fluxos têm um resultante que se expressa espacialmente em duas escalas: a cidade, na escala dos lugares; e a rede urbana, enquanto a manifestação espacial da cooperação entre lugares (Limonad, 1999, 71).

Sendo assim, o espaço compartilha de outras interações para a sua construção que ultrapassa os limites da cidade. A expressão das relações sociais e espaciais provocam as transformações no território que se constitui na escala do lugar, ou seja, nas especificidades dos espaços da cidade e do campo, e que na dimensão administrativa brasileira tem expressividade nas cidades pequenas. Nesse sentido, compreende-se que as cidades pequenas, as menores unidades dentro do sistema de redes de cidades, são os espaços com número considerável de pessoas sendo impactadas por decisões maiores, conforme explica Fernandes (2018): É preciso considerar, também, que as pequenas cidades não estão isoladas e fixadas na rede urbana brasileira, ou seja, elas compõem na rede; estão inseridas, articuladas e conectadas às dinâmicas urbanas, inclusive em esfera global, pois fazem parte do modo de produção capitalista e fazem parte - e são influenciadas por - do fenômeno da globalização, sofrendo as consequências e a perversidade desses processos. Assim, as maiores parcelas da população dessas pequenas cidades têm suas vidas condicionadas às decisões do capital (Fernandes, 2018, 14). 
Olanda (2019) enfatiza que no estudo das pequenas cidades são necessários referenciais apropriados a essa escala, diferente dos utilizados para cidades médias e dos espaços metropolitanos, cujas comparações quantitativas diminuem significativamente a importância desses municípios. O autor pontua ainda a necessidade de mudar o prisma de análise para os aspectos que estão diretamente relacionados a vida das pessoas: a qualidade das informações e a importância dos serviços.

Assim sendo, na busca por compreender as cidades pequenas e suas dinâmicas territoriais, partimos de uma análise da área central de duas cidades. Entendendo que a centralidade ocorre de maneira linear, onde estão espacializados comércios e serviços no espaço urbano das cidades. É importante destacar que não existe um único entendimento do termo centralidade, conforme assinalado no Diccionario de Geografía Aplicada y Profesional. Portanto, a centralidade neste artigo refere-se ao parâmetro que representa a extensão e o valor do exercício das funções centrais a um local central em relação à área em que atua. (Dicionário, 2015, tradução nossa). Este estudo apresenta como metodologia de pesquisa estruturada nas seguintes etapas:

- Etapa 1. Delimitação e caracterização das cidades selecionadas: elegeu-se duas cidades brasileiras localizadas no Estado de Goiás a partir dos seguintes critérios: tamanho populacional, de acordo com a classificação apresentada pelo IBGE; posição geográfica e ligação rodoviária com a capital Goiânia. Foi realizado também pesquisa bibliográfica sobre a formação e organização das cidades.

- Etapa 2. Definição e apresentação das categorias de análise na pesquisa de campo: esta etapa consiste na definição de variáveis que serão utilizadas na pesquisa de campo, que compreendem a identificação das centralidade intra-urbana das cidades a relação urbano-rural (conteúdos sociais especializados).

A seguir será abordado um estudo realizado sobre duas cidades localizadas no interior do Estado de Goiás.

\section{UMA ANÁLISE DE GOIÁS E ITABERAÍ}

Conforme apontado na introdução deste trabalho, 89,76\% das cidades brasileiras são classificadas como cidades pequenas. No Estado de Goiás o cenário não é diferente, visto que $94 \%$ dos 246 municípios são classificados como pequenas, assim como apresentado na Tabela 1. 
Tabela 1. População dos municípios em Goiás

\begin{tabular}{|c|c|c|}
\hline Cidades ( $\mathbf{n}^{\circ}$ de hab.) & $\mathbf{N}^{\circ}$ de cidades & \% sobre o total \\
\hline Até 20 mil habitantes & 188 & $76 \%$ \\
\hline De 20 a 50 mil habitantes & 36 & $15 \%$ \\
\hline De 50 a 100 mil habitantes & 8 & $3,3 \%$ \\
\hline De 100 a 250 mil habitantes & 11 & $4,5 \%$ \\
\hline De 250 a 500 mil habitantes & 1 & $0,4 \%$ \\
\hline Acima de 500 mil habitantes & 2 & $0,8 \%$ \\
\hline Total & $\mathbf{2 4 6}$ & $\mathbf{1 0 0} \%$ \\
\hline
\end{tabular}

Fonte: IBGE, 2019

É pertinente destacar que, historicamente, as rodovias têm papel importante no desenvolvimento das cidades goianas. A posição geográfica de Goiás beneficia a movimentação de produtos e bens no/do Estado e de outras unidades federativas brasileira. Essa malha viária, que possui quase $28 \mathrm{mil} \mathrm{km}$ de extensão (IMB, 2018), promove o dinamismo do setor econômico com o surgimento de novas demandas, e assim o surgimento de novas cidades. Posto a estes fatos elencados, as cidades de Goiás e Itaberaí foram os municípios selecionados para o objeto de estudo desta pesquisa, conforme demonstrado na Figura 1. 
Figura 1. Mapa localização das cidades Goiás e Itaberaí

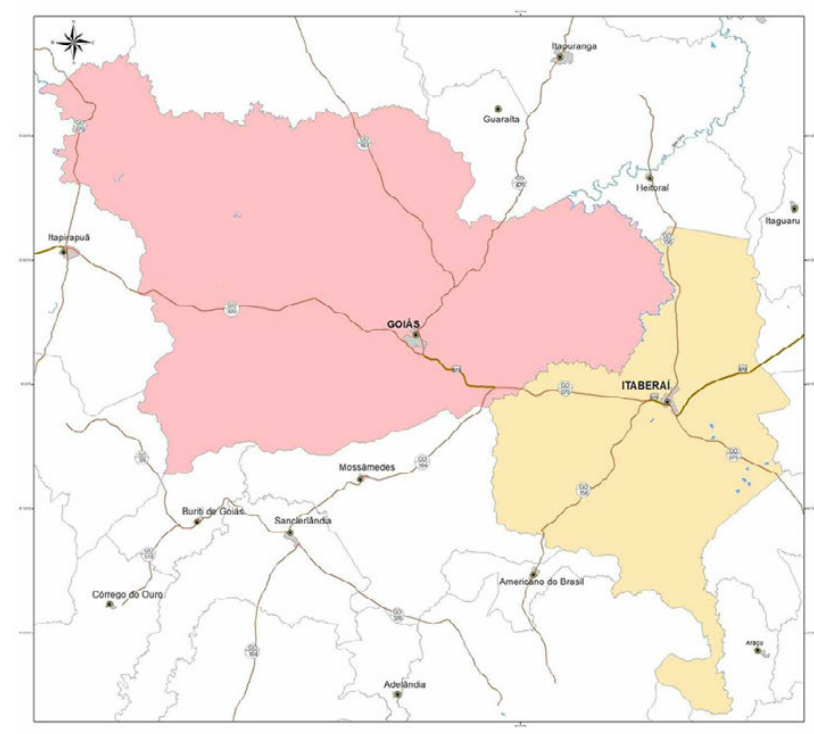

Fonte: Erika Munique de Oliveira, 2020
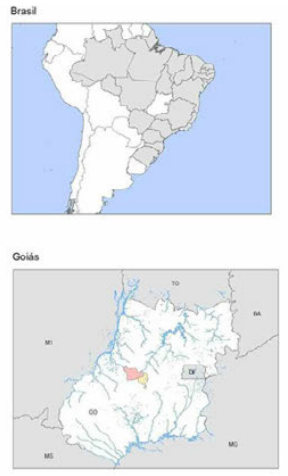

LEGENDA

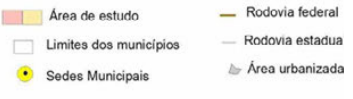

Drenagem

$\begin{array}{ll}\text { Escala Grafica } \\ 5 \quad 10 & 20 \mathrm{~km}\end{array}$

Sistema de Coordenadas Geográficas Datum. SIRGAS, 2000
Base de dados: IBGE (2010); SIEG (2017) Conceppaso: Autores
Elaboraço: Erika Munique de Oliveira

As cidades são cortadas por duas importantes rodovias, cujo trecho entre Itaberaí e Goiás são coincidentes: a estadual GO-070 que as ligam até a capital Goiânia, sendo considerado eixo viário turístico conhecido como Rota do Araguaia (Goinfra, 2017); e a rodovia federal BR-070 que liga Brasília ao extremo oeste do país até o município de Cáceres (MT).

\subsection{CARACTERIZAÇÃO DAS CIDADES DE GOIÁS E ITABERAÍ}

A cidade de Goiás edificada em 1729, durante o ciclo do ouro, foi capital do estado homônimo até a década de 1930 quando foi inaugurada Goiânia (IBGE, 2017). De acordo com o Iphan (2020), dada sua arquitetura barroca peculiar, suas tradições culturais seculares e sua natureza exuberante que circunda o município, Goiás foi reconhecida como Patrimônio Cultural da Humanidade em 2001 pela Unesco, que a definiu com o desenho e a morfologia urbana de exemplo do desenvolvimento orgânico de uma cidade mineradora, adaptada às condições da região.

Assim, a gênese da formação urbana, do que na atualidade conhecemos como cidade de Goiás, remonta do século XVII, época de ascendência do ouro enquanto atividade econômica no Brasil. Localizada na mesorregião 
noroeste do estado de Goiás, o município tem uma área de 3.108,019 km², com uma densidade demográfica de $7,96 \mathrm{hab} / \mathrm{km}^{2}$, e segundo estimativa do IBGE (2019), o município' possui 22.645 habitantes, conforme o Censo de 2010. Já o surgimento da cidade de Itaberaí, ocorreu no século XVII, por volta do ano 1770, da necessidade de arrebanhar gado às margens do Rio das Pedras pela construção de currais e implantação da Capela Nossa Senhora da Abadia. Essas ocupações iniciam progressivamente os assentamentos de ranchos que, em 1819, com 52 casas, tornou-se conhecido como Curralinho. A povoação ficou assim conhecida por mais de um século, até que em 1924 foi aprovado o projeto de mudança do nome de Curralinho para Itaberaí (Itaberaí, 2017).

O município tem uma área de $1.457,280$ km² com uma densidade demográfica de 24,27 hab/ $\mathrm{km}^{2}$ e encontra-se na mesorregião do centro goiano. Segundo estimativa do IBGE (2019), Itaberaí possui aproximadamente 43 mil habitantes.

\subsection{ATIVIDADES ECONÔMICAS DE GOIÁS E ITABERAÍ}

É importante destacar que o Estado de Goiás é a nona economia do país e o que mais recebeu investimentos nos últimos anos (ANA, 2013). Considerando o Produto Interno Bruto (PIB), o setor de serviços (varejo e atacado) é o que se destaca, representando $65,6 \%$ do fluxo de produção. O setor industrial corresponde a $24,5 \%$, e o agropecuário com 10,4\%, de acordo com o IMB (2018). Vale ressaltar a importância do setor agropecuário que, mesmo com a menor participação na economia do Estado, é dele que surge a agroindústria, com a produção de carne, leite, açúcar e soja, itens prioritários para subsidiar a indústria.

A importância em ultrapassar o critério demográfico para classificar como cidade pequena, é que tal situação desconsidera, por exemplo, a importância e poder econômico da cidade. Haja vista, tendo como base o perfil econômico geral do, é considerável estabelecer comparação entre as duas cidades, no caso Itaberaí e Goiás, e observar que o cenário econômico do Estado segue a mesma tendência, tendo como maior destaque o setor de serviços, conforme exposto na Tabela 2 .

1 Olanda (2019) argumenta que na discussão sobre as cidades pequenas, pelo menos em alguns momentos, há necessidade de mencionar o município, uma vez que ele enquanto unidade federativa tem papel fundamental no processo de organização espacial, assim como na definição das funções das cidades pequenas. Nesse sentido, ao concordar com essa questão alguns elementos sobre ele serão colocados em discussão neste tópico. 
Tabela 2. Composição do Produto Interno Bruto de Goiás e Itaberaí

\begin{tabular}{|c|c|c|c|c|}
\hline \multirow{2}{*}{ Municípios } & & \multicolumn{2}{|c|}{ Atividades econômicas } & \\
\cline { 2 - 5 } & Agricultura & Indústria & Serviços & $\begin{array}{c}\text { Administração } \\
\text { Pública }\end{array}$ \\
\hline Goiás & $\mathrm{R} \$ 88.030 .040$ & $\mathrm{R} \$ 27.419 .900$ & $\mathrm{R} \$ 212.409 .840$ & $\mathrm{R} \$ 96.416 .730$ \\
\hline Itaberaí & $\mathrm{R} \$ 154.209 .340$ & $\mathrm{R} \$ 261.587 .700$ & $\mathrm{R} \$ 528.615 .640$ & $\mathrm{R} \$ 172.749 .740$ \\
\hline
\end{tabular}

Fonte: IBGE (2010)

\subsection{CENTRALIDADES E RELAÇÃO URBANO-RURAL}

Quais as similaridades entre uma cidade da Antiguidade, da cidade de Tóquio e de uma cidade no interior de Goiás? Há uma complexidade em torno dessa resposta, como indica Souza (2005), dada a sensibilidade do conceito de cidade e cuja discussão ganha controvérsia com o passar do tempo.

Ainda assim, o estudo sobre essa temática exige a compreensão sobre conceitos fundamentais como cidade, campo, urbano, rural, que já foram explorados na introdução.

Na discussão sobre centralidade e seguindo um outro viés ideológico, Souza (2005), ao revisar a bibliografia sobre o tema, esclarece que toda a cidade é um local de mercado, onde se dá um intercâmbio regular de mercadorias. Do contrário o campo, assentamentos não urbanos ou povoados, são os lugares onde não existe esse aspecto regular. Com base na teoria dos lugares centrais, Souza ${ }^{2}$ (2005) ainda destaca que: [...] Toda cidade é, do ponto de vista geoeconômico, das atividades econômicas vistas a partir de uma perspectiva espacial, uma localidade central, de nível maior ou menor de acordo com sua centralidade, ou seja, de acordo com a quantidade de bens e serviços que ela oferta e que fazem com que ela atraia compradores apenas das redondezas, de uma região inteira ou, mesmo, de acordo com o nivel de sofisticação do bem ou serviço, do país inteiro e até de outros países (Souza, 2005, 25).

A partir desses conceitos, buscou-se identificar no trabalho de campo as centralidades relativas às cidades de Goiás e Itaberaí e ao mesmo tempo as relações urbano-rural.

2 Souza embasa seus estudos em Walter Christaller, geógrafo alemão cuja principal contribuição para a disciplina foi a Teoria do Lugar Central em 1933. 
A partir do pensamento de Souza (2005), Goiás e Itaberaí são localidades centrais, ou seja, sua atração está onde a área central de negócios atrai os consumidores de todo o tecido urbano, fazendo com que as atenções dos citadinos se voltem para o centro da cidade.

\subsection{CENTRALIDADES EM GOIÁS E ITABERAÍ}

Na cidade de Goiás, a pesquisa de campo possibilitou a identificação de duas centralidades que se diferem sobretudo pelas tipologias de usos: área do centro histórico e o eixo viário da Avenida Dario Paiva Sampaio.

\section{Figura 2. Imagem representativa das centralidades em Goiás}

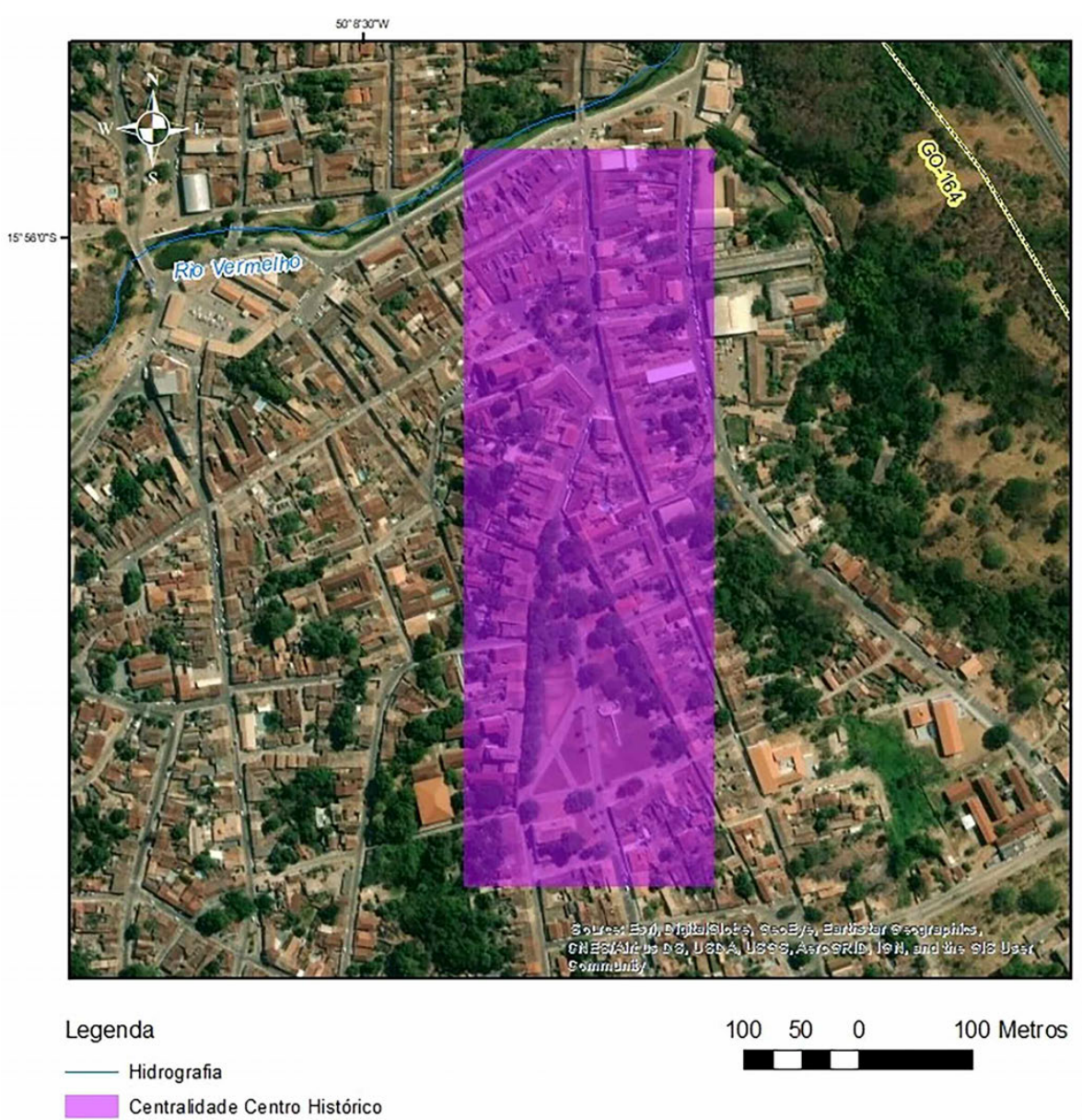

Fonte: Acervo dos autores, 2019 
Na abordagem urbana estruturalista pode existir várias centralidades, o centro econômico e financeiro, os subcentros. Já nessa cidade, a diversidade apresenta-se na centralidade exercida na composição do centro histórico (vide Figura 2) que integra o conjunto arquitetônico, paisagístico e urbanístico do centro de Goiás, agrupa-se um conjunto de usos de comércios e serviços relacionados ao turismo, instituições públicas e privadas e residenciais. As atividades de maior evidência estão estruturadas em torno do caráter turístico, delimitado pela área de tombamento, na qual as construções preservadas ganham usos contemporâneos voltados para serviços e comércios, embora ainda prevaleça os usos residenciais. O comércio artesanal, restaurantes e hotéis constituem as práticas mais comuns, dentre os usos de serviços.

Nessa centralidade encontram-se os edifícios históricos com usos culturais, sendo que alguns mantêm suas atividades, tais como a Igreja Matriz de Santana (Catedral) e o Palácio do Governo (Conde dos Arcos). Outros passaram a abrigar novas tipologias, como os museus do Quartel do Vinte, a Casa de Fundição, os Correios e a Casa de Câmara e Cadeia (atual Museu das Bandeiras). O Chafariz de Cauda, antigo ponto de coleta da água, permanece como um monumento.

Nesta área concentram-se também as principais instituições financeiras públicas e privadas (Figura 6), juntamente com a Secretaria de Estado da Fazenda e do Ministério do Trabalho, e demais serviços públicos, cuja influência ultrapassa os limites do perímetro urbano.

Em Goiás, as relações urbano-rurais na área do centro histórico aparecem na própria forma urbana preservada pelo tombamento. $O$ traçado das vias e as edificações são o registro de momento histórico ligado ao modo de vida no qual havia uma maior dependência a mineração e ao trabalho no campo. Esse caráter é reforçado pelos museus, e especialmente, em alguns aspectos pelo «modo de vida» ainda presentes nos produtos comercializados, na culinária e no artesanato produzido pela população rural e indígena, principais ingredientes para o mercado turístico.

Por coincidir o centro histórico com o local de fundação da cidade, este espaço é constituído com maior significância social e ao mesmo tempo palco de conflitos sociais. Por exemplo, a situação de ocupação dos imóveis no perímetro tombado revela-se como um processo de especulação imobiliária, que de acordo com Costa et. al. (2017), 53\% são utilizados para aluguel, 29\% cedidos temporariamente, e 18\% moradia fixa.

A centralidade do eixo viário Avenida Dario Paiva Sampaio (Figura 7) corta a cidade no sentido leste-oeste, conectando as rodovias BR-070 e a GO-184. Ao longo da via urbanizada estabelecem-se uma série de usos de serviços e comércios, como farmácias, restaurantes, serviços de beleza, vestuário, supermercados, clínicas particulares entre outros, que geram um fluxo interno e externo ao município. 
Figura 3. Em destaque na cor laranja, a centralidade do eixo viário Avenida Dario Paiva Sampaio

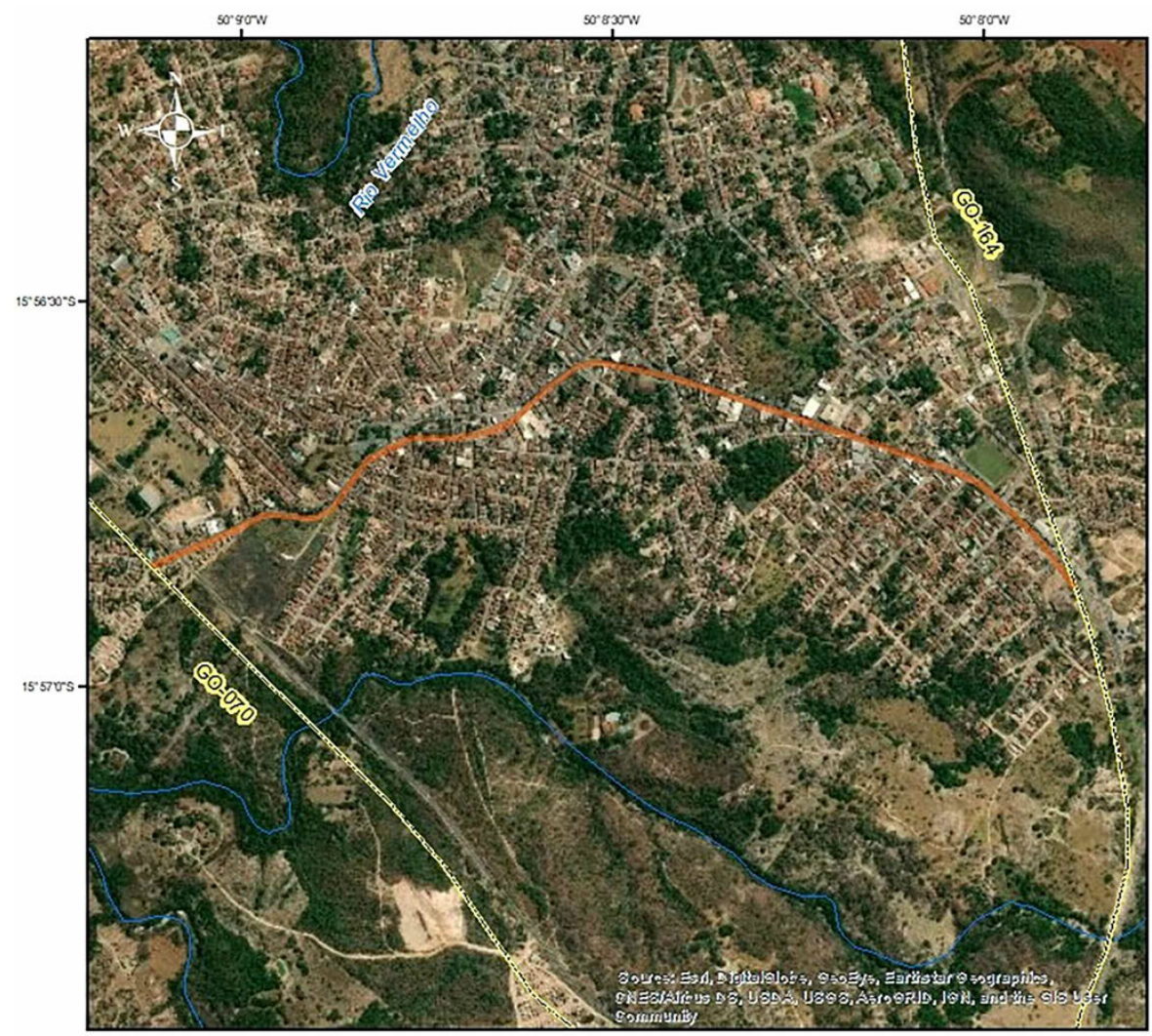

$400200 \quad 0 \quad 400$ Metros

\section{Legenda}

Centralidade Eixo Av. Dario de Paiva Sampaio Hidrografia

Fonte: Google Earth com edição dos autores, 2020

A presença da Rodoviária neste eixo afigura um dos usos geradores de fluxos que conecta Goiás aos demais municípios do estado e a capital. Outra importante constatação foi em relação ao número de estabelecimentos agropecuários (Figura 8): dada a relevância do caráter rural e histórico de Goiás, imaginou-se encontrar um número considerável dessa tipologia, contudo, não se percebeu uma quantidade significativa.

Conforme relato de um dos proprietários durante a pesquisa de campo, os produtores recorrem às cidades vizinhas quanto a necessidade de produtos 
ou equipamentos agropecuários sofisticados, especialmente na cidade de Itaberaí. Mas as referências rurais com viés histórico estão presentes no nome dos estabelecimentos comerciais e de serviços.

$\mathrm{Na}$ visita de campo a cidade de Itaberaí foram reconhecidas duas centralidades na cidade (Figura 4): ao longo do eixo viário BR-070, e outro dentro da cidade ao longo da Avenida Pio XII. Esses dois eixos fazem conexão com outras duas importantes vias: a sentido norte e oeste de Goiás dentro do perímetro urbano de Itaberaí, e que levam a outros destinos do Estado, respectivamente às rodovias GO-156 e GO-070.

Figura 4. Itaberaí: centralidade eixo viário BR-070 dentro da cidade e centralidade eixo ao longo da Avenida Pio XII

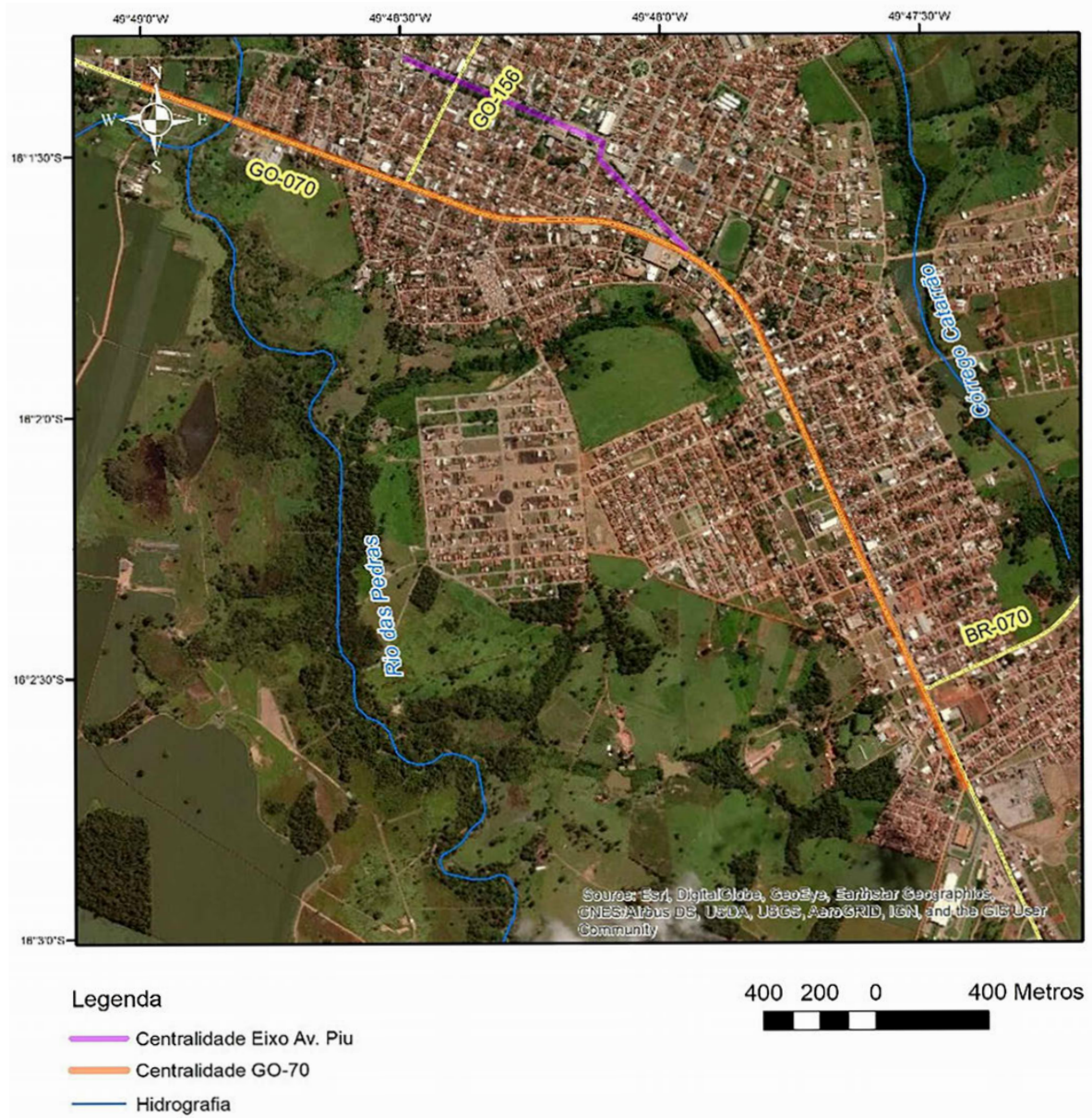

Fonte: Google Earth com edição dos autores, 2020 
No eixo da BR-070 prevalecem dois segmentos diferenciados pelas atividades. No trecho que marca acesso em direção à Goiânia (Figura 11), percebeuse a presença de galpões industriais, armazéns e fábricas que se destacam na paisagem, em que esses usos relacionam-se sobretudo com a produção de frango, ovos e seus derivados.

Figura 5. Itaberaí: à esquerda a centralidade eixo viário BR-070, no Trecho saída para Goiânia com destaque para o uso industrial

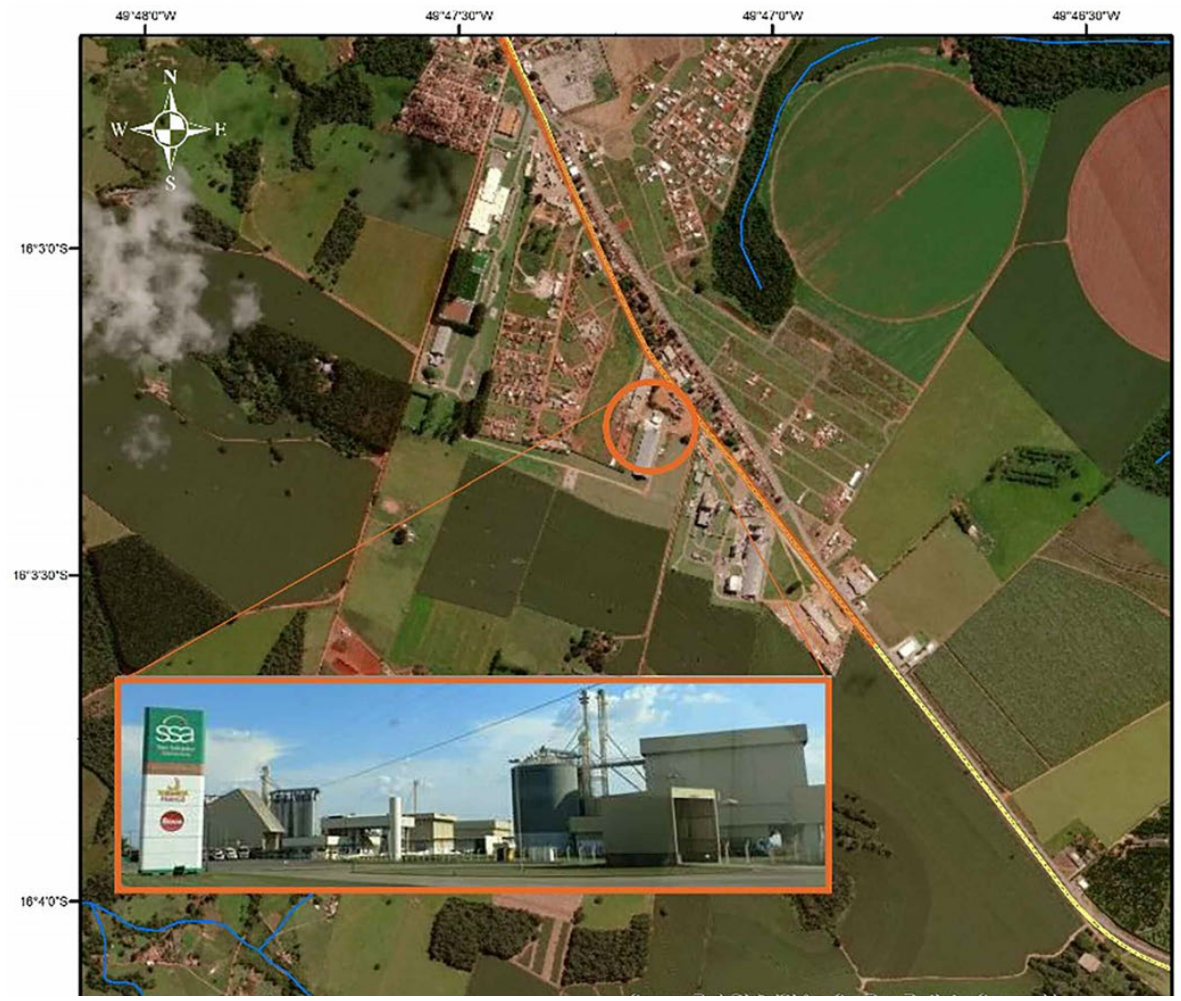

Fonte: Acervo dos autores, 2019

O outro trecho compreende a porção urbanizada da BR-070 (Figura 12), no qual usos comerciais, serviços, instituições públicas e residenciais utilizam-se das duas margens da via. Os usos comerciais agropecuários aparecem com maior frequência, variando o porte tanto no tamanho do lote quanto da edificação, nos quais a diversidade de produtos atende até maquinário de grande porte. Sendo este trecho uma avenida-rodovia com fluxo intenso de carros, caminhões e motocicletas, nela concentram-se oficinas mecânicas ao lado dos postos de combustíveis. 
Nessa centralidade entende-se que a relação urbano-rural aparece sobretudo na quantidade de estabelecimentos comerciais agropecuários. Com base nos dados econômicos, as demandas por esses produtos demonstram uma área de campo diversificada e em grande escala com suporte às atividades industriais.

As referências com o rural apresentam-se na culinária oferecida, e em menor quantidade nos produtos regionais, quando comparado a Goiás. Contudo, a referência mais evidente com o rural local ou com a história do lugar ocorre sobretudo no nome dos estabelecimentos.

A outra centralidade estrutura-se pela conexão da BR-070 com a Avenida Pio XII, e que tem sua continuidade em uma faixa que integra 06 praças com edifícios públicos, demonstrado na Figura 6.

Figura 6. Itaberaí: centralidade no eixo viário ao longo da Avenida Pio XII

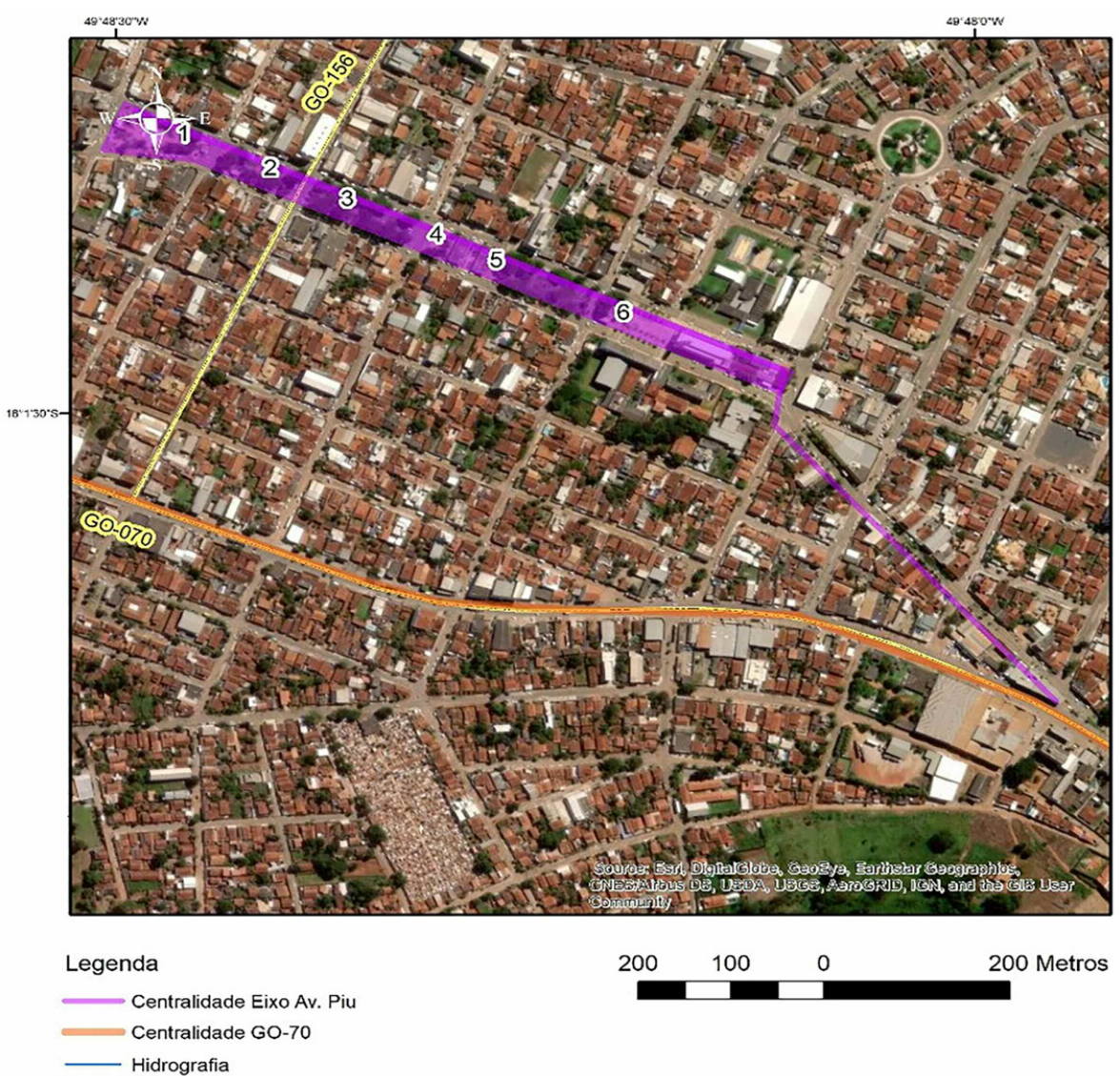

Fonte: Google Earth com edição dos autores, 2019 
Os quarteirões são ocupados por usos de comércio e serviços, instituições financeiras públicas e privadas, administrativas e residências. Compreende o espaço urbano onde encontram-se os estabelecimentos de um comércio e serviços especializados, usos educacionais e institucionais, assim como atividade de comércio informal ao longo dos espaços públicos.

As relações urbano-rural aparecem minimamente representado neste espaço. O centro especializado é representado por edificações de alvenaria convencional, sem diferenças entre si ou referências com o lugar. Alguns edifícios históricos ainda mantêm sua arquitetura, embora tenham sofrido pequenas intervenções. Outra forma de representação aparece também na culinária regional e na presença de veículos de tração animal, como carroças e charretes.

\section{CONSIDERAÇÕES FINAIS}

Para compreender as cidades pequenas, fundamentado nos estudos e conceitos sobre o tema, refletiu-se acerca do entendimento de que as cidades respondem às relações, conteúdos sociais. Esses estão em constante transformação, influenciados pelo processo de urbanização. Cidade e campo não se anulam, mas se renovam no tempo e podem adquirir novas organizações territoriais. Nesse sentido, foi através da centralidade e da relação urbanorural, os aspectos considerados relevantes para percepção do que seria uma cidade pequena no interior do Estado de Goiás.

Ao analisar as centralidades, reconhecidas nas cidades de Goiás e Itaberaí percebeuse que, embora sejam cidades nascidas no período colonial e possuam dimensões territoriais e demográficas aproximadas, estas apresentaram conteúdos sociais distintos, sobretudo na relação urbano-rural e que aparecem na organização espacial.

Em Goiás, na centralidade identificada pelo centro histórico tombado percebeu-se a constituição de uma «ruralidade histórica». Este modo rural específico foi adaptado ao turismo que ao utilizar o espaço cenográfico da cidade, transformar seus usos, e se apoia principalmente nesse modo de vida: artesanato, culinária, festas típicas, e etc.

Ainda assim, os imóveis são em sua maioria residências e estão frequentemente vazios. Percebeu-se ainda que existe por parte do Estado, investimentos públicos direcionados a esses espaços, sobretudo aos usos culturais. Sendo assim, a população local não se apropria efetivamente desses lugares. A outra centralidade, no eixo da Avenida Dario Paiva, apresenta vitalidade pela tipologia de serviços e comércios básicos, pouco especializados. Percebeu-se a referência da ruralidade histórica apenas nos nomes dos estabelecimentos. O que chama a atenção é o fato que, ao longo desse eixo encontram-se apenas três estabelecimentos que comercializam produtos agropecuários, o que contrasta com a estrutura do município que possui maior área de campo e 
no qual se estabelecem aglomerados, povoados, comunidades quilombolas e fazendas particulares.

Em Itaberaí, a análise trouxe outros resultados. A centralidade do eixo da BR070 apresenta tipologias de usos de serviços, comércios de produtos, equipamentos e veículos sofisticados, voltados em sua maioria para atender atividades agropecuárias de grande escala e para produção industrial. A consolidação de um polo industrial para beneficiamento de frango dá ao lugar a percepção de um rural modernizado na análise da relação urbano-rural. No eixo da Avenida Pio XII, as tipologias identificadas contribuem para percepção de um centro de negócios, com tipologias de serviços e comércios sofisticados para atendimentos local e da região. São poucas ou nenhuma as referências com Itaberaí ou sua história. De modo geral, e assim como Goiás, observou-se nesse local a presença dos trabalhadores e não da população do local.

Em Itaberaí nas centralidades observadas, campo e cidade possuem uma relação econômica evidente, embora tenha-se identificado minimamente na culinária e na venda de produtos rurais uma ruralidade pouco expressiva.

A conexão entre a cidade pequena e sua importância pode definir sua escala de influência: menor, regionalizada, local. Pelas conjunções, não coube comparar qualitativamente as cidades estudadas com outras e nem entre si, mas sim compreender os espaços, que são diferentes, com essências próprias e demonstrar as suas principais características, e serviços ofertados (privados ou públicos) de cada cidade.

As cidades, em especial as pequenas, Goiás e Itaberaí são, em um universo, apenas duas representações no Estado de Goiás, mas que são únicas e específicas. Por isso, mais do que estruturar uma metodologia para categorizar cidade é necessário buscar caminhos para compreendê-las.

\section{REFERÊNCIAS BIBLIOGRÁFICAS}

ANA (Agência Nacional das Águas) (2013). Panorama da Qualidade das águas superficiais no Brasil: 2013. Agência Nacional das Águas - Brasília.

Carlos, A. F. A. (2007). Seria o Brasil «menos urbano do que se calcula»?. In: O Espaço Urbano: Novos Escritos sobre a Cidade. São Paulo: FFLCH.

Costa, L. F., Silva, N. B. da, Laner, I. C., Silva, N. C. G., Silva, M. C. B. y Oliveira, F. K. M. de. (2017). A extensão universitária popular como prática reflexiva: Interlocuções entre Arquitetura-Urbanismo e Serviço Social. Anais do // Seminário Nacional: pensando o projeto pensando a cidade, 45-46. Programa de Pós - Graduação Projeto e Cidade - FAV/UFG. ISSN: 2525-9407.

Fernandes, P. H. C. (2018). O urbano brasileiro a partir das pequenas cidades. Revista Eletrônica Geoaraguaia. Barra das Garças - MT. v. 8, n. 1, 13-31. 
Goinfra (2017). Rota do Araguaia: Condições das rodovias. Disponível em: http://www.goinfra.go.gov.br/noticias/rota-do-araguaia-condicoes-dasrodovias/212764. [Acesso em: 24 de janeiro de 2020]

Instituto Mauro Borges - IMB (2018). Goiás: Visão geral sobre o estado de Goiás referentes a seus aspectos físicos, econômicos e sociais. Disponível em: http://www.imb.go.gov.br/files/docs/publicacoes/goias-visao-geral/goiasvisaogeral.pdf [Acesso em: 28 de janeiro de 2020]

Instituto Brasileiro de Geografia e Estatística - IBGE (2010). Produto Interno Bruto dos Municípios. Disponível em:

https://cidades.ibge.gov.br/brasil/go/ [Acesso em: 24 de janeiro de 2020]

Instituto Brasileiro de Geografia e Estatística - IBGE (2017). Cidade de Goiás História \& Fotos. Disponível em:

https://cidades.ibge.gov.br/brasil/go/goias/historico. [Acesso em: 24 de janeiro de 2020]

Instituto Brasileiro de Geografia e Estatística - IBGE (2019). IBGE divulga as estimativas da população dos municípios para 2019. Disponível em: https://agenciadenoticias.ibge.gov.br/agencia-sala-de-imprensa/2013agencia-denoticias/releases/25278-ibge-divulga-as-estimativas-da-populacao-dos-municipios-para2019. [Acesso em: 26 de janeiro de 2020]

Instituto do Patrimônio Histórico e Artístico Nacional - IPHAN (2020). Cidade de Goiás, patrimônio mundial. Disponível em:

http://portal.iphan.gov.br/go/pagina/detalhes/578. [Acesso em: 24 de janeiro de 2020]

Itarabaí, Prefeitura Municipal de (2017). História, Educação e Cultura. Disponível em:

http://itaberai.go.gov.br/site/itaberai/historia. [Acesso em: 26 de janeiro de 2020]

Limonad, E. (1999). Revista GEOgraphia, Ano 1, n 1, 71-91.

López Trigal, L. (Dir.), Rio Fernandes, J. A., Savério Sposito, E. e Trinca Fighera, D. (Coord.) (2015). Diccionario de Geografía Aplicada y Profesional: terminología de análisis, planificación y gestión del territorio/ director. León: Universidad de León.

Olanda, E. R. (2019). Cidade Pequena e Central. $1^{a}$ ed. Curitiba: Appris. Sobarzo, O. (2006). O urbano e o rural em Henri Lefebvre. In: M. E. Beltrão Sposito y A. M. Whitacker (Orgs). Cidade e Campo: relações e contradições entre o urbano e rural, pp. 53-64. $3^{a}$ ed. São Paulo: Outras Expressões.

Souza, M. L. (2005). ABC do Desenvolvimento Urbano. $2^{a}$ ed. Rio de Janeiro. Bertrand Brasil. 



\title{
O PROCESSO DE DENSIFICAÇÃO E VERTICALIZAÇÃO E SEUS IMPACTOS NO SISTEMA DE DRENAGEM DE ÁGUAS PLUVIAIS: ESTUDO DE CASO DO JARDIM GOIÁS EM GOIÂNIA, GOIÁS - BRASIL \\ THE PROCESS OF DENSIFICATION AND VERTICALIZATION AND ITS IMPACT \\ ON THE STORMWATER DRAINAGE SYSTEM: JARDIM GOIÁS CASE STUDY IN GOIÂNIA, GOIÁS - BRAZIL
}

\author{
Sueli Souza de Oliveira Soares \\ Universidade Federal de Goiás
}

Resumo

O crescimento e a expansão das cidades brasileiras ocorreram de forma acelerada sem que houvesse um planejamento urbano adequado, ocasionando uma crise urbana sem precedentes, que se intensificam até os dias de hoje. Os problemas relacionados com o escoamento de águas pluviais podem ser encontrados na lista dos mais preocupantes, pois a urbanização está relacionada diretamente à impermeabilização do solo. O aumento das ocorrências, nos últimos anos, de alagamentos em Goiânia, Goiás - Brasil, motivou este estudo, no qual se pretende analisar o processo de densificação e verticalização em uma região intensamente urbanizada de Goiânia e seus impactos no sistema de drenagem de águas pluviais, face aos mecanismos de indução do desenvolvimento urbano previstos nos planos de desenvolvimento urbano. A metodologia proposta se divide em três etapas: (i) delimitação e caracterização da área de estudo; (ii) definição de cenários de urbanização que representam momentos de importância histórica para a análise do processo de expansão urbana e; (iii) definição de critérios para comparação dos cenários de urbanização. O estudo permitiu inferir que as legislações urbanísticas promoveram um incremento na densificação e verticalização da área de estudo, entretanto, a infraestrutura urbana de Goiânia não acompanhou o processo de expansão urbana da cidade.

Palavras-Chave: densificação, verticalização, drenagem urbana, desenvolvimento urbano.

\section{Abstract}

The growth and expansion of Brazilian cities occurred at an accelerated rate without adequate urban planning, leading to an unprecedented urban crisis, which has intensified until today. The problems related to stormwater runoff can be found in the list of the most worrying because urbanization is directly related to soil sealing. The increase in flooding occurrences in Goiânia, Goiás-Bra- 
zil, in recent years, motivated this study, in which it is intended to analyze the densification and verticalization process in an intensely urbanized region of Goiânia and its impacts on the rainwater drainage system, in view of the mechanisms for inducing urban development provided for in urban development plans. The proposed methodology is divided into three stages: (i) delimitation and characterization of the study area; (ii) definition of urbanization scenarios that represent moments of historical importance for the analysis of the urban expansion process and; (iii) definition of criteria for comparing urbanization scenarios. The study allowed to infer that the urban legislation promoted an increase in the densification and verticalization of the study area, however, the urban infrastructure of Goiânia did not follow the urban expansion process of the city.

Keywords: densification, verticalization, urban drainage, urban development.

\section{INTRODUÇÃO}

Atualmente, o ambiente urbano é o habitat de mais de 50\% da população mundial. Este percentual deve aumentar consideravelmente nos próximos anos. Estimativas da Organização das Nações Unidas (ONU) para 2030 apontam que serão mais de dois terços da população mundial vivendo em cidades, sendo que para 2050, este número pode aumentar para mais de 70\% (ONU$\mathrm{BR}, 2013)$. A ONU ainda ressalta que, o crescimento da população urbana mundial, por ser elevado, especialmente nos países em desenvolvimento ou subdesenvolvidos, não ocorreu de maneira sustentável, acarretando diversos problemas sociais, ambientais e até climáticos.

No Brasil, o processo de urbanização deu-se praticamente no século XX, iniciando na década de 1930 e tendo seu auge após a década de 1970. Este processo ocorreu de forma acelerada sem que houvesse um planejamento urbano adequado, ocasionando uma crise urbana sem precedentes. Esta crise está relacionada diretamente com a deterioração de um meio ambiente rico e diversificado em muitas regiões e foi caracterizada por uma série de problemas urbanos que se intensificam até os dias de hoje (Maricato, 2001).

Para Villanueva et al (2011), entre os elementos que impactam no desenvolvimento urbano, os problemas associados com o escoamento das águas pluviais podem ser encontrados na lista dos mais preocupantes, pois a urbanização está diretamente associada à impermeabilização do solo. Cabe ressaltar que a pavimentação das vias urbanas é uma ação de planejamento urbano que objetiva um aumento na qualidade de vida, possibilitando melhoria da circulação interna nas cidades. No entanto, a impermeabilização generalizada dos solos pode representar um catalisador para a ocorrência de eventos de alagamentos, inundações, além de erosão, assoreamentos e proliferação de doenças de veiculação hídrica, dentre outros impactos. 
Goiânia, capital do estado de Goiás, exemplifica bem o processo de urbanização brasileiro. Fundada em 1933, foi projetada para 50 mil habitantes, sob a influência do movimento que valorizava os espaços livres e a integridade ambiental, o que refletiu no estabelecimento de diversas áreas verdes no município (Graeff, 1983). No entanto, segundo o Instituto Brasileiro de Geografia e Estatística (IBGE, 2013a), a cidade ultrapassou esta marca já na década de 1950, quando já possuía 53.589 habitantes, dos quais 39.881 habitantes moravam em área urbana, equivalente a $75 \%$ da população. Atualmente, Goiânia possui uma população 1.302.001 habitantes, com uma densidade demográfica de $1.776,74 \mathrm{hab} / \mathrm{m}^{2}$, sendo o $12^{\circ}$ município mais populoso do país, segundo censo do IBGE realizado em 2010 (IBGE, 2013b).

O processo de urbanização de Goiânia, desde sua fundação, resultou em problemas ambientais relacionados ao escoamento de águas pluviais e que se intensificam ao longo do tempo. De acordo com o Comando de Operações de Defesa Civil do município (Defesa Civil, 2014), de 2010 a 2014, foram registradas 43 ocorrências de alagamentos, 9 de inundações e 9 de enxurradas, inclusive com perdas materiais e humanas. Os dados são preocupantes, considerando-se que em 2010 houve 2 eventos de alagamentos, já em 2014, foram registrados 14 alagamentos, totalizando um aumento no número de ocorrências de $600 \%$ em quatro anos.

O aumento das ocorrências de alagamentos no município de Goiânia nos últimos anos motivou o desenvolvimento deste trabalho, no qual se objetiva analisar o processo de densificação e verticalização de uma região intensamente urbanizada de Goiânia e seus impactos sobre o sistema de drenagem de águas pluviais, face aos mecanismos de indução do desenvolvimento urbano previstos em lei, em especial, previstos nos planos diretores de desenvolvimento urbano. Para tanto, será feita uma avaliação das diretrizes urbanísticas e do processo de urbanização do bairro Jardim Goiás, bem como a identificação dos efeitos do seu processo de urbanização, em especial, do processo de densificação e verticalização sobre o sistema de drenagem de águas pluviais.

A metodologia proposta para o desenvolvimento deste estudo foi estruturada em três etapas:

- Etapa 1. Delimitação e caracterização da área de estudo: Para alcançar o objetivo proposto, adotou-se como área de estudo, uma região intensamente urbanizada de Goiânia, como é o caso do bairro Jardim Goiás. Foi elaborada uma pesquisa documental e histórica sobre o processo de urbanização de Goiânia, considerando as leis urbanísticas e ambientais, com foco no sistema de drenagem.

- Etapa 2. Definição dos cenários da urbanização da área de estudo: Para auxiliar no desenvolvimento da pesquisa, foram estabelecidos quatro cenários distintos de urbanização, representando momentos de importância histórica no processo de urbanização do Jardim Goiás. Estes cenários 
foram utilizados como parâmetro para avaliar o processo de urbanização do Jardim Goiás, mediante aplicação dos instrumentos de indução ou de contenção de desenvolvimento do bairro, previstos nas normas urbanísticas de regulamentação da ocupação e uso do solo de Goiânia. Os cenários adotados sao:

- Ano de 2003: durante a vigência do plano diretor de desenvolvimento urbano de 1992.

- Ano de 2007: ano de inauguração do Parque Flamboyant, um importante parque público urbano de Goiânia.

- Ano de 2009: com o Parque Flamboyant completamente implantado.

- Ano de 2015: ano com altos índices de alagamentos em Goiânia.

- Etapa 3. Definição dos critérios utilizados na comparação dos cenários de urbanização da área de estudo: Os critérios adotados para análise do processo de densificação e verticalização da área de estudo foram três e envolvem aspectos urbanísticos e ambientais, sociais e econômicos, e são:

- Avanço do percentual de área impermeabilizada.

- Crescimento populacional.

- Valorização imobiliária.

\subsection{ALGUMAS CONSIDERAÇÕES SOBRE A DRENAGEM DE ÁGUAS PLUVIAIS}

O Art. $3^{\circ}$ da Lei de Saneamento Básico Brasileira, a Lei Federal 11.445/2007, define drenagem e manejo de águas pluviais urbanas como o conjunto de atividades, infraestruturas e instalações operacionais de drenagem urbana de águas pluviais, de transporte, de detenção ou retenção para o amortecimento de vazões de cheias, tratamento e disposição das águas pluviais drenadas nas áreas urbanas (Brasil, 2007).

De acordo com o Ministério das Cidades $(2012,5)$, este conjunto de atividades tem como objetivo minimizar os riscos e os prejuízos a que a população está sujeita, causados por alagamentos e inundações, para que possibilite um desenvolvimento urbano harmônico, articulado e sustentável. A qualidade desse sistema, que compreende a rede coletora de água pluvial, o seu tratamento e o retorno aos rios, é que determinará se os benefícios ou prejuízos à população serão maiores ou menores.

Para a completa e correta análise dos riscos que incidem sobre a população, inicialmente, considera-se necessário apresentar os conceitos dados aos principais problemas derivados de fenômenos ou perigos naturais, de caráter hidrológico, relacionados à drenagem urbana, e que são: as inundações, os alagamentos e as enxurradas. De acordo com a COBRADE (Codificação Brasileira de Desastres), tais problemas são considerados desastres naturais do Grupo Hidrológico, cujas definições e características são (Ministério Da Integração Nacional, 2012, 73): 
- Inundações. Submersão de áreas fora dos limites normais de um curso d'água em zonas que normalmente não se encontram submersas. O transbordamento ocorre de forma gradual, geralmente ocasionado por chuvas prolongadas em áreas de planície.

- Alagamentos. Extrapolamento da capacidade de escoamento de sistema de drenagem urbana e consequente acúmulo de água nas ruas, calçadas ou outras infraestruturas urbanas, em decorrência de precipitações intensas.

- Enxurradas. Escoamento superficial de alta velocidade e energia, provocado por chuvas intensas e concentradas, normalmente em pequenas bacias de relevo acidentado. Caracterizada pela elevação súbita das vazões de determinada drenagem e transbordamento brusco da calha fluvial e apresenta grande poder destrutivo.

No Brasil, os fenômenos relacionados a desastres naturais de caráter hidrológico ocorrem normalmente associados aos eventos pluviométricos intensos e prolongados, nos períodos chuvosos de cada região. Cabe destacar que, a questão da drenagem urbana envolve, além dos processos hidrológicos de cheias e inundações diretamente ligadas aos cursos d'água naturais, os processos de alagamentos e enxurradas, decorrentes de deficiências no sistema de drenagem urbana e que podem ou não ter relação com os processos de natureza fluvial. Em muitas cidades o descompasso entre o crescimento urbano e a drenagem urbana tem originado graves problemas de alagamentos e enxurradas (Ministério Das Cidades, 2007, 97).

Importante salientar que, a pavimentação das vias urbanas é ação de planejamento urbano que objetiva um aumento na qualidade de vida, possibilitando melhoria da circulação interna nas cidades. No entanto, a impermeabilização generalizada dos solos pode representar um catalisador para a ocorrência de eventos de alagamentos, inundações, além de erosão, assoreamentos e proliferação de doenças de veiculação hídrica, dentre outros. Sendo assim, podese dizer que o sistema de drenagem de águas pluviais foi idealizado para funcionar como um mecanismo de controle dos problemas oriundos da impermeabilização do solo no perímetro urbano das cidades.

Para Menezes Filho e Tucci $(2012,50)$, a área impermeável define a repartição entre o volume de escoamento superficial e subterrâneo. Quanto maior o escoamento superficial, maiores são as vazões de cheia da bacia. Uma cidade com grande área impermeável deverá ter um maior volume de escoamento superficial e vazão máxima, o que implica em altos custos em obras de drenagem urbana e potenciais impactos sobre a população e infraestrutura.

\subsection{DELIMITAÇÃO E CARACTERIZAÇÃO DA ÁREA DE ESTUDO}

O Jardim Goiás é um bairro localizado na região sul de Goiânia, Goiás - Brasil, próximo a outros bairros altamente adensados como Setor Leste Universitá- 
rio, Jardim Novo Mundo, Alto da Glória, Setor Sul e Setor Pedro Ludovico. Limita-se a leste pela BR-153, principal rodovia de acesso ao município, e a oeste pelo Córrego Botafogo.

Figura 1. Delimitação e caracterização da área de estudo, bairro Jardim Goiás
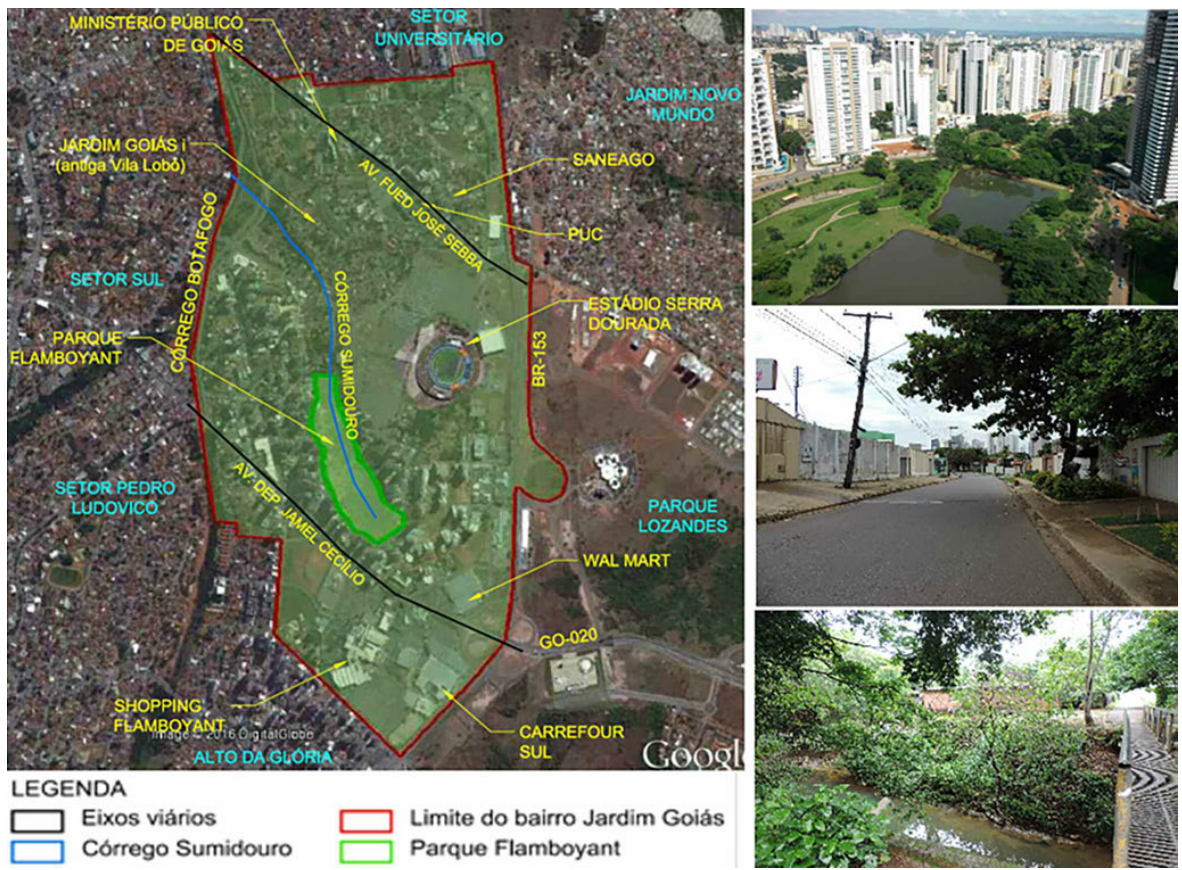

Fonte: Imagem aérea (Google Earth) e fotos

da paisagem diferenciada do bairro (acervo da autora), 2015

A Figura 1 apresenta a delimitação e caracterização da área de estudo, por meio de uma imagem aérea do Jardim Goiás e do seu entorno intensamente urbanizado e de ilustrações da paisagem diferenciada do bairro. Na imagem aérea pode-se observar os equipamentos públicos de grande porte, como o Estádio Serra Dourada e o Shopping Flamboyant, e o Parque Flamboyant, importante parque público destinado a melhoria da qualidade de vida da população, tanto pelo seu aspecto de preservação ambiental, quanto de sociabilidade. No que se refere à drenagem, o Parque Flamboyant apresentase como importante possibilidade de infiltração de águas pluviais, devido ao fato de possuir solos argilo-arenosos. Estes tipos de solos permitem boa infiltração favorecendo a recarga do lençol freático, o qual é responsável pela manutenção da lâmina d'água de seus lagos e do curso do Córrego Sumidouro, cuja nascente localiza-se no perímetro do parque. 
O Jardim Goiás possui formas de ocupação bem diferenciadas que compõem a paisagem do bairro: uma predominantemente residencial, verticalizada, localizada no entorno do Parque Flamboyant e ao longo das principais vias de acesso ao bairro; outra predominantemente residencial, horizontalizada, localizada ao norte do bairro, nas quadras próximas à Avenida Fued José Sebba; um terceiro tipo de ocupação caracterizada pelos grandes equipamentos públicos, urbanos e de serviços, considerados indutores de seu crescimento, como o Estádio Serra Dourada, o Shopping Center Flamboyant, hipermercados e equipamentos institucionais, dentre outros. Por fim, uma ocupação caracterizada pelas invasões da década de 1950, atualmente regularizadas e urbanizadas pelo poder público, mais conhecida por Vila Lobó, mas que após a regularização, recebeu a denominação de Jardim Goiás-Área.

A formação da paisagem urbana do Jardim Goiás começou a se consolidar a partir de 2007, quando da implantação do Parque Flamboyant. A partir de então, o bairro experimentou um crescimento acelerado de sua população e um incremento na verticalização das edificações, além de considerável valorização imobiliária.

\section{PROCESSO DE DENSIFICAÇÃO E VERTICALIZAÇÃO DO JARDIM GOIÁS E OS IMPACTOS NO SISTEMA DE DRENAGEM}

\subsection{O PROCESSO DE URBANIZAÇÃO DO JARDIM GOIÁS}

O projeto urbanístico do Jardim Goiás foi aprovado através do Decreto $n^{\circ} 18$ de 1950. Entretanto, segundo Oliveira (2011), até a década de 1980 o crescimento do setor ocorreu de forma muito lenta, quase imperceptível. O início do aquecimento no mercado imobiliário só ocorreu após a construção do Shopping Flamboyant, inaugurado em 1981, o primeiro do ramo na cidade. O empreendimento causou impacto na economia local, agregando uma série de benfeitorias para o setor, incluindo vias de acesso, transporte público e até determinadas infraestruturas que o local não detinha. Estes altos investimentos e a proximidade a uma importante rodovia de acesso à capital também colaboraram com a chegada dos novos empreendimentos ao local, na mudança na imagem do bairro e incremento à oferta do comércio e dos serviços, potencializando o mercado imobiliário da região. Para Brito et al (2012, 6), estes fatores são considerados indutores do processo de adensamento e de crescimento econômico do Jardim Goiás.

A partir do ano de 2003, conforme figura 2, inicia-se o processo de ocupação do entorno do Parque Flamboyant, com uma ocupação um pouco mais densa ao longo dos eixos viários de acesso, sob a vigência do Plano Diretor de 1992. Este plano é considerado o plano diretor que impulsionou a ocupação e o desenvolvimento do Jardim Goiás ao caracterizar o setor como Polo 
de Desenvolvimento Regional, sendo objeto de ação estratégica, tendo como meta a valorização e o fortalecimento do uso e ocupação do solo.

Figura 2. Processo de ocupação urbana no entorno do Parque Flamboyant, no Jardim Goiás - Ano 2003

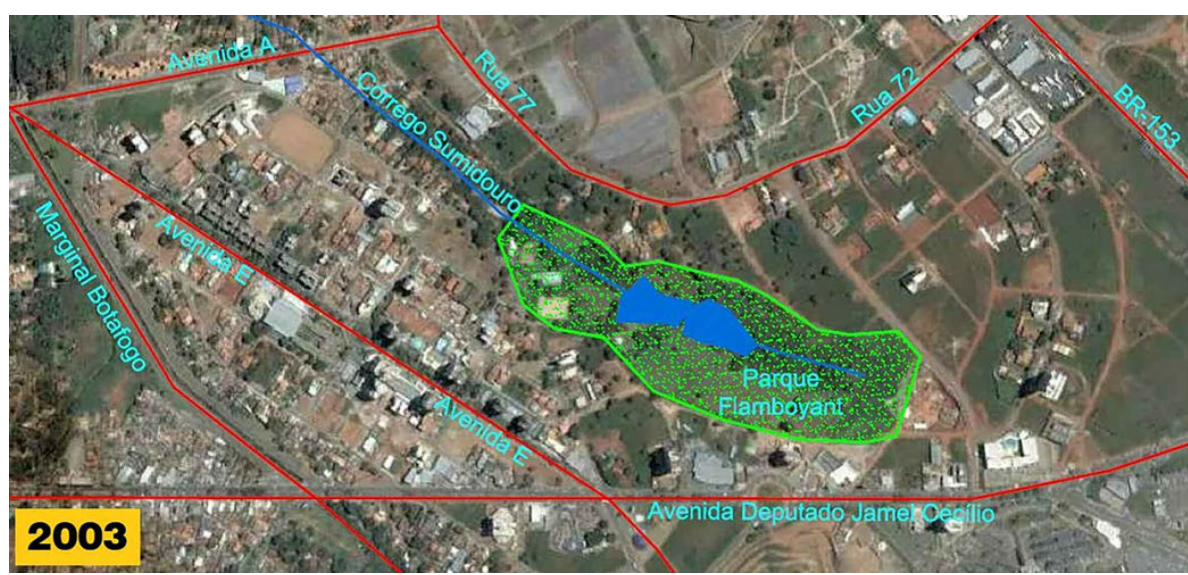

Fonte: Imagem Google Earth, sem escala

Em 2007, o Plano Diretor atual é aprovado. Este plano tenta conter os processos de verticalização e adensamento iniciados nos anos anteriores, inserindo o Jardim Goiás e o Alto da Glória em Área de Desaceleração de Densidade (ADD). De acordo com o Plano Diretor de 2007, todos os empreendimentos construídos em quadras em ADD devem possuir afastamentos frontais, laterais e de fundos maiores, quanto maior for a altura da edificação, sem admissão de excepcionalidade. Além disso, este plano prevê como medida restritiva para ocupação dos lotes, o pagamento de Outorga Onerosa do Direito de Construir, que incide sobre edificações com área construída superior à área da unidade imobiliária (área do terreno) ou altura superior a 6,00 metros.

Entretanto, em 2007, conforme figura 3, observa-se o processo de verticalização um pouco mais representativo no entorno do parque, junto aos eixos viários. Isso se deve ao fato de que neste ano de 2007 ocorre a inauguração do Parque Flamboyant, com ampla infraestrutura de lazer e recreação, induzindo a ocupação da região e agregando valor imobiliário às edificações da região.

O cenário que se apresenta nos próximos anos é um cenário de adensamento e verticalização ainda mais intensos, a despeito dos parâmetros urbanísticos restritivos de densidade previstos no Plano Diretor de 2007 para lotes em ADD. Em 2009, (Figura 4), observa-se a existência de novos canteiros de 
obras, tanto nas quadras lindeiras ao parque, quanto nas quadras localizadas entre o Parque Flamboyant e a Rodovia BR-153, evidenciando que o processo de urbanização continua, agora com início da ocupação das quadras localizadas entre a Rua 77 e o Parque Flamboyant.

Figura 3. Processo de ocupação urbana no Jardim Goiás, no entorno do Parque Flamboyant - Ano 2007

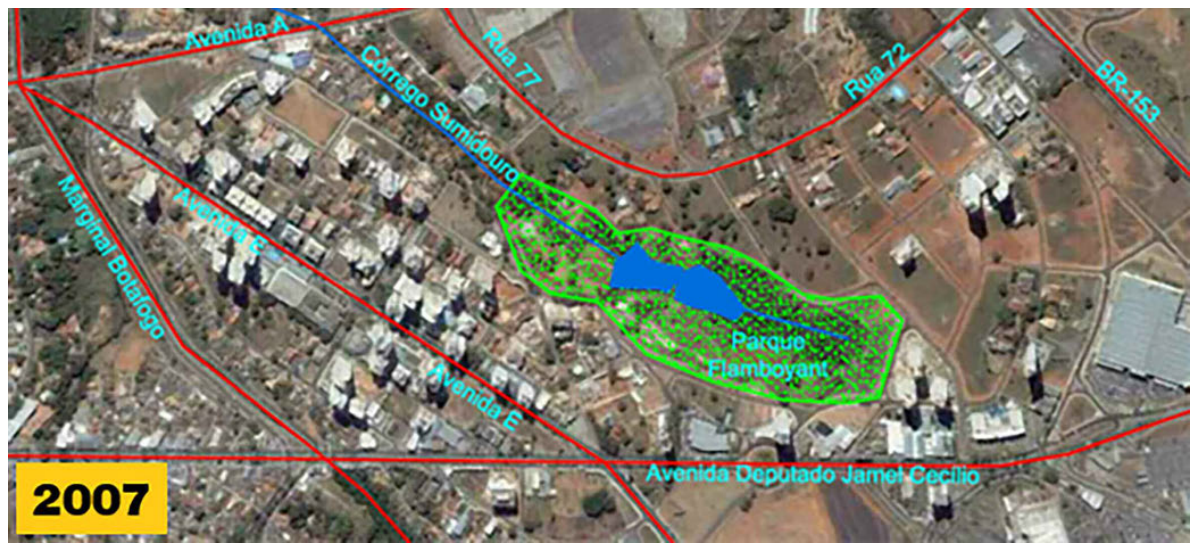

Fonte: Imagem Google Earth, sem escala

Figura 4: Processo de ocupação urbana no Jardim Goiás, no entorno do Parque Flamboyant - Ano 2009

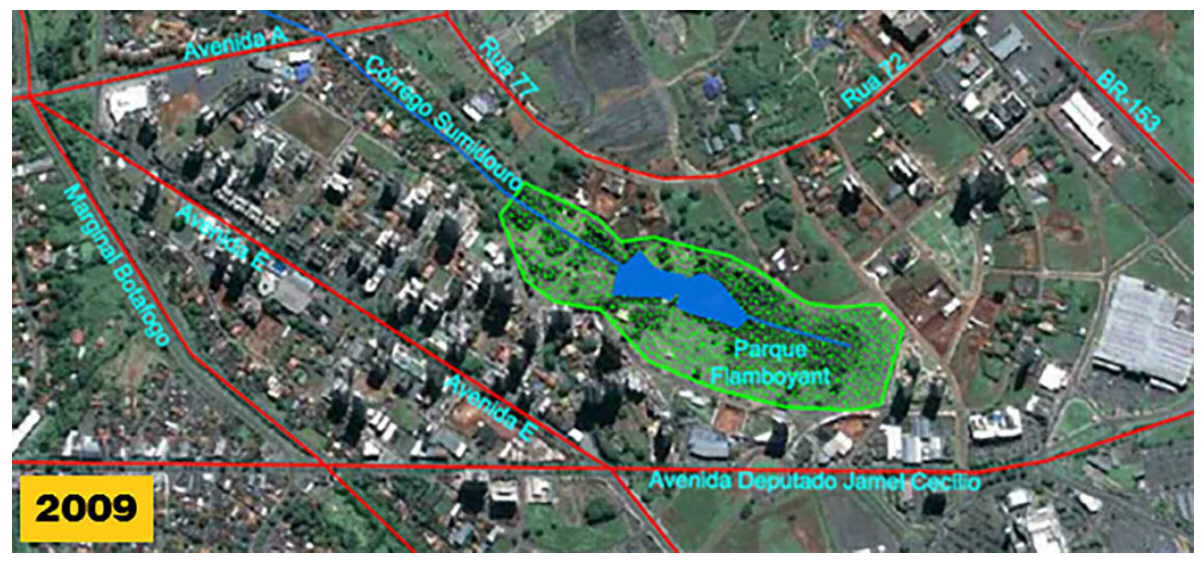

Fonte: Imagem Google Earth, sem escala 
Em 2015, conforme figura 5, o processo de adensamento e verticalização do entorno do Parque Flamboyant apresenta-se totalmente consolidado com poucas quadras vagas. De acordo com observação dos empreendimentos in loco, a maioria dos edifícios são de grande porte, com altura entre sessenta e noventa metros, com cerca de vinte a trinta andares, e pelo menos um nível de subsolo. A malha viária no entorno do parque encontra-se totalmente concluída.

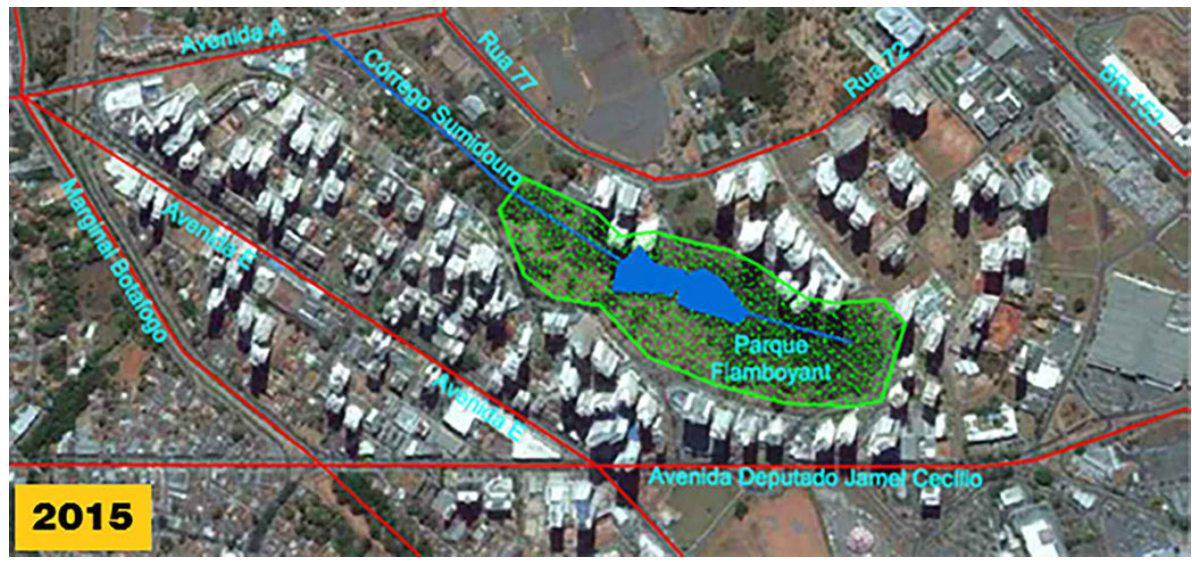

Fonte: Imagem Google Earth, sem escala

Comparando as imagens aéreas apresentadas nas figuras 2, 3, 4 e 5, pode-se deduzir que o crescimento do Jardim Goiás ocorreu principalmente no entorno do Parque Flamboyant impulsionado pela inauguração do mesmo em 2007. As imagens confirmam que mesmo com a aprovação do Plano Diretor atual, que inseriu as quadras do entorno do parque em Áreas de Desaceleração da Densidade (ADD), os novos parâmetros mais restritivos de ocupação não foram capazes de conter o crescimento da região.

No que se refere ao estudo da impermeabilização do solo do Jardim Goiás para os anos analisados, pode-se mensurar o crescimento das áreas impermeáveis por meio de mapas de impermeabilidade do solo elaborados no software QGIS, utilizando-se como base de dados o Mapa Urbano Básico Digital de Goiânia de 2015 e imagens aéreas obtidas no Google Earth. Para elaboração de tais mapas, foi considerado o critério adotado por Sebusiani e Bettine (2011), que define como categoria de impermeabilização baixo, os parques, pastos e áreas cultivadas; o grau médio consiste no uso residencial em lotes com área superior a $1.000 \mathrm{~m}^{2}$ e o grau alto abrange os usos residenciais 
em lotes entre $100 \mathrm{~m}^{2}$ e $1.000 \mathrm{~m}^{2}$, além dos edifícios, indústrias, comércios e rodovias.

A Tabela 1 apresenta o resultado do estudo da impermeabilização do solo para o Jardim Goiás. Este estudo demonstra que o processo de densificação e verticalização, ocorrido no Jardim Goiás, está associado ao aumento de impermeabilidade do solo grau alto. Em um intervalo temporal de 06 (seis) anos (2003 a 2009), o Jardim Goiás teve o seu percentual indicativo de impermeabilização do solo, categoria grau alto, passando de 54\% em 2003 para 56\% em 2009. Entretanto, de 2009 a 2015, este valor saltou de 56\% para $65 \%$, o que comprova a influência dos novos parâmetros urbanísticos e da inauguração do Parque Flamboyant.

Tabela 1. Estudo da impermeabilização do solo do Jardim Goiás

\begin{tabular}{|c|c|c|c|}
\hline $\mathbf{2 0 0 3}$ & BAIXO (\%) & MÉDIO (\%) & ALTO (\%) \\
\hline $\mathbf{2 0 0 7}$ & 28 & 18 & 54 \\
\hline $\mathbf{2 0 0 9}$ & 29 & 17 & 54 \\
\hline $\mathbf{2 0 1 5}$ & 28 & 16 & 56 \\
\hline
\end{tabular}

Fonte: A autora, 2015

No que se refere ao crescimento populacional, foi possível fazer uma análise utilizando-se os anos de 2000 e 2010, pois foram os anos em que o IBGE disponibilizou os dados censitários para o Jardim Goiás. De acordo com o IBGE (2013b), no ano de 2000 o Jardim Goiás possuía uma população residente de 6.711habitantes. No entanto, em 2010 este número saltou para 11.826, o que representa um acréscimo de 76,22\% em 10 anos em sua população residente. Em Goiânia, segundo dados do IBGE (2013a), a população residente em 2000 era 1.090.737 habitantes passando em 2010 para 1.302.001 habitantes, representando um acréscimo de $19.37 \%$ na população. Os dados populacionais do município de Goiânia e do Jardim Goiás indicam que o bairro teve taxa de crescimento populacional bem acima da taxa de crescimento do município. E no que se refere à valorização imobiliária, dados da ADEMI-GO (2012 apud Brito et al, 2012) indicam que em 2008, o valor do metro quadrado do Jardim Goiás em 2008 era $\mathrm{R} \$ 1.974,40$, passando para $\mathrm{R} \$ 4.353,60$ em 2012, representando um aumento de 120,5\% em 04 (quatro) anos.

1 ADEMI-GO - Associação das Empresas do Mercado Imobiliário de Goiás. Relatório mensal do mercado imobiliário de Goiânia, 2005 a 2012. Goiânia: 2012. 


\subsection{OS IMPACTOS DA DENSIFICAÇÃO E DA VERTICALIZAÇÃO NO SISTEMA DE DRENAGEM DO JARDIM GOIÁS}

De acordo com a AMMA (2010, 1), considerando-se o crescimento da cidade de Goiânia e a intensificação do processo de urbanização do espaço geográfico, faz-se necessário o planejamento e execução de obras de drenagem a fim de minimizar as alterações no ciclo hidrológico, quais sejam: aumento da vazão de escoamento superficial; diminuição da capacidade de infiltração das águas pluviais e, consequentemente, da recarga do lençol freático; surgimento ou potencialização de processos erosivos; aumento do carreamento de sedimentos e de outros poluentes.

A AMMA $(2010,2)$ destaca que, as quadras lindeiras ao Parque Flamboyant estão localizadas na área caracterizada geomorfologicamente como Fundo de Vale, onde o nível de lençol freático aproxima-se da superfície, aflorando em depressões no terreno, onde a cota ou o nível de base é mais baixo, que no caso da área em questão refere-se às nascentes do Córrego Sumidouro. Segundo o Parecer Técnico n 66/2010 (AMMA, 2010, 1) observa-se uma impermeabilização excessiva da cabeceira de drenagem do Córrego Sumidouro, ocasionando problemas de drenagem na região.

Outro efeito adverso da impermeabilização no meio urbano é o aumento da vazão de pico a jusante. O Córrego Botafogo recebe contribuição de águas de 03 (três) afluentes localizados em sub-bacias altamente urbanizadas: o Córrego Areião, cujas nascentes encontram-se no Parque Aeirão, no Setor Pedro Ludovico; o Córrego Sumidouro, onde as principais nascentes afloram no Parque Flamboyant, no Jardim Goiás e o Córrego Capim Puba, que nasce no Jardim Botânico, no Setor Oeste da cidade.

A Figura 6 ilustra o aumento da vazão de pico a jusante, com o transbordamento do Córrego Botafogo ocorrido em 2013 e também em 2015, na região do Setor Central e o alagamento do Túnel Jaime Câmara, inaugurado em outubro de 2013, mas que apresenta problemas graves de drenagem. Nestes eventos, a Marginal Botafogo inundou por conta do Córrego Botafogo que transbordou com a chuva intensa que caiu em Goiânia, causando transtornos aos motoristas, além de estragos na marginal. (Jornal O Hoje, 2015).

De uma maneira geral os impactos da urbanização mais perceptíveis na drenagem urbana são os relacionados ao escoamento superficial. A ocorrência de curtos e intensos períodos de chuva tem ocasionado inúmeros transtornos e prejuízos diversos à população. 

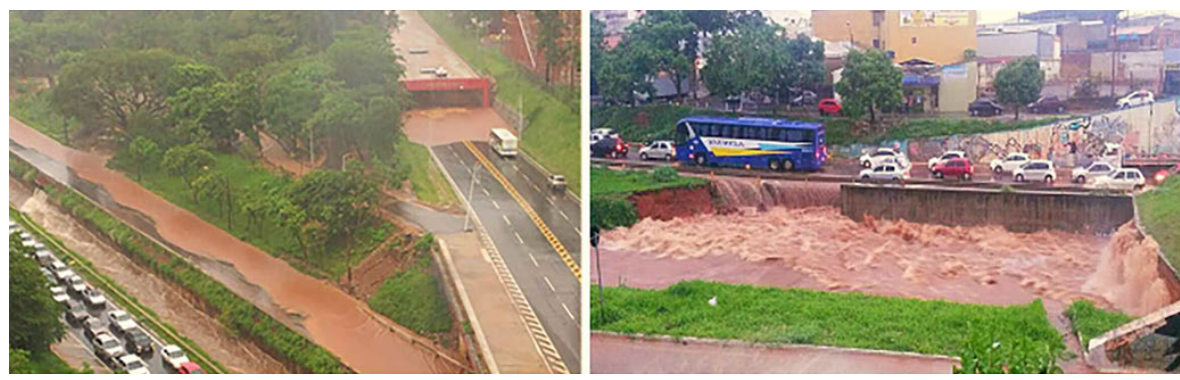

Fonte: Jornal O Hoje, 2015

\section{CONSIDERAÇÕES FINAIS E RECOMENDAÇÕES}

O município de Goiânia é marcado por um intenso incremento populacional, principalmente a partir da década de 1970, causando uma concentração dos espaços urbanos, refletida na verticalização acelerada das regiões central e sul da cidade, onde se localiza o Jardim Goiás, área de estudo deste trabalho. Esta pesquisa permitiu inferir que o próprio poder público promoveu um incremento na densificação e verticalização através dos instrumentos jurídicos, políticos, institucionais e urbanísticos previstos nos planos diretores de desenvolvimento urbano, em especial, no Plano Diretor de 1992. As alterações nos parâmetros urbanísticos referentes ao uso e ocupação do solo por parte da prefeitura, como por exemplo, o aumento do potencial construtivo em determinadas regiões da cidade, promoveram o aumento da impermeabilização de consideráveis parcelas da bacia de drenagem. Desta forma, foram registrados nos últimos anos até os dias de hoje, um aumento no número de ocorrências de alagamentos, inundações e enxurradas em Goiânia, gerando transtornos e prejuízos à população nas margens dos córregos e em vários pontos da malha viária do município.

O bairro Jardim Goiás recebeu importantes incrementos de densificação e de verticalização do Plano Diretor de Goiânia de 1992, que transformou a região em Polo de Desenvolvimento Regional. Esta alteração nos parâmetros urbanísticos do Jardim Goiás, dentre outras, refletiu em intenso adensamento e verticalização, tanto que, com o novo Plano Diretor de Desenvolvimento Urbano aprovado em 2007, o bairro teve novamente seus parâmetros urbanísticos alterados. Dessa vez as quadras do entorno do Parque Flamboyant e as quadras lindeiras aos principais eixos viários do bairro foram inseridas em Área de Desaceleração da Densidade (ADD).

Entretanto, na realidade de mercado imobiliário, o setor continua classificado em segundo lugar na tabela de setores com maior concentração de unidades 
imobiliárias. Conclui-se que os instrumentos urbanísticos, jurídicos e tributários de restrição da densificação adotados no Plano Diretor de 2007 têm sido ineficientes no sentido de conter o adensamento acelerado e a verticalização da região. É notório o fato de que esse processo não está sendo contido, mas pelo contrário, sendo ampliado conforme demonstrado nas imagens aéreas dos anos de 2003, 2007, 2009 e 2015, que demonstram um aumento considerável na impermeabilidade do solo na área de estudo. Cabe destacar que estes anos correspondem ao período onde foram registrados pelo Comando de Operações da Defesa Civil do município, o aumento das ocorrências dos alagamentos, enxurradas e inundações na cidade, sobretudo após o ano de 2009.

A ocupação desordenada do entorno e adjacências do parque geraram comprometimentos em nível ambiental e urbano para o loteamento e para a cidade. O impacto da urbanização mais perceptível na drenagem no Jardim Goiás foi o relacionado à alteração no escoamento superficial gerados pela intensa impermeabilização na região.

No sentido de prevenir e mitigar os efeitos decorrentes da extensiva impermeabilização do solo em Goiânia, as ações da Prefeitura de Goiânia que se destacam se referem ao aparato legal relacionado a drenagem, no período pós-2007. Dentre as leis vigentes, que estabelecem desde índices mínimos de permeabilidade por edificação até a obrigatoriedade de elaboração de um plano diretor de drenagem urbana, destaca-se dentre outras, um projeto de lei que objetiva fomentar ações que promovem o ideário de Cidade Sustentável. Esta lei propõe a concessão de benefícios tributários para os cidadãos que implantarem em sua propriedade medidas de controle do escoamento na fonte, como sistema de captação e reutilização de águas pluviais, calçadas ecológicas, arborização no calçamento público, além de participação em coleta seletiva, construção em material sustentável, instalação de telhado verde, utilização de energia eólica e sistemas de aquecimento solar hidráulico e/ou elétrico.

A redução dos processos de infiltração e o aumento dos volumes e da velocidade do escoamento superficial são os grandes desafios a serem enfrentados não só no Jardim Goiás, mas como em todo o município e até mesmo do mundo, e constituem-se num dos importantes impactos sobre a sociedade, trazendo diversos transtornos de ordem econômica e social, sobretudo em função da dinâmica do crescimento das cidades.

\section{REFERÊNCIAS BIBLIOGRÁFICAS}

AMMA, Agência Municipal do Meio Ambiente de Goiânia (2010). Parecer Técnico 066/2010 (Parque Flamboyant - Rebaixamento de Lençol Freático). Goiânia, Goiás. 
Brasil. (2007). Lei n 11.445 de 05 janeiro 2007. Estabelece diretrizes nacionais para o saneamento básico. Disponível em:

http://www.planalto.gov.br/ccivil_03/_ato2007-2010/2007/lei/111445.htm. Acesso em: 24 set2018.

Brito, L. S., Magalhães, V. R. e Brandstetter, M. C. G. O.(2012). Análise do Bairro Jardim Goiás: Variáveis do mercado imobiliário goianiense. $12^{a}$ Conferência Internacional da LARES, Centro Brasileiro Britânico, São Paulo.

Defesa Civil Do Município De Goiânia (2014). Balanço Anual de Ocorrências 2010-2014. Goiânia.

Graeff, E. A. (1983). Goiânia: 50 anos. Goiânia: Ed. da UCG.

IBGE, Instituto Brasileiro De Geografia e Estatística (2013a). Sinopse do Censo Demográfico 2010. Rio de Janeiro. Disponível em:

https://www.censo2010.ibge.gov.br/sinopse/index.php?dados=8. Acesso em 16nov2019.

IBGE, Instituto Brasileiro De Geografia e Estatística (2013b). Censo Demográfico e Cotagem da População 2010. Rio de Janeiro. Disponível em:

https://www.sidra.ibge.gov.br/bda/tabela/protabl.asp?c=1552\&z=cd\&o=7\&=P. Acesso em 16out2018.

Jornal O Hoje. (2015). Seinfra promete reparar Marginal Botafogo em até 72 horas. Disponível em:

http://ohoje.com/jornal/ler/noticia/27169/titulo/seinfra-promete-repararmarginal-botafogo-em-ate-72-horas. Acesso em 30 nov 2015.

Maricato, E. (2002). Brasil, cidades: alternativas para a crise urbana. Petrópolis: Ed. Vozes.

Menezes Filho, F. C. M. de e Tucci, C. E. M. (2012). Alteração na relação entre a densidade habitacional x área impermeável: Porto Alegre-RS. REGA, Vol. 9, n. 1, 49-55, jan./jun. 2012.

Ministério Da Integração Nacional. Secretaria Nacional de Defesa Civil. (2012). Anuário Brasileiro de Desastres Naturais: 2011. Brasília. Disponível em: http://www.integracao.gov.br/c/document_library/get_file?uuid=e3cab906c3fb-49fa-945d-649626acf790\&groupld=185960. Acesso em 24jan2015.

Ministério Das Cidades / IPT - Instituto de Pesquisas Tecnológicas. (2007). Mapeamento de riscos em encostas e margens de rios. Brasília: MC/IPT.

Ministério Das Cidades / SNSA - Secretaria Nacional de Saneamento Ambiental (2012). Manual para apresentação de propostas para drenagem urbana sustentável e de manejo de águas pluviais. Brasília: Ministério das Cidades/SNSA.

Oliveira, M. A. (2011). Parque Flamboyant: Transformação da paisagem urbana em Goiânia-Goiás. Dissertação (Mestrado em Ecologia e Produção Sustentável) - Universidade Católica de Goiás - Goiânia.

ONU-BR - Nações Unidas No Brasil (2013). ONU: mais de 70\% da população mundial viverá em cidades. Disponível em:

http://nacoesunidas.org/onu-mais-de-70-da-populacao-mundial-vivera- 
em-cidades-ate-2050/. Acesso em 240ut2019.

Sebusiani, H. R. V. e Bettine, S. C. (2011). Metodologia de análise do uso e ocupação do solo em micro bacia urbana. Revista Brasileira de Gestão e Desenvolvimento Regional, v. 7, n. 1, 256- 285.

Villanueva, A. O. N., Tassi, R., Allasia, D. G., Bemfica, D. e Tucci, C. E. M. (2011). Gestão de drenagem urbana, da formulação à implementação. REGA, Vol. $8, n^{\circ} .1,5-18$, jan/jun 2011. 



\title{
PROPUESTA METODOLÓGICA PARA EL ESTUDIO DE LA JUSTICIA ESPACIAL EN RELACIÓN CON LOS PARQUES URBANOS. UN CASO APLICADO A TARRAGONA ${ }^{1}$
}

\section{METHODOLOGICAL PROPOSAL FOR THE STUDY OF SPACE JUSTICE IN RELATION TO URBAN PARKS. A CASE APPLIED TO TARRAGONA}

\author{
Joan Alberich González \\ Universitat Rovira i Virgili \\ María Yolanda Pérez Albert \\ Universitat Rovira i Virgili \\ Adrià Balart Casas \\ Universitat Rovira i Virgili \\ José Ignacio Muro Morales \\ Universitat Rovira i Virgili
}

Resumen

Un enfoque habitual de la justicia espacial en relación a los parques urbanos se refiere a la valoración de la distribución de los espacios verdes y la medición de la accesibilidad o la relación entre proximidad y cantidad de espacios verdes y las características sociodemográficas de los residentes. El presente trabajo pretende presentar y aplicar una metodología para medir la justicia espacial en Tarragona a partir del análisis de la calidad de los parques en relación con las características sociodemográficas y económicas de la población más cercana a éstos (300 metros). Así, se ha diseñado un modelo de evaluación multicriterio (EMC) que valora los elementos de vegetación, equipamientos y mobiliario de cada parque (número, distribución...). En relación con la población, han sido seleccionados el nivel de estudios y su origen y, con la intención de medir su nivel económico, el precio medio de venta y alquiler de la vivienda. Finalmente, la correlación entre estas informaciones permite valorar la existencia o no de justicia espacial. Los resultados obtenidos validan la metodología propuesta obteniendo un modelo de EMC que, correlacionado con una selección de variables sociodemográficas, ofrece información sobre la justicia espacial.

Palabras clave: justicia espacial, parques urbanos, sistemas de información geográfica, Tarragona.

1 Este trabajo se enmarca en el proyecto de investigación «El paisaje como valor colectivo. Análisis de su significado, usos y percepción social» (CHORA), financiado por el Ministerio de Ciencia, Innovación y Universidades (Programa Estatal de Fomento de la Investigación Científica y Técnica de Excelencia, Subprograma Estatal de Generación del Conocimiento. 2018-2020. CSO2017-82411-P), AEI/FEDER, UE y el Departament de Recerca i Universitats de la Generalitat de Catalunya (2017SGR22). 


\section{Abstract}

A common approach to spatial justice in relation to urban parks refers to the assessment of the distribution of green spaces and the measurement of accessibility or the relationship between proximity and quantity of green spaces and the sociodemographic characteristics of residents. This work aims to present and apply a methodology to measure spatial justice in Tarragona based on the analysis of the quality of the parks in relation to the sociodemographic and economic characteristics of the population closest to them (300 meters). Thus, a multi-criteria evaluation model (MCE) has been designed that assesses the elements of vegetation, equipment and furniture of each park (number, distribution...). In relation to the population, the level of studies and their origin have been selected and, with the intention of measuring their economic level, the average sale and rental price of the home. Finally, the correlation between this information allows us to assess the existence or not of spatial justice. The results obtained validate the proposed methodology, obtaining an EMC model that, correlated with a selection of sociodemographic variables, offers information on spatial justice.

Keywords: spatial justice, urban parks, geographic information systems, Tarragona

\section{A MODO DE INTRODUCCIÓN. UN BREVE ESTADO DE LA CUESTIÓN SOBRE LA JUSTICIA ESPACIAL}

El concepto de justicia ambiental aparece en el último tercio del siglo XX en el marco de «la valoración de la distribución de los beneficios y perjuicios generados por agentes humanos entre lugares y grupos de población, con el fin de determinar si existe discriminación seria o no» (Moreno, 2009), y ello especialmente en un contexto donde se estaba tomando una consciencia creciente de que la distribución espacial de algunas actividades humanas (como, por ejemplo, la generación, tratamiento y almacenamientos de residuos peligrosos o la distribución territorial de ciertas industrias contaminantes) era claramente discriminatoria para una parte de la población.

Este concepto implica, en consecuencia, asumir que «hay un derecho universal a la naturaleza» a todas las escalas (individual, familiar, comunitaria...), entendiendo el medio ambiente como un bien común (Flipo, 2002). Así, la base del concepto es la no discriminación de los beneficios y perjuicios ambientales y la necesidad de establecer mecanismos participativos de decisión «que puedan viabilizar un reparto equitativo de aquéllos entre una comunidad de justicia compuesta por entes (sujetos y objetos) localizados, actuales y futuros, los cuales pueden ostentar derechos y obligaciones desiguales» (Moreno, 2009). 
Desde este punto de vista, la medida de la justicia o la discriminación ambiental puede hacerse, en términos generales, a partir del cálculo del cómputo global (social, territorial y temporal) de los costes y beneficios ambientales (lo que a menudo se denomina en términos económicos como «externalidades») ocasionados por una determinada actividad o proyecto, para poder luego dilucidar si el reparto de los mismos es justo o no entre los distintos colectivos que, de un modo u otro, pueden verse afectados por dicha actuación. Sin embargo, otros autores defienden incorporar elementos no sólo económicos en el análisis y optar por el uso de indicadores y variables de distinto nivel de medida a partir de la aplicación del análisis multicriterio (Martínez-Alier, 1999, 2000).

En el caso de la justicia espacial en relación con las áreas verdes urbanas, la mayoría de los enfoques se han centrado, por un lado, en evaluar la distribución de espacios verdes en la ciudad y su accesibilidad (La Rosa, 2014; Silva et al., 2018), mediante el cálculo de la distancia entre el lugar de residencia y el área verde más cercana utilizando un sistema de información geográfica (Xiao et al., 2017) o bien a través de la incorporación de elementos relativos a la densidad de población (de Sousa Silva et al., 2018). Por el otro, en examinar la relación entre la proximidad y el número de espacios verdes y la caracterización socioeconómica de los habitantes (Almohamad et al., 2018; Shen et al., 2017; Tu et al., 2018; Xiao et al., 2017), a los que a veces se agrega composición étnica (Rigolon et al., 2018). En algunas ocasiones, a estas características se añade la composición étnica de un grupo de población concreto, debido a su vulnerabilidad, como los jóvenes (Rigolon, 2017) o los migrantes (Kabisch y Haase, 2014).

La mayoría de los trabajos que analizan la justicia espacial de parques o áreas verdes se basan en la adopción de una perspectiva cuantitativa, y son relativamente escasos los planteamientos cualitativos. De la misma forma, la mayoría de los estudios valoran algún aspecto concreto de los parques. Entre otros, su distribución territorial o la dotación de equipamientos. Estos análisis no tienen una visión amplia de las diferentes aproximaciones al problema.

Además de explicitar el contexto sobre la justicia ambiental y espacial, este trabajo contextualiza el área de estudio, explicita la metodología utilizada, con los diferentes métodos y herramientas de análisis empleadas, reseña la construcción de los indicadores de valoración de la calidad de los parques urbanos, selecciona los indicadores propios de la caracterización socioeconómica empleados y la construcción del modelo de evaluación multicriterio y presenta los resultados de la justicia espacial de los parques urbanos de la ciudad de Tarragona. 


\section{OBJETIVOS Y ÁREA DE ESTUDIO}

El objetivo principal de la investigación es desarrollar una metodología para la evaluación de la justicia ambiental en relación a las características sociodemográficas de la población y la proximidad, disponibilidad y calidad de los parques urbanos. Se trata de una cuestión hasta cierto punto poco desarrollada en nuestro país, por lo que, como objetivo secundario e instrumental, se ha optado por aplicar el modelo diseñado a la ciudad de Tarragona, para, por un lado, validar su utilidad y, por el otro, configurar así un caso de estudio que puede ser desarrollado en otras áreas urbanas.

La ciudad de Tarragona forma parte de un área urbana de cerca de 380.000 habitantes, con 16 municipios y algo más de 350 kilómetros cuadrados de superficie. En el año 2016 (fecha que tomamos como referencia para nuestro estudio) contaba con una población de 135.304 habitantes, que, distribuidos en los 57,88 kilómetros cuadrados del término municipal, dan lugar a una densidad de $2.337 \mathrm{hab} . / \mathrm{km}^{2}$. Sin embargo, se trata de un valor medio que no refleja las desigualdades internas, pues la ciudad presenta una clara configuración en forma de «mancha de aceite», con un centro urbano consolidado y densamente poblado y una periferia muy polarizada (Saladié et al., 2012). Así, mientras en la llamada zona de Poniente, al sur del río Francolí, predominan los barrios obreros (Bonavista, Torreforta, Campclar...), surgidos durante las oleadas migratorias de la segunda mitad del siglo XX, en la zona de Levante abundan las urbanizaciones privadas de baja densidad a lo largo de la costa (Cala Romana, Monnars, la Móra-Tamarit). En los últimos años, dichas urbanizaciones están más conectadas con el centro urbano gracias a la expansión de un nuevo ensanche, de clase media-alta, en la zona de la Vall de l'Arrabassada, zona de máximo crecimiento urbano actual.

La ciudad de Tarragona cuenta con 15 parques urbanos, distribuidos a lo largo del término municipal, excepto en la zona de las urbanizaciones de levante, donde muy probablemente el área de verde privado suple la función de los equipamientos públicos (Figura 1). Estos equipamientos públicos responden a tipologías muy variadas, desde plazas urbanas ajardinadas, como el parque de Sant Antoni, de poco más de $1.200 \mathrm{~m}^{2}$ o 0,12 hectáreas, hasta extensas zonas de vegetación natural, como el parque fluvial del río Francolí, de 13,7 hectáreas. 
Figura 1. Trama urbana y localización de los parques urbanos de Tarragona

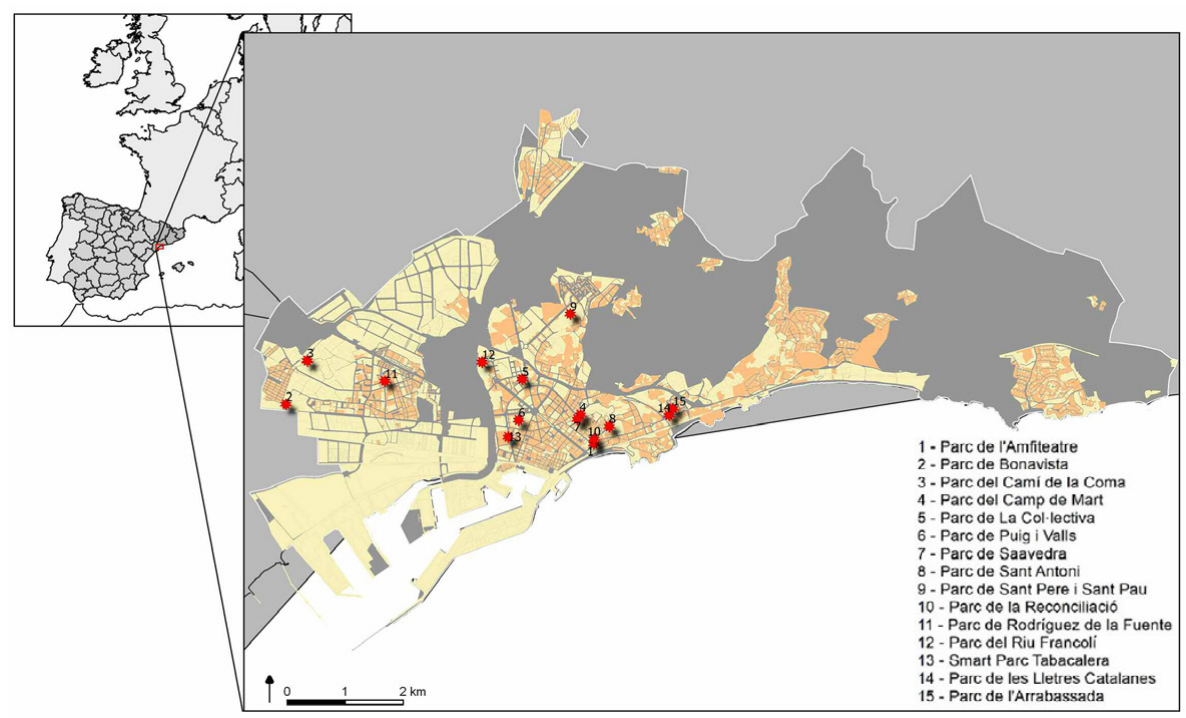

Fuente: Elaboración propia

\section{METODOLOGÍA GENERAL}

En este trabajo hemos empleado diferentes métodos y herramientas de análisis. Por un lado, se ha desarrollado un Sistema de Información Geográfica que ha permitido (1) la digitalización de los elementos presentes en los parques y sus límites; (2) la geolocalización de los datos del padrón municipal de Tarragona; (3) la selección de la población objetivo, es decir, aquella que reside a 300 metros o menos del centroide del polígono de cada uno de los parques; (4) la obtención de parte de la información necesaria para elaborar los factores mediante operaciones de análisis espacial. Por otro lado, se ha efectuado trabajo de campo visitando todos los parques incluidos en el estudio entre primavera-verano de 2018. El objetivo de estas visitas ha sido (5) la obtención de información directa para elaborar los indicadores de calidad de los parques; (6) la comprobación de la cartografía realizada mediante digitalización y (7) la realización de fotografías para la caracterización de los espacios. Finalmente, (8) se ha realizado un análisis estadístico de la muestra extraída de la selección del padrón de los residentes a una distancia igual o menor de 300 metros del centro del parque con la intención de caracterizar desde el punto de vista sociodemográfico la población usuaria del mencionado espacio. Con el conjunto de indicadores, tanto directos como indirectos, que caracterizan la calidad de los parques urbanos, hemos diseñado un (9) 
Modelo de Evaluación Multicriterio jerárquico y ponderado que ha permitido obtener el Índice de Calidad de los Parques (ICP). Finalmente, (10) dicho índice se ha correlacionado con los las características demográficas y socioeconómicas de la población objetivo.

\section{INDICADORES DE VALORACIÓN DE LA CALIDAD DE LOS PARQUES}

Para la selección de los indicadores se ha tomado como referencia y se ha reinterpretado el trabajo de Rivera (2014) sobre los parques urbanos como indicadores de calidad de vida en Bucaramanga (Colombia) que, a su vez, es una adaptación del estudio llevado a cabo por Canosa, Sáez, Sanabria y Zavala (2003) en Madrid.

Para cada uno de los parques se ha generado una base de datos espacial y temática que recogía aspectos tales como la ubicación de árboles, la superficie ocupada por la vegetación, la que correspondía a la sombra verde en la vertical, los espacios destinados a equipamientos como zonas de recreo infantil o de «pipican». Esta información se ha digitalizado a partir del Mapa Topográfico 1:5.000 y ortofotografía a la misma escala y se utiliza para construir alguno de los indicadores como, por ejemplo, el de superficie de sombra verde que mide el porcentaje de superficie ocupada por la sombra verde respecto al total de superficie del parque. En la Figura 2 se puede observar el ejemplo de una de estas bases de datos.

Figura 2. Ejemplo de base de datos cartográfica del parque de Puig i Valls

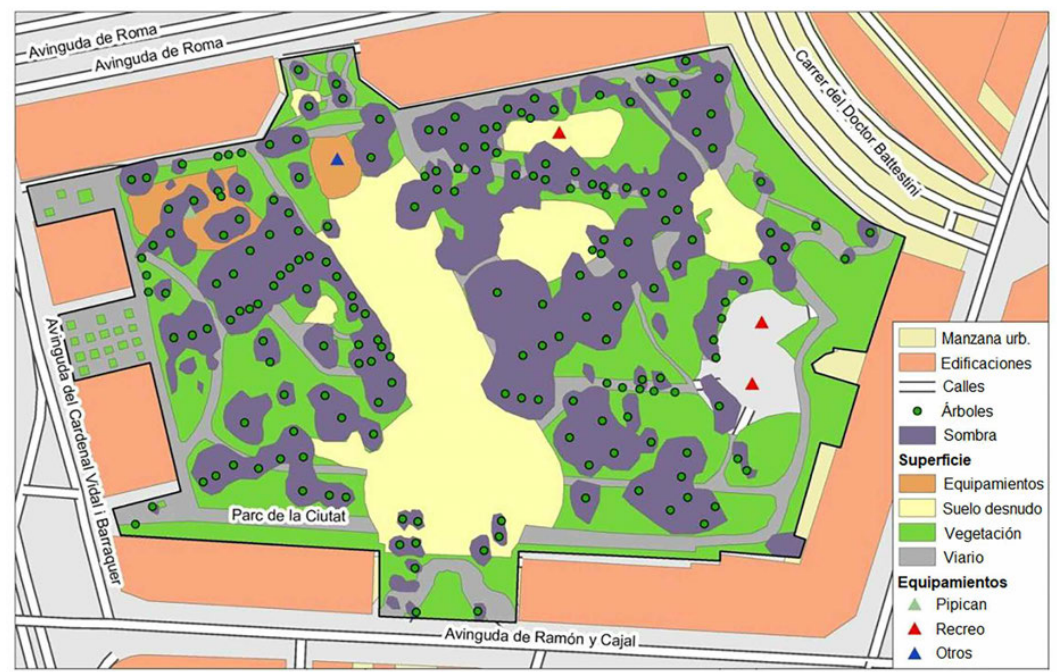

Fuente: Elaboración propia. 2019 
El trabajo de campo se realizó durante la primavera-verano de 2018 y la visita a los parques analizados permitió, por un lado, completar y revisar la bondad de la información elaborada a partir de la digitalización del SIG y, por otro, obtener información de tipo cualitativo, sobre todo la que hace referencia al estado de conservación, de funcionamiento o de limpieza del mobiliario o equipamiento presente en los parques.

Los factores analizados son los siguientes:

- Presencia de vegetación: entendida como el porcentaje de superficie arbolada, arbustiva o herbácea respecto al total de superficie del parque sin tener en cuenta la sombra que proporcionan.

- Sombra verde: calculada como el porcentaje de superficie con sombra a medio día en relación al total de superficie del parque.

- Presencia de vegetación peligrosa o alérgena: durante el trabajo de campo se contabilizó el número de especies vegetales presentes que cumplían con este criterio.

- Viales: el objetivo de este factor es analizar la existencia, adecuación y calidad de los caminos y/o senderos presentes en cada parque para la movilidad de las personas.

- Barreras arquitectónicas: se analiza la presencia de elementos que dificultan o impiden el acceso, así como si se han implantado medidas para superarlos.

- Equipamientos deportivos: se contabiliza la existencia de equipamientos deportivos en el parque como la presencia de espacios para jugar al fútbol con porterías o con canastas para practicar el baloncesto.

- Parques para personas mayores: también se denominan gimnasio para mayores y suelen estar dentro de itinerarios biosaludables que permiten a las personas de la tercera edad disfrutar del aire libre mientras realizan ejercicio físico. En este caso se ha tenido en cuenta la existencia o no de este equipamiento y su estado.

- Vallados de separación de equipamientos deportivos: permiten la delimitación de las zonas deportivas con el objetivo de evitar situaciones de peligro para el resto de usuarios del parque.

- Otros equipamientos deportivos: en este factor se han agrupado el resto de equipamiento deportivo considerados de uso minoritario como las pistas de hockey o de voleibol. Se considera que a mayor diversidad de equipamientos mayor calidad del parque.

- Instalaciones para actividades culturales en espacios abiertos: se valora la existencia de zonas en los parques, de carácter abierto y sin cubiertas, destinadas a acoger eventos y actividades culturales como, por ejemplo, anfiteatros o graderías.

- Instalaciones para actividades culturales en espacios cerrados: se tiene en cuenta la existencia de instalaciones dedicadas a eventos o actividades culturales de carácter cerrado, es decir, con cubierta y cerramiento que evite las inclemencias del tiempo. 
- Otras instalaciones: recoge aquellas instalaciones que no se agrupan en equipamientos deportivos o culturales como, por ejemplo, quioscos o presencia de paradas de venta semipermanentes o estacionales.

- Iluminación: la presencia de una iluminación con una potencia y distribución adecuada hace que un parque sea percibido como un espacio seguro por este motivo se ha valorado la presencia y calidad de la iluminación de los parques.

- Bancos: la presencia de bancos distribuidos de forma adecuada y en buen estado permiten el descanso de los usuarios, el disfrute y contemplación de la naturaleza o del juego de los niños y la socialización con otros usuarios del parque.

- Otro mobiliario: agrupa a elementos como las fuentes de agua potable, los estanques o esculturas o monumentos que con su presencia y buen estado de mantenimiento aportan calidad a los parques urbanos.

- Juegos infantiles: se valora a partir de la agrupación de los diferentes columpios, toboganes, balancines, etc. y no como elementos individuales o independientes. Se tiene en cuenta que el número y el estado sean adecuados en cada uno de los parques.

- Juegos para adultos: presencia y estado de espacios y mobiliario para el juego de adultos como pueden ser las pistas de petanca o zonas habilitadas para juegos de mesa.

- Papeleras: este factor mide la presencia y estado de las papeleras puesto que facilitan la limpieza del parque y de sus equipamientos.

- «Pipicanes»: presencia y estado de espacios destinados a la realización de las necesidades de los perros, principal animal de compañía de los habitantes de las ciudades españolas y acompañante habitual de una parte de los usuarios de los parques. Estas zonas permiten realizar tratamientos sanitarios específicos para evitar la transmisión de enfermedades infecciosas. En algunos casos estas instalaciones están acompañadas de áreas de juego para los animales lo que evita posibles conflictos con otros usuarios.

- Lavabos: se analiza la presencia de lavabos como un elemento que facilita la estancia y el uso de los parques. Para su valoración, además de su existencia se tiene en cuenta su estado de conservación, funcionamiento y limpieza.

Cada uno de estos factores ha sido valorado en una escala del 0 al 3 donde de forma estandarizada el valor de 0 corresponde a la situación de menor calidad del parque mientras que el valor 3 hace referencia a la situación de mayor calidad del mismo. En la Tabla 1 se recogen algunos ejemplos de los descriptores utilizados para cada uno de los factores que pueden ser de tipo cuantitativo o combinado, es decir, que tienen en cuenta tanto el número de elementos presentes en el parque como su estado y adecuación a la función que desempeñan. 
Tabla 1. Descriptores y escala de valoración de cada uno de los indicadores

\begin{tabular}{|c|c|c|c|c|}
\hline \multirow{2}{*}{ Factor } & \multicolumn{4}{|c|}{ Valoración } \\
\hline & 0 & 1 & 2 & 3 \\
\hline $\begin{array}{r}\text { Presencia } \\
\text { de } \\
\text { vegetación }\end{array}$ & $\begin{array}{c}\text { No existe } \\
\text { vegetación }\end{array}$ & $\begin{array}{l}<25 \% \text { de } \\
\text { superficie con } \\
\text { vegetación }\end{array}$ & $\begin{array}{l}25 \%-50 \% \text { de } \\
\text { superficie con } \\
\text { vegetación }\end{array}$ & $\begin{array}{c}>50 \% \text { de } \\
\text { superficie con } \\
\text { vegetación }\end{array}$ \\
\hline $\begin{array}{r}\text { Sombra } \\
\text { verde }\end{array}$ & $\begin{array}{l}\text { No existe } \\
\text { sombra o es } \\
<25 \% \text { de la } \\
\text { superficie }\end{array}$ & $\begin{array}{c}\text { Entre el } 25 \% \text { y el } \\
50 \% \text { de superficie } \\
\text { cubierta de } \\
\text { manera poco } \\
\text { compacta }\end{array}$ & $\begin{array}{c}\text { Entre el } 25 \% \text { y el } \\
50 \% \text { de superficie } \\
\text { cubierta de } \\
\text { manera } \\
\text { compacta }\end{array}$ & $\begin{array}{l}\text { Cubre más del } \\
\text { 50\% de superficie }\end{array}$ \\
\hline Iluminación & $\begin{array}{l}\text { No hay } \\
\text { iluminación }\end{array}$ & $\begin{array}{l}\text { No hay una } \\
\text { buena } \\
\text { distribución y } \\
\text { predominan } \\
\text { zonas oscuras }\end{array}$ & $\begin{array}{c}\text { No hay una } \\
\text { buena } \\
\text { distribución y hay } \\
\text { alguna zona } \\
\text { oscura }\end{array}$ & $\begin{array}{c}\text { Hay una } \\
\text { distribución } \\
\text { adecuada, sin } \\
\text { zonas oscuras }\end{array}$ \\
\hline Papeleras & No existen & $\begin{array}{l}\text { Su número es } \\
\text { insuficiente y su } \\
\text { distribución } \\
\text { inadecuada }\end{array}$ & $\begin{array}{c}\text { Su número y } \\
\text { distribución es } \\
\text { aceptable }\end{array}$ & $\begin{array}{c}\text { Su número y } \\
\text { distribución es } \\
\text { óptima }\end{array}$ \\
\hline
\end{tabular}

Fuente: Elaboración propia

\section{INDICADORES PARA LA CARACTERIZACIÓN DEMOGRÁFICA Y SOCIOECONÓMICA DE LA POBLACIÓN}

Con el fin de caracterizar la población de la ciudad de Tarragona se han utilizado, por un lado, los datos del padrón municipal de habitantes y, por el otro, estadísticas del precio de la vivienda extraídas de un portal inmobiliario. Se ha optado por utilizar el padrón municipal de habitantes puesto que, al almacenar la dirección postal de los residentes, se han geolocalizados los registros a partir de dicha dirección construyendo una capa cartográfica. Posteriormente, se han seleccionado aquellos habitantes que residen a menos de 300 metros de distancia real de un parque.

\subsection{EL PADRÓN MUNICIPAL DE HABITANTES}

El padrón municipal de habitantes es un registro administrativo gestionado por cada uno de los municipios existentes en el Estado español y que, bajo la coordinación del Instituto Nacional de Estadística (INE) recoge información 
básica sobre la población residente: lugar y fecha de nacimiento, sexo, edad, nacionalidad, nivel de estudios y dirección actual de residencia. Desde 1996 se hace un tratamiento «continuo» de la información, de manera que se halla actualizado con la información más reciente facilitada por el ciudadano, por lo que es posible realizar la consulta de sus datos para cualquier momento temporal. En el caso de nuestro estudio, la información se refiere al mes de enero de 2016.

Tal como se ha indicado, la población objeto de nuestro estudio es la que vive a menos de 300 metros de un parque urbano, por lo que la digitalización de las direcciones, por un lado, y del perímetro de cada parque, por el otro, ha permitido, en primer lugar, discriminar la población según la distancia a cada zona verde, y, en segundo lugar, asignar a cada individuo el parque más cercano a su lugar de residencia.

De las variables recogidas en el padrón para la caracterización demográfica de la población, se han utilizado dos: el nivel de estudios y la nacionalidad, información que ha requerido de un tratamiento específico en ambos casos. En primer lugar, el nivel de estudios recogido en el padrón hace referencia únicamente a la población de 16 años y más y ha sido agrupada en cinco categorías: «población analfabeta» (no sabe leer ni escribir), «población sin estudios» (personas que saben leer y escribir, pero con menos de cinco años de escolarización), «Población con estudios de primer grado» (personas que no han alcanzado el último curso de ESO, EGB o del bachillerato elemental); «población con estudios de segundo grado» y «población con estudios universitarios».

Con el fin de permitir la comparabilidad entre las diferentes unidades territoriales analizadas, y no tener que analizar así uno por uno los porcentajes de población con cada uno de los cinco niveles formativos, se ha optado para crear un índice sintético de formación (ISF), a partir de la ponderación del peso de la población con cada nivel formativo, según la fórmula siguiente:

$(\%$ analfabetos $\times 7)+(\%$ sin estudios $\times 2)+(\%$ primer grado $\times 3)+(\%$ segundo grado $\times 4)+(\%$ universitarios $\times 5)$ 5

Se obtiene, así, un índice que toma valores comprendidos entre 0 y 1 , donde O equivaldría a la totalidad de la población analfabeta y 1 al extremo opuesto, con la totalidad de población con un nivel de estudios universitarios. Igualmente, hay que tener en cuenta que el nivel de estudios de la población está muy influenciado por la estructura por edades de la población, ya que una población más envejecida tiende a presentar unos niveles formativos más bajos que una más joven, en cuanto que la formación de primer grado entre las generaciones recientes no tan sólo es un hecho universalizado, sino que buena parte de esta población sigue cursando estudios de tipos postobligatorios. Así, para contrarrestar el posible efecto de las diferentes estruc- 
turas por edad de los vecindarios analizados, se ha procedido a realizar un ejercicio de estandarización directa a partir de aplicar una estructura de población tipo (en este caso, se ha optado para utilizar la del conjunto de la ciudad de Tarragona) a los catorce vecindarios analizados (Tabla 2).

Tabla 2. Población según el nivel de estudios y la proximidad a un parque urbano. Tarragona, 2016

\begin{tabular}{|c|c|c|c|c|c|c|c|c|}
\hline $\begin{array}{c}\text { Distancia } \\
\text { al parque } \\
\text { urbano } \\
\text { más } \\
\text { cercano }\end{array}$ & $\begin{array}{c}\text { Pobla- } \\
\text { ción } \\
\text { total }\end{array}$ & $\begin{array}{c}\text { Población } \\
\mathbf{1 6} \text { años o + } \\
\text { y estudios } \\
\text { conocidos }\end{array}$ & $\begin{array}{c}\text { Analfa- } \\
\text { betos }\end{array}$ & $\begin{array}{c}\text { Sin } \\
\text { estudios }\end{array}$ & $\begin{array}{c}\text { Primer } \\
\text { grado }\end{array}$ & $\begin{array}{c}\text { Segundo } \\
\text { grado }\end{array}$ & $\begin{array}{c}\text { Tercer } \\
\text { grado }\end{array}$ & ISF \\
\hline$<300 \mathrm{~m}$. & 40.844 & 33.853 & $1,5 \%$ & $5,5 \%$ & $10,9 \%$ & $62,9 \%$ & $19,2 \%$ & 0,785 \\
\hline$\geq 300 \mathrm{~m}$. & 94.460 & 78.184 & $1,7 \%$ & $6,0 \%$ & $12,1 \%$ & $62,9 \%$ & $17,3 \%$ & 0,776 \\
\hline $\begin{array}{c}\text { Total } \\
\text { ciudad }\end{array}$ & $\mathbf{1 3 5 . 3 0 4}$ & $\mathbf{1 1 2 . 0 3 7}$ & $\mathbf{1 , 6 \%}$ & $\mathbf{5 , 8} \%$ & $\mathbf{1 1 , 7 \%}$ & $\mathbf{6 2 , 9 \%}$ & $\mathbf{1 7 , 9 \%}$ & $\mathbf{0 , 7 7 9}$ \\
\hline
\end{tabular}

Fuente: Elaboración propia a partir del Padrón Municipal de Habitantes 2016

La segunda variable extraída del padrón hace referencia al origen de la población. Hemos optado por utilizar la nacionalidad ya que presenta la ventaja frente a lugar de nacimiento que, por un lado, capta aquellas personas que, a pesar de haber nacido en el Estado español, tienen nacionalidad extranjera; $y$, por el otro, tiene en cuenta la adquisición de la nacionalidad española de aquellas personas extranjeras que, de acuerdo con los requisitos legales, cumplen las condiciones necesarias para lograr esta condición.

Como en el caso del nivel de estudios, y con el fin de simplificar el análisis, se ha optado por no trabajar con cada una de las nacionalidades de manera desagrupada, sino calcular el valor medio del Índice de Desarrollo Humano (IDH) de la población según su nacionalidad a partir de los datos que anualmente publica la División de Población de Naciones Unidas. Por coherencia con la fecha del padrón utilizado, se han utilizado los datos publicados por la ONU referentes en 2016. A causa de la imposibilidad de asignar un valor del IDH a las cuatro personas "apátridas» (solo una de las cuales vive en un radio inferior a los 300 metros de distancia respecto a un parque urbano), se ha optado por excluirlas del estudio (Tabla 3). 
Tabla 3. Población según la nacionalidad y la proximidad a un parque urbano.

\begin{tabular}{|r|c|c|c|c|}
\hline $\begin{array}{c}\text { Distancia al parque } \\
\text { más cercano }\end{array}$ & Población total & $\begin{array}{c}\text { Nacionalidad } \\
\text { española }\end{array}$ & $\begin{array}{c}\text { Nacionalidad } \\
\text { extranjera }\end{array}$ & IDH \\
\hline$<300 \mathrm{~m}$. & 40.844 & $81,8 \%$ & $18,2 \%$ & 0,860 \\
\hline$\geq 300 \mathrm{~m}$. & 94.460 & $80,7 \%$ & $19,3 \%$ & 0,858 \\
\hline Total ciudad & $\mathbf{1 3 5 . 3 0 4}$ & $\mathbf{8 1 , 1 \%}$ & $\mathbf{1 8 , 9 \%}$ & $\mathbf{0 , 8 5 9}$ \\
\hline
\end{tabular}

Fuente: Elaboración propia a partir del Padrón Municipal de Habitantes 2016

\subsection{UNA APROXIMACIÓN AL PRECIO DE LA VIVIENDA}

Por su parte, debido a la falta de información desagregada de datos del nivel de renta para el año 2016, la caracterización económica de la población se ha realizado de manera indirecta a partir del precio de la vivienda. Esta información ha sido extraída del portal inmobiliario Idealista.com, que permite realizar la consulta de los precios medios de alquiler y de compra por metro cuadrado de los pisos en un área concreta. De este modo, esta opción ha permitido delimitar el buffer de 300 metros alrededor de cada parque, de manera que la información así obtenida es plenamente comparable con la del padrón de población.

\section{EL MODELO DE EVALUACIÓN MULTICRITERIO}

En la elaboración del ICP se ha adaptado esta técnica para conocer el grado de calidad o aptitud de los parques urbanos a partir de la selección de una serie de indicadores, subindicadores y factores. Para ello se han agrupado los 20 factores mencionados en el apartado 4 (primer nivel de la jerarquía) en 7 subindicadores (segundo nivel de la jerarquía) y, a su vez, éstos se han unido en 3 indicadores que corresponden a la (1) calidad de la vegetación, (2) la calidad de los equipamientos y (3) la calidad del mobiliario urbano (nivel 3). Finalmente, la combinación de los tres indicadores da lugar al ICP (nivel 4) (Figura 3).

El indicador de la calidad de la vegetación se construye directamente con los tres factores implicados, mientras que los indicadores de calidad de los equipamientos y calidad del mobiliario urbano se han establecido a partir de subindicadores que agrupan factores que miden un aspecto en concreto de los parques. Así, por ejemplo, la calidad del mobiliario urbano se calcula a partir de los subindicadores de calidad del ambiente, calidad del uso recreativo y calidad de la limpieza e higiene. A su vez, el primer subindicador, ambiente se calcula a partir de 3 factores: la iluminación, la presencia de bancos y la existencia de otro mobiliario del parque. En la Figura 3 se puede comprobar la jerarquía establecida en el modelo de EMC. 
Figura 3. Modelo de Evaluación Multicriterio de la calidad de los parques urbanos

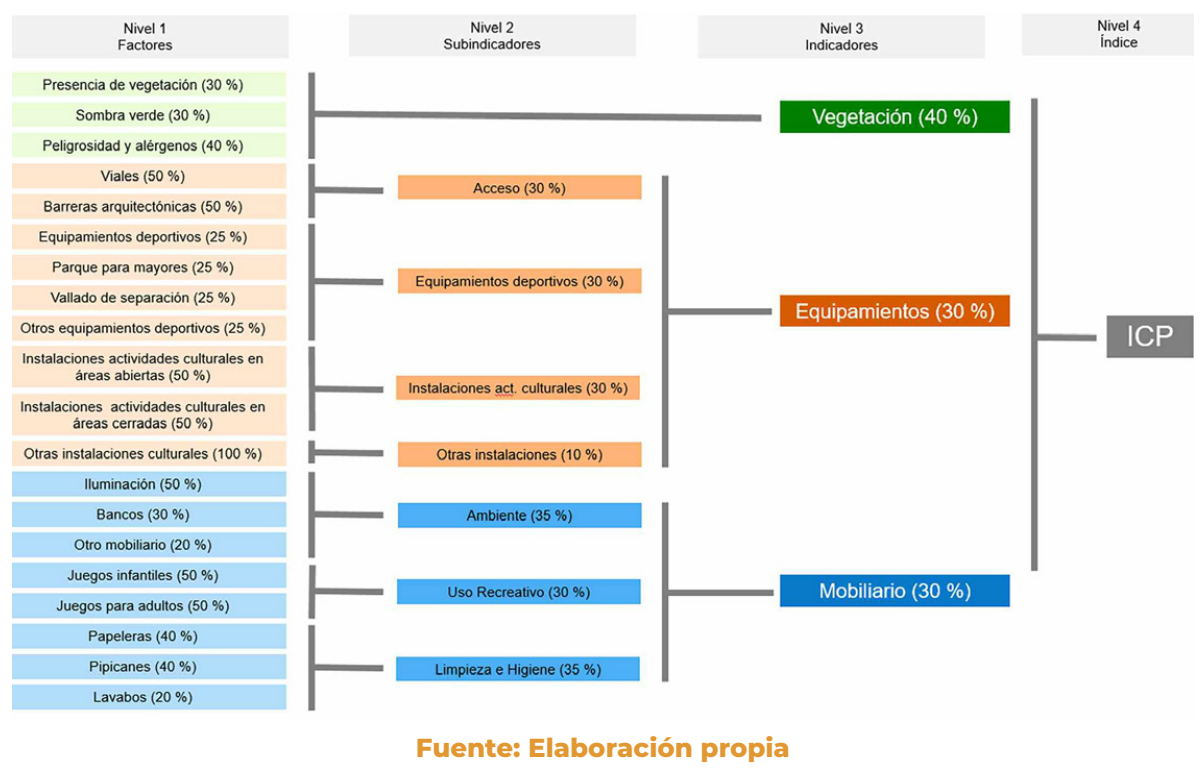

Otra de las características que se establecen en un Modelo de EMC es la importancia o pesos en porcentaje de cada uno de los factores, subindicadores e indicadores que intervienen en el modelo. Este aspecto es de suma importancia puesto que del peso que se asigne a cada una de las partes del modelo, dependerá en buena medida el resultado final obtenido. En este caso, la asignación de los pesos también guarda relación con las jerarquías y agrupaciones establecidas de modo que cada una de ellas ha de sumar 100\%. Tomando como ejemplo el tercer nivel de la jerarquía y aplicando la fórmula o regla de decisión, se combina la vegetación con un peso de $40 \%$, los equipamientos con 30\% mientras que el peso del mobiliario es de otro 30\%. De esta forma y tal y como se representa en la fórmula que aparece a continuación, el valor de la vegetación se multiplica por 40, el de los equipamientos por 30 y el del mobiliario por 30. La suma de estos indicadores dará lugar al Índice de Calidad de los Parques (100\%).

$$
(\text { Vegetación×40)+(Equipamiento×30)+(Mobiliario×30 })=I C P
$$

\section{LA JUSTICIA ESPACIAL DE LOS PARQUES URBANOS DE TARRAGONA}

De acuerdo con los objetivos planteados, los resultados obtenidos se pueden agrupar en tres cuestiones: en primer lugar; sobre la dotación de los parques urbanos; en segundo lugar, la determinación del índice de calidad de cada 
parque y sus componentes; y, en tercer lugar, la determinación de la justicia ambiental en relación a las características sociodemográficas de la población. En lo referente a la primera cuestión planteada, un primer resultado a constatar es que la superficie media de parques urbanos era el año 2016 en Tarragona de $3,24 \mathrm{~m}^{2}$ por habitante, cifra relativamente baja pero que alcanza los 17,46 m²/habitantes cuando se amplía al conjunto de las zonas verdes (no necesariamente urbanas ni urbanizadas) de la ciudad. En este sentido, bajo este criterio más laxo, se cumplen los estándares de la Unión Europea, que recomiendan una superficie mínima de zonas verdes por habitante de entre 10 y 20 metros cuadrados.

Tabla 4. Calidad y distancia media a la población

de los parques urbanos. Tarragona, 2016

\begin{tabular}{|c|c|c|c|c|c|}
\hline Parque & Vegetación & Equipamientos & Mobiliario & $\begin{array}{l}\text { Índice de } \\
\text { calidad } \\
\text { (ICP) }\end{array}$ & $\begin{array}{c}\text { Distancia } \\
\text { media }\end{array}$ \\
\hline Amfiteatre & 83,33 & 39,00 & 40,02 & 61,42 & 612,71 \\
\hline Bonavista & 86,67 & 31,60 & 33,67 & 59,65 & 580,90 \\
\hline Camí de la Coma & 36,67 & 54,28 & 52,00 & 44,90 & 565,68 \\
\hline Camp de Mart & 63,33 & 35,48 & 41,34 & 50,87 & 581,11 \\
\hline La Col.lectiva & 80,00 & 15,65 & 47,00 & 55,66 & $2.448,88$ \\
\hline Puig i Valls & 80,00 & 32,08 & 59,15 & 62,81 & 425,66 \\
\hline Saavedra & 63,33 & 34,63 & 36,60 & 49,47 & 440,79 \\
\hline Sant Antoni & 66,67 & 1,25 & 56,60 & 47,80 & 685,92 \\
\hline Sant Pere i Sant Pau & 83,33 & 30,20 & 27,35 & 56,05 & 871,18 \\
\hline Reconcilació & 63,33 & 14,40 & 45,58 & 46,66 & 178,16 \\
\hline $\begin{array}{l}\text { Rodríguez de la } \\
\text { Fuente }\end{array}$ & 63,33 & 33,15 & 16,55 & 44,04 & 824,31 \\
\hline Riu Francolí & 53,33 & 74,78 & 67,43 & 62,22 & 157,28 \\
\hline Tabacalera & 50,00 & 33,33 & 39,67 & 43,25 & 548,55 \\
\hline Lletres Catalanes & 100,00 & 34,17 & 40,67 & 68,71 & 448,08 \\
\hline Arrabassada & 63,33 & 41,85 & 48,35 & 54,22 & $3.393,95$ \\
\hline Total ciudad & 69,11 & 33,72 & 43,47 & 53,85 & $1.000,51$ \\
\hline
\end{tabular}

Fuente: Elaboración propia

Sin embargo, este valor medio esconde una distribución desigual entre los habitantes de la ciudad, pues tan solo el 30 \% viven a menos de 300 metros de un parque urbano (distancia máxima igualmente recomendada por la 
Unión Europea), siendo la distancia media entre el lugar de residencia y el parque más cercano de poco más de un quilómetro (1.000,51 metros).

El segundo resultado hace referencia al índice de calidad de los parques, obtenido a partir del análisis multicriterio descrito. De los 15 parques urbanos existentes en la ciudad, ninguno obtiene una calificación «alta» (por encima de 70 puntos), de manera que tan sólo 4 obtienen la calificación «media-alta», 5 «media-baja» y 6 «baja» (Tabla 4). Este hecho determina que más de la mitad de la población (el 54 \%) está servida por parques urbanos de calidad baja. El último aspecto a analizar es si existe relación entre la calidad del parque y las características demográficas y económicas de los residentes más cercanos a él. Los resultados (Figura 4) muestran una relación positiva, aunque débil, en tres de las cuatro variables analizadas. Así, mientras no existe relación positiva respecto al nivel de educación de la población, en el caso de las variables restantes se cumple el supuesto inicial: por un lado, los parques con mayor calidad se relacionan positivamente $\left(R^{2}=0,1574\right)$ con los vecindarios con menor presencia de población extranjera, lo que vendría a confirmar una cierta segregación residencial de esta última a causa de su dificultad por acceder a zonas acomodadas de la ciudad. Por el otro, el ICP se relaciona igualmente de manera positiva con el precio medio del metro cuadrado de viviendas, tanto si ésta es de alquiler $\left(R^{2}=0,2058\right)$ como, sobre todo, de compra $\left(R^{2}=0,0888\right)$.

Figura 4. Coeficientes de relación entre el índice de calidad del parque y las variables socioeconómicas y demográficas de la población
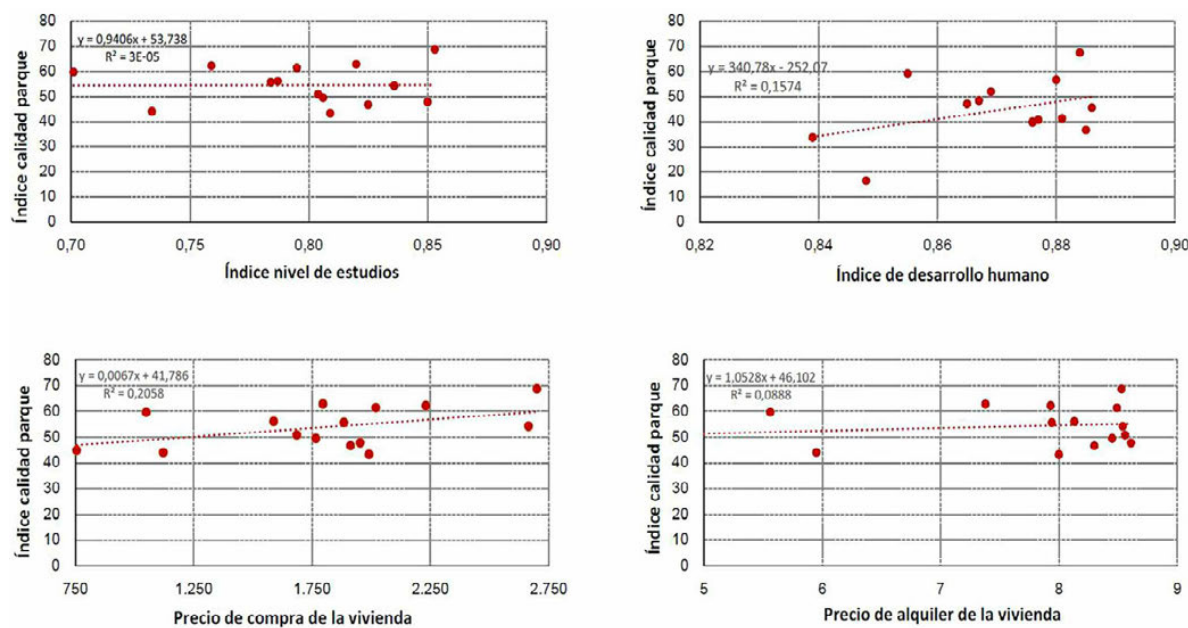

Fuente: Elaboración propia 


\section{CONCLUSIONES}

La creación de un Índice de Calidad de Parques urbanos de la ciudad de Tarragona y su correlación con variables sociodemográficas, ha permitido comparar de manera objetiva la situación de cada uno de éstos con los demás. La aplicación de políticas de regeneración y mejora urbana contribuirá a mejorar la calidad de vida de los habitantes y equilibrar la justicia espacial en la ciudad. Los aspectos más relevantes de la aplicación metodológica son: a) reúne técnicas de gabinete utilizando herramientas de sistemas de información geográfica con métodos de trabajo de campo como la observación directa para obtener información diversa que se integra en un modelo de evaluación multicriterio; b) combina una valoración de tipo cuantitativo, obtenida a partir del sistema de información geográfica, con otra de tipo cualitativo (estado de conservación, de funcionalidad o limpieza) que permite perfilar la primera valoración (la cuantitativa); c) integra la valoración de diferentes dimensiones de los parques traspasando enfoques parciales (por ejemplo, estudios enfocados en el análisis de la vegetación en los parques o en las actividades de ocio); d) utiliza técnicas estadísticas para relacionar la calidad de los parques urbanos con variables sociodemográficas que valoran de forma objetiva la justicia espacial de la ciudad.

Sin duda, existen otros aspectos mejorables en esta propuesta entre los que destacan:

- La realización de un análisis de sensibilidad para establecer la robustez del modeloy, además, identificar los factores principales del mismo. En el modelo actual parece que el subindicador de vegetación tiene una alta influencia en los resultados. Ello permitiría reducir el número de factores a trabajar a los realmente esenciales.

- Sería posible afinar el análisis identificando la población servida de cada parque a partir de los puntos de acceso al mismo en vez de utilizar como referencia el centro del parque, tal y como se ha realizado en este estudio.

- Se considera que los resultados podrían ser más concluyentes si se añadiera el aspecto cualitativo de todas las variables. Por ejemplo, además de tener en cuenta el número y la distribución de los bancos, reseñar si están en buen estado de uso.

Finalmente, es indudable que desde un punto de vista objetivo o técnico los resultados son comparables entre sí, pero sería necesario incorporar la percepción y opinión de los residentes y usuarios de los parques. La calidad objetiva de los parques establecida a partir del ICP puede ser corregida a partir de un Índice de Calidad Percibida de los Parques Urbanos generado a partir de las opiniones o niveles de satisfacción de usuarios y residentes. Además, estos resultados podrían ayudar a validar el Índice de Calidad (Objetiva) de los Parques presentado en este trabajo. 


\section{BIBLIOGRAFÍA}

Almohamad, H., Knaack, A. L. y Habib, B. M. (2018). Assessing spatial equity and accessibility of public green spaces in Aleppo City, Syria. Forests, 9 (11), art. 706. https://doi.org/10.3390/f9110706

Canosa Zamora, E., Sáez Pombo, E., Sanabria Brassart, C. y Zavala Morencos, I. (2003). Metodología para el estudio de los parques urbanos: la Comunidad de Madrid. GeoFocus, 3, 160-185.

http://www.geofocus.org/index.php/geofocus/article/view/28

De Sousa Silva, C., Viegas, I., Panagopoulos, T. y Bell, S. (2018). Environmental Justice in Accessibility to Green Infrastructure in Two European Cities. Land, 7, 134.

Flipo, F. (2002). L'espace écologique: fondements d'une théorie politique de la dimension naturelle de la liberté. Les Cahiers du pôle de recherche et d'enseignement Proses.

Kabisch, N. y Haase, D. (2014). Green justice or just green? Provision of urban green spaces in Berlin, Germany. Landscape and Urban Planning, 122, 129139. https://doi.org/10.1016/j.landurbplan.2013.11.016

La Rosa, D. (2014). Accessibility to greenspaces: GIS based indicators for sustainable planning in a dense urban context. Ecological Indicators, 42, 122134. https://doi.org/10.1016/j.ecolind.2013.11.011

Martínez Alier, J. (1999). Introducción a la economía ecológica. Barcelona: Rubes.

Martínez Alier, J. Y Roca, J. (2000). Economía ecológica y política ambiental. Ciudad de México: Fondo de Cultura Económica.

Moreno, A. (2009). Justicia ambiental. Del concepto a la aplicación en planificación y análisis de políticas territoriales. Scripta Nova. Revista electrónica de geografía y ciencias sociales, vol. XIV, núm. 316.

http://www.ub.edu/geocrit/sn/sn-316.html

Rigolon, A. (2017). Parks and young people: An environmental justice study of park proximity, acreage, and quality in Denver, Colorado. Landscape and Urban Planning, 165, 73-83. https://doi.org/10.1016/j.landurbplan.2017.05.007

Rigolon, A., Browning, M. y Jennings, V. (2018). Inequities in the quality of urban park systems: An environmental justice investigation of cities in the United States. Landscape and Urban Planning, 178, 156-169.

https://doi.org/10.1016/j.landurbplan.2018.05.026

Rivera Martínez, L. M. (2014). Los parques urbanos como indicadores de calidad de vida, símbolos de bienestar y espacios de uso recreativo: una investigación en Bucaramanga (Colombia). Universidad \& Empresa, vol. 16, núm. 27, 215-237. http://www.redalyc.org/articulo.oa?id=187241606008

Saladié, Ò., Roquer, S., Oliveras, J. y Muro, J. I. (2012). Història de Tarragona. Volum VI: La ciutat actual. Geografia i urbanisme. Lleida: Pagès Editors. 
Shen, Y., Sun. F. y Che. Y. (2017). Public green spaces and human wellbeing: Mapping the spatial inequity and mismatching status of public green space in the Central City of Shanghai. Urban Forestry and Urban Greening, 27, 59-68. https://doi.org/10.1016/j.ufug.2017.06.018

Silva, C. S., Viegas, I., Panagopoulos, T. y Bell, S. (2018). Environmental justice in accessibility to green infrastructure in two European Cities. Land, 7 (4), art. 134. https://doi.org/10.3390/land7040134

Tu, X., Huang, G. y Wu. J. (2018). Contrary to common observations in the West, urban park access is only weakly related to neighborhood socioeconomic conditions in Beijing, China. Sustainability. 10(4), art. 1115.

https://doi.org/10.3390/su10041115

Xiao. Y., Wang. Z., Li, Z. y Tamg, Z. (2017). An assessment of urban park access in Shanghai. Implications for the social equity in urban China. Landscape and Urban Planning, 157, pp. 383-393.

https://doi.org/10.1016/j.landurbplan.2016.08.007 


\section{LA SEGREGACIÓN RESIDENCIAL Y CONDICIONES DE VIDA. UN ANÁLISIS DE LAS DESIGUALDADES SOCIALES EN CATALUNYA A PARTIR DE CUATRO PERSPECTIVAS ESPACIALES RESIDENTIAL SEGREGATION AND LIVING CONDITIONS. SPATIAL PERSPECTIVES ON SOCIAL INEQUALITIES IN CATALONIA

\author{
Joan Checa \\ Universitat Autònoma de Barcelona \\ Oriol Nel·lo \\ Universitat Autònoma de Barcelona
}

\section{Resumen}

Las desigualdades territoriales en las condiciones de vida de la población han sido tradicionalmente atribuidas a la posición geográfica, la oposición entre los entornos urbanos y rurales o el tamaño de los asentamientos. Así, la literatura geográfica ha utilizado dichas oposiciones para explicar tanto las diferencias relativas al acceso a la educación, al trabajo y a los servicios, como a la diversidad en las formas de vida, las creencias e incluso las actitudes políticas. Sin embargo, en las últimas décadas, las áreas urbanas han ampliado su ámbito, la urbanización se ha extendido, el territorio se ha hecho más interdependiente y las jerarquías espaciales han tendido a reducirse. Al mismo tiempo se han acentuado las desigualdades sociales que se plasman espacialmente a través de la segregación residencial. La comunicación postula la tesis de que hoy, en los espacios regionales, la segregación residencial supone un factor notablemente más explicativo que la posición geográfica, el eje urbano/rural o el tamaño de los asentamientos a la hora de explicar las desigualdades sociales y la diversidad en las condiciones de vida. Para ello, analiza un conjunto de indicadores clave de la población residente en Cataluña a partir de diversas agrupaciones espaciales con el fin de identificar el potencial explicativo de cada una de ellas.

Palabras clave: segregación residencial, proceso de urbanización, condiciones de vida.

\section{Abstract}

Spatial inequalities in the living conditions of the population have traditionally been attributed to geographical position, opposition between urban and rural environments or the size of settlements. Thus, geographical literature has used these oppositions to explain the differences related to access to education, work and services, as well as to diversity in ways of life, beliefs and 
even political attitudes. However, in recent decades, urban areas have expanded their scope, urbanization has scattered, places have become more interdependent and spatial hierarchies have tended to weaken. At the same time, social inequalities embedded in residential segregation have been accentuated. The contribution propounds the thesis that today, in regional spaces, residential segregation is a significantly more explanatory factor than the geographical position, the urban/rural divide or the size of the settlements when explaining social inequalities and diversity in the living conditions. In order to discuss the argument, a set of key indicators of the population resident in Catalonia are analyzed by using from different spatial perspectives to test the explanatory potential of each of them.

Keywords: residential segregation, urbanization process, living conditions.

\section{INTRODUCIÓN: EL DEBATE SOBRE EL ORIGEN Y LAS REPERCUSIONES DE LAS DESI- GUALDADES ESPACIALES}

A lo largo de las últimas décadas y, especialmente, a raíz de la crisis económica iniciada en 2007, se ha producido un incremento de las desigualdades en los ingresos y el bienestar de la población en buena parte de las sociedades contemporáneas. Se trata de un fenómeno constatado a nivel mundial, siendo España uno de los países de la Unión Europea donde el aumento de las desigualdades ha sido más acusado. El tema ha sido objeto de reiterada atención y debate internacional, dando lugar a la aparición de obras particularmente influyentes (Piketty. 2013; Stiglitz 2012; Someiller y Price, 2014; Milanovic, 2016, y Atkinson 2015).

El incremento de las desigualdades que se hizo patente ya en el último ventenio del siglo pasado, ha resultado tanto más llamativo por producirse después de décadas de relativos avances en materia de equidad. Su origen ha sido atribuido a las combinación de diversos factores: la crisis del Estado del Bienestar (Judt, 2011), la asimetría en la movilidad de capital y trabajo (Urry, 2014), la generalización de las políticas neoliberales (Fontana, 2013), la creciente incompatibilidad entre la economía capitalista y las instituciones democráticas (Streeck, 2016), así como a los efectos de la globalización económica (Milanovic, 2016).

En los últimos años, la cuestión ha visto aumentar su relevancia debido al surgimiento, en buena parte de las ciudades y países europeos, de actitudes políticas y comportamientos electorales de carácter disruptivo (Traverso, 2019; Rodríguez Pose, 2017; Guilluy, 2014; Nel·lo y Gomà 2018a). Actitudes y comportamientos que expresan la insatisfacción y los temores de amplias capas de la población con respecto a las transformaciones sociales y urbanas en curso, así como a las políticas que las han acompañado. Los cambios en las actitudes políticas se han evidenciado a lo largo de la última década en diversos episodios, de características muy variadas. Entre los más visibles des- 
tacan las resistencias a la imposición a las medidas de austeridad en diversos países europeos en el momento más álgido de la crisis económica (Grecia, España, Portugal), el surgimiento del movimiento de los «gilets jaunes» en Francia o los movimientos por la independencia de algunos territorios (Escocia, 2017; Cataluña, 2017). Como es sabido, el malestar se ha expresado electoralmente de formas muy diversas. Por una parte, ha dado lugar al ascenso de fuerzas políticas de nuevo cuño que desafían los partidos tradicionales (Syriza en Grecia, Podemos en España), por otro ha impulsado el renovado ímpetu de partidos y movimientos de extrema derecha (presentes en buena parte de los Parlamentos nacionales y en el gobierno de diversos países europeos). Asimismo, se han producido resultados electorales que alteran claramente el statu quo (referéndums sobre el Brexit en el Reino Unido o sobre la reforma constitucional en Italia, ambos en 2016).

Como puede verse, se trata de un conjunto de fenómenos de muy diverso cariz, cuya complejidad desafía las simplificaciones: tanto las de aquellos que han querido enaltecerlos como el surgimiento de un puro dinamismo cívico destinado a impulsar políticas progresistas "desde abajo», como de quienes los han querido anatemizar bajo diversas etiquetas («populismo», «irracionalismo»). En todo caso, los cambios en las actitudes políticas de la población suponen uno de los fenómenos más relevantes en la evolución de las sociedades europeas contemporáneas, tanto por las contradicciones que expresan como por las consecuencias históricas que de ellos pueden derivarse.

Pues bien, a la hora de profundizar en su análisis, diversos autores han subrayado la importancia de las variables territoriales en la evolución del descontento social y la desafección política. Así, se han buscado los orígenes de estos movimientos en, por ejemplo, la oposición entre la «France péripherique» y la metrópolis parisiense (Guilluy, 2014), entre las antiguas periferias industriales británicas y el gran centro terciario de Londres (McCann, 2016), entre el mezzogiorno italiano y las regiones más acomodadas del norte y el centro de Italia, o entre la «España vacía» y las áreas metropolitanas (Del Molino, 2016). Así, desde el punto de vista espacial, el descontento podría ser interpretado, hasta cierto punto, como «la venganza de los lugares que no importan» (Rodríguez Pose, 2017), de tal modo que el descontento sería más el resultado del sentimiento de postergación de determinados territorios y no tanto de las desigualdades sociales.

Este debate enlaza de manera directa con un tema clásico en el análisis geográfico: el estudio de la diversidad territorial en las condiciones de vida de la población. En la literatura éstas han sido tradicionalmente atribuidas a la posición geográfica, la oposición entre los entornos urbanos y rurales o el tamaño de la población. Así, la literatura geográfica ha utilizado dichos criterios como factores explicativos tanto las diferencias relativas al acceso a la educación, al trabajo y a los servicios, como a la diversidad en las formas de vida, las creencias e incluso las actitudes políticas. Sin embargo, en las últimas dé- 
cadas, se ha ido abriendo paso cada vez con mayor fuerza la noción de que -en un contexto de expansión de las áreas urbanas, dispersión de la urbanización y disminución relativa de las jerarquías espaciales- el factor clave para explicar las desigualdades espaciales en las condiciones de vida debe buscarse no tanto en aquellas oposiciones territoriales clásicas, sino en la segregación residencial. Así, sería ante todo la tendencia de los grupos sociales a separarse entre ellos - tanto a escala urbana como regional por razón de su renta u origen- el factor territorial que de forma más clara incidiría en el mantenimiento y la reproducción de las desigualdades sociales.

La presente aportación trata de verificar la hipótesis según la cual, hoy, a escala regional y estatal, la segregación residencial supone un factor notablemente más explicativo que otras variables geográficas a la hora de explicar las desigualdades sociales y la diversidad en las condiciones de vida. La discusión se lleva a cabo a partir del estudio del caso específico de Cataluña, en las primeras dos décadas del siglo XXI.

El método empleado para debatir la cuestión consiste, en primer lugar, en seleccionar una serie de indicadores sociales relativos a las condiciones de vida de la población residente en Cataluña. A continuación, estos indicadores serán analizados siguiendo diversas agregaciones espaciales de los datos: el ámbito geográfico, el tamaño poblacional, la intensidad de la urbanización y la percusión de la segregación urbana. Así, se mostrará cómo esta última aproximación es la que resulta más discriminante a la hora de explicar los condicionantes territoriales sobre la vida de las personas.

Atendiendo a los objetivos, a la hipótesis y el método propuesto, el presente trabajo se estructura en cuatro apartados: la presente introducción; un breve epígrafe metodológico donde se especifican los datos utilizados y la forma de análisis seguida; el análisis y discusión de resultados obtenidos; y, finalmente, unas breves conclusiones?

\section{METODOLOGÍA}

A la hora de estudiar la distribución espacial de las diferencias sociales dos son los elementos clave a determinar: las variables seleccionadas como indicadores de las condiciones de vida y las agregaciones territoriales utilizadas en su análisis. Tal como se ha indicado, en la presente investigación se estudian varios indicadores relativos a las condiciones de vida de las personas

1 Una primera explotación de los datos que a continuación se presentan ha sido realizada en el marco de la investigación Informe sobre la cohesió social a la Catalunya del segle XXI, impulsada por el Institut d'Estudis Catalans y coordinada por el sociólogo Salvador Cardús. La metodología adoptada sigue en parte la empleada en Nel.lo \& Gomà (2018b). 
según su lugar de residencia en el territorio catalán, comparando de manera sistemática diversas agrupaciones territoriales de los datos. Los indicadores utilizados provienen de la explotación de la Encuesta de Condiciones de Vida y Hábitos de la Población (ECVHP) correspondiente al año 2011². En concreto, se han seleccionado cinco variables siguientes:

- Nivel de estudios acabados. Nivel de formación reglada alcanzada por las personas de 25 años y más. Se diferencian dos grupos: población con y sin estudios superiores.

- Estructura social. Estructura social para la población ocupada de 16 años a 64 años de acuerdo con los criterios de la European Socio-Economic Classificatión (ESECC $9+1$ ). Se utiliza la aproximación a las clases sociales construida a partir de agrupaciones de empleos (es decir, clases ocupacionales). A los efectos de nuestro análisis se construyen dos grupos: cualificados (ESEC $=1,2$ y 3) $)^{3}$ y resto de la población (ESEC »3).

- Tasa de riesgo de pobreza de la población. Porcentaje de personas que antes de recibir todas las transferencias sociales, excepto jubilaciones y prestaciones de supervivencia, se encuentran por debajo del umbral de pobreza. Se fija este umbral al $60 \%$ de la media de los ingresos por unidad de consumo de las personas. Se diferencian dos grupos: en riesgo de pobreza y fuera del riesgo de pobreza.

- Salud autopercibida. Percepción subjetiva del estado de salud de los individuos, para la población de 16 años y más. Se diferencian dos grupos: los que afirman disfrutar de un estado de salud muy bueno o bueno, y los que dicen encontrarse en un estado regular, malo o muy malo.

- Satisfacción global con la vida. Percepción subjetiva de la satisfacción vital de personas de 16 y más años. Se utiliza una escala de 0 a 10 en el grado de satisfacción ( 0 = insatisfacción absoluta; 10 = satisfacción total).

Estas variables, tal como se ha enunciado, son analizadas de acuerdo con cuatro agregaciones territoriales diversas, relativas a la posición geográfica,

2 La ECVHP elaborada por el Institu d'Estudis Regionals i Metropolitans de Barcelona (IERMB) y el Institut d'Estadística de Catalunya (IDESCAT) tiene periodicidad quinquenal. Se emplea aquí la edición 2011, que cubre el conjunto del territorio de Cataluña con una muestra efectiva de 4.235 entrevistas. La elección de la edición se corresponde con la disponibilidad de los datos relativos a la segregación residencial, tal como más adelante se detalla. Para el detalle de la metodología de la ECVHPC véase Antón-Alonso y Porcel (2019).

3 ESEC 1,2 y 3: Grandes empleadores, directivos y profesionales de alto nivel; Directivos y profesionales de nivel bajo; y Empleados de cuello blanco nivel alto. Para el detalle de esta clasificación puede ver Sarasa et al., 2013. 
el tamaño poblacional, la intensidad de urbanización y la vulnerabilidad social. Para ello se utilizan las cuatro agrupaciones siguientes.

- Ámbito territorial. Ámbitos de planeamiento territorial vigentes en CataIuña: Metropolità, Comarques Gironines, Camp de Tarragona, Terres de l'Ebre, Ponent y Alt Pirineu i Aran, Comaques Centralas y Penedès. Por razones de representatividad de la muestra, se ha reunido en uno solo los ámbitos de Ponent y Alt Pirineu i Aran.

- Tamaño poblacional. Clasificación de la totalidad de los municipios de Cataluña según el número de habitantes empadronados, de acuerdo con los datos del Padrón Continuo de Habitantes del IDESCAT. Los municipios han sido agrupados según los siguientes tramos: menores de 5.001 habitantes, entre 5.001 y 10.000 , entre 10.001 y 50.000 , entre 50.001 y 100.000 , mayores de 100.000 y Barcelona ciudad.

- Grado de urbanización. Clasificación del territorio catalán en tres categorías definidas a partir de la densidad poblacional de cada municipio y su contigüidad a otros núcleos ${ }^{4}$. Las categorías son las siguientes: Zona densamente poblada: delimitada por un conjunto contiguo de municipios, cada uno con una densidad $>500$ habitantes por $\mathrm{km}^{2}$, y con una población total del conjunto >50.000 habitantes; Zona semiurbana o intermedia: conjunto contiguo de municipios que no pertenecen a una zona densamente poblada, donde cada uno de los municipios tiene una densidad $>100$ habitantes por $\mathrm{km}^{2}$ y donde la población total del conjunto >50.000 habitantes o es adyacente a una zona densamente poblada; Zona escasamente poblada: el conjunto contiguo de municipios que no forman parte ni de una zona densamente poblada ni de una zona intermedia y que, por tanto, tienen un marcado carácter rural.

- Intensidad de segregación residencial. Clasificación de las secciones censales de Cataluña atendiendo a cuatro variables estrechamente relacionadas con la renta: porcentaje de población extranjera, porcentaje de población en situación de paro, superficie media de la vivienda y valor catastral de la vivienda. De este análisis resulta la agrupación de las secciones censales en área de tres categorías: con segregación urbana inferior extrema (barrios vulnerables, 484 secciones censales); con segregación urbana superior extrema (barrios acomodados: 586 secciones censales); sin segregación extrema (barrios intermedios, 4.359 secciones censales) ${ }^{5}$.

4 Se emplea el método establecido por el sociólogo Sergio Porcel y utilizada para el análisis de la Encuesta de la Juventud de Cataluña de 2012 y 2017 (Nel·lo y Gomà 2018b; Porcel, 2013).

5 La clasificación ha sido establecida en la investigación Barrios y crisis y corresponden al año 2012. Para los detalles metodológicos de la clasificación véase Blanco y Nel·lo, 2018. 
Estas agregaciones territoriales permiten clasificar la población de Cataluña de acuerdo con los ámbitos y magnitudes demográficas que figuran en las Figuras 1 y 2. Conviene señalar que, en todas las agregaciones, los ámbitos resultantes tienen un volumen de población considerable (el menos poblado, Tierras Ebro, 191.631 habitantes) lo que asegura un nivel de representatividad estadística adecuado.

Figura 1. Distribución de la población por agregaciones territoriales. Catalunya, 2011

\begin{tabular}{|c|c|c|c|c|c|c|c|c|}
\hline $\begin{array}{l}\text { Ámbito } \\
\text { territorial }\end{array}$ & Metropolità & $\begin{array}{l}\text { Comarques } \\
\text { Gironines }\end{array}$ & $\begin{array}{l}\text { Camp de } \\
\text { Tarragona }\end{array}$ & $\begin{array}{l}\text { Terres de } \\
\text { l'Ebre }\end{array}$ & $\begin{array}{l}\text { Ponent y } \\
\text { Alt } \\
\text { Pirincu i } \\
\text { Aran }\end{array}$ & $\begin{array}{l}\text { Comarques } \\
\text { Centrals }\end{array}$ & Penedès & Total \\
\hline \multirow{3}{*}{$\begin{array}{c}\text { Tamaño } \\
\text { poblacional }\end{array}$} & 4.636.077 & 741.899 & 518.655 & 191.631 & 443.211 & 405.489 & 602.656 & 7.539 .618 \\
\hline & $\begin{array}{l}\text { Hasta a } \\
5.000 \text { hab. }\end{array}$ & $\begin{array}{l}\text { De } 5.001 \text { a } \\
10.000 \text { hab. }\end{array}$ & $\begin{array}{l}\text { De } 10.001 \text { a } \\
50.000 \text { hab. }\end{array}$ & $\begin{array}{c}\text { De } \\
50.001 \text { a } \\
100.000 \\
\text { hab. }\end{array}$ & $\begin{array}{c}\text { Más de } \\
100.000 \\
\text { hab. }\end{array}$ & Barcelona & Total & \\
\hline & 790.319 & 645.951 & 2.097 .920 & 1.056 .294 & 1.333 .687 & 1.615 .448 & 7.539 .618 & \\
\hline \multirow[t]{2}{*}{$\begin{array}{c}\text { Grado } \\
\text { urbanización }\end{array}$} & $\begin{array}{c}\text { Zona } \\
\text { densamente } \\
\text { poblada }\end{array}$ & $\begin{array}{l}\text { Zona semiurbana } \\
\text { o intermedia }\end{array}$ & $\begin{array}{c}\text { Zona } \\
\text { escasamente } \\
\text { poblada }\end{array}$ & Total & & & & \\
\hline & 6.087 .671 & 818.436 & 633.511 & 7.539 .618 & & & & \\
\hline \multirow[t]{2}{*}{ Segregación } & $\begin{array}{l}\text { Ámbito } \\
\text { vulnerable }\end{array}$ & $\begin{array}{l}\text { Ámbito no } \\
\text { vulnerable }\end{array}$ & $\begin{array}{c}\text { Ámbito } \\
\text { acomodado }\end{array}$ & Total & & & & \\
\hline & 676.365 & 6.239 .062 & 624.191 & 7.539 .618 & & & & \\
\hline
\end{tabular}

Fuente: Elaboración propia a partir del Padrón continúo del INE 
Figura 2. Agregaciones territoriales. Catalunya, 2011

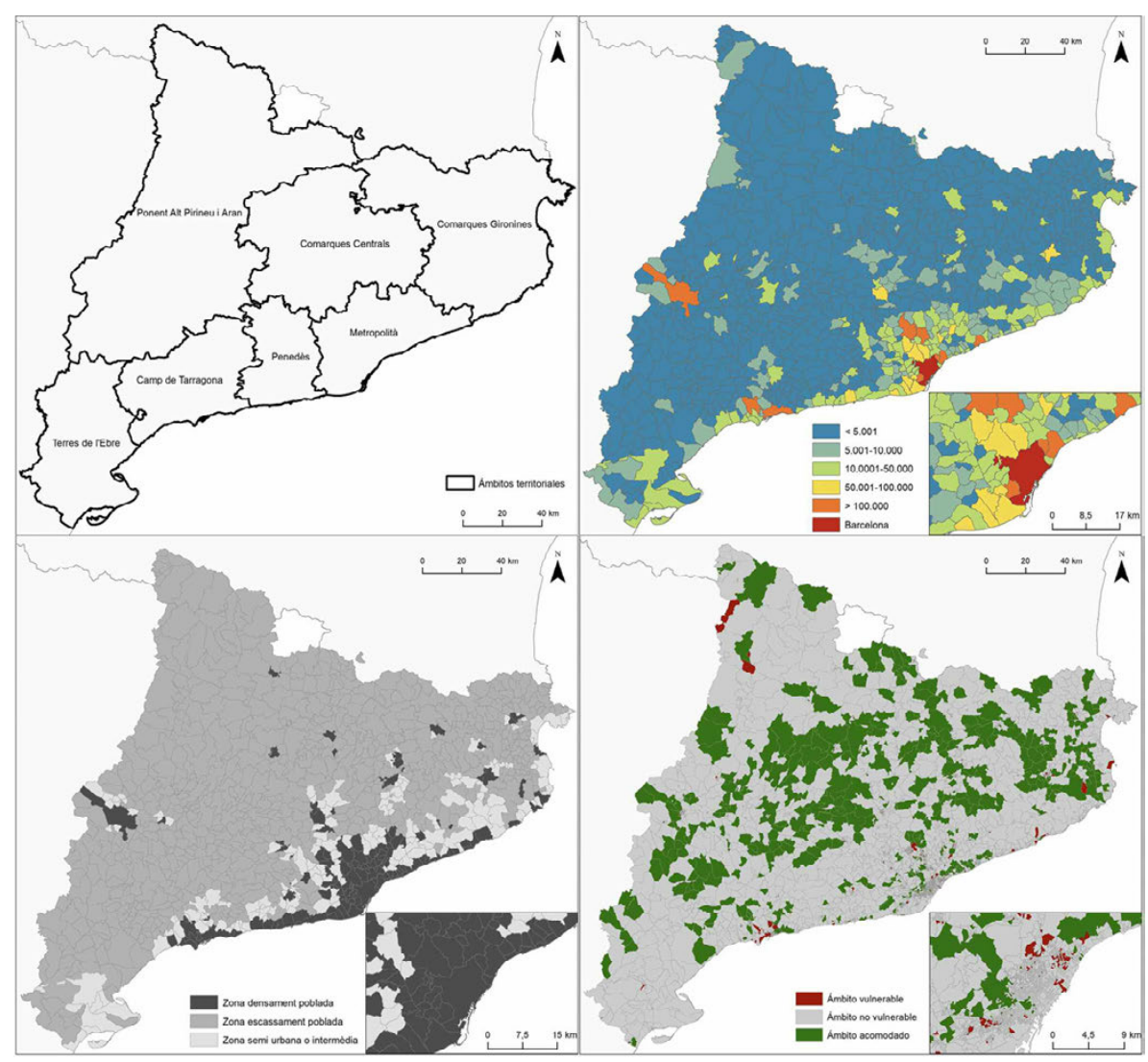

Fuente: Elaboración propia a partir

del Padrón continúo del INE y bases cartográficas IGN

\section{RESULTADOS}

Los resultados obtenidos a partir del análisis de las cinco variables confirman, con algunas variantes, las hipótesis de partida y muestran que, desde el punto de vista territorial, las fracturas o desigualdades sociales más destacadas no se corresponden tanto al ámbito geográfico de referencia, el tamaño poblacional o la intensidad de urbanización, como a la segregación residencial. Veámoslo con algún detalle. 


\subsection{NIVEL DE ESTUDIOS ALCANZADO}

Los factores territoriales constituyen un elemento crucial en este debate sobre las potencialidades sociales del sistema educativo. En particular, el acceso a la educación superior ha sido tradicionalmente bastante más dificultoso para la población residente en áreas alejadas de los principales centros urbanos, donde suelen radicar los principales equipamientos universitarios. Por otra parte, estudios recientes (Bonal, 2018; Gomà y Muñoz, 2018) han mostrado que las oportunidades de formación están estrechamente condicionadas por el área de residencia y por el nivel socio-económico del entorno, tal como evidencian los fenómenos de migraciones escolares (matriculación fuera del barrio o municipio de residencia) tan comunes en Cataluña. Por ello, a la hora de estudiar las desigualdades territoriales resulta de gran importancia observar cuáles son las principales diferencias que se encuentra en el ámbito educativo.

Figura 3. Nivel de estudios alcanzados.

Catalunya, población de 25 años i más. Año 2011

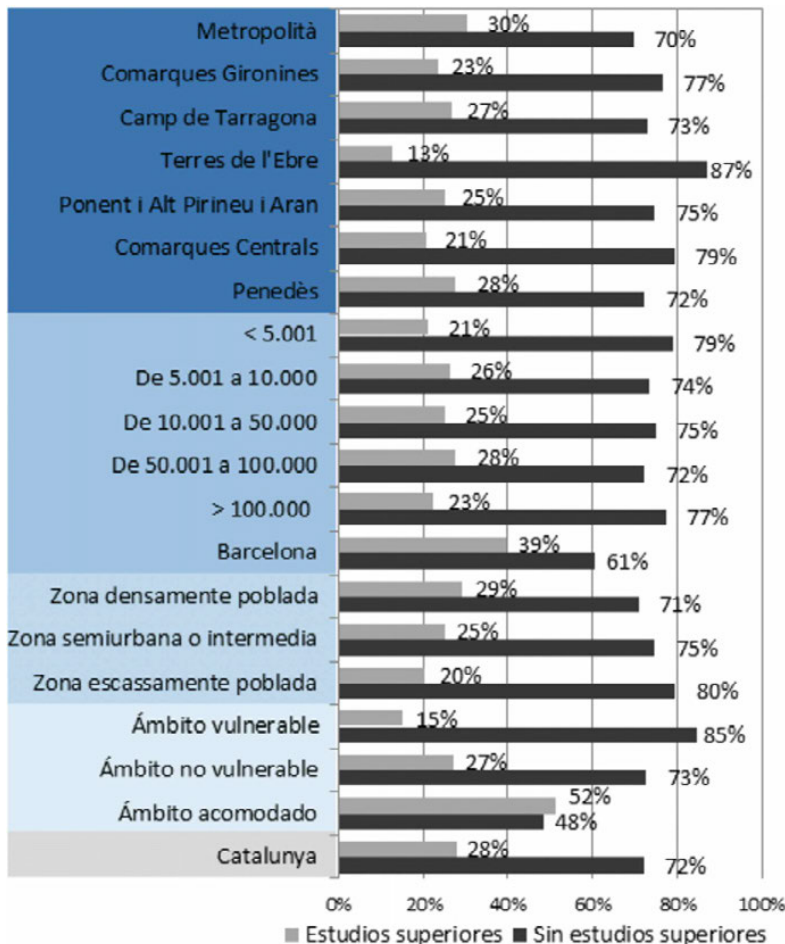

Fuente: Elaboración propia a partir de ECVHP, 2011 
La Figura 3 muestra los datos del nivel de estudios superiores alcanzados por la población catalana de 25 años y más, agrupada de acuerdo con las cuatro categorías territoriales que empleamos aquí (ámbito geográfico, tamaño población, intensidad de urbanización y vulnerabilidad). Como se puede ver, la media de la población catalana con estudios superiores es del $28 \%$. Ahora bien, en seguida se constata que existen diferencias importantes entre las diversas áreas territoriales. Así, la comparación entre grandes ámbitos geográficos muestra que el porcentaje de población con estudios superiores es más alto en las áreas más urbanizadas: la Región Metropolitana de Barcelona, en primer lugar, seguida de cerca por el Penedès y el Camp de Tarragona. En cambio, Comarques Centrals y Terres de l'Ebre presentan valores muy inferiores. Así, el porcentaje de población con estudios superiores residente en el ámbito metropolitano barcelonés es más de dos veces superior al de las Terres de l'Ebre. De todos modos, debe tenerse en cuenta que las trayectorias educativas dependen no sólo de la renta de las familias y la oferta formativa existente en cada territorio sino también de otros factores, tales como la estructura productiva, el dinamismo del mercado de trabajo y sus exigencias de calificación, así como de factores socioculturales vinculados a las características de los lugares de residencia. El hecho de que el ámbito de Ponent y Alt Pirineu i Aran doble el porcentaje de población con estudios superiores de las Terres de l'Ebre vendría a confirmar la dificultad de asociar, de manera mecánica, la proximidad geográfica en el ámbito metropolitano como principal factor explicativo en este campo.

La lectura de los datos relativos al nivel de estudios alcanzado por la población según el tamaño de la localidad de residencia conduce a conclusiones similares. En primer lugar, se observa la oposición entre la ciudad de Barcelona, donde 4 de cada 10 residentes adultos tienen estudios superiores, con las localidades de menos de 5.001 habitantes, donde la proporción es de apenas la mitad. Se trata de una diferencia que puede explicarse, probablemente, por la existencia de una amplia oferta formativa en la capital, acompañada de un mercado de trabajo con empleos de alta cualificación, así como del desplazamiento de población con niveles de educación superiores hacia Barcelona, atraída por empleos especializados. De todos modos, la observación atenta de los datos muestra que el tamaño poblacional del municipio de residencia no guarda una relación directa con el nivel de estudios. Así, el porcentaje de población con estudios superiores residente en localidades de entre 5.001 y 100.000 habitantes supera, en todos los tramos, la de los residentes en ciudades de más 100.000, excepción hecha de Barcelona. El hecho de que las localidades de menos de 5.001 habitantes y las de más de 100.000 compartan las últimas posiciones en el ranking de titulados superiores, muestra que el tamaño de la localidad de residencia tiene una limitada capacidad explicativa en relación a esta variable. 
Algo similar ocurre en relación a la intensidad de urbanización, es decir, lo que se ha denominado el eje urbano/rural. Tradicionalmente se había entendido que la ruralidad era uno de los principales obstáculos para el acceso a la educación en general y a los estudios superiores en particular. Sin embargo, los datos muestran que en la clasificación de las localidades de acuerdo con el eje urbano/rural, las diferencias son las menores de todas las agregaciones empleadas. Ciertamente, la población residente en las áreas escasamente pobladas tiene una menor propensión a alcanzar estudios superiores que la residente en áreas densas, pero la diferencia dista de ser abrumadora.

Más concluyentes parecen, en cambio, las diferencias asociadas a la segregación residencial. Mientras 1 de cada 2 personas adultas residentes en áreas acomodadas ha alcanzado estudios superiores, en el caso de las residentes en áreas vulnerables la proporción es apenas un poco superior a 1 de cada 7. Se trata de la mayor diferencia entre todas las clasificaciones ensayadas, muy superiores a las que se derivan de las áreas geográficas, el tamaño poblacional o el carácter más o menos urbano de la localidad de residencia. La segregación residencial parece ser pues la dimensión que se relaciona (condiciona y/o refleja) de una manera más clara con el hecho de disponer o no de estudios superiores.

\subsection{ESTRUCTURA SOCIAL}

Observaciones complementarias a las anteriores se pueden obtener a partir del estudio de la distribución de los grupos sociales sobre el territorio. Los datos utilizados aquí para observar la distribución de los grupos sociales sobre el espacio catalán deben ser forzosamente más limitadas. En concreto, como se ha explicado en el apartado metodológico, empleamos la European Socio-economic Classificatión, construida a partir de categorías ocupacionales, diferenciando entre dos grupos: población que ocupa puestos de trabajo cualificados (ESEC = 1,2 y 3) y resto de la población (ESEC> 3).

Los datos muestran que las categorías ocupacionales altas comprenden algo más de una cuarta parte de la población de la población ocupada de Cataluña (un 27,7\% para ser exactos). Su distribución territorial sigue, no por casualidad, un patrón bastante similar a la variable relativa al nivel de estudios superiores: el ámbito territorial que presenta una mayor proporción de categorías ocupacionales superiores es la Región Metropolitana —claramente condicionada por la presencia de Barcelona- que dobla el peso que estas categorías tienen en las Terres de l'Ebre o las Comarques Centrals. Las desigualdades asociadas a los tamaños poblacionales y en la intensidad de urbanización replican, de manera casi idéntica, los valores observados en la variable anterior. 
De nuevo, es en la agregación territorial correspondiente a la segregación residencial donde se observan las desigualdades más destacables, las cuales resultan incluso más acusadas que en la distribución de los estudios superiores. Si, 5 de cada 10 personas ocupadas que residen en las áreas acomodadas pertenecen a categorías de alta calificación, en las áreas vulnerables la proporción es de poco más de 1 de cada 10.

Figura 4. Estructura social ESEC (9+1). Personas ocupadas de 16 a 64 años, Cataluña

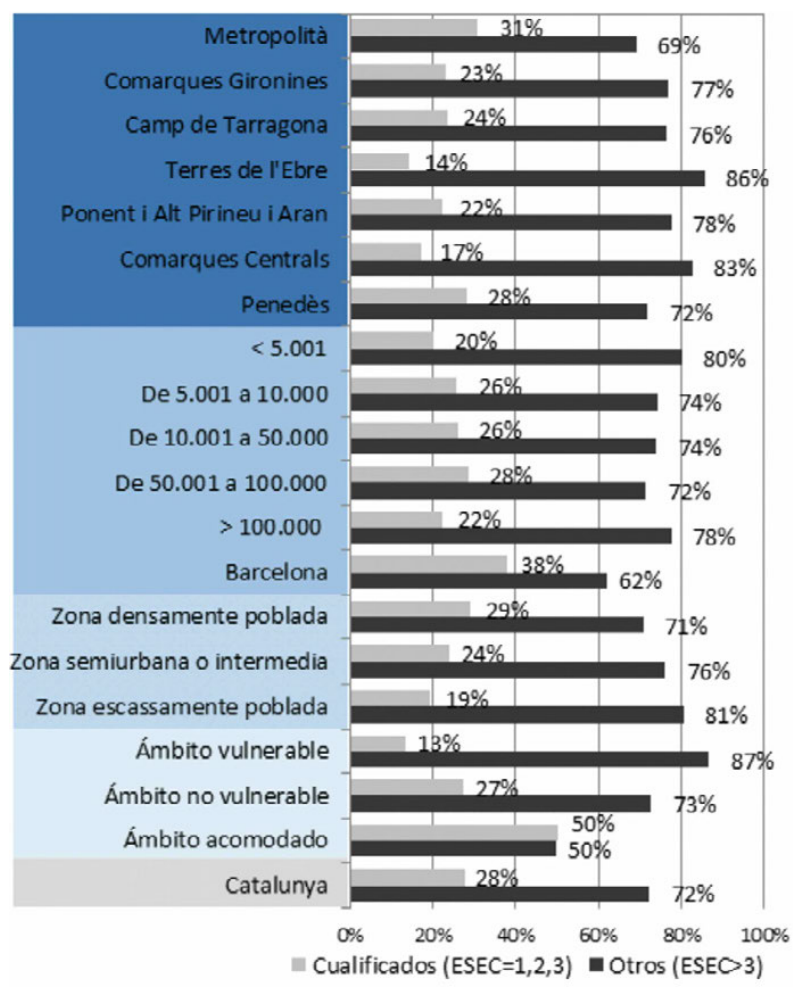

Fuente: Elaboración propia a partir de ECVHP, 2011

\subsection{RIESGO DE POBREZA}

Uno de los efectos más notables de la crisis económica iniciada en 2008 y las políticas que la han acompañado ha sido el incremento de la población que se halla en riesgo y en situación de pobreza (Flores Martos, Gómez Morán, y Renes Ayala, 2016; Nel.lo y Donat, 2014; Sarasa, Porcel, y Navarro-Varas, 2013). Los datos que se ofrecen a continuación indican el porcentaje de la población catalana que vive en unidades de consumo con ingresos por debajo del um- 
bral del 60\% de la media catalana (antes de las transferencias sociales, excepción de pensiones y prestaciones de supervivencia). Los datos tienen el inconveniente de haber sido calculados por umbrales homogéneos para toda Cataluña, a pesar de que los ingresos y los costes de vida resultan relativamente diferentes en las diversas partes del territorio. En este sentido, los ámbitos que debido a su posición en el sistema urbano de Cataluña tienden a tener rentas medias más elevadas presentan resultados aparentemente mejores respecto al conjunto, aunque los costes de vida resulten en ellos comparativamente más altos. Por el contrario, los territorios con rentas medias bajas, se sitúan en las últimas posiciones con respecto a estos parámetros, aunque la situación resulte atenuada debido a la existencia de costes de vida más bajos. De todos modos, la variable permite también una aproximación interesante a las diferencias territoriales.

Figura 5. Tasa de riesgo de pobreza. Porcentaje de población residente en unidades de consumo con ingresos inferiores al 60\% de la media. Cataluña, 2011

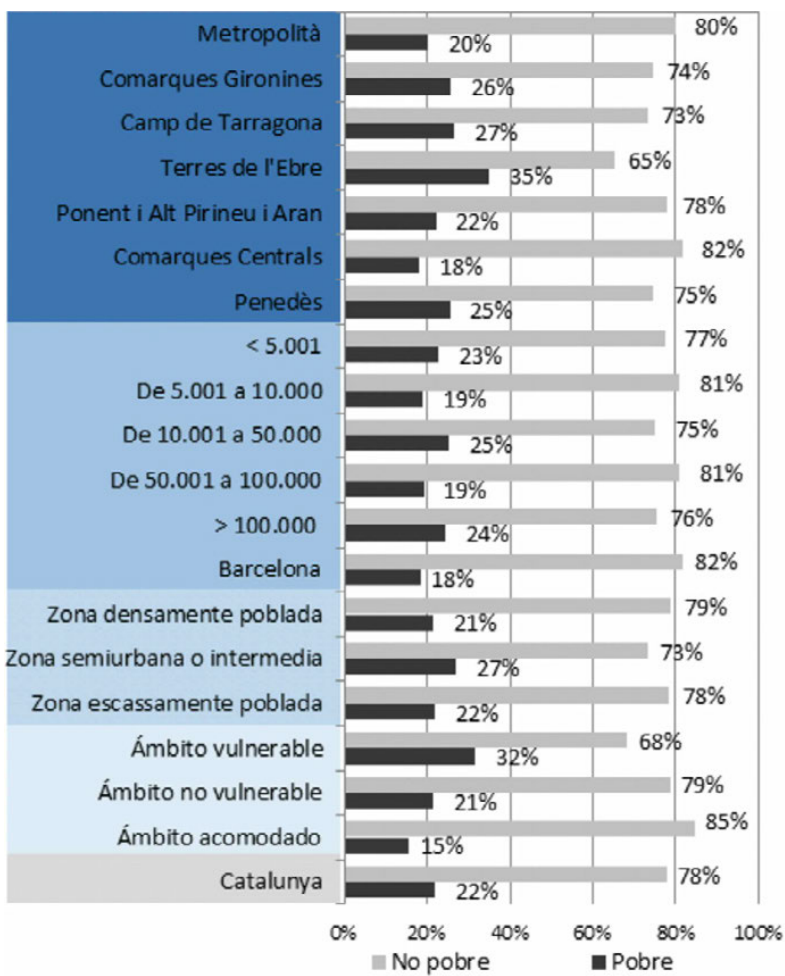

Fuente: Elaboración propia a partir de ECVHP, 2011 
La primera constatación es que, según los datos del ECVHP 2011, la tasa de pobreza se sitúa en el de 21,9\% de la población de Cataluña. Dicho de otro modo, 1 de cada 5 ciudadanos de Cataluña se encontraba en esta situación. En cuanto a la comparación entre ámbitos territoriales, hay que tener particularmente en cuenta las prevenciones que se han indicado sobre los desiguales niveles de ingresos y costes medios. Tal como puede verse en la Figura 5, las Tierras del Ebro son, de nuevo, el ámbito que presenta una mayor tasa de pobreza que afectaría casi el 35\% de su población. Seguirían el Camp de Tarragona, las Comarques de Girona y el Penedès, todos ellos alrededor del $25 \%$. Los ámbitos con menor tasa de pobreza serían Ponent y Alt Pirineu i Aran y las Comarques Centrals. La región metropolitana se situaría en cambio por debajo de la media de pobreza catalana.

Relativamente menos afectadas por los sesgos resultantes de la presencia del umbral único para toda Cataluña y, por tanto, más interesantes, resultan los datos relativos a la tasa de pobreza por tamaño poblacional y por intensidad de la urbanización. En cuanto a la primera, la ciudad de Barcelona presenta la tasa de pobreza más baja. Pero si se deja aparte la capital, se observa como la pobreza no guarda una relación directa y unívoca con el tamaño poblacional. Lo mismo ocurre con los datos relativos al grado de urbanización, donde los territorios con mayor porcentaje de pobreza son los intermedios, aunque las diferencias entre los territorios de alta y baja intensidad de urbanización no son excesivamente elevadas.

La falta de relación clara entre las variables territoriales y la situación de pobreza, contrasta claramente con el análisis resultante de la agrupación territorial según el nivel de segregación residencial. De manera bien patente, la población residente en los ámbitos vulnerables presenta una propensión más de dos veces superior que la de los ámbitos acomodados a encontrarse en una situación de pobreza: mientras en los primeros 1 de cada 3 personas se halla en esta situación, en los segundos su proporción es apenas de 1 de cada $7^{6}$.

\subsection{SALUD AUTOPERCIBIDA}

Analizados los indicadores relacionados con las oportunidades vitales, la categoría ocupacional y la pobreza, podemos aproximarnos a la cuestión de las

6 Hay que tener en cuenta, de todos modos, que en este caso los resultados pueden resultar hasta cierto punto tautológicos, ya que las variables utilizadas para construir la clasificación de las secciones censales en ámbitos vulnerables, acomodadas e intermedios - porcentaje de población en paro, porcentaje de población extranjera, valor catastral y superficie media de la vivienda- se encuentran estrechamente correlacionados con la renta. 
desigualdades territoriales a través de otra variable relacionada de manera directa con las condiciones de vida de la población: el estado de salud. Como es sabido, los expertos en materia de salud pública han explicado de manera fehaciente como las desigualdades sociales y territoriales en materia de salud son sistemáticas y producidas socialmente (Borrell y Benach, 2014; Mehdipanah et al., 2014). Así, la salud no es un vector que afecte sólo a los individuos a partir sus eventuales condicionantes genéticos, sino que está estrechamente relacionada con sus condiciones de vida. A su vez, estas dependen en buena medida del entorno, es decir de las condiciones ambientales, la contaminación, las el trabajo y las características de la vivienda. La cuestión que hay que desentrañar aquí es si estas diferencias de entorno son más decisivas cuando se analizan en términos de áreas geográficas, tamaños poblacionales, intensidad de urbanización o segregación residencial.

Figura 6. Salud auto-percibida. Población de 16 y más años. Catalunya

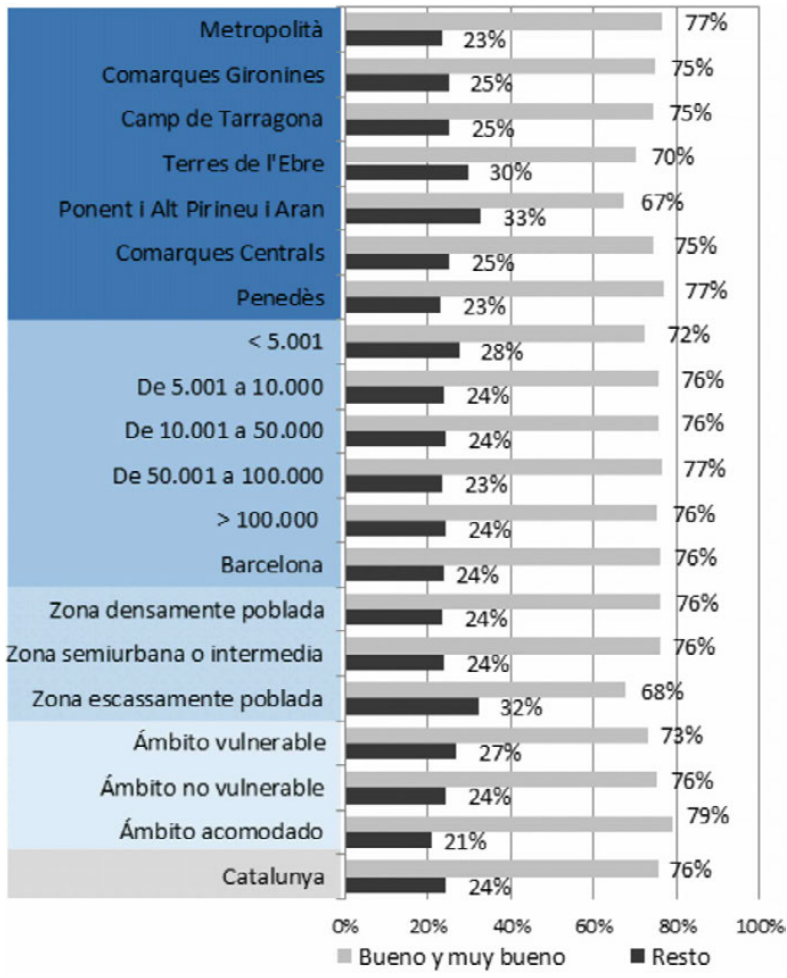

Fuente: Elaboración propia a partir de ECVHP, 2011 
Las diferencias territoriales en salud suelen ser estudiadas a partir de las tasas de mortalidad y la esperanza de vida estableciendo las relaciones que éstas tienen con las condiciones socioeconómicas, laborales y de privaciones materiales. Aquí seguiremos un camino relativamente menos trillado y estudiaremos la salud auto-percibida de las personas de 16 y más años, un indicador de autoevaluación de la salud que combina la experiencia subjetiva en cuanto a enfermedades y otras sensaciones como el agotamiento (Borrell y Benach, 2005). En particular, emplearemos, tal como ya se ha indicado, los datos relativos a la salud auto-percibida procedentes del ECVHP estableciendo dos categorías: la de aquellas personas que aseguran encontrarse en un estado de salud muy bueno o bueno, y el resto de la población, es decir la que, según su percepción subjetiva, tiene un estado de salud regular, malo o muy malo.

Los datos muestran, en este caso, sesgos que en parte pueden atribuirse no tanto a los factores territoriales, sino a la estructura de edades de la población residente en cada ámbito. Así, territorios que tienen, por término medio, una población más envejecida que el conjunto de Cataluña — como Ponent y Alt Pirineu i Aran o las Terres de l'Ebre, las villas y pueblos más chicos de 5.000 habitantes y las zonas escasamente pobladas- presentan una condición de salud auto-percibida inferior al resto. Fuera de estos extremos, las diferencias entre ámbitos -ya sean clasificados por áreas geográficas, por tamaños poblacionales, o por intensidad de urbanización - resultan poco relevantes. Tampoco son excesivas las diferencias entre los ámbitos vulnerables y los acomodados, aunque estos últimos, como sería de esperar, presentan un estado de salud auto-percibida notablemente superior al de los primeros.

Seguramente, se podrían obtener resultados más taxativos empleando otros indicadores - como la esperanza de vida al nacer o determinadas patologías, como la obesidad-y ajustando las escalas del análisis, para evitar sesgos como el de la estructura de edades (Borrell, Rodríguez-Sanz, Ricart, y Pérez, 2005; Checa y Robles, en prensa), pero esto nos llevaría ya más allá del alcance de este trabajo.

\subsection{SATISFACCIÓN VITAL}

La última variable estudiada es la satisfacción subjetiva con la vida. Como se ha indicado, los datos utilizados, procedentes del ECVHP, reflejan la percepción subjetiva de la satisfacción vital de personas de 16 y más años, utilizando una escala de 0 a 10 en el grado de satisfacción, en la que 0 responde al nivel más bajo de satisfacción 10 el más alto.

La media de satisfacción vital de la población catalana es bastante elevada y se sitúa en torno al 7,33. Las diferencias en relación al eje urbano / rural son, en este caso, casi irrelevantes y oscilan muy cerca de la media. Más significativas son las diferencias en la clasificación por tamaños poblacionales, pero 
sin seguir un patrón claro que permita relacionar ambas variables. Allí donde se producen diferencias relativamente más relevantes es entre grandes ámbitos geográficos, sin que, sin embargo, se pueda deducir un orden lógico. De nuevo, la diferencia seguramente más significativa y la más explicable es la distancia que separa la satisfacción con la vida de los que viven en los ámbitos acomodadas de los que residen en los ámbitos vulnerables. De hecho, si se obvia el contraste entre algunos de los ámbitos geográficos, se trata de la diferencia más acusada y la que afecta a más personas.

Figura 7. Satisfacción con la vida. Población de 16 y más años. Cataluña

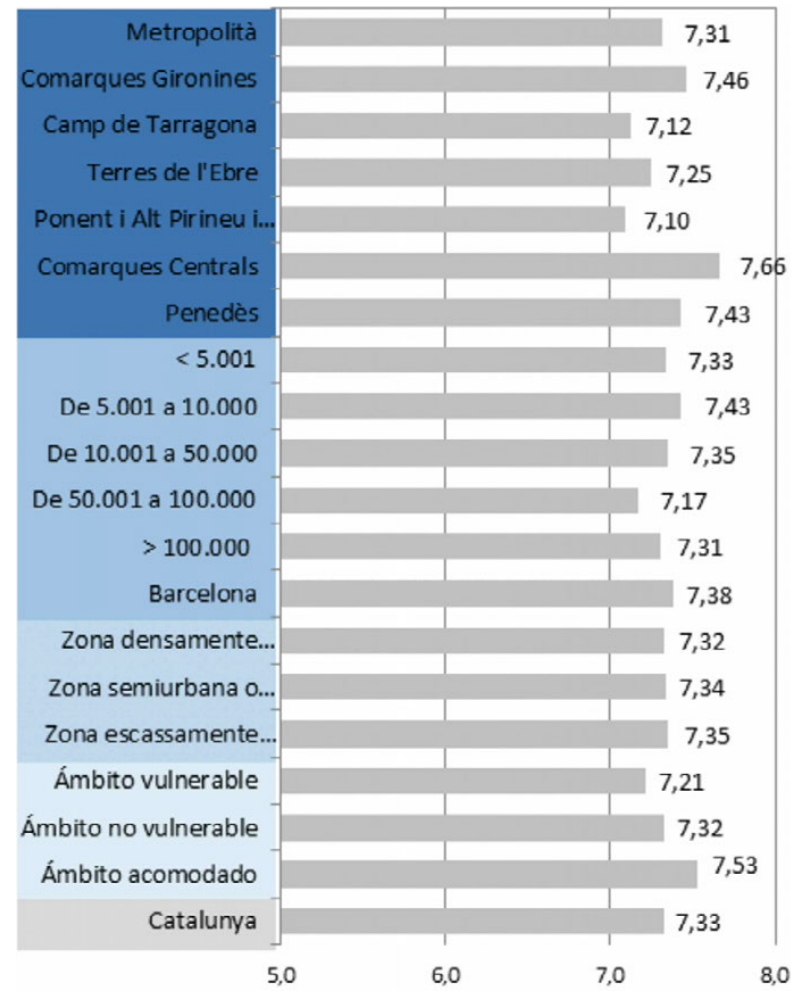

Fuente: Elaboración propia a partir de datos de la ECVHP 2011

\section{SÍNTESIS Y CONCLUSIONES}

Nuestro trabajo ha tenido como objetivo determinar si en el territorio de Cataluña se pueden observar desigualdades significativas que afecten las trayectorias y condiciones de vida de las personas, y, por tanto, la cohesión social 
del país. Para ello, se ha querido analizar la relación entre, por una parte, el territorio de residencia de la población y, por otra un conjunto de indicadores sociales (el nivel de instrucción, la posición socioeconómica, el riesgo de pobreza, la salud auto-percibida y la satisfacción vital). Para ello se han agrupado las localidades catalanas en cuatro agregaciones territoriales diversas, correspondientes a los ámbitos geográficos, el tamaño poblacional, la intensidad de urbanización y la segregación residencial.

A modo de síntesis, se han resumido los resultados obtenidos en la Tabla 1. Para facilitar la comparación hemos procedido a igualar los valores de cada una de las cinco variables analizadas en números índice (Cataluña = 100) y calculado las desviaciones medias de las observaciones. Esto permite contrastar las desviaciones obtenidas en cada uno de los tratamientos territoriales de los datos, de modo que cuando más alta sea la desviación, más discriminante resulta la agregación territorial propuesta con las desigualdades sociales. Los resultados, tal como se puede ver, son bastante ilustrativos, y permiten en buena medida confirmar la hipótesis de partida según la cual existen en Cataluña notables diferencias o fracturas territoriales, pero en vez de responder a las variables sobre las que ha girado el debate tradicional sobre el tema -la posición geográfica, el tamaño poblacional o la intensidad de la urbanización- se relacionan sobre todo con la segregación espacial de las personas y los grupos sociales en función de su renta.

Tabla 1. Síntesis de los indicadores analizados y sus desviaciones. Cataluña, base 100

\begin{tabular}{|c|c|c|c|c|c|c|c|c|c|c|c|c|c|}
\hline \multirow{2}{*}{\multicolumn{2}{|c|}{ Indicadores índice 100}} & \multicolumn{2}{|c|}{$\begin{array}{c}\text { Nivel de estudios } \\
\text { acabados (25 años y } \\
\text { mas) }\end{array}$} & \multicolumn{2}{|c|}{ 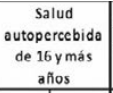 } & \multirow{2}{*}{\begin{tabular}{|c|}
$\begin{array}{c}\text { Satisfacción } \\
\text { vida de } 16 y \\
\text { más años }\end{array}$ \\
del 0 al 10
\end{tabular}} & \multicolumn{2}{|c|}{$\begin{array}{c}\text { Tasa de riesgo a la } \\
\text { pobreza } \\
\text { 60\%mediana - Total } \\
\text { CAT } \\
\end{array}$} & \multicolumn{2}{|c|}{$\begin{array}{c}\text { Clases sociales ESECC } \\
(9+1) \text { Personas de } 16 i \\
\text { más años }\end{array}$} & \multirow[t]{2}{*}{\begin{tabular}{|c|} 
medio \\
indices
\end{tabular}} & \multirow[t]{2}{*}{$\begin{array}{c}\text { Suma } \\
\text { desviaciones } \\
\text { medias }\end{array}$} & \multirow[t]{2}{*}{ media } \\
\hline & & $\begin{array}{c}\text { Sin } \\
\text { estudios } \\
\text { superiores }\end{array}$ & $\begin{array}{c}\text { Estudios } \\
\text { superiores }\end{array}$ & Resto & $\begin{array}{c}\text { Buenoy } \\
\text { muy } \\
\text { bueno }\end{array}$ & & No pobre & Pobre & $\begin{array}{c}\text { Cualificados } \\
\text { (ESEC-1,2,3) }\end{array}$ & $\begin{array}{c}\text { Otros } \\
\text { (ESEO 3) }\end{array}$ & & & \\
\hline \multirow{8}{*}{$\begin{array}{l}\text { Ambito } \\
\text { territorial }\end{array}$} & Metropolita & 96,8 & 108,4 & 95,5 & 101,4 & 99,8 & 102,3 & 91,8 & 111,4 & 95,6 & 100,3 & & \\
\hline & Comarques Gironines & 106,2 & 84,0 & 102,5 & 99,2 & 101,9 & 95,3 & 116,9 & 83,1 & 106,5 & 99,5 & & \\
\hline & Camp de Tarragona & 101,3 & 96,7 & 103,6 & 98,8 & 97,2 & 94,0 & 121,4 & 85,0 & 105,7 & 100,4 & & \\
\hline & Terres de l'Ebre & 121,0 & 45,9 & 121,4 & 93,1 & 98,9 & 83,5 & 159,0 & 52,0 & 118,4 & 99,2 & & \\
\hline & Ponent i Alt Pirineu i Aran & 103.7 & 90,4 & 133,8 & 89,1 & 96,8 & 99,8 & 100,5 & 80,5 & 107.5 & 100,2 & & \\
\hline & Comarques Centrals & 110,0 & 74,1 & 103,7 & 98,8 & 104,6 & 104,9 & 82,7 & 62,3 & 114,4 & 95,1 & & \\
\hline & Penedès & 100,4 & 99,0 & 94,4 & 101,8 & 101,4 & 95,5 & 116,0 & 101,8 & 99,3 & 101,1 & & \\
\hline & desviación media & 6,5 & 16,9 & 10,7 & 3,5 & 2,2 & 5,6 & 19,9 & 21,5 & 8,2 & & 94,95 & 10,55 \\
\hline \multirow{7}{*}{$\begin{array}{c}\text { Tamaño } \\
\text { poblacional }\end{array}$} & hasta a 5.000 hab. & 109.6 & 75,3 & 112.7 & 95.9 & 100.1 & 99.0 & 103.4 & 72.1 & 110.7 & 97.6 & & \\
\hline & De 5.001 a $10.000 \mathrm{hab}$. & 102,1 & 94,5 & 98,6 & 100,5 & 101,4 & 103,8 & 86,5 & 93,0 & 102,7 & 98,1 & & \\
\hline & De 10.001 a 50.000 hab. & 104,0 & 89,7 & 99,3 & 100,2 & 100,3 & 95,9 & 114,6 & 94,0 & 102,3 & 100,0 & & \\
\hline & De 50.001 a 100.000 hab. & 100,2 & 99,4 & 96,2 & 101,2 & 97,9 & 103,6 & 87,2 & 102,9 & 98,9 & 98,6 & & \\
\hline & Más de 100.000 hab. & 107,4 & 80,8 & 100,3 & 99,9 & 99,7 & 96,7 & 111,7 & 80,9 & 107,3 & 98,3 & & \\
\hline & Barcelona & 83,9 & 141,5 & 97,4 & 100,8 & 100,7 & 104,6 & 83,5 & 137,4 & 85,7 & 104,0 & & \\
\hline & desviación media & 6,6 & 17,0 & 3,6 & 1,2 & 0,8 & 3,4 & 12,1 & 16,7 & 6,4 & & 67,68 & 7,52 \\
\hline \multirow{4}{*}{$\begin{array}{c}\text { Grado de } \\
\text { urbanización }\end{array}$} & Zona densamente poblada & 98,4 & 104,0 & 96,9 & 101,0 & 99,9 & 100,8 & 97,1 & 104,9 & 98,1 & 100,1 & & \\
\hline & Zona semiurbana & 103,8 & 90,3 & 98,1 & 100,6 & 100,2 & 93,8 & 122,2 & 86,1 & 105,3 & 100,0 & & \\
\hline & Zona escasamente poblada & 110,4 & 73,1 & 131,8 & 89,7 & 100,3 & 100,2 & 99,3 & 70,3 & 111,4 & 98,5 & & \\
\hline & desviación media & 5,3 & 13,6 & 12,3 & 4,0 & 0,2 & 2,4 & 8,6 & 16,2 & 6,2 & & 68,61 & 7,62 \\
\hline \multirow{5}{*}{ Segregación } & Ámbito vulnerable & 117,6 & 54,7 & 110,3 & 96,7 & 98,4 & 87,5 & 144,7 & 48,0 & 119,9 & 97,5 & & \\
\hline & Ambito no vulnerable & 100,9 & 97,7 & 100,1 & 100,0 & 99,9 & 100,6 & 97,8 & 98,7 & 100,5 & 99,6 & & \\
\hline & Ámbito acomodado & 67,3 & 184,5 & 85,2 & 104,8 & 102,8 & 108,3 & 70,6 & 181,9 & 68,6 & 108,2 & & \\
\hline & desviación media & 17,1 & 44,1 & 8.4 & 2.7 & 1.5 & 7.1 & 25,4 & 45,1 & 17,3 & & 168,67 & 18,74 \\
\hline & Media Cataluña & 100 & 100 & 100 & 100 & 100 & 100 & 100 & 100 & 100 & 100 & & \\
\hline
\end{tabular}


Así, en 3 de las 5 variables estudiadas — nivel de estudios, posición socioeconómica y riesgo de pobreza - las mayores diferencias se dan claramente entre las categorías asociadas a la segregación residencial. En otros dos variables — salud autopercibida y satisfacción vital — hay una mayor dispersión asociada a los ámbitos geográficos y a otros factores como la edad media de la población. Por su lado, las diferencias asociadas al tamaño poblacional o la intensidad de la urbanización resultan en general menos relevantes. Si, para obtener un valor de síntesis, sumamos las desviaciones medias asociadas a cada una de las agregaciones territoriales, podemos observar como el valor más elevado es el que se deriva de la agrupación territorial basada en la segregación residencial. Tanto es así que la media de las desviaciones medias resultante del análisis de la segregación prácticamente dobla las medias asociadas a los análisis por ámbitos geográficos, tamaño poblacional y grado de urbanización.

Podemos concluir pues con los postulados siguientes que, como se verá, confirman, en buena medida, la hipótesis de partida:

1. Existen en Cataluña notables desigualdades en las condiciones de vida media de las personas residentes en diversas partes del territorio. Estas desigualdades son constatables a través del estudio de variables como el nivel formativo, la posición socioeconómica, el riesgo de pobreza, la salud y la satisfacción respecto a la propia vida.

2. Los datos disponibles parecen ratificar la afirmación, repetida en la literatura, según la cual el lugar de residencia condiciona las oportunidades y las características de la vida de la población, y lo hace en una doble vertiente: por un lado, las diferencias sociales condicionan la capacidad de los individuos, las familias y los grupos sociales de asentarse y utilizar las diversas áreas del territorio; por otra parte, la distribución de la población sobre el territorio contribuye a consolidar y reproducir las diferencias sociales.

3. Las variables que presentan diferencias territoriales más acusadas son, por este orden, la posición socioeconómica de la población ocupada, el nivel de estudios alcanzado y el riesgo de pobreza.

4. El análisis de las variables sociales a partir la agrupación de las localidades según su tamaño y según la intensidad de urbanización (lo que tradicionalmente se ha denominado el eje urbano/rural) tiene una escasa capacidad discriminatoria y explicativa. Esta constatación tiene implicaciones relevantes, ya que el tamaño de las localidades y la ruralidad han sido los factores tradicionalmente tomados como referencia a la hora de analizar y debatir las desigualdades territoriales, y vertebran buena parte del imaginario y el debate territorial, tanto en Cataluña como fuera de ella.

5. Más significativa resulta, en cambio, la agrupación de las localidades segundo los grandes ámbitos geográficos. Sin embargo, las diferencias entre estos ámbitos son especialmente relevantes en relación a variables que 
tienen un componente subjetivo (salud percibida, satisfacción vital) y, en todo caso, resultan difíciles de reducir a oposiciones simplificadoras del tipo litoral/interior, montaña/llano o metropolitano/no metropolitano.

6. En todo caso, las desigualdades territoriales más destacadas son las que se asocian a la segregación residencial. Así las fracturas territoriales más importantes en variables clave, como el nivel de estudios o la posición socioeconómica, se encuentran entre los ámbitos acomodados y los ámbitos vulnerables.

7. Debe recordarse que en las áreas vulnerables del territorio catalán residía en el año 2012 un total de cerca de 700.000 personas y en las áreas acomodadas hay vivían más de 600.000. Estos ámbitos caracterizados por la segregación residencial extrema, discontinuos sobre el territorio, contenían pues una población superior a la de cualquiera de los ámbitos territoriales de Cataluña, excepción hecha del metropolitano. Llama pues poderosamente la atención que, en el debate político y ciudadano acerca de las fracturas territoriales, la discusión sobre la segregación residencial y sus efectos tenga una presencia relativamente escasa.

\section{BIBLIOGRAFÍA}

Atkinson, T. (2015). What can be done about inequality? Juncture, 22(1), 32-41. https://doi.org/10.1111/j.2050-5876.2015.00834.x

Antón-Alonso, F. y Porcel, S. (2019). Del barri a la metròpoli: dinàmiques de mobilitat residencial metropolitanes. En J. Clapés (Ed.), Anuari metropolità de Barcelona 2018: Del barri a la metrópoli, pp. 11-24. Bellaterra: Institut d'Estudis Regionals i Metropolitans de Barcelona.

Blanco, I. y Nel|lo, O. (Eds.). (2018). Barrios y Crisis. Crisis económica, segregación urbana e innovación social en Cataluña. València: Tirant lo Blanch.

Bonal, X. (2018). La política educativa ante el reto de la segregación escolar en Cataluña (Prospectivas). París: UNESCO IIEP.

Borrel, C., y Benach, J. (2014). Els determinants socials de la salut. Espai fàbrica.

Borrell, C., y Benach, J. (Coord). (2005). Evolució de les desigualtats en la salut a Catalunya. Barcelona: Editorial Mediterrània, Fundació Jaume Bofill.

Borrell, C., Rodríguez-Sanz, M., Ricart, I. y Pérez, G. (2005). Les desigualtats socials en salut a Barcelona. Barcelona Societat 13, 104-113.

Checa, J. y Robles, M. (en prensa), ¿Mueren antes los pobres? Esperanza de vida, salud mental y obesidad en la ciudad. En Oriol Nel.lo (Ed.), Efecto barrio. Segregación social i condiciones de vida en las grandes ciudades ibéricas (en prensa).

Del Molino, S. (2016). La España vacia. Viaje por un país que nunca fue. Madrid: TURNER. 
Flores Martos, R., Gómez Morán, M. y Renes Ayala, V. (2016). La transmisión intergeneracional de la pobreza: factores, procesos y propuestas para la intervención. Madrid: Fundación FOESSA; Cáritas Españolas.

Fontana, J. (2013). El futuro es un pais extraño: una reflexion sobre la crisis social de comienzos del siglo XXI. Barcelona: Ediciones de Pasado y Presente. Gomà, A., y Muñoz, J. (2018). Segregated in the City, Separated in the School. The Reproduction of Social Inequality through the School System. Urban Science, 2(4), 112. https://doi.org/10.3390/urbansci2040112

Guilluy, C. (2014). La France périphérique : comment on a sacrifié les classes populaires. Paris: Flammarion.

Judt, T. (2011). III fares the land: a treatise on our present discontents. New York: Penguin Books.

McCann, P. (2016). The UK Regional-National Economic Problem: Geography, Globalisation and Governance. Abingdon: Routledge.

Mehdipanah, R., Rodríguez-Sanz, M., Malmusi, D., Muntaner, C., Díez, E., Bartoll, X. y Borrell, C. (2014). The effects of an urban renewal project on health and health inequalities: a quasi-experimental study in Barcelona. Journal of Epidemiology and Community Health, 68(9), 811-817. https://doi.org/10.1136/jech-2013-203434

Milanovic, B. (2016). Global inequality: a new approach for the age of globalization. Cambridge, Massachusetts: Harvard University Press.

Nel.lo, O. y Gomà, A. (2018a). Geographies of discontent: urban segregation, political attitudes and electoral behaviour in Catalonia. City, Territory and Architecture, 5(1), 23.

Nel·lo, O. y Gomà, A. (2018b). Territori. Diversitat espacial en els hàbits i condicions de vida juvenils: el paper clau de la segregació residencial. En P. Sarrecant (Ed.), Enquesta de Joventut de Catalunya 2017 Vol. 2. Experiències juvenils i desigualtats socials, pp. 441-534. Barcelona: Generalitat de Catalunya. Departament de Treball, Afers Socials i Families.

$\mathrm{Nel} \cdot$ lo, O. y Donat, C. (2014). Los efectos territoriales de la crisis econòmica en la región metropolitana de Barcelona. En J. M. Albertos y J. L. Sánchez (Eds.), Geografia de la crisis económica en España (pp. 565-608). Valencia: Publicacions Universistat de València.

Rodríguez-Pose, A. (2017). The revenge of the places that don't matter (and what to do about it). Cambridge Journal of Regions, Economy and Society, 11(1), 189-209. https://doi.org/10.1093/cjres/rsx024

Piketty, T. (2013). Le Capital au XXIe siècle. Éditions du Seuil. Harvard University Press.

Porcel, S. (2013). Desigualtats territorials i mobilitat quotidiana. Una aproximació socioterritorial a la realitat juvenil catalana. En P. Serracant (Ed.), Enquesta a la joventut de Catalunya 2012, Volumen 2, pp. 315-379. Barcelona: Generalitat de Catalunya Departament de Benestar Social i Família Direcció General de Joventut. 
Sarasa, S., Porcel, S., y Navarro-Varas, L. (2013). L'impacte social de la crisi a l'Àrea Metropolitana de Barcelona i a Catalunya. Papers: Regió Metropolitana de Barcelona, 56, 10-87.

Sommeiller, E., y Price, M. (2014). The Increasingly Unequal States of America: Income Inequality by State, 1917 to 2017.

Stiglitz, J. E. (2012). The Price of Inequality: How Today's Divided Society Endangers Our Future. London: W. W. Norton \& Company.

Streeck, W. (2016). How will capitalism end? Verso. London, United Kingdom.

Traverso, E. (2019). The new faces of fascism: populism and the far right. Verso Books.

Urry, J. (2014). Offshoring. Cambridge, United Kingdom: Polity Press. 


\title{
BARRIOS TURÍSTICOS Y NUEVOS PROCESOS DE DESIGUALDAD SOCIO-URBANA EN BALEARES Y CANARIAS ${ }^{1}$
}

\author{
TOURISM NEIGHBORHOODS AND NEW SOCIO-URBAN INEQUALITY PROCESSES \\ Josefina Domínguez-Mujica \\ Universidad de Las Palmas de Gran Canaria \\ Jesús M. González-Pérez \\ Universitat de les IIles Balears \\ Juan Parreño-Castellano \\ Universidad de Las Palmas de Gran Canaria \\ Dolores Sánchez-Aguilera \\ Universidad de Barcelona
}

Resumen

Los barrios turísticos maduros son un valioso laboratorio para el estudio de procesos socio-urbanos. En ellos es posible analizar las transformaciones urbanas y los cambios sociales vinculados a los ciclos turísticos: los correspondientes a las etapas de desarrollo y consolidación turísticos; a la de estancamiento y declive y a la de rejuvenecimiento y rehabilitación urbana. En la actualidad, hay indicios de un cuarto ciclo, donde la vivienda vacacional y la llegada de nuevos colectivos de extranjeros están originando un proceso de gentrificación turística.

En este contexto, el objetivo de este trabajo es estudiar las transformaciones sociourbanas de dos barrios turísticos maduros en Palma (El Terreno) y Las Palmas de Gran Canaria (Santa Catalina-Canteras) y detectar este proceso de gentrificación turística. El análisis lo realizamos a partir de indicadores de población residente (total de población y extranjeros por nacionalidades), vivienda (mercado de alquiler vacacional y del mercado inmobiliario) y niveles socio-económicos (renta), lo que nos permite detectar la existencia de un nuevo ciclo urbano-turístico que, apoyado en fuertes inversiones asociadas a planes de rehabilitación, está produciendo la sustitución de extranjeros del Sur por los del Norte, del alquiler residencial por el vacacional, en un contexto de elitización.

1 Este trabajo ha sido realizado gracias a los proyectos de investigación I+D «Vivienda y movilidad internacional en las ciudades de Canarias. La aparición de nuevas formas de desigualdad urbana» (RTI2018-093296-B-C21) y «Vivienda y movilidad internacional en ciudades de las Islas Baleares. La aparición de nuevas formas de desigualdad urbana» (RTI2018-093296-B-C22), financiados por el Fondo Europeo de Desarrollo Regional (FEDER) / Ministerio de Ciencia, Innovación y Universidades - Agencia Estatal de Investigación (AEI). 
Palabras clave: gentrificación turística, mercado inmobiliario, migraciones internacionales, renovación urbana, niveles de renta.

\begin{abstract}
Mature tourism neighborhoods are a valuable laboratory for the study of socio-urban processes. In them, it is possible to analyze the urban transformations and social changes linked to tourism cycles: those corresponding to the stage of tourism involvement, development and consolidation, the one of stagnation and urban decline and the one of tourism rejuvenation and urban rehabilitation. Currently, there are indications of a fourth cycle, where vacation rentals and the arrival of new groups of foreigners are causing a tourism gentrification process.

In this context, the aim of this work is to study the socio-urban transformations of two mature tourism neighborhoods in Palma (El Terreno) and Las Palmas de Gran Canaria (Santa Catalina-Canteras) and detect this tourism gentrification process. The analysis is based on indicators of resident population (total population and foreigners by nationalities), housing (holiday rental market and real estate market) and socio-economic levels (income), which allows us to detect the existence of a new urban-tourism cycle. This, supported by strong investments associated with rehabilitation plans, is producing the substitution of foreigners from the South for those from the North, from the residential rental by the vacation rentals, in a context of elitization.
\end{abstract}

Keywords: tourism gentrification, real estate market, international migrations, urban rejuvenation, income levels.

\title{
1. INTRODUCCIÓN. EL DESARROLLO TURÍSTICO DESDE UNA PERSPECTIVA URBANA. ESTADO DE LA CUESTIÓN
}

Las capitales de Mallorca y Gran Canaria, como ciudades insulares que desarrollaron una temprana actividad turística desde finales del siglo XIX, respondieron al turismo de masas a partir de los años cincuenta del siglo XX incrementando su oferta hotelera y extrahotelera en determinados barrios, como es el caso de los de El Terreno, en Palma, y Santa Catalina-Canteras, en Las Palmas de Gran Canaria. A medida que la actividad turística ganó importancia en otras localidades de las islas, las inversiones en estos sectores urbanos se redujeron y la infraestructura alojativa comenzó a deteriorarse. «El turismo de elite de la primera etapa dio paso a un turismo de masas en los años cincuenta y sesenta y a una situación de profunda crisis y reconversión desde mediados de los años setenta» (Domínguez, González y Parreño, 2008, 16). La reestructuración postfordista de los años ochenta y noventa contribuyó al declive de estos barrios desde la perspectiva de la explotación para el ocio. 
Al mismo tiempo, desde el punto de vista de la oferta residencial, el mercado inmobiliario revalorizó algunas propiedades de antiguo uso turístico reconvirtiéndolas en viviendas, especialmente las que se hallaban en el frente marítimo, y puso en circulación, directamente, para el mercado del alquiler no-turístico, algunos de los inmuebles ya obsolescentes.

La situación de declive se mantuvo hasta bien entrado el siglo XXI, pues a la deficiente adaptación se sumó el impacto de la crisis económica, de forma que se registraba en ellos una oferta turística marginal (aunque con notables excepciones, pues seguían funcionando algunos hoteles de máxima categoría) y una oferta de antiguos inmuebles de uso turístico, como viviendas en alquiler. Este hecho propició la ocupación de una parte de estos inmuebles por inmigrantes laborales de escasa renta. Por tanto, estas modificaciones en el uso de los inmuebles pusieron de manifiesto la incierta adaptación de estos sectores urbanos al modelo postfordista, como bien describíamos en un texto redactado en 2008, en el que destacábamos el fenómeno demográfico que lo acompañaba, es decir, el proceso de residencialización de inmigrantes con bajos niveles de renta en dichos barrios. Este proceso (filtering) suele preceder las dinámicas gentrificadoras, que se activan cuando se dan las condiciones de mercado como para que se inicie una revalorización, es decir, cuando los inmuebles rehabilitados o renovados permiten un margen de beneficio (rent gap) (Domínguez, Parreño y Moreno, 2020).

Esto es lo que ha sucedido en los últimos siete $u$ ocho años, que se ha desencadenado un proceso de gentrificación turística (aunque más intenso en Santa Catalina-Canteras y menos notable en El Terreno), a consecuencia de las estrategias de adquisición de los agentes del mercado turístico, financiero-inmobiliario y de las empresas de la llamada economía colaborativa que operan en el mercado del alquiler turístico, a medida que estos inversores han apreciado nuevas oportunidades de negocio (Lee, 2016).

Aunque la gentrificación turística en los espacios urbanos desborda los espacios de ocio tradicionales; en el caso que nos ocupa, turismo y gentrificación se refuerzan mutuamente (Maitland y Newman, 2018), dando lugar a cambios definitivos en la infraestructura alojativa de estos barrios, favoreciendo la reducción del número de viviendas y desplazando a grupos de población de escasa renta a favor de residentes con un mayor nivel de ingresos, es decir, favoreciendo un proceso de elitización.

La evolución que hemos venido describiendo puede ser interpretada a la luz del modelo que Butler acuñó como TALC (Tourism Area Life Cycle - ciclo de vida de un área turística) (Butler, 1980), según el cual los destinos turísticos tienen una naturaleza dinámica, pasando por distintas fases de evolución. En la última cabe el rejuvenecimiento o el declive de dicho destino. Esta interpretación, que ha dado lugar a numerosas controversias (Butler, 2011), puede sernos útil como modelo descriptivo para analizar las primeras fases de evoIución de los barrios de El Terreno y Santa Catalina-Canteras. 
Sin embargo, para caracterizar el proceso de evolución, en su conjunto, nos parece más acertado hacerlo desde una perspectiva crítica que conecte el desarrollo turístico con la sucesión de los distintos regímenes de acumulación del capital (Soja, 1989; Harvey, 2002), especialmente si consideramos las transformaciones que se producen a partir de la segunda década del siglo XXI. Así, la tesis re-estructurante (Dicken, 1992; Boyer, 2011), defiende que el sistema económico del fordismo ha dado paso a un régimen de acumulación flexible, el del capitalismo global y el del modelo de acumulación digital, un marco teórico de referencia que nos permite interpretar las recientes transformaciones que se producen en los ámbitos de estudio de este trabajo. Incluso, desde la perspectiva de las mutaciones demográficas, la tesis referida nos es de interés pues la movilidad humana es teorizada como una condición necesaria para la re-estructuración económica, al mismo tiempo que como consecuencia de ella (Domínguez, González y Parreño, 2011).

\section{FUENTES, METODOLOGÍA Y OBJETIVOS DE LA INVESTIGACIÓN}

Con la finalidad de caracterizar las dinámicas socio-urbanas de los barrios turísticos maduros de El Terreno y Santa Catalina-Canteras, hemos combinado distintas fuentes de investigación, algunas de ellas relativas a la población según origen geográfico (datos del Padrón Continuo de Población a nivel de microescala); otras a la infraestructura turística (número de camas en alojamientos turísticos y viviendas de uso turístico según datos de portales como AIRDNA y de los Patronatos de Turismo de las islas respectivas); y, por último, la información sobre el nivel socioeconómico de la población de dichas entidades (datos de renta de la Agencia Tributaria de España).

Los datos procedentes de estas fuentes han sido tratados con procedimientos de estadística descriptiva, aunque la mayor dificultad para la selección de la información ha derivado de las distintas referencias espaciales que nos brindan las distintas fuentes a nivel microescalar. Así, los datos demográficos corresponden a las secciones censales, los datos turísticos a unidades específicas (inmuebles) y los datos de renta a distritos postales. En cualquier caso, hemos tratado de homogeneizar la información mediante un SIG.

Este procedimiento de trabajo nos ha permitido alcanzar los siguientes objetivos: a) caracterizar la evolución demográfica de dichos barrios, los incrementos o retrocesos de población y, especialmente, las dinámicas de la inmigración según orígenes geográficos; b) analizar la evolución de la oferta alojativa para calibrar el peso de los establecimientos turísticos y de las viviendas de uso turístico en las zonas de estudio; y c) interpretar la evolución del nivel socio-económico de dichos barrios. La combinación de estos objetivos nos ofrece una imagen del proceso de gentrificación turística de ambos barrios, en una fase tardía del capitalismo que los revaloriza para nuevos usos productivos y que consolida una ciudad desigual: la de inversores frente a la de vecinos. 


\section{3. ÁMBITOS GEOGRÁFICOS DE ESTUDIO}

Santa Catalina-Canteras se halla en los confines septentrionales del istmo de Guanarteme, la lengua de arenas que descansa sobre las coladas lávicas que, procedentes de los conos volcánicos holocenos de la península de La Isleta, unen aquélla, situada en el extremo nororiental de la ciudad, con el resto de la isla de Gran Canaria (Figura 1). Se trata de un barrio delimitado por la playa de Las Canteras, al oeste del istmo, y por el recinto del puerto de La Luz, al este, el puerto más importante del Atlántico Medio y uno de los cinco españoles (Eurotransmer, 2019).

El proceso de urbanización de este istmo se demoró hasta fines del siglo XIX, cuando comenzó la construcción del primer muelle, el de Santa Catalina (1883) (Solbes, 2004). Por las mismas fechas, también inició su especialización turística, pues comenzaron a erigirse viviendas de veraneo por parte de algunos propietarios de la burguesía y aristocracia locales (Domínguez, González y Parreño, 2011) y a ello se sumaron otras iniciativas de inversión extranjera, como las de balnearios. La urbanización de la zona se realiza mediante un procedimiento de ensanche con una trama ortogonal adaptada a edificaciones de baja altura. Desde los sesenta se multiplican actuaciones de renovación que supusieron un importante incremento de la edificabilidad. Buena parte de estos nuevos edificios correspondieron con hoteles y complejos de apartamentos, posteriormente residencializados de tal modo que hoy en día se puede considerar que Santa Catalina-Canteras es un barrio híbrido de carácter residencial, comercial y turístico.

Figura 1. Perspectiva aérea de Santa Catalina-Canteras

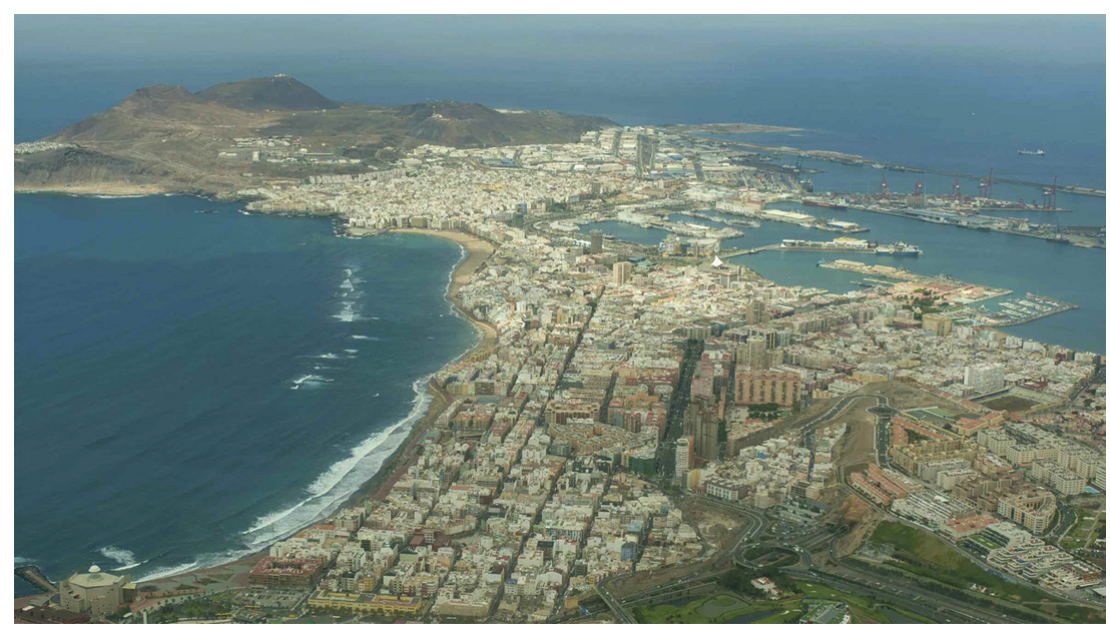

Fuente: Claudio Moreno 
El Terreno era un pequeño núcleo extramuros desconectado de la ciudad hasta 1932. Auspiciada por la pequeña burguesía de Palma, a mediados del siglo XIX se dio inicio a una importante actividad edificatoria en el barrio con el objetivo de construir residencias para su disfrute durante el período estival. En 1910, El Terreno estaba plenamente constituido y en ese mismo año se inauguró el primer hotel (Reina Victoria). Aunque continuaba siendo un lugar de edificación laxa, con viviendas mayoritariamente unifamiliares provistas de jardín, en las dos siguientes décadas las casas crecieron en altura (Barceló, 1963). Algunas de éstas comenzaron a ser alquiladas también a turistas extranjeros, especialmente ingleses. Y, como consecuencia de ello, desde mediados de los años 1920, El Terreno dejó de ser un caserío de veraneo para las clases medias de Palma y se convirtió en una zona turística hotelera y residencial (Seguí, 2001).

A partir de 1950, el despegue turístico transformó y dio la forma urbana actual del barrio. Por un lado, la función residencial perdió fuerza en beneficio de la turística. Por otro, la construcción del paseo marítimo desplazó la centralidad del barrio desde el interior del entramado urbano hacia la vía litoral. Por último, el aumento del valor del suelo hizo que muchos propietarios sustituyeran sus antiguas casas por bloques de apartamentos, y que la primera línea del paseo marítimo se inundara de edificios de gran altura que contribuyeron al aislamiento del barrio original (Domínguez, González y Parreño, 2008).

En la actualidad, el barrio está claramente segregado en dos zonas, alta y baja. La avenida Joan Miró, calle principal del barrio hasta la construcción del paseo marítimo, actúa de frontera urbana. La zona alta se caracteriza por calles estrechas y fuertes pendientes, y combina viviendas unifamiliares de las primeras etapas del turismo (arquitectura de «villes») con otras plurifamiliares de baja calidad. La zona baja, situada entre el paseo marítimo (avenida Gabriel Roca) y la avenida Joan Miró, es una zona altamente revalorizada. (Figura 2).

Figura 2. Perspectiva aérea y grandes zonas urbanas de El Terreno
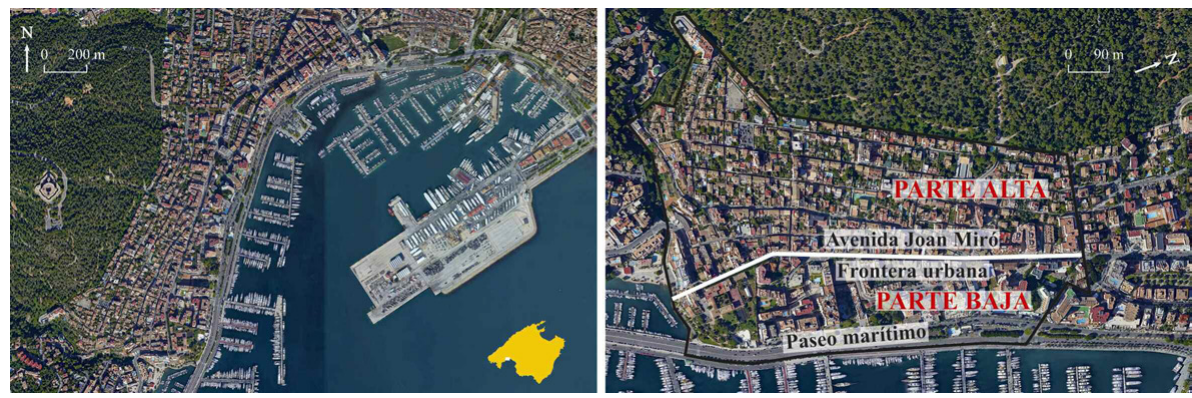

Fuente: Elaboración propia a partir de Google Earth (2020) 
Esta zona baja, en la que se concentran muchos de los locales de ocio nocturno, se caracteriza por sus edificaciones altas y de efecto muralla, especializados en la función residencial o en la oferta turística de alta calidad. En medio, la calle Joan Miró atraviesa un profundo deterioro. Pequeño comercio, locales de ocio nocturno alternativo y función residencial degradada caracterizan esta parte central del barrio, antiguamente reconocido centro turístico del Mediterráneo y previsiblemente una de las futuras nuevas áreas gentrificadas de la ciudad.

\section{EVOLUCIÓN DEMOGRÁFICA Y MODIFICACIÓN DE LOS STOCKS DE INMIGRANTES SEGÚN NACIONALIDAD}

En una ciudad de 379.925 habitantes en 2019, las secciones censales correspondientes al barrio de Santa Catalina-Canteras arrojaban una cifra de población de 21.732 habitantes, es decir, un 5,7 \% de la población municipal, siendo una quinta parte, extranjeros (21,6\%).

Cuando comparamos estos datos con los de la población de 15, 10 y 5 años atrás (Tabla 1), se aprecia que el ritmo de crecimiento fue muy intenso entre 2004 y 2009 (5,93\% quinquenal), cuando la obsolescencia turística confirmó la tendencia hacia una oferta de viviendas que reutilizaba la antigua planta extrahotelera, en un momento de gran atracción inmigratoria, vinculada a los años del boom inmobiliario de la economía española. Por ello, el crecimiento de este vecindario se debía al de población extranjera, cuyo número se incrementó en un 3,9\% anual en esos cinco años. A partir de la crisis, la población redujo su ritmo de crecimiento drásticamente y, en la incipiente fase de recuperación económica se registran tasas negativas, a medida que se ha producido una revalorización del uso turístico, tendencia que está afectando especialmente a la población de origen extranjero.

Tabla 1. Población de Santa Catalina-Canteras

\begin{tabular}{|c|c|c|c|c|c|}
\hline & Españoles & Extranjeros $^{2}$ & Total & \% Tc anual españoles & \% Tc anual extranjeros \\
\hline 2004 & 15.951 & 5.465 & 21.416 & & \\
\hline 2009 & 16.164 & 6.522 & 22.686 & 1,2 & 3,9 \\
\hline 2014 & 17.205 & 5.682 & 22.887 & 0,2 & $-2,6$ \\
\hline 2019 & 17.033 & 4.699 & 21.732 & $-1,0$ & $-3,5$ \\
\hline
\end{tabular}

Fuente: Padrón Continuo de Población. INE. Elaboración propia

2 La población extranjera considerada es la de nacionalidad extranjera en todos los años, y no la población nacida en el extranjero (inmigrantes propiamente dichos), 
En cuanto a la composición de la población extranjera y su evolución en términos relativos, la Figura 3 permite apreciar que la participación de los extranjeros procedentes de Europa Comunitaria ha ido ganando peso, estabilizándose en torno al 37\%, que ha perdido presencia la procedente de África, y que ha reforzado su importancia la población de origen asiático, manteniéndose la de origen americano en torno al $18 \%$.

Una vez seleccionadas las nacionalidades con un número superior a 150 personas en 2019, se advierte además: un decrecimiento continuado de los residentes marroquíes, colombianos y cubanos $^{3}$, una evolución creciente de italianos y un incremento de alemanes y chinos entre 2009 y 2014 y posterior decrecimiento entre 2014 a 2019. Todo ello informa de una modificación del vecindario en función de procesos de elitización, por la previsible correlación entre nacionalidad y renta.

Figura 3. Evolución de la población extranjera en Santa Catalina-Canteras

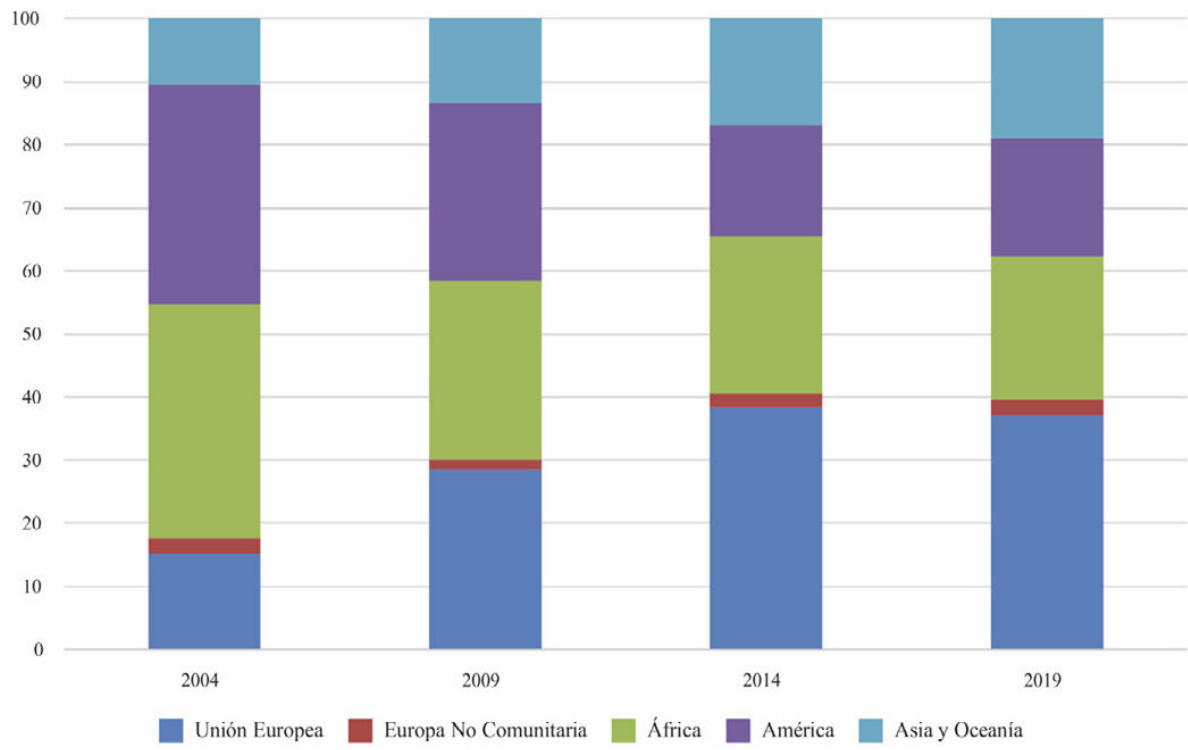

Fuente: Padrón Continuo de Población. INE. Elaboración propia

dado que el Padrón sólo ofrece información relativa al lugar de nacimiento en los años 2004 y 2009 a nivel de microdatos. Por tanto, los efectos de los procesos de nacionalización pueden influir en los resultados.

3 En la disminución del número de extranjeros también ha podido influir la nacionalización de algunos de ellos. 
En el caso de El Terreno, los poco más de 5.600 habitantes del barrio suponen apenas un 1,35\% de la población de Palma. De estos, un 29,5\% tiene nacionalidad extranjera. Un porcentaje superior a la del municipio (15,84\%). No obstante, los comportamientos socio-urbanos que conoce esta pequeña parte de la ciudad son una muestra de los procesos de transformación social, económica, paisajística y cultural que están afectando a núcleos turísticos maduros que, tras sucesivas etapas de esplendor y degradación, se están reinventando a través de la gentrificación.

La evolución de población en los últimos quince años en El Terreno fue contraria a la conocida en Santa Catalina-Las Canteras. La degradación urbana del barrio en su etapa de obsolescencia turística retrajo el número de habitantes, especialmente aquellos de nacionalidad extranjera. Una caída de efectivos a partir de 2009 que, en el caso de los no españoles, se puede explicar fundamentalmente por las consecuencias de la crisis económica y el impacto del desempleo en la población inmigrante laboral. Esto explica que, en sólo cinco años (2009-2014), los extranjeros redujeron su representación en casi un $27 \%$.

Por el contrario, los últimos cinco años, cuando los efectos de la crisis se han reducido de manera significativa en la economía turística balear, la población recupera su dinamismo apoyado en una creciente llegada de extranjeros. Eso sí, extranjeros de otra procedencia. Estamos ante un primer indicador de las transformaciones sociourbanas del barrio en la etapa poscrisis. (Tabla 2).

Tabla 2. Población de El Terreno

\begin{tabular}{|c|c|c|c|c|c|}
\hline & Españoles & Extranjeros & Total & \% Tc anual españoles & \% Tc anual extranjeros \\
\hline 2004 & 3.812 & 2.377 & 6.189 & & \\
\hline 2009 & 3.781 & 2.159 & 5.940 & $-0,81$ & $-9,17$ \\
\hline 2014 & 3.797 & 1.577 & 5.374 & $-0,42$ & $-26,96$ \\
\hline 2019 & 3.993 & 1.673 & 5.666 & 5,16 & 6,09 \\
\hline
\end{tabular}

Fuente: Elaboración propia a partir de estadísticas de Institut d'Estadística de les Illes Balears (IBESTAT)

Esta tendencia queda refrendada con el análisis de la evolución de la población extranjera según origen (Figura 4). Tal y como sucede en el caso canario, aumenta la representación de los extranjeros de la Unión Europea (casi el 50\% del total en 2019) y, en menor medida, la asiática (China y Filipinas, fundamentalmente). Este crecimiento relativo se produce sobre todo a costa de una pérdida de representatividad de americanos. Estos últimos han pasado de ser casi el 40\% en 2004 a menos de un 25\% en 2019.

Si tomamos como referencia las nacionalidades más numerosas en 2019 , la evolución señala un aumento de alemanes, italianos y, en menor medida, bri- 
tánicos y franceses. Y una caída de búlgaros y colombianos. El caso de los nacionales de Bulgaria es un indicador de los cambios sociales y económicos del barrio: en sólo diez años han pasado de liderar el número de extranjeros a ocupar la cuarta posición y, lo que es más importante, manifestando una tendencia claramente descendente.

En definitiva, a partir de evoluciones poblacionales contrapuestas (aumento de la población en El Terreno y decrecimiento en Santa Catalina-Las Canteras), Ios dos barrios caminan en una misma dirección: la elitización. Una gentrificación donde los colectivos extranjeros del Norte desempeñan un papel fundamental en los dos barrios de estudio. En estos, los europeos comunitarios sustituyen progresivamente a los hasta hace poco mayoritarios inmigrantes laborales del Sur.

Figura 4. Evolución de la población extranjera en El Terreno

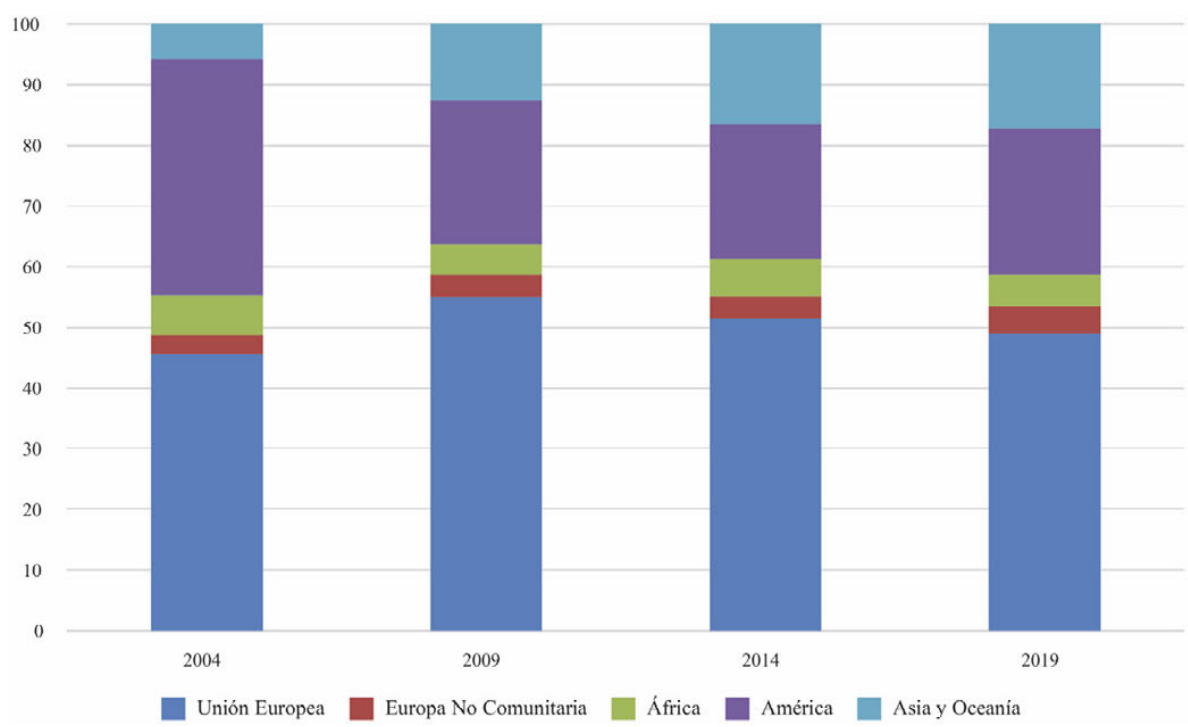

Fuente: Elaboración propia a partir de INE, Padrón Continuo de Población

\section{GENTRIFICACIÓN TURÍSTICA EN SANTA CATALINA-CANTERAS}

El barrio de Santa Catalina-Puerto cuenta con veintiún hoteles y 3.221 plazas, que componen una oferta diversa: dos establecimientos de cinco estrellas, cuatro de cuatro estrellas, ocho de tres estrellas y los restantes siete con inferior categoría. La oferta es también variada en relación con el tamaño de los establecimientos: tres de ellos de gran tamaño para un entorno urbano, con más de 400 plazas, cuatro de tamaño intermedio y la gran mayoría, pequeños hoteles con menos de 100 plazas. 
La mayoría de estos negocios fueron inaugurados en la década de los sesenta, y, salvo algunos de menor categoría, han sido reformados en profundidad y recualificados en la última década. A ellos hay que sumar otros de pequeño y mediano tamaño que se han inaugurado en los últimos años y que conforman un tejido de hoteles emblemáticos en edificios históricos, hoteles de colección y hoteles boutique, orientados a un cliente con poder adquisitivo medio-alto. Precisamente, la reciente apertura de nuevos hoteles y las perspectivas futuras al respecto han motivado que el portal Trip Advisor haya reconocido a la ciudad como el primer destino emergente de Europa en 2016.

La oferta hotelera se completa en el barrio con una también amplia oferta de apartamentos. Diecisiete complejos de apartamentos están en explotación en el barrio de Santa Catalina-Canteras, alcanzando 1.288 plazas. Son todos complejos de tamaño pequeño o mediano que comenzaron su explotación en los sesenta y setenta. Los complejos de apartamentos del barrio son la mejor expresión del devenir turístico de la ciudad. Encontramos unos pocos, los mejor situados, que han realizado procesos de remodelación y que mantienen la unidad de explotación, sumándose a la tendencia turística que caracteriza a la ciudad. En algunos casos nuevas empresas explotadoras llevan su comercialización. Otros siguen orientados a un segmento de bajo precio sin obtener renta de su excelente localización. Y otros muchos simplemente se ha residencializado, convirtiéndose en segundas residencias o entrando en el negocio del alquiler convencional, orientados en ocasiones a grupos sociales con pocos recursos.

A toda esta oferta turística reglada presente en el barrio hay que sumar tres hostales y, sobre todo, 2.188 plazas en viviendas turísticas. La vivienda turística es un tipo de alquiler de reciente implantación en Canarias, con una todavía más reciente regulación a nivel autonómico y municipal.

Por su origen y forma de explotación cabe encontrar tres situaciones diferenciadas. Primero, viviendas principales o que estaban en alquiler inmobiliario que se han registrado como viviendas turísticas por sus propietarios. Segundo, antiguos complejos de apartamentos que se residencializaron entre los setenta y noventa con el declive turístico de la ciudad y que han empezado a comercializarse bajo esta fórmula, ante la mayor perspectiva de negocio, por sus propietarios o a través de empresas explotadoras que se han introducido en este nuevo mercado del alojamiento, bajo fórmulas contractuales que conllevan la remodelación de los inmuebles. Y, tercero, complejos de apartamentos que cambian de modelo de explotación, sin que medie un proceso de residencialización. Por tanto, el panorama actual aglutina situaciones propias de la economía colaborativa con otras claramente profesionalizadas.

Las expectativas turísticas del barrio han impulsado su sector inmobiliario, implicando un incremento en los alquileres y en los precios de compraventa. 
En relación con estos últimos, el mayor valor en el barrio se alcanzó en septiembre de 2019 (3.104 euros por $\mathrm{m}^{2}$ ), muy por encima del valor promedio en la ciudad, según el portal inmobiliario Idealista.com.

En una perspectiva diacrónica, el distrito registraba una continua bajada de precios hasta verano de 2014 para, a partir del primer trimestre de 2016, iniciar una escalada que culmina 2019. Esta tendencia también se dio en el conjunto de la ciudad, pero el incremento reciente en los precios ha sido mucho más moderado (Figura 5), lo que se pone de manifiesto en las diferencias absolutas de los valores promedio, que llega a ser de hasta 1.100 euros. Estas mismas tendencias se pueden apreciar en la evolución de los alquileres. El barrio registra el alquiler promedio más caro por $\mathrm{m}^{2}$ en la ciudad, habiendo alcanzado su máximo valor en 2018 (13,06 euros). En 2018, el Paseo de Las Canteras era la quinta calle con los alquileres promedio más caros de España, según Tecnitasa.

Figura 5. Precio medio del $\mathrm{m}^{2}$ en euros de las compraventas realizadas entre 2009 y 2019

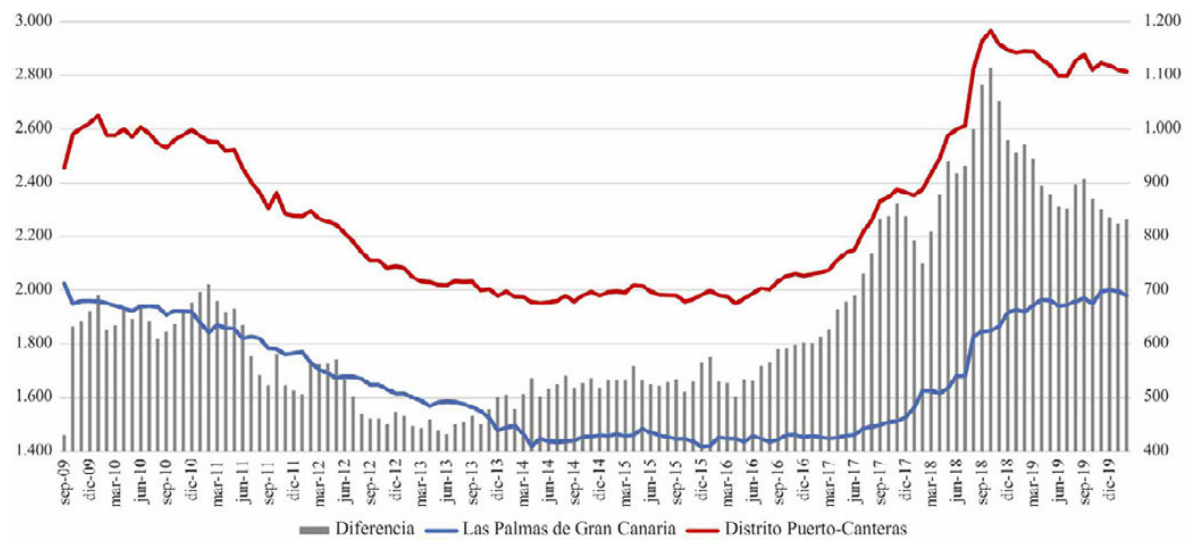

Fuente: El Idealista. Elaboración propia.

Eje izquierdo: precio medio. Eje derecho: diferencia de precios.

Pues bien, las diferentes pendientes en el crecimiento registrado en los últimos años en el distrito y en la ciudad se explican por varias razones. En primer lugar, la importancia que tiene la reestructuración productiva del sector turístico, ya que impulsa la compra de inmuebles para alquiler turístico y nuevos productos hoteleros. En segundo lugar, la compra de inmuebles por parte de la demanda internacional con fines vacacionales y productivos. Los datos del Colegio de Registradores lo avalan para el conjunto de Canarias. En 2018 más del 31\% de las operaciones de compraventa en las islas la realizaron extranjeros, especialmente británicos, alemanes, franceses, belgas y suecos. Por último, la revalorización temprana de las inversiones y la calidad ambiental del entorno ha hecho que la demanda local haya crecido en buena parte 
de la zona, pero posiblemente orientada más al negocio que a la residencia. Todos estos procesos urbanos recientes tienen consecuencia en el incremento de los niveles de renta de la población residente. Efectivamente, tomando como referencia los datos del distrito postal, que es el que coincide en mayor media con el barrio, la renta media bruta, según la Estadística de los declarantes del Impuesto sobre la Renta de las Personas Físicas, pasó de 29.370 euros, en 2013, a 31.261 euros, en 2017. Ahora bien, aunque estos valores están por encima de la renta media de la ciudad en ambos años, el crecimiento de la renta en el conjunto de la ciudad es mayor que en el distrito postal de Santa Catalina. Además, en 2017, siete de los 19 distritos postales de la ciudad presentaban rentas brutas mayores. Todo ello nos informa de que la actividad turística y la demanda internacional, que no se refleja de manera directa en los valores de renta, son los que sostienen los precios de los inmuebles del barrio y no tanto la llegada de población local con más poder adquisitivo. En otros términos, la expulsión de residentes que no pueden pagar sus alquileres o que ven ventajoso vender o poner su propiedad en alquiler turístico, hay que ponerla en el marco de un proceso de gentrificación turística con una clara dimensión internacional.

\section{RESIDENCIALIZACIÓN Y PÉRDIDA DE FUNCIONALIDAD TURÍSTICA EN EL TERRENO}

El Terreno, considerado el primer barrio turístico de las Islas Baleares y categorizado como enclave turístico maduro, abandona progresivamente su especialización turística y potencia su función residencial. Lo turístico es secundario: baja la oferta hotelera, predomina la de baja calidad, crecen las viviendas turísticas, pero a un ritmo menor que en otras partes de Palma, la oferta de ocio es amplia pero cada vez más concentrada en el paseo marítimo, etc.

El barrio tiene cinco hoteles y suma 603 plazas en 2020. Uno de 5 estrellas, otro de tres, y el resto son hoteles y hostales de baja categoría. A diferencia de la moderna y lujosa oferta hotelera de pequeños establecimientos, tipo boutique, que aumentan su oferta de manera constante en el centro histórico de Palma (González-Pérez, 2019), en El Terreno todos los hoteles tienen más de 60 años. Es decir, fueron construidos durante el denominado primer boom turístico. El de más categoría y plazas está localizado en primera línea de mar, en el mismo paseo marítimo. Los de menos categoría están en la degradada calle Joan Miró, antiguo epicentro del turismo de las décadas de 1950 y 1960. La parte alta de la ciudad concentra 14 de las 16 ETV (estancias turísticas en vivienda) del barrio. Las otras dos están en Joan Miró. La más antigua abrió en 2014. Doce son de 2017 y la última es de 2018. Estas 16 ETV ofertan 91 plazas. Estos son los datos oficiales, ofrecidos por el Govern de les Illes Balears. No obstante, la realidad y el uso de otras fuentes alternativas ponen de manifiesto una oferta mucho más importante. Airdna, a partir de las viviendas localizadas en las plataformas Airbnb y Vrbo, contabiliza 75 alquileres activos 
en el cuarto trimestre de 2019. Unos datos inferiores a los obtenidos cuatro años antes (cuarto trimestre de 2016) cuando sumaban 123. Un descenso previsiblemente vinculado a los efectos de la zonificación turística (zonas aptas para poder llevar a cabo la comercialización turística) consecuencia de la aplicación de la Ley 6/2017 de Turismo de las Illes Balears. En abril de 2018, Palma se declara como zona única. Esto prohíbe, sin excepciones, el arrendamiento de pisos a turistas y, con algunas salvedades, se permite en viviendas unifamiliares. Palma se convirtió así en la primera ciudad española en tomar una medida de este alcance (González-Pérez, 2019).

Frente a este incierto futuro turístico del barrio, se consolida un influyente sector inmobiliario y se produce una creciente residencialización vinculada a población de alto nivel económico. Por lo tanto, en este nuevo ciclo turístico, la reactivación del barrio se asocia a un dinámico mercado inmobiliario, y menos a un nuevo despegue como destino turístico. La numerosa oferta de viviendas en alquiler y, sobre todo, de venta; los elevados precios alcanzados y unos niveles de renta media en constante aumento, están en la base de estos procesos.

El número de viviendas en venta es importante en todas las secciones censales, superando las 200 en aquellas situadas en las partes central (entorno calle Joan Miró) y baja (paseo marítimo) del barrio. La parte coincidente con la fachada marítima obtiene los precios relativos de venta más elevados. Estas dos secciones también lideran la oferta de alquiler, aunque con un número sensiblemente inferior. La sección 007, limítrofe con los barrios fuertemente gentrificados de Santa Catalina y Espanyolet, tiene los precios más altos. Por su parte, la sección 010 presenta los valores más bajos. Esta zona se corresponde a la parte más alta de la ciudad, en contacto con el Parc de Bellver y donde se combina vivienda unifamiliar tradicional con bloques plurifamiliares de baja calidad. (Tabla 3).

Tabla 3. Viviendas en venta y alquiler residencial por secciones censales en El Terreno (13-03-2020)

\begin{tabular}{|l|c|c|c|c|}
\hline Sección censal & $\begin{array}{c}\text { Total viviendas } \\
\text { venta }\end{array}$ & $\begin{array}{c}\text { Total viviendas } \\
\text { alquiler }\end{array}$ & $\begin{array}{c}\text { Precio medio } \\
\text { venta }\left(€ / \mathrm{m}^{2}\right)\end{array}$ & $\begin{array}{c}\text { Precio medio } \\
\text { alquiler }\left(€ / \mathrm{m}^{2}\right)\end{array}$ \\
\hline 07-040-02-007 & 121 & 24 & 4.397 & 14,60 \\
\hline 07-040-02-008 & 244 & 82 & 4.266 & 12,67 \\
\hline 07-040-02-009 & 229 & 59 & 4.029 & 11,91 \\
\hline 07-040-02-010 & 152 & 16 & 3.744 & 11,77 \\
\hline El Terreno & 746 & 181 & 4.015 & 12,69 \\
\hline Palma & 8.036 & 1.537 & 3.784 & 13,44 \\
\hline
\end{tabular}


El nivel de renta de la población es uno de los indicadores más utilizados para evaluar la elitización de los barrios. Aunque El Terreno no forma un código postal único, sino que se integra en un territorio más extenso (código postal 07014, Son Dureta), la evolución de este indicador nos proporciona algunas pistas de las transformaciones sociourbanas del barrio. Por un lado, la renta media bruta de 2017, últimos datos disponibles, está entre los más altos de Palma. Se supera la media municipal en casi 17.000 euros. Por otro, las diferencias entre códigos postales se acrecientan, síntoma de un aumento de las desigualdades urbanas en esta etapa poscrisis. Entre 2013 y 2017, la media municipal ha aumentado en unos 4.000 euros, por más de 11.000 en nuestro territorio de estudio. Mientras en Palma, el crecimiento porcentual interanual se sitúa alrededor de un $4 \%$ desde 2014 , en Son Dureta se llega a superar el 14\% en 2016-2017. (Tabla 4).

Tabla 4. Evolución de los indicadores de renta media bruta 2013-2017. Código postal 07014, Son Dureta

\begin{tabular}{|l|c|c|c|c|c|}
\hline & $\mathbf{2 0 1 3}$ & $\mathbf{2 0 1 4}$ & $\mathbf{2 0 1 5}$ & $\mathbf{2 0 1 6}$ & $\mathbf{2 0 1 7}$ \\
\hline Son Dureta & 36.007 & 37.534 & 38.127 & 41.251 & 47.300 \\
\hline Palma & 26.452 & 26.841 & 27.994 & 28.973 & 30.343 \\
\hline & - & $\mathbf{2 0 1 3 - 2 0 1 4}$ & $\mathbf{2 0 1 4 - 2 0 1 5}$ & $\mathbf{2 0 1 5 - 2 0 1 6}$ & $\mathbf{2 0 1 6 - 2 0 1 7}$ \\
\hline Son Dureta & - & $4,24 \%$ & $1,58 \%$ & $8,19 \%$ & $14,66 \%$ \\
\hline Palma & - & $1,47 \%$ & $4,30 \%$ & $3,50 \%$ & $4,73 \%$ \\
\hline
\end{tabular}

Fuente: Elaboración propia a partir de Estadística de los declarantes del Impuesto sobre la Renta de las Personas Físicas de los mayores municipios por código postal, Agencia Tributaria

Como en el caso de Santa Catalina-Canteras, las políticas públicas de rehabilitación urbana han desempeñado un papel fundamental en la gentrificación de El Terreno. Desde la aprobación en 2007 del Plan Especial de Reforma Interior (PERI) del barrio se han puesto las bases para que hoy en día todos quieran comprar en Joan Miró, como publicaba el Diario de Mallorca el 24 de noviembre de 2019.

\section{CONCLUSIONES}

El estudio de las transformaciones urbanas y de los cambios sociales vinculados a los ciclos turísticos gana una mayor importancia cuando se afronta desde una perspectiva comparada. Los barrios de El Terreno en Palma (Mallorca) y Santa Catalina-Canteras en Las Palmas de Gran Canaria (Gran Canaria), situados en las dos ciudades más populosas de sus respectivos archipié- 
lagos, tuvieron un desarrollo urbano-turístico semejante hasta fines del siglo $X X$. Son barrios que albergaron, originalmente, viviendas de veraneo para propietarios de sus ciudades respectivas y que, posteriormente, se convirtieron en una zona hotelera y residencial que acogía turistas extranjeros, una especialización que se incrementó a partir de los años cincuenta del siglo XX hasta los años ochenta, cuando su madurez como barrios turísticos se vio afectada por una cierta obsolescencia.

En el caso de Santa Catalina-Canteras, las actuaciones de renovación acometidas incrementaron la residencialización del barrio, confiriéndole una cierta hibridez turístico-residencial. Sin embargo, en El Terreno, se produjo una cierta diferenciación de usos entre un área más alta y distante de la costa, de carácter residencial, más degradada, y la zona litoral, con una función residencial y oferta turística, ambas de mayor calidad.

Hasta la crisis económica de 2008 y sucesivos, tanto en Santa Catalina-Canteras como en El Terreno (especialmente, en su zona alta), los inmuebles más deteriorados y que habían sido retirados de la oferta de alojamiento turístico, se pusieron en el mercado de alquiler, accediendo a su arrendamiento muchos trabajadores con escasos recursos, en su mayor parte, inmigrantes laborales procedentes de países no comunitarios. Sin embargo, mientras que a principios del siglo XXI, Santa Catalina-Canteras crecía, a consecuencia de este proceso, El Terreno decrecía, pues el nivel de obsolescencia fue tal que disminuyó el número de residentes. A partir de 2009, se reduce la tasa de crecimiento en ambos barrios, pero mucho más en el segundo que en el primero, pues a la pérdida de funcionalidad turística se añade la pérdida de población extranjera a consecuencia de la crisis económica. Sin embargo, desde 2014, las dinámicas demográficas divergen. En el primer caso, la revalorización del barrio para el uso turístico origina una pérdida demográfica mientras que, en el segundo, se ha recuperado su fortaleza residencial, atrayendo extranjeros de alto poder adquisitivo.

Desde el punto de vista de la oferta turística, Santa Catalina-Canteras cuenta con 3.221 plazas en 21 hoteles; con 1.288 plazas en 17 complejos de apartamentos y tres hostales; además de 2.188 plazas en viviendas turísticas, una modalidad de reciente aparición y expansión. La revalorización turística ha supuesto un incremento en los alquileres y en los precios de compraventa e, indirectamente, en los niveles de renta de la población.

En El Terreno, la oferta turística es mucho menor, de tan sólo cinco hoteles con 603 plazas y hostales de baja categoría, al mismo tiempo que el número de viviendas de uso turístico es escaso (75 según Airdna), pero lo que es más importante, a la baja, a consecuencia de la aplicación de la Ley 6/2017 de Turismo de las Illes Balears que excluye este barrio de la zonificación turística. Ahora bien, ello no obsta para que se consolide un influyente sector inmobiliario y una residencialización vinculada a población de alto nivel económico, 
lo que ha hecho que la renta media bruta de este sector urbano esté entre las más altas de Palma.

En síntesis, estos dos barrios turísticos maduros, de las ciudades insulares de Palma y Las Palmas de Gran Canaria, of recen trayectorias divergentes en esta fase del capitalismo tardío, en que la reorganización productiva y la búsqueda de nuevas plusvalías devienen en un proceso de gentrificación, ya sea predominantemente turística en el primer caso o residencial en el segundo, condicionando su especialización funcional y fomentando la desigualdad social.

\section{BIBLIOGRAFÍA}

Barceló, B. (1963). El Terreno. Geografía urbana de un barrio de Palma. Boletín de la Cámara Oficial de Comercio, Industria y Navegación de Palma de Mallorca, año LXV, n 640, 127-178.

Boyer, R. (2011). Is a finance-led growth regime a viable alternative to Fordism? A preliminary analysis. Economy and Society, 29, 111-145.

Butler, R. W. (1980). The concept of a tourist area cycle of evolution: Implications for management of resources. Canadian Geographer 24(1), 5-12.

Butler, R. W. (2011). Contemporary Tourism Reviews. Woodeaton: Goodfellow Publishers Limited.

https://www.goodfellowpublishers.com/free_files/fileTALC.pdf [acceso 0103-2020]

Dicken, P. (1992). Global shift: The internationalization of economic activity. London: Chapman Publishing.

Domínguez-Mujica, J., Parreño-Castellano, J., y Moreno-Medina, C. (2020). Vacation Rentals, Tourism and International Migrations: Gentrification in Las Palmas de Gran Canaria (Spain) from a diachronic perspective, In Ribeiro de Almeida, C. et al. (Ed.) Handbook of Research on the Impacts, Challenges, and Policy Responses to Overtourism, pp. 237-260. Hershey, USA: IGI Global.

Domínguez-Mujica, J., González-Pérez, J., y Parreño-Castellano, J. M. (2011). Tourism and human mobility in Spanish Archipelagos. Annals of Tourism Research, 38(2), 586-606.

Domínguez-Mujica, J., González-Pérez, J. M., y Parreño-Castellano, J. M. (2008). Transformaciones recientes en barrios turísticos maduros. Los casos de Palma de Mallorca y Las Palmas de Gran Canaria, España. Scripta Nova. XII, 270 (93).

Eurotransmer, (2019). Cinco puertos mueven cerca del 90\% del tráfico de contenedores en España.

https://www.aeutransmer.com/2019/05/20/cinco-puertos-mueven-cercadel-90-del-trafico-de-contenedores-en-espana/ [acceso 01-03-2020]

González Pérez, J. M. (2019). The dispute over tourist cities. Tourism gentrification in the historic Centre of Palma (Majorca, Spain). Tourism Geographies. DOI: 10.1080/14616688.2019.1586986. 
Harvey, D. (2002). Spaces of capital: Towards a critical geography. London: Routledge.

Instituto Nacional de Estadística (2020). Padrón Continuo de Población. https://www.ine.es/dyngs/INEbase/es/operacion.htm?c=Estadistica_C\&cid= $1254736177012 \&$ menu=ultiDatos\&idp=1254734710990 [acceso 01-03-2020]

Lee, D. (2016). How Airbnb short-term rentals exacerbate Los Angeles's affordable housing crisis: analysis and policy recommendations. Harvard Law \& Policy Review, 10, 229-253.

Maitland, R., y Newman, P. (2008). Visitor-host relationships: conviviality between visitors and host communities. In B. Hayllar, T. Griffin, \& D. Edwards (Eds) City Spaces-Tourist Places: Urban Tourism Precincts, pp. 223-242. New York and London: Elsevier.

Seguí, M. (2001). La arquitectura del ocio en Baleares. La incidencia del turismo en la arquitectura y el urbanismo. Palma: Lleonard Muntaner.

Solbes Ferri, S. (2004). La necesaria construcción de un puerto marítimo para Las Palmas de Gran Canaria como complemento a los decretos de puertos francos (1852-1883). XV Coloquio de Historia Canario-Americana, pp. 211251. Las Palmas de Gran Canaria: Cabildo de Gran Canaria.

Soja, E. W. (1989). Postmodern geographies: The reassertion of space in critical social theory. Brooklyn NY: Verso Books. 


\title{
SEGREGACIÓN RESIDENCIAL Y RECURSOS MUNICIPALES. EL CASO DE LOS SISTEMAS URBANOS DEL ARCO METROPOLITANO DE BARCELONA \\ RESIDENTIAL SEGREGATION AND MUNICIPAL RESOURCES. THE CASE OF THE URBAN SYSTEMS OF THE SECOND RING OF BARCELONA METROPOLITAN REGION \\ Carles Donat Muñoz \\ Universidad Autónoma de Barcelona
}

Resumen

En este artículo se analiza la relación entre la segregación residencial y el gasto público de los municipios. El ámbito territorial de estudio son los sistemas urbanos que pivotan sobre las seis ciudades del arco metropolitano de Barcelona: Mataró, Granollers-Congost, Sabadell, Terrassa, Vilafranca del Penedès y Garraf. Para aproximarse a la segregación residencial se toman como referencia las secciones censales más vulnerables y las más acomodadas. Los resultados indican que la capacidad de gasto de las ciudades centrales, donde hay una mayor concentración de áreas vulnerables, es de media un $14,1 \%$ inferior al de los municipios del entorno, donde hay una mayor presencia de secciones acomodadas. Esta situación se reproduce de manera individual en cinco de los seis sistemas urbanos. La única excepción, es el sistema urbano de Granollers-Congost y se debe, precisamente, a una mayor concentración de áreas vulnerables en los municipios del entorno. Los resultados son coherentes con investigaciones previas que tenían como ámbito de estudio el conjunto de la región metropolitana de Barcelona.

Palabras clave: segregación residencial, región metropolitana de Barcelona, financiación municipal, equidad intermunicipal, efecto barrio.

\begin{abstract}
This paper analyses the relationship between residential segregation and municipal public expenditure. The area of the study is the urban systems of the Barcelona metropolitan region second ring: Mataró, Granollers-Congost, Sabadell, Terrassa, Vilafranca del Penedès and Garraf. To approach residential segregation, the most deprived and well-off census sections are taken as a reference. The results show that the spending capacity of the central cities, where there is a greater concentration of deprived areas, is on average $14.1 \%$ lower than that of the surrounding municipalities, where there is a greater presence of well-off census sections. This situation is reproduced individually in five of the six urban systems. The only exception is the Granollers-Congost urban system due to a greater concentration of vulnerable areas in the surrounding municipalities. The results are consistent with previous research
\end{abstract}


that had the whole of the metropolitan region of Barcelona as its area of study.

Keywords: residential segregation, Barcelona metropolitan area, municipal financing, inter-municipal equality, neighborhood effect.

\section{INTRODUCCIÓN}

La relación entre la segregación residencial y los recursos municipales, tema del presente trabajo, relaciona campos de estudio que, en no pocas ocasiones, se han abordado por separado desde diferentes disciplinas de las ciencias sociales.

Los estudios sobre segregación residencial tienen un extenso bagaje en la literatura internacional, y en el caso español han proliferado de manera notable en las dos últimas décadas, como ya hemos estudiado en trabajos previos (Donat, 2018). Dentro de los estudios sobre segregación residencial, uno de los temas que más interés han despertado es su interrelación con las desigualdades sociales (Domínguez, Leal, y Martínez-Goytre, 2012; Fujita, 2012; Nel·lo, 2014; Porcel, 2020; Sassen, 1991). Así, el enfoque mayoritario considera la segregación residencial como parte de un proceso en el cual, la segregación no es sólo el resultado final, sino que, la segregación puede incidir, a su vez, sobre la reproducción de las desigualdades. Es lo que se conoce como efecto barrio. Bien es cierto, que existen dificultades empíricas para demostrar esta relación causa-efecto (entre segregación y desigualdades). No obstante, las posiciones más comunes han tendido a afirmar la existencia de efectos perniciosos para la población de bajo nivel de renta, derivados específicamente del hecho de vivir en barrios segregados (van Ham, Manley, Bailey, Simpson, y Maclennan, 2012). Por su parte, en los debates sobre financiación municipal, uno de los objetos de estudio más recurrentes ha sido el del principio de equidad intermunicipal, lo que se conoce como equidad horizontal (Castells, Esteller, y Vilalta, 2003; Vilalta, 2018). En este sentido, algunos trabajos han mostrado, la ausencia en España de un mecanismo de distribución de las transferencias, desde el Estado y las Comunidades Autónomas a los municipios, basado en criterios de equidad, no solo poblacional, sino de equilibrio y compensación entre las diferentes capacidades fiscales de los municipios y sus necesidades. Estos mecanismos permitirían hacer compatibles los principios de autonomía y equidad en la financiación municipal (Vilalta, 2015).

Pues bien, este artículo busca puntos de intersección entre los dos temas, analizando la relación entre la segregación residencial y el gasto público de los municipios. Se trata de un efecto barrio, indirecto si se quiere, pero que tiene unas consecuencias finales sobre la reproducción de las desigualdades sociales bien evidente, ya que se traduce en diferentes capacidades de prestación de servicios públicos. 
Este artículo da continuidad a diversas líneas de investigación. Así, en primer lugar, para aproximarse a la segregación residencial se parte del mapa de áreas vulnerables y áreas acomodadas de Cataluña, resultado del proyecto «Barrios y Crisis»', donde se observó la tendencia a la separación en el territorio de la población con más y menos recursos (Donat, 2017; Nel·lo, 2018; Nel·lo y Blanco, 2015), en línea con algunas de las tendencias que se observaban en otras ciudades (Musterd, Marcińczak, van Ham, y Tammaru, 2017; Tammaru, Marcinczak, van Ham, y Musterd, 2016). En segundo, lugar la estrategia de análisis toma como referencia los trabajos desarrollados en el marco del proyecto «Efecto Barrio»², donde ya se ha analizado la relación existente entre la segregación residencial y el gasto público de los municipios de la región metropolitana de Barcelona (Nel·lo y Donat, 2017).

De los resultados obtenidos en estos proyectos, se puede concluir que los municipios con secciones censales en ambos extremos (vulnerables y acomodadas) tienen el gasto per cápita más reducido, incluso inferior a los municipios con solo secciones censales vulnerables. En cambio, los municipios sin secciones censales en ningún extremo y, especialmente, los municipios con solo secciones censales acomodadas tienen un gasto per cápita superior. De esta manera, los municipios que concentran más secciones vulnerables, y por lo tanto más necesidades, disponen de menos capacidad de gasto. En cambio, los municipios con más secciones acomodadas, y con menos necesidades, tienen disponibles más recursos.

Con estos antecedentes como hipótesis de partida, en este artículo el ámbito territorial de estudio se sitúa, no en el conjunto de la región metropolitana de Barcelona, sino en seis de sus subsistemas urbanos: Mataró, GranollersCongost, Sabadell, Terrassa, Vilafranca y Garraf. El objetivo es doble. En primer lugar, analizar las particularidades de estos territorios, tanto por lo que respecta a los procesos de segregación urbana, como al gasto municipal. En segundo lugar, contrastar si las tendencias detectadas para la aglomeración metropolitana se reproducen también en estos ámbitos territoriales.

Por lo que respecta a la metodología, ya se ha avanzado que la aproximación a la segregación residencial se realiza considerando las secciones censales más vulnerables y las más acomodadas, definidas en el proyecto Barrios y Crisis (Jiménez y Donat, 2018). Esta aproximación se entronca, en parte, con

1 «Barris desafavorits davant la crisi. Segregació urbana, innovació social i capacitat cívica» financiado por el programa de investigación Rercaixa. Ref: 2012ACUP00004.

2 «Efecto Barrio. Los impactos sociales de las desigualdades territoriales y las políticas urbanas redistributivas en las grandes ciudades españolas» financiado por la convocatoria 2016 del Programa Estatal de investigación, desarrollo e innovación orientada a los retos de la sociedad (Referencia CSO2016-75236-C2-2-R) en el marco del Plan Estatal de Investigación Científica y Técnica y de Innovación 2013-2016. 
la línea de otros trabajos que se han desarrollado en las últimas décadas en España, focalizados en detectar las secciones vulnerables, en muchos casos con el objetivo de orientar las actuaciones públicas (DOGC, 2004b, 2004a; Hernández-Aja, 1997; Hernández-Aja, Matesanz, y García, 2015; Vázquez, Palacios, y Martínez, 2018). No obstante, en nuestro caso este enfoque se amplía, incorporando también las secciones acomodadas. De esta manera, se pone el énfasis en las dos situaciones extremas, el crecimiento de las cuales es común en los procesos de segregación en muchas ciudades, y que con otro tipo de indicadores - por ejemplo, el índice de disimilitud_- serían más difíciles detectar (Jiménez y Donat, 2018)3.

En cuanto a los datos de gasto municipal, se ha tomado como fuente las liquidaciones de presupuestos de los entes locales de Cataluña publicados por la Dirección General de Administración Local de la Generalitat de Catalunya para el período 2012-20174. Para evitar el efecto de años atípicos se ha trabajado con el promedio del período. Esta información también se puede descargar en el portal habilitado por el Ministerio de Hacienda del Gobierno de España ${ }^{5}$.

Un último aspecto metodológico con relación a la delimitación de los sistemas urbanos. En este trabajo se han utilizado las divisiones del Plan Territorial Metropolitano de Barcelona (Departament de Política Territorial i Obres Públiques, 2010). Se trata del documento de planeamiento territorial vigente en el ámbito de estudio. La delimitación está basada en criterios funcionales a partir de la movilidad cotidiana residencia-trabajo.

Después de esta introducción, en el segundo apartado se presenta información de contexto del territorio de estudio, para a continuación analizar el mapa de secciones vulnerables y acomodadas. Asimismo, se establece una tipología de municipios en función de la presencia o no de este tipo de secciones. En el tercer apartado, se analizan los datos de gasto municipal relacionándolos con la estructura territorial de los sistemas urbanos y con las tipologías de municipios elaboradas con anterioridad. Finalmente, en el cuarto apartado se presentan las conclusiones.

\section{LA SEGREGRACIÓN RESIDENCIAL EN LOS SISTEMAS URBANOS DEL ARCO METRO- POLITANO DE BARCELONA}

Una de las principales características de la región metropolitana de BarceIona es su carácter policéntrico (Nel·lo, 2002; Trullén y Boix, 2003). Bien es

3 Para un mayor detalle de las fuentes y de la metodología utilizada puede consultarse la publicación referenciada.

4 http://municat.gencat.cat/ca/Temes/hisendes-locals/publicacio_de_les_dades/\#bloc3

5 https://serviciostelematicosext.hacienda.gob.es/SGFAL/CONPREL 
cierto que la aglomeración central de la ciudad de Barcelona y su continuo urbano concentran el 50,4\% de los 5.155.174 de habitantes (Tabla 1). No obstante, a lo largo de un arco circundante se localizan un conjunto de seis ciudades de dimensiones poblacionales muy notables, que funcionan como subcentros metropolitanos y alrededor de las cuales se han configurado unos subsistemas urbanos ( $\mathrm{Nel} \cdot \mathrm{lo}, 2000$ ). Entre todas estas ciudades concentran 730.572 habitantes, el 14,2\% de la población de la región metropolitana, y el conjunto de estos sistemas urbanos alcanzan 1.150 .908 habitantes, el $22,3 \%$ del total metropolitano.

Tabla 1. Población de las ciudades del arco metropolitano de Barcelona y de sus sistemas urbanos. 2019

\begin{tabular}{|c|c|c|c|c|c|}
\hline \multicolumn{4}{|c|}{ Ciudades centrales } & \multicolumn{3}{c|}{ Sistemas urbanos } \\
\hline Granollers & 61.275 & $1,20 \%$ & Granollers-Congost & 170.722 & $3,30 \%$ \\
\hline Mataró & 128.265 & $2,50 \%$ & Mataró & 171.974 & $3,30 \%$ \\
\hline Sabadell & 213.644 & $4,10 \%$ & Sabadell & 260.517 & $5,10 \%$ \\
\hline Terrassa & 220.556 & $4,30 \%$ & Terrassa & 324.419 & $6,30 \%$ \\
\hline Vilafranca del Penedès & 39.746 & $0,80 \%$ & Vilafranca & 72.389 & $1,40 \%$ \\
\hline Vilanova i la Geltrú & 67.086 & $1,30 \%$ & Garraf & 150.887 & $2,90 \%$ \\
\hline Subtotal & 730.572 & $14,20 \%$ & Subtotal & 1.150 .908 & $22,30 \%$ \\
\hline Total RMB & 5.155 .174 & $100,00 \%$ & Total RMB & 5.155 .174 & $100,00 \%$ \\
\hline
\end{tabular}

Fuente: Padrón continuo de población. INE

Las ciudades de Terrassa (220.556 habitantes) y Sabadell (213.644) son las más pobladas, así como sus sistemas urbanos (324.419 habitantes el de Terrassa y 260.517 el de Sabadell). En un segundo nivel se encuentran Mataró (128.265 habitantes la ciudad y 171.974 el sistema urbano), Vilanova i la Geltrú (67.086 y 150.887) y Granollers (61.275 y 170.722); y, finalmente, Vilafranca del Penedès (39.746 y 72.389$)$.

Además de su peso poblacional, cabe destacar, al menos, otro atributo de estas ciudades, que ayuda a comprender, tanto el carácter policéntrico de la región metropolitana, como los procesos de segregación residencial. En efecto, las ciudades del arco metropolitano de Barcelona se caracterizan por la variedad de tejidos urbanos, fruto del pasado industrial y de su evolución posterior. Cada uno de estos tejidos, y dentro de estos sus diferentes barrios, presentan atributos de centralidad, accesibilidad, nivel de servicios y equipamientos, características del parque de viviendas, estigmatización, entre otros, que los hacen particulares y al mismo tiempo más o menos atractivos y accesibles desde el punto de vista del esfuerzo económico de los hogares. No es el objetivo de este artículo entrar en las diferentes causas de la segrega- 
ción residencial. En cambio, si se quiere resaltar que las pautas de localización de las áreas vulnerables y acomodadas, que se muestran a continuación, presentan una estrecha relación con unas tipologías de tejidos concretas y no con otras.

Figura 1. Secciones censales vulnerables y acomodadas en los sistemas urbanos de la región metropolitana de Barcelona. 2012

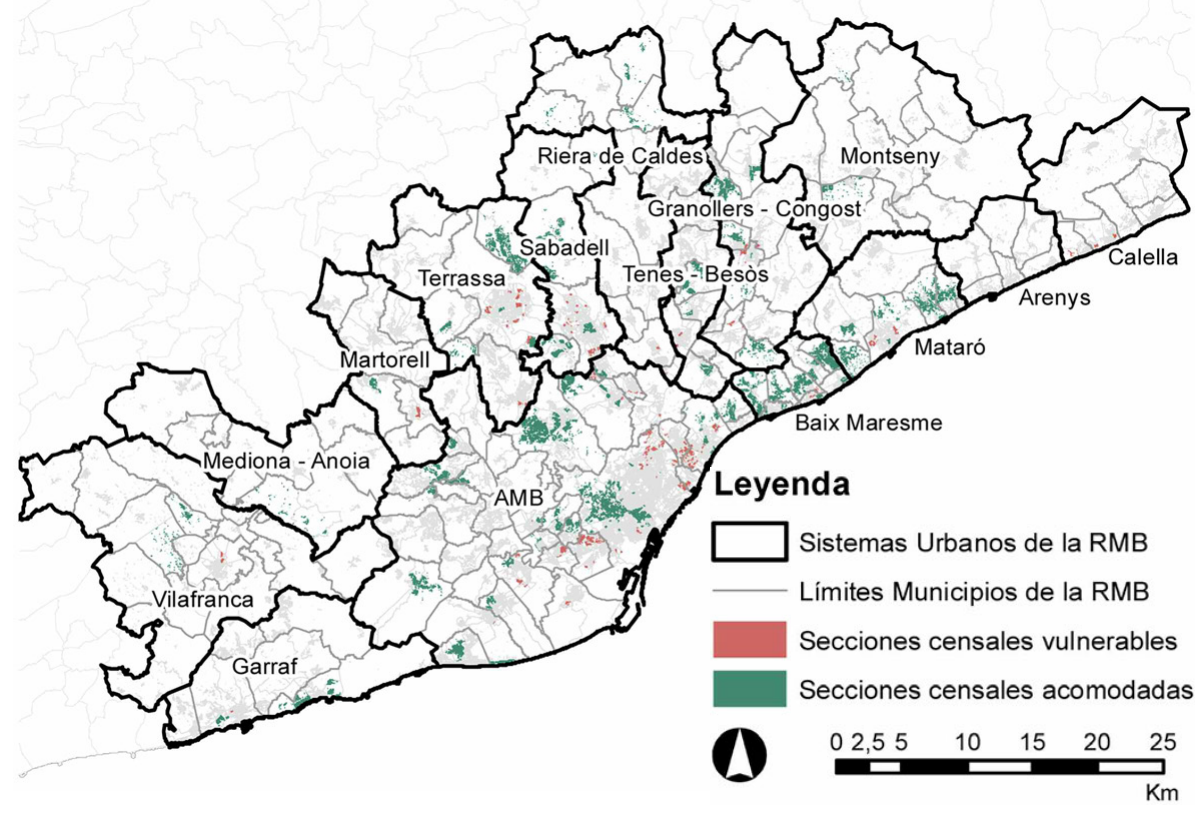

Fuente: Elaboración propia a partir de «Barrios y crisis» (2018)

En la Figura 1 se han representado las secciones censales más vulnerables y las secciones censales más acomodadas de la región metropolitana de Barcelona. Por lo que respecta a las ciudades del arco metropolitano, una primera idea que se puede extraer cuando se observa el mapa es que cinco de las seis ciudades (Mataró, Granollers, Sabadell, Terrassa y Vilanova i la Geltrú) cuentan con secciones censales situadas en ambos extremos, tanto vulnerables como acomodadas. Hay que destacar que es una situación poco común entre los municipios metropolitanos — solo se da en 15 de 164-, y que es debida en buena medida a la diversidad de tejidos urbanos a la que se ha hecho referencia más arriba.

Si se reduce la escala sobre cada una de las ciudades se puede apreciar que las secciones acomodadas se localizan en dos tipos de áreas (Figura 2). En primer lugar, en tejidos centrales situados en los cascos históricos (casos de 
Mataró, Granollers, Terrassa y Sabadell) o en los ensanches de finales del siglo XIX y principios del siglo xx (en Sabadell). En segundo lugar, hay algunos emplazamientos de secciones censales acomodadas en barrios situados en los límites externos de los municipios y que responden a una tipología de urbanización de baja densidad (barrio de Vista Alegre en Mataró, L'Aragai en Vilanova i la Geltrú y Can Parellada en Terrassa).

Por su parte, las secciones censales vulnerables se localizan también en diferentes tipos de tejidos urbanos: desarrollos que originariamente fueron de urbanización marginal (Torre-Romeu en Sabadell); en polígonos de viviendas del período 1955-1975 (Espronceda y Campoamor en Sabadell, Can Bassa en Granollers, Sant Llorenç en Terrassa); en áreas que combinan promociones pequeñas y medianas y de autoconstrucción del periodo 1955-1975 (PalauRocafonda y Cerdanyola en Mataró, Espinell en Vilafranca del Penedès); y, finalmente, en cascos históricos (Vilafranca del Penedès). Cabe decir, que en algunas de las áreas vulnerables se suceden diferentes tejidos a los que se acaban de hacer referencia (Can Puiggener, en Sabadell; Can'Anglada en Terrassa; Congost en Granollers, por destacar algunas).

En conjunto, se trata de áreas periféricas dentro de estos municipios (a excepción del centro de Vilafranca del Penedès), con malas calidades edificatorias y que en su origen estuvieron privadas de servicios urbanos básicos. Asimismo, pese a las mejoras experimentadas desde la reinstauración de los ayuntamientos democráticos, aún presentan algunos déficits importantes. Además, en la mayoría de los casos se trata de secciones censales con un porcentaje de población extranjera muy por encima de la media de los municipios.

Ahora bien, el análisis de la estructura socio-territorial de estas ciudades no se puede circunscribir a sus límites municipales, sino que, como se puede deducir de un contexto metropolitano, abraza un territorio más extenso de escala supramunicipal. Así, en las Figuras 1 y 2 se puede apreciar como la mayoría de los municipios circundantes, o bien no tienen secciones censales situadas en los extremos, o bien, en caso de tenerlas, son siempre acomodadas. Las únicas excepciones se dan en los sistemas urbanos de Granollers-Congost y en el de Terrassa. En el primero, las ciudades de Canovelles y les Franqueses del Vallès tienen áreas vulnerables que presentan continuidad con los tejidos urbanos de la ciudad central. Asimismo, en la parte situada al sur de este sistema urbano se localizan secciones vulnerables en el municipio de Montornés del Vallès. Por su parte, en el sistema urbano de Terrassa hay dos emplazamientos de secciones vulnerables en el municipio de Rubí. 
Figura 2. Secciones censales vulnerables y acomodadas.

Detalle de los seis sistemas urbanos del arco metropolitano de Barcelona
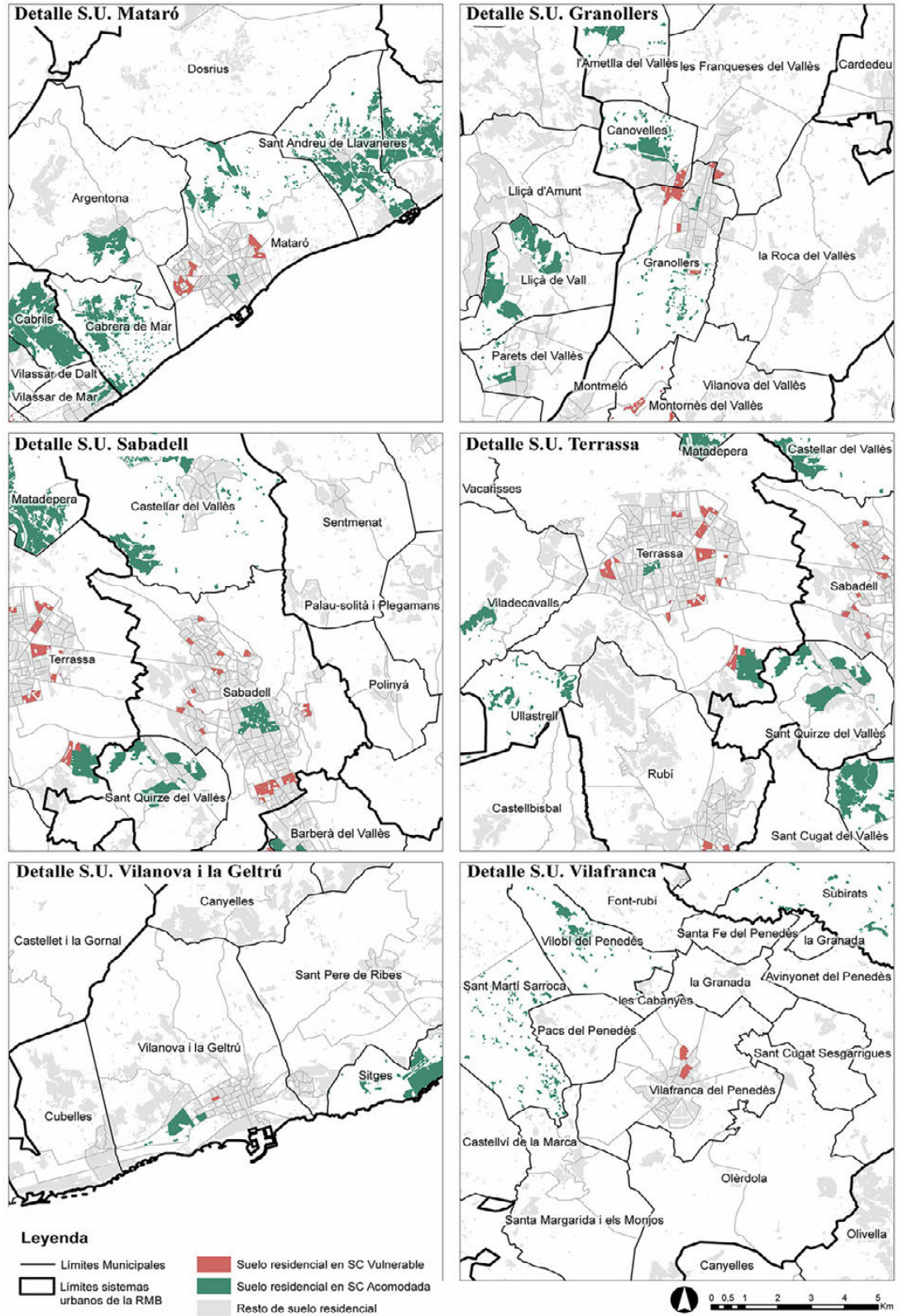

Fuente: Elaboración propia a partir de «Barrios y crisis» (2018) 
Trabajos más detallados sobre los tejidos urbanos de los municipios con secciones acomodadas, han llegado a dos conclusiones de especial interés para el análisis que se ha llevado a cabo en este artículo. En primer lugar, hay un peso importante de tipologías edificatorias unifamiliares en urbanizaciones de baja densidad (Muñoz, 2004; Nel·lo, 2018). En segundo lugar, una parte significativa de la población de estos municipios, y por ende de las secciones acomodadas, procede de las ciudades centrales de los sistemas urbanos que estamos analizando (Ruiz, Velasco, y Serrano, 2017; Serra, 2003).

En definitiva, el análisis de la segregación urbana desde una perspectiva supramunicipal permite aproximarse de una manera más adecuada al fenómeno y poner en relación los territorios y la población de los municipios de los sistemas urbanos. De esta manera, se puede apreciar que en las ciudades centrales se localizan muchos de los barrios y áreas más desfavorecidas, mientras que en algunos municipios del entorno se concentra la población con más recursos.

\section{RECURSOS MUNICIPALES EN LOS SISTEMAS URBANOS}

Una de las consecuencias del proceso de integración metropolitana es, como se acaba de ver, la configuración de un mapa de áreas vulnerables y acomodadas con desequilibrios muy significativos entre municipios y, de manera notable, en los sistemas urbanos del arco metropolitano de Barcelona. En este apartado el foco se sitúa en la relación entre las pautas de segregación residencial y el gasto municipal liquidado per cápita. Cabe recordar que, para evitar años atípicos, se utiliza el promedio del periodo 2012-2017.

Como dato de contexto, hay que situar el gasto por habitante de los seis sistemas urbanos de las ciudades del arco metropolitano ligeramente por debajo, pero próximos a la media, del conjunto de la región metropolitana ${ }^{6}$ (1.008,1€ frente a 1.022,1€). Si se pone el foco en los seis sistemas urbanos, un primer resultado a destacar es que el gasto medio por habitante de las ciudades centrales durante el periodo $2012-2017$ es un 14,1\% inferior al del resto de municipios de los sistemas urbanos (951,8€ frente a 1.107,4€) (Tabla 2).

6 Se excluye el municipio de Barcelona con un gasto y un peso poblacional muy superiores a la media. 
Tabla 2. Gasto per cápita de los Ayuntamientos. Promedio 2012-2017 (en €).

\begin{tabular}{|c|c|c|c|c|}
\hline $\begin{array}{c}\text { Sistema } \\
\text { urbano }\end{array}$ & $\begin{array}{c}\text { Total sistema } \\
\text { urbano }\end{array}$ & $\begin{array}{c}\text { Ciudad central } \\
(1)\end{array}$ & $\begin{array}{c}\text { Resto sistema urbano } \\
(2)\end{array}$ & $\begin{array}{c}\text { Diferencia } \\
(1-2)\end{array}$ \\
\hline Granollers & $1.123,0$ & $1.201,3$ & $1.078,8$ & $11,4 \%$ \\
\hline Mataró & $1.085,3$ & $1.030,9$ & $1.247,7$ & $-17,4 \%$ \\
\hline Sabadell & 919,9 & 902,1 & $1.001,8$ & $-10,0 \%$ \\
\hline Terrassa & 912,0 & 824,8 & $1.100,7$ & $-25,1 \%$ \\
\hline Vilafranca & $1.096,2$ & $1.070,1$ & $1.129,9$ & $-5,3 \%$ \\
\hline Vilanova & $1.106,9$ & $1.075,9$ & $1.132,4$ & $-5,0 \%$ \\
\hline Total & $1.008,1$ & 951,8 & $1.107,4$ & $-14,1 \%$ \\
\hline
\end{tabular}

Fuente: Elaboración propia a partir de Liquidaciones de presupuestos de los entes locales de Cataluña. Dirección General de Administración Local de la Generalitat de Catalunya y Padrón continuo de población. INE

Además, esta situación se repite, con diferentes intensidades, en todos los sistemas urbanos, excepto en el de Granollers-Congost. Así, en el sistema urbano de Terrassa la diferencia del $25,1 \%$ entre el gasto de la ciudad central y el resto de los municipios es la más elevada (824,8€ frente a $1.100,7 €)$, seguida del de Mataró (17,4\%, 1.030,9€ frente a 1.247,7€). En tercer lugar, se sitúa el sistema urbano de Sabadell, donde el gasto de la ciudad central es un 10\% inferior que el del conjunto de municipios circundantes $(902,1 €$ frente a $1.001,8 €)$. En el sistema de Vilafranca del Penedès la ciudad central tiene un $5,3 \%$ menos de gasto que el resto de las localidades (1.070,1€ frente a 1.129,9€). En quinto lugar, se sitúa el sistema del Garraf, donde el gasto de Vilanova i la Geltrú es un 5\% inferior al del resto de municipios $(1.075,9 €$ frente a 1.132,4€). Finalmente, como se ha avanzado, el sistema urbano de Granollers-Congost es la única excepción, ya que el gasto de la ciudad central es un 11,4\% superior al del resto de municipios (1.201,3€ frente a 1.078,8€). Por un lado, Granollers tiene un gasto per cápita muy superior a la del resto de las ciudades del arco metropolitano. Por otro lado, en este sistema urbano hay hasta tres municipios (Canovelles, les Franqueses del Vallès y Montmeló) con una presencia significativa de áreas vulnerables. Estas particularidades explican la excepcionalidad de este sistema urbano y vienen a ratificar la incidencia del fenómeno de la segregación residencial en los recursos municipales.

Los datos indican, pues, que, efectivamente, los municipios del entorno de las ciudades del arco metropolitano, donde hay una mayor concentración de áreas acomodadas y, en cambio, menor presencia de secciones vulnerables, tienen una mayor capacidad de gasto que las ciudades centrales, que concentran más zonas vulnerables. Esta afirmación se puede acabar de corro- 
borar si se agrupan los 50 municipios de los entornos urbanos en función de su situación con respecto a la segregación residencial (Figura 3).

Figura 3. Gasto per cápita de los Ayuntamientos según tipología de municipio y ámbito territorial. Promedio 2012-2017 (en €)

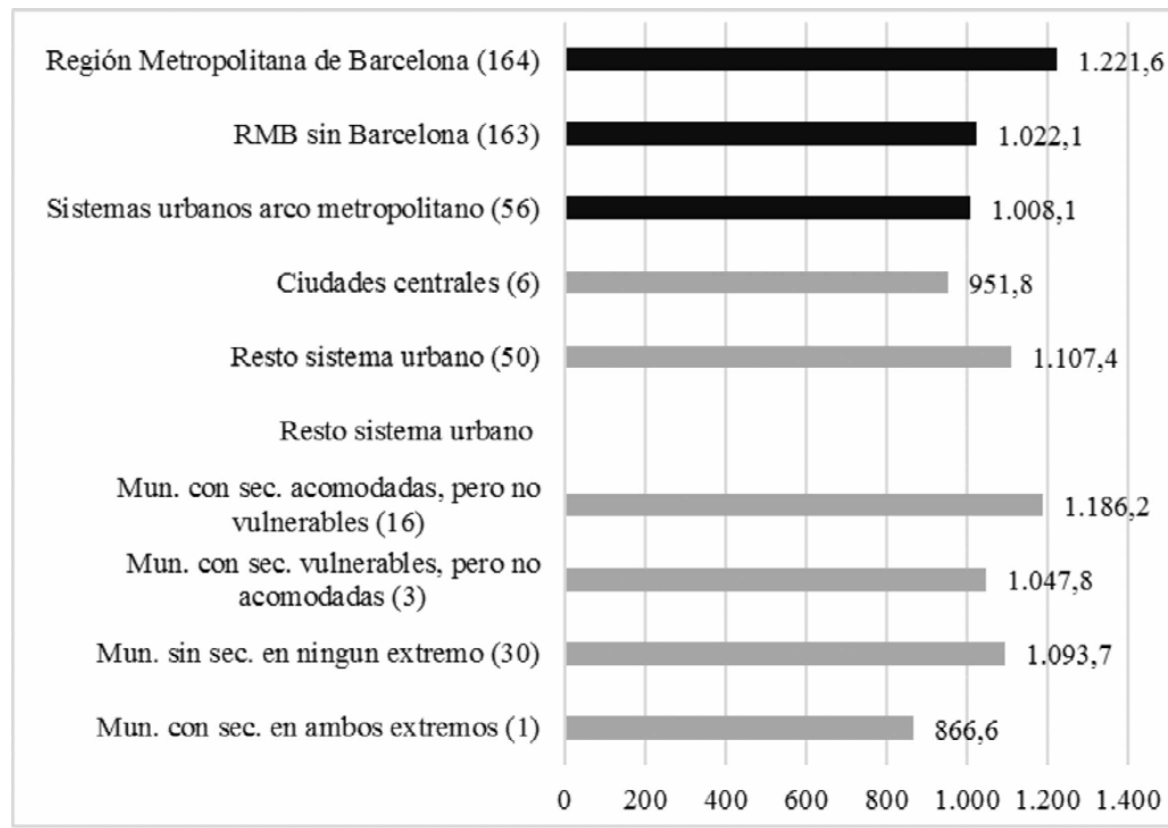

Fuente: Elaboración propia a partir de Liquidaciones de presupuestos de los entes locales de Cataluña. Dirección General de Administración Local de la Generalitat de Catalunya y Padrón continuo de población. INE

Así, en primer lugar, los 16 municipios que responden a la tipología con secciones acomodadas, pero no vulnerables, disponen del gasto per cápita más elevado durante el periodo 2012-2017, llegando a los 1.186,2€. En segundo lugar, los municipios en la situación contraria, es decir, con secciones vulnerables, pero no acomodadas, ven bajar su gasto per cápita de manera notable hasta los 1.047,8€. La diferencia de 138,4€ por habitante no es menor, sino todo lo contrario, ya que se sitúa en el 13,2\%. En tercer lugar, los municipios sin secciones censales en ninguno de los dos extremos tienen un gasto de 1.093,7€ por persona y se sitúan en un punto intermedio, más próximos a los municipios con barrios vulnerables. Finalmente, el único municipio, a excepción de las ciudades centrales, con secciones censales en ambos extremos, Canovelles, presenta un gasto público de $866,6 €$ per cápita, muy por debajo del resto. 
En definitiva, se puede apreciar cómo, atendiendo a la capacidad de gasto de los municipios, la distribución de los recursos no sigue el principio de equidad horizontal al que se hacía referencia en la introducción. Esta inequidad, además se ve amplificada por los diferentes niveles de necesidad en cada una de las tipologías de municipios.

\section{CONCLUSIONES}

Este trabajo tiene por objetivo analizar la relación entre la segregación residencial y los recursos de los municipios, en concreto sobre su capacidad de gasto. Para ello se ha focalizado el estudio en los sistemas urbanos de las ciudades del arco metropolitano de Barcelona. Estas ciudades, se caracterizan por su pasado industrial, lo cual, unido a su evolución posterior, ha dado lugar a una diversidad de tejidos en su interior $\mathrm{y}$, al mismo tiempo, a una integración funcional con los municipios de su entorno. Desde el punto de vista de la segregación residencial, las ciudades centrales de estos sistemas urbanos tienden a concentrar la mayoría de las secciones censales vulnerables, principalmente en tejidos urbanos que tienen su origen en barrios periféricos desarrollados en el periodo 1955-1975. Por su parte, las secciones censales acomodadas, aunque aún presentes en las ciudades centrales, se concentran, principalmente, en algunos de los municipios del entorno de estas ciudades, en general, en tejidos de baja densidad con predominio de tipologías unifamiliares cuyos desarrollos se aceleraron a partir de mediados de la década de 1980.

Sobre esta base socio-territorial se ha analizado el gasto per cápita de los ayuntamientos durante el periodo 2012-2017. Los resultados indican que las ciudades centrales de los sistemas urbanos tienen de media un gasto el 14,1\% inferior al del conjunto de municipios de su entorno. Esta situación se reproduce de manera individual en cinco de los seis sistemas urbanos analizados, pero sobresalen las diferencias que se dan en Terrassa (25,1\%) y Mataró (17,1\%). En un segundo nivel se sitúa Sabadell (10\%) y, finalmente, Vilafranca del Penedès (5,3\%) y el Garraf (5\%). Granollers-Congost es la excepción, ya que la ciudad central tiene un gasto el 11,4\% superior que el conjunto de municipios del entorno.

Estos resultados tienen una elevada correlación con la distribución de las áreas vulnerables y acomodadas. Así, a más concentración de secciones vulnerables, es decir, en las ciudades centrales, el gasto per cápita es inferior. En cambio, a más presencia de secciones censales acomodadas, como es el caso de los municipios del entorno, el gasto per cápita es mayor. De hecho, cuando se ha entrado a estudiar el sistema urbano de Granollers-Congost se ha visto que la excepcionalidad -además de tratarse de la ciudad con mayor gasto de las seis consideradas- se deriva de la mayor dispersión de las secciones censales vulnerables en el conjunto de municipios de su entorno. 
Los resultados van en la línea de los que ya se habían obtenido en trabajos previos para el conjunto de la región metropolitana de Barcelona y vienen a confirmar la estrecha relación existente entre segregación residencial y gasto de los Ayuntamientos. Así, pues, se puede reafirmar la hipótesis de partida a modo de conclusión general y hacerla extensiva a los sistemas urbanos del arco metropolitano de Barcelona: los municipios con mayor concentración de áreas vulnerables y, por lo tanto, de necesidades, tienen menor capacidad de gasto. En cambio, los municipios con una presencia mayor de zonas acomodadas y, con unas necesidades inferiores - o por lo menos no tan acuciantes-, disponen de más capacidad de gasto. Dicho de otro modo, la segregación residencial se ve reflejada en el gasto de los municipios, y con ello en la capacidad de prestar servicios públicos. De esta manera, la segregación residencial incide sobre el sistema de bienestar e, indirectamente si se quiere, sobre la reproducción de las desigualdades sociales.

Se espera dar continuidad a la línea de trabajo iniciada ampliando el ámbito territorial de estudio y profundizando en el análisis de los presupuestos municipales, tanto en el capítulo de gastos como en el de ingresos. No obstante, los resultados obtenidos hasta ahora pueden servir de orientación para algunas políticas públicas. En primer lugar, se reafirma la necesidad de afrontar la financiación municipal desde el principio de la equidad horizontal, entre otras cosas, para intentar revertir el efecto barrio que se acaba de mostrar. En segundo lugar, se ponen de manifiesto las dificultades que los municipios, de manera individual, pueden tener para mejorar las condiciones de vida en los barrios más vulnerables. Para desarrollar estas políticas «territorializadas», serían necesarios, pues, instrumentos y programas con financiación supramunicipal.

\section{BIBLIOGRAFÍA}

Castells, A., Esteller, A. y Vilalta, M. (2003). Tax capacity disparities and fiscal equalization: The case of Spain Local Goverments. En G. Fäber y N. Otter (Eds.), Reforms of local fiscal equalization en Europe, pp. 297-338. Speyer: Deutsches Forschungsinstitut für öffentliche Verwaltung.

Departament de Política Territorial i Obres Públiques. (2010). Pla Territorial Metropolità de Barcelona. Barcelona: Departament de Política Territorial i Obres Públiques. Generalitat de Catalunya.

DOGC. Decret 369/2004, de 7 de setembre, pel qual es desenvolupa la Llei 2/2004, de 4 de juny, de millora de barris, àrees urbanes i viles que requereixen atenció especial, (2004a).

DOGC. Llei 2/2004, de 4 de juny, de millora de barris, àrees urbanes i viles que requereixen atenció especial, (2004b).

Domínguez, M., Leal, J. y Martínez-Goytre, E. (2012). The Limits of Segregation as an Expression of Socioeconomic Inequality: The Madrid Case. En T. Maloutas 
y K. Fujita (Eds.), Residential Segregation en Comparative Perspective. Making Sense of Contextual Diversity, pp. 217-236. Surrey (England): Ashgate. Donat, C. (2017). Crisis, ciclo inmobiliario y segregación urbana en la región metropolitana de Barcelona. Archivio Di Studi Urbani e Regionali, (118 supl.), 195-219. doi: 10.3280/ASUR2017-118S10

Donat, C. (2018). La segregación urbana: marco teórico-conceptual y estado de la cuestión. En O. Nel.lo y I. Blanco (Eds.), Barrios y Crisis. Crisis económica, segregación urbana e innovación social en Cataluña, pp. 27-50. Valencia: Tirant Humanidades.

Fujita, K. (2012). Conclusion: Residential Segregation and Urban Theory. En T. Maloutas y K. Fujita (Eds.), Residential Segregation en Comparative Perspective. Making Sense of Contextual Diversity, pp. 286-322. London: Ashgate.

Hernández-Aja, A. (1997). Análisis urbanístico de barrios desfavorecidos: catálogo de áreas vulnerables españolas. Cuadernos de Investigación Urbanística, (19), 1-104.

Hernández-Aja, A., Matesanz, Á. y García, C. (2015). Atlas de los barrios vulnerables de España. 12 ciudades 1991/2001/2006. Madrid: Instituto Juan de Herrera.

Jiménez, E. y Donat, C. (2018). El estudio de la segregación urbana: estrategia metodológica. En O. Nel.lo y I. Blanco (Eds.), Barrios y Crisis. Crisis económica, segregación urbana e innovación social en Cataluña, pp. 51-71. València: Tirant Humanidades.

Muñoz, F. (2004). La Producció residencial de baixa densitat a la província de Barcelona, 1985-2001. Universitat Autònoma de Barcelona, Barcelona.

Musterd, S., Marcińczak, S., van Ham, M., y Tammaru, T. (2017). Socioeconomic segregation en European capital cities. Increasing separation between poor and rich. Urban Geography, 38(7), 1.062-1.083. doi: 10.1080/02723638.2016.1228371

Nel.lo, O. (2000). Ciudades intensas. Reflexiones sobre el papel de las ciudades de la segunda corona metropolitana en la articulación del área urbana de Barcelona. En C. Bellet y J. M. Llop (Eds.), Ciudades intermedias. Urbanización y sostenibilidad, pp. 225-245. Lleida: Milenio.

Nel.lo, O. (2002). Cataluña, ciudad de ciudades. Lleida: Editorial Milenio.

$\mathrm{Nel} \cdot \mathrm{lo}, \mathrm{O}$. (2014). Desigualdad social y segregación urbana en la región metropolitana de Barcelona. XII Coloquio Del Grupo de Geografía Urbana (GGU) de La Asociación de Geógrafos Españoles (AGE). Madrid, 11-13 de junio 2014.

Nel.lo, O. (2018). La segregación urbana en Cataluña. En I. Blanco y O. Nel.lo (Eds.), Barrios y Crisis. Crisis económica, segregación urbana e innovación social en Cataluña, pp. 71-110. Valencia: Tirant Humanidades.

Nel.lo, O. y Blanco, I. (2015). La segregació urbana a la regió metropolitana de Barceona. Publicacions Del Pla Estratègic Metropolità de Barcelona, 24. 
Nel·lo, O. y Donat, C. (2017). Segregación residencial y gasto municipal en la región metropolitana de Barcelona: la necesidad de políticas supramunicipales. XXV Congreso de La AGE. Naturaleza, Territorio y Ciudad En Un Mundo Global, 2.545-2.553. Madrid: Asociación de Geografos Españoles.

Porcel, S. (2020). Desigualdad social y segregación residencial, una relación compleja. Madrid: Fundación FOESSA.

Ruiz, E., Velasco, A. y Serrano, M. (2017). Migracions intermunicipals al territori metropolità de Barcelona, 2001-2015. Barcelona: Àrea Metropolitana de Barcelona. Servei d'Estudis Territorials.

Sassen, S. (1991). The Global City: New York, London, Tokyo. Princeton: Princeton University Press.

Serra, J. (dir). (2003). El Territori metropolità de Barcelona. dades bàsiques, evolució recent i perspectives. Barcelona: Mancomunitat de Municipis de l'Àrea Metropolitana de Barcelona.

Tammaru, T., Marcinczak, S., van Ham, M. y Musterd, S. (Eds.). (2016). SocioEconomic Segregation en European Capital Cities. East meets west. Abingdon, Oxon: Routledge.

Trullén, J. y Boix, R. (2003). Barcelona, Metropolis policentrica en red. Departament d'Economia Aplicada, Working Paper, 31.

van Ham, M., Manley, D., Bailey, N., Simpson, L. y Maclennan, D. (Eds.). (2012). Neighbourhood Effects Research: New Perspectives.

doi: dx.doi.org/10.1007/978-94-007-2309-2

Vázquez, C., Palacios, A. y Martínez, J. (2018). Housing en the context of urban vulnerability: Madrid's municipal policies and practices tackling residential vulnerability. En E. Bargelli y T. Heitkamp (Eds.), New developments en southern european housing, pp. 79-126. Pisa: Pisa University Press.

Vilalta, M. (Ed.). (2015). Autonomía y equidad en la financiación municipal: dos principios compatibles. Barcelona: Publicacions i edicions de la Universitat de Barcelona.

Vilalta, M. (2018). La hisenda local a Catalunya: Evolució recent, situació actual i principals reptes - Dialnet. Revista Catalana de Dret Públic, (57), 97-112. doi: 10.2436/rcdp.i57.2018.3236 



\section{PATRONES ESPACIALES DE LA MOVILIDAD RESIDENCIAL DE LOS ESPAÑOLES Y EXTRANJEROS EN ZARAGOZA (2003-2017)

\author{
SPATIAL PATTERNS OF RESIDENTIAL MOBILITY OF \\ SPANIARDS AND FOREIGNERS IN ZARAGOZA (2003-2017)
}

Severino Escolano-Utrilla

Universidad de Zaragoza

Carlos López-Escolano

Universidad de Zaragoza

Ángel Pueyo-Campos

Universidad de Zaragoza

José Antonio Salvador Oliván

Universidad de Zaragoza

Resumen

La magnitud y configuración espacial de la movilidad residencial intraurbana se relacionan con numerosos factores económicos, sociales y espaciales. La mayor parte de la investigación sobre los patrones espaciales de la movilidad residencial se ha centrado en el análisis de la relación de estos factores con las características de los territorios de origen y destino de los cambios de residencia, pero apenas se han estudiado las estructuras espaciales conformadas por la conexión origen-destino de los flujos residenciales. Aquí se acepta que la valoración de los diversos factores que intervienen en los procesos de decisión de cambio de residencia difiere según la condición social, económica y cultural. Con esta premisa, a partir del análisis de datos individuales de cambio de residencia en la ciudad de Zaragoza (España), se han identificado los espacios de la movilidad residencial (módulos, clusters) definidos por los territorios de origen y destino del cambio de residencia, mediante la aplicación de técnicas de análisis de redes geoespaciales. Los resultados obtenidos muestran que los patrones espaciales de la movilidad residencial de españoles y de extranjeros presentan diferencias en su tamaño y forma. También se observa que la movilidad residencial es un medio importante de diferenciación y homogeneización social de buena parte del espacio urbano.

Palabras clave: movilidad residencial intraurbana, inmigrantes extranjeros, redes socioespaciales, Zaragoza (España).

\section{Abstract}

The magnitude and spatial configuration of intra-urban residential mobility are related to economic, social and spatial factors. The research on the spatial 
patterns of residential mobility has focused on the analysis of the relationship of these factors with the characteristics of the origin-destination territories of the changes of residence. However, the spatial configurations formed by the origin-destination connection of residential flows have hardly been studied. Here it is accepted that the valuation of the various factors involved in the residence change decision processes differs according to the social, economic and cultural condition. With this premise, from the analysis of individual data of change of residence, the residential mobility spaces (clusters) defined by the origin-destination territories of the change of residence have been identified, through the application of analysis techniques of geospatial networks. The results show that the spatial patterns of residential mobility of Spaniards and foreigners present differences in their size and shape. Additionally, residential mobility is an important mean of differentiation and social homogenization of a large part of the urban space.

Keywords: intraurban residential mobility, foreign immigrants, sociospatial networks, Zaragoza (Spain).

\section{INTRODUCCIÓN}

La movilidad residencial intraurbana es una de las prácticas materiales y simbólicas que más contribuye a transformar la geografía social y funcional de las ciudades, por cuanto la residencia es el centro de gravedad más importante de los territorios cotidianos y uno de los puntos de anclaje de la identidad de los individuos y grupos sociales.

Los científicos sociales han estudiado la movilidad residencial, a diversas escalas, para conocer las características de quién cambia de residencia (o permanece en la misma), por qué razones lo hace, cómo se producen estos cambios y, en bastante menor medida, entre qué lugares se producen. El estudio de la movilidad residencial ha enriquecido su marco teórico y datos empíricos desde los primeros trabajos, centrados en el análisis de las decisiones de cambio y de elección de residencia, hasta la consideración de la movilidad residencial como un fenómeno social complejo (Torrado, 2019, 17), como una práctica relacional que conecta vidas en el tiempo y en el espacio (Coulter et al., 2016).

Este cambio ha implicado el desplazamiento del enfoque desde el estudio de las decisiones individuales de cambio de residencia que buscan la maximización del beneficio, hasta la consideración de la movilidad residencial como una práctica social concreta que se desarrolla en el contexto de interacción entre las preferencias individuales, las opciones e información disponible sobre las mismas, las oportunidades, la percepción y los condicionantes estructurales de los agentes urbanos. A los factores clásicos que impulsan o limitan los cambios residenciales intraurbanos, referidos a las necesidades 
de vivienda asociadas al ciclo de vida familiar, se han sumado otros como el estatus socioeconómico de los migrantes, la distancia o accesibilidad al trabajo, las características del entorno (Bible y Brown, 1981; Brummell, 1979; Clark y Dieleman, 1996), la mejora de la accesibilidad al trabajo o a los servicios y equipamientos públicos (Morris et al., 2018), las oportunidades de inversión o cambios en el estilo de vida (Méndez y Gayo, 2019; Van der Vlist et al., 2011), con la búsqueda de mejor calidad de los servicios y equipamientos públicos, la dinámica y políticas de los mercados de vivienda (Andrews y Caldera Sánchez, 2011; Bayoh et al., 2006), razones emocionales (Raulin, 2014; Villani, 2014) y otros. La localización de la vivienda actual y la nueva forma parte de los factores que se toman en cuenta en los procesos de decisión, por lo que las trayectorias espaciales y la estructura de los cambios de residencia expresan, en parte, las relaciones entre los migrantes y los territorios de origen y destino de sus residencias.

Desde esta perspectiva, la identificación de las migraciones como objeto de estudio se relaciona con la escala y la resolución de las investigaciones. A escala metropolitana Torrado $(2019,18)$ distingue tres formas principales de movilidad residencial, cada una con implicaciones propias en los procesos de reconfiguración metropolitana: los movimientos de suburbanización, que se producen entre el centro y la franja externa de crecimiento metropolitano; los de centralización, desde la corona exterior hacia la ciudad central; y la movilidad entre los municipios de la corona. El municipio es considerado como la unidad espacial adecuada para el estudio de la movilidad residencial metropolitana. En el caso de ciudades compactas y de elevada densidad, los movientes internos también son importantes.

La investigación de la movilidad residencial se ha centrado en el estudio de los procesos de decisión de cambios de residencia y los factores que intervienen. El análisis de los tipos de movilidad espacial ha recibido menos atención y apenas se ha estudiado la configuración territorial que emerge de la combinación de los diferentes tipos de movimientos.

Los territorios, o cuencas de movilidad residencial, están constituidos por el conjunto de lugares relacionados por el vínculo origen-destino de la residencia habitual y la nueva. La estructura de las cuencas de movilidad resulta de la actuación de dos lógicas: una geográfica, se fundamenta en el principio de autocorrelación espacial, es decir, que la los cambios residenciales cercanos entre si tienen alta probabilidad de presentar propiedades similares; la otra, se basa en el principio de homophily, que permite aceptar que los migrantes con estándares sociales parecidos (estatus económico, nivel educativo, modelo familiar, etc.) es probable que muestren patrones migratorios semejantes, independientemente de donde residan. De ambos principios se desprende que la movilidad residencial del grupo de españoles y del de extranjeros presentará, con alta probabilidad, patrones espaciales diferentes, puesto que las características demográficas —estructura por edades, com- 
posición de los hogares-, sociales, económicas y otros factores que influyen en las decisiones de los cambios de residencia, son distintos en ambos grupos.

Con este contexto, esta investigación tiene por objeto delimitar, caracterizar y explicar la configuración espacial de la movilidad residencial de españoles y extranjeros en Zaragoza durante el período 2003-2017.

\section{CARACTERIZACIÓN DEL ÁREA DE ESTUDIO}

La ciudad de Zaragoza ha experimentado profundas transformaciones de su geografía social, espacial y funcional durante los años transcurridos del siglo $X X I$. La población, ha registrado un crecimiento del $9 \%$ en el periodo de estudio 2003-2017, y roza los 700.000 habitantes en 2017. El crecimiento del contingente de extranjeros ha sido mayor, pues su número prácticamente se ha duplicado durante el quindenio de estudio. Sin embargo, este incremento demográfico ha sido desigual en el tiempo y en el espacio de acuerdo con los ciclos económicos y migratorios: i) un periodo inicial (2003-2008) de expansión demográfica y urbana orientada hacia la dispersión en la periferia (Callizo Soneiro, 2017; De Miguel González, 2015) y ii) otro ciclo posterior (20082017) de reorganización interior y escaso desarrollo urbano y estabilidad de la población como en otras ciudades españolas (Martori et al., 2016).

En conjunto, Zaragoza presenta algunas características de ciudad intermedia a escala espacial y demográfica: escala humana que permite el conocimiento y experiencia personal de gran parte del espacio urbano; tamaño de población intermedio en relación a las ciudades del país; composición de la población semejante a la media nacional; rango relevante en el entramado político-administrativo del país; procesos metropolitanos a escala moderada; procesos de suburbanización, dispersión y fragmentación espacial (EscolanoUtrilla et al., 2018); creación de centralidades en la periferia; buena calidad media de vida; o fácil acceso al centro urbano caminando o en transporte público para gran parte de la población (Arranz-López et al., 2017).

En Zaragoza, las migraciones centro-periferia han sido el vector principal de la redistribución de la población en los últimos años (42.318 nuevas viviendas construidas entre 2003 y 2017, IAEST) debido a la disponibilidad de suelo para urbanizar en torno a la ciudad compacta, lo que ha limitado la dispersión de población en otros municipios del área metropolitana respecto a lo sucedido en otras ciudades españolas (Jiménez et al., 2018). Hasta estos espacios se ha trasladado mayoritariamente población joven en edad de emancipación procedente de los barrios centrales de la ciudad con estatus socioeconómico medio-alto, mientras que una parte muy significativa de la población de origen extranjero se ha asentado en barrios centrales donde el envejecimiento ha dejado libres numerosas viviendas económicamente más accesibles, y más deterioradas, frente a las nuevas ubicadas en la periferia (Ebrópolis, 2019). 
La ciudad actual se puede caracterizar por cinco grandes tipos socioespaciales, que se utilizan exclusivamente con fines de descripción e interpretación; son las siguientes: i)

Centro urbano: comprende el espacio situado entre el río Ebro y el primer cinturón (muralla medieval) incluyendo el Casco Histórico, así como los ensanches más nobles; aquí se localiza el distrito central de negocios (CBD) y el principal entorno comercial; ii) Barrios populares de la margen derecha del río Ebro: se desarrollan entre el centro histórico hasta el cinturón Z-30, también se incluyen los barrios tradicionales del «extrarradio», Oliver y Valdefierro, iii) Barrios populares de la margen izquierda del río Ebro: conforman un espacio cercano al centro urbano entre el río Ebro y el cinturón Z-30; iv) Periferia próxima: corresponde al espacio urbano desarrollado entre los cinturones Z30 y Z-40 (exceptuando Oliver y Valdefierro), caracterizado por su notable fragmentación espacial, la presencia de condominios de clase alta y la mezcla de usos del suelo; y v) Periferia lejana: designa al espacio urbano construido entre el cinturón Z-40 y los límites del municipio. Sus características son similares a las del tipo anterior y además añade algunos núcleos rurales tradicionales.

Finalmente, la expresión «espacio urbano tradicional» se emplea aquí para designar a la ciudad existente hasta mediados de la década de 1980, es decir, aproximadamente el espacio comprendido dentro del cinturón Z-30 y los barrios Oliver y Valdefierro.

\section{DATOS Y MÉTODOS}

Los datos utilizados en esta investigación expresan el número de personas que ha cambiado de residencia entre 2003 y 2017 dentro del municipio de Zaragoza. Se han obtenido a partir de la agregación, en secciones censales homogeneizadas, de los cambios de residencia individuales registrados en el Padrón Municipal de Habitantes, que gestiona el Ayuntamiento de Zaragoza. Las secciones censales son unidades estadísticas inframunicipales formadas por un territorio continuo cuya población oscila entre 500 y 2.500 habitantes, salvo excepciones. La considerable resolución espacial y su semejanza de tamaño hacen que las secciones sean unidades espaciales muy apropiadas para el estudio, a mesoescala, de las migraciones residenciales en las ciudades españolas. Esta fuente es muy fidedigna, ya que el empadronamiento es un requisito para recibir diversas prestaciones sociales, sanitarias y educativas, lo que permite conocer también la población en situación irregular.

A estos datos se les ha aplicado una secuencia metodológica acorde con los objetivos, en la que se diferencian dos fases: la elaboración de la red y su análisis consiguiente. A partir de la matriz origen-destino de la movilidad residencial se han construido dos redes geoespaciales: una para modelar la 
movilidad de los españoles y otra para la de los extranjeros. Los nodos de la red representan a las secciones (los centroides de las mismas) y las aristas (conexiones) simbolizan la dirección origen-destino y la magnitud del flujo migratorio entre secciones. Los nodos contienen información espacial y temática; las conexiones, el monto de los cambios residenciales entre los nodos. El siguiente paso para completar la descripción de la estructura de la red ha consistido en identificar y caracterizar los agrupamientos que forman los nodos (secciones censales) según la intensidad de sus conexiones, lo que permite conocer hasta qué punto las migraciones residenciales están confinadas espacialmente en determinados barrios o bien se producen entre áreas alejadas y socialmente diferentes. Los agrupamientos, módulos o clústeres se definen como el conjunto de nodos cuyas conexiones mutuas tienen densidades relativas más elevadas que con su entorno. Entre los múltiples métodos de detección de módulos en redes complejas (Malliaros y Vazirgiannis, 2013), se ha utilizado el algoritmo de agrupamiento jerárquico de nodos basado en la similitud de su estructura de los flujos (Clauset et al., 2004) implementado en el programa ORA NET SCENES 3.0 (Carley, 2017).

La modularidad (Newman, 2003; 2006), es una magnitud que mide la fuerza con que una red está estructurada en módulos. Su cálculo relaciona, de forma normalizada, la fracción de conexiones entre los nodos (centroides) de un grupo respecto de las que cabría esperar en una distribución aleatoria con el mismo número de elementos. Los valores de este indicador varían entre -0,5 y 1 ; el valor es positivo si las conexiones observadas son más que las esperadas por azar. Su ecuación es la siguiente:

$$
Q=\frac{1}{4 m} \sum_{i j}\left(A_{i j} \frac{k_{i} k_{j}}{2 m}\right) s_{i} s_{j}
$$

Donde: $1 / 4 \mathrm{~m}$ : normalización; $\mathrm{s}_{i}=1 \mathrm{si}$ el vértice i pertenece al grupo 1 y $\mathrm{s}_{i}=-1 \mathrm{si}$ pertenece al grupo 2; $A_{i j}$ : número de aristas (conexiones) entre los vértices (nodos $i, j$ ) (Aij: elementos de la matriz de adyacencia); $\mathrm{k}_{j} \mathrm{k}_{j} / 2 \mathrm{~m}$ : número de aristas esperado entre los vértices $i$ y $j$ si aquellas se distribuyen aleatoriamente; $\mathrm{k}_{i} \mathrm{y} \mathrm{k}_{j}$ : grado de los vértices; $1 / 2 \sum_{i} \mathrm{k}_{i}$ : número total de aristas de la red. Además de la forma y localización de los módulos, el índice E-I es un indicador normalizado de la cohesión de cada módulo que expresa la proporción de relaciones migratorias bilaterales entre las comunas del mismo grupo (conexiones internas: I) y las relaciones con las comunas que no forman parte del mismo grupo (conexiones externas: E). Su ecuación se puede generalizar para utilizar los pesos (migrantes: $w$ ) de las conexiones:

$$
E-I=\left(E_{W}-I_{w}\right) /\left(E_{W}+I_{w}\right)
$$


Su valor varía entre -1 (todas las conexiones son internas, es un grupo aislado) hasta 1, todas las aristas son externas; el valor 0 indica el mismo número de aristas (o migrantes) internas y externas.

\section{RESULTADOS E INTERPRETACIÓN}

Entre 2003 y 2017 cambiaron de lugar de residencia dentro del espacio urbano de Zaragoza más de medio millón de personas, la mayor parte de las cuales se mudaron a corta distancia de su domicilio de origen (dentro de la misma sección) y el resto, el 29,6\% lo hicieron a media y larga distancia (entre secciones). La Tabla 1 recoge también la tendencia contrapuesta entre los grupos de población estudiados: el 76\% de los extranjeros cambiaron de domicilio fuera de su sección mientras que el 72,8\% de los españoles trasladaron su domicilio dentro de la sección de su residencia de origen.

Las redes de movilidad de ambos grupos son diferentes en tamaño, definido por el número de nodos y conexiones, así como en el valor medio de cada relación, debido a que el número total de migrantes residenciales del grupo de españoles es muy superior al del grupo de extranjeros.

Tabla 1. Principales cifras de las migraciones residenciales intraurbanas en Zaragoza, 2003-2017

\begin{tabular}{|c|c|c|c|}
\hline & Españoles & Extranjeros & Total \\
\hline \multicolumn{4}{|l|}{ Población total: } \\
\hline 2004 & 595.444 & 43.355 & 638.799 \\
\hline 2017 & 605.620 & 94.084 & 699.704 \\
\hline \multicolumn{4}{|l|}{ Migraciones residenciales 2003-2017 } \\
\hline Total (100\%): & 481.771 & 25.801 & 507.572 \\
\hline Entre secciones (\% del total) & $130.888(27,2)$ & $195.87(76,0)$ & 150.475 \\
\hline Intrasecciones (\% del total) & $350.883(72,8)$ & $6.214(24,0)$ & 357.097 \\
\hline Número de secciones & \multicolumn{3}{|c|}{487} \\
\hline $\begin{array}{l}\text { Número de secciones con balance migratorio } \\
\text { neto (inmigrantes-emigrantes) positivo }\end{array}$ & 118 & 258 & \\
\hline $\begin{array}{l}\text { Número de secciones con balance migratorio } \\
\text { neto (inmigrantes-emigrantes) negativo }\end{array}$ & 371 & 220 & \\
\hline Número de relaciones bilaterales & 59.313 & 11.757 & \\
\hline $\begin{array}{l}\text { Personas/relación bilateral: promedio, } \\
\text { mínimo; máximo }\end{array}$ & 2,2;1;279 & 1,$66 ; 1 ; 30$ & \\
\hline
\end{tabular}

Fuente: Padrones Municipales de Habitantes. Elaboración propia 


\subsection{DIFERENTE ESTRUCTURA ESPACIAL DE LA MOVILIDAD RESIDENCIAL DE LOS ESPAÑOLES Y EXTRANJEROS}

La estructura y configuración espacial de las redes de cambio residencial de ambos grupos presentan varios rasgos diferenciales.

Figura 1. Flujos residenciales de españoles y extranjeros en Zaragoza, 2013-2017

(mayores de 10 migrantes españoles y mayores de 5 migrantes extranjeros)
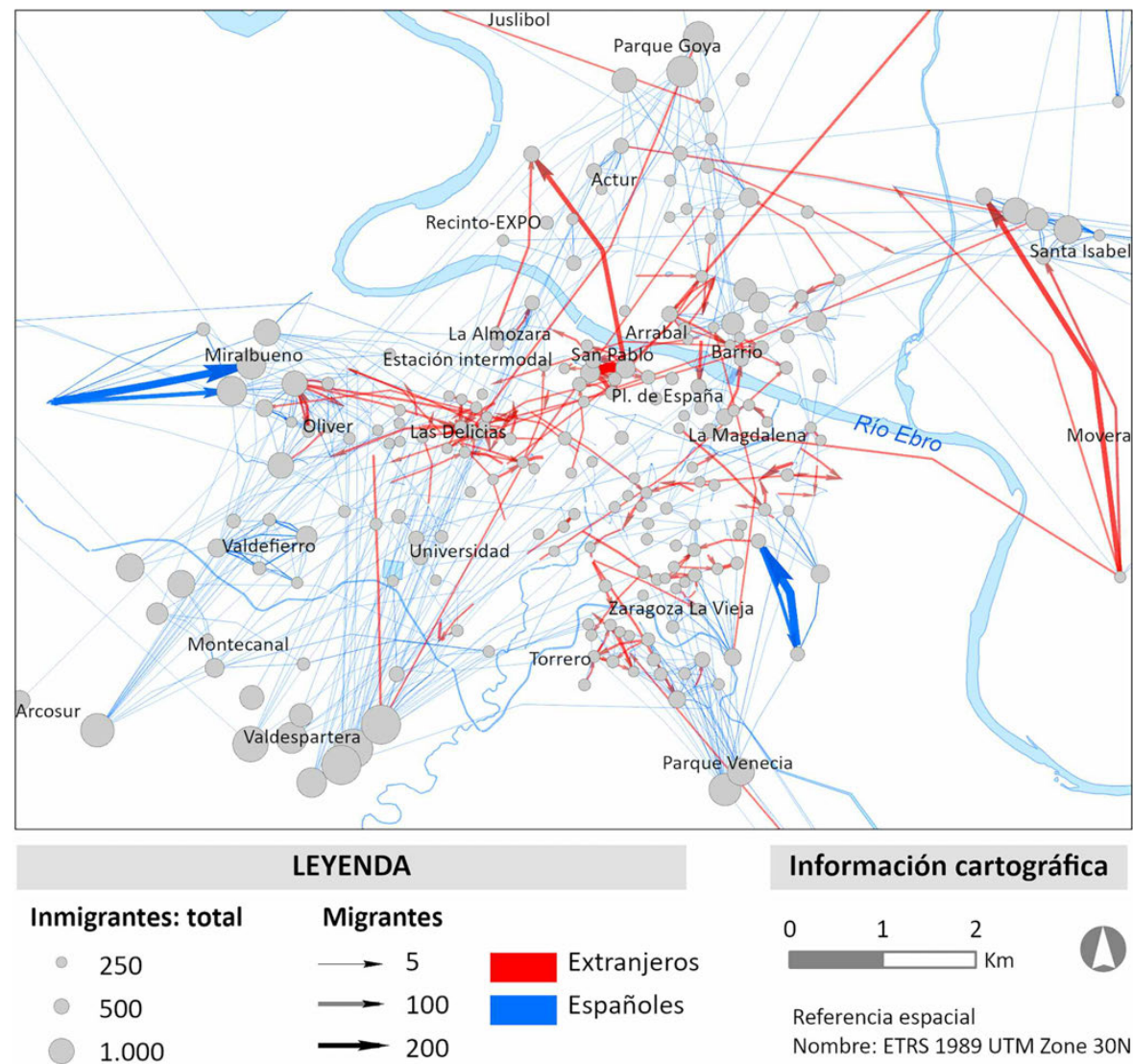

Extranjeros: más de 5 personas

Españoles: más de 10 personas

Fuente: Padrones Municipales de Habitantes. Elaboración propia

Círculos (inmigrantes): valor máximo 1.696 personas.

Líneas (migrantes): valor máximo 279 personas. 
Por una parte, el grado de concentración de los destinos de los movimientos residenciales es más elevado en el caso del grupo de españoles que el de los extranjeros, a pesar de que el número de secciones con saldo neto positivo (llegan más residentes de los que salen) es mayor que el de secciones con saldo neto negativo. En el caso del grupo de extranjeros, la situación es la contraria. Esta distribución implica que los cambios de residencia de los españoles se dirigen a múltiples destinos, pero la concentración en algunos de ellos es considerable. Al contrario, los destinos residenciales de los extranjeros no se dispersan tanto, pero su grado de concentración no es tan acusado como el de los españoles.

Por otra, la configuración espacial de ambas redes también muestra diferencias significativas. En la figura 1 se observa que los cambios de residencia de los extranjeros se producen, preferentemente, entre diversas secciones del centro histórico (principalmente de los barrios de San Pablo y La Magdalena) y de los centros de los barrios de la margen derecha (Delicias) y de la margen izquierda (El Rabal, Barrio Jesús). Al contrario, los cambios de residencia de los españoles tienen como destino preferente secciones de la periferia próxima —entre las autovías de circunvalación Z-30 y Z-40-y, en menor medida, lejana (fuera de la autovía Z-40). También son destacables algunos agrupamientos de secciones en la periferia, caracterizados por el fuerte intercambio mutuo de flujos residenciales (Santa Isabel, Valdefierro, Oliver-Miralbueno). En la Figura 1 también se aprecia que la red de cambios residenciales está organizada en estructuras y subestructuras jerarquizadas (agrupamientos, clústeres o módulos), compuestas por agrupamientos de secciones con intensos intercambios residenciales. La división analítica de la red mediante el método de Newman produce un valor de modularidad de $Q=0,23$ para ambas redes, lo que indica que, en el nivel que estudiamos, los módulos tienen una funcionalidad moderada, es decir, la red presenta un elevado grado de integración global. Este valor del modularidad, relativamente bajo, se produce porque los flujos de poco volumen (menos de cinco personas) son muy numerosos y unen todos los nodos de la red en el caso de los españoles y casi todos en el de los extranjeros. Sin embargo, cuando se pondera la influencia de los flujos más débiles, el valor de la modularidad asciende a $Q=0,77$ para las dos redes, lo que expresa que el grueso de las migraciones se produce en espacios bien diferenciados (este nivel no se analiza aquí). Los clústeres identificados se componen de agregados de secciones con diferencias destacables en su tamaño, propiedades y organización espacial (Tabla 2). 
Tabla 2. Principales características de los agrupamientos de los flujos residenciales intraurbanos de los españoles y de los extranjeros en Zaragoza, 2003-2017

\begin{tabular}{|c|c|c|c|c|c|c|c|c|c|}
\hline \multicolumn{5}{|c|}{ Españoles } & \multicolumn{5}{|c|}{ Extranjeros } \\
\hline \multirow{2}{*}{$\begin{array}{l}\text { Grupo } \\
\text { (módulo } \\
\text { clúster) }\end{array}$} & \multirow{2}{*}{$\begin{array}{l}\text { Seccio- } \\
\text { nes }\end{array}$} & \multirow{2}{*}{$\begin{array}{l}\text { Pob. } \\
\text { total }\end{array}$} & \multicolumn{2}{|c|}{ Movilidad } & \multirow{2}{*}{$\begin{array}{l}\text { Grupos } \\
\text { (módulo } \\
\text { clúster) }\end{array}$} & \multirow{2}{*}{$\begin{array}{c}\text { Seccio- } \\
\text { nes }\end{array}$} & \multirow{2}{*}{$\begin{array}{l}\text { Pob. } \\
\text { total }\end{array}$} & \multicolumn{2}{|c|}{ Movilidad } \\
\hline & & & Interna & Externa & & & & Interna & Externa \\
\hline 1 & 168 & 240.770 & 27.101 & 16.449 & 1 & 126 & 199.975 & 2.432 & 2.541 \\
\hline 2 & 146 & 216.627 & 22.866 & 16.244 & 2 & 101 & 129.587 & 1.592 & 2.047 \\
\hline 3 & 136 & 184.280 & 19.032 & 19.032 & 3 & 47 & 67.852 & 302 & 993 \\
\hline 4 & 32 & 52.322 & 2.508 & 6.757 & 4 & 121 & 170.006 & 3.706 & 2.459 \\
\hline 5 & 5 & 7.576 & 457 & 442 & 5 & 81 & 116.694 & 1.361 & 1.897 \\
\hline Total & 487 & 701.575 & 71.964 & 58.924 & 6 & 9 & 14.389 & 100 & 141 \\
\hline & & & & & 7 & 2 & 3.072 & 3 & 13 \\
\hline & & & & & Total & 487 & 701.575 & 9.496 & 10.091 \\
\hline
\end{tabular}

Fuente: Padrones Municipales de Habitantes. Elaboración propia

Los cambios residenciales de los españoles se organizan, en el nivel más elevado, en cinco espacios con diferencias considerables en tamaño: los tres primeros (clústeres 1, 2 y 3) concentran cada uno más del 25\% de la población total, de los movimientos flujos residenciales internos y de los externos. Los dos módulos restantes son bastante más pequeños y presentan otras características particulares. El 4, es un agrupamiento espacialmente fragmentado en dos sectores compuestos por secciones de las que principalmente salen residentes (secciones de una franja en torno al río Ebro, desde La Almozara hasta Juslibol) que se dirigen, fundamentalmente, a Valdespartera. El agrupamiento 5 recoge los flujos migratorios entre varios núcleos rurales vecinos, situados al noreste del término municipal (Figura 2a). Además, como expresa el indicador E-I, los cambios de residencia dentro de cada módulo predominan ligeramente sobre los externos. El grupo 1, una cuña de dirección centrooeste, presenta, junto con el grupo 2, al norte, el mayor grado de endogamia de movilidad residencial.

Los cambios residenciales de los extranjeros se estructuran en un número mayor de módulos y, además, todos ellos espacialmente fragmentados. Los agrupamientos 1, 2 y 4 son los de mayor tamaño y cada uno concentra entre el $20 \%$ y el $40 \%$ de la población y los cambios residenciales internos o externos. Los restantes módulos son bastante más pequeños. Por otra parte, el 
grueso de la movilidad se produce entre módulos, excepto en un caso, el 4, correspondiente al área centro-oeste (Figura 2b).

La configuración espacial de los agrupamientos de los cambios residenciales de los extranjeros es más compleja que la de los españoles. El fraccionamiento de los espacios migratorios deriva, por una parte, del menor número de desplazamientos y, por otra, de las fuertes ligazones entre espacios no contiguos, aunque generalmente próximos.

Figuras 2a y 2b. Agrupamientos de secciones (método de Newman) de los flujos residenciales de españoles y extranjeros en Zaragoza, 2003-2017

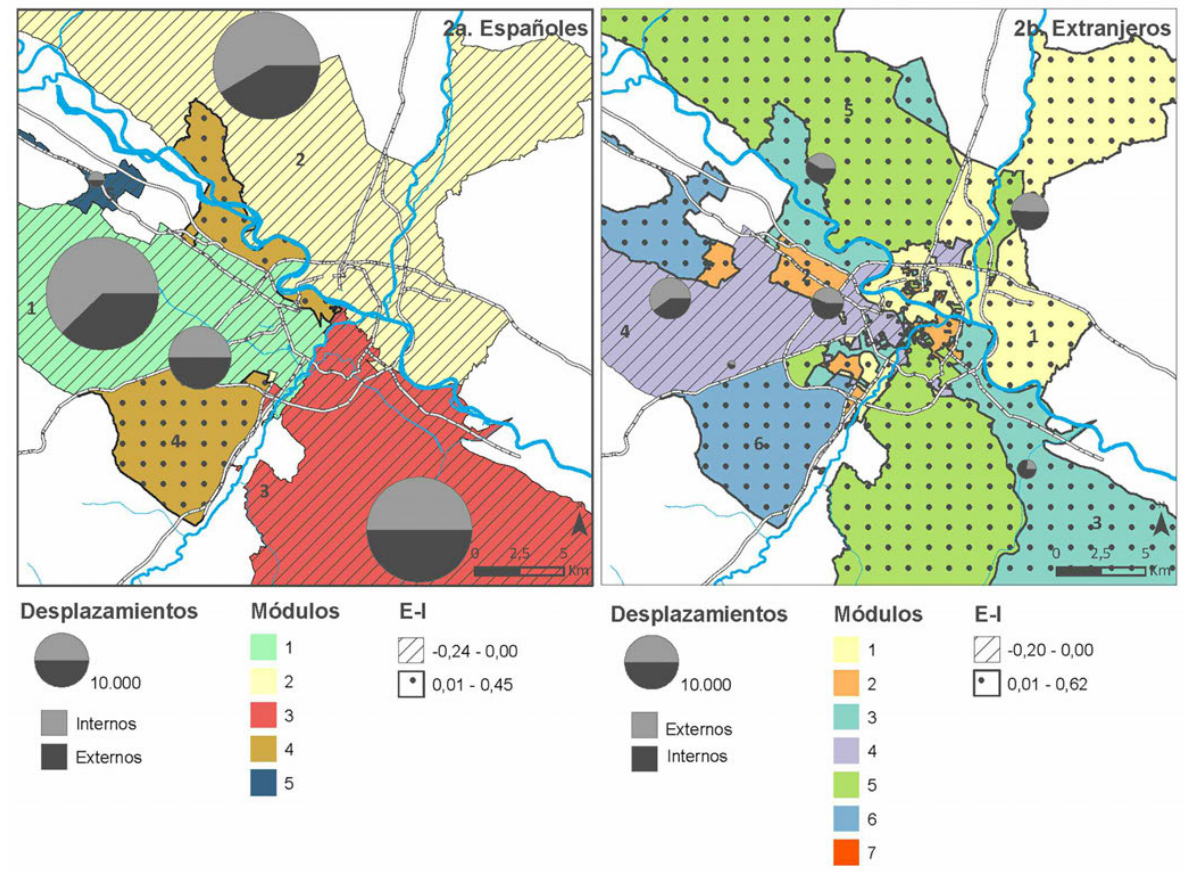

Fuente: Padrones Municipales de Habitantes. Elaboración propia

En resumen: las trayectorias espaciales de la movilidad residencial conforman una red única que integra todo el espacio urbano de Zaragoza, aunque con densidades variables en la dirección y magnitud de los cambios de residencia. El método aplicado ha permitido diferenciar, a macroescala, cinco grandes sectores de movilidad residencial del grupo de españoles, asimilables a un modelo de tipo hoytiano (Hoyt, 1939) que se desdibuja para el grupo de extranjeros, en el que se distinguen siete cuencas de movilidad fragmentadas, especialmente en las áreas centrales de la ciudad. Debido a su configuración sectorial, cada módulo tiene cierta heterogeneidad social y espacial, 
pues comprende espacios centrales, intermedios y periféricos, entre los que se producen, aproximadamente, la mitad de los cambios de residencia, cortos o largos; la otra mitad de los cambios de residencia se produce con los restantes módulos. Además, el balance de intercambios entre cada sector es bastante equilibrado.

\subsection{TERRITORIOS CONTINUOS DELIMITADOS POR MOVIMIENTOS CENTRO-PERIFERIA EN ESPAÑOLES VERSUS TERRITORIOS FRAGMENTADOS Y DELIMITADOS POR MOVIMIENTOS DE CORTO RECORRIDO}

Los resultados obtenidos muestran que la configuración espacial de los cambios de residencia de españoles y extranjeros presenta diferencias, que expresan los diversos contextos y criterios de valoración de los factores de la movilidad residencial que enmarcan y ponen en práctica ambos grupos.

En primer lugar, los cambios de residencia de los españoles consolidan un proceso de suburbanización que conduce a la despoblación de varios sectores del centro de la ciudad y de los sectores más antiguos de los barrios tradicionales, y al asentamiento de una proporción creciente de población en la periferia. Este proceso es explicable por la combinación de factores considerados en las teorías «evolución natural» y «flight from blight» (Mieszkowski y Mills, 1993, 137-138) que, fundamentalmente, se concretan en la existencia de una amplia oferta de viviendas nuevas en la periferia bien comunicadas por vehículo privado con el resto de la ciudad a través de los cinturones Z-30 y Z-40. Las promociones de viviendas sociales en algunos barrios nuevos (Valdespartera, Arcosur, Rosales del Canal, Parque Goya) junto con la mejora de su accesibilidad, a raíz de la puesta en marcha de la línea 1 del tranvía, han sido también factores importantes de atracción de población hacia varios sectores de la periferia (De Miguel González, 2015; Escolano-Utrilla et al., 2018). Las trayectorias de la salida de residentes hacia el exterior del área urbana reflejan cambios de residencia de recorrido medio y largo, con orígenes dispersos por todo el espacio urbano continuo y direcciones múltiples, aunque predominan las orientaciones radiales, centrífugas. Esta diversidad de vectores obedece a la combinación de dos lógicas: una económica, que condiciona el abanico de opciones para elegir residencia; y otra espacial, que suele privilegiar, ceteris paribus, la cercanía a la residencia de origen.

La forma sectorial nítida de las cuencas migratorias implica que cada sector se caracteriza por cierta heterogeneidad social y espacial, pues comprende espacios centrales, intermedios y periféricos, entre los que se producen la mitad de los cambios de residencia, centrífugos o centrípetos, cortos o largos. Los sectores expresan, también, que las preferencias espaciales de los migrantes tienden al limitarse a determinados espacios urbanos.

Por otro lado, la movilidad residencial de los extranjeros está más inscrita en el espacio urbano, en parte debido a que el volumen de cambios residencia- 
les entre secciones es mucho menor que en el grupo de españoles. En general, el grueso de los cambios de residencia se produce en sectores del centro histórico (San Pablo, La Magdalena) y de las partes más antiguas de los barrios (Delicias y, en menor medida, Arrabal y San José). Estas áreas están bien comunicadas y los precios de las viviendas y de los alquileres son más reducidos que en otros sectores del tejido urbano continuo. La combinación de todos los movimientos de cambio residencial genera territorios fragmentados, en general de menor tamaño que las cuencas migratorias de los españoles, aunque también mantienen la configuración sectorial.

La fuerte migración dentro de las secciones, así como los agrupamientos de secciones, revelan que buena parte de la movilidad residencial es de corto recorrido. Esto significa que la proximidad de la nueva residencia al domicilio actual se valora como una cualidad fundamental de la nueva vivienda, es decir, si todas las demás condiciones se mantienen iguales, se prefiere una vivienda nueva en el entorno social y urbano ya conocido. Incluso, se pueden intercambiar algunos inputs (incremento de precio, reducción de la superficie) para adquirir una vivienda cercana a la que se habita; esta vinculación es especialmente fuerte en la clase-media alta. Esta modalidad de cambio residencial a corta distancia se explica porque la vinculación con los lugares permite mantener, no solo lazos afectivos y prácticas cotidianas, sino también el capital social. En el caso de los extranjeros, además, facilita los procesos de reterritorialización, bien visibles en los barrios citados. Estos cambios residenciales a corta distancia, muy probablemente, no van acompañados de un cambio de estatus social del migrante. En conjunto, distancia social y distancia espacial son pequeñas en esta categoría de movilidad residencial.

La movilidad residencial de mediana y larga distancia se corresponde, con salidas de residentes de secciones del centro hacia las de la periferia, próxima y más alejada. Muy probablemente, los cambios espaciales van acompañados de otros cambios sociales o están motivados por condicionantes de mayor peso que la proximidad, como variaciones en la composición de la familia, en la localización del lugar de trabajo, o en el estilo de vida (residencias unifamiliares en condominios cerrados). En otros casos, la salida hacia la periferia se debe, principalmente, a la mayor oferta de viviendas sociales para grupos de ingresos modestos.

\section{CONCLUSIONES}

Las migraciones residenciales internas forman parte de los procesos de relocalización de la población y, por tanto, de la recomposición permanente de espacios sociales económicos y funcionales de las ciudades. En Zaragoza, los cambios de residencia han contribuido notablemente a la diversificación social de la periferia urbana, con la formación de barrios y núcleos de nuevos residentes de clases medias, que se suman a las anteriores urbanizaciones 
dispersas de residentes de grupos de estatus económico más elevado. En general, la movilidad hacia el exterior presenta una configuración sectorial, es decir, la salida de residentes del espacio urbano tradicional hacia el exterior sigue, preferentemente, una trayectoria radial.

La preferencia de la movilidad residencial de los extranjeros hacia ciertos espacios ha conducido a la fuerte concentración espacial de determinados grupos nacionales y culturales, lo que ha cambiado el paisaje y la identidad de algunos sectores de la ciudad, en particular del centro histórico y de algunos barrios. El modelo descrito indica que la influencia de la movilidad residencial en la diversificación u homogeneización social alcanza a buena parte del espacio urbano. La información obtenida es relevante para la formulación de políticas públicas en las principales áreas de la planificación y gobernanza urbanas, como la delimitación y formas del crecimiento urbano, la rehabilitación de áreas degradadas, la aplicación de políticas públicas de provisión de viviendas, equipamientos y servicios.

Finalmente, el método utilizado es eficaz para delimitar las cuencas de movilidad residencial, entendidas como los espacios que emergen de la conexión entre la localización de la residencia de origen y la de destino. Una vez establecidos los patrones geográficos de la movilidad residencial agregada para el grupo de españoles y extranjeros, se propone, como línea lógica de investigación futura, diferenciar y caracterizar los modelos migratorios de algunos estos dos grupos sociales a diferentes escalas, definidos por la ocupación, el nivel de cualificación, la edad y el tamaño de los hogares de los migrantes residenciales.

\section{AGRADECIMIENTOS}

Este trabajo se ha realizado con el apoyo del proyecto de investigación «Indicadores multiescalares y herramientas cartográficas para el análisis de la vulnerabilidad socioeconómica y residencial en áreas urbanas. Aplicación al caso de Zaragoza» (proyecto n 14932: cso2016-74888-c4-3-r), del Programa Estatal de Investigación, Desarrollo e Innovación Orientada a los Retos de la Sociedad, del Ministerio de Economía, Industria y Competitividad del Gobierno de España; y con el apoyo de la Cátedra Territorio, Sociedad y Visualización Geográfica (Universidad de Zaragoza y Ayuntamiento de Zaragoza).

\section{BIBLIOGRAFÍA}

Andrews, D. y Caldera Sánchez, A. (2011). Residential Mobility and Public Policy in OECD Countries. OECD Journal: Economic Studies, 2011(1), 1-22.

https://doi.org/, https://doi.org/10.1787/eco_studies-2011-5kgOvswqt240.

Arranz-López, A., Soria-Lara, J. A., López-Escolano, C. y Pueyo Campos, Á. (2017). Retail Mobility Environments: A methodological framework for in- 
tegrating retail activity and non-motorised accessibility in Zaragoza, Spain. Journal of Transport Geography, 58, 92-103.

https://doi.org/10.1016/j.jtrangeo.2016.11.010

Bayoh, I., Irwin, E. G. y Haab, T. (2006). Determinants of Residential Location Choice: How Important Are Local Public Goods in Attracting Homeowners to Central City Locations? Journal of Regional Science, 46(1), 97-120. https://doi.org/10.1111/j.0022-4146.2006.00434.x

Bible, D. S. y Brown, L. A. (1981). Place utility, attribute tradeoff, and choice behavior in an intra-urban migration context. Socio-Economic Planning Sciences, 15(1), 37-44. https://doi.org/10.1016/0038-0121(81)90016-1

Brummell, A. C. (1979). A Model of Intraurban Mobility. Economic Geography, 55(4), 338-352. https://doi.org/10.2307/143165

Callizo Soneiro, J. (2017). La ville espagnole à l'âge post industriel: De la crise du « fordisme » à l'éclatement de la bulle immobilière. Méditerranée, 129, 73-90. https://doi.org/10.4000/mediterranee.9222

Carley, K. M. (2017). ORA-NET SCENES. Center for Computational Analysis of Social and Organizational Systems (CASOS), Institute for Software Research International (ISRI), School of Computer Science, Carnegie Mellon University.

Clark, W. A. V. y Dieleman, F. M. (1996). Households and housing: Choice and outcomes in the housing market. Center for Urban Policy Research.

Clauset, A., Newman, M. E. J., y Moore, C. (2004). Finding community structure in very large networks. Physical Review E, 70, 066111.

https://doi.org/10.1103/PhysRevE.70.066111

Coulter, R., Van Ham, M. y Findlay, A. M. (2016). Re-thinking Residential Mobility: Linking Lives through Time and Space. Progress in Human Geography, 40(3), 352-374.

De Miguel González, R. (2015). Transformación urbana y procesos territoriales recientes en Zaragoza y su espacio metropolitano. Estudios Geográficos, 76(278), 63-106. https://doi.org/10.3989/estgeogr.201503

Ebrópolis. (2019). Estrategia Zaragoza +20. Zaragoza. Recuperado de: http://www.ebropolis.es/files/File/Estrategia20/ESTRATEGIA/Estrategia\% 20Zaragoza+20-Ebropolis-2019.pdf [Consulta: 30 de abril de 2020]

Escolano-Utrilla, S., López-Escolano, C. y Pueyo-Campos, Á. (2018). Urbanismo neoliberal y fragmentación urbana: El caso de Zaragoza en los primeros quince años del siglo XXI. EURE, 44(132), 183-210.

Hoyt, H. (1939). The structure and growth of residential neighborhoods in American cities. Washington, D.C.: Federal Housing Administration.

Jiménez, V., Hidalgo, R., Campesino, A.-J. y Alvarado, V. (2018). Normalización del modelo neoliberal de expansión residencial más allá del límite urbano en Chile y España. EURE, 44(132), 27-46.

Malliaros, F. D., y Vazirgiannis, M., (2013). Clustering and community detection in directed networks: A survey. Physics Report, 533, 95-142.

https://doi.org/10.1016/j.physrep.2013.08.002 
Martori, J. C., Madariaga, R. y Oller, R. (2016). Real estate bubble and urban population density: Six Spanish metropolitan areas 2001-2011. The Annals of Regional Science, 56(2), 369-392. https://doi.org/10.1007/s00168-016-0743-z Méndez, M. L. y Gayo, M. (2019). Social Mobility over Time and in Space: Ascending Residential and Social Trajectories. En M. L. Méndez y M. Gayo (Eds.), Upper Middle Class Social Reproductio. Wealth, Schooling, and Residential Choice in Chile (pp. 29-54). Cham: Palgrave Macmillan. Disponible en: http://link.springer.com/10.1007/978-3-319-89695-3_2 [Consulta: 13 abril 2020]. Mieszkowski, P. y Mills, E. S. (1993). The Causes of Metropolitan Suburbanization. the Journal of Economic Perspectives, 7(3), 135-147.

Morris, T., Manley, D. y Sabel, C. E. (2018). Residential mobility: Towards progress in mobility health research. Progress in Human Geography, 42(1), 112-133. https://doi.org/10.1177/0309132516649454

Newman, M. E. J. (2003). The Structure and Function of Complex Networks. SIAM Review, 45, 167-256. https://doi.org/10.1137/S003614450342480

Newman, M. E. J. (2006). Modularity and community structure in networks. Proceedings of the National Academy of Science of the United States of America, 103(23), 8577-8582. https://doi.org/10.1073/pnas.0601602103

Raulin, A. (2014). Anthropologie urbaine. París: Armand Colin.

Torrado, J. M. (2019). Flujos espaciales y dinámicas residenciales de centralización en las áreas metropolitanas españolas. Granada: Universidad de Granada. Recuperado de http://hdl.handle.net/10481/59770

Van der Vlist, A. J., Czamanski, D. y Folmer, H. (2011). Immigration and urban housing market dynamics: The case of Haifa. The Annals of Regional Science, 47(3), 585-598. https://doi.org/10.1007/s00168-010-0396-2

Villani, T. (2014). Psychogéographies urbaines corps, territoires et technologies. Paris: Eterotopia. 


\title{
¿HACIA LA CIUDAD FRAGMENTADA? NUEVAS TENDENCIAS DEMOGRÁFICAS METROPOLITANAS EN EL PERIODO DE POSCRISIS'
}

\section{TOWARDS A FRAGMENTED CITY? NEW METROPOLITAN DEMOGRAPHIC TRENDS IN THE POST-CRISIS PERIOD}

\author{
Fernando Gil-Alonso \\ Universitat de Barcelona \\ Cristina López-Villanueva \\ Universitat de Barcelona \\ Jordi Bayona-i-Carrasco \\ Universitat de Barcelona \\ Isabel Pujadas-Rúbies \\ Universitat de Barcelona
}

Resumen

Después de la profunda crisis económica iniciada en 2008, en 2014 España comienza a mostrar signos de recuperación. Sin haber alcanzado a toda la población, esta mejoría económica — la «poscrisis»— ha tenido un impacto positivo en el mercado inmobiliario, actividad y empleo. La movilidad residencial también ha crecido, pero los flujos se han vuelto más inestables y complejos. Su dirección, las razones para mudarse, las categorías socioeconómicas y las edades de los migrantes se han diversificado. Estas «nuevas movilidades» estarían reconfigurando la distribución espacial de la población en las áreas urbanas españolas. Utilizando los microdatos del Padrón Continuo, la comunicación tiene como objetivo inicial estudiar el crecimiento demográfico en las 69 áreas urbanas funcionales (AUF) españolas definidas por el INE/Eurostat, más específicamente en sus centros y periferias durante la crisis (2011-2015) y la poscrisis (2015-2019). Posteriormente, las cinco grandes metrópolis españolas (Madrid, Barcelona, Valencia, Sevilla y Bilbao) son analizadas más detenidamente. Los resultados han corroborado la hipótesis de que, en la poscrisis, se está reconfigurando el crecimiento demográfico en centros y periferias y, por lo tanto, la distribución espacial de la población en

1 Esta investigación es un resultado del proyecto I+D+i Nuevas movilidades y reconfiguración sociorresidencial en la poscrisis: consecuencias socioeconómicas y demográficas en las áreas urbanas españolas (RTI2018-095667-B-100), dirigido por Cristina López Villanueva y Fernando Gil Alonso y financiado por el Ministerio de Ciencia e Innovación, la Agencia Estatal de Investigación y el Fondo Europeo de Desarrollo Regional (AEI/FEDER, UE), y se enmarca en el trabajo efectuado por el grupo de investigación consolidado Territorio, Población y Ciudadanía (GRC_2017SGR1298), reconocido por la Generalitat de Catalunya y coordinado por Fernando Gil Alonso. 
las áreas urbanas españolas, dándose una fragmentación demográfica cada vez mayor de los espacios urbanos españoles.

Palabras clave: crecimiento demográfico, reconfiguración espacial, grandes metrópolis, poscrisis, España.

\begin{abstract}
After the deep economic crisis that began in 2008, in 2014 Spain started to show signs of recovery the so-called "post-crisis» period. Though it has not yet reached the entire population, economic improvement has had a positive impact on the real estate market, activity and employment. Residential mobility has also grown, but flows have become more unstable and complex. The direction of these flows, the reasons for moving, the age and socioeconomic category of migrants have diversified. These complex «new mobility» patterns are reconfiguring the spatial distribution of population in Spanish urban areas. By using Continuous Register (Padrón Continuo) microdata, the paper initially intends to study population change in the 69 Spanish functional urban areas (FUA) defined by the INE/Eurostat, focusing on their centre and periphery demographic growth or decline during the crisis (20112015) and post-crisis (2015-2019) phases. Then, the paper analyses the five major Spanish metropolises (Madrid, Barcelona, Valencia, Sevilla y Bilbao) in greater depth. Findings confirm the hypothesis that, during the post-crisis period, the population growth of cores and rings, and therefore the spatial distribution of urban inhabitants, is changing, resulting in a growing demographic fragmentation of Spanish urban areas, that are diversifying both internally and among them.
\end{abstract}

Keywords: population growth, spatial reconfiguration, large urban areas, post-crisis period, Spain.

\title{
1. INTRODUCCIÓN
}

\subsection{JUSTIFICACIÓN Y ANTECEDENTES}

El período de crecimiento económico que experimentó España desde mediados de la década de 1990 terminó repentinamente en 2008 con el impacto de la crisis económica y financiera, que agudizó los procesos de desindustrialización y globalización y favoreció procesos de desigualdad (Piketty, 2014). Esta recesión tuvo parte de su origen en la burbuja inmobiliaria, que multiplicó la inversión en mercados globalizados y los destinó a un mercado secundario de acumulación ligado a la producción de espacio urbano para lograr una gran rentabilidad a corto plazo; a ello se sumó la crisis de la deuda. 
Esta base urbana de la crisis explicó que los efectos más negativos se concentraran, también, en las grandes ciudades, mostrando la vulnerabilidad de los espacios urbanos (Méndez, 2018).

La recesión económica no sólo afectó a la migración internacional —el crecimiento migratorio positivo se tornó negativo- (Domingo y Blanes, 2015) sino que tuvo sus consecuencias en la movilidad residencial: los flujos de suburbanización disminuyeron (Bayona et al., 2018; Bayona y Pujadas, 2020) y los centros urbanos acentuaron su potencial de atracción (López Gay, 2014 y 2017). Los efectos de la expansión y la crisis en los flujos residenciales y las dinámicas urbanas han sido ampliamente estudiados para España (Feria Toribio, et al., 2015; Gil-Alonso et al., 2016, Palomares et al. 2017; Bayona et al. 2018; Bayona y Pujadas, 2020) o para los casos de las regiones urbanas de Madrid y Barcelona (Pujadas, 2009; Pozo y Rodríguez, 2018; Bayona y Gil-Alonso, 2012; Bayona y Pujadas 2014; García Coll et al. 2016; López Villanueva, et al. 2017; Andújar, 2017). Pocos trabajos han analizado, sin embargo, las consecuencias de la recuperación en las dinámicas urbanas.

En efecto, a partir de 2014 se comienzan a apreciar atisbos de una recuperación económica (Myro, 2018) que ha incrementado los niveles de actividad y empleo y que ha impactado en el mercado inmobiliario (Alves, Urtasun, 2019). Se observan signos de recuperación de los niveles de movilidad, diversificándose las estrategias sociorresidenciales (García Coll y López Villanueva, 2018), a la vez que se transforman las relaciones entre los espacios intrametropolitanos (Thiers y Gil-Alonso, 2020; Otero et al., 2019).

De esta manera, coincidiendo con la cronología de los ciclos económicos, se ha pasado de un crecimiento sin precedentes a un estancamiento demográfico en las áreas urbanas españolas y, más recientemente, a una nueva fase todavía poco estudiada. En cada una de estas fases se han reconfigurado las relaciones entre centros urbanos y periferias. El crecimiento demográfico desigual de cores y rings (Hall, 1971; Klaasen et al., 1981; Berg et al., 1982; Champion, 2001), así como las migraciones entre ellos (Fielding, 1982; Geyer y Kontuly, 1993), han sido ampliamente estudiados y modelizados en distintas etapas sucesivas de desarrollo urbano. Trabajos posteriores han criticado estos modelos cíclicos y han mostrado que, en cada país europeo, existen áreas urbanas en cada una de estas fases, las cuales no se dan de dan de un modo sucesivo sino simultáneo, siendo el desarrollo económico quien determina principalmente el dinamismo demográfico de las ciudades, tanto de sus centros urbanos como de sus periferias (Kabisch y Haase, 2011), e incluso su crecimiento o decrecimiento global (sobre shrinking cities en Europa véase Wolff y Wiechmann, 2018). Rérat (2012), por su parte, enfatiza el papel de los flujos de inmigración exterior en el crecimiento reciente de los centros urbanos, más allá de un proceso de reurbanización generado por los flujos desde la periferia. En la actualidad, con la recuperación económica, el proceso de desarrollo urbano se encuentra en un nuevo estadio, donde el incremento de los flujos 
migratorios tanto residenciales como internacionales (Otero, et al. 2019) dependen de la evolución de otros factores como el mercado de la vivienda, el acceso a créditos hipotecarios o las políticas de vivienda, entre otros (Clark, 2012 y 2017; Andújar, 2017). En España, como en otros países de la Europa mediterránea, los jóvenes o determinados colectivos de población inmigrada tienen considerables dificultades para acceder a la vivienda (Módenes et al., 2013; Leal y Martínez del Olmo, 2017). Éstas habrían aumentado al remitir la crisis, pues aunque la construcción de viviendas ha repuntado ligeramente, su acceso se ha visto dificultado por el alza de los precios de compra y, especialmente, de alquiler, sobre todo en las grandes ciudades, donde además se ha unido la presión turística (Colomb y Novy, 2016; Donat, 2018).

A pesar de la recuperación económica los nuevos flujos de movilidad residencial no recuperan las características anteriores a la crisis. Se han vuelto más inestables, más complejos y más fragmentarios. La dirección, las razones para mudarse, las categorías socioeconómicas y las edades de los migrantes se han diversificado, y así lo habría hecho también su impacto sobre los centros y las periferias de las áreas urbanas españolas, dándose en la actualidad - esta es nuestra hipótesis de partida- una diversidad de situaciones respecto a las fases de crecimiento urbano, es decir, respecto a si crece más el centro o la periferia, y si aumenta la población global del área urbana o si ésta disminuye.

\subsection{OBJETIVOS, MARCO GEOGRÁFICO, FUENTES Y METODOLOGÍA}

Utilizando los microdatos del Padrón Continuo (INE), la comunicación tiene como primer objetivo estudiar esta reconfiguración demográfica en el periodo de poscrisis - comparando esta fase con la anterior de crisis- en las 69 áreas urbanas funcionales (AUF) españoles definidas por el INE/Eurostat², focalizándose en el crecimiento o decrecimiento demográfico de sus centros

2 Para la metodología de delimitación de las AUF o zonas supramunicipales definidas por su influencia laboral, véase: https://ec.europa.eu/eurostat/web/cities/spatial-units Se ha adoptado el criterio de las áreas urbanas funcionales para la delimitación de las áreas urbanas españolas puesto que toma como referencia la ciudad y su área de influencia o hinterland; de esta manera, contempla un espacio integrado en términos de mercado de trabajo y consumo. Para acotar el área de influencia se tienen en cuenta los desplazamientos diarios (conmuting) entre la ciudad y los municipios limítrofes, identificando como criterio básico aquellos en los que al menos el 15\% de sus residentes se desplazan por trabajo o estudios a la ciudad (Dijkstra y Poelman, 2012). Este criterio, además de ofrecer una definición de la ciudad más allá de los límites administrativos, permite la comparabilidad con el resto de áreas urbanas europeas. 
y periferias. Más específicamente, se calcula la tasa de crecimiento anual acumulativo (TCAA o r\%) para el periodo 1 de enero 2011 -1 de enero 2015 (fase de crisis) y 1 de enero 2015- 1 de enero 2019 (poscrisis) ${ }^{3}$. Como segundo objetivo se analiza, para los mismos dos periodos cuatrienales, el crecimiento o decrecimiento en los municipios que componen las cinco grandes metrópolis españolas. Si la primera parte pretende estudiar si aumenta la diversificación de situaciones entre las áreas urbanas españolas, en la segunda se analiza si esta diversificación —o «fragmentación»— aumenta en el interior de las áreas urbanas.

\section{RESULTADOS}

\subsection{CRECIMIENTO DEMOGRÁFICO EN LAS 69 ÁREAS URBANAS FUNCIONALES: DIVERSI- DAD DE SITUACIONES EN UN CONTEXTO DE RECUPERACIÓN DEL CRECIMIENTO}

\subsubsection{CENTROS VERSUS PERIFERIAS: COMPARACIÓN ENTRE CRISIS Y POSCRISIS}

La Figura 1 muestra un contraste muy significativo entre los dos periodos analizados: durante la fase de crisis la mayor parte de las áreas urbanas perdieron población (esferas de color blanco); sólo 23 de las 69 ganaron habitantes (esferas de color azul). El grupo más numeroso - 33 casos- combinó una pérdida de población en los centros urbanos con una ganancia en sus municipios periféricos, seguido por 18 áreas urbanas donde tanto el centro como la periferia perdieron población.

En 12 casos ambos ámbitos ganaron residentes, mientras que sólo 6 áreas urbanas combinaron un crecimiento de sus centros con un decrecimiento de sus periferias. En total, durante el periodo 2011-2015 las áreas urbanas analizadas perdieron población (TCAA de -0,10\%), pues el aumento de las periferias $(0,31 \%)$, leve pero positivo, fue compensado por el decrecimiento de las ciudades centrales $(-0,44 \%)$.

Si en la fase de crisis se da una diversidad de situaciones, pero con mayor número de áreas en fase de desurbanización, en la etapa de recuperación económica se observa como predominan las dinámicas de suburbanización con descentralización relativa, con un crecimiento conjunto de las áreas urbanas analizadas del 0,44\% anual, resultado del incremento global de los centros $(0,32 \%)$ y las periferias, que crecen con mayor intensidad $(0,59 \%)$. Aunque la gran mayoría de áreas urbanas españolas tiene ahora un crecimiento demo-

3 Teniendo en cuenta que los ciclos económicos no impactaron con la misma intensidad ni con el mismo calendario en todas las áreas urbanas analizadas, se han realizado diversos ensayos de delimitación temporal de las fases, obteniéndose el mejor resultado con los intervalos seleccionados. 
gráfico positivo - 40, de las cuales en 32 crecen tanto el centro como la periferia-, sigue habiendo, sin embargo, 29 áreas urbanas que pierden población, de las cuales 15 tienen una disminución demográfica simultánea de cores y rings. En 14 áreas disminuye el municipio central pero no los periféricos mientras que, finalmente, en 8 áreas se produce el fenómeno inverso. Por lo tanto, un panorama diverso y en el que se produce una ingente combinación de situaciones: sólo en 9 áreas urbanas (Algeciras, Almería, Girona, Lleida, Málaga, Marbella, Santiago de Compostela, Toledo y Vitoria) crecen tanto el centro como la periferia a lo largo de los dos periodos analizados, tiempo en el que hay 10 áreas urbanas (Ávila, Avilés, Cádiz, Córdoba, Cuenca, Ferrol, Gijón, Linares, Oviedo y Ponferrada) que pierden población en ambos ámbitos.

Figura 1. Tasa de crecimiento anual acumulativo (TCAA) del conjunto de los municipios centrales y periféricos de las 69 AUF españolas. Comparación de los períodos 2011-2015 y 2015-2019

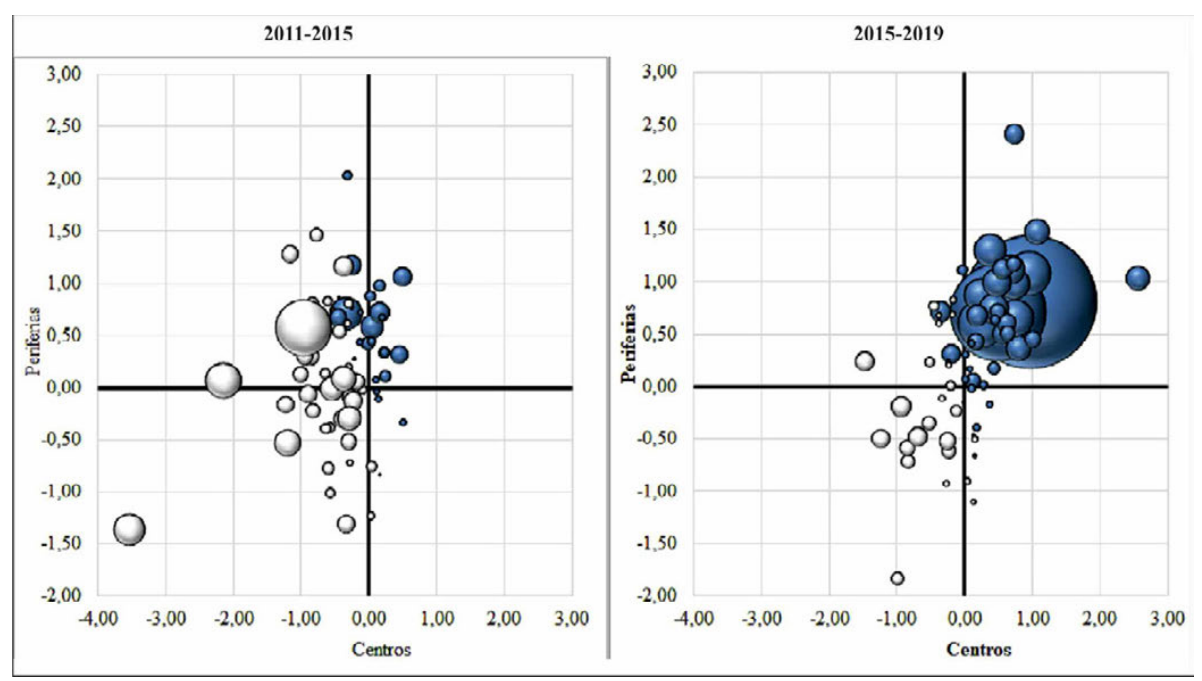

\section{Fuente: Elaboración propia a partir de los microdatos del Padrón continuo de 2011, 2015 y 2019 (INE).}

Nota: el tamaño de las burbujas indica el crecimiento absoluto metropolitano, con un máximo de 238 mil personas en Madrid en el segundo periodo. El color azul indica crecimiento del conjunto del AUF, el color blanco indica decrecimiento. 
Figura 2. Tasa de crecimiento anual acumulativo (TCAA) de las 69 AUF españolas en 2011-2015 y 2015-2019. Comparación de los centros urbanos y de los municipios periféricos

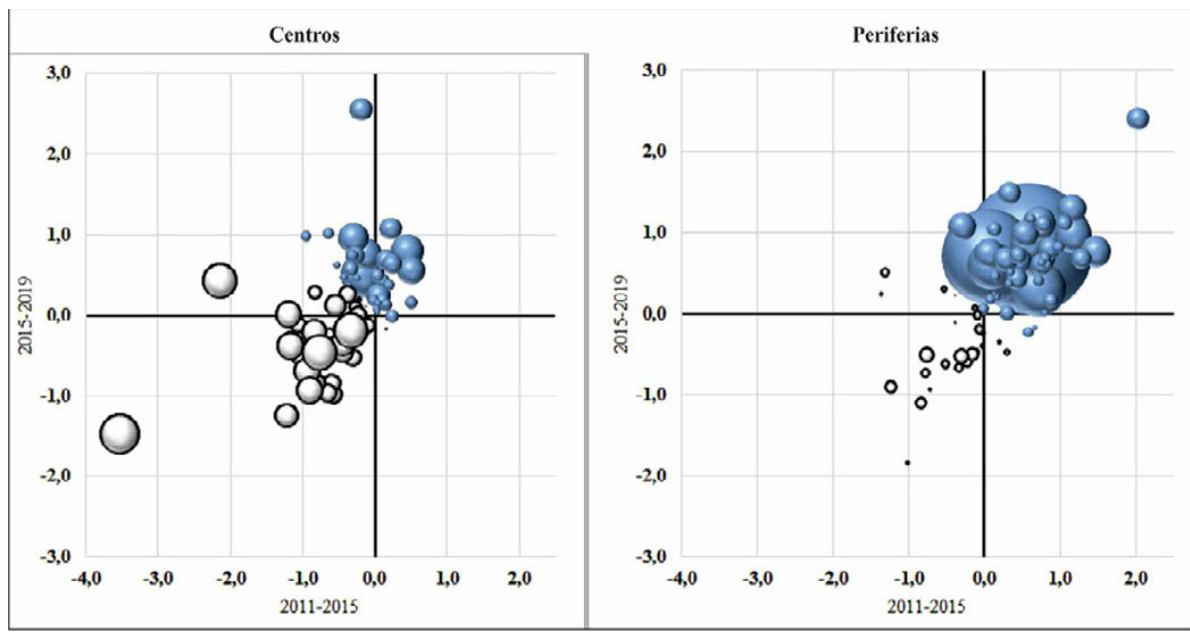

\section{Fuente: Elaboración propia a partir de los microdatos del Padrón continuo de 2011, 2015 y 2019 (INE).}

Nota: el tamaño de las burbujas indica el crecimiento absoluto metropolitano, con un máximo de $\mathbf{2 3 8}$ mil personas en Madrid en el segundo periodo. El color azul indica crecimiento del conjunto del AUF, el color blanco indica decrecimiento

La Figura 2 muestra que, de los 51 centros urbanos que perdían población en el periodo de crisis, 24 tienen ahora un crecimiento positivo, aunque la mayoría (27) siguen decreciendo, todos ellos en áreas con crecimiento negativo (esferas de color blanco). En el cuadrante opuesto, y con esferas de color azul que muestran un crecimiento urbano positivo, prácticamente todos los cores que ganaron población durante la crisis, siguen creciendo ahora (16 de 18); solo dos - Cartagena y Jerez- han invertido la tendencia. Respecto a las periferias, prácticamente todas las que crecían durante la crisis, lo siguen haciendo durante la poscrisis — de hecho, crecen mucho más que los centros-, mientras que la mayoría de las que decrecieron lo siguen haciendo, aunque a un ritmo menor que sus centros urbanos.

\subsubsection{CLASIFICACIÓN DE LAS AUF ESPAÑOLAS: UNA GRAN DIVERSIFICACIÓN DE SITUACIONES}

Dejando de lado la diferenciación entre centro y periferia, el grupo más numeroso de áreas urbanas son las 26 que han perdido población en los dos 
periodos analizados ${ }^{4}$, seguido por el conformado por las 20 que han tenido un crecimiento positivo tanto en la crisis como en la poscrisis ${ }^{5}$ —Sevilla es la única de las grandes metrópolis españolas que se encuentra en este grupoy por las también 20 que decrecieron durante la recesión pero que han vuelto al crecimiento durante la fase de recuperación económica ${ }^{6}$ (aquí encontramos a Barcelona, Bilbao, Madrid y Valencia). Por último, tres áreas urbanas, Cartagena, Jerez y Mérida7, ganaron población entre 2011 y 2015, pero han perdido habitantes entre 2015 y 2019. Por tanto, los resultados ponen de manifiesto una diversidad de situaciones que dificulta establecer pautas generales de desarrollo de las áreas urbanas.

\subsection{IMPACTO DE LA POSCRISIS EN LAS CINCO GRANDES METRÓPOLIS ESPAÑOLAS: FRAGMENTACIÓN DE LAS PERIFERIAS}

\subsubsection{CRECIMIENTO GENERALIZADO DE LOS MUNICIPIOS CENTRALES Y PERIFÉRICOS...}

Para analizar la diversificación de las dinámicas urbanas en el interior de las áreas urbanas españolas, se ha escogido únicamente el caso de las cinco más pobladas según los indicadores urbanos del INE; de mayor a menor: Madrid, Barcelona, Valencia, Sevilla y Bilbao. Centrándonos, primero, en las diferencias entre centro y periferia (Figura 3), se ha pasado de una situación, en el periodo de crisis, en la que los cinco centros urbanos perdían población —-de manera particularmente notable en el caso de la ciudad de Madrid-a otra con ga-

4 De este grupo, la periferia ha tenido una dinámica más negativa que el centro en ambos periodos en Ávila, Cáceres, Gijón, Linares, Lugo y Pontevedra; y lo mismo, pero solo en el periodo más reciente, en Benidorm, Córdoba y Oviedo. Por el contrario, la ciudad ha tenido una dinámica más negativa que los municipios suburbanos en el resto de áreas: Alcoy, Avilés, Burgos, Cádiz, Cuenca, Ferrol, Jaén, León, Ourense, Palencia, Ponferrada, Salamanca, Santander, Talavera, Torrevieja, Valladolid y Zamora.

5 Albacete, Badajoz, Santiago y Vitoria son las cuatro áreas de este grupo con una dinámica más positiva en el centro en los dos periodos; Algeciras, Irún y Murcia, lo mismo, pero solo en el último periodo. La gran mayoría, por el contrario, se caracteriza por el predominio de la suburbanización: Almería, Ciudad Real, Donostia, Girona, Granada, Guadalajara, Huelva, Lleida, Málaga, Marbella, Pamplona, Sevilla y Toledo.

6 De este grupo, Elche es la única área urbana donde el centro ha tenido una dinámica más positiva que la periferia en los dos periodos analizados, mientras que sí se da este fenómeno, pero sólo en el periodo más reciente, en Arrecife, Bilbao, Madrid, Manresa, Reus, Tarragona y Vigo. En las restantes, predomina siempre la suburbanización: A Coruña, Alicante, Barcelona, Castellón, Logroño, Lorca, Palma de Mallorca, Las Palmas de Gran Canaria, Sagunto, Santa Cruz de Tenerife, Valencia y Zaragoza.

7 De las tres, Cartagena tiene una periferia más dinámica que el centro, pero lo opuesto ocurre, en ambos periodos, en Jerez de la Frontera y Mérida. 
nancias generalizadas, con la excepción de Sevilla (cuya ciudad sigue perdiendo población, aunque menos), y ahora con Madrid presentando las dinámica más positivas, seguida, a distancia, por Barcelona, Valencia y Bilbao. En concreto, las ciudades de Madrid y Bilbao habrían tenido mayor crecimiento que sus periferias durante el periodo de poscrisis, lo que podría ser un indicio de (re)centralización relativa.

Respecto a los municipios periféricos, las cinco AUF presentan un crecimiento positivo en ambos periodos — con la excepción de Bilbao, cuya periferia muestra un leve decrecimiento entre 2011 y 2015-, incremento que es superior en la fase de poscrisis, excepto en el caso de Sevilla, cuya periferia creció más durante la crisis. Este debilitamiento de la suburbanización también podría indicar cierta (re)centralización.

Figura 3. Crecimiento absoluto (izquierda) y relativo (derecha) en los centros, periferias y conjunto de las AUF de Barcelona,

Bilbao, Madrid, Sevilla y Valencia en 2011-2015 y 2015-2019

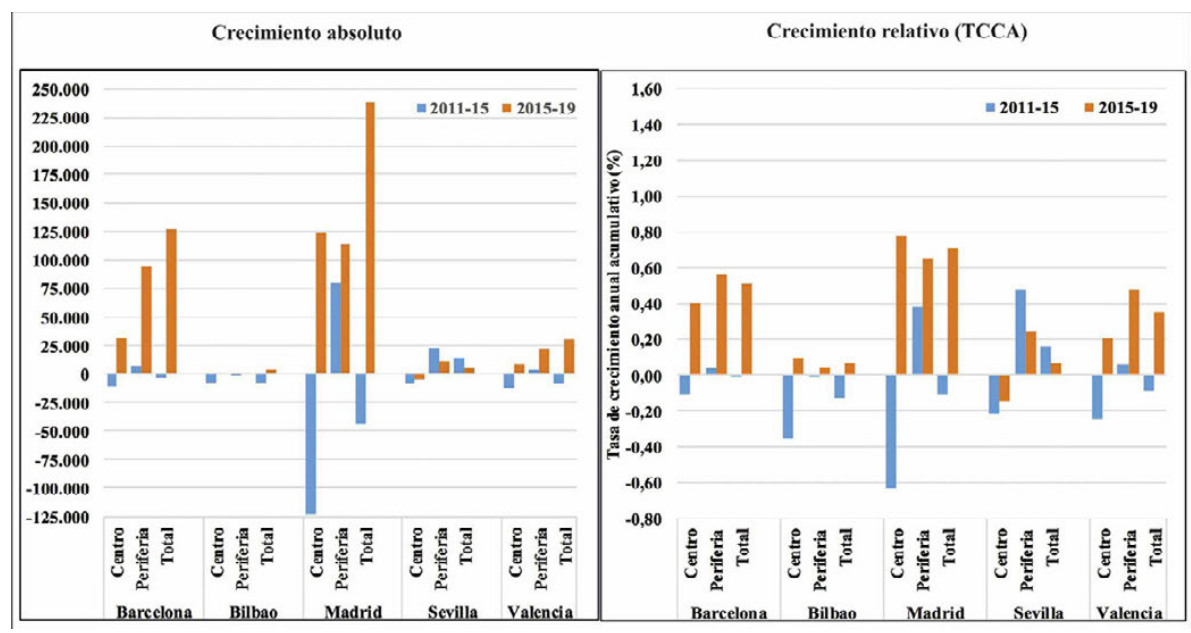

Fuente: Elaboración propia a partir de los microdatos del Padrón continuo de 2011, 2015 y 2019 (INE)

\subsection{2. ... AUNQUE CON DIVERSIFICACIÓN DE LAS PERIFERIAS}

Finalmente, los mapas de la Figura 4 muestran que la recuperación económica de la poscrisis ha dado lugar a una nueva fase de incremento demográfico metropolitano, tras el debilitamiento del crecimiento y de las dinámicas de suburbanización durante la crisis. Fase en la que las periferias ganaron menos población que en las décadas anteriores, mientras que los 
centros urbanos, aunque decrecieron por tener crecimientos naturales y migratorios negativos, dejaron de perder tanta población por cambios residenciales hacia la periferia (Bayona y Pujadas, 2020; Bayona et al., 2018).

Figura 4 (I). Tasa de crecimiento anual acumulativo (TCAA) de los municipios de las AUF de Barcelona, Bilbao, Madrid, Sevilla y Valencia. Comparación de los períodos 2011-2015 (izquierda) y 2015-2019 (derecha)

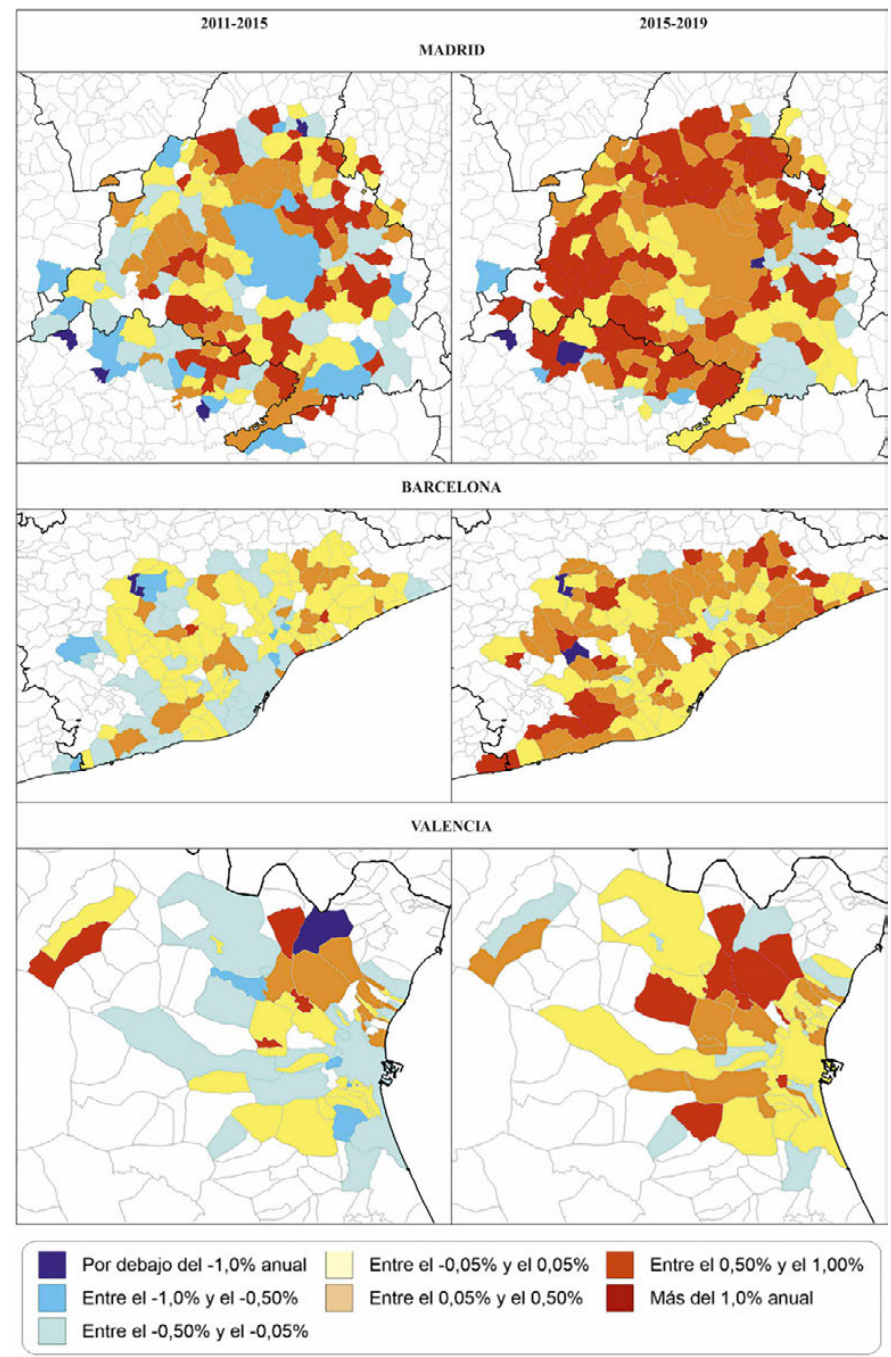

Fuente: Elaboración propia a partir de los microdatos del Padrón continuo de 2011, 2015 y 2019 (INE) 
Figura 4 (II). Tasa de crecimiento anual acumulativo (TCAA) de los municipios de las AUF de Barcelona, Bilbao, Madrid, Sevilla y Valencia. Comparación de los períodos 2011-2015 (izquierda) y 2015-2019 (derecha)

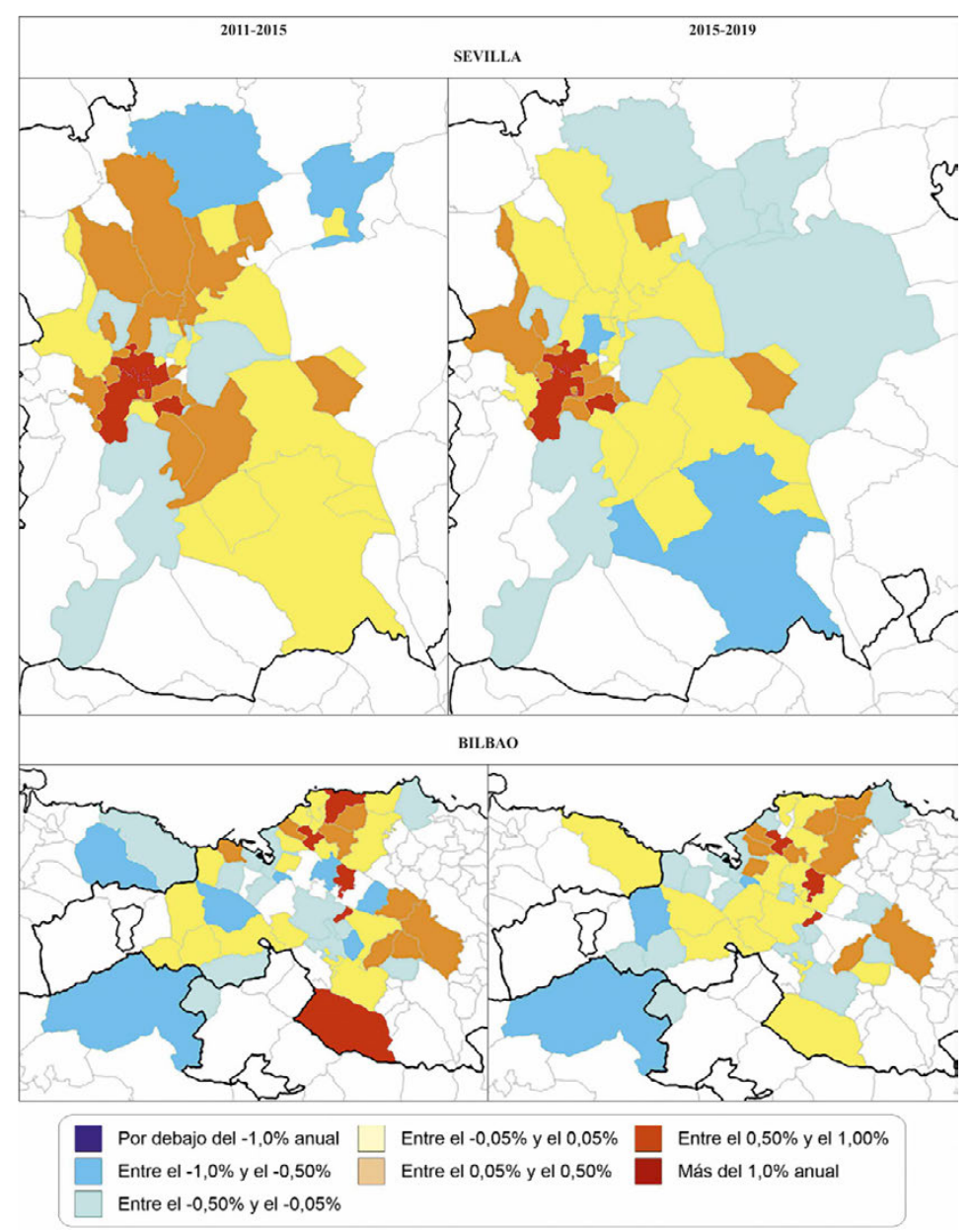

Fuente: Elaboración propia a partir de los microdatos del Padrón continuo de 2011, 2015 y 2019 (INE)

Esta mayor capacidad relativa de retener su población que los centros urbanos mostraron durante la crisis se habría convertido, entre los años 2015 y 2019, en un renovado poder de atracción de la migración internacional que compensaría la reactivación de los flujos de periurbanizacón (Gil-Alonso y Thiers, 2020; Thiers y Gil-Alonso, 2020). En consecuencia, las cuatro ciudades 
centrales pasan a tener un crecimiento positivo durante la poscrisis, con la excepción ya comentada de Sevilla, debido a su menor atracción de inmigración internacional. Particularmente significativo es el cambio en la ciudad de Madrid, que pasa de tener el mayor decrecimiento, entre las cinco, a tener el mayor incremento.

También las periferias reactivan su crecimiento en Madrid, Barcelona y Valencia. En el ring de Bilbao no hay grandes cambios: algunos municipios que perdían población en el periodo de crisis, ahora la ganan (y viceversa), pero el conjunto es bastante estable. Por el contrario, los municipios periféricos de Sevilla muestran, en general, un menor crecimiento o incluso un decrecimiento, con la excepción de la periferia occidental.

Pero incluso en las zonas suburbanas de Madrid, Barcelona y Valencia aparecen novedades que demuestran que el crecimiento actual no es una copia del que se dio durante la fase de expansión económica previa a la Gran Recesión. En efecto, ni los municipios periféricos crecen tanto como entonces, ni crecen todos los municipios, pues en las tres áreas metropolitanas aparecen municipios - generalmente en los bordes de las regiones metropolitanas-que continúan perdiendo población durante la fase de poscrisis, tal como lo hicieron antes durante la crisis. Se trata, en general, de municipios pequeños que se incorporaron tardíamente, durante la fase de expansión económica, a las dinámicas de periurbanización y que, por su mayor lejanía a los centros urbanos, fueron golpeados por la recesión económica que, en su caso, causó también una recesión demográfica que todavía continúa.

\section{CONCLUSIONES}

Los resultados de la investigación han corroborado la hipótesis de que, coincidiendo con la cronología de la recuperación económica «poscrisis», se está reconfigurando el crecimiento y, por lo tanto, la distribución espacial de la población en las áreas urbanas españolas, diversificándolas internamente entre centros y periferias, así como también entre diferentes municipios periféricos-y también entre ellas. Respecto a este último punto, los resultados muestran que se ha pasado de una situación (2011-2015) en la que la mayoría de las 69 áreas urbanas funcionales perdían población, a otra situación (20152019) en la que la mayor parte de ellas tiene un crecimiento positivo. Sin embargo, tanto en la primera fase analizada como en la segunda, se dan una gran variedad de situaciones de ganancia o pérdida de población de los centros urbanos y sus periferias. Pero se podría afirmar que esta diferenciación de situaciones incluso se ha incrementado en la etapa más reciente, puesto que, por ejemplo, dentro de las áreas urbanas que siempre han ganado población —o que siempre la han perdido- aparecen nuevas realidades como que algunos centros urbanos pasan ahora a crecer más que sus periferias. 
También Madrid y Bilbao, entre las grandes ciudades, muestran esta situación causada por la reactivación de la inmigración internacional.

En todo caso, parece difícil señalar patrones geográficos evidentes. Quizás el más claro sería el que atañe a las áreas urbanas que han perdido población de manera continua desde 2011, pues parecen ser mayoritariamente, o bien capitales de provincia de la España interior (Burgos, Cuenca, Jaén, León, Ourense, Palencia, Salamanca, Valladolid y Zamora), o bien situadas en zonas industriales en declive (Alcoy, Avilés, Cádiz, Ferrol, Ponferrada y Talavera). Algo más diverso es el conjunto de las áreas urbanas que han ganado población en las dos etapas analizadas, aunque predominan las situadas en el litoral o cerca de las grandes áreas urbanas españolas, y con una base económica industrial y/o diversificada (Almería, Ciudad Real, Donostia, Girona, Granada, Guadalajara, Huelva, Lleida, Málaga, Marbella, Murcia, Pamplona, Sevilla y Toledo).

Finalmente, esta diversificación de situaciones también aparece en el interior de las cinco grandes metrópolis analizadas, tanto en el crecimiento o decrecimiento de sus capitales como de sus municipios periféricos. Es cierto que se da, de nuevo, un aumento de las dinámicas de suburbanización, pero en combinación con una capacidad de atracción mayor de las grandes ciudades (eso se deduce del crecimiento demográfico de todas ellas, con la excepción de Sevilla, pero que también decrece menos que durante la crisis) y con una «fragmentación» de las dinámicas de los municipios periféricos que suponemos similar a la diversificación que se puede estar produciendo en el interior de las grandes ciudades, entre unos barrios y otros. Poner el microscopio en las secciones censales y analizar los flujos migratorios -y de crecimiento natural- ayudará a responder los interrogantes generados por esta investigación que, en todo caso, ha demostrado que el modelo de las etapas de crecimiento urbano no es válido para analizar e interpretar las dinámicas hacia una mayor fragmentación presentes actualmente en las áreas urbanas españolas.

Obviamente, los resultados de esta investigación reflejan la realidad existente durante la fase de poscrisis, la cual tuvo un abrupto final con la irrupción en España de la pandemia del covid-19 y el consiguiente establecimiento del estado de alarma a mediados de marzo de $2020^{\circ}$. El obligatorio confinamiento decretado por el gobierno para parar la expansión del virus ha tenido profundas consecuencias económicas y sociales que modificarán, al menos a corto y medio plazo, las dinámicas demográficas urbanas descritas, dando

8 Real Decreto 463/2020, de 14 de marzo, por el que se declara el estado de alarma para la gestión de la situación de crisis sanitaria ocasionada por el COVID-19 (enlace al BOE consultado el 6 de mayo de 2020:

https://www.boe.es/diario_boe/txt.php?id=BOE-A-2020-3692). 
paso a una nueva fase de evolución futura incierta que requerirá de nuevas investigaciones.

\section{BIBLIOGRAFÍA}

Alves, P. y Urtasun, A. (2019). Evolución reciente del mercado de la vivienda en España. Boletín Económico. Banco de España ( $\left.n^{\circ} 2\right)$. Madrid.

Andújar, A. (2017). Movilidad residencial y (re)composición social del espacio urbano en el municipio de Madrid. Papers de Sociologia, 102(4), 761-792.

Bayona, J. y Gil-Alonso, F. (2012). Suburbanisation and international immigration: The case of the Barcelona Metropolitan Region (1998-2009). Tijdschrift voor Economische en Sociale Geografie, 103(3), 312-329.

Bayona, J., Gil-Alonso, F.; Pujadas, I. y Rubiales, M. (2018). New Spatial Mobility Patterns in Large Spanish Cities: From the Economic Boom to the Great Recession. Applied Spatial Analysis and Policy, 11(2), 287-312.

Bayona, J. y Pujadas, I. (2020). Las grandes áreas metropolitanas en España: del crecimiento y la expansión residencial al estancamiento poblacional. Documents d'Anàlisi Geogràfica, 66(1), 27-55.

Bayona, J. y Pujadas, I. (2014). Movilidad residencial y redistribución de la población metropolitana: Ios casos de Madrid y Barcelona. EURE, 40(119), 261-287.

Berg, L. van den, Drewett, R. y Klaassen, L. H. et al. (1982). A Study of Growth and Decline. Oxford: Pegasus.

Champion, A. G. (2001). Urbanization, Suburbanization, Counterurbanization and Reurbanization. En R. Paddison. (ed.), Handbook of Urban Studies (pp.143-161). Londres: SAGE.

Clark, W. A. V. (2017). Residential mobility in context: Interpreting behavior in the housing market. Papers de Sociología, 102(4) 575-605.

Colomb, C. y Novy, J. (2016). Protest and Resistance in the Tourist City. Londres: Routledge.

Dijkstra, L, y Poelman, H. (2012). Cities in Europe. The new OECD-EC definition. Regional Focus, 1, 1-13.

Domingo, A. y Blanes, A. (2015). Inmigración y emigración en España: Estado de la cuestión y perspectivas de futuro. En: J. Arango, et al. (eds.), Anuario de la Inmigración en España 2014, 94-122. Barcelona: CIDOB.

Donat, C. (2018). La gentrificació i el problema de l'habitatge a Barcelona. Papers: Regió Metropolitana de Barcelona, 60, 114-129.

Feria-Toribio, J. M. y Andújar Llosa, A. (2015). Movilidad residencial metropolitana y crisis inmobiliaria. Anales de Geografía, 35(1), 13-40.

Fielding, A. J. (1982). Counterurbanisation in Western Europe. Progress in Planning, 17(1), 1-52.

García-Coll, A., López-Villanueva, C. y Pujadas, I (2016). Movilidad residencial en tiempos de crisis. El caso de la Región Metropolitana de Barcelona. Scripta Nova: Revista Electrónica de Geografía y Ciencias Sociales, 20(549(04)). 
García-Coll; A. y López-Villanueva, C. (2018). The impact of economic crisis in areas of sprawl in Spanish cities. Urban Science, 2(4), 113-132.

Geyer, H. S. y Kontuly, T. M. (1993). A theoretical Foundation for the concept of differenteial urbanistaion. International Regional Science Review, 15(12), 157-77.

Gil-Alonso, F., Bayona, J. y Pujadas, I. (2016). From boom to crash: Spanish urban areas in a decade of changes (2001-2011). European Urban and Regional Studies, 23(2), 198-216.

Gil-Alonso, F. y Thiers, J. (2020, en prensa). Population and economic cycles in the main Spanish urban areas: the migratory component. Comparative Population Studies.

Kabisch, N. y Haase, D. (2011). Diversifying European Agglomerations: Evidence of Urban Population Trends for the $21^{\text {st }}$ Century. Population, Space and Place, 17(3), 236-253.

Klaasen, L. H., Molle, W. y Paelink, J. H. (1981). Dynamics of urban development. Proceedings of an International Conference Held on the Occasion of the $50^{\text {th }}$ Anniversary of the Netherlands Economic Institute in Rotterdam. Aldesrshot: Gower.

Leal, J. y Martínez del Olmo, A. (2017). El progresivo abandono de la política de vivienda en España. Cuadernos de Relaciones Laborales, 35(1), 15-41.

López-Gay, A. (2014). Population growth and re-urbanization in Spanish inner cities: The role of internal migration and residential mobility. Revue Quetelet, 2 (1), 67-92.

López-Gay, A. (2017). Hacia un patrón territorial complejo de la movilidad residencial: El caso de la Región Metropolitana de Barcelona. Papers: Revista de Sociología, 104(4), 793-823.

López Villanueva, C. et al., (2017). Los efectos de la crisis económica en el urbanismo disperso de la Región Metropolitana de Barcelona. Clivatge, 5 , 291-331.

Méndez, R. (2018) La telaraña financiera: Una geografía de la financiarización y su crisis. Barcelona: RiL Editores.

Módenes, J. A., Fernández, C. y López, J. (2013) La formación de hogares y la tenencia de viviendas de los jóvenes en la reconfiguración de los sistemas residenciales europeos. Scripta Nova: Revista Electrónica de Geografía y Ciencias Sociales, XVII(460).

Myro, R. (2018). Crecimiento económico con equilibrio exterior. Un nuevo escenario para la economía española. EuropeG, Policy Brief, (13).

Otero, R., García-Abad, J., Domínguez, J. y Pérez-Caramés, A. (2019). Inmigración y dinámicas territoriales en España: crisis y recuperación (2008-2017). Anuario CIDOB de la Inmigración, 2019 (pp. 190-217). Barcelona: CIDOB.

Palomares-Lin, I., Feria-Toribio, J. M. y Susino-Arbucias, J. (2017). Medida y evolución de la movilidad residencial en las áreas metropolitanas españolas. Papers. Revista de Sociología, 102(4), 545-574. 
Piketty, T. (2014). Capital in the $27^{\text {st }}$ Century. Cambridge: Harvard University Press.

Pozo, E. y Rodríguez Moya, J. M. (2018). Impacto de la crisis en los movimientos migratorios en la comunidad de Madrid (2007-2013). Boletín de la Asociación de Geógrafos Españoles, 77, 229-255.

Pujadas, I. (2009). Movilidad residencial y expansión urbana en la Región Metropolitana de Barcelona, 1982-2005. Scripta Nova: Revista Electrónica de Geografía y Ciencias Sociales, XIII(290).

Rérat, P. (2012). The new demographic growth of cities. Urban Studies, 49(5), 1107-1125.

Thiers, J. y Gil-Alonso, F. (2020). Dinámicas residenciales de la inmigración latinoamericana en las metrópolis de Barcelona y Madrid: cambios de tendencias durante la expansión, la crisis y la poscrisis. Documents d'Anàlisi Geogràfica, 66(1), 57-82.

Wolff, M. y Wiechmann, T. (2018). Urban growth and decline: Europe's shrinking cities in a comparative perspective 1990-2010. European Urban and Regional Studies, 25(2), 122-139. 
Tabla anexo. Tasa de crecimiento anual acumulativo de los centros urbanos y periferias de las AUF analizadas. España, 2011-2015 y 2015-2019

\begin{tabular}{|c|c|c|c|c|c|c|}
\hline & \multicolumn{3}{|c|}{ 2011-2015 } & \multicolumn{3}{|c|}{ 2015-2019 } \\
\hline & Centro & Periferia & Total & Centro & Periferia & Total \\
\hline A Coruña & $-0,22$ & 0,28 & $-0,02$ & 0,19 & 0,67 & 0,39 \\
\hline Albacete & 0,11 & $-0,04$ & 0,09 & 0,17 & $-0,40$ & 0,12 \\
\hline Alcoy & $-0,63$ & $-0,39$ & $-0,59$ & $-0,24$ & 0,23 & $-0,16$ \\
\hline Algeciras & 0,23 & 0,34 & 0,25 & 0,63 & 0,51 & 0,61 \\
\hline Alicante & $-0,43$ & 0,54 & $-0,16$ & 0,47 & 0,99 & 0,62 \\
\hline Almería & 0,50 & 1,06 & 0,58 & 0,55 & 1,12 & 0,63 \\
\hline Arrecife & $-0,18$ & 0,12 & $-0,04$ & 2,56 & 1,04 & 1,85 \\
\hline Ávila & $-0,28$ & $-0,72$ & $-0,30$ & $-0,26$ & $-0,93$ & $-0,30$ \\
\hline Avilés & $-0,83$ & $-0,22$ & $-0,62$ & $-0,84$ & $-0,59$ & $-0,76$ \\
\hline Badajoz & 0,14 & $-0,11$ & 0,10 & 0,13 & $-0,47$ & 0,03 \\
\hline Barcelona & $-0,17$ & 0,05 & $-0,02$ & 0,50 & 0,71 & 0,64 \\
\hline Benidorm & $-1,06$ & 0,57 & $-0,17$ & $-0,12$ & $-0,23$ & $-0,18$ \\
\hline Bilbao & $-0,54$ & $-0,01$ & $-0,19$ & 0,12 & 0,06 & 0,08 \\
\hline Burgos & $-0,30$ & 0,80 & $-0,17$ & $-0,18$ & 0,69 & $-0,08$ \\
\hline Cáceres & 0,16 & $-0,84$ & $-0,04$ & 0,13 & $-1,10$ & $-0,10$ \\
\hline Cádiz & $-0,90$ & $-0,06$ & $-0,46$ & $-0,93$ & $-0,19$ & $-0,53$ \\
\hline Cartagena & 0,16 & 0,98 & 0,23 & $-0,17$ & 0,82 & $-0,09$ \\
\hline Castellón de la Plana & $-1,19$ & $-0,53$ & $-1,02$ & 0,01 & 0,31 & 0,09 \\
\hline Ciudad Real & $-0,12$ & 0,72 & 0,11 & 0,11 & 0,41 & 0,19 \\
\hline Córdoba & $-0,10$ & $-0,02$ & $-0,09$ & $-0,13$ & $-0,23$ & $-0,14$ \\
\hline Cuenca & $-0,57$ & $-0,38$ & $-0,55$ & $-0,33$ & $-0,11$ & $-0,32$ \\
\hline Donostia & $-0,01$ & 0,42 & 0,18 & 0,18 & 0,43 & 0,29 \\
\hline Elche & $-0,33$ & $-1,31$ & $-0,45$ & 0,57 & 0,51 & 0,56 \\
\hline Ferrol & $-1,23$ & $-0,16$ & $-0,65$ & $-1,24$ & $-0,50$ & $-0,84$ \\
\hline Gijón & $-0,30$ & $-0,52$ & $-0,31$ & $-0,23$ & $-0,61$ & $-0,26$ \\
\hline Girona & 0,22 & 0,34 & 0,27 & 1,08 & 1,48 & 1,25 \\
\hline Granada & $-0,45$ & 0,67 & 0,19 & $-0,36$ & 0,71 & 0,27 \\
\hline Guadalajara & $-0,32$ & 2,03 & 0,30 & 0,74 & 2,41 & 1,20 \\
\hline Huelva & $-0,44$ & 0,87 & 0,02 & $-0,46$ & 0,80 & 0,00 \\
\hline Irún & 0,19 & 0,67 & 0,30 & 0,37 & $-0,17$ & 0,25 \\
\hline Jaén & $-0,30$ & 0,20 & $-0,16$ & $-0,52$ & $-0,35$ & $-0,47$ \\
\hline Jerez de la Frontera & 0,24 & 0,11 & 0,23 & $-0,01$ & $-0,16$ & $-0,02$ \\
\hline León & $-0,94$ & 0,30 & $-0,45$ & $-0,69$ & $-0,48$ & $-0,61$ \\
\hline Linares & $-0,57$ & $-1,01$ & $-0,59$ & $-0,99$ & $-1,84$ & $-1,02$ \\
\hline Lleida & 0,02 & 0,88 & 0,24 & 0,07 & 0,17 & 0,10 \\
\hline Logroño & $-0,21$ & 0,77 & $-0,01$ & $-0,03$ & 1,11 & 0,21 \\
\hline Lorca & $-0,31$ & 0,61 & $-0,19$ & 0,73 & 1,17 & 0,79 \\
\hline Lugo & 0,03 & $-1,23$ & $-0,21$ & 0,04 & $-0,91$ & $-0,14$ \\
\hline Madrid & $-0,96$ & 0,58 & $-0,16$ & 0,97 & 0,81 & 0,89 \\
\hline Málaga & 0,05 & 0,58 & 0,23 & 0,24 & 0,87 & 0,45 \\
\hline Manresa & $-0,64$ & 0,13 & $-0,33$ & 1,01 & 0,46 & 0,79 \\
\hline Marbella & 0,16 & 0,72 & 0,47 & 0,68 & 1,12 & 0,92 \\
\hline Mérida & 0,50 & $-0,34$ & 0,24 & 0,15 & $-0,66$ & $-0,10$ \\
\hline Murcia & $-0,13$ & 0,44 & 0,03 & 0,75 & 0,65 & 0,72 \\
\hline Ourense & $-0,41$ & 0,16 & $-0,25$ & $-0,24$ & 0,21 & $-0,11$ \\
\hline Oviedo & $-0,39$ & $-0,30$ & $-0,37$ & $-0,25$ & $-0,52$ & $-0,33$ \\
\hline Palencia & $-0,61$ & 0,83 & $-0,35$ & $-0,37$ & 0,60 & $-0,19$ \\
\hline Palma de Mallorca & $-0,29$ & $-0,30$ & $-0,29$ & 0,95 & 1,08 & 1,00 \\
\hline $\begin{array}{l}\text { Palmas de Gran } \\
\text { Canaria, Las }\end{array}$ & $-0,23$ & $-0,13$ & $-0,19$ & 0,01 & 0,07 & 0,04 \\
\hline Pamplona & $-0,26$ & 1,17 & 0,41 & 0,73 & 0,98 & 0,85 \\
\hline Ponferrada & $-0,60$ & $-0,77$ & $-0,64$ & $-0,84$ & $-0,72$ & $-0,81$ \\
\hline Pontevedra & 0,04 & $-0,76$ & $-0,30$ & 0,15 & $-0,51$ & $-0,12$ \\
\hline Reus & $-0,83$ & 0,80 & $-0,63$ & 0,28 & 0,01 & 0,25 \\
\hline Sagunto & $-0,25$ & 0,76 & $-0,07$ & 0,46 & 0,63 & 0,49 \\
\hline Salamanca & $-1,17$ & 1,28 & $-0,52$ & $-0,38$ & 0,68 & $-0,08$ \\
\hline $\begin{array}{l}\text { Santa Cruz de } \\
\text { Tenerife }\end{array}$ & $-2,14$ & 0,07 & $-0,86$ & 0,43 & 0,74 & 0,62 \\
\hline Santander & $-0,84$ & 0,30 & $-0,23$ & $-0,20$ & 0,01 & $-0,09$ \\
\hline
\end{tabular}

Fuente: Elaboración propia. Microdatos del Padrón continuo 2011-2019 (INE) 



\title{
ESTALLIDO CARTOGRÁFICO DE UNA CRISIS DE MODELO-PAÍS: EL CASO DE SANTIAGO DE CHILE (OCTUBRE-NOVIEMBRE 2019) \\ CARTOGRAPHIC OUTBREAK OF A MODEL-COUNTRY CRISIS: THE CASE OF SANTIAGO, CHILE (OCTOBER-NOVEMBER 2019)
}

\author{
Víctor Jiménez Barrado \\ Pontificia Universidad Católica de Chile
}

Resumen

El 18 de octubre de 2019 estalló en Santiago de Chile una de las mayores crisis sociales de la historia reciente del país. El alza de 30 pesos chilenos en las tarifas del transporte en metro inició una ola de protestas, que rápidamente alcanzó trasversalidad social y de temas, con el denominador común de crítica al modelo neoliberal. Dentro de un contexto de represión estatal y de desinformación surgieron múltiples iniciativas dedicadas a reunir, de manera colaborativa, información espacial. El objetivo del presente trabajo es referir y analizar el tipo de registros cartográficos, así como determinar su origen, metodología, características y formas de difusión. De este modo, se persigue determinar su significado y utilidad durante los hechos. Complementariamente, el análisis de la acción de gobierno y la actividad mediática (prensa y redes sociales) se utiliza para establecer puntos de control de los eventos y cambios urbanos acaecidos. Los resultados permiten aventurar que esta cartografía ha significado simultáneamente una estrategia de cuidado mutuo, un entorno de lucha y un hito fundamental para la persistencia del fenómeno. En todo ello, la tecnología ha sido decisiva.

Palabras clave: cartografía colaborativa, cartografía disidente, Chile, ciudad, lucha social, modelo neoliberal.

\section{Abstract}

On October 18, 2019, one of the biggest social crises in the country's recent history broke out in Santiago, Chile. The rise of 30 Chilean pesos in subway transportation rates began a wave of protests, which quickly reached social and themes transversality, with the common denominator of criticism of the neo-liberal model. Within a context of state repression and disinformation, multiple initiatives emerged to gather, collectively, spatial information. The objective of this work is to refer and analyse the type of cartographic records, as well as determine their origin, methodology, characteristics and forms of dissemination. In this way, it seeks to determine its meaning and usefulness during the events. In addition, the analysis of government action and media activity (press and social networks) is used to establish control points for 
events and urban changes. The results allow to venture that this cartography has simultaneously meant a strategy of mutual care, a fighting environment and a fundamental milestone for the persistence of the phenomenon. In all this, technology has been decisive.

Keywords: collaborative mapping, dissent mapping, Chile, city, social struggle, neo-liberal model.

\section{INTRODUCCIÓN}

\subsection{INDICADORES DEL ÉXITO NEOLIBERAL CHILENO: LA CARA MACROECONÓMICA DE LA MONEDA}

Chile ha sido reconocido internacionalmente como uno de los laboratorios iniciales del modelo neoliberal (Harvey, 2007; Stiglitz, 2012). Las recetas de la teoría económica se implantaron forzosamente desde 1973, por un gobierno dictatorial y militar con apoyo exterior (Harvey, 2012; Janoschka y Hidalgo, 2014), hasta 1990. Entre tanto, estos ideales se consolidaron mediante la Constitución política del Estado de 1980. Ésta es, por lo tanto, pilar fundamental para la reproducción de un sistema que, si bien es hegemónico en el mundo, muestra en Chile trazos singulares de máxima radicalidad.

De ella se descuelga todo un corpus legal que otorga a gran parte de los bienes nacionales de uso público un estatus de «transabilidad» en el libre mercado y que ha rentado unos óptimos datos macroeconómicos.

Sus logros se condensan en una tasa de desempleo que no sube del 8,5\% en los últimos 9 años y su posición cuadragésimo-segunda a nivel mundial como país con mayor Producto Interior Bruto según los datos del Fondo Monetario Internacional, ocupando el mismo lugar en términos del Índice de Desarrollo Humano y el $53^{\circ}$ en cuanto a PIB per cápita.

Junto con esto, la deuda pública económica es muy baja con relación al PIB (25,56\%), pero se dispara si atendemos a la «deuda pública social», es decir, la obligación del Estado de proveer a sus ciudadanos de igualdad de oportunidades (Artículo 1 de la Constitución).

\subsection{LA POLARIZACIÓN SOCIAL Y LA PRECARIEDAD: EL REVÉS DESIGUAL DE LA MONEDA}

El triunfo macroeconómico chileno ha obtenido notables resultados, entre ellos la rápida reducción de la pobreza. Según la encuesta CASEN, el porcentaje de personas en situación de pobreza y pobreza extrema en Chile ha pasado de un 16,5\% y 12,6\% respectivamente en el año 2006 a un 6,3\% y un 2,3\% en 2017. Para funcionar de forma próspera, el modelo neoliberal reduce la pobreza y requiere de un estrato socioeconómico lo suficientemente ancho 
para constituir simultáneamente una fuerza de trabajo barata y un nicho demandante, aunque precarizado, de bienes y servicios: la clase media.

La precarización comienza en la institucionalidad. El Estado chileno es un Estado subsidiario que obliga a que sea la población la que auxilie las responsabilidades mínimas que a él le corresponden (Borgias, 2018). Esto se muestra en el rol que la solidaridad popular ejerce como muleta del neoliberalismo, haciéndose cargo de primeras necesidades en materia de educación o sanidad (Humeres, 2019). Un sistema basado en el individualismo radical tal y como lo describe De Julios (1995), que necesita de la sumisión y del convencimiento del individuo, actuando éste como célula del organismo neoliberal nacional. Así, el manejo elevado de anglicismos económicos del chileno promedio (Gerding, Fuentes y Kotz, 2012) es un indicio de la primacía de lo económico, aunque este conocimiento no se corresponda con una educación familiar y académica en buenas prácticas (Denegri et al., 2005), entendiendo como tales el fomento del ahorro y el abandono de un consumo compulsivo apoyado en el crédito. De hecho, según los datos del Banco Central de Chile, la deuda de los hogares aumentó en sólo 4 años (2015-2019) desde el 65,9\% al 74,3\% del ingreso disponible. Así, el ingreso fijo mensual a través de la renta laboral se hace completamente necesario, dependencia que se encona en una etapa crítica como la de jubilación. En ella, los gastos sanitarios aumentan mientras la capacidad financiera se ve muy reducida debido a la insuficiencia económica que genera el actual sistema de pensiones privado, obligatoriamente gestionado por las Administradoras de Fondos de Pensiones (AFP) (Vives et al., 2016).

Así, en un contexto de libre empresa y protección a ultranza de la propiedad privada, sin atisbo de su función social, Chile es, junto con México, el país con mayor desigualdad de la OCDE (Keeley, 2018). Un coeficiente de Gini por sobre 0,45 coincide con los informes de CEPAL (2019), los cuales indican que el $1 \%$ más acaudalado de la población chilena concentra más de un cuarto de la riqueza (26,5\%), mientras que la mitad más pobre de la población sólo retiene un $2,1 \%$ de la riqueza.

El modelo neoliberal extractivista de los recursos naturales, también lo es de su proletariado. Por supuesto, este expolio no se refiere a los recursos retraídos por el Estado del salario a través de la vía impositiva, que con un 7\% en promedio son - por mucho_ los más bajos de la OCDEl, sino a la diferencia en términos de plusvalía que le otorga al sector privado un nivel de salarios mensuales promedio en 2018 de 652.397 pesos chilenos. Esta cifra esconde una realidad más depredadora y precarizada, puesto que el ingreso mediano

1 El promedio de la OCDE en el año 2017 es del 25,5\%. El registro más aproximado a nivel nacional procede del otro país latinoamericano integrante de la OCDE, México $(11,2 \%)$. 
se sitúa en 411.100 pesos chilenos, dentro de un contexto de servicios públicos básicos privatizados y un coste de la canasta básica de alimentos de 43.091 pesos chilenos por persona.

\subsection{EL CANTO DE LA MONEDA: TERRITORIO Y CIUDAD, VOCEROS DE LA DESIGUALDAD}

Espacialmente la inequidad se muestra sin tapujos en Chile, con una amplia disparidad regional en cuanto a PIB per cápita (Figura 1). El país está desprovisto de políticas e instrumentos redistributivos en lo espacial (Maturana et al., 2017). Esta ausencia deja a los territorios (y sus pobladores) a la deriva, a la vez que ahonda, aún más, en las problemáticas consecuencias de la segregación social chilena.

Dentro de una agenda político-normativa liberal y centralista, esto supone la explotación sin fin de la naturaleza en regiones (tales como Antofagasta, rica en recursos minerales) y la concentración de capitales públicos y privados en Santiago, a la que sigue una corriente demográfica.

Figura 1. PIB per cápita en las regiones chilenas
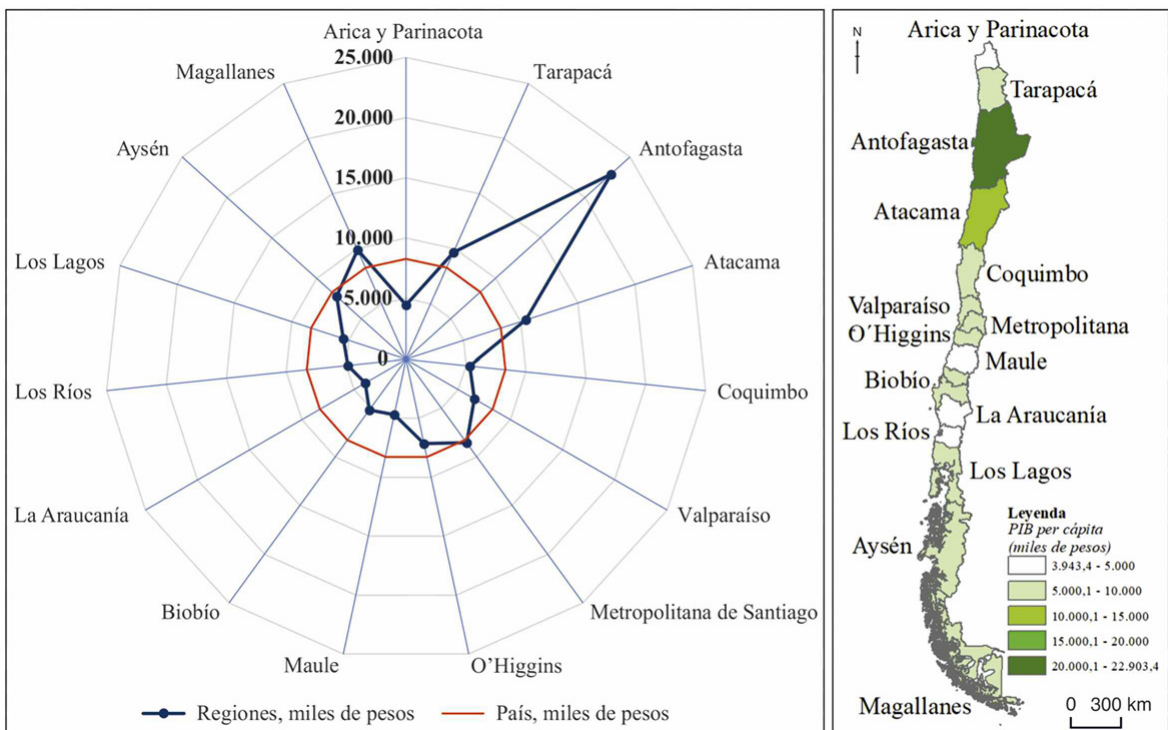

Fuente: Elaboración propia. 2019

Por su parte, las políticas urbanas en Chile han estado altamente ideologizadas durante los últimos 50 años (Navarrete-Hernández y Toro, 2019). Se han combinado periodos dónde se primaba la búsqueda de la igualdad (1952- 
1973) o donde sólo el mercado guiaba los criterios de ocupación del suelo (1973-1989), seguidos de otro donde se trataba de mitigar, con giros improvisados (Román y Barton, 2018), la segregación social (1990-2010), para final y recientemente volver a una hegemonía economicista.

Así, el status quo aúpa a la capital a una macrocefalia donde se sintomatiza de forma más clara la desigualdad (Figura 2). Según el reciente índice PICSA (2019), referido a esta variable, la gran metrópoli chilena ocupa el puesto $93^{\circ}$ a nivel mundial, la sexta en el contexto latinoamericano. En ella, comunas del llamado «cono de alta renta» (ubicado al noreste), como Vitacura, exhiben un nivel de ingresos promedio más de cinco veces superior al de comunas como Pedro Aguirre Cerdá (PAC), situada a apenas 8,5 kilómetros en línea recta. Junto a este hecho, tanto el Censo más reciente (2017) como la encuesta CASEN ofrecen un panorama capitalino muy polarizado en el que ese grupo de sólo seis comunas presenta un perfil muy diferente del resto. Esto alcanza a cuestiones tales como el tipo de actividad predominante, con una clara hegemonía del sector terciario, pero también a los perfiles profesionales que habitan este espacio (gran concentración relativa de intelectuales y profesionales relacionados con las altas instituciones políticas, judiciales, educativas y empresariales). Este retrato socioeconómico afecta finalmente a cuestiones materiales como una menor dificultad de acceso a servicios básicos (educación, sanidad, habitabilidad, etc.), lo que en síntesis divide la ciudad en un espacio privilegiado y otro, más amplio, que queda relegado en múltiples dimensiones.

Por lo tanto, Santiago es paradigma de la ciudad neoliberal, la cual no garantiza si quiera el derecho a la vivienda digna para buena parte de su población (Bruey, 2012). De hecho, cuando éste se ha provisto de manera subsidiada por el Estado, se ha realizado de nuevo bajo un paradigma individualista y competitivo, disfrazado de mecanismo participativo y autogestionado, tal y como lo concibe Muñoz (2007).

La realidad es que las políticas de «rostro humano» (Atria, 2013; Hidalgo, Alvarado y Santana, 2017; Tapia, 2018) han estado más preocupadas de salvar objetivos cuantitativos que cualitativos, resultando analgésicas. Por esta razón, la producción de viviendas sociales fue un éxito de cara a subsanar el déficit habitacional (Hidalgo, 1999), aunque cimentó las bases de un modelo urbanístico guettificado. 
Figura 2. Distribución espacial de los grupos socioeconómicos en Santiago de Chile

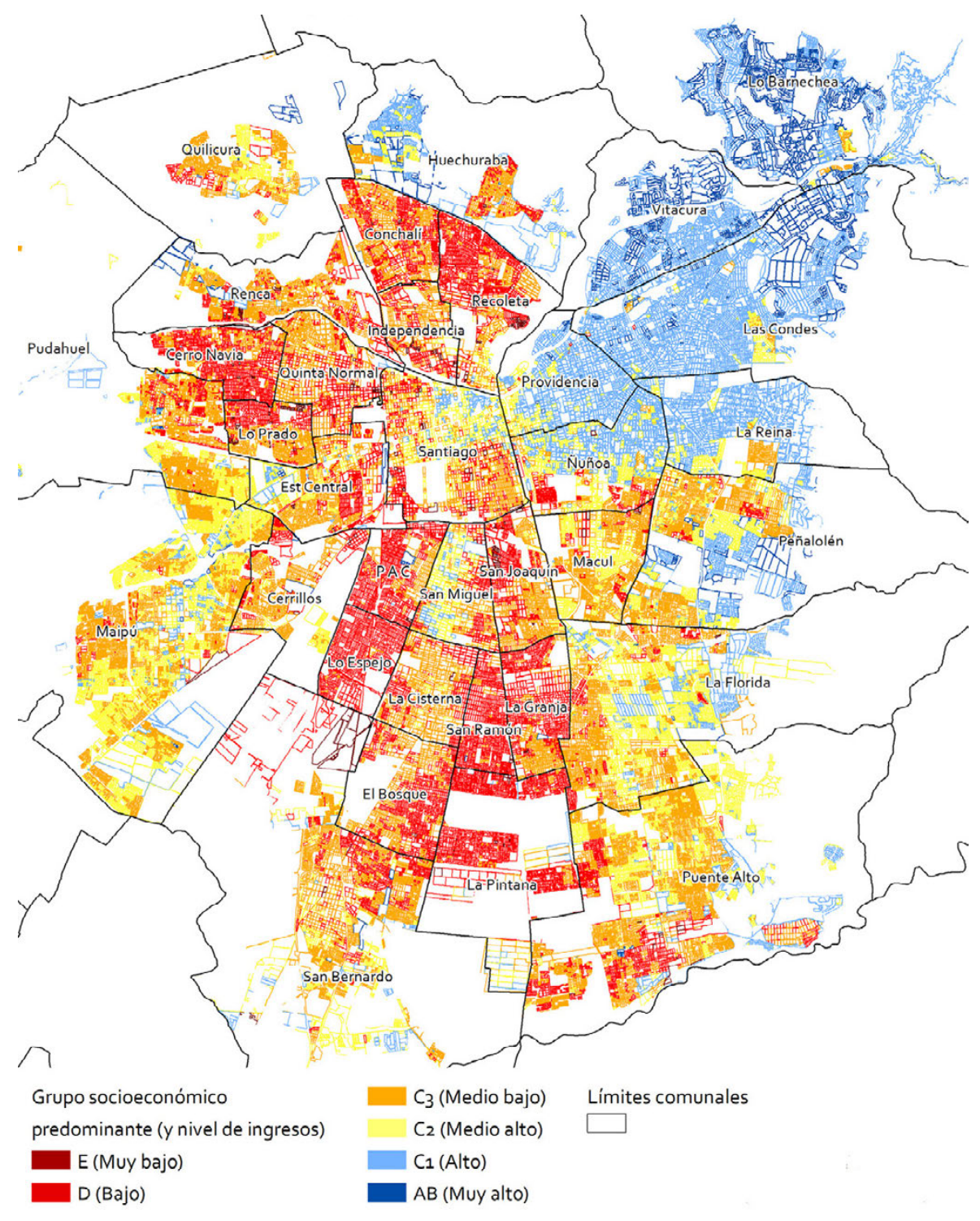

Fuente: Juan Correa. 2018

En consecuencia, la liberalización del suelo, instrumentalizada y normalizada (Jiménez et al., 2018), permite a las élites elegir preferentemente la ubicación 
y la morfología urbana, mientras que las clases populares no pueden. Bajo estas condiciones, existe una clara estigmatización social fundamentada en el lugar de residencia (Méndez y Otero, 2018), en el que las unidades barriales se enclaustran y compiten entre ellas (Letelier et al., 2019), alejando el desarrollo integrado de la ciudad, que carece de gobierno metropolitano.

Esta desigualdad social repercute en una crisis de representatividad, que aleja del juego democrático particularmente a las clases sociales más perjudicadas (Fernández, Manuel-Navarrete y Torres-Salinas, 2016). En este clima de angustia individual, descontento popular y falta de representatividad estalló el 18 de octubre de 2019 en Santiago un movimiento social que no es atribuible en exclusiva al alza de 30 pesos en el billete de metro, sino a 30 años en los que se apuntalan las condiciones explicadas. Las protestas tomaron diversas formas, algunas de las cuales provocaron inseguridad tanto por sus características, como por la represión violenta de Carabineros (cuerpo nacional de policía) y el ejército. Es en este peligroso escenario cuando y donde aparece la cartografía colaborativa del estallido social.

\section{METODOLOGÍA}

El proceso metodológico toma la observación participante no estructurada ni inducida como método más adecuado y factible. La espontaneidad, inmediatez y novedad de la cartografía, así como su potencial fugacidad, impide una recopilación de datos y fuentes etapizada y ordenada previamente. Además, la condición de académico, geógrafo y residente santiaguino del autor, lo sitúa en una posición no impostada, preexistente e integrada en redes profesionales, académicas y sociales vinculadas a la producción cartográfica, facilitando el acceso a la información.

La eventualidad provoca que el primer paso sea identificar y acceder a las fuentes. Esto se realizó por dos vías; una marginal, a través de notificaciones en redes profesionales y/o académicas (vía correo electrónico), las cuales dieron aviso de iniciativas cartográficas al respecto; y otra, general, mediante el seguimiento de redes sociales (RRSS) hasta el final de noviembre. Para esto último se simuló la actividad diaria de un usuario de Twitter durante los acontecimientos, reportando información espacial derivada de la búsqueda por eventos y localizaciones que, por experiencia vivencial o aparición en medios de comunicación, eran relevantes. Adicionalmente, se hizo uso durante todo el proceso del listado de tendencias en Chile (Trending Topics), realizando búsquedas sobre las publicaciones asociadas a etiquetas (hashtags) más recurrentes, aun cuando ya no lo eran. Entre ellas destacan las referidas a lugares específicos (\#PlazaDignidad, \#barricadas, estaciones de metro, etc.), eventos concretos (\#toquedequeda; \#EstadoDeExcepcion) o generales (\#RenunciaPiñera; \#EvasionMasivaTodoEIDia; \#LaMarchaMasGrandedeChile) e, incluso, algunas que coincidentemente fueron útiles (\#30DayMapChallenge). 
Esta búsqueda fue replicada en términos, periodo y cadencia en Instagram. Cuando las etiquetas coincidían con lugares exactos, se procedía a realizar una búsqueda de publicaciones geolocalizadas.

Si bien este procedimiento genera incertidumbre ante la representatividad de la muestra, sí es prueba de que lo aquí examinado compone el grueso y parte más accesible (y, por consiguiente, utilizada por la población) de la cartografía estudiada².

Esta búsqueda entregó resultados directos sobre cartografía en muy pocas ocasiones, aunque ha resultado útil para identificar los mapas más relevantes, pero fundamentalmente, las fuentes y usuarios más activos, cuyos productos cartográficos se servían adicional o exclusivamente en otras plataformas como Google Maps y sus derivados. Estos mismos resultados han propiciado un posterior muestreo en «bola de nieve», que ha permitido localizar nuevos agentes que ayudaban a cartografiar lo ocurrido, encontrando coyunturalmente experiencias de otras ciudades chilenas o que rebasan la escala urbana, las cuales han sido depuradas mediante Sistemas de Información Geográfica (conversión de capas KML a formato shapefile y selección y examen de datos referidos en particular a Santiago).

\section{RESULTADOS}

Los acontecimientos de octubre y noviembre de 2019 encuentran notables paralelismos con las Jornadas Nacionales de Protesta celebradas en los 80, tanto en las formas de las protestas como en los métodos represivos por parte del Estado (Bravo, 2012). Entre ellos se incluyen la declaración del Estado de Emergencia y toque de queda, detenidos, muertes civiles y violaciones a los derechos humanos por parte de cuerpos policiales y militares (ACNUDH, 2019).

Sin embargo, la hoy presencia extendida de dispositivos móviles con acceso a internet en Chile ha significado una diferencia clave a la hora de oponer resistencia. Los avances tecnológicos facilitan la organización popular a la vez que ayudan a contrarrestar el discurso oficialista en un ámbito global. En términos cartográficos esto significa que el proceso «mapeador» nace y se instala en la resistencia al oficialismo, sin una de las principales limitaciones para su éxito, es decir, las dificultades de acceso a la red o los dispositivos que la proveen (Sullivan-Wiley, Short y Casellas, 2019; Nicolosi, French y Medina, 2019). Con estos medios, el proceso colaborativo adquiere sencillez. Todo pro-

2 Aquellas cartografías en construcción o en constante producción han sido examinadas según su estado a 30 de noviembre de 2019, independientemente de que se refieran a un periodo temporal concreto o no. 
ceso cartográfico requiere de «información geográfica voluntaria», con la particularidad que en Chile los «prosumidores» (Ritzer y Jurgenson, 2010) lo han sido en directo.

Así, una de las cartografías más relevantes y útiles fue la promovida por el «Colectivo de Geografía Crítica Gladys Armijo», que recopiló y publicó prácticamente en tiempo real sucesos durante los momentos más álgidos del estallido. Se trata de una cartografía de tipo colaborativo a la que se suman aportes voluntarios captados en RRSS (Twitter e Instagram), utilizadas también como medio de difusión. La información espacial se aloja en los servidores de Google, de acceso y uso gratuito, a través de su herramienta multiplataforma «My Maps» (Figura 3).

Figura 3. Mapa colaborativo del estallido social (18 y 19 de octubre)

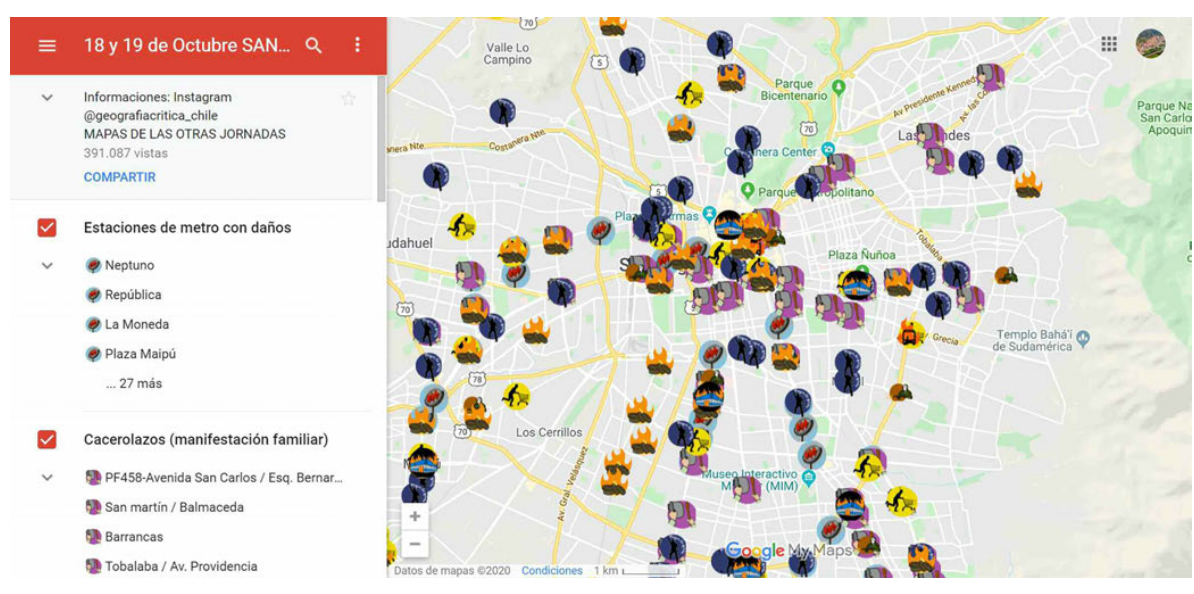

Fuente: Geografía Crítica Gladys Armijo. 2019

La información, que es descargable, se presenta mayoritariamente en topología de puntos y se compartimenta fundamentalmente por periodos temporales y espacios, aunque también existen algunas dedicadas a temáticas específicas (muertes, daños oculares y movilizaciones). Su fácil e intuitiva leyenda y manejo facilita su comprensión y trasversalidad social, lo que, combinado con su viable consulta en dispositivos móviles, potencia su uso.

Entre los mapas referidos a la capital destacan el de las jornadas del 18 y 19 de octubre, así como las del 20, 21, 22, 23 y 24 del mismo mes, teniendo estas últimas cuatro fechas una cobertura nacional.

Su contenido varía, ampliándose y reduciéndose (Tabla 1) en función del propósito declarado del colectivo en su web: «la difusión de la protesta en el mapa tiene por objetivo visibilizar situaciones que la prensa está ocultando». 
Este «mapa dinámico» se convierte así en una herramienta que, según definen sus creadores, lucha contra la criminalización de la protesta popular generada por el gobierno y los grandes grupos mediáticos. Al mismo tiempo, este libre acceso no es compatible con su aprovechamiento por las fuerzas policiales al resguardar el anonimato de lo reportado y sus protagonistas, así como de los informantes.

De este modo, los muy mediatizados daños en las estaciones de metro dejan de referirse, para incluir progresivamente otros registros menos expuestos a la opinión pública.

Tabla 1. Contenido de la cartografía colaborativa del Colectivo Geografía Crítica Gladys Armijo

\begin{tabular}{|c|c|c|c|c|c|c|c|}
\hline \multicolumn{2}{|c|}{18 y 19 octubre } & \multicolumn{2}{|c|}{20 octubre } & \multicolumn{2}{|c|}{21 y 22 octubre } & \multicolumn{2}{|c|}{23 y 24 octubre } \\
\hline Evento & Magnitud & $\bar{E}$ & $\mathbf{M}$ & $\bar{E}$ & $M$ & $\mathbf{E}$ & $M$ \\
\hline $\begin{array}{l}\text { Estaciones de } \\
\text { metro con daños }\end{array}$ & 31 & & & & & & \\
\hline Cacerolazos & 89 & & 23 & & 78 & & 50 \\
\hline $\begin{array}{l}\text { Recuperaciones/ } \\
\text { Saqueos }\end{array}$ & 31 & & & & & & \\
\hline $\begin{array}{l}\text { Disparos: } \\
\text { Balas/Perdigones }\end{array}$ & 14 & & 11 & & 16 & & 5 \\
\hline $\begin{array}{l}\text { Resistencia al } \\
\text { toque de queda }\end{array}$ & 60 & & 20 & & 53 & & 21 \\
\hline Quema de buses & 6 & & & & & & \\
\hline $\begin{array}{l}\text { Barricadas/ } \\
\text { Quemas }\end{array}$ & 46 & & 7 & & & & 2 \\
\hline \multirow[t]{7}{*}{$\begin{array}{l}\text { Inmuebles } \\
\text { incendiados }\end{array}$} & 6 & & 4 & & & & \\
\hline & & Muertes & 10 & & 3 & & 1 \\
\hline & & $\begin{array}{l}\text { Situaciones } \\
\text { emergentes }\end{array}$ & 6 & & 11 & & 2 \\
\hline & & & & $\begin{array}{l}\text { Centro de } \\
\text { torturas }\end{array}$ & 2 & & 1 \\
\hline & & & & $\begin{array}{c}\text { Represión } \\
\text { policial }\end{array}$ & 31 & & 4 \\
\hline & & & & & & $\begin{array}{l}\text { Huelga } \\
\text { Nacional }\end{array}$ & 7 \\
\hline & & & & & & $\begin{array}{l}\text { Convocatoria } \\
\text { de cabildo }\end{array}$ & 11 \\
\hline
\end{tabular}

Fuente: Geografía Crítica Gladys Armijo. Elaboración propia 
En esta última línea avanza otra iniciativa, esta vez constituida ex profeso por un conjunto de geógrafos agrupados bajo el nombre de "Geo Constituyente», en la que se determina la fecha, hora y lugar de celebración de cabildos, a lo que se suma la entidad o grupo de personas convocantes. Al igual que el anterior es un mapa colaborativo de acceso libre que utiliza la plataforma de Google My Maps, aunque esta vez restringe a Instagram su forma de captar y difundir la información. Su razón de ser es el fomento de la participación en estos enclaves y eventos de representación de la soberanía popular, en contestación a la inacción gubernamental. Según la consulta del 3 de noviembre de 2020 a esta cartografía, en Chile habían sido convocados hasta 416 cabildos, de los cuales 193 tenían como sede la capital. Con esta labor que aún continúa (Figura 4), no sólo se favorece la participación sino también la continuidad de la protesta y la discusión acerca de la Constitución, tema inicialmente rechazado por el gobierno.

Figura 4. Mapa colaborativo de cabildos y asambleas autoconvocadas en Chile

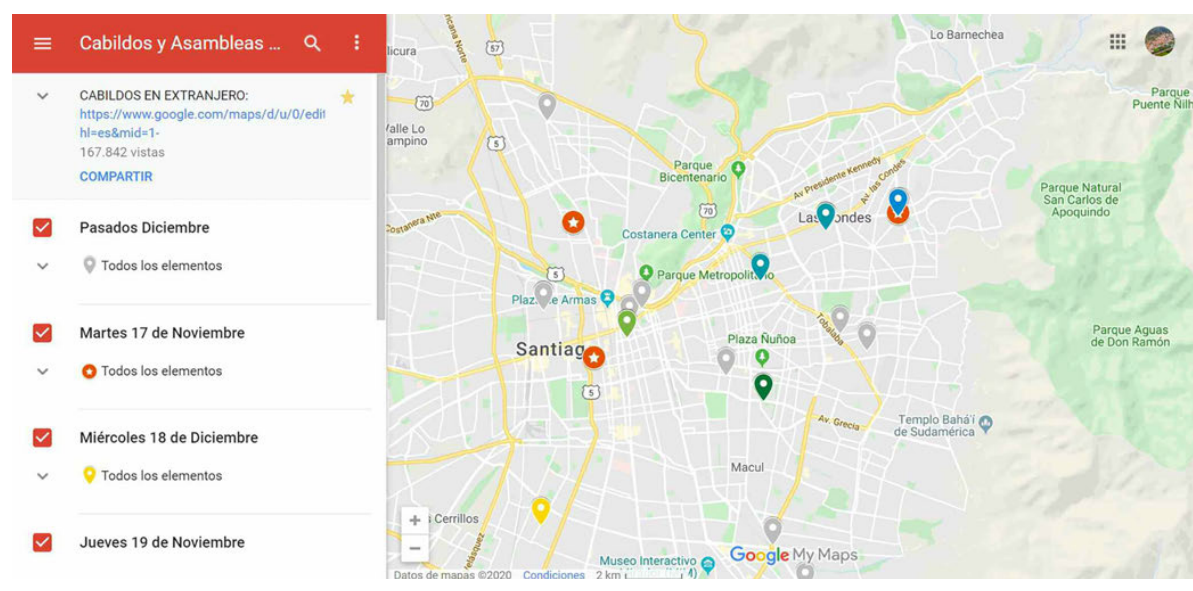

Fuente: Geo Constituyente. 2018

Esto demuestra que la cartografía responde a una orfandad social con respecto al gobierno, la cual se recrudeció en momentos críticos como el toque de queda. En ese contexto, el 23 de octubre aparece un mapa generado y publicitado por el medio local de comunicación alternativo «La Voz de Maipú», como forma de «servicio social» ante los problemas para abastecerse. Por ello, en él se reportan, de nuevo a través de Google My Maps, todos los almacenes y negocios en Maipú, comuna integrante de la capital. En un espectro parecido se podría incluir también el mapa de semáforos fuera de servicio que el 4 de noviembre ofreció Emol en la misma plataforma de Google, aunque 
bajo un argumento más próximo al relato gubernamental que abogaba por «una vuelta a la normalidad».

Durante el toque de queda, rápidamente se pasó del sentimiento de desamparo al de inseguridad. La represión policial llevó aparejadas violaciones a los derechos humanos que el colectivo «Desclasificación Popular» ha llamado a georreferenciar (fundamentalmente a través de las RRSS) bajo el proyecto "Cartografías de la represión», con el fin de «constatar la producción de espacios represivos como parte de una política de Estado». Iniciativas parejas surgieron en la academia, desde una actividad similar del colectivo estudiantil «Piquete geográfico» de la Pontificia Universidad Católica de Valparaíso hasta la celebración de talleres de cartografía organizados por diversas organizaciones de geógrafos e institutos de la Pontificia Universidad Católica de Chile.

Figura 5. Mapa de Pymes afectadas por los saqueos en Santiago de Chile
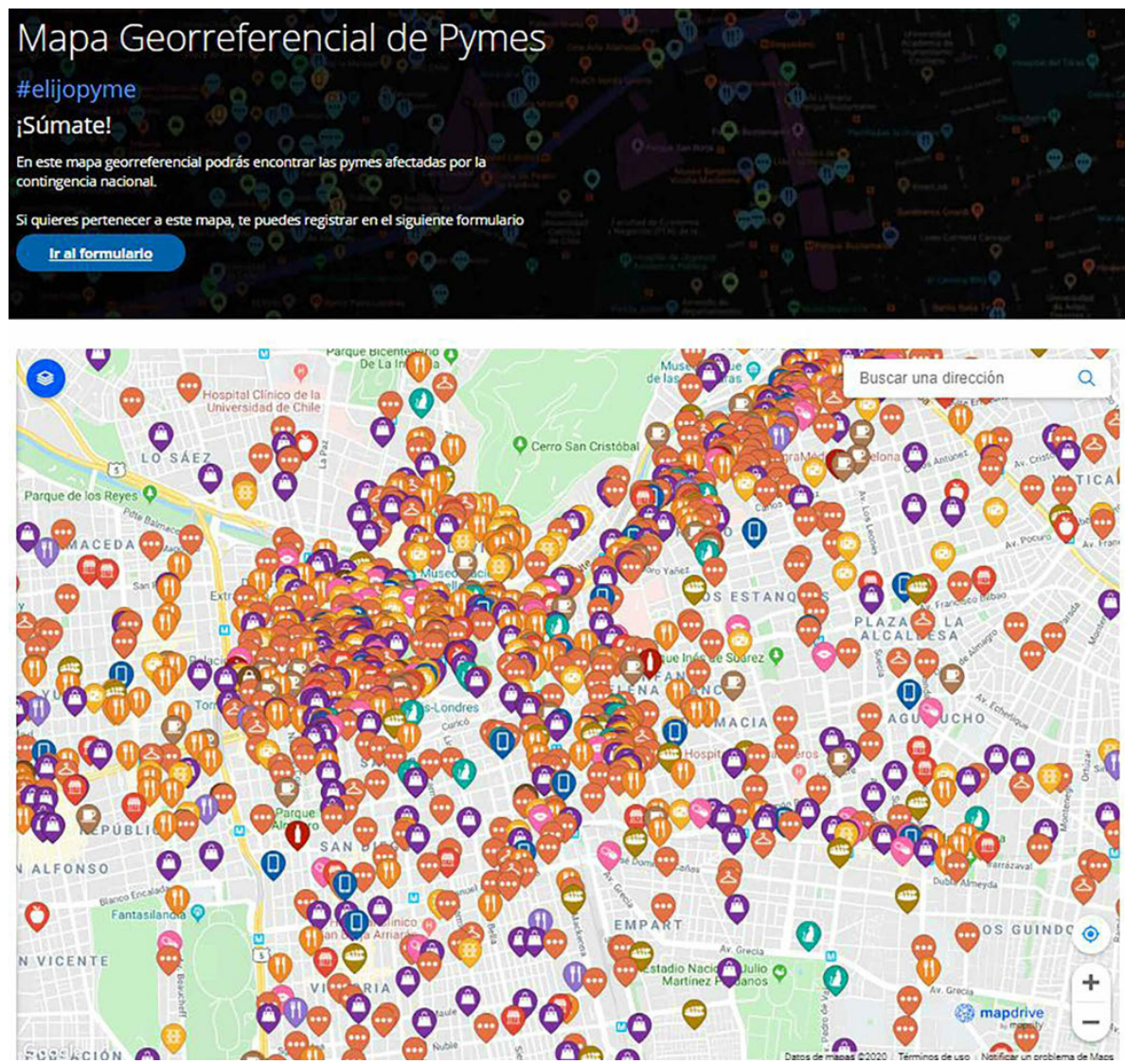

Fuente: CORFO. 2019 
A esta institución también pertenece el Centro de Desarrollo Urbano Sustentable (CEDEUS), que puso a disposición del público su herramienta cartográfica colaborativa «Mi ciudad». En ella se pueden construir de forma anónima y libre mapas de puntos de temática abierta, complementados con descripciones y fotografías. Se incluyen en ella mapas que georreferencian desde marchas pacíficas hasta saqueos y disparos de la policía.

En una lucha por el relato, la Corporación de Fomento de la Producción (CORFO), agencia gubernamental, ha elaborado una cartografía siguiendo la misma metodología y plataforma dominante entre la resistencia civil (Google My Maps). En ella (Figura 5) se realiza un catastro de las pequeñas y medianas empresas (Pymes) »afectadas por la contingencia nacional», incluidas presumiblemente por sus propietarios en la base de datos. Este mapa, publicitado a través del hashtag \#elijopyme, presenta una serie de registros no contrastables en bloque debido a que, a diferencia de los ejemplos vistos anteriormente, la información no es descargable.

Esta disputa adquiere su culmen a la hora de dominar un espacio, y parte de esta dominación recae en la capacidad de darle nombre. Durante este proceso se han vivido cambios espontáneos en la toponimia de la ciudad, como forma de ejercer apropiación y acción sobre el espacio geográfico (Núñez, Zambra y Aliste, 2017). El más notable es el que afecta al epicentro físico de las protestas, oficialmente denominado Plaza Baquedano, tras 3 designaciones anteriores. La cuarta nominación y resignificación tras la original se produjo el 11 de noviembre de 2019, cuando las etiquetas de Google Maps fueron modificadas en un ejercicio de «activismo virtual», para renombrar este lugar como «Plaza de la Dignidad». Esto, que aún no ha alcanzado oficialidad, adquirió materialidad dos días después mediante un grafiti de gran formato en el asfalto (Figura 6).

Figura 6. Plaza Dignidad (Ex Plaza Italia)

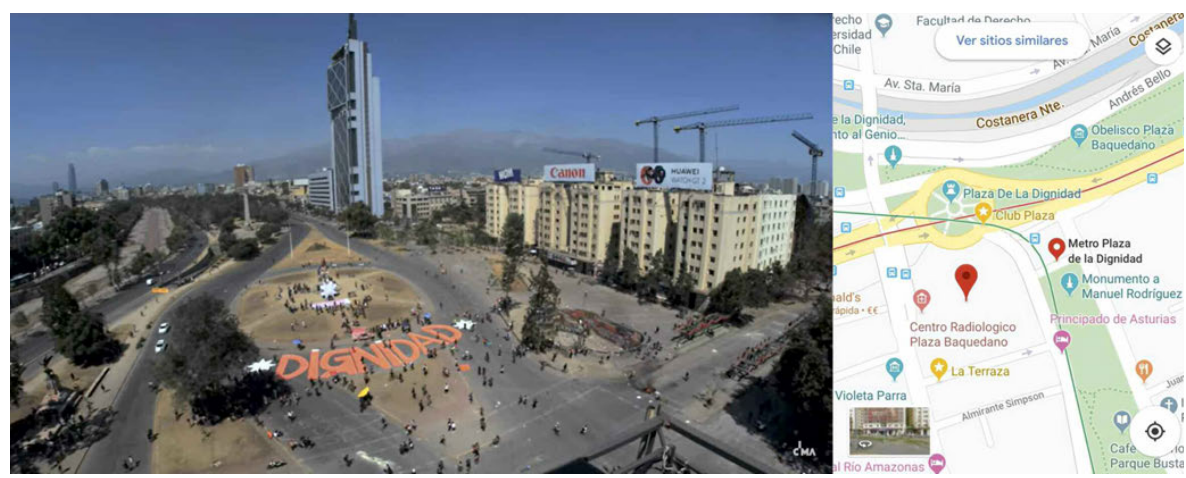

Fuente: Galería CIMA (Youtube) y Google Maps. 2019 
Este hecho responde a un imaginario social de este espacio, que lo interpreta como puesto de resistencia cívica. No en vano, en él han tenido lugar continuas movilizaciones, siendo la del 25 de octubre de 2019 conocida como «La marcha más grande de Chile», la más multitudinaria: 1,2 millones de personas (Intendencia Metropolitana).

De hecho, este registro ha sido fruto de controversia, por lo cual han aparecido varias respuestas desde la academia (particularmente por el profesor Pablo Guzmán del Instituto de Estudios Urbanos y Territoriales de la Pontificia Universidad Católica de Chile) y otros expertos profesionales del campo de la ingeniería que, si bien no se han plasmado todavía en estudios científicos publicados, sí fueron dados a conocer en las RRSS (Figura 7).

Figura 7. Tweets sobre los cálculos de asistencia de manifestantes a «La marcha más grande de Chile»

\section{(2) Estudios Urbanos UC @IEU_T}

Más de 1 millón 200 mil personas asistieron a la histórica marcha del pasado viernes 25 de octubre, de acuerdo a un interesante análisis realizado por el profesor y Jefe del Diplomado en Instrumentos de Planificación Urbana, Pablo Guzmán.
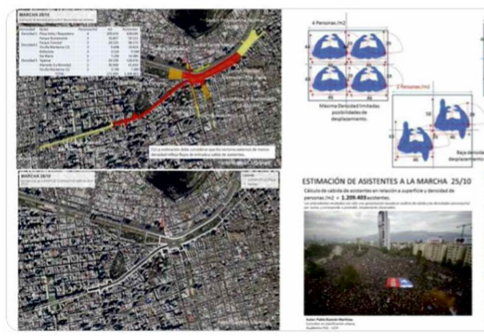

2 Universidad Católica y 8 más

7:24 a. m. 28 oct. $2019 \cdot$ Twitter for iPhone

170 Retweets 269 Me gusta

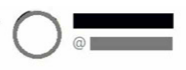

Basándome en lo que han mostrado y comentado los canales de TV estimé con Google Earth el área en m2 que abarca la concentración de personas en Santiago Centro. A 3 personas/m2, en este momento hay al menos 1 millón de personas manifestándose \#LaMarchaMasGrandeDeChile

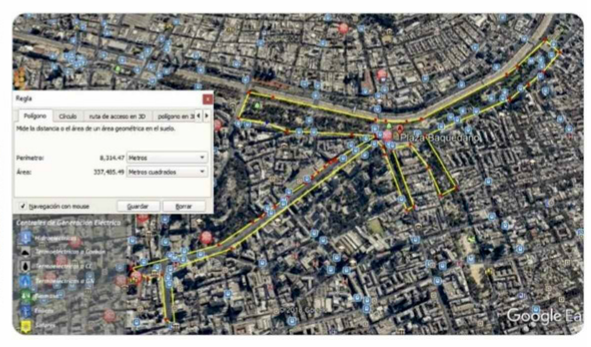

6:31 p. m. $\cdot 25$ oct. $2019 \cdot$ Twitter Web App

54 Retweets 54 Me gusta

De esta forma, la producción cartográfica no sólo ha tenido un carácter colaborativo y guiado por asociaciones y colectivos, sino que parte de ella ha sido fruto de un trabajo individual, como en las Figuras 2 y 7 . Estas cartografías han aprovechado toda la potencialidad de las RRSS y la coincidencia con hashtags no relacionados con la protesta, como \#30DayMapChallenge, para difundir su mensaje, en muchas ocasiones contrario al oficialismo. 


\section{CONCLUSIONES}

La cartografía generada en Chile debido al estallido social vivido el 18 de octubre de 2019 ha sido fundamental para su pervivencia en el tiempo. Esta resistencia ha resultado a su vez indispensable para cosechar logros tan importantes como el plebiscito constitucional pactado para el 26 de abril de 2020, aunque pospuesto hasta el 25 de octubre del mismo año a tenor de la crisis sanitaria desatada por el Covid-19.

El desarrollo tecnológico y su democratización ha sido un componente diferenciador con respecto al papel de la cartografía y su incidencia en este tipo de procesos. Por ello, los nuevos mapas han sido eficaces por 4 ventajas comparativas.

En primer lugar, la gratuidad y su amplia difusión. El acceso libre a un entorno digital a través de una extensa gama de dispositivos móviles ha permitido trasversalidad social y la multiplicación de los actores implicados como productores y receptores de la producción cartografía.

En segundo lugar, la anulación de las limitaciones espaciales (y temporales). Durante un contexto crítico y de inseguridad, la generación de la información al igual que su transmisión y recepción ha estado garantizada por las redes móviles.

Seguidamente, la inmediatez. La producción cartográfica se ha realizado mayoritariamente con aportes voluntarios y masivos, que han reducido a la mínima expresión el proceso de captación de datos y su publicación. Por esta razón y la naturaleza de sus contenidos, estos mapas son eminentemente una cartografía de uso (durante los eventos) y no de análisis. Su trasversalidad social y rapidez, da buena cuenta del carácter espontáneo de lo producido, lo que contrarresta el mensaje oficialista que defiende la confluencia de estrategias premeditadas en su contra.

Por último, resulta principal su intercomunicación. Esto redunda en una mayor capacidad organizativa y evolutiva. El avance en paralelo de distintas iniciativas con diferentes orígenes, pero cuyos resultados eran de acceso público e inmediato, ha impedido la existencia de duplicidades. Cuando estas eran detectadas, los contenidos de los mapas variaban. Otro factor que ha introducido cambios ha sido el mensaje gubernamental y mediático. Esto ha provocado que cada cartografía se convierta rápidamente en referencia dentro de la temática que aborda y en contraparte del oficialismo.

De esta forma, los mapas generados han sido consumidos por la sociedad desde sus hogares y las calles con distintos propósitos, que eran cambiantes según las necesidades y la evolución del conflicto. La adaptación del resultado cartográfico es fruto de esta retroalimentación.

Prueba del éxito e influencia de la cartografía colaborativa es que desde el gobierno se ha intentado replicar su metodología e, incluso, se han utilizado sus mismos canales de captación y difusión. Esto demuestra lo afirmado por 
Lacoste (1977) sobre la importancia del espacio, la geografía y su representación gráfica, esto es, los mapas, en la confrontación entre partes anunciada para Chile por el Presidente de la República³. Así, de un lado se encuentra el gobierno y su ponderación del orden público, y de frente, la cartografía socialmente construida, con apoyos puntuales e individuales desde la academia y otros sectores, en defensa de los derechos humanos.

\section{AGRADECIMIENTOS}

Este trabajo no hubiera sido posible sin la financiación del Programa de Inserción Académica del Instituto de Geografía de la Pontificia Universidad Católica de Chile. Del mismo modo, quiero agradecer a Rodrigo Hidalgo, Voltaire Alvarado y Federico Arenas por ilustrarme con sus charlas sobre la realidad chilena, complementando mi conocimiento, en parte adquirido por la vivencia personal en la ciudad durante los hechos.

\section{BIBLIOGRAFÍA}

ACNUDH (2019). Informe sobre la misión a Chile «30 de octubre-22 de noviembre de 2019». Recuperado de:

https://www.ohchr.org/Documents/Countries/CL/Report_Chile_2019_SP.pdf

Atria, F. (2013). Neoliberalismo con rostro humano: veinte años después. Santiago de Chile: Catalonia.

Borgias, S. L. (2018). "Subsidizing the State:» The political ecology and legal geography of social movements in Chilean water governance. Geoforum, 95, 87-101. doi: https://doi.org/10.1016/j.geoforum.2018.06.017

Bravo, V. (2012). Neoliberalismo, protesta popular y transición en Chile 19731989. Política y Cultura, (37), 85-112.

Bruey, A. J. (2012). Limitless Land and the Redefinition of Rights: Popular Mobilisation and the Limits of Neoliberalism in Chile, 1973-1985. Journal of Latin American Studies, 44(3), 523-552. doi: https://doi.org/10.1017/S0022216X12000399

CEPAL (2019). Panorama Social de América Latina 2018. Recuperado de: https://repositorio.cepal.org/bitstream/handle/11362/44395/11/S1900051_es.pdf

Denegri, M., Palavecinos, M., Gempp, R. y Caprile, C. (2005). Socialização econômica em famílias chilenas de classe média: educando cidadãos ou consumidores? Psicologia \& Sociedade, 17(2), 88-98.

3 A tres días del estallido social, el 21 de octubre, y momentos antes de declarar el estado de emergencia y toque de queda, el presidente Sebastián Piñera declaró: «estamos en guerra contra un enemigo poderoso». 
De Julios, A. (1995). Individualismo y modernidad. Una lectura alternativa. Anuario de Filosofía del Derecho, (12), 239-268.

Fernández, I.C., Manuel-Navarrete, D., y Torres-Salinas, R. (2016). Breaking Resilient Patterns of Inequality in Santiago de Chile: Challenges to Navigate towards a More Sustainable City. Sustainability, (8), 820. doi:10.3390/su8080820

Gerding, C., Fuentes, M. y Kotz, G. (2012). Anglicismos y aculturación en la sociedad chilena. Onomázein, (25), 139-162.

Harvey, D. (2007). Breve historia del Neoliberalismo. Madrid: Akal.

Harvey, D. (2012). El enigma del capital y las crisis del capitalismo. Madrid: Akal.

Hidalgo, R. (1999). La vivienda social en Chile: La acción del Estado en un siglo de planes y programas. Scripta Nova, 3(45). Recuperado de:

http://www.ub.edu/geocrit/sn-45-1.htm

Hidalgo, R., Alvarado, V. y Santana, D. (2017). La espacialidad neoliberal de la producción de vivienda social en las áreas metropolitanas de Valparaíso y Santiago (1990-2014): ¿hacia la construcción ideológica de un rostro humano? Cadernos Metrópole, 19(39), 513-535. doi:

http://dx.doi.org/10.1590/2236-9996.2017-3907

Humeres, M. (2019). «Gane usted y ayude a la Teletón»: mecanismos neoliberales en la gestión del bienestar. Convergencia. Revista de Ciencias Sociales, (81), 1-24. doi: https://doi.org/ 10.29101/crcs.v26i81.11641

Janoschka, M. y Hidalgo, R. (2014). La ciudad neoliberal: estímulos de reflexión crítica. En R. Hidalgo y M. Janoschka (Ed.), La ciudad neoliberal. Gentrificación y exclusión en Santiago de Chile, Buenos Aires, Ciudad de México y Madrid. pp. 7-32. Santiago, Chile: Serie GeoLibros.

Jiménez, V., Hidalgo, R., Campesino, A. J. y Alvarado, V. (2018). Normalización del modelo neoliberal de expansión residencial más allá del límite urbano en Chile y España. EURE, 44(132), 27-46. doi: http://dx.doi.org/10.4067/sO25071612018000200027

Keeley, B. (2018). Desigualdad de ingresos. La brecha entre ricos y pobres. París: Esenciales OCDE, OECD Publishing

Lacoste, Y. (1977). La geografía: un arma para la guerra. Barcelona, España: Anagrama.

Letelier, L. F., Tapia, V. C., Irazábal, C. y Boyco, P. (2019). Políticas de fragmentación vs. prácticas de articulación: limitaciones y retos del barrio como dispositivo de planificación neoliberal en Chile. Boletín de la Asociación de Geógrafos Españoles, (81), 1-38. doi: http://dx.doi.org/10.21138/bage.2698

Méndez, M. L. y Otero, G. (2018). Neighbourhood conflicts, socio-spatial inequalities, and residential stigmatisation in Santiago, Chile. Cities, 74, 75-82. doi: https://doi.org/10.1016/j.cities.2017.11.005

Maturana, F., Fuenzalida, M., Arenas, F. y Henríquez, C. (2017). La planificación territorial en Chile y el proceso de descentralización. En C. Vial y J. Hernán- 
dez (Ed.), ¿Para qué descentralizar? Centralismo y políticas públicas en Chile: Análisis y Evaluación por Sectores, pp. 181-208. Santiago, Chile: Instituto Chileno de Estudios Municipales y Universidad Autónoma de Chile. Muñoz, C. (2007). Vivienda progresiva, un programa del sector público que se potenció en el hábitat rural chileno. Revista INVI, 22(59), 132-150.

Navarrete-Hernández, P. y Toro, F. (2019). Urban Systems of Accumulation: Half a Century of Chilean Neoliberal Urban Policies. Antipode, 57(3), 899926. doi: 10.1111/anti.12504

Nicolosi, E., French, J. y Medina, R. (2019). Add to the map! Evaluating digitally mediated participatory mapping for grassroots sustainabilities. The Geographical Journal, 185, 1-14. doi: https://doi.org/10.1111/geoj.12315

Núñez, A., Zambra, A. y Aliste, E. (2017). El poder de los mapas, los mapas del poder: la construcción del saber geográfico de Patagonia-Aysén. Universum, 32(2), 149-162.

Román, Á. y Barton, J. R. (2018). Los supuestos del pensamiento urbano en Chile: justicia y equidad en la planificación de las ciudades. En F. Encinas, A. Wechsler, W. Bustamante, y F. Díaz (Ed.), Intersecciones: // Congreso Interdisciplinario de Investigación en Arquitectura, Diseño, Ciudad y Territorio, pp. 14-27. Santiago, Chile: Ediciones ARQ.

Stiglitz, J. (2012). El precio de la desigualdad. Madrid: Taurus.

Tapia, V. (2018). Geografías de la contención: el rol de las políticas de escala barrial en el Chile neoliberal. Scripta Nova, 22(592).

PICSA (2019). Creating an Inclusive Prosperity Cities Index. Background and Methodology. Recuperado de:

https://www.picsaindex.com/wp-content/uploads/2019/11/Creating-anInclusive-Prosperity-Cities-Index-final-PICSA-report_Nov2019.pdf

Ritzer, G. y Jurgenson, N. (2010). Production, Consumption, Prosumption: The nature of capitalism in the age of the digital 'prosumer'. Journal of Consumer Culture, 10(1), 13-36. doi: https://doi.org/10.1177/1469540509354673

Sullivan-Wiley, K.A., Short, A.G., y Casellas, J.P. (2019). Mapping vulnerability: Opportunities and limitations of participatory community mapping. Applied Geography, 105, 47-57. doi: https://doi.org/10.1016/j.apgeog.2019.02.008 Vives, A., Molina, A., Gray, N. y González, F. (2016). Envejecimiento y trabajo en Chile: propuesta para el monitoreo de la salud laboral. En I. Irarrázaval, E. Piña, y M. Letelier. (Ed.), Propuestas para Chile, pp. 17-50. Santiago de Chile: Centro UC Políticas Públicas. 


\title{
GENTRIFICACIÓN Y TURISTIFICACIÓN EN LAS ÁREAS URBANAS CENTRALES DE SEVILLA Y CÁDIZ \\ GENTRIFICATION AND TOURISTIFICATION IN THE \\ CENTRAL URBAN AREAS OF SEVILLE AND CADIZ
}

\author{
Julio José Parralejo Sánchez \\ Universidad de Sevilla \\ Ibán Díaz Parra \\ Universidad de Sevilla
}

\begin{abstract}
Resumen
En los centros históricos de las ciudades se viene dando un turismo intensivo que está generando unos impactos socio-espaciales ya visibles para la sociedad. Esto hace que se haya centrado el foco en el tema por parte de políticos y académicos, creándose un debate sobe gentrificación en ciertas áreas urbanas centrales solapándose con los estudios de turistificación, lo que se entiende por algunos autores como una gentrificación turística. El objetivo de este artículo es identificar si se han producido cambios socio-demográficos, identificables como turistificación, en los centros históricos de dos ciudades andaluzas, Sevilla y Cádiz, y que se interpretan aquí como una sustitución de residentes por visitantes. El trabajo se basa fundamentalmente en el análisis exploratorio de datos sociodemográficos del Padrón y datos sobre vivienda $\mathrm{y}$ alquileres suministrados por distintas fuentes. El trabajo muestra fuertes indicios de una relación entre el incremento de los apartamentos turísticos y pérdidas de residentes en ambos centros históricos. A este respecto se concluye señalando la necesidad de profundizar en la investigación sobre esta relación en la estadística pública que puedan guiar la futura adopción de medidas políticas.
\end{abstract}

Palabras clave: gentrificación, turistificación, vivienda turística, Airbnb, centro histórico.

\begin{abstract}
In historical city centres, intensive tourism has been taking place, generating social and spatial impacts that are already visible to society. This has led politicians and academics to focus on the issue, creating a debate on gentrification in certain central urban areas that overlaps with studies on tourism, what is understood by some authors as a tourist gentrification. The aim of this article is to identify whether socio-demographic changes, identifiable as touristification, have occurred in the historical centres of two Andalusian cities, Seville and Cadiz, and which are interpreted here as a
\end{abstract}


substitution of residents for visitors. The work is based fundamentally on the exploratory analysis of sociodemographic data from the census and data on housing and rentals provided by different sources. The work shows strong indications of a relationship between the increase in tourist apartments and losses of residents in both historical centres. In this respect, it is concluded by pointing out the need for further research on this relationship in public statistics that can guide the future adoption of political measures.

Key words: gentrification, touristification, tourist housing, Airbnb, historical center.

\section{INTRODUCCIÓN}

En los últimos años se ha producido un incremento de la preocupación por los impactos del turismo intensivo, tanto política como académica. Esto ha sido especialmente notorio en las ciudades del sur de Europa como Atenas, Barcelona, Lisboa o Roma entre otras. El carácter de potencia turística de España ha potenciado la relevancia de este tipo de procesos (Marchena Gómez y Vera Rebollo, 1990).

Este tipo de impactos ha llamado la atención de la Organización Mundial para el Turismo y del Parlamento Europeo (Peeters et al. 2018). A pesar de que la preocupación por los impactos del turismo no es una novedad, la atención reciente responde a una intensificación de los flujos de turistas y a la expansión de los procesos turísticos a nuevas áreas. Los motivos pueden ser varios. El turismo se ha convertido para regiones relativamente pobres en la principal fórmula para atraer recursos económicos (Capocchi, Vallone, Pierotti y Amaduzzi, 2019). Además, en los últimos años se han desarrollado o se ha reforzado el rol de determinadas innovaciones en el sector turístico con un impacto determinante, como serían las aerolíneas low-cost, el turismo de cruceros y la más reciente irrupción de las plataformas on-line que ofrecen alojamientos turísticos (Veiga et al, 2018, Postma y Schuecker, 2017). De esta forma, el turismo se ha convertido en la principal fuente de ingresos para muchas ciudades del país, dando lugar a la profesionalización del sector y al cada vez mayor uso de nuevas tecnologías (Chamorro, 2008) pudiendo ofrecer servicios de alta calidad y posibilitando el acceso al mismo de distintos estratos sociales, además de una fuerte internacionalización que ha ido creciendo en los últimos años. Tras la crisis económica de 2008, el turismo ha ganado más peso si cabe en la creación de empleo y en la participación en el PIB (Cuadrado Roura y Lopez Morales, 2018). Esto ha coincidido con cierta alarma social en torno a la saturación de visitantes en determinadas ciudades, especialmente en los centros históricos, con especial atención al crecimiento de la fórmula de los pisos turísticos (Cócola Gant, Durán, y Janoschka, 2016; Gil y Sequera, 2018) El impacto de los alquileres turísticos temporales y las plata- 
formas tipo Airbnb, al mismo tiempo que multiplica las posibilidades para los turistas a la hora de visitar ciudades y acceder a un amplio rango de experiencias, ha podido intensificar el número de turistas, tanto en ciudades tradicionalmente turísticas como en otras que no lo eran tanto, conduciendo a ciertos tipos de congestión y a la competencia por el espacio con los alquileres convencionales en las áreas históricas más visitadas. Esto trae a colación la cuestión de la necesidad de regulación estatal de estas actividades (Milano, 2018).

El termino turistificación ha proliferado especialmente en la academia española en el último lustro, estrechamente vinculado a los estudios sobre gentrificación en las áreas centrales de las grandes ciudades que venían desarrollándose una década atrás. Esta narrativa tiene su origen en gran parte en la idea de gentrificación turística, introducida por primera vez por Gotham (2005). Una idea que ha sido seguida a posteriori por numerosos investigadores (Cócola Gant, 2019; Füller y Michel, 2014). Cuestionando la idoneidad de hablar de gentrificación turística, Jover y Díaz-Parra (2019), argumentan la necesidad de diferenciar la gentrificación residencial tradicional y la turistificación, dado que, a pesar de responder a mecanismos similares, tendrían unos efectos demográficos distintos. Siguiendo a Clark (2004), la gentrificación referiría el fenómeno de la sustitución de los residentes y usuarios de cierto sector urbano por otros con mayor poder adquisitivo, mediada por la inversión en el entorno construido a población tradicional de un barrio. Este elemento respondería a la conceptualización clásica de Smith (1996) que explicaba la gentrificación como consecuencia de la reinversión de capital inmobiliario sobre zonas previamente desvalorizadas, siendo el principal motor de esta transformación el beneficio derivado del incremento de las rentas de suelo, lo que denomina rent gap o diferencial de renta. La noción de gentrificación transnacional, por su parte, puede interpretarse como el proceso protagonizado por nuevos residentes con mayor estatus, procedentes de otros países (Jover y Díaz, 2019). Por su parte, la turistificación podría ser tomada como una sustitución protagonizada, en lugar de por nuevos hogares de un estrato social superior a los preexistentes, por turistas y visitantes eventuales (Cócola Gant, 2015). Jover y Díaz (2019) remarcan esta diferencia, en la medida en que la turistificación, al contrario que la gentrificación debería conducir a cierto despoblamiento (en relación a residentes establecidos). Mientras que Wachsmuth y Weisler (2018) hablan de un rent gap turístico que situaría el motor del proceso en la diferencia existente entre los alquileres convencionales y los alquileres turísticos. El presente trabajo se enmarca en una investigación doctoral más amplia sobre los procesos de gentrificación y turistificación en las ciudades andaluzas de Cádiz y Sevilla. De este supone una primera parte centrada principalmente en el análisis exploratorio y descriptivo sobre el impacto de la intensificación de usos turísticos sobre la vivienda y la estructura y evolución socio-demográfica de las áreas centrales de estas ciudades. 
Figura 1. Centros históricos

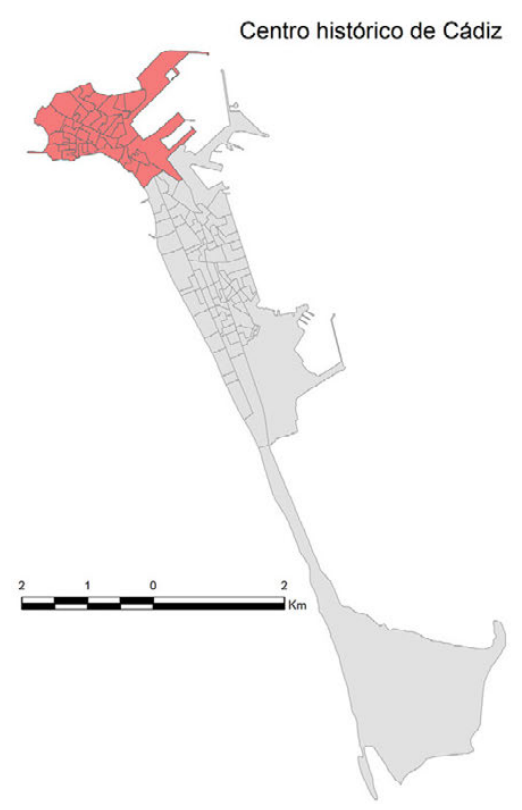

-

Centro histórico de Sevilla

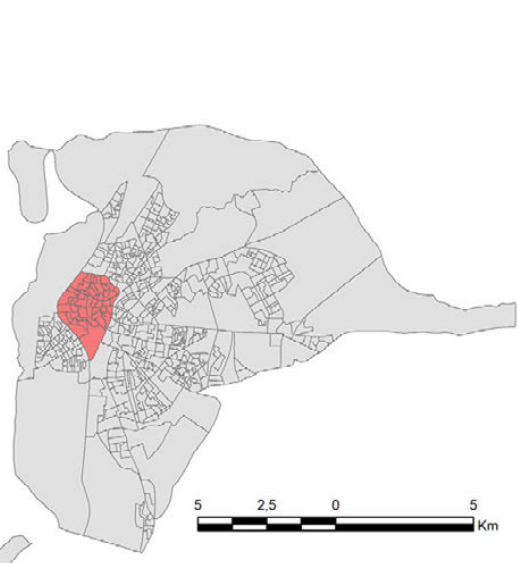

Fuente: Elaboración propia a partir de los datos de IECA

Los casos de Sevilla y Cádiz tienen un interés notable. Ambos son ciudades turísticas con centros históricos de grandes dimensiones y que se han convertido en un importante recurso económico para la economía local. Sevilla es la ciudad de Andalucía con la mayor cantidad de viviendas turísticas y la segunda ciudad de España, después de Madrid, con la mayor proporción de viviendas residenciales dedicadas a uso turístico en su centro histórico. Por su lado, Cádiz ocupa un lugar más secundario respecto del número de apartamentos turísticos, pero es la ciudad donde más ha crecido el turismo de cruceros en los últimos años, fuera de los territorios insulares.

Después de esta breve introducción, que incluye un escueto estado de la cuestión, sigue un apartado metodológico, donde se describen los pasos que ha seguido en análisis, fuentes utilizadas y justificación de los distintos indicadores. A continuación, se exponen los resultados, donde se explora de forma comparativa y sucesiva, primero, los datos sobre viviendas turísticas y usos de la vivienda, y segundo, la evolución socio-demográfica de la población. El artículo termina con un breve apartado de conclusiones. 


\section{METODOLOGÍA}

Se va a realizar un análisis exploratorio comparativo entre las dos ciudades. Este análisis se divide en dos partes bien diferenciadas. Una primera parte se centra en los datos sobre vivienda y alquileres turísticos. Una segunda parte analiza los cambios sociodemográficos en estas ciudades. La zona de estudio está delimitada por los términos municipales de ambas ciudades y, dentro de estas, los centros históricos, delimitados por su recinto amurallado. El periodo de estudio cubre el recorrido de estas ciudades durante el siglo XXI. Tomando como referencia inicial el 2001, fecha del penúltimo censo de población y vivienda, y terminando en 2018, fecha de los últimos datos del padrón publicados por el Instituto de Estadística y Cartografía de Andalucía. La temporalidad de los datos varía según la fuente. Es posible obtener los datos demográficos para cada año entre 2001 y 2018, mientras que los datos sobre vivienda en su mayoría se ofrecen exclusivamente de manera sincrónica, para 2018.

El análisis de las estadísticas demográficas parte de la hipótesis de que el incremento de los apartamentos turísticos, a raíz del impacto de plataformas como Airbnb, podría suponer un freno a la tendencia de las últimas dos décadas de los centros históricos andaluces a revertir o al menos frenar el declive demográfico que venían arrastrando desde la segunda mitad del siglo XX. Estas ganancias previas sería fruto de un proceso de gentrificación, por lo que la turistificación y la gentrificación estarían actuando de forma contradictoria sobre este tipo de espacios.

El estudio de los usos de la vivienda recurre a una diversidad de fuentes. En primer lugar, se utiliza la información que proporciona el censo de población y vivienda, que cuenta con la limitación conocida de su periodicidad, con lo que contamos exclusivamente con datos de 2001 y 2010, pero ofrece alguna información de interés sobre el uso de la vivienda. Los datos sobre viviendas turísticas responden a la compilación de datos en la plataforma Datahippo. Esta última fuente no ofrece por el momento series temporales, con lo que solo se cuenta con datos de stock. El impacto de las plataformas online que facilitan la transformación de viviendas en apartamentos turísticos (Airbnb, Homeaway, etcétera) se reduce al último lustro y los registros of iciales apenas han empezado a funcionar hace un par de años, cuando se estableció la obligatoriedad de declarar las viviendas con fines turísticos (Junta de Andalucía, 2016). Para el impacto del alquiler turístico mediante plataforma digitales se toma como referencia la fecha de 2012, que fue el año en que Airbnb se internacionalizó y abrió su primera oficina en España (Barcelona).

Se ha tomado como variable explicativa la diferencia entre el alquiler convencional y el turístico, entendido como proxy al mencionado rent gap turístico (Wachsmuth y Weisler, 2018). Los datos sobre alquiler convencional se han extraído de la página Idealista.com y los de alquiler turístico directa- 
mente de la plataforma Airbnb para identificar los precios medios del alquiler turístico en los centros históricos de estas ciudades. El dato del precio del alquiler turístico cuenta con el obstáculo de la extremada variabilidad de los precios del alquiler a lo largo del año. Esto se ha solventado parcialmente obteniendo los datos para distintos periodos del año (temporada alta y temporada baja). Ante la falta datos sobre los metros cuadrados del alquiler turístico se han comparado los alquileres en viviendas con dos habitaciones. Con las diferencias para los distintos tipos de vivienda y distintas épocas del año se extrae una media, indicador que reflejaría aproximadamente la diferencia de beneficios entre el alquiler convencional y turístico como motor de la turistificación.

Tabla 1. Indicadores de vivienda

\begin{tabular}{|l|l|}
\hline \multicolumn{1}{|c|}{ Fenómeno } & \multicolumn{1}{c|}{ Indicador } \\
\hline Incremento del peso de las viviendas secundarias & Incremento \%viviendas secundarias (2001-2011) \\
\hline Infrautilización del parque de viviendas & Incremento \%viviendas vacías (2001-2011) \\
\hline Peso del inquilinato & $\begin{array}{l}\text { Incremento \%viviendas en alquiler sobre las } \\
\text { viviendas principales (2001-2011) }\end{array}$ \\
\hline Turistificación de la vivienda & $\begin{array}{l}\text { \% alojamientos turísticos respecto del total de } \\
\text { alojamientos. }\end{array}$ \\
\hline Centralización de la vivienda turística & $\begin{array}{l}\text { \% de viviendas turísticas en el centro histórico } \\
\text { sobre el total de la vivienda }\end{array}$ \\
\hline Rent Gap turístico & $\begin{array}{l}\text { Diferencia entre el precio medio del alquiler } \\
\text { convencional y el precio medio de la vivienda } \\
\text { turística }\end{array}$ \\
\hline
\end{tabular}

\section{Fuente: Elaboración propia}

Para la dimensión socio-demográfica, se han obtenido los datos del Censo de Población y Vivienda de 2001 y 2011 y del Padrón, entre los años 2001-2018, proporcionados por Instituto Nacional de Estadística (INE), del Instituto de Estadística y Cartográfica de Andalucía (IECA). El Censo de población y vivienda ofrece la ventaja de presentar datos sobre la condición socio-laboral y nivel de estudios, lo que puede utilizarse como proxy del estatus de la población de un determinado sector urbano.

El indicador de gentrificación se construye a partir de la variación del porcentaje de población con oficios profesionales y técnicos. Se utiliza el conocido como índice de Marcuse (en Rasse et al. 2019), cuya definición operativa sería el porcentaje de cambio de un grupo socioeconómico en el área en cuestión menos el porcentaje de cambio de ese mismo grupo en la ciudad. Esto permite saber si en una determinada zona un grupo social que contextualmente se considera privilegiado ha crecido a un ritmo mayor o menor 
que el de la ciudad. El indicador de gentrificación transnacional usa de nuevo el índice de Marcuse, pero tomando como grupo privilegiado la población extranjera procedente de la UE-15, EEUU y Japón, que reflejaría lo que tiende a reconocerse como países centrales o países con mayor nivel de desarrollo. Una elección poco polémica si hablamos de la primera década del siglo XXI.

Tabla 2. Indicadores socio-demográficos

\begin{tabular}{|l|l|}
\hline Fenómeno & Indicador \\
\hline Incremento de la población & $\begin{array}{l}\text { Incremento total de la población viviendo en el centro } \\
\text { histórico (2001-2018) }\end{array}$ \\
\hline $\begin{array}{l}\text { Peso demográfico del centro } \\
\text { histórico }\end{array}$ & $\begin{array}{l}\text { Incremento del \% de población viviendo en el centro } \\
\text { histórico (2001-2018) }\end{array}$ \\
\hline Envejecimiento del centro histórico & Incremento \% mayores de 65 (2001-2018) \\
\hline Transnacionalización de las áreas & Incremento\% extranjeros en el centro histórico (2001-2018) \\
\hline Gentrificación & $\begin{array}{l}\text { Incremento \% personas con estudios superiores en el } \\
\text { centro respecto del incremento en el conjunto de la ciudad }\end{array}$ \\
\hline Gentrificación transnacional & $\begin{array}{l}\text { Incremento \% originarios de países con alto IDHen el centro } \\
\text { respecto del incremento en el conjunto de la ciudad }\end{array}$ \\
\hline
\end{tabular}

Fuente: Elaboración propia

\section{RESULTADOS}

\subsection{VIVIENDAS TURÍSTICAS Y DIFERENCIAL DE RENTA}

Tabla 3. Viviendas secundarias y vacías (2001-2011)

\begin{tabular}{|l|c|c|c|c|c|c|c|c|c|}
\cline { 2 - 10 } \multicolumn{1}{c|}{} & \multicolumn{2}{c|}{$\%$ Vivienda secundaria } & \multicolumn{2}{c|}{$\%$ Vivienda Vacía } & \multicolumn{2}{c|}{$\%$ Vivienda en Alquiler } \\
\cline { 2 - 10 } & 2001 & 2011 & $\begin{array}{c}\Delta 2001- \\
2011\end{array}$ & 2001 & 2011 & $\begin{array}{c}\Delta 2001- \\
2011\end{array}$ & 2001 & 2011 & $\begin{array}{c}\Delta 2001- \\
2011\end{array}$ \\
\hline Cádiz & 6,14 & 9,03 & $+2,89$ & 10,36 & 11,62 & $+1,25$ & 31,59 & 24,85 & $-6,74$ \\
\hline Cádiz CH & 3,90 & 6,80 & $+2,91$ & 14,76 & 19,72 & $+4,96$ & 54,99 & 44,90 & $-10,80$ \\
\hline Sevilla & 7,22 & 6,11 & $-1,11$ & 14,71 & 14,29 & $-0,42$ & 10,35 & 11.81 & $+1,46$ \\
\hline Sevilla $\mathrm{CH}$ & 9,09 & 9,10 & $+0,01$ & 29,27 & 24,37 & $-4,90$ & 26,52 & 27,04 & +0.52 \\
\hline
\end{tabular}

Fuente: Elaboración propia 
La Tabla 3 representa el peso de las viviendas secundarías, vacías y en alquiler y su variación entre los dos últimos censos de población. Como es habitual en las ciudades andaluzas, el mayor peso del alquiler en ambas ciudades se concentra en sus respectivos centros históricos. No obstante, el peso del alquiler es mucho mayor en el caso del centro histórico de Cádiz, donde oscila en torno a la mitad de las viviendas principales, mientras que en Sevilla se encuentra por encima de una cuarta parte. Por otro lado, la vivienda secundaria y la vivienda vacía tienen mucho mayor peso en el caso del centro histórico de Sevilla que en el de Cádiz. En Sevilla, el periodo intercensal supone una cierta dinamización residencial, ya que la vivienda vacía reduce su peso y la secundaria queda estancada, mientras que el alquiler se incrementa ligeramente, aunque menos que en el conjunto de la ciudad. En Cádiz sucede el fenómeno contrario, el alquiler desciende, perdiendo hasta 10 puntos en el centro histórico, y se incrementa el peso de las viviendas vacías y secundarias. El comportamiento de Sevilla parece corresponder con el crecimiento demográfico, rejuvenecimiento e incremento de la población extranjera en la primera década del siglo XXI, poniendo en juego un mayor número de viviendas, muchas en alquiler. En el caso de Cádiz, el mercado inmobiliario en este periodo parece dirigirse en mayor medida a otras formas de tenencia, principalmente la propiedad, y también a viviendas secundarias.

Tabla 4. Turistificación de la vivienda y centralización de la vivienda turística

\begin{tabular}{|c|c|c|c|}
\hline $\begin{array}{c}\text { Centro } \\
\text { histórico }\end{array}$ & $\begin{array}{c}\text { Número total de } \\
\text { viviendas turísticas }\end{array}$ & $\begin{array}{c}\text { Centralización de la } \\
\text { vivienda turística }\end{array}$ & $\begin{array}{c}\text { Turistificación de } \\
\text { la vivienda }\end{array}$ \\
\hline Cádiz & 897 & 61,61 & 6,51 \\
\hline Sevilla & 4.840 & 65,20 & 18,24 \\
\hline
\end{tabular}

Fuente: Elaboración propia

En la Tabla 4 se muestra que el número de viviendas turísticas varía mucho entre el centro histórico de Cádiz y el de Sevilla, siendo mucho más elevado en este último, coincidiendo con el mayor tamaño en superficie y población de este. El indicador de la centralización de este tipo de vivienda muestra un dato similar, por encima del 60\% de este tipo de viviendas concentradas en los respectivos centros históricos, lo que muestra la relevancia de la vivienda turística en este tipo de espacios. Finalmente, la turistificación de la vivienda muestra un dato mucho más elevado en el caso de Sevilla hasta de 18,24 puntos, frente a los 6,51 puntos del centro histórico de Cádiz, lo que implica que en el centro histórico de Sevilla la vivienda turística estaba acercándose al $20 \%$ del total de stock de viviendas (principales y de otro tipo). A través de Airbnb e Idealista se ha buscado una aproximación a la diferencia de renta 
que arroja el valor del alquiler convencional con respecto al alquiler turístico. Los datos se calculan de manera anual. Se ha calculado en viviendas con dos habitaciones. Teniendo en cuenta la fuerte variación estacional de los alquileres turísticos, se ha calculado la diferencia entre temporada alta y temporada baja. Las fechas para calcular la temporada alta han tomado el mes de carnavales en Cádiz y abril en Sevilla (Semana Santa y Feria). A partir de aquí se asumen dos presupuestos relevantes. Primero, se presuponen tres meses de temporada alta para ambas ciudades. Segundo, se presupone que la vivienda turística estaría alquilada durante todo el mes en los meses de temporada alta y la mitad del mes en temporada baja.

Tabla 5. Diferencial de renta anual en viviendas con dos habitaciones

\begin{tabular}{|c|c|c|}
\hline \multicolumn{3}{|c|}{ Diferencial renta turística con renta convencional } \\
\hline Sevilla centro histórico & $17.888,32 €$ & $58,02 \%$ \\
\hline Cádiz centro histórico & $23.721,24 €$ & $75,08 \%$ \\
\hline
\end{tabular}

\section{Fuente: Elaboración propia}

La diferencia del beneficio que obtendría un arrendatario entre un alquiler convencional y turístico se observa en la Tabla 5. En el centro de la capital andaluza la diferencia es de 58,02\% más de beneficios para el alquiler turístico de una vivienda, mientras que el centro histórico de Cádiz es aún mayor llegando al 75,08\%. Esta diferencia justifica el paso de alquileres convencionales a alquileres turísticos. Estos beneficios se multiplicarían en los meses con mayor afluencia de turistas. Para un mes de temporada alta, en Sevilla el arrendador obtiene $5.000 €$ de beneficios más de media que un alquiler convencional siendo en Cádiz esa diferencia de más de $7.000 €$.

3.2. Cambios socio-demográficos y gentrificación

Durante la segunda mitad del siglo XX los centros históricos de las ciudades de Sevilla y Cádiz se encontraban en fuerte regresión demográfica. Perdían población, generalmente a favor de otros barrios de sus respectivas ciudades o en favor de sus áreas metropolitanas y envejecían notoriamente. La renovación urbana sobre este tipo de centros históricos, generalizada en las ciudades de cierto tamaño de España, se produjo a partir de la década de los años noventa (Díaz Parra, 2010). 
Tabla 6. Cambios en la población de los centros históricos de Cádiz y Sevilla

\begin{tabular}{|l|c|c|c|}
\cline { 2 - 4 } \multicolumn{1}{c|}{} & Año & $\begin{array}{c}\text { Centro histórico } \\
\text { de Sevilla }\end{array}$ & $\begin{array}{c}\text { Centro histórico } \\
\text { de Cádiz }\end{array}$ \\
\hline \multirow{2}{*}{$\begin{array}{l}\text { \% Crecimiento de la } \\
\text { población }\end{array}$} & 2001 & 52,84 & 42,26 \\
\cline { 2 - 4 } & 2018 & 56,42 & 35,11 \\
\cline { 2 - 4 } & $\Delta 2001-2018$ & 3,58 & $-8,15$ \\
\hline \multirow{2}{*}{$\begin{array}{l}\text { \% Peso demográfico del } \\
\text { centro histórico }\end{array}$} & 2001 & 7,52 & 31,36 \\
\cline { 2 - 4 } & 2018 & 8,19 & 30,01 \\
\cline { 2 - 4 } & $\Delta 2001-2018$ & 0,67 & $-1,35$ \\
\hline \multirow{3}{*}{ \% Envejecimiento } & 2001 & 20,37 & 36,25 \\
\cline { 2 - 4 } & 2018 & 20,19 & $-7,87$ \\
\cline { 2 - 4 } & $\Delta 2001-2018$ & $-0,18$ & 0,55 \\
\hline \multirow{3}{*}{ \% Transnacionalización } & 2001 & 1,96 & 2,67 \\
\cline { 2 - 4 } & 2018 & 6,24 & 2,12 \\
\cline { 2 - 4 } & $\Delta 2001-2018$ & 4,27 & \\
\hline
\end{tabular}

Fuente: Elaboración propia

En la Tabla 6 observar como el centro histórico de Cádiz tiene más peso poblacional que la ciudad de Sevilla, a pesar de haber perdido habitantes Cádiz y Sevilla de haberlos ganado. En el centro histórico de Cádiz sigue viviendo un 30,01\% de la población total de la ciudad mientras que en Sevilla tan solo un 8,19\%. Más allá de esto el comportamiento de ambos centros históricos es notoriamente disímil. El centro histórico de Cádiz ha seguido perdiendo población, más de 8.000 habitantes para todo el periodo. La pérdida del peso demográfico del centro histórico era muy acelerada en los primeros años del siglo XXI. Sin embargo, estás perdidas en favor del conjunto de la ciudad, se frenan desde 2009, llegando a ganar peso entre este año y 2012, para volver a caer a partir de esta fecha, aunque levemente. En este proceso, el envejecimiento de la población se reduce muy notablemente, de un 36\% a un 28\% de viejos y viene acompañado también por un incremento de la transnacionalización del centro histórico, si bien muy moderado. En Sevilla por el contrario el peso demográfico de la población del centro histórico se ha incrementado en el periodo 2001-2018, aunque mínimamente. La población aumentó su peso de forma muy notable en la primera década del siglo XXI y hasta 2012, fecha a partir de la cual, pasa a perder peso en el conjunto de la ciudad. El número total de residentes del centro histórico de Sevilla venía incrementándose desde principios del siglo XXI de forma notable, año a año. Esta tendencia se frena y se invierte desde el año 2013, desde el cual se han perdido 3.653 residentes, lo que lamina gran parte del crecimiento anterior. 
El envejecimiento de la población en este periodo apenas cambia y sí se produce una mayor transnacionalización que en el caso de Cádiz, aunque el porcentaje de extranjeros escasamente supera el 6\% de la población. En Cádiz el envejecimiento se ha reducido de manera más o menos constante, en Sevilla, mientras crecía el peso demográfico del centro, también rejuvenecía, pero desde 2013, cuando se frena ese crecimiento, pasa a envejecer de nuevo año a año. Por otro lado, es notorio como el incremento de la proporción de extranjeros ha sido constante año a año, pero ha pasado a reducirse en ambas ciudades, precisamente a partir de 2013, coincidiendo en ambos casos con el freno a las tendencias previas a incrementar la población en Sevilla o frenar el declive demográfico en Cádiz. En síntesis, en el caso de Sevilla se produce un claro cambio en las tendencias demográficas, con un punto de inflexión en 2012, mucho más atenuado en el centro histórico de Cádiz. En el periodo previo a 2013 hay un crecimiento de la población, acompañado por el incremento en el peso de la población extranjera y el rejuveneciendo la población, lo que implica algún tipo de reemplazo de la población anciana por la entrada de nuevos pobladores, jóvenes y con cierto peso de la población extranjera. El caso de Cádiz es similar pero este proceso solo permite cierto freno de la regresión demográfica entre 2005 y 2012. El decrecimiento de la población posterior a partir de 2013 en el centro histórico de Sevilla implica pérdida de peso de la población extranjera y un nuevo envejecimiento, lo que indica que la población que se está perdiendo en ese periodo es población joven e incluye la población extranjera. Este último punto también es extensible al centro histórico de Cádiz, aunque en este caso el envejecimiento no para de caer durante toda la serie de datos.

Tabla 7. Gentrificación y gentrificación transnacional

\begin{tabular}{|c|c|c|c|c|c|}
\hline & $\begin{array}{c}\text { Índice de } \\
\text { gentrificación } \\
2001-2011\end{array}$ & $\begin{array}{r}\text { Profes } \\
\text { y téc } \\
\Delta 200\end{array}$ & $\begin{array}{l}\text { nales } \\
\text { icos } \\
2011\end{array}$ & $\begin{array}{c}\text { Índice de } \\
\text { gentrificación } \\
\text { transnacional } \\
2001-2018\end{array}$ & $\begin{array}{c}\text { \% Extranjeros } \\
\text { EU-15, EEUU, } \\
\text { Canadá y Japón } \\
\Delta 2001-2018\end{array}$ \\
\hline \multirow{2}{*}{$\begin{array}{l}\text { Centro histórico } \\
\text { Cádiz }\end{array}$} & \multirow{2}{*}{4,15} & $21,23 \%$ & \multirow{2}{*}{$+1,08$} & & \\
\hline & & $22,31 \%$ & & 0,38 & $+0,73$ \\
\hline \multirow{2}{*}{$\begin{array}{l}\text { Centro histórico } \\
\text { Sevilla }\end{array}$} & \multirow{2}{*}{1,91} & $51,42 \%$ & \multirow[b]{2}{*}{$+0,67$} & \multirow[b]{2}{*}{1,60} & \multirow[b]{2}{*}{$+1,97$} \\
\hline & & $52,06 \%$ & & & \\
\hline
\end{tabular}

Fuente: Elaboración propia

En la Tabla 7 los índices de gentrificación muestran una variación positiva durante el periodo de estudio para ambos casos, aunque el incremento es más bien tímido. El índice de gentrificación general es mayor en el centro 
histórico de Cádiz, por encima del 4\%, coincidiendo con un incremento de un punto en el peso de los profesionales y técnicos sobre el total de población en edad de trabajar. En el caso del centro histórico de Sevilla el índice está algo por debajo del $2 \%$ expresando un incremento menor de este grupo. Hay que señalar que el centro histórico de Sevilla se caracteriza como un sector muy privilegiado en comparación con el de Cádiz para este periodo, con más de la mitad de la población ocupada desempeñando oficios profesionales, un porcentaje que es menor a la cuarta parte en el caso de Cádiz. Quitando la cuestión de la gran diversidad interna que existe en ambos centros históricos, esto podría apuntar a un proceso de gentrificación más temprano en el caso de Sevilla, como de hecho indica la bibliografía disponible (Díaz-Parra, 2014). En el caso de la gentrificación transnacional parece ocurrir lo contrario. También cuenta con valores positivos. Sin embargo, esta vez la gentrificación transnacional es mucho mayor en el caso del centro histórico de Sevilla donde arroja un 1,6\%, coincidiendo con un incremento notable del porcentaje de extranjeros procedentes de los países más desarrollados. En Cádiz el dato es mucho menor y se queda en un 0,38\%

Los datos de la Tabla 7 añaden un matiz a las observaciones anteriores sobre el cambio poblacional en los dos centros históricos objeto de estudio. La población que ha promovido el crecimiento y rejuvenecimiento durante ciertos periodos ha sido una población socialmente privilegiada, lo que implica cierto grado de gentrificación del sector que es más notorio durante el periodo de estudio en Cádiz, e incluso cierto grado de gentrificación transnacional que sería más importante en Sevilla.

\section{CONCLUSIONES}

El elevado número de viviendas turísticas y la diferencia de renta arrojada entre la vivienda turística y el alquiler convencional podría ser la principal variable explicativa de las pérdidas de población en estos centros históricos en los últimos años. El impacto del crecimiento de este tipo de alojamientos turísticos desde 2012 justifica las pérdidas de población, especialmente en Sevilla, revirtiendo las tendencias anteriores. Por otro lado, la elevada turistificación de la vivienda en Sevilla coincide con cierto grado de gentrificación transnacional, lo que parece en primera instancia una relación lógica entre la presencia de residentes extranjeros procedentes de países ricos y la oferta de alojamientos temporales para visitantes de estos mismos países. En Sevilla el fenómeno de turistificación como sustitución de residentes por visitantes, es más claro, pero Cádiz tiene algunos elementos de mayor vulnerabilidad: principalmente el hecho de que su centro histórico aloja a una población de menor estatus y con un mayor peso de los inquilinos, lo que reduciría su capacidad de competir por el espacio residencial de la zona y aumenta el riesgo de un desplazamiento involuntario. 
La hipótesis de una relación entre turistificación y pérdida de población sale reforzada de este trabajo. No obstante, para poder inferir una relación causa efecto entre el incremento de los pisos turísticos temporales y las pérdidas de población habría que contar con series temporales de datos sobre los primeros y aplicar algún tipo de regresión lineal a un nivel elevado de desagregación dentro de los centros históricos, lo que podría ser una futura línea de trabajo.

La relación entre gentrificación y turistificación se muestra asimismo como un aspecto complejo. De partida parece existir cierta correlación entre gentrificación transnacional y turistificación. Sin embargo, la gentrificación en términos generales, asociada al rejuvenecimiento de los centros históricos parece anterior e incluso podría verse afectada negativamente por la pérdida de residentes, que afecta a los hogares jóvenes y también a los hogares extranjeros. Respecto del carácter beneficioso o no de este tipo de procesos. Si la principal virtud de la gentrificación pudo ser el rejuvenecimiento y reversión del declive demográfico de los centros históricos, la intensificación de estas dinámicas relacionadas con la turistificación podría estar laminando estos pequeños logros. Esta es una proposición que debe seguir trabajándose en el desarrollo futuro de esta investigación.

\section{BIBLIOGRAFÍA}

Capocchi, A., Vallone, C., Amaduzzi, A. y Pierotti, M. (2019). Is 'overtourism' a new issue in tourism development or just a new term for an already known phenomenon? Current Issues in Tourism, O(0), 1-5.

https://doi.org/10.1080/13683500.2019.1638353

Chamorro, R. (2008). Una revolución en el turismo gracias a las TIC. Revista $B I T, N^{\circ} 170,30-33$.

Clark, E. (2004). The order and simplicity of gentrification: A political challenge, (January 2004). https://doi.org/10.4324/9780203392089

Cócola Gant, A. (2015). Boletin sobre el turismo reponsable. Tursimo y Desarrollo, 15, 12.

Cócola Gant, A., Durán, G. y Janoschka, M. (2016). La ciudad del siglo XXI: políticas públicas urbanas, desplazamientos y contestaciones. ĺconos - Revista de Ciencias Sociales, (56), 11. https://doi.org/10.17141/iconos.56.2016.2351

Cócola Gant, A. (2019). Gentrificación y desplazamiento: desigualdad urbana en ciudades del capitalismo tardío: Manual de Geografía Urbana, 297-310. https://doi.org/10.4337/9781785364600.00030

Cuadrado Roura, J. R. y Lopez Morales, J. M. (2018). El turismo en la recuperación y el equilibrio exterior de España. Papeles de Economía Española, 154171.

Díaz Parra, I. (2010). Cambios en la geografía social de Sevilla 1981-2001. Cuadernos Geográficos, n46, 139-161. 
Díaz-Parra, I. (2014). ¿Gentrificación o barbarie? Disciplinamiento y transformación social de barrio de la Alameda de Sevilla.

Füller, H. y Michel, B. (2014). «Stop Being a Tourist!» New Dynamics of Urban Tourism in Berlin-Kreuzberg. International Journal of Urban and Regional Research, 38(4), 1.304-1.318. https://doi.org/10.1111/1468-2427.12124

Gil, J. y Sequera, J. (2018). Expansión de la ciudad turística y nuevas resistencias. El caso de Airbnb en Madrid. Revista de Metodología de Ciencias Sociales, 15-32.

Gotham, K. F. (2005). Tourism gentrification: The case of New Orleans' vieux carre (french quarter). The Gentrification Debates, 42(7), 145-176. https://doi.org/10.4324/9781315881096

Jover, J. y Díaz-Parra, I. (2019). Gentrification, transnational gentrification and touristification in Seville, Spain. https://doi.org/10.1177/0042098019857585

Marchena Gómez, M. y Vera Rebollo, J. F. (1990). Turismo y Desarrollo: Un planteamiento actual. Papers de turisme, 3, 59-84.

Milano, C. (2018). Overtourism, malestar social y turismofobia. Un debate controvertido. PASOS. Revista de Turismo y Patrimonio Cultural, 18(3), 551-564. https://doi.org/10.25145/j.pasos.2018.16.041

Peeters, P., Gössling, S., Klijs, J., Milano, C., Novelli, M. Dijkmans, C., (...) y Postma, A. (2018). Research for TRAN Committee - Overtourism: Impact and possible policy responses. Study for European Parlament.

Postma, A. y Schmuecker, D. (2017). Understanding and overcoming negative impacts of tourism in city destinations: conceptual model and strategic framework. Journal of Tourism Futures, 3(2), 144-156

Rasse, A., Sabatini, F., Sarella-Robles, M., Gomez-Maturano, R., Cáceres, G. y Trebilcock, M. P. (2019). Metodologías de identificación de zonas en gentrificación. Santiago de Chile y Ciudad de México. http://dx.doi.org/10.15446/bitacora.v29n1.70035

Smith, N. (1996). La nueva frontera urbana. Ciudad revanchista y gentrificación.

Veiga, C., Santos, M. C., Águas, P., y Santos, J. A. C. (2018). Sustainability as a key driver to address challenges. Worldwide Hospitality and Tourism Themes, 10(6), 662-673. https://doi.org/10.1108/WHATT-08-2018-0054

Wachsmuth, D., y Weisler, A. (2018). Airbnb and the rent gap: Gentrification through the sharing economy. Environment and Planning A, 50(6), 11471170. https://doi.org/10.1177/0308518X18778038 


\title{
EL PROCESO DE TRANSFORMACIÓN DE LA PLAZA DE MERCADO DE BELLO (COLOMBIA), HACIA UN ESPACIO PERCIBIDO \\ THE TRANSFORMATION PROCESS OF THE BELLO (COLOMBIA) MARKET SQUARE, TO A PERCEIVED SPACE
}

\author{
Santiago Rojas Tavera \\ Universidad Pontificia Bolivariana
}

Elizabeth Dahiana Londoño Toro

Universidad Pontificia Bolivariana

Resumen

Bello es un municipio localizado en Antioquia-Colombia, en la cordillera central de los Andes. Caracterizado por su industrialización y comercialización, prácticas agrícolas y distribución que benefician a sus habitantes. Las actividades productivas del municipio han sufrido cambios. La desindustrialización y expansión de la urbanización, generan una transformación en el uso del suelo, particularizando: la verticalización, el déficit del espacio público y la modernización de espacios tradicionales como la plaza de mercado. La plaza de Bello es un espacio público, con dinámicas de abastecimiento, interacción y adquisición de recursos; un sustento para las familias involucradas con la actividad comercial que se desarrolla allí. Describir los intereses económicos que se tejen en las transformaciones socio-espaciales de la plaza de mercado del municipio, es el objetivo de esta ponencia. Teniendo en cuenta: usuarios, comerciantes, constructoras y funcionarios públicos. Se diseñaron encuestas (plan de análisis en Epi-Info) y entrevistas. Lefebvre y la producción del espacio desde el espacio percibido, son el sustento teórico. Como principales resultados están: la transformación de la plaza está asociada a un proceso de gentrificación. La plaza es un espacio más de reproducción del capital con procesos de coerción a los comerciantes para que no se resistan al desalojo.

Palabras clave: gentrificación, Espacio Percibido, Espacio Público, Plaza de Mercado, Bello-Antioquia.

\section{Abstract}

Bello is a municipality located in Antioquia-Colombia, in the central mountain of the Andes. Characterized by its industrialization and commercialization, agricultural practices and distribution that benefit its population. Productive activities of the municipality have changed. The deindustrialization and the urbanization expansion generate a transformation in land use, particularizing, the verticalization, the public space deficit and the modernization of traditional 
spaces like marketplace. Bello 's marketplace, is a public space, with catering dynamics, interaction and acquisition of resources; a sustenance for the families involved in the commercial activity that is developed there. Describing the economic interests that are woven in the socio-spatial transformations of the marketplace of the municipality, is the objective of this presentation. Keeping in mind: users, merchants, construction companies and public workers. Surveys (analysis plan in Epi-Info) and interviews were designed. Lefebvre, and the production of the space from the perceived space, are the theoretical support. As main results there are: The marketplace transformation is associated to a gentrification process, the marketplace is more for capital reproduction with coercion processes for merchants so that they do not resist eviction.

Keywords: gentrification, Perceived Space, Public Space, Market Square, Bello-Antioquia.

\section{INTRODUCCIÓN}

El municipio de Bello del departamento de Antioquia (Colombia) está localizado al costado norte del área metropolitana del valle de Aburrál (ver Figura 1). Este valle es una subregión del departamento de Antioquia que se extiende a lo largo de diez municipios. Está localizado en la cordillera central de los Andes, tiene una extensión de 1.165,5 km². La conformación del valle resulta de la determinación de la unidad geográfica de la cuenca del río Aburrá-Medellín (principal arteria fluvial que lo recorre de sur a norte) y por sus afluentes. El valle está enmarcado por una topografía irregular y pendiente, que oscila entre 1.300 y 2.800 msnm, lo que da al territorio una diversidad climática (Área metropolitana, 2019).

Los municipios del valle son: Caldas, La Estrella, Sabaneta, Itagüí, Envigado, Medellín, Bello, Copacabana, Girardota y Barbosa. El municipio de Bello limita por el norte con el municipio de San Pedro de los Milagros, por el oriente con Copacabana, por el sur con Medellín y por el occidente con los municipios de Medellín y San Jerónimo (ver Figura 1).

1 Las Áreas Metropolitanas son entidades administrativas de derecho público, formadas por un conjunto de dos o más municipios integrados alrededor de un municipio núcleo, vinculados entre sí por dinámicas e interrelaciones territoriales, ambientales, económicas, sociales, demográficas, culturales y tecnológicas que para la programación y coordinación de su desarrollo sustentable, desarrollo humano, ordenamiento territorial y racional prestación de servicios públicos requieren una administración coordinada (Ministerio del interior, 2013). 
Figura 1. Localización del municipio de Bello, Antioquia (Colombia)

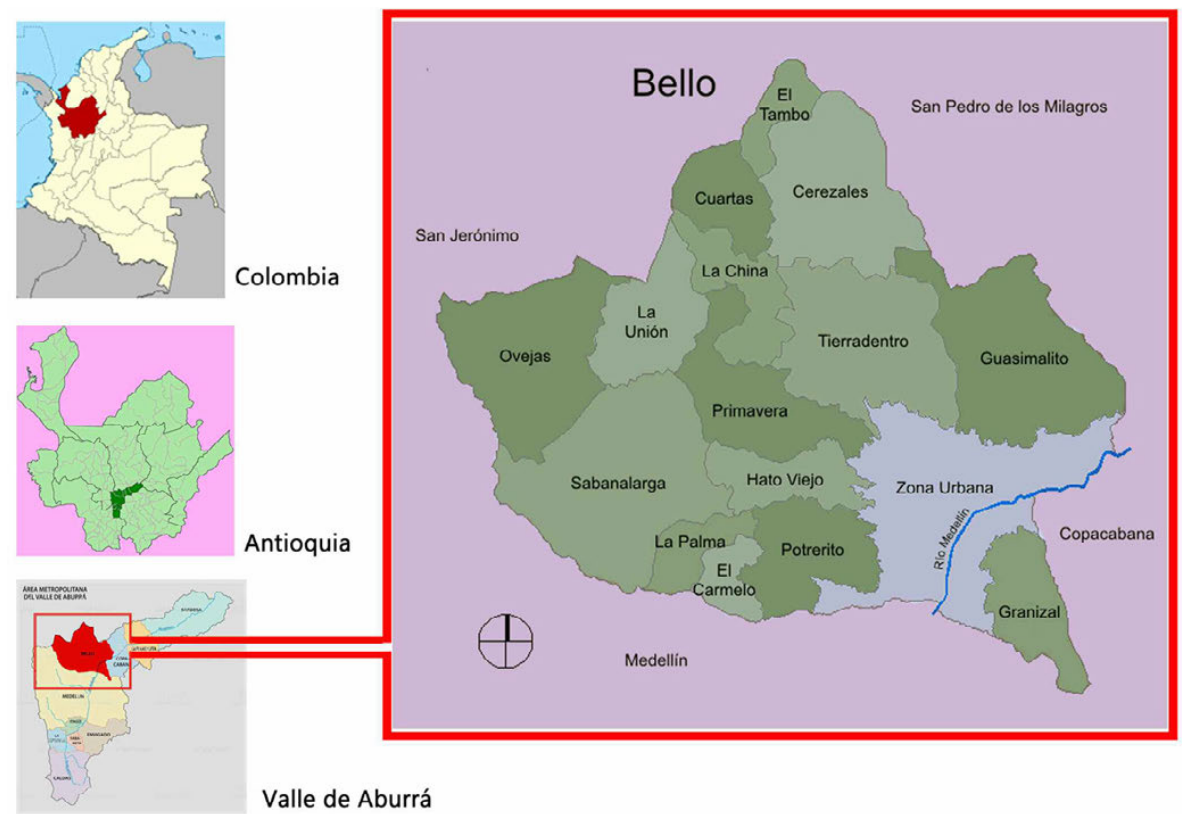

Fuente: Elaboración propia. 2020

Este municipio dispone de un área de $142 \mathrm{~km}^{2}$, con una altura promedia de 1.450 msnm, una latitud norte de $6^{\circ} 21^{\prime} 24^{\prime \prime}$, y una longitud oeste de Greenwich de $75^{\circ} 34^{\prime} 00^{\prime}$. Topográficamente, el municipio está conformado por montañas, cerros y valles con alturas desde los 1.400 y 3.100 msnm. Por otro lado, la hidrografía del municipio se caracteriza por, el río de Medellín que lo cruza de sur a norte y las principales quebradas, que son: El Hato, La García, La Loca, Las Baldías y La Madera al costado occidental; y la quebrada La Gabriela en el costado oriental. Sin embargo, estas corrientes de agua se han visto afectadas en los últimos años por los procesos de urbanización e industrialización, las cuales han sido producto de la transformación territorial que detenta el municipio de Bello desde hace varias décadas (Corporación Semiosfera, s.f). Históricamente, antes de la declaración del 29 de abril de 1913 donde se nombra a Bello como un municipio autónomo con patrimonio propio e independiente, este territorio era conocido como Hato Viejo, en mención a las actividades agrícolas y de ganadería que desarrollaban sus pobladores alrededor de los hatos asentados en este espacio. Sin embargo, este apelativo dejó de generar identidad desde 1873, a razón de los procesos de poblamiento y las transformaciones en las dinámicas económicas y sociales del municipio. Con la llegada de las primeras fábricas al territorio, se produjo una transición del 
campesinado a la inserción del capital humano en la industrialización (Corporación Semiosfera, s.f).

Los primeros intentos de creación de industria en el municipio estuvieron enfocados a la producción de ladrillos, no obstante, su fracaso le conllevó a replantear su desarrollo a partir del sector textil. Así aparecieron las primeras empresas orientadas a la oferta de hilados y tejidos en Bello. Bajo este ideal, en el municipio se constituyeron la empresa de Don Indalecio Uribe en 1877, y la Compañía Antioqueña de Tejidos², con lo que nace la industria textil colombiana, e inicia así un imparable proceso migratorio hacia lo que entonces era la aldea de Bello (Corporación Semiósfera, s.f).

La industrialización del mercado y el crecimiento económico no solo fueron los factores que detonaron un cambio significativo para el municipio. En el año de 1913, llega al municipio el ferrocarril de Antioquia, lo que permitió el ingreso de los futuros pobladores de Bello. De esta manera, este pasó repentinamente de ser un poblado aislado, a tener una conexión directa con los principales centros productivos del país. (Alcaldía de Bello, 2017).

El 26 de febrero de 1920, se constituyó por escritura pública y como sociedad anónima la Fábrica de Hilados y Tejidos del Hato S. A. (Fabricato), mítica en su época por sus avances tecnológicos que la consagraron como líder en la producción y comercialización de textiles. Esta empresa en particular, posicionó al municipio como un territorio de oportunidades, ocasionando una innumerable oleada de nuevos inmigrantes en búsqueda de trabajo. De esta manera, Fabricato se reconoce como una entidad transversal en la historia del municipio, puesto que contribuyó con el crecimiento del mismo, potencializando el territorio con la creación de escuelas, clubes sociales, barrios, clínicas, teatros y otras obras que transformaron el contexto de la población bellanita (Alcaldía de Bello, 2017).

Con el crecimiento de la actividad industrial, aumentó la población obrera en el municipio y a su vez la demanda de múltiples servicios y espacios, entre los cuales se destaca la creación de la plaza de mercado en 1942, ubicada en el centro del municipio para favorecer el desplazamiento de los habitantes de los barrios recientemente creados (Restrepo, 2012). Además, permitió conservar esa identidad campesina de los primeros pobladores y satisfacer las necesidades comerciales, culturales y sociales.

Si bien la producción textil se convierte en el icono industrial del municipio, la plaza de mercado marcó una distinción comercial. Razón por la que, en

2 La Compañía iaeña de Tejidos, fue resultado de la compra de los bienes del malogrado proyecto: Compañía de tejidos de Medellín, de las burguesías del municipio de Medellín, que habían elegido el sector de Bellavista perteneciente a Bello (Corporación Semiósfera, s.f). 
1999, el municipio en dirección de su entonces alcalde, adquirió la plaza de mercado, que hasta ese momento era propiedad de particulares nativos de Bello (Restrepo, 2012). A partir de esa fecha no existe registro de ninguna intervención por parte de la administración local en la plaza. Es por ello que hoy, a pesar de la utilidad y el valor simbólico de la plaza, esta presenta condiciones de abandono y deterioro que ponen en riesgo su estructura y la integridad de quienes trabajan allí (ver Figura 2).

Figura 2. Estado actual de la plaza de mercado de Bello

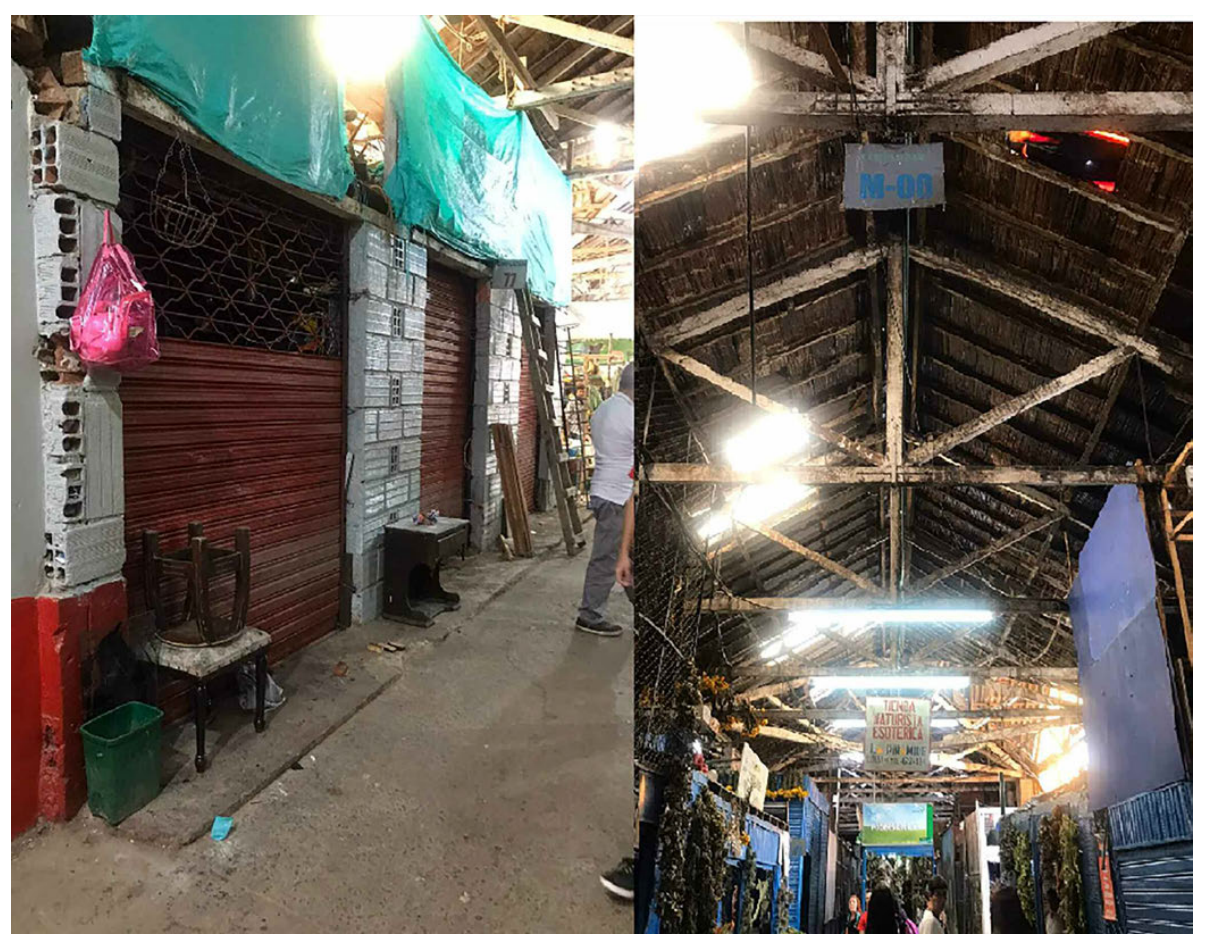

Fuente: Elaboración propia. 2019

Paralelo al abandono de la administración para con la plaza, el municipio empezaba a incursionar en el mercado inmobiliario debido al desplazamiento que tuvo esta actividad hacia los costados sur y norte del Área Metropolitana. Por lo cual el interés de la administración local por repotencializar las estructuras tradicionales fue nulo, de hecho, la permanencia de la plaza en el municipio ha sido producto de la persistencia de sus arrendatarios. 
Como consecuencia de lo anterior, según exconcejal, (comunicación personal, abril 2019) en el año 2011 surge una acción popular ${ }^{3}$ que buscaba exigir una repotencialización o reconstrucción de la plaza de mercado del municipio, donde para fortuna de los bellanitas el fallo se dio a su favor. En este se exigía el cumplimiento de los derechos en ciertas medidas durante un tiempo estimado de máximo 60 días. Esta intervención comprendía la reconstrucción del techo y reformas en los sistemas eléctricos y de alcantarillado, no obstante, aquella intervención nunca se ejecutó.

Según el exconcejal (comunicación personal, abril 2019), para el año 2014, y en razón al desacato del fallo judicial por parte de la Alcaldía, esta planteó una alternativa que actuó como forma de dilatación del proceso, contratando a la Universidad Nacional para el estudio de mitigación del riesgo en la plaza. Dicho estudio arrojó como resultado, que el sitio presentaba un alto riesgo de incendio y de colapso de su cubierta por su estado generalizado de deterioro, por tanto, se concluye que se necesita un presupuesto de $\$ 3.049 .636 .859$ para la reestructuración del lugar (Universidad Nacional de Colombia, 2015, 33). A dicho estudio, la administración local respondió con una aparente falta de presupuesto. Sin embargo, en palabras del exconcejal del municipio, «las reformas eran viables en ese momento ya que el presupuesto del municipio para el año 2016 se calculaba en \$359.773.761.340» (Ciro, 2019, 10).

En palabra del exconcejal (comunicación personal, abril 2019), con el fin de recolectar información suficiente que soportara su decisión, la Alcaldía se resguardó en un estudio realizado por el Politécnico Colombiano Jaime Isaza Cadavid que pretendía una caracterización sociodemográfica y económica de la plaza de mercado de Bello. Sin embargo, este estudio presentó una deficiencia al no incluir la totalidad de las redes económicas que operaban en el lugar, debido a su informalidad. No obstante, bajo la determinación de no reconstruir o potencializar, el municipio acató una de las recomendaciones de este estudio, en la que se sugiere «realizar un estudio econométrico que mida el cambio en el bienestar (medida monetaria) de los usuarios de la plaza y el entorno» (Politécnico Colombiano Jaime Isaza Cadavid, 2016, 45). Para 2017, El municipio contrató el estudio econométrico con la Universidad de Antioquia, con el objetivo de indemnizar a los ocupantes formales del lugar, dejando como producto compensaciones económicas muy bajas. Por tanto, los comerciantes manifiestan no entender los parámetros empleados para las compensaciones destinadas a mitigar los impactos sociales y eco-

3 Las acciones populares son: los medios procesales para la protección de los derechos e intereses colectivos. Empleadas para evitar el daño contingente, hacer cesar el peligro, la amenaza, la vulneración o agravio sobre los derechos e intereses colectivos, o restituir las cosas a su estado anterior cuando fuere posible (Colombia, Congreso de la República, Ley 472, 1998). 
nómicos, puesto que las cifras de las personas más beneficiadas no sobrepasan los \$15.000.000 (Ciro, 2019).

Los estudios mencionados han sido el respaldo de las acciones de desalojo 4 ejecutados por la administración local. Según la Secretaría de Gobierno del municipio «las condiciones de vulnerabilidad han aumentado considerablemente y por ello se toma la decisión del desalojo, así como de la demolición del edificio» (Herrera, 2018, 3). En contraposición a ello, los afectados denunciaron irregularidades en dicho proceso. Afirman además que la administración municipal tiene un interés por destinar el predio de la plaza para la inversión inmobiliaria (Herrera, 2018).

Pese a las dinámicas socioeconómicas que produce la plaza de mercado y su valor cultural, que en conjunto con la producción de hilados y tejidos originaron el desarrollo del territorio, hoy la plaza está expuesta a desaparecer en noción al desarrollo inmobiliario, que se convirtió en el interés de las últimas administraciones. Como muestra de ello, el Plan de Ordenamiento Territorial (POT) del municipio fue reconfigurado en 2009, permitiendo edificaciones de gran altura y residencias de estratos altos ${ }^{5}$, contrario a lo que estaba establecido. A razón de lo anterior, el costado norte del valle de Aburrá volvió a ser llamativo para las constructoras (Pareja, 2014). Y se generan a su vez estímulos en los procesos de gentrificación del municipio.

Bajo este marco de crecimiento inmobiliario, el lote que ocupa la plaza de mercado se reconoce como un área propicia y estratégica para este sector ${ }^{6}$. De esta manera, es el escenario de los intereses del mercado, que la contemplan como una oportunidad de producción del espacio, para Lefebvre el espacio percibido.

En razón a este panorama que se agudiza cada vez más, como consecuencia de la incesante disputa de intereses entre: la administración municipal y los comerciantes y usuarios. El presente trabajo ${ }^{7}$ investigativo de corte descrip-

4 El 13 de noviembre de 2018, la administración local llevo a cabo un operativo de desalojo y cierre de los locales de la plaza de mercado, debido al estado de vulnerabilidad del lugar (Herrera, 2018).

5 Concepto utilizado en Colombia, que según la Ley 142 de 1994 «clasifica los inmuebles residenciales de un municipio, que se hace en atención a los factores y procedimientos que determina la ley». Asumiendo una estratificación, Estrato 1. Bajo-Bajo; Estrato 2. Bajo; Estrato 3. Medio-Bajo; Estrato 4. Medio; Estrato 5. Medio-Alto y Estrato 6. Alto.

6 La plaza de mercado se encuentra a menos de 600 metros de la estación de metro Bello.

7 Este trabajo hace parte de una investigación mayor que tiene por título: La plaza de mercado Bello (Colombia) entre lo tradicional y lo moderno. Realizada en el semillero de investigación de Territorio, de la Facultad de Trabajo Social - Universidad Pontificia Bolivariana. 
tivo-reflexivo, con fines académicos, tiene por objetivo caracterizar el proceso de transformación socioespacial de la plaza de Bello, con respecto a las relaciones y los intereses del mercado (espacio percibido). Para el cumplimiento de este objetivo, se consideraron 4 grupos poblacionales: comerciantes, usuarios, constructoras y funcionarios públicos, para los dos primeros se diseñó una encuesta la cual fue aplicada a 80 comerciantes y 58 usuarios, esta información fue analizada con ayuda del programa Epi-Info generando las tablas de frecuencia. Para los funcionarios y constructoras se diseñó una entrevista que se realizó de manera personal, telefónica y vía electrónica, estas se analizaron en una matriz categorial. Además, también se requiere de un marco teórico provisionado de categorías conceptuales para dicho cumplimiento y el reconocimiento de la realidad.

\section{MARCO CONCEPTUAL}

La esfera pública, el espacio percibido y la gentrificación son conceptos necesarios para abordar de manera teórica el objetivo propuesto. Así, partiendo de la premisa que el espacio público como lugar común a sus habitantes, es creador de ciudadanía, la plaza de mercado del municipio de Bello como espacio público ha sido una amalgama de configuraciones culturales para la población bellanita, puesto que su valor material, pero, además simbólico han significado años de trabajo, subsistencia, costumbre y tejido social. Lo que según Arendt (2003), desde su definición de lo público, es necesario una interacción con el otro para lograr una construcción. Es decir, lo público hace referencia a lo que es corriente para todos y que a su vez sobrepasa la esfera de lo privado, relacionándose con los asuntos de quienes habitan juntos en el mundo hecho por el hombre. Lo que significa que un mundo de cosas está entre quienes lo tienen en común.

El mundo, como todo lo que está en medio, une y separa a los hombres al mismo tiempo. "La plaza de bello es un lugar público que atrae por igual a humildes y personas de la alta sociedad, todos los que visitan este lugar siempre tienen un objetivo principal: la comodidad y la economía. Desde temprano los trabajadores y campesinos llegan a este lugar cargados de sus productos para venderlos a los habitantes, por eso es muy importante que no sea destruida, sino que la arreglen para bienestar de trabajadores y público. La plaza es un lugar generador de empleo y un patrimonio del municipio.» (Comunicación personal, febrero 2020).

Sin embargo, y a pesar de que el espacio público debe ser generador de lo anteriormente mencionado, existen teorías que, a través de otros factores, dan paso a observar que la configuración del espacio se encuentra permeada por determinaciones desde lo percibido, lo concebido y lo vivido. Explicado por Lefebvre (1974), quien mediante una triada conceptual precisa que en la producción del espacio convergen las prácticas espaciales (espacio percibido), 
las representaciones del espacio (espacio concebido) y los espacios de representación (espacio vivido).

Para el enfoque de esta comunicación, es necesario situarse en el marco de lo que supone el espacio percibido:

El espacio percibido, debe entenderse como el espacio de la experiencia material, que vincula realidad cotidiana (uso del tiempo) y realidad urbana (redes y flujos de persona, mercancías o dinero que se asientan en -y transitanel espacio), englobando tanto la producción como la reproducción social (Lefebvre, 1974. 15).

Frente a estas determinaciones y en el contexto del municipio de Bello, es importante decir que quienes perciben el espacio de la plaza de mercado, como referente de transformación y planificación urbana son: el capital inmobiliario, representado por las constructoras presentes en el municipio. Estos intereses se amparan en las decisiones de la administración municipal, la cual a través del POT en el año 2009, según excandidato a la alcaldía 2019 (Comunicación personal, noviembre, 2019) rebajó las compensaciones urbanísticas de un 20\% a un 10\%, estimulando el crecimiento de este sector en el municipio. De esta manera, la dinámica actual de la plaza puede explicarse a través de la triada conceptual propuesta por Lefebvre enmarcado en la línea del espacio percibido, en su producción y reproducción, y las características que el conjunto espacial da a la formación social. Exigiendo en este caso, que el mercado tradicional se transforme.

Es así entonces, como los mercados municipales se han visto en la necesidad de enfrentar diferentes desafíos debido a las transformaciones dadas en la estructura urbanística y demográfica de las ciudades, el cambio en las pautas de consumo y la competencia de formas de distribución y comercio que se ejecutan desde los supermercados.

El modelo urbano desarrollista, ha implementado los hipermercados no solamente en Europa, sino en diferentes países. Las características de este modelo en Europa fueron: la suburbanización, los conjuntos residenciales de baja densidad y la construcción de autovías (Hernández, 2017). Para el municipio de Bello, este modelo se caracteriza por: la redensificación del suelo urbano, ocupación de las periferias con construcciones campestres de lujo y nuevos centros comerciales (Puerta del Norte, Ciudad Fabricato, entre otros). Lo que, según López (2002; 2007), citado en Hernández (2017), ocasionaría una ruptura entre el espacio público y el comercio debido a la individualización y privatización de las formas de consumo. Además, las políticas públicas han permitido el establecimiento de este modelo, tal como lo afirma (Hernández, 2017): Las políticas públicas urbanas enfocadas hacia el crecimiento de la periferia, así como la salida de las clases medias de las zonas centrales influenciadas por imaginarios suburbanos provocaron que los centros de las ciudades y sus mercados experimentan un proceso de desinversión y pérdida de valor simbólico (Hernández, 2017, 168). 
Lo anterior, da cuenta de lo que hace referencia a los procesos de gentrificación relacionados a nivel local, e incluso mundial, permitiendo hacer una analogía entre el municipio de Bello y diferentes ciudades europeas. Entendida aquí la gentrificación como, un proceso asociado a la modernización de las ciudades. El cual es liderado por las entidades del gobierno con apoyo de los promotores inmobiliarios. Estos últimos, compran lotes a precios bajos y aún con los costos de construcción pueden obtener ganancias considerables. Logrando atraer una población de mayor renta y una expulsión de la población tradicional (Smith, 2012).

Según Hernández (2017), para las dinámicas de la gentrificación confluyen algunas características que son similares en el marco de nuestra investigación, siendo estas: incremento de los flujos migratorios hacia las zonas centrales del territorio y procesos de reurbanización, que implican expulsión de la población tradicional, y transformaciones en los estilos de vida. Es así entonces, como la estructura urbana de los centros locales hacen parte de los fenómenos de «abandono y destrucción».

Sin embargo, los centros de abastecimiento y mercado siguen siendo un sector altamente atractivo para el comercio, la administración y el sector empresarial, pero en Bello, al igual que en diferentes ciudades del mundo, surge la conocida gentrificación comercial. Este es el punto donde la densificación urbana y la construcción de nuevos centros, disputan que la forma del comercio tradicional y minorista deba ser sustituido por grandes proyectos. Además, se desplazan a comerciantes que subsisten de la plaza de mercado, lo que supone entonces no sólo una cuestión material, sino también simbólica. (Hernández, 2017).

\section{RESULTADOS}

Los hallazgos principales de este trabajo investigativo sobre el reconocimiento de la plaza de mercado como un espacio percibido, emergen de los cambios en el uso del suelo, con relación a la revisión del POT del municipio. En el año 2009, el POT tuvo un cambio importante el cual partió del principio de la sana mezcla de usos, actividades, estratos socio-económicos y reorientación en la asignación de los usos comerciales. Permitiendo edificaciones en altura, zócalos comerciales y vivienda para estratos medio y medio-alto. En este sentido, el lineamiento de «vivienda digna y de alta calidad» adquiere mayor respaldo por la administración local, que favorece la construcción de viviendas de mayor estrato en sus diversas tipologías: casa, casa-finca y apartamentos, bajo el ideal de: «óptimas condiciones de habitabilidad y calidad» (Alcaldía de Bello, 2009). No obstante, algunos analistas perciben estas acciones como una estrategia, que legitima la creación de plusvalías para los inversionistas privados (Restrepo, 2012).

Las inmobiliarias ejecutaron nuevos proyectos de diseños de vivienda enfocadas para la población de mayor poder adquisitivo. Según exalcalde (2014), 
"La nueva ciudad no piensa en viviendas baratas o de interés social sino en las de alto rango» (Pareja, 2014). Lo que produjo un urbanismo a partir de edificaciones de altura y del concepto de ciudadela (ciudades dentro de ciudades), caracterizada por ser una aglomeración de edificios y apartamentos que comparten espacios y servicios como: comercio, recreación y transporte (Restrepo, 2012). Estas nuevas incursiones en el municipio revelan la densificación inmobiliaria como resultado del cambio estratégico realizado en el POT del 2009, en comparación con el POT del 2000.

Como producto de los cambios ya anunciados, Bello enfrenta un proceso de gentrificación, el cual permitió que desde 2014 hasta el primer semestre del 2019, el municipio alcanzara el mayor número de ventas de viviendas reportadas y licencias otorgadas, en relación con el área metropolitana.

Para el 2019, de las 21.700 unidades que se vendieron en Antioquia, en Bello compraron 4.522. Es decir, un $24 \%$ del total (Suárez, 2019). Bello pasó de tener 18 proyectos de vivienda en 2010 a 74 reportados para el segundo semestre de 2019 (García, 2019). Los proyectos más destacados que han transformado el paisaje urbanístico, son: Ciudad Central (596 apartamentos), Ciudadela Oporto (744 apartamentos), Ciudadela Campestre Amazonia (hasta el momento 254 casas y 400 apartamentos), Puerta Madera Club Residencial (912 apartamentos) y Ciudadela Norteamérica (Un complejo de apartamentos, casas que según el periódico El Tiempo, será ocupado por lo menos por 25 mil habitantes, más que muchos pueblos de Antioquia) (Restrepo, 2012).

Una de las inmobiliarias con mayor influencia en la construcción urbanística del municipio, encargada del proyecto comercial más grande actualmente en Bello «Plaza Fabricato» afirma: que el municipio es exitoso en ventas, pues que goza de atributos como: ubicación estratégica, cerca de toda la infraestructura de servicios de Medellín y el valle de Aburrá. Al tiempo, sostiene que utilizar el predio para la actividad comercial es una buena elección, puesto que se tiene la oportunidad de atender un mercado de 600 mil habitantes que demandan productos y servicios (Comunicación vía electrónica, febrero de 2020).

Otra de las inmobiliarias que incursiona en Bello, detonó otras cualidades como: el crecimiento en infraestructura, la evolución de la movilidad y fluidez de sus vías, su excelente topografía y las amplias actividades industriales, comerciales y educativas que ofrece el municipio (Óptima, 2019).

Sin embargo, en la actualidad de los 74 proyectos solo $35 \%$ de estos, corresponde a edificaciones de vivienda de interés social (Informe inmobiliario, 2019). Lo que deja en evidencia, la prioridad que la administración local le otorga al capital privado en la producción del espacio. En este sentido, la relación Estado e inmobiliarios privados antepone sus intereses sobre los del colectivo.

La ambición de demoler antes que potencializar o reconstruir, es producto de los procesos de gentrificación que pretenden romper con el tejido social y las relaciones del mercado engendradas en las necesidades básicas como 
la alimentación. Logrando con ello una edificación que aumente la renta del suelo. Como prueba de esto, en el 2019 el DANE señaló que los precios de venta de vivienda nueva en el valle de Aburrá se incrementaron un $8.9 \%$. Sin embargo, sólo durante el segundo trimestre de este mismo año, Bello registró una valorización próxima al 6\% de los proyectos de vivienda nueva (García, 2019).

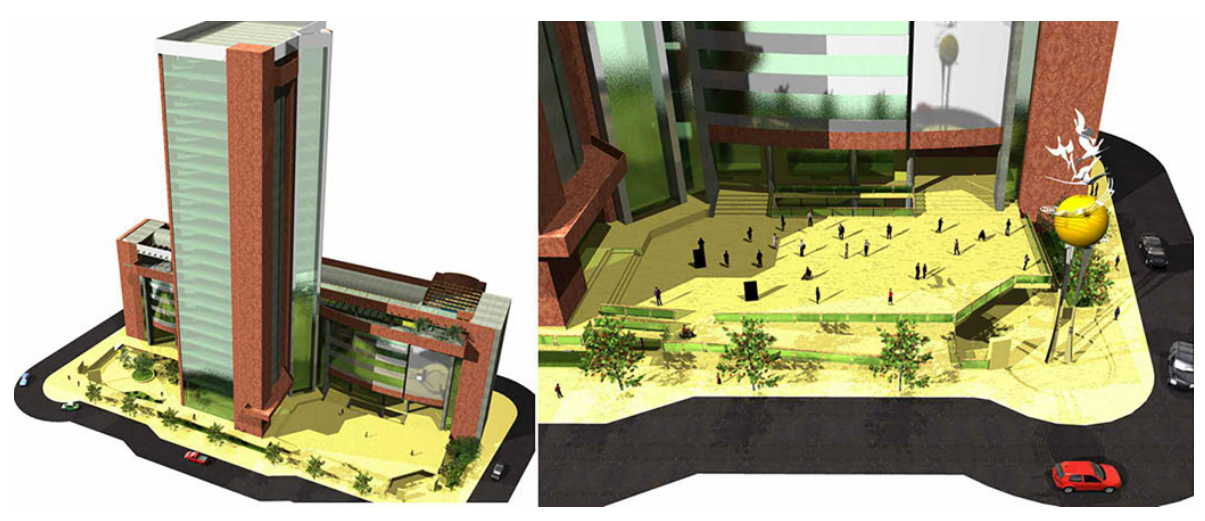

Fuente: Alcaldía de Bello, 2012

El predio de la plaza de mercado es reconocido como un área estratégica para el crecimiento urbano, debido a: su centralidad en el municipio, cercanía al parque principal y proximidad a la estación del metro. Lo que la convierte en un predio fascinante para la edificación de proyectos inmobiliarios. Por ello, según exconcejal (comunicación personal, abril 2019), la administración local en su interés por favorecer al capital privado sobre las demandas de comerciantes y usuarios, no tiene planeado reconstruir o potencializar, como lo exige el fallo judicial. Contrario a ello, anhela llevar a cabo en este predio un proyecto comercial e inmobiliario, ligado a las nuevas concepciones arquitectónicas concebido desde el año 2012. Estas afirmaciones son reforzadas por el excandidato a la alcaldía del municipio 2019, quien sostiene que el proyecto ya fue planificado de manera confidencial, aun cuando no se ha obtenido un nuevo dictamen judicial (comunicación personal, noviembre 2019). El proyecto «Plaza Centro» que se pretende llevar a cabo en el predio ocupado hoy por la plaza de mercado (ver Figura 3), planea contar con locales comerciales en el primero, segundo y tercer nivel, oficinas y auditorios en el cuarto y quinto. En tanto, el sexto piso está programado para ser una zona de spa, mientras que, desde el séptimo nivel hasta el 24 , se proyecta dedicarlos a la ocupación de vivienda nueva. También cabe añadir, que esta edi- 
ficación contará con parqueaderos y a su vez pretende dedicar locales para la reubicación del comercio de la plaza (Alcaldía de Bello, 2012). Sin embargo, esta última pretensión es cuestionable, ya que estaría en contra de las nuevas lógicas comerciales que se proponen para el predio, puesto que los establecimientos que operan en la plaza responden a la tradición campesina, contrario, a las nuevas demandas que espera atender la administración local con este proyecto.

Además de lo anterior, el proyecto urbanístico propuesto desde el 2012, no ha sido informado ni a la comunidad, ni a los comerciantes que trabajan en la Plaza. Esto lo muestra particularmente en la respuesta de dos de las preguntas del cuestionario (Tabla 1). A la pregunta ¿Conoce usted los proyectos que se van a realizar en la plaza de mercado? De los 138 encuestados entre usuarios y comerciantes, el 72,4\% contestaron no conocer ningún proyecto. A quienes respondieron de manera afirmativa, se confirmó la respuesta, preguntando por el tipo de proyecto. De las 38 personas que respondieron saber del proyecto el 50\% contestó que iba a ser demolida, pero no anunció ningún proyecto en particular. Solo 5 personas de las 38, es decir el 13,1\% mencionó proyecto urbanístico y centro comercial.

Tabla 1. Conocimiento sobre el proyecto Plaza Centro

\begin{tabular}{|l|c|c|}
\cline { 2 - 3 } \multicolumn{1}{c|}{} & SI & NO \\
\hline Comerciantes & 29 & 51 \\
\hline Usuarios & 9 & 49 \\
\hline Total & 38 & 100 \\
\hline \multicolumn{2}{|c|}{ Tipo de proyecto } \\
\hline Demolición & \multicolumn{2}{|c|}{19} \\
\hline Lucro político & \multicolumn{2}{|c|}{2} \\
\hline Remodelación & \multicolumn{2}{|c|}{3} \\
\hline Centro comercial & \multicolumn{2}{|c|}{} \\
\hline Proyecto Urbanístico & \\
\hline
\end{tabular}

Fuente: Elaboración propia

Como consecuencia de lo expuesto, los encuestados manifiestan incertidumbre frente a su futuro en la plaza, puesto que, alrededor del predio se especulan diferentes proyectos, y la administración local no se pronuncia frente a la comunidad. 


\section{CONCLUSIONES}

Se concluye, que el cambio en el uso del suelo establecido en el POT del 2009 produjo un proceso de gentrificación de gran escala en el municipio.

Para 2019, en Bello se vendieron 4.522 unidades de vivienda nueva, principalmente viviendas para población de mayor renta, lo que cuadruplicó la cifra reportada para 2010 y provocó un tránsito de estratos bajos a medios y altos en algunas zonas del municipio, en función de su desarrollo urbanístico y comercial.

La densificación de las nuevas tipologías de vivienda que han incursionado en el municipio logró una transformación del paisaje urbanístico del municipio y produjeron una intensificación del fenómeno inmobiliario, que hoy compromete la permanencia de sitios emblemáticos para la ciudad, como lo es la plaza de mercado.

El nuevo modelo de ciudad que emprende Bello no concibe dentro de su paisaje urbanístico una plaza de mercado tradicional, por ende, la administración local ha empleado el abandono como una estrategia para deshacerse de la infraestructura asentada en este predio, pese a las exigencias del fallo judicial. No obstante, ha recurrido al desalojo como una forma directa de expulsión y clausura de la operatividad del lugar.

Así mismo, la reducción del flujo de usuarios, debido a la actual apariencia de la plaza y el pago de extorsión que los comerciantes enfrentan, ha generado una expulsión indirecta, puesto que, al aumentar el costo de vida se afectan las utilidades de los negocios.

Frente al predio de la plaza se han construido múltiples especulaciones, que han logrado una desinformación en la comunidad respecto a su destino. El, $72,4 \%$ de la población encuestada dice no conocer sobre el proyecto de la plaza, mientras que el porcentaje restante brindó diversas respuestas sobre el futuro del predio.

Bajo este marco y en vinculación con el objetivo de este trabajo, se acierta en la presunción de la plaza de mercado como un espacio percibido, según a la triada de Henri Lefebvre. Y a su vez, se reconoce dicha connotación como producto del cambio en el uso del suelo y el aumento de la renta del mismo.

\section{BIBLIOGRAFÍA}

Alcaldía de Bello (2009). Plan de ordenamiento territorial de Bello. Bello, Antioquia. Recuperado de https://bello.gov.co/index.php/features/nuestrosplanes/item/81-plan-de-ordenamiento-territorial-pot [Consultado: 3 de febrero de 2020].

Alcaldía de Bello (2012). Proyecto Plaza Centro (presentación PowerPoint). [Consultado: 3 de noviembre de 2019]. 
Alcaldía de Bello (2017). Historia del municipio de Bello. Bello, Antioquia. Recuperado de https://bello.gov.co/index.php/styles/ciudad-de-bello/item/85historia-del-municipio-de-bello [Consultado: 14 marzo de 2019].

Área metropolitana Valle de Aburrá (2019). Historia. Valle de aburrá, Colombia. Recuperado de:

https://www.metropol.gov.co/area/Paginas/somos/Historia.aspx [Consultado: 3 de febrero de 2020].

Arendt, A. (2003). La condición humana. Estados Unidos: University of Chicago Press.

Ciro, B. (16 de enero de 2019). Desalojamiento en la plaza de mercado de Bello. El colectivo. Recuperado de:

https://elcolectivocomunicacion.com/2019/01/16/desalojo-en-la-plaza-demercado-de-bello/ [Consultado:7 de noviembre de 2019].

Colombia. Congreso de la República, Ley 472. (5, agosto, 1998). Por la cual se desarrolla el artículo 88 de la Constitución Política de Colombia en relación con el ejercicio de las acciones populares y de grupo y se dictan otras disposiciones. Recuperado de:

http://www.secretariasenado.gov.co/senado/basedoc/ley_0472_1998.html. [Consulta: 01 de noviembre de 2019).

Corporación Semiosfera, (s.f). Historia de Bello. Bello, Antioquia. Recuperado de http://www.semiofera.org.co/bello/historia.htm [Consultado: 19 marzo de 2019].

García, P. (2019). Bello dinamiza y potencia el desarrollo de Antioquia. Camacol Antioquia. Recuperado de https://www.camacolantioquia.org.co/bellodinamiza-y-potencia-el-desarrollo-de-antioquia/ [Consultado: 13 febrero de 2019]

Hernández Cordero, A. (2017). Los mercados públicos: espacios urbanos en disputa. Universidad Autónoma Metropolitana Iztapalapa, Ciudad de México.

Herrera, V. (13 de noviembre de 2018). Disturbios tras desalojo de plaza de Mercado en Bello. El Colombiano. Recuperado de https://www.elcolombiano.com/antioquia/desalojo-de-plaza-de-mercado-de-bello-antioquiaDB9650162 .[Consultado: 7 de febrero de 2020].

Informe inmobiliario (2019). Informe inmobiliario proyectos vis. Mercadeo en Internet SAS. Recuperado de https://informeinmobiliario.com/proyectosmi-casa-ya-vivienda-subsidio/5/espl/. [Consultado: 18 enero de 2020].

Lefebvre, H. (1974). La producción del espacio. Madrid: Capitan Swing.

Ministerio del Interior (2013). Definición área metropolitana. Recuperado de https://www.mininterior.gov.co/content/area-metropolitana. [Consulta: 19 de noviembre de 2019)

Óptima (2019). ¿Por qué invertir en Bello? Óptima vivienda y construcción. Recuperado de https://www.optima.com.co/por-que-invertir-en-bello/. [Consultado: 30 enero de 2020] 
Pareja, D. (21 de julio de 2014). Bello sube el estrato de las viviendas y es exitoso en inversión. El Tiempo. Recuperado de https://www.eltiempo.com/archivo/documento/CMS-14278536 [Consultado: 3 de febrero de 2020].

Politécnico Colombiano Jaime Isaza Cadavid (2016). Caracterización socioeconómica de los comerciantes ocupantes de la plaza de mercado municipio de Bello, Y los ocupantes del entorno de la plaza. (Tesis inédita). Politécnico Colombiano Jaime Isaza Cadavid, Medellín, Antioquia.

Restrepo, E. (2012). Crecimiento urbano y especulación inmobiliaria en Bello, 2000-2012. Revista centro histórico de Bello. Vol. (14), 61-74. Recuperado de https://centrodehistoriadebello.org.co/huellas-de-ciudad-numero-14.

Smith, N. (2012). La nueva frontera urbana-ciudad revanchista y gentrificación. Madrid: Traficantes de sueños.

Suárez, V. (17 de agosto de 2019). Bello, el nuevo horizonte para vivir en el Aburrá. El Colombiano. Recuperado de:

https://www.elcolombiano.com/negocios/economia/pese-a-inseguridadbello-es-atractivo-para-vivir-OG11428978 [Consultado: 3 febrero de 2020].

Universidad Nacional de Colombia. (2015). Mitigación del riesgo en la plaza de mercado del municipio de Bello (Tesis inédita). Universidad nacional de Colombia, Medellín, Antioquia. 



\title{
LOS MISMOS VECINOS, ELECCIÓN DE PREFERENCIA PARA UNA NUEVA UBICACIÓN EN LA REPOSICIÓN DEL BARRIO LAS REHOYAS-ARAPILES \\ (LAS PALMAS DE GRAN CANARIA)
}

\author{
THE SAME NEIGHBORS, CHOICE OF PREFERENCE FOR A NEW \\ LOCATION IN THE REPOSITION OF THE NEIGHBORHOOD LAS REHOYAS-ARAPILES \\ (LAS PALMAS DE GRAN CANARIA)
}

Federico E. GonZÁlez-RAmírez

Universidad de Las Palmas de Gran Canaria

\section{Resumen}

El barrio de Las Rehoyas-Arapiles, integrado por 2.558 viviendas, con una estructura original de principios de los años 60 del pasado siglo y dentro de un área estadística vulnerable, es el mayor proyecto de reposición de vivienda que se pretende ejecutar en la ciudad de Las Palmas de Gran Canaria. En este contexto, las prácticas de planificación participativas adquieren relevancia como instrumento de intervención, motivo por el que llevamos a cabo un estudio sobre las expectativas residenciales de sus moradores para el Ayuntamiento de la ciudad. El objetivo de esta comunicación se centra en mostrar las preferencias y prioridades vecinales sobre su propia ubicación y la conformación del nuevo barrio, para lo que usamos una metodología cualitativa —entrevistas semiestructuradas y narraciones conjuntas-. La contigüidad con los mismos vecinos es, junto a la ocupación de la misma zona en el interior del barrio, con cinco sectores diferenciados, la elección de preferencia de los habitantes de este entorno sociourbano.

Palabras clave: sociología del espacio, política habitacional, estudios urbanos, participación ciudadana, vulnerabilidad urbana.

\section{Abstract}

The neighborhood of Las Rehoyas-Arapiles, integrated by 2,558 households, whose original structure was designed in the early 60's of the past century and placed into a statistically vulnerable area, it is the biggest project of household replacement that is going to be developed in the city of Las Palmas de Gran Canaria. In this context, the participative planification practices acquire relevance as an intervention tool, which is the reason why we develop, for the Town Hall of the city, a study about the residential expectations of the dwellers. Using qualitative methods (semi-structured interviews and joined narrations), this article is focused on showing the preferences and priorities of the neighbors about the location and the structuring of the new neighborhood. The contiguity with the same neighbors and the location in the same area 
of the neighborhood are, with five differentiated sectors, the preferent election of the inhabitants of this socio-urban environment.

Keywords: sociology of space, housing policy, urban studies, citizen participation, urban vulnerabity.

\section{INTRODUCCIÓN}

El barrio de Las Rehoyas-Los Arapiles, en Las Palmas de Gran Canaria, es objeto de un proceso de renovación integral «a la vista del deterioro generalizado que se aprecia» debido «a la deficiente calidad de los materiales con que se construyeron las viviendas, así como a la falta de planificación urbanística en los trazados viarios» (Resolución de 20 de diciembre de 2017, de la Dirección General de Arquitectura, Vivienda y Suelo) según se justifica en el convenio establecido entre el Ministerio de Fomento, la Comunidad Autónoma de Canarias y el Ayuntamiento de Las Palmas de Gran Canaria.

La reforma de este entorno se plantea desde hace años, como consecuencia de su catalogación como Área Estadística Vulnerable por el Observatorio de la Vulnerabilidad Urbana, del Ministerio de Fomento, junto al barrio colindante de El Polvorín, cuyo proceso de reposición, iniciado en 1992, concluyó en 2009 (Gago Vaquero, 2010). Las Rehoyas-Arapiles constituye un Área Diferenciada (ficha estadística Las Rehoyas 35016009. Catálogo 2001) de esa Área Estadística Vulnerable, y así consta en el Plan General de Ordenación Urbana de Las Palmas de Gran Canaria de 2012 (APR-01).

Como consecuencia de ese proceso de reforma, la institución municipal ha abordado a lo largo de los años sucesivos estudios, como la encuesta realizada sobre población y vivienda y contenida en la diagnosis sobre el perfil sociourbano del entorno (Geursa, 2013). En 2012, Las Rehoyas fue objeto de un Taller Internacional de Diseño Urbano con la participación de la Universidad de Las Palmas de Gran Canaria, Universidad Europea de Madrid y Universidad de Pensilvania, en el que se reflexionó sobre la necesidad de que no fuera sometido a la cirugía del urban renewal, y se optara por un proceso de regeneración urbana, dado que «Las Rehoyas representa una oportunidad de actuación alternativa al fallido resultado del urban renewal, a partir de la articulación de un proceso que vaya regenerando el lugar con el tiempo, ofreciendo la posibilidad de prosperar de manera sostenible» (Barnett, 2017, 10).El debate entre reposición y regeneración urbana se planteaba debido a que «la destrucción y reinvención total de este tipo de proyecto fallido o venido a menos es una solución tentadora, pero, en esencia, sería caer en el mismo error al desconocer la memoria física y cultural, por imperfecta que ésta sea» (Gouverneur y Grauer, 2017, 153). El último convenio entre Administraciones certifica la reforma integral para Las Rehoyas que, al igual que en El Polvorín, garantiza la permanencia de los vecinos en el mismo territorio y a la vez su- 
pone la modificación de la morfología actual del barrio. El desarrollo del informe cualitativo de diagnosis sobre expectativas vecinales sobre esa reforma integral del barrio (González Ramírez, 2017), algunos de cuyos resultados parciales recoge este artículo, elaborado de forma paralela a la firma del convenio, ha permitido explorar en aquellos aspectos que ofrecían reticencia a la opción de la reforma integral, dado que «sus residentes y usuarios aún mantienen vínculos emocionales con el barrio y, probablemente, se resistirían a su demolición y su desplazamiento hacia otro emplazamiento» (Gouverneur y Grauer, 2017, 153).

Los resultados de la investigación cualitativa aportan análisis y herramientas para la conciliación entre esos futuros desplazamientos, propiciados por la reposición, y la conservación de los vínculos vecinales diagnosticados. Posteriormente, se desarrollaron dos investigaciones cuantitativas (Geursa, 2017, 2018) para una diagnosis integral.

\section{CONCIENCIA ESPACIAL Y GEOGRAFÍA AFECTIVA: LA RECIPROCIDAD VECINAL}

La aportación de las preferencias vecinales a la conformación de su nuevo entorno sociourbano excede las necesidades funcionales de un diagnóstico de nuevas condiciones de habitabilidad. La interpretación de esas preferencias, y el proceso de la propia investigación, requiere del apoyo conceptual de la imaginabilidad de la ciudad de Lynch (1998), del derecho de apropiación lefebvriano (1975), de la conciencia espacial y los conceptos de redistribución y reciprocidad de Harvey (2007), y del "giro afectivo» de las ciencias sociales categorizado por Clough (2010).

La indagación en la nueva morfología del futuro barrio se encuentra estrechamente vinculada a la preservación y la reconstrucción de la identidad del entorno y de sus habitantes, y del significado que conceden a su nueva ubicación, los tres pilares conceptuales seminales de la percepción geográfica —estructura, identidad, significado- (Lynch, 1998) y su cristalización: la imaginabilidad del nuevo barrio, por parte de sus propios vecinos, aunque en virtud de procesos sociales ya existentes.

Esa imaginabilidad del nuevo espacio está imbricada con los derechos de actividad participante - el derecho de obra-y de apropiación — de reapropiación, en este caso- que conforman el derecho a la ciudad lefebvriano (Lefebvre, 1975, 159): Ios habitantes producidos de Las Rehoyas-Arapiles, vecinos de viviendas de producción pública que, sesenta años después, intervienen en la conformación de su nuevo barrio.

La decisión de mantener a los habitantes de un área vulnerable, y en origen situado en el margen de la ciudad, pero ahora reubicados en una mayor centralidad como consecuencia de la dinámica urbana, supone una fractura de las relaciones de intercambio de mercado de una sociedad capitalista. Una reposición que dota de nueva vivienda a las familias en el mismo territorio, 
pero en una relación mejorada de su comunicación con el resto de la ciudad, y establece una redistribución del ingreso en coherencia con «los programas de política social (que) se elaboran como intentos de mantener una distribución dada del ingreso dentro de un sistema social» (Harvey, 2007, 48).

Una redistribución que puede conducir a la paradoja que supone que «mecanismos ocultos de redistribución del ingreso normalmente aumentan las desigualdades en lugar de reducirlas» en "un complejo sistema urbano» (Harvey, 2007, 49): en este caso, mecanismos ocultos que pudieran cristalizar en procesos de interacción social interrumpidos, pese a las nuevas viviendas y sus mejores condiciones de habitabilidad, ante los que la perspectiva vecinal opondrá un segundo elemento equilibrador del intercambio de mercado, la reciprocidad, entendida como sentido de comunidad (Harvey, 2007, 294). La arquitectura conceptual que establece Harvey se sustenta en la capacidad para una conciencia espacial, una imaginación geográfica: la ecuación de la imaginación sociológica de Mills (1959) —la capacidad del individuo para entender su vinculación con su tiempo histórico y sociedad-para la resolución de incógnitas individuales y sus dimensiones sociales, es transformada en imaginación geográfica, con la adición del término espacial a la ecuación por parte de Harvey (2007). Esa conciencia espacial permite interpretar los hallazgos de la investigación entendiendo, como hace Harvey, la ciudad «como un complejo sistema dinámico en el cual las formas espaciales y los procesos sociales se encuentran en continua interacción» (41).

Una interacción que propicia nuevos significados, un marco de «relaciones significativas» que conducen a un «espacio social» que «está compuesto por un conjunto de sentimientos, imágenes y reacciones con respecto al simbolismo espacial que rodea al individuo. Cada persona, según parece, vive en su propia red de relaciones espaciales personalmente construidas» (28).

Como advierte Harvey, ese espacio social de relaciones significativas, que concede significado simbólico al espacio, está mediado por un complejo de procesos cognoscitivos. Pero, consideramos, no solo cognoscitivos. El análisis de las expectativas vecinales se encuentra inmerso en el «giro afectivo» que advierte Clough (2010) en las ciencias sociales, y presentes en los análisis de la afectividad como vector explicativo del tejido social (Massumi, 1995; Brennan, 2004; Ahmed, 2015), en relación a lo íntimo y los lazos sociales como vínculos problemáticos en la teoría social (Baumann, 2008; Illouz, 2007, 2009; Hochschild, 2008) o la dimensión afectiva de la vida pública (Macón, 2013). El establecimiento de una "geografía afectiva» (Depetris, 2019) introduce como categoría de análisis los vínculos sociales sustentados en los afectos generados por las prácticas espaciales compartidas (12). 


\subsection{VIVIENDA MÍNIMA, Y POBLACIÓN ENVEJECIDA Y DEPENDIENTE}

El barrio de Las Rehoyas-Los Arapiles comenzó a construirse en 1961, sin proyecto de trazado viario, ni proyecto de urbanización, ni Plan de Ordenación (Cerpa, 2017). Está integrado por 2.558 viviendas, integrando el ámbito geográfico APR-01 del Plan General de Ordenación de Las Palmas de Gran Canaria de 2012 (Áreas Diferenciadas) (Figura 1). Este Área Diferenciada conforma, junto a El Polvorín, y como se señaló, el Área Estadística Vulnerable determinado por el Observatorio de la Vulnerabilidad Urbana. Esta investigación aborda solo el Área Diferenciada, y no el Área Estadística Vulnerable. Las viviendas se distribuyen en cinco sectores en el interior del propio barrio: Martín Cobos (885 viviendas), Patronato del Aire (96 viviendas), Nuestra Señora de la Paz (500 viviendas), Grupo 322 (326 viviendas) y Grupo 720 (751 viviendas) (Figura 2).

\section{Figura 1. Ámbito geográfico Área Diferenciada APRO1 Las Rehoyas-Arapiles}
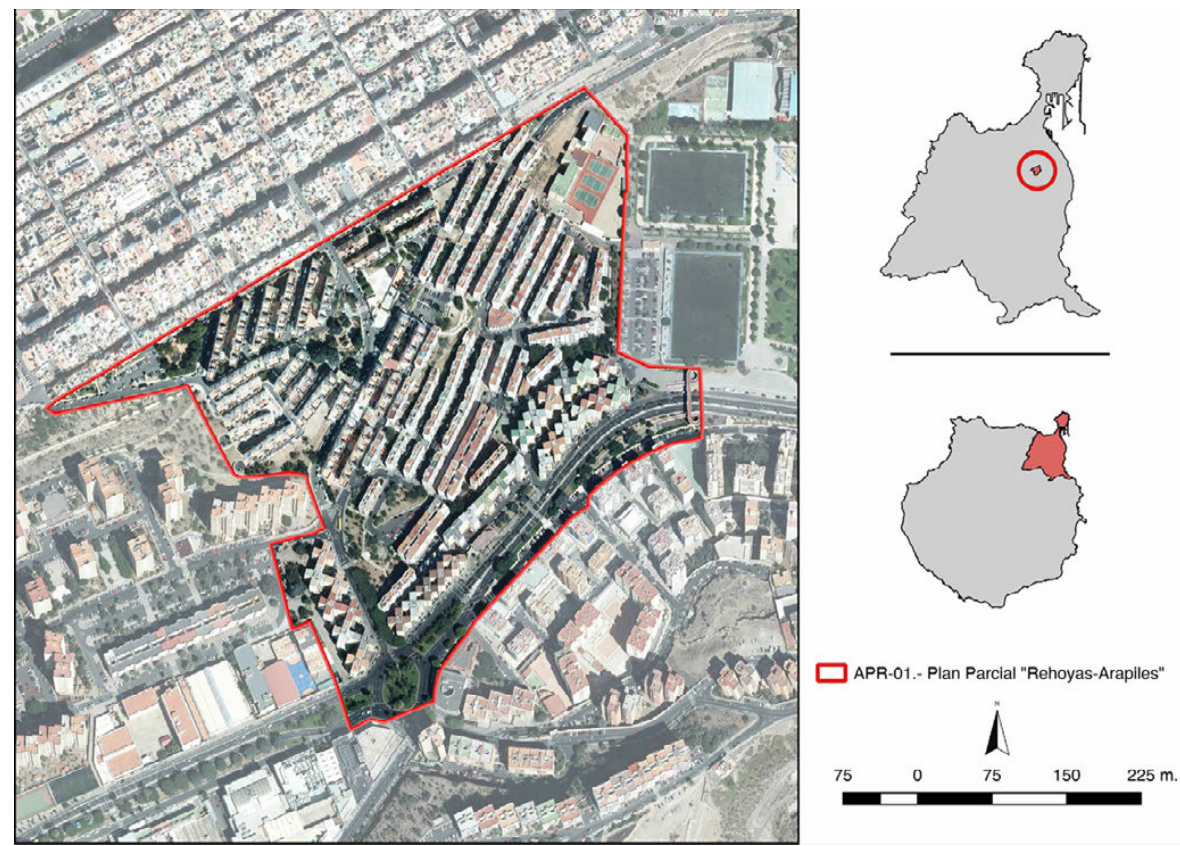

Fuente: A partir de Servicio de Urbanismo del Ayuntamiento de LPGC.

Autor: Jordi Boldú Hernández 


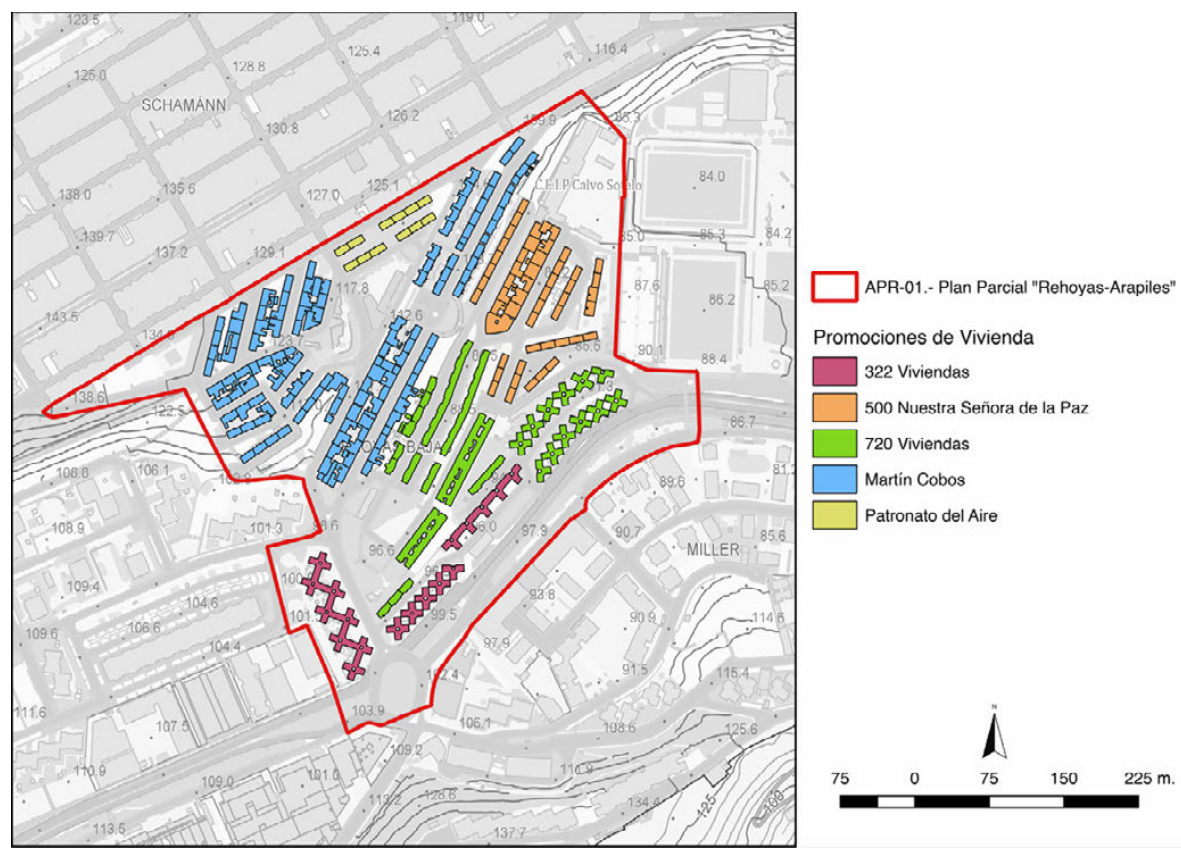

Fuente: A partir de datos del Servicio de Urbanismo del Ayto. de LPGC y Dirección General del Catastro. Autor: Jordi Boldú Hernández

La categorización de las viviendas de Las Rehoyas se corresponde con la vivienda mínima impulsada desde la Carta de Atenas y el II Congreso Internacional de Arquitectura Moderna (CIAM), de 1929 (Aymonino, 1976) en el que las transformaciones demográficas y sociales exigían la búsqueda de soluciones habitacionales racionales masivas, apoyadas además en una incipiente disciplina sociológica (Gropius, 1976). Una vivienda mínima que suponía un «instrumento social indispensable« en su momento histórico (Le Corbusier y Jeanneret, 1976, 126-138).

En el caso de Las Rehoyas, esas 2.558 viviendas se distribuyen en dos variantes tipológicas: el $77 \%$ en bloques de hileras de 4 y 5 plantas, con 2 viviendas por planta y escalera central. El resto, con bloques en cruz, de 5 plantas y escalera central, y con 3 o 4 viviendas por planta. Pero todas ellas con una superficie útil de 40,30 $\mathrm{m}^{2}$, la expresión de esa vivienda mínima: un salón de 10,50 $\mathrm{m}^{2}$, cocina de 5,5 $\mathrm{m}^{2}$, baño de 2,20 $\mathrm{m}^{2}$, dormitorio principal de $9 \mathrm{~m}^{2}, \mathrm{y}$ dos dormitorios secundarios de $6 \mathrm{~m}^{2}$. Las zonas comunes son un portal de $10,5 \mathrm{~m}^{2}$ y una escalera de $0,80 \mathrm{~m}^{2}$ de ancho (Cerpa, 2017, 37). 
La escasa dimensión habitacional, junto a otras características, ya habían propiciado que el Plan General de Ordenación Urbana de la ciudad, desde el año 2000, categorizara a Las Rehoyas como Área de Sustitución, dado que lo definía como «barrio con un modelo de ocupación del suelo con escasas posibilidades de desarrollo, alta densidad de viviendas, déficits de equipamientos para albergar las actividades de ocio y relación, con mantenimiento de la construcción y con escasos metros cuadrados por vivienda para los mínimos estándares de habitabilidad al uso» (Cerpa, 2017, 38).

Características que hacían que se optara «por una operación de sustitución de las viviendas si lo que queremos es aportar soluciones definitivas para este barrio» (38).

El perfil vecinal se corresponde con una población mayoritariamente femenina, dependiente y con una dilatada permanencia en el barrio. El 64,35 de sus habitantes es mujer, por 35,7\% de hombres. El 33,7\% de los vecinos tiene más de 65 años, y un 20\% entre 55 y 64 años. El 13\%, entre 18 y 34 años. Lo que se corresponde con el hecho de que un 34\% de los vecinos llegó al barrio entre 1960 y 1970, un 12,7\% entre 1970 y 1980.

A este perfil de población envejecida se añade su dependencia: el $43 \%$ es pensionista, un $13 \%$ desempleado, y un 5\% son amas de casa. Entre quienes trabajan, el $26 \%$ lo hace por cuenta ajena, un $9 \%$ son funcionarios, un $4 \%$ autónomos (Geursa, 2017).

\section{METODOLOGÍA}

La investigación se desarrolló mediante entrevistas semiestructuradas, realizadas entre el 25 de septiembre y el 19 de octubre de 2017. La estructura de ese guion abierto se sustentaba en tres dimensiones de evaluación: características de los vecinos del barrio, de las viviendas, y las del propio barrio. Algunas de las preguntas contenidas en esas tres dimensiones fueron extraídas de las cuestiones planteadas en un documento previo por parte de la Plataforma Vecinal Las Rehoyas-Arapiles (2017).

Dada la naturaleza de la investigación, de financiación institucional, a ese guion se incorporaban tres preguntas precisas, requeridas para la adopción de decisiones públicas, una de las cuales era: «¿Le importaría, preferiría o rechaza trasladarse a una nueva vivienda en otro barrio?». Su objetivo era explorar las preferencias por cambiar de barrio ante la imposibilidad de que todas las familias pudieran contar con una nueva vivienda en Las Rehoyas, una vez culminada la reposición.

Se realizaron 25 entrevistas a 32 vecinos. La diferencia entre entrevistas y entrevistados se debe al desarrollo de algunas mediante la técnica de narraciones conjuntas. Se distribuyeron, para una mayor representatividad, entre los 5 sectores del barrio: Grupo Martín Cobos (34,60\% de las viviendas y 44\% de las entrevistas); Patronato de Aviación (3,75\% de las viviendas, 8,00\% de las 
entrevistas); Nuestra Señora de la Paz más Grupo 720 viviendas (48,91\% de las viviendas, 44,00\% de las entrevistas); y Grupo de 322 viviendas (12,74\% de las viviendas, 4,00\% de las entrevistas) (Tabla 1). Además, se realizaron 11 entrevistas a agentes sociales e institucionales.

Tabla 1. Entrevistas por número de viviendas (por sector)

\begin{tabular}{|c|c|c|c|c|c|}
\cline { 2 - 6 } \multicolumn{1}{c|}{} & $\begin{array}{c}\text { SECTOR 1 } \\
\text { (MARTÍN } \\
\text { COBOS) }\end{array}$ & $\begin{array}{c}\text { SECTOR 2 } \\
\text { (PATRONATO } \\
\text { DE AVIACIÓN) }\end{array}$ & $\begin{array}{c}\text { SECTORES 3-4 } \\
\text { (NTRA SRA. DE LA } \\
\text { PAZ+GRUPO 720) }\end{array}$ & $\begin{array}{c}\text { SECTOR 5 } \\
\text { (GRUPO 322) }\end{array}$ & TOTAL \\
\hline $\mathbf{N}$ & 11 & 2 & 11 & 1 & 25 \\
$\%$ & 44,00 & 8,00 & 44,00 & 4,00 & 100,00 \\
\hline $\begin{array}{c}\% \\
\text { BARRIO }\end{array}$ & 34,60 & 3,75 & 48,91 & 12,74 & 100,00 \\
\hline
\end{tabular}

Fuente: Elaboración propia

La elección de entrevistados fue aleatoria, representativa en virtud de zona de residencia en el barrio, género y cohorte de edad, con datos del censo de población de Las Palmas de Gran Canaria de 2011. Un 34,38\% de los entrevistados son hombres (cuando supone un $48,17 \%$ de la población del barrio) y un 65,62\% mujeres (cuando su presencia en el barrio es del 51,83\%). Esta mayor representación femenina se corresponde con el sesgo de género en la proclividad a participar de la investigación (Tabla 2).

Tabla 2. Entrevistas (por género)

\begin{tabular}{|c|c|c|c|}
\cline { 2 - 4 } \multicolumn{1}{c|}{} & HOMBRE & MUJER & $\mathbf{N}$ \\
\hline $\mathbf{N}$ & 11 & 21 & 32 \\
$\%$ & 34,38 & 65,62 & 100 \\
\hline$\%$ BARRIO & 48,17 & 51,83 & 100 \\
\hline
\end{tabular}

Fuente: Elaboración propia

En relación a las cohortes de edad, todos los grupos se encuentran representados, excepto en el caso de los hombres (15-20, 20-24, 30-34, y 40-44 años), en correspondencia con esa dificultad para su participación en las entrevistas. Las cohortes de edad de 40-44 años y 55-59 años han quedado sobrerrepresentadas, en virtud de las condiciones referidas.

El diseño muestral de la investigación cuantitativa vinculada, realizada con posterioridad (Geursa, 2017), y que sirve de elemento de replicabilidad del estudio cualitativo, se desarrolló también en virtud de 2.558 viviendas y 6.395 vecinos del censo de 2011. Se realizaron 300 encuestas, con un error muestral 
del $\pm 5,32 \%$ en viviendas y el $\pm 5,52 \%$ en cuanto a vecinos del barrio, y un nivel de confianza del $\pm 95,5 \%$. Un segundo estudio cuantitativo fue realizado por el propio Servicio de Urbanismo del Ayuntamiento de Las Palmas de Gran Canaria, con trabajo de campo entre el 19 de septiembre y 19 de diciembre de 2018. Se entrevistó a 2.103 titulares (el 82,21\%) de las viviendas del barrio.

\subsection{ANÁLISIS: TEORÍA FUNDAMENTADA Y MÉTODO DEL ENCUADRE}

El análisis cualitativo se ha desarrollado mediante las premisas de la Teoría Fundamentada (Glaser y Strauss, 1967), sin hipótesis previas y con una categorización derivada del trabajo de campo. La estructura de esas categorías emergentes, para su ordenamiento, se ha realizado mediante la adaptación (González Ramírez, 2015) del método del encuadre (Entman, 1993), con una disposición binaria de diagnosis (evaluación) y pronósticos (expectativas) derivada del análisis de las entrevistas.

Ese análisis estableció 17 categorías. Seis de diagnosis: percepción del barrio, estado de la vivienda, ocupación ilegal de viviendas, convivencia, centro de salud, y limpieza e higiene del entorno. Otras ocho categorías que combinan diagnosis y pronósticos: comunidad de propietarios, movilidad, instituciones educativas y culturales parque de Las Rehoyas, seguridad, aparcamientos, comercios y seguridad ciudadana.

Otras cuatro categorías de pronósticos: modelo de barrio, ubicación en el nuevo barrio, traslado a otro barrio y futuras viviendas. De ese análisis - desarrollado con el apoyo del software Atlas.ti, en su versión 6.0.16.- nos centramos en los resultados de los pronósticos vecinales sobre ubicación en el nuevo barrio y traslado a otro entorno urbano.

\section{RESULTADOS}

La contigüidad con los mismos vecinos es, junto a la ocupación de la misma zona en el interior del barrio, con cinco sectores diferenciados, la elección de preferencia de los habitantes del entorno sociourbano Las Rehoyas-Arapiles, en Las Palmas de Gran Canaria, sujeto a un proceso de reposición. Mujer, con más de veinte años de residencia en el barrio, y que opta por la narración conjunta junto a su familia u otras vecinas, es el perfil del ciudadano que manifiesta esa contigüidad vecinal como elección preferente para su nueva ubicación en el barrio.

El objetivo de la investigación de origen era conocer la preferencia o rechazo respecto de la mudanza a una vivienda en otro barrio de Las Palmas de Gran Canaria, dada la imposibilidad de que Las Rehoyas acogiera, en el futuro, a todos los habitantes actuales. El enunciado de la pregunta era: «¿Le importaría, preferiría o rechaza trasladarse a una nueva vivienda en otro barrio?».

El 43,15\% de los entrevistados (14) manifestó su preferencia por quedarse en 
Las Rehoyas, tras la reposición. Un 15,62\% (5) adujo que les gustaría optar a una nueva vivienda en otro barrio. Un 18,75\% (6) manifestó que estudiaría la posibilidad, en virtud de varios factores (barrio de ubicación de la nueva vivienda, preferentemente). El resto, un $22,48 \%$, prefirió no contestar.

Sin embargo, un 56,25\% de los entrevistados (18) añadió a sus respuestas preferencias respecto de su ubicación en el nuevo barrio, algunas no estrictamente espaciales, y no contempladas de forma implícita en el enunciado de la pregunta. El análisis de sus entrevistas permitió el establecimiento de tres categorías de preferencia:

a. Con los mismos vecinos/Con «buenos» vecinos. Prevalencia de la contigüidad vecinal, con los mismos vecinos o buenos vecinos, ante la posibilidad de una elección estrictamente espacial.

b. En la zona actual. Preferencia por una vivienda en la misma zona en que vive actualmente, reproducida en la nueva morfología del barrio.

c. En una zona distinta. Una tercera opción manifestada fue la de mudarse a una nueva zona dentro del nuevo barrio.

La preferencia por la contigüidad con los mismos vecinos en la elección de la ubicación en el nuevo barrio fue una opción aportada en la investigación por parte de los propios vecinos. No se encontraba implícita en el enunciado de la pregunta del estudio.

Además, los vecinos que en el desarrollo de la entrevista aportaron esa preferencia también pidieron que la entrevista se produjera de manera coral, junto a familiares y vecinos: madre con hija, madre con hija y vecina, y pareja. La investigación añadió, de esta forma, la técnica de la narración conjunta, no prevista inicialmente. La preferencia de contigüidad con los mismos vecinos, de forma preferente a la elección zonal, tiene perfil femenino: siete mujeres y un hombre, del total de 8 vecinos que subrayaron esta preferencia. Esta preferencia emergió en cuatro de las cinco zonas del barrio: Nuestra Señora de la Paz, Grupo 720, Grupo 322, y Patronato de Aviación.

Esas vecinas que añadieron la preferencia de contigüidad vecinal se corresponden con el perfil mayoritario del barrio: mayores de 55 años, y con muchos años de permanencia en el mismo, con anterioridad a 1980.

El análisis del contenido de los relatos vecinales nos permite establecer vínculos entre éstos y dimensiones teóricas relativas a la conciencia espacial:

a. Imaginabilidad (identidad y significado): «deberían tocarnos los mismos vecinos en el mismo bloque, que todos nos llevamos bien, muchos años...», «sí, porque ya son vecinos que conoces de toda la vida».

b. Espacio social: «ay, el bloque, aunque sea que estemos todas juntas», «sí, porque ya son vecinos que conoces de toda la vida».

c. Reciprocidad: "con los mismos vecinos», «espero que nos pongan con la misma gente», "yo el día que las quiten, a mí que me pongan al lado tuya otra vez eh, a mí que no me manden lejos». 
d. Apropiación: «y si es posible con los mismos vecinos», «espero que nos pongan a la misma gente», "sí sería conveniente que quizás se pudiera saber en su momento cuando ya eso se esté, quiénes van a vivir dónde, quiénes han dicho yo quiero esto, quiénes tienen el derecho», «a mí me pone en el barrio donde haya gente tranquila y en paz y que no sea escandalosa y yo me voy tranquila».

El resultado de la investigación invitó a la incorporación de una pregunta específica en la investigación cuantitativa posterior vinculada (Geursa, 2017), que permite la replicabilidad de los resultados cualitativos. En ese estudio, un 55,4\% quiere permanecer en el barrio, y un 38\% estudiaría la posibilidad de aceptar una vivienda en otra zona de la ciudad (p. 40). Del 55,4\% que quiere permanecer en Las Rehoyas, el 13,3\% de los vecinos prefiere estar con sus mismos vecinos, sea cual sea la futura zona del barrio donde deban vivir; y un 67\% prefiere vivir en el mismo lugar del barrio. A un 9\% no le importaría vivir en otras zonas del barrio y con diferentes vecinos.

Un segundo estudio cuantitativo (Geursa, 2018), eludió preguntar por esa variable de contigüidad vecinal, y solo planteó la posibilidad de elegir entre el mismo barrio (el 62,58\%) o en otro barrio (24,49\%) (p. 23). En él, los vecinos ya conocían alternativas precisas y podían elegir entre varias zonas de la ciudad donde podrían estar ubicadas sus nuevas viviendas. Entre ese 62,58\% que prefería quedarse en Las Rehoyas, el 88,07\% prefería quedarse en su misma zona (p. 26), lo que se corresponde con la suma de $67 \%$ y 13,3\% que elegía quedarse en la misma zona y mismos vecinos del estudio anterior.

\section{CONCLUSIONES}

La contigüidad con los mismos vecinos, junto a la ocupación de la misma zona en el interior del barrio, con cinco sectores diferenciados, como elección de preferencia de los habitantes de Las Rehoyas-Arapiles para su futura ubicación tras el proceso de reposición, muestra la emergencia en el proceso de imaginabilidad del nuevo barrio, desde la percepción vecinal, de una estrecha vinculación entre la permanencia en el espacio - en la misma zona del barrio-, la identidad alcanzada y el significado profundo de las relaciones espacial-afectivas construidas: un espacio social compartido.

Un espacio social cuya permanencia debe procurarse en conciliación con el proceso de reposición. La decisión de adoptar la reforma integral por parte de las instituciones es dilatada en el tiempo, desde su consideración como Área de Sustitución en el Plan General de Ordenación Urbana de la ciudad (2000), hasta la confirmación de dicha reforma integral en el convenio institucional (2017). Esa decisión parece avalada por las características del propio barrio señaladas en ambos documentos, y la reposición experimentada —aunque no 
evaluada - del barrio contiguo de El Polvorín, que integra el mismo Área Estadística Vulnerable, culminada en 2010.

Las amenazas para las relaciones y vínculos vecinales preexistentes, advertidas por investigadores que insistían en que se apostara por un proceso de regeneración urbana, y no de reposición, parecen constatarse en las aportaciones vecinales a la investigación.

La conciencia espacial de los vecinos de Las Rehoya, constatado a través de las «relaciones significativas» que emergen en los resultados de la investigación, les permite aunar al proceso de redistribución, impulsado por las políticas públicas - una nueva vivienda, de mejores condiciones de habitabilidad, con la conservación de la centralidad urbana adquirida - los elementos de reciprocidad, de sentido comunitario, construidos en el barrio a lo largo de sesenta años de convivencia. La aportación vecinal de su preferencia por permanecer con los mismos vecinos es una advertencia para los mecanismos ocultos que subraya Harvey en las políticas de redistribución: una nueva y mejor casa podría acabar, de no tenerse en cuenta, con el espacio social construido por los propios vecinos, y generar nuevas formas de desigualdad. El perfil femenino, de mujeres de más de 55 años, con permanencia extensa en el barrio, y que prefieren expresarse mediante narraciones conjuntas, indica la fortaleza de ese espacio social compartido, de sus relaciones significativas, y también de su vulnerabilidad ante políticas públicas de vocación redistributiva.

La aportación de su preferencia por el mantenimiento de los vínculos sociales, y no exclusivamente espaciales, para la construcción del nuevo barrio, y las educadas formas de esa expresión - «y si es posible con los mismos vecinos», «espero que nos pongan a la misma gente», "sí sería conveniente...»muestran la vocación por el ejercicio de los derechos de apropiación y de actividad participante en la conformación del nuevo barrio, por parte de un vecindario que ha experimentado la desigualdad, en su itinerario vital y familiar, mediante la producción de un espacio que se vio abocado a habitar, y de mudanzas que fracturaron sus relaciones sociales previas.

Los argumentos para la expresión de esa preferencia — «porque ya son vecinos que conoces de toda la vida», "que todos nos llevamos bien, muchos años»- permiten constatar la naturaleza de esos vínculos espaciales, temporales y emocionales, y la conformación de una geografía afectiva propiciada por prácticas espaciales de vecindad.

\section{AGRADECIMIENTOS}

El estudio cualitativo Diagnosis sobre Expectativas vecinales para la Reforma Integral de Las Rehoyas-Arapiles (2017) fue financiado por la Sociedad de Gestión Urbanística de Las Palmas de Gran Canaria (Geursa). Las figuras de ubicación y sectorización de Las Rehoyas-Arapiles han sido realizadas por 
el Graduado en Geografía y Ordenación del Territorio Jordi Boldú Hernández, al que expreso mi agradecimiento.

\section{BIBLIOGRAFÍA}

Ahmed, S. (2015). La política cultural de las emociones. México: Centro de Investigaciones y Estudios de Género, UNAM.

Aymonino, C. (ed.) (1976) [1971]. La vivienda racional. Ponencias de los Congresos CIAM 1929-1930, 211-232. Barcelona: Gustavo Gili.

Barnett, J. (2017). Prólogo. En E. Guerra (Ed.), Reconsiderando la renovación urbana. Alternativas para la vivienda pública en Las Palmas de Gran Canaria, pp. 1011. Las Palmas de Gran Canaria: Ayuntamiento de Las Palmas de Gran Canaria.

Bauman, Z. (2008). Amor líquido: Acerca de la fragilidad de los vínculos humanos. Buenos Aires: Fondo de Cultura Económica.

Brennan, T. (2004). The Transmission of Affect. Ithaca: Cornell UP.

Cerpa, J. M. (2017). Las Rehoyas. Crónica de una reposición anunciada. En Guerra, E. (Ed.), Reconsiderando la renovación urbana. Alternativas para la vivienda pública en Las Palmas de Gran Canaria, pp. 32-38. Las Palmas de Gran Canaria: Ayuntamiento de Las Palmas de Gran Canaria.

Clough, P. (2010). The Affective Turn. En M. Gregg. y G. Seigworth (Eds.) The Affect Theory Reader, pp. 206-225. Durham: Duke UP.

Depetris Chauvin, I. (2019). Geografías afectivas. Desplazamientos, prácticas espaciales y formas de estar juntos en el cine de Argentina, Chile y Brasil (2002-2017). Pittsburgh: Latin American Research Commons. DOI: https://10.25154/book3. Licencia: CC BY-NC 4.0.

Entman, R. (1993). Framing: Toward clarification of a fractured paradigm. Journal of Communication, 43 (4), 51-58.

Gago Vaquero, J. L. (2010). El Polvorín. Reposición e historia de un barrio. Las Palmas de Gran Canaria: Ayuntamiento de Las Palmas de Gran Canaria

Geursa (2013). Diagnóstico Social del Barrio de Las Rehoyas-Arapiles 2012 y opinión sobre su reposición. Recuperado de:

https://www.geursa.es/wp-content/uploads/2018/07/INFORME-2012Encuesta-Poblaci\%C3\%B3n-Vivienda-Rehoyas-Arapiles.pdf

Geursa (2017). Diagnosis sobre Expectativas Vecinales para la Reforma de Las Rehoyas-Arapiles. Estudio Cuantitativo. Recuperado de:

https://www.geursa.es/wp-content/uploads/2018/07/informe-2017-diagnosisnecesidades-vecinos-arapiles-rehoyas_opt.pdf.

Geursa (2018). Encuesta de opinión y preferencias para la reposición. Barrio de Las Rehoyas-Arapiles. Recuperado de https://www.geursa.es/wpcontent/uploads/2018/07/Informe-2018-Encuesta-Rehoyas-Arapiles.pdf

González Ramírez, F. E. (2015). Polígono de Jinámar, la isla interior: la producción de espacios sociourbanos y habitus educativos de exclusión (19671987). (Tesis inédita). Universidad de Las Palmas de Gran Canaria. 
González Ramírez, F. E. (2017). Diagnosis sobre Expectativas Vecinales para la Reforma de Las Rehoyas-Arapiles. Estudio Cualitativo. Recuperado en: https://www.geursa.es/wp-content/uploads/2018/07/informe-2017-diagnosisnecesidades-vecinos-arapiles-rehoyas_opt.pdf

Glaser B. G. y Strauss, A. L. (1967). The discovery of grounded theory: strategies for qualitative research. New York: Aldine.

Governeur, D. y Grauer, O. (2017). Soportes paisajísticos. Para una regeneración urbana no violenta. En E. Guerra (Ed.), Reconsiderando la renovación urbana. Alternativas para la vivienda pública en Las Palmas de Gran Canaria, pp. 138-166. Las Palmas de Gran Canaria: Ayuntamiento de Las Palmas de Gran Canaria.

Gropius, W. (1976). Los presupuestos sociológicos de la vivienda mínima (para la población obrera de la ciudad). En C. Aymonino (Ed.), La vivienda racional. Ponencias de los Congresos CIAM 1929-1930, pp. 211-232. Barcelona: Gustavo Gili. Harvey, D. (2007) [1977]. Urbanismo y desigualdad social. (7 ${ }^{a}$ ed.). Madrid: Siglo XXI.

Hochschild, A. (2008). La mercantilización de la vida íntima. Buenos Aires: Katz. Illouz, E. (2007). Intimidades congeladas. Buenos Aires: Katz.

Illouz, E. (2009). El consumo de la utopía romántica. Buenos Aires: Katz.

Le Corbusier y Jeanneret, P. (1976). Análisis de los elementos fundamentales en el problema de de la 'vivienda mínima'. En C. Aymonino (Ed.), La vivienda racional. Ponencias de los Congresos CIAM 1929-1930, pp. 126-138. Barcelona: Gustavo Gili.

Lefebvre, H. (1975) [1967]. El derecho a la ciudad. (3a ed.). Barcelona: Ed. Península.

Lynch, K. (1998) [1960]. La imagen de la ciudad. (3ª ed.). Barcelona: Ed. Gustavo Gili. Macón, C. (2013). Sentimus ergo sumus: el surgimiento del 'giro afectivo' y su impacto sobre la filosofía política. Revista Latinoamericana Filosofía Política II (6), 1-32.

Massumi, B. (1995). The Autonomy of Affect. Cultural Critique, 83-109.

Mills, Ch. W. (2003) [1959]. La imaginación sociológica. México: Fondo de Cultura Económica.

Plataforma Vecinal Las Rehoyas-Arapiles (2017). Una propuesta vecinal para el barrio Rehoyas-Arapiles. Las Palmas de Gran Canaria.

Resolución de 20 de diciembre de 2017, de la Dirección General de Arquitectura, Vivienda y Suelo. Convenio con la Comunidad Autónoma de Canarias y el Ayuntamiento de Las Palmas de Gran Canaria, para la renovación urbana del barrio de Las Rehoyas (Canarias). BOE 317, de 30 de diciembre de 2017, pp. 131050-131054. Recuperado de:

https://www.geursa.es/wp-content/uploads/2018/07/APR01_BOE-2017_ Convenio.pdf 


\title{
¿INTEGRACIÓN SOCIAL Y TERRITORIAL EN CIUDADES FLUVIALES, MARINAS Y LACUSTRES? EFECTOS ESPACIALES EN LAS VIVIENDAS SUBSIDIADAS LITORALES \\ DE LA SERENA, VALDIVIA Y VILLARRICA, CHILE (2000-2018)' \\ SOCIAL AND TERRITORIAL INTEGRATION IN RIVER, MARINE AND LAKE CITIES? \\ SPATIAL EFFECTS ON THE COASTAL SUBSIDIZED HOUSING OF LA SERENA, VALDIVIA AND VILLARRICA, CHILE (2000-2018)
}

\author{
Rodrigo Hidalgo \\ Pontificia Universidad Católica de Chile \\ Laura Rodríguez \\ Universidad Austral de Chile \\ Voltaire Alvarado \\ Universidad Academia de Humanismo Cristiano (Chile) \\ Federico Arenas \\ Pontificia Universidad Católica de Chile
}

Resumen

Las actividades turísticas en ciudades lacustres, fluviales y marinas silencian procesos de transformación espacial basados en la integración social y territorial, principalmente por su rol en el sostenimiento de las economías locales. En las áreas urbanas de La Serena, Valdivia y Villarrica, el impulso a la vivienda subsidiada ha ido progresando conforme se densifican las actividades de amenidad y ocio. Las nuevas políticas de subsidios impactan en la formación de un entorno turístico próspero a la vista de quienes disfrutan de sus amenidades. Sin embargo, ¿ha sido efectiva la integración social y territorial en las ciudades mencionadas?, ¿existe una diferenciación geográfica que deba ser reclasificada desde su condición de sitio y emplazamiento?

A partir de la recopilación de datos de subsidios habitacionales ejecutados para las ciudades en estudio, entre 2000 y 2018, se propone un ejercicio singularizado para las trayectorias y situación de integración acontecería, en menor o mayor grado, de la mano con el impulso turístico durante el mismo periodo. Se problematizará el concepto de integración que exponen los instrumentos subsidiarios, a partir de las posibles limitaciones y resultados existentes frente a la ejecución de estas políticas.

Palabras clave: integración subsidiaria, ciudades fluviales, marinas y lacustres, turismo y desarrollo urbano local.

1 Esta comunicación forma parte del trabajo realizado en FONDECYT 1191555 «La producción de vivienda subsidiada en ciudades fluviales, marinas y lacustres en Chile: integración y sostenibilidad 2000-2017». 


\section{Abstract}

Tourism activities in lake, river and marine cities silence spatial transformation processes based on social and territorial integration, mainly due to their role in sustaining local economies.

In the urban areas of La Serena, Valdivia and Villarrica, the drive for subsidized housing has been progressing as amenity and leisure activities have become denser. The new subsidy policies impact on the formation of a prosperous tourist environment in full view of those who enjoy its amenities. However, has social and territorial integration been effective in the aforementioned cities? Is there a geographical differentiation that must be reclassified from its status as site and location?.

Based on the collection of data on housing subsidies executed for the cities under study, between 2000 and 2018, a singular exercise is proposed for the trajectories and integration situation that would occur, to a lesser or greater degree, hand in hand with the tourist impulse during the same period. The concept of integration that the subsidiary instruments expose will be problematized, based on the possible limitations and existing results in the face of the execution of these policies.

Keywords: subsidiary integration, river, marine and lake cities, tourism and local urban development.

\section{INTRODUCCIÓN}

Las actividades turísticas en Chile se han consolidado dentro de la proyección económica en el país, con un 3,3\% del PIB para 2017². Desde 1990 a la fecha, las cifras de ingreso al país con motivos turísticos han aumentado sin detenciones significativas, aún considerando los impactos de las dos grandes crisis globales de 1998 (asiática) y 2008 (subprime). Esto ha expandido la oferta de vuelos locales, la optimización de los aeropuertos regionales y la mejora en la capacidad hotelera y de hospedaje en general, específicamente en los destinos más atractivos: San Pedro de Atacama y Torres del Paine. Si en 2001 ingresaban 1.759.962 turistas extranjeros, en 2016 el número llegaba a 5.640.700 visitantes (SERNATUR, 2017).

Por otro lado, el acceso de turistas fuera de la región manifiesta patrones históricos de movilidad por amenidad transfronteriza. Es el caso de veraneantes procedentes de las próximas ciudades argentinas de San Juan, Mendoza, San Rafael, Neuquén, Zapala y Río Gallegos, que aportan más de la mitad de los

2 Subsecretaría de Turismo y Recreación. Disponible en:

http://www.subturismo.gob.cl/wp-content/uploads/2017/12/16_Sintesis_nacional.pdf (Consultado 19 de marzo de 2020). 
visitantes estivales, llegando a 3.016.124 en 2016 (SERNATUR, 2017). La estacionalidad de estas visitas se localiza de preferencia en los meses de diciembre y enero, mientras que los visitantes locales se desplazan a las principales ciudades litorales chilenas en el mes de febrero. Estos datos tienen una relevancia sustantiva para reconocer las adaptaciones del mercado de alquileres estacionales, la oferta de tiempos compartidos $u$ otros nichos de la actividad de amenidad, algunos incipientes dentro de la economía chilena.

Por turísticas que se tipifiquen, estas ciudades mantienen una vida urbana proyectada por sobre los meses estivales. La tensión que propone abordar la presente comunicación está situada particularmente en los procesos residenciales que, por obliterados que parecieran, siguen generándose en los espacios urbanos de las grandes ciudades turísticas de Chile. Si bien el turismo puede convertirse en una clave para el desarrollo local y la gestión de economías de escala, también debe observarse en ellas que las políticas habitacionales se instalan en medio de la convergencia de las amenidades de playa-sol, culturales, gastronómicas, entre otras.

Los casos de estudio, situados en La Serena, Valdivia y Villarrica comparten una característica morfológica excepcional, que define su emplazamiento y evolución de situación urbana. Los cuerpos de agua convocan el interés por el desarrollo turístico, en medio de las demandas por vivienda. Lo mismo acontece con el tipo de proyectos habitacionales producidos, las orientaciones políticas e ideológicas que se plasman en ellos y la relevancia que tienen los resultados espaciales de los ajustes políticos bajo dos paradigmas hoy transversales en la gestión de la vivienda en Chile: la integración social y territorial.

Para estas ciudades, esta comunicación discutirá la progresión de proyectos habitacionales subsidiados durante el periodo entre 2000 y 2018 . Esta franja de tiempo contiene un cambio de base en la forma que se entiende el concepto de vivienda social en la política chilena, pasando de una orientación próxima a la teoría de los «con techo» (Rodríguez y Sugranyes, 2004), para avanzar durante las primeras décadas del siglo XX a una idea de vivienda subsidiada de mayor valor material y relacional. El propósito es discutir la orientación política de integración social y territorial en estos espacios marinos, fluviales y lacustres con énfasis en la relación que su vocación turística tiene frente al desarrollo de promovidas políticas espaciales pensadas desde la justicia espacial.

El plan del escrito contempla la presentación de la metodología de captura y construcción de la información espacial, para luego dar paso a una discusión teórica centrada en los ejes de la comunicación: integración social y territorial, amenidades urbanas y desarrollo habitacional. Posteriormente, se trabajarán los casos de las ciudades de La Serena, Valdivia y Villarrica desde la producción de espacio relacional de la vivienda subsidiada frente a los paradigmas instalados desde las políticas señaladas, para finalizar con una dis- 
cusión reflexiva, caracterizando el sentido y proyección del plan trazado en las últimas dos décadas como idea de integración urbana.

\section{METODOLOGÍA}

El trabajo contempla el desarrollo descriptivo de la situación de los subsidios habitacionales entregados entre 2000 y 2018 en las ciudades de La Serena, Valdivia y Villarrica. El cruce con las variables turísticas estará definido por la expoliación de los frentes de agua, lo que será representado cartográficamente para los casos señalados.

Se analizará sintéticamente la relación entre lo turístico y lo habitacional, en el sentido que los datos principales serán los residenciales y los de amenidad se utilizarán de forma explicativa y complementaria.

\section{LOS ESPACIOS DE AMENIDAD EN EL MARCO DE LA INTEGRACIÓN SOCIAL Y TERRI- TORIAL}

Las ciudades turísticas se constituyen como espacios de amenidad desde al menos dos vertientes. La primera de ellas tiene que ver con la lógica de los usos mercantiles que determinadas entidades urbanas desarrollan como matriz productiva (de Mattos, 2002). Por otro lado, la segunda apunta a la condición de sitio y emplazamiento, ambas determinantes de las orientaciones de crecimiento, expansión y ordenamiento de ciudades en borde litoral marino, fluvial y lacustre (Hidalgo, Rodríguez y Alvarado, 2018).

Los estudios respecto a la amenidad han tenido un alto impacto en la producción académica, con casos de estudio de México, Brasil y España, entre otros, trabajados desde las Geografía Turística y Urbana. Estos últimos responden a que los procesos de turistificación en espacios urbanos tienden a detonar expansiones en ciudades de menor tamaño, cuyo emplazamiento tiene una significativa asociación entre el valor del paisaje y la propia condición de sitio que las define. Ambas situaciones se han manifestado en los casos de las Islas Baleares estudiados por Murray y otros (Fletcher et al., 2019); el cambio climático y la situación de los propietarios de amenidad en Florida, Estados Unidos (Atzori, Fyall y Miller, 2018); y el turismo clínico y vientres de alquiler en España (Leinaweaver, Marre y Frekko, 2017).

En el caso de Latinoamérica, los estudios sobre la amenidad urbana tienden a concentrarse en la evaluación temprana de los efectos espaciales de la iniciativa Pueblos Mágicos en México y el desplazamiento de artesanía indígena ancestral desde las áreas centrales por elitización turística en el casco histórico de Oaxaca (Vargas, 2015). Para Brasil, el trabajo de Paulo Rodrigues Soares sobre el impacto urbano de los mega eventos deportivos acontecidos como la Copa Mundial de Fútbol de 2014, particularmente en Porto Alegre (Rodrigues Soares, 2018), y los Juegos Olímpicos de 2016 en la ciudad de Rio de Ja- 
neiro (Magalhães, 2019; Provasi, 2016). Estos trabajos abordan la transformación en infraestructura, cuyos resultados más notorios han estado en la reestructuración inmobiliaria de las áreas urbanas posindsutriales, situación ya denunciada por Lencioni en el Sao Paulo metropolitano (Lencioni, 2008); y la expoliación de favelas utilizando la base institucional del programa de vivienda subsidiada Minha Casa Minha Vida (Rufino, 2018).

Con todo, los eventos deportivos en Chile, al tener un carácter metropolitano en su celebración, no han afectado a las ciudades medias o grandes urbes en proceso de expansión, como el caso de La Serena-Coquimbo. Sin embargo, los efectos de la hiperfocalización turística en espacios marinos, lacustres y fluviales tienden a silenciar las demandas y procesos estructurales de subsidiarización de viviendas, situación a verificar en esta comunicación para los casos señalados.

\subsection{LA CATEGORIZACIÓN DE LA INTEGRACIÓN SOCIAL Y TERRITORIAL EN AMÉRICA LATINA}

La tendencia a observar y describir la transformación de las economías monetaristas a sistemas financiarizados ha retirado la atención sobre aquellos procesos de inversión pública, desatendiendo la participación del Estado como estructura de base en la producción de ciudad. Sin embargo, el cuestionamiento a las posibilidades y metas de integración social y territorial se mantienen incólumes al total del espectro urbano-residencial en la región. Ciertas investigaciones han desarrollado la trayectoria subsidiaria que los Estados de América del Sur han emprendido hacia la concreción de metas políticas para el acceso a la vivienda, particularmente enfocada a las clases populares y medias, también denominadas emergentes (Santana, 2018). De la misma forma, los medios de acceso y tipificación de las transacciones de compraventa también han representado una diversidad de actores y elementos que convergen en la generación de nuevos emplazamientos residenciales (Pírez, 2018). Estas evidencias exhiben el rol del Estado y la ciudadanía en la provisión y demanda habitacional, las que se sostienen incluso por sobre los escenarios de financiarización ampliamente debatidos en los países del Norte Global (Aalbers, 2019). De todas maneras, la integración social aparece como objetivo central en todas las políticas que los países de la región han emprendido. Si bien en las décadas pasadas, la meta urbana residía en la provisión de unidades de viviendas aun sin servicios, la tendencia actual señala que la integración social no solo se trataría de mejorar las características de localización de los conjuntos habitacionales, indicadores que por largo tiempo permitieron modelar a la segregación espacial como una de las principales características de las ciudades latinoamericanas (Borsdorf y Hidalgo, 2008).

Ciertamente, la segregación define las condiciones de ruptura y encuentro social establecidas por medio de políticas habitacionales expoliativas, las que 
pueden ser interpretadas desde la ingenuidad de las políticas públicas hasta la incapacidad de los gobiernos locales en la provisión de suelos competentes para el desarrollo residencial. Estas explicaciones se agotan ante el crecimiento de nuevos espacios suburbanos de alto precio, en donde lo natural cobra un valor diferenciado. La ocupación del delta del río Tigre en Argentina, transformando manglares en espacios urbanos exclusivos ha demostrado la capacidad que el valor de cambio planteado para la teoría urbana desde Lefebvre en adelante sigue en vigor para modelar los límites de la integración social (Baer y Kauw, 2016).

Por otro lado, la cuestión territorial es confusa en los estudios urbanos contemporáneos. La categoría territorial desde la Geografía apunta a describir las formas espaciales que el poder cobra bajo determinadas condiciones políticas, culturales o económicas. El territorio no es un concepto anodino, al cual se le puedan fijar fronteras taxativas a partir, por ejemplo, de la manifestación de una lengua determinada. Recientes estudios han argumentado que el territorio es flexible, portable y temporalmente resistente a una serie de cambios de distinta naturaleza (Elden, 2010; Galindo Gonzalez y Sabaté Bel, 2009). En la investigación urbana, el territorio ha sido tomado como faceta en las geopolíticas locales en que la racionalidad de la propiedad fisiocrática en tanto cualidad de los sujetos por delimitar la acción de sus necesidades y objetivos (Álvarez y Cavieres, 2016). El confinamiento urbano, encerramiento y vallado de conjuntos residenciales de alto valor ha dibujado el espectro de los territorios urbanos, en disputa por el acceso a los cuerpos de agua y las amenidades que les caracterizan (Zunino e Hidalgo, 2009).

Esta comunicación propone tensionar los conceptos de integración social y territorial precisamente desde esta caracterización, cuya dominancia en la discusión académica ha permeado la generación de políticas públicas en la región y particularmente en Chile. A continuación, se desarrollarán los casos indicados, guardando la tarea de definir qué es la integración social y territorial en el apartado final del manuscrito.

\section{LA SITUACIÓN DE LA INTEGRACIÓN SOCIAL Y TERRITORIAL EN CASOS MARINOS, FLU- VIALES Y LACUSTRES DE CHILE}

La escala, entendida metodológicamente como el tamaño material de unidades espaciales describibles, medibles y analizables no es, para la condición de las urbes revisadas durante la presente comunicación, un factor que impida establecer una mirada de casos diferenciada y excepcional. De hecho, la riqueza morfológica de las ciudades chilenas por sí misma define patrones de expansión y comportamiento urbanos incomparables entre sí. Más allá de las válidas tendencias para el estudio de la metropolización, es cierto también que su progresión espacial y temporal no dependen únicamente de una sola variable. 
Buscando desarrollar estas bases de discusión es que los casos a revisar transitan desde lo fluvial hacia lo marino, entendiendo que esta primera condición de sitio se abre por entre las otras debido a la ocupación ribereña temprana que presenta, desde una perspectiva antropológica del paisaje y la transformación de la naturaleza.

\subsection{LA CIUDAD DE VALDIVIA}

Recientes estudios acerca de la evolución de los espacios de amenidad y las actividades turísticas, elaboradas precisamente para la región andino-lacustre de la Araucanía chilena, han evidenciado que los atractivos de Valdivia ostentan al menos de un siglo de progresión para visitantes desde las áreas centrales del país (Martínez, 2019). La creencia de que la colonización alemana habría diseñado las formas modernas del asentamiento urbano, llevando a la ciudad hacia un estadio superior al resto de las urbes forzosamente integradas al Estado chileno hacia finales del siglo XIX colisiona con la realidad de miseria de tomas de terreno emplazadas hacia los sectores ribereños en el sector sur del sistema fluvial valdiviano (Hidalgo et al., 2018). Ello no tuvo grandes modificaciones en el tiempo, aunque el distanciamiento del borde de los ríos Calle Calle y Valdivia, por ejemplo, se aprecia con fuerza hacia la segunda mitad del siglo XX. Barrios como Las Ánimas contienen parte importante de los proyectos de vivienda social promovida por las agencias estatales en operaciones hasta 1976, fecha en la que se instala el nuevo sistema de subsidiarización estatal rompiéndose cuatro décadas de corporativismo y mutualismo habitacional (Cartes, 2012).

Para la década de 1980, el desplazamiento y concentración habitacional se concentra en el tronco interior del sector sur de Valdivia, dejando para el siguiente decenio la ocupación de los extremos meridionales de la misma zona. Ya para los 2000, el patrón de asentamiento es más bien distante, pero ingresa en competencia con operaciones inmobiliarias de condominios cerrados. Esta disputa de suelos se genera a partir de las capturas de paisaje, ya sea de los frentes de humedales localizados en la zona o de la proximidad ribereña. La creencia de que lo natural robustece y acrecienta el plusvalor de la propiedad habitacional no es baladí en el mercado chileno. Se trata de un metalenguaje inserto en los canales de transacción que ha impregnado a la oferta habitacional subsidiada, atrayendo conceptos alóctonos a estas materias, como sustentabilidad o integración social (Figura 1). 
Figura 1. Distribución de viviendas sociales y económicas en Valdivia 1980-2018

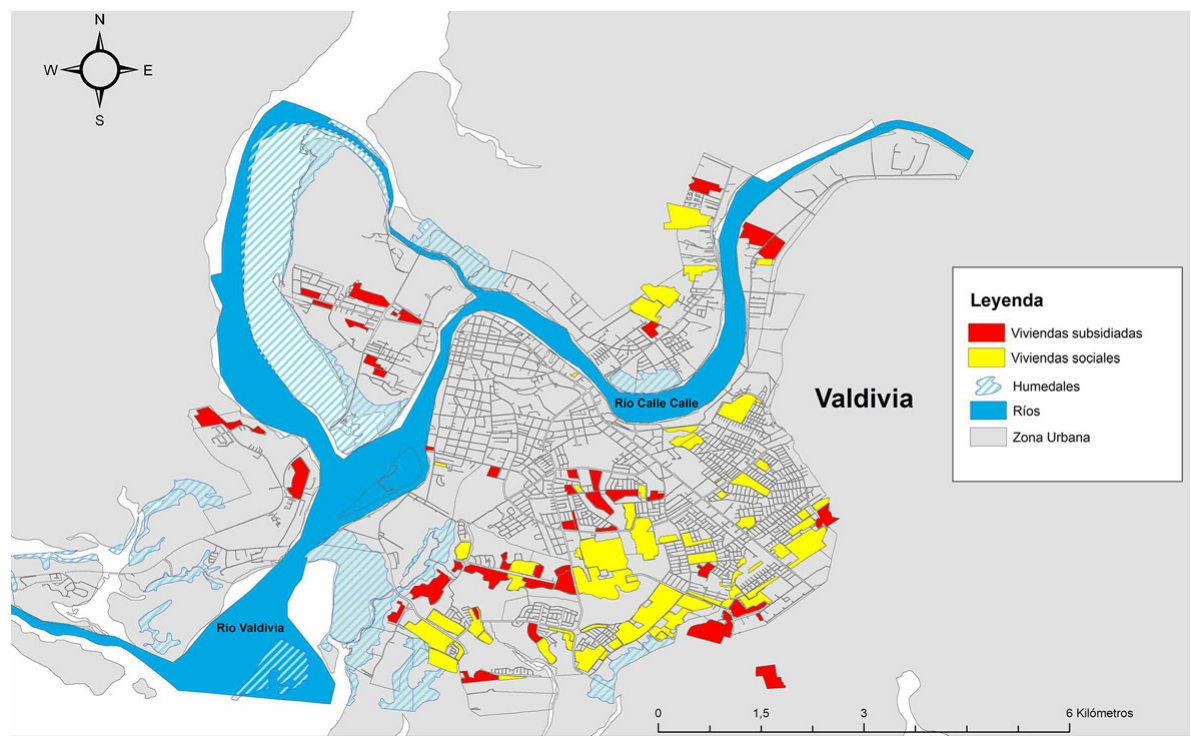

Fuente: FONDECYT 1191555

\subsection{VILLARRICA DE ESPALDAS AL VOLCÁN Y FRENTE AL LAGO}

El atractivo turístico de la región andino-lacustre posee un impacto significativo para los municipios de la zona. Tal es su relevancia que impulsó la construcción de un aeropuerto emplazado más cerca del empalme de las autopistas que conectan hacia los lagos Colico, Villarrica, Caburgua y Calafquén. Esta acción desahució el antiguo aeródromo Maquehue, situado en el periurbano de la capital regional, Temuco.

El caso de Villarrica es singular en las formas de ocupación habitacional. Para finales de la década de 1990, la ciudad se enfocaba con un amplio crecimiento de actividades urbanas dedicadas a educación, salud y servicios en general, lo que se acompañó de viviendas subsidiadas y procesos de erradicación de tomas de terreno, muchas de ellas relocalizadas como nuevos conjuntos de vivienda en la zona del camino Segunda Faja-El Volcán.

Con el inicio del siglo XXI, estas acciones se mantuvieron y acrecentaron, estableciéndose en estos paños rurales una forma urbana de alta concentración, emplazada a una distancia considerable del borde lacustre, dedicado en su totalidad a servicios de turismo gastronómico, hotelería y esparcimiento. La alta concentración en la sección oriental de la ciudad para desarrollos de proyectos inmobiliarios de alto valor señala, además, la clausura en el acceso al borde lacustre de conjuntos subsidiados de vivienda con aporte 
estatal (Salazar, Fonck y Vergara 2018; Salazar y Jalabert, 2016). Esto último ha sido verificado en los últimos años, generando un cordón intercomunal entre Villarrica y la vecina Pucón, cuya principal definición territorial apunta a parcelaciones de agrado, clubes de campo y negocios turísticos de tiempo compartido o alquiler de cabañas, como se denominan mayoritariamente en Chile a las viviendas de veraneo (Figura 2).

Figura 2. Localización de viviendas subsidiadas Villarrica y la condición de sitio en torno al lago

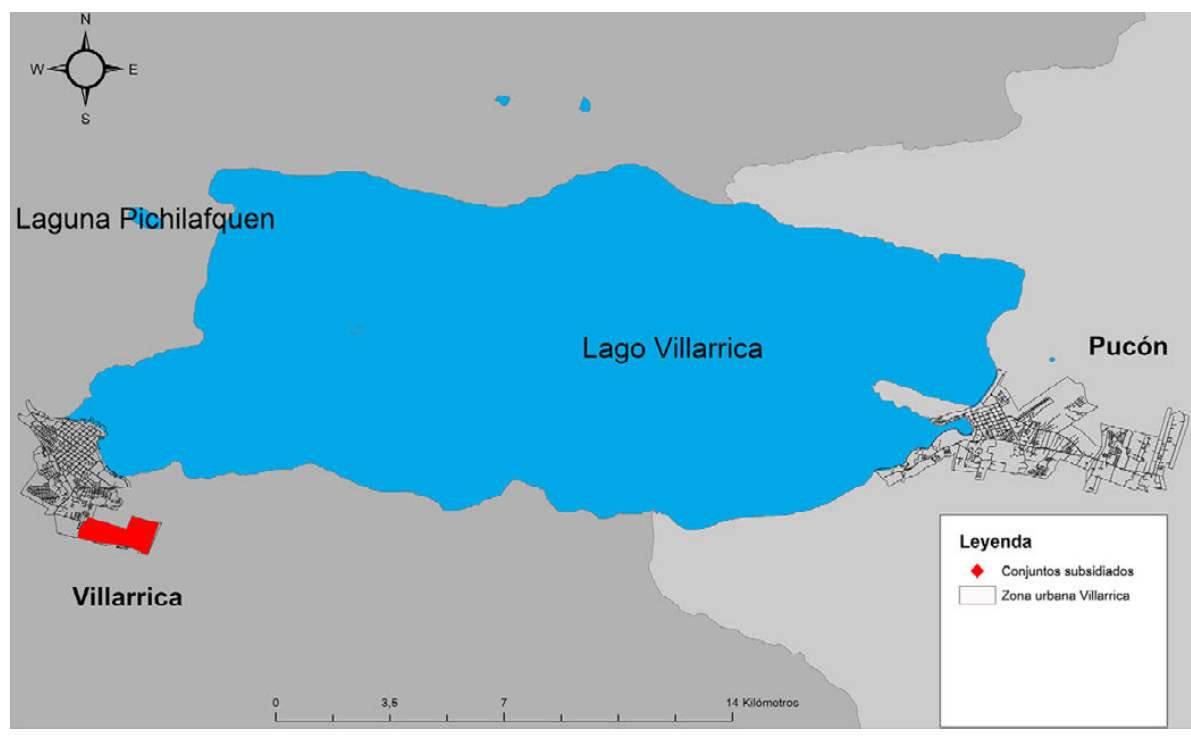

Fuente: FONDECYT 1191555

\subsection{LA METRÓPOLIS EN FORMACIÓN DE LA SERENA}

A 472 kilómetros al norte de Santiago, se localizan dos de las grandes ciudades del Norte Chico: La Serena y Coquimbo. Esta división regional, cuyo origen puede encontrarse en los estudios de la Corporación de Fomento de la década de 1950 permitió zonificar áreas de desarrollo económico siguiendo la regla del análisis regional basado en las condiciones intrínsecas de cada espacio, a partir de la capacidad que cada uno de ellos tendría enfocada como contribución al país (CORFO, 1982).

En este volumen, la cuestión turística es observada con atención como polo de desarrollo económico local, pero la vocación territorial de La Serena estuvo también en la trayectoria de las metrópolis duales, donde entre dos ciudades una asume el peso productivo mientras que la otra sirve de habitación. La 
Serena quedó con esta última mientras que Coquimbo creció en torno a las actividades portuarias (Cortés, 2016; Daher, 2016).

Lo más complejo de La Serena es que la localización de la vivienda social anterior a la década de los 2000 siguió el patrón expoliativo de las grandes ciudades definido por las políticas del último decenio dictatorial (1980-1990), pero con una gran proyección hacia poblar los bordes de estos sectores con conjuntos subsidiados de mayor valor, incluso distribuyendo algunos de ellos, más recientes, en las cercanías de las avenidas que movilizan el borde litoral marino. De este espacio, casi en su totalidad distribuidas a la vivienda en altura, las posibilidades de integración frente al mar fueron reduciéndose (Figura 3).

Figura 3. Oferta residencial subsidiada en La Serena periodo 2010-2018
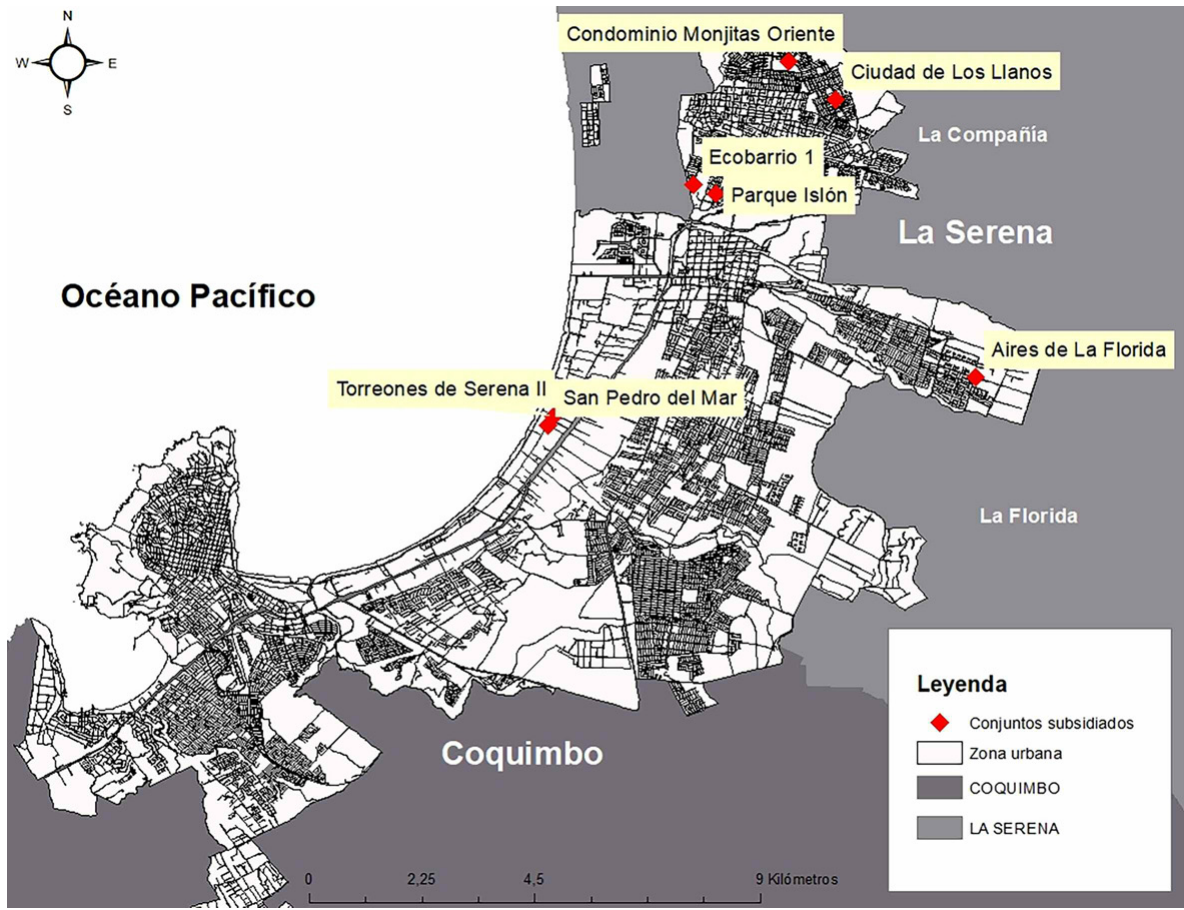

Fuente: FONDECYT 1191555

\section{PARA DISCUTIR, AVANZAR Y CERRAR}

La pregunta por la situación de la integración se hace un tanto imprecisa a la luz de los resultados observados. Sabida la localización y entendido que li- 
torales y riberas son arenas de disputa por una mayor valorización de los espacios urbanos, cabe tensionar estas evidencias, aun iniciales.

El desarrollo de la vivienda con financiamiento del Estado, sea este parcial o total, es una realidad de los modelos socioeconómicos actuales. Es probable que este postulado de inicio sea el principal justificativo del comportamiento predatorio que suele asignársele a los operadores inmobiliarios, particularmente en unidades metropolitanas. Es aquí donde está el prejuicio académico en la discusión por la integración social y territorial, ya que las demandas metropolitanas no son ubicuas y lo que podría entenderse como derecho a la ciudad tampoco lo sería.

Las ciudades como La Serena, cuya vocación metropolitana podría estar más definida por las formas espaciales, podría clasificarse como enclave inmobiliario para amenidades y residencias definitivas, pero ¿cuál es el impacto de una fuerte política subsidiaria ante el avance de modelos como AirBnB?.

Esta pregunta puede exportarse a los casos de Valdivia y Villarrica sin mayores complicaciones. Sin duda es un tema por considerar, más cuando en Chile el alquiler de viviendas para veraneo siempre ha transitado en la informalidad, el trato de palabra y el pago en efectivo. Estas estructuras locales de desarrollo habitacional, que aportan a la gestión económica a nivel de ciudades medias resultan incuantificables a la luz de indicadores hegemónicos, como sucede con la financiarización. Valdrá observar el avance de la integración en estos espacios, porque cuando todo se convierte en objeto fungible de las amenidades, a las definiciones de justicia es poca el espacio que les queda.

\section{BIBLIOGRAFÍA}

Aalbers, M. (2019). Financial Geography II: Financial Geographies of Housing and Real Estate. Progress in Human Geography, 43(2), 376-87.

Álvarez, A. M. y Cavieres, H. (2016). El Castillo: territorio, sociedad y subjetividades de la espera. EURE, 42(125), 155-74.

Atzori, R., Fyall, A. y Miller, G. (2018). Tourist Responses to Climate Change: Potential Impacts and Adaptation in Florida's Coastal Destinations. Tourism Management, 69, 12-22.

Baer, L. y Kauw, M. (2016). Mercado inmobiliario y acceso a la vivienda formal en la Ciudad de Buenos Aires, y su contexto metropolitano, entre 2003 y 2013. EURE, 42(126), 5-25.

Borsdorf, A. y Hidalgo, R, (2008). The Urban Sprawl in Europe and Latin America. A Comparison of the Growth of Urban Agglomerations. Mitteilungen Der Osterreichischen Geographischen Gesellschaft, 150, 229-50.

Cartes, I. (2012). Territory and evolution of the urban landscape post-disaster. Revista 180, 30, 10-15. 
CORFO (1982). Geografía Económica de Chile (Texto Refundido). Santiago de Chile: Andrés Bello.

Cortés, L. (2016). El pericentro de Coquimbo como escenario de renovación estratégica. AUS, 19, 10-17.

Daher, A. (2016). Metropolización en la región de mayor crecimiento de Chile, Coquimbo. AUS, 19, 45-50.

De Mattos, C. (2002). Mercado metropolitano de trabajo y desigualdades sociales en el Gran Santiago ¿Una ciudad dual? EURE, 28(85), 51-70.

Elden, S. 2010. Land, Terrain, Territory. Progress in Human Geography, 34(6), 799-817.

Fletcher, R., Murray, I., Blanco-Romero, A. y Blázquez-Salom, M. (2019). Tourism and Degrowth: An Emerging Agenda for Research and Praxis. Journal of Sustainable Tourism 27(12), 1.745-1.763.

Galindo Gonzalez, J. y Sabaté Bel, J. (2009). El valor estructurante del patrimonio en la transformación del territorio. Apuntes, 22, 20-33.

Hidalgo, R., Rodríguez, L. y Alvarado, V. (2018). Arriba del cerro o sobre el humedal: producción de naturaleza y expansión inmobiliaria en ciudades marinas y fluviales. El caso de Valparaíso y Valdivia, Chile. Diálogo Andino, 56, 87-100.

Leinaweaver, J. B., Marre, D. y Frekko, S. (2017). 'Homework' and Transnational Adoption Screening in Spain: The Co-Production of Home and Family. Journal of The Royal Anthropological Institute, 23(3), 562-79.

Lencioni, S. (2008). Concentração e Centralização Das Atividades Urbanas: Uma Perspectiva Multiescalar. Reflexões a Partir Do Caso de São Paulo 1. Revista de Geografía Norte Grande, 39, 7-20.

Magalhães, A. (2019). A «lógica da intervenção» e a questão da circulação: As remoções de favelas como forma de gerir o espaço urbano no Rio de Janeiro dos Jogos Olímpicos. Tempo Social, 31(2), 221-242.

Martínez, P. (2019). Los espacios turísticos: producción, experiencias e imaginarios. el caso de la Araucanía andino-lacustre chilena 1900-1940. Cuadernos de Turismo, 44, 219-246.

Pírez, P. (2018). Distribución, insolvencia y urbanización popular en América Latina. Revista de Geografía Espacios, 8(15), 67-93.

Provasi, B. (2016). Acts as Performances in the Occupation of the Urban Space: against a model of city for mega-events. Revista Brasileira de Estudos da Presença, 6(3), 429-459.

Rodrigues Soares, P. (2018). Metropolização, aglomerações urbano-industriais e desenvolvimento regional no sul do Brasil. Cadernos Metrópole, 20(41), $15-$ 34.

Rodríguez, A., y Sugranyes, A. (2004). El problema de vivienda de los «con techo». EURE, 30(91), 53-65.

Rufino, M. B. C. (2018). A disseminação da forma condomínio no Programa Minha Casa Minha Vida (PMVMC): privatização da urbanização para os pobres? Revista de Geografía Espacios, 8(16), 107-231. 
Salazar, G. y Jalabert, D. (2016). Towards a Landscape Ecosophy. Interpreting How the Villarrica-Pucon Urban System Inhabitants in the Araucania Region of Chile Perceive and Relate with the Dynamics of Landscape. URBERevista Brasileira de Gestao Urbana, 8(1), 28-41.

Salazar, G., Fonck, M. y Vergara, L. (2018). Ciudades intermedias: dinámicas de intermediación desde la noción de lugar. El caso de la región de la Araucanía, Chile. Revista de Geografía Norte Grande, 70, 10-30.

Santana, L. (2018). Introducción a los metromarxismos geográficos latinoamericanos: Perspectivas sobre la ciudad, lo urbano y la urbanización. Cuadernos De Vivienda y Urbanismo, 11(22), 1-20.

SERNATUR (2017). Estadísticas. Recuperado de:

https://www.sernatur.cl/informes-estadisticos/ (Consulta: 19 de marzo de 2020).

Zunino, H. y Hidalgo, R. (2009). Spatial and socioeconomic effects of social housing policies implemented in neoliberal Chile: the case of Valparaiso. Urban Geography, 30(5), 514-42.

Vargas del Río, D. (2015). Turismo de segundas residencias y turismo de naturaleza en el espacio rural mexicano. Estudios Sociales, 23(46), 290-312. 



\section{DESPOSESIÓN DE VIVIENDA Y ESPACIOS COMERCIALES EN NÚCLEOS TURÍSTICOS. ANALIZANDO LA RECONFIGURACIÓN DE LAS DINÁMICAS DESPLAZADORAS EN LOS CRISTIANOS/LAS AMÉRICAS (TENERIFE)' \\ HOME DISPOSSESSION AND COMMERCIAL REAL ESTATE DISPOSSESSION \\ IN TOURIST CONURBATIONS. ANALYZING THE RECONFIGURATION \\ OF DISPLACEMENT DYNAMICS IN LOS CRISTIANOS/LAS AMÉRICAS (TENERIFE)

\author{
Dennis Hof \\ Universität Leipzig
}

Resumen

Este trabajo aborda la dinámica de desposesión inmobiliaria de la conurbación turística Los Cristianos/Las Américas a escala intraurbana. Para ello se comienza presentando los patrones espacio-temporales de las desposesiones del período 2001-2015 a partir de la explotación de la base de datos ATLANTE del Consejo General del Poder Judicial. En concreto, se analizan las ejecuciones hipotecarias y los desahucios por impago de alquiler, tanto de espacios residenciales como de locales comerciales; para luego profundizar, mediante cuestionarios, en las experiencias de desposesión de la población residente y sus condiciones de vivienda e ingresos.

Los datos obtenidos muestran, de un lado, que las ejecuciones hipotecarias y las desposesiones de los espacios residenciales son característicos de los primeros años de la crisis, aunque su incidencia espacial varía en el ámbito analizado. De otro, el aumento de los desahucios por impago de alquiler a partir de 2014 apunta a una reconfiguración de las dinámicas de desposesión. Esta tendencia sugiere como causa la acumulación de alquileres a corto plazo en el sur de la isla, tal como reflejan las experiencias de las personas encuestadas. No obstante, a diferencia de otros contextos no se detectan formas de protesta contra estas formas de desposesión.

Palabras clave: desposesión, alquiler vacacional, financiarización, Canarias.

1 El presente trabajo ha sido posible gracias a los proyectos de investigación del Ministerio de Ciencia, Innovación y Universidades. Agencia estatal de investigación: El conflicto urbano en los espacios de reproducción. La vivienda como escenario de conflictividad social (RTI2018-094142-B-C22); del Ministerio de Economía y Competitividad. Agencia estatal de investigación, y Fondo Europeo de Desarrollo Regional (FEDER): Crisis y vulnerabilidad social en ciudades insulares españolas; así como el proyecto financiado por el programa de investigación e innovación de la Unión Europea Horizonte 2020 con la referencia Marie Skłodowska-Curie número 873082 (CONTESTED_TERRITORIES). 


\section{Abstract}

This paper addresses the dynamics of dispossession of housing in the tourist conurbation of Los Cristianos/Las Américas on an intra-urban scale. We begin by presenting the spatial-temporal patterns of dispossessions for the period 2001-2015, using the ATLANTE database of the General Council of the Judiciary. Specifically, foreclosures and evictions due to non-payment of rent, both for residential and commercial spaces, are analyzed. Then, through questionnaires, we delve deeper into the experiences of dispossession of the resident population and their housing and income conditions.

The data obtained shows, on the one hand, that mortgage foreclosures and dispossessions of residential spaces characterize the initial years subsequent to the crisis, although their spatial incidence varies in the area analysed. On the other hand, the increase in evictions for non-payment of rent from 2014 points to a reconfiguration of the dynamics of dispossession. This trend points to the accumulation of short-term rents in the south of the island, as reflected in the experiences of the interviewees. However, unlike other contexts, no forms of protest against these forms of dispossession do emerge up to now.

Keywords: real estate dispossession, short-term rentals, financialization, Canary Islands.

\section{INTRODUCCIÓN}

Más de una década después del estallido de la crisis financiera mundial, la inseguridad material y las condiciones laborales precarias siguen determinando la vida cotidiana de muchas personas en España (García-Lamarca y Kaika 2016; Schwaller 2019). Lejos de haberse contraído, en los últimos años se ha puesto de manifiesto que continúan las tendencias generadoras de crisis, basadas en un sector inmobiliario orientado a la maximización de los beneficios especulativos. Lo que ha ocurrido es que estas estrategias se han trasladado al sector del alquiler, donde se están promoviendo nuevas dinámicas de desplazamiento y desposesión que, aparte de las grandes ciudades, vuelven a afectar principalmente a las regiones turísticas insulares y mediterráneas (González-Pérez et al. 2020; Parreño-Castellano et al. 2018a).

Esta tendencia se inició con la promoción política de la vivienda en propiedad y la acumulación de capital inmobiliario durante la dictadura de Franco (Di Feliciantonio y Aalbers 2018). La base del crecimiento económico ha sido el alto volumen de construcción y el aumento de los precios de los bienes inmuebles, que ha sido impulsado por la inversión extranjera en el sector turístico desde la entrada de España en la UE (Marisol 2010). Al mismo tiempo, la deuda privada se estaba expandiendo ampliamente, en especial a través de la concesión de hipotecas ilegales a hogares de bajos ingresos (Sabaté 
2018). Tras el estallido de la burbuja inmobiliaria en 2008 , las actividades de construcción se paralizaron, el desempleo alcanzó niveles récord y en 2014, 570.000 hogares habían perdido sus viviendas por ejecuciones hipotecarias —especialmente en el Mediterráneo, las Islas Canarias y las Baleares, es decir, algunos de los puntos de brutal acumulación durante los años de auge (Cano Fuentes et al. 2013; Padberg y Schraven 2015).

De un lado, durante la reestructuración bancaria, las propiedades ejecutadas fueron gestionadas por la SAREB antes de ser revendidas a precios de descuento a fondos de capital privado como Blackstone o Cerberus. En forma de SOCIMIS, estos inversionistas transnacionales últimamente actúan cada vez más controlando los precios en el sector del alquiler. De otro, en las regiones turísticas, el mercado local de inquilinos compite de forma creciente con los alquileres de corto plazo/vacacionales, que son más rentables. Esto crea considerables barreras de entrada para los inquilinos de bajos ingresos y los comerciantes que, al haber perdido sus hipotecas y sus empleos, dependen más que nunca de un espacio de vida y trabajo asequible en el sector del alquiler. No es sorprendente, por tanto, que el número de desahucios y desplazamientos relacionados con el alquiler esté aumentando. De este modo, a pesar de la aparente recuperación económica, está surgiendo una nueva crisis de la vivienda, favorecida por las administraciones (Janoschka et al. 2020; Parreño-Castellano et al. 2018a; Vives-Miró 2018). Es más, contrariamente a lo que se sugiere por la caída de los alquileres y el abandono de los alquileres a corto plazo como resultado de la pandemia del COVID-19 (Bayona 2020), es muy probable que la precariedad de la vivienda se agudice aún más en los próximos años (Harvey 2020). Por ejemplo, a pesar de las moratorias de alquiler que se han acordado, muchas personas ya han sido expulsadas de sus hogares tras haber perdido su empleo y ante la ausencia de medidas sociales durante la pandemia (Carretero 2020), mientras que los fondos buitre como Blackstone y Lazora están aprovechando una vez más la crisis para provocar desahucios y subidas de alquiler (Torreblanca 2020b, 2020a).

No debe sorprender que, bajo estas circunstancias, en el último decenio se haya establecido en España un amplio campo de investigación sobre la geografía de la desposesión de la vivienda. Esto comenzó con estudios a gran escala, que analizaron la distribución socio-espacial de las ejecuciones hipotecarias y las razones del estallido de la burbuja inmobiliaria en el país basándose en los distritos judiciales (Obeso Muñiz 2014; Valle 2017). En trabajos posteriores, el nivel intraurbano surgió gradualmente como un campo central de investigación de las desigualdades urbanas. Destacan los estudios de Cataluña, las Islas Baleares, Ias Islas Canarias, Madrid y Valencia. Junto a la distribución intraurbana, también se abordan las nuevas entidades propietarias de las viviendas previamente desahuciadas y la correlación espacial con los indicadores socioeconómicos o los alquileres a corto plazo (GarcíaHernández et al. 2018; González-Pérez et al. 2020; Janoschka et al. 2020; Ji- 
ménez Barrado y Martín Sánchez 2016; Parreño-Castellano et al. 2018a; VivesMiró et al. 2015; Vives-Miró y Rullan 2017). A pesar de la crisis social generada por el elevado número de personas desplazadas en los últimos años, el acceso a los datos oficiales a nivel inframunicipial sigue siendo difícil. Es más, los datos existentes, ofrecidos por el Consejo General del Poder Judicial (CGPJ), suelen ser deficientes en la medida en que no informan del número de personas afectadas, ni diferencian con mayor precisión entre los bienes desahuciados, por ejemplo, entre los bienes residenciales y comerciales. A ello hay que añadir que los desalojos ordenados judicialmente que se registran en estos datos son, sin duda, sólo la punta del iceberg, ya que los procesos de desplazamiento suelen ir acompañados de acuerdos extrajudiciales, (semi)voluntarios y más neutros en cuanto a costes, lo que dificulta su recopilación (Parreño-Castellano et al. 2018a: 6).

Siguiendo estos trabajos, en esta comunicación se realiza un análisis intraurbano de la distribución temporal y espacial de las ejecuciones hipotecarias y los desahucios por impago de alquiler para el período 2001-2015 en la aglomeración de Los Cristianos/Las Américas (LC/LA) en el sur de Tenerife. Como se ha mencionado anteriormente, ya existen trabajos sobre la desposesión en las Islas Canarias, pero — con la excepción de Las Palmas de Gran Canaria - estos trabajos se han centrado hasta ahora en el fenómeno principalmente a nivel regional (Díaz-Rodríguez et al. 2017; García-Hernández et al. 2018; Parreño-Castellano et al. 2018a). Dado que en esos estudios ya se ha señalado que los distritos turísticos se ven particularmente afectados y que los alquileres a corto plazo/vacacionales abundan de forma especial en los destinos turísticos, la selección de LC/LA como zona de estudio es relevante para reconstruir la reconfiguración de las dinámicas de desposesión en un contexto determinado. Mediante la base de datos ATLANTE del CGPJ, se puede obtener una visión diferenciada de la propiedad residencial y comercial, lo que permite también sacar conclusiones sobre el impacto en los espacios de trabajo. Este estudio va más allá de las desposesiones meramente judiciales, a través de la evaluación complementaria de cuestionarios realizados in situ en 2018. Ello permite sacar conclusiones sobre las experiencias de expropiación de los afectados y las sitúa en el contexto de sus circunstancias socioeconómicas y la aparición de alquileres a corto plazo/vacacionales.

Este trabajo se estructura de la siguiente manera. En el próximo epígrafe se desarrollará el enfoque teórico, poniendo el foco en los procesos de desposesión y financiarización, como procesos que han centrado la investigación crítica sobre la vivienda de las últimas décadas. A continuación, se presenta el material empírico y el enfoque metodológico, en concreto se explica cómo se analiza de la base de datos y cuáles son los elementos del cuestionario. Seguidamente se realiza una introducción contextual al área de estudio, incidiendo sobre la génesis del sur de Tenerife, impulsada por la inversión extranjera y orientado al turismo. Otro epígrafe explora la distribución tem- 
poral-espacial de las expropiaciones y las experiencias de expropiación de los afectados en el área de estudio. Por último, se resumen los resultados teniendo en cuenta sus referentes teóricos, antes de que la contribución concluya con una breve reflexión sobre las posibilidades y los límites de la regulación política y las prácticas insurgentes, así como la necesidad de una investigación con un compromiso crítico.

\section{FINANCIARIZACIÓN Y DESPOSESIÓN DE LA VIVIENDA}

La cuestión de la vivienda resurge en los últimos años y está cobrando su importancia como una nueva cuestión social (Unterzeichnenden 2018), en algunos lugares incluso como un aspecto relacionado con la ecología y la sostenibilidad (Vollmer y Michel 2020). En este contexto, varios estudios de geografía urbana crítica ya han señalado una intensificación de la crisis de la vivienda a escala mundial, que va acompañada cada vez más de barreras al acceso a la vivienda en forma de cargas cada vez más elevadas para su alquiler o propiedad, reducción del parque de vivienda social, pero también de desplazamientos y desposesiones (Fields y Hodkinson 2018; Madden y Marcuse 2016; Soederberg 2018; Wetzstein 2017). El desplazamiento y la desposesión de la vivienda se consideran elementos esenciales del cercamiento (enclosure) de las esferas públicas y urbanas en los últimos decenios de la reestructuración neoliberal (Hodkinson 2012). La vivienda ha estado y sigue estando cercado principalmente por la creciente financialización del sector inmobiliario, ya sea a través de valores hipotecarios y la deuda hipotecaria privada o el aumento de las viviendas privadas de alquiler como activos financieros en manos de las empresas transnacionales (Aalbers 2019a; Heeg 2013). A raíz de la crisis financiera mundial, las dinámicas de desplazamiento y desposesión afectaron sobremanera el ámbito de la propiedad de la vivienda, especialmente en las sociedades de propietarios, como los Estados Unidos o España (Aalbers 2009; Martin 2011). Sin embargo, tras la correspondiente disminución de las tasas de propiedad de viviendas sobrevenida tras el crash financiero de 2008, han afectado principalmente a las viviendas en alquiler: Los inversores mundiales están acumulando más participaciones en el sector de los alquileres en forma de Real Estate Investment Trusts, que son equivalentes de los SOCIMIS en España. Entre otras cosas, adquieren viviendas sociales (re)mercantilizadas, pero también se hacen con propiedades previamente desahuciadas que les ofrece una elevada rentabilidad (Beswick et al. 2016; Wijburg et al. 2018). De esta manera, aparecen cada vez más actores privados que determinan los precios y con ello promueven procesos de desplazamiento (August y Walks 2018). En especial, con la aparición de plataformas de alquiler a corto plazo por Internet como Airbnb, estas dinámicas están adquiriendo una nueva dimensión en los barrios afectados por el turismo disruptivo (Aalbers 2019b). Airbnb ofrece a los agentes profesionales oportunidades de 
inversión más flexibles para comprar o alquilar, ya que a diferencia de las viviendas con un alquiler a largo plazo, las ofrecidas en alquiler a corto plazo pueden ser revendidas en cualquier momento (Montezuma y McGarrigle 2019). Como resultado de esta financialización del sector del alquiler impulsada por Airbnb, los propietarios y arrendadores locales están siendo reemplazados por inversores corporativos globalmente activos cuyo grupo destinatario son los turistas más pudientes en lugar de los inquilinos de bajos ingresos. Como resultado, la composición social de los barrios está cambiando gradualmente, mientras que los inquilinos que resisten están siendo sometidos a medidas más violentas de desplazamiento en forma de intimidación deliberada como obras de renovación selectivas (Cocola-Gant y Gago 2019). Desde la perspectiva de los afectados, el desplazamiento y la desposesión no sólo significa la pérdida de espacio para vivir o trabajar, sino que también va acompañado de una ruptura con las relaciones y los vínculos cotidianos (Blomley 2008).

En el contexto actual de la caída de los alquileres y del desplome del alquiler vacacional relacionado con la pandemia (Bayona 2020), la tensa situación de los mercados inmobiliarios se ha calmado temporalmente, lo que también debería aliviar la presión del desplazamiento. Sin embargo, los informes iniciales indican que los inversores mundiales de la vivienda como Blackstone continuarán expandiendo sus actividades de inversión en los próximos años, lo que supone una concentración aún mayor del poder empresarial y otro refuerzo de la financialización de la vivienda (Elorduy 2020; Lee 2020).

Esta estrecha interacción entre la financiarización de la vivienda y la desposesión a escala mundial se trata de un proceso que afecta de la misma manera a todas las regiones y ciudades. Inevitablemente, existen estrechas interrelaciones entre los sectores financiero e inmobiliario mundiales, las desigualdades urbanas y las experiencias locales de desposesión y desplazamiento. Ahora bien, una visión contrastada de las políticas y realidades de vivienda de cada país revela diferencias regionales y locales en la lógica de los efectos y las experiencias (variegation) (Aalbers 2017; Janoschka et al. 2020; Sokol 2017). Es necesario examinarlos para comprender mejor el panorama general en el contexto de los estudios de casos regionales en sus respectivos contextos e interrelaciones. Por este motivo, en la siguiente sección se presenta la región de estudio y se destacaran sus características especiales en el contexto del desarrollo inmobiliario español. Pero antes de ello, se expondrá brevemente el procedimiento metodológico.

\section{MATERIAL Y METODOLOGÍA}

Como ya se ha mencionado, los datos y estadísticas oficiales sobre la desposesión en España están limitados al nivel regional de los distritos judiciales y no permiten diferenciar entre vivienda y comercio. La base de datos inédita 
ATLANTE (CGPJ), es una excepción. En ella se enumeran todas las ejecuciones hipotecarias y desahucios por impago de alquiler a nivel intraurbano en las Islas Canarias que han terminado en procedimientos judiciales para el período 2001-2015. Además, los comentarios que contiene sobre las propiedades, apartamentos y negocios permiten realizar un análisis diferenciado de los casos. El enfoque metodológico se basa en estos datos. En un primer paso, se trata de elaborar la distribución temporal y espacial de las desposesiones a nivel intraurbano en LC/LA —divididas en cada caso en ejecuciones hipotecarias y desahucios por impago de alquiler, así como desposesiones residenciales y comerciales. Para la preparación del material, se delimitaron inicialmente las 1.695 entradas de la base de datos relativas al distrito de Arona, en el sur de Tenerife. Tras una cuidadosa depuración de los datos, quedaron 1.414, de las cuales 393 procedimientos de desposesión relativos al área de estudio de LC/LA fueron georreferenciados. Los Cristianos y Playa de Las Américas representan unidades administrativas diferentes, pero debido a su morfología urbana pueden considerarse como una aglomeración compacta. El procesado cartográfico del material se basa en la utilización de un sistema de información geográfica (SIG) con el fin de descubrir las desigualdades socio-espaciales. En este sentido, las posibilidades técnicas de los SIG se consideran un medio para enriquecer la investigación crítica (Harvey et al. 2005; O'Sullivan 2006; Thatcher et al. 2016). En un segundo paso, partiendo del análisis temporal-espacial, se consideran los desarrollos más recientes en el mercado inmobiliario y las experiencias de desposesión cotidianas (Hodkinson y Essen 2015). Según los principios del SIG cualitativo, se considera que la combinación con métodos cualitativos como las encuestas exploratorias no representativas es útil para contextualizar la información cuantitativa del SIG, basada en datos, mediante la reconstrucción de procesos más cotidianos (Bittner y Michel 2018; Knigge y Cope 2009). En agosto de 2018, se realizaron 50 entrevistas estandarizadas in situ con este fin. El muestreo se llevó a cabo de manera no aleatoria en torno a los «zonas calientes» de desposesión espacial previamente identificados. En el cuestionario se interroga, de un lado, sobre el conocimiento de la expulsión involuntaria de hogares y negocios y así se exploran los procedimientos judiciales de expropiación. De otro lado, se pregunta por las condiciones de vivienda y empleo, así como las cargas del coste de la vivienda, a fin de ilustrar las experiencias de desposesión también en el contexto de la evolución actual del mercado de la vivienda. Esto también se basa en el conocimiento de la polarización social en torno a la génesis del régimen de acumulación de turismo, tal como se explica en la siguiente sección. 


\section{AUGE INMOBILIARIO EN EL SUR DE TENERIFE}

El sur de Tenerife, con su zona turística Los Cristianos/Las Américas, es un ejemplo que ilustra bien el crecimiento inmobiliario orientado al turismo durante los años de auge en España (López y Rodríguez 2011). Para situar mejor en su contexto las dimensiones regionales de la desposesión y el desplazamiento, es importante comprender la génesis del régimen de acumulación basado en el turismo y los bienes inmuebles en la región.

Las Islas Canarias fueron un pilar importante del crecimiento inmobiliario español. Durante los años de auge, el aumento del volumen de construcción y de los precios de las propiedades aquí superó claramente la dinámica a nivel nacional (García-Hernández et al. 2018: 27). Esto se basó esencialmente en una reorganización territorial del archipiélago mediante la promoción política de nuevos regímenes de acumulación turística desde los años de 1960, especialmente en el sur de Tenerife. Después de que en los años 1950 esta zona árida se hubiese modernizado mediante la introducción de sistemas de riego, se produjo un cambio gradual de la utilización de las tierras agrícolas hacia una utilización de las tierras costeras más rentables y orientadas al turismo. Para ello, los propietarios locales cooperaron en gran medida con las administraciones municipales, que promovieron políticamente la litoralización y la aseguraron legalmente mediante planes especiales. En particular, el Plan Insular de Tenerife (1969), encargado al servicio de planificación Doxiadis Ibérica, constituyó un hito para las décadas siguientes. Entonces se iniciaron casi todos los grandes proyectos de infraestructura del sur de Tenerife (Autopista del Sur, Aeropuerto Reina Sofía) y se consideró la bahía de Los Cristianos, en el distrito de Arona, como el futuro centro turístico de la isla. Tan sólo en 1980, se habían desarrollado 2.967 hectáreas de tierra para el turismo, de las cuales 1.099 hectáreas se correspondían con el término municipal de Arona. Sin embargo, en general, sólo tuvieron éxito los proyectos turísticos e inmobiliarios en los que colaboraron propietarios canarios con inversores peninsulares o extranjeros. Cabe destacar la colaboración entre Antonio Domínguez Alfonso y el empresario catalán Rafael Puig Lluvina en la ejecución del proyecto de 281 hectáreas Playa de Las Américas Fase III, que a partir de la década de los ochenta pretendía vincular morfológicamente a Los Cristianos con la Fase I y la Fase II ya finalizada. Como resultado, esta alianza de planificación urbana, grandes terratenientes e inversores extranjeros logró dar al régimen de acumulación de una región anteriormente agrícola, una orientación fundamentalmente nueva en menos de tres decenios. En el proceso, LC/LA se convirtió en el epicentro turístico de Tenerife y hoy en día determina la orientación económica y espacial de la isla junto a la región metropolitana de Santa Cruz/La Laguna (Martín Martín 2005, 2000).

En los años de auge de la década de 1990, la entrada de España en la Unión Europea provocó una mayor intensificación de las inversiones inmobiliarias, 
con la participación de capital alemán en particular en nuevos proyectos turísticos. Desde entonces, el desarrollo inmobiliario ha incluido también el resto de la región insular, especialmente los asentamientos periféricos de los residentes locales (Martín Martín 1999). A pesar de todo ello, no es evidente que los habitantes locales y los migrantes no comunitarios que trabajan en los sectores del turismo y la construcción hayan participado en los beneficios del crecimiento inmobiliario. Por el contrario, los trabajos, en su mayoría de baja calificación, en estos sectores eran muy precarios y se caracterizaban por el empleo temporal sin contratos fijos y con bajos ingresos (Delgado Acosta y Díaz-Rodríguez 2010). Además, las prestaciones sociales en las Islas Canarias, incluso para los estándares nacionales, eran débiles y faltaban políticas de vivienda social, lo que significaba que la contratación de una hipoteca en riesgo era a menudo la única manera de acceder a la vivienda (Díaz-Rodríguez et al. 2017: 1028; García-Hernández et al. 2018: 28). En este sentido, la deuda hipotecaria privada estaba muy arraigada en la vida cotidiana de la población (García-Lamarca y Kaika 2016) y promovía aún más la polarización social.

El estallido de la burbuja inmobiliaria agravó entonces las precariedades y vulnerabilidades estructurales que ya existían: El volumen de construcción se estancó de 28.798 proyectos de construcción recién iniciados en 2006 a sólo 394 en 2014, al tiempo que se produjo un desempleo y una insolvencia generalizada (García-Hernández et al. 2018: 29). A nivel nacional, las sucesivas olas de desposesión impactaron sobre todo al tejido social del archipiélago canario (Colau y Alemany 2013: 6). A nivel intrarregional, las islas turísticas de Fuerteventura, Lanzarote y las regiones turísticas del sur de Gran Canaria y Tenerife se vieron particularmente afectadas (Díaz-Rodríguez et al. 2017). Una primera idea del alcance de estos acontecimientos en el sur de Tenerife es posible si se consideran las variaciones de la población en Arona -en ausencia de indicadores relacionados con la propiedad a nivel inframunicipal (ver Tabla 1). El crecimiento demográfico pronunciado hasta 2008 puede interpretarse como una expresión del inmenso crecimiento inmobiliario durante los años de auge, mientras que las tendencias decrecientes y en parte negativas a partir de 2008 - sobre todo en las ciudades costeras de Costa del Silencio y Los Cristianos - indican pérdidas de viviendas relacionadas con la crisis. 
Tabla 1. Porcentaje de crecimiento de población en Arona (2001-2015)

\begin{tabular}{|c|c|c|c|}
\hline Unidad poblacional & $2000-2008$ & 2008-2017 & 2000-2017 \\
\hline ARONA (Municipio) & 97.58 & 3.99 & 105.46 \\
\hline ARONA & 29.52 & -5.08 & 22.93 \\
\hline BUZANADA & 85.99 & 9.94 & 104.48 \\
\hline CABO BLANCO & 49.80 & 10.41 & 65.39 \\
\hline LA CAMELLA & 60.52 & 11.32 & 78.70 \\
\hline LOS CRISTIANOS & 85.10 & -9.03 & 68.38 \\
\hline $\mathrm{CHO}$ & 262.62 & 32.69 & 381.17 \\
\hline EL FRAILE & 90.52 & 20.47 & 129.52 \\
\hline LAS GALLETAS & 118.76 & 5.67 & 131.16 \\
\hline GUAZA & 133.88 & 12.24 & 162.50 \\
\hline COSTA DEL SILENCIO & 242.59 & -12.39 & 200.14 \\
\hline CHAYOFA & 167.53 & 0.40 & 168.60 \\
\hline PALM-MAR & 533.89 & 91.15 & 1111.67 \\
\hline $\begin{array}{l}\text { PLAYA DE LAS } \\
\text { AMÉRICAS }\end{array}$ & 91.09 & 1.32 & 93.60 \\
\hline VALLE DE SAN LORENZO & 71.39 & 3.76 & 77.84 \\
\hline GUARGACHO & 127.13 & 1.68 & 130.94 \\
\hline
\end{tabular}

Fuente: INE. Nomenclátor. Población del Padrón Continuo por Unidad Poblacional.

Elaboración propia

Contrariamente a la creencia generalizada de que el sector inmobiliario se ha recuperado en los últimos años, las personas de bajos ingresos siguen teniendo dificultades para establecerse en el mercado de la vivienda (ParreñoCastellano et al. 2018a). Por un lado, ahora dependen más que nunca del sector del alquiler debido a las condiciones más estrictas para obtener un préstamo hipotecario. Por otra lado, la penetración en el mercado de inquilinos de los fondos de inversión mundiales y de los alquileres a corto plazo/vacacionales también provoca importantes aumentos de los alquileres en las Islas Canarias. En Las Palmas de Gran Canaria, los desalojos de inquilinos se observan de forma creciente en este contexto desde 2014 (ibid.). En cuanto a Tenerife, todavía no hay estudios detallados de esta situación. Sin embargo, la fuerte acumulación de ofertas de Airbnb en manos de unos pocos anfitriones profesionales en los distritos turísticos de Arona y Adeje indica que la reciente dinámica de desplazamiento afecta de nuevo al sur de la isla (Sán- 
chez et al. 2018). Particularmente en Los Cristianos, esta oferta parecen concentrarse más alejada de los complejos hoteleros, es decir, en las zonas residenciales (Delgado González y Slylus Pyzh 2018: 24). Esto se examinará ahora con más detalle en la parte más empírica de este trabajo.

\section{DESPOSESIÓN Y DESPLAZAMIENTO EN LOS CRISTIANOS/LAS AMÉRICAS}

Después de explicar los contextos teóricos y regionales, se llevará a cabo un análisis de casos de estudio de las dinámicas de desposesión y desplazamiento en LC/LA en dos etapas. Inicialmente se presentará la distribución temporal-espacial de las desposesiones ordenadas judicialmente en el centro de las ciudades. Luego, con miras a los acontecimientos recientes, se examinarán las experiencias más cotidianas de desposesión y desplazamiento en el contexto de un mercado de alquileres a corto plazo/vacacionales que incrementa los precios.

Figura 1. Evolución temporal de las desposesiones en Arona (2001-2015)

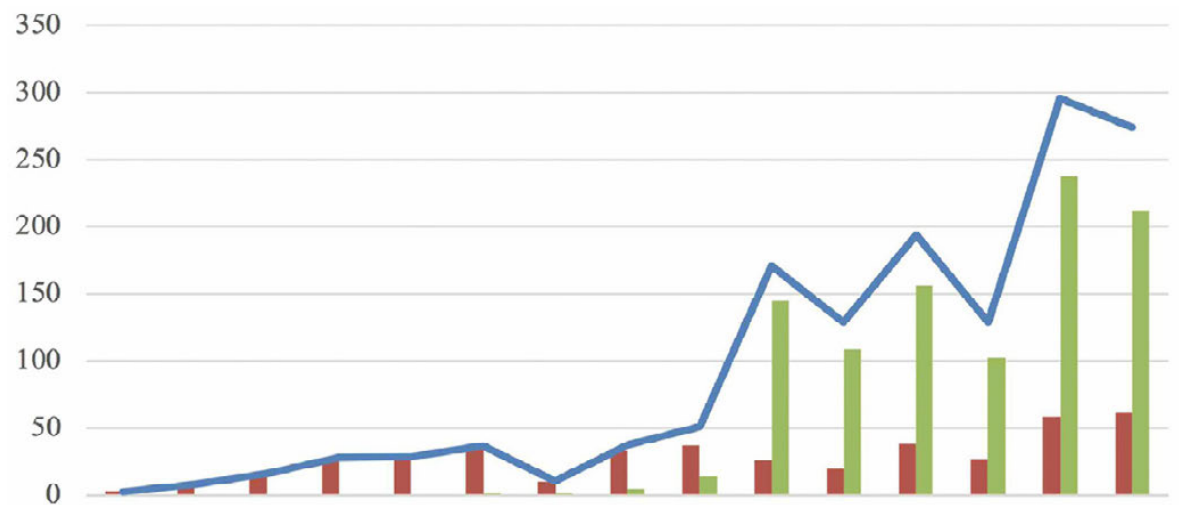

200120022003200420052006200720082009201020112012201320142015

Desahucios por impago de alquiler Ejecuciones hipotecarias

Desposesiones

Fuente: Base de datos ATLANTE. Elaboración propia

\subsection{TEMPORALIDADES Y ESPACIALIDADES DE LA DESPOSESIÓN}

En la Figura 1 se presenta un panorama general de las temporalidades de la desposesión: al igual que las tendencias a nivel nacional, la mayoría de las desposesiones en Arona se producen después del estallido de la crisis inmobiliaria y se caracterizan por la aparición de ejecuciones hipotecarias, que 
prácticamente no existían durante los años de auge. Sin embargo, en los dos últimos años del período se observa un ligero aumento de los desahucios por impago de alquiler. La Tabla 2 matiza nuevamente estas tendencias a nivel inframunicipal: las ejecuciones hipotecarias también dominan en casi todas las unidades de población, pero en Los Cristianos y Playa de Las Américas se verifica la mayor cantidad de desahucios. Además, este núcleo también concentra el número más elevado de desposesiones: 393 o el 27.8\% de todas las registradas. Asimismo, si se analiza el número de desposesiones con respecto a la población, se muestra que las tasas de desposesión son más elevadas en Playa de Las Américas (23.7\%o), junto a los asentamientos periféricos de Guaza (29.68\%o) y Guargacho (37\%o). Por consiguiente, esta aglomeración urbana merece una consideración especial, tanto en lo que respecta a la cantidad de desposesiones, como en la medida en que afecta a la población.

Tabla 2. Desposesiones en Arona separados por desahucios por impago de alquiler y ejecuciones hipotecarias (2001-2015)

\begin{tabular}{|c|c|c|c|}
\hline Unidad poblacional & Desposesiones & Alquiler (\%) & Hipoteca (\%) \\
\hline ARONA (Municipio) & 1414 & 30.55 & 69.45 \\
\hline ARONA & 34 & 11.76 & 88.24 \\
\hline BUZANADA & 50 & 22.00 & 78.00 \\
\hline CABO BLANCO & 100 & 17.00 & 83.00 \\
\hline LA CAMELLA & 69 & 17.39 & 82.61 \\
\hline LOS CRISTIANOS & 272 & 40.07 & 59.93 \\
\hline $\mathrm{CHO}$ & 55 & 29.09 & 70.91 \\
\hline EL FRAILE & 121 & 33.88 & 66.12 \\
\hline LAS GALLETAS & 79 & 32.91 & 67.09 \\
\hline GUAZA & 59 & 27.12 & 72.88 \\
\hline COSTA DEL SILENCIO & 182 & 27.47 & 72.53 \\
\hline CHAYOFA & 34 & 26.47 & 73.53 \\
\hline PALM-MAR & 28 & 25.00 & 75.00 \\
\hline $\begin{array}{l}\text { PLAYA DE LAS } \\
\text { AMÉRICAS }\end{array}$ & 121 & 52.07 & 47.93 \\
\hline $\begin{array}{l}\text { VALLE DE SAN } \\
\text { LORENZO }\end{array}$ & 136 & 19.12 & 80.88 \\
\hline GUARGACHO & 74 & 33.78 & 66.22 \\
\hline
\end{tabular}


De hecho, la trayectoria temporal en LC/LA ya presenta peculiaridades que la distinguen de otras entidades a nivel municipal. Aunque las ejecuciones de hipotecas también dominan en los años posteriores a la crisis ( 49 casos registrados sólo en 2014) y sobre el total (56.23\%), los desahucios desempeñan un papel más relevante en la comparación inframunicipal. Ya en los años anteriores a la crisis, 2001-2007, los desahucios representaban por sí solos el 15.01\% del total de las desposesiones en el campo de estudio; a nivel municipal la cifra es del $9.33 \%$. Esto deja claro que las condiciones de vivienda inestables e inseguras en el sector del alquiler ya desempeñaban un papel importante en los años anteriores a la crisis (Pareja Eastaway y Varo 2002). A su vez, el continuo aumento del número de desahucios a partir de 2010 indica que en los últimos años la dinámica de desplazamiento y desposesión se ha traslado cada vez más hacia el sector de los alquileres (Parreño-Castellano et al. 2018a).

Ahora bien, es evidente que no todo el espacio urbano se ve igualmente afectado por estas dinámicas. Si se consideran las entidades costeras de Arona en particular, se constata que están experimentando tendencias demográficas negativas desde 2008. En concreto, un análisis de las secciones censales situadas en LC/LA mostró que los lugares centrales en torno a los paseos marítimos y la Montaña Chayofita en particular están experimentando las mayores pérdidas de población a partir de 2008. Tal como muestra un análisis de densidad de puntos de todas las desposesiones georreferenciadas, esto también refleja los patrones espaciales dominantes de las pérdidas de viviendas intraurbanas (véase la Figura 2). La mayor densidad de desposesiones puede observarse en el casco histórico de Los Cristianos - en concordancia con estudios de otros entornos turísticos como Menorca (Vives-Miró et al. 2017) se trata esencialmente de ejecuciones hipotecarias. Si bien, éstas dominan en general en el ámbito de Playa de Las Américas (52.07\% de todos los desalojos), salvo la urbanización El Camisón donde están mucho más dispersos, lo que probablemente se debe a la morfología extensa de esta parte de la ciudad planificada. También hay que destacar el Edificio Edén, al noreste del centro de Los Cristianos. Allí se encuentra una agencia de empleo temporal y la agencia municipal de empleo, por lo que el edificio funciona como un referente para la población local que trabaja en las industrias locales del turismo y los servicios, que por lo tanto parecen estar particularmente afectadas. 
Figura 2. Densidad de desposesiones en Los Cristianos/Las Américas (2001-2015)

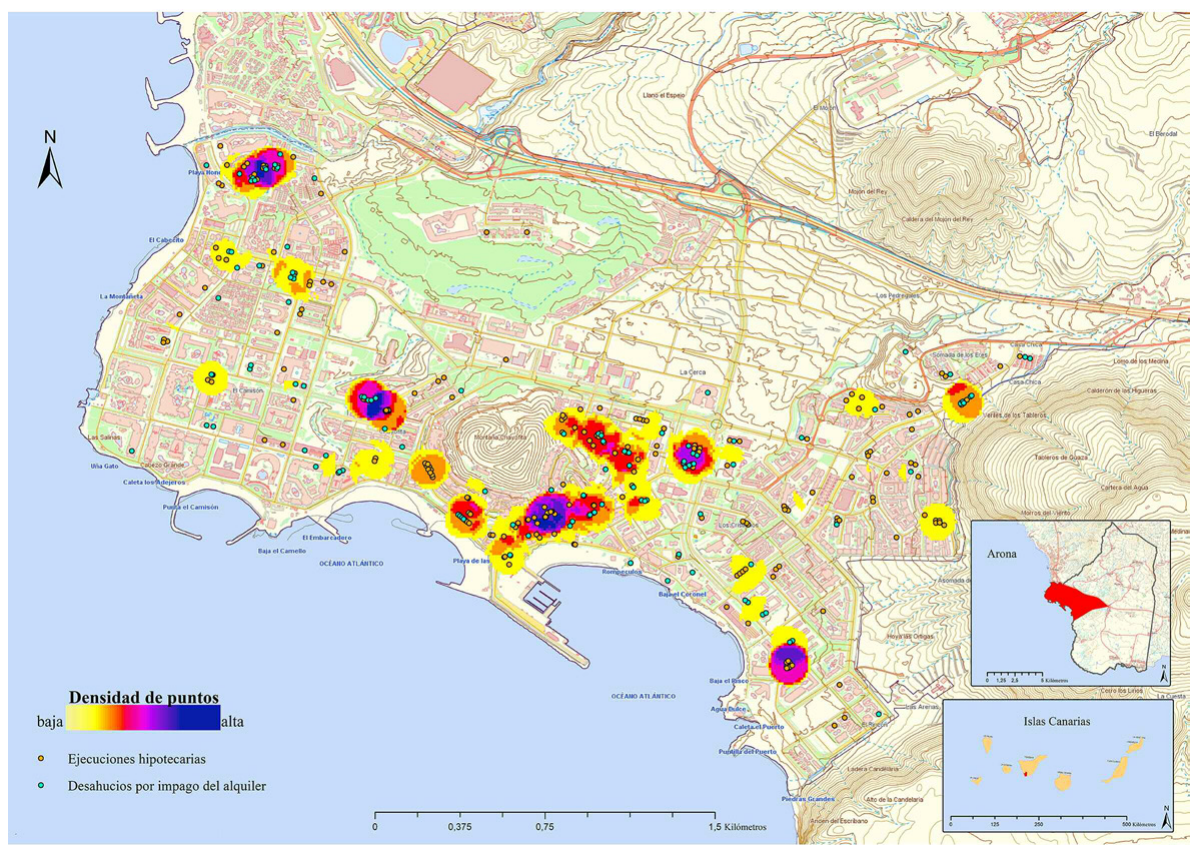

Fuente: Base de datos ATLANTE (CGPJ). Elaboración propia. Mapa topográfico Integrado GRAFCAN 2014

Como ya se ha mencionado, una característica singular del conjunto de datos es que permite diferenciar entre propiedades residenciales y comerciales (tiendas, restaurantes, oficinas): 70 de las 393 expropiaciones localizadas pueden asignarse a negocios, que se concentran principalmente en los centros comerciales de la Playa de Las Américas; las estribaciones noroccidentales de la ciudad muestran la mayor acumulación. Por lo tanto, hay que señalar que la crisis inmobiliaria no sólo ha dificultado el acceso a la vivienda, sino también al espacio de trabajo.

\subsection{EXPERIENCIAS VIVIDAS DE DESPOSESIÓN Y DESPLAZAMIENTO}

Mediante el análisis intraurbano de las pautas de desposesión temporal-espacial, ya ha se ha puesto de relieve que las desposesiones relacionadas con los alquileres están aumentando en los últimos años y que los negocios se ven también afectados por la desposesión. El análisis de los cuestionarios realizados in situ en 2018 ilustrará aún más las actuales tendencias en el espacio vital y laboral. 
Las personas entrevistadas son principalmente asalariadas o autónomas entre 18 y 50 años con un nivel educativo relativamente alto. Algunos estudios ya han dejado claro que la sobrecualificación en el sector turístico es elevada, es decir, que las ofertas de empleo y las oportunidades de obtener ingresos no tienen por qué armonizar necesariamente con las cualificaciones obtenidas (Delgado Acosta y Díaz-Rodríguez 2010; Lillo-Bañuls y Casado-Díaz 2012). Además, buena parte de las personas entrevistadas proceden de otros países (sobre todo de Suramérica y de la UE), por lo que no es sorprendente que el $65 \%$ no resida en la aglomeración más de cuatro años. Por consiguiente, las experiencias de desposesión reconstruidas aquí reflejan en gran medida los años más recientes.

Resulta que la gran proporción de los encuestados vive ahora en alquiler, y que las hipotecas desempeñan un papel menor. Por lo tanto, no es sorprendente que los aumentos de los alquileres se consideren la principal razón para tener que abandonar el espacio de vida o de trabajo de forma involuntaria. A ello hay que añadir el menor poder adquisitivo de los clientes como consecuencia de la crisis, especialmente para los comerciantes, lo que llevó al abandono de sus negocios. Las pérdidas de empleo y las deudas hipotecarias, en cambio, han perdido su relevancia. Esto también fue confirmado por un agente inmobiliario encuestado, que declaró que los aumentos de los alquileres desde 2015 han desempeñado el papel dominante en el desplazamiento, especialmente con la aparición de plataformas de alquiler a corto plazo como Airbnb. En otras palabras, antes de la financialización del sector del alquiler (Vives-Miró 2018) se están generando nuevas dinámicas de desposesión.

Las experiencias de desposesión mencionadas se relacionaron en su mayoría con Los Cristianos y Playa de Las Américas, y en parte también con Tenerife y Lanzarote, es decir, con los contextos locales y regionales. Sin embargo, pocas de las personas entrevistadas recuerdan el paradero de quienes fueron expulsadas (puesto que ellas mismas no se vieron afectadas), lo que ilustra que la expropiación suele ir acompañada del corte de las relaciones y los vínculos cotidianos (Blomley 2008). En declaraciones más generales se señaló que la mayoría de los migrantes afectados habían regresado a sus países de origen, mientras que muchos residentes afectados se vieron obligados a vivir con otros miembros de su familia.

Dado que la mayoría de las entrevistas se realizaron con comerciantes, dos tercios de las experiencias de desposesión se refieren a espacios de trabajo. Los negocios que fueron abandonados involuntariamente eran bares y restaurantes locales orientados al turismo, así como tiendas de ropa y decoración. Hoy en día muchas de estas tiendas están vacías, pero la mayoría son administradas por nuevos propietarios, para los cuales algunos de los antiguos comerciantes entrevistados trabajan ahora como asalariados.

Con todo, los niveles de ingresos actuales de los encuestados revelan una elevada carga de alquileres e hipotecas en este contexto: Del 80\% de los encues- 
tados que viven con alquiler o hipoteca, el 47.5\% tiene que gastar más del $40 \%$ de sus ingresos mensuales en gastos de la vivienda. Estas cifras superan claramente el límite superior del 30\% que a menudo se cita en el debate sobre la vivienda asequible (Woetzel et al. 2014). Además, existe una estrecha correlación entre la carga del coste de la vivienda y las experiencias de desposesión: Los que tienen que pagar altos costes de vivienda tienden a saber más sobre la desposesión y viceversa. En este sentido, la desposesión y el desplazamiento se desarrollan especialmente en la vida cotidiana de los grupos de bajos ingresos. Más de diez años tras el comienzo de la crisis inmobiliaria, la inseguridad de la vivienda sigue estando a la orden del día en LC/LA.

\section{CONCLUSIONES}

Las interdependencias de la financialización de la vivienda y la desposesión que se observan a nivel mundial también se hacen notar en las Islas Canarias. El estudio de caso presentado aquí deja claro que la desposesión y el desplazamiento repercuten cada vez más en el sector del alquiler. Al mismo tiempo se puede mostrar los aspectos locales y regionales de estas lógicas «variegated» (Aalbers 2017). En España, la inseguridad en materia de vivienda es también el resultado de una práctica políticamente cuestionable que durante décadas ha permitido la especulación inmobiliaria, los préstamos hipotecarios ilegales e incluso la creación de los REIT sin introducir ninguna medida significativa para promover la vivienda asequible (Janoschka et al. 2020). En las Islas Canarias, esto está estrechamente vinculado a la génesis de los regímenes de acumulación turística, que se apoyaron en una alianza de propietarios locales, inversores extranjeros y administraciones regionales, con lo que se precarizaron las condiciones de trabajo y de vivienda, lo que sentó las bases para los efectos socialmente devastadores de la crisis inmobiliaria. Utilizando el ejemplo de LC/LA, es posible entender cómo esta reconfiguración de la dinámica de desplazamiento y desposesión tiene lugar a nivel intraurbano. La mayoría de las desposesiones registradas se caracterizan por las ejecuciones hipotecarias y conciernen esencialmente al centro de la ciudad de Los Cristianos. Al mismo tiempo, es evidente que el espacio de trabajo también se ve afectado y que los desahucios por impago de alquiler han experimentado un auge en los últimos años. Las entrevistas estandarizadas ponen de relieve que la reciente financialización del sector del alquiler (VivesMiró 2018) va acompañada de una carga cada vez mayor de los costes de la vivienda. Así, el aumento de las rentas está desplazando ostensiblemente a los hogares de bajos ingresos y a los operadores comerciales. Se necesitan más investigaciones y datos para obtener una visión más completa de estas dinámicas. Esto implica un desglose de los procedimientos de desposesión intraurbana después del período de observación, que debe compararse espacialmente con las ofertas existentes de alquileres a corto plazo. Al mismo 
tiempo, las entrevistas narrativas pueden proporcionar una visión más profunda de las historias de expropiación que hay más allá de los datos ofrecidos desde la perspectiva de los agentes inmobiliarios, los planificadores urbanos, los trabajadores sociales y los afectados. Además, algunos diseños de investigación críticos desarrollados en los últimos años tienen como objetivo involucrar activamente a las personas afectadas en el diseño de las investigaciones con el fin de promover el control a la autonomía colectiva (Thurber et al. 2018). Se necesitan igualmente políticas de vivienda social más amplias y la voluntad política de aplicarlas. En las Islas Canarias se lleva años debatiendo sobre una regulación más estricta de los excesos especulativos del turismo, pero los esfuerzos anteriores de una moratoria de los alquileres a corto plazo/vacaciones ha quedado en nada (González Cabrera 2018; Parreño-Castellano et al. 2018b). Así, con políticas nacionales y regionales que muestran poca voluntad de garantizar una vivienda asequible, las esperanzas de muchos investigadores críticos en materia de vivienda descansan en las prácticas insurgentes de los movimientos sociales (García-Lamarca 2017). Sin embargo, en los años transcurridos desde el estallido de la crisis de la vivienda, a diferencia de lo que ocurre en otras ciudades españolas, no se ha producido ningún movimiento masivo significativo contra la desposesión de la vivienda en las Islas Canarias (ArmasDíaz y Sabaté Bel 2020). Para el sur de Tenerife, se puede especular que la estructura dispersa de los asentamientos de trabajadores periféricos, por un lado, y los numerosos migrantes que trabajan en el sector del turismo, poco arraigados, por otro, limitan las posibilidades de movilizar formas de protesta. Además, con mucha probabilidad se haga aún más difícil la capacidad de protesta durante el avance la pandemia, ya que la organización colectiva, por ejemplo en forma de huelgas de alquiler solo puede tener lugar en estos momentos en línea (Dougherty y Eligon 2020). Mientras tanto, los principales actores ya están planeando lanzar una nueva ronda de acumulación de la vivienda (Elorduy 2020). Debido a estas incertidumbres y ambigüedades que resultan de la pandemia actual, queda claro que la investigación crítica debe continuar poniendo el foco en especial en los procesos de acumulación y desposesión de vivienda, y expandirlos para entender mejor los efectos que tendrá sobre la vida de las personas y su capacidad de protestar contra estos procesos.

\section{BIBLIOGRAFÍA}

Aalbers, M. (2009): Geographies of the financial crisis, Area 41 (1), 34-42, doi:10.1111/j.1475-4762.2008.00877.x.

Aalbers, M. B. (2017): The Variegated Financialization of Housing, Int J Urban Reg Res 41 (4), 542-554, doi:10.1111/1468-2427.12522.

Aalbers, M. B. (2019a): Financial geography II: Financial geographies of housing and real estate, Progress in Human Geography 43 (2), 376-387, doi:10.1177/0309132518819503. 
Aalbers, M. B. (2019b): Introduction To The Forum: From Third To Fifth-Wave Gentrification, Tijds. voor econ. en Soc. Geog. 110 (1), 1-11, doi:10.1111/tesg.12332. Armas-Díaz, A. y Sabaté Bel, F. (2020): Struggles on the Port of Granadilla: Defending the right to nature, Territory, Politics, Governance.

August, M. y Walks, A. (2018): Gentrification, suburban decline, and the financialization of multi-family rental housing: The case of Toronto, Geoforum 89 124-136, doi:10.1016/j.geoforum.2017.04.011.

Bayona, E. (2020): El pinchazo de la burbuja del alquiler por el coronavirus en seis claves, Público, 03.05.2020: https://www.publico.es/economia/burbujaalquiler-pinchazo-burbuja-alquiler-coronavirus-seis-claves.html, last access: 5 May 2020.

Beswick, J., Alexandri, G., Byrne, M., Vives-Miró, S., Fields, D., Hodkinson, S. y Janoschka, M. (2016): Speculating on London's housing future, City 20 (2), 321-341, doi:10.1080/13604813.2016.1145946.

Bittner, C. y Michel, B. (2018): Qualitative Geographische Informationssysteme. In: Wintzer, J. (ed.): Sozialraum erforschen: Qualitative Methoden in der Geographie, Springer Spektrum, Berlin, Heidelberg, 151-166.

Blomley, N. (2008): Enclosure, Common Right and the Property of the Poor, Social y Legal Studies 17 (3), 311-331, doi:10.1177/0964663908093966.

Cano Fuentes, G., Etxezarreta Etxarri, A., Dol, K. y Hoekstra, J. (2013): From Housing Bubble to Repossessions: Spain Compared to Other West European Countries, Housing Studies 28 (8), 1197-1217, doi:10.1080/02673037.2013.818622.

Carretero, N. (2020): Desahuciados por la pandemia, El País, 19.04.2020: https://elpais.com/sociedad/2020-04-18/desahuciados-por-lapandemia.html, last access: 21 April 2020.

Cocola-Gant, A. y Gago, A. (2019): Airbnb, buy-to-let investment and tourismdriven displacement: A case study in Lisbon, Environ Plan A 0308518X1986901, doi:10.1177/0308518X19869012.

Colau, A. y Alemany, A. (2013): 2007-2012: retrospectiva sobre desahucios y ejecuciones hipotecarias en España, estadísticas oficiales e indicadores, $\mathrm{PAH}$ - Plataforma de afectados por la hipoteca: http://afectadosporlahipoteca.com/wp-content/uploads/2013/O2/RETROSPECTIVA-SOBRE-DESAHUCIOS-Y-EJECUCIONES-HIPOTECARIAS-EN-ESPA\%C3\%91A-COLAUALEMA NY1.pdf, last access: 31 July 2019.

Delgado Acosta, C. R. y Díaz-Rodríguez, M. d. C. (2010): Educación y empleo en Canarias.: Situación y estrategias para el cambio económico, BLOQUE $X$ : La Educación en la Formación de Activos para la Economía (Capítulo 40), 664-699.

Delgado González, G. A. y Slylus Pyzh, V. (2018): Análisis de las Viviendas Vacacionales en la localidad de Los Cristianos, Arona: Bachelorarbeit, Facultad de Economía, Empresa y Turismo, Universidad de La Laguna. 
Di Feliciantonio, C. y Aalbers, M. B. (2018): The Prehistories of Neoliberal Housing Policies in Italy and Spain and Their Reification in Times of Crisis, Housing Policy Debate 28 (1), 135-151, doi:10.1080/10511482.2016.1276468.

Díaz-Rodríguez, M. d. C., Ginés de la Nuez, Carmen, García-Hernández, J. S. y Armas-Díaz, A. (2017): Desposesión de vivienda y crisis social en Canarias, Naturaleza, territorio y ciudad en un mundo global. Actas del XXV Congreso de la Asociación de Geógrafos Españoles 1.025-1.034, doi: $10.15366 /$ ntc. 2017.

Dougherty, C. y Eligon, J. (2020): Protesting Without Gathering, Tenant Organizers Get Creative: Making the rent has gotten harder. So have conventional demonstrations. Housing activists are trying to raise their voices despite social distancing., New York Times, 23.04.2020:

https://www.nytimes.com/2020/04/23/business/economy/coronavirustenants-rent-protests.html, last access: 24 April 2020.

Elorduy, P. (2020): Amazon, Blackstone y BlackRock, los grandes beneficiados en la economía tras el covid-19, El Salto, 21.04.2020: https://www.elsaltodiario.com/crisis-economica/amazon-blackstone-blackrock-crisis-oportunidad-acumulacion-poder-economico, last access: 22 April 2020.

Fields, D. J. y Hodkinson, S. N. (2018): Housing Policy in Crisis: An International Perspective, Housing Policy Debate 28 (1), 1-5, doi: 10.1080/10511482.2018. 1395988.

García-Hernández, J. S., Díaz-Rodríguez, M. d. C. y García-Herrera, L. M. (2018): Auge y crisis inmobiliaria en Canarias: desposesión de vivienda y resurgimiento inmobiliario, INGEO (69), 23-39, doi:10.14198/INGEO2018.69.02.

García-Lamarca, M. y Kaika, M. (2016): «Mortgaged lives»: the biopolitics of debt and housing financialisation, Transactions (Institute of British Geographers 1965) 41 (3), 313-327, doi:10.1111/tran.12126.

García-Lamarca, M. (2017): From Occupying Plazas to Recuperating Housing: Insurgent Practices in Spain, International Journal of Urban and Regional Research 41 (1), 37-53, doi:10.1111/1468-2427.12386.

González Cabrera, I. (2018): ¿La necesaria regulación «ad hoc» de las viviendas vacacionales? El caso de Canarias, RIDETUR 2 (1), 23-54:

http://helvia.uco.es/xmlui/bitstream/10396/17155/1/2.pdf, last access: 15 May 2019.

González-Pérez, J. M., Vives-Miró, S. y Rullan, O. (2020): Evictions for unpaid rent in the judicial district of Palma (Majorca, Spain): A metropolitan perspective, Cities 97 102466, doi:10.1016/j.cities.2019.102466.

Harvey, D. (2020): We Need a Collective Response to the Collective Dilemma of Coronavirus, Jacobin, 24.04.2020:

https://www.jacobinmag.com/2020/04/david-harvey-coronavirus-pandemiccapital-economy, last access: 8 May 2020. 
Harvey, F., Kwan, M.-P. y Pavlovskaya, M. (2005): Introduction: Critical GIS, Cartographica: The International Journal for Geographic Information and Geovisualization 40 (4), 1-4, doi:10.3138/04L6-2314-6068-43V6.

Heeg, S. (2013): Wohnen als Anlageform: Vom Gebrauchsgut zur Ware, Emanzipation. Zeitschrift für sozialistische Theorie und Praxis 6 (2013), 5-20.

Hodkinson, S. (2012): The new urban enclosures, City 16 (5), 500-518, doi: 10.1080/13604813.2012.709403.

Hodkinson, S. y Essen, C. (2015): Grounding accumulation by dispossession in everyday life: the unjust geographies of urban regeneration under the private finance initiative, International Journal of Law in the Built Environment 7 (1), 72-91, doi:10.1108/IJLBE-01-2014-0007.

Janoschka, M., Alexandri, G., Ramos, H. O. y Vives-Miró, S. (2020): Tracing the socio-spatial logics of transnational landlords' real estate investment: Blackstone in Madrid, European Urban and Regional Studies 27 (2), 125 141, doi:10.1177/0969776418822061.

Jiménez Barrado, V. y Martín Sánchez, J. M. (2016): Banca privada y vivienda usada en la ciudad de Madrid, Investigaciones Geográficas (66), 43-58.

Knigge, L. y Cope, M. (2009): Grounded Visualization and Scale: A Recursive Analysis of Community Spaces. In: Cope, M., Elwood, S. (eds.): Qualitative GIS: A mixed methods approach, SAGE, Los Angeles, 97-114.

Lee, P. (2020): Private equity can be the big winner from Covid-19 sell-off: Private equity buyers have never had so much cash to put to work; they are already looking to make new investments in companies that will survive the lockdowns, Euromoney, 02.04.2020: https://www.euromoney.com/article/bllor609mm870v/private-equity-can-be-the-big-winner-from-covid19-sell-off, last access: 7 May 2020.

Lillo-Bañuls, A. y Casado-Díaz, J. M. (2012): Individual Returns to Education in the Spanish Tourism Sector during the Economic Crisis, Tourism Economics 18 (6), 1229-1249, doi:10.5367/te.2012.0171.

López, I. y Rodríguez, E. (2011): The Spanish Model, New Left Review 69 (3), 5-29. Madden, D. y Marcuse, P. (2016): In defense of housing: The politics of crisis, Verso, London, New York.

Marisol, G. (2010): The Breakdown of the Spanish Urban Growth Model: Social and Territorial Effects of the Global Crisis, International Journal of Urban and Regional Research 34 (4), 967-980, doi:10.1111/j.1468-2427.2010.01015.x.

Martin, R. (2011): The local geographies of the financial crisis: from the housing bubble to economic recession and beyond, Journal of Economic Geography 11 (4), 587-618, doi:10.1093/jeg/lbq024.

Martín Martín, V. O. (1999): Tenerife: Coyuntura económica y transformación espacial en una isla turística, Cuadernos del Turismo 1999 (3), 69-91.

Martín Martín, V. O. (2000): El Turismo en el Sur de Tenerife: De la Renta Agraria a la Renta de Ocio, Ediciones del Cabildo de Gran Canaria y Cabildo de Tenerife, Santa Cruz de Tenerife. 
Martín Martín, V. O. (2005): De la agricultura al turismo: la génesis del espacio turístico en el Sur de Tenerife, Revista Basa 28 44-49.

Montezuma, J. y McGarrigle, J. (2019): What motivates international homebuyers? Investor to lifestyle «migrants» in a tourist city, Tourism Geographies 21 (2), 214-234, doi:10.1080/14616688.2018.1470196.

O'Sullivan, D. (2006): Geographical information science: critical GIS, Progress in Human Geography 30 (6), 783-791, doi:10.1177/0309132506071528.

Obeso Muñiz, Í. (2014): Análsis geográfico de los desahucios en España, Ería 95 (2014), 327-342.

Padberg, S. y Schraven, M. (2015): «Warum Spanien ein paar Jahre reich war?» Darf mit Wohnungen spekuliert werden?, GW-Unterricht 139 (3/2015), 42-53.

Pareja Eastaway, M. y Varo, I. S. M. (2002): The Tenure Imbalance in Spain: The Need for Social Housing Policy, Urban Studies 39 (2), 283-295, doi:10.1080/00420980120102975.

Parreño-Castellano, J., Domínguez-Mujica, J., Armengol-Martín, M., Pérez García, T. y Boldú Hernández, J. (2018a): Foreclosures and Evictions in Las Palmas de Gran Canaria during the Economic Crisis and Post-Crisis Period in Spain, Urban Science 109 (2), 1-15, doi:10.3390/urbansci2040109.

Parreño-Castellano, J. M., Morales, A. G. y Hernández Luis, J. A. (2018b): La (des)regulación territorial del crecimiento del alojamiento turístico. El ejemplo de Lanzarote, Islas Canarias (1991-2008), Ciudad y territorio: Estudios territoriales (195), 53-70.

Sabaté, I. (2018): To repay or not to repay: financial vulnerability among mortgage debtors in Spain, etnografica 22 (1), 5-26, doi:10.4000/etnografica.5130.

Sánchez, R., et al. (2018): MAPA | Así colonizan las principales ciudades y zonas turísticas españolas los grandes «caseros» de Airbnb, eldiario.es:

https://www.eldiario.es/economia/propietarios-especializadas-gestionanalojamientos-Airbnb_0_806669806.html, last access: 15 May 2019.

Schwaller, C. (2019): Crisis, austerity and the normalisation of precarity in Spain - in academia and beyond, Social Anthropology 27 (S2), 33-47, doi:10.1111/ 1469-8676.12691.

Soederberg, S. (2018): Evictions: A Global Capitalist Phenomenon, Development and Change 49 (2), 286-301, doi:10.1111/dech.12383.

Sokol, M. (2017): Financialisation, financial chains and uneven geographical development: Towards a research agenda, Research in International Business and Finance 39 678-685, doi:10.1016/j.ribaf.2015.11.007.

Thatcher, J., Bergmann, L., Ricker, B., Rose-Redwood, R., O'Sullivan, D., Barnes, T. J., Barnesmoore, L. R., Beltz Imaoka, L., Burns, R., Cinnamon, J., Dalton, C. M., Davis, C., Dunn, S., Harvey, F., Jung, J.-K., Kersten, E., Knigge, L., Lally, N., Lin, W., Mahmoudi, D., Martin, M., Payne, W., Sheikh, A., Shelton, T., Sheppard, E., Strother, C. W., Tarr, A., Wilson, M. W. y Young, J. C. (2016): Revisiting critical GIS, Journal of Economic Geography 48 (5), 815-824, doi:10.1177/0308518 X15622208. 
Thurber, A., Collins, L., Greer, M., McKnight, D. y Thompson, D. (2018): Resident experts: The potential of critical Participatory Action Research to inform public housing research and practice, Action Research 19147675031772579 , doi:10.1177/1476750317725799.

Torreblanca, M. E. (2020a): El fondo Lazora plantea subidas del $40 \%$ en las renovaciones de contratos de alquiler en plena crisis del coronavirus, El Diario, 24.04.2020:

https://www.eldiario.es/economia/Lazora-programa-extraordinario-renovaciones-contratos_0_1020148231.html, last access: 1 May 2020.

Torreblanca, M. E. (2020b): Inquilinos de Blackstone denuncian un aumento de presiones durante la crisis de la COVID para futuros desalojos, El Diario, 27.04.2020: https://www.eldiario.es/economia/Inquilinos-Blackstone-denuncian-adicionales-COVID_0_1021198277.html, last access: 28 April 2020.

Unterzeichnenden, D. (2018): Für eine wirklich soziale Wohnungspolitik, sublurban. zeitschrift für kritische stadtforschung 6 (2/3), 205-222.

Valle, R. M. G. d. (2017): De la hipoteca al desahucio: ejecuciones hipotecarias y vulnerabilidad territorial en España, Revista de Geografía Norte Grande 67 (2017), 9-31.

Vives-Miró, S. (2018): New rent seeking strategies in housing in Spain after the bubble burst, European Planning Studies 26 (10), 1920-1938, doi: 10.1080/ 09654313.2018.1515180.

Vives-Miró, S., González-Pérez, J. M. y Rullan, O. (2015): Home dispossession: the uneven geography of evictions in Palma (Majorca), DIE ERDE - Journal of the Geographical Society of Berlin 146 (2-3), 113-126.

Vives-Miró, S. y Rullan, O. (2017): Desposesión de vivienda por turistización? Revalorización y desplazamientos en el Centro Histórico de Palma (Mallorca), Revista de Geografía Norte Grande 0 (67), 53-71.

Vives-Miró, S., Rullan, O. y Pérez, J. M. G. (2017): Consecuencias sociales del modelo económico basado en el crédito. Geografía de las ejecuciones hipotecarias en Menorca, Scripta Nova. Revista Electrónica de Geografía y Ciencias Sociales 21 (553), doi:10.1344/sn2017.21.17363.

Vollmer, L. y Michel, B. (2020): Wohnen in der Klimakrise, sublurban. zeitschrift für kritische stadtforschung

https://zeitschrift-suburban.de/sys/index.php/suburban/article/view/552, last access: 23 January 2020.

Wetzstein, S. (2017): The global urban housing affordability crisis, Urban Studies 54 (14), 3.159-3.177, doi:10.1177/0042098017711649.

Wijburg, G., Aalbers, M. B. y Heeg, S. (2018): The Financialisation of Rental Housing 2.0: Releasing Housing into the Privatised Mainstream of Capital Accumulation, Antipode 50 (4), 1.098-1.119, doi:10.1111/anti.12382.

Woetzel, J., Ram, S., Mischke, J., Garemo, N. y Sankhe, S. (2014): A blueprint for addressing the global affordable housing challenge, McKinsey Global Institute: https://www.mckinsey.com/featured-insights/urbanization/tacklingthe-worlds-affordable-housing-challenge, last access: 21 February 2019. 


\title{
FINANCIARIZACIÓN Y MERCADO DE ALQUILER EN LAS CIUDADES ESPAÑOLAS \\ FINANCIALIZATION AND RENTAL MARKET IN SPANISH CITIES \\ Ricardo Méndez Gutiérrez del Valle \\ Universidad Complutense de Madrid
}

\begin{abstract}
Resumen
La evolución reciente de las ciudades españolas está condicionada por la creciente atracción del capital financiero hacia la inversión inmobiliaria. Tras la burbuja de precios producida a comienzos de siglo que tuvo como soporte el crédito hipotecario, cuyo estallido provocó una profunda crisis, desde 2013 se inició un nuevo ciclo inmobiliario que incluye la reactivación del mercado de alquiler, generadora de fuertes contradicciones sociales y espaciales. El texto analiza la evolución reciente de la vivienda en alquiler y de sus precios, así como sus fuertes desigualdades espaciales a diferentes escalas, interpreta los principales factores de la reactivación, con especial protagonismo de nuevos actores financieros, y destaca su importancia actual como modo de extracción de rentas y factor de exclusión residencial.
\end{abstract}

Palabras clave: financiarización, ciclos inmobiliarios, mercado de alquiler, desigualdades urbanas.

\begin{abstract}
In recent years, the evolution of Spanish cities is conditioned by the growing attraction of financial capital towards real estate investment. After the housing bubble produced at the beginning of the century that was supported by mortgage credit, whose burst caused a deep crisis, since 2013 a new real estate cycle began that includes the reactivation of the rental market, which causes strong social and spatial contradictions. The text analyzes the recent evolution of rental housing and its prices, as well as its strong spatial inequalities at different scales, explain the main factors of revitalization, with the special leadership of new financial actors, and highlight its current importance as a way of rent extraction and a factor of residential exclusion.
\end{abstract}

Keywords: financialization, real estate cycles, rental market, urban inequalities.

\section{INTRODUCCIÓN}

Pese a su reducida importancia en el contexto europeo, la proporción de población que reside en viviendas de alquiler ha experimentado un crecimiento significativo desde hace algo más de una década, aunque con notables di- 
ferencias según grupos sociales y territorios. Esa reactivación se ha acompañado por un paralelo incremento del precio de los alquileres, que en algunas ciudades y determinados barrios evidencia la aparición de procesos especulativos antes vinculados casi en exclusiva a los precios de venta. El resultado ha sido un agravamiento del estrés residencial que padecen algunos colectivos y la aparición de movimientos sociales urbanos que han puesto en marcha de acciones de resistencia frente a los procesos de desposesión que se siguen produciendo en nuestras ciudades, ahora derivados en su mayoría del impago de esas rentas. Por todo ello, la vivienda en alquiler se convierte en uno de los ámbitos donde mejor se manifiesta la actual reconfiguración capitalista de los espacios urbanos en este nuevo ciclo de acumulación, construido sobre los escombros dejados por la última gran crisis.

Con ese contexto, tras un breve apartado teórico inicial sobre la necesidad de incorporar el concepto de financiarización a los actuales estudios urbanos y, en particular, sus vínculos con las dinámicas inmobiliarias, el objetivo de la comunicación es analizar la evolución reciente de la vivienda en alquiler en las ciudades españolas, identificar su desigual reflejo en el incremento de sus precios a diferentes escalas, así como algunas de sus consecuencias más negativas. Pero, de forma especial, se pretende participar en el debate sobre las claves explicativas de ese rápido encarecimiento en determinados espacios urbanos, cuestionando las interpretaciones que fijan su atención en el simple desajuste entre oferta y demanda para destacar el protagonismo de nuevos actores, con atención especial - aunque no exclusiva- a los financieros (Méndez, 2019). Se analiza por ello especial detenimiento lo ocurrido en la ciudad de Madrid, que resulta un excelente laboratorio para comprender el auge del alquiler como mecanismo de extracción de rentas en perjuicio de los grupos sociales más desfavorecidos.

Respecto a las fuentes, la dificultad que supone la ausencia de una estadística oficial exige combinar otras alternativas, resumidas en el boletín sobre alquiler residencial que, desde 2017 publica el Observatorio de Vivienda y Suelo del antiguo Ministerio de Fomento, con datos que hasta el momento alcanzan a 2018 (OVS, 2019). Aquí se incluyen la Encuesta de Condiciones de Vida (INE) y la Encuesta Financiera de las Familias (Banco de España), que permiten identificar su importancia, evolución y características de los residentes, mientras la Encuesta Continua de Hogares (INE) aproxima la situación del parque de vivienda en alquiler y la estadística que elabora el propio OVS a partir de la Agencia Tributaria y la Dirección General del Catastro, posibilita una desagregación para provincias y municipios con más de 25.000 habitantes. Con relación al precio, resulta habitual la utilización de los de oferta que recogen diversos portales inmobiliarios (Idealista, Fotocasa, Gesvalt), pues la única alternativa son los registros administrativos de algunas Comunidades Autónomas, con información sobre los depósitos de fianza por parte de los arrendadores (García Montalvo, 2019), si bien el hecho de que esa 
información no exista para 19 provincias justificó utilizar aquí los datos del portal idealista.com, disponibles hasta diciembre de 2019, por contar con la mayor cobertura del mercado y desagregación espacial, pese a que puedan introducir cierta sobrevaloración sobre el precio efectivo.

\section{FINANCIARIZACIÓN URBANA Y NUEVO CICLO INMOBILIARIO}

El mundo ha conocido en las últimas décadas un proceso de expansión financiera sin precedentes que ha acentuado el poder de las finanzas, tanto en el ámbito económico como en la acción de los gobiernos, las dinámicas urbanas o la vida cotidiana de los ciudadanos. La posición hegemónica del capital financiero, así como la difusión de su lógica de funcionamiento, genera impactos múltiples, lo que ha difundido las referencias a la existencia actual de un proceso de financiarización que resulta indisociable de la progresiva imposición de una racionalidad neoliberal hoy hegemónica (Chesnais, 2003; Lapavitsas, 2016).

Este capitalismo financiarizado tiene su propia geografía, pues tanto las estrategias de las diferentes entidades financieras como el trazado que siguen los movimientos del capital, muestran comportamientos espaciales muy selectivos, con las áreas urbanas —en especial las de mayor tamaño- como principales centros donde se acumula, gestiona e invierte ese capital (Méndez, 2018). En consecuencia, comprender mejor las transformaciones recientes de las ciudades exige prestar mayor atención a factores y actores de carácter financiero, cuyo interés por el negocio urbano ha sido creciente. Entre las diversas manifestaciones de esa influencia destaca la mayor atracción del capital financiero hacia el negocio inmobiliario. De este modo, «la vivienda y los bienes inmuebles urbanos se han convertido en producto de elección para el sector financiero corporativo, una caja de depósitos para los ricos, un depósito de capital y del exceso de liquidez de los mercados emergentes y un lugar conveniente para que las empresas ficticias guarden su dinero con muy poca transparencia» (Farha, 2017, 10).

No puede negarse la influencia que sobre la actividad inmobiliaria y los precios de la vivienda ejerce el incremento de la demanda derivado del aumento de la población o del número de hogares, el empleo o los ingresos. Pero esa interpretación ignora que el capital es el combustible esencial que pone en marcha la máquina del crecimiento urbano y, por tanto, las estrategias de los actores financieros - que son sus principales proveedores - resultan esenciales. Para este tipo de operadores, el suelo y la vivienda son un activo más del que extraer beneficios, lo que contribuye a la creciente mercantilización de una ciudad entendida como negocio, en detrimento de su función social como espacio para habitar, lo que la somete al imperio de los mercados (Theodore, Peck y Brenner, 2009).

La explicación más consistente de esa creciente simbiosis entre finanzas e inmobiliario fue propuesta por Lefebvre (1970) mediante la teoría del segundo 
circuito de acumulación, reformulada luego por Harvey (1985) y recogida por otros autores (Aalbers, 2016; Lois, Piñeira y Vives-Miró, 2016; Rolnik, 2018; De Mattos, 2018). Según esta propuesta, en las sociedades capitalistas avanzadas la tendencia estructural a reducir las plusvalías obtenidas en el circuito primario (producción, intercambio y distribución de bienes y servicios) favorece la reorientación de una parte creciente de esos excedentes hacia un circuito secundario relacionado con la producción del espacio, lo que convierte al inmobiliario y las áreas urbanas en fuente esencial de acumulación de capital, contando siempre con al apoyo del Estado.

No obstante, la evolución de la inversión y la producción inmobiliaria, el volumen de transacciones y los precios de venta o alquiler de las viviendas, están sometidas a oscilaciones cíclicas. Alternan así periodos de fuerte expansión, cuando la abundancia de capital y la facilidad para obtener crédito favorecen la creación de burbujas especulativas, con momentos de crisis, cuando el riesgo acumulado por el sobreendeudamiento alcanza sus límites, suben los tipos de interés y se frena la concesión de crédito, provocando una contracción que paraliza el mercado, devalúa los inmuebles y expulsa de sus viviendas a quienes no pueden pagar la deuda contraída.

En el caso de las ciudades españolas, tras los años de la burbuja inmobiliaria, la profunda crisis desatada a partir de 2007 tocó fondo en el año 2013, para iniciarse una recuperación desde entonces visible en múltiples indicadores y acompañada por nuevas contradicciones y desigualdades socio-espaciales. Pero esta fase expansiva de un nuevo ciclo no resulta una mera repetición de la registrada en 1996-2007, sino que presenta novedades sustanciales entre las que deben considerarse dos de particular importancia para los objetivos planteados: la incorporación de nuevos operadores financieros que comparten con los tradicionales el negocio de la ciudad y la dinamización del mercado de la vivienda en alquiler tras décadas de constante retroceso. Es indudable que en el ciclo anterior los bancos y cajas de ahorros fueron protagonistas destacados mediante la expansión sin precedentes de un crédito hipotecario que se convirtió en parte esencial de su negocio. La competencia por captar clientes propició la difusión de estrategias hipotecarias de riesgo y un masivo endeudamiento de promotores inmobiliarios, familias y empresas, que acabaron provocando el brusco final del proceso y una profunda crisis bancaria. Tras sanear sus balances, la banca española ha vuelto a impulsar desde 2013 la concesión de crédito para la promoción y compra de vivienda, con un aumento del $72,8 \%$ de las hipotecas entre ese año y 2018 , que alcanzó el $113,8 \%$ en su importe, aunque con cifras aún lejanas a las alcanzadas en los años de la burbuja.

Pero la principal novedad ahora radica en la mayor penetración del capital transnacional a través de diversos tipos de fondos de inversión y, entre ellos, de aquellos especializados en la actividad inmobiliaria, que en el ámbito internacional se conocen como REIT (Real Estate Investment Trust) y en Es- 
paña como SOCIMI (Sociedades Cotizadas de Inversión en el Mercado Inmobiliario). Se trata de sociedades de gestión colectiva de fondos obtenidos de bancos, empresas, inversores particulares, aseguradoras, etc., con los que realizan inversiones en actividades y territorios diversos buscando maximizar su beneficio a corto plazo y repartir dividendos anuales. Su penetración en el mercado inmobiliario español tuvo lugar a partir de 2013, concentrando buena parte de sus acciones en las grandes áreas urbanas y espacios turísticos litorales, considerados más rentables y de menor riesgo.

Por un lado, mediante compra grandes bolsas de suelo e inmuebles propiedad de bancos o de la SAREB, resultado de procesos de desahucio ejecutados a promotores o familias, que adquirieron muchas veces a precio de saldo. También por adquisición de grandes promotoras preexistentes o la creación de otras nuevas, lo que les permite controlar buena parte de la oferta de vivienda nueva (Méndez, 2019, 236-237). Por último, mediante la compra de viviendas sociales a gobiernos autonómicos o locales imbuidos del credo neoliberal, deseosos de hacer caja y con frecuentes connivencias con los gestores de esos fondos, con Madrid como principal ejemplo. En el caso de las SOCIMI, a eso se sumó un tratamiento fiscal favorable desde 2012, que les exime de pagar el impuesto de sociedades junto a una bonificación del 95\% en el de transmisiones patrimoniales y actos jurídicos documentados (VivesMiró y Rullán, 2014). El resultado ha sido un trasvase masivo de propiedad en pocos años, que se hace especialmente patente en las más de 100.000 viviendas que destinan al alquiler, con su máximo exponente representado por Blackstone, el mayor casero de España.

Junto al incremento de una demanda cautiva, que no puede acceder hoy a la compra de vivienda, la presencia de estos actores ha contribuido a elevar una oferta de vivienda en alquiler que cobra creciente importancia en este nuevo ciclo inmobiliario. Analizar sus principales características y su particular geografía, así como apuntar algunas estrategias extractivas asociadas es el contenido de esta investigación, que toma como base informes recientes sobre este mercado en España (Alves y Urtasun, 2019; García Montalvo, 2019; López Rodríguez y Matea, 2019) pero incide en su territorialización y, al descender al ámbito intraurbano en el caso de Madrid, permite hacer algunas aportaciones al debate actual sobre las claves de la llamada burbuja del alquiler.

\section{LA REACTIVACIÓN DE LA VIVIENDA EN ALQUILER Y SU RÁPIDO ENCARECIMIENTO}

La recuperación de la actividad inmobiliaria en España se inició en 2013 y se ha consolidado desde entonces, tal como evidencian numerosos indicadores que invierten las fuertes tendencias recesivas del sexenio anterior (Méndez, 2019,172 ), pero el cambio de tendencia más significativo corresponde a la vivienda en alquiler, que acaba con medio siglo de retroceso relativo. Según 
datos de la Encuesta de Condiciones de Vida del INE (Tabla 1), los hogares que en 2007 residían en una vivienda en propiedad eran cuatro de cada cinco, mientras la vivienda en alquiler o por cesión gratuita sumaba el 19,9\% restante. El estallido de la crisis paralizó el crédito y la compra de vivienda, por lo que en 2013 esa proporción había aumentado (22,3\%), pero la posterior recuperación no cambió la tendencia (23,9\% en 2018), con lo que los hogares que viven ahora en alquiler superan los tres millones y medio. Lo esencial de ese crecimiento corresponde a las viviendas en alquiler a precio de mercado (14,8\% del total), frente al constante retroceso del alquiler a precio inferior por contar con algún tipo de protección (2,7\%), agravando así la tradicional anemia del parque de vivienda pública en arrendamiento.

Tabla 1. Evolución del régimen de tenencia de la vivienda en España, 2007-2018 (\%)

\begin{tabular}{|l|c|c|c|c|c|}
\hline Años & $\begin{array}{c}\text { Vivienda en } \\
\text { propiedad }\end{array}$ & $\begin{array}{c}\text { Alquiler a } \\
\text { precio } \\
\text { mercado }\end{array}$ & $\begin{array}{c}\text { Alquiler a } \\
\text { precio } \\
\text { inferior }\end{array}$ & $\begin{array}{c}\text { Cesión } \\
\text { gratuita }\end{array}$ & $\begin{array}{c}\text { Alquiler } \\
\text { + cesión }\end{array}$ \\
\hline $\mathbf{2 0 0 7}$ & 80,1 & 10,4 & 3,2 & 6,3 & 19,9 \\
$\mathbf{2 0 1 3}$ & 77,7 & 12,9 & 2,5 & 6,9 & 22,3 \\
$\mathbf{2 0 1 8}$ & 76,1 & 14,8 & 2,7 & 6,4 & 23,9 \\
\hline
\end{tabular}

Fuente: INE. Encuesta de Condiciones de Vida

Ese incremento se ha producido, sobre todo, en las grandes áreas urbanas y los litorales turísticos, donde se alcanzan las tasas más elevadas. De este modo, el alquiler a precio de mercado supera el $20 \%$ de las viviendas en Baleares, Cataluña y Madrid, mientras en volumen absoluto, las provincias de Madrid (509.083) y Barcelona (474.550) suman casi un millón de viviendas y las mediterráneas comprendidas entre Girona y Málaga otras 590.183, que con las 219.852 de las tres provincias insulares reúnen más de la mitad de las contabilizadas. A escala municipal, las ciudades de Madrid (312.970) y BarceIona (180.128) se sitúan a notable distancia del resto, con Valencia y Zaragoza también por encima de las 50.000 viviendas, concentrando en sólo diez ciudades una quinta parte del total (788.267 viviendas).

Ese rápido aumento responde a la confluencia de diversos factores que han incrementado su demanda. Por una parte, el alquiler es la opción preferida por personas con elevada movilidad laboral, que no desean atarse al pago de una vivienda durante largos periodos de tiempo, con el segmento de profesionales jóvenes de alta cualificación como principal exponente. Pero la mayor parte de los que arriendan lo hacen más por necesidad que por voluntad, al enfrentar barreras de entrada para la compra debido a sus bajos ingresos o precariedad laboral, lo que les excluye del acceso al crédito hipotecario. Por ese motivo, la vivienda en alquiler tiene mayor presencia entre 
los grupos sociolaborales de riesgo. Sobre un promedio del $17,5 \%$, que asciende al 19,3\% en el caso de la mujer, el alquiler alcanza un 52,4\% entre los jóvenes con menos de 30 años, el 58,9\% entre los extranjeros procedentes de la Unión Europea y hasta el 77,3\% si lo hacen del resto del mundo. En cuanto al nivel de ingresos según Eurostat, el alquiler - junto a la cesión gratuita en este caso - tiene una presencia moderada (17,3\%) entre los hogares que superan el $60 \%$ de la renta media, frente al 43,3\% en el resto. Por esa razón, su rápido encarecimiento se convierte para una parte de la población en causa de estrés residencial, cuando no de exclusión.

Los datos disponibles sustentan la aparición en los últimos años de una burbuja del alquiler, si se entienden las burbujas de precios como episodios de fuertes y sostenidas alzas de precios de ciertos activos, no explicables por las condiciones del mercado. Según la fuente utilizada, en diciembre de 2006 el precio medio de oferta se situaba en 8,8 euros $/ \mathrm{m}^{2}$, pero el impacto de la crisis y las políticas de austeridad lo redujo a 7,2 euros al finalizar 2013. A partir de esa fecha, la reactivación del sector inmobiliario se reflejó de forma moderada hasta 2015, para iniciar desde entonces una escalada que alcanza los 10,9 euros en diciembre de 2019. Eso equivale a un encarecimiento del 45,3\% en los últimos cuatro años (Figura 1) y sitúa su precio medio muy por encima del anterior a la crisis, lo que no ocurre con el de venta, poniendo así en evidencia su creciente importancia como forma de extracción de rentas en un contexto de elevadas dificultades para el acceso a la propiedad de amplios sectores sociales. No obstante, la evolución interanual del precio confirma cierta moderación en el último año (4,8\%), pues la desaceleración general de la economía y unos precios excesivos en las grandes ciudades plantean crecientes dificultades a la población más vulnerable, evidenciando los límites que enfrentan incrementos de precio ajenos a toda racionalidad.

Un fenómeno especulativo aún más evidente si se compara la evolución de los alquileres y los precios de venta con la evolución de los salarios reales según la Encuesta Trimestral de Coste Laboral del INE. Mientras estos últimos crecieron poco más de un 3\% desde 2013, los precios de venta lo hicieron en promedio un 20\% y los del alquiler casi un 50\%. La intensificación del esfuerzo para acceder a una vivienda a que se enfrentan los arrendatarios tiene, como consecuencia directa, un aumento de los desahucios derivados del impago de los alquileres, que se convierten así en predominantes como forma de desposesión, al tomar el relevo a los que con anterioridad se derivaban del impago de las hipotecas.

Según datos del Consejo General del Poder Judicial, los lanzamientos recibidos en los servicios comunes del TSJ sumaron 708.292 entre enero de 2008 y el tercer trimestre de 2019, pero si en el primer trienio su promedio era de 102 por día, en el último alcanzó los 192 diarios. Por su parte, los lanzamientos practicados por los Juzgados de Primera Instancia desde el inicio de la reactivación en 2013, alcanzan los 426.593 hasta el tercer trimestre de 2019 (173 
por día), de los que 243.968 (57,2\%) lo fueron en aplicación de la Ley de Arrendamientos Urbanos, frente a 162.258 (38,0\%) por ejecución hipotecaria y el resto (20.367) por otras causas. Esa primacía de los desahucios por impago del alquiler se refuerza con el paso del tiempo: representaron el 52,9\% del total en 2014 , pero alcanzaron ya el 66,6\% en los tres primeros trimestres de 2019.

Figura 1. Evolución del precio del alquiler, venta de vivienda y salarios reales, 2006-2019
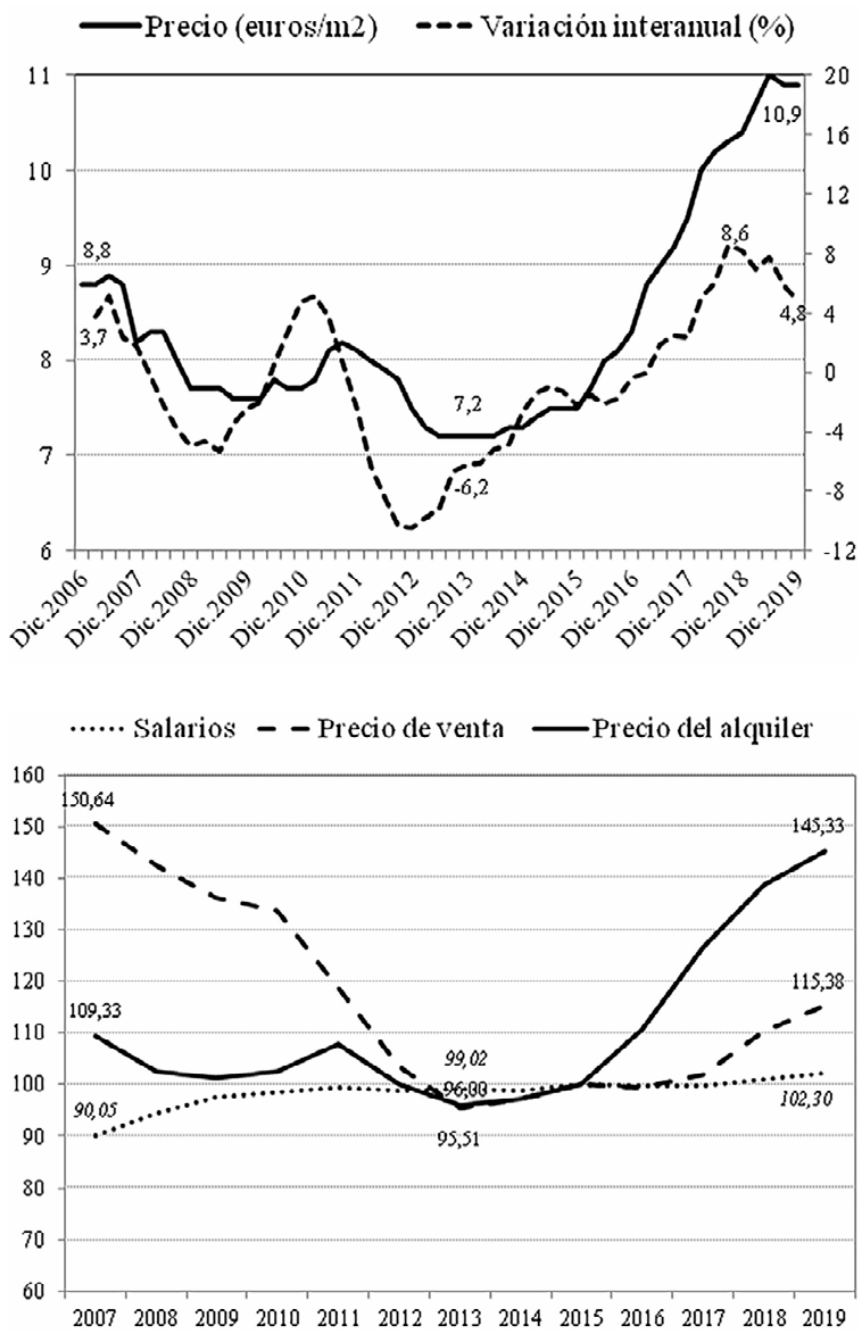

Fuente: idealista.com y elaboración propia 


\section{4. ¿BURBUJA DEL ALOUILER?: UNA PERSPECTIVA INTERURBANA}

La reactivación del mercado de vivienda en alquiler y la paralela subida de precios son procesos consolidados, pero sometidos a fuertes contrastes espaciales que acentúan la segmentación del territorio basada en una lógica mercantil, cualquiera que sea la escala de análisis utilizada. Pese a basarse en simples promedios estadísticos que ocultan importantes diferencias internas, el mapa provincial ofrece ya una visión sintética de esas tendencias y sus principales desequilibrios (Figura 2).

Figura 2. Distribución provincial de precios del alquiler 2019 y evolución 2013-2019

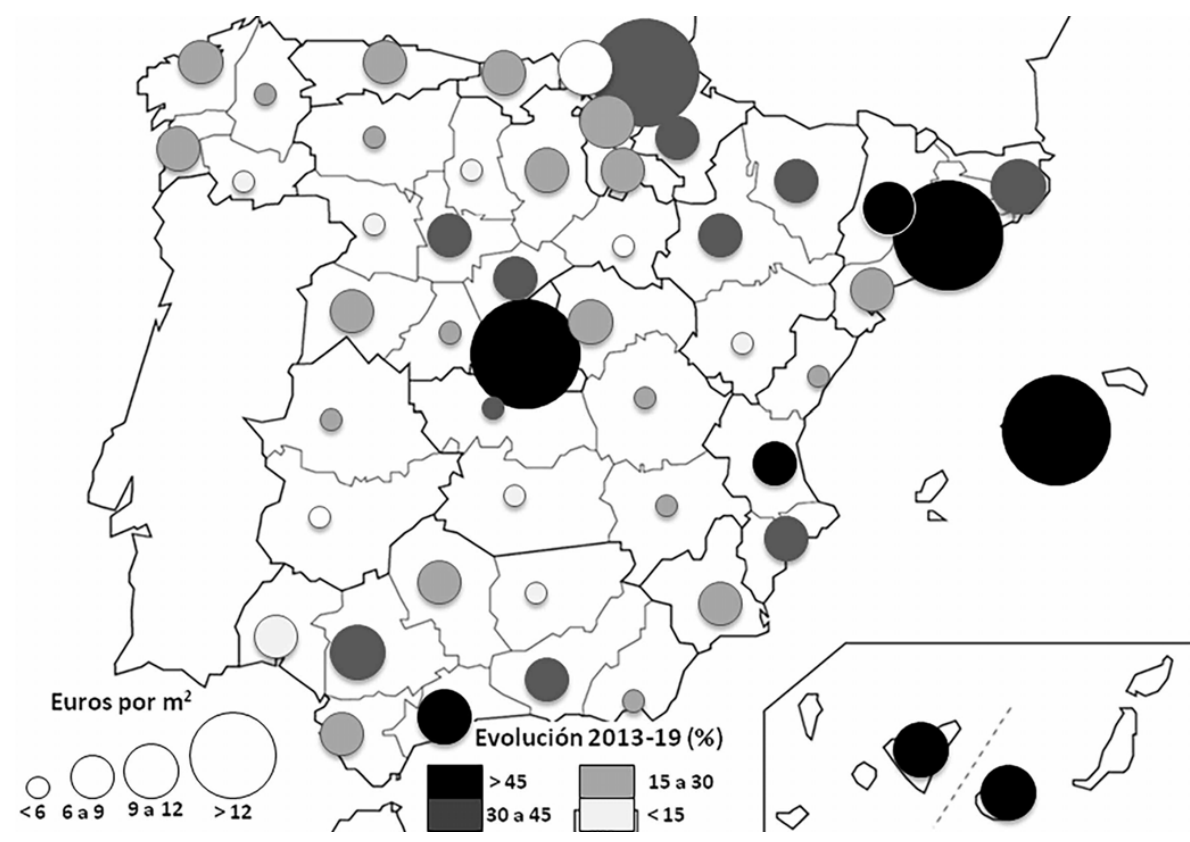

Fuente: idealista.com y elaboración propia

En diciembre de 2019 los precios medios de alquiler en Barcelona (14,9 euros $\left./ \mathrm{m}^{2}\right)$ y Madrid $(14,7)$ superan ampliamente los del resto, con valores elevados en las provincias con mayores ingresos por habitante, que cuentan con mercados de vivienda más dinámicos. Situación opuesta es la de provincias interiores aquejadas por una mayor atonía, aún por debajo de los 6 euros $/ \mathrm{m}^{2}$. Pero lo ocurrido en el último sexenio de recuperación económica ha extremado esa desigualdad, pues frente a un encarecimiento que supera el $50 \%$ en Illes Balears, Barcelona, Las Palmas, Santa Cruz de Tenerife, Valencia, Málaga, Madrid o Lleida, diez provincias no alcanzaron aumentos del 15\%, con la 
práctica estabilización de precios en algunas de ellas. Esa reactivación a diferentes velocidades contrapone, pues, la fuerte subida de precios en las provincias con grandes áreas urbanas y turísticas a un crecimiento muy moderado en territorios interiores que pierden población, pero también en provincias del litoral atlántico poco implicadas en los ciclos inmobiliarios de estas últimas décadas.

Si Burriel $(2014,106)$ afirmó que el mapa de la crisis era prácticamente el negativo del mapa de la burbuja, ahora vuelve a serlo del de la reactivación, con el alquiler como una de sus principales manifestaciones, tal como se constata cuando se aproxima la lente al ámbito urbano. Con la información disponible en el portal inmobiliario aquí utilizado como fuente, puede compararse la evolución de los precios de oferta durante el sexenio 2013-2019 en 220 municipios urbanos con más de 25.000 habitantes, frente a 63 sin información por la escasez de transacciones realizadas (Tabla 2).

Tabla 2. Precios extremos del alquiler en municipios con más de 25.000 habitantes

\begin{tabular}{|l|c|c|c|}
\hline \multicolumn{1}{|c|}{ Municipio } & $\begin{array}{c}\text { Valores máximos } \\
\text { (diciembre 2019) }\end{array}$ & Municipio & $\begin{array}{c}\text { Máximo aumento } \\
\text { 2013-2019 (\%) }\end{array}$ \\
\hline Eivissa & 17,4 & Granadilla de Abona & 76,92 \\
Barcelona & 16,5 & Estepona & 70,91 \\
Santa Eulalia del Río & 16,4 & Manacor & 70,59 \\
Madrid & 16,1 & Arrecife & 68,00 \\
S.Bartolomé Tirajana & 15,3 & Santa Eulalia del Río & 64,00 \\
San Sebastián/Donostia & 14,7 & Puerto del Rosario & 61,36 \\
Gavà & 14,6 & Arona & 60,27 \\
Sant Adrià de Besòs & 14,5 & Inca & 60,00 \\
Castelldefels & 14,4 & Eivissa & 59,63 \\
Calvià & 13,6 & Gavà & 56,99 \\
\hline \multicolumn{1}{|c|}{ Municipio } & Valores mínimos & Municipio & Mínimo aumento \\
& (diciembre 2019) & 2013-2019 (\%) \\
\hline Narón & 4,5 & S. Andrés Rabanedo & 4,08 \\
Lucena & 4,4 & Leioa & 4,04 \\
Puertollano & 4,2 & Santurtzi & $-4,12$ \\
Tomelloso & 4,0 & Melilla & $-4,55$ \\
Elda & & Puertollano & $-12,50$ \\
\hline
\end{tabular}

Fuente: idealista.com y elaboración propia

Como espacios privilegiados para la atracción de capital, así como de grupos socio-profesionales cualificados y de altos ingresos, las metrópolis de Barce- 
lona y Madrid superan los 16 euros $/ \mathrm{m}^{2}$, tal como también ocurre en los municipios turísticos de Santa Eulalia del Río y Eivissa. Valores también elevados se registran en otras grandes ciudades (San Sebastián, Bilbao), pero son más numerosos los núcleos turísticos insulares y algunos de los situados en entornos metropolitanos, sobre todo de Barcelona. En el extremo opuesto, pequeñas ciudades que han padecido procesos de declive industrial como Linares, Narón, Lucena, Puertollano o Tomelloso no superan los 4,5 euros $/ \mathrm{m}^{2}$, con Elda $(3,7)$ como máximo exponente.

Cuando se considera la evolución de esos precios en el último sexenio, se hacen más evidentes unos procesos especulativos con fuerte selectividad espacial, alcanzando tasas de crecimiento superiores al 70\% en los núcleos turísticos de Granadilla de Abona, Estepona y Manacor, mientras 15 de los 20 municipios con mayores incrementos tienen esa misma especialización funcional, superando incluso a las grandes ciudades. Como contrapunto, los alquileres aumentaron por debajo del 6\% en Ciudad Real, Elda, San Andrés del Rabanedo y Leioa, registrando incluso valores negativos en Santurtzi, Melilla o Puertollano. Pero es en la escala intraurbana donde pueden obtenerse resultados de mayor interés para entender las claves que justifican tales contrastes.

\section{ALQUILERES EN MADRID: UN MAPA DE CONTRASTES}

Como ciudad primada dentro del sistema urbano español, Madrid resulta un exponente destacado de las relaciones asimétricas entre propietarios y demandantes de vivienda, así como las notables desigualdades espaciales, que se suman a las sociales para construir un espacio urbano altamente fragmentado. Los más de 16 euros por metro cuadrado en diciembre de 2019 sitúan al municipio entre los más caros de España y el 45\% de aumento registrado en el último sexenio también resulta uno de los más elevados, pero es al analizar la situación en sus 21 distritos cuando se hace evidente la lógica mercantil que guía el proceso (Tabla 3).

Los 18,7 euros $/ \mathrm{m}^{2}$ del distrito Centro, junto a los 18,9 de Salamanca o los 18,1 de Chamberí, en los sectores más valorados del Ensanche, casi duplican los menos de 11 euros de Villaverde o Vicálvaro. Al descender a los barrios la brecha se hace más profunda, con los de Recoletos (Salamanca) y Trafalgar (Chamberí) por encima de los 20 euros $/ \mathrm{m}^{2}$, con los de Chueca-Justicia, Sol y Malasaña-Universidad (Centro), o los de Castellana y Goya (Retiro) en precios muy próximos, frente a los 9,8 euros de San Fermín (Usera) y los poco más de diez en Butarque y Los Ángeles (Villaverde), Rosas (San Blas-Canillejas), Valdebernardo-Valderribas (Vicálvaro), o Buenavista (Carabanchel). Pervive así la tradicional divisoria que contrapone los espacios centrales a los periféricos y los del noroeste a los del sureste de la ciudad, dibujando barreras intangibles que se resisten a desaparecer (Figura 3). 
Tabla 3. Precios de alquiler y venta de viviendas en los distritos de Madrid, 2013-2019

\begin{tabular}{|c|c|c|c|c|c|c|}
\hline Distrito & $\begin{array}{c}\text { Precio } \\
\text { alquiler } \\
\text { dic-2019 } \\
\left(\text { euros } / \mathrm{m}^{2}\right)\end{array}$ & $\begin{array}{l}\text { Evolución } \\
\text { alquiler } \\
\text { 2013-2019 } \\
\text { (\%) }\end{array}$ & $\begin{array}{l}\text { Evolución } \\
\text { alquiler } \\
2013-2016 \\
(\%)\end{array}$ & $\begin{array}{l}\text { Evolución } \\
\text { alquiler } \\
2016-2019 \\
(\%)\end{array}$ & $\begin{array}{c}\text { Evolución } \\
\text { precio venta } \\
2013-2019 \\
\text { (\%) }\end{array}$ & $\begin{array}{l}\text { Evolución del } \\
\text { precio de } \\
\text { alquiler/venta } \\
\text { (\%) }\end{array}$ \\
\hline Arganzuela & 15,80 & 45,14 & 23,74 & 17,30 & 49,85 & 90,56 \\
\hline Barajas & 11,70 & 14,91 & 3,86 & 10,64 & 25,83 & 57,72 \\
\hline Carabanchel & 12,00 & 36,18 & 18,41 & 15,02 & 27,22 & 132,93 \\
\hline Centro & 18,70 & 39,74 & 32,22 & 5,69 & 56,14 & 70,78 \\
\hline Chamartín & 16,30 & 32,83 & 14,81 & 15,69 & 29,44 & 111,50 \\
\hline Chamberí & 18,10 & 39,19 & 33,21 & 4,49 & 46,60 & 84,10 \\
\hline Ciudad Lineal & 13,50 & 32,13 & 19,66 & 10,42 & 22,18 & 144,84 \\
\hline Fuencarral-El Pardo & 12,60 & 27,54 & 15,58 & 10,34 & 26,52 & 103,83 \\
\hline Hortaleza & 12,30 & 12,86 & 6,49 & 5,99 & 28,60 & 44,98 \\
\hline Latina & 12,40 & 46,66 & 23,12 & 19,12 & 37,67 & 123,87 \\
\hline Moncloa-Aravaca & 14,60 & 28,52 & 26,76 & 1,39 & 29,98 & 95,12 \\
\hline Moratalaz & 11,20 & 34,45 & 16,66 & 15,25 & 32,51 & 105,95 \\
\hline Puente de Vallecas & 12,40 & 43,51 & 18,24 & 21,37 & 38,78 & 112,21 \\
\hline Retiro & 16,40 & 42,37 & 23,39 & 15,37 & 42,47 & 99,75 \\
\hline Salamanca & 18,90 & 42,18 & 25,71 & 13,10 & 46,39 & 90,92 \\
\hline San Blas-Canillejas & 11,90 & 28,20 & 14,40 & 12,06 & 14,79 & 190,64 \\
\hline Tetuan & 16,00 & 42,57 & 33,59 & 6,73 & 40,72 & 104,55 \\
\hline Usera & 11,90 & 34,57 & 10,30 & 22,01 & 27,98 & 123,57 \\
\hline Vicálvaro & 10,90 & 33,22 & 11,28 & 19,71 & 27,85 & 119,27 \\
\hline Villa de Vallecas & 11,30 & 29,19 & 10,71 & 16,69 & 23,10 & 126,36 \\
\hline Villaverde & 10,70 & 34,87 & 12,47 & 19,92 & 28,38 & 122,88 \\
\hline MADRID & 16,10 & 43,66 & 28,37 & 11,90 & 38,17 & 114,37 \\
\hline
\end{tabular}

Fuente: idealista.com y elaboración propia

Pero al considerar la evolución de esas desigualdades se confirma un efecto de contagio o difusión desde los distritos más valorados de la ciudad hacia otros contiguos e, incluso, algunos periféricos, en los que reside una población con menos ingresos y cualificación. Así, mientras en el trienio 2013-2016 el mayor encarecimiento afectó a los de Chamberí, Centro, Tetuán y Salamanca, todos localizados en el interior de la M-30, en el siguiente los incrementos más acusados se desplazaron a Usera, Puente de Vallecas, Villaverde, Latina y Vicálvaro, todos periféricos.

Su consecuencia, reflejo de unas dinámicas donde el precio de la vivienda responde a la lógica de un mercado sin apenas regulación, es una nueva división del espacio urbano -menos evidente que la anterior-que contrapone dos tipos de distritos (Tabla 3). Por un lado, aquellos con residentes de ingresos más elevados y mayores posibilidades de adquirir una vivienda, donde la 
subida del precio de venta superó la del alquiler, con todos los centrales y Moncloa-Aravaca, junto a Hortaleza y Barajas. Por otro, distritos con mayor presencia de residentes de bajos ingresos, donde el encarecimiento del alquiler superó al del precio de venta, con diferencias »20\% en San Blas-Canillejas, Ciudad Lineal, Carabanchel, Latina, Villa de Vallecas, Usera o Villaverde.

Figura 3. Precios de alquiler y evolución en los distritos de Madrid, 2013-2019

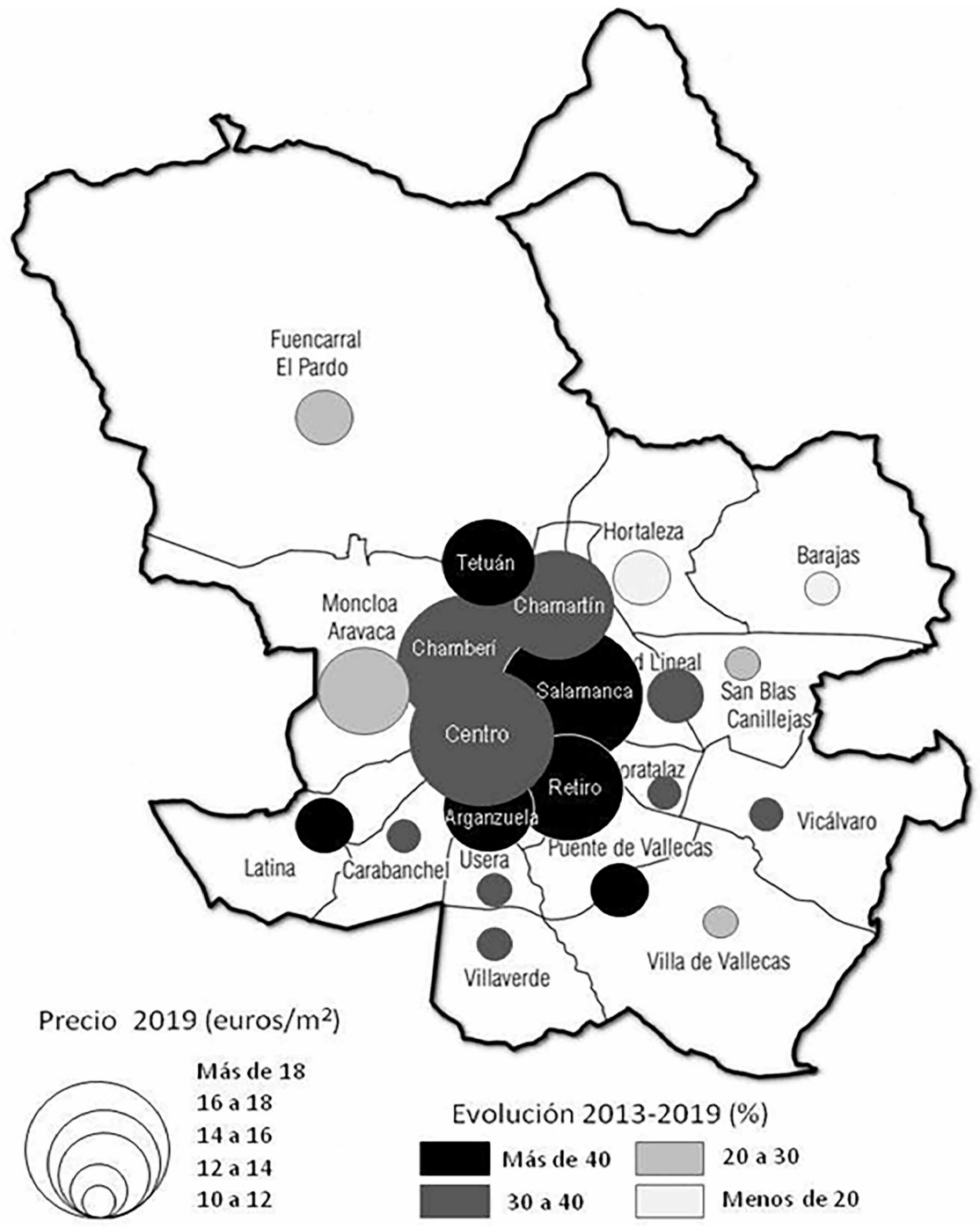

Fuente: idealista.com 
El arrendamiento se consolida, así como mecanismo extractivo, que presiona sobre los grupos sociales más vulnerables y acentúa los problemas de estrés residencial, al exigirles una proporción demasiado elevada de los ingresos familiares. También en vehículo que perpetúa los procesos de desposesión, pues entre enero 2013 y diciembre 2018 los lanzamientos practicados en Madrid por impago del alquiler fueron 17.446, tres cuartas partes de los 23.588 registrados en la capital.

Las claves del desigual aumento de precios son múltiples, pero se evidencian algunas regularidades significativas, que los diagramas y coeficientes de determinación de la Figura 4 sintetizan. Existe una elevada correlación positiva $\left(R^{2} \gg 0,50\right)$, de los precios del alquiler con las rentas por habitante y los valores catastrales de los inmuebles. Pero los mayores coeficientes son los que relacionan esos precios con la oferta turística total según número de plazas en hoteles y otro tipo de alojamientos contabilizadas por el Registro de Establecimientos Turísticos de la Comunidad de Madrid $\left(R^{2}=0,543\right) \mathrm{y}$, sobre todo, con las vinculadas a las viviendas de uso turístico $\left(R^{2}=0,727\right)$, que compiten con el alquiler residencial por espacios concretos del centro urbano.

Parece razonable asociar también ese incremento con la presencia de inmuebles propiedad de las 22 SOCIMIs especializadas en el alquiler residencial y de fondos de inversión, que gestionan las viviendas como activos de los que obtener unos dividendos anuales crecientes y provocan un efecto de arrastre sobre los precios de su entorno, lo que parece de especial importancia en algunos distritos periféricos donde esas entidades adquirieron inmuebles resultado de desahucios a la SAREB o diferentes bancos. La falta de información sobre la localización precisa de esa oferta inmobiliaria impide medir con precisión ese impacto, pero análisis monográficos como el de Janoschka et al. (2019) sobre la presencia de Blackstone en Madrid permiten deducir una significativa influencia, al constatar su elevada oferta de viviendas en alquiler en algunos de esos distritos que han conocido fuertes aumentos de precio en los tres últimos años. 
Figura 4. Relación del alquiler por distritos de Madrid en 2019 con otros indicadores socioeconómicos
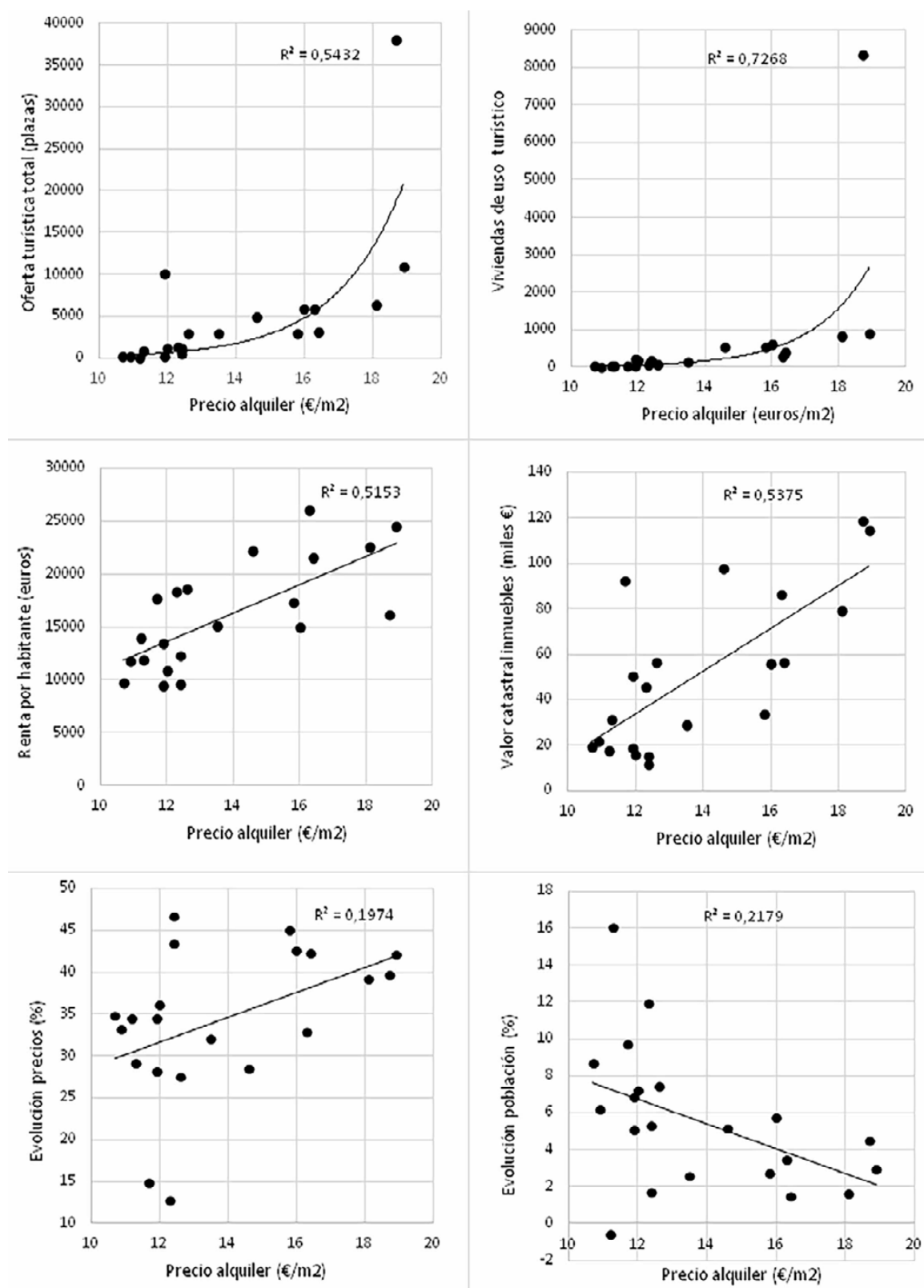

Fuente: idealista.com y elaboración propia 


\section{CONCLUSIONES BREVES}

En resumen, tal como afirman Madden y Marcuse $(2018,30)$, la vivienda «plantea interrogantes sobre el poder, la desigualdad y la justicia en la sociedad capitalista», lo que convierte hoy al alquiler en un campo de fuerzas desequilibrado, donde se contraponen actores con intereses diversos y se generan conflictos crecientes.

Más allá de la creciente demanda suscitada por el difícil acceso al crédito de amplios grupos sociales y la falta de respuesta pública en forma de una oferta suficiente de alquiler social, sólo una mayor colaboración entre los estudios de geografía urbana y geografía económica puede permitir comprender mejor los procesos de mercantilización urbana que subyacen a estas tensiones y la lógica espacial profundamente desigualitaria que conllevan. Pero las ciudades son también construcciones sociales y, por tanto, los actuales desequilibrios sólo podrán reorientarse si las demandas ciudadanas y la acción política promueven, de modo inaplazable, acciones reguladoras que permitan frenar los actuales excesos, hacer más efectivo el derecho a la vivienda y avanzar en la construcción de ciudades más equitativas y habitables.

\section{BIBLIOGRAFÍA}

Aalbers, M. (2016). The Financialisation of Housing: a Political Economy Approach. Londres-Nueva York: Routledge.

Alves, P. y Urtasun, A. (2019). Evolución reciente del mercado de la vivienda en España. Boletín Económico del Banco de España, 2/2019, 1-11 «https://www.bde.es/f/webbde/SES/Secciones/Publicaciones/InformesBoletinesRevistas/ArticulosAnaliticos/19/T2/descargar/Fich/be1902-art9.pdf»

Burriel, E. (2014). El estallido de la burbuja inmobiliaria y sus efectos en el territorio. En J. M. Albertos y J. L. Sánchez (Coords.). Geografía de la crisis económica en España. Valencia: Publicacions Universitat de Valéncia, pp. 101-140.

Chesnais, M. (2003). La teoría del régimen de acumulación financiarizado: contenido, alcance e interrogantes. Revista de Economía Crítica, 1, 37-72 «http:// www.revistaeconomiacritica.org/sites/default/files/revistas/n1/4_teoria_regimen.pdf»

De Mattos, C. (2018). Crecimiento urbano financiarizado. Documentos de Trabajo IEUT, 4, 1-30 «https://www.researchgate.net/publication/328428857 Crecimiento_urbano_financiarizado»

Farha, L. (2017). Informe de la Relatora Especial sobre una vivienda adecuada como elemento integrante del derecho a un nivel de vida adecuado y sobre el derecho de no discriminación a este respecto. Nueva York: Naciones Unidas, Consejo de Derechos Humanos, 1-25.

García Montalvo, J. (2019). Retos del mercado del alquiler en España. Cuadernos de Información Económica, FUNCAS, 269, 1-11. 
Harvey, D. (1985). The Urbanization of Capital. Studies on the Story and Theory of Capitalist Urbanization. Baltimore: Johns Hopkins University Press. Janoschka, M., Alexandri, G., Orozco, H. y Vives-Miró, S. (2019). Tracing the socio-spatial logics of transnational landlords' real estate investment: Blackstone in Madrid. European Urban and Regional Studies, 20 enero 2019, 1-17.

Lapavitsas, C. (2016). Beneficios sin producción. Cómo nos explotan las finanzas. Madrid: Traficantes de Sueños.

Lefebvre, H. (1970). La révolution urbaine. París: Éditions Gallimard.

Lois, R., Piñeira, M. J. y Vives-Miró, S. (2016). El proceso urbanizador en España (1990-2014): una interpretación desde la geografía y la teoría de los circuitos de capital. Scripta Nova, XX, 539, 1-27 «http://www.ub.edu/geocrit/sn/sn539.pdf»

López Rodríguez, D. y Matea, M. L. (2019). Evolución reciente del mercado del alquiler de vivienda en España. Boletín Económico, Madrid: Banco de España, 3.

Madden, D. y Marcuse, P. (2018). En defensa de la vivienda. Madrid: Capitán Swing.

Méndez, R. (2018). La telaraña financiera. Una geografía de la financiarización y sus crisis. Santiago de Chile-Barcelona: RIL Editores.

Méndez, R. (2019). Ciudades en venta. Estrategias financieras y nuevo ciclo inmobiliario en España. Valencia: PUV.

Observatorio de Vivienda y Suelo (2019). Boletín especial. Alquiler residencial, 2019. Madrid: Ministerio de Fomento.

Rolnik, R. (2018). La guerra de los lugares. La colonización de la tierra y la vivienda en la era de las finanzas. Barcelona: Descontrol.

Theodore, N., Peck, J. y Brenner, N. (2009). Urbanismo neoliberal: la ciudad y el imperio de los mercados. Temas Sociales, 1-11, «file:///C:/Users/usuario/Downloads/SUR-TemasSociales066.pdf».

Vives-Miró, S. y Rullán, O. (2014). La vivienda en el tránsito de la reproducción ampliada del capital a la acumulación por desposesión en España. XII Coloquio y Trabajos de Campo del Grupo de Geografía Urbana (ACE): Territorios inconclusos y sociedades rotas, 1-15. 




\section{LA PLANIFICACIÓN URBANA EN CIUDADES MEDIAS CATALANAS 1979-2019. MANRESA Y LLEIDA \\ URBAN PLANNING IN MEDIUM SIZED CATALAN CITIES \\ (1979-2019). MANRESA Y LLEIDA \\ Carme Bellet Sanfeliu \\ Universitat de Lleida}

Resumen

La planificación urbana, sus estrategias y el modelo de ciudad en la que se basan y a la vez promueven, ha cambiado mucho desde los ayuntamientos democráticos de 1979. El trabajo pretende caracterizar, a través de los casos de Lleida y Manresa, la transformación que ha experimentado el planeamiento urbano de primera escala (planeamiento general), la gestión en su despliegue (planeamiento derivado), así como los modelos de ciudad subyacentes. Todo ello se realiza a través del análisis bibliográfico y documental del planeamiento aprobado que se acompaña del estudio de las dinámicas de crecimiento de la población y vivienda a través de los Censos.

Palabras clave: planificación urbana, Planes de Ordenación Urbana, proyectos urbanos, ciudades medias, neoliberalismo.

\section{Abstract}

Urban planning strategies and the city model on which they are based, and at the same time promote, has changed a lot since the first democratic city councils in 1979. The work aims to characterize, through the cases of Lleida and Manresa, the transformation that has undergone first-scale urban planning (master plans), management in its deployment (secondary scale urban planning), as well as city models underlying. All this is done through the bibliographic and documentary analysis of the approved master plans that is accompanied by the study of the dynamics of population growth and housing through the Census.

Keywords: urban planning, master plans, urban projects, medium sized cities neoliberalism.

\section{EL CONTEXTO DEL PLANEAMIENTO EN ESPAÑA Y CATALUNYA: 1979-2019}

Como muchos trabajos han ido ya mostrando, existe en el país desde mediados de siglo XX, una fuerte vinculación entre crecimiento económico y crecimiento del sector de la construcción (López y Rodríguez, 2010), que lleva a 
algunos autores a hablar del capitalismo inmobiliario español (Naredo, 2010). Esta vinculación ha configurado un modelo urbano expansivo, especulativo e insostenible que ha resultado en un frenético ritmo de artificialización del suelo, con la inestimable cobertura de la legislación vigente y un planeamiento urbano sometido a los designios del urbanismo neoliberal (Gaja, 2015, Górgolas, 2017).

El planeamiento urbano ha favorecido estos procesos y ha pasado de ser una garantía de racionalidad territorial y de defensa del interés general, «a convertirse en un instrumento de seguridad jurídica al servicio de intereses económicos particulares» (Romero et al., 2015).

Figura 1. Dinámica inmobiliaria en España y Catalunya

y períodos de planeamiento urbano municipal

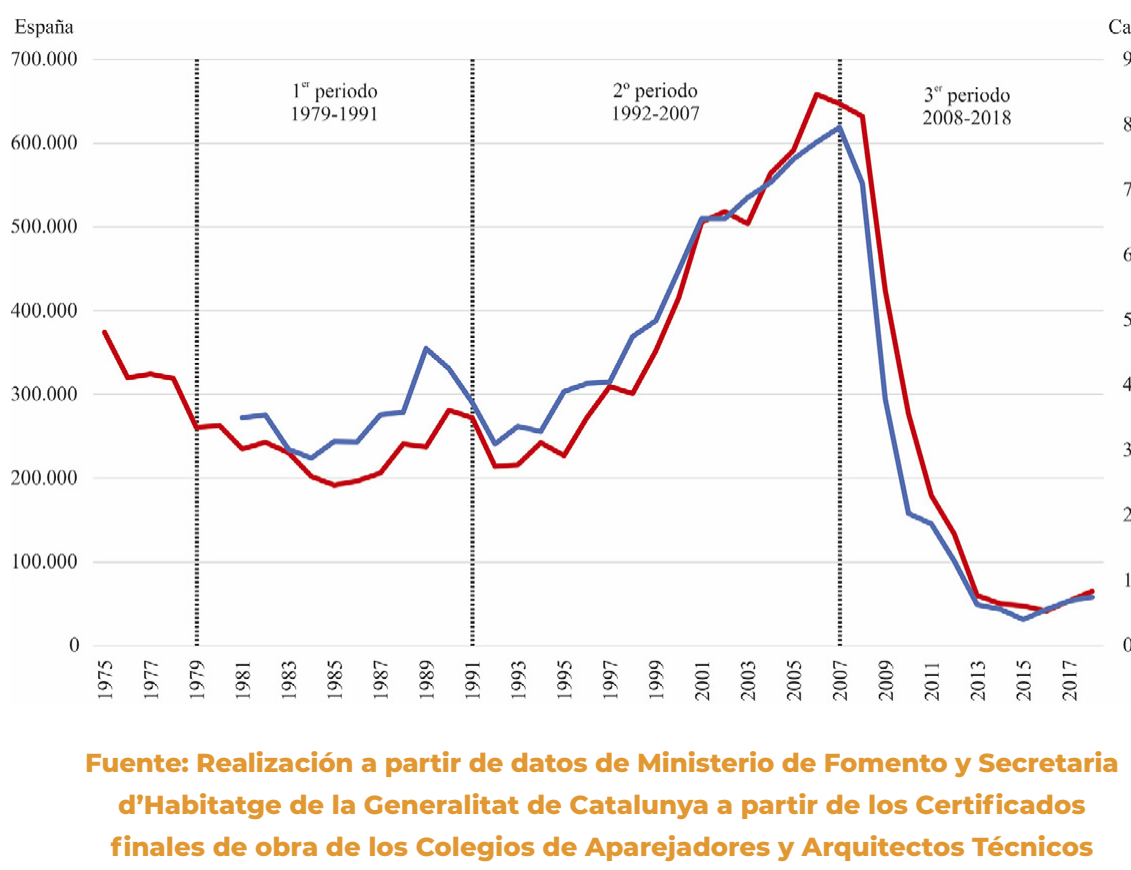

El trabajo plantea la relación existente entre las características del planeamiento urbano, los modelos de urbanización subyacentes en ellos y la urbanización resultante.

A través, fundamentalmente del análisis bibliográfico el apartado trata de caracterizar la evolución de las políticas urbanísticas desplegadas desde los primeros ayuntamientos democráticos hasta la actualidad. Para ello, establecemos tres períodos de análisis: 1979-1991; 1992-2007 y 2008-2019, cuya deli- 
mitación se define a partir de la evolución de la dinámica inmobiliaria y las fechas de celebración de las elecciones a gobiernos municipales desde 1979 (Bellet, 2020).

\subsection{LA REVISIÓN DEL PLANEAMIENTO ANTERIOR Y EL NUEVO MODELO DE CIUDAD ASO- CIADO AL «URBANISMO URBANO» (1979-1991)}

El primero de los períodos transcurriría desde las primeras elecciones democráticas de 1979 hasta 1991. En este período los nuevos ayuntamientos emprendieron la definición de las nuevas agendas municipales en las que el urbanismo ocuparía un papel central. Los nuevos consistorios empezaron revisando el planeamiento urbano municipal (Planes Generales o Normas Subsidiarias) cuya revisión iría más allá de la adaptación de los preceptos de la Ley del Suelo de 1975 (Ley 19/1975). Los ayuntamientos aprovecharon para reorientar el modelo y las dterminaciones del Plan revisando las especulativas ordenanzas de edificación y las sobredimensionadas expectativas de crecimiento del planeamiento anterior. Los nuevos documentos priorizarían la reestructuración, la reforma y la mejora de la ciudad ya existente, a través de un tipo de urbanismo que ha venido siendo caracterizado como «urbanismo urbano» (MOPU, 1990). Se impondría así, en general, la reforma y la transformación urbana frente al crecimiento desmesurado del período anterior.

En 1982 se procede al traspaso de las competencias en materia de ordenación del territorio, urbanismo y vivienda del Estado a la Generalitat de Catalunya. Con el traspaso Ilegan las primeras actuaciones de la Generalitat que se centrará especialmente en la revisión y en la redacción de planeamiento general para los municipios que no disponían de él o tenían figuras no pertinentes. Así, se aprueban en el período un gran nombre de planes de ordenación cuyos contenidos serán claramente diferentes de aquellos de los años 1960s y 1970s '. Un nuevo planeamiento que expresa la voluntad de afrontar las principales problemáticas urbanas heredadas, aumentar las condiciones y la calidad de las dotaciones urbanas y parar el desarrollismo y destrucción del territorio (Ferrer, 1989).

Se producen así, por un lado, desclasificaciones de suelo y la revisión de aquellos planes parciales aprobados o en que ya estaban en tramite. En caso de contemplar nuevo suelo urbanizable y nuevos sectores de desarrollo, éstos se prevén como forma de completar la estructura urbana, e integrar áreas urbanas semiconsolidadas y semiperifericas o periféricas. Por otro, se revisa la zonificación, a veces muy generalista y poco adecuada al territorio o lugar,

1 Se cifran en 450 los documentos de Plan General o Normas Subsidiarias de planeamiento aprobados en Catalunya entre 1979 y 1989 (Ferrer, 1989). 
y las ordenanzas de edificación maximalista que provocaba la desintegración e inadecuación a los entornos existentes. Además, se aumentarán las reservas de suelo para dotaciones urbanas, parques y espacios libres y verdes.

En la gestión y despliegue de los nuevos Planes Generales el gran protagonista es la figura del Plan Especial (reforma, protección o mejora urbana). Este protagonismo le viene dado no sólo por el gran número de documentos redactados y aprobados en Catalunya, sino, también, porque el plan especial se convierte en una de las figuras que mejor reflejan las nuevas ideas urbanísticas del período. La mejora y reforma de la ciudad, así como la protección de centros históricos y paisajes o espacios naturales, serán su principal objetivo. Sin embargo, las características y naturaleza de los documentos van a ir cambiando a lo largo de la década y pronto los iniciales y ambiciosos proyectos sociales van a acabar convirtiéndose en proyectos formales y puramente arquitectónicos (Bellet, 1999).

Con la atención puesta en la ciudad más o menos consolidada no se hizo frente a la protección de espacios de interés especial (ambiental, patrimonial o paisajístico), a la protección de espacios vulnerables en suelo no urbanizable y a la coordinación supramunicipal en unos momentos en los que los procesos de suburbanización y periurbanización se encontraban ya más o menos avanzados en áreas metropolitanas y se iniciaban con fuerza alrededor de ciudades medias y territorios más dinámicos (Cebrián, 2007; Olazabal y Bellet, 2019).

\subsection{EL URBANISMO ESPECULATIVO Y EXPANSIONISTA ASOCIADO AL BOOM INMOBILIARIO (1992-2007)}

En una segunda etapa, que fijamos entre 1992-2007, se producen cambios urbanos notables derivados, por un lado, del nuevo contexto socioeconómico y financiero, y por otro, de la amplia aplicación de las políticas neoliberales (Naredo, 1996).

Pero, sin embargo, el cambio más importante del período es la desregulación de los mercados hipotecario y de suelo (Ley sobre el régimen del Suelo y Valoraciones Urbanas, Ley 6/1998)² que se sumó a la flexibilización del planeamiento y a la relegación de los planes reguladores en favor de la planificación estratégica y el despliegue de proyectos urbanos (Gaja, 2008). Con ello se renunciaba expresamente a la definición de un modelo de ciudad (Vives y Rullán, 2014; Méndez, 2018). La hipertrofia legislativa y la planificación urbanística fueron alimentando la producción de lo urbano, convirtiendo la ciudad y el territorio en

2 No es objeto del trabajo realizar un seguimiento profundo de la legislación urbanística pero se tratará de indicar aquello que se estime fundamental. Para el caso Español puede consultarse el trabajo de Calderón y García 2017. 
el objeto y sujeto de acumulación a través de clasificación como urbanizable de partes importantes del suelo municipal y de las continuas modificaciones del planeamiento (Calderón y García, 2017; Burriel, 2009; Rullán, 2016).

En lugar de regular el crecimiento urbano, el urbanismo se dirigia a fomentarlo con todos los recursos disponibles a su alcance. Y para ello se traladarían al urbanismo los principios neoliberales que Fernando Gaja concreta en: reclasificaciones y recalificaciones urbanísticas, el desarrollo de megaproyectos, la privatización de los servicios urbanos básicos y equipamientos públicos, la elitización de áreas de alto valor expectante y concesiones urbanísticas (Gaja, 2015).

En Catalunya, y una vez superados los déficits iniciales, se va elaborando una segunda generación de planes con características muy diferentes a los aprobados y desarrollados en el primer período (Ferrer y Solà Morales, 2005). Todo ello bajo el despliegue de la nueva Llei d'Urbanisme 2/2002 (Texto refundido $\mathrm{DL} 1 / 2010)^{3}$ que contemplaba los cambios derivados por la experiencia adquirida y algunos de los nuevos principios introducidos por la Ley estatal 6/19984. La Llei d'urbanisme 2/2002, aunque con particularidades, se ajusta en su contenido y estructura básica a aquello establecido en la Ley del Suelo de 1975. La segunda generación de planes generales en Catalunya, aprobados durante los años noventa, no supone tanto una gran renovación metodológica o del carácter de los documentos, pero si se introducen nuevas visiones de entre las que destacamos las tres siguientes:

- La ciudad o área urbana trata de vincular ciertas decisiones del propio Plan (estructura de los nucleos, viario, espacios verdes y dotaciones, etc) a la mirada territorial. Una de las líneas de la política sobre ordenación territorial en Catalunya se centrará precisamente, a partir del 2004 y tras el cambio político en el Parlament de Catalunya de $2003^{5}$, en el despliegue del planeamiento territorial (escala supramunicipal) ${ }^{6}$. (Nel.lo, 2010)

3 La Llei 2/2002, cita entre sus objetivos: apostar por un desarrollo urbanístico sostenible y, la siempre prometida, simplificación de los procedimientos urbanísticos. Los principios de la Ley se recogen en el texto refundido en el $D L 1 / 2010$, de 3 de agosto (Llei 16569/2010) que continua hoy vigente en Catalunya.

4 La Sentencia del Tribunal Constitucional 164/2001, deja sin efecto la Ley estatal 6/1998 y confirma la competencia autonómica en la definición de los criterios de clasificación de suelo, cerrando el debate que se fué produciendo desde la promulgación de la Ley estatal 8/1990 sobre Reforma del Régimen Urbanístico y Valoraciones de Suelo.

5 Pese a que las elecciones al Parlament de 2003 son ganadas por CiU, la coalición tripartita entre PSC, ERC y ICV logra formar gobierno después de 23 años de gobierno ininterrumpido de CiU.

6 Respecto al planeamiento territorial se redactan y aprueban en Catalunya los Planes Parciales Territoriales (6 en total), en despliegue de la Llei 23/1983 sobre el modelo Te- 
- La gran proliferación de los proyectos urbanos, quizás uno de los aspectos más característicos del urbanísmo español del período (Bellet, 2017), se contemplaban como instrumentos catalizadores para impulsar la transformación espacial, con el objetivo último (quizás el más discutible) de procurar la dinamización económica de la ciudad. Proyectos urbanos o proyectos de escala intermedia, que se califican de estratégicos, para los que se diseñan mecanismos específicos de gestión y a los que se confía la capacidad de transformar amplias áreas de la ciudad.

La herencia del período legó tras de sí planes con previsiones de crecimiento desmesuradas y proyectos urbanos fuera de escala, pero, sobre todo, la ilustrativa paradoja expresada por Fernado Gaja «suelo sin casas, casas sin gente, gente sin casa» (Gaja, 2008).

\subsection{LOS CAMBIOS TRAS EL URBANISMO «POST-CRISIS». LA EXPLOTACIÓN DE LAS PLUS- VALÍAS MÁS 0 MENOS CENTRALES (2008- EN ADELANTE)}

Tras los excesos, llegó la Ley estatal de suelo 8/2007, aunque tarde e insuficiente para lo que supuestamente pretendía corregir: introducir un cambio de paradigma incorporando criterios de sostenibilidad, eficiencia y ahorro energético. Entre otras cuestiones, establece que: solamente pueda clasificarse como urbanizable el suelo preciso para satisfacer las necesidades que lo justifiquen; se protege a los propietarios frente a los promotores de la actuación; se eleva la reserva minima para la construcción de viviendas protegidas, al 30 \% de la edificabilidad residencial, tanto en actuaciones de nueva urbanización, que suponen el paso de suelo rural a urbanizado, como en actuaciones que tengan por objeto reformar o renovar la urbanización de un ámbito de suelo urbano. Con las revisiones y las adaptaciones autonómicas a la Ley y la llegada de la crisis cambia el ciclo y la mirada del planeamiento hacía la ciudad. El urbanismo postcrisis, pero sobretodo la imposibilidad de continuar con la lógica de desarrollo, provocará un cambio en el modelo urbano expansivo volviendo a resurgir (aparentemente) el discurso del «urbanismo urbano» (Calderón y García, 2017). Por un lado, empiezan a proliferar las revisiones de los Planes Generales confirmando la tendencia a la desclasificación y revision de las previsiones de suelo urbanizable que inevitable-

rritorial del Plan General de Catalunya (PTCC). A su vez la Llei d'Urbanisme 2/2002 (art. 56) introduce como novedad la figura de los Planes Directores Urbanisticos que tienen, enre sus objetivos, fijar las directrices para la coordinación de la ordenación urbanística supramunicipal. 
mente generará mayor presión e incremento del valor del suelo urbano consolidado y, especialmente, del urbano no consolidado.

La mirada se vuelca hacía el suelo urbano tratando con actuaciones pequeñas (también para garantizar la viabilidad y la agilidad de las operaciones) de explotar las plusvalías de los espacios mejor localizados, los centrales. Ese cambio se refleja en los nuevos planes generales que ya contienen actuaciones que se concretan con un detalle casi de proyecto de intervención.

Estas actuaciones centrales vinen también a ser impulsadas por la Ley 8/2013, de Rehabilitación, Regeneración y Renovación urbanas (la Ley de las tres R). Tras la crisis, las nuevas estrategias inmobiliarias abandonan las grandes operaciones en la periferia urbana para dirigirse al desarrollo de proyectos en el interior de la ciudad a través de la rehabilitación o renovación (Calderón y García, 2018), que incidirán en cambios funcionales y del perfil socioeconómico de la población (García-Herrera, 2018). En paralelo, se van recuperando algunos grandes proyectos, especialmente tras la ligera recuperación del mercado en 2016, que contribuyen a consolidar una ciudad de fragmentos, privativa y colonizada por el capital financiero (Romero et al., 2015; Méndez, 2018).

\section{LAS ÁREAS URBANAS DE MANRESA Y LLEIDA. CONTEXTO TERRITORIAL Y DINÁMICAS DE CRECIMIENTO DE POBLACIÓN Y VIVIENDA}

El área urbana de Manresa, delimitada por el Ministerio de Fomento, es relativamente pequeña, con $96,9 \mathrm{~km}^{2}$ y contempla cuatro municipios: Manresa (77.714 habitantes en 2019), San Joan de Vilatorrada (10.936 hab.), Sant Fruitós de Bages (8.703 hab.) y Santpedor (7.554 hab.), que en total suman 106.926 hab. El área urbana se localiza en el interior y forma parte del Pla de Bages, un Ilano moldeado por los ríos Llobregat y Cardener, rodeado por un conjunto de sierras que han condicionado de forma notable el desarrollo urbano del área. Un espacio localizado en la depresión central de Catalunya, que se encuentra muy bien comunicada especialmente con Barcelona. El área con una base económica de industrialización histórica concentra los servicios y equipamientos más especializados de la comarca del Bages y del conjunto de comarcas de la Catalunya central. 
Figura 2. Área urbana de Lleida y Manresa

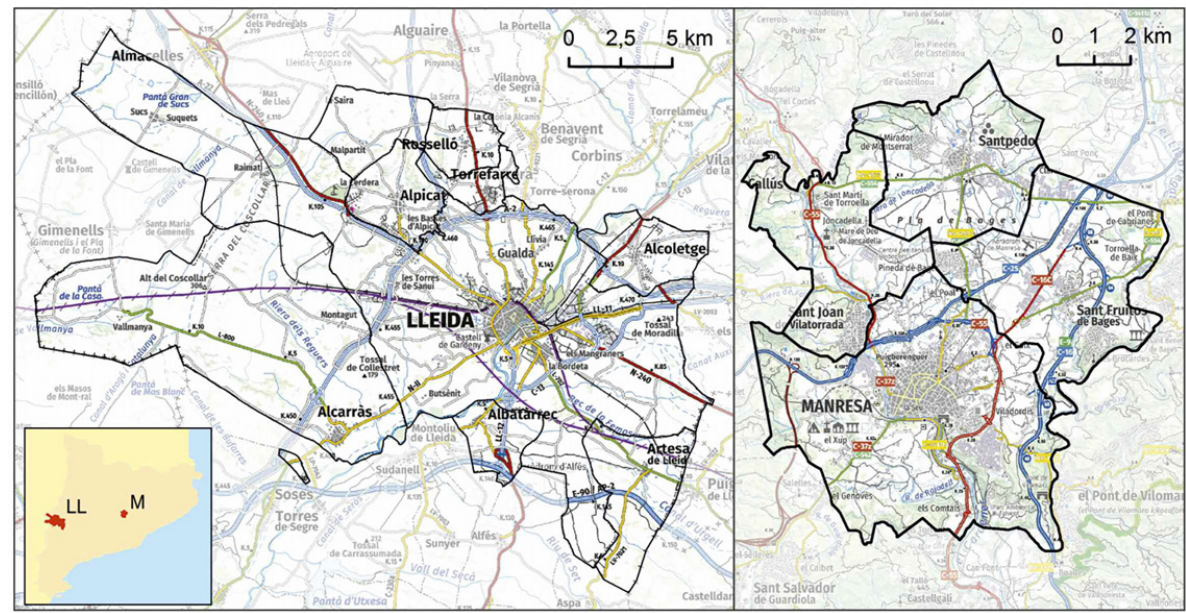

Fuente: Realización propia a partir de topográficos del Institut Cartogràfic i Geològic de Catalunya (IGCC)

El caso del área urbana de Manresa es interesante por varios motivos. Primero, por tratarse de una de las áreas con mayor recorrido en la planificación territorial con incidencia en el municipal, convirtiéndose en un notable referente en el contexto catalán. En especial por la tradición de la planificación territorial a escala de comarca y supramunicipal se refiere, antes incluso de la aprobación del Pla Terrtitorial General de Catalunya (PTGC), Ley 1/1995, y su desarrollo (Pla Territorial Parcial de les Comarques Centrals - PTPCC, 2008). Esta última figura se substituye con las indicaciones del Pla Director Urbanístic del Bagès (PDU del Bages, 2006), plan supramuniciapl destinado a orientar y coordinar el planeamiento local para hacer frente a las notables dinámicas de tranformación y dar una respuesta de conjunto a la problemática de los asentameintos urbanos, las infraestructuras y espacios abiertos del territorio (Sabaté, 2006) y cuyas propuestas básicas están integradas en el PTCC de 2008. Segundo, porque Manresa cuenta con tres Planes Generales aprobados desde 1979 lo que nos permite analizar el recorrido de las diferentes generaciones de Planes?.

Por su parte, el área urbana de Lleida, notablemente mayor con 426,3 km², integra 8 municipios que alojan 168.560 habitantes (2019) de los que el 87,8\%

7 Manresa cuenta ya con 5 planes de ordenación urbana: el Plan de Reforma y Ensanche de 1939, el Plan General de 1964, el Plan General de 1981, el Pla General de 1997 y, el último y vigente, el Plan de 2017. 
se concentran en la ciudad de Lleida. Los otros municipios integrantes del área urbana, según el Atlas del Ministerio de Fomento son: Albatàrrec (2.221 hab. en 2019), Alcarràs (9.514 hab.), Alcoletge (3.420 hab.), Alpicat (6.255 hab), Artesa de Lleida (1.504 hab.), Rosselló (3.145 hab.) y Torrefarrera (4.605 hab.).

Tabla 1. Dinámicas de crecimiento de población y vivienda en las áreas urbanas de Manresa y Lleida

\begin{tabular}{|c|c|c|c|c|c|c|c|c|c|}
\hline & \multirow{2}{*}{$\begin{array}{l}\text { Población } \\
2019\end{array}$} & \multicolumn{4}{|c|}{$\begin{array}{c}\text { Dinámicas de crecimiento } \\
\text { anual población }\end{array}$} & \multirow{2}{*}{$\begin{array}{l}\text { Vivienda } \\
2011\end{array}$} & \multicolumn{3}{|c|}{$\begin{array}{c}\text { Dinámicas de } \\
\text { crecimiento anual } \\
\text { vivienda }\end{array}$} \\
\hline & & $\begin{array}{l}1981- \\
1991\end{array}$ & $\begin{array}{l}1991- \\
2001\end{array}$ & $\begin{array}{c}2001- \\
2011\end{array}$ & $\begin{array}{l}2011- \\
2019\end{array}$ & & $\begin{array}{c}1981- \\
1991\end{array}$ & $\begin{array}{l}1991- \\
2001\end{array}$ & $\begin{array}{c}2001- \\
2011\end{array}$ \\
\hline $\begin{array}{c}\text { Municipio de } \\
\text { Manresa }\end{array}$ & 77.714 & $-0,1$ & $-0,4$ & 1,9 & 0,2 & 39.605 & 0,9 & 1,7 & 2,1 \\
\hline $\begin{array}{c}\text { Área Urbana } \\
\text { Manresa }\end{array}$ & 106.926 & 0,3 & 0,1 & 2,1 & 0,3 & 51.530 & 1,1 & 2,0 & 2,5 \\
\hline $\begin{array}{l}\text { Municipio de } \\
\text { Lleida }\end{array}$ & 138.956 & 0,5 & 0,0 & 2,2 & 0,2 & 66.415 & 1,5 & 2,4 & 1,6 \\
\hline $\begin{array}{c}\text { Área Urbana } \\
\text { Lleida }\end{array}$ & 169.620 & 0,5 & 0,2 & 2,8 & 0,3 & 79.825 & 1,6 & 2,3 & 2,3 \\
\hline
\end{tabular}

Fuente: Censos de Población, Edificios y Vivienda

(1981, 1991, 2001 y 2011) y Padrón Municipal de Habitantes de 2019

La ciudad es la capital de servicios de una extensa área territorial notablemente especializada en el sector agrario y agroindustrial, el Ilano de Lleida, en el poniente catalán. La ciudad y el área disfruta de una excelente conectividad a través de infraestructuras de transporte de alta capacidad. Su experiencia en la planificación territorial es menor que en el caso anterior. El Pla Territorial Parcial de les Terres de Lleida fue aprobado en 2004 que condicionó, de forma moderada, los crecimientos de los municipios del área, pero potenciaba el de Lleida a tratarse de la principal polaridad ${ }^{8}$.

Las dos áreas experimentan moderados crecimientos de población y vivienda en las décadas de los 1980s y 1990s, inferior al 0,5\% anual, para experimentar un crecimiento más importante durante la primera década del 2000, gracias especialmente a los aportes de la inmigración, notable en el área de Lleida. Otro paralelismo entre las dos áreas es el crecimiento relativo superior de los municipios immediatos a las cabeceras, alimentados especialmente por procesos de suburbanización y periurbanización, cuyas dinámicas se encuentran

8 El municipio de Lleida cuenta ya con 5 planes de ordenación aprobados: el Plan de Ensanche de 1865, el Plan de Ensanche de 1925, el Plan General de Ordenación Urbana de 1957, el Plan General Municipal de 1979 y el Plan General de Ordenación Urbana de 1999. Se encuentra en fase de tramitación un nuevo Plan General (2015-2020) que fue aprobado inicialmente en 2018. 
muy relacionadas con las dinámicas de migración residencial de la población procedente de la ciudad central. Ello explica el extraordinario crecimiento en población y vivienda de municipios como Alcarràs, Torrefarrera, Alcoletge y Albatàrrec en el área urbana de Lleida, o los más moderados de Santpedor y Sant Fruitós del Bages en el área de Manresa. De hecho, las dinámicas del mercado inmobiliario y de suelo, así como sus consecuencias, son desde los años 80 s supramunicipales. Pese a ello, y pese a la existencia de planificación territorial en Catalunya con incidencia en el potencial de crecimiento de los municpios en las dos áreas urbanas, el planeamiento y la política de suelo desplegada registra lógicas municipales y políticas de desarrollo de suelo (y de vivienda) bastante sobredimensionadas y que compiten entre sí ${ }^{9}$.

\section{EL PLANEAMIENTO MUNICIPAL APROBADO EN LLEIDA Y MANRESA (1979-2019)}

\subsection{PRIMER PERÍODO (1979-1991)}

En pleno contexto de cambio sociopolítico los municipios de Lleida y Manresa aprueban la revisión de sus respectivos Planes General, el primero aprobado en 1979 y el segundo en 1981. Las dos revisiones van mucho más allá de la adopción de los preceptos de la Ley del Suelo de 1975 y plantean, como en otros muchos casos, la recomposición de la ordenación urbana y la regulación normativa establecida por los anteriores planes generales, siguiendo la tendencia del urbanismo urbano. Los dos además reflejan perfectamente la reorientación del planeamiento que se viene redactando en Catalunya desde los últimos años de la dictadura y la transición, a través sobretodo de los profesionales formados en la Escuela de Arquitectura de Barcelona y el influyente Laboratorio de Urbanismo de la Escuela. La atención a la forma urbana, a la morfología de los tejidos, a la estructura y capacidad de recomposición a través del espacio público, son algunas de las señas de identidad de la escuela que se ven perfectamente en ambos Planes.

En ambos casos, además, se empieza por repensar los excesos de potenciales de crecimeintos del planeamiento anterior y tratar de corregir la desestructuración provocada por el desarrollo de suelo inadecuado (posición, características, planteamiento). En el caso de Manresa, por ejemplo, se plantea la reducción drástica de las densidades ya que con similar cantidad de suelo el Plan anterior permitía hasta 260.000 habitantes. En Lleida, el Plan de 1979 preve un máximo de habitantes para 1999 muy parecido al que el anterior Plan (Plan de Ordenación Urbana de 1957) ya había dispuesto: 137.369 habi-

9 Aunque no es objeto de este trabajo el anàlisis, que se está realizando en el marco de un proyecto más amplio, refleja la reacción al alza de la revisión del planeamiento de los municpios limítrofes a Lleida y Manresa con notables expectativas de crecimeinto y fuertes dinámicas de producción de suelo urbano. 
tantes previstos para 1979 en el Plan 1957-1979) y un máximo de 13.000 el Plan 1979-1999. En ambos casos se reducen las densidades de muchos de los planes parciales o sectores a desarrollar que se incorporan del planeamiento anterior, además de aumentar las dotaciones, parques y los esacios libres en todos los casos. Sorprende en el caso de Lleida las $1.340 \mathrm{Ha}$ de suelo urbanizable no delimitado que proviene de un proyecto heredado del período franquista, promovida por el sindicato vertical, que preveía en el oeste de la ciudad y desintegrado del núcleo urbano principal la construcción de una nueva ciudad Ilamada Ilerda 2000, para acoger 20.000 habitantes con más de 5.000 viviendas. En el área sólo acaban construyéndose unos equipamientos. El Plan de 1979 pasa esa situación a urbanizable no delimitado y queda desclasificado en el siguiente Plan General (1999).

Tabla 2. Potenciales de crecimiento, vivienda y clasificación de suelo en los diferentes Planes Generales de Lleida y Manresa

\begin{tabular}{|c|c|c|c|}
\hline Lleida & 1979 & 1999 & 2018 - A. Inicial \\
\hline Potencial máx. población & 150.000 hab. & $\begin{array}{c}\text { 144.623 hab. } \\
\text { (200.000 PTGC) }\end{array}$ & $\begin{array}{c}\text { 136.000-170.000 } \\
\text { hab. }\end{array}$ \\
\hline Potencial viviendas (a) & $\begin{array}{ll}------ \\
--1\end{array}$ & 25.781 viv. & 29.298 viv.(b) \\
\hline Suelo Urbano & $1.234 \mathrm{Ha}$ & $1.430,47 \mathrm{Ha}$ & $1.823,8 \mathrm{Ha}$ \\
\hline Suelo Urbanizable delimitado & $132,68 \mathrm{Ha}$ & $\begin{array}{c}503,8 \mathrm{Ha} \\
\text { (385 Ha suelo } \\
\text { residen.) }\end{array}$ & $\begin{array}{c}239,1 \mathrm{Ha} \\
\text { (61,4 Ha Suelo } \\
\text { residen.) }\end{array}$ \\
\hline $\begin{array}{l}\text { Suelo Urbanizable no } \\
\text { delimitado }\end{array}$ & $1.340,64 \mathrm{Ha}$ & $307,58 \mathrm{Ha}$ & $531,3 \mathrm{Ha}$ \\
\hline Total Suelo Urbanizable & $1.473,32 \mathrm{Ha}$ & $811,38 \mathrm{Ha}$ & $770,4 \mathrm{Ha}$ \\
\hline Manresa & 1981 & 1997 & 2017 \\
\hline Potencial máx. población & $\begin{array}{l}\text { 135.000-150.000 } \\
\text { hab. }\end{array}$ & 90.000 hab. & $\begin{array}{c}\text { 92.042-100.000 } \\
\text { hab. }\end{array}$ \\
\hline Potencial viviendas & ------- & 13.246 viv. & 10.505 viv. \\
\hline Suelo Urbano & $631,52 \mathrm{Ha}$ & $642,25 \mathrm{Ha}$ & $778,99 \mathrm{Ha}$ \\
\hline Suelo Urbanizable delimitado & $77,79 \mathrm{Ha}$ & $164,0 \mathrm{Ha}$ & $153,507 \mathrm{Ha}$ \\
\hline $\begin{array}{l}\text { Suelo Urbanizable no } \\
\text { delimitado }\end{array}$ & $176,32 \mathrm{Ha}$ & $223,7 \mathrm{Ha}$ & $56,36 \mathrm{Ha}$ \\
\hline Total Suelo Urbanizable & $254,11 \mathrm{Ha}$ & $387,76 \mathrm{Ha}$ & $209,867 \mathrm{Ha}$ \\
\hline
\end{tabular}

Fuente: Realización propia a partir de los documentos de Planeamiento. El planeamiento no vigente fué consultado en los Archivos del Ayuntamiento de Lleida y en el Archivo de Planeamiento del Departament de Territori i Sostenibilitat de la Generalitat de Catalunya en Barcelona. El planeamiento vigente en febrero de 2020 se ha consultado a través de la plataforma Registre de Planejament Urbanístic de Catalunya (RPUC: http://ptop.gencat.cat/rpucportal/inici/ca/index.html)

a) Viviendas potenciales en suelo urbano no consolidado y suelo urbanizable delimitado/sectrizado o no

b) 10.295 viviens en suelo urbano no consolidado y 15.909 en urbanizable no delimitado 
En el caso de Manresa la clasificación de suelo en la ciudad del Plan de 1981 tiene además en cuenta la dinámica y estado de suelo del territorio inmediato. Por ello acaba desclasificándose mucho suelo, especialmente industrial en un contexto de crisis del sector, y en los usos residenciales se baja mucho las densidades ya que el planeamiento anterior con una cantidad similar de suelo permitía una población de hasta casi 260.000 habitantes ${ }^{10}$.

Figura 3. Plan General Municipal de Lleida de 1979 (izquierda) y Plan General Municipal de Manresa 1981 (derecha)

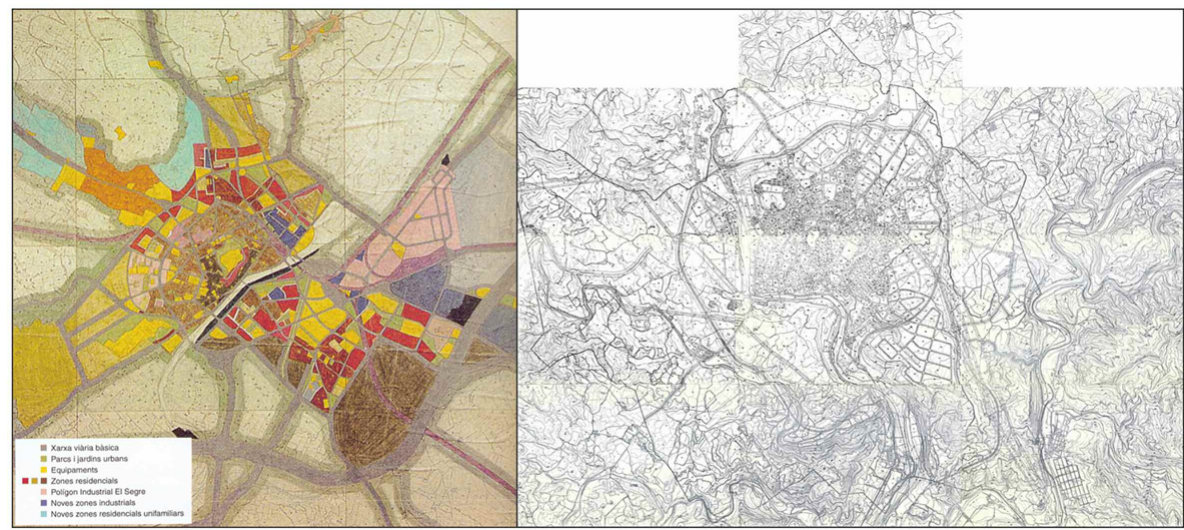

Fuente: Documentos originales presentados a la aprobación definitiva en ambos casos

Las orientaciones de ambos planes van en la misma dirección: pasan de zonificaciones de tipo abstracto a planes más comprometidos con la forma física; se revisan y reducen las sobredimensionadas previsiones de crecimiento heredadas del período anterior; los planes se centran más en la reforma y mejora de lo ya consolidado que en el crecimiento de suelo, estableciendo un buen número de planes especiales de mejora y unidades de actuación dirigidas a la reordenación de espacios urbanos y obtención de dotaciones; $y$, finalmente, los planes se muestran mucho más precisos en la definición de los sistemas de control y ejecución. En Lleida, por ejemplo, se aprueban hasta la aprobación del Plan General de 1999, 6 planes Parciales (residenciales: Joc de la Bola, Balàfia Nord, sector F de la Bordeta y área de Campus Uni-

10 La Memoria del Plan de 1981 de Manresa apunta en su introducción que va a limitarse la localización de la actividad industrial al polígono de Bufalvent y Dolors y que va establecer el crecimiento residencia en función de las posibilidades del sistema territorial. 
versitari (mixto); industriales: Camí dels Frares y Creu del Batlle) que suponen creca de 200 Ha. Mientras se despliegan 26 Planes Especiales de Mejora y Reforma en suelo urbano y 34 Unidades de Actuación. Mientras en Manresa se aprueban 4 Planes Parciales (Les Bases, la Parada, Concòrdia, Ametllers) y 23 Planes Especiales de Mejora y Reforma en suelo urbano.

En ambos casos, hay que apuntar la aprobación de Planes Especiales para la reordenación, reforma y mejora de sus respectivos Centros Históricos, planes modélicos en Catalunya, que pretenden parar los procesos de degradación, dinamizar las áreas, recuperar su centralidad funcional y valorizar/proteger su patrimonio. Descatar en este sentido el Plan Especial del Centro de Lleida de 1986", el Plan Especial de Mejora Urbana del centro urbano de Manresa de 1985.

Tambien encontramos planes especiales destinados a ordenar vacíos urbanos, más o menos centrales, que han quedado fuera del mercado (por razones topográficas, especulativas, antiguas propiedades del INV (caso por ejemplo del Plan especial del Canyeret en Lleida de 1983), antiguo suelo industrial procedente de procesos de obsolescencia en el caso de Manresa (els Panyos, la Florinda), espacios ocupados previamente por grandes infraestructuras ferroviarias (Plan Especial del Recorrido de 1984 (9,96 Ha) y reconversion de antiguas instalaciones militares en Manresa. La ordenación de estos espacios permite, por una parte, superar «barreras» internas y vacíos urbanos que han ido adquiriendo posiciones centrales y, por otra, supone la oportunidad única de mejorar las dotaciones en equipamientos y espacios libres de la ciudad. Buena parte de estas actuaciones se lleva a cabo con adquisiciones públicas de suelo por parte de las administraciones locales.

\subsection{EL SEGUNDO PERÍODO: 1992-2007}

Los Planes Generales del período, el de Lleida aprobado en 1999 y el de Manresa apobado en 1997, presentan ya características muy diferentes. En pimer lugar, cabe llamar la atención a las expectativas de crecimientos y de desarrollo de suelo que presentan en los dos casos opciones diferentes. El de Manresa, como muestra la Tabla 2 , reduce notablemente las expectativas de crecimiento de población y de forma coherente clasifica como urbanizable poco suelo (164 Ha en suelo urbanizable delimitado/sectorizado y 223,7 Ha en urbanizable no delimtado). Por su parte el de Lleida acoge como horizonte de población el máximo fijado por el Plan Territorial General de Catalunya, que potencia el crecimiento del municipio, para llegar a los 200.000 en 2015 ,

11 El Plan Especal del Centro Histórico de Lleida recibe el Premio Nacional de Urbanismo de 1986 
aunque la proyección demográfica que acompaña el documento en su escenario más optimista sólo llegaba a los 144.600 en 2015. Para ello clasifica 503, Ha. de suelo urbanizable delimitado (385 Ha para usos residenciales) y un total de 25.781 nuevas viviendas (en suelo urbanizable y urbano no consolidado).

Las características técnicas y contenidos se corresponden a aquellas que se han venido identificando con los Planes Generales de segunda generación desde la recuperada democracia en Catalunya (Ferrer y Sabaté, 1999). Los Planes Generales identifican las cuestiones de las infraestructuras de comunicación y transporte como claves en este tipo de ciudades para reforzar su capitalidad y posición en el territorio. Esta es una de las cuestiones más destacadas en el Plan General de Manresa de 1997 en el que se fija como uno de los objetivos más importantes «la correcta integración de la ciudad en el territorio asegurando una óptima accesibilidad a partir de su conexión a las infraestructuras de transporte, carretera y ferrocarril» (Memoria del Plan General de Manresa, 1997, punto 2). El de Lleida identifica como uno de los proyectos estratégicos para la ciudad la integración de la alta velocidad en la ciudad. Identifican además otros proyectos clave que se considera estratégicos o espacios oportunidad. Ambos Planes proponen renovar el transcurso urbano de los ríos Segre en Lleida y Cardener en Manresa como espacio público y potenciar la urbanización de los bordes, así como controlar y recualificar las fachadas al mismo. Los dos Planes proponen continuar con la recuperación de sus respectivos centros históricos que articulan con mecanismos de gestión y compra de suelo a través de la creación de empresas municipales: Empresa Municipal de Urbanismo en Lleida y Forum en Manresa, creadas ambas dos en 1994.

Otro de los proyectos contemplados como estratégicos en ambas áreas son sendos Parques científicos y tecnológicos. El proyecto en Manresa, el Parc Tecnològic de la Catalunya Central, empieza a despelgarse en 2005 sobre suelo que comparte con el municipio vecino de Sant Fruitós del Bages, en un área de $35 \mathrm{Ha}$ (cerca de $22 \mathrm{Ha}$ destianadas a un gran parque, el Parc de l'Agulla). En Lleida el Parc Científic i Tecnològic Agroalimentari de Lleida (PCiTAL) empieza a desplegarse en 2005 gracias a un consorcio entre la Universitat de Lleida (UdL) y el Ayuntamiento y con las aportaciones del programa del FEDER. Buena parte de sus instalaciones se localizan sobre las antiguas instalaciones militares de la meseta de Gardeny, sobre una plataforma elevada de $28 \mathrm{Ha}$.

Sin embargo, lo más ilustrativo es la diferencia en el despliegue del planeamiento derivado y en especial la aprobación del planeamiento parcial. En Lleida se aprueban 15 Planes Parciales, en Manresa 16 Planes Parciales. El impacto de la aprobación y desarrollo de suelo puede verse en la Tabla 2 contrastando las cifras de suelo urbano de los dos últimos Planes Generales. En Lleida la diferencia de suelo urbano entre los Planes de 1999 y 2018 arroja un 
total de $400 \mathrm{Ha}$, mientras en Manresa, mucho más contenido, refleja sólo un aumento de unas 130 Ha entre los Planes de 1997 y de 2017.

Figura 4. Plan General de Lleida de 1999 (izquierda),

Plan General de Manresa 1997 (derecha)

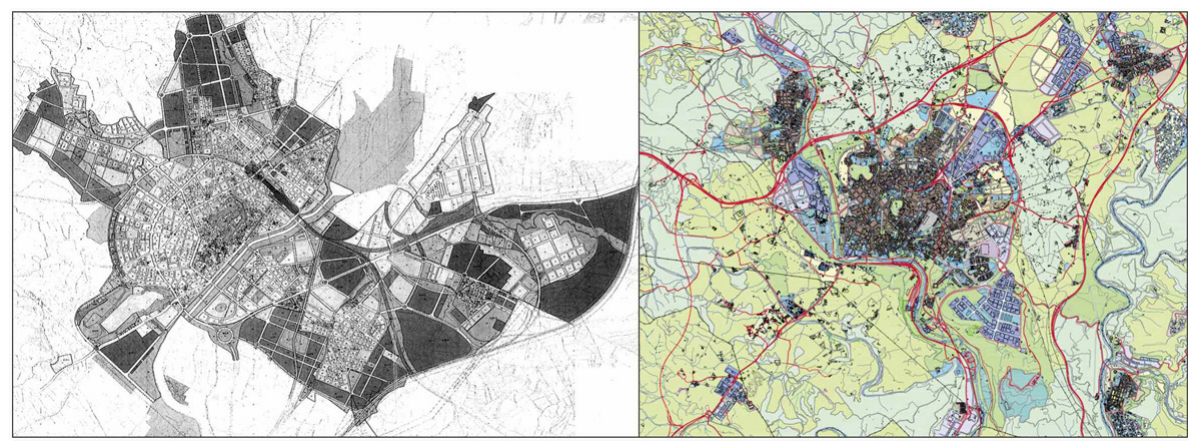

Fuente: Documentos originales de planeamiento aprobados

Otra de las cuestiones que debe destacarse es el alto número de modificaciones de Plan General aprobadas durante el período en ambos casos, modificaciones que desnaturalizan el Plan y su discrecionalidad. En Manresa se produjeron 59 modificaciones del Plan General de 1997 hasta la aprobación del de 2017. En el de Lleida se han producido 76 modificaciones del Plan desde su entrada en vigor en 1999 hasta el momento, aunque algunas no abordan cuestiones de fondo. Sólo la cantidad de modificacions realizadas en los documentos ya justificaria de por sí la revisión de los mismos.

\subsection{EL TERCER PERÍODO: 2008-2019}

Finalmente, los Planes Generales del último período en las ciudades son: el Plan de Ordenación Urbana Municipal de Lleida 2018 (A. Inicial en 2018) y el Plan de Ordenación Urbana de Manresa aprobado definitivamente en 2017. Lo primero que llama la atención de ambos es la restrictiva previsión de crecimiento y, en coherencia, de la clasificación de suelo urbanizable. En el caso de Lleida, como muestra la Tabla 2, es de 239,1 Ha en Lleida (sólo 61,4 Ha de suelo residencial), aunque se clasifican 531,3 Ha en urbanizable no delimitado, la práctica mayoria para suelo industrial y logístico. En el caso de Manresa se clasifica 153,5 Ha como suelo urbanizable delimitado y 56,4 Ha en no delimitado ${ }^{12}$.

12 En 2006 se aprueba el Plan Director Urbanístico del Bages una figura que en Catalunya promueve la regulación supramunicipal del suelo y al que se acoge el Plan de Ordenación de Manresa de 2017. 
Pero sin duda, lo que más llama la atención es la detallada ordenación y regulación que se realiza del suelo urbano (consolidado y no consolidado). Al respecto apuntar que en el caso de Lleida se delimitan 7 Planes de Mejora Urbana, 75 polígonos de actuación urbanística y Unidades de Actuación, todos ellos instrumentos para la transformación del suelo urbano. En Manresa, el Plan contempla 85 polígonoes de actuación urbanística y 53 Planes de Mejora Urbana, 7 de los cuales contemplan transformaciones puntutales. Entre las actuaciones destacan aquellas dedicas a recuperar la funcionalidad de los centros urbanos con un acento importante en procurar la regeneración de la edficicación y la reordenación de la movilidad.

Figura 5. Plan de Ordenación Urbana Municipal de Lleida de 2018 (A. Inicial)

(izquierda) y Plan de Ordenación Urbana de Manresa 2017 (derecha)

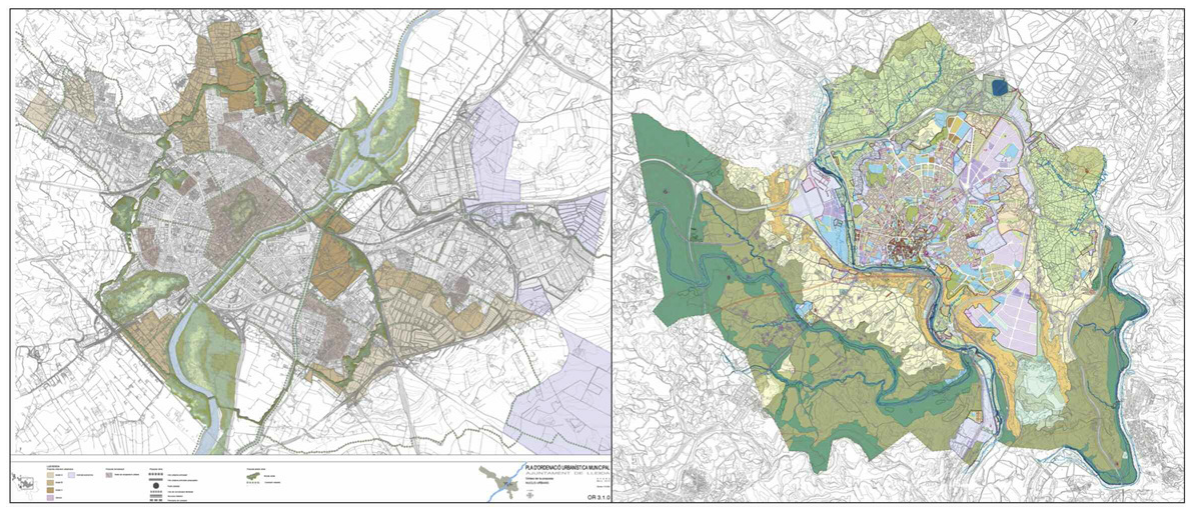

Fuente: Documentos originales de planeamiento aprobados

Otra cuestión interesante es el especifico tratamiento del suelo no urbanizable que trata de establecer y proteger espacios de especial interés natural, ambiental y paisajístico en la línea que los planes territoriales y supramunicipales habían ido fijando desde mediados de la década de los 2000. Los dos planes tratan de conjugar la preservación de las zonas de mayor interés en el suelo no urbanizable con su utilización como espacio productivo y de ocio. En este sentido destacan, primero, la propuesta de amplios anillos verdes, que permiten recorridos sobre los términos municipales en bicicleta y a pie, $y$, segundo, las regulaciones para proteger y mantener productivas las huertas que rodean los núcleos urbanos. Destacar en el caso de Manresa, por ejemplo, se recoge la figura de Parque agrario que ya proponía el Plan Director Urbanístico del Bages de 2007. 


\section{A MODO DE CONCLUSIONES}

Los objetivos, estrategias e instrumentos de la planificación urbana han ido cambiando a lo largo del período analizado. El planeamiento municipal ha ido pasando, así, de la inicial exigencia de regular las actividades y el crecimiento (1979-1991), a facilitar, el desarrollo de suelo y artefactos urbanos a través de un urbanismo de corte neoliberal claramente expansivo y especulativo (1993-2007), para llegar, en la actualidad, a un urbanismo en el que coexiste la tendencia anterior mientras se ensaya, en paralelo, con nuevas orientaciones. El análisis de los documentos de planeamiento permite también concluir cómo se han trasladado los principios clave de la ciudad neoliberal al urbanismo a través de: sobredimensionamiento, re-clasificaciones y recalificaciones; grandes proyectos urbanos; convenios y concesiones; y la mercantilización de áreas con alto valor expectante.

En el último período parace que el planeamiento y el urbanismo vuelve a centrarse en la ciudad más o menos consolidada con el peligro, pero, de convertirse en un mecanismo que contribuya a capturar de forma selectiva la renta urbana por parte de algunos agentes urbanos. La planificación urbana en el futuro deberá hacer hincapié en la regeneración urbana y en la rehabilitación, y no tanto en su crecimiento, sin embargo, no parece claro que los mecanismos vigentes y establecidos, su desarrollo y su gestión no generen una mayor fragmentación. El contenido y objetivos de los planes deberían de estar más atentos a la dimensión social y entender que el objetivo último del urbanismo debería ser el de hacer fácil y agradable la vida de las personas en nuestras ciudades y no facilitar el negocio inmobiliario.

\section{AGRADECIMIENTOS}

El presente trabajo se ha realizado al amparo del proyecto de investigación «Evolución de las políticas urbanísticas en ciudades medias españolas y sus áreas urbanas: 1979-2019» (RTI2018-096435-B-C21), financiado por el Ministerio de Ciencia e Innovación.

\section{BIBLIOGRAFÍA}

Bellet, C. (1999). El plan especial y la transformación de la ciudad consolidada. En R. Domínguez (1999), La ciudad: tamaño y crecimiento. Actas del III Coloquio de Geografía Urbana, pp. 51-62. Málaga: Publicaciones de la Universidad de Málaga.

Bellet, C. (2017). Proyectos y grandes operaciones urbanas. En AA.VV. Naturaleza, territorio y ciudad en un mundo global, pp. 1.249-1.265. Madrid: Universidad Autónoma de Madrid y AGE. 
Bellet, C. (2020). Municipal planning policies in Spain: 40 years of democratic city councils (1979-2019). Boletín de la Asociación de Geógrafos Españoles, 85, 2.877, 1-38. https://doi.org/10.21138/bage.2877

Burriel, E. (2009). Los límites del planeamiento urbanístico municipal. El ejemplo valenciano. Documents d'Anàlisi Geogràfica, 54, 33-54.

Calderón, B. y García, J.L. (2017) Legislación urbanística y planeamiento urbano en España, 1998-2015. Del despilfarro a la sostenibilidad. Scripta Nova. Revista Electrónica de Geografía y Ciencias Sociales. Barcelona: Universidad de Barcelona, XXI, 570.

Calderón, B. y García, J. L. (2018). La estructura de las ciudades españolas: un complejo entramado de relaciones entre permanencias y cambios, formas y usos. Boletín de la Asociación de Geografía Española, 77, 283-314. http://dx.doi.org/10.21138/bage.2542

Cebrián, F. (2007). Ciudades con límites y ciudades sin límites. Manifestaciones de la ciudad difusa en Castilla-La Mancha. Boletín de la Asociación Española de Geografía, 43, 221-240.

Ferrer, A. y Sabaté, J. (1999). Introducció: I'urbanisme municipal vist pels professionals. Papers. Revista de la Regió Metropolitana de Barcelona, 32, 9 18.

Ferrer, A. (1989). El planejament urbanístic. En O. Nel.lo (Coord) 70 anys d'ajuntaments democràtics. pp. 133-179. Barcelona: Federació de Municipis de Catalunya.

Ferrer, A, y Solà-Morales, M. (2005). El urbanismo municipal en España. Papers. Regió metropolitana de Barcelona, 43. Recuperado de: https://ddd.uab.cat/record/29506? In=ca

Gaja Díaz, F. (2008). El «tsunami urbanizador» en el litoral mediterráneo. El ciclo de hiperproducción inmobiliaria 1996-2006. Scripta Nova. Revista Electrónica de Geografía y Ciencias Sociales, XII, 270 (66). Recuperado de: http://www.ub.es/geocrit/sn/sn-270/sn-270-66.htm

Gaja Díaz, F. (2015). Urbanismo concesional. Modernización, privatización y cambio de hegemonía en la acción urbana. Ciudades, Instituto Universitario de Urbanística, Universidad de Valladolid, 18, 1, 103-126. https://doi.org/10.24197/ciudades.18.2015.103-126

Górgolas, P. (2017). Burbujas inmobiliarias y planeamiento urbano en España: una amistad peligrosa. Cuadernos de Investigación urbanística-Ci[ur] 111, 3-65. Doi: 10.20868/ciur.2017.111.3536

García-Herrera, L. M. (2018). Mercantilización del espacio urbano bajo la lógica neoliberal: gentrificación y redefinición de los espacios públicos en España. En AA.VV. Naturaleza, territorio y ciudad en un mundo global, pp. 858-877. Madrid: Universidad Autónoma de Madrid y AGE.

López, I. y Rodríguez, E. (2010). Fin de ciclo. Financiarización, territorio y sociedad de propietarios en la onda larga del capitalismo hispano (19592010). Madrid: Traficantes de sueños. 
Méndez Gutiérrez del Valle, R. (2018). La telaraña financiera. Una Geografía de la financiarización y su crisis. Santiago de Chile: RiL Editores, Instituto de Geografía, Pontificia Universidad Católica de Chile.

Ministerio de Obras Públicas y Urbanismo-MOPU (1990). 10 Años de planeamiento urbanístico en España. Madrid: Instituto del Territorio y Urbanismo.

Naredo, J. M. (1996). La burbuja económico-financiera en la coyuntura económica reciente (1985-1995). Madrid: Siglo XXI de España.

Naredo, J. M. (2010). El modelo inmobiliario español y sus consecuencias. Boletín CF+S, 44, 13-27. Recuperado de:

http://habitat.aq.upm.es/boletin/n44/ajnar.html

$\mathrm{Nel} \cdot \mathrm{lo}, \mathrm{O}$. (2010). El planeamiento territorial en Cataluña. Cuadernos Geográficos, 47/2, 131-167.

Olazabal, E. y Bellet, C. (2019). De la ciudad compacta a la ciudad extensa. Procesos de urbanización recientes en áreas urbanas españolas articuladas por ciudades medias. Anales de Geografía de la Universidad Complutense de Madrid, 39(1), 149-17. http://dx.doi.org/10.5209/AGUC.64681

Romero, J., Brandis, D. y Melo, C. (2015). El giro neoliberal de las políticas para la Ciudad en España. Balance a partir de los casos de Madrid y Valencia. Boletín de la Asociación de Geografía Española, 69, 369-386.

http://dx.doi.org/10.21138/bage.1901

Rullán, O. (2016). La planificación urbana y territorial en tiempos de crisis. En J. Olcina, y A. Rico (Coord.) Libro jubilar en homenaje al profesor Antonio Gil Oncina, pp.1.267-1.286. Alicante: Publicaciones de la Universidad de Alicante.

Sabaté, J. (2006). El Pla director urbanístic del Bages. Espais. Revista del Departament de Política Territorial i Obres Públiques, 52, Monográfico: Els plans directors urbanístics de Catalunya.

Vives, S. y Rullán, O. (2014). La apropiación de las rentas del suelo en la ciudad neoliberal española, Boletín de la Asociación Española de Geografía, 65, 387-408. Recuperado de:

https://bage.age-geografia.es/ojs//index.php/bage/article/view/1758/1674 



\title{
LA TRANSFORMACIÓN DE ENCLAVES PERIFÉRICOS DEL CENTRO CIUDAD. LA OPERACIÓN MAHOU-CALDERÓN, MADRID
}

THE CHANGE TO MADRID CITY OUTSKIRTS. THE MAHOU-CALDERÓN URBAN SCHEME

\author{
Dolores Brandis García \\ Universidad Complutense de Madrid
}

\begin{abstract}
Resumen
Los espacios de borde del centro de las ciudades están soportando en las últimas décadas importantes transformaciones con el fin de eliminar sus atributos originales, más propios de las periferias urbanas, y adecuarlos a la condición de centralidad alcanzada. El objetivo del trabajo es poner en evidencia cómo el modelo de urbanismo neoliberal propicia su cambio mediante proyectos urbanos fundamentados en la colaboración de agentes públicos y privados. Hay ejemplos de este proceder en la Almendra Central de Madrid y se dedica el estudio a la última actuación en pleno desarrollo, la operación Mahou-Calderón. En el análisis cobran protagonismo las fuentes documentales y las estrategias de los promotores interesados en sacar adelante el proyecto, y las posiciones contrarias de los colectivos ciudadanos. También se da entrada a los nuevos dueños del suelo y a las empresas inmobiliarias que se suman a la transformación.
\end{abstract}

Palabras clave: urbanismo, proyecto urbano, transformación urbana, agentes urbanos, centro ciudad, Madrid.

\begin{abstract}
Madrid city outskirts are experiencing important changes over the last decades when turning their role of suburb areas into downtown area. This paper intends to highlight how the neoliberal urban policy is driving such a change on the outskirts by promoting town planning projects funded by public and private actors. The Mahou-Calderón urban scheme is the most recent ongoing example of it in Madrid city. It has been analysed not just the available data sources but also the interaction between promoters, public protests, land-owners and real estate companies.
\end{abstract}

Keywords: town planning, urban project, city change, city agents, downtown, Madrid. 


\section{INTRODUCCIÓN}

El objetivo del trabajo es constatar cómo en determinados enclaves localizados en los extremos del centro de la ciudad, que funcionaron en su origen como periferia y todavía conservan parte de sus atributos, el modelo de urbanismo neoliberal facilita su transformación mediante proyectos urbanos, fundamentados en la colaboración de agentes públicos y privados, con el propósito de adecuarlos a la condición de centralidad ya adquirida. Esta forma de actuar se confirma en la última gran transformación urbana que está teniendo lugar en Madrid, la operación Mahou-Calderón, en el borde sur de la Almendra Central. En un anterior trabajo, con el respaldo de la bibliografía correspondiente, dimos entrada a los principios generales del modelo urbano aplicado en la dinámica actual de reproducción de la ciudad consolidada (Brandis, 2017). Baste ahora, en primer lugar, una breve síntesis de las constantes más significativas que se reconocen en la gestión llevada a cabo en las recientes transformaciones de los espacios de borde del centro de las ciudades. La política urbana neoliberal, sustentada en los principios clave de desregulación, flexibilidad, competitividad y privatización, subordina la gestión de la ciudad a las exigencias del mercado y delega en los agentes privados la definición y ejecución de la ordenación urbana. En dicho modelo se sitúan los proyectos de remodelación sobre determinados enclaves mediante operaciones especulativas que prometen inversiones muy rentables asociadas a cambios en el rango social del espacio. Y en su puesta en práctica se arbitran estrategias de promoción e intensificación de dinámicas de valoración inmobiliaria, con el fin de atraer actividades económicas y clases sociales significativas del capitalismo globalizado.

En los proyectos urbanos, que combinan las ventajas de la flexibilidad normativa con la eficacia de la gestión, los gobiernos locales agilizan el proceso administrativo y proporcionan las autorizaciones, y las empresas privadas aportan la seguridad de la inversión sin otra justificación que las expectativas del beneficio. La necesidad de la intervención en los enclaves de borde es el argumento más comúnmente empleado por los gobiernos locales. Recurren a la situación de degradación, obsolescencia o disfuncionalidad de los espacios ocupados en su origen, bien por industrias, infraestructuras ferroviarias, establecimientos portuarios y fluviales, instalaciones militares o equipamientos todavía presentes en las áreas centrales. Publicitan la reorganización estructural de su tejido físico y económico como fórmula para transformarlos en modernas áreas de producción y consumo, adaptadas a las exigencias de las nuevas demandas locales y globales.

A finales del siglo pasado en Madrid todavía existen en los bordes de su área central, encerrada por la vía de circunvalación M-30, espacios expuestos al cambio e idóneos para llevar a efecto proyectos de transformación de corte neoliberal. Tras revisar las operaciones llevadas a cabo en una larga etapa de gobiernos 
municipales y autonómicos conservadores', se confirma la puesta en práctica del modelo anteriormente descrito. En este sentido, los proyectos se insertan en la agenda urbana cuando deciden los agentes públicos y privados interesados en sacar provecho de las circunstancias más favorables. Entre sus estrategias de actuación se evidencian las modificaciones forzadas en el planeamiento y en la legislación, las contrapartidas arbitrarias suscritas en los convenios, o los cambios habidos en la formulación de los proyectos. Y todo ello con el fin de conseguir las condiciones necesarias que permitan a los promotores privados, los grandes inversores, obtener los mayores beneficios de la transformación. Como ejemplos de este proceder baste hacer alusión a las últimas operaciones localizadas en el extremo norte de la Almendra Central: la culminada de las Cuatro Torres y la proyectada Madrid Nuevo Norte. A la operación MahouCalderón, en el borde sureste y en desarrollo actualmente, dedicaremos el cuerpo del estudio (Figura 1).

Figura 1. Grandes Operaciones Urbanas

1. Cuatro Torres; 2. Madrid Nuevo Norte; 3. Mahou-Calderón

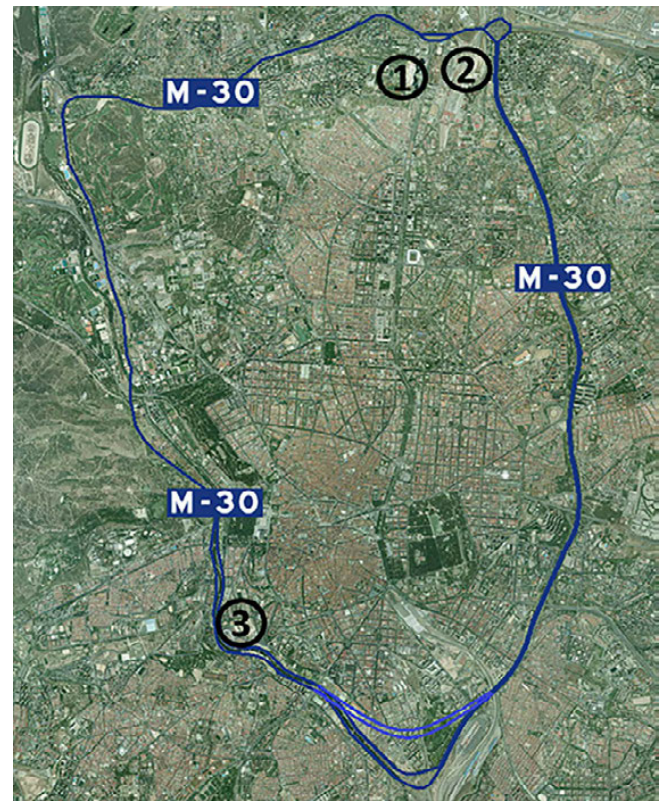

Fuente: Elaboración propia a partir de Google Earth (2020)

1 Tras diez años de gobierno municipal socialista (1979-1989) el consistorio lo ocupa el partido popular durante 25 años (1990-2015). La política urbana de este último periodo es fiel ejemplo del modelo de corte neoliberal descrito. La Comunidad de Madrid, después de doce años a cargo del PSOE (1983-1995) pasará a manos del PP hasta la actualidad. 
Las Cuatro Torres se erigen en el lugar ocupado por la antigua ciudad deportiva del club de fútbol del Real Madrid, sobre terrenos expropiados en 1955 y vendidos en 1960 al club para levantar su ciudad deportiva. La entidad conseguirá plusvalías millonarias tras el convenio firmado en 2001 con el Ayuntamiento y con la modificación del Plan General de 1997 que recalifica el suelo deportivo en terciario. La ciudad deportiva desaparece en 2004 y se sustituye por cuatro torres de 35 plantas. En el reparto al club le corresponderán dos torres y los dos tercios de otra que comparte con la Comunidad de Madrid, quedando la cuarta torre para el Ayuntamiento. Además, el club conseguirá un suelo muy barato para sus nuevas instalaciones en la periferia noreste de la ciudad, tras firmar el Ayuntamiento y los propietarios de los terrenos de Valdebebas un convenio que facilitará a los dueños del suelo el desarrollo residencial del ámbito (Arias, 2009).

La operación Chamartín, rebautizada actualmente como Madrid Nuevo Norte, la formula la empresa estatal Renfe en 1992 sobre terrenos de la estación ferroviaria con el objetivo de cubrir las vías, remodelar la estación y construir 5.000 viviendas². En 1997 las tres administraciones suscriben un consorcio urbanístico para desarrollar el Área de Planeamiento Remitido Prolongación de la Castellana. Desde entonces el proyecto, todavía sin aprobación definitiva, ha redimensionado su superficie original, incrementando la edificabilidad, modificado el reparto de los usos lucrativos y alterado el número de viviendas a construir. Todo ello para obtener una rentabilidad suficientemente elevada que haga posible a los poderes públicos financiar su parte de la operación y a la sociedad promotora, la financiera BBVA y la constructora San José, alcanzar los mayores beneficios (Brandis, 2018).

En el desarrollo de la operación Mahou-Calderón. En el proceso se suceden dos proyectos de ordenación que responden a gobiernos locales con formas muy dispares de entender la política y gestión urbanas. Para introducir el caso, y como punto de arranque al análisis, incorporamos algunas observaciones sobre el espacio en que se inscribe, el distrito de Arganzuela, y de los inmuebles afectados, una cervecera y un estadio de fútbol, que ayudarán a la interpretación del proceso. Y como cuestión final se hace un seguimiento de los nuevos dueños del suelo y de las empresas inmobiliarias interesadas en su construcción.

\section{EL DISTRITO DE ARGANZUELA, LA CERVECERA Y EL ESTADIO DE FÚTBOL}

Arganzuela es el distrito que encierra la Almendra Central por el sur y se corresponde con el sector meridional del ensanche madrileño que linda con el

2 El PSOE ocupa el gobierno central desde 1982 y será sustituido por el PP entre 1996 y 2004. La operación, en la que el Estado es parte interesada, pasará por los distintos partidos políticos que se suceden en el gobierno: PSOE (2004-2011), PP (2011-2018) y PSOE (desde 2018 hasta hoy). 
río Manzanares. El espacio nació con vocación fabril y obrera en la segunda mitad del siglo XIX, cuando el Plan de Ensanche de Castro le asigna una ocupación industrial, de servicios a la ciudad y de vivienda obrera. Esta dedicación vendría condicionada por la existencia previa del ferrocarril de cintura, que recorre el distrito de este a oeste entre las estaciones de Atocha y Príncipe Pío. Pronto se incorporan a su trazado las estaciones de Imperial, Peñuelas y Delicias para dar apoyo a los establecimientos manufactureros.

A mediados del siglo pasado el distrito alcanza su máxima expansión fabril, y a finales de los años sesenta se inicia la desindustrialización del interior de la ciudad y los primeros desalojos de fábricas que abren el camino hacia la transformación de Arganzuela. Lo explican, entre otros factores, el decaimiento generalizado del transporte ferroviario, el traslado de las industrias hacia áreas de la periferia y las facilidades del Plan General de Madrid de 1963 para el cambio de uso. La salida de la industria libera suelo urbano y favorece la conversión de los vacíos en conjuntos residenciales, que progresivamente revalorizan el distrito y generan expectativas para maniobras lucrativas en los espacios que con el tiempo van adquiriendo centralidad (Pardo, 2004).

El Plan General 1985 coincide con la etapa más aguda de la desindustrialización y pretende mantener la actividad y el empleo, y minimizar las operaciones especulativas asociadas a los abandonos industriales. La reactivación económica y la superación de la crisis a mediados del decenio facilitarán que las fuerzas del mercado urbano se impongan, reactivándose el desmantelamiento de las industrias a través de recalificaciones del suelo favorables al negocio inmobiliario, práctica que se verá incrementada con la normativa flexible del Plan General de 1997 (Río, 2000).

En este contexto tiene lugar la operación Pasillo Verde que impulsará definitivamente la transformación de Arganzuela. La promueve un consorcio formado en 1987 por el Ayuntamiento y la Renfe, con el fin de articular el distrito dividido por el ferrocarril de cintura, y mejorar la calidad ambiental del conjunto. La operación contempla el enterramiento de las vías férreas y su adaptación al tráfico de viajeros, la reorganización de las estaciones para incorporar espacios verdes y dotaciones, el desmantelamiento de las instalaciones industriales obsoletas adosadas a las vías, un paseo sobre el trazado del ferrocarril y la ocupación del suelo liberado por viviendas, oficinas y equipamientos. El plan original sufre una modificación en 1992, coincidente con el fin de la etapa de crecimiento económico y el proyecto registra un aumento espectacular del uso y la edificabilidad residencial, la reducción de los usos dotacionales y ferroviarios y la eliminación de la industria (Brandis y Río, 1995).

La cervecera Mahou y el estadio del club de fútbol del Atlético de Madrid se instalan en los años sesenta del siglo pasado en el sur del distrito donde todavía hay suelo sin ocupar en contacto con el río (Figura 2). La cervecera lo hace en 1962 sobre 61251 metros cuadrados, tras abandonar su emplazamiento original ubicado desde 1894 en el noroeste del casco antiguo. La fá- 
brica se trasladará en 1966 a Alovera (Guadalajara) pero no derriba la instalación de Arganzuela hasta 2011, cuando decide formar parte de la operación de transformación Mahou-Calderón. Por su parte, el club de fútbol tras vender en 1961 el Metropolitano, su antiguo estadio próximo a la ciudad Universitaria, compra 31046 metros cuadrados de suelo vacío entre la cervecera y el río donde levanta en 1966 el estadio del Manzanares, más conocido como Vicente Calderón. Una vez aprobada la operación de transformación y construido en la periferia oriental de la ciudad su nuevo estadio, el Wanda Metropolitano, inicia su desmantelamiento en 2019.

Figura 2. La cervecera Mahou y el estadio Vicente Calderón

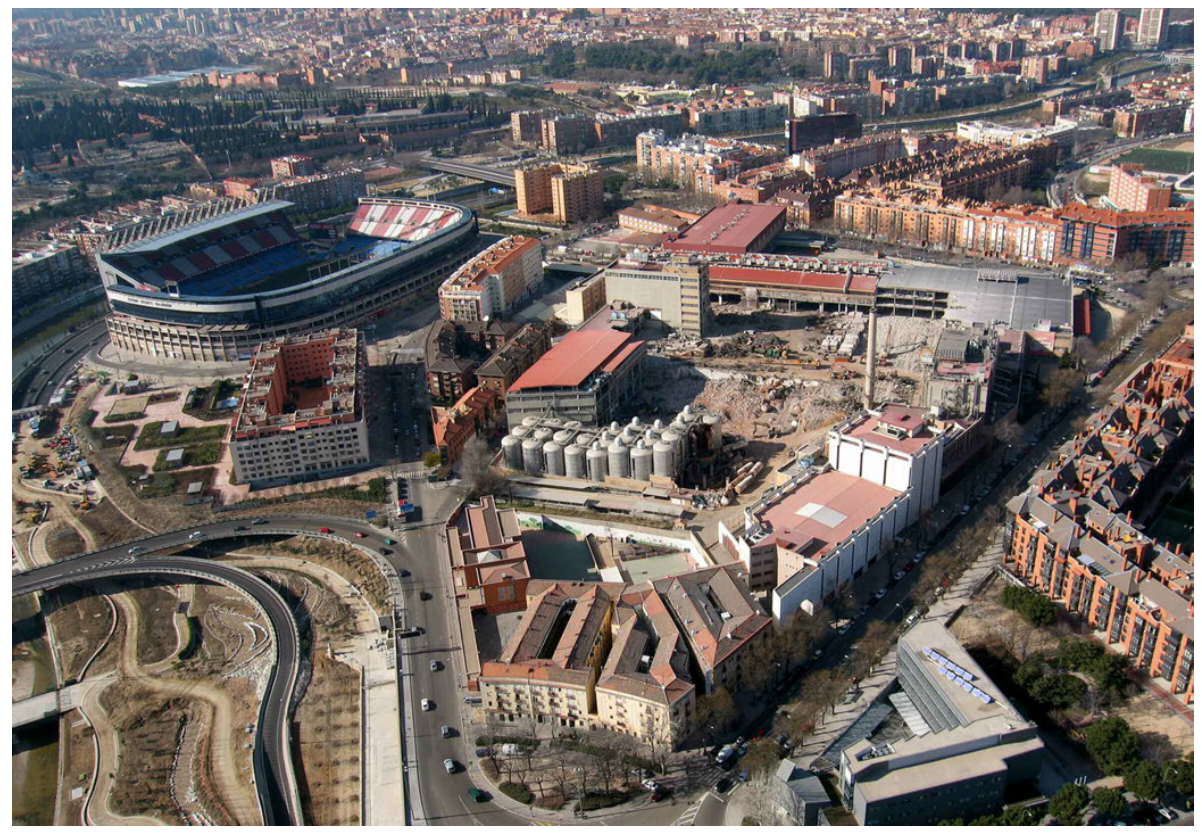

Fuente: www.nuevosvecinos.es

\section{LA TRANSFORMACIÓN URBANA DEL ÁMBITO MAHOU-CALDERÓN}

En el desarrollo de la operación se distinguen dos proyectos de ordenación que se adscriben en el tiempo a gobiernos municipales de distinto signo político. El primer proyecto lo proponen los dueños del suelo a un consistorio regido por el Partido Popular. El segundo, de iniciativa municipal y actualmente en desarrollo, se aprueba cuando la corporación progresista Ahora Madrid ocupa el Ayuntamiento. La secuencia de los hechos hablará por sí sola de las estrategias que arbitran los distintos agentes urbanos a lo largo del proceso. 


\subsection{EL PROYECTO «MAHOU-VICENTE CALDERÓN». EL MODELO NEOLIBERAL (2004-2015)}

Entre las circunstancias que rodean la transformación del ámbito no se puede obviar el hecho de que de principio a fin se encuentra emparentada con el antiguo estadio de atletismo de La Peineta ${ }^{3}$, en la periferia oriental de la ciudad y actual emplazamiento del estadio olímpico Wanda Metropolitano. El proceso se inicia en 2004 cuando el club del Atlético de Madrid y el Ayuntamiento negocian el traslado del campo del Calderón a La Peineta. El club exige el mismo tratamiento que recibió el Real Madrid para su mudanza a Valdebebas, esto es, agilizar la modificación del planeamiento general para el terreno afectado, obtener una edificabilidad del suelo liberado de 1,49 metros cuadrados, y cuantas gestiones fuesen necesarias para facilitar la construcción del nuevo estadio en La Peineta.

Es el momento en que el club funda la sociedad División Inmobiliaria del Club Atlético de Madrid S.L. a la que transfiere el suelo del Calderón y, con el fin de conseguir financiación, otorga una opción sobre futuros derechos urbanísticos a un consorcio inmobiliario formado por Martinsa y Andria 4 . En 2008 firma un convenio con el Ayuntamiento que le compromete a comprar La Peineta y construir en su lugar un nuevo estadio olímpico con vistas a la celebración de los Juegos de 2012, que finalmente recaerán en Londres.

Las gestiones para sacar adelante la transformación urbana del ámbito Mahou-Calderón se inician con la solicitud de ambas empresas al Ayuntamiento para recalificar los suelos con el fin de promover su desarrollo. La Comunidad de Madrid aprueba la modificación puntual del Plan General de Ordenación Urbana de 1997 que recalifica los suelos industrial y deportivo a residencial, remitiendo la ordenación del terreno a la redacción de un Plan Parcial de Reforma Interior (BOCM, 2010) $)^{5}$.

A partir de este momento entran en escena los tribunales de justicia que acompañarán a la operación durante todo el proceso de tramitación. A ellos acuden las asociaciones ciudadanas y distintos colectivos contrarios a la

3 El estadio de la Peineta lo construye el gobierno autonómico en 1994 para acoger los mundiales de atletismo de 1997, finalmente celebrados en Atenas. En 2002 el estadio se trasfiere al municipio a cambio del Palacio de los Deportes, ubicado en el sector noreste del Ensanche de la ciudad.

4 Tras los problemas concursales de Martinsa-Fadesa el club contacta con Fomento de Construcciones y Contratas (FCC) para continuar con el proyecto, y en 2010 firman un acuerdo por el que FCC se encargará de derribar el campo de fútbol y la cervecera, levantar las viviendas, derribar La Peineta y construir el nuevo estadio. En 2014 FCC se desvincula de la operación y el club recupera los derechos del suelo.

5 La modificación puntual fija una edificabilidad lucrativa total del ámbito de 175365 metros cuadrados. 
transformación del ámbito, y también las partes directamente proclives a la operación que recurren las sentencias dictadas por los tribunales. La primera demanda la interpone en 2009 la asociación deportiva Señales de Humo, integrada por seguidores del equipo de fútbol críticos con la gestión del club, contra la modificación puntual aprobada. El Tribunal Superior de Justicia de Madrid (TSJM) anula en 2012 la modificación puntual por vulnerar la normativa urbanística que prohíbe edificar por encima de las cuatro plantas, tal y como establece la ley regional del suelo en 2007. Las partes interesadas recurren el fallo ante el Tribunal Supremo, que devuelve el caso al tribunal madrileño para su nuevo estudio y sentencia. Y en 2015 el TSJM reitera su anterior dictamen de nulidad.

En 2014, sin estar resuelto todavía el fallo judicial, el Ayuntamiento aprueba definitivamente el Plan Parcial de Reforma Interior «Mahou-Vicente Calderón» que define la ordenación urbanística del ámbito (BOMC, 2015) ${ }^{6}$. El diseño del proyecto corre a cargo del estudio de arquitectura Rubio \& Álvarez-Sala e introduce rascacielos de 36 plantas, torres de hasta 20 y bloques de 8 (Figura 3).

Figura 3. Recreación del Plan Parcial de 2014

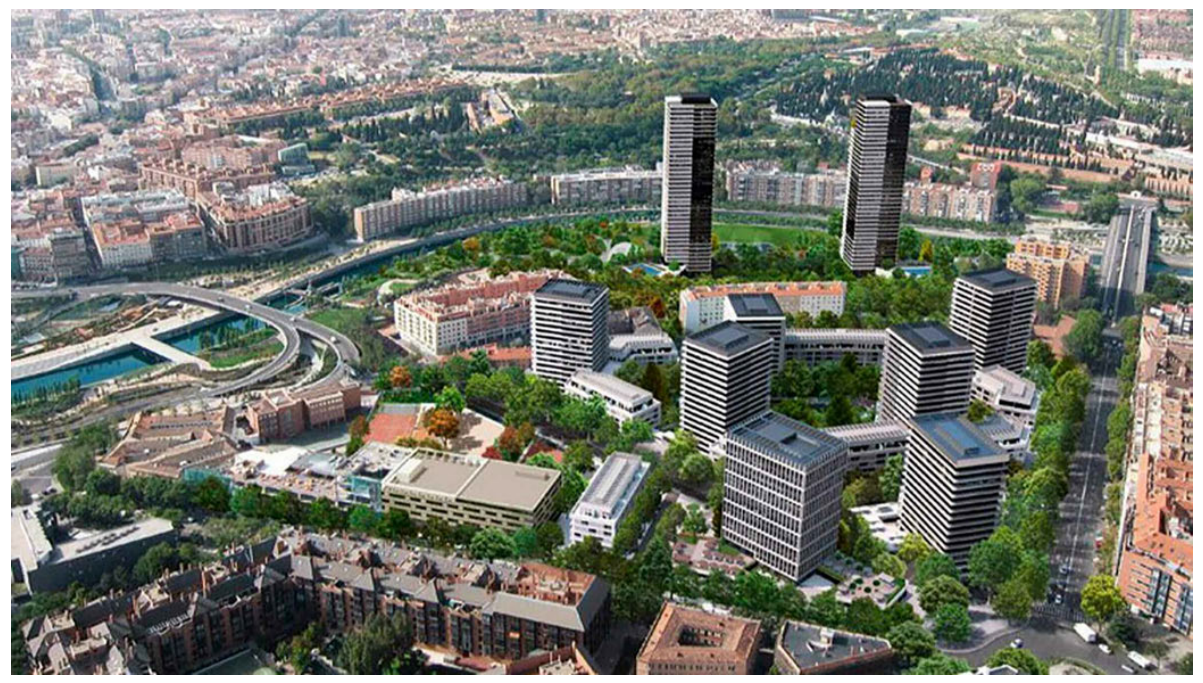

Fuente: http://www.telemadrid.es/onda-madrid-noticias/TSJM-Ecologistas-AccionMahou-Calderon-9-1689521044-20150603111616.html

6 El Plan Parcial mantiene la edificabilidad lucrativa total de 175365 metros cuadrados que fijaba la modificación puntual, y establece como tipología edificatoria la aislada con alturas variables desde torres a bloques para alojar 2000 viviendas. 
Los promotores publicitan la oportunidad y calidad del proyecto por su rentabilidad económica, social y ambiental y contribuir a crear una zona residencial monumental icónica y de referencia en Madrid, que vienen a llamar «La Nueva Puerta del Sur». Partidos políticos en la oposición y otras asociaciones ciudadanas crean la Plataforma Contra el Plan Mahou-Calderón que exige la retirada del plan y se manifiestan con proclamas como «No a la Operación Mahou-Calderón. No a una política de especulación» y «iNo se juega, Arganzuela no es Manhattan!». En paralelo, Ecologistas en Acción denuncia el proyecto por haberse aprobado sin estar resuelto judicialmente. Tras diversas sentencias, el Supremo devuelve en 2016 el expediente al TSJM para que resuelva de nuevo sobre todas las cuestiones controvertidas.

Pero todavía colea La Peineta, pues para formalizar la venta era necesario cambiar la titularidad del suelo de deportivo público a privado. La solicitud de modificación la aprueba el Ayuntamiento a principios de 2015 pero no así la Comunidad Autónoma por no ser conforme con las medidas compensatorias que fija la ley del suelo en la venta de terrenos municipales.

\subsection{EL PROYECTO «NUEVO MAHOU-CALDERÓN» Y LOS PACTOS HEREDADOS (2015-2019)}

A mediados de 2015 el gobierno municipal recae en la plataforma progresista ahora Madrid y paraliza todas las grandes transformaciones urbanas pendientes en la ciudad para su replanteamiento, entre ellas la operación MahouVicente Calderón. el ayuntamiento quiere retomar la actuación desde el principio y negociar con todos los actores urbanos, incluidos los colectivos ciudadanos ausentes anteriormente, para diseñar un modelo nuevo con una escala similar a la del entorno y con menos viviendas. el consistorio se verá respaldado por las resoluciones de los tribunales en 2017 que vuelven a declarar la nulidad del plan parcial y de la modificación puntual en lo relativo a las alturas, como por no prever las reservas de suelo obligatorias destinadas a la construcción de viviendas protegidas.

Pero el ayuntamiento no podrá eludir los compromisos suscritos en el convenio firmado en 2008 por el anterior consistorio y el club, y que condicionarán en buena parte sus propósitos de ordenación. lo más perentorio es aprobar la operación, pues de encontrarse frenada a finales de 2016 tendría que abonar al club una indemnización millonaria. y el nuevo plan se confecciona en un tiempo record. el club acepta que el proyecto se plantee sin rascacielos y con menor número de viviendas, con la condición de que las plusvalías compensen el coste del nuevo estadio. a partir de aquí se inicia la tramitación de una nueva modificación puntual del plan general y un nuevo plan parcial, y se celebra un concurso restringido de profesionales del urbanismo para abordar una nueva ordenación del ámbito que recae en el estudio E. Bardají y Asociados S.L. 
La nueva propuesta se expone a la mesa de negociación formada por colectivos ciudadanos, colegios profesionales de arquitectos e ingenieros y partidos políticos con representación municipal. La queja fundamental de los interlocutores es la referente a la edificabilidad del ámbito, al haber sido acordada previamente por los propietarios y el consistorio, lo que supone una seria merma de eficacia y bondad del proceso participativo. No obstante, reconocen las mejoras adoptadas porque introducen cambios significativos, y proponen repartir mejor la edificabilidad para equilibrar las alturas y conseguir un aspecto más homogéneo y mayores condiciones de soleamiento. Éstas y otras demandas se incorporan en la memoria (Ayuntamiento, 2016) presentada al gobierno autonómico, que la aprueba definitivamente a finales de 2017 (BOCM, 2017), así como la normativa urbanística aplicable al año siguiente (BOCM, 2018). (Figura 4).

Figura 4. Edificios recreados en la propuesta aprobada «Nuevo Mahou-Calderón»

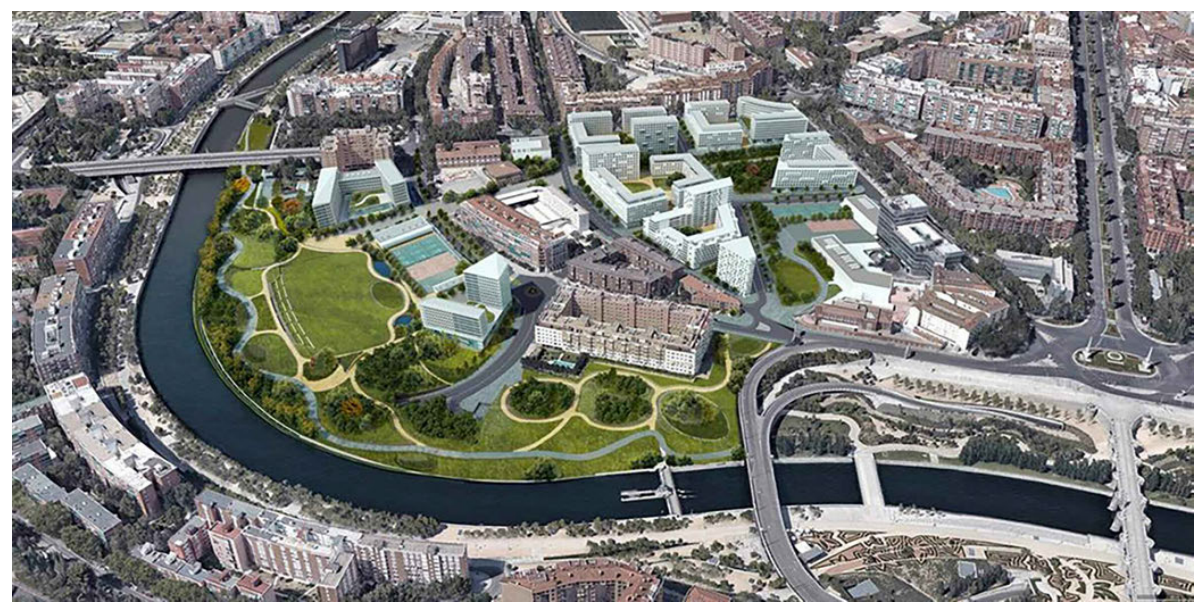

Fuente: https://www.planur-e.es/pdf/12_Planur-e_Mahou\%20Calderon.pdf

El plan aprobado presenta diferencias significativas con respecto al propuesto en 2014 por los promotores: las alturas de las edificaciones se han limitado a magnitudes similares a las del entorno con la excepción de algunos hitos arquitectónicos de 12 plantas; la superficie del ámbito se reduce en un 5,2 \%; el índice bruto de edificabilidad pasa de 1,0 a 0,76; la edificabilidad lucrativa disminuye en un 16\%; el número de viviendas libres se rebaja un 34,7\% y el 11,2\% tendrán algún régimen de protección; las superficies dedicadas a equipamientos se amplían en un $34,7 \%$ y las zonas verdes en un $41,1 \%$. (Tabla 1). 
Tabla 1. Principales parámetros urbanísticos de los proyectos de 2014 y 2017

\begin{tabular}{|c|c|c|}
\hline Parámetros & Proyecto de 2014 & Proyecto de 2017 \\
\hline Superficie & $204.216 \mathrm{~m}^{2}$ & $193.632 \mathrm{~m}^{2}$ \\
\hline Diseño arquitectónico & $\begin{array}{c}\text { Dos rascacielos de 36 } \\
\text { plantas, torres de 22 y } \\
\text { bloques de 8 }\end{array}$ & $\begin{array}{c}\text { Manzanas cerradas de 8 } \\
\text { plantas y excepcionalmente } \\
\text { edificios de 12 }\end{array}$ \\
\hline $\begin{array}{c}\text { Edificabilidad lucrativa }\left(\mathrm{m}^{2}\right) \\
\text { Índice bruto de edificabilidad } \\
\left(\mathrm{m}^{2} / \mathrm{m}^{2}\right)\end{array}$ & 175.365 & 147.050 \\
\hline Número de viviendas & 2000 libres & 0,76 \\
\hline Equipamiento $\left(\mathrm{m}^{2}\right)$ & 22.115 & 29.79173 libres y 132 protegidas \\
\hline Zonas verdes $\left(\mathrm{m}^{2}\right)$ & 54.675 & 77.142 \\
\hline $\begin{array}{c}\text { Solución para el tramo de la } \\
\text { M-30 }\end{array}$ & $\begin{array}{c}\text { Soterramiento por los } \\
\text { promotores }\end{array}$ & $\begin{array}{c}\text { Recubrimiento por el } \\
\text { Ayuntamiento }\end{array}$ \\
\hline
\end{tabular}

Fuente: Elaboración propia de https://sede.madrid.es/csv

con el código $0901 e 24081712 \mathrm{a} 6$

Pero todavía se encuentran en los tribunales de justicia cuestiones sin resolver. Una de ellas pareciera aclararse en 2018, al derogar la Comunidad de Madrid por vía de urgencia la limitación de alturas de la ley regional del suelo. Pero Ecologistas en Acción, la Asociación Vecinal Pasillo Verde-Imperial, la asociación Señales de Humo y la Federación Regional de Asociaciones Vecinales de Madrid presentan un recurso de inconstitucionalidad contra la reforma de la ley.

La segunda se refiere a la modificación del Plan General para cambiar la titularidad del suelo de La Peineta. La Comunidad de Madrid aprueba la modificación, pues si la cesión de los terrenos no se completara antes de finalizar 2016, el club podía exigir 200 millones de indemnización al consistorio por incumplimiento del convenio firmado entre ambos. Pero la asociación Señales de Humo denuncia la modificación ante el TSJM, que falla en 2018 en contra por falta de motivación y déficit de análisis y previsión de las necesidades de la ciudad, y por priorizar el interés privado al general. La sentencia está actualmente recurrida ante el Supremo por las dos administraciones. No obstante, el club ya derribó el estadio en 2011, comprado el suelo en 2017 e iniciado los primeros movimientos de tierra para construir el Wanda Metropolitano, que se inaugura en 2019.

\subsection{LOS NUEVOS DUEÑOS DEL SUELO Y LOS PROMOTORES INMOBILIARIOS}

El proyecto de reparcelación de los terrenos del ámbito se aprueba a mediados de 2019. Dos parcelas corresponden al Ayuntamiento en virtud de las cesiones obligatorias (las RC.3 y RC.6) y las restantes las ponen a la venta los propietarios del suelo. Fondos, promotores, socimis y cooperativas apuestan fuerte por hacerse con algunos de los terrenos de una de las pocas bolsas de 
suelo a la venta dentro de la Almendra Central, una auténtica oportunidad para los inversores. El resultado ha sido el siguiente: las parcelas que corresponden a la cervecera las consiguen Ibosa (las RC.1 y RC.2) y Pryconsa (la RC.5) y con las del club de fútbol se queda Vivenio (la RC.4) y Azora (las RC.7 y RC.8)7. La superficie restante se destina a equipamientos (Figura 5).

Figura 5. La distribución de las parcelas (2019)

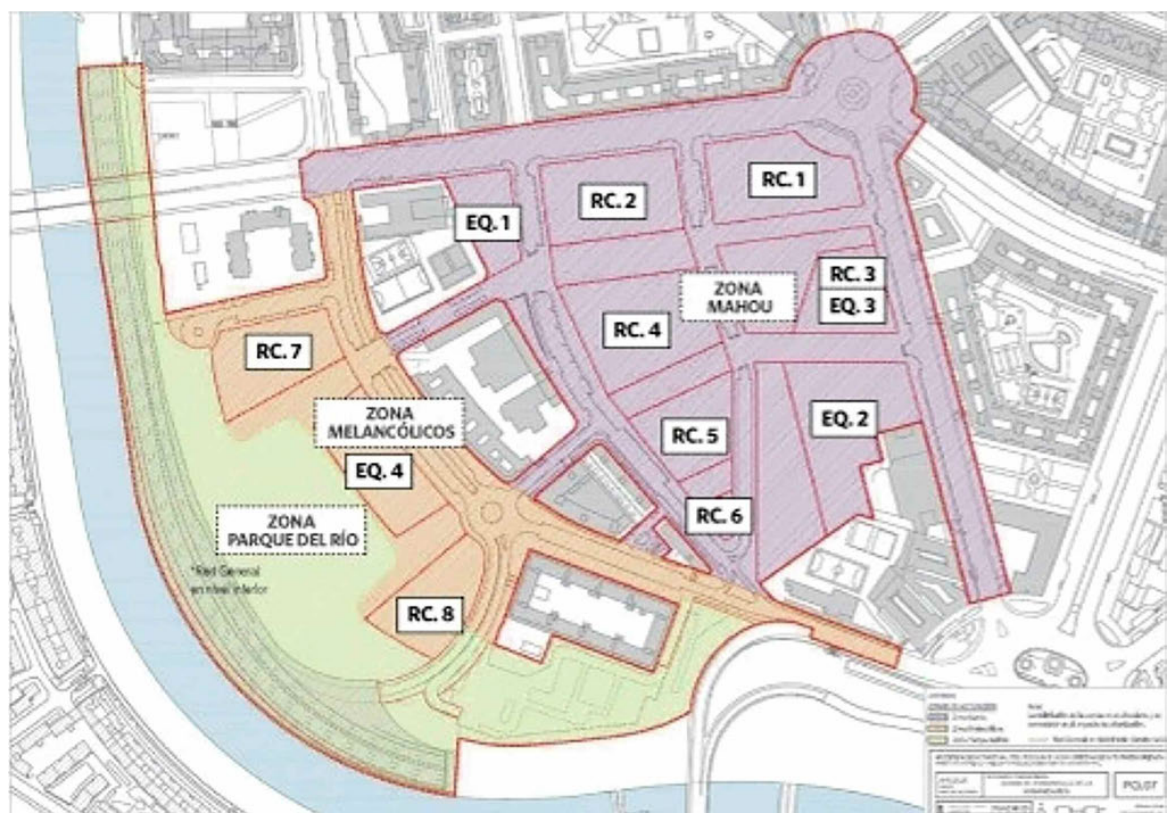

Fuente: https://ecodiario.eleconomista.es/empresas-

finanzas/noticias/10059959/08/19/Mahou-encarga-a-Colliers-la-venta-de-todos-sussuelos-en-el-ambito-del-Calderon.html (30-8-2019)

Aunque falta tiempo para el inicio de la construcción de los nuevos edificios, algunos propietarios del suelo se han lanzado ya a comercializar sus promo-

7 Ibosa es una empresa de promoción y gestión inmobiliaria que adquiere la RC.1 por 70 millones de euros, y se asocia con el fondo estadounidense Greennoak para comprar la RC.2 por 70 millones. Pryconsa es la promotora inmobiliaria de la familia Colomer que consigue la RC.5 por 55 millones. Vivenio es una socimi del fondo holandés APG y Renta Corporación que se hace con la RC.4 por 82 millones. Azora es una gestora de viviendas que se asocia con la constructora CBRE GIP para comprar las RC.7 y RC.8 por 100 millones. 
ciones. El proyecto en fase más avanzada es el «Residencial Zuarak Imperial» del grupo Ibosa. El complejo fue diseñado con antelación al tratarse de una promoción en forma de cooperativa, pues el grupo necesitaba acudir a la subasta del suelo con un porcentaje de ventas elevado. Ofrece en la RC.1 una urbanización con jardines, piscina, spa, gimnasio y solárium, y los precios de viviendas oscilan entre 260.000 y 720.000 euros.

También Azora y CBRE han lanzado el proyecto residencial «River Park» en sus dos parcelas, RC.7 y RC.8 donde se levantarán las torres de 12 plantas. La singular promoción cuenta con áreas ajardinadas, pista de pádel, piscinas, área infantil, sala comunitaria, work space, gimnasio, buzones inteligentes para compras, zona de lavado para mascotas y coches, zona de mantenimiento para bicicletas, espacios cardio protegidos, y el precio de las viviendas se encuentra entre 285000 y 957828 euros.

Por el momento, los precios medios de las viviendas de la cooperativa de lbosa (4.914 euros $/ \mathrm{m}^{2}$ ) y de la promotora Azora (5350 euros $/ \mathrm{m}^{2}$ ) están convirtiendo la zona en una de las más caras de la capital, acercándose a los tradicionales distritos de mayores precios como son Salamanca, Chamberí y Centro ${ }^{8}$.

\section{CONCLUSIONES}

Se ha constatado que las operaciones de transformación urbana proyectadas en los últimos años en los bordes de la Almendra Central de Madrid responden a un modelo de urbanismo fundamentado en la colaboración de los agentes públicos y privados directamente implicados, en el que a la oportunidad política de los primeros se suma el negocio de los segundos. Se trata de prácticas especulativas en enclaves que prometen inversiones muy rentables, especialmente para los operadores privados interesados en el negocio inmobiliario y apoyado por un marco institucional que proporciona los instrumentos y mecanismos para su ejecución.

El caso del ámbito Mahou-Calderón presenta un valor añadido, al sucederse a lo largo del proceso dos administraciones municipales con distinta filosofía urbana. El consistorio progresista de 2015 cuestionará el proyecto conservador neoliberal, aunque el peso de las negociaciones heredadas limite las posibilidades para obtener un resultado conforme a su proyecto de gobierno. No obstante, la nueva administración incorpora modos de gobernanza participativa que permiten a los vecinos y colectivos sociales, contrarios al urbanismo anterior, aportar formulaciones más orientadas al servicio de la ciudadanía. En definitiva, se consigue rebajar los propósitos de un programa neoliberal que

8 El precio medio más alto del metro cuadrado se encuentra en los distritos de Salamanca (5890), Chamberí (5280) y Centro (5043).

https://www.merca2.es/calderon-mahou-barrio-rico-madrid/ (21-12-2019). 
antepuso la rentabilidad económica de los intereses privados al bien general durante los diez primeros años de vida de la operación urbana.

No está de más traer aquí unas palabras del arquitecto Enrique Bardají que deberían animar a reflexionar tanto a los que practican el urbanismo como a los responsables de la política y gestión de la ciudad:

Cuando la opinión pública sigue considerando al planeamiento urbano como un conjunto de complejísimos y oscuros procesos, algo estamos haciendo muy mal los profesionales del urbanismo. De algún modo deberíamos empujar para que acabe considerándose como normal que la transformación de la ciudad es una actividad NOBLE sometida al conocimiento y la reflexión, al criterio de las mayorías democráticamente elegidas, al respeto de las minorías, a unas leyes comprensibles y a una transparencia completa en los procedimientos (Bardají, 2018, 28).

Para finalizar nos permitimos hacer una breve reflexión acerca de las cuestiones que todavía están sin resolver en los tribunales de justicia. Por desgracia, la práctica de los hechos consumados, a los que nos tienen acostumbrados los gobiernos conservadores en este país, con toda seguridad saldrá triunfante. Sobre todo cuando el consistorio de la ciudad ha vuelto a manos de un gobierno, si cabe, más conservador.

\section{AGRADECIMIENTOS}

Este trabajo se ha realizado dentro del Proyecto de Investigación PGC 2018098209-b-i00 del Ministerio de Ciencia, Innovación y Universidades.

\section{BIBLIOGRAFÍA}

Arias, F. (2009). Megaproyectos urbanos madrileños. En F. Aguilera y J. M. Naredo (Eds), Economía, poder y megaproyectos, pp. 181-208. Madrid: Fundación César Manrique.

Bardají, E. (2018). La ordenación urbana del ámbito «Mahou Calderón» (Madrid). Planur-e: territorio, urbanismo, paisaje, sostenibilidad y diseño urbano, (12). Recuperado de:

https://www.planur-e.es/articulos/ver/la-ordenaci-n-urbana-del-mbito-umahou-calder-n-madrid-

Brandis, D. y Rio, I. (1995). Las grandes operaciones de transformación urbana. El Pasillo Verde Ferroviario de Madrid. Ería, (37), 113-128.

Brandis, D. (2017). Grandes proyectos de transformación urbana pendientes en Madrid. En M. Castañer et al. (Eds.), Nuevos escenarios urbanos: nuevos conflictos y nuevas políticas, pp. 151-168. Girona: Universidad de Girona/ AGE.

Brandis, D. (2018). Grandes proyectos urbanos y desarrollos residenciales: del urbanismo de mercado a un nuevo modelo para Madrid. Ciudad y Territorio. Estudios Territoriales, Vol. 9 (198), 731-747. 
Pardo Abad, C. J. (2004). Vaciado industrial y nuevo paisaje urbano en Madrid. Madrid: Ediciones La Librería.

Rio, I. (2000). Planeamiento versus industria en las áreas centrales metropolitanas. La experiencia de Madrid en los últimos años. En V. Gonzálvez Pérez (Ed.), Industria y medio ambiente, pp. 159-169. Murcia: Universidad de Alicante/AGE.

\section{FUENTES DOCUMENTALES}

Ayuntamiento de Madrid (2016). Modificación Puntual del Plan General de Ordenación Urbana de Madrid de 1997 Área de Planeamiento Específico A.P.E. 02.27 «Nuevo Mahou-Calderón» Distrito de Arganzuela. Madrid: Ayuntamiento. Recuperado de https://www.comunidad.madrid/transparencia/sites/default/files/expedientes/nuevo-mahou-calderon/01_Aprobaci\%C3\%B3n\%2OInicial/O1_Modificaci\%C3\%B3n\%20de\%20Plan\%20Gener al/11_011\%20Memoria\%20Modificaci\%C3\%B3n\%20Puntual\%20Plan\%20General/ES_L01280796_2017_9024e4e80075469.pdf

BOCM (2010). Resolución de 12 de enero de 2010, por la que se hace público el Acuerdo del Consejo de Gobierno de fecha 29 de diciembre de 2009, por el que se aprueba definitivamente la Modificación Puntual del Plan General de Ordenación Urbana de Madrid de 1997, en el ámbito «Mahou-Vicente Calderón». (11). Madrid: Comunidad de Madrid. Recuperado de:

https://www.bocm.es/boletin/CM_Orden_BOCM/2010/01/14/2010-0114_13012010_0219.pdf.

BOCM (2015). Aprobar definitivamente el Plan Parcial de Reforma Interior de desarrollo del Área de Planeamiento Remitido 02.21 «Mahou-Vicente Calderón», Distrito de Arganzuela, promovido por la Comisión Gestora del ámbito, de conformidad con lo establecido en el artículo 59.4, en relación con los artículos 57 y 67 de la Ley 9/2001, de 17 de julio, del Suelo de la Comunidad de Madrid. (52). Madrid: Comunidad de Madrid. Recuperado de:

http://www.bocm.es/boletin/CM_Orden_BOCM/2015/03/03/BOCM20150303-55.PDF

BOCM (2017). Acuerdo de 19 de diciembre de 2017, del Consejo de Gobierno, por el que se aprueba definitivamente la Modificación Puntual del Plan General de Ordenación Urbana de Madrid, para la creación del APE 02.27, «Nuevo Mahou-Calderón», en el Distrito de Arganzuela. (306). Madrid: Comunidad de Madrid. Recuperado de:

https://www.comunidad.madrid/sites/default/files/doc/urbanismo/cma_urb_ bocm-20171226-48.pdf.

BOCM (2018). Modificación Puntual del Plan General de Ordenación Urbana de Madrid de 1997 Área de Planeamiento Específico A.P.E. 02.27 «Nuevo Mahou-Calderón» Distrito de Arganzuela. (160). Madrid: Comunidad de Madrid. Recuperado de: 
https://www.bocm.es/boletin/CM_Orden_BOCM/2018/01/16/BOCM-2018011655.PDF 


\title{
LA RESIGNIFICACIÓN DEL ESPACIO PÚBLICO CONTEMPORÁNEO: EXPERIENCIAS ALTERNATIVAS EMERGENTES (CASOS DE AMÉRICA Y EUROPA) \\ RESIGNIFICATION OF CONTEMPORARY PUBLIC SPACE: \\ EMERGING ALTERNATIVE EXPERIENCES (CASES IN AMERICA AND EUROPE)
}

\author{
Juan Manuel Bueno Carvajal \\ Universitat Politècnica de València
}

Resumen

Algunas de las problemáticas más relevantes de las ciudades en general, como la inaccesibilidad, la privatización de lo público, el miedo o la falta de identidad, están relacionados de manera directa con el espacio público, el cual, hemos concebido, diseñado y gestionado desde las disciplinas del estudio urbano causando en parte estos conflictos y afectando la calidad de vida de la ciudadanía. De manera paralela, han surgido nuevas experiencias alternativas, que se expresan en proyectos en el espacio público que cuestionan los procesos convencionales de actuación, por sus calidades participativas, temporales, recicladas, y de identidad y apropiación de las comunidades beneficiadas. Con este artículo se propone una revisión de estos temas a partir de un enfoque teórico, para así presentar algunos proyectos representativos en Latinoamérica, Norteamérica y Europa, compilados a partir de un ejercicio comparativo que los evalúa desde una batería de criterios, construida, con el ánimo de proponer reflexiones que conduzcan a una resignificación del espacio público contemporáneo.

Palabras clave: espacio público, diseño urbano, participación comunitaria, ciudadanía.

\section{Summary}

Some of the most relevant problems of cities in general, like the inaccessibility, the privatization of the public, the fear or the absence of identity, are directly related to public space, which, we have conceived, designed and managed from the disciplines of urban study, causing in most of the cases, these conflicts affecting the social welfare. At the same time, new alternative experiences have emerged, which are expressed in projects in the public space questioning the conventional urbanism, because these have participatory process, new temporalities, recycled materials, and generate identity qualities in beneficiary communities. This article proposes a review of these issues based on a theoretical approach, in order to present some representative projects in Latin America, North America and Europe, compiled from a compa- 
rative exercise that evaluates them, from criteria to propose reflections on the resignification of contemporary public space.

Keywords: public space, urban design, community participation, citizenship.

\section{INTRODUCCIÓN}

El espacio público, concebido como un importante componente urbano por sus características sociales y como escenario contenedor, donde las personas se identifican como ciudadanía al hacer uso del conjunto de sus funciones potenciales sin restricción (Rueda, 2011), manifiesta problemáticas que repercuten en cómo lo concebimos y lo entendemos desde disciplinas del estudio urbano. Estos problemas inciden en la calidad de vida de la ciudadanía y es posible entenderlos desde los que provienen de la gestión, y otros desde las dinámicas del espacio público. Es por ello, que se ha observado en la historia reciente unas manifestaciones alternativas y emergentes, que se contraponen con efectos positivos inmediatos en los contextos urbanos y en la ciudadanía, cuestionando las formas tradicionales, explorando nuevas metodologías, materiales, escalas, y tiempos para dar cabida a nuevos proyectos en el espacio público. Los principales objetivos que se plantean en la investigación son definir estas problemáticas y presentar qué experiencias emergentes han surgido en el espacio público, para luego exponer algunos proyectos producto de estas experiencias, en los contextos de Latinoamérica, Norteamérica y Europa, cate-

gorizados en tres grupos: efímeros, puntuales, y de barrio, con un ejercicio de análisis a través de criterios que valoran su acción en el espacio público. Finalmente, proponer algunas reflexiones, con el ánimo de construir una resignificación del espacio público con estas visiones contemporáneas.

El artículo se desarrolla primero, mostrando el tema de los problemas del espacio público y la mención de las experiencias emergentes desde un punto de vista teórico. Segundo, con los resultados, donde se presentará la metodología del ejercicio compilatorio y la presentación de los proyectos. Y por último en las conclusiones se valorarán los proyectos y se propondrá una reflexión final que abre el debate hacia la resignificación.

\section{LAS PROBLEMÁTICAS DEL ESPACIO PÚBLICO CONTEMPORÁNEO Y EL SURGIMIENTO DE LAS EXPERIENCIAS ALTERNATIVAS}

Es posible denunciar que el espacio público, ha sido un escenario que en parte ha definido algunas problemáticas de las ciudades contemporáneas, que sin importar sus contextos, se pueden puntualizar graves problemas generales que lo caracterizan y que han llegado incluso a normalizarse y hacer que los ciudadanos nos hayamos acostumbrado a comprenderlo a través de estos problemas como un asunto del cotidiano. 
Así, se define un grupo de conflictos, que se entienden a partir de la gestión. Primero, se evidencian problemas con la accesibilidad social y física, ya que se han acentuado las demarcaciones entre zonas ricas y pobres y así se ha creado una barrera que ha llevado a cerrar el espacio, señalando diferencias entre la población y agrupando sectores sociales por su poder económico, edad y sexo (Frank, 2003). Así, el acceso en condiciones igualitarias dentro de la ciudad a través del espacio público está condicionado, incluso por la planeación, que en muchos casos está en función de la separación. También, la accesibilidad física es constante, ya que existen barreras y elementos, incluso estandarizados, que obstaculizan el uso del espacio público. Estas barreras son una manifestación de que el diseño urbano ha dejado de lado a la ciudadanía, en especial a las personas vulnerables, quienes requieren alguna asistencia para su movilidad, a la niñez y a los ancianos; siendo estos dos estados, parte de ciclo inicial y final de la vida que determinan la forma de percibir, comprender y usar el espacio (Tonucci, 2004).

Como segunda amenaza, se evidencia a la privatización. La debilidad política de la iniciativa pública, la influencia económica privada, la obediencia al mercado, la obsesión de la competitividad y el urbanismo como generador de productos, son las dinámicas que conforman argumentos de privatización (Borja y Muxí, 2003). Como consecuencia de lo anterior, está el tercer problema: el espacio público falso, que se manifiesta en los centros comerciales, simulando escenarios públicos para propiciar ambientes de consumo y seguridad. Y también se presenta en los conjuntos cerrados de vivienda, que referencian a la propiedad privada de uso colectivo, donde este valor de lo restringido devalúa al espacio abierto y público de la ciudad (Martínez, 2016), simulando aspectos del espacio público de una forma cerrada, generando que la vitalidad urbana desaparezca y se interrumpa.

Por último se incluye la forma en la que el espacio público se ha diseñado, la cual le ha otorgado protagonismo y valores que no posee. Podríamos llamar a esto como el espacio público sobrediseñado, el cual pretende figurar por encima del contexto urbano e introducirse como solución absoluta. Lo concibe como una parcela individual dentro de la ciudad, como un elemento independiente, es una copia de modelos, del derroche económico, de la arbitrariedad de los proyectos, de la moda y de los actores políticos beneficiados (de Solà-Morales, 2010).

El otro grupo de conflictos, se conciben a partir de las dinámicas, uno muy grave es el miedo, que puede transformarse en agorafobia urbana. El temor hacia el espacio público, se puede presentar más evidente en contextos de segregación predominante. Esto genera un discurso ciudadano articulado en la tendencia de privilegiar el uso de espacios privados sobre los públicos y en su reconocimiento como peligroso por episodios de violencia; que impacta a cada persona y causa que se refugie en su esfera privada y que alimente un imaginario social de miedo (Dammert, 2004). Otro problema es la 
identidad, ya que la función social del espacio permite establecer significados en lugares de la ciudad, y se evidencia cómo el espacio público está perdiendo esta función, creando espacios socialmente homogéneos que como consecuencia hacen poco probables los encuentros ciudadanos (Aramburu, 2008). Esto se interpreta desde el concepto de anomia', ya que se puede dilucidar una falta de identificación, que los ciudadanos no se sientan parte de algo. Entonces desembocará en ciudades anómicas.

Como respuesta a estos problemas y otras causas, han surgido en distintas ciudades nuevas experiencias en el espacio público, que desafían las actuaciones tradicionales y han logrado traer efectos positivos importantes por sus características alternativas, participativas y recursivas. Su relación teórica es nueva y por ello ponemos en valor que es una materia de estudio importante del urbanismo contemporáneo. Se identifican:

1. Diseño participativo: define criterios para la toma de decisiones en los proyectos, en diferentes etapas, desde la formulación, diseño y construcción. Es indispensable porque las comunidades realizan los aportes más valiosos para los proyectos ya que así se asegura la pertenencia de estos desde el momento del diseño.

2. Los urbanismos alternativos, el táctico y el hecho a mano: el primero reivindica, se desarrolla en el tiempo, es un instrumento al alcance de la ciudadanía que actúa con acciones participativas, a veces autoconstruidas, o también temporales y generan pertenencia y apropiación en el espacio y cuestionan el poder (Mozas, 2011). Y el otro, se lleva a cabo por los mismos vecinos, que proponen soluciones usando la creatividad para transformar recursos, comparten responsabilidades para construir espacios colectivos en el espacio público entre asociaciones culturales, líderes comunales, residentes, usuarios, artistas, arquitectos, gobiernos, academia y privados (Rosa y Weiland, 2013).

3. Materialización desde el reciclaje: se vale de la habilidad de gestión de recursos usados como materiales para realizar proyectos de espacios públicos. También se manifiesta como reciclaje urbano, con actuaciones en lugares que no tienen uso y son vacíos urbanos.

4. La ocupación de solares²: es un ejemplo de reciclaje y de actuación de los urbanismos alternativos. Se trata de solares en la ciudad que se encuentran sin edificar, los cuales se apropian de forma alegal, o a veces con autorización de los dueños, por parte de la comunidad de vecinos, para

1 Es posible referenciar el tema de anomia en la teoría de Émile Durkheim (1885 - 1917). Se concibe como un estado de asilamiento individual causada por alguna inconsistencia social.

2 El solar materializa la propiedad del suelo y sus límites pueden ser materializados. Es un espacio privado y está afectado por los usos del suelo (Boire y Danieuil, 1985). Pueden ser denominados con el término de lote, parcela, o predio. 
generar proyectos efímeros que dan nuevos usos y lo convierten en espacios colectivos activos.

5. El arte urbano: se reconoce a través de la pintura (mural y el grafiti), la escultura contemporánea, la performance y las instalaciones. Logra generar distintas relaciones con la ciudad y se integra en el espacio público.

\section{RESULTADOS: CASOS DE ESTUDIO}

\subsection{METODOLOGÍA: EJERCICIO DE COMPILACIÓN DE LOS CASOS DE ESTUDIO}

Para este ejercicio, se han localizado y seleccionado algunos proyectos representativos en Europa, Latinoamérica y Norteamérica. Con esta muestra, se aprecia que las manifestaciones emergentes acontecen en distintos contextos con distintas características geográficas y sociales. Al revisar los caos de estudio seleccionados, se ha resuelto que pueden ser expuestos claramente a partir de una categorización, la cual se ha propuesto a partir de las cualidades comunes que comparten estos casos. Se proponen tres grupos: Primero los efímeros, que son aquellos que presentan condiciones temporales, que por sus condiciones físicas, se realizan de manera eventual. Segundo, los puntuales, que son permanentes, y comparten algunos rasgos cercanos a la planeación tradicional, pero su condición urbana y arquitectónica, como sus procesos de diseño y ejecución son diferenciadores. Y por último los de barrios, extendidos en una escala significativa que comparte una identidad consolidando comunidades en sectores.

Por medio de un método descriptivo y comparativo, se ha diseñado una batería de análisis de criterios, con los que presentaremos cada proyecto otorgado un puntaje de cero a diez, donde cero indica que no tiene representación, y diez, la máxima representación en cada caso. Finalmente, se presenta un comparativo general entre todos los proyectos para analizar la pertinencia de estos criterios como pauta para poder concluir ideas relevantes que permitan reflexionar sobre la resignificación del espacio público. 


\subsection{PROYECTOS EFÍMEROS}

Figura 1. Proyectos efímeros

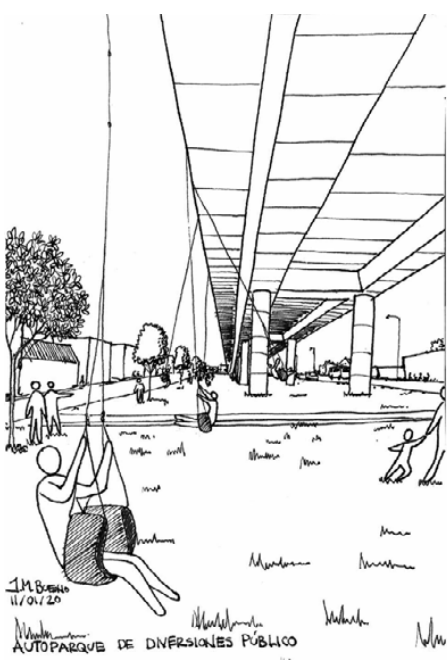

Autoparque de Diversiones Público

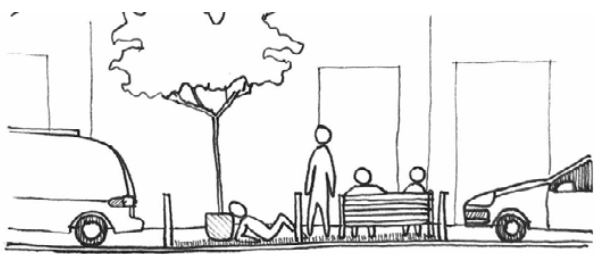

19:101019

Park(ing)

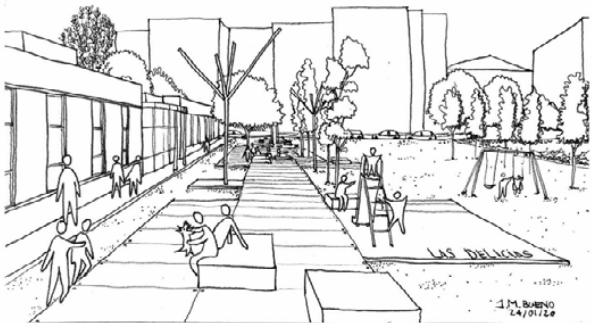

Esto no es un Solar. Lote en Las Delicias / Parque con juegos

Fuente: Elaboración propia

Tabla 1. Proyectos efímeros

PARK(ING)

\begin{tabular}{|c|c|c|}
\hline \multicolumn{3}{|c|}{ DESCRIPCIÓN POR CRITERIOS } \\
\hline 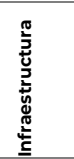 & $\begin{array}{l}\text { Consiste en recrear una escena de un parque en una plaza de aparcamiento en la calle. } \\
\text { Elementos: una moqueta verde, una banca y un árbol. Este ejercicio se replicó a nivel mundial } \\
\text { en } 47 \text { ciudades, consolidando un park(ing) day, y un Parkcicle donde desarrollaron muestras } \\
\text { mucho más diversas con espacios lúdicos, comerciales y simbólicos. }\end{array}$ & 3 \\
\hline 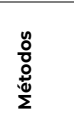 & $\begin{array}{l}\text { Su carácter efímero se debe al tiempo de uso de la plaza de dos horas. El montaje es rápido ya } \\
\text { que los elementos en sí solo se acomodan en la escena. El registro de la experiencia incluye la } \\
\text { expectativa que genera el montaje hasta la reacción e interacción de las personas que } \\
\text { transitan. }\end{array}$ & 8 \\
\hline 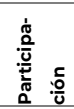 & $\begin{array}{l}\text { La participación se contempla desde los equipos de trabajo que se conforman para el montaje, } \\
\text { y con las personas que se encuentran desprevenidamente con el proyecto, que se acercan a } \\
\text { participar. }\end{array}$ & $\mathbf{5}$ \\
\hline 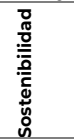 & $\begin{array}{l}\text { Se da desde el reciclaje y la acción de los urbanismos alternativos implementados, ya que es } \\
\text { a través de reutilizar y reconvertir, que el proyecto se sustenta a través de tácticas. Se puede } \\
\text { ver desde el uso urbano transformado y desde los propios elementos físicos que lo componen, } \\
\text { ya que pueden reutilizarse después en otros espacios. }\end{array}$ & 8 \\
\hline 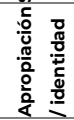 & $\begin{array}{l}\text { El poder generar espacios verdes usando materiales que son simbólicamente asociados a los } \\
\text { parques con la idea de replicar el ejercicio (Merker, 2010), es una manera de reforzar una } \\
\text { identidad urbana potente que estimula el uso y la vitalidad del espacio público. }\end{array}$ & 7 \\
\hline
\end{tabular}




\begin{tabular}{|c|c|c|}
\hline \multicolumn{3}{|c|}{ AUTOPARQUE DE DIVERSIONES PÚBLICO } \\
\hline \multicolumn{3}{|c|}{ Localización: Lima, Perú Año: 2010. Autores: Basurama } \\
\hline \multicolumn{3}{|c|}{ DESCRIPCIÓN POR CRITERIOS } \\
\hline 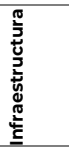 & $\begin{array}{l}\text { Es un parque implantado en las vías del tren elevado eléctrico (línea } 1 \text { del metro) que estuvo } \\
\text { detenido durante su construcción por muchos años, dejando una estructura inconclusa, la } \\
\text { cual es aprovechada quince días para instalar juegos (las sillas voladoras, el toro loco, el barco } \\
\text { pirata, el mirador, el tren fantasma...) materializados a partir de elementos reciclados. }\end{array}$ & 4 \\
\hline 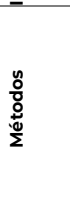 & $\begin{array}{l}\text { Primero hay una iniciativa del colectivo Basurama en hacer una gira por Latinoamérica para } \\
\text { realizar este tipo de proyectos con el apoyo de la AECID (Agencia Española de Cooperación } \\
\text { Internacional al Desarrollo). Se gestiona con artistas locales, quienes aportaron la iniciativa de } \\
\text { reflexionar sobre este espacio sin uso y el acercamiento a la comunidad para que participe en } \\
\text { el proyecto. Y por último en la ejecución, se acude a un diseño de lógica prefabricada y } \\
\text { reciclada para optimizar la instalación. }\end{array}$ & 9 \\
\hline$\frac{0}{\frac{\pi}{0}}$ & $\begin{array}{l}\text { La participación se contempla desde los equipos de trabajo que se conforman para el } \\
\text { montaje, y con las personas que se encuentran desprevenidamente con el proyecto e } \\
\text { interactúan con este. }\end{array}$ & 8 \\
\hline 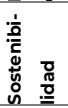 & $\begin{array}{l}\text { Con el lugar de implantación, en la estructura elevada, vemos una variable de sostenibilidad } \\
\text { al poner en uso un vacío urbano. La materialidad de los juegos son piezas metálicas de coches } \\
\text { y neumáticos reciclados, con los que se logra concebir elementos urbanos complejos. }\end{array}$ & 10 \\
\hline 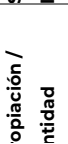 & $\begin{array}{l}\text { Un aporte significativo fue la gama cromática usada en los juegos y en revestimientos de } \\
\text { papel de las columnas de colores (gamas neón de colores verde, naranja y rosa) que emulan } \\
\text { a los posters de conciertos de música popular locales. El Autoparque es una reconciliación con } \\
\text { la obra abandonada, ya que ofreció una oportunidad de uso y es un mensaje de atención a las }\end{array}$ & 8 \\
\hline
\end{tabular}

\section{ESTO NO ES UN SOLAR}

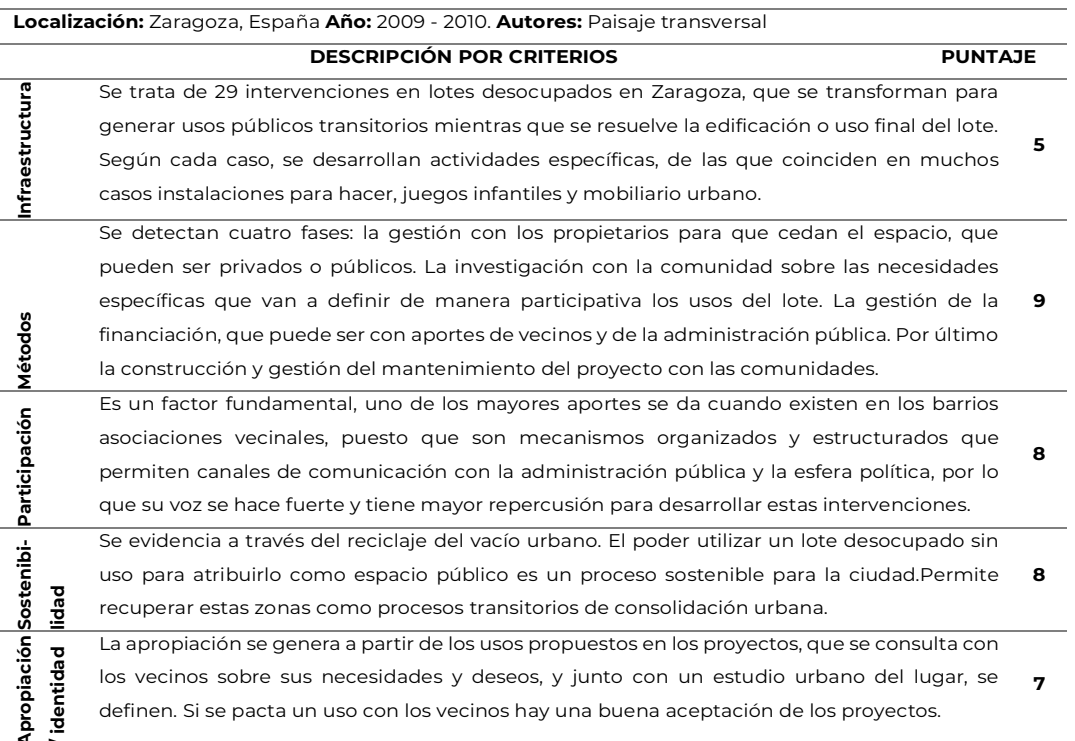

\section{Fuente: Elaboración propia}




\subsection{PROYECTOS PUNTUALES}

Figura 2. Proyectos puntuales

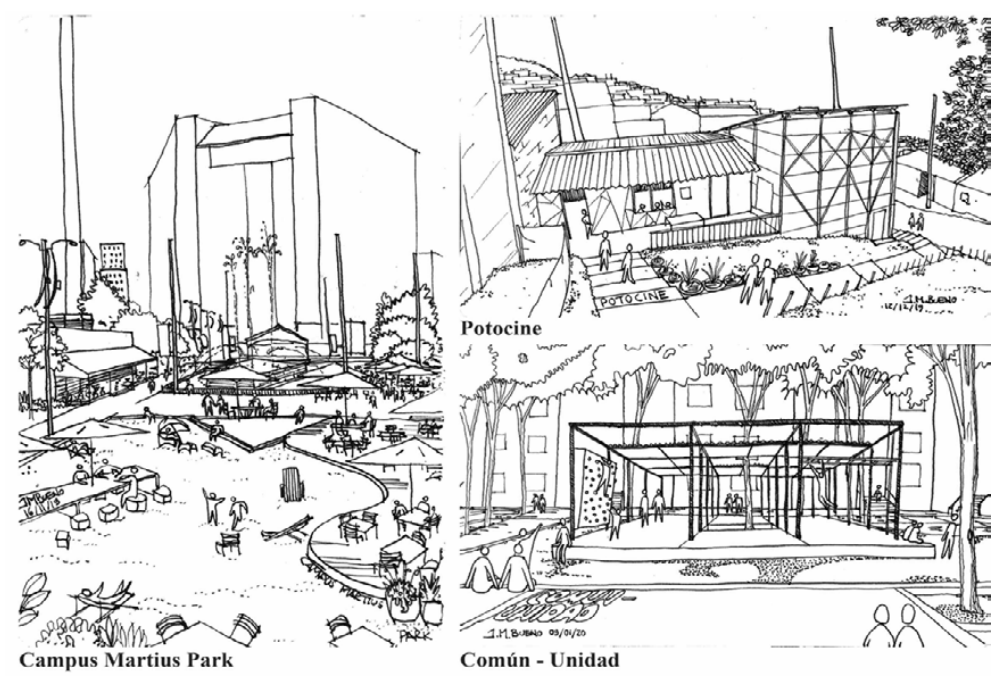

Fuente: Elaboración propia

Tabla 2. Proyectos puntuales

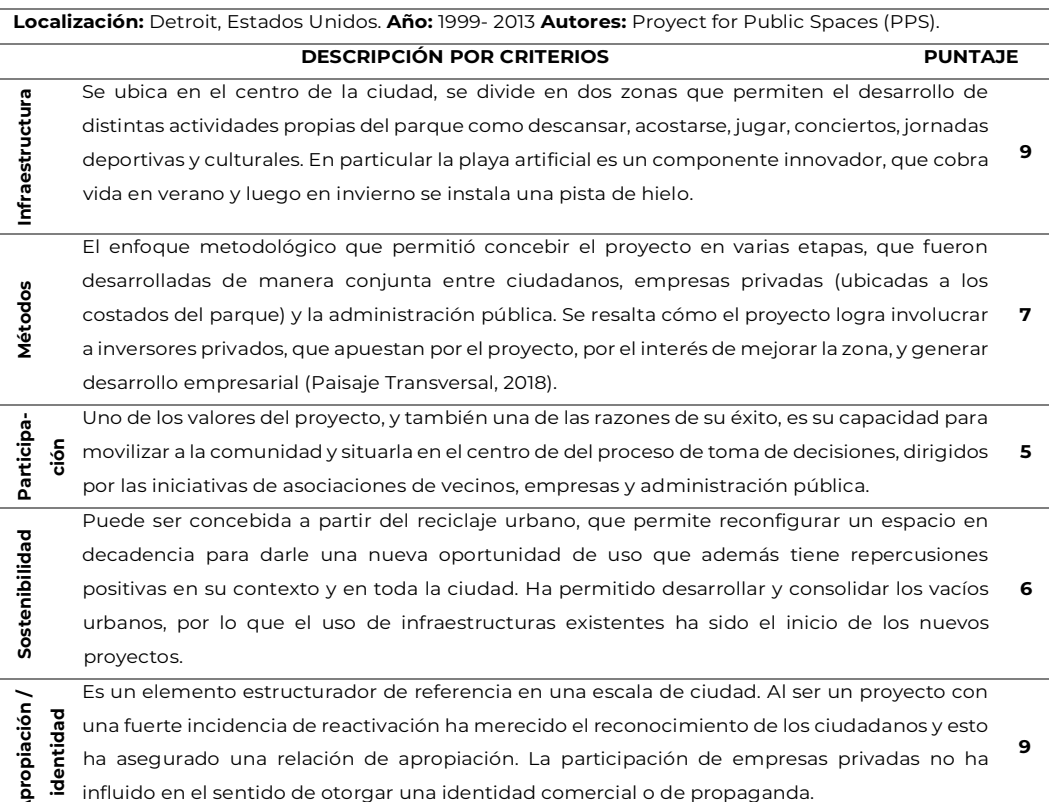




\section{POTOCINE}

Localización: Bogotá, Colombia Año: 2016 Autores: Comunidad barrio Potosí, Escuela de Cine

Comunitaria y Festival de Cine Comunitario Ojo al Sancocho, Instituto Educativo Cerros del Sur y Colectivo Arquitectura Expandida.

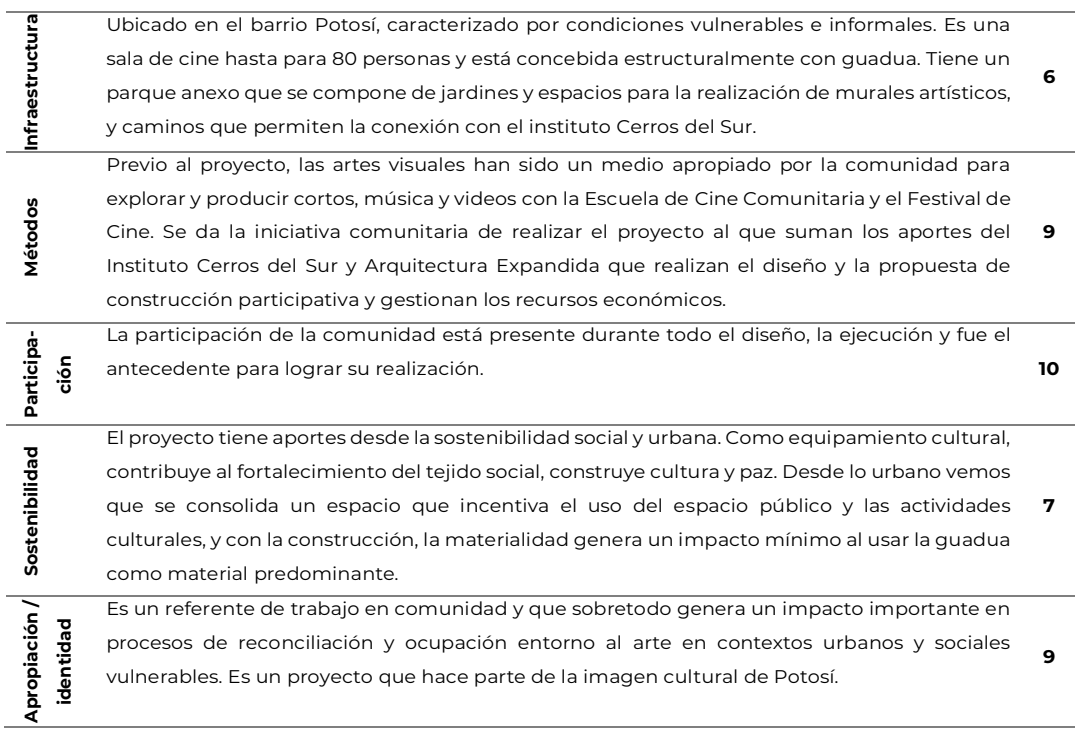

\section{COMÚN - UNIDAD}

Localización: ciudad de México, México. Año: 2015. Autores: Rozana Montiel Estudio de Arquitectura y residentes unidad habitacional San Pablo Xalpa.

Es una intervención del espacio público de la unidad habitacional San Pablo Xalpa, que desde

预 su diseño original fue un espacio residual, que con el tiempo los vecinos fueron poniendo

cerramientos y privatizándolo. El proyecto lo rehabilita con la integración de recorridos y la

đ instalación de unos módulos metálicos que abarcan distintas funciones como juegos

玹 infantiles y áreas de reunión para eventos.

气 El proyecto es una solicitud de la comunidad, que fue redireccionada y potencializada como

\% partícipe en una experiencia mutua de trabajo colaborativo. Se aplican metodologías de

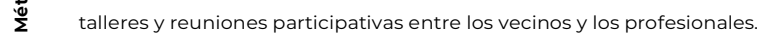

. A través de la participación la misma comunidad identifica que las barreras físicas impiden el

을 desarrollo de la rehabilitación y que el proyecto requiere espacios adaptativos. La comunidad

$\frac{0}{\overline{0}} \quad$ interviene en el diseño y construcción, proponiendo ideas para los módulos metálicos y con e

党 derribo de las rejas existentes.

T Es vista desde un carácter social, ya que responde y contribuye a mejorar la calidad de vida de

una población con importantes problemáticas sociales. Son las nuevas infraestructuras físicas

que logran adaptarse a las dinámicas sociales existentes y se potencializa el uso y la vida

comunal.

La apropiación surgía desde las iniciativas y concepciones privadas de cada uno de los vecinos

은 응 al integrarse en actividades comunitarias y al intervenir el espacio público como

manifestación de proyección de su propiedad privada. Es un proyecto que genera una oportunidad para que los vecinos reinterpreten el significado de lo público.

\section{Fuente: Elaboración propia}




\subsection{PROYECTOS BARRIOS}

Figura 3. Proyectos barrios
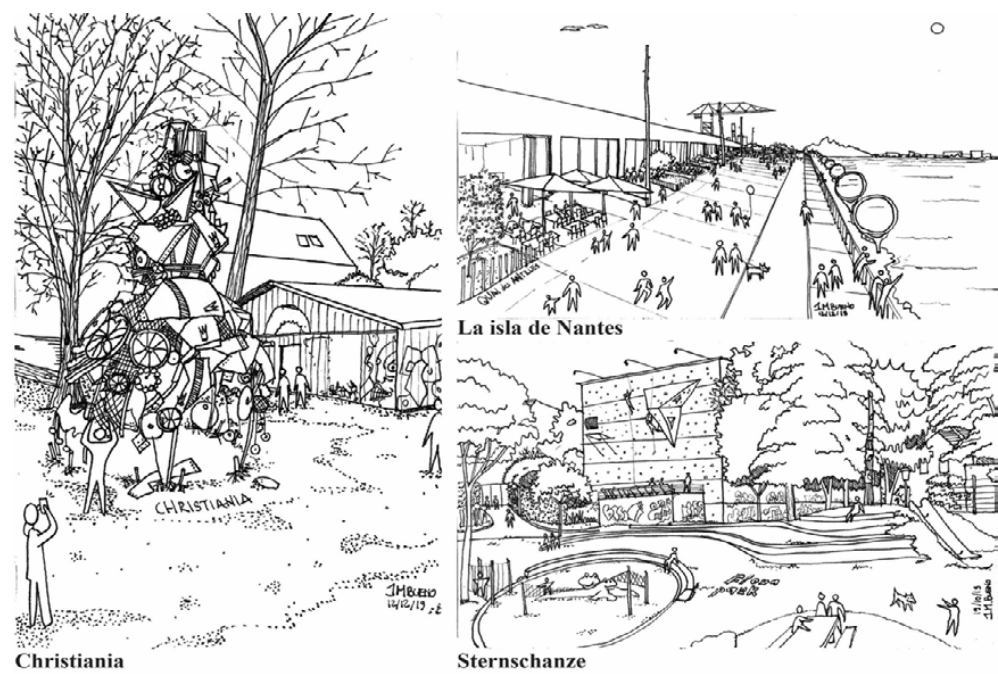

Fuente: Elaboración propia

Tabla 3. Proyectos barrios

\section{STERNSCHANZE}

Localización: Hamburgo, Alemania Año: 1989, 2013 - Actualidad. Autores: Comunidad local.

\begin{tabular}{|c|c|c|}
\hline 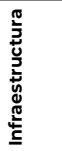 & $\begin{array}{l}\text { Es un barrio con una dinámica social influyente en el espacio público, que ha evolucionado } \\
\text { con el ambiente local como punto de expresión insurgente, demostrado en su intervención, } \\
\text { a través de parques interiores de manzana, el uso de solares vacíos y la ocupación del Rote } \\
\text { Flora, un antiguo teatro abandonado del que se ha apropiado la comunidad local. }\end{array}$ & 3 \\
\hline 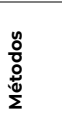 & $\begin{array}{l}\text { Ha sido un proyecto que como nueva identidad de barrio, se ha construido progresivamente } \\
\text { desde los últimos } 30 \text { años, que supone la organización de vecinos, y distintos colectivos } \\
\text { locales, para intervenir y desarrollar actividades en el espacio público, que rechazan los } \\
\text { sistemas tradicionales de gestión que han afectado el barrio con problemas de gentrificación. }\end{array}$ & 4 \\
\hline 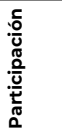 & $\begin{array}{l}\text { Las intervenciones en el barrio se dan a partir de la acción entre residentes y artistas locales. } \\
\text { También hay otros grupos de residentes más resientes y empresarios que han aprovechado } \\
\text { la imagen independiente e insurgente para generar dinámicas comerciales. Estos grupos a } \\
\text { veces entran en conflicto, y en ocasiones sus acciones se sincronizan y se apoyan. }\end{array}$ & 9 \\
\hline 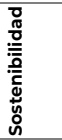 & $\begin{array}{l}\text { La sostenibilidad se puede ver desde el reciclaje, al implementar materiales reciclados en los } \\
\text { proyectos, desde el mobiliario hasta el uso de la estructura del Rote Flora, un equipamiento } \\
\text { abandonado, que era un antiguo teatro y hoy es una sede ocupada por personas sin hogar y } \\
\text { también por los vecinos, que usan la instalación para reuniones y eventos culturales. }\end{array}$ & 5 \\
\hline 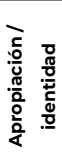 & $\begin{array}{l}\text { El uso espontáneo del espacio es el mecanismo que puede, que ha construido la identidad } \\
\text { del lugar y ha motivado a la actividad de la protesta por defender una filosofía de convivencia } \\
\text { alternativa, enmarcada en la resistencia al desplazamiento, y a ser absorbidos por un modelo } \\
\text { económico influyente a escala de ciudad, impulsado por privados y desatendido por la } \\
\text { administración pública. }\end{array}$ & 10 \\
\hline
\end{tabular}


LA ISLA DE NANTES

Localización: Nantes, Francia Año: 1989 - Actualidad. Autores: SAMOA (Société d'Aménagement de la Métropole Ouest Atlantique), comunidad local de vecinos, sectores privados culturales.

\begin{tabular}{|c|c|c|}
\hline \multicolumn{3}{|c|}{ DESCRIPCIÓN POR CRITERIOS } \\
\hline 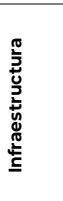 & $\begin{array}{l}\text { El proyecto en su totalidad es una actuación que reestructura una pieza de la ciudad tras el } \\
\text { abandono de su uso inicial como puerto y sede industrial, a partir de actuaciones en el espacio } \\
\text { público integrando acciones públicas y privadas con participación ciudadana. Se destaca la } \\
\text { red de transporte público, puentes peatonales y vehiculares de conexión, adecuación de } \\
\text { zonas especializadas para usos culturales y de bordes con paseos peatonales y parques y } \\
\text { proyectos como Las Máquinas de la Isla. }\end{array}$ & 3 \\
\hline$\stackrel{\text { on }}{\mathrm{o}}$ & $\begin{array}{l}\text { El apoyo de la comunidad, la academia, el sector privado y la administración pública es el valor } \\
\text { más importante: Hay políticas públicas que permiten transformaciones de usos y prioridad a } \\
\text { proyectos de espacio público. El vínculo del sector privado a través de condiciones enfocadas } \\
\text { en la cultura y el arte como medios impulsores de la definición, uso y apropiación del espacio } \\
\text { público (Velazquez y Verdaguer, 2011). }\end{array}$ & 4 \\
\hline 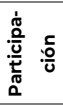 & $\begin{array}{l}\text { Se da a través de mecanismos de gestión, liderados de manera recíproca entre las } \\
\text { administraciones y la ciudadanía. Es importante su aporte en la definición de problemáticas y } \\
\text { en los objetivos del proyecto, que a su vez permitió el control y supervisión. }\end{array}$ & 9 \\
\hline 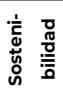 & $\begin{array}{l}\text { El reciclaje urbano es la principal metodología de sostenibilidad, al adecuar varias estructuras } \\
\text { antiguas del puerto. }\end{array}$ & 5 \\
\hline 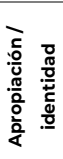 & $\begin{array}{l}\text { La identidad siempre ha rondado la noción portuaria. El vínculo directo con esta industria en } \\
\text { la historia y la influencia del río en la isla son una fortaleza que aporta valores importantes al } \\
\text { paisaje local al conservar infraestructuras. Se devuelve a la ciudad de Nantes un espacio } \\
\text { olvidado y golpeado por momentos de crisis económica con la experimentación de usos } \\
\text { culturales y activación del espacio público. }\end{array}$ & 10 \\
\hline
\end{tabular}

\section{CHRISTIANIA}

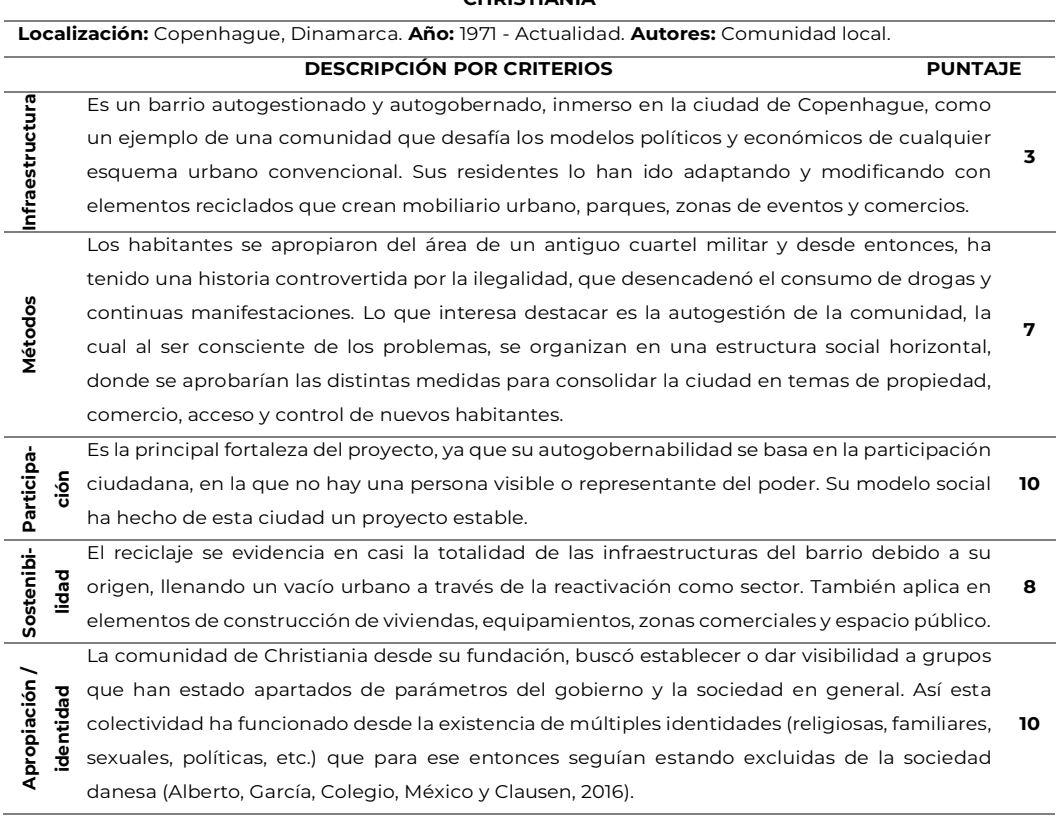

\section{Fuente: Elaboración propia}




\section{CONCLUSIONES}

\subsection{CALIFICACIÓN DE LOS PROYECTOS}

Figura 4. Comparativo de proyectos.

A. Gráfico de barras de evaluación de los criterios de estudio y proyectos

B. Peso de cada criterio a nivel global entre los proyectos descrito
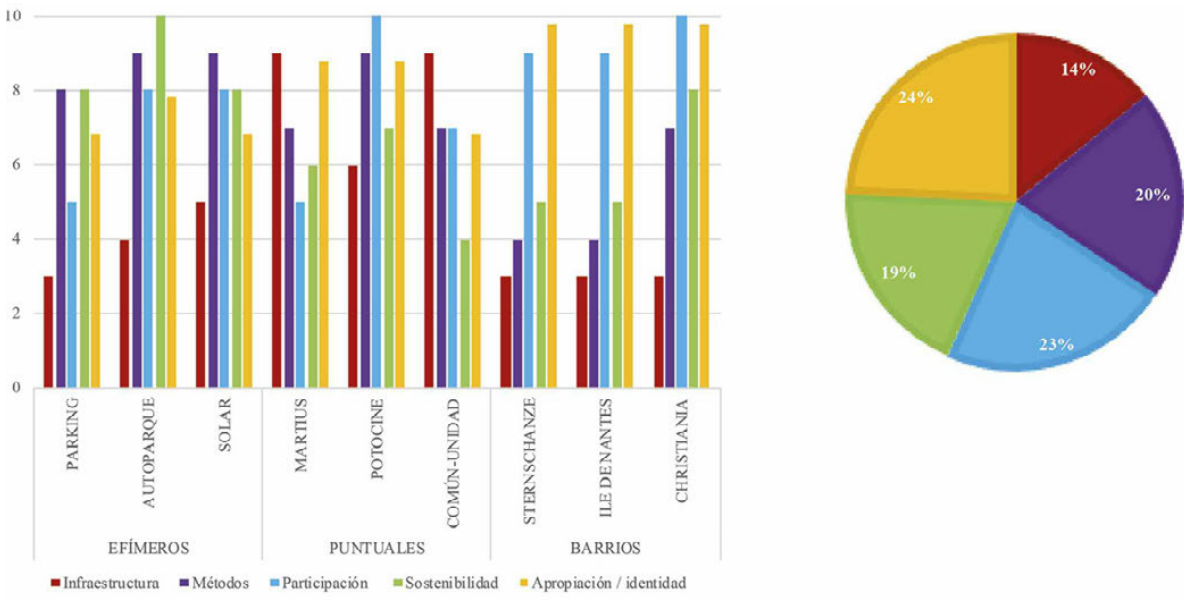

Fuente: Elaboración propia

Con este comparativo, se concluye que los proyectos efímeros tienen una gran fortaleza en los métodos y la sostenibilidad, debido a la influencia del reciclaje como elemento de materialización y de localización, resaltando la innovación que presentan desde los procesos colaborativos entre profesionales y comunidades. Por otro lado, la infraestructura es el elemento menos relevante, debido a su carácter efímero. Para los proyectos puntuales la apropiación e identidad es lo mejor evaluado a causa del componente social, que ha permitido recuperar y rehabilitar espacios públicos con conflictos que reservan un espacio importante en la identidad colectiva y que con las intervenciones logran potenciarse. Y en el caso de los barrios, la identidad está forjada desde un inicio y coinciden en que son proyectos que se han ejecutado desde el siglo pasado, por lo que su incidencia es más compleja.

Por último, con el comparativo general de todos los proyectos, se evidencia que lo menos valorado es la infraestructura, lo más valorado es la apropiación y la identidad, y los otros tres criterios son constantes. Esto significa que se anuncia un efecto importante: que no hay valor en el aspecto físico, dando mayor énfasis a actuaciones que permiten generar actividades y usar el espacio público sin importar si son efímeras, para impactar de manera importante la identidad. Esto permite revelar que estos criterios requieren un 
espacio importante en la escena del espacio público y como se ha anunciado son el inicio para plantear una necesario resignificación.

\subsection{INSUMOS COMO RESIGNIFICACIÓN DEL ESPACIO PÚBLICO}

Con la exposición de los problemas del espacio público, entendemos que existe una relación con el surgimiento de las experiencias alternativas. Existen insolvencias en la comprensión, diseño y gestión el espacio público, por lo que, es posible ver cómo han surgido de forma paralela estas experiencias que incluso, se han acercado a procesos sociales relacionados con la alegalidad o la insurgencia. Es por ello que este tema requiere un espacio importante como materia de estudio de la ciudad contemporánea, ya que a partir de la teoría y práctica podemos trazar un camino para subsanar, los distintos vacíos creados en el ámbito del espacio público, el cual se puede denunciar además, que ha sido un componente descuidado y sobrevalorado desde la gestión urbana y la academia. El debate sobre cómo estas experiencias estén al margen de procesos de gestión formales o sean incluidas, puede ser una circunstancia de la que dependa su evolución, y es posible afirmar que son una semilla de cambios más profundos en los barrios en los que se desarroIlan y cómo pueden replicarse en toda la ciudad a través de la gestión y las políticas públicas (Ocupa tu calle., ONU-Habitat., y Fundación Avina. 2018).

La comprensión de estas experiencias es un llamado hacia la responsabilidad original de concebir a la ciudad como un lugar protector y de bienestar, donde las administraciones públicas, en parte, tienen un deber con los ciudadanos; aunque no son tampoco la solución definitiva, con los casos de contextos vulnerables en Latinoamérica, por ejemplo, donde existen necesidades de movilidad, equipamientos, servicios e infraestructuras, no es posible resolverlos a partir de estos proyectos. Así pues, como resultado representativo, se plantean las siguientes reflexiones como un insumo de resignificación:

La participación siempre: la acción de participación ciudadana es el aporte más relevante que un proyecto puede ofrecer a la ciudad si está contemplada desde todas las etapas de los proyectos: el diseño, gestión, construcción, mantenimiento, etc. Vemos que es por la participación que se generan vínculos de apropiación e identidad a partir de las acciones creadas entre los distintos frentes que pueden involucrarse: comunidades, colectivos, profesionales, administraciones y sector privado.

La infraestructura física no es una condición determinante: el carácter social y cambiante del espacio público es un factor determinante para comprenderlo no desde su forma física, sino de lo que ocurre en él y en su contexto. Con esto se puede dejar de lado la prioridad física del diseño y sobretodo, para dar prioridad a la actividad, que puede ser efímera, espontánea, o ligada al arte urbano y puede ser la generadora del espacio físico y es por esto que los espacios se pueden ser diferenciadores, propiciando la identidad. 
El espacio público también son los edificios: vemos proyectos de equipamientos que abiertos a su contexto se integran desde su arquitectura y desde las actividades que generan, las cuales se apoyan con el espacio público para poder desarrollarse. Es por ello que el espacio público no sólo tiene una taxonomía clasificada en calles, parques o plazas, también lo son las fachadas de los edificios, la estructura natural que contenga, y los edificios sociales que ofrecen servicios de manera integrada con la ciudad.

Definir las acciones urbanas de actuación desde pequeñas escalas: es posible concebir una reunión conjunta de actuaciones puntuales en el espacio público como un gran proyecto que se articula. Como lo han anunciado los urbanismos alternativos, la escala puntual crea mayor facilidad de gestión y de participación, además, particulariza las distintas expresiones que pueden acontecer en un mismo sector. Es una suma de acciones.

Que intervengan todos los implicados: los procesos participativos, deben contemplar a todos los frentes. El sector privado, por ejemplo, tiene un espacio importante, y pueden crear formas de obtención de recursos o servicios para el mantenimiento de los proyectos. Esto también abre el debate sobre la responsabilidad de las administraciones y los gobiernos, ya que en parte, todo esto es causado por la falta de cubrimiento de las necesidades de los ciudadanos y el descuido de muchos aspectos del espacio público.

La naturaleza de experimentación: finalmente, este es un llamado para continuar desarrollando, documentando, teorizando y practicando estos nuevos caminos en el espacio público, que aseguran una opción sostenible para nuestras ciudades, desde la puesta en valor del rol del espacio público en la ciudad y que como resultado continuará determinando cómo las sociedades se irán empoderando, proponiendo nuevas estéticas y estructuras que determinarán la arquitectura y el urbanismo del presente siglo.

\section{BIBLIOGRAFÍA}

Alberto, M., García, V., Colegio, E., México, D. H. y Clausen, H. B. (2016). Christiania, Dinamarca , y San Cristóbal de las Casas, México, 14, 353-368.

Aramburu, M. (2008). Usos y significados del espacio público. ACE: Architecture, City and Environment, Año III, 143-151.

Boire, A. y Danieuil, F. (1985). Método de análisis morfológico de tejidos urbanos. París: UNESCO.

Borja, J. y Muxí, Z. (2003). El espacio público: ciudad y ciudadanía. Barcelona: Electa.

Dammert, L. (2004). ¿Ciudad sin ciudadanos? Fragmentación, segregación y temor en Santiago. Revista Eure, 30, No 91, 87-96.

de Solà-Morales, M. (2010). The imposible project of public space. In In favour of public space. Ten years of the european prize for urbanpublic space (pp. 24-32). Barcelona: ACTAR. 
Frank, E. (2003). Vejez arquitectura y ciudad. Buenos Aires: Nobuko.

Martínez, H. (2016). Origen, causas y consecuencias de los conjuntos residenciales cerrados en Valledupar-Colombia. Prospectiva. Revista de Trabajao Social e Intervención Social, No. 21, 137-156.

Merker, B. (2010). Taking place. Rebar's absurd tactics in generous urbanisim. In Insurgent public space. Guerrilla urbanisim and the remaking of contemporary cities (pp. 45-58). New York, NY: Routledge.

Mozas, J. (2011). El espacio público como campo de batalla. A+t Strategy and Tactics in Public Space, 38, 6-19.

Ocupa tu calle., ONU-Habitat., y Fundación Avina. 2018. Intervenciones urbanas hechas por ciudadanos: Estrategias hacia mejores espacios públicos. Lima: Ocupa tu calle., ONU-Habitat., y Fundación Avina.

Paisaje Transversal. (2018). Escuchar y transformar la ciudad. Urbanismo colaborativo y participación ciidadana. Madrid: Catarata.

Rosa, M. y Weiland, U. (2013). Handmade Urbanism From community initiatives to participatory models. Berlín: Jovins.

Rueda, S. (2011). El urbanismo ecológico. In Transformaciones urbanas sostenibles (pp. 234-267). Pontevedra: Universidad Internacionalo Menéndez Pelayo.

Tonucci, F. (2004). La ciudad de los niños (5a edición). Madrid: Fundación Germán Sánchez Ruipérez.

Velazquez, I. y Verdaguer, C. (2011). Regeneración urbana integral: tres experiencias europeas innovadoras. Madrid: SEPES. 



\section{POTENCIALIDADES DEL PARADIGMA DE LA INFRAESTRUCTURA VERDE PARA LA RECUPERACIÓN DE SISTEMAS FLUVIALES PERIURBANOS. EL CASO DEL ARROYO PORZUNA (SEVILLA) \\ POTENTIALITIES OF THE GREEN INFRASTRUCTURE PARADIGM FOR THE SUBURBAN FLUVIAL SYSTEMS RESTORATION. THE PORZUNA STREAM CASE (SEVILLE) \\ Daniel Fazeli Tello \\ Universidad de Sevilla \\ Leandro Del Moral Ituarte \\ Universidad de Sevilla}

Resumen

La comunicación muestra las potencialidades del enfoque de la Infraestructura Verde para recuperar servicios ecosistémicos asociados a sistemas fluviales en contextos periurbanos. Se toma como caso de estudio las oportunidades que ofrece el proyecto de intervención en el arroyo Porzuna (Sevilla), cuya situación y contexto territorial muestra características comunes a gran parte de los sistemas fluviales metropolitanos, marcados por un considerable grado de antropización. Con este fin, la comunicación define, en primer lugar, el concepto de Infraestructura Verde multifuncional, en el que se encuadra la investigación. A continuación, se definen los servicios ecosistémicos propios de los sistemas fluviales que se pretenden recuperar, destacando los relacionados con la gestión de inundaciones y la mejora de la calidad ambiental. Posteriormente, se caracterizan los aspectos territoriales más relevantes del ámbito sobre el que se centra el caso de estudio, relacionándolos con los principales problemas diagnosticados. Por último, se analizan las oportunidades existentes para intervenir en este sistema fluvial, apoyándolo en diversos elementos identificados en planes y programas medioambientales, urbanísticos y de ordenación del territorio con incidencia en el ámbito estudiado.

Palabras clave: infraestructura verde, sistemas fluviales, servicios ecosistémicos, gestión de inundaciones, soluciones basadas en la naturaleza, áreas metropolitanas.

\section{Abstract}

The paper analyses the potential of the Green Infrastructure to recover ecosystem services associated with fluvial systems in metropolitan contexts. The opportunities offered by the intervention project in the Porzuna stream (Seville) are taken as a case-study, whose situation and territorial context share 
common characteristics with other metropolitan fluvial systems, characterized by a high level of anthropization. To this end, the communication defines, first of all, the concept of multifunctional Green Infrastructure in which the research is located. Then, it defines the set of fluvial ecosystem services that this study proposes to recover, highlighting those related to flood management and the improvement of environmental quality. Subsequently, the most relevant territorial aspects of the field in which the case of study is centered are characterized, relating them to the main problems identified. Finally, the paper analyses existing opportunities to intervene in this fluvial system, supporting it on the content of several environmental, urban and land use management plans and programs with incidence on the study area.

Keywords: green infrastructure, fluvial systems, ecosystem services, flood risk management, nature based solutions, metropolitan areas.

\section{INTRODUCCIÓN}

El modelo territorial y de urbanización imperante y el alto grado de consumo de recursos (territorio, energía, agua, etc.) en el que se han venido basando, especialmente en las últimas décadas (Naredo Pérez, 2004), es uno de los factores que ha intensificado la exposición y vulnerabilidad frente al cambio climático, conllevando una importante disminución de la capacidad de resiliencia de los espacios urbanos frente a fenómenos naturales extremos (Olcina Cantos et al., 2017).

El ámbito de estudio al que aplicamos en esta investigación los planteamientos que desarrollamos, el sector occidental del área metropolitana de Sevilla (véase la Figura 1), se caracteriza precisamente por el importante consumo de suelo producido sobre todo en las últimas décadas (Fazeli Tello, Del Moral Ituarte y Morales González, 2018). Esta dinámica resulta clave para comprender la degradación de los elementos naturales aún existentes en este territorio. Y si nos referimos a los aspectos hidrológicos, se potencia a su vez una mayor degradación ambiental de éstos de manera directa e indirecta: por ocupación de las zonas asociadas a cauces y por los efectos de impermeabilización de los suelos y aumento de las escorrentías superficiales debido al sellado de suelo, respectivamente.

No obstante, existen formas alternativas de actuar en el territorio a lo que se ha venido implementando hasta ahora, que of recen las Soluciones Basadas en la Naturaleza (MITECO, 2019, 3) y que ya han sido puestas en marcha en numerosos lugares de la geografía nacional e internacional, obteniendo resultados positivos y eficientes en sus objetivos (Centro de Estudios Ambientales, 2014; Sánchez Zaplana et al., 2016; Hofstra, 2009). Esto da lugar al paradigma de la Infraestructura Verde (COM 2013, 249 final), que pretende ampliar, integrar e interconectar el capital natural existente en los territorios 
potenciando la calidad ambiental y los servicios ecosistémicos que pueden aportar (Valladares, Gil y Forner, 2017).

Figura 1. Ámbito territorial de estudio

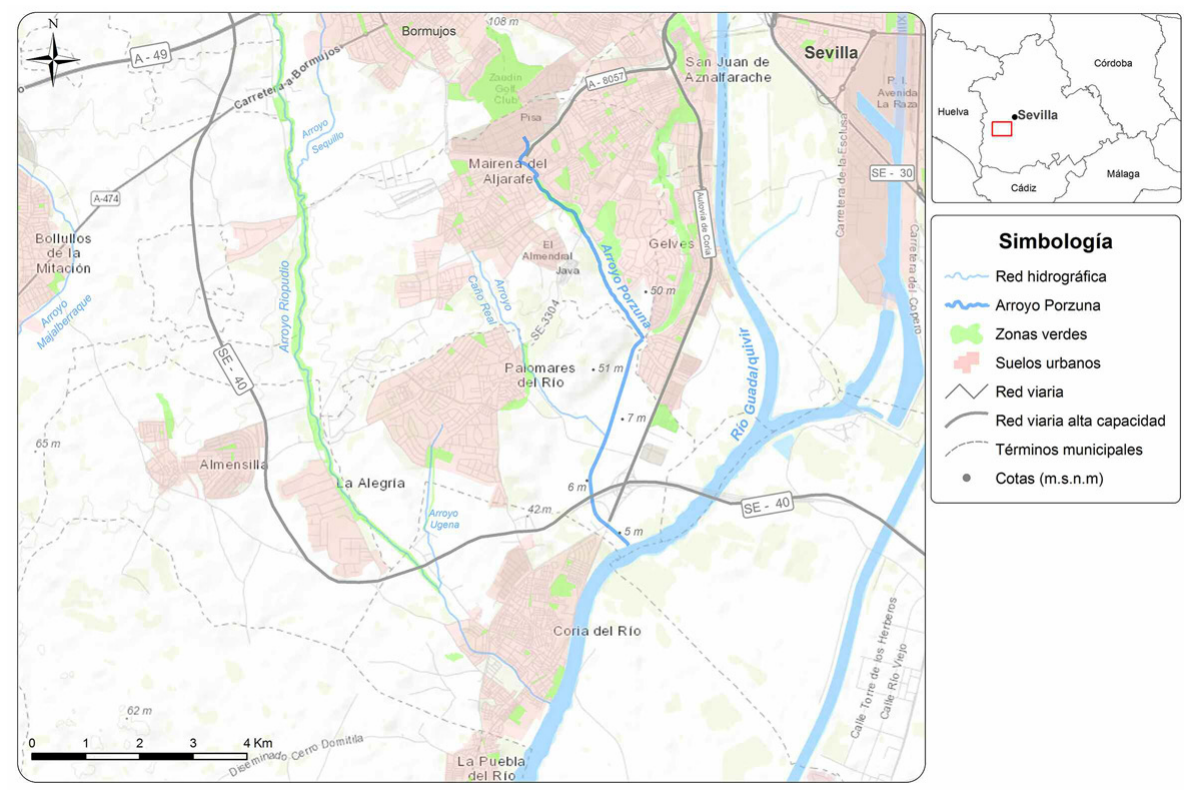

Fuente: Elaboración propia a partir de los datos espaciales de DERA 100 (IECA) y base cartográfica de ESRI

\section{EL CONCEPTO DE INFRAESTRUCTURA VERDE}

Según la citada Comunicación de la Comisión Europea, la infraestructura verde se define como «una red de zonas naturales y seminaturales y de otros elementos ambientales, planificada de forma estratégica, diseñada y gestionada para la prestación de una extensa gama de servicios ecosistémicos. Incorpora espacios verdes (o azules en el caso de los ecosistemas acuáticos) y otros elementos físicos de espacios terrestres (incluidas las zonas costeras) y marinos. En los espacios terrestres, la infraestructura verde está presente en los entornos rurales y urbanos» (COM 249 final, 2013, 3).

\subsection{EL CARÁCTER MULTIFUNCIONAL DE LA INFRAESTRUCTURA VERDE}

Una de las características fundamentales de la Infraestructura Verde es su multifuncionalidad, ya que es capaz de ofrecer múltiples servicios ecosistémicos de manera simultánea, mediante la suma de sus funciones en vez de 
su intersección, como sucede en el concepto de sostenibilidad (Valladares, Gil y Forner, 2017, 58).

Según el documento de Bases para la Estrategia estatal, las funciones que aporta la infraestructura verde «favorecen la conectividad de las poblaciones de fauna y flora para garantizar su conservación a largo plazo al mismo tiempo que mejora y fortalece las funciones de los ecosistemas, que son los responsables del suministro de los servicios ecosistémicos». Mejorando así la calidad de vida social, ambiental y económicamente, «basándose en el uso multifuncional del capital natural»; lo que a su vez «permite la consecución de una amplia serie de objetivos de diferentes políticas tanto transversales como sectoriales y cumplir con las necesidades de una amplia variedad de grupos de interés» (Valladares, Gil y Forner, 2017, 58-59).

\subsubsection{SERVICIOS ECOSISTÉMICOS POTENCIALES LIGADOS A LOS ECOSISTEMAS FLUVIALES}

La degradación de los ecosistemas y los servicios asociados a ellos se prevé que sea incrementada en el futuro en el marco del Cambio Climático al acentuarse la variabilidad climática y aumentar la probabilidad de eventos extremos (Bates et al., 2008, 27-28). No obstante, «los ecosistemas pueden contribuir a reducir el impacto asociado a estos eventos extremos, ofreciendo protección y barreras estructurales que interfieren o ralentizan los flujos de materia y energía, proporcionando espacio físico para procesos naturales (por ejemplo [referido a ecosistemas fluviales] las llanuras de inundación con funciones de laminación y retención frente a grandes avenidas)» (Valladares, Gil y Forner, 2017, 49). De esta manera, un ecosistema fluvial en condiciones óptimas puede aportar:

- Fomento de la conectividad espacial y funcional entre áreas naturales y semi-naturales.

- Mejora de la permeabilidad y reducción de la fragmentación.

- Fomento de la conexión entre sociedad y naturaleza a través de la implicación de grupos de interés, conectando el mundo rural y el urbano.

- Contribución a la adaptación al cambio climático y a su mitigación.

- Reducción de la vulnerabilidad y aumento la resiliencia frente a desastres naturales como el fuego, la sequía o las inundaciones.

- «Protección del patrimonio cultural y los paisajes tradicionales» (Valladares, Gil y Forner, 2017, 85).

\section{CARACTERÍSTICAS TERRITORIALES DEL ÁMBITO DE ESTUDIO Y PROBLEMAS ASOCIADOS}

Nos encontramos en el ámbito territorial de la comarca del Aljarafe, cuyo relieve y topografía se refleja en la etimología del propio término Aljarafe, que en árabe significa «lugar elevado». Este enclave geográfico, al situarse a mayor altura que la vega del Guadalquivir y a su oeste, disfruta de un clima 
más benigno (mayores precipitaciones y aire más fresco del Atlántico). A esto se une la facilidad de obtención de agua y la calidad de sus suelos, aspectos que históricamente han atraído a numerosas civilizaciones, desde al menos el neolítico hasta la actualidad (Centro de Estudios Paisaje y Territorio, 2014). Las características de la meseta aljarafeña explican el desarrollo de las primeras actividades agrícolas, el uso tradicional más extendido durante toda su historia hasta que comenzara la proliferación de segundas residencias de la clase pudiente sevillana (Ayuntamiento de Palomares del Río, 2000), con antecedentes en el siglo XVIII. Este proceso experimentó una intensidad mucho mayor y una nueva significación demográfica en las últimas décadas del siglo XX (Fernández Tabales y Cruz Mazo, 2011), en forma de urbanizaciones extensivas y viviendas unifamiliares que transformaron tanto la configuración territorial como la estructura de la propia población, siguiendo el modelo general de crecimiento finisecular de las áreas metropolitanas (Cruz Villalón, 2003, 455-458).

Como consecuencia de este proceso, desde la década de los años sesenta y hasta la actualidad esta comarca se encuentra fuertemente influenciada por las dinámicas socioeconómicas del área metropolitana de Sevilla, habiéndose convertido en una de las aglomeraciones urbanas de mayor expansión y crecimiento de toda Andalucía (García Martín, 2014, 29-30). Este gran crecimiento urbano residencial extensivo, en forma de conurbación difusa (Naredo Pérez, 2004), es una de las dinámicas antrópicas que más han transformado y degradado los cauces fluviales de manera sistemática en los ámbitos con incidencia urbana (González Fustegueras y De la Lastra Valdor, 2007), no siendo los del Aljarafe una excepción (ADTA, 2011; González del Tánago 2010).

Estos impactos han derivado en una serie de problemáticas relacionadas con el estado de los sistemas fluviales. En el caso del arroyo Porzuna, podemos destacar las siguientes:

- Desestabilización hidrogeomorfológica del cauce y desaparición de la vegetación de ribera:

Si establecemos como punto de partida la evidencia de que el incremento de generación de escorrentías superficiales es consecuencia directa del aumento de la impermeabilización de suelos (McGrane, 2016), es posible relacionar esto último con los incrementos de caudal en los cauces que recepcionan dichas escorrentías. De esta forma, esto provoca procesos de incisión del lecho fluvial por el aumento de la energía hidráulica (González Fustegueras y De la Lastra Valdor, 2007), lo que deriva en un progresivo encajonamiento del cauce y posterior erosionado de márgenes, provocando la desestabilización hidrogeomorfológica de las mismas, así como de las estructuras riparias que se asientan sobre ellas (González del Tánago y García de Jalón, 2007, 167). A su vez, conduce a una desconexión de las riberas con el nivel freático y el propio cauce, provocando la desaparición de vegetación natural riparia y sus formaciones en bosques de ribera. Es- 
pacio que luego es ocupado por especies invasoras (Magdaleno Mas, 2011, 215) como las existentes precisamente a lo largo del cauce objeto de estudio, destacando de entre ellas las cañas (Arundo donax).

- Irreversibilidad de los impactos derivados de la impermeabilización de suelos: Otra de las cuestiones a tener en consideración es el carácter irreversible de la impermeabilización de suelos por urbanización de los mismos que comentamos (Naredo Pérez, 2004; Camarasa-Belmonte et al., 2018), siendo importante el esfuerzo a realizar cuando se pretende mitigar los impactos que ello conlleva (Lara García, 2018). Este hecho complejiza las opciones de intervención sobre el sistema fluvial, por los procesos explicados en el apartado anterior.

No obstante, la adjetivación de «irreversibilidad» que hemos aplicado para los procesos de impermeabilización de suelos por crecimientos urbanísticos, deberíamos matizarla en cuanto a que realmente podríamos llegar a revertirlo, a pesar de la complejidad jurídica-administrativa y socioeconómica que conllevaría la desurbanización en estos casos (Ollero Ojeda, 2015, 97-98). Ya que este tipo de acciones comienzan a plantearse de manera más incisiva por algunos responsables políticos de territorios afectados por los impactos de los últimos fenómenos meteorológicos extremos en España (Cadena Ser, 28/01/2020).

- Contaminación de las aguas:

El aumento de la urbanización de la cuenca, en las condiciones en las que se viene gestionando tradicionalmente el ciclo urbano del agua (Lara García, 2018), ha conllevado el incremento de la presencia de elementos contaminantes de origen antrópico en el cauce, destacando especialmente los derivados de vertidos de aguas residuales a través de los numerosos aliviaderos que vierten al cauce. Así como la derivada del proceso de contaminación difusa. Esto es, sin poder identificar un punto de origen concreto, los diversos contaminantes que arrastra la escorrentía superficial del lavado de calles y demás superficies impermeabilizadas, pudiendo ser restos de aceites de los motores de los vehículos, plásticos o demás elementos acumulados (Direction de l'urbanisme et des paysages, 1982).

Esto redunda a su vez en la potenciación de la presencia de vegetación invasora que, a diferencia de las especies riparias autóctonas, soportan mejor altos grados de contaminación (Del Toro Torró et al., 2012, 20-21).

Por añadidura, no debe obviarse también la contaminación resultado de las deposiciones directas de basuras y escombros al cauce y su entorno más cercano.

- Falta de capacidad para la autoregulación de las avenidas y ocupación de su llanura de inundación:

Uno de los elementos determinantes en el diagnóstico de problemas es la existencia de motas junto al cauce, a lo largo de todo el tramo encauzado hasta la desembocadura. 
Estas motas, al construirse al mismo tiempo que se le dio el nuevo trazado al cauce (entre 1946 y 1956, según puede apreciarse en la comparación de las respectivas ortofotografías aéreas realizadas en los Vuelos Americanos), han impedido desde el principio la conexión con la llanura de inundación y, por tanto, anulado la dimensión transversal del sistema fluvial y su capacidad de autorregulación de avenidas. Debido a que las aguas desbordadas no tienen capacidad de regresar al cauce, quedando embalsadas en los terrenos colindantes durante semanas (véase la Figura 2).

Figura 2. Balsas de agua junto al cauce y la colada de gelves

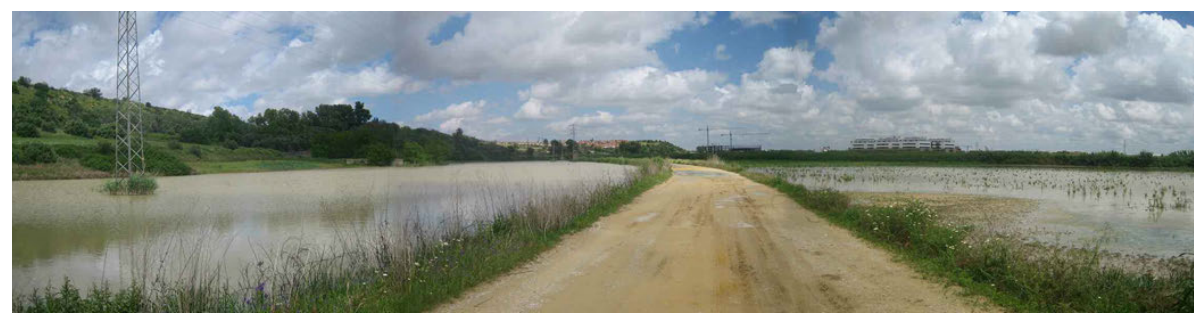

Fuente: Juan Antonio Morales, 22/4/2010

Además, la facilidad de desbordamiento es bastante alta a causa de que el cauce moteado ha ido colmatándose de sedimentos en diversos tramos, dando lugar a una escasa o nula capacidad de drenaje de las aguas.

El nivel de colmatación llegar a alcanzar situaciones tales que, durante aproximadamente 200 metros, se produce el fenómeno de avulsión del cauce, ya que el flujo sale del canal y discurre por la colada de Gelves, manteniéndola permanentemente inundada en ese tramo, aun en ausencia de precipitaciones. Por otro lado, también resulta determinante la construcción de nuevas zonas residenciales muy próximas al cauce en su llegada a la vega del Guadalquivir, correspondientes en este caso al límite del vecino término municipal de Gelves (véase la Figura 3). A esto último, debemos añadir las afecciones por incremento de la ocupación de la llanura de inundación, que resultarían de la planificación territorial vigente, referida al Plan de Ordenación Territorial de la Aglomeración Urbana de Sevilla (Consejería de Vivienda y Ordenación del Territorio, 2009). Ya que en este se contiene la previsión de desarrollar un Área de Oportunidad de tipo Empresarial justo a continuación, del sector residencial señalado anteriormente. 
Figura 3. Panorámica visual del tramo bajo del arroyo Porzuna desde la cornisa del Aljarafe. A la derecha, los edificios residenciales del sector sur del límite municipal de Gelves. A la izquierda, sobre la continuación de la cornisa, la urbanización de Simón Verde. Al fondo, el puente del Centenario sobre el río Guadalquivir, en la ciudad de Sevilla

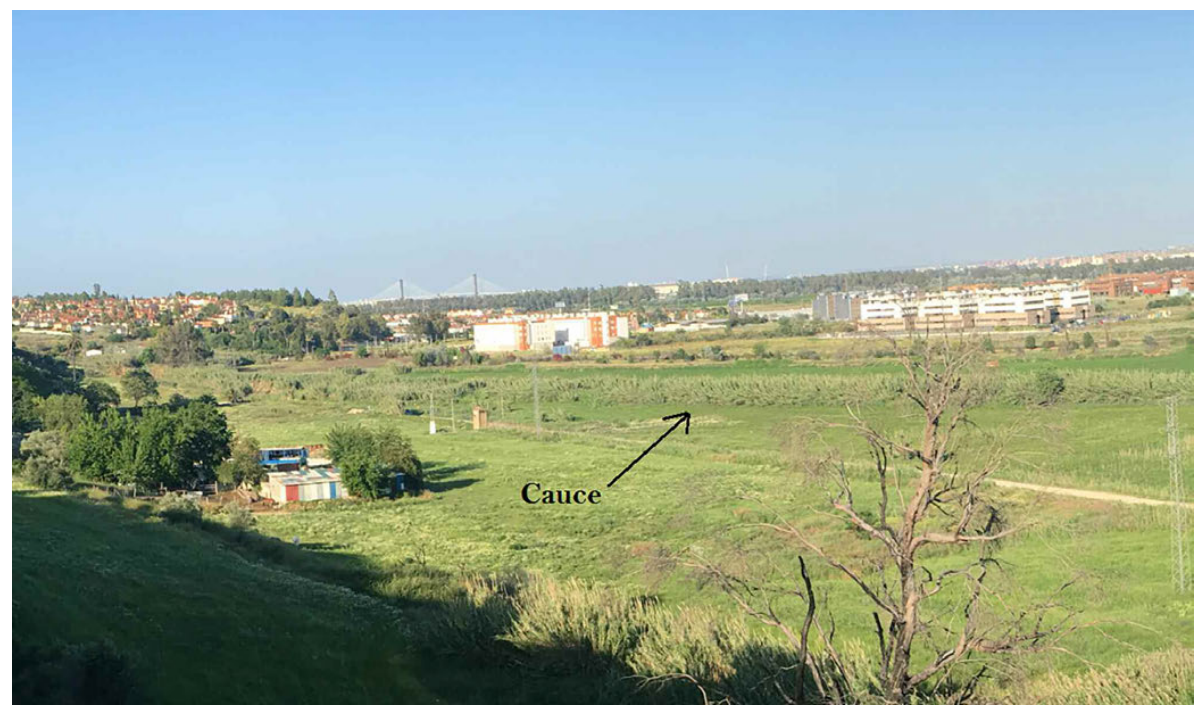

Fuente: Daniel Fazeli Tello, 5/5/2019

\section{OPORTUNIDADES DE ACTUACIÓN EN EL MARCO DE LA INFRAESTRUCTURA VERDE}

Entendemos como oportunidades todos los elementos o circunstancias existentes o por existir (integrados oficialmente en documentos de planificación con incidencia territorial) que, por sus características y la posibilidad de establecer sinergias con la propuesta de intervención, permiten incrementar los beneficios y el potencial de incidencia de ésta sobre el territorio (Yoe y Orth, 1996, 79-80).

Por ello, la restauración ecológica de este sistema fluvial podría, en este caso, «contribuir al desarrollo y mejora de la red de espacios naturales y semi-naturales terrestres, ribereños y acuáticos que constituyen la infraestructura verde (...), ya que posee el potencial de mejorar elementos pre-existentes y conectarlos entre sí» (Valladares, Gil y Forner, 2017, 85). Relacionamos a continuación alguna de las oportunidades más destacadas que hemos podido detectar:

- La rehabilitación ambiental ya ejecutada aguas arriba:

En primer lugar, es importante destacar la reciente finalización de las obras de rehabilitación ambiental acometidas por la CHG sobre unos 400 
metros del final del tramo urbano del arroyo que discurre en cabecera por Mairena del Aljarafe. Tomando esto en consideración, si tenemos en cuenta el buen estado de conservación en el que se encuentra el tramo medio del arroyo (desde la hacienda Porzuna hacia aguas abajo, hasta la llegada a la vega), podría darse la oportunidad de lograr la continuidad longitudinal de un posible corredor ecológico. Este corredor enlazaría el nuevo tramo rehabilitado por la CHG aguas arriba y el tramo bajo sobre el que pretendemos intervenir, hasta la desembocadura al río Guadalquivir.

- Creación de un corredor verde ecológico y Complementación y potenciación del sistema de Infraestructura Verde metropolitana:

Sobre la base de lo comentado, se van construyendo el resto de oportunidades ya que, por ejemplo, directamente relacionado con lo comentado sobre el posible corredor ecológico, destacamos que precisamente en la desembocadura del arroyo Porzuna al río Guadalquivir, cercano al núcleo urbano de Coria del Río, está planificado por el Plan General de Ordenación Urbana de Palomares del Río 2 ha de Espacios Libres pertenecientes al Sistema General de Espacios Libres (en adelante, SGEL).

Con la creación de este corredor, quedarían conectadas las Zonas Verdes de la cabecera en el núcleo urbano de Mairena del Aljarafe, con el SGEL del término de Palomares del Río comentado, mediante un corredor verde fluvial de más de $6 \mathrm{~km}$ de longitud. Además, también quedaría incorporado al corredor el Parque Periurbano Hacienda de Porzuna, que se encuentra catalogado como Espacio Natural Protegido e incluido en la Red de Espacios Naturales Protegidos de Andalucía (en adelante, RENPA), bajo la figura de Parque Periurbano (véase la Figura 4). 
Figura 4. Localización de elementos que componen la Infraestructura Verde del ámbito territorial estudiado
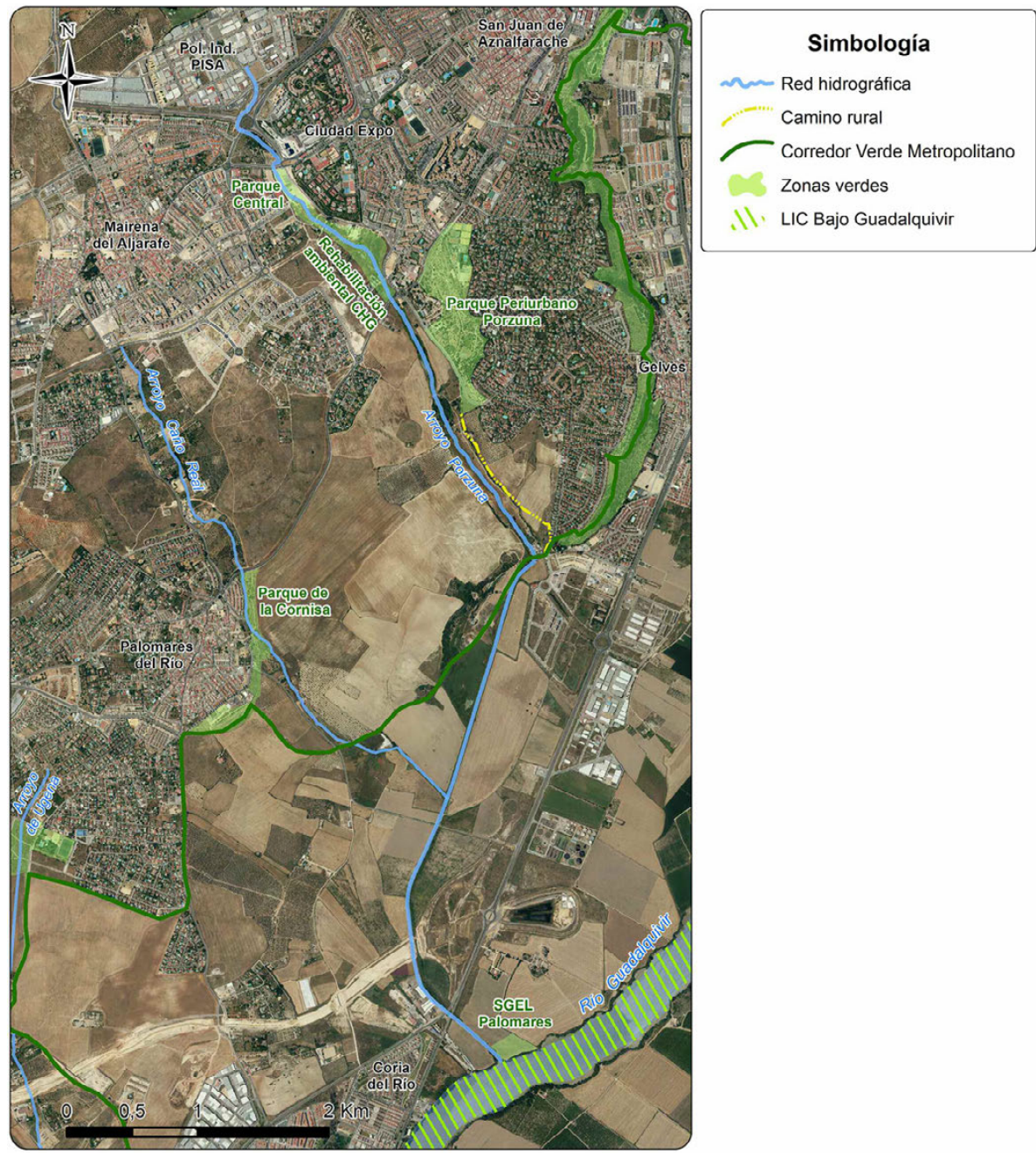

Fuente: Elaboración propia a partir de ortofoto del PNOA del año 2016

Así mismo, cabe recordar que el río Guadalquivir y sus márgenes están catalogados, hasta la presa de Alcalá del Río, como Lugar de Interés Comunitario (en adelante, LIC) e incluido en la Red Natura 2000. Por lo que, al crear un corredor que alcance éste, tal y como hemos descrito anteriormente, interconectaríamos también los espacios verdes antes señalados con el LIC del Guadalquivir. 
Pero el papel potencial como nuevo elemento de la Infraestructura Verde territorial, que ya ha quedado patente en el apartado anterior, puede verse todavía más incrementado si tenemos en cuenta que el actual Corredor Verde Metropolitano gestionado por la Junta de Andalucía e integrado en el Programa Corredores y Puertas Verdes de la misma administración autonómica (Consejería de Agricultura, Ganadería, Pesca y Desarrollo Sostenible, 2019), intersecta con el arroyo Porzuna precisamente en el espacio donde este llega a la vega desde el escarpe de la cornisa (véase la Figura 4). Es en ese mismo enclave donde el Corredor Metropolitano llega desde el núcleo de Palomares del Río por la colada de Gelves y se dirige hacia la cornisa del Aljarafe. Por lo que quedaría conectado a los más de $60 \mathrm{~km}$ de longitud de corredor verde ya ejecutados y existentes y, por tanto, también a todos los espacios verdes metropolitanos que este recorre, así como los diversos territorios integrados en él.

- Contribución del paisaje fluvial a los valores paisajísticos de la cornisa del Aljarafe:

Según la publicación resultante de la colaboración entre el Centro de Estudios Paisaje y Territorio de la Universidad de Sevilla y la CHG, los proyectos que se ejecutan con el fin de alcanzar los objetivos que planteamos para este caso de estudio, se encuadran por lo general en lo que denominan como Grupo I.B; ya se trate de proyectos de restauraciones fluviales o encauzamientos y canalizaciones. Estos son definidos como «proyectos que actúan a lo largo del cauce [integrándose] en la escena fluvial, modificando sus principales elementos, aunque conservando su organización escenográfica» (Zoido Naranjo et al., 2012, 109).

No obstante, el documento señala que el alcance de transformación estética y de significado es mayor con un tipo de proyecto que con otro. La transformación presenta sentidos distintos para cada tipo de proyecto, ya que los que persiguen una restauración fluvial (Grupo I.B, Tipo 4) «recuperan elementos naturales perdidos como la vegetación riparia o las pozas», mientras que los proyectos de encauzamientos o canalizaciones «añaden paramentos y paredes artificiales a menudo de hormigón al ámbito del cauce, riberas y márgenes» (Zoido Naranjo et al., 2012, 111).

No es casualidad que el espacio de la cornisa, a cuyos pies discurre el tramo a intervenir, se encuentre protegido por el PGOU de Palomares del Río, clasificándolo como Suelo No Urbanizable de Especial Protección. Esto lo fundamenta en la Memoria de Información del mismo (Tomo 1, página 41) por estar catalogado, en el capítulo 3 del Plan Especial de Protección del Medio Físico de la provincia de Sevilla, como «Paisaje Sobresaliente». Así mismo, basándose nuevamente en el citado Plan Especial, en el documento de la Memoria de Información del planeamiento municipal se hace referencia expresa a la importancia de reforestar y renaturalizar el escarpe que articula la meseta 
de la cornisa con la vega, vaguadas por donde discurre el agua y terrenos contiguos a los cauces; tanto por razones ecológicas como paisajísticas.

\section{CONCLUSIONES}

La evolución de este ámbito territorial y la degradación ambiental que ha llevado asociada, puede presentarse como un ejemplo ilustrativo de las generalizadas dinámicas de deterioro ambiental sobre las que los expertos vienen advirtiendo. Lo cual resulta más preocupante si se atiende a que el escenario que proyecta el fenómeno global de Cambio Climático nos indica que, precisamente en casos como el analizado, la tendencia apunta a una intensificación del deficiente estado de los ecosistemas actualmente degradados y vulnerables, así como de los riesgos asociados.

No obstante, a lo largo del estudio realizado se ha podido constatar que, a pesar de dicho estado de deterioro del sistema fluvial, el potencial existente para acometer una intervención bajo el paradigma de la Infraestructura Verde es muy significativo. Debido a que:

- Se permitiría estimular y complementar el actual sistema de Infraestructura Verde del sector occidental del área metropolitana de Sevilla, permitiendo la interconexión de multitud de espacios verdes del territorio metropolitano y potenciando así la calidad ambiental y las posibilidades de su uso y disfrute por la población.

- Mejoraría la capacidad del sistema fluvial para autorregular las avenidas, facilitando una gestión del riesgo de inundación más adecuada y mitigando sus impactos.

- La posibilidad de mejorar el paisaje fluvial del tramo que discurre por la vega en este caso, suponen una oportunidad importante de reforzar y potenciar los valores paisajísticos aún existentes en el entorno donde se plantea intervenir.

- Facilitaría la recuperación de las características identitarias de la comarca como elemento fundamental para impulsar un modelo de desarrollo socioeconómico y territorial realmente sostenible, que permita contener la progresiva dependencia que viene generándose desde hace décadas con respecto a la cabecera metropolitana. Aspectos que resultan fundamentales para incorporar la dimensión socio-cultural y la cohesión social a la gestión de territorios tan complejos como las áreas metropolitanas.

\section{BIBLIOGRAFÍA}

ADTA, Asociación en Defensa del Territorio del Aljarafe (2011). Segundo Informe sobre los cauces del Aljarafe. Recuperado de: https://drive.google.com/file/d/OB72YmtqnrdxhZHFTWkI1WjR1QjQ/edit 
Bates, B. C., Kundzewicz, Z. W., Wu, S. y Palutikof, J. P. (Eds.) (2008). El Cambio Climático y el Agua. Documento técnico del Grupo Intergubernamental de Expertos sobre el Cambio Climático, Secretaría del IPCC, Ginebra. Recuperado de:

https://archive.jpcc.ch/pdf/technical-papers/ccw/climate-change-water-sp.pdf Camarasa-Belmonte, A. M., Caballero López, Mª P. e Iranzo García, E. (2018). «Cambios de uso del suelo, producción de escorrentía y pérdida de suelo. Sinergias y compensaciones en una rambla mediterránea (Barranc del Carraixet, 1956-2011)». Boletín de la Asociación de Geógrafos Españoles, Nº 78, 127-153. Recuperado de:

https://www.age-geografia.es/ojs/index.php/bage/article/viewFile/2714/2463

Centro de Estudios Ambientales (2014). La infraestructura verde urbana de Vitoria-Gasteiz. Documento de Propuesta. Ayuntamiento de Vitoria-Gasteiz. Recuperado de: https://www.vitoria-gasteiz.org/wb021/http/contenidosEstaticos/adjuntos/eu/32/95/532 95.pdf

Centro de Estudios Paisaje y Territorio (2014). El Aljarafe y el Campo. En Catálogo de Paisajes de Andalucía; Catálogo de Paisajes de la Provincia de Sevilla, Sevilla, pp. 141- 149. Recuperado de:

http://paisajeyterritorio.es/assets/capa_sevilla.pdf.

Cruz Villalón, J. (2003). Características del desarrollo urbano reciente en Andalucía. El siglo XX. En A. López Ontiveros (Coord.) Geografía de Andalucía, pp. 433-462. Barcelona: Editorial Ariel.

Direction de l'urbanisme et des paysages (1982). La maîtrise du ruissellement des eaux pluviales. Ministère de L'Urbanisme et du Logement. Paris. Recuperado de:

https://www.oieau.fr/eaudoc/eaudoc/notice/LA-MAITRISE-DU-RUISSELLEMENT- DES-EAUX-PLUVIALES-O.

Deltoro Torró, V., Jiménez Ruiz, J. y Vilán Fragueiro X. M. (2012). Bases para el manejo y control de Arundo donax L. (Caña común). Colección Manuales Técnicos de Biodiversidad, 4. Conselleria d'Infraestructures, Territori i Medi Ambient. Generalitat Valenciana. Valencia.

Fazeli Tello, D., Del Moral Ituarte, L. y Morales González, J. A. (2018). Cambios de usos del suelo y «Áreas de Oportunidad» en la cuenca hidrográfica del arroyo Riopudio (Sevilla). Evolución reciente, perspectivas e impactos potenciales sobre su dinámica hidrológica. X Congreso Ibérico de Gestión y Planificación del Agua, Coimbra. Fundación Nueva Cultura del Agua. Recuperado de:

https://idus.us.es/bitstream/handle/11441/83141/Leandro_del_moral.pdf?sequence=1\&isAllowed $=\mathrm{y}$

Fernández Tabales, A. y Cruz Mazo, E. (2011). Territorio y actividad constructora: del «Tsunami» a la crisis. Factores explicativos y propuesta de indicadores a escala municipal en Andalucía. Boletín Oficial de la Asociación de Geógrafos Españoles, N 56, 79-110. 
García Martín, M. (2014). Transformaciones recientes en el Aljarafe Sevillano: de la vocación rural a la integración metropolitana. Cuadernos Geográficos, Vol.53, N², 25-53. Universidad de Granada. Recuperado de: http://www.redalyc.org/articulo.oa?id=17132953002

González del Tánago, M. y García de Jalón, D. (2007). Guía metodológica para la elaboración de proyectos de restauración de ríos. En M. González del Tánago (Coord.) Estrategia Nacional de Restauración de Ríos. Escuela Técnica Superior de Ingenieros de Montes de la Universidad Politécnica de Madrid y Ministerio de Medio Ambiente y Medio Rural y Marino.

González del Tánago, M (2010). Informe al proyecto de rehabilitación del arroyo Riopudio. E.T.S. Ingenieros de Montes, Universidad Politécnica de Madrid.

González Fustegueras, M. A. y De La Lastra Valdor, I. (2007). La urbanización y su efecto en los ríos. En M. González del Tánago (Coord.) Estrategia Nacional de Restauración de Ríos. Mesa de Trabajo de Urbanismo, pp.1-42. Escuela Técnica Superior de Ingenieros de Montes de la Universidad Politécnica de Madrid y Ministerio de Medio Ambiente y Medio Rural y Marino. Hofstra, M. (2009). International cooperation on the river Rhine. Unesco-I HE/Water Governance Centre NL. The Netherlands. Recuperado de:

https://www.unece.org/fileadmin/DAM/env/water/cadialogue/docs/Almaty_Oct2010/Eng/Hofstra_Eng.pdf

Lara García, A. (2018). Agua y espacio habitado. Propuestas para la construcción de ciudades sensibles al agua. Ed. Universidad de Sevilla, Sevilla.

Magdaleno Mas, F. (2011). Manual de técnicas de restauración fluvial. Centro de Estudios y Experimentación de Obras Públicas, Ministerio de Fomento. Segunda Edición.

McGrane, S.J. (2016). Impacts of urbanisation on hydrological and water quality dynamics, and urban water management: a review. Hydrological Sciences Journal, Vol. 61, N 13, 2.295-2.311. Recuperado de:

https://doi.org/10.1080/02626667.2015.1128084

MITECO (2019). Soluciones Basadas en la Naturaleza para la gestión del agua en España. Retos y oportunidades. Informe de la Jornada. 22 de marzo de 2019, Madrid.

Naredo Pérez, J. M. (2004). Desarrollo sostenible y territorio. En Urbanismo para un desarrollo más sostenible. Equilibrio territorio. Hacia una utilización más responsable del territorio, pp. 17-31. Colegio Oficial de Arquitectos, Illes Balears, Palma de Mallorca, Consejo Superior de los Colegios de Arquitectos de España.

Olcina Cantos, J., Pérez morales, A., Rico Amorós, A., Gil Guirado, S. y López Martínez, F. (2017). The significance of vulnerability and exposure in increased flood risk on the mediterranean coast, Consor/Seguros, num. 07 | Autumn 2017. 
Ollero Ojeda, A. (2015). Guía metodológica sobre buenas prácticas en restauración fluvial. Manual para Gestores.

Sánchez Zaplana, A., Simón Plá, D. y Morales Belvis, J. (2016). Soluciones naturales para los retos urbanos de la ciudad de Alicante. // Congreso Ciudades Inteligentes. Madrid.

Valladares, F., Gil, P. y Forner, A. (Coords.) (2017). Bases científico-técnicas para la Estrategia estatal de infraestructura verde y de la conectividad y restauración ecológicas. Ministerio de Agricultura y Pesca, Alimentación y M. A., Madrid.

Yoe, C. E. y Orth, K. D. (1996). Planning Manual. Institute for Water Resources, U.S. Army Corps of Engineers. Report 96-R-21.

Zoido Naranjo, F., Rodríguez Rodríguez, J., Español Echániz, I., Frolova, M., García Martín, M., Martínez Bravo, E. (...) y Trout Tate, A. L. (2012). Los paisajes fluviales en la planificación y gestión del agua. Centro de Estudios Paisaje y Territorio y Confederación Hidrográfica del Guadalquivir. Sevilla.

\section{PLANES Y PROGRAMAS}

Ayuntamiento de Palomares del Río (2000). Plan General de Ordenación Urbana de Palomares del Río. Memoria de Información. Palomares del Río.

Consejería de Agricultura, Ganadería, Pesca y Desarrollo Sostenible (2019). Estado de los trabajos en las Puertas Verdes [en línea]. Junta de Andalucía. Recuperado de: http://www.juntadeandalucia.es/medioambiente/site/portalweb/menuitem.7elcf46ddf59bb227a9ebe205510elca/?vgnextoid=bcc4fc 8634cd6410VgnVCM1000001325e50aRCRD\&vgnextchannel=1001e95d4cb5 6410VgnVCM2000000624e50aRCRD\#apartado14c4fc8634cd6410VgnVCM $1000001325 e 50 a$ [Consulta: 11/02/2020]

Consejería de Vivienda y Ordenación del Territorio (2009). Plan de Ordenación del Territorio de la Aglomeración Urbana de Sevilla (POTAUS). Boletín Oficial de la Junta de Andalucía, N. 132, de 6 de julio de 2009, pp. 68, 69, 100, $114,115$.

\section{TEXTOS NORMATIVOS}

Comisión Europea (2013). Infraestructura verde: mejora del capital natural de Europa, COM (2013) 249 final, Bruselas, 6.5.2013.

\section{HEMEROTECA}

Cadena Ser (28/01/2020). Un alcalde descarta reconstruir el paseo marítimo de su pueblo: Lo del cambio climático va en serio. Madrid. Recuperado de https://cadenaser.com/programa/2020/01/28/la_ventana/1580227097_6854 33.html [Consulta: 12/02/2020]. 



\section{MODELO SMART CITY: INICIATIVAS EUROPEAS Y DEL ESTADO ESPAÑOL PARA SU IMPLEMENTACIÓN \\ SMART CITY MODEL: EUROPEAN AND SPANISH STATE INITIATIVES FOR ITS IMPLEMENTATION \\ Mireia Ferrer Vilanova \\ Universitat de Barcelona}

\section{Resumen}

El crecimiento de las aglomeraciones urbanas ha planteado modelos de crecimiento y desarrollo que contemplan una aproximación más sostenible del territorio, consecuentemente, la Unión Europea ha tratado de dirigir sus estrategias hacia escenarios más sostenibles, mediante la creación de instrumentos, que incentivan la implementación de nuevas ordenanzas y reglamentos a sus países miembros.

El modelo Smart City emerge como una de las opciones preferidas por los ayuntamientos, ya que las nuevas tecnologías posibilitan la implementación de dichos instrumentos de gestión de manera más eficaz, dando solución a algunas problemáticas presentes en las ciudades.

Desde Europa, se crean programas de financiación para desarrollar la estrategia Europa 2020, ayudando a desarrollar estrategias del modelo Smart City. En el territorio español, las iniciativas de la UE se han tratado de implementar mediante diversas acciones, como la creación del Plan Nacional de Ciudades Inteligentes (2015), el Plan Nacional de Territorios Inteligentes (2017) y otros instrumentos y organismos que tratan de desarrollar el modelo en el territorio. Mediante el estudio bibliográfico de fuentes oficiales, el presente trabajo analiza cuáles son las iniciativas existentes que la UE y el Estado han creado para implementar el modelo Smart City en el territorio español.

Palabras clave: smart city, desarrollo sostenible, estrategia Europa 2020, territorio español, aglomeraciones urbanas.

\section{Abstract}

The growth of urban agglomerations has proposed growth and development models that contemplate a more sustainable approach to the territory; consequently, the European Union has tried to direct its strategies towards more sustainable scenarios, through the creation of instruments that encourage the implementation of new ordinances and regulations to its member countries. The Smart City model emerges as one of the preferred options for municipalities, since new technologies make it possible to implement these management instruments more effectively, solving some problems present in cities. 
From Europe, financing programs are created to develop the Europe 2020 strategy, helping to develop Smart City model strategies. In Spanish territory, EU initiatives have been tried to implement through various actions, such as the creation of the National Plan for Smart Cities (2015), the National Plan for Smart Territories (2017) and other instruments and organizations that seek to develop the model in the territory.

Through the bibliographic study of official sources, this work analyses what are the existing initiatives that the EU and the State have created to implement the Smart City model in Spanish territory.

Keywords: smart city, Sustainable development, Europe 2020 Strategy, spanish territory, urban agglomerations.

\section{INTRODUCCIÓN}

A medida que las aglomeraciones urbanas han ido desarrollándose, se han encontrado una serie de problemas, que ponen en duda la sostenibilidad de éstas en un futuro inmediato. No es poca la preocupación que los actores implicados en la gestión de las ciudades tienen en la actualidad, ya que las ciudades, no tienen un retroceso o estabilización de la población, y cada vez presentan escenarios más complejos, que necesitan modelos de gestión más adecuados.

La Unión Europea, comenzó a dirigir sus estrategias hacia escenarios más sostenibles, a mitad del siglo XX. Para que los países miembros pudieran implementar las nuevas ordenanzas y reglamentos, comenzaron a crear una serie de instrumentos, como las Agendas local 21. Durante este proceso, el término sostenibilidad fue cogiendo fuerza, y hoy en día, es prácticamente impensable, que un ayuntamiento o institución, no tenga ninguna regulación a favor de la sostenibilidad.

Pero un sector emergente, las nuevas tecnologías, empezaron a considerarse un posible factor para que las estrategias a favor del desarrollo sostenible, de las ciudades, se llevaran a cabo de manera más eficaz. En este momento, se propusieron, por la Unión Europea, instrumentos que necesitaban de las nuevas tecnologías para funcionar, como las Agendas Digitales. Este fue el comienzo del nacimiento del modelo Smart City, ciudades que tienen un desarrollo sostenible con la ayuda de las nuevas Tecnologías de la Información y Comunicación (TIC).

El modelo Smart City, comenzó a desarrollarse en muchas ciudades, mediante la implementación de actuaciones, como la creación de las Sedes Electrónicas en los Ayuntamientos, aunque en muchos casos, se ha llegado a la conclusión, que el funcionamiento del modelo no es el adecuado.

El modelo Smart City, representa una posible solución futura a los problemas actuales de las ciudades, y que es necesaria si quieren seguir creciendo y do- 
tando a los ciudadanos de una buena calidad de vida, sin poner en riesgo los recursos para las generaciones futuras. Sin una buena planificación inicial, este modelo es imposible de implementar, y por ello, este estudio trata de averiguar cuáles son las iniciativas que, desde la UE y desde el gobierno español, se han impulsado para permitir que dicho modelo pueda ser desarrollado de forma correcta en las ciudades.

Como objetivos secundarios, se pretende: 1.Conocer las características básicas del modelo Smart City. 2. Extraer las actuaciones que ha realizado la Unión Europea para ayudar a implementar este modelo en todos sus países miembros. 3. Conocer cuál es la situación actual en materia de Smart City en el territorio español: cuáles son los empujones que ha realizado el territorio español para que se introduzca este modelo en las ciudades.

Para poder realizar el marco conceptual de este, se ha hecho una comparación de datos proporcionados por diferentes organismos e instituciones. Para conocer las características básicas del modelo, se ha hecho una comparación de diferentes estudios y publicaciones, como el libro verde de las Smart Cities, realizado por una institución pública. Para conocer las ayudas de la Unión Europea, se ha realizado una extracción de datos de la página web de la UE, como la Estrategia Europea 2020, y también se han utilizado datos de estudios realidades por el Ministerio Español, como la guía metodológica y el Plan Nacional de Ciudades Inteligentes. Para conocer la situación en España, se ha realizado una revisión de los diferentes planes del Ministerio, y de las páginas web oficiales de las redes de ciudades con iniciativas inteligentes. Además, en este apartado, se ha empleado la realización de cartografía, para situar las ciudades que pertenecen a la RECl.

\section{MARCO CONCEPTUAL}

\subsection{CONCEPTO Y CARACTERÍSTICAS DEL MODELO SMART CITY}

Smart City es un modelo de ciudad que se inició para mejorar la gestión de las ciudades bajo la ayuda de las TIC (Tecnologías de la Información y Comunicación), y que permite que las ciudades se desarrollen y sean competentes con los requisitos de los nuevos tiempos, sin poner en riesgo los recursos de los que dispongan (siendo sostenibles), mediante políticas de la administración pública, bien planificadas y transparentes, que tengan muy en cuenta la participación y la opinión ciudadana.

El modelo de ciudad inteligente, se plantea su aplicación a comienzos del siglo pasado, cuando el uso de las tecnologías comienza a ser real. Casi más de 500 ciudades se encuentran hoy en día alrededor del mundo, y no paran de aumentar. Se estima que el $70 \%$ de la población vivirá en ellas en 2050 , dato que pone de manifiesto la necesidad de tener una mejor organización a la hora de gestionar los recursos de los que disponen, para evitar que se desperdicien y 
acaban agotándose. Se contempla emplear estos recursos de una manera eficiente, que permita desarrollar la actividad económica y social propia de una ciudad, que consiga, finalmente, el bienestar de los ciudadanos, para que puedan disfrutar de unos servicios eficientes (Moreno y Gutiérrez, 2012).

Según Eloy Álvarez (2012) citado en el Libro Blanco de las Smart Cities, la finalidad de este modelo es «encontrar una gestión eficiente con todas las áreas de la ciudad, que satisfaga a la vez las necesidades de la urbe y de los ciudadanos, todo en consonancia con los principios del desarrollo sostenible expuestos al programa 21, tomando la innovación tecnológica y la cooperación entre los agentes económicos y sociales como los principales motores del cambio« (16).

«Las ciudades de menos de diez millones de habitantes serán las que protagonizan, en los próximos años, los mayores procesos de acumulación de capital y personas» (Álvarez, 2012, 13). Van a ser este tipo de ciudades las que más necesitan del modelo de Smart City, porque son las que mayores problemas de gestión de recursos y armonización social van a tener.

No obstante, puede ser aplicado a diferentes tipos de ciudades, que tienen características diversas como su situación geográfica; su tamaño; sus razones históricas; su actitud (sobre todo política); su experiencia comercial o industrial, que van a ser tomadas en cuenta a la hora de hacer las estrategias y los proyectos propios que quieren emplearse para la ciudad (Álvarez, 2012, 16). Por lo tanto, para aplicar este modelo, se deben diseñar y establecer una serie de medidas políticas que sean concordantes con las necesidades específicas que plantee la ciudad, es decir, los objetivos generales de una Smart City deben adaptarse dependiendo las características propias de la ciudad a tratar (Moreno y Gutiérrez, 2012). Y debe ser así, ya que si no se trata de esta manera tan «personal», es posible que no llegue a los propósitos planteados. La gestión que se va a realizar mediante las políticas establecidas, cada vez va a ser más compleja, dado que cada vez los ciudadanos van a estar más interconectados y participativos, y consecuentemente, van a demandar más efectividad de la administración, y más accesibilidad los dispositivos tecnológicos que ofrezcan, encima de exigir un precio razonable (un entramado bastante difícil) (Álvarez, 2012, 15).

El uso de las nuevas tecnologías, las TIC, es imprescindible para poder aplicar este modelo de ciudad, dado que gracias a ellas se puede almacenar, actualizar, obtener y utilizar la información para llegar a la sostenibilidad social y ambiental (Moreno y Gutiérrez, 2012, 19). Además, han resultado ser un elemento básico para el desarrollo de una economía más productiva, dado que los sectores que han utilizado las TIC son los que más han contribuido a este crecimiento (Álvarez, 2012, p.19). Para que esta información, que obtenemos con las TIC, sea bien utilizada, necesita de una gran voluntad política, un complemento obligatorio y que sin este es totalmente imposible conseguir la efectividad del modelo. 
Además, este modelo necesita de la cooperación entre los ciudadanos y los gestores públicos, a la hora de proponer y decidir las actuaciones, es decir, habrá una participación ciudadana y una transparencia política, que junto a la ayuda de las TIC, harán posible la aplicación de las propuestas planteadas. La participación ciudadana y la gestión pública, no podrán ser prácticas si no hay una buena planificación inicial, con la redacción de unos objetivos y un fin bien claros. La línea principal de acción debe intentar convertir la ciudad en un espacio sostenible, eficiente e innovador donde el ciudadano sea el eje y el motor principal del cambio (Costa, 2012, 4). Esta planificación inicial es tan importante porque va a marcar el tipo de Ciudad Inteligente que va a ser en el futuro.

\subsection{ESTRATEGIAS QUE IMPULSAN LA APLICACIÓN DEL MODELO EN LA UNIÓN EUROPEA}

En 2010, comienza a surgir en Europa la idea de impulsar la creación de una economía «inteligente, sostenible e integradora» para que el territorio europeo llegara a ser competitivo en el panorama mundial, y, consecuentemente, que generara el empleo suficiente para salir de la crisis económica. Esta fue la estrategia conocida como Europa 2020 (Comisión Europea, 2010).

Entonces, esta estrategia marcó tres prioridades esenciales a conseguir:

1. Tenía que ser una economía basada en el conocimiento y la innovación.

2. Debía generar trabajo y conseguir una cohesión social y territorial.

3. Debía conseguir un uso eficaz de los recursos, que fueran verdes y competitivos. Estas tres prioridades, responden a los tres pilares fundamentales del desarrollo sostenible, que fueron puestos sobre la mesa con la creación de las Agendas 21 y de la conferencia de las Naciones Unidas sobre el Medio Ambiente y el Desarrollo Sostenible (1992). Estos pilares son el desarrollo ecológico, el desarrollo económico y el desarrollo social (Rueda, 2012), y los tres deben ser desarrollados para que esta estrategia funcione.

Con las prioridades bien marcadas, la estrategia creó cinco objetivos claros para que fueran cumplidos para el 2020 por los países miembros, y son:

1. El Aumento del empleo.

2. La inversión del 3\% del PIB de la UE en I + D.

3. La reducción de los gases de efecto invernadero en un $20 \%$, el aumento del uso de energías renovables en un $20 \%$ y el aumento de la eficiencia energética en un $20 \%$.

4. El descenso del abandono escolar y el aumento de personas que finalizan sus estudios.

5. Conseguir reducir 20 millones de las personas que se encuentran en situación de pobreza y de exclusión social.

Para que la estrategia se pudiera llevar a cabo, una serie de organismos e instituciones se han encargado: 
1. El Consejo Europeo, que hace que la estrategia siga en marcha mediante la evaluación general de los avances, el debate continuo, y las recomendaciones específicas para cada país.

2. El Consejo de Ministros de la UE, que lo hace mediante el seguimiento y la revisión entre padres.

3. La Comisión Europea, que supervisa la situación con una serie de indicadores, y publica un Estudio Prospectivo Anual, donde da recomendaciones específicas a cada uno de los países miembros.

4. El Parlamento Europeo, que da una mayor transparencia a los procesos que realiza la Comisión y el Consejo Europeo.

5. El Comité Económico y Social europeo, se encarga de estructurar las reuniones y la participación de todos los implicados.

6. El Comité de las Regiones, que da apoyo a la Estrategia Europea a nivel regional.

7. El Banco Europeo de Inversiones y el Fondo Europeo de Inversiones, son los encargados de diseñar los nuevos instrumentos para financiar los proyectos innovadores (Comisión Europea, 2010).

Para que todos estos objetivos se cumplan, fueron propuestas siete acciones llamadas «iniciativas emblemáticas», y que los países podrían tomar de ejemplo y aplicar a sus políticas, y son:

1. Unión por la innovación.

2. Juventud en movimiento.

3. Agenda Digital para Europa.

4 Una Europa que emplee eficazmente los recursos.

5. Una política industrial para la era de la globalización.

6. Agenda de nuevas cualificaciones y trabajos.

7. Plataforma europea contra la pobreza (Comisión Europea, 2012).

El Parlamento Europeo, con la creación del Mapping Smart Cities in the EU (Mapeo de las Ciudades Inteligentes + en la UE) y con el ranking de las ciudades europeas de tamaño medio, ha establecido las condiciones que debe tener una ciudad para considerarse Smart City. Estas condiciones, se resumen en haber desarrollado iniciativas en al menos uno de estos seis ámbitos como mínimo: «Smart Economy, Smart People, Smart Mobility, Smart Environment, Smart Governance y Smart Living» (MINETUR, 2015, 2).

La UE ha creado diferentes programas de financiación para permitir a sus países miembros cumplir con los objetivos propuestos en la Estrategia Europa 2020. Los fondos FEDER (Fondos Europeos para el Desarrollo Regional) y el Horizonte 2020, han sido necesarios para poner en marcha acciones a favor del desarrollo del modelo Smart City. En la Tabla 1 se exponen algunos de los programas que se pusieron en marcha, y que tienen fecha de caducidad, este mismo 2020, para que se pudieran desarrollar las estrategias del programa Europa 2020 en relación al modelo Smart City. 
Tabla 1. Programas europeos que permiten desarrollar el modelo S. C. de 2014-2020

\begin{tabular}{|c|c|c|c|}
\hline Nombre de los programas & Millones & Programa global & $\begin{array}{l}\text { Entidad } \\
\text { Emisora }\end{array}$ \\
\hline $\begin{array}{c}\text { Programa de trabajo } \\
\text { plurianual LIFE 2014-2017 }\end{array}$ & $100-125$ & $\begin{array}{l}\text { Programa de Medio Ambiente y Acción } \\
\text { por el Clima }\end{array}$ & $\begin{array}{l}\text { Banco Europeo } \\
\text { de Inversiones }\end{array}$ \\
\hline JESSICA F.I.D.A.E & 123 & $\begin{array}{l}\text { Fondo Europeo de Desarrollo Regional } \\
\qquad \text { (FEDER) }\end{array}$ & $\begin{array}{l}\text { Banco Europeo } \\
\text { de Inversiones }\end{array}$ \\
\hline $\begin{array}{l}\text { ELENA- European Local } \\
\text { Energy Assistance }\end{array}$ & 1.600 & $\begin{array}{c}\text { European Comission's intelligent } \\
\text { Energy-Europe programme }\end{array}$ & $\begin{array}{l}\text { Banco Europeo } \\
\text { de Inversiones }\end{array}$ \\
\hline $\begin{array}{l}\text { Programa para la PYMES } \\
\text { (COSME) (2014-2020) }\end{array}$ & 2.500 & Horizonte 2020 & $\begin{array}{l}\text { Comisión } \\
\text { Europea }\end{array}$ \\
\hline $\begin{array}{l}\text { ERA-NET COFUND Smart } \\
\text { Cities Communities (ENSCC) }\end{array}$ & 26 & $\begin{array}{l}\text { Horizonte 2020, JPI Irban Europe, } \\
\text { Smart Cities Member States Initiative }\end{array}$ & $\begin{array}{c}\text { Comisión } \\
\text { Europea y CDTI }\end{array}$ \\
\hline Programa de iniciativa PYME & 800 & $\begin{array}{l}\text { European Structural and Investment } \\
\text { Funds, FEDER (FEDER 2014-2020) }\end{array}$ & $\begin{array}{l}\text { Comisión } \\
\text { Europea }\end{array}$ \\
\hline $\begin{array}{c}\text { Programa para el } \\
\text { crecimiento sostenible }\end{array}$ & 5.520 & $\begin{array}{l}\text { European Structural and Investment } \\
\text { Funds, FEDER (FEDER 2014-2020) }\end{array}$ & $\begin{array}{l}\text { Comisión } \\
\text { Europea }\end{array}$ \\
\hline $\begin{array}{c}\text { Programa para el } \\
\text { crecimiento inteligente }\end{array}$ & 3.939 & $\begin{array}{l}\text { European Structural and Investment } \\
\text { Funds, FEDER (FEDER 2014-2020) }\end{array}$ & $\begin{array}{l}\text { Comisión } \\
\text { Europea }\end{array}$ \\
\hline $\begin{array}{c}\text { Plan Nacional de Ciudades } \\
\text { inteligentes }\end{array}$ & 153 & FEDER (FEDER 2014-2020) & $\begin{array}{l}\text { Comisión } \\
\text { Europea }\end{array}$ \\
\hline $\begin{array}{c}\text { Programas Operativos } \\
\text { Regionales }\end{array}$ & 9.009 & FEDER (FEDER 2014-2020) & $\begin{array}{l}\text { Comisión } \\
\text { Europea }\end{array}$ \\
\hline
\end{tabular}

Fuente: ONTSI, 2015. Elaboración propia

Estos son algunos de los programas que desde el 2014 han ayudado a que los países miembros de la UE puedan emprender el camino hacia la sostenibilidad, y en cierto modo, a aplicar algunas de las estrategias que el modelo de Ciudad Inteligente contempla.

La UE continúa pensando que el mejor camino para garantizar la calidad de vida de sus ciudadanos es trabajar hacia una Europa sostenible, y apostar por las nuevas tecnologías para desarrollar los nuevos objetivos propuestos. «El desarrollo sostenible ocupa un lugar central en las propuestas, es una prioridad transversal, no solo de una partida o de un programa preciso» (Comisión Europea, 2015). Para promover la sostenibilidad, se ha apostado por poner en marcha programas como Horizonte Europa, un programa para fomentar la investigación e innovación de la UE, con un presupuesto de 100.000 millones, el programa Europa Digital, para fomentar la inteligencia artificial y nuevas oportunidades que ayuden al desarrollo sostenible, con un presupuesto de 
9.200 millones (Comisión Europea, 2015). Estos y otros programas tienen como fecha final el 2030, y se espera que con ellos se pueda alcanzar de una forma más exitosa los 17 objetivos propuestos para el Desarrollo Sostenible (Comisión Europea, 2019).

\subsection{EXPANSIÓN Y DIFUSIÓN DE LAS ESTRATEGIAS SMART EN EL TERRITORIO ESPAÑOL}

El territorio español está compuesto por un total de 8.131 municipios. Sólo hay 151 municipios españoles que tengan de 50.000 hasta 100.000 habitantes, y 63 municipios con más de 100.000 (INE, 2019). Este dato es muy significativo, ya que, de 8.131 municipios, 214 son los que soportan la acumulación de capital y de personas, y esta tendencia va en aumento.

Esta acumulación en las ciudades medianas y grandes, ha tenido como consecuencia una grave despoblación, con un $72 \%$ del total de municipios con una población inferior a 2.000 habitantes, y con tendencia al empeoramiento (Galán, 2016).

Este problema de distribución desigual, comporta dificultades para los ayuntamientos a la hora de garantizar el aprovisionamiento de recursos a sus ciudadanos, y de garantizar una buena calidad de vida.

Desde el Estado se han realizado diferentes medidas para tratar de solucionar estos problemas, que han ido desde la creación del Plan Nacional de Ciudades Inteligentes 2015, hasta la creación del Plan Nacional de Territorios Inteligentes actual. Entre estos dos planes nacionales, ha habido un salto muy importante, donde se ha pasado de considerar sólo a las ciudades, para aplicar las estrategias elaboradas, a considerar todos los territorios que necesitan mejorar su gestión.

El Plan Nacional de Ciudades Inteligentes, creado por el Ministerio de Energía, Turismo y la Agenda Digital, trata de conseguir que los municipios lleguen a ser inteligentes, empleando una política industrial y otras sectoriales, que ayuden al sector tecnológico y aumenten el sector industrial español. La Agenda Digital para España, marca que «España debe seguir impulsando el desarrollo de un sector industrial fuerte, competitivo y de referencia internacional, que contribuya a la recuperación de la actividad económica y a la creación de trabajo» (MINETUR, 2015, 1). Por tanto, con este plan, se quiere seguir el modelo que marca la UE en la Estrategia Europa 2020, y «conseguir que el sector industrial represente el 20\% del PIB en el año 2020» (MINETUR, 2015). Para conseguir este objetivo, se propuso el año 2013, diez líneas de actuaciones y más de 97 medidas para «aumentar la aportación de las TIC al PIB del sector industrial, para mejorar la eficacia y la eficiencia de los servicios públicos, para avanzar en la gobernanza de las entidades locales e impulsar la estandarización, la regulación o la normativa en relación a las ciudades inteligentes» (ONTSI, 2015). Por el momento, según el último Barómetro Industrial de 2019, que fue elaborado por el COGITI [Consejo General de la Ingeniería Téc- 
nica Industrial] y el CGE [Consejo General de Economistas], no se ha llegado al objetivo de la Estrategia, y en vez de suponer un $20 \%$ del PIB, ha disminuido hasta el 16\% en 2018, dato alarmante si lo comparamos con el 18'7\% que suponía en el año 2000, antes de iniciarse las medidas para tratar de aumentarlo (COGITI, 2019).

En 2012 se creó la RECl [Red Española de Ciudades Inteligentes], con la intención de ser una red de comunicación entre las diversas ciudades inteligentes españolas, para que pudieran intercambiar experiencias, llegando a desarrollar en cada ciudad un modelo sostenible, mejorando la calidad de vida de sus ciudadanos (RECl, 2016).

Figura 1. Mapa que representa la evolución de las ciudades pertenecientes a la RECI, desde 2012 a 2019. RECI, 2019

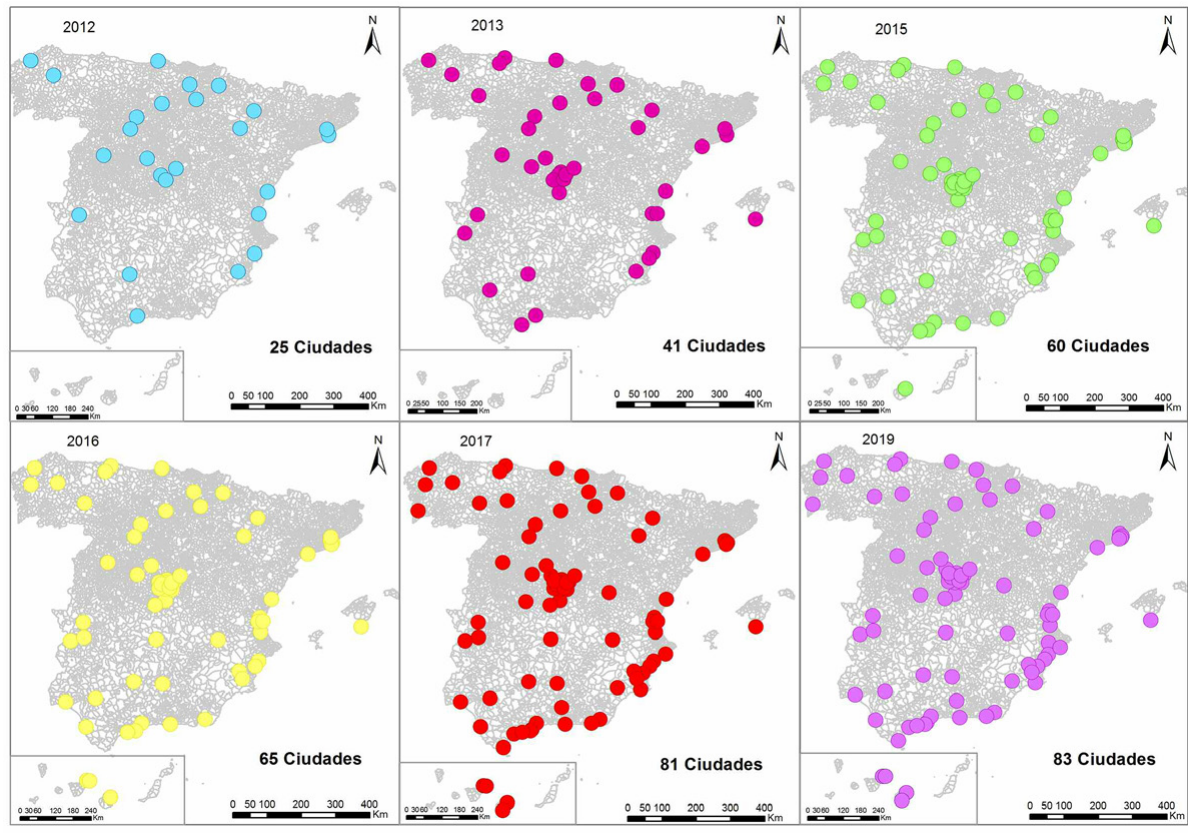

Fuente: Elaboración propia

Como vemos en la Figura 1, la evolución del número de ciudades que pertenecen a la RECl ha aumentado mucho desde su creación en 2012, cuando fueron 25 las ciudades pioneras en apoyar el proyecto. Actualmente ya cuenta con 83 ciudades, que están desarrollando el modelo Smart City en su ciudad. Además de las 83 ciudades que forman parte de la RECl, también existen los 33 municipios amigos, que no entran a formar parte porque tienen 
menos de 50.000 habitantes (RECl, 2019). Para acceder a la RECl, una ciudad debe tener como mínimo 50.000 habitantes, y debe presentar un proyecto innovador, que pasará por una comisión de valoración donde será aceptado o no.

También hay dos redes más que tratan de impulsar las iniciativas del modelo Smart City, la red INNPULSO, y la RIU. La red INNPULSO forma parte del Ministerio de Economía, Industria y Competitividad, y para entrar en ella el ministerio debe haber premiado a la ciudad con el galardón de Ciudad de la Ciencia y la Innovación (MICINN, 2017). Estas ciudades, para ser premiadas deben haber presentado un proyecto, y en un plazo de tres años avanzar en su desarrollo. Si no cumplen este requisito, a los tres años es retirado el galardón. Por tanto, no tiene la misma finalidad medio para compartir datos como la $\mathrm{RECl}$, si no que sirve para crear proyectos innovadores, y fomentar así la aplicación del modelo Smart City. Una vez se encuentran dentro de la red INNPULSO pasan a formar parte de la Arinna [Asociación de la Red INNPULSO].

La RIU [Red de Iniciativas Urbanas] está dirigida por el Ministerio de Fomento y el Ministerio de Hacienda y Administraciones Públicas. Además, también cuenta con representantes de la FEMP [Federación Española de Municipios y Provincias]. La RIU pretende «definir una Agenda Urbana para España, estudiar y aprobar las propuestas (documentos técnicos y herramientas) y presentar y analizar el desarrollo de las políticas urbanas en España y Europa» (MFOM, MH y MAP, 2013). Los fondos FEDER son los que financian los proyectos que se ponen en marcha a partir de esta red, ya que es una de las estrategias de financiación europeas para garantizar que se aplique la Estrategia Europa 2020. La Estrategia Dusi, «Estrategias de Desarrollo Urbano Sostenible e Integrado», es uno de los programas que ofrece la RIU para obtener financiación (MFOM, MH y MAP, 2013). La SETSI [Secretaría de Estado de Telecomunicaciones y Sociedad de la Información] propuso la creación del estudio y la guía metodológica sobre las Ciudades Inteligentes españolas, que fue realizado por ONTSI [Observatorio Nacional de las Telecomunicaciones y de la Sociedad de la Información] a finales de 2015. Este estudio, hizo un análisis de la situación de partida de los municipios españoles que comenzaban a introducir iniciativas del modelo Smart City. La intención era poner a disposición de los municipios herramientas destinadas a lograr la transformación de éstos en Ciudades inteligentes.

Hasta el 2017, la situación para fomentar la implementación de este modelo en los municipios españoles, se reducía a la creación del Plan Nacional, y la creación de redes para recibir financiación europea, teniendo en cuenta que su entrada está limitada a municipios medios, y que, además, ya tienen un desarrollo fuerte en el sector de las innovaciones.

Todos los servicios Inteligentes, que ofrecen los municipios, han podido ser desarrollados gracias a los fondos que han recibido de la UE, de la CE y del 
$\mathrm{BEl}$, que se transmiten a los municipios mediante los Fondos FEDER (Fondos Europeos para el Desarrollo Regional) y el programa Horizonte 2020, para tratar de cumplir los objetivos de la Estrategia europea 2020. Estos fondos se transmiten al Ministerio de Industria, Energía y Turismo de España, que es la institución que se encarga de otorgar la financiación, a los diferentes municipios que presentan proyectos innovadores. Emplea otros organismos que pertenecen a este ministerio, el SETSI, la entidad pública empresarial RED.es, SEGITUR [Sociedad Estatal para la Gestión de la Innovación y las Tecnologías Turísticas], el IDAE [Instituto para la Diversificación y Ahorro de la Energía], la EOI [Escuela de Organización Industrial] y el CDTI [Centro para el Desarrollo Tecnológico Industrial] el único que pertenezca al Ministerio de Economía y Competitividad. Algunas de las empresas y entidades privadas que colaboran con el desarrollo del modelo Smart City en España son AENOR [Asociación Española de Normalización y Certificación], AMETIC [Asociación Multisectorial de Electrónica, Tecnologías de la Información, Comunicaciones y Contenidos Digitales] y también ISO (MINETUR, 2016).

A finales de 2017, el Colegio Oficial de Ingenieros de Telecomunicaciones (COIT), por su grupo de Smart Cities, ha presentado un estudio llamado «La tendencia inteligente de las ciudades españolas» para analizar cómo han evolucionado las ciudades después de la puesta en marcha del Plan Nacional de ciudades inteligentes de 2015. Este estudio argumenta que es importante replantear los objetivos iniciales del plan, ya que generalmente los municipios o ciudades pequeñas se han quedado fuera de todo tipo de ayudas, y entonces sólo se beneficia a las medianas y grandes ciudades (COIT, 2017).

El 29 de diciembre de 2017, el Ministerio de Energía, Turismo y Agenda Digital lanzó el Plan Nacional de Territorios Inteligentes, un plan estratégico con horizonte del 2020 al 2025, y con una dotación de 170 millones de euros. Cambia los objetivos iniciales del antiguo plan, añadiendo otras zonas de actuación, como los territorios rurales. Se trata el tema del turismo inteligente y los territorios rurales inteligentes, es decir, va más allá de las grandes zonas de aglomeración urbanas, que hasta entonces eran las únicas donde se podía concebir el modelo «Smart», y contempla un escenario futuro con una mayor preocupación por todo el territorio español (MINETAD, 2017).

\section{CONCLUSIONES}

La importancia de fomentar el Desarrollo Sostenible en las políticas europeas es evidente, y por ello se ha puesto especial énfasis, en que, para conseguirlo, los países miembros han de apostar por el uso de las nuevas tecnologías. Para conseguir dicho desarrollo, se ha creado la Estrategia Europa 2020 y la actual Estrategia Europa 2030. Ambas pretenden albergar un gran número de objetivos, con tal de mejorar la Europa actual, pero que por el momento no están siendo cumplidos. 
La voluntad por parte de Europa y del Estado español es evidente, y han apostado por impulsar un gran número de programas que, mediante financiación, posibilitan la implementación de acciones propias del modelo Smart City. El modelo Smart City ha supuesto una opción y respuesta para tratar de paliar los problemas causados por las grandes aglomeraciones urbanas. En el estado español ya existen muchos municipios que están tratando de desarrollar dicho modelo, mediante la creación de Planes Directores, que introducen las iniciativas del modelo en todos los ámbitos del municipio, llegando a crear acciones transversales que tienen como fin el Desarrollo Sostenible. El modelo no es perfecto, y es por ello que los Planes Nacionales han ido cambiando para tratar de adecuarse a las necesidades de los municipios, e intentar cubrir las necesidades del territorio.

\section{REFERENCIAS}

Álvarez, E. (Enerlis, Ernst and Young, Ferrovial and Madrid Network) (2012). Libro Blanco Smart Cities, 9-16. Madrid: Imprintia. Recuperado de: http://www.innopro.es/pdfs/libro_blanco_smart_cities.pdf [Consulta el 16 de marzo de 2020]

Colegio Oficial de Ingenieros en Telecomunicación (COIT) (2017). Recuperado de: https://www.coit.es/sites/default/files/informes/pdf/2018-01-30_coit_grupo_ scsr_informe_tendencia_smart_version_final.pdf_[Consulta: el 5 de febrero de 2019]

Comisión Europea (2010). Estrategia Europa 2020. Recuperado de: http://eurlex.europa.eu/LexUriServ/LexUriServ.do?uri=COM:2010:2020:FIN:ES:PDF [Consulta: 8 de junio de 2017]

Comisión Europea (2012). Europa 2020: La estrategia europea del crecimiento. Recuperado de:

http://www.lamoncloa.gob.es/espana/eh15/politicasocial/Documents/Europa-2020-la-estrategia-europea-de-crecimientoA.pdf [Consulta el 8 de junio de 2017]

Comisión Europea (2015). La contribución de la comisión Juncker a los objetivos de desarrollo sostenible. Recuperado de:

https://ec.europa.eu/commission/sites/beta-political/files/reflection_paper_ sustainable_annexi_es.pdf [Consulta: 16 de marzo de 2020]

Comisión Europea (2019). Documento de reflexión para una Europa Sostenible de aquí a 2030. Recuperado de:

https://ec.europa.eu/commission/sites/beta-political/files/rp_sustainable_ europe_es_v2_web.pdf [Consulta: 16 de marzo de 2020]

Costa, J. (Ernst and Young, Ferrovial and Madrid Network) (2012). Libro Blanco Smart Cities (p.4). Madrid: Imprintia. Recuperado de:

http://www.innopro.es/pdfs/libro_blanco_smart_cities.pdf 
El Consejo General de la Ingeniería Técnica Industrial de España (COGITI) (2019). Presentando el Barómetro Industrial 2019 del COGITI-Cátedra Internacional COGITI de Ingeniería y Política Industrial (UCAM). Recuperado de https://cogiti.es/presentando-el-barometro-industrial-2019-del-cogiti-catedra-internacional-cogiti-de-ingenieria-y-politica-industrial-ucam-urge-unpacto-de-estado-que-permita-implementar-politicas-activas-que-doten [Consulta: 17 de marzo de 2020]

Galán, J. (2016). El mapa de los municipios menos habitados. El País. Recuperado de:

http://politica.elpais.com/politica/2016/08/23/actualidad/1471967709_624259.html

INE (2019). Estadística del Padrón Continuo. Datos provisionales a 1 de enero de 2019. Recuperado de:

https://mww.ine.es/jaxi/Tabla.htm?path=/t20/e245/p04/provi/lO/\&file=0tamu001. px\&L=O_[Consulta: 17 de marzo de 2020]

MFOM, MH y MAP (2013). Red de Iniciativas Urbanas. RIU. Recuperado de http://www.rediniciativasurbanas.es/RIU/LANG_CASTELLANO/ [Consulta: el 11 junio de 2017]

MICINN (2017). Distinción Ciudades de la Ciencia y la Innovación. Red INNPULSO. Recuperado de:

http://www.ciencia.gob.es/portal/site/MICINN/menuitem.7eeac5cd345b4f3

4f09dfd1001432eaO/?vgnextoid=1b550alf8925b210VgnVCM1000001d04140a RCRD [Consulta: el 11 de junio de 2017]

MINETAD (2017). Plan Nacional de Territorios Inteligentes. Recuperado de http://www.agendadigital.gob.es/agenda-digital/noticias/Documents/PNTI/ plan-nacional-territorios-inteligentes.pdf [Consulta: el 19 de abril de 2018]

MINETUR (2015). Plan Nacional de Ciudades Inteligentes. España. Recuperado de:

http://www.agendadigital.gob.es/planes-actuaciones/Paginas/plannacional-ciudades-inteligentes.aspx [Consulta: el 3 de junio de 2017]

MINETUR (5 de octubre de 2016). Inauguración Green Cities. Recuperado de: http://www.minetad.gob.es/eses/gabineteprensa/notasprensa/2016/documents/np\%20inaguraci\%C3\%B3n\%20green\%20cities\%2005\%2010\%2016.pdf [Consulta: el 9 de noviembre de 2016]

Moreno, L. y Gutiérrez, A. (2012). Ciudades inteligentes: Oportunidades para generar soluciones sostenibles, 1-28. Bogotá: Cintel. Recuperado de:

http://cintel.org.co/wpcontent/uploads/2013/05/01.Ciudades_Inteligentes_CINTEL.pdf [Consulta el 23 de mayo de 2017]

Observatorio Nacional de las Telecomunicaciones y de la Sociedad de la Información (ONTSI) (2015). Estudio y guía metodológica sobre ciudades inteligentes. España. Recuperado de:

http://transparencia.gob.es/transparencia/dam/jcr:49c89e9e-52e0-4baeb9fd-d199f76b1779/Estudio_ciudades_inteligentes.pdf [Consulta el 24 de mayo de 2017] 
RECl (2016). Red Española de ciudades inteligentes. Recuperado de: http://www.redciudadesinteligentes.es/sobrelared/quienessomos/ampliar.php/Id_contenido/301/v/O/ [Consulta: el 30 de mayo de 2017] RECl (2019). Mapa de la Red Española de Ciudades Inteligentes, que incluye tanto ciudades miembro como municipios amigos. Recuperado de: https://www.google.com/maps/d/u/O/viewer?mid=1HZWgeg8ar74LSxhOUz Y5CIpjpGCTfI9\&II=36.10419244429042\%2C-6.046411250000006\&z=5 [Consulta: el 5 de febrero de 2020]

Rueda, S. (Ministerio de Agricultura, Alimentación y Medio Ambiente). (2012). El Libro Verde de Sostenibilidad Urbana y Local en la Era de la Información. Madrid: V.A. Impresores, S.A. Recuperado de:

https://ovacen.com/wp-content/uploads/2013/11/libro-verde.pdf [Consulta el 2 de febrero de 2018]

Sánchez, J. y García, F. (2015). Gobierno y participación ciudadana en el nuevo modelo de ciudad las TIC como herramienta de desarrollo de la Ciudad. ECOnomía industrial, Ciudades inteligentes ( $\left.n^{\circ} 395\right), 135-146$. Recuperado de: https://pdfs.semanticscholar.org/8014/f7fec6e8b6d0a56a26276503e3eda26 debca.pdf 


\title{
URBAN PLANNING AND RAILWAY INTEGRATION IN MEDIUM-SIZED CITIES: COMPARATIVE ANALYSIS IN SANTANDER AND TORRELAVEGA \\ PLANIFICACIÓN URBANÍSTICA E INTEGRACIÓN FERROVIARIA EN CIUDADES MEDIAS: ANÁLISIS COMPARADO DE SANTANDER Y TORRELAVEGA
}

\author{
Francisco García Sánchez \\ Universidad de Cantabria \\ Cecilia Ribalaygua \\ Universidad de Cantabria
}

\begin{abstract}
The railway station has historically played a key role in the morphological and functional configuration of cities since its arrival in the 19th century. These nodes, initially planned to serve sectoral needs, have become poles of urban development.

After half a century of decline, we are living a period of transformation of the railway mode, either due to the arrival of high-speed, to the policies for a required multi-modality, or due to the large amount of obsolete railway spaces for contemporary technical requirements remaining vacant. These vacant spaces awaiting transformation in the heart of cities become opportunities for urban renewal, incorporating variables that are no longer just from the railway's viewpoint, but are considered key pieces for urban regeneration from the spatial planning perspective.

The objective of the article focuses on analyzing this phenomenon in the Spanish medium-sized cities which, having specific socioeconomic characteristics, are in disadvantage relating to resources for carrying out large urban transformation operations in these sectors. Through a comparison between both Santander and Torrelavega planning proposals, relevant conclusions can be drawn on the role of Urban Planning in defining a local policy regarding integration in a holistic urban strategy.
\end{abstract}

Keywords: railway integration, urban planning, urban renewal, strategies, high-speed rail, medium-sized cities.

Resumen

La estación ferroviaria desempeña históricamente un rol clave en la configuración morfológica y funcional de las ciudades desde el siglo XIX. Estos nodos, planificados inicialmente para dar servicio a las necesidades sectoriales, se han convertido en polos del desarrollo urbano de buena parte de nuestras ciudades. 
Después de medio siglo de declive de los entornos asociados al tren, vivimos un momento de transformación del modo ferroviario, bien por la llegada de la alta velocidad, bien por las políticas de unificación y concentración para la requerida multi-modalidad, o bien por la gran cantidad de suelo ferroviario obsoleto para los requisitos técnicos contemporáneos que queda vacante. Estos espacios vacantes a la espera de transformación en el corazón de las ciudades se convierten en oportunidades de transformación urbana, incorporando variables que han dejado de ser sólo ferroviarias, y son consideradas en el planeamiento urbanístico local como piezas clave para la regeneración urbana.

El objetivo del artículo se centra en analizar este fenómeno en las ciudades medias españolas que por sus características socioeconómicas se ven desfavorecidas en la recepción de recursos para realizar grandes operaciones de transformación urbana de estos entornos. Mediante un comparativa entre las propuestas de Santander y Torrelavega podemos extraer conclusiones extrapolables sobre la función del Planeamiento en la definición de una política local respecto a la integración de los espacios ferroviarios en la estrategia urbana.

Palabras clave: integración ferroviaria, planeamiento urbanístico, regeneración urbana, estrategias, alta velocidad ferroviaria, ciudades medias.

\section{INTRODUCTION}

The railway infrastructure has left its mark on urban morphology during last two centuries, and continues to be an important driver of change in contemporary cities. Although the railway was originally received as a symbol of progress with the possibility of generating new capital gains on the edge of the traditional city (Calvo, 1998), it became, in the last third of the 20th century, a physical barrier to the growth of cities (Santos y Ganges, 2011) that led to new ways of urban expansion with poor quality neighborhoods. However, an apparent new resurgence of railway stations has been taking place with the optimization of obsolete surfaces meant for infrastructure and the recovery of urban surroundings around transport centers (Van den Berg \& Pol, 1998; Bertolini \& Spit,1998). In this sense, the arrival of new railway modes, such as high-speed services (HSR), or the improvement of commuter services, light rail and trams, allows the creation of new railway areas (Ribalaygua, 2004; Zemp, 2014; Loukaitou-Sideris et al, 2017) in line with the expectations of the urban renewal desired by society. This article focuses on analyzing the transformation phenomena of the disused railway spaces and in the surroundings of the stations in the Spanish medium-sized cities not linked to large metropolitan areas. The low strategic weight of medium-sized cities in terms of mobility has meant a low investment in improving their railway infrastructures and reorganizing station areas (Bellet \& Santos, 2016). However, it is been noticed that, beyond the role as transportation nodes offered by the stations of the medium-sized cities, 
there are a greater number of urban renewal projects focused on railway spaces conceived as places of opportunity and catalysts of new dynamics of transformation (Mohino et al., 2014; Ribalaygua \& Pérez-del-Caño, 2019; Ribalaygua \& García, 2010). Station areas have undergone through spatial transformations over time, in numerous situations far from the premises established in the urban plans of our cities. Sometimes the infrastructure has limited the capacity of renovating the urban fabric and, in others, they have induced urban renewal processes with the opening of large open spaces or with the re-densification under the idea of taking advantage of the accessibility they offer. In all cases the station area has remained as a representative place of the city (Bertolini, 2008), as rail transport plays a valuable role in the spatial structure of cities, especially when this system is connected to other modes of transport (Bertolini \& le Clercq, 2003; Banister, 2008).

Within the European context, inspiring examples of strategies and practices are found in cases such as Łódź Fabryczna central station, in the Polish city of Łódź, which reorganizes its city core through an adequate distribution of open spaces (Giedryś \& Raczyński, 2017). The same role is played by Bern station, generating a pole of tertiary activities, in line with the criteria of commercial enhancement of the stations and their areas of influence, known as the RailCity initiative (Peters \& Novy, 2012). In both cases, rail depression is a strategic element in the urban project. However, all processes of urban transformation developed have the station as the leitmotif of the urban operation, node and place (Bertolini \& Spit, 1998).

\section{INTRAURBAN RAILWAY SPACE IN SPANISH MEDIUM-SIZED CITIES}

The Spanish railway network began in the mid-nineteenth century, developing more expansively at the end of the century, where all the provincial capitals already had rail services (Monclús \& Oyón, 1996). After a decline in the railway mode and its urban surroundings in the second half of the 20th century, the network is still changing and there is currently a widespread process of renovation of infrastructures and stations.

On numerous occasions, railway environments have been doomed to spatial degradation and are far from their corresponding urban reference image. This is due, among other causes increased by the deep economic crisis in the real estate sector, to the fact that many of the rail depression projects in mediumsized cities are not within the reach of municipal governments, which must take advantage of national funds or railway entities to finance the initial investments (Zembri \& Libourel, 2017; Martí-Henneberg, 2015). Some Spanish such as Barcelona (Sants or La Sagrera Station), Zaragoza (El Portillo Station) or Córdoba (Central Station) have managed to develop railway integration projects with the improvement of urban connectivity in surface, relying on large infrastructure projects such as high-speed lines. Even so, the reorganization of ob- 
solete railway spaces remains a pending exercise for large cities such as Madrid, Seville or Valencia (Marquínez, 2017; Ribalaygua \& Pérez-del-Caño, 2019). Only seven of the 46 Spanish medium-sized cities with a railway station have been able to generate urban transformation projects in their surroundings (Table 1). The high costs of these operations have limited their execution, except when the railway entity leads the initiative in exchange for modifications in municipal planning that favor land monetization. The need to promote the development of Spatial Plans around the station (Plan de Reforma Interior-for Interior Renewal Plans in English), sometimes with severe modifications to the municipal planning, has been one of the strategies followed for the success of urban renewal proposals. With few exceptions, a large part of the Spanish mediumsized cities with railway services have station surroundings in a process of degradation since the last quarter of the 20th century, with poorly urbanized sectors or with difficulties of access. From the 46 Spanish cities analyzed, 15 of them have stations on the urban fringe and two on the periphery', where the improvement of their surroundings mainly benefits the railway entity (Table 1).

Table 1. Case studies according to its railways integration

\begin{tabular}{|l|c|c|}
\cline { 2 - 3 } \multicolumn{1}{c|}{} & Municipalities & Population 2018 \\
\hline \multirow{2}{*}{$\begin{array}{l}\text { Cities with } \\
\text { depressed } \\
\text { railway }\end{array}$} & Gandía & 73.829 \\
\cline { 2 - 3 } & Orihuela & 76.778 \\
\cline { 2 - 3 } $\begin{array}{l}\text { Partial railroad } \\
\text { depression with } \\
\text { barrier effect }\end{array}$ & Castellón de la Plana & 170.888 \\
\cline { 2 - 3 } & León & 124.772 \\
\cline { 2 - 3 } & Lleida & 137.856 \\
\cline { 2 - 3 } & Salamanca & 143.978 \\
\hline
\end{tabular}

\begin{tabular}{|l|c|c|}
\hline \multirow{4}{*}{$\begin{array}{l}\text { Cities with } \\
\text { barrier effect } \\
\text { by railroads }\end{array}$} & $\begin{array}{c}\text { Vila-real, Cuenca, Ávila, Mérida, Ponferrada, } \\
\text { Ciudad Real, Torrelavega }\end{array}$ & Between 50.000 to 75.000 \\
\cline { 2 - 3 } & Manresa, Palencia, Santiago de Compostela, Lorca & Between 75.000 to 100.000 \\
\cline { 2 - 3 } & Girona, Reus, Algeciras, Tarragona, Ourense & Between 100.000 to 150.000 \\
\cline { 2 - 3 } & $\begin{array}{c}\text { Badajoz, Almería, Pamplona/Iruña, } \\
\text { Cartagena, Santander, Vitoria-Gasteiz }\end{array}$ & Between 150.000 to 250.000 \\
\hline
\end{tabular}

Source: Compiled by authors

At central stations, railway integration projects have a greater capacity to generate economic capital gains and facilitate urban operation. Considering the 29 central stations found, only 7 cities have fully or partially materialized

1 The following medium-sized cities Huelva, Albacete, Toledo, Cáceres, Talavera de la Reina, Lugo, Elda, Alcoy/Alcoi, Zamora, Sagunto/Sagunt, Huesca, Aranjuez, Jaén, Ferrol and Guadalajara locate the railway stations in the urban fringe meanwhile, Burgos and Segovia have peripheral ones, in the outskirts. 
the depression of the tracks through the appropriate modifications to municipal planning (Table 1).

However, the execution of depressed infrastructure does not guarantee subsequent urban development on the surface. In the case of Castellón de la Plana (Figure 1), despite completing the underground works 20 years ago, and incorporating the execution units (residential and tertiary) in the western sector of the station in the 2012 Master Plan, none of the urban actions planned have been developed. This lack of development in this area (called Crèmor) is partly due to the fact that landowners currently live there in traditional houses (masets) and do not want to assume the transformation of their neighborhood. Despite the fact that the new Plan has tried to encourage change by increasing the Floor Area Ratio to $1.5 \mathrm{~m}^{2} / \mathrm{m}^{2}$, residents resist and carry out an active legal and social mobilization that manages to paralyze the urban process.

Figure 1. Castellón Station Area proposed in the City Master Plan and at the present time
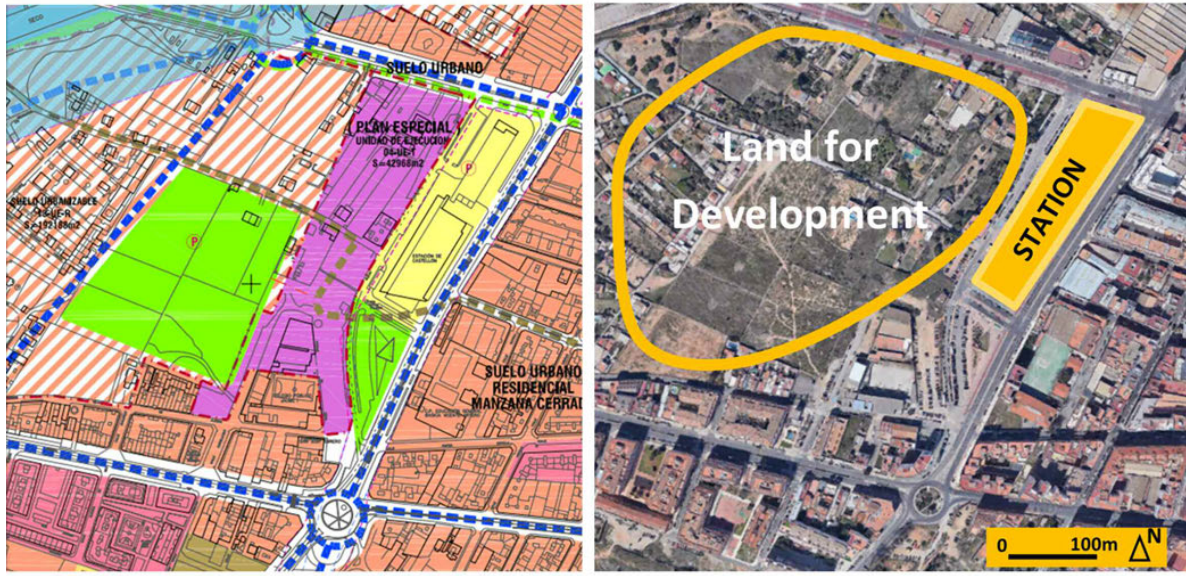

Source: Compiled by authors based on City Master Plan

(PGOU, 2012) and Google Earth orthoimage (2018)

On the contrary, Logroño presents more favorable conditions for economic investment. Its Spatial Plan demonstrated the municipal vision of the rail depression and the urban reference value of the new station with the creation of a vast residential complex (Ribalaygua \& García, 2010; Ribalaygua \& Pérezdel-Caño, 2019). Planning is certainly a necessary condition, but not sufficient. The success of station area renewal requires an urban planning that favors the development of its surrounding. 
In this line, five railway integration projects are currently in process in Spanish medium-sized cities (Table 2). The placing on market of spaces released in this kind of urban operations makes sense when the resulting surface allows a sufficiently profitable urban development for real estate investment. In these cases, the partial financing of the new railway infrastructures is obtained from the value generated.

Table 2. Railway integration projects in development phase

\begin{tabular}{|c|c|c|c|c|}
\hline Municipalities & $\begin{array}{c}\text { Population } \\
2018\end{array}$ & $\begin{array}{c}\text { Barrier } \\
\text { Effect }\end{array}$ & $\begin{array}{c}\text { Project for Railroad } \\
\text { Depression }\end{array}$ & $\begin{array}{c}\text { Station Area } \\
\text { Renewal Plan }\end{array}$ \\
\hline Torrelavega & 51.687 & Yes & $\begin{array}{l}\text { Informative Report for } \\
\text { railroad depression }\end{array}$ & No \\
\hline Lorca & 93.079 & Yes & $\begin{array}{l}\text { Informative Report } \\
\text { for urban integration } \\
\text { project and railroad } \\
\text { adaptation to HSR }\end{array}$ & No \\
\hline Ourense & 105.505 & Yes & In phase of development & $\begin{array}{l}\text { Informative Report for a } \\
\text { new Intermodal Station }\end{array}$ \\
\hline Santander & 172.044 & Yes & No & $\begin{array}{c}\text { Informative Report for } \\
\text { space reorganization } \\
\text { around Station }\end{array}$ \\
\hline $\begin{array}{l}\text { Vitoria- } \\
\text { Gasteiz }\end{array}$ & 249.176 & Yes & $\begin{array}{l}\text { Informative Report for } \\
\text { railroad urban integration }\end{array}$ & $\begin{array}{c}\text { In phase of } \\
\text { development }\end{array}$ \\
\hline
\end{tabular}

Source: Compiled by authors

In the case of Lorca, the strip of rail area released by the infrastructure depression could hardly accommodate a real estate development to generate economic returns. Only the fact of receiving a high-speed infrastructure such as the HSR Murcia-Almería line is sufficient reason for the railway manager to coordinate the modification of the urban planning with the municipality. Other projects continue their development along the lines of railway integration, such as those at the Ourense and Vitoria stations, which are in the process of overcoming conflicts arising from the surface railway. Among them, Santander and Torrelavega are also designing their station areas, and a more detailed analysis will be made in the next section.

\section{METHODOLOGY}

The study of urban renewal proposals in the station areas of medium-sized cities is initiated with the identification of a group of cities with similar conditions. The case selection was limited to a population range between 50,000 and 300,000 inhabitants, (following the criteria of the research project in which this contribution is integrated) ruling out those attached to a metropolitan area whose main city exceeded this limit. Selected the group of cities, a qualitative analysis of the station areas was carried out in each case in order 
to identify: parameters of urban integration, accessibility to the station, existence or not of a physical barrier due to the layout of the routes that prevent relations between both sides of the city, planning in process and the existence of an urban renewal project.

Finally, two case studies were selected from the same Autonomous Community (so that they share a common legal framework) but with different urban planning strategies. With this criterion the case studies of Santander and Torrelavega are chosen. Case analysis is based on field work as well as literature review of the technical and legal documentation of each case. The objective of the analysis is to obtain extrapolated conclusions on Planning tools, identifying their capacity to generate an adequate integration of railway spaces in the urban structure.

\section{ANALYSIS AND DISCUSSION}

\subsection{TORRELAVEGA AND SANTANDER, TWO SIDES OF THE SAME COIN}

The metropolitan area of «Santander-Torrelavega», located in the central area of northern Spain, covers $256.8 \mathrm{~km}^{2}$ and includes six more municipalities: El Astillero, Camargo, Miengo, Piélagos, Polanco and Santa Cruz de Bezana. With a density of 1249.5 inhabitants per $\mathrm{km}^{2}$, it is the third densest of the 55 urban areas of medium-sized cities identified by the Ministry of Development (Ministerio de Fomento, 2018a). Santander is located on the north side of a bay, providing shelter and easing marine communication. Its waters are fed by wide estuaries which flow into it from the south, favoring settlements since Roman times. Torrelavega, in the south west, belongs to the Besaya region and is located in a valley about eight kilometers from the Cantabrian coast where the Saja and Besaya rivers meet, favoring productive activities.

Both cities are linked by the regional main road, being $25 \mathrm{~km}$ distant from each other, and maintain strong functional links with a high degree of interdependence (Olazábal \& Bellet, 2020; Delgado, 1999). On the one hand, Santander, capital of the autonomous community, is predominantly administrative and services, and tourism plays an important role in its economy. On the other, Torrelavega contributes to the area with the industrial fabric and is consolidated as a commercial nucleus. The urban distribution of the region is characterized by a scattered built between the two large cities, initially as a result of an explosive process of industrialization and later outsourcing of the offer to tourism, especially in the coastal strip (Delgado, 2011; De Meer \& de Cos, 2013).

These cases are two medium-sized nuclei within the Spanish national context which polarize the activities of the secondary sector and the supply of tertiary and administrative services over a metropolitan region made up of a set of urban nuclei that oscillate between 10,000 and 25,000 inhabitants and 
which concentrate two thirds of the population of the autonomous community of Cantabria (Figure 2). The image shows a territory with a strong anthropic charge in what some authors have identified as a process of ruurbanization (Delgado, 1999). As result of this, a vast transition space between the two main poles is developed, where the Santander - Torrelavega axis is positioned as the center and driving force of the regional economy.

Figure 2. Santander - Torrelavega Metropolitan Area

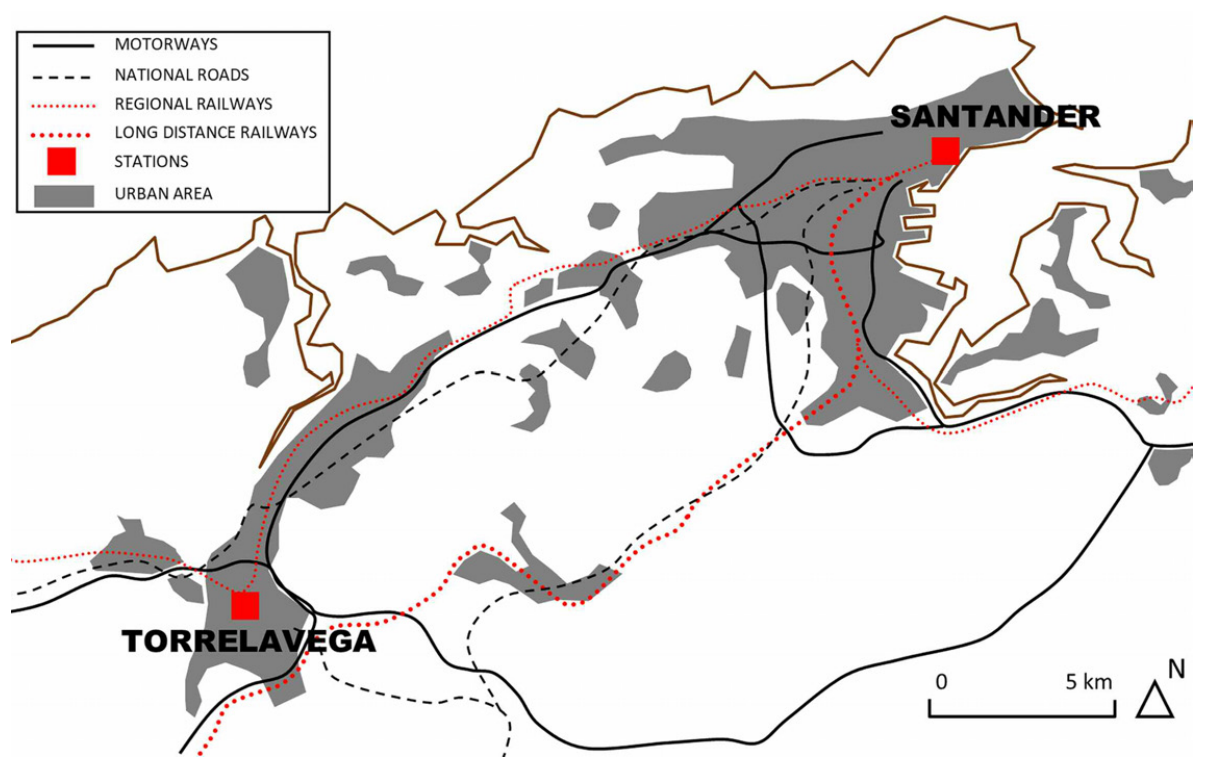

Source: Compiled by authors

The urban railway stations of Santander and Torrelavega are positioned as benchmarks within regional mobility. Nevertheless, in recent years deficiencies in the provision of narrow-gauge railway services (FEVE) and the improvement of the network of motorways between the two cities and other points in the region have reduced their global transportation capacity. In any case, demand for better accessibility through the railway remains between the two cities, which has generated a deep social debate on the need to improve service conditions and, therefore, the improvement of the railway station areas. The current process of urban regeneration of these stations is analyzed below. 


\subsubsection{THE RAILWAY DEPRESSION OPTION IN TORRELAVEGA}

Torrelavega station is located very close to the city center, where the main commercial and administrative activities take place. The railway area crosses the surface and generates a barrier effect that interrupts the connections between the urban center and the Northern sector of the city to the Besaya river. In 2018, the agreement between the State; Regional Government and the Municipality is signed for the integration of the railway depression, as well as the urban transformation of the surroundings.

The action is proposed outside the municipal planning, which only establishes the area as railway facility (General System). However, the informative report establishes the need for the station surrounding to be considered in the future revision of the local Master Plan. Thus, criteria for the intervention is specified through inter-administrative agreement, understanding, the urban implications of the railway intervention from the very beginning of the process. For the execution of the works, a temporary railway variant is created with the condition of being eliminated once the station enters in service (in red in Figure 3). The scope of integration is limited between the streets Paseo del Niño and Pablo Garnica with a total of 532 meters of covered tracks (Ministerio de Fomento, 2018b). This will allow the adaptation of the surface and the recovery of connections between the two parts of the city, historically divided in two. However, the municipality must develop and approve a spatial plan ex post in order to reshape the released space, that is, a Special Plan for the railway area (Figure 3).

Figure 3. Railway Integration Project in Torrelavega, City Master Plan and aerial view
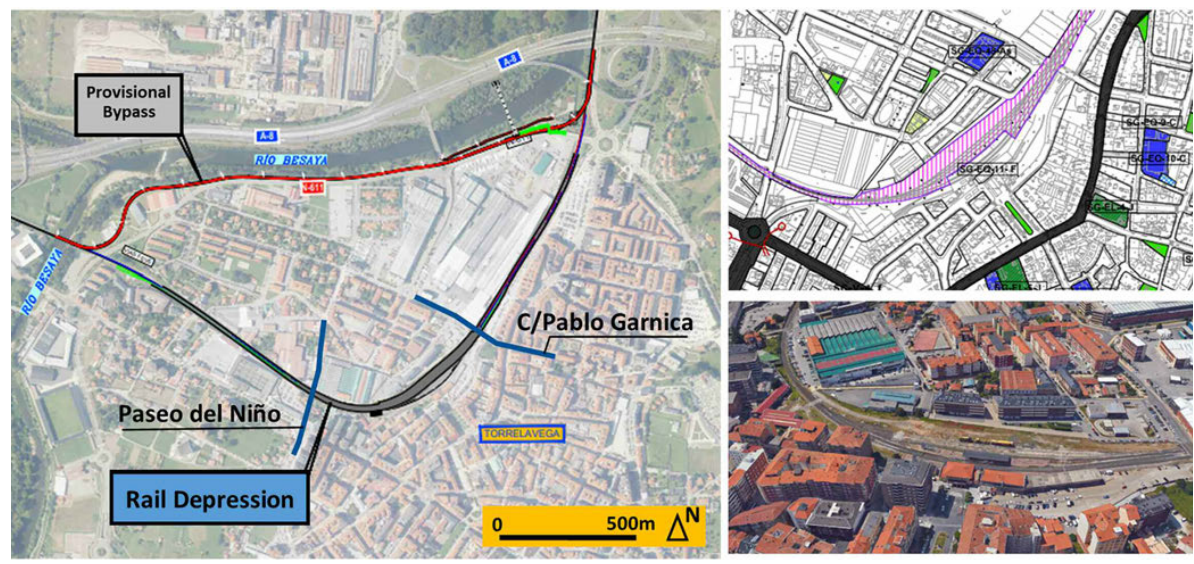

Source: Compiled by authors, adapted from Ministerio de Fomento-Ayuntamiento de Torrelavega and Google Earth, 2018 
The current planning is the Master Plan (called PGOU in Spanish) approved in 1985. A new PGOU is currently being processed addressing the integrative nature of the operation and conceiving the area as a significant reference in the city. However, the limited area identified, limited to the space owned by the railway entity, delays the possibilities of extending the benefits of the operation beyond the station. In this sense, the future intervention should take center stage if the new PGOU assigns an adequate intermodal role and seeks the expansion of the project to other plots that respond to the deficiencies in services and facilities in the nearby neighborhoods.

\subsubsection{THE HISTORICAL OPPORTUNITY OF SANTANDER RAILWAY STATION AREA}

The current Santander station is located at the end of the railway line, penetrating the urban network and hindering possible connections between the North and South sectors. Towards the North and parallel to the railway, a mountainous slope of about 25 meters serves as a natural limit where the Parque del Agua is located, a linear green open space. To the South, the populous Castilla-Hermida neighborhood, with its own urban expansion structure, plunges towards the maritime edge of the port area. In the middle, an enormous surface of railway space was identified at the current Master Plan (PGOU, 1997) as a sector ready for urban renewal.

According to the Spanish legal system, this sector defined as Specific Area 9 (PGOU of 1997) needs to be developed by a Special Plan. The Station Area Special Plan will coordinate the railway uses, facilities, tertiary, commercial, hotel or residential activities and, in particular, will facilitate the connections between the two parts of the city that are currently separate. Also, in this case, it is observed that the organization of the space released by the railway is subject to the guidelines established by the ex post planning.

In this local urban context, the Ministry of Development makes a proposal in 2018 (Figure 4) that overlaps with the management capacity of the Special Plan (Ministerio de Fomento, 2018c). In this proposal, which is currently under negotiation and modification with the City Council, the railway problem is solved with a technical solution concerned with the resolution of the sectoral problems of the train, alien to the detected urban problems.

The operation is limited to defining the shrink of the railway space in order to release a large surface area identified graphically as open space (Figure 4). The station is designed as a large 3-hectares meccano that, apparently, allows the connection of the Parque del Agua with the Castilla-Hermida neighborhood through the roof. The proposal incorporates the recovery of the old station, including a significant decontextualized parking area close to the new station. 
Figure 4. Urban Renewal Project with transversal section and aerial view of Santander Rail Station
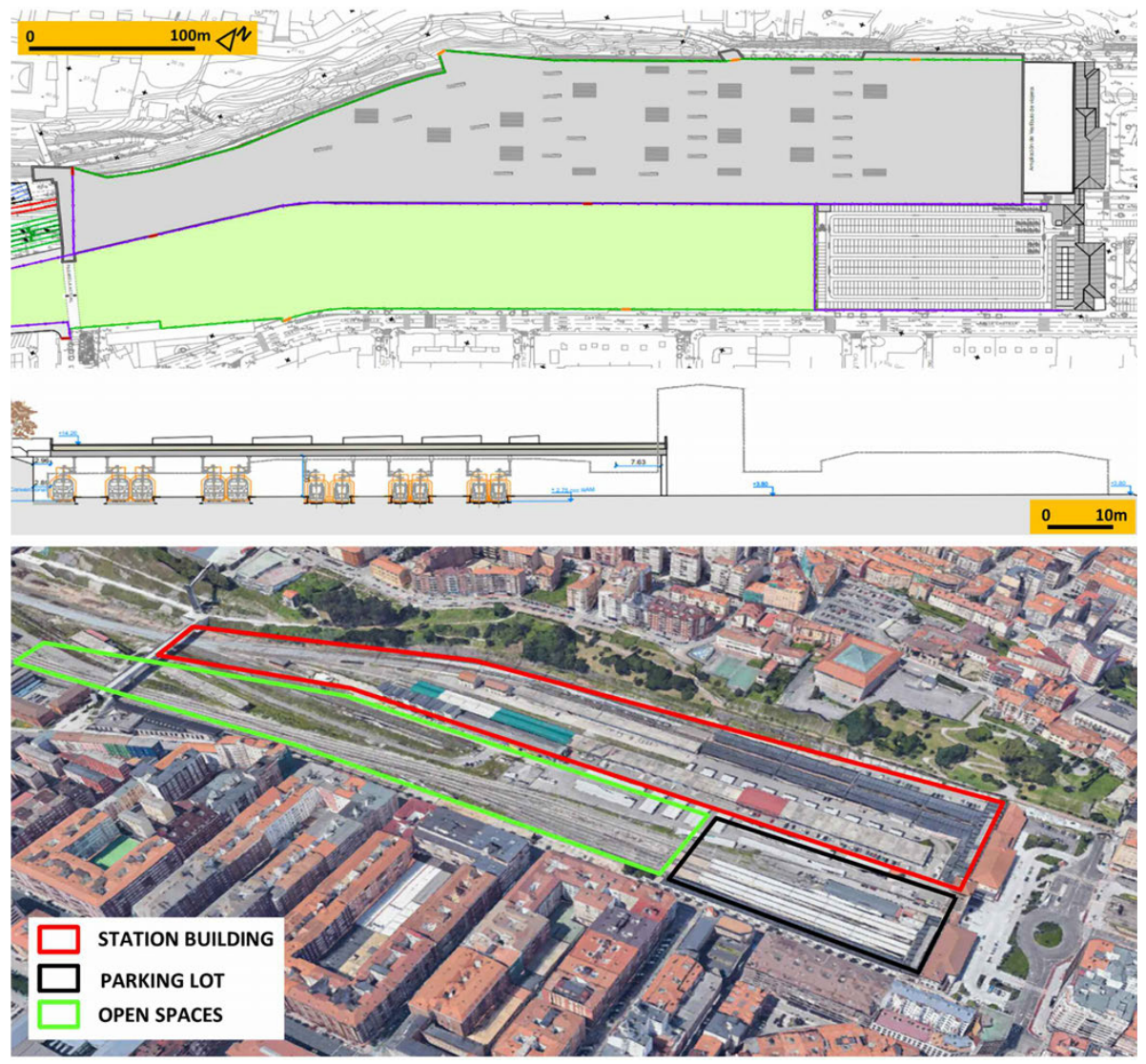

Source: Compiled by authors and adapted from

Ministerio de Fomento and Google Earth, 2018

The proposal of the Ministry of Development is not accompanied by an urban renewal project and is inconsistent with what is determined in the Santander Master Plan. This municipal planning calls for a holistic plan of the total area of 30 hectares, and not just the specific space of the station (5 hectares), considering the effects of the different alternatives (the document asks for including three options, considering the total or partial depression of the tracks). In this controversy, there is a citizen movement and the City Council itself demanding a global project by the Ministry within a new Master Plan (PGOU) that determines the characteristics of infrastructure integration. This same conflict has previously occurred repeatedly in the process of many other Spa- 
nish stations (Segovia, Guadalajara, Lleida among others), given that the municipal management capacity of these areas is limited by the imposition of railway needs (and property), not very often concerned with the strategic role that the railway area can play in the city.

\subsection{URBAN PLANNING VERSUS SECTORIAL DEVELOPMENTS}

In the cases presented, we can verify the difficulties in managing railway integration and the relative weight of municipal planning in these strategic decisions. Although, in the case of Torrelavega, the station area allows a functional arrangement of the exterior space, it is subject to the subsequent definition of the planning. Santander, on the other hand, generates a new station project intended to solve the technical deficiencies of the railway infrastructure, but not helpful for the numerous problems of urban connection between the North and South sides of the city, as well as to solve the deficits of services around the station area. In both cases, the railway action releases public space that must be reorganized in a subsequent operation of the municipal planning.

The following lessons are extracted from the comparative analysis of the railway area plans both at Santander and Torrelavega:

First, understanding that the station project is a city project, planning actions should be aimed not only at resolving the conflicts of functional integration of the railway but as a resource to improve the city center. This resource has a double function: on the one hand, from a functional point of view, to facilitate the lack of open spaces or facilities in surrounding neighborhoods; but also, on the other hand, to offer demonstrative urban quality solutions, so they can later be upscaled to the rest of the city. Therefore, it is necessary that the urban planning documents, in coordination with the railway entity, identify an area large enough to develop the urban renewal project responding to its potential strategic role within the city. Under this premise, direct benefits will be obtained on accessibility and mobility management.

Secondly, in order to guarantee the success of the intervention, the role played by the station as an urban and inter-urban modal node must be taken into account, generating a transit-oriented development. In this sense, on the one hand, a higher-scale Plan is required to guarantee coordinated and sustainable mobility; and on the other hand, an adequate arrangement of the area. For the latter, the instrument of the Special Plan for Internal Renewal avoids isolated and decontextualized arrangements within the strict railway area. Through an adequate study of the urban conditioning factors, the railway integration project will extend its benefits beyond the functional space of the station.

Finally, in both interventions the planning of an identity space with the configuration of the station plaza is pending, the result of which will determine 
the success of the proposal. Station areas must become urban benchmarks and, therefore, the terminal renovation project must assume the referential role that the railway infrastructure has always had since its creation.

\section{CONCLUSIONS}

The study has verified that most of the Spanish medium-sized cities with a railway station maintain the original nineteenth-century line with obstacles which limit the continuity of the urban fabric. However, urban renewal projects are being developed intending the recovery of the railway areas by depressing the line.

Municipal planning, a key tool in these transformations, is subject to the functional determinations established by the railway needs. Thus, it has been possible to verify in the cases of Torrelavega and Santander, where urban planning must order ex post railway actions. To take advantage of these opportunities, greater inter-administrative coordination must take place, integrating the urban value of the area as a priority in the decision-making of the Ministry of Development. In addition, the station plans must take into account the capacity of the tool of the Special Plan to guarantee the insertion of this space in the urban fabric and solve city broad problems, beyond the railway.

\section{ACKNOWLEDGEMENTS}

Work on this article was conducted within the research project Ciudades Medias Españolas: Urbanización y Políticas Urbanísticas. 40 años de Ayuntamientos democráticos. This project was funded by the Ministerio de Ciencia e Innovación (Spanish Ministry of Science and Innovation) No. RTI2018096435-B-C21 during 2019-2021 period.

\section{REFERENCES}

Banister, D. (2008). The sustainable mobility paradigm. Transport Policy, 15(2), 73-80.

Bellet, C. \& Santos, L. (2016). The high-speed rail project as an urban redevelopment tool: The cases of Zaragoza and Valladolid. BELGEO, (3). https://doi.org/10.4000/belgeo.18153

Bertolini, L. (2008). Station areas as nodes and places in urban networks: An analytical tool and alternative development strategies. In: F. Bruinsma, E. Pels, H. Priemus, P. Rietveld \& B. van Wee (Eds.), Railway development: Impacts on urban dynamics, pp. 35-57. Heidelberg: Physica-Verlag.

Bertolini, L. \& le Clercq, F. (2003). Urban development without more mobility by car? Lessons from Amsterdam, a multimodal urban region. Environment and Planning A, 35(4), 575-589. 
Bertolini, L. \& Spit, T. (1998). Cities on rails: the redevelopment of railway station areas. London: Taylor \& Francis Books Ltd.

Calvo, J. L. (1998). Las llegadas del ferrocarril y ferrocarril de alta velocidad las ciudades. OP, Monográfico Ferrocarril y Ciudad, 45, 14-21.

De Meer, A. \& de Cos, O. (2013): Las áreas metropolitanas de tamaño medio: la configuración de un espacio de cohesión en el conjunto polinuclear Santander-Torrelavega, Ciudad y territorio: Estudios territoriales, 176, 351-362

Delgado, C. (1999). Los procesos de difusión urbana en Cantabria. Polígonos, 9, 71-96.

Delgado, C. (2011). Efectos territoriales, socioeconómicos y legislativos del urbanismo expansivo en Cantabria. In: Gozálvez Pérez, V. \& Marco Molina, J. A. (Coord.). Urbanismo expansivo de la utopía a la realidad. Alicante. 203217.

Giedryś, A. \& Raczyński, J. (2017). Multifunctional hub Łódź Fabryczna. TTS Technika Transportu Szynowego, 9, 9-14.

Loukaitou-Sideris, A., Peters, D., Colton, P. \& Eidlin, E. (2017). A comparative analysis of high-speed rail station development into destination and multi-use facilities: The case of San Jose Diridon. Mineta Transportation Institute, MTI Report 12-75. Retrieved from:

https://scholarworks.sjsu.edu/cgi/viewcontent.cgi?referer=https://www.google.com/\&httpsredir=1\&article=1223\&context=mti_publications [Query: 05 may 2020]

Marquínez, I. (2017). Urban development planning and sustainability: A comparative study of the alternatives to the "Operación Chamartín" (Madrid, Spain). (Unpublished grade dissertation thesis), University of Cantabria, Santander.

Martí-Henneberg, J. (2015). Attracting travellers to the high-speed train: A methodology for com- paring potential demand between stations. Journal of Transport Geography, 42, 145-156.

https://doi.org/10.1016/j.jtrangeo.2014.11.003

Ministerio de Fomento (2018a). Áreas urbanas en España 2018. Constitución, cuarenta años de las ciudades españolas. Retrieved from https://apps.fomento.gob.es/CVP/handlers/pdfhandler.ashx?idpub=BAW058 [Query: 05 may 2020]

Ministerio de Fomento (2018b). Estudio Informativo del soterramiento del ferrocarril en Torrelavega. Retrieved from: https://www.mitma.gob.es/ferrocarriles/estudios-en-tramite/estudios-y-proyectos-en-tramite/torrelavega [Query: 05 mayo 2020]

Ministerio de Fomento (2018c). Estudio Informativo para la Reordenación de Espacios en la Estación de Santander. Retrieved from:

https://www.mitma.gob.es/ferrocarriles/estudios-en-tramite/Estacion-Santander [Query: 05 may 2020] 
Mohino, I., Loukaitou-Sideris, A. \& Urena, J.M. (2014). Impacts of high-speed rail on metropolitan integration: An examination of London, Madrid and Paris. International Planning Studies, 19(3-4), 306-334.

https://doi.org/10.1080/13563475.2014.950638.

Monclús, F. J. \& Oyón, J. L. (1996). Transporte y crecimiento urbano en España, mediados s. XIX- finales s. XX. Ciudad y Territorio, Estudios Territoriales XXVIII, n 107-108, Ministerio de Fomento, 217-240.

Olazábal, E. \& Bellet, C. (2020): Cambios en los modelos de crecimiento urbano de las ciudades medias. Santander-Torrelavega, Manresa, Pamplona/ Iruña y Guadalajara (1987-2011). In: Cebrián, F. (Ed.) Dinámicas de urbanización en ciudades medias interiores: ¿hacia un urbanismo más urbano?, pp. 175-208, Valencia: Triant lo Blanch.

Peters, D. \& Novy, J. (2012). Train Station Area Development Mega-Projects in Europe: Towards a Typology. Built Environment, 38(1), 12-30. https://doi.org/10.2148/benv.38.1.12

Ribalaygua, C. (2004). Evolución de las estrategias de incorporación de la alta velocidad ferroviaria y sus efectos urbanísticos en ciudades medias francesas. Aplicación a los casos españoles (Unpublished doctoral dissertation), Universidad Politécnica de Madrid.

Ribalaygua, C. \& García, F. (2010). HSR Stations in Europe: New Opportunities for Urban Regeneration. 50th Congress of the European Regional Science Association: Sustainable Regional Growth and Development in the Creative Knowledge Economy, 19-23 August, Jönköping, Sweden, European Regional Science Association (ERSA). Retrieved from: https://www.econstor.eu/handle/10419/119181 [Query: 05 may 2020]

Ribalaygua, C. \& Pérez-del-Caño, S. (2019). Assessing spatial planning strategy in high-speed rail station areas in Spain (1992-2018): towards a sustainable model. European Planning Studies, 27(3), 595-617. https://doi.org/10.1080/09654313.2018.1564189

Santos y Ganges, L. (2011). Integrating the train into the city: some thoughts from Spain. Metropolitics, (translated by Eric Rosencrantz), 21 September. Retrieved from: http://www.metropolitiques.eu/Integrating-the-train-intothe.html [Query: 05 may 2020]

Van den Berg, L. \& Pol, P. (1998). The European High Speed Train and Urban Development. Ashgate, Burlington.

Zembri, P. \& Libourel, E. (2017). Towards oversized high-speed rail systems? Some lessons from France and Spain. Transportation Research Procedia, 25, 368-385. https://doi.org/10.1016/j.trpro.2017.05.414

Zemp, S. (2014). Sustainable positioning of railway stations systematic analysis for knowledge integration (Doctoral Thesis), ETH Zurich. https://doi.org/10.3929/ethz-a-007178093 



\title{
DIAGNÓSTICO, DIDÁCTICA Y ATENCIÓN A LA \\ VULNERABILIDAD EN LA PLANIFICACIÓN URBANA DE LOS BARRIOS: \\ EL CASO DE LAS PALMAS DE GRAN CANARIA \\ DIAGNOSIS, DIDACTICS AND ATTENTION TO VULNERABILITY \\ IN THE URBAN PLANNING OF THE NEIGHBORHOODS: \\ THE CASE OF LAS PALMAS DE GRAN CANARIA
}

\author{
Santiago Hernández Torres \\ Universidad de Las Palmas de Gran Canaria \\ Carmen Ginés de la Nuez \\ Universidad de Las Palmas de Gran Canaria \\ María Yazmina Lozano Mas \\ Universidad Internacional del Atlántico Medio
}

Resumen

Esta comunicación expone una valoración de los retos y condicionantes en la planificación urbana en los barrios vulnerables desde el análisis geográfico. Sus objetivos incluyen compendiar y actualizar las principales variables en el diagnóstico y la planificación urbana de los barrios vulnerables y reflexionar sobre el papel de la didáctica ciudadana en la relación entre el proceso de regeneración y sus efectos territoriales. Para ello se propone una metodología de implementación de los Objetivos del Desarrollo Sostenible mediante la cual se obtengan modelos de estrategias transversales y distintas del urbanismo del siglo XX. Los resultados en Las Palmas de Gran Canaria se corresponden con las dificultades de la planificación integrada en estas formaciones residenciales. Es evidente la complejidad en la valoración de la eficacia de las estrategias ante la diversidad y confrontación de problemáticas, expectativas y resultados en la población, en la situación medioambiental, en la herencia histórica. Es oportuna la proliferación de mecanismos didácticos hacia la ciudadanía, reglados y no regladas de interés y una atención a la coexistencia de conjuntos sociales con rasgos demográficos y culturales específicos. La visión integrada de una dimensión territorial, didáctica y regeneradora puede aportar una metodología eficaz en la planificación.

Palabras clave: barrios, ordenación del territorio, vulnerabilidad urbana, agenda urbana, diagnóstico urbano.

\section{Abstract}

This article exposes an assessment of the challenges and conditions in urban planning in vulnerable neighborhoods from the geographical analysis. Its 
objectives include summarizing and updating the main variables in the diagnosis and urban planning of vulnerable neighborhoods and reflecting on the role of citizen education in the relationship between the regeneration process and its territorial effects. To this end, a methodology for the implementation of the Sustainable Development Goals is proposed, through which models of different transversal strategies from urban planning of the 20th century are obtained. The results in Las Palmas de Gran Canaria correspond to the difficulties of integrated planning in these residential formations. The complexity in assessing the effectiveness of strategies in the face of diversity and confrontation of problems, expectations and results in the population, in the environmental situation, in historical heritage is evident. Also, the didactic mechanisms towards citizenship, regulated and unregulated of interest and an attention to the coexistence of social groups with specific demographic and cultural features are appropriate. The integrated vision of a territorial, didactic and regenerative dimension can provide an effective planning methodology.

Keywords: neighborhoods, land use planning, urban vulnerability, urban agenda, urban diagnosis.

\section{INTRODUCCIÓN}

La formulación de los Objetivos del Desarrollo Sostenible, la celebración de la Conferencia de las Naciones Unidas sobre la Vivienda y el Desarrollo Urbano Sostenible (Quito. Octubre de 2016) con su Nueva Agenda Urbana (2017) y la aprobación de su referente en España (Agenda Urbana Española. Febrero de 2019) han añadido un nuevo mecanismo a la planificación y gestión de la ciudad y su entorno.

Pese al tiempo transcurrido esos acontecimientos son plenamente oportunos en un escenario en el que la crisis de la década pasada acrecentó la vulnerabilidad social, ambiental, económica y territorial de los barrios, poniendo en mayor valor si cabe las estrategias de regeneración urbana.

Las ciudades españolas aglutinan un buen número de experiencias. Más de un centenar de proyectos se encuentran en estos momentos desarrollando la Estrategia de Desarrollo Urbano Sostenible e Integrado con esa perspectiva y, desde el ámbito científico-académico, ha arreciado la aparición de proyectos de investigación que aporten luz a un complejo galimatías de variables, casuística e indicadores que actualmente conforma uno de los principales retos de la Geografía Urbana y el Urbanismo.

Los autores hemos venido desarrollando en la última década una línea de trabajo e investigación con la que se ha pretendido defender la hipótesis de que los barrios son realidades específicas y fundamentales en la comprensión de la ciudad en conjunto; realidades que no pueden abordarse desde la 
sesgada intervención edificatoria y urbanizadora, sino desde un tratamiento integrado de las múltiples capas que protagonizan y dan forma a estas formaciones residenciales.

En ese esfuerzo, la presente comunicación persigue ahondar en la estructura de diagnóstico sobre la que se soporta la toma de decisiones en el planteamiento estratégico de la regeneración; concepto éste que consideramos básico en su delimitación frente a otros más comunes como reposición, rehabilitación, renovación, etc.

Los objetivos incluyen, desde la preceptiva limitación de contenidos en este documento, proponer una estructura de variables en el diagnóstico de los barrios, compendiar las líneas estratégicas de la planificación urbana y reflexionar sobre el papel de la didáctica ciudadana en la relación entre el proceso planificador y sus efectos territoriales.

Seleccionamos el caso de Las Palmas de Gran Canaria por constituir un correcto laboratorio para estos fines ante el importante dinamismo que ha existido durante los últimos años en esta ciudad en el ámbito de la regeneración de los barrios, en la diversa casuística de los acontecimientos y en la revitalización de la participación ciudadana en el proceso, sumando entre todos estos aspectos un volumen nada desdeñable de información crítica.

Nos interesa en definitiva sintetizar el estado actual de este tema y su enriquecimiento con la potencial implementación de la Agenda Urbana Española y la transversalidad de variables de los Objetivos del Desarrollo Sostenible como paradigma en vigor.

\section{DELIMITACIÓN CONCEPTUAL Y PILARES DE LA METODOLOGÍA}

El artículo centra su atención en los mecanismos para definir una estructura metodológica en el reconocimiento de la vulnerabilidad territorial de los barrios y el establecimiento propositivo de la respuesta a la misma como premisa para la regeneración urbana y la consecución de los anteriores Objetivos. Estamos ante un concepto con apreciable desarrollo en su delimitación (Alguacil, Camacho y Hernández, 2014, 77). Su definición ha venido siendo utilizada por el actual Ministerio de Transportes, Movilidad y Agenda Urbana en la habilitación de herramientas que son hitos en esta temática: el proyecto sobre La Desigualdad Urbana en España (Arias, 2000), el Análisis Urbanístico de los barrios vulnerables (Ministerio de Fomento, 1991, 2001, 2006 y 2011) o, por último, el Observatorio de Barrios Vulnerables (Ministerio de Fomento, 2020). Incluyendo acepciones más específicas en materia de riesgos, de situaciones sociales o desigualdad económica, proponemos implementar este concepto en la visión del dinamismo urbano que expusimos en el apartado anterior, lo cual conlleva ampliar su alcance. De ese modo, entendemos la vulnerabilidad territorial de los barrios como la cualidad de ese espacio urbano en que el conjunto de su situación o determinados rasgos y condiciones motiven la sus- 
ceptibilidad para reducir, obstaculizar o impedir su desarrollo sostenible e integrado, teniéndose como mecanismo de respuesta la regeneración urbana. Esa regeneración y la estructura del diagnóstico integrado como soporte al desarrollo de estrategias a definir en la planificación y gestión urbana son dos elementos cruciales en nuestra línea de trabajo.

Ante el requerimiento de síntesis en este documento, consideramos oportuno subrayar algunos aspectos sobre dichos elementos con vistas a una adecuada comprensión de las reflexiones que proponemos en este Coloquio. La regeneración urbana tal como hoy la entendemos es un concepto que supera en amplitud temática y alcance a otros que se habían convertido en acepciones obligadas durante los procesos de planificación de la ciudad de finales del siglo XX: rehabilitación urbana, renovación urbana, revitalización urbana, remodelación urbana, intervención urbana, etc.

Iniciado el siglo XXI, varios autores nos delimitan este concepto como un desarrollo integrado de acciones que desde la exhaustividad en el tratamiento de las variables implicadas conduce a la resolución de los problemas urbanos, «buscando una solución perdurable en ámbitos económicos, físicos, sociales y ambientales» del barrio sujeto a transformación (Roberts y Sykes, 2000, 15). Con la Declaración de Toledo (Consejo de la Unión Europea, 2010) se consolida en el mundo del Urbanismo la «regeneración urbana integral» como horizonte de referencia en las estrategias públicas de transformación o mejora de las áreas residenciales. Se concibe como un proceso planificado que trasciende los ámbitos y enfoques parciales hasta ahora habituales para abordar la ciudad como totalidad funcional y sus partes como componentes del organismo urbano, con el objetivo de desarrollar plenamente y de equilibrar la complejidad y diversidad de las estructuras sociales, productivas y urbanas, impulsando al mismo tiempo territorio ecoeficiente, sostenible, inteligente e inclusivo (Consejo de la Unión Europea, 2010, 7).

Este acontecimiento derivó en un nuevo acontecimiento que participa en la actualidad del marco conceptual en la materia: la estrategia de desarrollo urbano sostenible e integrado.

Apoyado en el papel financiador de los fondos comunitarios FEDER, varios centenares de proyectos estratégicos en las ciudades españolas continúan la herencia de los programas URBAN.

Sin embargo, con un matiz de interés en el discurso que proponemos en esta comunicación. Frente al esfuerzo centrado en las obras de rehabilitación de los barrios degradados en la etapa precedente (construcción o rehabilitación de nuevos equipamientos, reurbanización del espacio de movilidad, mejora o acondicionamiento paisajístico-medioambiental, etc), ahora observamos una intencionalidad integradora del espacio urbano en una perspectiva transversal en las variables implicadas.

La aportación al concepto implícito de regeneración urbana incluye con un protagonismo ineludible capítulos que eran ignorados o marginalizados a fi- 
nales del siglo XX: metabolismo urbano, transición energética, cambio climático, procesos participativos, dinamización social de barrios, movilidad sostenible, gestión de la igualdad e inclusividad en el espacio urbano, universalización del disfrute en el espacio público con atención especial a la población vulnerable o calidad ambiental.

El escenario en el que se desarrolla este contexto es el barrio como entidad urbana que desde el punto de vista del análisis geográfico juega un papel imprescindible en toda configuración y dinamismo de la ciudad.

Estamos ante una pieza del puzzle urbano con una configuración integral homogénea, que en si misma constituye una unidad identificativa en la percepción de la ciudad. A partir de una morfología física y una exposición paisajística distinguible respecto a su entorno, refleja las características y modos de vida de sus pobladores y proporciona a sus vecinos identidad y puntos de referencia dentro de la población. Por ello, el patrimonio ambiental y cultural es un pilar básico en su concepción espacial. Constituye un lugar de vida, de actividades, de relaciones y de construcción de unas señas de identidad colectiva, la cual muchas veces se expresa en el propio nombre del barrio (ADUAR, 2000, p. 46).

Como ya comentamos en una comunicación precedente (Hernández, Ginés y Lozano, 2018, 3), es una unidad territorial dinámica que resulta de una evolución cronológica en el proceso de ocupación humana y de configuración de la ciudad. Tiene su origen en el acto genérico y espontáneo de la residencia, producción, actividad económica u otro uso por parte de la población en un enclave determinado.

Dicha evolución ha ido perfilando la configuración del barrio de acuerdo a los criterios, pautas y estrategias de cada período temporal; evolución que ha permitido conservar su fisonomía tradicional en el contexto genérico de la ciudad. Este tipo de características conduce a unidades urbanas bien diferenciadas en su forma, distinguiendo las que podemos considerar como parte del casco antiguo, de las diversas modalidades de ensanche, de la variedad de ejemplos de autoconstrucción, de procesos planificados en polígonos o del fenómeno de ciudad jardín (Capel, 2002).

Este concepto de barrio es implícito al diagnóstico de su desarrollo urbano sostenible e integrado y, por tanto, participa de modo troncal en nuestra propuesta de investigación. Se implementa a la valoración de las vulnerabilidades, conflictos y potencialidades en la ciudad residencial a través de una metodología de diagnóstico con un ADN basado en la transversalidad y la multidimensionalidad de las variables y sus indicadores.

Es un diagnóstico que se estructura en tres dimensiones fundamentales que se conforman integradas entre sí y dependientes una de las otras en todo objetivo de conocer la compleja realidad en un barrio, a saber:

- Dimensión territorial.

- Dimensión didáctica. 
- Dimensión regeneradora.

De una parte, la dimensión territorial conforma el escenario más tradicional del análisis geográfico de la ciudad, con independencia de que requiera una constante actualización y adaptación al dinamismo de los paradigmas que definen la ciudad y su apropiación residencial.

El esfuerzo continúa dirigiéndose hacia el reconocimiento de la configuración o forma y su expresión estética, el dinamismo con sus factores, variables y condicionantes, los flujos o relaciones que dan visibilidad a la situación y caracterización del barrio como subsistema específico en la urbe. Seguimos dando especial valor a las infraestructuras de datos espaciales y los sistemas de información geográfica, los mecanismos cualitativos y cuantitativos en la lectura del espacio y las múltiples herramientas de observación y evaluación del mismo.

De otra parte, la dimensión didáctica se corresponde con los rasgos y acontecimientos del proceso analítico de los barrios que muestran la obtención de información y la implicación de la población y los agentes sociales que protagonizan el dinamismo de dichas unidades espaciales.

En esa interacción cobra especial interés el esfuerzo en el aprendizaje mutuo (científico-técnico y ciudadano) en la forma de reconocimiento y concepción del espacio, sus características, sus valores y sus desequilibrios.

El proceso participativo adquiere aquí la condición de problema para la Geografía y la Ordenación del Territorio, en el que son necesarios los mecanismos de didáctica del espacio urbano, de acontecimientos para el acopio de información «no oficial» y de objetivación del carácter mayoritariamente cualitativo en la implicación «ciudadana» en el diagnóstico y la atención a la vulnerabilidad.

Una tercera dimensión se corresponde con lo que proponemos considerar el conjunto de acciones, determinaciones y decisiones que conforman la dimensión regeneradora. Viene a ser la respuesta a la situación, comportamientos y expectativas que aglutinan estas formaciones residenciales en su diversa y compleja casuística de escenarios, condicionantes y prioridades. Las técnicas propositivas en el diseño del espacio físico y el cualitativo, así como en el de la regeneración urbana tienen su papel determinante. Las habilidades de la ciencia geográfica coexisten necesariamente con la urbanística y de gestión de la ciudad, con el trabajo social y la intervención comunitaria, con el derecho y las restantes ciencias sociales, con las asociadas al patrimonio natural y cultural, entre otras.

Se hace necesario entonces optimizar el potencial integrador de la geografía y la ordenación del espacio urbano, junto con otras habilidades científicas. A modo de muestra, en el trabajo que aquí sintetizamos es especialmente clarificador el enriquecimiento en materia de gestión del patrimonio cultural o de la didáctica de las ciencias sociales sobre la ciudadanía en general. 


\section{RESULTADOS DE LA INVESTIGACIÓN. EL ANÁLISIS GEOGRÁFICO DE LA VULNERABILIDAD Y LA REGENERACIÓN URBANA}

\subsection{LA DIMENSIÓN TERRITORIAL. EL DIAGNÓSTICO TÉCNICO}

El ecosistema del trabajo geográfico ha consolidado un conjunto de herramientas y técnicas para el análisis del espacio urbano que tiene una base empírica basada en los datos estadísticos oficiales, la recopilación informativa a través del trabajo de campo, su ponderación o interpretación mediante métodos cuantitativos y cualitativos, su gestión a través de los sistemas de información geográfica o la aplicación de experiencias afines al ámbito de observación; todo ello dinamizado mediante un bagaje científico de la geografía urbana y la ordenación del territorio en constante producción y renovación.

Excepto en necesidades informativas de la escala de detalle para algunos barrios y zonas, la disponibilidad metodológica en general no suele ser un problema en las ciudades españolas y europeas atendiendo al destacado volumen de técnicas, variables e indicadores de reconocimiento y valoración del espacio urbano (Blanco y Nel.lo, 2018, 19).

El mismo Grupo de Geografía Urbana que coorganiza este Coloquio, junto con el de Geografía de la Población y otros de la Asociación de Geógrafos Españoles ha ido disponiendo una extensa biblioteca de monografías, de actas de congresos precedentes o de trabajos concretos en el conocido Boletín de la AGE. Las principales universidades españolas han ido conformando grupos de investigación cuya productividad científica suma igualmente un importante bagaje de respuesta. Las administraciones locales en las principales ciudades se han acompañado, o lo hacen ahora, de proyectos, observatorios y herramientas que tienen un papel directo en la eficacia en la gestión y planificación urbana reciente. Y la literatura científica especializada, incluida la virtual, ha continuado su riquísima aportación en la globalidad de la temática que abordamos o en aspectos concretos de la misma.

Claro, la constante evolución de los comportamientos e interpretaciones de la ciudad trae como resultado frecuentes incertidumbres en las concretas necesidades de información sobre la vulnerabilidad. La respuesta suele ser rápida en forma de proyectos de investigación desde el ámbito comunitario, estatal, autonómico, universitario e, incluso, local.

Entonces, la dimensión territorial como pilar del tratamiento de la vulnerabilidad de los barrios desde la planificación urbana tiene una base conceptual y metodológica bien nutrida. El problema está en la amplitud de las opciones y la adaptación a las especificidades de cada formación urbana.

Hemos tenido la oportunidad de participar en la formulación de sendos planes especiales de rehabilitación de los 4 barrios tradicionales en riscos de Las Palmas de Gran Canaria (San Francisco-San Nicolás, San Roque, San Juan, San José), en el plan especial de protección del centro histórico y en el de su 
ensanche (Vegueta-Triana y Perojo, respectivamente), en el plan parcial de renovación-reposición de un barrio con función originaria de vivienda pública en bloques y con una destacada vulnerabilidad ambiental, social y funcional (Las Rehoyas), en la Estrategia de Desarrollo Urbano Sostenible e Integrado (EDUSI) de la ciudad en los barrios del Cono Sur. En todos los casos, ha sido necesaria la singularización metodológica en el diagnóstico atendiendo a una realidad territorial propia o a las particularidades de la regeneración prevista. Es una definición a la carta en la que, no obstante, el bagaje disciplinar antes sintetizado nos ha permitido proponer una estructura de capas o bloques básicos en que se desgrana la situación territorial de los barrios como entidad genérica. Podemos relacionar dichos bloques de siguiente modo:

- Bloque 1. Estructura morfológica y urbanística.

- Bloque 2. Estructura social.

- Bloque 3. Estructura residencial.

- Bloque 4. Estructura dotacional.

- Bloque 5. Estructura de tejido económico.

- Bloque 6. Estructura de calidad ambiental.

- Bloque 7. Estructura de movilidad

Figura 1. Ejemplo de expresión de la dimensión territorial. Resumen cartográfico en San Juan-San José
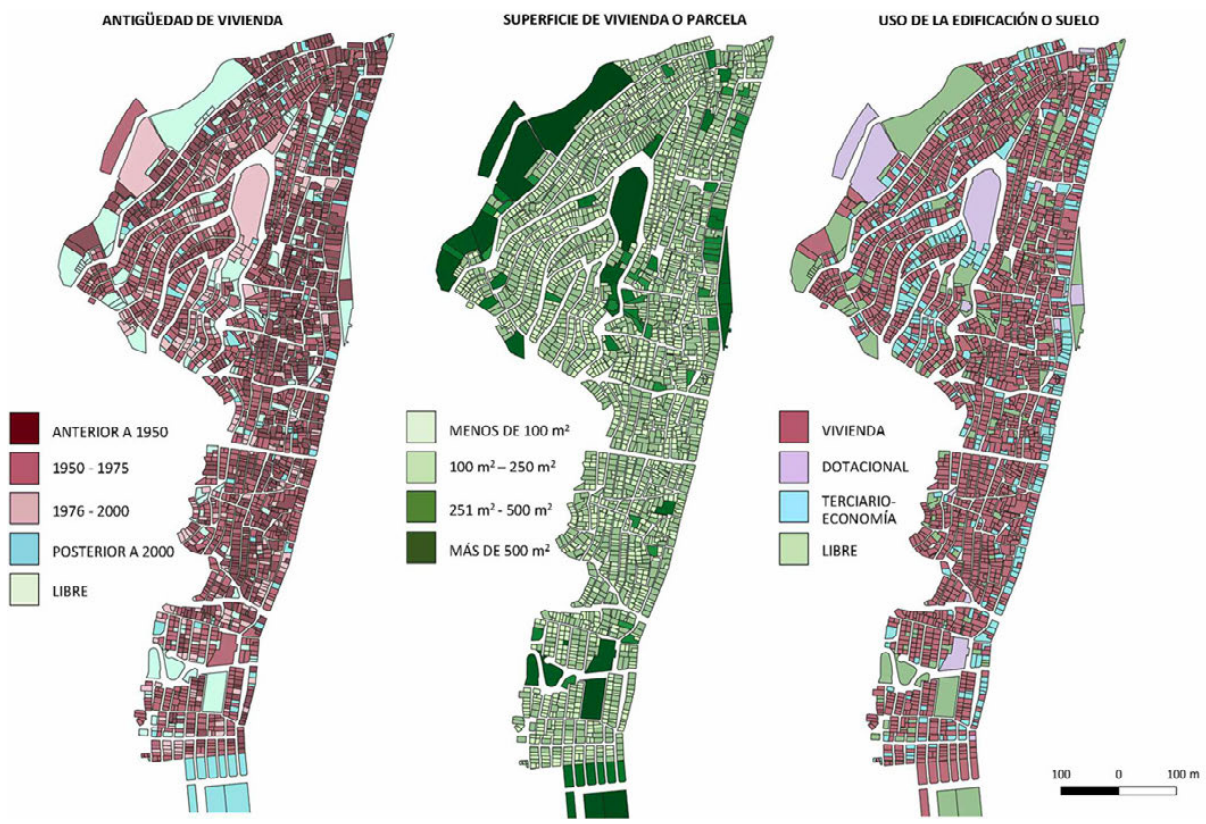

Fuente: Elaboración propia a partir del Catastro 
Tabla 1. Ejemplo de expresión de la dimensión territorial.

Resumen demográfico en los Riscos

\begin{tabular}{|c|c|c|c|c|c|}
\hline & $\begin{array}{c}\text { Las Palmas } \\
\text { G.C. }\end{array}$ & $\begin{array}{c}\text { San } \\
\text { Nicolás }\end{array}$ & $\begin{array}{c}\text { San } \\
\text { Roque }\end{array}$ & $\begin{array}{c}\text { San } \\
\text { Juan }\end{array}$ & San José \\
\hline Población en 2010 & 383.308 & 2.644 & 2.895 & 2.844 & 4.617 \\
\hline Población en 2019 & 379.959 & 2.489 & 3.042 & 2.665 & 4.286 \\
\hline Diferencia 2000-2019 & $-1,5 \%$ & $-5,9 \%$ & $+5,0 \%$ & $+6,3 \%$ & $-7,2 \%$ \\
\hline $\begin{array}{c}\text { Densidad poblacional } \\
\text { (hab./km })\end{array}$ & 10.850 & 15.306 & 18.300 & 16.750 & 19.272 \\
\hline $\begin{array}{c}\text { Población con } \\
\text { más de 74 años }\end{array}$ & $7,4 \%$ & $9,3 \%$ & $10,1 \%$ & $9,1 \%$ & $8,9 \%$ \\
\hline $\begin{array}{c}\text { Renta media por } \\
\text { persona en 2017 }\end{array}$ & $11.365 €$ & $7.654 €$ & $8.877 €$ & $7.692 €$ & $8.334 €$ \\
\hline $\begin{array}{c}\text { Renta media por } \\
\text { hogar en 2017 }\end{array}$ & $31.172 €$ & $20.779 €$ & $25.272 €$ & $20.743 €$ & $23.567 €$ \\
\hline
\end{tabular}

Fuente: Instituto Nacional de Estadística

\subsection{LA DIMENSIÓN DIDÁCTICA. EL ACERCAMIENTO CIUDADANÍA-PLANIFICACIÓN URBANA}

La ordenación del territorio como disciplina ha demostrado ser una forma de dotar a la población de las herramientas necesarias para observar, comprender e interpretar el barrio, el espacio urbano y su vulnerabilidad. Se activan un conjunto de herramientas y generan una serie de actividades que conducen a la producción de una valiosísima información. La clave se manifiesta en poner especial énfasis en acercar a las vecinas y vecinos a una adecuada comprensión de los pilares básicos de reconocimiento territorial, de diagnóstico empírico-objetivo y de toma de decisiones desde una estructura de prioridades, marco jurídico y urgencias. Lo concebimos como una dimensión didáctica del proceso planificador.

Su condición de servicio público se desarrolla a través de criterios estructurantes de la ordenación y de puesta en escena de un entorno con unas cualidades identitarias. Y éstas justifican el arraigo en el espacio como formación social, a partir del cual incentiva la valorización como factor de calidad de vida y bienestar. En este proceso, la participación de la población ha crecido en complejidad, casuística de condicionantes y experiencias con diversa eficacia y eficiencia, en función de factores como la oferta institucional, la capacidad 
organizativa de la sociedad y los rasgos estructurales del espacio (Manero, 2011, 61).

La crítica constructiva la situamos en la ineficiencia de la comunicación entre la Administración promotora y gestora en lo jurídico, por una parte, y la ciudadanía o estamentos educativos, por otra. No ha sido suficiente la constante exposición en Internet junto con toda la complejidad documental del planeamiento. Entonces, podemos hacer énfasis en la falta de mecanismos específicos de integración en el proceso formativo de la población. La cuestión es a quien corresponde ese esfuerzo. ¿Sólo al Ayuntamiento?

El sistema educativo oficial of rece dos áreas del conocimiento y la formación que pueden tener un papel activo en la complementación de ese objetivo: las Didácticas Especiales, a través de la Didácticas de las Ciencias Sociales (Geografía e Historia) y la Geografía y Ordenación del Territorio.

Su cometido en las aulas está lleno de contenidos, herramientas, métodos, criterios que pueden ser una oportunidad para su aplicación fuera del recinto docente y extender el alcance de la población destinataria a los vecinos en los barrios, quienes tienen o pueden tener en el paisaje y su entorno un recurso para su bienestar (calidad ambiental, identidad, ocio y esparcimiento, saludabilidad, memoria geográfica, desarrollo local, etc).

Existe un escenario propicio para multiplicar la aportación de la Universidad a la sociedad en este aspecto; pero también una necesidad de constante mejora, innovación y respuesta a los condicionantes. El presente Coloquio es sin duda un mecanismo adecuado en esa línea.

Dentro de ese esfuerzo, varios trabajos nos han demostrado el interesante alcance de esta interacción: «Urbanismo para Todos. La Isleta» (Hernández, Ginés y Lozano, 2017), vinculado a la convocatoria municipal de los presupuestos participativos, $\mathrm{y}$ «Barrios Pendientes» (Ayuntamiento de Las Palmas de Gran Canaria, 2018-2019), vinculado a la renovación de los planes especiales de ordenación de los barrios en riscos.

El planteamiento nos recuerda al objetivo de formar al vecino de modo que pueda concebir el barrio o la ciudad como espacio con el que se identifica, comprender su dinamismo y definir mejoras eficaces para su futuro (Alderoqui, 2002,24$)$.

Sistematizamos las variables y mecanismos de evaluación del espacio y la vulnerabilidad a partir de la percepción de la población; en especial en cuanto al papel de la gestión pública y la planificación urbana. Es un programa de acciones a pie de calle y su objetivo principal es dinamizar un proceso didáctico del espacio urbano y la ordenación del territorio en un escenario social de limitada comprensión de los entresijos técnicos del urbanismo y la toma de decisiones sobre su espacio cotidiano.

Se prioriza la esquematización del espacio urbano y su funcionamiento en términos de comprensibilidad y análisis por los vecinos. Y con ello se acercan los mecanismos de objetividad y eficacia en la definición vecinal de las po- 
tencialidades y debilidades del barrio, y la viabilidad-oportunidad de las soluciones.

La experiencia científica, profesional y bibliográfica acumulada durante las últimas décadas nos permite disponer de una extensa base empírica sobre la que estructurar un proceso de formación fuera de las aulas universitarias y educativas. Es imprescindible un continuado esfuerzo de formación, innovación y reciclaje de ese conocimiento que debe rebasar los límites del mundo científico para ayudar a la población a entender estas cuestiones técnicas, ofrecerle un servicio público que afiance la comprensión del espacio en que vive y, de paso, beber de su conocimiento sobre la vida en su entorno cotidiano.

No olvidemos que el vecino es un potencial experto en su territorio doméstico, siendo capaz de entender la complejidad de sus rasgos y funcionamientos, los factores, las tendencias de desarrollo futuro. La perspectiva desde la Geografía centra ese esfuerzo en la capacidad de síntesis del espacio y sus elementos, de diagnóstico, de planteamiento de estrategias y prioridades, de evaluación de las actuaciones y determinaciones resultantes y, en definitiva, percibir la sostenibilidad, los equilibrios, las vulnerabilidades y las potencialidades de la ciudad o el barrio.

A partir de un sondeo de comprobación del grado de conocimiento del entorno cotidiano y la concepción e impronta de su vulnerabilidad, el uso de fichas, ortoimágenes, mapeados e imágenes propias del análisis geográfico se guio el proceso comprensivo a partir de una serie de fases y variables de referencia que sintetizamos en la Figura 2.

Figura 2. Fases y variables del proceso en la dimensión didáctica

Acercamiento vecinal a los expertos. Intercambio / Recopilación de referencias

Reconocimiento. EI barrio y su paisaje

- Estructura morfológica y urbanística - Estructura social

- Estructura del conjunto edificado

- Estructura de dotaciones y equipamientos Disfrute del paisaje y el espacio público

- Estructura de tejido económico

- Estructura de calidad ambiental - Estructura de movilidad
Concreción de valores y fragilidades

- Patrimonio natural. Hitos ambientales

- Patrimonio arquitectónico. Monumentos.

- Patrimonio arqueológico.

- Patrimonio social y etnográfico.

TIEMPO / FORMA / IMPRONTA 
Figura 2 (continuación). Fases y variables del proceso en la dimensión didáctica

Acercamiento vecinal a los expertos. Intercambio / Recopilación de referencias

Diagnóstico. Problemas y potencialidades

- Identificación. Concreción. Caracterización.

- Elementos espaciales afectados.

- Cualidades vulnerables.

- Relación con otros problemas. / Intensidad.

- Reversibilidad de los efectos.

- Alcance temporal.

- Alcance espacial.

- Urgencia, prioridad

\section{Mis soluciones para el barrio}

- Identificación. Concreción. Caracterización

- Estímulo. Objetivo. Problema a resolver.

- Viabilidad legal. Consulta a servicios técnicos y públicos.

- Titularidad del suelo.

- Prioridad.

- Referencias de viabilidad económica.

- Impacto previsto.

- Seguimiento, criterios de gestión posterior.

\begin{tabular}{|c|c|c|c|}
\hline $\begin{array}{l}\text { Calidad ambiental / } \\
\text { Riesǵos }\end{array}$ & $\begin{array}{l}\text { Estruetura } \\
\text { urbana }\end{array}$ & Vivienda & $\begin{array}{l}\text { Espacio público / } \\
\text { Equipamientos }\end{array}$ \\
\hline $\begin{array}{l}\text { > Paisaje. } \\
\text { > Laderas / orografía. } \\
\text { > Residuos / limpieza. } \\
\text { > Bco. Guiniguada. } \\
\text { > Zonas verdes. }\end{array}$ & $\begin{array}{l}\text { > Barrio pendiente. } \\
\text { > Trama abigarrada. } \\
\text { > Relación con la ciudad. } \\
\text { > Barrio tradicional. } \\
\text { > Espacios de oportunidad. }\end{array}$ & $\begin{array}{l}\text { > Casas terreras. } \\
\text { > Abandono/ ruinas. } \\
\text { > Arquitectura humilde. } \\
\text { > Focos de infraviviendas. } \\
\text { > Habitabilidad. }\end{array}$ & $\begin{aligned} \text { > Enclaves de ocio y deporte. } \\
\text { > Equipamientos } \\
\text { no desarrollados. } \\
\text { > Parques, plazas, rincones. } \\
\text { > La calle como espacio cívico. } \\
\text { > Cologios / polivaloneia do uso. }\end{aligned}$ \\
\hline $\begin{array}{l}\text { Movilidlad } \\
\text { > Ladera / pendiente. } \\
\text { > Accoso do vohículos / parking. } \\
\text { > Transporto público / sorvicios. } \\
\text { > Rocorridos peatonalos } \\
\text { > Accosibilidad vortical } \\
\text { para todos. }\end{array}$ & $\begin{array}{l}\text { Emprendiduría / } \\
\text { Desarrollo local } \\
\text { > Tejido de comercios } \\
\text { y sorvicios. } \\
\text { > Emploo local. } \\
\text { > Turismo. } \\
\text { > Emprondiduría / formación. } \\
\text { > Rocursos comunitarios. }\end{array}$ & $\begin{array}{l}\text { Cultura / } \\
\text { Comunidad } \\
\text { > Recursos / locales polivalentes. } \\
\text { > Arte / artosanía local. } \\
\text { > Cohosión social / Urbanismo } \\
\text { para atonder la pobroza. } \\
\text { > Clubes / formaciones socialos. } \\
\text { > Hitos do idontidad. }\end{array}$ & $\begin{array}{l}\text { Historia / } \\
\text { Patrimonio } \\
\text { > Castillos. } \\
\text { > Iglosias y ormitas históricas. } \\
\text { > Patrimonio otnográfico. } \\
\text { > Arquitoctura singular. } \\
\text { > Routilización / rohabilitación. }\end{array}$ \\
\hline
\end{tabular}

\section{Fuente: Elaboración propia}

En estas formaciones sociales, el carácter reivindicativo, la constante búsqueda de una ciudad mejor, el especial cariño a su paisaje y los valores ambientales del entorno o el instinto integrador de culturas e inquietudes explican su continua vigilancia sobre las estrategias y el esfuerzo planificador que busque introducir nuevos ingredientes al barrio. Se requiere del esfuerzo didáctico y del de aprendizaje, por cuanto se precisan canales y herramientas adecuadas para complementarlos de manera eficaz. Más allá de las obligaciones legales que empiezan a consolidarse en los instrumentos en materia del suelo y ordenación del territorio en Canarias, los procesos participativos son una herramienta ya indispensable en la geografía y en la regeneración urbana. El individuo debe manifestarse como observador interesado en su entorno y en su valorización, para convertirse en vecino y en parte de un colectivo que decide cómo quiere que sea su entorno cotidiano (Pérez y Rodríguez, 2007, 218). 


\subsection{LA DIMENSIÓN REGENERADORA. LA RELEVANCIA DE LAS ALTERNATIVAS DE ORDE- NACIÓN}

El tratamiento de la vulnerabilidad urbana en los barrios incluye un tercer conjunto de acontecimientos relacionados con la observación del espacio y que se encuentra estrechamente imbricado con los anteriores. No se entiende uno sin los otros. Se corresponde con la dimensión regeneradora, en tanto aglutina la materialización territorial o documental de una estrategia a través de la que se responde a los objetivos de un desarrollo urbano sostenible e integrado en un horizonte temporal que permita la consecución de los mismos y la consideración de las expectativas sociales.

El papel de la geografía y la ordenación del territorio se observa especialmente en responder a la compleja casuística observada en las otras dimensiones del proceso, a través de la propuesta de diversos modelos o escenarios en los que observar los potenciales resultados de regeneración: las alternativas de ordenación.

Algunos compendios muestran la diversidad de circunstancias y soluciones, reforzando la necesaria adaptación a las condiciones particulares de cada ámbito y elementos protagonistas, si bien tipificados en modelos de referencia (Aparicio y Di Nanni, 2011).

Podemos considerarla como la documentación de un escenario territorial que resulta del interés por observar posibles formas de implementar las determinaciones, actuaciones y medidas que hagan posible el cumplimiento o materialización de los objetivos de regeneración urbana, cuya selección implica al capítulo disciplinar de la evaluación ambiental y territorial. Incorporan las cualidades y condicionantes que emanan de las dimensiones territorial y didáctica. De este modo, rasgos relacionados con el consenso, la transversalidad de las variables, la forma en que se plasman los objetivos del desarrollo sostenible son factores que engrosarán la carga cualitativa de las distintas alternativas. Un ejemplo instructivo podemos sintetizarlo en la evaluación ambiental estratégica del proceso de reposición del barrio de Las Rehoyas, un conjunto residencial de vivienda en bloque surgido a mediados del siglo XX con múltiples problemas estructurales en sus elementos urbanos y un trasfondo social y ambiental con alta carga de vulnerabilidad. 
Figura 3. Ejemplo de alternativas evaluadas en un proceso de regeneración urbana
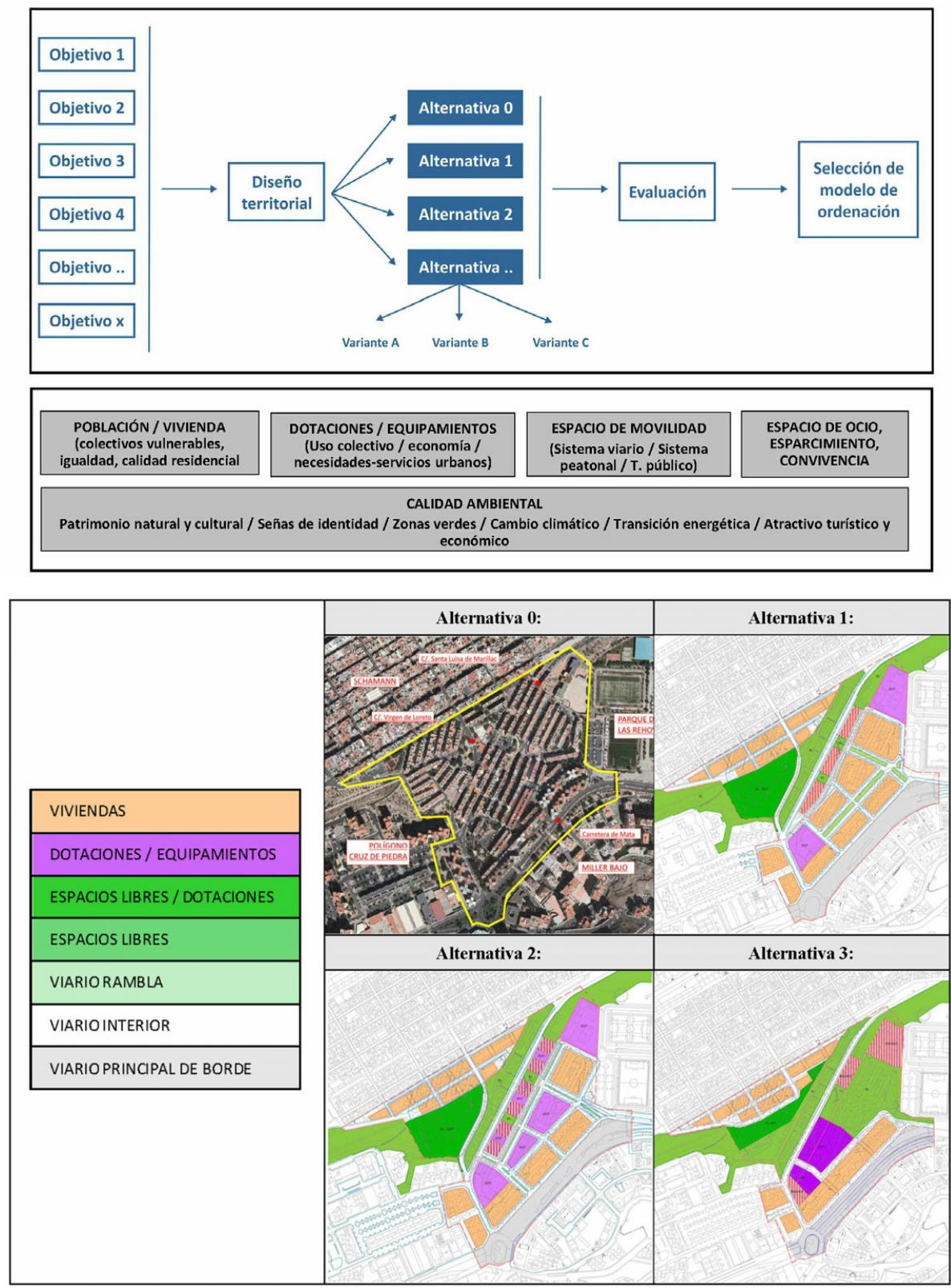

Fuente: Plan Parcial de Las Rehoyas-Arapiles.

Ayto. de Las Palmas de Gran Canaria. 2019 


\section{CONCLUSIONES}

El tratamiento de la vulnerabilidad y la regeneración urbana es un tema de especial interés en la conceptualización teórica de la ordenación del territorio y geografía como disciplinas profesionales que sirven a la población y le propician unos niveles de calidad ambiental e identidad con el entorno.

Sin embargo, ha existido una escasa preocupación desde el análisis geográfico sobre esta cuestión, al menos desde una escala local adaptada a las actuaciones y demandas concretas de la ciudadanía. La implicación en los procesos de participación ciudadana, en la gestión de la información analítica o en el diseño de indicadores y escenarios de percepción sobre el paisaje son deficiencias que consideramos inaceptables.

A través del ejemplo de Las Palmas de Gran Canaria, hemos observado como la ordenación urbanística de la ciudad y los barrios es un mecanismo de dotación a la población de las herramientas necesarias para observar, comprender e interpretar el desarrollo urbano sostenible e integrado que conduce a su bienestar.

Su condición de servicio público se desarrolla a través de criterios estructurantes de la ordenación y de puesta en escena de un entorno con unas cualidades identitarias. Las mismas justifican el arraigo en el espacio como formación social, a partir del cual incentiva la valorización como factor de calidad de vida y bienestar.

Desde el alcance sintético del presente documento, hemos podido cubrir los objetivos previstos. Entendemos de interés la propuesta de un tratamiento «geográfico» de la regeneración de los barrios desde un enfoque basado en la estructura integrada de una dimensión territorial, otra didáctica-participativa y otra regeneradora-evaluadora.

Es un esquema que a través de la experiencia de los autores ha observado una destacada implicación de los especialistas y los mecanismos del análisis geográfico de la ciudad y su acompañamiento por las ciencias sociales.

Existe un buen conjunto de expectativas sobre la continuidad y productividad del proceso en los próximos años, aprovechando sin duda el destacado volumen de reflexiones desde este Coloquio.

\section{BIBLIOGRAFÍA}

ADUAR (2000). Diccionario de Geografía Urbana, Urbanismo y Ordenación del Territorio, Barcelona: Ariel.

Alderoqui, S. (2002). Enseñar a pensar la ciudad. Ciudad y ciudadanos. Aportes para la enseñanza del mundo urbano. Buenos Aires: Paidós.

Alguacil, J., Camacho, J., y Hernández, A. (2014). La vulnerabilidad urbana en España. Identificación y evolución de los barrios vulnerables. EMPIRIA. Re- 
vista de metodología de las Ciencias Sociales. N²7. 73-94. Recuperado de: http://revistas.uned.es/ index.php/empiria/article/view/10863

Aparicio, A., y Di Nanni, R. (2011). Modelos de regeneración urbana. Madrid: SEPES. Arias, F. (2000). La desigualdad urbana en España. Madrid: Ministerio de Fomento.

Ayuntamiento de Las Palmas de Gran Canaria (2018 y 2019). Jornadas Abiertas de Participación Vecinal "BARRIOS PENDIENTES». Ordenación y rehabilitación urbana de barrios en riscos. Memoria de resultados. Las Palmas de Gran Canaria.

Blanco, I., y Nel·lo, O. (2018). Barrios y crisis. Crisis económica, segregación urbana e innovación social en Cataluña. Barcelona: Tirant Humanidades

Capel, H. (2002). La morfología de las ciudades. Sociedad, cultural y paisaje urbano. Barcelona: Serbal.

Consejo de la Unión Europea (2010). Reunión Informal de Ministros del Desarrollo Urbano. Declaración. Toledo. Recuperado de:

https://www.mitma.gob.es/ recursos_mfom/pdf/8343F582-2844-4F9CBDEF-4C2E2AFC547C/111530/6_declaracion_Toledo.pdf. [Consulta: 14 de enero de 2020].

Hernández, S., Ginés, M ${ }^{a}$ C. y Lozano, Mª Y. (2017). Taller didáctico «Urbanismo para Todos. La Isleta». Ayuntamiento de Las Palmas de Gran Canaria.

Hernández, S., Ginés, $M^{a}$ C. y Lozano, $M^{a}$ Y. (2018). Barrios tradicionales y espacio público: Usos y potencialidades en los Riscos de Las Palmas de Gran Canaria. XXII Coloquio de Historia Canario-Americana. Recuperado de https://mdc.ulpgc.es/ digital/document/content/coloquios_2413/40. [Consulta: 10 de diciembre de 2019].

Manero, F. (2011). La participación ciudadana en la Ordenación del Territorio. Posibilidades y limitaciones. Cuadernos Geográficos. N 47. 47-71. Recuperado de https://revistaseug.ugr.es/index.php/cuadgeo/article/view/601

Ministerio de Fomento (1991, 2001, 2006, 2011). El análisis urbanístico de los barrios vulnerables. Madrid. Recuperado de:

https://www.mitma.gob.es/areas-de-actividad/arquitectura-vivienda-ysuelo/urbanismo-y-politica-de-suelo/observatorio-de-la-vulnerabilidad-urbana/analisis-urbanistico-de-barrios-vulnerables. [Consulta: 3 de febrero de 2020].

Ministerio de Fomento (2020). Observatorio de barrios vulnerables. Madrid. Recuperado de https://apps.fomento.gob.es/barriosvulnerables. [Consulta: 3 de febrero de 2020].

Pérez, A. y Rodríguez, L. (2007). Ciudadanía a través del reconocimiento de la ciudad. Didáctica Geográfica, № 9, 215-232. Recuperado de:

http://www.age-geografia.es/didacticageografica/index.php/didacticageografica/article/ view/14.

Roberts, P. y Sykes, H. (2000). Urban Regeneration: A Handbook. Londres, Reino Unido: SAGES. 


\title{
NON-TRANSPARENT URBANISM? URBAN PLANNING AND STAKEHOLDERS IN THE MEGAPROJECT SANTA CRUZ VERDE 2030 (CANARY ISLANDS, SPAIN) \\ ¿EL URBANISMO OPACO? PLANIFICACIÓN Y ACTORES EN EL MEGAPROYECTO SANTA CRUZ VERDE 2030 (ISLAS CANARIAS, ESPAÑA)
}

\author{
Marcus Hübscher \\ Universidad de Leipzig (Alemania) \\ Johannes Ringel \\ Universidad de Leipzig (Alemania)
}

Resumen

En verano de 2018, CEPSA y el alcalde de Santa Cruz anunciaron el proyecto «Santa Cruz Verde 2030» - un plan ambicioso cuyo objetivo es la transformación de la refinería de petróleo en un barrio urbano. Sin embargo, hasta ahora no existe ninguna discusión crítica, aunque el proyecto podría reconfigurar el acceso de la ciudad al mar y su modelo turístico. En este contexto, este ensayo of rece un análisis cualitativo mediante cinco entrevistas con actores del mercado inmobiliario, política, planificación urbanística y una asociación medioambiental.

El análisis señala que los encuestados se sienten mal informados por parte de los precursores del megaproyecto. El proyecto es interpretado como un símbolo elitista de cómo los desarrolladores entienden el urbanismo. Aparte de esto, las entrevistas identifican expectativas contradictorias en relación al megaproyecto. Mientras algunos actores apoyan que el proceso sea más acelerado, otros demandan un proceso de planificación más pensado, integrativo y participativo. Además, la campaña de marketing está observada críticamente y puesta en relación directa con las elecciones municipales. Los actores basan sus opiniones en experiencias con el barrio de Cabo-Llanos, un megaproyecto local anterior, que ha tenido efectos de polarización en la ciudad.

Palabras clave: megaproyectos, desarrollo urbano, planificación, participación, actores, Santa Cruz de Tenerife.

\section{Abstract}

In summer of 2018, Santa Cruz' mayor José Bermúdez and the local oil refinery's manager announced the megaproject «Santa Cruz Verde 2030» —an ambitious plan that seeks to transform the city's largest industrial plant into an urban quarter. However, until now no critical public discussion has taken place, although the project is expected to reconfigure the city's access to the sea and its tourist model. In this context, this paper offers a qualitative analy- 
sis by means of five interviews with stakeholders from the real estate sector, politics, urban planning and an environmental association.

The analysis shows that the interviewees feel insufficiently informed by the project's initiators. The project is interpreted as an elitist symbol of how the project developers understand urban development and participation. Apart from that, the interviews identify a number of contradicting expectations regarding the megaproject. While some of the stakeholders want to accelerate the whole process, others call for a more integrative and participative planning approach. Moreover, the observed marketing campaign is viewed with criticism and thought to be directly linked to the upcoming elections. The stakeholders base their opinions on experiences from the Cabo-Llanos district, a former local megaproject that had polarizing effects on the city.

Keywords: megaprojects, urban development, planning, participation, stakeholders, Santa Cruz de Tenerife.

\section{INTRODUCTION}

Megaprojects have become typical elements of today's urbanism around the globe. Cities such as Barcelona (22@), Valencia (Ciutat de les Arts i les Ciències) or Hamburg (Hafencity) have shown how megaprojects are used as an effective tool to reposition themselves within the global competition. However, behind the bright mask of megaprojects, there is often a less appealing story of underestimated costs, construction time and overestimated benefits. A «new generation of megaprojects» (Díaz Orueta y Fainstein, 2009, 761) is observed, which is linked to neoliberal practices and marked by the creation of sustainable project images. However, unmasking these concepts reveals rather unsustainable practices, particularly in the field of planning.

Against this background, this paper focuses on Santa Cruz Verde 2030, an emerging megaproject on Tenerife, Spain, that was announced in summer of 2018 (see Figure 1). The project deals with the conversion of an inner-city oil refinery into a mixed-use urban quarter covering an area of more than $500,000 \mathrm{sqm}$. Until now, the urban planning process was characterized by exclusiveness, as the two project's initiators, the local government of Santa Cruz de Tenerife and the refinery's owner, the Compañía Española de Petróleos (CEPSA), have been negotiating behind closed doors. Yet, the project is expected to have considerable effects on the city's urbanism. According to other studies (Hübscher, 2019), the project will double the city's number of hotel beds and completely reconfigure the current urban setting. 
Figure 1. Geographical setting of the megaproject

Santa Cruz Verde 2030 in Santa Cruz de Tenerife, Canary Islands

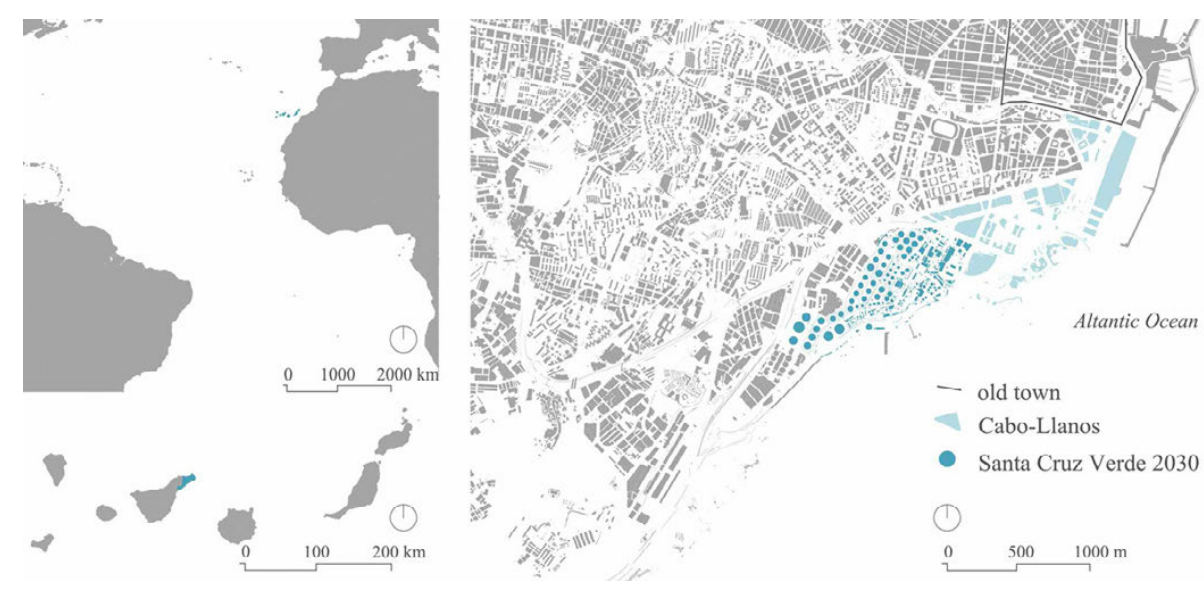

Source: Own elaboration based on Open Street Map (2019)

In spite of that, little public discussion can be observed so far. Hence, this study contributes to enhancing the discussion by focusing on the planning process itself as seen through the perspective of relevant urban stakeholders in Santa Cruz rather than the project's design as presented by the developers. By means of five qualitative interviews conducted with stakeholders from politics, urban planning, the real estate sector and an environmental association, the goal is to understand their perspective on the megaproject. Moreover, the question is raised if the experience of the Cabo-Llanos district, a previous local megaproject in Santa Cruz, has had effects on the stakeholder's views of this project (see Figure 1).

The article is structured as follows. Based on the described motivation, chapter two sets up a theoretical framework for analyzing the megaproject. In chapter three the case study is introduced. The applied methods are discussed in chapter four. The fifth part of this article presents the empirical results and puts emphasis on planning, image and learning processes. A final conclusion summarizes these findings.

\section{MEGAPROJECTS: GRAND IMAGES, LITTLE TRANSPARENCY?}

Megaprojects (Flyvbjerg, 2017), large scale urban development projects (Moulaert, Swyngedouw y Rodríguez, 2001) or grands projets (Hanakata y Gasco, 2018), are terms often synonymously used to describe projects that are complex from different points of view (Brookes, 2014). On the one hand, mega- 
projects are instruments to gain international audience and are expected to lead to multiple direct and indirect effects for the surroundings (Bruzelius, Flyvbjerg, y Rothengatter, 2002, 144). On the other hand, they have a long trajectory of faulty estimates, particularly when it comes to costs, construction time and final output, which is also referred to as the «iron law of megaprojects» (Flyvbjerg, 2014, 2).

In terms of defining megaprojects, different approaches exist. While some scholars focus on quantitative aspects such as costs and scale (Bruzelius et al., 2002) others put emphasis on qualitative elements. In this paper, I mostly refer to the second concept, as it allows me to explore (a) the large networks of stakeholders involved (Ruuska, Artto, Aaltonen, y Lehtonen, 2008, 142), (b) the intertwined relationship between public and private actors (Richard, 2011, 240) and (c) the characteristics of the urban transformations induced by megaprojects (Moulaert et al., 2001, 75).

During the last two decades, Díaz Orueta and Fainstein observe a new generation of megaprojects (2009). This new wave is characterized by projects that try to avoid public protest, an experience which during the 80 s and 90 s of the last century put a hold on numerous megaprojects (Lehrer y Laidley, 2008,788 ). In order to avoid protest movements, «new» megaprojects firstly incorporate mixed uses instead of focusing on a single aspect. By doing so, the projects can be marketed to a variety of groups as beneficial (Lehrer y Laidley, 2008, 800). Secondly, present megaprojects are often situated on brownfield sites, which minimizes direct displacement of inhabitants or local businesses (Díaz Orueta y Fainstein, 2009, 760). Thirdly, project managers put notable emphasis on marketing and image. One particularly popular concepts seem to revolve around sustainability. Green logics sometimes even serve to legitimize projects. The output, however, might significantly differ from what was promised. (Díaz Orueta y Fainstein, 2009, 764).

Deconstructing the sustainable mask of these projects may reveal numerous unsustainable practices, such as non-transparent planning mechanisms, as has been illustrated by Lehrer and Laidley $(2008,795)$. Rather than applying a participative approach to planning, megaprojects cater to the interests of the selected middle and upper classes (Swyngedouw, Moulaert, y Rodríguez, $2002,547)$. Simultaneously, their conception lies at the margins of formal planning structures (Swyngedouw et al., 2002, 577). Hence, another paradox is identified when it comes to the relationship between project management and civil society. Megaprojects are often used to gain a wide public audience and thus increase the city's visibility on a global scale (Cerro Santamaría, 2013, 54). Project marketing and communication focus on potential benefits of the project which are often expected to extend to the whole city. This also explains the high attractiveness to use megaprojects as a means during election campaigns (Locatelli, Mariani, Sainati, y Greco, 2017, 257). In this respect, a tendency of masking certain aspects such as high social and economic 
costs of the projects is observed, also referred to as the «hiding hand» (Hirschman, 2015, 12).

The rise of megaprojects as a common tool of urban planning is not only linked to general political settings, but also to spatial and structural conditions in cities. It is observed that this kind of cooperation between public and private stakeholders has become an important tool in neoliberal frameworks (Harvey, 2007, 76) used to «reconfigure local land-use patterns» (Peck, Theodore, y Brenner, 2009, 61). Based on the increasing inter-city competitiveness and the prevailing logics of «producing a successful city» (Vives Miró, 2011, 1), city governments look for fostering growth and communicating economic success in order to reposition themselves within the global urban hierarchy. Particularly large scale urban development projects are not only regarded as powerful tools, but also as a new means to do planning and to achieve the mentioned objectives (Swyngedouw et al., 2002, 547). Against this background, deconstructing these planning processes is a compelling research focus, particularly if addressed from a local stakeholder's point of view. Considering the current popularity of megaprojects as an urban development tool, the considerable number of cost overruns, time delays or even project failures are astounding. Flyvbjerg concludes that, effectively, no learning has taken place $(2005,20)$, which can partially be traced back to the complexity and singularity of each megaproject (Brookes, Locatelli, y Mikic, $2015,5)$. In the field of project design, however, megaprojects seem to have successfully learned from past protest movements. Considerable effort goes into presenting the project's functions and benefits for all of civil society in a way that undermines the formation of resistance (Lehrer y Laidley, 2008, 787). Unlike in planning practice, science has undergone a documented learning process (for an overview of contributions, see for example Brookes (2015) and Zidane (2013)). What is left to examine is how civil stakeholders as a third relevant group next to scientists and practitioners learn from these experiences. Academic discourse has (widely) failed to pay attention to this field so far, which is why this article analyzes this angle by means of field research. Based on the research interest addressed here, the following chapter introduces Santa Cruz de Tenerife as a case study.

\section{SANTA CRUZ: SELECTING THE CASE STUDY}

This paper deals with the megaproject «Santa Cruz Verde 2030» on Tenerife, Spain. Santa Cruz is the capital of Tenerife and co-capital of the Canary Islands, one of the 17 Spanish autonomous communities. With its 200,000 inhabitants the city forms part of the metropolitan area of the island, where approx. 400,000 inhabitants live (ISTAC, Instituto Canario de Estadística, 2019). The case has been chosen for two reasons, linked both to the specific conditions of the place as well as to the identified research interest (Chapter 2). 
Firstly, the analysis of the mentioned megaproject gives insights about whether and how local stakeholders have learned from previous large-scale urban developments in the city. Santa Cruz allows research into this specific angle because the deindustrialization of the oil refinery can be considered a long-term process that started in the 1990s (see Figure 2). More than 30 years ago, the eastern part of the refinery was dismantled, leaving space for the implementation of the so-called Cabo-Llanos Plan (Arencibia de Torres, 2005, 95). This megaproject had the objective to build a new and representative city center with commercial, administrative and recreational functions (García Herrera, Smith, y Mejías Vera, 2007, 292). However, the project has shown polarizing impacts on urban development, as gentrification processes have been observed (García Herrera, 2003). Two decades later, efforts of initiating a second deindustrialization process are observed. The argument that is put forward by the project's initiators is linked to environmental and safety issues, as the industry is on the list of the 200 most contaminating industries in the EU (AbcCanarias, 2004). In June 2018, CEPSA and the city's local government announced they would be dismantling the oil refinery and presented «Santa Cruz Verde 2030» (Santa Cruz de Tenerife Ayuntamiento y CEPSA, 2018b). Although experiences from other megaprojects did show severe difficulties when it comes to initiating learning processes, this essay supports the hypothesis that learning took place due to the same urban setting that the megaprojects «Cabo-Llanos» and «Santa Cruz Verde 2030» are located in.

The second motivation for choosing the case study is that the analysis will contribute to the ongoing planning process. As the project has just begun, the starting point of my investigation lies on the public-private agreement, announced in summer of 2018 (Santa Cruz de Tenerife Ayuntamiento y CEPSA, 2018a). However, the importance of this document can be questioned due to various reasons. First, the document is not binding, as it is not implemented in formal planning instruments. Second, a considerable amount of technical questions remain, such as juridical problems concerning the land classification and upcoming claims of formerly expropriated land owners (Reverón, 2019). Thirdly, the local government of the municipality has just changed in summer of 2019 after elections and the new mayoress has yet to comment on her vision of the project. In spite of that, the announced public-private agreement is currently the only existing and most detailed document of how the involved project's initiators imagine the construction process of the megaproject to take place. It is therefore argued that the analysis of this case study not only enriches the discussion about megaprojects and governance in academia, but also helps understand the planning process of Santa Cruz Verde 2030 and thus contributes to increasing its transparency. This is also relevant against the background of the polarized urban setting, as the quarters surrounding the refinery have different social and economic vulnerabilities (Hübscher, 2018). The following chapter presents the methods applied in this study. 
Figure 2. The history of the oil refinery «Tenerife» in Santa Cruz of Tenerife between foundation and deindustrialization

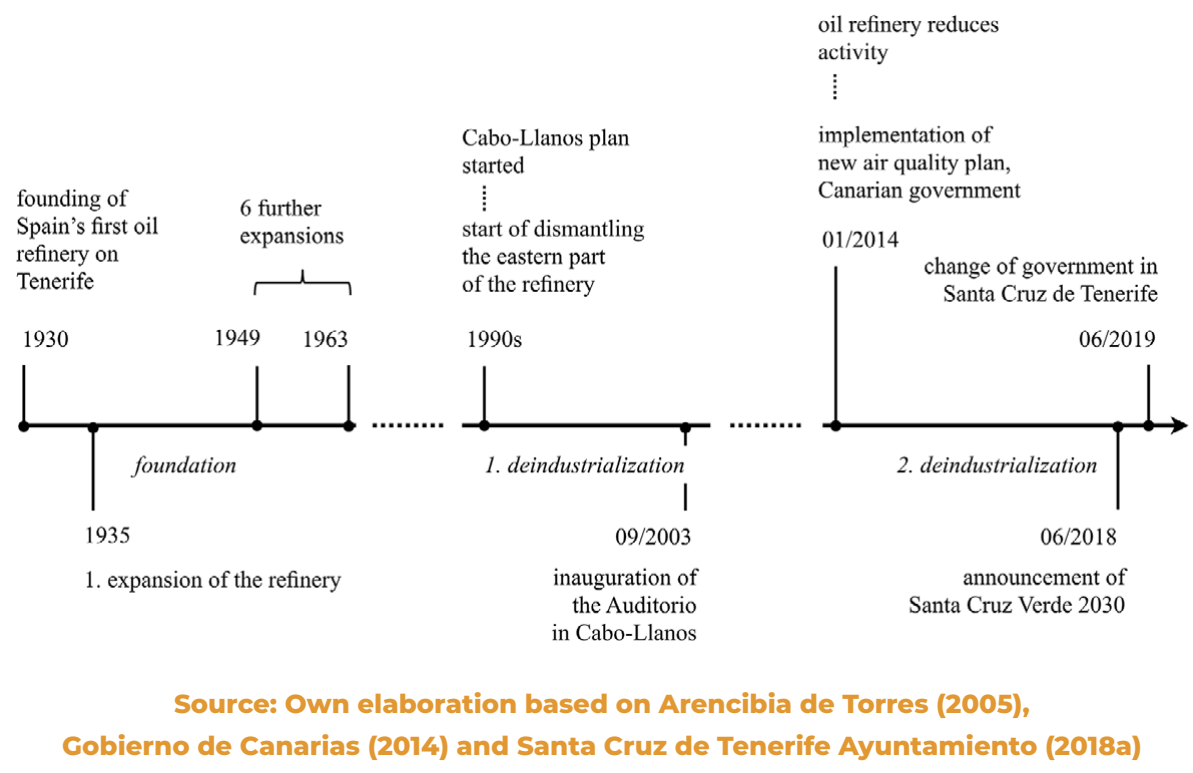

\section{QUALITATIVE INTERVIEWS AS RESEARCH APPROACH}

This paper aims to understand the planning process of the megaproject Santa Cruz Verde 2030 from a stakeholder perspective using a qualitative approach. Experts are interviewed with the help of semi-structured guidelines (Hernández Sempieri, Fernández Collado y Baptista Lucio, 2010, 418) that consist of key questions (Gill, Steward, Treasure y Chadwick, 2008, 291). This helps the conductor to stay focused on core research topics as well as enabling the respondent to put personal emphasis on certain aspects (Helfferich, 2011, 179). Hence, semi-structured interviews are regarded as a valuable tool in understanding not only stakeholder's opinions, but also the logics in the background (Flick, 2004).

Five qualitative interviews were conducted in summer of 2019 in Santa Cruz de Tenerife (see Table 1). The interviewees were chosen by means of desktop research online. Some of them were selected due to their profession, others because they had joined the public discussion and commented on the megaproject by means of newspaper articles and interviews. 
Table 1. Interviewees and their professions

\begin{tabular}{|c|l|c|l|}
\hline No. & \multicolumn{1}{|c|}{ Profession/ Function } & \multicolumn{1}{|c|}{ Date } & \multicolumn{1}{c|}{ Place } \\
\hline 11 & $\begin{array}{l}\text { Territorial representative of the } \\
\text { Professional Association of Real Estate } \\
\text { Experts (APEI) }\end{array}$ & 23.08 .2019 & $\begin{array}{l}\text { Office of the interviewee, } \\
\text { Santa Cruz de Tenerife }\end{array}$ \\
\hline I2 & $\begin{array}{l}\text { Representative of the urban planning } \\
\text { office, Santa Cruz de Tenerife }\end{array}$ & 30.08 .2019 & $\begin{array}{l}\text { Office of the interviewee, } \\
\text { Santa Cruz de Tenerife }\end{array}$ \\
\hline I3 & $\begin{array}{l}\text { Real Estate Agent, 40 years of working } \\
\text { experience in Santa Cruz de Tenerife }\end{array}$ & 02.09.2019 & $\begin{array}{l}\text { Office of the interviewee, } \\
\text { Santa Cruz de Tenerife }\end{array}$ \\
\hline 14 & $\begin{array}{l}\text { Preservationist; former politician } \\
\text { (Coalición Canaria) }\end{array}$ & $\begin{array}{l}\text { Representative of an local environmental } \\
\text { association (Ecologistas en Acción) }\end{array}$ & $\begin{array}{l}\text { Public café, Santa Cruz de } \\
\text { Tenerife }\end{array}$ \\
\hline
\end{tabular}

Source: Own elaboration

Apart from the interviewees listed above, I also contacted the initiators that were responsible for the elaboration of the plan Santa Cruz Verde 2030, but at this point they were not willing to take part in the investigation. However, their opinion is essential in order to contrast both internal and external points of view. Consequently, it must be highlighted that the prevailing results are limited to some extent as they focus on the external view of the megaproject in question.

The material was transcribed and analyzed using the software MAXQDA with a mixed-approach code system. While some of the codes were already defined based on the interview guideline (deductive), the code system was complemented by the material itself (inductive, Kuckartz, 2018, 64).

\section{SANTA CRUZ VERDE 2030 - THE STAKEHOLDER'S PERSPECTIVE}

This chapter presents the empirical findings of the conducted interviews and puts them into their theoretical context. Three subtopics are addressed. First of all, the general planning process is analyzed. Secondly, the created image of the megaproject in question is deconstructed. Thirdly, a potential learning process between the two local megaprojects «Cabo-Llanos» and «Santa Cruz Verde 2030» is investigated.

Although it was argued that the megaproject forms part of a long-term deindustrialization process, it is the surprising announcement of the megaproject that is causing contradicting perceptions among the interviewees. For some of them, such as those from the real estate sector, the project is not advancing fast enough. The representative of the local real estate association points out that from his point of view «there is no formalized agreement» (I1 Real 
Estate Expert, 2019, I.6). He even questions the title of the announcement and insists that the document should rather be regarded to as "pre-agreement» (I1 Real Estate Expert, 2019, I.25). For the others the process is far too rushed (I2 Urban Planning Office, 2019, I.8). All of the stakeholders highly doubt the quality of the planning process and criticize prevailing uncertainties in the plan. Criticism ranges from «there is literally nothing» (11 Real Estate Expert, $2019,1.24$ ) to «it's a plan without urbanism» (I4 Preservationist, 2019, I.18). Interestingly, the new head of the municipal planning office admits that he did not even study in detail the public-private agreement that was announced by the anterior government (I2 Urban Planning Office, 2019, I.5), which reflects the value he assigns to the document in question.

Apart from that, only one out of five interviewees felt sufficiently informed about the project itself. Only the representative of a monument protection association had insights into the process because she actively investigated and had contacts to the initiators in charge due to her former political career (14 Preservationist, 2019, I.22). All the others clearly criticized the inadequate communication management of the megaproject's initiators (I1 Real Estate Expert, 2019, I.24; 13 Real Estate Agent, 2019, I.32). One interviewee summarized it the following way: «In the initial phase of the agreement between CEPSA and the local government the process was not transparent at all, which means, [...] they sat down, they negotiated, they signed and there was nothing communicative about it.» (I5 Environmental Association, 2019, I.32). This policy of non-transparency is linked directly to the lack of substantial public discussion: "Those of us who could have been critical did not have enough information to be critical» (I5 Environmental Association, 2019, I.56). This observation mirrors what was described in chapter two as the underlying intention to prevent critical opinions. The problem is considered to be a structural one: «Certain political organizations have a habit of not being transparent, but of doing everything behind the citizen's back. It's a historical habit» (I5 Environmental Association, 2019, I.38). This non-transparent situation leaves stakeholders disappointed, particularly because it seems to be a regular thing in the city's urban planning: «Every time the politicians go ahead, without considering that they motivate us [the urban stakeholders; author's note], and then the years pass by, as it has happened in so many cases» (I1 Real Estate Expert, 2019, I.6).

As already indicated in chapter two, a strong focus on image related instruments is a typical character trait of current megaprojects. This is also observed in the prevailing case study. The interviewees notice «a very strong marketing campaign [...]» (I5 Environmental Association, 2019, I.32), among them representative 3D models in images and videos published by the megaproject's initiator (14 Preservationist, 2019, I.100). However, the whole marketing campaign is perceived as disproportional: «these are information and news with a hype, simply to create sensationalism in that moment» (I1 Real 
Estate Expert, 2019, I.6). It is observed that «behind [the image], there is no contents» (I4 Preservationist, 2019, I.22). It needs to be emphasized, that the interviewees assign the strong motivation to present the megaproject on the media in a favorable light to the local government rather than CEPSA (I5 Environmental Association, 2019, p. 32). According to the interviews, this is based on political interests. A direct relation to the upcoming municipal election that took place within one year after the first announcement of Santa Cruz Verde 2030 is suggested (11 Real Estate Expert, 2019, I.22; 15 Environmental Association, 2019, 1.52). Others even see the upcoming election campaign as the main motivation behind the project: "l know that their priority was to announce the project before the elections» (I4 Preservationist, 2019, I.22). For the former mayor Bermúdez and his party, the regionalist Coalición Canaria, this strategy has paid off, as they increased their result about $28 \%$ and thus defended their place as the largest parliamentary group with currently more than one third of all city councilors (La Vanguardia, 2019). Nevertheless, they lost the mayoralty, as oppositional left-wing parties formed a stronger coalition, which led to a change in the municipal's government.

In this paper, the idea of a potential learning process in megaproject developments is put forward. Although other scholars observe that no such learning process is taking place, this study is based on the hypothesis that learning is expected due to a former local large-scale urban development project. This is because of the functional, spatial and temporal relation between both projects (Cabo-Llanos and Santa Cruz Verde 2030) that are analyzed here. The interviews show that such experience definitely exists. The knowledge that was built based on the first megaproject "Cabo-Llanos» is identified in two different fields, namely the conception of the project itself and the planning process.

When it comes to the conception, various interviewees criticize the exclusive character of Cabo-Llanos. From the perspective of real estate economics, «it's a good area with a high demand» (I3 Real Estate Agent, 2019, I.57). However, the outcome is not affordable for the majority of the city's population due to the strong speculation (I3 Real Estate Agent, 2019, I.42) This is an aspect that also other interviewees addressed (14 Preservationist, 2019, 1.22). Moreover, the quarter is still not entirely integrated into the city, both from a social and a spatial point of view (11 Real Estate Expert, 2019, 1.24). The prices on the CaboLlanos housing market (2,300 €/sqm on average; 11 Real Estate Expert, 2019 , I.52) are more than $60 \%$ higher than the city wide average $(1,400 € / \mathrm{sqm}$; Idealista, 2019). Yet, a large disparity between price and quality is observed: «The buildings that we have here are simply miserable [...] and there is no architectural aesthetics» (I1 Real Estate Expert, 2019, I.24). Based on that experience, interviewees have the expectation that the Cabo-Llanos case should be taken as a lesson, «because we would do the same mistakes for a second time, as Cabo-Llanos' urbanism has not been thought through either [...]. It 
has generated urban spaces that are not urban at all.» (14 Preservationist, 2019, I.18). In spite of that, it is observed that the current urban planning of Santa Cruz Verde 2030 is even less prepared than the Cabo-Llanos concept (I4 Preservationist, 2019, I.128). The consequences of this superficial planning approach in Cabo-Llanos are still seen today, as a considerable number of land plots have not been developed, particularly the ones with intended public use (14 Preservationist, 2019, I.102). Contrary to that, publicly financed projects with tourist uses at the waterfront have been finished, such as the concert hall «El Auditorio», a congress center and a waterpark (see Figure 3). This is why there are those who call for a shift in priorities. Instead of starting to plan a new megaproject, the previous one should be completed first (I2 Urban Planning Office, 2019, I.8).

Figure 3. Cabo-Llanos: spatial disparities between waterfront, brownfield sites and completed buildings

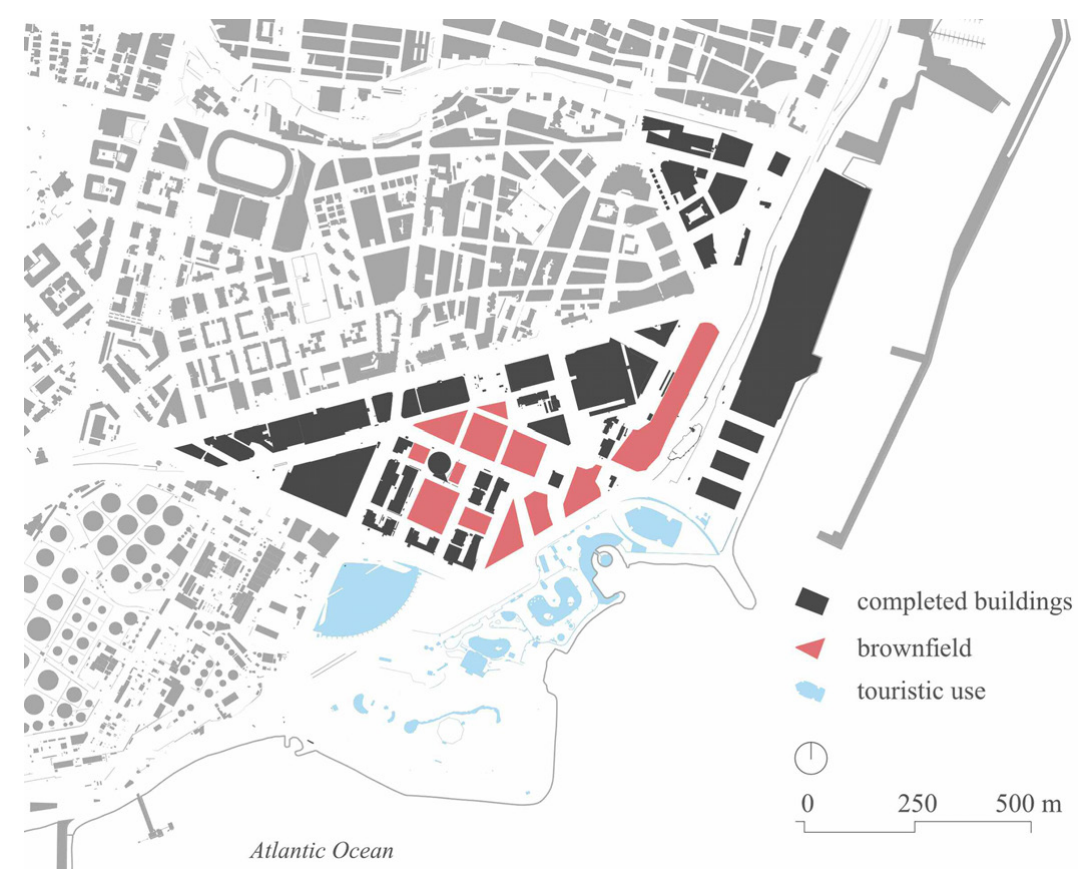

Source: Own elaboration based on Open Street Map (2019)

\section{CONCLUSION}

When it comes to the planning process, Santa Cruz Verde 2030 reflects what has been observed in other case studies as well, such as a strong focus on 
image related aspects and exclusive negotiation processes without participatory elements. However, this study could not prove or disprove one of the main points found in theory, namely the fact that the project design was intended to avoid protest movements, as the project initiators did not wish to be interviewed. Nevertheless, the interviewed stakeholders in the city support this allegation and argue that the megaproject was used as a political instrument during the municipal election campaign. From their point of view the whole process is highly obscure. This completely contradicts what has been promised by project initiators. The mismanagement of information that is viewed to be intentional, results in negative attitudes of the local stakeholders. While some of them are just very sceptical about the feasibility of the project, others are disappointed because of what they expect to happen moving forward. Santa Cruz Verde 2030 is presented in a way that does not encourage public discussions, but puts focus on image-related aspects instead. This seems to prove that project initiators are more concerned about selling the project as a success, rather than putting emphasis on contents or participation. These findings are in line with what other scholars have described (see Chapter 2). Santa Cruz Verde 2030 is thus regarded as another example of the new generation of megaprojects that is being observed worldwide. With regards to the learning process between «Cabo-Llanos» and «Santa Cruz Verde 2030», a gap can be identified. All of the interviewed stakeholders have negative associations with Cabo-Llanos relating to the planning process and the outcome. The interviewees name speculation, non-integration and poor urban qualities as the main deficits of the quarter. This is alarming because the available material of the current planning process of Santa Cruz Verde 2030 suggests even less quality than the former megaproject. Hence, the observation that project initiators are not «learning from past mistakes, or no one wants to learn» (Flyvbjerg, 2005, p. 20) also seems to apply to the prevailing case study. However, what other studies often neglect to address is the question if and to what extend learning took place within the broader urban network. In this respect, it has been shown that different local stakeholders have made similar experiences. Based on that, they actively propose ideas for improving the current planning process. This entails the request to enable an integration of stakeholders from different backgrounds (14 Preservationist, 2019 , I.24). Moreover, one interviewee suggests holding an international planning competition in order to increase the quality of the output (I1 Real Estate Expert, 2019, I.29). Apart from that, induced gentrification processes as previously observed in Cabo-Llanos are likewise seen as a major threat in neighboring quarters of the new megaproject and should thus be tackled ex-ante (I5 Environmental Association, 2019, I.120).

This paper puts emphasis on the planning process of Santa Cruz Verde 2030 and reveals various deficits from different stakeholders' points of view. More research remains to be done in order to learn about the project's initiators 
standpoint, although interviewing them proves to be difficult due to the high politic relevance of the topic. It is vital however, as it will contribute to a deeper understanding of the wider urban process, as neoliberal logics, touristification and waterfront redevelopment are the main drivers that have been shaping Santa Cruz de Tenerife for various decades.

\section{REFERENCES}

AbcCanarias (2004). La refinería de Tenerife, entre las 200 industrias más contaminantes de Europa. abc.es. Retrieved from https://www.abc.es/hemeroteca/historico-06-03-2004/abc/canarias/la-refineria-de-tenerife-entre-las -200-industrias-mas-contaminantes-de-europa_962287394532.html\#

Arencibia de Torres, J. (2005). Refinería de Tenerife, 1930 - 2005: 75 años de historia. Santa Cruz de Tenerife: CEPSA.

Brookes, N. (2014). Mankind and Mega-projects. Frontiers of Engineering Management, 7(3), 241-245. doi:https://doi.org/10.15302/J-FEM-2014033

Brookes, N., Locatelli, G. y Mikic, M. (2015). Learning Across Megaprojects. The INNOMET Working Group Report. Retrieved from http://www.mega-project.eu/assets/exp/docs/Learning_Across_Megaprojects.pdf

Bruzelius, N., Flyvbjerg, B. y Rothengatter, W. (2002). Big decisions, big risks. Improving accountability in mega projects. Transport Policy, 9, 143-154. doi:http://dx.doi.org/10.1016/S0967-070X(02)00014-8

Cerro Santamaría, G. d. (2013). The alleged Bilbao miracle and its discontents. In G. d. Cerro Santamaría (Ed.), Urban Megaprojects: A Worldwide View (pp. 27-60). New York: Emerald.

Díaz Orueta, F. y Fainstein, S. (2009). The New Mega-Projects: Genesis and Impacts. International Journal of Urban and Regional Research, 32, 759-767. doi:http://doi.org/10.1111/j.1468-2427.2008.00829.x

Flick, U. (2004). Qualitative Sozialforschung. Eine Einführung (2. ed.). Reinbeck bei Hamburg.

Flyvbjerg, B. (2005). Machiavellian megaprojects. Antipode, 37(1), 18-22.

Flyvbjerg, B. (2014). What You Should Know About Megaprojects, and Why: An Overview. Project Management Journal, 45(2), 6-19. doi:http://doi.org/10.1002/pmj.21409

Flyvbjerg, B. (Ed.) (2017). The Oxford Handbook of Megaproject Management. London: CPI Group.

García Herrera, L. M. (2003). ¿De Cabañas a Palacios? Vivienda y Proceso de Elitización en el Cabo-los Llanos (Santa Cruz de Tenerife, Canarias). Scripta Nova. Revista Electrónica de Geografía y Ciencias Sociales, 7(146). Retrieved from http://www.ub.edu/geocrit/sn/sn-146(075).htm

García Herrera, L. M., Smith, N. y Mejías Vera, M. Á. (2007). Gentrification, Displacement, and Tourism in Santa Cruz de Tenerife. Urban Geography, 28(3), 276-298. doi:https://doi.org/10.2747/0272-3638.28.3.276 
Gill, P., Steward, K., Treasure, E. y Chadwick, B. L. (2008). Methods of data coIlection in qualitative research: Interviews and focus groups. British Dental Journal, 204(6), 291-295. doi:http://www.doi.org/10.1038/bdj.2008.192

Gobierno de Canarias. (2014). Plan de Calidad del Aire de la Aglomeración Santa Cruz de Tenerife - San Cristobal de la Laguna, por dióxido de azufre. Retrieved from:

http://www.gobiernodecanarias.org/cptss/sostenibilidad/temas/planificacion-ambiental/planes_calidad_aire/

Hanakata, N. y Gasco, A. (2018). The Grand Projet politics of an urban age: urban megaprojects in Asia and Europe. Palgrave Communications, 4(86). doi:http://doi.org/10.1057/s41599-018-0141-5

Harvey, D. (2007). A Brief History of Neoliberalism. New York: Oxford University Press.

Helfferich, C. (2011). Die Qualität qualitativer Daten. Manual für die Durchführung qualitativer Interviews (4. ed.). Wiesbaden: VS Verlag für Sozialwissenschaften.

Hernández Sempieri, R., Fernández Collado, C. y Baptista Lucio, M. d. P. (2010). Metodología de la Investigación (5 ed.). Mexico D.F.: Mc Graw Hill.

Hirschman, A. (2015). Development Projects Observed. Washington D.C.: Brookings Institutions Press.

Hübscher, M. (2018). Gentrificación y Vulnerabilidad. Evaluación de Aspectos Sociales y Urbanísticos en Santa Cruz de Tenerife (Islas Canarias). Paper presented at the Ciudades Medias y Áreas Metropolitanas. De la Dispersión a la Regeneración. XIV Coloquio de Geografía Urbana., Albacete, Valencia. Hübscher, M. (2019). From megaprojects to tourism gentrification? The case of Santa Cruz Verde 2030 (Canary Islands, Spain). Boletín de la Asociación de Geógrafos Españoles, 83(2813), 1-47. doi:http://dx.doi.org/10.21138/bage.2813

11 Real Estate Expert. (2019, 23.08.2019) Interview about Santa Cruz Verde 2030/Interviewer: Author. Santa Cruz de Tenerife.

12 Urban Planning Office. (2019, 30.08.2019) Interview about Santa Cruz Verde 2030/Interviewer: Author. Santa Cruz de Tenerife.

13 Real Estate Agent. (2019, 02.09.2019) Interview about Santa Cruz Verde 2030/Interviewer: Author. Santa Cruz de Tenerife.

14 Preservationist. (2019, 04.09.2019) Interview about Santa Cruz Verde 2030/Interviewer: Author. Santa Cruz de Tenerife.

I5 Environmental Association. (2019, 04.09.2019) Interview about Santa Cruz Verde 2030/Interviewer: Author. Santa Cruz de Tenerife.

Idealista (2019). Evolución del precio de la vivienda en alquiler en Santa Cruz de Tenerife. Retrieved from https://www.idealista.com/sala-de-prensa/informes-precio-vivienda/alquiler/canarias/santa-cruz-de-tenerifeprovincia/santa-cruz-de-tenerife/ 
ISTAC, Instituto Canario de Estadística. (2019). Población según sexos y grupos de edad grandes y quinquenales. Comarcas por islas de Canarias y años. Retrieved from http://www.gobiernodecanarias.org/istac/jaxi-istac/tabla.do Kuckartz, U. (2018). Qualitative Inhaltsanalyse. Methoden, Praxis, Computerunterstützung (4 Ed.). Weinheim: Beltz Juventa.

La Vanguardia (2019). Resultados Elecciones municipales 2019 en Santa Cruz de Tenerife. La Vanguardia. Retrieved from:

https://www.lavanguardia.com/elecciones/elecciones-municipales-2019/canarias/santa-cruz-de-tenerife/santa-cruz-de-tenerife

Lehrer, U. y Laidley, J. (2008). Old Mega-Projects Newly Packaged? Waterfront Redevelopment in Toronto. International Journal of Urban and Regional Research, 32, 786-803. doi:http://doi.org/10.1111/j.1468-2427.2008.00830.x

Locatelli, G., Mariani, G., Sainati, T. y Greco, M. (2017). Corruption in public projects and megaprojects: There is an elephant in the room! International Journal of Project Management, 35(3), 252-268.

doi:https://doi.org/10.1016/j.ijproman.2016.09.010

Moulaert, F., Swyngedouw, E. y Rodríguez, A. (2001). Large Scale Urban Development Projects and Local Governance: from Democratic Urban Planning to Besieged Local Governance. Geographische Zeitschrift, 89(2), 71-84.

Open Street Map y Geofabrik GmbH (Cartographer). (2019). Canary Islands. Retrieved from https://www.geofabrik.de/de/index.html

Peck, J., Theodore, N. y Brenner, N. (2009). Neoliberal Urbanism: Models, Moments, Mutations. SAIS Review of International Affairs, 29(1), 49-66. doi:https://doi.org/10.1353/sais.0.0028

Reverón, E. (2019). La descontaminación del suelo de la Refinería arrancará en abril de 2020. El Día. Retrieved from https://www.eldia.es/santa-cruz-detenerife/2019/10/11/descontaminacion-suelo-refineria-arrancara-abril/ 1015680.html

Richard, L. (2011). The Emerging Role of Public-Private Partnerships in Megaproject Delivery. Public Works Management y Policy, 16(3), 240-249. doi:http://doi.org/10.1177/1087724X11409244

Ruuska, I., Artto, K., Aaltonen, K. y Lehtonen, P. (2008). Dimensions of distance in a project network: Exploring Olkiluoto 3 nuclear power plant project. International Journal of Project Management, 27, 142-153.

doi:http://doi.org/10.1016/j.ijproman.2008.09.003

Santa Cruz de Tenerife Ayuntamiento y CEPSA (2018a). Acuerdo de Colaboración Público-Privada para el Plan Santa Cruz Verde 2030. Retrieved from https://www.santacruzdetenerife.es/scverde2030/fileadmin/user_upload/w eb/SCverde2030/NotadePrensa26062018.pdf

Santa Cruz de Tenerife Ayuntamiento y CEPSA (2018b). Santa Cruz y Cepsa sellan una Allianza para estudiar la transformación de la ciudad sobre los terrenos de la Refinería. Retrieved from: 
https://uww.santacruzdetenerife.es/scverde2030/fileadmin/user_upload/web/ SCverde2030/NotadePrensa26062018.pdf

Swyngedouw, E., Moulaert, F. y Rodriguez, A. (2002). Neoliberal Urbanization in Europe: Large-Scale Urban Development Projects and the New Urban Policy. Antipode, 34(3), 542-577.

Vives Miró, S. (2011). Producing a «Successful City»: Neoliberal Urbanism and Gentrification in the Tourist City - The Case of Palma (Majorca). Urban Studies Research, 2011, 1-13. doi:http://doi.org/10.1155/2011/989676

Zidane, Y., Johansen, A. y Ekambaram, A. (2013). Megaprojects - Challenges and Lessons Learned. Procedia - Social and Behavioral Sciences, 74, 349357. doi:http://doi.org/10.1016/j.sbspro.2013.03.041 


\section{CRISIS Y REGENERACIÓN EN ÁREAS URBANAS: EL CASO DE LINARES (JAÉN)' CRISIS AND REGENERATION IN LINARES URBAN AREA (JAÉN) \\ Juan Jesús Lara Valle \\ Universidad de Granada \\ Luis Miguel Sánchez Escolano \\ Universidad de Granada}

Resumen

El pacto de Amsterdam, acordado en 2016, será el documento que ponga en marcha la Nueva Agenda Urbana Europea, en ella se señalan los temas prioritarios de actuación hacia una ciudad sostenible; y entre los doce que se seleccionan se incluye el uso sustentable del suelo. Cada uno de ellos tiene su origen, entre otras razones, en la crisis urbana experimentada en muchas áreas urbanas en los últimos años. La de Linares será una de esas áreas que experimentará un proceso de crisis que se pondrá de manifiesto tanto en plano territorial como en el económico y social.

El objeto de esta comunicación es doble, por un lado, evaluar las características de la crisis del crecimiento urbano experimentado en esta área urbana y, la propuesta metodológica que nos permitirá establecer las conclusiones sobre dicho proceso. Este primer aspecto se centrará en el análisis de la ocupación y usos del suelo de tipo residencial y espacios libres; para ello se utilizarán algunos de los indicadores del SMISUL y las herramientas de análisis espacial de los SIG; por otro, se abordará los proyectos e iniciativas de regeneración urbana y su impacto urbanístico.

Palabras clave: ocupación del suelo, desarrollo residencial, zonas verdes, ciudad sostenible, Linares.

\section{Abstract}

The Amsterdam Pact, agreed in 2016, is the document that start the New European Urban Agenda, which highlights the priority issues of action towards a sustainable city; sustainable land use is included among them. Each of them has its origin in the urban crisis experienced in many urban

1 Esta contribución ha sido desarrollada en marco del proyecto de investigación titulado «Evolución de las políticas urbanísticas en ciudades medias españolas y sus áreas urbanas: 1979-2019» (RTI2018-096435-B-C21), financiado por el Ministerio de Ciencia, Innovación y Universidades (España), Proyectos I+D+i en la convocatoria «Retos Investigación» de 2018. 
areas in recent years. Linares (Jaén, Spain) will be one of those areas that will undergo a crisis process, revealed both territorially, economically and socially. The purpose of this communication is twofold. On the one hand, it evaluates the characteristic sof the urban growth crisis experienced in the urban area of Linares, obtaining the methodological proposal that will allow us to establish the conclusions on this process. This first aspect will focus on the analysis of occupancy and land uses of residential type and free spaces. Some of the SMISUL indicators and the GIS tool will be used. Secondly, urban regeneration projects and initiatives and their urban impact will be addressed.

Key Words: land use, residential development, green areas, sustainable city, Linares.

\section{INTRODUCCIÓN. CRISIS EN EL ÁREA URBANA DE LINARES (JAÉN)}

En estos últimos años se ha puesto de manifiesto la preocupación por la crisis de las áreas urbanas. En el 2011, se publica: «Ciudades del Mañana: Retos, visiones y caminos a seguir» (Unión Europea, 2011), en donde se sistematizan los factores y componentes de la crisis. El título de uno de los epígrafes: «un modelo europeo de desarrollo urbano amenazado» ya es de por sí ilustrativo de la importancia del problema. En su diagnóstico se aborda el declive demográfico, la creciente polarización social y el agotamiento de los recursos naturales debido a la dispersión de la urbanización y el consumo de suelo. Consecuencia del interés despertado por el problema será la toma en consideración del mismo en el XIII Coloquio de Urbana, celebrado en Girona en 2016 y un número apreciable de publicaciones aparecidas en los últimos años. (Campos, F., 2016). El documento marco en el que se inscribe este trabajo, en su concepción epistemológica, es la Agenda Urbana Española 2019. (Gobierno de España: 2019). La crisis que ha afectado a la ciudad de Linares puede detectarse en diferentes aspectos; nuestro objetivo es centrarnos en algunos indicadores de la ocupación del suelo urbano, básicamente el uso del suelo residencial y el de espacios libres. Pero esta dimensión de la crisis no se puede entender si no se tiene en cuenta, al mismo tiempo, las demás variables de su situación socioeconómica. Las referencias a la decadencia experimentada por la ciudad de Linares en los años recientes quedan registradas tanto en los medios de comunicación como en trabajos publicados en revistas científicas. Titulares como: «Miles de personas se manifiestan en la ciudad con más paro de España: ¡Linares no se rinde!» (OK DIARIO 18/05/2018); «Cientos de personas claman en Sevilla por reflotar a Linares» (IDEAL 05/10/2018); «Propuestas contra la crisis demográfica. El Ayuntamiento de Linares trabaja en un paquete de medidas para frenar la sangría poblacional» (VIVIR LINARES 04/11/2019), por citar sólo algunos, son ilustrativos de la preocupación social existente. Por otro lado, el INE, en sus notas de prensa correspondientes a los años 2017,2018 y 2019 sobre indi- 
cadores urbanos, cita a Linares en la lista de Ámbitos Urbanos Funcionales (AUF) entre las que presentan el menor porcentaje en el sector servicios, las ciudades con mayor tasa de paro, las que ofrece una menor tasa de actividad con el 51,3\%, las que la esperanza de vida es menor o entre las que tiene una renta neta media anual más baja. Esta situación coloca a Linares en los últimos lugares del ranking de Grandes Áreas Urbanas. Esta situación de crisis fue puesta de manifiesto también, en la etapa post-crisis, por distintos autores en el ámbito de geografía urbana, industrial o regional (Méndez, R., 2007; Caravaca, I. et al., 2008; Caravaca, I. et al., 2014).

Se ha actualizado la situación de estos indicadores socioeconómicos (Tabla 1), quedando de manifiesto una tendencia negativa en la evolución de la población, el aumento de la edad media, un descenso en el número total de hogares, y el descenso en la tasa de actividad; mientras que parecen mejorar la tasa de desempleo o la proporción del empleo en el sector industrial y servicios.

Tabla 1. Selección de indicadores socioeconómicos del Área de Linares

\begin{tabular}{|l|c|c|c|c|}
\hline INDICADORES SOCIOECONÓMICOS LINARES & $\mathbf{2 0 1 8}$ & $\mathbf{2 0 1 7}$ & $\mathbf{2 0 1 6}$ & $\mathbf{2 0 1 5}$ \\
\hline Población residente (Personas) & $57.811^{*}$ & 58.449 & 58.829 & 59.737 \\
\hline Edad mediana de la población (años) & $42,9 *$ & 43,02 & 42,46 & 41,8 \\
\hline Número total de hogares (Número) & & 21.171 & 21.219 & 21.229 \\
\hline Tamaño medio de los hogares (Número) & & 2,71 & 2,78 & 2,79 \\
\hline Tasa de desempleo (Porcentaje) & 32,81 & 39,04 & 44,53 & 46,67 \\
\hline $\begin{array}{l}\text { Proporción de ocupados entre 20-64 años } \\
\text { sobre la población activa (Porcentaje) }\end{array}$ & 66,93 & 60,86 & 55,49 & 53,33 \\
\hline Tasa de actividad (Porcentaje) & 54,31 & 54,97 & 55,38 & 55,94 \\
\hline $\begin{array}{l}\text { Proporción de empleo en servicios } \\
\text { (NACE Rev.2 G-U) (Porcentaje) }\end{array}$ & 75,93 & 76,07 & 74,38 \\
\hline $\begin{array}{l}\text { Proporción de empleo en industria } \\
\text { NACE Rev.2 B-E) (Porcentaje) }\end{array}$ & & 14,25 & 14,69 & 12,62 \\
\hline Renta neta media anual por habitante (Euros) & & & 9.047 & $8.793,34$ \\
\hline
\end{tabular}

Fuente: INE: Indicadores Urban Audit para Ciudades.

Elaboración propia* completado con otra fuente

Metodológicamente el recurso a los SIG como instrumento para el análisis de la información, procedente de diversas fuentes, así como para su representación cartográfica ha sido fundamental. Así a partir de la construcción de la red de carreteras y utilizando como criterios: distancia y tiempos de desplazamiento, se ha podido determinar el área de influencia funcional de Linares. Para la evaluación del crecimiento poblacional y urbano se ha adoptado 
la metodología utilizada por la Directiva Inspire (Eurostat, 2018) (Djkistra, L. y Poelman, H., 2014) y adaptada por el IECA a la Comunidad Andaluza. El proceso de ocupación del suelo artificial y el desarrollo del tipo residencial se ha realizado mediante la comparación de los datos contenidos en el CLC 1990 a 2018 y los correspondientes al proyecto SIOSE. A escala de detalle los datos ofrecidos por el Catastro de Urbana, Censos de viviendas y planeamiento urbano también han sido tenidos en cuenta y cotejados entre sí para el análisis del parque de viviendas, la obtención del indicador de compacidad absoluta y el desarrollo de espacios libres.

\section{EL AUF DE LINARES Y SUS ÁMBITOS DE INFLUENCIA}

La determinación del área de influencia de una ciudad ha sido un problema complejo por la diversidad de factores que pueden entrar en juego. Para evitar esta confusión, Urban Audit estableció los criterios que debe cumplir la llamada AUF, en los que la movilidad laboral entre la ciudad y su área de commuting es básica. Sin embargo, en la Administración se siguen utilizando diferentes tipos de divisiones funcionales sobre un mismo centro nodal; el caso de Linares es uno de ellos.

Figura 1. Ámbitos funcionales de Linares

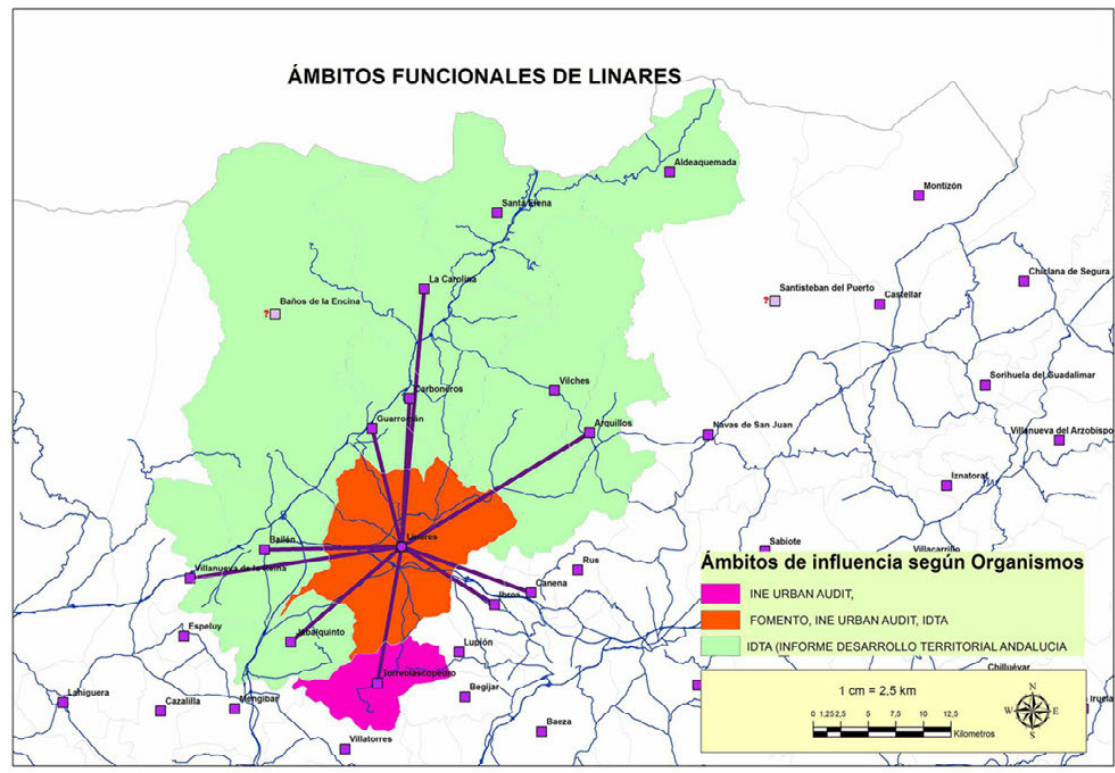

Fuente: Elaboración propia 
Según la clasificación contenida en el último Atlas Estadístico de Áreas Urbanas de España (2018), Linares aparece dentro de la categoría de Grandes Áreas Urbanas (GAU), pero formada por un solo municipio; esta composición se viene manteniendo desde 1996. Sin embargo, el INE y Urban Audit, en 2018, le incorporan el municipio de Torreblascopedro, por lo que Linares como AUF abarcaría solamente el territorio de estos dos municipios. Sin embargo, reducir la influencia de esta área según los criterios establecidos para la distinción de AUF establecidos por Urban Audit puede, cuando menos, distorsionar y constreñir el mapa de influencia del AU de Linares. Por su parte el IECA tiene delimitados los municipios a los que, según diferentes funciones, Linares actúa como centro de las mismas. Las divisiones van desde aquellas que solamente sirven al municipio de Linares, (Junta Electoral de Zona, Demarcación Agencia Tributaria o Distrito Notarial), hasta las más numerosas como corresponde al distrito Sanitario; pero las más frecuentes son las que abarcan entre los 4 o 12 municipios, como la demarcación judicial (4), las Zonas Básica de Salud (7), (del IDTA, Informe de Desarrollo Territorial de Andalucía) (11), o las Oficinas de Comarcalización Agraria (12).

Teniendo en cuenta que los criterios de tiempo de viaje y distancias reales son factores importantes que influyen en los flujos de movilidad en general, se ha elaborado un mapa con la aplicación Network Analyst de ArcGis que permite, a partir de la construcción de una capa de red de transporte, determinar la vinculación entre Linares y el resto de los municipios (Figura 1). Estableciendo como umbral de corte en tiempo de viaje los 20 minutos, el resultado es que 10 municipios se encuentran dentro de ese radio de influencia, comprendiendo unas distancias que oscilan entre los 16 y $31 \mathrm{~km}$. La comparación de los 10 municipios vinculados con relación a las demarcaciones territoriales establecidas por el IECA se observa que: $1^{\circ}$, tres de los diez (Ibros, Canena y Villanueva de la Reina) aparecen fuera de las diferentes demarcaciones seleccionadas. $2^{\circ}$, de los siete restantes Jabalquinto es el municipio que se encuentra incluido en más demarcaciones (siete en total); después estarían Arquillos, Bailén, Carboneros, Guarromán presentes en cinco demarcaciones, La Carolina en cuatro y Torreblascopedro en tres. $3^{\circ}$, finalmente tendríamos los municipios que se hayan dentro de alguna de las demarcaciones establecidas por el IECA, pero que caen fuera del área de influencia establecido en este trabajo, que serían Aldeaquemada, Baños de la Encina, Mengíbar, Santa Elena, Vílchez y Villatorres.

Del análisis efectuado se puede deducir las deficientes condiciones de accesibilidad que todavía presentan algunas poblaciones que se hallan dentro del área de influencia de Linares según el criterio de tiempo de viaje que se ha establecido. Poblaciones que se encuentran dentro de la distancia límite marcada según el tiempo de viaje, pero que no han sido seleccionadas, se hallan Úbeda, Baeza, Vilches, Villatorres, Navas de San Juan, Mengíbar y algunas otras de menor importancia. 


\section{LA CRISIS DE CRECIMIENTO URBANO}

\subsection{LA POBLACIÓN URBANA Y EL GRADO DE URBANIZACIÓN}

La pérdida de población en los últimos años ha sido continuada (Tabla 1); entre 2015 y 2018, Linares ha perdido casi 2000 habitantes. Resulta de interés, igualmente, observar, el cambio producido en la distribución de la población. El IECA proporciona los datos que permiten, a partir de la Base de Datos Longitudinal de Población de Andalucía (BDLPA), realizar la representación de la distribución de la población, para los años 2002 a 2017, en una malla de 250 * 250 m, gracias a la georreferenciación que ha realizado de la localización de la población. A continuación, se presentan los resultados del cambio experimentado entre ambas fechas (Tabla 2; Tabla 3; Figura 2). Lo primero que cabe destacar es la pérdida de población en las celdas con mayor volumen de población pasando de representar el 42,98 \% de la población en el 2002 al 30,87 \% en el 2017. En cambio, experimentan un crecimiento entre esas fechas las que contiene un rango de población entre los 501 y 1.000 hab. Pero lo que refleja este cambio es el proceso de despoblación que ha venido sufriendo el centro de la población, pues es en esta zona donde se observa el decaimiento de celdas con alto volumen poblacional. Son las zonas de Plaza de Toros, Miranda y La Florida las más afectadas por el descenso poblacional. Mientras que se produce un crecimiento en torno a los ejes de la Avd. Primero de Mayo, Calle Úbeda y Camino de Fuente Álamo, donde se viene desarrollando la Urbanización Álamo.

Esta dinámica, de continuar la tendencia señalada, iría en contra de unos de los principios de la ciudad sostenible que aboga por la mayor densificación de los centros urbanos y la contención de la dispersión de la población por las periferias urbanas, así se recoge, entre otros documentos, en la Estrategia Española de Sostenibilidad Urbana y Local (Gobierno de España, 2011).

Tabla 2. Distribución de la población

\begin{tabular}{|l|c|c|c|c|c|c|c|c|}
\hline \multirow{2}{*}{$\begin{array}{l}\text { Tramos de } \\
\text { población }\end{array}$} & \multicolumn{4}{|c|}{ POBLACIÓN 2002 } & \multicolumn{4}{c|}{ POBLACIÓN 2017 } \\
\cline { 2 - 9 } & celdas & $\begin{array}{c}\text { Población } \\
\text { total 2002 }\end{array}$ & $\begin{array}{c}\% \\
\text { celdas }\end{array}$ & $\begin{array}{c}\% \\
\text { población }\end{array}$ & $\begin{array}{c}\mathbf{N}^{\circ} \text { de } \\
\text { celdas }\end{array}$ & $\begin{array}{c}\text { Población } \\
\text { total 2017 }\end{array}$ & $\begin{array}{c}\% \\
\text { celdas }\end{array}$ & $\begin{array}{c}\% \\
\text { población }\end{array}$ \\
\hline Hasta 100 & 55 & 1.354 & 37,93 & 2,31 & 48 & 1.726 & 33,10 & 2,96 \\
\hline de 101 a 300 & 21 & 3.923 & 14,48 & 6,69 & 29 & 5.477 & 20,00 & 9,38 \\
\hline de 301 a 500 & 20 & 7.529 & 13,79 & 12,84 & 17 & 6.856 & 11,72 & 11,74 \\
\hline de 501 a 1000 & 29 & 20.625 & 20,00 & 35,18 & 37 & 26.311 & 25,52 & 45,06 \\
\hline $\begin{array}{l}\text { de 1001 a } \\
2000\end{array}$ & 20 & 25.200 & 13,79 & 42,98 & 14 & 18.024 & 9,66 & 30,87 \\
\hline Totales & 145 & 58.631 & 100 & 100 & 145 & 57.394 & 100 & 100 \\
\hline
\end{tabular}

Fuente: Elaboración propia 
La información ofrecida por el IECA sobre la distribución de la población permite también analizarla en función del nivel de urbanización, según las tipologías establecidas por Eurostat (2018). La población de Linares aparece englobada dentro de la categoría de ciudades, presentando el siguiente reparto en el 2017: el 89,3\% de la población como residente en centro urbano y el 10,70 \% en malla rural; no se encuadra ninguna en la categoría intermedia de agrupaciones urbanas.

Tabla 3. Evolución y distribución del grado de urbanización de la población

\begin{tabular}{|c|c|c|c|c|c|c|c|c|c|c|}
\cline { 2 - 10 } & \multicolumn{4}{c|}{ Urbanización $\mathbf{2 0 0 2}$} & \multicolumn{4}{c|}{ Urbanización $\mathbf{2 0 1 7}$} \\
\cline { 2 - 10 } & $\begin{array}{c}\text { Celdas } \\
\mathbf{n}^{\circ}\end{array}$ & $\begin{array}{c}\text { Área } \\
\text { has }\end{array}$ & $\begin{array}{c}\text { Población } \\
\text { hab. }\end{array}$ & $\begin{array}{c}\text { Superficie } \\
\%\end{array}$ & $\begin{array}{c}\text { Población } \\
\%\end{array}$ & $\begin{array}{c}\mathbf{N}^{\circ} \\
\text { celdas }\end{array}$ & $\begin{array}{c}\text { Área } \\
\text { has }\end{array}$ & $\begin{array}{c}\text { Población } \\
\text { hab. }\end{array}$ & $\begin{array}{c}\text { Superficie } \\
\%\end{array}$ & $\begin{array}{c}\text { Población } \\
\%\end{array}$ \\
\hline $\begin{array}{c}\text { TIPO } \\
\text { urbanización }\end{array}$ & 98 & 612,1 & 54.509 & 68,06 & 92,97 & 93 & 581 & 52.172 & 64,96 & 89,34 \\
\hline Malla rural & 47 & 287,3 & 4.122 & 31,94 & 7,03 & 52 & 313 & 6.222 & 35,04 & 10,66 \\
\hline TOTALES & 145 & 899,3 & 58.631 & 100 & 100 & 145 & 894 & 58.394 & 100 & 100 \\
\hline
\end{tabular}

Fuente: Elaboración propia

Figura 2. Distribución de la población y grado de urbanización
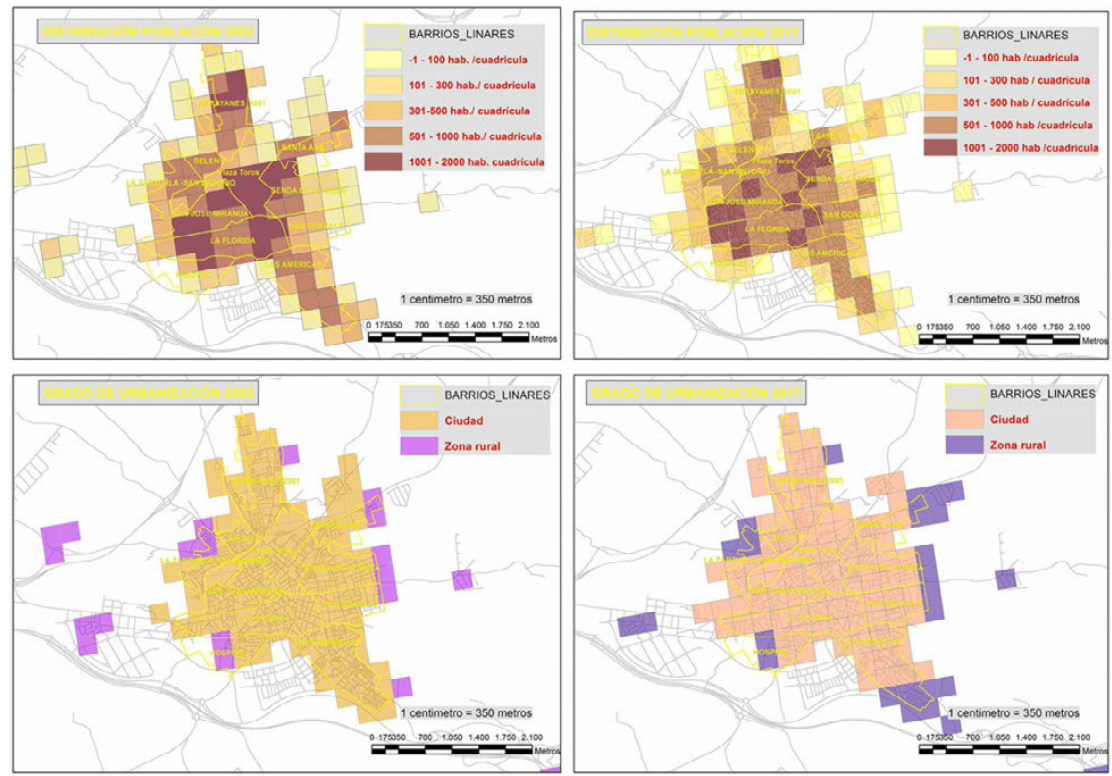

Fuente: Elaboración propia 
La evolución experimentada del 2002 al 2017 ofrece una inequívoca pérdida del peso de la población residente en el centro urbano frente al avance de la población residente en malla rural: 7,03 \% en 2002 y 10,66 \% en 2017. Del mismo modo se ha producido un cambio en la superficie ocupada por cada uno de los tipos de residencia. En el primer caso (población en centros urbanos) se produce una pérdida de 62 has, mientras que la superficie en malla rural gana en más de 26 has. Así pues, en tanto que la clasificación de tipologías urbanas establecidas por Eurostat conjuga los criterios de densidad poblacional con los de contigüidad de las celdas, esa pérdida de la intensidad en el nivel de urbanización es lo que mejor puede apreciarse (Figura 2).

\subsection{LA OCUPACIÓN DEL SUELO}

La crisis urbana de Linares ha alcanzado también a este componente de la realidad territorial. El proceso de artificialización del suelo en las últimas décadas ha sido ampliamente abordado a diferentes escalas de análisis. Los datos of recidos por el CLC permiten cuantificar cuál ha sido la evolución de los suelos artificiales desde 1990 a 2018. En Linares el suelo artificial ha crecido desde las 842,88 has a las 1.734,81 has en el 2018; la diferencia es de 891,93 has lo que supone un incremento del $105,82 \%$. El peso del suelo artificial sobre la superficie municipal, en 2018, sería del 8,82\%. Entre estos años el suelo urbano continuo ha bajado de representar el 50,62 \% en 1990 al 33,65 \% en 2018.Esta pérdida de peso del suelo urbano continuo en relación a la superficie artificial no quita que se haya producido un aumento de 157 has desde 1990 a 2018. En cambio, sí experimentan un crecimiento absoluto y relativo, aunque con desigual proporción, el tejido urbano discontinuo y las zonas en construcción. El peso más alto del tejido discontinuo durante este periodo de tiempo se alcanza en el CLC del año 2000, mientras que el de las zonas en construcción en el CLC del 2012.

La información del SIOSE abarca el periodo que va desde 2005 a 2014. El porcentaje de lo que representan las superficies artificiales alcanzaba, en 2014, el 10,56\% de la superficie municipal, porcentaje superior al que ofrece el CLC para 2018.En relación al suelo urbano, la superficie ocupada por el urbano consolidado (casco) no presenta ninguna variación; en cambio sí son importantes los experimentados por el urbano de tipo ensanche y el urbano discontinuo. El suelo calificado como ensanche gana entre 2005 y $201.465,7$ has, lo que supone un incremento del 16,6\%; y el urbano discontinuo aumenta en 10,86 has, esto es, un aumento del 9,95\%. El otro dato significativo será la pérdida que se produce en el suelo artificial no edificado, que pasa de las 271.7 has a 229,5 has.

El proceso seguido no presenta, sin embargo, un ritmo en el cambio regular, sino que claramente se pueden establecer dos etapas marcadas. El aumento significativo en el suelo urbano tipo ensanche y el urbano discontinuo se pro- 
duce entre 2005 y 2009, mientras que, a partir de este año, el cambio es inapreciable; lo mismo podría decirse respecto al suelo calificado como artificial no edificado. De los datos ofrecidos por el CLC se observa igual, para el suelo urbano discontinuo, una etapa de crecimiento hasta el año 2006, un descenso en el 2012 y una recuperación para el 2018.

\subsubsection{EL SUELO DE USO RESIDENCIAL}

Tabla 4. Uso suelo residencial según PGOU 1995 y 2009

\begin{tabular}{|c|c|c|c|c|c|c|c|c|}
\hline Clase suelo & 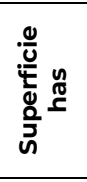 & 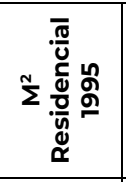 & 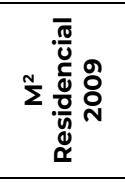 & $\begin{array}{l}\text { Ln } \\
\text { O } \\
\dot{z} \\
\text { z } \\
\text { z }\end{array}$ & 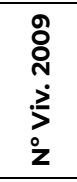 & 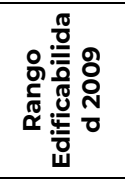 & 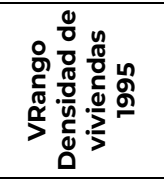 & 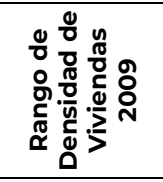 \\
\hline Urbano C & 12,78 & 74.902 & 114.211 & 810 & 728 & $\begin{array}{c}0,43 a \\
2,11\end{array}$ & $\begin{array}{c}26,63 \mathrm{a} \\
144,39\end{array}$ & $\begin{array}{c}26,63 a \\
147,78\end{array}$ \\
\hline Urbano NC & 59,39 & 363.216 & 560.575 & 1.575 & 1.775 & 0,15 a 1,25 & 5,65 a 74,07 & 5,65 a 190,38 \\
\hline $\begin{array}{l}\text { Urbanizable } \\
\text { Sectorizado }\end{array}$ & 128,11 & 1.321 .499 & 1.212 .649 & 3.696 & 3.667 & 0,4 a 0,9 & $\begin{array}{r}4,97 a \\
226,85\end{array}$ & $\begin{array}{r}4,97 a \\
226,85\end{array}$ \\
\hline $\begin{array}{l}\text { Urbanizable } \\
\text { No } \\
\text { Sectorizado }\end{array}$ & 41,71 & 0 & 7404 & 0 & 0 & 0 & 0 & 0 \\
\hline Totales & 242,01 & 1.759 .617 & 1.894 .839 & 6.081 & 6.170 & 0 & 0 & 0 \\
\hline
\end{tabular}

\section{Fuente: Elaboración propia}

EI CLC ofrece los datos referidos a la clasificación del suelo (urbano, urbanizable y no urbanizable), superficie de las áreas en desarrollo, número de viviendas previstas y pendientes, edificabilidad residencial prevista y pendiente y densidad de viviendas. EI SIOSE nos permite evaluar la evolución de la edificación en general y la tipología edificatoria. Con los datos contenidos en el Catastro podremos obtener el volumen y densidad de viviendas por ha y el indicador de compacidad absoluta. Finalmente, la consulta del Plan General de Ordenación Urbana (PGOU) de 1995 y 2009 nos presenta las tendencias actuales en la política urbana municipal.

En el PGOU de 1995 el suelo de uso residencial (sin contabilizar el suelo urbanizable no sectorizado) suma $1.759 .617 \mathrm{~m}^{2}$, mientras que en el PGOU del 2009 son $1.894 .839 \mathrm{~m}^{2}$, se ha producido, pues, un aumento del uso residencial de 11,61 has. También se produce un incremento en el número de viviendas programadas 6.081 en el de 1995 frente a las 6.170 en el de 2009. Y más del 85 \% de estas viviendas se localizan en suelo urbano no consolidado y urbanizable sectorizado.

Los datos del SIOSE permiten conocer la tipología de vivienda; así la edificación entre 2005 y 2014 ha aumentado en algo más de 24 has, crecimiento 
que se produce sobre todo entre los años 2005 y 2009. Siendo lo más característico de este crecimiento que estará protagonizado por la vivienda unifamiliar aislada o adosada y edificios aislados.

Determinar si el desarrollo urbanístico residencial se adapta a los estándares establecidos de una ciudad sostenible obliga a descender a la escala de unidades de planeamiento. La LOUA en su art.17 manda que la construcción de viviendas «cuando se refiera al uso característico residencial la densidad no podrá ser superior a 75 viviendas por hectárea y la edificabilidad a un metro cuadrado de techo por metro cuadrado de suelo». De la información contenida en el Plan de 2009 se desprende que en las unidades de suelo urbano no consolidado la norma se cumple en todas, salvo en dos casos (P-3 y P-8), en tanto que en las unidades de suelo urbanizable sectorizado la norma se respeta en todas, salvo en la SOU-S5 que ofrece una densidad de 226,85 viviendas/ha.

Para ver una imagen sobre la densidad de viviendas real y sobre la edificabilidad se ha elaborado la Figura 3. Los datos del Catastro nos han permitido realizar el mapa de densidad de viviendas y el de compacidad absoluta, dos indicadores incluidos dentro de sistema de indicadores de la ciudad sostenible. Los valores de densidad de viviendas se reparten de manera desigual; dentro del límite del casco urbano, en su parte central, es donde se concentra mayoritariamente las celdas que están por encima de las 75 Viv/ha; en cambio, en los sectores en proceso de urbanización la densidad se mantiene por debajo del estándar establecido salvo en el sector S-5, S-6. La comparación de los datos de viviendas construidas según catastro en cada sector con lo que figura en el documento del PGOU arroja diferencias sensibles en cuanto a número de viviendas y densidad en cada unidad del suelo urbano no consolidado y urbanizable sectorizado. En el urbano no consolidado la unidad P-2 y P-8 tienen densidades muy por encima de las $75 \mathrm{Viv} / \mathrm{h} a$. que rige la norma; y lo mismo puede decirse de las unidades del urbanizable sectorizado S-5, S6 (Barriada de San Gonzalo) y S-22 (Barriada de Santa Ana).

El indicador de compacidad pone en relación el volumen edificado con la superficie de suelo ( $\mathrm{m}^{3}$ de techo/ $\mathrm{m}^{2}$ de suelo). Para obtenerlo se ha utilizado la información del catastro y una malla de 100 m de lado. Los valores se han clasificado en seis clases. Aquellas celdas que tienen valores iguales o superiores a los 2,5 $\mathrm{m}$ se pueden considerar con un valor de compacidad aceptable; estas representan solamente el $21 \%$ sobre el total. El reparto sobre el suelo urbano evidencia que tienen valores aceptables el centro urbano y barrios como Los Arrayanes, Las Américas, La Florida, Santa Ana y San Gonzalo. Cuatro ejes viarios concentran en torno suyo los mayores índices de compacidad: Avd. de Andalucía, Paseo de la Virgen de Linarejos, Avd. Primero de Mayo y Paseo de los Marqueses de Linares. 
Figura 3. Usos del suelo, densidad de viviendas y compacidad urbana
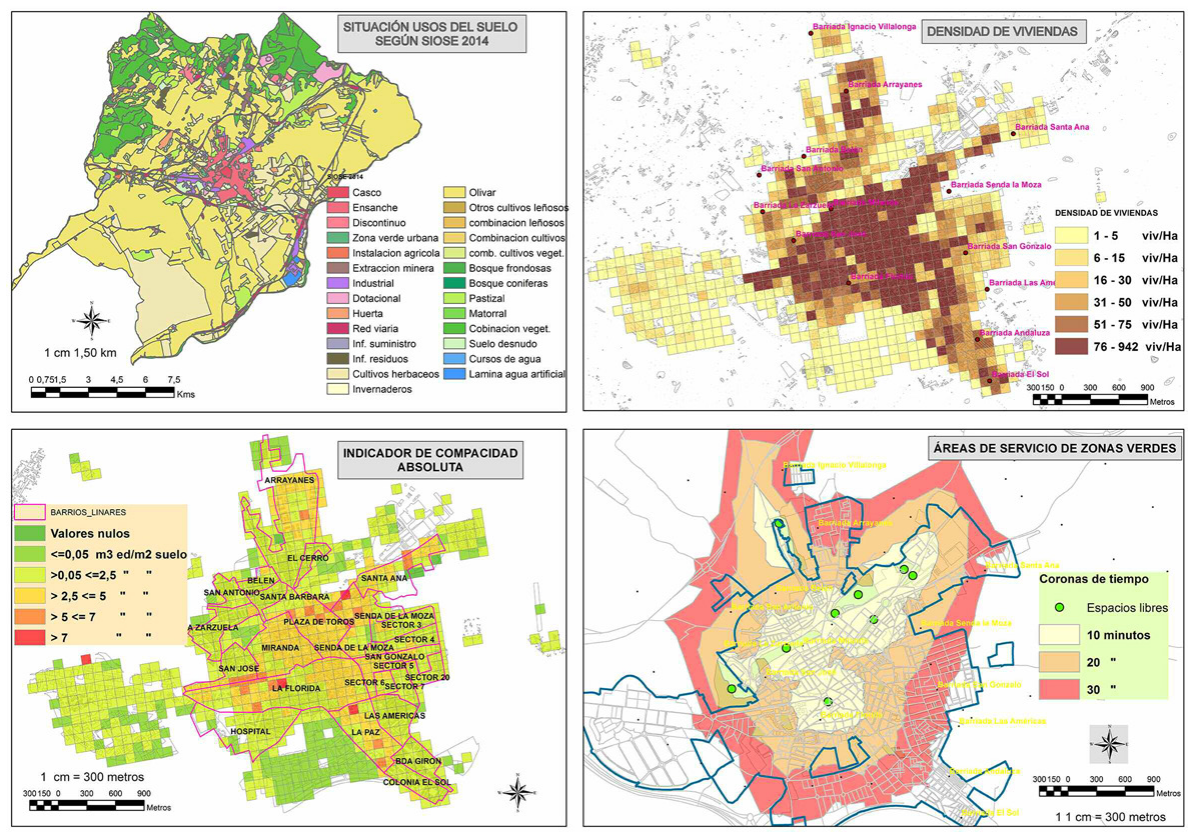

Fuente: Elaboración propia

\subsubsection{EL SUELO DESTINADO A ESPACIOS LIBRES}

Finalmente, otro de los aspectos que más ha caracterizado la crisis de Linares ha sido el déficit de zonas verdes (Goerlich F., Reig, E., Pérez, C. y Robledo, J., 2019). El interés despertado por la presencia de espacios libres en las ciudades tiene que ver con su influencia, como indicador, sobre la calidad de vida de la población. Para ello ya no basta si se cumple un indicador global como puede ser el de $\mathrm{m}^{2}$ de zona verde por hab., sino que conviene tener en cuenta otros aspectos como su distribución en la ciudad, o la accesibilidad a los ciudadanos. Según el SIOSE Linares habría pasado de las 10,92 has de parques y jardines que tenía en 2005, a las 17,27 has de 2014. Si en 2014 la población de Linares era de 60.290 hab. quiere decir que la razón de $\mathrm{m}^{2}$ de zona verde por hab. era de $2.86 \mathrm{~m}^{2}$, bastante por debajo de los estándares que se consideran aconsejables. Para conocer la situación actual, la información contenida en el último PGOU nos permite entrar en su análisis. En el mismo se delimitan nueve espacios libres como parques y jardines que totalizan $411.330 \mathrm{~m}^{2}$, de los cuales 49.595 (12.05 \%) se localizan en suelo urbano, $231.447 \mathrm{~m}^{2}$ (56.26\%) en suelo urbanizable y 130.288 en suelo no urbanizable. En suelo urbano se hallan el 
Paseo de Linarejos, el Parque Empresarial Santana, Parque Rodríguez de la Fuente, Parque Mariana Pineda y Plaza del Ayuntamiento; en suelo urbanizable El Pisar I y II y en no urbanizable Cantarranas. Con estos datos los índices globales para la ciudad serían de $7.11 \mathrm{~m}^{2}$ de zonas verdes por hab. y 4,24 $\mathrm{m}^{2}$ por superficie de suelo urbano.

Desde el punto de vista de su configuración urbanística se presenta una clara linealidad en siete de los nueve espacios libres, en sentido SW-NE, tomando como ejes de referencia las calles Virgen de la Antigua, Eriazos de la Virgen y Paseo de la Virgen de Linarejos; a un lado y otro de este eje verde estarían la Plaza del Ayuntamiento, al sur y el que se encuentra próximo a la barriada de Arrayanes, al norte (Figura 3).

Tabla 5. Población servida por zonas verdes

\begin{tabular}{|c|c|c|c|c|c|c|c|c|}
\hline \multirow{2}{*}{$\begin{array}{c}\text { Tramos de } \\
\text { Tiempo }\end{array}$} & \multicolumn{4}{|c|}{ Población 2017 } & \multicolumn{4}{c|}{ Población 2002 } \\
\cline { 2 - 9 } & $\begin{array}{c}\mathbf{N}^{\circ} \\
\text { Puntos }\end{array}$ & Población & $\%$ & $\begin{array}{c}\text { \% sobre } \\
\text { Población } \\
\text { Total }\end{array}$ & $\begin{array}{c}\mathbf{N}^{\circ} \\
\text { Puntos }\end{array}$ & Población & \% & $\begin{array}{c}\text { \% sobre } \\
\text { Población } \\
\text { Total }\end{array}$ \\
\hline $0-10$ & 32 & 21.678 & 41,67 & 37,09 & 33 & 22.861 & 43,2 & 39,55 \\
\hline $10-20$ & 39 & 19.768 & 38 & 33,82 & 39 & 20.583 & 38,89 & 35,61 \\
\hline $20-30$ & 19 & 10.571 & 20,32 & 18,09 & 19 & 9.476 & 17,91 & 16,39 \\
\hline Total & 90 & 52.017 & 99,99 & 89 & 91 & 52.920 & 100 & 91,56 \\
\hline $\begin{array}{c}\text { Total } \\
\text { Población }\end{array}$ & & 58.449 & 89 & & & 57.800 & 91,56 & \\
\hline
\end{tabular}

Fuente: Elaboración propia

La accesibilidad a los espacios libres es uno de los aspectos críticos en la planificación de los mismos. Para analizar esta característica hemos utilizado Network Analyst, que mediante la aplicación «Área de servicio» permite delimitar diferentes zonas en función del tiempo de acceso a cada espacio libre. Para ello se han establecido tres franjas de 10, 20 y 30 minutos; tiempo que tardaría un peatón en acceder a ellas. El cruce de esta capa con la capa de distribución de la población del IECA para 2002 y 2017 ha permitido determinar la población a la que sirve cada corona y la queda fuera, porque el tiempo invertido en acceder a cualquiera de ellas superaría los 30 minutos. Como se observa, el porcentaje de población que está dentro de los umbrales establecidos ha descendido entre el 2002 y el 2017, del 91,56 al 89 \% (Tabla 5). El porcentaje de población de los que están más próximos a un espacio libre ha disminuido entre el 2002 y el 2017 y, al mismo tiempo, es significativo el aumento que se produce en el porcentaje de población que tarda más tiempo en alcanzar una zona verde, es decir, aquellos que se encuentran en la franja de los 20 a 30 minutos. Finalmente, la población que queda fuera de las áreas de servicio establecidas ha aumentado en el periodo de referencia. 
Todo lo anterior viene a corroborar, por este otro indicador, el desplazamiento hacia la periferia urbana de la población y el paulatino vaciamiento de la parte central de la ciudad. Tendencia, por lo tanto, que parece contradecir una de los objetivos estratégicos de la ciudad sostenible.

\section{A MODO DE CONCLUSIÓN. REGENERACIÓN URBANA Y SOSTENIBILIDAD EN LINARES}

La situación actual de Linares es el resultado de décadas de decaimiento urbano. Y esta pérdida de relevancia afecta a todos los órdenes de la vida en la urbe y, por extensión, al conjunto de su comarca. Comenzando por la desestructuración del tejido económico desde los años 1980, que actuó con especial saña sobre el sector industrial en un proceso prolongado hasta nuestros días. Continuando por los efectos devastadores de la burbuja inmobiliaria en la primera década de este siglo, que distrajo la inversión y el esfuerzo productivo de la zona - por modestos que estos pudieran ser- en proyectos que no aportaron nada en términos de empleo y riqueza en el medio y largo plazo; a lo que se unió la ligera pero aparentemente incorregible decadencia del contexto productivo rural de la ciudad (agroindustria, olivicultura), mal organizados productivamente y muy atomizados, y por tanto, con serios problemas de competitividad en sus respectivos sectores.

Incluso en un contexto tan dificultoso como este, las oportunidades y proyectos encaminados a regenerar la trama urbana y la construcción de escenarios de oportunidad empresarial, favoreciendo al mismo tiempo una mayor calidad de vida para sus habitantes, han existido también en Linares. Y algunos de ellos son viejos conocidos de la planificación y la gestión urbanas, si bien no siempre estas herramientas han sido utilizadas en el sentido que aquí se defiende.

En primer lugar, nos encontramos con los PGOUs de 1995 y 2009. El PGOU es la principal herramienta con la que cuenta un ayuntamiento para impulsar procesos de desarrollo territorial a escala local. El urbanismo no es sólo, por tanto, una fuente legítima de ingresos, sino que debería servir para diseñar y construir, física y socialmente, un espacio para la calidad de vida y un entorno de oportunidades para la inversión. EI PGOU de 1995 ponía coto a desmanes históricos (desarrollismo, ausencia de planificación integrada histórica), comenzaba a encarar la desaparición de la minería y la industria en la ciudad (contaminación, residuos, solares y desempleo), la postración económica y social del casco histórico, y afrontaba lacras seculares en barrios periféricos como las bolsas de pobreza, falta de servicios básicos y, en general, la existencia de barrios aislados y desconectados de la trama urbana principal (física y socialmente).El de 2009, adaptado a la LOUA de 2002, continuaba el esfuerzo anterior - que en muchos casos tuvo un resultado insatisfactorio por, entre otras cosas, los efectos de la burbuja inmobiliaria-y encaraba otros nuevos, como afrontarla incorporación de la ciudad a nuevas dinámicas 
territoriales o el impulso al acceso a nuevos servicios como zonas verdes, instalaciones deportivas, educativas u hospitalarias, buscando garantizar la igualdad de los ciudadanos en estas materias (Territorio Urbanístico, 2009). En segundo lugar, y llevando un poco más allá las prescripciones y normas del plan general, en el marco 2014-2020 de inversiones con fondos de la política de cohesión de la Unión Europea, se puso en marcha la «Estrategia de Desarrollo Urbano Sostenible Integrado -EDUSI- de Linares». Documento holístico en sus pretensiones y propuestas, pretendía reforzar la dimensión de sostenibilidad —no sólo en el aspecto ambiental, también social, democrático, económico y territorial — de la vida urbana de la ciudad. Para ello, el presupuesto total de 12,5 millones de $€$ abarca intervenciones por la regeneración de áreas urbanas desfavorecidas (24\% del total), promover la protección del patrimonio e impulsar fines turísticos en torno a él $(33,6 \%)$, fomentar estrategias de reducción del $\mathrm{CO}_{2}$ a través del impulso a la movilidad urbana sostenible y la eficiencia energética (28,5\%) y, finalmente, impulsar el desarrollo del proyecto «Smart city» y las TIC en el municipio $(9,6 \%)$ (Ayto. Linares, 2014).

Finalmente, y como parte de las iniciativas urbanas impulsadas desde la Unión Europea, Linares también participó de los planes URBAN, que con casi 14 ' 5 millones de $€$ de presupuesto asignado, permitió afrontar algunas intervenciones -es verdad que más bien puntuales-, en la zona del casco urbano (viales y Paseo del Arroyo, saneamiento y servicios básicos en barrios periféricos, asistencia técnica al ayuntamiento...). El sentido último del plan estaba centrado en la recualificación de la trama urbana y, como parte complementaria a un plan más global como el que impulsaban el mismo PGOU y otras estrategias, sumaba esfuerzos en la vertebración social y física del mismo (Comisión Europea, 2006).

En suma, se trata de un conjunto de esfuerzos que, a través de la aplicación de los valores de la gobernanza, la participación pública a distintos niveles y los medios con que cuentan las herramientas de la gestión urbana tradicional, intentan hacer frente a un escenario de conflictos y disfunciones que, hasta ahora, no se ha sabido siquiera reconducir, y que plantea múltiples desafíos de cara a un futuro inmediato en todo lo relacionado con la articulación física y la cohesión social de este espacio urbano.

\section{REFERENCIAS}

Ayuntamiento de Linares (2014). Estrategia de Desarrollo Urbano Sostenible Integrado (EDUSI), Linares 2016-2020. Linares: Ayuntamiento de Linares, Fondos FEDER.

Campos, F. (2016). Ciudades medias españolas Siglo XXI. Revisión y análisis bibliométrico de enfoques y temáticas predominantes. Cuadernos Geográficos 56 (1), 217-241. 
Caravaca, I., González, G., Mendoza, A. y Silva, R. (2008). Dinamismo, innovación y desarrollo en ciudades pequeñas y medias de Andalucía. Sevilla: Consejería de empleo. Consejo Económico y Social de Andalucía.

Caravaca, I., González, G. y López, P. (2014). Crisis y desarrollo territorial en las ciudades de Andalucía. Revista Estudios Regionales, 100, 47-82.

Comisión Europea (2006): Plan URBAN Linares. Linares: Ayuntamiento de Linares.

Dijkstra, L. y Poelman, H. (2014). Regional Working Paper 2014. A harmonized definition of cities and rural areas: the new degree of urbanization.

EUROSTAT (2018). Methodological manual on territorial typologies. Luxembourg: Publications Office of the European Union.

Goerlich F., Reig, E., Pérez, C. y Robledo, J. (2019). Las áreas urbanas funcionales en España: Economía y Calidad de vida. Madrid: Fundación BBVA.

Méndez, R. (2007). Dinámica de las ciudades en Andalucía. IEA. Sevilla: Consejería de Economía y Hacienda.

Gobierno de España (2011). Estrategia Española de Sostenibilidad Urbana y Local (EESUL). Madrid: Ministerio de Medio Ambiente y Medio Rural y Marino. Ministerio de Fomento.

Gobierno de España (2019). Agenda Urbana Española 2019. Ministerio de Fomento.

Territorio Urbanístico U.T.E. (2009). Plan General de Ordenación Urbana (PGOU). Adaptación parcial a la ley 7/2002 de Ordenación Urbanística de Andalucía. Linares: Ayuntamiento de Linares.

Unión Europea. Comisión Europea, Dirección General de Política Regional (2011). Ciudades del Mañana: Retos, visiones y caminos a seguir. Luxemburgo: Oficina de Publicaciones de la Unión Europea. 



\title{
DE MACROFESTIVALES A MEGAPROYECTOS URBANOS. DOS EXPERIENCIAS EN LA COMUNIDAD VALENCIANA (CULLERA Y BURRIANA) \\ FROM MACROFESTIVALS TO URBAN MEGAPROJECTS. TWO EXPERIENCES IN COMUNIDAD VALENCIANA (CULLERA AND BURRIANA)
}

\author{
Jaime Martínez Ruiz
}

Universidad de Barcelona

Resumen

Cada vez proliferan más los festivales de música en nuestras ciudades intermedias. Su gran asistencia ha generado experiencias de fidelización en torno a la industria de la música (musical) y al turismo local con un carácter festivo. Estas áreas se convierten en espacios de encuentro que, durante un breve lapso, son escenario de pernoctaciones y generan numerosos ingresos y empleos. Sin embargo, en la ubicación de algunos se aprecian indicios de promoción de viejos proyectos urbanísticos, que se revitalizan a través de estos eventos. Se trata de grandes proyectos urbanos que quedaron aparcados en la peor etapa de la recesión económica y que resurgen con la recuperación, intentando sortear las normativas de protección costera.

El objetivo es analizar la relación entre la celebración de dos macrofestivales y la revitalización de estos antiguos megaproyectos. Para ello, se realizará un estudio comparativo de Cullera (Manhattan de Cullera) y Burriana (PAI Golf Sant Gregori) con una metodología que combina el análisis hemerográfico y la revisión normativa. En ambos casos, se detecta un retorno a patrones especulativos anteriores a la crisis económica, revelando disputas por el control del uso del suelo y una cierta falta de visión integral de la gestión territorial.

Palabras clave: planificación territorial, eventos multitudinarios, promoción, proyectos urbanísticos y gobernanza.

\section{Abstract}

Music festivals are proliferating more and more in Spanish intermediate cities. The great attendance has generated bindings towards the music industry and to local tourism, with a festive character. These areas have become a meeting point, as they are the background scenario of overnights stays and a unique experience. Furthermore, they generate great incomes and employments. However, they suppose a revitalisation of the promotion of elder urbanistic projects. This is seen in the ubication. These great projects were set aside because of the economic recession and have remerged in a better economic state, where they have tried to avoid the coastal protection normative. The aim is the analysis of the relationship between the celebration of two macro- 
festivals and the revitalisation of the superprojects. That is the reason why a comparative study of Cullera (Manhattan de Cullera) and Burriana (PAI Golf Sant Gregori) is carried out using a methodology which combines hemerographic analysis and normative revision. In both cases, it is detected a retorn to speculative patrons from before the economic crisis. This revealed some arguments about the land utilisation control and a certain lack of vision about the integral territorial management.

Keywords: territorial planification, multitidinary events, promotion, urbanistic projects, governance.

\section{INTRODUCCIÓN}

En una sociedad como la actual, en la que todo el mundo posee todos los bienes terrenales, la venta de una experiencia inigualable se convierte en un nuevo método de regalar y sorprender. Así, con la existencia de estos festivales cubrimos estas expectativas, que se potencian gracias a las redes sociales, que generan, a su vez, una exclusividad y un sentimiento de pertenencia a un grupo. La sensación de libertad que otorgan influye en la elección del escenario o del artista que el consumidor quiere escuchar en cada momento. Tras el estallido de la burbuja inmobiliaria, la mayoría de los proyectos urbanísticos de la Comunidad Valenciana quedaron paralizados. Algunos de ellos con la intención de ser guardados hasta una coyuntura económica más favorable. De esta manera, como respuesta, muchas otras comunidades autónomas, especialmente aquellas situadas en el litoral, se aventuraron a aprobar instrumentos de protección con el objetivo de cambiar el modelo de urbanismo que había estado vigente durante las dos últimas décadas anteriores. Un urbanismo que ha generado un litoral fragmentado y vulnerable, con una gran presión urbanística de miles de viviendas, hoteles y campos golf a lo largo de toda la costa.

Así pues, la reciente reactivación de la economía y el mercado de la vivienda han acelerado la puesta en marcha de estos megaproyectos urbanísticos. Con el foco puesto en espacios de zonas vírgenes, limítrofes con espacios protegidos de la costa mediterránea, se reavivan estas ciudades o zonas ya conocidas turísticamente. De esta manera, la crisis en el sector inmobiliario ha derivado en el surgimiento de nuevas plataformas de promoción urbanística, como es la celebración de determinados macrofestivales. La ubicación de estos puede considerarse una nueva forma de promoción de terrenos baldíos. Detrás de estos actos multitudinarios no deja de haber una finalidad de resolver los grandes condicionantes generados en largas sentencias judiciales y un urbanismo desenfrenado, que ha derivado en enfrentamientos a distintos niveles de gobernanza traspasando el conflicto más allá de la escala local. 
Consecuentemente, estos festivales suponen un cambio de imagen para estas zonas, que ha traído consecuencias directas en el cambio del perfil turista más bien nacional por uno internacional. También, su ubicación supone una dinamización de negocios cercanos al festival y una internacionalización de unas ciudades que vuelven a nacer dentro de un contexto turístico boyante. Esta internacionalización, se consigue en parte gracias al uso de las nuevas redes sociales, que, al compartir la experiencia a través de posts, imágenes, vídeos, etc. permiten llegar a más gente de diferentes partes de la aldea global. De este modo, este trabajo se estructura en dos partes. Una primera parte que trata de explicar como estos eventos funcionan como auténticas ciudades informales. La idea central del trabajo es resaltar como la geolocalización de estos eventos puede funcionar como plataformas de promoción urbanística. Posteriormente, la segunda parte, se centra en dos experiencias, que, salvando las distancias, muestran como los festivales son, además, un argumento para evitar normativas y desarrollar antiguos megaproyectos urbanísticos. La metodología del trabajo se fundamenta en un análisis de fuentes secundarias, que combina el análisis hemerográfico de los principales periódicos nacionales y autonómicos con la revisión de la normativa que ha afectado a ambos casos.

\section{LOS FESTIVALES COMO PLATAFORMAS DE PROMOCIÓN URBANÍSTICA}

Lo urbano, ante todo, es una realidad cambiante; el escenario de encuentro para la construcción de la vida colectiva, un ser vivo que crece y muta constantemente. Su definición, por tanto, siempre es imprecisa, pues no puede abarcar todas las connotaciones que este concepto implica (Lefebvre, 1974). En este sentido, existen ciudades que no se encuentran en el mapa, que nacen y mueren súbitamente, y que vuelven a nacer —otra vez. Son, por tanto, espacios de encuentro intermitentes que aglutinan a miles de personas durante unos días, comportándose como ciudades desordenadas cuya localización se encuentra entre el éxito de un plan de negocios y una ciudad de vacaciones temporal.

Estas ciudades indefinidas tienen la característica de ocupar enclaves privilegiados de entornos naturales con largos kilómetros de costa y próximos al mar (Rubio y De Cárdenas, 2006). Una localización, no exenta de polémica, que se constituye alrededor de cuatro elementos fundamentales: El primero, la ubicación en ciudades costeras consolidadas del turismo de sol y playa. Seguidamente, la presencia de comercios pequeños que tienen cierta actividad nocturna en los meses de verano. Tercero, una tipología edificatoria principalmente de segunda residencia con la presencia de construcciones diferenciadas (apartamentos unifamiliares, apartamentos en altura en primera línea de playa y viviendas unifamiliares), que generan un alzado heterogéneo de diferentes estilos arquitectónicos. Por último, un elemento esencial, que es 
la disposición de solares vacíos con diversos propietarios (ayuntamientos, costas y propietarios privados) próximos al paseo marítimo y a playas lo suficientemente amplias como para albergar un camping y el recinto para un evento multitudinario.

De ahí que, la transformación de estos solares baldíos a ciudades del entretenimiento se convierte en la principal plataforma de comunicación y promoción de los folletos turísticos de la ciudad. Con ello, la celebración de estos actos multitudinarios acaba invadiendo las redes sociales, internet, merchandainsing y la franja de edad comprendida entre 20 y 30 años. Así, la estrategia de comunicación se convierte en imprescindible para el desarrollo de estos eventos y su internacionalización. Como si fuera una mancha de aceite, en plataformas como Instagram, Facebook, Twitter y YouTube se publica los 365 días, interactuando con los asistentes de manera continua, proyectando la imagen de que el festival y público hablan el mismo idioma.

Con el tiempo, la influencia de estos medios sociales acaba otorgando la pertenencia a un grupo y diferenciación social, con la denominación de una jerga común (Sounders, Fiberos, Sansaneros, etc.), la vestimenta propia (ropa cómoda, pulsera identificativa, gafas de sol, etc.) o incluso la misma moneda de pago (Tokens, Tuents, etc.). También, permite la sensación de libertad, con la presencia de recintos abiertos, equipamientos básicos, zonas exclusivas de aparcamiento, etc. Que juegan un papel fundamental a la hora de tomar una elección de escenario, artista o el tipo de comida que deseamos consumir. Y eso hace que - al menos por unos momentos_- sea posible compartir ideas o sensaciones similares con otras personas o con un mismo grupo. Además, estos eventos ofrecen la oportunidad de tener días previos para instalar la tienda de campaña, practicar todo tipo de deportes acuáticos (vela, buceo, snorkel, etc.), actividades deportivas (vóley, futbol playa, buggies, etc.), locales chill out, sol y playa. Esto supone un elemento fundamental que genera una experiencia positiva previa a la celebración del acto, que nos muestra el reconocimiento de ese territorio como un espacio amigable o conocido.

De esta manera, la geolocalización de estos eventos multitudinarios pasa a ser la razón por la cual nacen y se llevan a cabo. Un elemento que parece obvio, pero que no siempre se tiene presente. Los festivales son el medio para conseguir una experiencia, compartir y promocionar el espacio físico y virtual. El éxito o el fracaso depende de la presencia activa en redes sociales y la disponibilidad de suelo. Por tanto, los festivales se convierten en una plataforma para establecer espacios de encuentro, interrelaciones con los clientes actuales y potenciales, ajustar los productos a sus necesidades, etc. Consecuentemente, la expansión de estos eventos puede influir en el cambio del matiz de protesta por la adquisición de una experiencia positiva del entorno en el que se ubica el evento. 


\section{NUEVOS ARGUMENTOS PARA VIEJOS PROYECTOS URBANISTICOS. LA NECESIDAD DE UN CAMBIO DE GOBERNANZA}

\subsection{DEL VEGA PORT AL MANHATTAN DE CULLERA PASANDO POR EL MEDUSA SUNBEACH FESTIVAL. EL CASO DE CULLERA}

Por el año 2003, el Ayuntamiento de Cullera y el Instituto Valenciano (IVVSA), organismo independiente de la Generalitat, firmaron un acuerdo para desarrollar el Programa de Actuación Integrada (PAI) del sector de la Vega-Port de Cullera. Un macroproyecto urbanístico que planeaba urbanizar 610.000 metros cuadrados prevista para duplicar la población de Cullera con la construcción de un total de 33 rascacielos de 25 alturas, dos hoteles de 40 plantas, un palacio de congresos y un puerto deportivo con 800 amarres junto a la desembocadura del Júcar (Valero, 2018). La judicialización del conflicto y su difusión por movimientos sociales, como Greenpeace, hicieron que el macroproyecto urbanístico adquiriera la denominación de Manhattan de Cullera.

Figura 1. Proyecto del Manhattan de Cullera
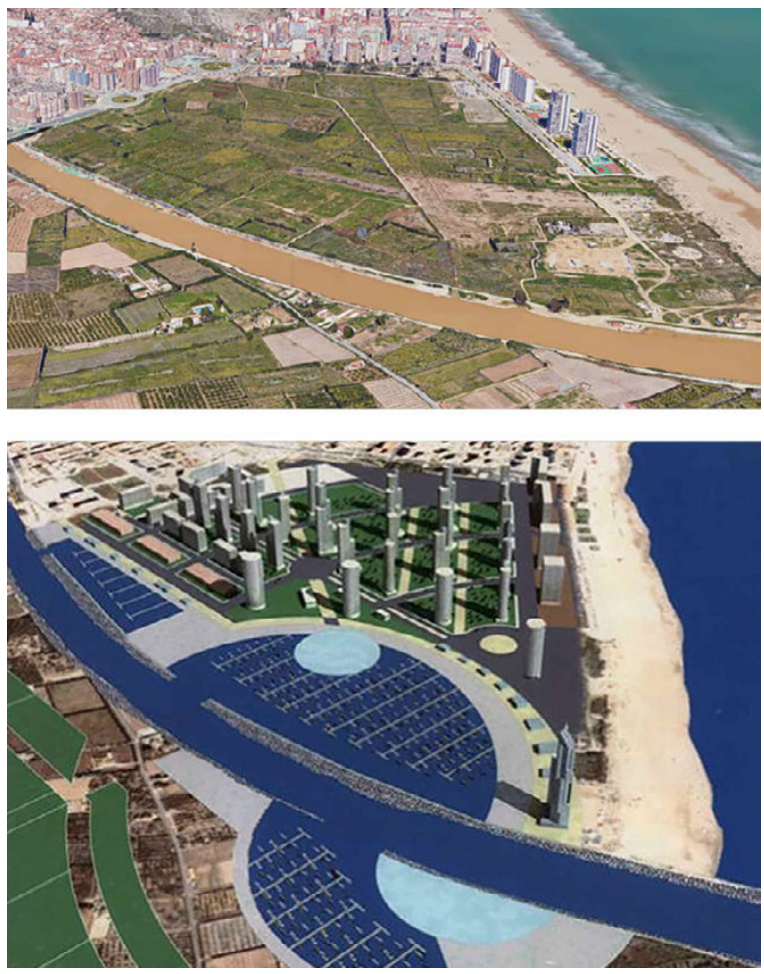

Fuente: Valero, D., 2018 
Inicialmente, el proyecto recibió el visto bueno del gobierno local y de la Comisión Territorial de Urbanismo de Generalitat en el año de 2005. Una decisión envuelta en polémica, que recibió la oposición del Gobierno central que alegaba que las carreteras no podían absorber el tráfico previsto y el proyecto no aseguraba un informe hídrico favorable de la Confederación Hidrográfica del Júcar. Todo con eso, la Generalitat llevó el proyecto urbanístico al TSJCV, que meses más tarde rechazó la suspensión cautelar del PAl y en octubre, el ayuntamiento aprobó las modificaciones que cerraron la tramitación del programa, con dos informes contrarios al gobierno central. Un mes después, el PSPV abogó por pactar un Manhattan reducido sin torres elevadas, que cumpliera los parámetros del Plan General de Ordenacion Urbana (PGOU) y garantizase la disponibilidad de agua y conexiones viarias adecuadas. (Fundación Alternativas, 2007). A partir de entonces, en el año 2007, la Comisión Territorial de Urbanismo dio vía libre al proyecto urbanístico prácticamente en los mismos términos en los que se aprobar en el año 2005 (Colomina y Durán, 2018). Pero, con la llegada de la crisis económica, se frenó el macroproyecto urbanístico. La imposibilidad de asumir los 90 millones de euros necesarios para realizar el proyecto hizo que el ayuntamiento desestimará su intención inicial de encargarse directamente (Tudela y Delgado, 2019). Se of reció por su parte llevar el proyecto a los propietarios del suelo, pero la tramitación administrativa hacía imposible que el proyecto saliera a corto plazo (Colomina y Duran, 2018). En este contexto, el proyecto urbanístico no se abandonó y quedó a la espera de una coyuntura económica más favorable.

De este modo, aquellos solares desiertos adquirieron una nueva funcionalidad. Al final, cualquier espacio debe consumirse, suprimirse o utilizarse (Lefebvre, 1974). De modo que los solares pasaron a ser en una ciudad uniforme con la celebración del Medusa Sunbeach Festival. Un macro festival con escenarios de gran altura que recuerdan a las torres del Manhattan que desde 2012 ha supuesto un impacto directo anual de 25 millones de euros, más de 3.000 personas trabajando directa e indirectamente y una afluencia que, en los últimos años, ha sido de más de 300.000 asistentes con 12.000 plazas de camping. Todo ello, ha tenido implicaciones; posicionando la marca turística de Cullera como una ciudad referente en este tipo de actos, con una dinamización de los pequeños comercios situados en torno al recinto y un cambio del perfil turista, cada vez más internacional. 
Figura 2. Recinto del Medusa Sunbeach Festival

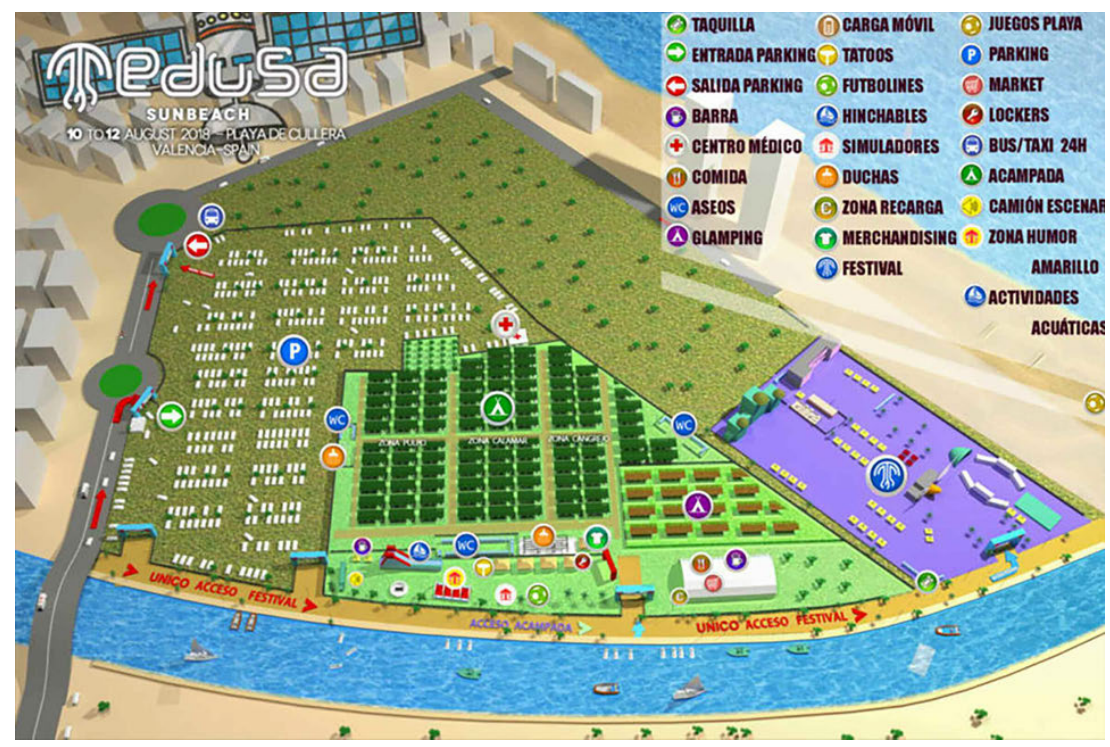

Fuente: culleraturismo.com, 2018

Así mismo, en mayo de 2018, la Generalitat Valenciana aprobó el Plan de Acción Territorial de la Infraestructura Verde del Litoral (Pativel), más conocido como el plan desurbanizador. Un plan ambicioso aprobado con la idea de cambiar el urbanismo que ha estado vigente durante las últimas dos décadas (Tudela y Delgado, 2019). En definitiva, un instrumento de ordenación territorial que se creó con un legado en el que la Comunidad Valenciana es la segunda costa más urbanizada de todo el litoral español (Greenpeace, 2019). Por consiguiente, el plan llegaba con la intención de identificar, proteger y garantizar los últimos suelos de elevada calidad ambiental, territorial y paisajística. Un instrumento que garantiza la protección de los suelos rústicos amenazados con una normativa suficiente para revertir lo que se zonificó de suelo urbanizable a suelo no urbanizable, al tiempo que se conserven espacios abiertos en municipios costeros, contribuyendo a mejorar la calidad de los tejidos urbanos. De esta manera, se protegen los primeros 500 metros desde la orilla hacia el interior, y se establecen condicionantes a los suelos no urbanizables que van desde los 500 metros hasta los 1.500 metros desde la ribera del mar' (Tudela y Delgado, 2019).

1 Para más información consultar el Decreto 58/2018, de 4 de mayo, del Consell, por el que se aprueba el Plan de Acción Territorial de la Infraestructura Verde del Litoral de la Comunitat Valenciana [2018/4631] 
A pesar de ello, y debido a las presiones por presentar recursos de demandas por responsabilidad patrimonial, unidas a una división de los municipios costeros con el mismo color político que el gobierno regional, se optó por flexibilizar la idea original. Una flexibilización que ha dado un plazo de cinco años para desarrollar proyectos programados sobre suelo urbanizable (con el PAI, aprobado antes del estallido de la crisis) y otros cinco años para llevar a cabo la urbanización transcurrido ese tiempo, de no implementarse el proyecto, el suelo volvería ser rústico (Tudela y Delgado, 2019).

Tras la flexibilización del Pativel y el éxito del Medusa Sunbeach Festival se abre una oportunidad para la reactivación del proyecto. Así mismo, los promotores han presentado recursos contra el plan en los tribunales en los plazos previstos. Al mismo tiempo que el ayuntamiento de Cullera se ha vuelto abrir a la gestión indirecta para desarrollar el proyecto por cualquier iniciativa de los propietarios de los terrenos o cualquier sociedad externa (Valero, 2019).

\subsection{DEL PAI DE SANT GREGORI AL ARENAL SOUND AL RETORNO DE UNA CIUDAD NUEVA EN PRIMERA LÍNEA DE PLAYA. EL CASO DE BURRIANA.}

Un caso parecido es el PAI Golf Sant Gregori (Burriana), un macroproyecto turístico surgido a principios de siglo por la Diputación de Castellón con la intención de justificar el coste cercano a los 200 millones de euros del Aeropuerto de Castellón. Una estrategia de dinamización que pretendía encajar el aeropuerto en torno al urbanismo, golf y la costa de Azahar. De esta manera, la megalómana infraestructura servía de engranaje para encajar la recalificación de 40.000 viviendas con miles de adosados, hoteles de lujo, un parque temático, centros comerciales y una docena de campos de golf en una zona deficitaria de agua (Fabra, 2012).

En esta coyuntura, el PAI Golf Sant Gregori, planteado en 2002 y aprobado en el año 2006, proyectó la urbanización de 700.000 metros cuadrados, construir 6.000 viviendas (para alrededor 15.000 residentes), 2 hoteles de lujo de 400 plazas, 1 campo de golf de 18 hoyos (inicialmente eran 27 hoyos) y centros comerciales cerca de la desembocadura del Rio Mijares con un coste aproximado de 85 millones de euros. Un proyecto, a 7 kilómetros de la ciudad de Burriana, considerado el segundo proyecto urbanístico con el campo de golf más grande de la provincia de Castellón después de Marina d'or Golf (anulado por los tribunales) y el quinto de toda la Comunidad Valenciana (Ortega, 2012). Al principio, como en el resto de los macroproyectos urbanísticos, las expectativas de ganancia crecieron. La construcción del aeropuerto de Castellón y el sueño de muchos vecinos de tener una segunda vivienda en la playa, hicieron del urbanismo, la playa y el golf la principal estrategia de dinamización socioeconómica del ayuntamiento. Este argumento se plasmó en el año 2006 al desarrollar cuatro proyectos urbanísticos, a parte del PAI Golf Sant Gregori, con un modelo de crecimiento propio de una ciudad difusa que con- 
figura áreas separadas y especializadas. Un modelo de ciudad en el cual diferencia las zonas de nueva vivienda (PAI Pedrera Port, Jardines de la Malvarosa y Novenes de Calatrava), el comercio y servicios (Núcleo urbano), la industria turística (la zona de playa) y el entretenimiento (PAl Golf Sant Gregori y Santa Bárbara Golf).

Figura 3. Modelo de crecimiento de ciudad difusa de Burriana

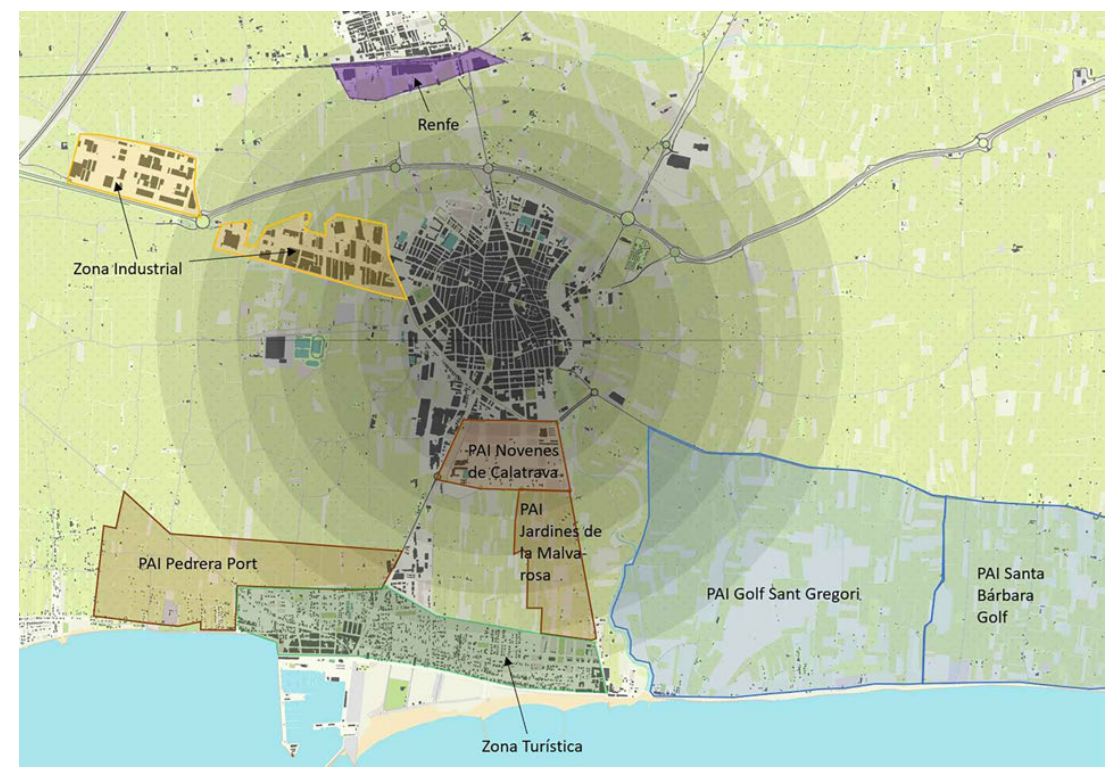

Fuente: Elaboración propia

Tras unos años, todos los proyectos se fueron dilatando en el tiempo y las expectativas iniciales del precio del suelo se devaluaron. Algunos se paralizaron (PAI Novenes de Calatrava). Otras veces, readaptaron sus terrenos para albergar el camping del Arenal Sound (PAl Jardines de la Malva-rosa). Al mismo tiempo que, el resto proyectos se encuentran a la espera de modificaciones en el Plan General con informes desfavorables de costas y riesgo de inundación (PAI Golf Sant Gregori, Santa Bárbara Golf y Pedrera Port). En este contexto, el gran proyecto urbanístico PAI Golf Sant Gregori siempre ha tenido dificultades. Ya, en plena burbuja, la sociedad encargada de las cuotas de urbanización se declaró en concurso voluntario de acreedores y su liquidación, con una deuda generada superior a los 40 millones de euros. Así, en el año 2016, la falta de un proyecto de recuperación del litoral, el aval de 3 millones de euros para garantizar la construcción del campo de golf y acceso al complejo y asumir las indemnizaciones para la expropiación motivó la decisión 
de declarar insolvente la sociedad urbanizadora y paralizar parcialmente el proyecto urbanístico (Fayos. 2019).

Paralelamente a estos proyectos, desde el año 2010 en la playa del Arenal se celebra el festival de Arenal Sound. Uno de los festivales más conocidos con más de los 300.000 asistentes (alrededor de 60.000 asistentes diarios y 16.000 personas acampadas), 4.500 puestos de trabajo directos e indirectos y más de 40 millones de euros de impacto directo en la provincia. Evento, que las administraciones consideraron una herramienta para dinamizar la actividad comercial y el entretenimiento del municipio (Olucha, 2011). Además, desde el año 2016 la Diputación de Castellón destina anualmente una subvención para potenciar la marca de «Castellón Tierra de Festivales».

Tras su décima edición, el Arenal Sound ha consolidado un nuevo motor socioeconómico de la ciudad. Certamen, que al menos durante 6 días, constituye, configura y conforma la ciudad alrededor del festival en áreas separadas y especializadas con zonas de camping y de descanso, la provisión de una flota de buses que acerquen la ciudad al festival y un espacio para la celebración de conciertos. Un evento, que funciona como una ciudad efímera que ha devuelto la confianza de los empresarios locales y la comprensión vecinal de implantar cualquier proyecto turístico-urbanístico. En definitiva, una herramienta que ha devuelto a Burriana el sueño de acercar la ciudad al mar y argumentos suficientes para que los proyectos urbanísticos vuelvan a coger forma.

Figura 4. Modelo de crecimiento a partir del festival Arenal Sound

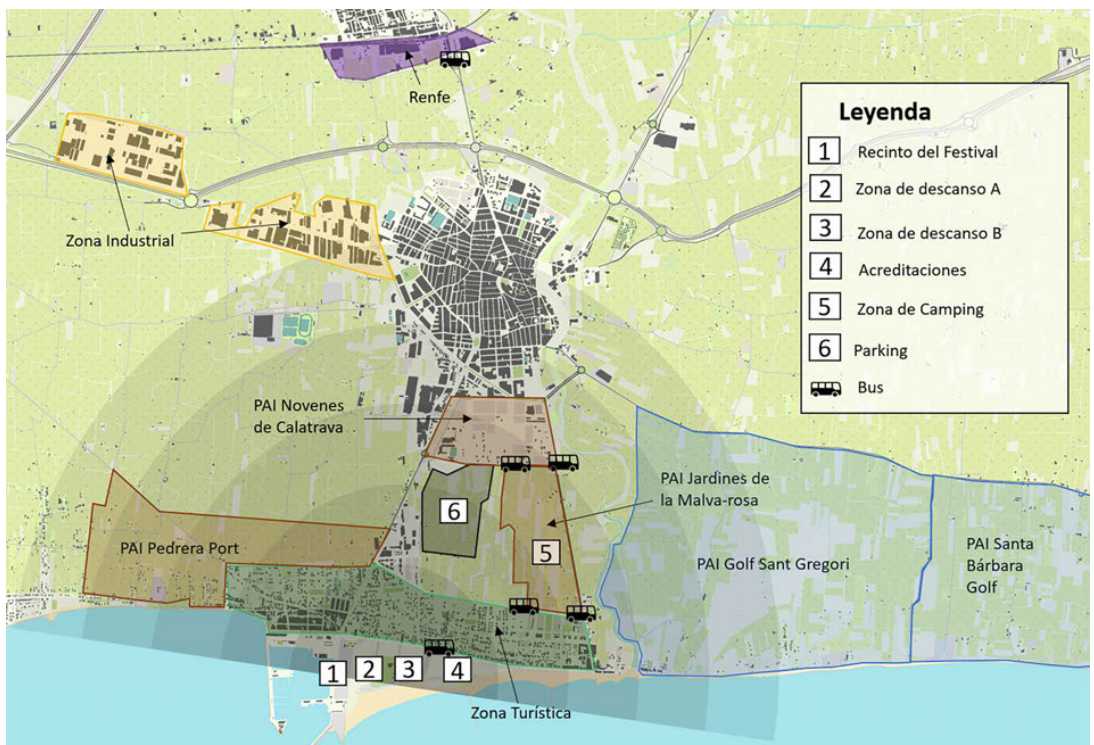

Fuente: Elaboración propia 
Consecuentemente, tras la consolidación del festival, el proyecto urbanístico ha vuelto a coger forma. A principios de 2019 se volvieron a iniciar las obras de derribo y deslinde de los terrenos. De la misma manera, meses más tarde, los nuevos propietarios asumieron la figura legal de «agente urbanizador»y la empresa urbanizadora el coste de las obras de urbanización, con un coste total de 7 millones de euros y un proyecto que asciende ya a los 97 millones de euros (Olivares, 2019).

Tras unos meses y con la flexibilización de el de Pativel, el ayuntamiento ha anunciado recientemente la exposición pública de la modificación del proyecto pidiendo a Costas para invertir 9 millones en las tres playas, la escollera y el paseo marítimo (Pérez, 2020). Cabe señalar que tanto el PAI Golf Sant Gregori como el Manhattan de Cullera tienen una tregua de 10 años (5 de tramitación del proyecto urbanístico y 5 para la ejecución). De este modo, el proyecto urbanístico espera realizarse entre 12-15 años, la creación de entre 800 y 1.000 puestos de trabajo. Haciendo del PAI Golf Sant Gregori como el mayor proyecto urbanístico en construcción de la Comunidad Valenciana en la actualidad. Proyecto, en el cual existen de nuevo dudas sobre si saldrá finalmente, pero el regreso de este macroproyecto ya es de nuevo una realidad.

\section{REFLEXIONES FINALES}

Como se ha podido observar, los festivales son una herramienta para dinamizar y promocionar el territorio. Una ocupación temporal y desmontable de escenarios, espacios abiertos y otros servicios que funciona de manera intermedia entre una ciudad de vacaciones y un plan de negocios. De este modo, el festival entendido como producto, busca con su celebración la adquisición de una experiencia, compartiendo y configurando el espacio físico y virtual, en el cual se difunden. Consecuentemente, la presencia y difusión del evento en medios sociales determina la dimensión y magnitud del evento. De esta manera, la geolocalización de estos certámenes se convierte en el medio para favorecer las interrelaciones entre los clientes actuales y potenciales, ajustando el producto a sus necesidades, pero también, una plataforma para promocionar el espacio físico en el cual se desarrollan.

El análisis de casos muestra como la proyección internacional de estos eventos ha devuelto la confianza de vecinos y empresarios locales a niveles anteriores a la recesión económica. Un argumento en el cual aparecen claros indicios de como estos eventos pueden convertirse directa o indirectamente en plataformas de promoción de antiguos proyectos urbanísticos. Plataformas, que crean entornos positivos en solares disfuncionales que a un tienen latente el recuerdo de proyectos especulativos. Una herramienta que generan experiencias positivas borrando el espejismo generado por la crisis económica, proyectando la marca turística de la ciudad dentro de los circuitos internacionales. 
La consolidación de estos eventos masificados enseña como se puede asentar -al menos temporalmente - ciudades informales en enclaves con altos valores paisajísticos. Unos espacios que durante la crisis económica se pusieron en valor y ahora quedan de nuevo cuanto menos cuestionados. De ahí que, el éxito o saturación de estos eventos ejemplifica como estos actos multitudinarios han sido entendidos más como una plataforma de promoción de planes durmientes que una herramienta de dinamización turística. La creación eventos musicales como estrategia de dinamización puede ser una oportunidad de gran impacto económico. Pero también, para entender que el territorio se compone y configura más allá de la ordenación pormenorizada de usos y otros sectores para establecer plataformas para desvirtuar normativas de protección.

\section{REFERENCIAS}

Colomina, X. y Duran, P. (2018). La resurrecció del macroprojecte «manhattan de cullera» posa en perill part de la desembocadura del riu xúquer. Directa. Cat. Recuperado de https://directa.cat/la-resurreccio-del-macroprojecte-manhattan-de-cullera-posa-en-perill-part-de-la-desembocadura-del -riu-xuquer/ [Consulta: 14 de enero de 2020].

Culleraturismo.com (2018). El Gran evento del verano. Recuperado de: https://www.culleraturismo.com/guia/festival-medusa/ [Consulta: 9 de enero de 2020].

Fabra, M. (2012). El aeropuerto de Castellón 'tapaba' una recalificación para 40.000 viviendas. El País. Recuperado de: https://elpais.com/politica/2012/01/15/actualidad/1326650326_763414.html [Consulta: 22 de enero de 2020].

Fayos, E. (2019). Un macroprojecte turístic es reactiva a borriana ple d'irregularitats. Directa.cat. Recuperado de https://directa.cat/un-macroprojecte-turistic-es-reactiva-a-borriana-ple-dirregularitats/ [Consulta: 24 de febrero de 2020].

Fundación Alternativas (2007). Mapa de presuntas irregularidades y actos de corrupción urbanística 2000-2007. Fundación Alternativa. Madrid, Recuperado de:

https://es.greenpeace.org/es/wp-content/uploads/sites/3/2019/06/Costas2019-completo-ver2.pdf [Consulta: 9 de enero de 2020].

Greenpeace (2019). A toda costa: Análisis de los ecosistemas naturales costeros vulnerables a la urbanización masiva del litoral. Greenpeace y Observatorio de la Sostenibilidad, Madrid. Recuperado de:

https://es.greenpeace.org/es/wp-content/uploads/sites/3/2019/06/Costas2019-completo-ver2.pdf [Consulta: 12 de enero de 2020].

Lefebvre, H. (1974). La producción del espacio. Madrid: Capitán Swing. 
Olivares, R. (2019). El modificado del proyecto de Golf Sant Gregori eleva el coste de la urbanización a 97 millones. Castellón Plaza. Recuperado de: https://castellonplaza.com/el-modificado-del-proyecto-de-golf-sant-gregori-eleva-el-coste-de-la-urbanizacion-a-97-millones [Consulta: 17 de febrero de 2020].

Olucha, A. (2011). Burriana apoya el Arenal Sound como herramienta para atraer al turismo. Las Provincias. Recuperado de https://www.lasprovincias.es/v/20110514/castellon/burriana-apoya-arenal-sound-20110514.html [Consulta: 15 de febrero de 2020].

Ortega, L. (2012). El fiasco del urbanismo playa y golf. El País. Recuperado de https://elpais.com/ccaa/2015/01/18/valencia/1421606665_076545.html [Consulta: 10 de febrero de 2020].

Pérez, D. (2020) Burriana pide el aval de Costas para invertir 9 millones en las tres playas y el paseo marítimo de Sant Gregori. Castellón Plaza. Recuperado de https://castellonplaza.com/burriana-pide-el-visto-bueno-alos-9-millones-para-las-tres-playas-y-el-paseo-maritimo-de-sant-gregori. [Consulta: 16 de febrero de 2020].

Rubio, M. y De Cárdenas, I. (2006). Conciertos como ciudades, ciudades como conciertos. Formas de arquitectura y arte. N. ${ }^{\circ} 15,16-18$.

Tudela, A. y Delgado, A. (2019). ¿El regreso de la especulación? Los últimos paraísos españoles amenazados por la codicia. El País. Recuperado de: https://elpais.com/elpais/2019/08/19/icon_design/1566216434_272618.html x [Consulta: 18 de enero de 2020].

Valero, D. (2018). Los promotores del Manhattan de Cullera llevan a los tribunales la protección de la costa del Consell. Valencia Plaza. Recuperado de: https://valenciaplaza.com/el-pai-del-manhattan-se-abre-a-la-gestion-indirecta-se-escogera-el-mejor-proyecto-para-cullera [Consulta: 14 de enero de 2020].

Valero, D. (2019). El PAl del Manhattan se abre a la gestión indirecta: «Se escogerá el mejor proyecto para Cullera». Valencia Plaza. Recuperado de: https://valenciaplaza.com/el-pai-del-manhattan-se-abre-a-la-gestion-indirecta-se-escogera-el-mejor-proyecto-para-cullera [Consulta: 11 de enero de 2020]. 



\title{
LOS MODELOS URBANÍSTICOS EN LA VEGA DE LA LAGUNA. SAN CRISTÓBAL DE LA LAGUNA. TENERIFE
}

\section{THE URBANISTIC MODELS IN THE VEGA DE LA LAGUNA. SAN CRISTÓBAL DE LA LAGUNA. TENERIFE}

\author{
Miguel Ángel Mejías Vera \\ Universidad de La Laguna \\ $M^{a}$ Mercedes Arranz Lozano \\ Universidad de La Laguna
}

Resumen

La corona rur-urbana que rodea a las ciudades constituye un elemento que forma parte de la periferia de las mismas. Aquella, por su localización, es muy apetecible para las instituciones oficiales (a partir de los Planeamientos de Ordenación Urbana) de ser convertida en espacio urbano y, por esta razón, susceptible de su desaparición. Sin embargo, nos encontramos con casos en que, debido a sus características morfogenéticas, valor simbólico que representa para sus habitantes, uso del suelo reutilizable en momentos de crisis, etc. Dicha corona rur-urbana debería de ser mantenida como un paisaje a preservar, mediante una figura de patrimonio agrario territorial, estableciendo el crecimiento urbano de la ciudad por otros sectores periféricos, sin tanta trascendencia alegórica. Esto es lo que vamos a tratar de esclarecer, en esta comunicación, con el desarrollo urbanístico que se está produciendo en estos momentos, en la Vega de La Laguna, de la ciudad de San Cristóbal de La Laguna (Tenerife).

Palabras clave: La Vega de La Laguna, desarrollo urbano, dispersión, unidad de paisaje, patrimonio agrario.

\section{Abstract}

The rur-urban crown that surrounds the cities is an element that is part of the periphery of the cities. That, because of its location, is very appealing to the official institutions (from the Urban Planning) to be converted into urban space and, for this reason, susceptible to their disappearance. However, we find cases where, due to its morphogenetic characteristics, symbolic value it represents for its inhabitants, reusable land use in times of crisis, etc., such a rur-urban crown should be maintained as a landscape to preserve, through a figure of territorial agrarian heritage, establishing the urban growth of the city by other peripheral sectors, without so much allegorical significance. This is what we will try to clarify, in this communication, with the urban develop- 
ment that is currently taking place, in the Vega de La Laguna, in the city of San Cristóbal de La Laguna (Tenerife).

Keywords: La Vega de La Laguna, urban development, urban sprawl, landscape unit, agricultural heritage.

\section{INTRODUCCIÓN}

La corona rur-urbana situada al NE de ciudad de La Laguna forma parte de la periferia de la ciudad, pero este sector en concreto, presenta como peculiaridad conformar el origen de la misma, ya que es rico en agua y depósitos de suelos ricos y fértiles de origen lacustre que justifican su ubicación.

Esta periferia empezó a experimentar el cambio de uso del suelo (de rural a urbano) a comienzos del siglo XX. Ya a partir de la década de los sesenta se intensificó el proceso de urbanización, principalmente a través de lo dispuesto en los distintos Planes de Ordenación Urbana aprobados por el Ayuntamiento, porque este sector está muy próximo a la ciudad y a las instituciones municipales les interesa económicamente mucho dicha transformación. Ello ha originado la pérdida de suelo potencialmente agrícola con características agrológicas excelentes, y abandono de las tierras de cultivo. En esta dialéctica, surgen procesos en los que el uso compartido residencial-agrario, que se formaliza a través de la casa-huerta, entendida ésta como un modelo de vida familiar que se vincula a la tierra, que mantienen la riqueza y heterogeneidad de su paisaje y en el que la población residente lo protege de manera intensa para evitar su sellado.

El suelo productivo de la Vega es tan importante como el casco histórico de la ciudad ya que su surgimiento, en el siglo XVI, se debió a la riqueza de este suelo. Esta reserva del mismo ha permanecido prácticamente intacta durante 500 años, desde la conquista de la Isla, pero en los últimos sesenta años asistimos a su práctica desaparición.

La Laguna se convirtió en el centro de la Isla y se expandió periféricamente de manera radial (Mejías, 2013, p. 50) y como en otras ciudades europeas, su expansión tiene forma de estrella, canalizada a través de las vías de comunicación (Antrop, 2004, p.16). Una de esas puntas de estrella de la ciudad es la del crecimiento urbano a través del sector histórico de La Vega de La Laguna, convertida hoy en periferia rur-urbana.

La aportación que ahora presentamos, supone la continuación de un trabajo, que ya iniciamos en el año 2017' , sobre la controversia que existía en este sector a partir de la negación de los vecinos a aprobar un nuevo Plan General de

1 Presentado en el XXV Congreso de la AGE, celebrado en Madrid del 25 al 27 de octubre de 2017 
Ordenación Urbana, (2014) porque ellos mismos querían y siguen queriendo evitar su transformación en espacio urbano.

Por tanto, partimos de la hipótesis de que la ordenación urbana no está diseñada a partir del estudio de la base estructural territorial y las necesidades poblacionales. De esta manera comprendemos que las soluciones planificadas en nuestro ámbito de análisis tengan poco éxito: el crecimiento urbano se produce en suelo rústico y el suelo urbano y urbanizable apenas se desarrolla. Nuestro objetivo se centra en demostrar, a través de métodos de análisis exploratorios y de datos obtenidos a partir del análisis y síntesis geoestadístico, las métricas de las combinaciones de múltiples componentes y variables que explican diferentes modelos de desarrollo urbano en La Vega y por tanto su transformación paisajística.

A partir de múltiples fuentes de información IGME, IGN, INE, Catastro, ISTAC y GRAFCAN, construimos una matriz de inventario de componentes abióticas y culturales que fuimos combinando entre sí, para responder a preguntas clave en la construcción de patrones: el desarrollo del espacio urbano ocupa el espacio Ilano o en ladera; los bienes inmuebles (viviendas) se desarrollan en suelo urbano o rústico, y en qué proporción. La densidad es importante y clarificadora, más aún, en un espacio insular. En La Vega deseamos analizar qué tipología edificatoria existe y su diferencia en el espacio urbano y rustico; cómo actúa el planeamiento ante los problemas requeridos por el crecimiento edificatorio; cuál es el espacio disponible para el desarrollo urbano; o cómo se ven amenazados los espacios productivos con un alto nivel agrológico.

Para ello es imprescindible definir la unidad de paisaje, hecho fundamental para conocer las relaciones que existen entre los elementos que conforma un sistema ecológico. Aquí intervienen todos los aspectos naturales y culturales del paisaje sobre los que han escrito diversos autores (Naveh, 2007; Zonneveld, 1989, Silva, 2009, etc.) a los que hemos hecho referencia a lo largo de nuestro trabajo. Dicho suelo rural constituye una unidad de paisaje única, que, en nuestra opinión, debe ser guardada con una figura de protección, como por ejemplo la de «patrimonio territorial agrícola local», con el fin de preservado como tal para las generaciones venideras, y no transformarlo en espacio urbano como ha ocurrido con el $36 \%$ del suelo que constituye La Vega Lagunera.

\section{UNIDADES DEL PAISAJE EXISTENTES EN LA VEGA DE LA LAGUNA}

\subsection{CARACTERÍSTICAS GENERALES}

Al analizar en esta comunicación el paisaje urbano de la Vega de la Laguna lo vamos a hacer de una unidad que integra las siguientes entidades de población establecidas por el I.N.E.: la Vega Lagunera, La Vega de Las Mercedes, 
las Mercedes y Jardina². Dicha unidad constituye el sector del crecimiento urbano del casco histórico de La Laguna, en su periferia rur-urbana por el sector NE, la cual (conocida popularmente como La Vega de La Laguna, La Vega o El Llano) posee un significado especial, ya que aquí fue donde tuvo lugar el origen de la ciudad de Los Adelantados.

Figura.1 Mapa de localización de las entidades que constituyen La Vega de La Laguna

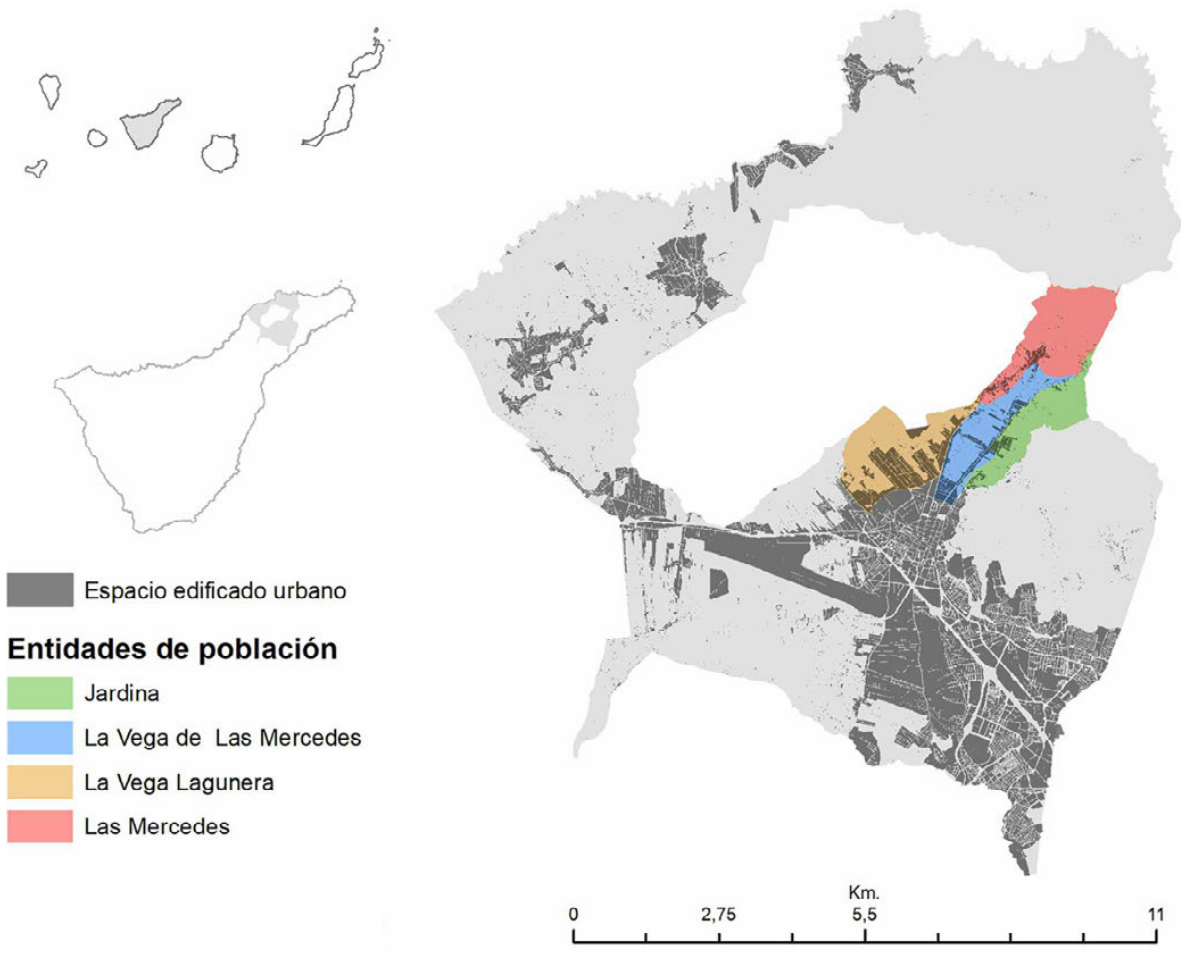

Fuente: GRAFCAN

Efectivamente, remontándonos al origen geomorfológico de esta unidad administrativa, cabe señalar que, situada en torno al macizo de Anaga, en ella se originaron emisiones basálticas que dieron lugar a que se cerrase la salida hacia el mar de las aguas de los barrancos, que por aquí discurrían, y fueran a converger a una laguna cerrada. Posteriormente el poblamiento produjo roturaciones para establecer diferentes cultivos, originando un desplaza-

2 Según el Nomenclátor (INE). 
miento del bosque de laurisilva hacia la cordillera de Anaga. Así pues, todo el conjunto de La Vega Lagunera constituye la periferia más antigua y la más próxima a la vieja ciudad, hoy centro histórico, convirtiéndose, por esta razón, en un sector muy codiciado para la especulación urbanística.

De acuerdo a la población que vive en La Vega, en el año 2000 se contabilizaban en total 5.442 habitantes, mientras que, en 2018, eran 7.924 personas, las que habitaban allí. Esta última cifra representaba, con respecto al total de la población de la Laguna (155.549 hab.), un 5,09\%. De ese total (7.924 hab.) la mayor parte se congrega en las entidades de La Vega de Las Mercedes (2.883 hab.) y La Vega Lagunera (2.577 hab.) que representan, respectivamente el $36,4 \%$ y el $32,5 \%$ del total de la población de La Vega. Esto se debe a que, de las cuatro entidades que integran La Vega, estas dos son las que se encuentran situadas más próximas al casco urbano. Por el contrario, los sectores menos poblados son Jardina (1.426 hab.) y Las Mercedes (1.038 hab.) que representan, respectivamente el $18,0 \%$ y el 13,1\% del total de La Vega y se sitúan más retiradas hacia el Este: entre 4 y 6 km. del centro de la ciudad (Ver Figuras 1 y 2 ).

La evolución de la población en el conjunto de la Vega en los ultimos veinte últimos años ha sido de ascenso en el número de habitantes hasta el año 2010, para perder población desde entonces. La tasa de crecimiento anual de la población, entre el año 2000 y 2018 ha sido de 0,62\%, la mitad de la producida en el mismo periodo en el conjunto municipal (1,2\%), el cual, a su vez, ha tenido un crecimiento inferior con respecto a la isla de Tenerife de un 0,1\%. Así pues, la relación que existe entre el número de habitantes y las superfice edificada en cada entidad es muy diferente. Mientras en Jardina y La Vega de las Mercedes indica que una menor superficie edificada está compartida por más personas (> densidad), en laVega Lagunera y Las Mercedes el espacio edificado está distribuido entre menos personas. Por tanto un densidad mucho más baja (Ver Figura 2 y Tabla 1). 
Tabla 1. Resultados del análisis del espacio edificado y su relación con el total de habitantes por entidad de población

\begin{tabular}{|c|c|c|c|c|c|c|}
\hline $\begin{array}{l}\text { Entidad de } \\
\text { población }\end{array}$ & Frecuencia & $\begin{array}{c}\text { Espacio } \\
\text { construido } \\
\text { Has. }\end{array}$ & $\begin{array}{l}\text { Población } \\
2000 \text { (a) }\end{array}$ & $\begin{array}{l}\text { Población } \\
2018 \text { (b) }\end{array}$ & $\begin{array}{c}\text { Diferencia } \\
\text { 2000-2018 } \\
(b-a)\end{array}$ & $\begin{array}{c}\mathrm{Hab} / \mathrm{m}^{2} \\
\text { construidos }\end{array}$ \\
\hline JARDINA & 977 & 5,46 & 1318 & 1426 & 108 & 0,026 \\
\hline $\begin{array}{c}\text { LA VEGA } \\
\text { DE LAS } \\
\text { MERCEDES }\end{array}$ & 1.711 & 11,79 & 2.432 & 2.883 & 451 & 0,024 \\
\hline $\begin{array}{c}\text { LA VEGA } \\
\text { LAGUNERA }\end{array}$ & 2.361 & 16,37 & 1.968 & 2.577 & 609 & 0,016 \\
\hline $\begin{array}{c}\text { LAS } \\
\text { MERCEDES }\end{array}$ & 1.259 & 7,10 & 1.078 & 1.038 & -40 & 0,015 \\
\hline TOTALES & 6.308 & 40,72 & 6.796 & 7.924 & 1128 & \\
\hline
\end{tabular}

Fuente: Elaboración propia

Si existe un patrón de uniformidad y riqueza en el paisaje que analizamos es su carácter llano y la espléndida calidad de sus suelos, desde el punto de vista agrológico. Este patrón es precisamente el que está en peligro de extinción, sustituyéndolo por un suelo sellado. Este modelo de desarrollo urbano aquí, es precisamente el menos sostenible.

Figura 2. Habitantes/m2 construido

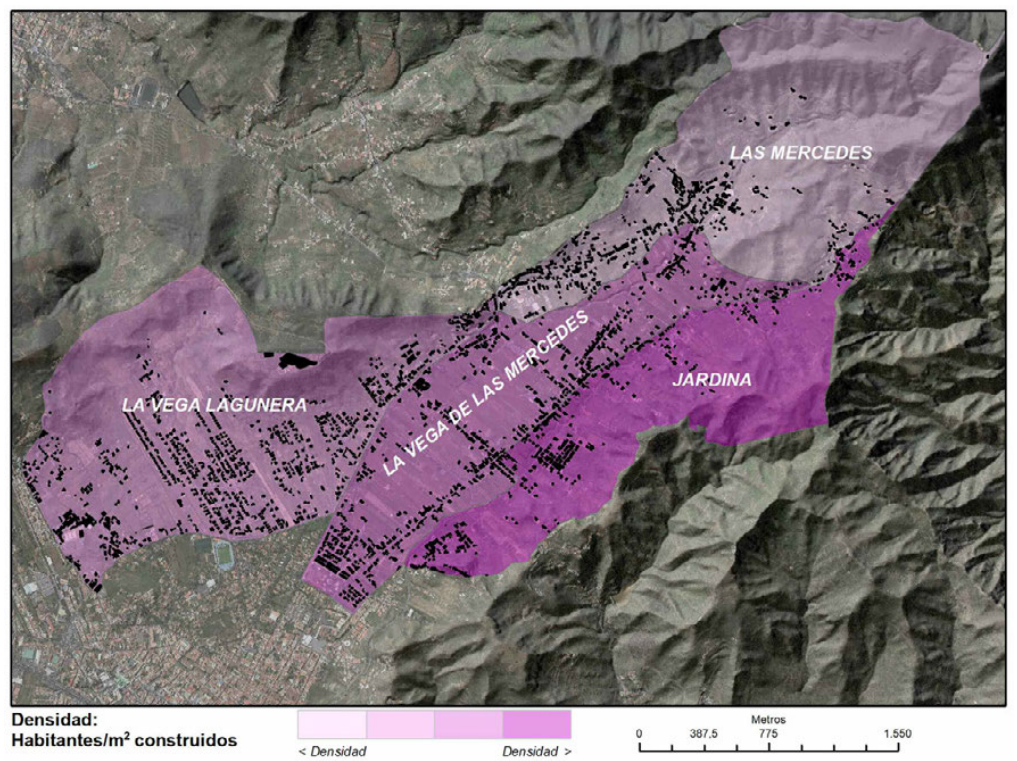

Fuente: Catastro, INE, GRAFCAN. Elaboración propia 
La unidad de paisaje analizada tiene el 30\% de su superficie llana. Es en esa superficie donde se desarrolla el 52\% de las construcciones. La otra mitad se desarrollan en laderas con diferentes grados de pendiente. Aquí evidenciamos dos modelos. ¿Es más adecuado la construcción en el llano, ocupando y sellando el suelo lacustre, agrológicamente más rico de Canarias? o en su caso, ¿es más adecuado la construcción en las laderas? La primera sucede de manera ordenada y abalada por el planeamiento, la segunda no. ¿Estamos planificando de manera correcta y siguiendo criterios de sostenibilidad? ¿La compactación es el método adecuado en esta unidad de paisaje? A nuestro juicio, no. Este proceso creciente no es uniforme en todo el conjunto de la Vega, diferenciando distintas formas de edificación. Así, podemos determinar dos unidades claramente diferenciadas: la más próxima al casco histórico, La Vega Lagunera que es la que tiene el mayor peso del suelo urbano y urbanizable; y una segunda unidad conformada por una zona de transición La Vega de Las Mercedes, donde el peso corresponde a la figura de asentamiento rural en suelo rústico. En sus límites al norte, flanqueado por laderas y cabecera de este valle se encuentra Jardina y Las Mercedes, donde sus pequeños núcleos urbanos están rodeados de un importante número de construcciones dispersas en suelo rústico.

Tabla 2. Espacio construido y disponible por clase y categoría de suelo según el $\mathrm{PGO}^{3}$ (2004)

\begin{tabular}{|c|c|c|c|c|c|c|}
\hline CLASE & CATEGORÍA & $\begin{array}{c}\text { CATEGORÍA } \\
\text { Has. (a) }\end{array}$ & $\begin{array}{c}\text { CONSTRUIDO } \\
\text { Has. (b) }\end{array}$ & $\begin{array}{c}\text { Has. } \\
\text { (a-b) }\end{array}$ & $\begin{array}{c}\text { OCUPACIÓN } \\
\mathbf{\%}\end{array}$ & $\begin{array}{c}\text { DISPONIBLE } \\
\mathbf{\%}\end{array}$ \\
\hline Urbano & Consolidado & 129,91 & 21,50 & 108,40 & 16,54 & 83,45 \\
\hline Urbano & No consolidado & 8,66 & 0,15 & 8,50 & 1,74 & 98,26 \\
\hline Urbano & Total & $\mathbf{1 3 8 , 5 7}$ & $\mathbf{2 1 , 6 5}$ & $\mathbf{1 1 6 , 9 0}$ & $\mathbf{1 8 , 2 8}$ & $\mathbf{8 4 , 3 6}$ \\
\hline Urbanizable & Sec. Orden. & 5,13 & 0,05 & 5,00 & 1,00 & 99,00 \\
\hline Urbanizable & Sec. No Ord. & 9,49 & 0,07 & 9,40 & 0,84 & 99,16 \\
\hline Urbanizable & Total & $\mathbf{1 4 , 6 2}$ & $\mathbf{0 , 1 2}$ & $\mathbf{1 4 , 4 0}$ & $\mathbf{1 , 8 4}$ & $\mathbf{9 8 , 4 9}$ \\
\hline Rústico & $\begin{array}{c}\text { Asentamiento } \\
\text { Rural }\end{array}$ & 58,31 & 9,47 & 48,80 & 16,25 & 83,75 \\
\hline Rústico & $\begin{array}{c}\text { Protección } \\
\text { Agraria } \\
\text { Tradicional 1 }\end{array}$ & $\mathbf{3 2 4 , 4 0}$ & 6,91 & 317,50 & 2,13 & 97,87 \\
\hline Rústico & $\begin{array}{c}\text { Protección } \\
\text { Paisajística 2 }\end{array}$ & 93,43 & 0,37 & 93,00 & 0,40 & 99,60 \\
\hline Rústico & $\begin{array}{c}\text { Protección de } \\
\text { Infraestructuras }\end{array}$ & 33,32 & 1,39 & 31,90 & 4,19 & 95,81 \\
\hline Rústico & $\begin{array}{c}\text { Protección } \\
\text { Natural }\end{array}$ & $\mathbf{2 5 9 , 7 2}$ & $\mathbf{2 , 1 7}$ & $\mathbf{2 5 7 , 5 0}$ & $\mathbf{0 , 8 4}$ & 99,16 \\
\hline Rústico & Total & $\mathbf{7 6 9 , 1 8}$ & $\mathbf{2 0 , 3 1}$ & $\mathbf{7 4 8 , 7 0}$ & $\mathbf{2 3 , 8 1}$ & $\mathbf{9 7 , 2 6}$ \\
\hline
\end{tabular}

Fuente: GRAFCAN y Catastro. Elaboración propia

3 Aprobación Definitiva Parcial de Adaptación Básica al D.L. 1/2000 de Plan General de Ordenación de San Cristóbal de La Laguna, el 7 de octubre de 2004y publicado en el BOC 067/05. 
Si cruzamos las categorias de suelo según el PGO vigente con la superficie construida, observamos dinámicas diferentes, mientras en La Vega Lagunera, espacio que da continuidad a la ciudad, se produce un estancamiento, donde apenas un $16 \%$ del suelo disponible urbano es consolidado y el urbanizable ni siquiera es transformado; es en el siguiente cinturón, especialmente en el de La Vega de Las Mercedes en el que se desarrolla la edificación al amparo de la categoría de Asentamiento Rural dentro del suelo rústico. El porcentaje de ocupación es exactamente igual que el producido en el suelo urbano. Al mismo tiempo, alrededor de estos asentamientos y núcleos, se desarollan edificaciones dispersas en diferentes categorías del suelo rústico (Ver Tabla 2).

\subsection{LA VEGA LAGUNERA}

Esta entidad poblacional se extiende al E, entre el casco histórico de la ciudad de La Laguna y la Vía de Ronda, es decir entre «La Mesa Mota y las Canteras, al norte; el casco urbano de la ciudad, al sur; Camino del Bronco y Jardina, al Este y San Diego al W» (Martínez de Pisón 1981, 31). Antaño, constituía un espacio con un uso del suelo marcadamente rural unido al centro de la ciudad mediante caminos ${ }^{4}$, formando una red, para «poner en comunicación la ciudad con los campos de cultivo que se iban creando en La Vega» (Calero, 2001, 246). Pero será sobre todo en las primeras décadas del siglo XX cuando este sector empiece a crecer y a configurarse como un poblamiento laxo, de gran calidad, formado por la edificación de chalets exentos, de grandes dimensiones, «dedicados, en su mayor parte, al uso estival de algunas importantes familias burguesas de Santa Cruz» (Calero, 2001, 326). Posteriormente, a partir de la década de los sesenta del siglo pasado, fue cuando se generalizó, de manera más extensa en el espacio, la construcción de diferentes urbanizaciones de chalets (exentos y adosados) como son las San Diego, Fuente Cañizares, Hespérides, Aguere, S. Benito, Manzanilla, Coral, Acaymo, Coral Verde, etc.., de gran dimensión (175 $\mathrm{m}^{2}$ de media), de una y dos plantas.

Esta entidad aún conservaba un gran espacio de uso rural, sin edificar hasta 1989 cuando se empezó a pensar en la construcción de la Vía de Ronda, la cual ya recogía el Plan General de Ordenación Urbana de la ciudad de 1964, cuyas obras comenzaron en mayo de $1991^{5}$ (Fernández, 2013, 25). La construc-

4 «Uno de estos caminos era un paseo que más tarde se llamará de la Universidad o Camino Largo, que, apareciendo por primera vez, junto con la carretera de Tejina, en los planos en 1830 se alarga desde uno de los extremos de la ciudad hacia el interior de La Vega» (Calero, 2001, 245).

5 Para un estudio detallado sobre la construcción de la Vía de Ronda, a su paso por La Vega de La Laguna, ver en bibliografía Fernández, C., 2013. 
ción de esta carretera, perimetral al casco antiguo de la ciudad que se dirigía a la costa norte de la isla, supuso una operación de especulación del suelo urbano sin precedentes en La Vega, originando la construcción de más de 200 viviendas, de chalets adosados dirigidos ya hacia una clase social media (conocida popularmente como «El Muro»), junto al famoso «Parque de la Vega». Todo ello constituyó la continuidad del crecimiento urbano, iniciado en los años sesenta, de esta periferia, hacia el este de la ciudad.

En el momento actual, dicho sector cuenta con 2.577 habitantes y ha sido, de las cuatro entidades, la que ha experimentado el mayor crecimiento urbano en los últimos dieciocho años. Aquí encontramos el mayor número de fincas urbanas en relación al conjunto total de la Vega: 769 del total de las 1.758, lo que supone el $44 \%$ de las mismas. Junto a la tipología urbanística de "ciudad jardín» ya mencionada, todavía quedan 75 fincas rurales, que ocupan una superficie de $298 \mathrm{~m}^{2}$, con una morfología de la Casa-Huerta principalmente (Ver Figura 2 y Tabla 1).

\subsection{LA VEGA DE LAS MERCEDES, LAS MERCEDES, JARDINA}

La construcción de la Vía de Ronda supuso, en primer lugar, la división bien clara de las cuatro entidades al Este y al Oeste de la misma. La primera, ya descrita quedó al oeste de la Vía de Ronda y las otras tres al este: Vega de Las Mercedes, Las Mercedes y Jardina (Figura 2). El modelo de ocupación del suelo viene determinado en cada una de ellas por tres unidades de paisaje bien diferenciadas: dos de tipo urbano y uno rural. Entre las dos de tipo urbano caben señalar, por una parte, el paisaje conformado por edificaciones de autoconstrucción, realizadas principalmente sobre las laderas de las estructuras volcánicas de los bordes de la Vega, dibujando asentamientos desordenados y aglomerados.

Junto a ellas encontramos el paisaje de edificación urbana de viviendas de primera residencia construidas por promotoras, en los siglos XX y XXI. Estas dos unidades de paisaje urbano presentan un número total de fincas urbanas de 989. El mayor número de ellas se localiza en La Vega de Las Mercedes con 442; constituyen el 44,69\% de total de fincas de este tipo que existe en toda La Vega y presentan una superficie media de $200 \mathrm{~m}^{2}$. Mientras, en Las Mercedes existen 302 fincas urbanas (30,54\%), con una superficie media de $144 \mathrm{~m}^{2}$, y en Jardina son 245 (24,77\%), con una superficie media de $141 \mathrm{~m}^{2}$. Todas ellas se extienden sobre una superficie total de 30,60 hectáreas (Ver Figuras 2 y 3 ).

Entre ambas, y especialmente en la Vega de Las Mercedes, se encuentran el modelo de ocupación rural, a partir de edificaciones de viviendas autoconstruidas que, situadas en parcelas rústicas, mantienen un uso compartido de carácter agrario y ganadero. Son éstas las que el plan general de ordenación de la Laguna (PGO) de 2004 agrupa en la categoría de Asentamiento Rural 
dentro de la clase de suelo rústico y en las que encontramos una morfología urbana de »Casa-Huerta».

\subsubsection{LA AUTOCONSTRUCCIÓN}

Las unidades de paisaje urbano de autoconstrucción surgieron en los años cincuenta del siglo pasado, como consecuencia del asentamiento de la población inmigrante en estas zonas. Así se desarrollaron Las Canteras, Fuentes Negras, San Roque o El Bronco. Pequeños núcleos urbanos que algunos autores han denominado de autoconstrucción espontánea en escalera, porque en ellos las viviendas han trepado por las laderas muy escarpadas del Macizo de Anaga. Todos ellos presentan «un paisaje urbano identificado por su morfología anárquica y escasa calidad estética, así como por su carácter de marginalidad social, ocupando terrenos poco propicios para la edificación» (Álvarez, 1992, 60-61). Estas construcciones pueden llegar a tener hasta tres y cuatro plantas, han sido construidas de manera individual, al margen de toda planificación y son las únicas que presentan esta altura en todo el conjunto de La Vega. En algunas ocasiones, dentro de este paisaje urbano de autoconstrucción encontramos casas terreras con chamizos, donde sus ocupantes han instalado pequeños huertos y corrales para ubicar algunas cabras, ovejas, vacas o caballos para el autoconsumo.

Un elemento común a todas estas construcciones es que se sitúan alrededor de un antiguo camino, convertido hoy en carretera. Así, por ejemplo, San Roque y el Bronco se localizan en el camino que, desde la antigua ciudad, se dirige hacia Las Mercedes, atravesado hoy por la Vía de Ronda. Fuentes Negras se asienta sobre uno de los caminos que va al Noreste, en dirección a Las Mercedes- El tercer núcleo de viviendas de autoconstrucción es el denominado Las Canteras. Se trata de un asentamiento espontáneo, popularmente muy conocido que se ha desarrollado en la Vega de Las Mercedes, al inicio de la TF-13: antiguo camino convertido hoy en carretera, que se dirige hacia la costa norte de la isla de Tenerife. 
Figura 3. Variación de la ocupación del suelo urbano desde 1964 hasta 2019 en el conjunto de La Vega

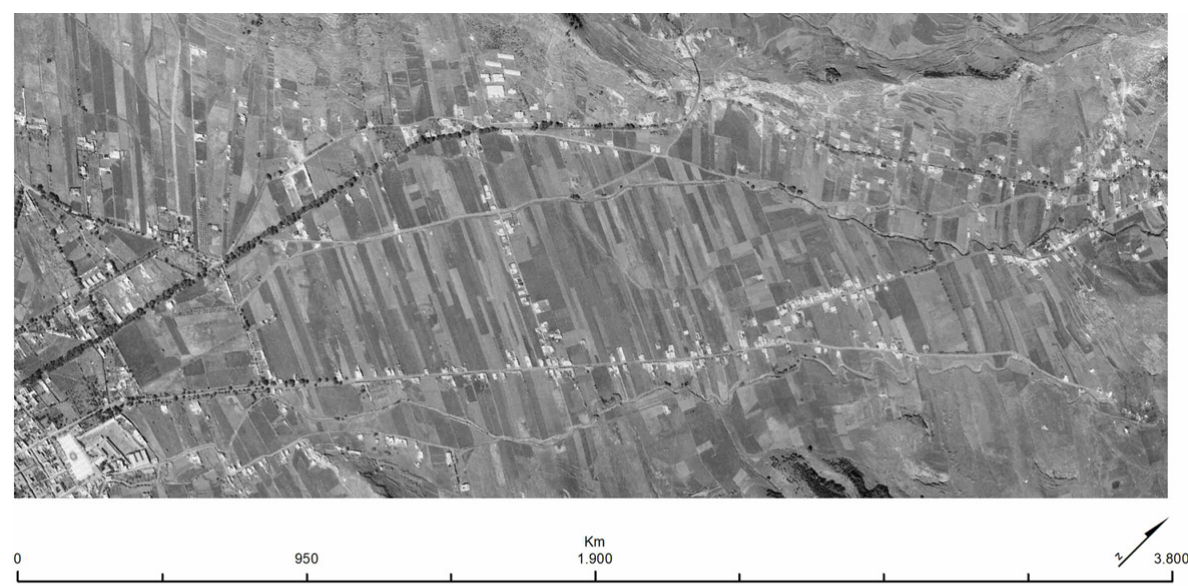

2019

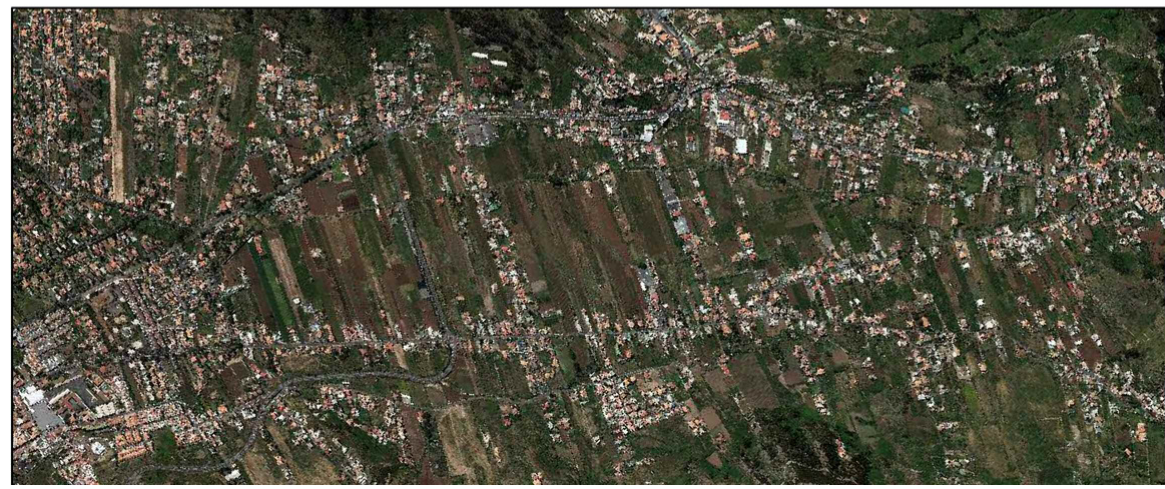

Fuente: Grafcan. Elaboración propia

\subsubsection{EL ASENTAMIENTO RURAL: MORFOLOGÍAS RESIDENCIALES A PARTIR DE LA CASA- HUERTA}

En las cuatro entidades existentes en La Vega de La Laguna y contiguas a las unidades urbanas descritas, encontramos fincas — de mayor o menor dimensión en cada una de las entidades-que han tenido y siguen manteniendo un marcado uso del suelo rural. Este espacio queda como testimonio identificador de la ocupación del suelo en sus orígenes de La Vega de La Laguna, el cual ha sido colonizado, poco a poco y de manera puntual, por la morfología de construcciones urbanas descritas. 
El número de fincas rurales que existe en toda La Vega, es de: 75 en la Vega Lagunera, 168 en Jardina, 185 en Las Mercedes y 201 en La Vega de Las Mercedes. Mientras que las superficies medias de aquellas, en cada una de las cuatro entidades, son de: $298 \mathrm{~m}^{2}$, en La Vega Lagunera; $118 \mathrm{~m}^{2}$, en Jardina; $146 \mathrm{~m}^{2}$, en la Vega de Las Mercedes y 148,43 $\mathrm{m}^{2}$ de Las Mercedes. Asimismo, presentan una densidad de habitantes $/ \mathrm{m}^{2}$ de suelo construido dentro de las viviendas que es mayor en las unidades periféricas y abruptas de Las Mercedes y Jardina. En cambio, en La Vega de Las Mercedes la relación es menor: muy pocas personas 3,3, en viviendas de $150 \mathrm{~m}^{2}$ de media. Son en estas parcelas donde sus propietarios combinan la residencia con actividad agraria, especialmente con cultivos de autoconsumo (papas, tomates, etc..) o bien pequeños establos de animales: ovejas, cabras, vacas o incluso caballos (Ver Figura 3).

\section{EL ASENTAMIENTO RURAL EN LA VEGA, UNIDAD DE PATRIMONIO TERRITORIAL}

Así pues, según hemos ido viendo, La Vega constituía ya desde comienzos del siglo $\mathrm{XX}$, una periferia rur-urbana donde el uso del suelo era mayoritariamente rural, siendo únicamente el sector más próximo al centro de la ciudad el que se consolidaba urbanísticamente. Ya desde la década de los sesenta y con más pujanza desde la apertura de la Vía de Ronda, el uso del suelo rural se va urbanizando poco a poco, hasta el punto de ir desapareciendo, debido fundamentalmente a la reclasificación del suelo de rural en urbano a partir de la aprobación de los distintos planes de ordenación urbana, siempre «de acuerdo a la lógica territorial marcada por los intereses de los diversos agentes con capacidad de intervenir en un contexto de confrontación de, al menos, dos tipos de reglas: las del mercado y las de las administraciones públicas» (Delgado, 2009, 110).

De acuerdo al vigente PGO de 2004, el suelo clasificado de urbano representa un $15 \%$, el urbanizable no llega al 2\%; mientras que la totalidad del rústico representa un 83,39\%. (Ver Tabla 2). Examinando estas cifras parecería extraña la hipótesis planteada al comienzo de nuestra exposición, en donde hemos dicho que es a costa de hacer desaparecer el suelo rústico de «La Vega» como se quiere establecer el crecimiento urbano en esta periferia. Pero ocurre que el porcentaje de todo el suelo rústico de la Vega, (83,39\% de la superficie de la Vega) está clasificado a su vez en, otros diversos: en los que el suelo rural protegido agrario tradicional 1, representa el 35'19 del total del suelo rústico; y el suelo de protección natural un 33,76\% del mismo, el cual corresponde al Parque Rural de Anaga (Ver Tabla 2).

Pues bien, dentro de este suelo rústico se encuentra el de Asentamiento Rural, que representa un $6,32 \%$ de la totalidad de la Vega (7,58\% del suelo rústico). Es éste el que constituye la unidad que define una unidad de paisaje rural, caracterizado por la morfología «Casa-Huerta» que se ha ido mezclando 
con las nuevas edificaciones urbanas descritas con anterioridad, en La Vega (Ver Figura 4). Pues bien, es en este tipo de suelo en el que el PGO abre la mano a la posibilidad de poder construir mayor volumen de edificación, al considerarlos como espacios que «conforman ciudad» (Arranz et al., 2017, 1.354). Nosotros pensamos que no hay necesidad de establecer un mayor crecimiento urbano en estos Asentamientos Rurales de La Vega, porque se asientan, como ya hemos expuesto, sobre uno de los suelos agrícolas más ricos de Canarias. Por otra parte, y según hemos visto, el crecimiento poblacional de La Vega, no ha sido elevado en los últimos veinte años, produciéndose, incluso, un descenso del mismo, por lo que no se justifica la necesidad de construir mayor número de edificaciones de viviendas. Además, este suelo rústico de Asentamiento Rural se encuentra protegido por ley. Así, la Ley 19/2003, de 14 de abril, de Directrices de Ordenación General y de Ordenación del Turismo de Canarias, señala que «El planeamiento insular, en el establecimiento de criterios de reconocimiento y ordenación, y el planeamiento general, en su ordenación pormenorizada, tratarán los asentamientos rurales como formas tradicionales de poblamiento rural, estableciendo como objetivo básico de su ordenación el mantenimiento de dicho carácter rural, evitando su asimilación y tratamiento como suelos urbanos o urbanizables en formación» ${ }^{6}$. Asimismo, el Plan Insular de Ordenación de Tenerife (P.I.O.T), define los asentamientos rurales como: «entidades de población existentes que cuenten con una red viaria y suficiente concentración edificatoria, para considerarlas como un recinto compacto de uso residencial pero cuyas características no aconsejen su clasificación como suelo urbano» ${ }^{7}$. Incluso la Nueva ley del Suelo en Canarias define como Suelo Rústico de Asentamiento Rural (SRAR), «al integrado por aquellos núcleos de población..., donde las actividades agrarias, en el caso de existir, tienen un carácter meramente residual, cuyas características no justifiquen su clasificación y tratamiento como suelo urbano» ${ }^{8}$. Por último, los propios residentes sienten este espacio como «algo suyo, heredado de sus antepasados y que quieren seguir manteniéndolo como tal» (Arranz et al., 2017, 1.358). A este sentimiento se une el hecho de que este espacio constituye, a la vez, un factor de agregación social y de territorialización muy importante donde no sólo, han heredado de sus antepasados, el marco espacial donde se asientan, que como bien dicen, si no

6 Capítulo IV relativo a «la protección del suelo rústico», punto 1 de la Directriz 63 dedicada a los asentamientos rurales.

7 Decreto 56/2011, de 4 de marzo, por el que se aprueba definitivamente el Plan Insular de Ordenación de Tenerife (P.I.O.T.) capítulo 8 dedicado a «la residencia», clasifica las áreas residenciales en: áreas urbanas residenciales, asentamientos rurales y asentamientos agrícolas.

8 Nueva ley del Suelo en Canarias de 4/2017, de 13 de julio, en su capítulo II, artículo 34 dedicado a las categorías y subcategorías del suelo rústico. 
también su cultura y sus costumbres, teniéndolo como proyecto colectivo común para seguir conservándolo como tal (Di Méo, 2007, 92).

Figura 4. Variación de la ocupación del suelo rústico en 2019, en el conjunto de La Vega

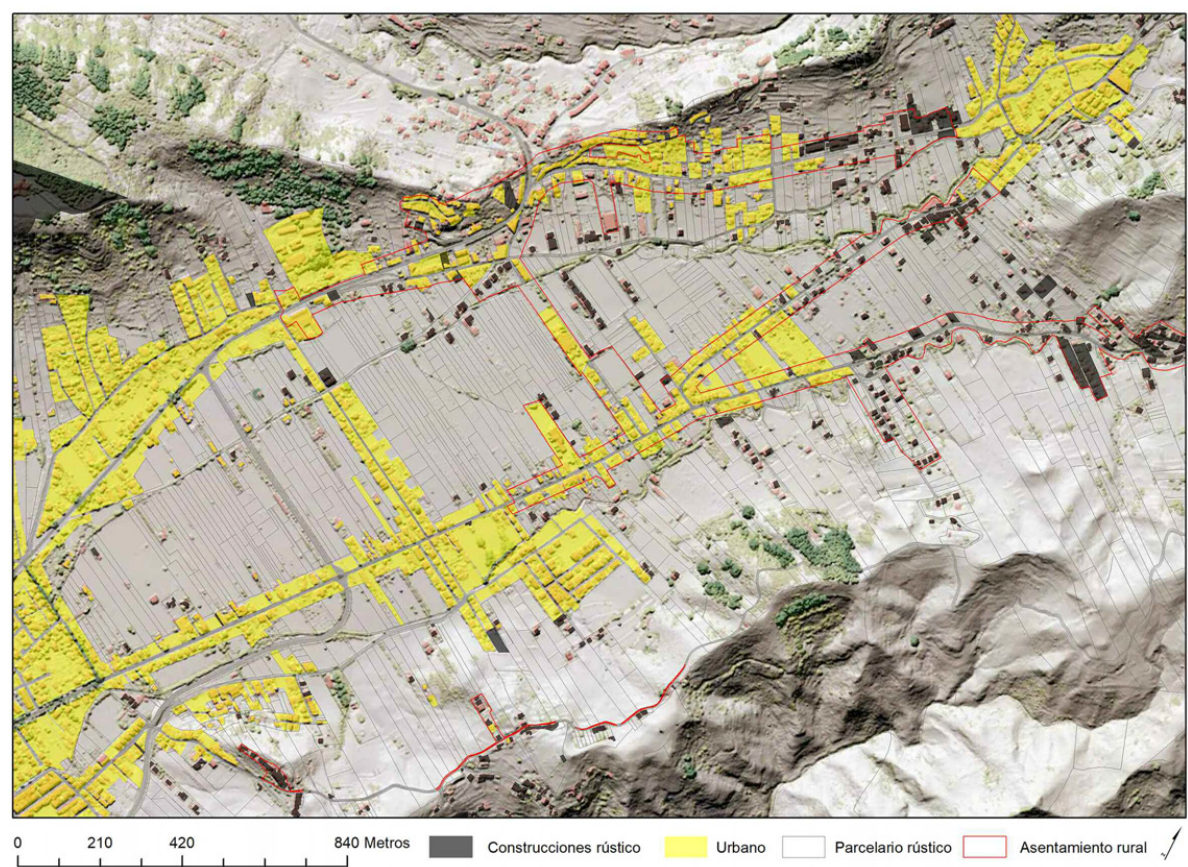

Fuente: GRAFCAN. Elaboración propia

Por todas estas razones consideramos que los Asentamientos Rurales en La Vega de La Laguna, no debieran tener una ampliación del suelo edificado, tal y como indica el PGO, siendo una manera de evitarlo la posibilidad de que las instituciones oficiales los dotasen de una figura de preservación, como por ejemplo la de considerarlos «Paisaje de Patrimonio territorial agrícola local», entendido éste como «un legado relacionado con la herencia histórica de la explotación agropecuaria, en un amplio sentido del término» (Silva, 2008 , 2). Si ello llegara a ocurrir, dicha figura de preservación institucional se uniría a las ya existentes en el municipio de La Laguna, como son: la de Reserva de la Biosfera, establecida en el Parque Rural de Anaga ${ }^{9}$, —en donde

9 Declarado Reserva de la Biosfera por la Unesco, el 9 de junio de 2015. 
tiene origen la cabecera del barranco que conforma La Vega-y la del Parque Agrario ${ }^{10}$, que identifica al Parque Agrícola de Bajamar.

\section{CONCLUSIONES}

La Vega, constituye en el momento actual el sector periférico E-NE de La Laguna. Dicho sector ha sido y es muy especial para ciudad, ya que fue aquí donde se produjo el nacimiento y desarrollo de la misma, al tratarse de un espacio conformado sobre suelos lacustres únicos en la isla, muy ricos para los cultivos. Esta periferia, constituida en el momento actual por cuatro entidades de población, presenta unas proyecciones de edificación urbana, establecidas por el PGO del 2004, que a nuestro parecer son desmesuradas en relación al crecimiento demográfico de sus moradores. A ello se une el hecho de que, en La Vega, la presencia del suelo rustico de "Asentamiento Rural», tiene una gran importancia entre sus residentes, para los que representa su espacio vivido a partir de la gran carga simbólica que presenta. Por esta razón, no desean ver efectuar su transformación en una zona urbana, hecho que significaría su total desaparición Así mismo, las diferentes normativas, de ámbito autonómico, también desean preservarlo tal y como se encuentra, instando a que no se llegue a ser suplantado por la total edificación. Por todas estas razones queremos hacer notar que no tiene sentido establecer La Vega de La Laguna como un sector más de crecimiento urbano de la ciudad, sino preservarla, para las promociones venideras, por valor patrimonial agrícola.

\section{REFERENCIAS}

Antrop, M. (2004). Landscape change and the urbanization process in Europe. Landscape and Urban Planning, (67), 9-26.

Doi: 10.1016/s0169-2046(03)00026-4

Álvarez Alonso, A. (1992). La conurbación Santa Cruz-la Laguna. En AA.VV., Geografía de Canarias 1985-1997. Tomo VII, Capítulo III, pp. 56-66. Santa Cruz de Tenerife: Editorial. Interinsular-Canaria.

Arranz Lozano, M., Jiménez Blasco, B. C., Mayoral Peñas, M. y Resino García, R. M. (2017). La franja rur-urbana en la ciudad de La Laguna, un espacio para la controversia. En AGE, XXV Congreso: Naturaleza, Territorio y ciudad en un mundo Global, 1.352- 1.361. Recomposición de las relaciones ciudadcampo: agriculturas periurbanas Madrid. Recuperado de: https://doi.org/10.15366/ntc.2017

Calero Martín, C. G. (2001). La Laguna. Desarrollo urbano y organización del espacio 1800-1936. La Laguna: Excmo. Ayuntamiento de La Laguna.

10 Figura esta del Parque Agrario en estrecha relación con el concepto de Paisaje Cultural definido así por la UNESCO. 
Decreto (2011). Decreto $56 / 2011$, de 4 de marzo, por el que se aprueba definitivamente el Plan Insular de Ordenación de Tenerife (P.I.O.T.), Tenerife. Recuperado de https://www.tenerife.es/planes/

Delgado Bujalance, B. (2009). Los paisajes periurbanos en los planes subregionales de las aglomeraciones urbanas andaluzas: logros, carencias y contradicciones. Boletín De La Asociación De Geógrafos Españoles, (49), 105-128. Recuperado de:

https://bageojs3.age-geografia.es/ojs/index.php/bage/article/view/777

Di Méo, G. (2007). Processus de patrimonialisation et construction des territoires. En Colloque Patrimoine et industrie en Poitou-Charentes: connaître pour valoriser, pp. 87-109. Poitiers-Châtellerault: France. Recuperado de https://halshs.archives-ouvertes.fr/halshs-00281934/document

Fernández Peraza, C. J. (2013). La Vega Lagunera, transformaciones recientes en un espacio periurbano (Tesis inédita). Universidad de La Laguna, San Cristóbal de La Laguna.

Ley 4/2017, de 13 de julio, del Suelo y de los Espacios Naturales Protegidos de Canarias. BOE núm. 216, de 8 de septiembre de 2017. Recuperado de https://www.boe.es/eli/es-cn/l/2017/07/13/4

Martínez de Pisón, E. (Coord.) (1981). Planificación y ordenación de La Vega Lagunera. Estudio geográfico realizado por encargo de Excmo. Ayuntamiento de Santa Cristóbal de La Laguna: Inédito.

Mejías Vera, M. A. (2013). ¿Cómo medir el fenómeno urban sprawl a través de indicadores paisajísticos? Aplicación a la isla de Tenerife. Boletín de la Asociación de Geógrafos Españoles, (62), 49-73. Recuperado de https://bageojs3.age-geografia.es/ojs/index.php/bage/article/view/1569

Naveh, Z. (2007). Landscape ecology and sustainability. Landscape Ecology, (22), 1.437-1.440. Doi: 10.1007/s10980-007-9171-x

Silva Pérez, R. (2009). Agricultura, paisaje y patrimonio territorial. Los paisajes de la agricultura vistos como patrimonio. Boletín de la Asociación de Geógrafos Españoles, (49), 309-334. Recuperado de https://bageojs3.age-geografia.es/ojs/index.php/bage/article/view/786

Silva Pérez, R. (2008). Hacia una valoración patrimonial de la agricultura. Scripta Nova. Revista Electrónica de Geografía y Ciencias sociales. Vol. XII, (275), 15 de octubre. Recuperado de http://www.ub.edu/geocrit/nova.htm.

Zonneveld, I. (1989). The land unit. A fundamental concept in landscape ecology, and its applications. Landscape Ecology vol. 3, (2), 67-86. Recuperado de:

http://citeseerx.ist.psu.edu/viewdoc/download?doi=10.1.1.4.766\&rep=repl\&type=pdf 



\title{
POLÍTICAS PÚBLICAS DE MOVILIDAD AUTÓNOMA Y SEGURA PARA LA POBLACIÓN ESCOLAR. ANÁLISIS DE CASO EN LAS PALMAS DE GRAN CANARIA
}

\section{PUBLIC POLITICS OF AUTONOMY AND SAFETY MOBILITY OF THE SCHOOL POPULATION. CASE ANALYSIS IN LAS PALMAS DE GRAN CANARIA}

\author{
Itahisa Chávez Santana \\ Universidad de Sevilla \\ Carmen Ginés de la Nuez \\ Universidad de Las Palmas de Gran Canaria
}

Resumen

En las últimas décadas, a través de las políticas públicas de movilidad urbana, se han desarrollado iniciativas para incrementar la autonomía de la población menor y mejorar la seguridad de sus desplazamientos. Dos cuestiones que figuran entre los objetivos de programas de camino escolar seguro o safe routes to school. Al respecto, tras una aproximación al marco teórico, se ha llevado a cabo un análisis que contrasta las intervenciones de transformación urbana en la localidad de Las Palmas de Gran Canaria con la realidad vivida y percibida por la población escolar. Un ejercicio que pone especial atención a la premisa de que sea más efectivo promocionar mejoras globales e integradoras frente a intervenciones aisladas de itinerarios concretos, respaldada, en cierto modo, por agentes como el Ministerio del Interior y la Dirección General de Tráfico en España. Como resultado se reconocen los esfuerzos y su lineamiento respecto del contexto de referencia, si bien se evidencia una brecha respecto del grado de autonomía deseado en los desplazamientos de los escolares y de su percepción de seguridad vial. Un hecho que invita a reflexionar a fin de ajustar los avances y de mejorar la efectividad de las políticas públicas en cuestión.

Palabras clave: política pública, movilidad, autonomía, seguridad vial, desplazamientos escolares.

\begin{abstract}
In recent decades, through public policies in urban mobility, initiatives have been developed to increase the autonomy of the minor population and improve the safety of their movements. Two issues that are among the objectives of safe school road or safe routes to school programs. In this sense, after an approach to the theoretical framework, an analysis has been carried out that contrasts the transformation interventions in the town of Las Palmas de Gran Canaria with the reality lived and perceived by the school population.
\end{abstract}


Exercise that pays special attention to the premise that it is more effective to promote global and inclusive improvements against isolated interventions of specific itineraries, supported, in a way, by agents such as the Ministry of Interior and the General Directorate of Traffic in Spain.

As a result, efforts and their guidelines are recognized with respect to the reference context, although there is a gap regarding the degree of autonomy desired in school trips and their perception of road safety. A fact that invites reflection in order to adjust efforts and improve the effectiveness of the public policies in question.

Keywords: public policy, mobility, autonomy, road safety, school trips.

\section{INTRODUCCIÓN}

Entre las publicaciones relacionadas con la formulación de políticas públicas de movilidad urbana es posible reconocer cómo, en las últimas décadas, se han venido perfilando análisis y propuestas relacionadas con la autonomía de los desplazamientos cotidianos de población escolar y con la mejora de la seguridad vial (España. Ministerio para la Transición Ecológica, 2020).

En líneas generales, la respuesta a estas cuestiones comenzó a canalizarse mediante el posicionamiento de la autonomía y de la seguridad vial como objetivos de los programas de camino escolar seguro, experiencias diseñadas a partir de los años 70 del siglo XX, cuando la localidad de Odense (Dinamarca) se propuso mejorar la seguridad de los traslados a la escuela a pie y en bicicleta (UNC Highway Safety Research Center, 2015). Esto supuso un precedente de lo que ha acabado siendo un movimiento internacional en el que, países de todo el mundo, han impulsado programas respaldados, incluso, por fondos públicos (Pedestrian and Bicycle Information Center, 2007). Una oleada de acciones motivada por el incremento de factores limitantes de la independencia de los desplazamientos de la población menor que, desde los años noventa, se perfilan fundamentalmente, de una parte, en la tendencia de países anglosajones y, de otra, en el enfoque del modelo italiano, por el que han mostrado especial interés numerosas ciudades de países latinos (Román y Salís, 2010).

Este último enfoque es el que está orientando, precisamente, las experiencias que se vienen desarrollando en España (España. Ministerio del Interior. DGT, 2020), entre las que destacan objetivos relacionados con la actividad física y con la seguridad vial en busca de soluciones para la reducción de la incidencia de los accidentes de tráfico en la población de menor edad (Alonso, Esteban, Calatayud, y Alamar, 2009), así como relacionados con la autonomía de los desplazamientos en la infancia y con el diseño de políticas públicas que integren a este colectivo como parámetro en el diseño y desarrollo de esas mismas políticas (Tonucci, 2009). Un planteamiento en el que se integra el 
análisis de la dimensión social del espacio público para favorecer el éxito de programas de camino escolar (Román Rivas, 2011), con especial atención a las características específicas de cada caso, a fin de facilitar el esbozo de la situación de partida y diseñar, con ello, políticas públicas que aseguren la efectividad de las estrategias de intervención.

En relación con lo anterior, y en el marco de la línea de investigación de Políticas Públicas y Servicios del Programa de Doctorado en Geografía de la Universidad de Sevilla, se ha iniciado el estudio de las políticas públicas locales que vienen orientando la transformación del modelo de ciudad y de movilidad en Las Palmas de Gran Canaria. Se trata de una exploración que, en general, busca contribuir a la efectividad de las estrategias locales, formulada a través de un análisis que se soporta, de una parte, en las características del diseño y desarrollo de las propias políticas y, de otra, en las características de la movilidad de la población escolar, así como en la percepción que este grupo refiere acerca del espacio público en el que desarrolla habitualmente sus desplazamientos, con especial atención a los factores de autonomía y seguridad.

En este sentido se plantea esclarecer la relación entre las referidas políticas y la movilidad de la población escolar. Esto es, el objetivo general que se trata en la presente comunicación y que, como objetivo específico, se concreta en dilucidar si para el diseño y desarrollo de las estrategias locales se viene tomado en consideración la situación del grupo social de interés, a fin de reconocer la contribución efectiva de estas políticas a respuestas para la movilidad del colectivo poblacional en cuestión.

Al respecto, se concreta el procedimiento de análisis que se ha llevado a cabo, combinando información cualitativa y cuantitativa, así como los resultados destacados a partir de los cuales se evidencia una dicotomía en relación con el objetivo previsto.

\section{INFANCIA Y MOVILIDAD EN EL FOCO DE LA CUESTIÓN}

El estudio que se aborda responde a uno de los nuevos enfoques de análisis de la movilidad cotidiana donde se ahonda, en relación con el marco conceptual y metodológico, atendiendo a variables y características sociales y urbanísticas, a partir de la persona como sujeto analítico. Un enfoque reciente en los estudios de la movilidad desde la disciplina geográfica (MirallesGuasch y Cebollada, 2009), que revierte en favor de la inclusión social que se ha venido restringiendo a partir del modelo de movilidad de las últimas décadas (Cebollada, 2006).

Así, las bases de este estudio encuentran afinidad en el cerco de la Geografía Crítica o Radical en la medida en que se atiende a las condiciones de vida de un colectivo, a fin de hacer por mejorar parte de sus derechos en pro de su calidad de vida (Gintrac, 2013), lo mismo que al interés por la incidencia de 
políticas públicas orientadoras de cambios profundos, a lo que tal enfoque señalaría como compromiso con matices revolucionarios (Mattson, 1978). Aunque otra de las claves del estudio pivota, con respecto a la geografía crítica, en el diseño de las referidas políticas y, particularmente, en el enfoque que se ha venido perfilando como parte de la geografía de la infancia (Ortiz, 2007), que integra la exclusión urbana de la población menor, como resultado de la expansión del capitalismo, hasta derivar en una crisis conceptual acerca de la funcionalidad del espacio público y de su aptitud como medio de control y disputa (Berroeta y Vidal, 2012). En cualquier caso, se reconoce también un nexo estrecho respecto de la geografía de la población, que integra la perspectiva de estudio a escala 1:1 hasta poner a la persona como individuo en el foco del análisis y, con ello, al interés por los estudios de carácter local para la comprensión de comportamientos espaciales (García, 2000).

De otra parte, en relación con la infancia como objeto de estudio, cabe citar la relación con la auto-representación propia de los nuevos discursos sobre políticas y derechos de la infancia, en la medida en que se integra a la población menor en primera persona en el proceso de análisis (Sünker y MoranEllis, 2018). Se trata de un planteamiento que, en relación con la participación efectiva y la opinión de niños y niñas como sujetos independientes, centra el debate de los principios y del diseño de las políticas desde hace algunas décadas, incluso, a escala internacional (Dávila y Naya, 2003). Es donde, además, se refiere la necesidad de atender a la planificación y gestión con la participación de la infancia en busca de la interacción con un entorno seguro. (UNICEF, 2012).

Así, a otra escala, las cuestiones referidas han pasado a integrarse en documentos de referencia para el desarrollo de la política pública, donde se recogen detalles acerca de la seguridad vial y de los desplazamientos autónomos en relación con la población menor, con orientaciones que se enfocan especialmente a la población escolar, que en el caso de España atienden tanto desde una perspectiva nacional (España. Ministerior del Interior. DGT, 2013) como a local (España. Ministerio del Interior. DGT, 2019). Se trata de referencias impulsadas con la colaboración de expertos, entre las que ha destacado la contribución del que fuera precursor de la experiencia de la ciudad de Fano (Italia), allá por el año 1991, acerca de, precisamente, el derecho de la infancia a la autonomía, así como a participar en el diseño de las políticas públicas urbanas (Tonucci, 2019).

En este sentido se reconoce cómo, con mayor profundidad y desde la disciplina geográfica, en la línea del modelo italiano, se han producido contribuciones al diseño de políticas públicas, dando luz al círculo vicioso en el que se cae con la exclusión de los menores del espacio público (Román Rivas, 2015). Aunque, además, se aporta cómo el comportamiento social ha contribuido a agravar prácticas con efectos desfavorables para la autonomía de la infancia (Roman Rivas, 2018). Tal es así que, en el caso de España, la edad 
media real de la autonomía de los desplazamientos se fija en 9,4 años mientras que la edad media prevista, que resulta de la estimación de quienes aún no brindan autonomía al menor a cargo, asciende a 12,6 años (Alonso, Esteban, Calatayud, y Alamar, 2009). Una disparidad que se relaciona a la sobreprotección a la que apuntaba Román Rivas, frente a la sensación de inseguridad retroalimentada. Pero el punto de inflexión de esta realidad es que, a pesar de todo ello, los expertos afirman a raíz del mismo estudio que los menores cuentan con la capacidad suficiente para desenvolverse con autonomía en las calles desde la etapa de 8 a los 12 años, por lo que se evidencia el problema no son en sí mismos los niños y niñas, sino que este queda determinado por condiciones externas que revierten sobre ellos. Una cuestión que, de pretender su mejora, debiera ser atendida de un modo integrado a otras realidades urbanas como parte de una política amplia relacionada al espacio público (Román Rivas, 2011).

En relación, entre otros municipios de Canarias, Las Palmas de Gran Canaria ha puesto el foco en tal cuestión, si bien las características de su movilidad reflejan la persistencia de un modelo obsoleto que, además de estar basado en el uso del vehículo privado, se ha nutrido de una configuración urbana y de un sistema de transporte han invitado a tal situación (Ayuntamiento de Las Palmas de Gran Canaria, 2010). Un escenario respecto del que se han formulado estudios diversos y diseñado estrategias variadas, pero para el que, hasta el momento, no se conocen resultados relacionados al modo en que estos integran e inciden en la realidad de la movilidad de la población de menor edad.

\section{MÉTODO Y HERRAMIENTAS}

Los resultados que se presentan derivan de una metodología de investigación mixta en la que destaca el uso de información cualitativa. Un procedimiento que si bien ha integrado un análisis de reconocimiento del proceso de reconversión urbanística del ámbito de estudio y del modelo de movilidad de la localidad, se soporta principalmente en las aportaciones obtenidas a través del diseño y desarrollo de una encuesta

de preguntas combinadas, de carácter descriptivo y analítico, con respuestas cerradas, acerca de información de carácter personal como sexo, edad, residencia y escolarización; hábitos de movilidad familiar y personal, percepciones relacionadas a la seguridad de los viajes y deseos de movilidad presente y futura. Se trata de un cuestionario para cuya aplicación se diseñó un proceso de selección muestral mediante el uso del programa estadístico R (Carleos y Corral, 2013), en el que se integró información de los centros escolares atendiendo a la tipología pública, concertada y privada, así como al número de grupos de clase vinculados a los diferentes centros educativo, de los niveles de sexto de primaria y primero de ESO, del curso escolar 2016/2017. 
De este modo se generaron estratos tras haber ordenado los referidos centros según su correspondencia con las macrozonas de movilidad', a los que posteriormente se aplicó la selección de grupos de clase, o conglomerados, de lo que resulta, por tanto, una muestra de carácter probabilístico con la que se ha asegurado una selección homogénea respecto de la distribución territorial de los centros educativos, a la vez que heterogénea y representativa en relación con los grupos de clase (López-Roldán y Fachelli, 2015). En síntesis, un total de 1.124 formularios realizados por estudiantes de entre 11 y 13 años, vinculados a 33 centros escolares de todo el municipio, con una participación de 545 alumnas y 579 alumnos.

Figura 1. Distribución territorial de la muestra
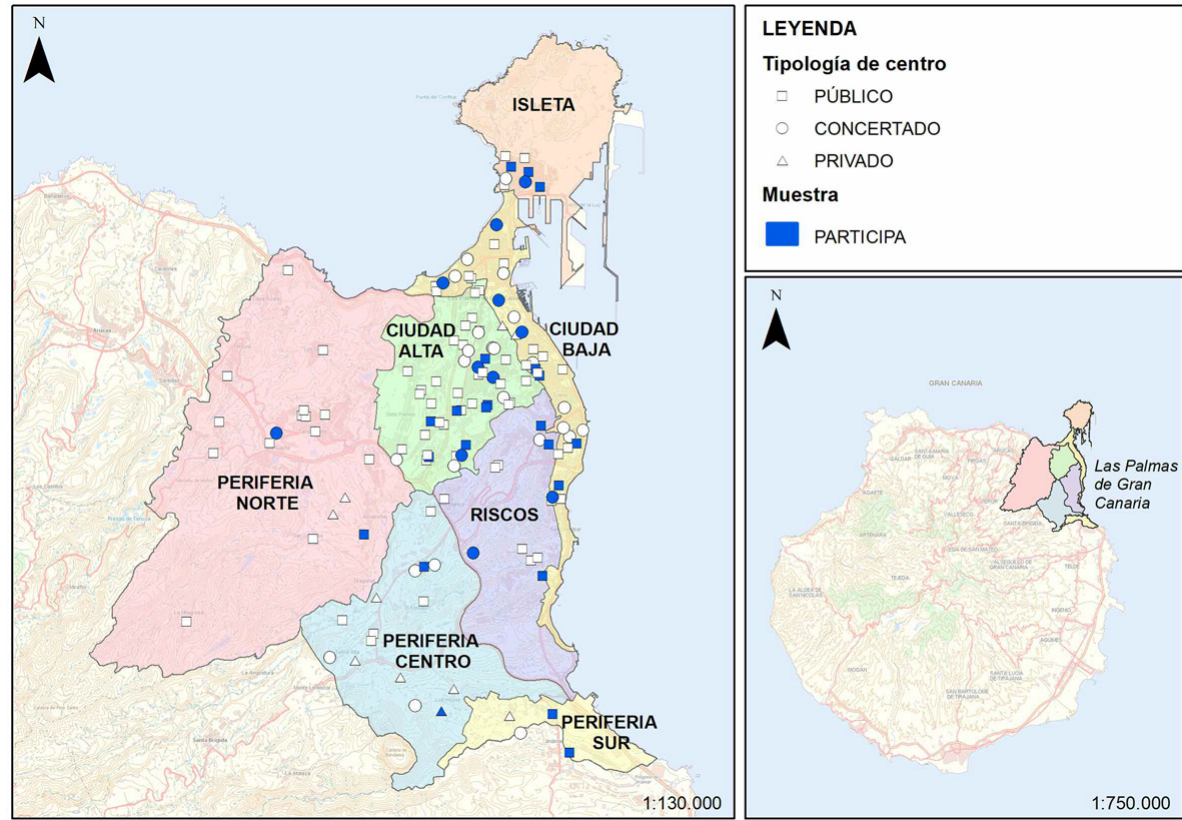

Fuente: Gobierno de Canarias. Elaboración propia

A partir de ello, se ha llevado a cabo un análisis de correlación entre los resultados de una y otra parte de la investigación, llegando a obtener, así, la respuesta al modo en que se alinean las políticas públicas locales respecto de la realidad vivida, percibida y deseada por la población objeto de estudio. De-

1 Unidades adaptadas a partir de Casariego-Guerra Arquitectos (2012). 
rivaciones que, en última instancia, son confrontadas al marco teórico y a las contribuciones y tendencias a las que se ha hecho referencia en el estado de la cuestión, permitiendo orientar con ello la formulación de líneas clave para el diseño de intervenciones futuras que permitan seguir avanzando en la autonomía y la seguridad de los desplazamientos escolares en el municipio. Una aproximación a la afinidad que presenta la realidad vivida y percibida por los escolares y las características del modelo de movilidad y de ciudad presentes actualmente en el ámbito de estudio o, dicho de otro modo, el modo en que las políticas públicas locales están siendo efectivas en la autonomía y la seguridad de los desplazamientos.

\section{ANÁLISIS Y DISCUSIÓN DE RESULTADOS}

Las características de movilidad de la población son parte del escenario sobre el que se diseñan las políticas públicas en la materia. Es por ello por lo que parece oportuno comenzar haciendo referencia a un indicador clave para, posteriormente, enlazar las políticas e iniciativas que resultan reveladoras para un cambio de situación, bien sea con incidencia indirecta o, en el mejor de los casos, con el foco puesto en la infancia.

Así, respecto de la movilidad autónoma, resulta revelador conocer que la edad real a la que comienzan a realizarse desplazamientos independientes en el ámbito de estudio supera los tres años respecto del valor nacional de referencia. Esto es, en torno a la edad de 12 años en Las Palmas de Gran Canaria frente a los 9 años cumplidos en los que se posiciona la edad media nacional (Alonso, Esteban, Calatayud, y Alamar, 2009). Y es, respecto de este hecho, que resulta oportuno introducir la situación de la distribución modal de los desplazamientos habituales de los escolares, puesto que la repartición la encabeza el coche particular $(53,47 \%)$, con una diferencia sensible frente a otros modos como los desplazamientos a pie (31,35\%) y del uso de transporte público colectivo (10,78\%). Una modalidad que, a pesar de ser excluyente para los desplazamientos autónomos de la población menor, en las macrozonas de periferia se relaciona hasta con el 70\%, y con hasta el 82,86\% en el caso de la periferia norte, reduciéndose para espacios urbanos de transición como Ciudad Alta (52,83\%) o Riscos (46,27\%), presentándose los valores más reducidos en Ciudad Baja (39,46\%), donde se localiza la plataforma litoral, así como en La Isleta (38,89\%). 
Tabla 1. Modo de desplazamiento habitual según macrozona de residencia

\begin{tabular}{|c|c|c|c|c|c|c|c|c|}
\hline MACROZONA & A pie & Bici & Guagua & Taxi & Moto & Coche & Otros & Nulo \\
\hline Ciudad Alta & 32,81 & 2,50 & 10,00 & 0,63 & 0,94 & 52,50 & 0,00 & 0,63 \\
\hline Ciudad Baja & 39,46 & 2,04 & 17,01 & 0,00 & 2,04 & 39,46 & 0,00 & 0,00 \\
\hline La Isleta & 50,78 & 0,78 & 7,03 & 0,00 & 1,56 & 38,28 & 1,56 & 0,00 \\
\hline Periferia Centro & 5,71 & 0,00 & 8,57 & 2,86 & 0,00 & 82,86 & 0,00 & 0,00 \\
\hline Periferia Norte & 13,01 & 3,25 & 6,50 & 0,00 & 0,00 & 76,42 & 0,81 & 0,00 \\
\hline Periferia Sur & 21,84 & 1,15 & 9,20 & 0,00 & 1,15 & 65,52 & 0,00 & 1,15 \\
\hline Riscos & 28,99 & 1,45 & 18,84 & 0,00 & 2,90 & 44,93 & 1,45 & 1,45 \\
\hline Total municipal & 31,35 & 1,98 & 10,78 & 0,33 & 1,21 & 53,47 & 0,44 & 0,44 \\
\hline
\end{tabular}

\section{Fuente: Elaboración propia}

Frente a ello, no obstante, se reconoce cómo hasta el 32\% de los escolares apuntan al tráfico como principal factor de rechazo del espacio público, por lo que se presenta la oportunidad de analizar si el hecho de permitirles la elección del modo habitual de desplazamiento pudiera generar cambios de escenario. Y así es que, en general, el uso del coche particular para desplazamientos habituales se reduciría hasta un $44,44 \%$ en el caso de los desplazamientos habituales y hasta un $25,96 \%$ para los desplazamientos por motivo de estudio, con un efecto semejante, a la vez que notorio, en el caso de los desplazamientos a pie, pero contrario, a la vez que positivo, en el caso del uso de la bici, especialmente para en lo que se refiere a deseo de desplazamiento por motivo de estudio.

Tabla 2. Modos de desplazamiento según escenarios de hábitos y deseos de movilidad

\begin{tabular}{|c|c|c|c|c|c|c|c|c|}
\hline ESCENARIO & A pie & Bici & Guagua & Taxi & Moto & Coche & Otros & Nulo \\
\hline Hábito general & 31,35 & 1,98 & 10,78 & 0,33 & 1,21 & 53,47 & 0,44 & 0,44 \\
\hline Deseo general & 10,45 & 15,95 & 6,27 & 0,55 & 16,50 & 44,44 & 5,28 & 0,55 \\
\hline Hábito escolar & 47,30 & 0,11 & 5,72 & 0,11 & 0,44 & 36,85 & 9,46 & 0,55 \\
\hline Deseo escolar & 24,42 & 17,16 & 5,83 & 0,22 & 15,29 & 25,96 & 10,67 & 0,44 \\
\hline
\end{tabular}

\section{Fuente: Elaboración propia}

Pero, en cualquier caso, si el análisis se centra en el peso de las respuestas que implican cambios modales, no pasa desapercibido que, a pesar de que el nuevo modelo de movilidad busca reducir la cautividad del transporte par- 
ticular motorizado, el $20 \%$ de los escolares que realizan habitualmente el camino escolar a pie elegiría el coche como modo de transporte para desplazamientos de estudios, frente a un 11\% que pasaría a hacerlo a pie a cambio del coche. Se trata de datos que rondan los referidos al deseo de uso de la bici, pero que, en el caso de esta última, se torna favorables. Y es que, si bien las dos representan una de las apuestas claves del nuevo modelo de movilidad, y aún se encuentran en la escalada para alcanzar una posición notable en el ámbito en cuestión, este modo captaría un 17\% de los desplazamientos escolares automovilísticos y a otro 17\% de los peatonales.

Concretadas las anteriores como características destacadas del estudio de movilidad de la población de referencia, merece señalar que la estrategia local, recogida fundamentalmente en el Plan Estratégico municipal PROA 2020, y el Plan de Movilidad Urbana Sostenible 2009 - 2012, establece la seguridad como uno de sus principios y, además, reconoce la falta de autonomía de la población menor, pero no la relaciona particularmente a los desplazamientos a los que se refieren los resultados del estudio anteriormente referido, sino a la pérdida de espacios de convivencia y socialización. En cualquier caso, el Estudio Municipal de Movilidad integrado en el planeamiento urbanístico vigente (Ayuntamiento de Las Palmas de Gran Canaria, 2012), incorpora los itinerarios seguros escolares como opción para la potenciación de la movilidad peatonal del grupo poblacional que se estudia. Una propuesta que, referida a la autonomía y a la seguridad de los desplazamientos, para los que además señala la modalidad a pie como en bici, guarda relación con iniciativas materializadas en los últimos años bajo el concepto de bicicaminos escolares y biciescuelas ligadas, particularmente, a centros educativos de la plataforma litoral de la ciudad. Pero, a pesar de ello, el primer estudio de movilidad escolar de la localidad fue elaborado con posterioridad a la puesta en marcha de las iniciativas (Chávez , 2017). Un hecho con el que se comienza a vislumbra el desajuste en el orden procedimental del caso que se trata respecto de las reseñas anteriormente referidas. No obstante, el estudio en cuestión ha servido de precedente para la formulación de caminos escolares a pie, iniciados a modo de experiencia piloto durante el curso 2018/2019, si bien se presenta un nuevo aspecto determinante para considerar el éxito del diseño y desarrollo de las políticas públicas que se abordan. Y es que, tras estar por finalizar un curso académico posterior (2019/2020) sin que se haya dado continuidad al proyecto, y conociéndose la falta de previsión para su implementación en el curso venidero (2020/2021), no se da respuesta a uno de los criterios de planificación previsto para este tipo de iniciativas en el propio Estudio Municipal de Movilidad, como tampoco se conoce que se haya efectuado el criterio de priorización semafórica al que también hace referencia.

En cualquier caso, a lo anterior han acompañado otras actuaciones e iniciativas de carácter didáctico y urbanístico que contribuyen a mejorar los hábitos 
de movilidad, a favor del modelo sostenible y equilibrado que se pretende. Estos son, por ejemplo, la recuperación de espacio para el peatón, la renovación y ampliación de la red ciclable o medidas disuasorias para el uso del automóvil y la velocidad del tráfico rodado, entre otras. Pero se trata de un conjunto de actuaciones que, aunque múltiples y de variada naturaleza y orientación, en ningún caso apuntan, entre sus objetivos prioritarios o motivación, a la autonomía y seguridad de la movilidad de la población más joven. Así, tras lo referido, se reconoce que, en el caso que se trata, la política pública local orientada a la movilidad busca el lineamiento respecto del modelo equilibrado y sostenible que se viene promulgado en el contexto de referencia (España. Ministerio de Fomento, 2019). No obstante, queda evidencia de la brecha que existe entre esta y las aportaciones de referencia acerca de cómo mejorar la autonomía y la seguridad de la población de interés, en la medida en que, en la misma, no se acaba de posicionar a la población menor en el centro del diseño o, dicho de otro modo, a la apropiación social del espacio, en un ejercicio de proximidad y de creación de un nuevo modelo de ciudad (Roch, 2008). Y es que no se reconoce una atención real y directa a las que se han concretado como principales preocupaciones de los escolares, con limitados ejemplos de estudios de detalle que integren al grupo de interés, a diferencia de cómo se viene orientando e implementando en otros casos de éxito. (Laria del Vas, J.; González, M. y Ortega Pérez , J., 2014).

En este sentido, la distancia entre el método de diseño y desarrollo previsible y el que se viene dando en el caso de estudio, parece que no alcanza a atender a cuestiones de base como la fisura reconocida para la edad de inicio de los desplazamientos autónomos. Y siendo así, no parece que fuese posible abordar, de tal forma, otras cuestiones como la posibilidad de incidir sensiblemente en la cautividad de desplazamientos peatonales o en modos de transporte blandos, si no se sostienen, por ejemplo, criterios de continuidad y amplitud territorial en las actuaciones. Una situación semejante a la que se prevé para la atención del deseo de cambio modal, como se deduce de las contribuciones de los expertos, cuando el enfoque sigue puesto en los sujetos y en los aspectos del modelo de intervención clásico: adultos y seguridad vial. Así, en definitiva, la contraposición de los resultados del estudio de caso respecto de las directrices y orientaciones del modelo de intervención reciente para el cambio de modelo de movilidad y, en particular, para la atención a las necesidades de la población menor, llevan a afirmar que, a pesar de reconocerse una intención positiva en el diseño y desarrollo de las políticas públicas locales, aún es necesario ajustar el enfoque para atajar la situación negativa de algunos indicadores y, además, para mejorar de manera real y efectiva las condiciones de autonomía y seguridad que demanda la población menor. 


\section{CONCLUSIONES}

Los estudios de movilidad cotidiana vienen poniendo especial énfasis en el diseño de políticas públicas centradas en las particularidades de hábitos y necesidades de las personas, con un interés que se centra, incluso, en grupos de población concretos como, por ejemplo, la población de menor edad (Miralles-Guasch y Cebollada, 2009). Un asunto que, más allá del marco teórico, ha ido orientando la materialización de diversidad de casos donde los espacios urbanos integran ya medidas orientadas a mejorar la autonomía de la población escolar y la seguridad de sus desplazamientos. Estos son, dos de los objetivos más comunes en la definición de los nuevos modelos de ciudad y de movilidad urbana que ubican a la infancia en el foco de la estrategia de cambio. (Villena y Molina, 2015).

Al respecto, Las Palmas de Gran Canaria es uno de los municipios que, en España, refiere a la población menor como parte de la estrategia en la que se viene trabajando desde principios de siglo, si bien el análisis de resultados lleva a reconocer que, a pesar de los esfuerzos materializados, la realidad de los desplazamientos cotidianos de niñas y niños se presenta aún limitada respecto de las previsiones de la propia política pública local. Esto es, por ejemplo, en relación con los valores de dependencia de los desplazamientos o a los principales aspectos de inseguridad a los que refieren los escolares. Y es que, si bien pudiera decirse que los resultados denotan una orientación al cambio, aún se requiere ajustar el proceso hacia un análisis más profundo acerca del grupo poblacional de interés, con especial atención, además, al modo en el que se deben afrontar los efectos que este grupo enfrenta, en el contexto de la movilidad urbana, como consecuencia de la neoliberalización del territorio (Calonge, 2015).

\section{BIBLIOGRAFÍA}

Alonso, F., Esteban, C., Calatayud, C. y Alamar, B. (Octubre de 2009). Los niños, las ciudades y la seguridad vial: Una visión a partir de la investigación. Attitudes, Instituto Universitario de Tráfico y Seguridad Vial (INTRAS), Universitat de València.

Ayuntamiento de Las Palmas de Gran Canaria (2010). LPA_GC Movilidad en Transformación. Las Palmas de Gran Canaria: Ayuntamiento de LPGC.

Ayuntamiento de Las Palmas de Gran Canaria (2012). Plan General de Ordenación. Aprobación definitiva por acuerdo de la COTMAC de 19 de octubre de 2012. Adaptación Plena al TR-LOTCENC y las Directrices de Ordenació [Ley 19/2003]. Las Palmas de Gran Canaria: Ayuntamiento de LPGC.

Berroeta, H. y Vidal, T. (2012). La noción de espacio público y la configuración de la ciudad: fundamentos para los relatos de pérdida, civilidad y disputa. Polis. 
Calonge, F. (2015). Neoliberalización del territorio y movilidad urbana, una agenda de investigación. Territorios, n³2, 133-156.

Carleos, C. y Corral, N. (2013). Paquetes estadísticos con licencia libre (I). Revista electrónica de Metodología Aplicada, 12-33.

Casariego-Guerra Arquitectos. (2012). Análisis urbano y estrategias espaciales para el Plan de Movilidad Urbana Sostenible (PMUS) de Las Palmas de Gran Canaria. Las Palmas de Gran Canaria: Equipo Redactor del PMUS: UTE Epypsa-EDEI.

Cebollada, A. (2006). Aproximación a los procesos de exclusión social a partir de la relación entre el territorio y la movilidad cotidiana. Doc. Anàl. Geogr., $n^{\circ} 48,105-121$.

Chávez , I. (2017). Estudio sobre hábitos de movilidad de la población escolar en Las Palmas de Gran Canaria. Las Palmas de Gran Canaria: Guaguas Municipales S.A.

Dávila, P. y Naya, L. (2003). La infancia en Europa: una aproximación a partir de la convención de los derechos del niño. Revista Española de Educación Comparada, $n^{\circ}$ 9, 83-133.

España. Ministerio de Fomento. (2019). Agenda Urbana Española 2019. Madrid: Centro de Publicaciones. Secretaría General Técnica.

España. Ministerio del Interior. DGT. (2019). Camino Escolar Seguro. Obtenido de https://www.caminoescolarseguro.com/

España. Ministerio del Interior. DGT. (15 de 03 de 2020). Camino Escolar Seguro. Obtenido de http://caminoescolarseguro.com/index.html

España. Ministerio para la Transición Ecológica. (2020). https://www.miteco.gob.es. Obtenido de https://www.miteco.gob.es/es/ceneam/recursos/mini-portales-tematicos/infancia-movilidad.aspx

España. Ministerior del Interior. DGT. (2013). Camino escolar paso a paso. Madrid.

García, A. (2000). La recuperación de la escala local en geografía de la población. Investigaciones Geográficas. Boletín del Instituto de Geografía, UNAM, n' $43,76-87$.

Gintrac, C. (2013). The contributions of radical and critical geography. Urban, 6, 53-61.

Laria del Vas, J., González, M. y Ortega Pérez , J. (2014). Manual de Inspecciones de Seguridad Vial en Entornos Escolares. Fundación Mapfre.

López-Roldán, P. y Fachelli, S. (2015). Metodología de la investigación social cuantitativa. Barcelona: Bellaterra - Universidad Autónoma de Barcelona.

Mattson, K. (1978). Una introducción a la geografía radical. Geo Crítica. Cuadernos Críticos de Geografía Humana.

Miralles-Guasch, C. y Cebollada, A. (2009). Movilidad cotidiana y sostenibilidad. Una interpretación desde la Geografía Humana. Boletín de la AGE, $n^{\circ} 50$, 193 - 216. 
Ortiz, A. (2007). Geografías de la infancia: descubriendo «nuevas formas» de ver y de entender el mundo. Doc. Anàl. Geog., n 49, 197-216.

Pedestrian and Bicycle Information Center. (2007). Safe Routes to School Guide. EEUU.

Roch, F. (2008). V Encuentro la Ciudad de los Niños. La Infancia y la Ciudad: Una relación difícil. Cambios en la ciudad actual y sus repercusiones en la vida ciudadana, 38 - 62. Madrid: Acción Educativa.

Román Rivas, M. (2011). Camino escolar, más allá de la movilidad. Estudios de Construcción y Transportes, $n^{\circ} 114,47-61$.

Román Rivas, M. (2015). Charla Coloquio Todos a la calle: reflexiones y experiencias para recuperar la vitalidad urbana de la mano de niñas y niños. Cartagena. Obtenido de https://www.youtube.com/watch?v=tzIN4_TneYM

Roman Rivas, M. (2018). Conversatorio con Marta Román: «La privatización de la infancia». Madrid. Obtenido de:

https://www.youtube.com/watch?v=aXe2cF4slqM

Román, M. y Salís, I. (2010). Guía "Camino escolar. Pasos hacia la autonomía infantil». Madrid: Gea 21 - Ministerio de Fomento.

Sünker, H. y Moran-Ellis, J. (2018). Nuevos estudios de infancia, política de infancia y derechos de los niños y niñas. Sociedad e infancias, n 2, 171 - 188.

Tonucci, F. (2009). Ciudades a escala humana: la ciudad de los niños. Revista de educación n extra 7, 147-168.

Tonucci, F. (15 de noviembre de 2019). Francesco Tonucci, creador de La Ciudad de los Niños: «Las ciudades tienen que elegir entre mejorar y desaparecer». (T. Alonso, Entrevistador) Obtenido de:

https://www.smartcitylab.com/blog/es/inclusion-y-compartido/francescotonucci-la-ciudad-de-los-ninos/

UNC Highway Safety Research Center. (2015). SRTS Guide. Obtenido de http://guide.saferoutesinfo.org/introduction/index.cfm

UNICEF. (2012). The State of the World's Children. Children in an Urban World. UNICEF.

Villena, J. y Molina, E. (2015). Ciudades con vida: infancia, participación y movilidad. España: Graò. 



\section{EL IMPACTO DE LAS NUEVAS MOVILIDADES ELÉCTRICAS URBANAS EN EL CONTEXTO DE LOS PLANES DE MOVILIDAD URBANA SOSTENIBLE DE LAS PALMAS DE GRAN CANARIA \\ THE IMPACT OF THE NEW URBAN ELECTRIC MOBILITIES IN THE CONTEXT OF THE SUSTAINABLE URBAN MOBILITY PLANS OF LAS PALMAS DE GRAN CANARIA \\ José Ángel Hernández Luis \\ Universidad de Las Palmas de Gran Canaria}

Resumen

Se estudia cómo pueden incidir las nuevas movilidades eléctricas que se están implementando en las ciudades occidentales y, en particular, en la ciudad de Las Palmas de Gran Canaria, a través, fundamentalmente, de la política de los Planes de Movilidad Urbana Sostenible (PMUS), que ha impulsado el Gobierno de Canarias.

La metodología se centrará en elaborar un diagnóstico sobre el comportamiento de la movilidad pasada y actual en Las Palmas de Gran Canaria. Una vez realizado ello, indagamos hacia dónde nos conduce la nueva movilidad electrificada, donde además de la potenciación del transporte público colectivo como elemento más sostenible del sistema, también se medirán esos nuevos impactos en el futuro (positivos y negativos), de esta nueva movilidad eléctrica urbana. Por tanto, la diagnosis nos lleva a la necesidad de buscar una estrategia más sostenible.

Desde el punto de vista de los resultados, destacamos que, si bien la electrificación de la movilidad presenta notorias ventajas, también existe el riesgo de aumentar la movilidad debido a un menor coste de los desplazamientos, la mejora de la calidad del aire, etc.

Palabras clave: movilidad sostenible, movilidad eléctrica, Las Palmas de Gran Canaria, planificación urbana.

\section{Abstract}

We study the new electric mobilities in western cities and, in particular, in the city of Las Palmas de Gran Canaria through the policy of the Sustainable Urban Mobility Plans (PMUS), which has been promoted by the Government of the Canary Islands.

In the methodology, we first made a diagnosis on the behavior of past and current mobility in Las Palmas de Gran Canaria. Once this is done, we investigate where the new electrified mobility takes us, where in addition to promoting collective public transport as a more sustainable element of the 
system, we will also analyze these new impacts in the future (positive and negative) of this new mobility urban electric. Therefore, the diagnosis leads us to the need to find a more sustainable strategy.

In the results, we say that, although the electrification of mobility has notable advantages, there is also the risk of increasing mobility due to a lower cost of travel, improved air quality, etc.

Keywords: sustainable mobility, electric mobility, Las Palmas de Gran Canaria, urban planning.

\section{INTRODUCCIÓN}

La movilidad en las ciudades es un problema cada vez más acuciante, pues ésta es la que posibilita en gran medida la actividad económica, las relaciones sociales, etc., a la vez que un impacto en el paisaje urbano relevante (UITP, 2003). Desde este punto de vista, las ciudades de crecimiento difuso, con baja densidad demográfica, como podría ser el caso de Los Ángeles como uno de los ejemplos más destacados, la ocupación de la red viaria dentro del cómputo del suelo urbano puede llegar a suponer más del 70 por ciento del suelo (Soria y Puig, 1980, 27), hecho que, por si solo, ya nos acerca al enorme impacto de las infraestructuras y medios de transporte en muchas ciudades del mundo, especialmente, como decimos, en las ciudades de crecimiento horizontal (Rueda, 1996). A su vez, los efectos de la contaminación acústica y atmosférica no son menos desdeñables (Gobierno de Canarias, 1998; Hernández Luis, 2007, 178; Banister, 2011, 1.539; ATM, 2013, 42; Glotz-Richter y Koch, 2016, 2.615), siendo esta última una de las principales causas del deterioro que sufre la ciudad contemporánea. Bien es verdad que, afortunadamente, cada vez más se están implementando los modos telemáticos, que eliminan, parcialmente, las necesidades de movilidad, sobre todo por cuestiones laborales (García Palomares, 2008, 10). Pero la movilidad motivada por ocio, compras, etc. es una cuestión innata a las ciudades y siempre estará presente, incluso por cuestiones relacionadas con la salud mental de los ciudadanos como se ha demostrado recientemente con la pandemia del Covid19, cuando se han impuesto restricciones a la movilidad de la población, viéndose los ciudadanos en situaciones complejas donde el espacio vital diario trasciende más allá de sus hogares.

Pues bien, los Planes de Movilidad Urbana Sostenible (PMUS), que ha impulsado el Gobierno de Canarias, es un requisito indispensable anejo al planeamiento general de los municipios y en concordancia con la Ley 13/2007, de 17 de mayo, de Ordenación del Transporte por Carretera de Canarias, donde en el artículo 35 se argumenta que los Planes Generales de Ordenación Municipal llevarán aparejados un estudio de demanda de la movilidad, el tráfico y del transporte público en el municipio denominado estudio municipal de 
movilidad. En concreto, la ciudad de Las Palmas de Gran Canaria, realizó dicho documento, siendo aprobado definitivamente por la Comisión de Ordenación del Territorio y Medio Ambiente de Canarias (Cotmac) en octubre de 2012. Como consecuencia de ello, se sugirió que la potenciación del transporte colectivo, preferentemente híbrido o eléctrico, además de la bicicleta, la patineta, el incentivo de los paseos para los peatones y, también la movilidad eléctrica privada, serían los pilares de una movilidad más sostenible en la ciudad de Las Palmas de Gran Canaria.

Para analizar esto último, partimos del análisis de un diagnóstico, considerando también las previsiones de los planes de movilidad que apuntan hacia la búsqueda de una movilidad más sostenible, analizando si la planificación propuesta es enteramente sostenible.

\section{OBJETIVOS}

El objetivo central de esta comunicación es evaluar cómo inciden —espacialmente en las pautas de movilidad y el medio ambiente-, las nuevas movilidades eléctricas que se están implementando en las ciudades occidentales y, en particular, en la ciudad de Las Palmas de Gran Canaria, a través, fundamentalmente, de la política de los Planes de Movilidad Urbana Sostenible (PMUS), que ha impulsado el Gobierno de Canarias y que está implementando la ciudad de nuestro estudio.

\section{METODOLOGÍA}

La metodología se centrará en elaborar un diagnóstico somero de las características principales de la ciudad de Las Palmas de Gran Canaria, como por ejemplo, dónde se concentra la población y determinados parámetros de ésta, que justifican en gran medida la demanda de viajes. Posteriormente, analizamos los modos de transporte utilizados, los principales motivos de desplazamiento, etc.

Una vez realizado ello, indagamos en determinados proyectos de transporte novedosos que están relacionados con la búsqueda de una mayor sostenibilidad del transporte en la ciudad, como es por ejemplo la denominada Metroguagua o también la mayor proliferación de vías ciclistas o de uso de patinetas. Todos estos medios de transporte se presentan como más sostenibles, ya que utilizan la energía humana para moverse, como es el caso de las bicicletas, o la patineta eléctrica, sin emisión de gases in situ y, además, con previsión de una considerable reactivación de la demanda del transporte público colectivo a través de la Metroguagua que, en las últimas décadas, se encontraba en franca recesión (Hernández Luis, 2007).

Sin poner en duda la mayor sostenibilidad del sistema de transporte público, máxime si éste se realiza sin emisiones nocivas in situ, analizamos luego, en 
el apartado de discusión y resultados, si la generalización de la electrificación en el transporte es una medida enteramente sostenible, sobre todo en los viajes que se realizan bajo la modalidad del vehículo particular que también se ha potenciado ostensiblemente en los últimos años.

\section{BREVE APROXIMACIÓN AL MEDIO FíSICO Y HUMANO}

Las características físicas y humanas de un territorio condicionan sobremanera la movilidad. En efecto, algunos parámetros como la topografía, condiciones climáticas, densidad demográfica, la estructura profesional y económica, la renta per cápita, la estructura demográfica, la tasa de empleo, etc., conllevan una determinada cantidad y manera de realizar la movilidad diaria. Determinadas circunstancias, como la topografía y las características climáticas en la Ciudad Baja de Las Palmas de Gran Canaria, son muy favorables para el transporte a pie, en patineta o bicicleta, ya que el relieve es bastante llano y las temperaturas, oscilación térmica y al menos precipitaciones, muy idóneas para este transporte.

En suma, por problemas de espacio, no es objeto de este estudio profundizar en estos aspectos, sino de mencionarlos someramente, partiendo sobre todo de las características de la denominada ciudad baja de Las Palmas de Gran Canaria, es decir, aquélla que, a grandes rasgos, presenta una distribución lineal más cercana a la franja costera, esto es, donde se concentra una mayor movilidad y donde se localiza una de las principales arterias de los desplazamientos: la Avenida Marítima y sus vías paralelas que conllevan una importante movilidad, sobre todo en el eje norte-sur. Es justamente en este eje donde, conscientes de la planificación que se ha realizado de los desplazamientos de la ciudad, se concentran los principales intercambiadores y paradas del transporte público regular: Teatro Pérez Galdós, San Telmo, Santa Catalina, Puerto y El Rincón (Ayuntamiento de Las Palmas de Gran Canaria, 2012). Presenta además y como decimos, una topografía llana muy favorable para el desarrollo del transporte público y, además, con alta concentración demográfica y de las actividades económicas (comercio, puerto), administraciones, centros educativos. Además, a priori, es justamente en este espacio donde se concentra un importante contingente de población en edad madura, cuyas características de mayor nivel cultural y renta, se convierten en colectivos de gran demanda de movilidad, frente a otros barrios donde la supremacía de otras situaciones sociales (mayor tasa de desempleo, menor nivel de instrucción, jubilados, etc.), se traducen en menor cantidad de viajes en relación a esos mismos grupos (Tindemans, 2005, 68). 
Figura 1. La ciudad baja de Las Palmas de Gran Canaria

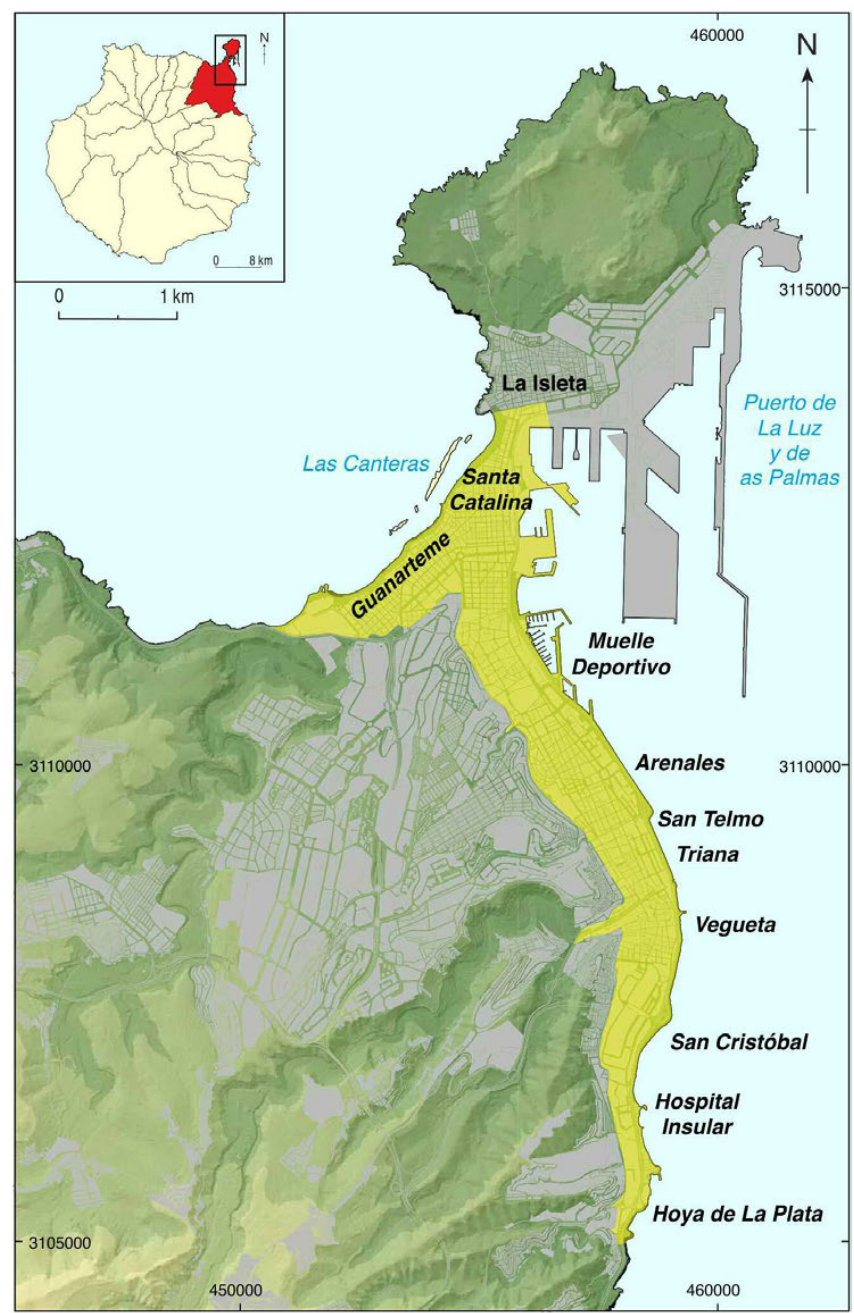

Fuente: Elaboración propia

Desde el punto de vista de la densidad demográfica en las grandes ciudades, algunos estudios ponen de manifiesto la importancia de este parámetro para los desplazamientos, particularmente para el transporte público y la generación de viajes a pie o en bicicleta, con lo que, a priori, una mayor densidad demográfica urbana, se presenta como un modelo de transporte más sostenible por su menor consumo de energía en movilidad, traduciéndose también en menor coste de los desplazamientos. 
Tabla 1. Densidad urbana y transporte en las grandes ciudades

\begin{tabular}{|l|c|c|c|}
\hline \multicolumn{1}{|c|}{ Tipología urbana } & $\begin{array}{c}\text { Densidad } \\
\text { (h./Ha.) }\end{array}$ & $\begin{array}{c}\text { Movilidad en } \\
\text { transporte público, } \\
\text { bicicleta y a pie (\%) }\end{array}$ & $\begin{array}{c}\text { Coste de la } \\
\text { movilidad } \\
\text { (\% del PIB) }\end{array}$ \\
\hline $\begin{array}{l}\text { EEUU, Canadá, Australia y } \\
\text { Nueva Zelanda }\end{array}$ & 18 & 15 & 12.7 \\
\hline Europa & 55 & 52 & 8.3 \\
\hline Japón, Hong Kong, Singapur & 134 & 62 & 5.4 \\
\hline
\end{tabular}

Fuente: Unión Internacional del Transporte Público, 2000

Realmente ello es lo que ocurre en la ciudad baja de Las Palmas de Gran Canaria, hecho que ha favorecido la planificación más profusa en transporte público' o modalidades alternativas al transporte motorizado con energías fósiles, como por ejemplo la bicicleta o las patinetas eléctricas, aproximándonos al modelo de la ciudad media europea de la tabla anterior.

\section{DIAGNÓSTICO DE LA MOVILIDAD EN LAS PALMAS DE GRAN CANARIA}

En general, cuanto mayor sea una aglomeración urbana, mayor será también su tendencia a utilizar, en un mayor porcentaje, los medios de transporte públicos, a pie, en bicicleta, u otras formas de movilidad más sostenibles derivadas, fundamentalmente, de la movilidad eléctrica (motocicletas, patinetas, etc.). Sin duda, ello es muy positivo, ya que de no ser así, la movilidad en las grandes ciudades sería totalmente insostenible (Torres Elizburu, 2005; Rode, 2017). Realmente esta mayor concentración urbana la encontramos en la ciudad baja, es decir, en la franja litoral Cono Sur-Isleta-El Rincón, donde como decimos, se concentra la principal movilidad diaria de la población de la ciudad, cifrándose en un 75 por ciento dentro de los límites de la ciudad. Además, es aquí donde el transporte público colectivo registra sus mayores cotas de aceptación, pues de los casi 14 millones de viajeros año registrados en toda la ciudad en 2013, más de 12,5 millones lo fue en este espacio litoral, esto es, exactamente un 90 por ciento (Ayuntamiento de Las Palmas de Gran Canaria, 2014, 54).

Pues bien, en la siguiente tabla mostramos los modos de transporte utilizados por la población que, en 2011, se desplazaba por motivos de estudio o la-

1 A finales del Siglo XIX entró en servicio un tranvía entre el barrio de Triana y el Puerto, a lo largo de la Calle León y Castillo, prestando un buen servicio hasta bien avanzado los años 40 del Siglo XX, aunque con la interrupción de la Guerra Civil. Entre 1974 y 1975, también entró en servicio un tren vertebrado en la Avenida Marítima, aunque con escaso éxito debido a su impacto ambiental y, sobre todo, la oposición de ciertos sectores muy interesados en otros medios de transporte públicos. 
borales en las principales ciudades canarias, es decir, se trataba de viajes cuyo origen y destino se circunscribía dentro de los propios municipios. Es por ello, por lo que el mayor peso demográfico de Las Palmas de Gran Canaria, dentro del contexto del Archipiélago, y la menor necesidad de movilidad de los ciudadanos de dicha urbe en relación con otras, donde la interdependencia entre municipios es mayor, como por ejemplo entre Santa Cruz de Tenerife y La Laguna, condicionaban una alta movilidad dentro del mismo municipio en relación con otras entidades. A su vez, el mayor peso del transporte público en la capital grancanaria (un 32 por ciento de los citados motivos de viaje) ${ }^{2}$ y bastante distanciado de las otras ciudades canarias, pone de relieve la mayor extensión superficial de la ciudad y, por consiguiente, las mayores distancias que no favorecían la movilidad peatonal sobre todo 3 . Desde este punto de vista, algunos autores argumentan que los desplazamientos a pie se ven superados por los motorizados a partir de los 2,7 kilómetros de distancia media, siendo prácticamente nulos a partir de los 5,5 kilómetros (Pozueta Echavarri, 2000, 33).

Tabla 2. Modos de transporte utilizados por motivos de estudio o laborales de la población de 16 y más años en las principales ciudades de Canarias en 2011

\begin{tabular}{|c|c|c|c|c|}
\hline \multirow[b]{2}{*}{ Ciudades } & \multirow[b]{2}{*}{$\begin{array}{c}\text { Movilidad } \\
\text { total }\end{array}$} & \multicolumn{3}{|c|}{ Modos de transporte (en \%) } \\
\hline & & $\begin{array}{c}\text { Coche, } \\
\text { furgoneta } \\
\text { y moto }\end{array}$ & $\begin{array}{c}\text { Guagua, } \\
\text { autocar o } \\
\text { minibús }\end{array}$ & $\begin{array}{c}\text { Andar, } \\
\text { bicicleta } \\
\text { y otros }\end{array}$ \\
\hline $\begin{array}{l}\text { Las Palmas de Gran } \\
\text { Canaria }\end{array}$ & 132.474 & 51.51 & 32.05 & 16.44 \\
\hline Santa Cruz de Tenerife & 57.146 & 51.98 & 21.41 & 26.61 \\
\hline La Laguna & 33.984 & 58.59 & 17.46 & 23.95 \\
\hline Telde & 19.526 & 64.39 & 15.77 & 19.84 \\
\hline Total de Canarias & 720.097 & 66.39 & 77.54 & 76.07 \\
\hline
\end{tabular}

Fuente: Censo de Población y Viviendas de Canarias de 2011, Instituto Canario de Estadística. Elaboración propia

2 Otras fuentes, pero considerando la movilidad en su conjunto -y no solo la laboral y escolar como aquí se toma-, aluden a solo un 13 por ciento la utilización del transporte público en la ciudad de Las Palmas de Gran Canaria (Ayuntamiento de Las Palmas de Gran Canaria, 2015; Gobierno de Canarias, 2018).

3 Un claro ejemplo de esto lo tenemos en la ciudad belga de Amberes, donde dos tercios de la movilidad hasta un kilómetro, se desplazaba caminando, mientras que el coche solo representaba un 12 por ciento, es decir, menos incluso que el 16 por ciento de la bicicleta, la cual consigue su mejor cuota de aceptación en las distancias comprendidas entre 1 y 5 kilómetros (hasta un 20 por ciento de la movilidad). En el otro extremo se encuentran las distancias superiores a los 20 kilómetros, donde el vehículo privado alcanza cuotas por encima del 90 por ciento. No obstante, se detecta que, progresivamente, va aumentando el índice de ocupación, pues el peso de un solo 
Por tanto, se deduce claramente de la anterior tabla que la demanda de transporte público - aún no siendo tan importante como en otras ciudades-, si que tenía un mayor grado de aceptación dentro del contexto de las Islas, por lo que la coyuntura de estancamiento e incluso pérdida ostensible de viajeros, tenía que derivar en una mejora muy importante de este transporte en aras de incrementar su representación. Es por ello, por lo que en la segunda década del Siglo XXI, las autoridades municipales implementaron la denominada Metroguagua, es decir, un sistema de transporte de alta capacidad cuyo funcionamiento se asemejará a un tranvía o un metro que transita por la superficie, pero utilizando guaguas de última generación con capacidad de 190 viajeros y con tecnología preferentemente eléctrica. Contará, entre otras ventajas, con carriles totalmente exclusivos, prioridad semafórica en los cruces, acceso a nivel desde la parada y alta frecuencia de paso, estimada en una cada cinco minutos (Ayuntamiento de Las Palmas de Gran Canaria, 2015). Sin duda, todos estos factores imprimen un gran salto cualitativo a la movilidad dentro de las ciudades y que ya aludíamos en anteriores trabajos como requisitos indispensables para la potenciación del transporte público (Hernández Luis, 2007).

Profundizando en los modos de transporte utilizados por la población, especialmente cuando se desplazaban en 2011 por motivos laborales o de estudio, se detecta que si bien Las Palmas de Gran Canaria presenta un ostensible menor uso del transporte privado en favor del transporte colectivo y en relación con las otras tres ciudades principales de las Islas, el modo andar representaba un porcentaje bajo, mientras que el uso de la bicicleta era prácticamente nula. Es pues sobre todo, la potenciación del modo andar, en detrimento en especial del vehículo particular y que ya tuvo un cierto impulso en la ciudad con la transformación de ciertas vías como las calles Luis Morote y de León y Castillo, entre otras, con la iniciativa URBAN de la Unión Europea en los años noventa ${ }^{4}$, el que va a marcar el inicio reciente de las políticas sostenibles de movilidad.

pasajero (el conductor), deja paso a una mayor presencia de los individuos que viajan como pasajeros a medida que se incrementa la distancia (Tindemans, 2005; 76), fenómeno éste que, afortunadamente dentro del contexto de la alta movilidad privada, también se da en Canarias.

4 En particular, URBAN fue una Iniciativa Comunitaria de la Unión Europea que se desarrolló en el periodo presupuestario 1994-1999. Entre sus objetivos se encontraba la dimensión físico-ambiental de las ciudades, destacando en particular la intervención en el viario y las redes de transporte: mejora de la accesibilidad vehicular, calmado de tráfico, provisión de plazas de aparcamiento, promoción de modos de transporte alternativos, etc., redundando en una mejora del arbolado y mobiliario urbano, reducción de la contaminación, etc. (De Gregorio Hurtado y Kocewicz, 2007, 7). 
Tabla 3. Modos de transporte utilizados por la población de 16 y más años que se desplazaba en 2011 por motivos laborales o de estudios en los municipios de mayor peso demográfico de Canarias (en \%)

\begin{tabular}{|l|c|c|c|c|c|c|}
\hline \multicolumn{1}{|c|}{ Modo } & $\begin{array}{c}\text { Las Palmas } \\
\text { de G.C. }\end{array}$ & $\begin{array}{c}\text { S/C de } \\
\text { Tenerife }\end{array}$ & $\begin{array}{c}\text { La } \\
\text { Laguna }\end{array}$ & Telde & $\begin{array}{c}\text { Resto } \\
\text { municipios }\end{array}$ & Canarias \\
\hline Coche como conductor & 41.05 & 41.41 & 47.60 & 50.19 & 42.79 & 52.27 \\
\hline Coche como pasajero & 7.19 & 6.97 & 8.48 & 11.71 & 7.68 & 10.05 \\
\hline Motocicleta & 2.84 & 3.05 & 1.73 & 1.98 & 2.66 & 7.91 \\
\hline Guagua & 31.78 & 21.18 & 17.23 & 15.65 & 25.95 & 77.10 \\
\hline $\begin{array}{l}\text { Subtotal dependiente } \\
\text { petróleo }\end{array}$ & 82.86 & 72.67 & 75.04 & 79.53 & 79.08 & 87.27 \\
\hline Andando & 15.89 & 25.99 & 23.19 & 19.37 & 19.57 & 15.27 \\
\hline Bicicleta & 0.11 & 0.06 & 0.17 & 0.08 & 0.10 & 0.10 \\
\hline Otros & 0.30 & 0.27 & 0.28 & 0.24 & 0.29 & 0.33 \\
\hline $\begin{array}{l}\text { Subtotal no } \\
\text { dependiente petróleo }\end{array}$ & 16.30 & 26.32 & 23.64 & 19.69 & 19.96 & 15.64 \\
\hline Segunda residencia & 0.84 & 1.07 & 1.32 & 0.78 & 0.96 & 3.09 \\
\hline Total & 100.00 & 100.00 & 100.00 & 100.00 & 100.00 & 100.00 \\
\hline
\end{tabular}

Fuente: Censo de Población y Viviendas de Canarias de 2011, Instituto Canario de Estadística. Elaboración propia

Con posterioridad, los planes a favor en especial de la bicicleta y la implementación de las nuevas movilidades con tecnología eléctrica, han venido marcando las pautas hacia una mejora de la sostenibilidad de los desplazamientos en las ciudades. Todo ello en aras de mejorar el paisaje urbano, así como disminuir la contaminación atmosférica y acústica. En relación sobre todo con este último parámetro, en un mapa de ruido realizado en Las Palmas de Gran Canaria en el año 2000 y que se presentó un año más tarde ${ }^{5}$, quedó patente

5 La Ley del Ruido, 37/2003 de 17 de noviembre (BOE del 18/17/2003), en su artículo 14, argumenta que las administraciones competentes habrán de elaborar mapas de ruido con carácter obligatorio, los cuales se deberán revisar cada cinco años. La Ley, por este orden, hace especial énfasis en los grandes ejes viarios (más de tres millones de vehículos al año), grandes ejes ferroviarios (más de 30 mil trenes por año), grandes aeropuertos (más de 50 mil movimientos por año) y en las aglomeraciones, entendiendo por tales los municipios mayores de 100 mil habitantes, al igual que -y de manera genérica-, las áreas acústicas en las que se compruebe el incumplimiento de los correspondientes objetivos de calidad acústica (artículo 14, apartado b). Obsérvese que sobre todo esta Ley hace hincapié en el transporte como principal fuente de contaminación. Además, estaría obligando a realizar los mapas de ruido en todas 
que ya algunas calles como Bravo Murillo, se superaban los 75 decibelios durante el día, al igual que Mesa y López o Las Alcaravaneras, con más de 70 decibelios, se correspondían con las áreas más afectadas por la contaminación acústica de la ciudad, correspondiéndose con la denominada ciudad baja. Se concluía que habría que trasladarse al barrio de Vegueta para encontrar niveles razonables de ruido con valores entorno a los 60 decibelios, que ya eran lo suficientemente importantes. Como se afirmaba de manera categórica, el trasiego de vehículos es la principal fuente de contaminación acústica en la capital grancanaria, aunque en algunas zonas a éste se le une el ruido que se genera en los lugares de ocio nocturno (Navarro Mesa, 2001, 14).

En suma, en la actualidad, la insostenibilidad de la movilidad terrestre en la ciudad de Las Palmas de Gran Canaria, viene definida por un alto uso del vehículo privado, el retroceso del transporte público y, sobre todo, la baja representatividad del modo de transporte en bicicleta y a pie. A todo ello hay que unirle una alta representación de las energías fósiles en el cómputo de la movilidad global, en detrimento de otras energías más sostenibles como es la movilidad eléctrica. Todas estas circunstancias se dan en la ciudad baja a pesar de las condiciones favorables donde predomina una pendiente llana y un entorno climático muy favorable para la movilidad a pie y en modos de transporte de dos ruedas, por lo que la sostenibilidad debe avanzar hacia la recuperación de la cuota de transporte global que había perdido el transporte público colectivo, así como la potenciación de medios de transporte basados en energías más limpias.

\section{PRINCIPALES PLANES DE MOVILIDAD LIBRES DE ENERGÍAS FóSILES}

Los planes de movilidad urbana más recientes, es decir, que fundamentalmente se han dado a conocer en la última década en la ciudad de Las Palmas de Gran Canaria y, particularmente en la ciudad baja, donde recordamos se registra el 75 por ciento de la movilidad dentro del municipio y, además, donde existen unas condiciones de densidad demográfica, actividad económica, topografía, etc., muy favorables para la implementación de nuevos modos de transporte, están relacionados fundamentalmente con el transporte público

las Islas, a excepción de La Gomera y de El Hierro, pues cuando se superen los 8.219 vehículos por día en una carretera, la Ley exige que al menos se realicen estos estudios con carácter quinquenal a partir de la fecha de aprobación. No obstante, esta legislación introduce unos plazos en los que alega que aquéllos ejes viarios en los que se superen los seis millones de vehículos al año (16.438 vehículos por día), es decir, también en todas las Islas menos las citadas, los mapas de ruido deberían estar aprobados antes del 30 de junio de 2007, dejando el plazo hasta cinco años más tarde en el caso particular de que el tráfico se encuentre entre los tres y seis millones de vehículos por año (Disposición adicional primera). 
colectivo y el impulso de la bicicleta. Igualmente, la peatonalización parcial o completa de ciertas vías con una actividad comercial muy importante como es la Calle de Mesa y López y sus entornos o también actuaciones en el entorno Puerto-Canteras (Calle Luis Morote, ensanche peatonal de Fernando Guanarteme, etc.), son el resultado en gran medida de la transformación urbana de la ciudad baja como apoyo fundamental también para el gran proyecto de transporte público colectivo denominado: Sistema de Transporte Público de Alta Capacidad (Bus Rapid Transit, BRT), más conocido como la Metroguagua.

Figura 2. Trazado de la Metroguagua de Las Palmas de Gran Canaria

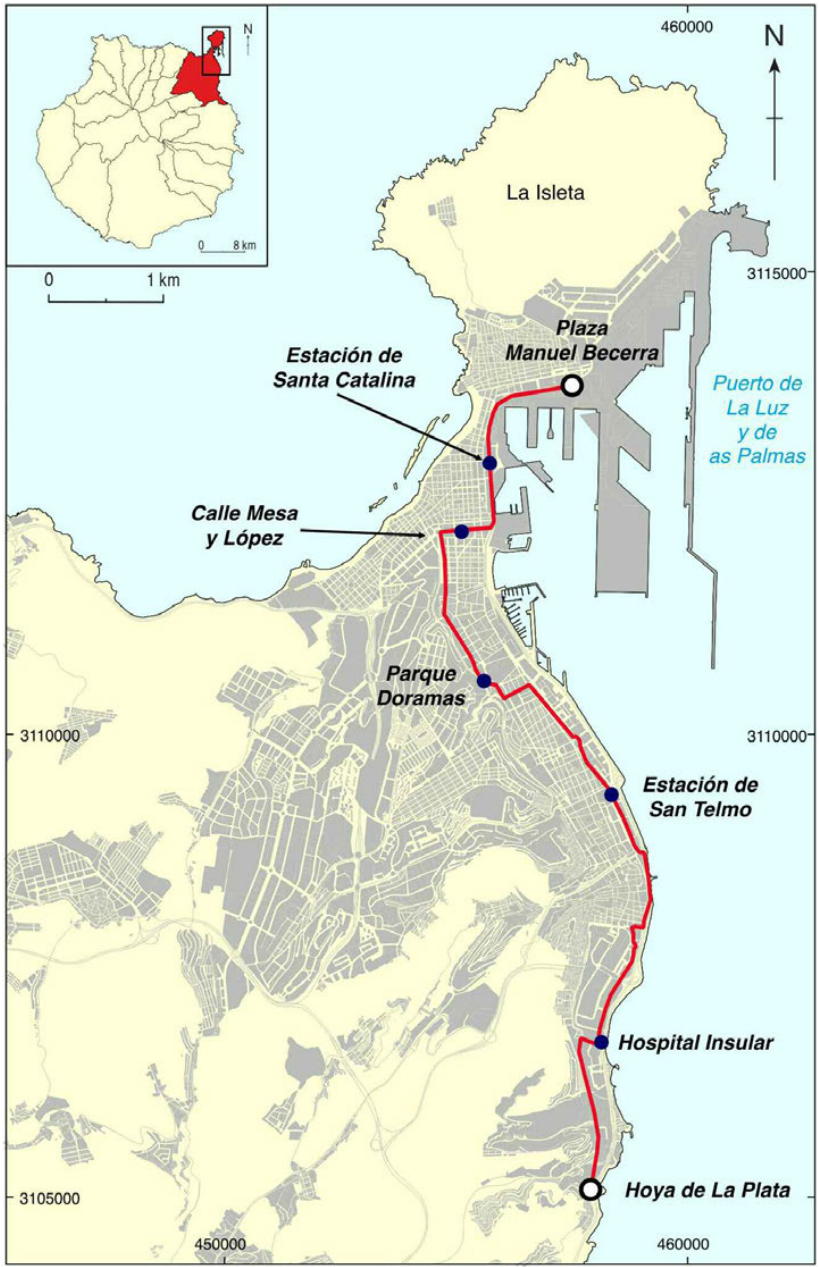

Fuente: Elaboración propia 
La Metroguagua, actualmente en obras, se configura como un sistema de transporte de alta capacidad, asemejándose a un tranvía o un metro de superficie, pero utilizando vehículos de última generación con capacidad de 190 viajeros y con tecnología preferentemente eléctrica. Contará, entre otras ventajas, con carriles totalmente exclusivos y prioridad semafórica en los cruces en sus 11.7 kilómetros de trazado, es decir, entre el cono sur de la ciudad baja (Hoya de La Plata), y el puerto de La Luz y de Las Palmas (Plaza de Manuel Becerra). Se han previsto unas 21 paradas, incrementando la velocidad media comercial desde los 11 a los 20 kilómetros por hora, lo que implicaría la realización del trayecto completo de ida en aproximadamente unos $35 \mathrm{mi}$ nutos. Destaca también el acceso a nivel desde la parada y la alta frecuencia de paso, estimada en una cada cuatro-cinco minutos (GEURSA, 2015). Todos estos factores le imprimirán regularidad y fiabilidad, factores ellos altamente apreciados por los viajeros del transporte público, por lo que éste se constituirá en el principal baluarte para el supuesto incremento de la demanda, ya que se prevé que transporte hasta unas 4.500 personas de media cada hora. Es, sin duda, el proyecto estrella de la movilidad reciente en la ciudad de Las Palmas de Gran Canaria.

Otro gran proyecto es el de la red de bicicletas y patinetas, cuya implementación en la ciudad implicaría, en su máximo desarrollo, una extensión de casi 52 kilómetros, fundamentalmente en la ciudad baja dónde, reiteramos, las características topográficas y de mayor concentración de la movilidad, conllevarían dicha planificación (Ayuntamiento de Las Palmas de Gran Canaria, 2016, 10), concentrándose dichas actuaciones en el eje norte-sur de la franja costera y en el entorno Puerto-Canteras-Mesa y López ${ }^{6}$. Habría que destacar el impulso que se está realizando de ésta en los últimos años amparándose en el sistema de la denominada e-sitycleta, es decir, la bicicleta eléctrica de préstamo público, con una autonomía de más de 60 kilómetros y que será vital para la expansión de este modo de transporte hacia la ciudad alta dada la mayor pendiente.

6 Ello también se fundamenta en que el 38,4 por ciento de los efectivos de Las Palmas de Gran Canaria disponen de un itinerario ciclista a menos de 300 metros de su vivienda habitual. Este dato, sin duda, juega a favor del actual contexto de expansión de la red ciclista. (Datos facilitados Zenaida Morales, Observatorio de Movilidad de Las Palmas de Gran Canaria). 
Figura 3. Carriles bici en la ciudad baja de Las Palmas de Gran Canaria

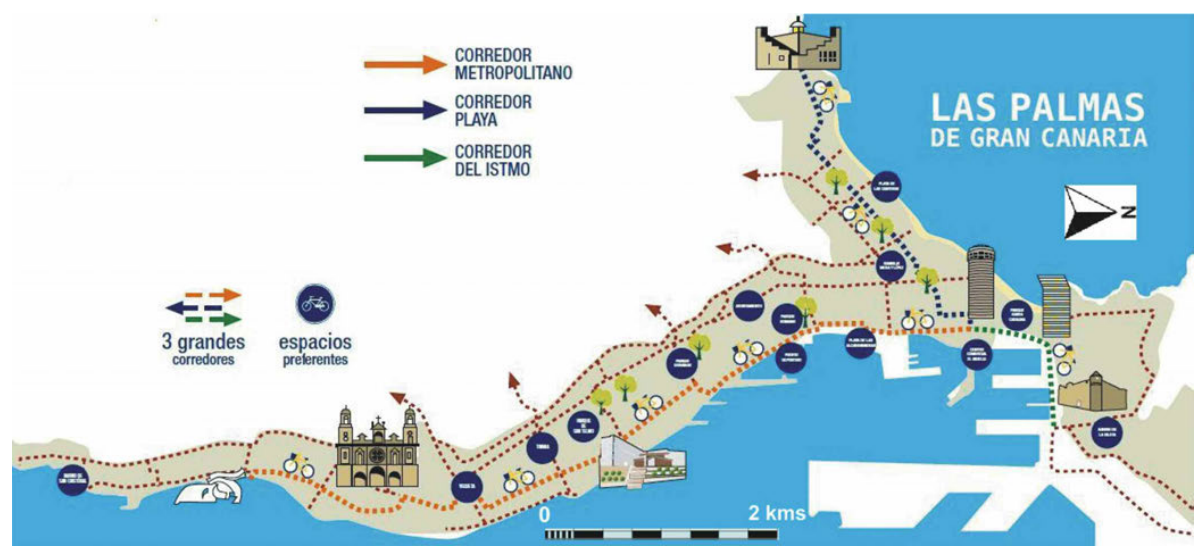

Fuente: Ayuntamiento de Las Palmas de Gran Canaria, 2014

Otra actuación prioritaria está relacionada con la potenciación de la movilidad eléctrica privada. En efecto, la Sociedad Municipal de Aparcamientos de Las Palmas de Gran Canaria (SAGULPA), dependiente del Ayuntamiento de la ciudad, cuenta en la actualidad con 35 puntos de recarga de vehículos eléctricos, distribuidos entre los diferentes aparcamientos de los cuales ostenta la titularidad7. Además dispone también de otro punto de recarga rápida, totalmente de uso público y gratuito, en la sede de la propia empresa municipal, ubicada en un enclave muy transitado de la ciudad baja ${ }^{8}$. Y es que la potenciación de los vehículos eléctricos en las ciudades canarias es uno de los objetivos fundamentales del Gobierno de Canarias a través de los Planes de Movilidad Urbana Sostenible, por los beneficios sobre todo medioambientales que ello generaría (Gobierno de Canarias, 2018, 111). El propio Ayuntamiento de Las Palmas de Gran Canaria afirma categóricamente en su página web que hay que promover los vehículos eléctricos (particulares) como motor de transformación de la ciudad?.

7 A ello hay que unirle que los vehículos eléctricos están exentos del pago del parking en la zona azul de la ciudad por un tiempo de hasta dos horas y hasta 60 minutos en la zona verde.

8 A ello hay que añadirle otros tres cargadores en la Institución Ferial de Canarias (Infecar) y dependientes del Cabildo Insular de Gran Canaria, también con carácter gratuito.

9 https://www.laspalmasgc.es/es/areas-tematicas/trafico-y-transportes/vehiculos-electricos/ (consulta realizada el 28 de abril de 2020). 
Son estas tres actuaciones en las que la movilidad eléctrica es el principal objetivo, las que sobre todo pretenden potenciar una mejora del medio ambiente urbano. En efecto, la disminución de la contaminación atmosférica y acústica se postula como una de las grandes ventajas de la mejora de la calidad de vida en las urbes e, inevitablemente, la electrificación de la movilidad es una gran justificación para ello.

\section{DISCUSIÓN Y RESULTADOS}

Desde el punto de vista de los resultados, destacamos que, si bien la electrificación de la movilidad presenta notorias ventajas, por ejemplo, en calidad del aire in situ, la ocupación de un menor espacio en el viario cuando se utiliza el patinete o la bicicleta, etc., no deducimos grandes ventajas con respecto al vehículo eléctrico particular, excepto la emisión de partículas claro está, pues casi todos los impactos de la movilidad de combustión actual siguen estando presentes con esta última.

Realmente, sin una potenciación clara de las energías renovables, los planes urbanos de movilidad sostenible, lo que están potenciando es la transferencia del carbono generado en ellas a la periferia, contribuyendo por igual a los efectos negativos del cambio climático. Es verdad que tendría, a priori, efectos muy beneficiosos para los ciudadanos, ya que la calidad del aire sería mejor y las emisiones acústicas disminuirían, parámetros todos ellos aplaudidos por la Organización Mundial de la Salud, pero como decimos, el problema persiste en la periferia con efectos globales.

Es más, hay que ser conscientes que la extensión de la movilidad eléctrica con unos costes de adquisición de los vehículos particulares, como se prevé a medio plazo, más asequibles —incluso a un precio inferior en comparación con los de combustión entre 2024 y 2027-, debe suponer una explosión de la movilidad motorizada en las ciudades, pues el coste de movilidad sería muy inferior debido al menor coste de la electricidad en relación con los combustibles fósiles ${ }^{10}$. Ello sin duda conllevaría mayor congestión y, previsible-

10 Ello se deriva de una simple encuesta que realizamos entre los integrantes de la Asociación de Usuarios de Vehículos Eléctricos (AUVE) de la provincia de Las Palmas, que contaba con 136 componentes en abril de 2020. A través de su grupo de whatsapp, nos respondieron 31 personas (un 23 por ciento), realizándoles la pregunta de si ellos habían detectado que tras la adquisición del vehículo eléctrico con fines privados, habían detectado un incremento de la movilidad en relación con la situación anterior como propietarios de un vehículo de combustión. De ellos, 13 respondieron que su movilidad era igual y los restantes 18, confesaron que su movilidad era mayor, incluso algunos de ellos consideraban que bastante mayor, sobre todo con otros municipios de la Isla, visitando espacios inexplorados para ellos desde hacía años. 
mente, menos espacio para generar una ciudad más humanizada en que el peatón, la bicicleta y el transporte público deberían ser la prioridad.

Es indudable que la electrificación de la movilidad motorizada de carácter público en las ciudades, así como la de los vehículos de dos ruedas (bicicletas y patinetas sobre todo), es muy beneficioso, pero no están tan claros los beneficios para la ciudad de la electrificación del parque automovilístico privado, pues si bien es verdad que cuenta con beneficios como hemos argumentado, también presenta serios riegos de sostenibilidad y consumo de espacio con un importante parque móvil de eléctricos.

\section{CONCLUSIONES}

En suma, en la actualidad, la insostenibilidad de la movilidad terrestre en la ciudad de Las Palmas de Gran Canaria, viene definida por un alto uso del vehículo privado, el retroceso del transporte público y, sobre todo, la baja representatividad del modo de transporte en bicicleta y a pie. A todo ello hay que unirle una alta representación de las energías fósiles en el cómputo de la movilidad global, en detrimento de otras energías más sostenibles como es la movilidad eléctrica. Todas estas circunstancias se dan en la ciudad baja a pesar de las condiciones favorables donde predomina una escasa pendiente y un entorno climático muy favorable para la movilidad a pie y en modos de transporte de dos ruedas, por lo que la sostenibilidad debe avanzar hacia la recuperación de la cuota de transporte global que había perdido el transporte público colectivo, así como la potenciación de medios de transporte basados en energías más limpias.

No obstante, si bien apreciamos que la movilidad motorizada en transporte colectivo, bicicleta y patinetas, movidas por tecnología eléctrica es muy positiva, al margen de algunos críticos que argumentan la ausencia de ruido y su peligrosidad para el peatón, no creemos que ocurra lo mismo con la potenciación de la movilidad de vehículos eléctricos de cuatro ruedas, pues además de consumir más energía en relación con la movilidad de dos ruedas, su consumo de espacio en el viario sería bastante mayor y, a pesar de ello, se está incentivando su uso en las ciudades con la política de cargadores públicos y aparcamientos gratuitos, no siendo una excepción de esta política la ciudad de Las Palmas de Gran Canaria.

\section{BIBLIOGRAFÍA}

ATM (2013). Observatori de la mobilitat, Area de Barcelona. Barcelona: Autoritat del Transport Metropolita.

Ayuntamiento de Las Palmas de Gran Canaria (2012): Plan General de Ordenación de Las Palmas de Gran Canaria. Anexo: Estudio municipal de movilidad. Las Palmas de Gran Canaria (inédito). 
Ayuntamiento de Las Palmas de Gran Canaria (2014). LPA_GC Movilidad en transformación. Las Palmas de Gran Canaria (inédito).

Ayuntamiento de Las Palmas de Gran Canaria (2015). Anteproyecto de sistema de transporte público rápido. Las Palmas de Gran Canaria (inédito).

Ayuntamiento de Las Palmas de Gran Canaria (2016). Plan Director de la bicicleta de Las Palmas de Gran Canaria. Las Palmas de Gran Canaria (inédito).

Banister, D. (2011). Cities, mobility and climate change. Journal of Transport Geography, 19(6), 1.538-1.546.

De Gregorio Hurtado, S. y Kocewicz, R. (2007). Iniciativa comunitaria URBAN 1994-99. Análisis comparativo de tres casos españoles de programas europeos de rehabilitación urbana. Cuaderno de Investigación Urbanística, 55, 1-96.

García Palomares, J. C. (2008). Incidencia en la movilidad de los principales factores de un modelo metropolitano cambiante. Eure, XXXIV(101), 5-23.

GEURSA (2015). Sistema de Transporte Público Rápido, Bus Rapid Transit, Las Palmas de Gran Canaria. Las Palmas de Gran Canaria (inédito).

Glotz-Richter, M. y Koch, H. (2016). Electrification of Public Transport in Cities. Transportation Research Procedia, 14, 2.614-2.619.

Gobierno de Canarias (1998). Libro Blanco de los transportes en Canarias. Las Palmas de Gran Canaria: Ed. Consejería de Turismo y Transportes.

Gobierno de Canarias (2018). Guía metodológica para la elaboración de Planes de Movilidad Urbana Sostenible. Las Palmas de Gran Canaria (inédito). Hernández Luis, J. Á. (2007). Tendencias de la movilidad terrestre en Canarias. Las Palmas de Gran Canaria: Ed. Anroart.

Navarro Mesa, J. L. (2001). Realización de un mapa de ruido de la ciudad de Las Palmas de Gran Canaria. Las Palmas de Gran Canaria: Ayuntamiento de Las Palmas de Gran Canaria, Concejalía de Limpieza, Medio Ambiente y Playas (inédito).

Pozueta Echavarri, J. (2000). Movilidad y planeamiento sostenible: hacia una consideración inteligente del transporte y la movilidad en el planeamiento y en el diseño urbano. Colección Cuadernos de Investigación Urbanística, 30. Madrid: Ed. Instituto Juan de Herrera.

Rode, P., Floater, G., Thomopoulos, N., Docherty, J., Schwinger, P., Mahendra, A. y Fang, W. (2017). Accessibility in Cities: Transport and Urban Form. En G. Meyer y S. Shaheen (Eds) Disrupting Mobility, pp. 239-273. Cham: Lecture Notes in Mobility. Springer.

Rueda, S. (1996). La ciudad compacta y diversa frente a la conurbación difusa. En Boletín Ciudades para un futuro más sostenible. Madrid: Escuela Técnica Superior de Arquitectura de Madrid, Universidad Politécnica de Madrid.

Soria y Puig, A. (1980). ¿A qué se llama transporte? Ciudad y Territorio, 2, 1932. 
Tindemans, H. (2005). Spatial analysis and modelling base on activities: a pilot study for Antwerpen and Gent, Belgium. En WILLIAMS, K. (ed.): Spatial Planning, urban form and sustainable transport, Ed. Ashgate, Aldershot. Torres Elizburu, R. (2005). La bicicleta, ¿una alternativa real de transporte urbano? El caso de Vitoria-Gasteiz. Boletín Ciudades para un futuro más sostenible, 28.

UITP (2003). Billete al futuro. Las 3 paradas de la movilidad sostenible. Bruselas: Ed. Unión Internacional de Transportes Públicos. 



\title{
DISEÑO Y CARACTERIZACIÓN ESPACIAL DE ESCENARIOS FUTUROS \\ DE DESARROLLO URBANO Y TRANSPORTE MEDIANTE \\ TÉCNICAS PARTICIPATIVAS EN EL CORREDOR DEL HENARES (MADRID)
}

\author{
DESIGN AND SPATIAL CHARACTERIZATION OF \\ FUTURE URBAN AND TRANSPORT SCENARIOS BY USING \\ Ramón Molinero-Parejo \\ Universidad de Alcalá \\ Amor Ariza-Álvarez \\ Universidad Politécnica de Madrid \\ Montserrat Gómez Delgado \\ Universidad de Alcalá \\ Francisco Aguilera-Benavente \\ Universidad de Alcalá \\ Julio A. Soria-Lara \\ Universidad Politécnica de Madrid
}

PARTICIPATORY APPROACHES IN THE HENARES CORRIDOR (MADRID)

Resumen

La planificación integrada de los usos del suelo y el transporte es fundamental para avanzar hacia un desarrollo urbano sostenible. Los escenarios futuros son herramientas que pueden ayudar a integrar ambas dimensiones. Sin embargo, las dificultades para su visualización espacial por parte de los diferentes agentes que forman parte del proceso de planificación, pueden condicionar su utilidad. El objetivo de esta investigación es comprobar si la caracterización espacial de escenarios futuros de transporte y usos de suelo urbano permite concretar de forma más detallada dichos escenarios. Para ello, se llevó a cabo un taller en el que participaron agentes relacionados con el desarrollo urbano y el transporte y en el que se cartografió de manera colaborativa tres escenarios futuros para el año 2050 en el Corredor del Henares (Comunidad de Madrid, España). Como resultado, se obtuvieron tres mapas, uno para cada escenario futuro, con la caracterización espacial de los cambios en los usos de suelo urbano y el transporte en el área de estudio. Esta investigación muestra el diseño del taller y los resultados obtenidos tras el cartografiado colaborativo, además de reflexionar sobre la capacidad de la metodología seguida para afrontar la caracterización espacial de escenarios futuros, facilitando el diálogo y el intercambio de conocimiento interdisciplinar.

Palabras clave: escenario, crecimiento urbano, transporte, taller participativo, cartografiado colaborativo. 


\section{Abstract}

The integration of land use and transport is essential to move forward in sustainable urban planning. Future scenarios can be tools that help integrate both dimensions. However, the difficulties for its spatial visualization by the different agents that take part in the planning process, can determine its usefulness. The objective of this study is to verify whether the spatial characterization of future urban transport and land use scenarios is useful to specify them in greater detail. For this purpose, a workshop was held in which agents related to urban development and transport were involved and in which three future scenarios were collaboratively mapped for the year 2050 in the Henares Corridor (Madrid, Spain). As a result, three maps were obtained (one for each future scenario) with the spatial characterization of changes in urban land use and transport infrastructure in the study area. This work shows the design of the participatory workshop, the results obtained after the collaborative mapping process and reflects on the capacity of the methodology followed to face the spatial characterization of future scenarios, facilitating dialogue and interdisciplinary knowledge exchange.

Keywords: scenario, urban growth, transport, participatory workshop, collaborative mapping.

\section{INTRODUCCIÓN}

En España, el rápido crecimiento de las áreas peri-urbanas, unido a la falta de coordinación con la planificación del transporte, ha causado serios problemas territoriales y sociales como congestión del tráfico, contaminación atmosférica, escasez de recursos territoriales, segregación social o descenso de la calidad de vida (Ustaoglu, Williams, y Petrov, 2017). El sistema de transportes tiene influencia sobre la localización de las actividades humanas, del mismo modo que el modelo de distribución de esas actividades influye en la movilidad de las personas (Button, Stopher, Hensher, y Haynes, 2004). Por ello, resulta fundamental una planificación a largo plazo que integre los usos del suelo y el transporte a nivel urbano (Bertolini, 2012; Wegener y Fuerst, 2004) y que involucre a los diferentes agentes interesados en un proceso colaborativo (Bertolini, 2007; Willson, 2001). En este contexto, la utilización de escenarios futuros (Scenario Planning) constituye una herramienta para lograr este propósito.

Los escenarios futuros facilitan, entre otros aspectos, la toma de decisiones estratégicas a largo plazo (Hickman, Ashiru, y Banister, 2011; Tuominen, Tapio, Varho, Järvi, y Banister, 2014; Zimmermann, Darkow, y von der Gracht, 2012). Su empleo es cada vez más frecuente en la literatura, ya sea para el estudio de los usos del suelo (Mallampalli et al., 2016; Pearson, Park, Harman, y He- 
yenga, 2010), el transporte (Geurs y Van Wee, 2000; Hickman et al., 2011) o a la integración de ambos (Bartholomew, 2007; Ustaoglu et al., 2017). Sin embargo, existen dificultades a la hora de comprender y visualizar correctamente estos escenarios futuros a largo plazo dado que la mayor parte de ellos consiste en un conjunto de narrativas que adolecen de representaciones espaciales explícitas (Banister y Hickman, 2013). Asimismo, cuando los escenarios futuros son empleados en un entorno de planificación colaborativo, al problema anterior se añade la falta de entendimiento y de un «lenguaje común» entre agentes procedentes de distintos dominios profesionales (Soria-Lara y Banister, 2017). En este sentido, la espacialización de los escenarios futuros mediante cartografiado colaborativo (collaborative mapping) puede ser una solución a estos problemas. Este consta de un conjunto de técnicas y herramientas que permiten representar las relaciones existentes entre el territorio, las actividades y la población a través de la cartografía (Cochrane y Corbett, 2018).

El objetivo principal de esta investigación es comprobar si la caracterización espacial de escenarios futuros de transporte y usos del suelo de carácter urbano a través de agentes con diferentes perfiles profesionales permite concretar de forma más detallada dichos escenarios. Con este propósito, se diseñó y llevó a cabo un taller de cartografiado participativo en el que se involucró a diferentes agentes relacionados con la planificación y el desarrollo de los usos del suelo y los sistemas de transporte urbanos: técnicos municipales, promotores inmobiliarios, planificadores y consultores. En dicho taller, se cartografiaron tres escenarios para el año 2050. El Corredor del Henares (Comunidad de Madrid, España) fue utilizado como área de estudio para esta investigación. Como resultado del taller, se obtuvieron tres mapas con la caracterización espacial de los cambios en los usos del suelo de carácter urbano y el transporte para cada escenario futuro.

La presente comunicación se estructura en los siguientes puntos: (1) Introducción, (2) Área de estudio y datos de partida, (3) Metodología, (4) Resultados de la investigación y (5) Conclusiones finales.

\section{2. ÁREA DE ESTUDIO Y ESCENARIOS DE PARTIDA}

\section{1. ÁREA DE ESTUDIO}

Esta investigación ha seleccionado como área de estudio el sector occidental del Corredor del Henares (Figura 1), ubicado al este del Área Metropolitana de Madrid. Este espacio se caracteriza por su distribución en torno a algunos de los principales ejes de comunicación a nivel nacional, situación que ha provocado su fuerte desarrollo y expansión. Especialmente en las últimas décadas ha experimentado un crecimiento urbano acelerado (Barreira-González, Aguilera-Benavente, y Gómez-Delgado, 2017), causando así una transforma- 
ción funcional en el modelo productivo (del Río Lafuente y Rodríguez Moya, 2009) y reconfigurando las relaciones entre los municipios adyacentes. Esta situación y contexto resulta de especial interés para el estudio de los cambios y distribución de los usos del suelo y los sistemas de transporte futuros.

Figura 1. Área de estudio. Distribución de las áreas urbanas y red de transporte

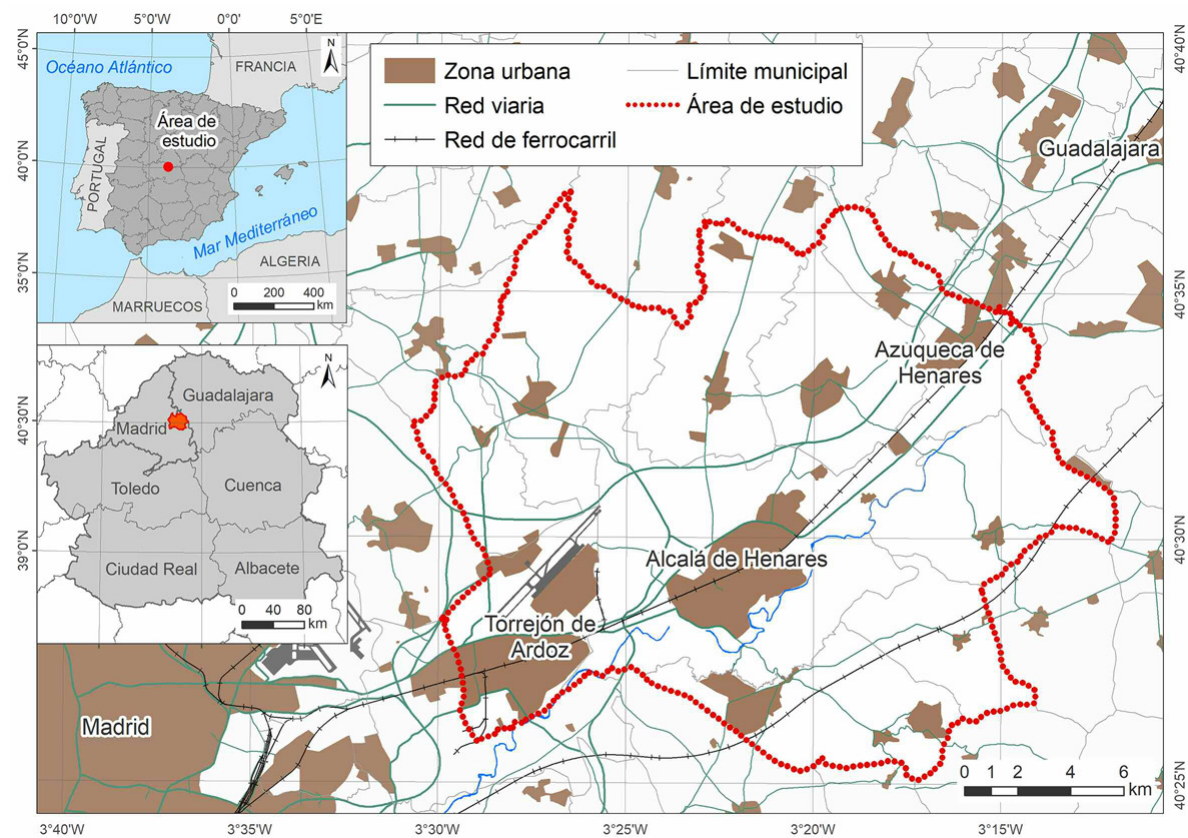

Fuente: IGN. Elaboración propia

\subsection{ESCENARIOS DE PARTIDA}

La investigación toma como datos de partida tres escenarios derivados de un proceso de participación pública. Durante dicho proceso, desarrollado en una etapa de investigación previa (Soria-Lara et al., 2020), se recabó información a través de un total de 129 entrevistas semi-estructuradas realizadas a la población residente en el área de estudio para conocer cómo imaginaban que serían determinados aspectos relacionados con los usos de suelo urbano y el transporte en el año 2050. Como resultado del análisis de dichas entrevistas, se obtuvieron 7 escenarios futuros identificando las principales características. Finalmente se seleccionaron los 3 escenarios más disruptivos con la finalidad de abarcar un mayor abanico de posibilidades respecto a los cambios que pudiesen producirse. Dichos escenarios se describen a continuación: 
Centros históricos no motorizados. Alta mezcla de funciones incluyendo residencia, compras, ocio y áreas industriales o empresariales. Transformación de las actuales áreas industriales y tecnológicas en lugares más multifuncionales. Los centros urbanos han recuperado una movilidad netamente no motorizada, lo que ha propiciado un mayor desarrollo de viviendas en altura para incrementar la densidad urbana y reducir distancias de viaje. Se establecerá una amplia red de espacios verdes que articulen todo el corredor. Estaciones de transporte público en superficie y fuertemente integradas con la red de espacios verdes. Caminar e ir en bicicleta serán los modos preferentes para la población residente. El coche tendrá un papel residual en el corredor, siendo más importante y usado el transporte público.

Un corredor superpoblado. Alta mezcla de funciones residenciales, ocio, compras e industria. Territorio polarizado: centros urbanos ocupados por rentas más bajas en bloques de mediana altura y periferia ocupada por rentas más altas en viviendas unifamiliares. Se establecerá una amplia red de espacios verdes que articulen todo el corredor. Estaciones de transporte público en superficie y fuertemente integradas con la red de espacios verdes. Reducción importante del uso del coche, mientras que el transporte público tendrá niveles similares a los actuales con preferencia por los sistemas ferroviarios. Altos niveles de inseguridad ciudadana. Baja mezcla de funciones residenciales, ocio, compras e industria. En los centros urbanos predomina el comercio, los servicios y las viviendas para clases más bajas. Los estratos con renta más alta de la población aspirarán a vivir en la periferia, en viviendas unifamiliares en urbanizaciones cerradas y protegidas. Los espacios verdes públicos no tienen protagonismo en el corredor. Predominio del coche como modo de transporte. El comercio electrónico ha crecido mucho sustituyendo un importante número de desplazamientos a los lugares comerciales.

\section{METODOLOGÍA}

La metodología seguida en esta investigación se estructura en tres fases principales: (3.1) preparación de la cartografía, (3.2) selección de los participantes del taller y (3.3) diseño y realización del taller de cartografiado participativo.

\subsection{PREPARACIÓN DE LA CARTOGRAFÍA BASE}

En primer lugar, se generó una cartografía base que recogiera las principales características de la situación de partida. En dicha cartografía se representaron aquellos elementos territoriales de posible interés en el proceso de planificación urbana, prestando especial atención a los usos de suelo urbano y las infraestructuras de transporte existentes. Concretamente, los usos seleccionados fueron representados mediante píxeles (Figura 2), con un tamaño real de $250 \mathrm{~m}$ de lado, capaces de albergar chinchetas de distinto color para 
representar los diferentes usos del suelo. Se facilitó así que durante el taller las chinchetas pudieran manejarse fácilmente para representar crecimientos (mediante la adición de nuevas chinchetas), cambios (permutación) o pérdidas (sustracción) de aquellos usos escogidos para la investigación (servicios y equipamientos, industrial, residencial unifamiliar, residencial multifamiliar y residencial mixto).

Figura 2. Proceso de tratamiento y construcción de la cartografía base
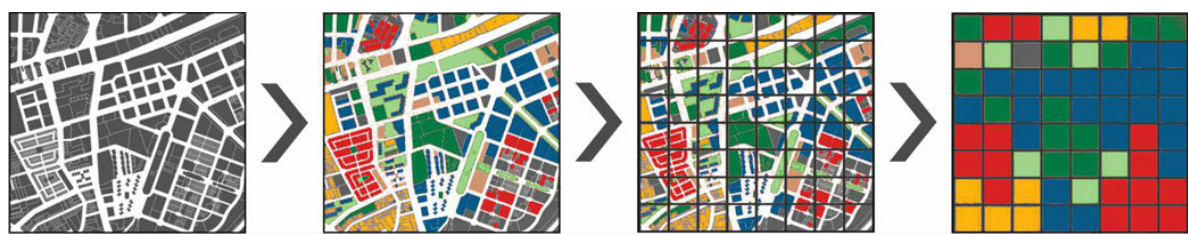

Fuente: Dirección General del Catastro. Elaboración propia

\subsection{SELECCIÓN DE LOS PARTICIPANTES}

Dado que las áreas urbanas son sistemas complejos donde sus componentes (social, económico, ambiental, político, etc.) están fuertemente interrelacionados, no deberían estudiarse de forma aislada (Bettencourt y West, 2010). Por consiguiente, para que estuvieran representados dichos componentes durante el proceso de cartografiado de escenarios, se consideró la combinación de diferentes perfiles profesionales adscritos a campos de estudio relacionados con el ámbito de la planificación urbana.

En primer lugar, se consideró de especial relevancia la participación de técnicos municipales. Su experiencia en seguimiento, inspección y gestión de obras municipales, unido a la realización de tareas destinadas a la elaboración de informes técnicos, ofrecía un perfil profesional óptimo para la presente investigación. En segundo lugar, como principales exponentes de la expansión urbana, se consideró necesaria la inclusión de promotores inmobiliarios en el conjunto de participantes. Sus conocimientos relativos al desarrollo de proyectos promoción inmobiliaria podrían ofrecer aportaciones relevantes respecto a la ubicación de determinados usos. En tercer lugar, para ofrecer una mayor interdisciplinariedad, se contactó con profesionales, tanto del sector público (ej. Consorcio de Transportes de la Comunidad de Madrid) como privado (ej. consultoras de transporte y urbanismo), encargados de realizar tareas relacionadas con el desarrollo urbano o la planificación del transporte. Por último, se contactó también con profesionales relacionados con el ámbito medioambiental y de salud pública.

De esta forma, un total de 18 participantes asistieron al taller de cartografiado participativo. Divididos en 3 grupos, se organizaron en función de su perfil 
profesional, de manera que cada grupo fuese lo más interdisciplinar posible. La descripción de los integrantes de cada grupo está recogida en la Tabla 1.

Tabla 1. Descripción de los participantes de cada grupo

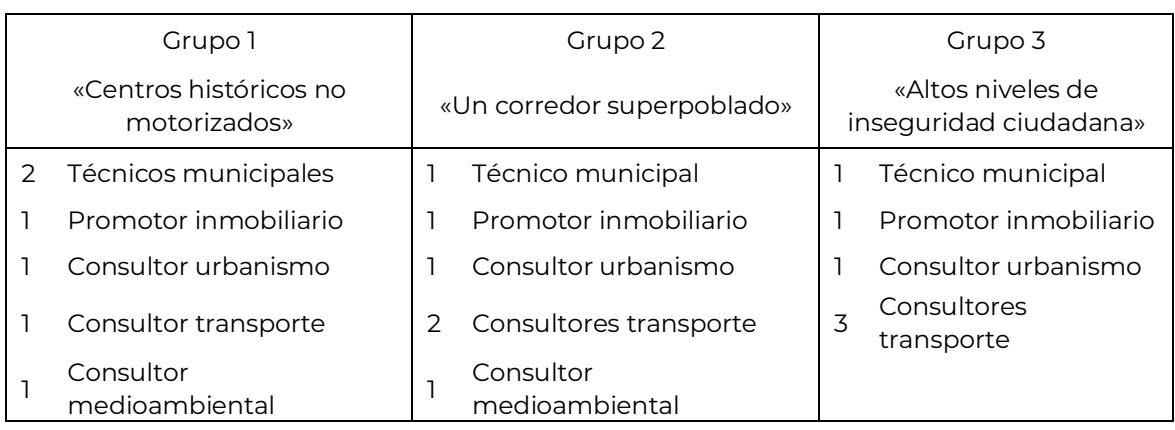

Fuente: Elaboración propia

\subsection{DISEÑO Y REALIZACIÓN DEL TALLER DE CARTOGRAFIADO PARTICIPATIVO}

El taller de cartografiado participativo fue diseñado en tres fases consecutivas. La primera fase consistió en una introducción donde los participantes se conocieron, se explicó la dinámica a seguir y se presentó el escenario asignado a cada grupo, familiarizándose con el mismo. A cada asistente se le facilitó un dosier con toda la información relativa con el objetivo del taller y una breve caracterización del área de estudio. En la segunda fase del taller, los participantes respondieron a un cuestionario en Google forms ${ }^{l}$, con cuestiones que permitirían refinar la descripción presentada de cada escenario a partir de la opinión de los participantes. Las preguntas versaban sobre las siguientes cuestiones: principales modos de transporte, presencia de espacios verdes, grado de mezcla de usos, grado de dispersión urbana y cantidad de crecimiento/pérdida que experimentarían los diferentes usos. Tras la finalización de los cuestionarios, se realizó una pausa que permitió el análisis de los mismos por parte del equipo investigador. En la Tabla 1 se representan los resultados analizados respecto a las cuestiones anteriormente mencionadas. Dichos resultados sirvieron como input para la siguiente fase del taller.

1 Un corredor superpoblado: https://goo.gl/forms/xkGmMrYqSV2HRbvF3 Centros urbanos no motorizados: https://goo.gl/forms/qrQzCnTKSapOlfnkl Altos niveles de inseguridad ciudadana: https://goo.gl/forms/oTsu3hLEie4Rm3672 
Tabla 2. Resultados del análisis de los cuestionarios

\begin{tabular}{|c|c|c|c|c|}
\hline & & Escenario 1 & Escenario 2 & Escenario 3 \\
\hline \multirow{5}{*}{ 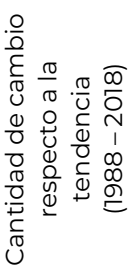 } & Plurifamiliar & $+25 \%$ & $+25 \%$ & ०\% \\
\hline & Mixto & $+25 \%$ & $+25 \%$ & ०\% \\
\hline & Unifamiliar & $-10 \%$ & $+50 \%$ & $+100 \%$ \\
\hline & Industrial & ०\% & O\% & - 10\% \\
\hline & Servicios & $+50 \%$ & $+50 \%$ & $+0 \%$ \\
\hline \multicolumn{2}{|c|}{ Dispersión } & Baja & Intermedia & Muy elevada \\
\hline \multicolumn{2}{|c|}{ Mezcla } & Elevada & Intermedia & Baja \\
\hline \multicolumn{2}{|c|}{ Presencia de zonas verdes } & Elevada & Elevada & Baja \\
\hline \multicolumn{2}{|c|}{$\begin{array}{c}\text { Modo de transporte más } \\
\text { relevante }\end{array}$} & $\begin{array}{l}\text { Tren de } \\
\text { cercanías y } \\
\text { autobús }\end{array}$ & $\begin{array}{l}\text { Tren de } \\
\text { cercanías y } \\
\text { autobús }\end{array}$ & $\begin{array}{c}\text { Servicios car- } \\
\text { sharing, vehículo } \\
\text { compartido } \\
\text { (conocidos) }\end{array}$ \\
\hline
\end{tabular}

\section{Fuente: Elaboración propia}

Durante la tercera fase del taller se llevó a cabo el cartografiado colaborativo. Para ello, se pidió que cartografiasen sobre el mapa base (mediante dibujo a mano alzada) nuevas infraestructuras viarias o de transporte público (líneas, paradas, estaciones, etc.) que se desarrollarían, según su criterio, en el contexto del escenario en cuestión. Al mismo tiempo, se les pidió que dibujasen (si aplicaba) las nuevas zonas o corredores verdes asociados a cada escenario. En tercer lugar, debieron localizar los crecimientos/pérdida y/o cambios de uso propuestos. En este ejercicio se les pidió que ubicasen mediante el uso de chinchetas de diferentes colores, los nuevos crecimientos, así como los posibles cambios de uso (p. ej. de industrial a residencial). Para ello, debían indicar sobre el mapa aquellos píxeles que experimentarían nuevos crecimientos de cada uso, colocando sobre ellos una chincheta con el color correspondiente, así como aquellos píxeles en los que desaparecería el uso existente, en este caso retirándola. Igualmente, estaba permitido sustituir las chinchetas de un color por otro en aquellas situaciones de cambio de uso, es decir, aunque no se produjesen crecimientos o pérdidas, se podían reubicar usos en nuevas localizaciones, ya que su ubicación original podía ser sustituida por otros usos (procesos de deslocalización industrial, por ejemplo).

Para cuantificar de manera explícita y controlar el número de chinchetas a colocar o retirar (crecimiento o pérdida), se establecieron unos umbrales basados en la evolución tendencial de los últimos 30 años (1988 - 1918). Así, para cada valor de cambio de uso obtenido y presentado en la Tabla 2 (pérdida ligera (-10\%), crecimiento ligero (25\%), moderado (50\%) o elevado (75\%)), se le proporcionaba a cada grupo (o se le indicaba retirar en caso de pérdida) un 
número de chinchetas equivalentes a la superficie de cambio dividido por la superficie equivalente a un píxel (6.25 ha). Es necesario reseñar que los tres ejercicios de esta fase no se realizaron de manera secuencial, realizándose de manera simultánea.

Figura 3. Fotografía de la tercera fase del taller de cartografiado participativo

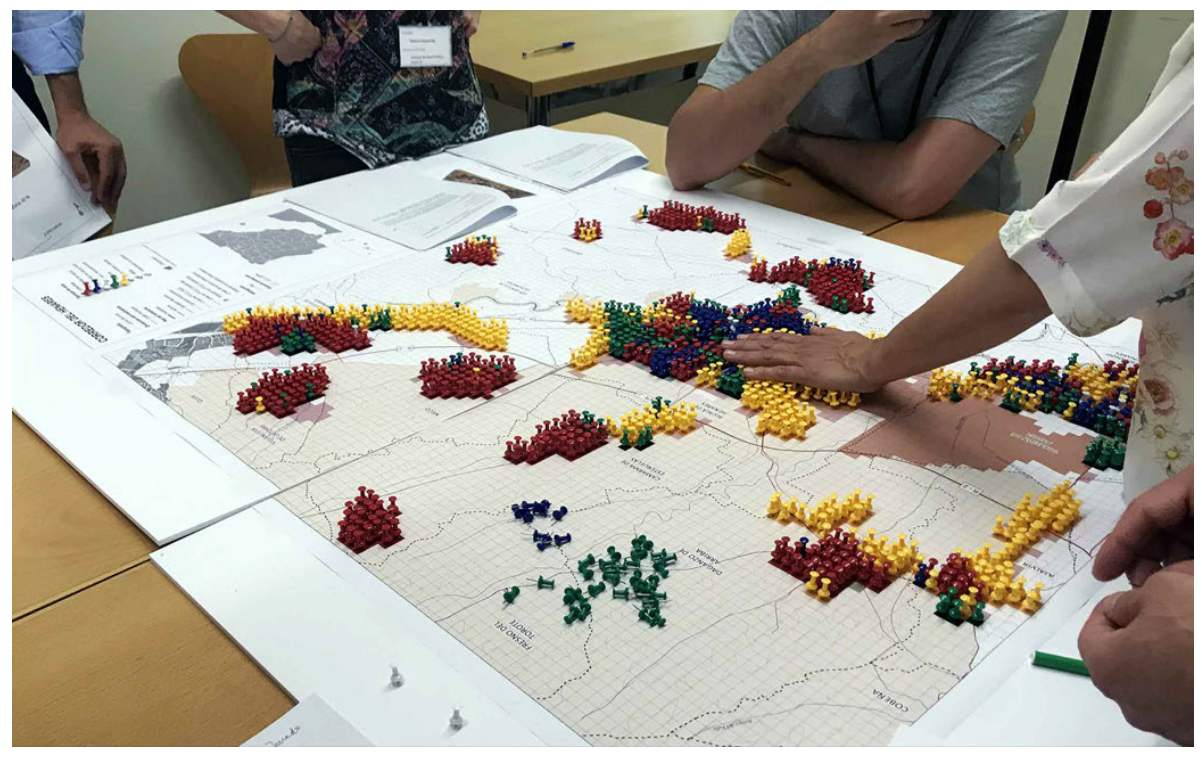

Fuente: Ramón Molinero (2019)

\section{RESULTADOS}

Tras la aplicación de la metodología descrita anteriormente, se obtuvo un mapa por cada escenario seleccionado. En la Figura 4 se puede observar su representación espacial junto con la situación inicial tomada como referencia para contrastar detalladamente los cambios deducidos durante el taller de cartografiado participativo en el periodo 2018-2050. Para facilitar su visualización, dichos resultados fueron representados mediante un software SIG (ArcGIS). 
Figura 4. Representación de los escenarios resultados del taller y comparación con la situación inicial (2018 - 2050)

Situación inicial (2018)

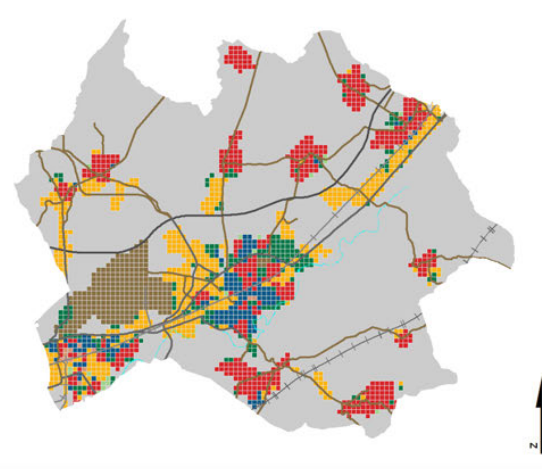

Centros históricos no motorizados (2050)

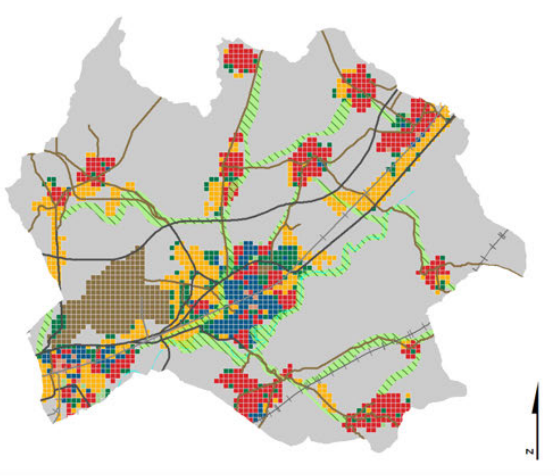

Un corredor superpoblado (2050)

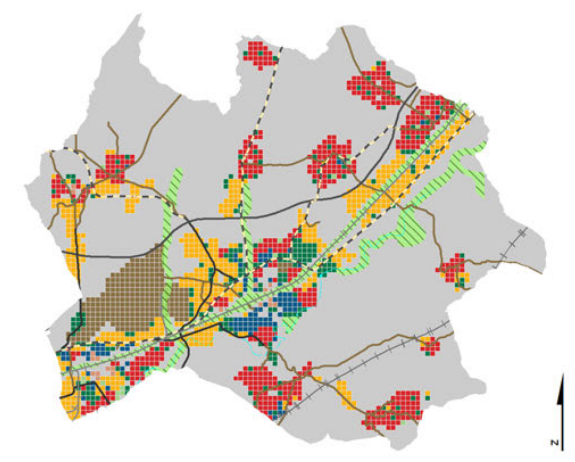

Altos niveles de inseguridad ciudadana (2050)

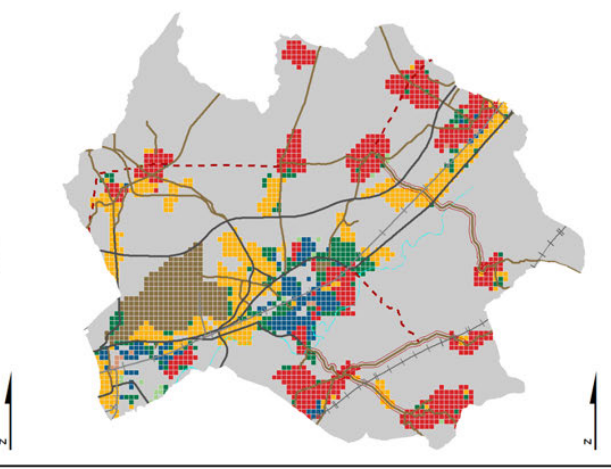

Usos del suelo urbano

Servicios y equipamientos

Industrial

Residencial unifamiliar

Residencial plurifamiliar

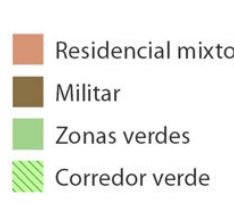

Infraestructuras de transporte

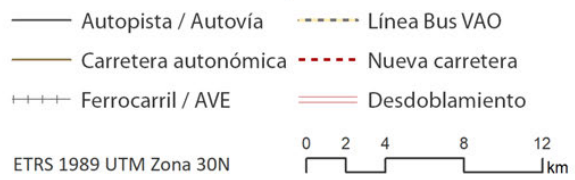

Fuente: IGN (Base cartográfica). Elaboración propia

Respecto al escenario Centros históricos no motorizados, los servicios y equipamientos crecerían 251 ha y el uso residencial multifamiliar 56 ha. Por otra parte, el uso residencial unifamiliar perdería 51,3 ha, sin observarse alteraciones en la cantidad de cambio en los usos industrial y residencial mixto. Dado que tanto en la descripción del escenario como en los resultados de los cuestionarios no se obtuvo una importante alteración en el sistema de transportes, 
no se cartografiaron nuevas vías de comunicación. Sin embargo, la alta presencia de zonas verdes concebida por los participantes se tradujo en la representación de una red de corredores verdes en torno al río Henares, conectando entre sí los principales núcleos de población.

El segundo escenario, Un corredor superpoblado, presentaría un crecimiento de los servicios y equipamientos igual que en el caso anterior, 251 ha. Dado el crecimiento poblacional elevado descrito, los tres usos residenciales aumentarían, concretamente crecería el uso multifamiliar 56 ha, el uso mixto 12 ha y el uso unifamiliar 257 ha. De forma paralela, el incremento de la demanda de transporte público se traduciría en el desarrollo de nuevas Vías de Alta Ocupación (VAO), nuevas paradas de autobús y la transformación de apeaderos en estaciones de tren de cercanías. El entorno cercano a la red de ferrocarril se transformaría en una red de espacios verdes que comunicaría con los municipios adyacentes del sector norte.

Por último, el escenario Altos niveles de inseguridad ciudadana presentaría únicamente un crecimiento notable del uso residencial unifamiliar (513 ha), especialmente localizado en la periferia. En contraposición, el uso industrial perdería peso, mientras que no se detectarían cambios en el crecimiento de los usos residencial multifamiliar, mixto y de servicios y equipamientos. La fuerte dispersión traería consigo un desplazamiento de los usos del suelo urbano del centro de los principales núcleos a las zonas más periféricas. Dicho proceso conllevaría un mayor uso del vehículo privado, por lo que se puede observar la construcción o ampliación de nuevas carreteras.

A pesar de observar cierta similitud entre los resultados de las encuestas de los escenarios 1 y 2 , en la Figura 4 pueden identificarse notables diferencias entre ambos. Dicha cuestión se vio afectada por cada decisión tomada a lo largo del taller de cartografiado participativo. El perfil de cada participante o el intercambio de ideas, entre otros factores de índole social, condicionó cada paso tomado en la fase de espacialización.

\section{DISCUSIÓN Y CONCLUSIONES}

La planificación de los espacios urbanos mediante el uso de escenarios es una práctica cada vez más utilizada para afrontar a futuro la problemática derivada de procesos de expansión urbana rápidos y poco controlados. Unido a ello, han proliferado múltiples investigaciones orientadas a involucrar a la población en las tareas de planificación (King, 2002; Portela y Errandonea, 2017), y más concretamente durante el diseño y cartografiado de los espacios urbanos (Cinderby, 2010). No obstante, esta investigación pretende ahondar más en este sentido.

Estableciendo las bases de los escenarios derivadas de la opinión ciudadana, fue posible desarrollar un taller de cartografiado participativo. Durante el mismo, numerosos profesionales que desempeñan tareas de planificación 
urbana y transporte, o relacionadas, demostraron sus capacidades para dialogar entre sí, tomar decisiones e interactuar con la cartografía de forma precisa, detallada y controlada. Hasta ahora, esta tarea había sido destinada principalmente a un público no especializado (Cadag y Gaillard, 2012; Cinderby, 2010; Dennis, 2006). Por tanto, para hacer efectivo el proceso de dialogo durante el taller, era importante que mantuviesen cierta interacción entre los participantes, una elevada diversidad de perspectivas y que poseyeran capacidades destacadas para tratar con problemas relacionados (Junghans, Kreft, y Welp, 2018). Estas dimensiones fueron alcanzadas gracias a la dinámica por grupos utilizada durante el taller y el trascendental proceso de selección de participantes. Esta metodología ha sido clave para ofrecer resultados más contrastados y realistas, fundamentados en la experiencia de un público especializado, como pueden ser los promotores inmobiliarios, (un eslabón fundamental en el crecimiento urbano, pero de difícil acceso), entre otros.

En definitiva, cabe destacar como la integración de técnicas participativas vinculadas al diseño de escenarios y a procesos de cartografiado permiten cuantificar y localizar de forma explícita elementos o fenómenos derivados de la dinámica urbana, tales como crecimiento, pérdida, segregación o mezcla de usos y la aparición de nuevas infraestructuras de transporte de carácter urbano.

Por consiguiente, para afrontar la incertidumbre inherente a la evolución de los espacios urbanos es importante incrementar el nivel de detalle a la hora de representar espacialmente futuros de desarrollo urbano a largo plazo. Para ello, es esencial ampliar las perspectivas de trabajo a través de la colaboración de agentes con conocimiento experto. En este punto, la cartografía juega un papel crucial para captar su atención (difícil tarea en numerosas ocasiones), además de actuar como intermediario para modelar las ideas expresadas durante todo el proceso, dejando a un lado las barreras técnicas del lenguaje.

\section{AGRADECIMIENTOS}

Este trabajo ha sido financiado por el Ministerio de Ciencia, Innovación y Universidades de España y el Fondo Social Europeo, bajo la subvención del Programa Estatal para la Promoción del Talento y su Empleabilidad en I+D (2018). Este trabajo también ha sido financiado por el Ministerio de Economía y Competitividad de España bajo la subvención del proyecto TRANSURBAN (CSO2017-86914-C2-1-P).

\section{REFERENCIAS}

Banister, D. y Hickman, R. (2013). Transport futures: Thinking the unthinkable. Transport Policy, 29, 283-293. https://doi.org/10.1016/j.tranpol.2012.07.005 
Barreira-González, P., Aguilera-Benavente, F. y Gómez-Delgado, M. (2017). Implementation and calibration of a new irregular cellular automata-based model for local urban growth simulation: The MUGICA model. Environment and Planning B: Urban Analytics and City Science, 46(2), 243-263. https://doi.org/10.1177/2399808317709280

Bartholomew, K. (2007). Land use-transportation scenario planning: promise and reality. Transportation, 34(4), 397-412. https://doi.org/10.1007/s11116-0069108-2

Bertolini, L. (2007). Evolutionary Urban Transportation Planning: An Exploration. Environment and Planning A: Economy and Space, 39(8), 1.998-2.019. https://doi.org/10.1068/a38350

Bertolini, L. (2012). Integrating Mobility and Urban Development Agendas: a Manifesto. DisP - The Planning Review, 48(1), 16-26.

https://doi.org/10.1080/02513625.2012.702956

Bettencourt, L. y West, G. (2010). A unified theory of urban living. Nature, 467(7318), 912-913. https://doi.org/10.1038/467912a

Button, K., Stopher, P., Hensher, D. y Haynes, K. (2004). Handbook of Transport Geography and Spatial Systems.

Cadag, J. R. D. y Gaillard, J. C. (2012). Integrating knowledge and actions in disaster risk reduction: The contribution of participatory mapping. Area, 44(1), 100-109. https://doi.org/10.1111/j.1475-4762.2011.01065.x

Cinderby, S. (2010). How to reach the 'hard-to-reach': the development of Participatory Geographic Information Systems (P-GIS) for inclusive urban design in UK cities. Area, 42(2), 239-251. https://doi.org/10.1111/j.1475-4762.2009.00912.x

Cochrane, L. y Corbett, J. (2018). Participatory Mapping. In Handbook of Communication for Development and Social Change, 1-9.

https://doi.org/10.1007/978-981-10-7035-8_6-1

del Río Lafuente, I. y Rodríguez Moya, J. (2009). Presente y futuro del Corredor del Henares en el área funcional madrileña. Anales de Geografía de La Universidad Complutense, 29, 139-165.

Dennis, S. F. (2006). Prospects for Qualitative GIS at the Intersection of Youth Development and Participatory Urban Planning. Environment and Planning A: Economy and Space, 38(11), 2.039-2.054.

https://doi.org/10.1068/a3861

Geurs, K. y Van Wee, B. (2000). Backcasting as a Tool to Develop a Sustainable Transport Scenario Assuming Emission Reductions of 80-90\%. Innovation: The European Journal of Social Science Research, 13(1), 47-62.

https://doi.org/10.1080/135116100111658

Hickman, R., Ashiru, O. y Banister, D. (2011). Transitions to low carbon transport futures: strategic conversations from London and Delhi. Journal of Transport Geography, 19(6), 1.553-1.562.

https://doi.org/10.1016/j.jtrangeo.2011.03.013 
Junghans, L., Kreft, S. y Welp, M. (2018). Inclusive Visions for Urban Transitions: Lessons from stakeholder dialogues in Asian medium sized cities. Sustainable Cities and Society, 42(February 2017), 512-520.

https://doi.org/10.1016/j.scs.2018.08.003

King, B. H. (2002). Towards a participatory GIS: Evaluating case studies of participatory rural appraisal and GIS in the developing world. Cartography and Geographic Information Science, 29(1), 43-52.

https://doi.org/10.1559/152304002782064565

Mallampalli, V. R., Mavrommati, G., Thompson, J., Duveneck, M., Meyer, S., Ligmann-Zielinska, A., ... Borsuk, M. E. (2016). Methods for translating narrative scenarios into quantitative assessments of land use change. Environmental Modelling and Software, 82, 7-20. https://doi.org/10.1016/j.envsoft.2016.04.011

Pearson, L. J., Park, S., Harman, B. y Heyenga, S. (2010). Sustainable land use scenario framework: Framework and outcomes from peri-urban SouthEast Queensland, Australia. Landscape and Urban Planning, 96(2), 88-97. https://doi.org/10.1016/j.landurbplan.2010.02.006

Portela, M. y Errandonea, L. P. (2017). The role of Participatory Social Mapping in the struggle of the territory and the right to the city. Proceedings of the 8th International Conference on Communities and Technologies - CyT '77, Part F1285, 100-104. https://doi.org/10.1145/3083671.3083676

Soria-Lara, J. A. y Banister, D. (2017). Dynamic participation processes for policy packaging in transport backcasting studies. Transport Policy, 58, 19-30. https://doi.org/10.1016/j.tranpol.2017.04.006

Soria-Lara, J. A., Ariza-Álvarez, M. A., Aguilera-Benavente, F., Cascajo, R., Arce, R., Lopez Garcia de Leaniz, C. y Gómez-Delgado, M. (2020). Participatory visioning for building disruptive future scenarios for transport and land use planning. Journal of Transport Geography. Manuscrito entregado para la publicación.

Tuominen, A., Tapio, P., Varho, V., Järvi, T. y Banister, D. (2014). Pluralistic backcasting: Integrating multiple visions with policy packages for transport climate policy. Futures, 60, 41-58. https://doi.org/10.1016/j.futures.2014.04.014

Ustaoglu, E., Williams, B. y Petrov, L. O. (2017). Scenario analysis of alternative land development patterns for the Leipzig-Halle region: Implications for transport-land-use sustainability. Urban Planning, 2(1), 108-129. https://doi.org/10.17645/up.v2i1.838

Wegener, M., y Fuerst, F. (2004). Land-Use Transport Interaction: State of the Art. SSRN Electronic Journal, (November), 1-119. https://doi.org/10.2139/ssrn.1434678

Willson, R. (2001). Assessing communicative rationality as a transportation planning paradigm. Transportation, 28(1), 1-31.

https://doi.org/10.1023/A:1005247430522 
Zimmermann, M., Darkow, I.-L. y von der Gracht, H. A. (2012). Integrating Delphi and participatory backcasting in pursuit of trustworthiness - The case of electric mobility in Germany. Technological Forecasting and Social Change, 79(9), 1.605-1.621. https://doi.org/10.1016/j.techfore.2012.05.016 



\section{TENDENCIAS RECIENTES DE LA PLANIFICACIÓN DEL TRANSPORTE Y LA MOVILIDAD EN HISPANOAMÉRICA: EL CASO DE LOS TFM DE UNIBA

\author{
RECENT TRENDS IN TRANSPORT AND MOBILITY PLANNING \\ IN SPANISH AMERICA: THE CASE OF UNIBA'S TFM \\ Verónica Quiroz López \\ Universidad de Barcelona
}

Resumen

El constante incremento de la movilidad cotidiana en Hispanoamérica -acompañado del acelerado crecimiento poblacional y territorial de sus ciudades, así como de sus cambios morfológicos y funcionales- está dirigiendo su planificación hacia la reconfiguración de sistemas de transporte y movilidad más eficientes y sostenibles. Esta comunicación presenta las tendencias de las investigaciones recientes que han realizado los estudiantes del programa de Máster en Planificación Territorial y Gestión Ambiental (MPGA) en su versión online, a través del Centro Universitario Internacional de Barcelona (UNIBA), adscrito a la Universidad de Barcelona (UB). Este trabajo compara la intensidad de su abordaje desde tres ámbitos distintos, definidos por su escala de gestión, sus ámbitos de actuación y sus particularidades. Desde políticas locales sobre el fomento al transporte colectivo o el Desarrollo Orientado al Transporte, hasta su inclusión en la planificación nacional del desarrollo económico, pasando por políticas de Ordenación Territorial regional en entornos periurbanos y metropolitanos. Ofreciendo una imagen actual de los estudios e instrumentos de planificación propuestos para la región desde nuestra institución y bajo el marco del paradigma actual de una movilidad más sostenible.

Palabras clave: transporte, movilidad, planificación urbana, ordenación territorial.

\section{Abstract}

The constant increase of daily mobility in Spanish America - accompanied by the accelerated population and territorial growth of its cities, as well as its morphological and functional changes - is directing the urban planning and management towards to reconfiguration of more efficient and sustainable transport and mobility systems. This paper presents the recent trends on this subject research that has been making as part of the Master's Degree in Territorial Planning and Environmental Management (MPGA) at the Interna-

1 Profesora/Tutora del MPGA, UNIBA-UB. 
tional University Center of Barcelona (UNIBA), a center attached to the Barcelona University (UB). The study compares the intensity of their approach from three different areas defined by their management scale and their fields of action. From local policies for promotion a collective transport to its inclusion in the national economic panning development, by way of regional land use policies in periurban and metropolitan environments. Offer an image of the planning instruments and policies that are being generated in this region under the paradigm of sustainable mobility.

Keywords: transport, mobility, urban and territorial planning, sustainability.

\section{INTRODUCCIÓN}

Uno de los fenómenos que más ha impactado nuestras ciudades desde la consolidación del llamado sistema capitalista es el constante aumento de la movilidad y por tanto de las formas de transporte que empleamos. Sin embargo, es hasta hace muy poco, las últimas décadas del s. XX, que se extiende una creciente conciencia global sobre los problemas ambientales derivados de los abusos de este modo de producción, lo cual está cambiando —o por lo menos cuestionando-el modelo de movilidad contemporáneo.

En particular para Hispanoamérica, esta alta demanda de transporte se fundamenta en el acelerado crecimiento poblacional y territorial de sus ciudades, derivado de procesos de modernización y de cambios morfológicos y funcionales de sus estructuras urbanas, que se muestran cada vez más obsoletas frente los nuevos usos del espacio y los patrones de movilidad de la sociedad actual. Esta situación, que en muchas urbes de la región llega a mostrarse como caos en la movilidad urbana, está reorientando los estudios y la práctica de la planificación, al incorporar la aspiración de un nuevo modelo de movilidad a través de la reconfiguración de sistemas de transporte más eficientes y sostenibles.

Y es que, aunque esta problemática emergente presenta grandes retos para el desarrollo sostenible de nuestros entornos en todas las escalas, es en la planificación del transporte urbano, de la movilidad y de sus infraestructuras en las que recae el mayor peso. En este contexto, la comunicación tiene el objetivo de mostrar las tendencias recientes de los trabajos de final de máster (TFM) que se están llevando a cabo en el marco del Máster en Planificación Territorial y Gestión Ambiental (MPGA) del Centro Universitario Internacional de Barcelona (UNIBA) adscrito a la Universidad de Barcelona (UB).

\subsection{PLANTEAMIENTO METOdOLÓgico}

El estudio compara la intensidad del abordaje de las investigaciones desde tres ámbitos diferenciados por su escala de acción y sus ámbitos de actua- 
ción². El primero de escala local, que engloba las políticas urbanas vinculadas a la gestión del transporte público o privado, su seguridad vial y pública, el diseño y la reordenación de sistemas integrales o su Orientación al Desarrollo del Transporte. El segundo, regional, refleja la importancia del transporte en la Ordenación del Territorio en entornos periurbanos y metropolitanos. Y finalmente uno de escala nacional, que explora la incorporación de la movilidad y el transporte en la planificación económica del desarrollo nacional y regional (Figura 1).

Figura 1. Diagrama conceptual

\section{Enfoque teórico y conceptual}

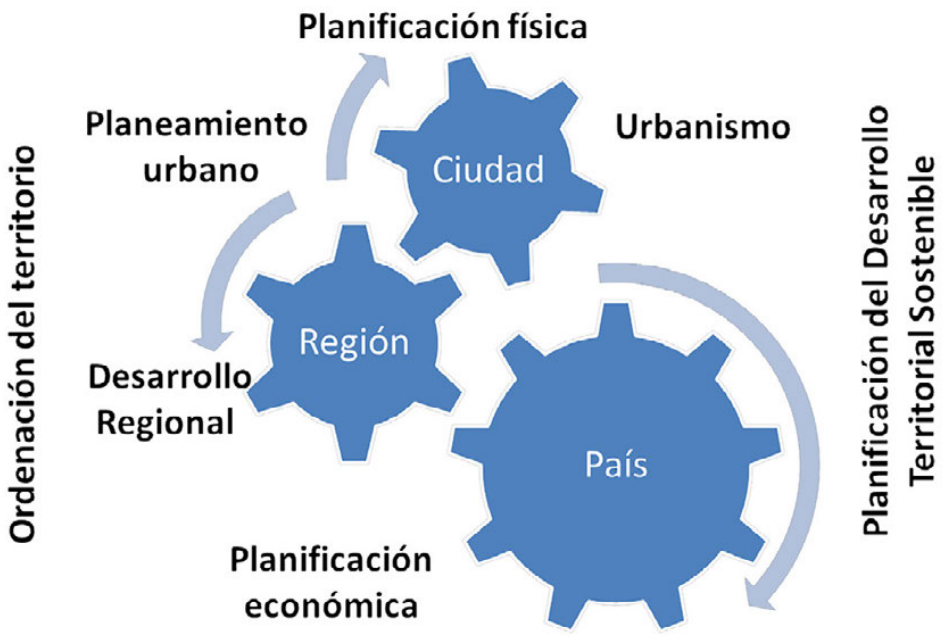

Fuente: Elaboración propia, 2020

La muestra de este estudio estuvo determinada por el acceso a los TFM para su revisión. Así, se analizaron cuarenta TFM adscritos a los bloques de investigación: Movilidad y planificación de infraestructuras, Planificación territorial y Planificación urbana: estudio de casos, los trabajos fueron realizados en las

2 Somos conscientes de las limitantes que tiene la distinción conceptual utilizada en esta comunicación entre urbanismo (local), ordenación del territorio (regional) y planificación territorial del desarrollo (nacional/supranacional) para marcar la diferencia de escalas, lo que ha suscitado un gran debate académico que desde luego supera el alcance de este trabajo para resolverlo, pero que pretende contribuir al mismo (Gómez Orea, 2007; Hildenbrand, 2007; Zoido, 2001, etc.). 
últimas ocho ediciones del programa, entre 2016 y 2020. El perfil internacional del programa determinó los países estudiados, con una mayoría de estudios sobre Colombia y Ecuador, pero con presencia de 6 países más y un total de 27 áreas de estudio distintas, entre ciudades, áreas metropolitanas, corredores de movilidad y un par de investigaciones de nivel nacional (Tabla 1).

Tabla 1. Distribución de los TFM de MPGA por país y escala

\begin{tabular}{lcccc}
\hline \multicolumn{1}{c}{ País/Escala } & Local & Regional & Nacional & $\begin{array}{c}\text { Trabajos de Final de Máster } \\
\text { por país }\end{array}$ \\
\hline Colombia & 7 & 6 & 2 & 15 \\
Ecuador & 8 & 7 & - & 15 \\
Chile & 1 & 2 & - & 3 \\
Perú & 2 & - & - & 2 \\
España & 2 & - & - & 2 \\
Panamá & 1 & - & - & 1 \\
Costa Rica & 1 & - & - & 1 \\
México & 1 & - & - & 1 \\
\hline \multicolumn{1}{c}{ TFM por escala } & $\mathbf{2 3}$ & $\mathbf{1 5}$ & $\mathbf{2}$ & $\mathbf{4 0}$ \\
\hline
\end{tabular}

\section{Fuente: Elaboración propia}

El análisis correlacionó estas escalas con una gama de propuestas sobre planificación y ordenación del territorio, lo que nos ofrece una imagen actual de los aportes de las investigaciones desarrolladas para obtener el grado y del diseño de los instrumentos favorecidos en la región, destacando los más socorridos y desarrollados, así como identificando las áreas menos favorecidas o no abordadas pese a su importancia.

\section{PLANIFICACIÓN TERRITORIAL DEL TRANSPORTE}

Desde sus inicios el estudio del transporte ha ocupado un lugar importante en las distintas disciplinas científicas, entre las que destaca la Geografía del Transporte. Y es que la perspectiva geográfica del territorio ha posibilitado acercamientos teóricos y analíticos al fenómeno en todas sus escalas, desde lo local hasta lo global. El territorio, entendido como una construcción socioecológica dónde los individuos modifican la naturaleza conforme a una visión sociocultural determinada de su entorno, permite una gran variedad de miradas e interpretaciones al respecto (Folch, 2003).

Así, la percepción de un hecho territorial como lo es el transporte ha transitado por distintas interpretaciones: productivistas, utilitaristas, funcionalistas, etc. Partiendo de una visión sistémica del territorio, muchas intervenciones territoriales actuales están ligadas de alguna manera a una práctica profe- 
sional que engloba aspectos como la gestión, la planificación y la ordenación del territorio (Subirats, 2002). El territorio es abordado como un sistema cuyos componentes y procesos hay que analizar, diagnosticar, gestionar y evaluar con base en un modelo territorial y que tiene como uno de sus elementos fundamentales los sistemas de transporte (Gómez Orea y Gómez Villarino, 2014).

Además, en el último medio siglo, estas políticas territoriales están buscando conjugar la eficacia económica con la pretendida sostenibilidad ambiental en todas las escalas de intervención ${ }^{3}$. Objetivo particularmente complejo cuando se trata de movilidad o de las infraestructuras para su transporte, ya que estos rubros representan por sí mismos una transformación física del territorio, además de contener una clara dimensión social, al ser el sujeto el que se mueve, lo cual está siendo abordado desde diversos enfoques de la planificación, como el urbanismo en la escala local o la planificación estratégica más económica y nacional o el enfoque regional de la Ordenación del Territorio (OT).

\subsection{LAS ESCALAS DE LA PLANIFICACIÓN TERRITORIAL Y EL TRANSPORTE}

Planificar un territorio en cualquiera de sus escalas significa la elaboración de procesos de intervención organizados bajo objetivos y acciones específicas que, ciertamente desestiman su desarrollo espontáneo es la racionalización del espacio a través de una mejor distribución de sus elementos naturales y artificiales, y de las actividades socio económicas de su población (Murcia, 1978). Más esta intervención tiene entre otros condicionantes: su escala geográfica, su carácter vinculante o indicativo, su orientación física o económica, su enfoque sectorial, estratégico o integral y sus distintos plazos. En este sentido, el planeamiento urbano o urbanismo es el enfoque más restringido de la planificación en el espacio, las ciudades son el terreno de las relaciones colectivas entre individuos con intereses y culturas diversas que sólo se pueden aglutinar a partir de la construcción y de la planificación de las perspectivas generales (Indovina, 2004). Esta planificación más física, además de normar los usos del suelo también responde a las políticas públicas del transporte y la movilidad urbana, así como de la planificación de infraestructuras viales y sistemas de transporte colectivo. Aunque en un sentido tra-

3 La preocupación internacional por la conservación del medio ambiente ha permeado los estudios de transporte en todas sus escalas de intervención, aunque con desigual magnitud. Las políticas territoriales sobre el transporte y la movilidad se despliegan de formas diversas, pero no siempre de forma coherente, generando tensiones o descoordinación entre sus distintos niveles de gobierno, con otras políticas sociales o económicas, mostrando fragmentación entre distintas políticas sectoriales. 
dicional este encuadre del transporte se debería corresponder a un enfoque más sectorial, puede formar parte de una propuesta integral ${ }^{4}$.

Mientras que, por ordenar un territorio entendemos «la voluntad y acción pública para mejorar la localización y disposición de los hechos en el espacio geográfico propio» (Zoido, 1998, 21). Una visión más regional y europea de la OT como la expresión espacial de la política económica, social, cultural y ecológica de una sociedad (CEOT, 1984). De tal forma que además de considerarse una disciplina científica, se presenta como política y técnica administrativa, el marco conceptual, operativo y administrativo de la planificación (Pujadas y Font, 1998). En referencia a nuestro ejercicio, estas políticas pasan por la planificación de las infraestructuras terrestres, aéreas o marítimas del transporte con un impacto más periurbano, metropolitano o incluso regional, lo que determina la necesaria coordinación entre municipios, cantones o provincias. Finalmente, en una escala mayor, nos encontramos con experiencias de planificación de más amplio espectro, enfocadas tanto al desarrollo económico como al físico, de nivel nacional o incluso supranacional. Una planificación que combina la práctica tradicional normativa con otra más flexible de carácter prospectivo, indicativo y estratégico, que se adapta mejor a contextos específicos y dónde el discurso de la sostenibilidad se enlaza con el de la cohesión territorial a través del papel que juegan los sistemas de transporte en su desarrollo (Farinós, 2014). En el entorno hispanoamericano se está intentando implementar, aunque de forma incipiente —en Ecuador, Costa Rica y Colombia- la también Ilamada Planificación del Desarrollo Territorial Sostenible (PDTS).

Aunque la gestión y planificación del transporte tiene su mayor nicho de intervención en las ciudades, dado que es en ellas dónde se intensifica la movilidad, el actual desarrollo de espacio urbanos más amplios, metropolitanos o periurbanos, así como su mejor accesibilidad y conexión con otras regiones, obliga al planificador a desarrollar experiencias de cooperación entre los distintos niveles de la gestión pública, incluso entre regiones o países con un enfoque más global. Prácticas actuales que tienden a una visión de la planificación integral y multinivel, concurrente en lo sectorial, flexible en su actuación y muchas veces orientada a determinados ejes estratégicos de las políticas de transporte y medio ambiente, con una perspectiva más transversal de la ordenación y gestión del territorio, en la que prevalezca un modelo de territorial basado en sistemas de transporte y de movilidad más sostenibles (ILPES, 2007).

4 En el sentido de una planificación territorial de tipo comprehensiva cuya política pública urbana de espectro amplio, englobe desde los usos del suelo, hasta el espacio público, la vivienda o el transporte, con instrumentos de planificación diversos, de largo alcance temporal y espectro geográfico amplio. 


\subsection{LA IRRUPCIÓN MUNDIAL DE LA SOSTENIBILIDAD EN EL DESARROLLO DEL TERRITORIO}

Sin duda, la aplicación de los principios de la sostenibilidad a nivel internacional toma mayor fuerza con los compromisos de la Agenda 21 establecidos en la Conferencia de las Naciones Unidas sobre Medio Ambiente de Rio de Janeiro, $1992^{5}$. Bajo este nuevo parteaguas, la planificación y la ordenación del territorio comienzan una renovación de estrategias y métodos que incorporan la visión de un desarrollo sostenible en la gestión del territorio tanto en Europa como en América Latina (Manero, 2014).

En 1999 la Unión Europea (UE) consolidaba la Estrategia Territorial Europea (ETE). Algunos de sus principales objetivos eran la gestión sostenible de los recursos naturales, un sistema urbano más equilibrado y una política de transportes adecuada a las nuevas exigencias ambientales que integrara y cohesionara el territorio (CE, 1999). Por su parte, en América Latina también se desarrolló cierta institucionalización de la gestión del territorio con el cuidado del medio ambiente 6 . Ante la compleja y problemática realidad del continente, esta voluntad política fue apoyada por instituciones como el Banco Interamericano de Desarrollo (BID) y los programas de cooperación entre la Unión Europea y la Organización de Estados Americanos (OEA) (Massiris, 2008).

Más es hasta principios del s. XXI, que los países americanos adoptan una planificación y ordenación territorial más sostenible, cuando la Comisión Económica para América latina y el Caribe (CEPAL) establece relaciones de cooperación estratégica7. Aunque se otorga el protagonismo a los gobiernos locales, la ordenación sostenible del territorio en el continente suele concentrar las decisiones en la escala nacional. Pero en la dinámica territorial se busca un abordaje de perspectiva sistémica y estratégica, por lo menos en la

5 Aunque encontramos su origen en los años cincuenta con el Informe de la Unión Internacional para la Conservación de la Naturaleza, en los setentas toma impulso con el Club de Roma y la conferencia de Estocolmo, para consolidarse a finales de los ochenta con el famoso Informe Brundtland (1987).

6 En Venezuela con la Ley Orgánica del Medio Ambiente (M.A.), 1976; la Ley de Protección del M.A. y del uso racional de los Recursos Naturales, 1981 de Cuba; la Ley de Protección y Mejoramiento del M.A. en Guatemala; la Ley General de Equilibrio Ecológico y protección al M.A., 1988 de México; la creación de la CONAMA en Chile, y otras instituciones similares en Costa Rica (SIDES), Honduras (SECPLAN), Argentina (COFEPLAN) o México (SEMARNAP). Y tras la Cumbre de Rio, se diseñan más leyes en Nicaragua (1992); Honduras (1993); Panamá (1998); El Salvador (1998) o Ecuador (1999).

7 La Alianza para el Desarrollo Sostenible de América Central (1994), la Comisión Centroamericana de Medio Ambiente y Desarrollo (2005) o la Conferencia Centroamericana para la Descentralización del Estado y el Desarrollo Local auspiciada por la Diputación de Barcelona son algunos de los ejemplos. 
norma, dónde la cooperación multinivel, la gobernanza territorial, la educación ambiental y la participación ciudadana se combinen con las innovaciones tecnológicas de los Sistemas de Información Geo-referenciados (SIG), la construcción de indicadores territoriales multiescalares y el rescate de buenas prácticas replicables.

\subsection{APUNTE SOBRE EL CAMBIO DE PARADIGMA DEL TRANSPORTE A LA MOVILIDAD}

Hace un par de décadas, en la literatura geográfica todavía era frecuente encontrar la utilización indistinta de los conceptos transporte y movilidad para referirse al fenómeno del desplazamiento de personas u objetos en general. Aunque ambos pueden llegar a ser parte de un mismo proceso, sobre todo en entornos urbanos, no son lo mismo. Mientras que el término transporte nos refiere más a los vehículos e infraestructuras por medio de los cuales se realiza el viaje, el concepto de movilidad alude a la acción misma y las condiciones del desplazamiento del individuo u objeto en movimiento.

En esta dirección, los debates académicos generados en el seno de la Geografía del Transporte de los últimos dos siglos ${ }^{8}$, las reivindicaciones sociales y las políticas a nivel mundial han derivado hacia nuevas formas de entender esta movilidad desde una perspectiva de sostenibilidad ambiental, conllevando una evolución más epistemológica —aunque menos metodológicasobre los estudios del transporte y la movilidad, lo cual finalmente están incidiendo en una comprensión integral del problema y desplazando su enfoque de estudio hacia el sujeto que se mueve más allá del objeto que lo mueve. Este cambio de paradigma, que desplaza su objeto de estudio del transporte al de la movilidad sostenible, no siempre es asumido. Por ello, en este trabajo abordamos tanto la planeación y políticas del transporte - sus infraestructuras y sus vehículos-, como la gestión de la movilidad - de personas o de mercancías - sobre todo la de carácter urbano o regional, todo y que en muchos de los trabajos analizados, se utilizan indistintamente ambos conceptos, creando confusión sobre el sujeto/objeto de estudio. Un problema conceptual y metodológico que tiene un debate pendiente en las disciplinas geográficas.

8 Desde la toma de conciencia del medio geográfico del determinismo histórico del s. XIX (K. Ritter, y F. Ratzel), la interpretación positivista y determinista del regionalismo francés (E. Reclús y Paul Vidal de la Blanche); hasta la revolución cuantitativa de los estudios de transporte de mediados del s.XX de la geografía americana (E. Ullman, J. Taaffe, y W Garrison) o la perspectiva socioeconómica (Alan M. Hay, Eliot Hurst, y Hägerstrand) o enfoques psicosociales más recientes (R. Kitamura, y J. Ritsma van Eck) que trazan una evolución epistemológica hacia una geografía de la movilidad (Quiroz, 2015). 


\section{ANÁLISIS Y PARTICULARIDADES DE LOS TFM DE UNIBA}

Bajo estas premisas teóricas, conceptuales y metodológicas de la planificación y el desarrollo territorial, a continuación, se presentarán los resultados del análisis de los TFM del MPGA desde la propia experiencia docente, rescatando las problemáticas del transporte y la movilidad abordadas en las áreas de estudio de América Latina y España por escalas, para concluir con una reflexión sobre sus desafíos futuros. (Figura 2).

Figura 2. Distribución de los TFM por país y escala de análisis

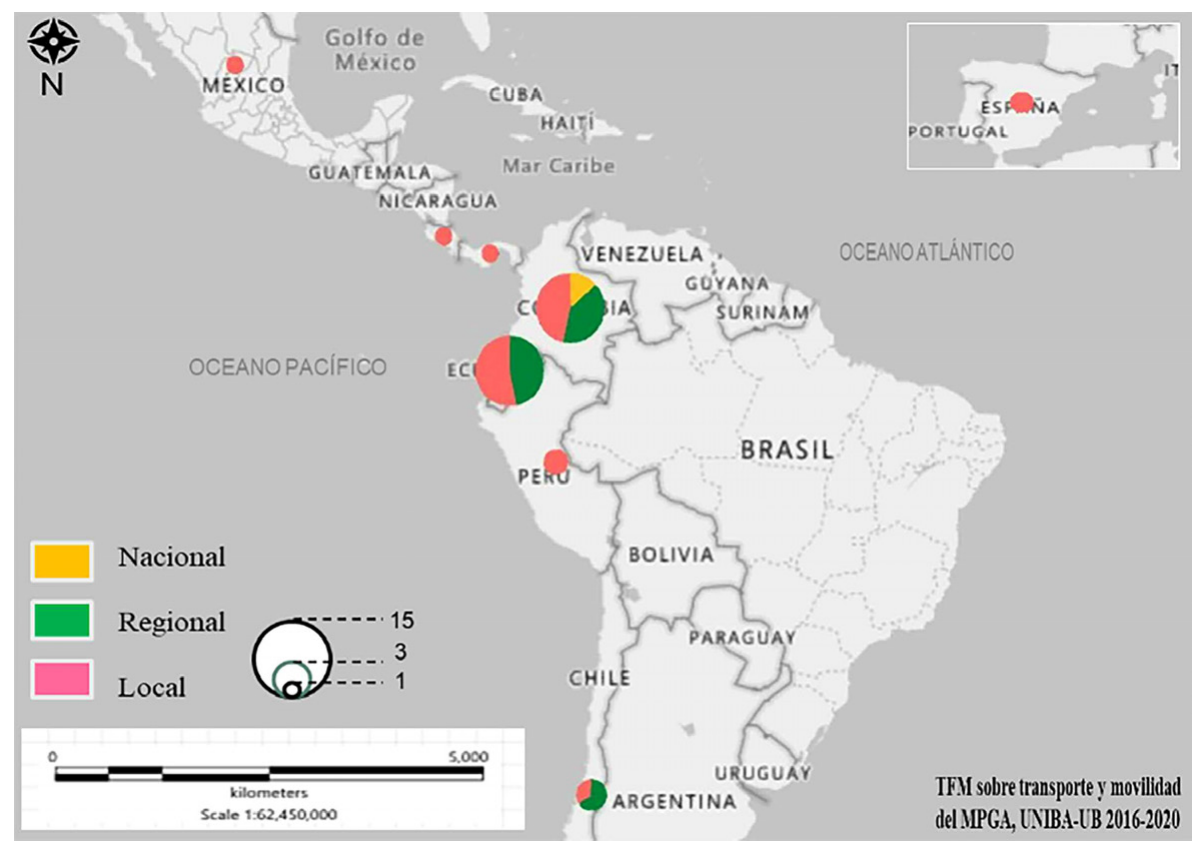

Fuente: Juan Carlos Hernández y Verónica Quiroz, 2020

\subsection{CIUDAD Y URBANISMO: MOVILIDAD URBANA Y PLANIFICACIÓN LOCAL}

En este grupo se encuentran más de la mitad de los trabajos de investigación realizados durante las últimas ocho ediciones del máster. Son estudios de ámbito urbano y local, como la introducción de sistemas masivos, la reordenación del transporte público o el desarrollo urbano orientado al transporte, las políticas de gestión de sus distintas formas (coche, bicicleta, tranvía, avión, cruceros) y la preocupación por la seguridad pública en el uso del transporte público y vial en el caso de peatones o ciclistas. 
Destacan los realizados sobre la introducción de Sistemas de Transporte Masivo Metro en ciudades capitales como Quito, Bogotá y Santiago de Chile. En ellos se aborda por un lado, la mejora de la movilidad cotidiana colectiva; y por otro, su impacto urbano en el territorio, ya sea porque la infraestructura proyectada es elevada, como en el caso de Bogotá, porque atraviesa el centro histórico de la capital ecuatoriana o porque su trazado favorece áreas de la ciudad de alto nivel adquisitivo y baja densidad, causando un efecto perverso sobre la especulación inmobiliaria del Gran Santiago en Chile?

Respecto a la implantación de sistemas de Buses de Tránsito Rápido (BRT), tenemos algún trabajo sobre la participación ciudadana y la ampliación de una línea en el caso de la Ciudad de México y la evaluación de su implementación en Bogotá, buscando lecciones desde una óptica del Desarrollo Orientado al Transporte (DOT) (Cavadía, 2019)ํ․ Más la tónica usual de las investigaciones locales es la reordenación de los sistemas masivos actuales, su informalidad, la inseguridad pública y peatonal, la baja calidad y eficiencia del servicio o la efectividad de programas de restricción vehicular sobre la calidad ambiental y el tránsito. Por tipos de transporte sobresale el interés por el uso de la bicicleta en Cuenca, Ecuador; y las potencialidades del bicitaxismo bogotano, para formar parte del Sistema de Transporte Colectivo. En contraposición, encontramos una propuesta madrileña que plantea el uso del vehículo eléctrico compartido como alternativa pública para atender la movilidad interurbana de la capital española"n.

También sigue teniendo buena presencia la línea más tradicional de la planificación de las infraestructuras y vías a escala local. Encontrando trabajos sobre la incidencia de las redes viales o la existencia de antiguos tranvías en la morfología urbana de ciudades medias como Manta o Cuenca en Ecuador; o el aumento de las actividades turísticas portuarias en el trazado vial para el caso de Puntarenas, Costa Rica12. No obstante, la diversidad de problemáticas abordadas en esta escala, aún se echan a faltar propuestas con una visión más integral del sistema de transporte y la movilidad urbana, salvo alguna aproximación general como en Miraflores de Lima, Perú (Wells, 2016).

9 Cardona, 2020 en Colombia y Novoa, 2017 para Chile.

10 Para Ciudad de México, Calva, 2020; y para Bogotá, Jiménez, 2016.

11 Seguridad pública en Bogotá (Beltrán, 2018); seguridad peatonal en Panamá (Matos, 2018) y Babahoyo, Ecuador (Yáñez, 2020); Restricción vehicular en Quito, (Reyes, 2020); Uso bicicleta (Larriva, M. 2016); bicitaxismo (Neira, 2019) y el coche eléctrico compartido (Quintanilla, 2019)

12 Vialidades y morfología urbana (Miranda, 2018); Corredores urbanos y tranvías (Mancheno, 2017); Ordenamiento vial y planeación de una ciudad portuaria en Costa Rica (Brenes, 2017). 


\subsection{PLANIFICACIÓN Y REORDENACIÓN DEL TRANSPORTE A NIVEL METROPOLITANO}

De escala regional, englobamos tres subconjuntos de investigaciones relacionadas con: 1) la reorganización de las infraestructuras viales y la movilidad a nivel metropolitano, provincial o cantonal; 2) nuevas propuestas transporte férreo o marítimo de escala regional y, 3) la financiación público-privada y la construcción de bases de información catastral como herramientas de gestión y planificación territorial en la materia.

Sin duda, el tema predominante de la ordenación territorial en esta escala para el transporte sigue siendo el papel del sistema vial y la construcción de nuevas vialidades, tan socorrida en ciudades medias del Ecuador y más a nivel regional en Colombia tras el impulso gubernamental a la creación de vialidades de $4^{a}$ generación (4C) ${ }^{13}$. Destaca un estudio para mejorar la conectividad vial rural tras el conflicto colombiano, que presenta una metodología novedosa para levantar información de campo con la ayuda de SIG y que puede ser fácilmente replicable a otras zonas del país (Lache, 2018). También encontramos interesante el estudio sobre la jerarquización de la inversión vial provincial para incentivar el desarrollo económico y productivo del Ecuador (Ramos, 2019).

En el segundo subgrupo encontramos una propuesta chilena de un tren de alta velocidad como solución a la necesidad de conexión del Puerto Montt con la capital; así como la de un tren de cercanías para el área metropolitana de Cali. Particularmente interesante es la revisión crítica de la planificación territorial en la Ciudad-Puerto de San Antonio, que demuestra la obsolescencia de los instrumentos actuales para abordar la vertiginosa transformación de la ciudad como Puerto de Gran Escala (Fernández, 2020).

Finalmente, algunos trabajos exploran nuevas formas de financiación a la planificación territorial en general, y en particular para la creación de infraestructuras de movilidad, ya sea a través de la gestión catastral en Colombia o Perú, como de la propuesta de nuevas formas de asociación de municipios en casos metropolitanos para suplir los vacíos normativos y de coordinación entre distintos niveles de la gestión urbana ${ }^{14}$. Sin embargo, aunque algunas las investigaciones en este nivel incorporan en su discurso la sostenibilidad, salvo alguna excepción, los trabajos carecen de una intencionalidad real de abordar en sus propuestas el cuidado del medio ambiente. Ello es compren-

13 Clasificación y regulación de la red vial en Rumiñahui, Pichancha, Ecuador, (Elejalde, 2017); Conectividad vial en el Distrito Metropolitano de Quito, Ecuador (Cáceres, 2017); Análisis de conectividad vial, aeropuerto Daular-Chongon, Guayaquil- Ecuador (Andrade, 2017).

14 Análisis del catastro multipropósito como herramienta de planificación territorial (Suárez, 2020). 
sible dadas las prioridades de los territorios que se están reconstruyendo tras años de atraso o de conflicto armado, entablando una lucha contra la especulación inmobiliaria en la necesaria creación de infraestructura vial básica que conecte las regiones.

\subsection{EL TRANSPORTE Y LA MOVILIDAD DENTRO DE LA PLANEACIÓN ECONÓMICA NACIONAL}

De las escalas analizadas, es la nacional o supranacional la que cuenta con menos TFM. Encontramos solo un par de estudios críticos sobre la falta de una política nacional y de instrumentos de planificación respecto a la modernización de la red vial estatal, la incidencia de la construcción de infraestructuras viales en el desarrollo sostenible y la ordenación del territorio o la estructuración de asociaciones públicas y privadas en proyectos de infraestructura vial15. Esta ausencia se muestra significativa en el sentido que, como hemos visto, han sido las propias naciones latinoamericanas las que se han adherido a acuerdos internacionales hacia un desarrollo territorial sostenible. En el panorama latinoamericano de la planeación a nivel nacional parece ser que existe un desfase entre la creación de instituciones o normas y la efectiva implementación de los instrumentos de planificación en el transporte, su gestión y la ordenación sostenible de sus territorios. En muchos casos, aún están por construir los mecanismos que lleven las directrices políticas nacionales a su aplicación al ámbito regional o local de forma coordinada. Políticas que aún están condicionadas por realidades de desigualdad territorial, la laxitud en la práctica de la planificación y la falta de debate público y participación ciudadana, con una insuficiencia presupuestal y cortoplacista, pero, sobre todo, por la ausencia de una política integral en materia de transporte y movilidad.

\subsection{EL DESAFÍO PENDIENTE DE LA PLANIFICACIÓN DEL DESARROLLO TERRITORIAL SOSTENIBLE}

Como lo hemos podido comprobar, a pesar de la creciente presencia del transporte y la movilidad entre los intereses de los estudiantes/profesionales de la región, de incluir una proyección metropolitana o la conciencia de su importancia en el desarrollo económico de las naciones iberoamericanas, los derroteros de la investigación realizada en el marco del MPGA aún no consolida la visión integral y multinivel de la práctica, su carácter sectorial le impide aún lograr la concurrencia con otras áreas, como la ambiental. Los marcos institucionales y normativos de los países aún en construcción no permiten una planificación en cascada definida y pautada, tampoco favorecen

15 Política Nacional (Lora, 2018). 
la flexibilidad en su actuación o una perspectiva más transversal de la ordenación y gestión de los territorios, en la que prevalezca un modelo territorial que se descanse en una planificación integral no solo de los sistemas de transporte y de movilidad, sino del desarrollo territorial en su conjunto, bajo la premisa de la sostenibilidad.

\section{CONCLUSIONES}

Desde un punto de vista geográfico y a través de una propuesta teórico-analítica propia, aunque limitada, pero diseñada exprofeso para este análisis y basada en la práctica contemporánea de la planificación y ordenación del territorio, hemos podido abordar las recientes investigaciones realizadas en el ámbito de nuestra práctica docente, que en el marco del Máster en Planificación Territorial y Gestión Ambiental UNIBA/UB se realizan sobre el transporte y la movilidad con una exigencia hacia la sostenibilidad. Encontrando una intensidad de abordaje en el nivel local y regional, así como su clara ausencia en términos de conformación de una política nacional en América Latina. Ello puede resultar un tanto paradójico en tanto que esta región de América ha sido partícipe del debate internacional que en materia de desarrollo sostenible ha tenido lugar en los últimos 50 años, y porque además sus gobiernos nacionales han mostrado su interés por desarrollar instituciones y normatividades que le den sustento al cuidado del medio ambiente. No obstante, en contraposición se encuentran una alto de rezago en materia de planeación de sus territorios, una diversidad y complejidad territorial de sus distintas realidades y la ausencia de condiciones suficientes para que se lleve a cabo, con lo cual ha quedado en el discurso político su implementación. En particular, para la problemática emergente de la movilidad y el transporte, la práctica de la planeación y ordenación del territorio tiene grandes retos no solo desde la óptica de la sostenibilidad, sino de diseño e implementación sobre todo en sus escalas regional y nacional, aún se arrastra una planificación más sectorial y menos integral del rubro. Falta una visión integral y multinivel, concurrente con otros sectores, pero flexible, estratégica y dinámica en su actuación, basada en una perspectiva sistémica más transversal del territorio, que incorpore nuevas innovaciones metodológicas y tecnológicas para el análisis de los territorios, que apoyados en SIG construya bases de datos con indicadores territoriales multiescalares y acopie las lecciones de aquellas prácticas que puedan ser replicables.

\section{BIBLIOGRAFÍA}

Andrade, H. (2017). Análisis de conectividad vial entre el nuevo aeropuerto intercontinental Daular-Chongon con la ciudad de Guayaquil-Ecuador, 2017. Trabajo final de Máster inédito, MPGA, UNIBA, Ecuador. 
Beltrán, D. (2018). Evaluación y propuestas en relación con la seguridad pública de los usuarios del sistema integrado de trasporte público en Bogotá, Colombia. Trabajo final de Máster inédito. MPGA, UNIBA, Colombia.

Brenes, D. (2017). Ordenamiento Vial en la Planeación de la Ciudad de Puntarenas, 2017. Trabajo final de Máster inédito, MPGA, UNIBA, Costa Rica.

Brundtland, G. H. (1987). Our common future. Oxford: Oxford University Press.

Cáceres, A. (2017). Análisis de la conectividad vial y de los diferentes tipos de transporte en el Distrito Metropolitano de Quito, Ecuador, 2017. Trabajo final de Máster inédito, MPGA, UNIBA, Ecuador.

Calva, G. (2020). La participación ciudadana en la ejecución de las obras de infraestructura de transporte, el caso de ampliación de la ruta 5 del Metrobús en la ciudad de México, 2020. Trabajo final de máster en curso al cierre de esta publicación, MPGA, UNIBA, México.

Cardona, J. (2020). El espacio público y la implantación de un nuevo Sistema de Transporte: El caso del Metro de Bogotá, Colombia. Trabajo final de Máster inédito, MPGA, UNIBA, Colombia.

Cavadía, P. (2019). Potencial del Desarrollo Orientado al Transporte DOT como transformador urbano, el caso del Transmilenio. Trabajo final de Máster MPGA, UNIBA, Bogotá, Colombia, publicado en el repositorio digital de la UB.

CEOT (Carta Europea de Ordenación del Territorio), Comité de Ministros a los Estados miembros del Consejo de Europa (1984). Recomendación n. R (84) 2, 26/1/1984.

Comisión Europea (1999). Estrategia Territorial Europea, hacia un desarrollo equilibrado y sostenible del territorio de la UE. Postdam: Comité de Desarrollo Territorial.

Elejalde, H. (2017). Clasificación y regulación de la red vial del cantón Rumiñahui, provincia de Pichancha, República del Ecuador, 2017. Trabajo final de Máster inédito, MPGA, UNIBA, Ecuador.

Farinós, J. (2014). Ordenación del territorio desde la geografía. De renovaciones conceptuales, retos, amenazas y espacios de oportunidad. Polígonos, Revista de Geografía, no. 26, 17-58.

Fernández, J. (2020). La planificación territorial y el desarrollo sostenible en la Ciudad-Puerto de San Antonio, 2019: ¿Instrumentos estáticos para resolver problemas dinámicos? Trabajo final de Máster MPGA, UNIBA, Viña del Mar, Chile.

Folch, R., Coord. (2003). El territorio como un sistema. Conceptos y herramientas de ordenación. Barcelona: Diputación de Barcelona, Red de Municipios.

Gómez Orea, D. (2007). Ordenación Territorial. Madrid: Ed. Mundi-Prensa/ Agrícola Española.

Gómez Orea, D. y Gómez Villarino, M. (2014). Marco conceptual para la ordenación territorial y reflexiones sobre el proceso ecuatoriano en la materia. 
IX Simposio Nacional de Desarrollo Urbano y Planificación Territorial. Cuenca.

Hildenbrand, A. (2007). Tres propuestas para una relación efectiva entre las escalas regional y local en materia de ordenación del territorio. En J. Farinós y J. Romero (Eds.), Territorialidad y buen gobierno para el desarrollo sostenible. Nuevos principios y nuevas políticas en el espacio europeo, no. 2, pp. 147-191. Valencia: IIDL/PUV, Colección Desarrollo Territorial.

Indovina, F. (2004). ¿Por qué la planificación hoy? En Territorio y Ciudad, pp. 1-7. Barcelona: Diputación de Barcelona, Boletín Digital de la oficina técnica de Cooperación.

ILPES (Instituto Latinoamericano de Política Económica y Social) (2007). Economía y territorio en América Latina y el Caribe. XII Conferencia de Ministros y jefes de Planificación de América Latina y el Caribe, Brasilia.

Jiménez, S. (2016). Lineamientos de desarrollo urbanos orientados a la introducción de sistemas de transporte BTR en la ciudad de Bogotá DC, Colombia. Trabajo final de Máster inédito, MPGA, UNIBA, Colombia.

Lache, J. (2018). La conectividad vial en los Montes de María en el postconflicto, 2018. Estudio de caso: El Carmen de Bolívar y Ovejas. Trabajo final de Máster inédito, MPGA, UNIBA, Colombia.

Larriva, M. (2017). La integración de la bicicleta al Sistema Integrado de Movilidad de la ciudad de Cuenca, Ecuador, 2017. Trabajo final de Máster inédito, MPGA, UNIBA, Ecuador.

Lora, A. (2018). La falta de inclusión en la modernización de la red vial como política nacional en los planes de Ordenamiento Territorial en Colombia, Estudio de caso: Corredor vial Cartagena Barranquilla y Circunvalar de la Prosperidad, 2018. Trabajo final de Máster inédito, MPGA, UNIBA, Colombia.

Mancheno, P. (2017). Corredores de transporte como elementos transformadores del uso del suelo urbano. Caso: El Tranvía de Cuenca en Ecuador, 2017. Trabajo final de Máster inédito, MPGA, UNIBA, Ecuador.

Manero, F. (2014). Desafíos e incertidumbres en torno a la Ordenación Sostenible del Territorio: Una perspectiva euro-latinoamericana. Boletín de la Asociación de Geógrafos Españoles, 65, 343-365.

Matos, A. (2018). Análisis y propuestas de mejora para la movilidad peatonal en el Casco Antiguo, corregimiento de San Felipe, ciudad de Panamá, 2018. Trabajo final de Máster inédito, MPGA, UNIBA, Panamá.

Massiris, A. (2008). Políticas latinoamericanas de ordenamiento territorial y sus perspectivas en un mundo globalizado. En M. Salinas (Coord.), El Ordenamiento Territorial. Experiencias internacionales, Guadalajara, México. Miranda, L. (2018). Incidencia del sistema vial en la transformación morfológica de la ciudad de Manta, Ecuador desde 1950 y su perspectiva futura. Trabajo final de Máster inédito, MPGA, UNIBA, Ecuador. 
Murcia, E. (1978). El paradigma sistémico en Geografía y Ordenación del Territorio. Ciudad y Territorio, 4, 35-50.

Neira, D. (2019). Potencialidades del bicitaxismo bogotano como modo alimentador del Sistema Integrado de Transporte Urbano. Estudio de caso en el portal Transmilenio Las Américas, 2019. Trabajo final de Máster inédito, MPGA, UNIBA, Colombia.

Novoa, S. (2017). Impacto de la futura Línea 7 de Metro en la comuna de Vitácura, Santiago de Chile. Trabajo final de Máster inédito, MPGA, UNIBA, Chile.

Pujadas, R. y Font, J. (1998). Ordenación y planificación territorial. Madrid: Editorial Síntesis.

Quintanilla, M. (2019). El vehículo eléctrico compartido como una de las alternativas a la movilidad interurbana en Madrid, 2018-2019. Trabajo final de Máster inédito, MPGA, UNIBA, España.

Quiroz López, V. (2015). Movilidad y Transporte: Una mirada cualitativa a la problemática de los viajeros metropolitanos en la Ciudad de México. Tesis Doctoral, Facultad de Geografía e Historia, Universidad de Barcelona, 440 pp, en el repositorio digital de la UB.

Ramos, L. (2019). Valoración de la inversión vial provincial rural y su impacto en el ámbito económico-productivo de la provincia de Tungurahua, Ecuador, 2018-2019. Trabajo final de Máster MPGA, UNIBA, Ecuador.

Reyes, V. (2020). Cambios en la movilidad habitual por transporte público bajo la implementación de medidas de restricción vehicular. Un análisis de isócronas para el Distrito Metropolitano de Quito, Ecuador, 2020. Trabajo final de Máster inédito, MPGA, UNIBA, Ecuador.

Suárez, F. (2020). El catastro multipropósito como herramienta de planificación territorial en Colombia, Año 2020. Trabajo final de Máster inédito, MPGA, UNIBA, Colombia.

Subirats, J. (Coord.) (2002). Nuevas respuestas a los retos de la globalización. Redes, territorios y gobierno. Barcelona: Diputación de Barcelona, Red de municipios.

Wells, J. (2016). Mejorando la movilidad desde el Distrito de Miraflores. Lima. Trabajo final de Máster inédito, MPGA, UNIBA, Perú.

Yáñez, C. (2020). Análisis de la seguridad vial de los peatones en la ciudad de Babahoyo, Ecuador, 2019-2020. Trabajo final de máster en curso al cierre de esta publicación, MPGA, UNIBA, México.

Zoido, F. (1998). Geografía y ordenación del territorio. En Íber, Didáctica de las ciencias sociales. Geografía e Historia, Barcelona, no. 16, Nuevas fronteras de los contenidos geográficos, 19-31.

Zoido, F. (2001). La ordenación del territorio a distintas escalas. En A. Gil Olcina et al. (Coords.), Geografía de España, pp. 595-618. Barcelona: Editorial Ariel. 


\title{
LA POSIBILIDAD DE RODAR EN UNA MEGACIUDAD: LA CIUDAD DE MÉXICO
}

\author{
THE POSIBILITY TO MAKE A ROLL IN A MEGACITY: MEXICO CITY \\ Alejandra Trejo Poo \\ Universidad Autónoma Metropolitana Unidad Cuajimalpa
}

\begin{abstract}
Resumen
El avance capitalista mundial ha tenido grandes consecuencias en todos los territorios; particularmente, en el desarrollo de las megaciudades. Una de ellas es la Ciudad de México, una megalópolis que ha presentado gran crecimiento de la desigualdad social y un descontrol en su extensión geográfica. Sin embargo, existen dinámicas que gracias al aumento territorial de la urbe han sido posibles, una de éstas son las rodadas nocturnas que realizan los ciclistas urbanos (los Bicitekas) de la Ciudad de México. En esta investigación se elige como caso de estudio a los ciclistas nocturnos para cumplir el objetivo de exhibir las posibilidades que presenta una ciudad tan compleja y enorme como la capital mexicana. Aún con sus dificultades, la geografía espacial y el interés social por el ciclismo nocturno, la ciudad muestra otra cara con diversos significados adquiridos sobre la misma gracias a que la recorren en bicicleta colectivamente. De esta manera, desde la antropología urbana buscamos visibilizar una forma de vivenciar la ciudad de noche a pesar de su complejidad, donde se exhiban las posibilidades que of rece para que existan alternativas incitadas por un grupo civil que quiere recorrer y conocer la ciudad nocturna.
\end{abstract}

Palabras clave: megaciudad, noche, espacio urbano, experiencia urbana, ciclismo.

\begin{abstract}
Global capitalist advance has had great consequences in all territories and especially in the growth of many megacities. One of them is Mexico City, a megalopolis that has seen growth in social inequality and also lack of control in its geographical extension. However, besides its problems, there have been positive dynamics that thanks the territorial expansion of the city became possible: one of those dynamics are the nighttime rolls made by a group of urban cyclists of Mexico City known as the Bicitekas. In this research, night cyclists are chosen as a case study to show the possibilities that a city as complex and enormous as the Mexican capital can have. Because, even with its problems, spatial geography and social interest in night cycling, the city shows another side with diverse meanings that have been acquired thanks to the travels, as a collective, of the urban night bike riders. Therefore, from
\end{abstract}


the perspective of urban anthropology, we seek to make visible a different way of experiencing the city despite its complexity, where the possibilities that it offers are exhibited trough the alternatives incited by a civil group that wants to travel and get to know the city at night.

Keywords: megacity, night, urban space, urban experience, cycling.

\section{INTRODUCCIÓN}

Las ciudades globales de la actualidad han sido núcleos de concentración social, económica y cultural que, por su gran diversidad (y desigualdad) social, las podemos percibir como centros de múltiples actividades en distintos ámbitos y tiempos. La urbe de la que partimos para este escrito, el cual proviene del proyecto que actualmente se está desarrollando dentro de la maestría en Ciencias Sociales y Humanidades de la Universidad Autónoma Metropolitana (México), es la actual Ciudad de México que, bajo la noción de Mattos e Iracheta (2008), entra en el concepto de megaciudades ${ }^{7}$, definiéndolas como aquellas «ciudades que se hinchan más que desarrollarse, en las que la planeación urbana es relativa y donde predominan los asentamientos precarios e informales en sus periferias, porque mantienen estructuras socioeconómicas con alta desigualdad» (ídem: 102)². Al mismo tiempo, la temporalidad particular y principal que abordaremos para este trabajo es la noche: el espacio-tiempo en el que se suspenden muchas prácticas una vez que se ausenta el sol, y a la vez se activan otras; por lo que la ciudad sigue teniendo movimiento y actividad sin parar, aunque haya algunos urbanitas que ni se enteren de qué tipo de cosas puedan suceder en ese periodo específico.

La Ciudad de México no sólo se le conoce por tener una geografía muy extensa $\left(1.485 \mathrm{~km}^{2}\right)$, por ser una de las urbes más pobladas del mundo (la quinta a nivel mundial con una población de 21,6 millones) o por ser una ciudad como el «espacio creado, modelado y ocupado por actividades sociales en el curso de un tiempo histórico» (Lefebvre, 2013: 130), sino también por la diversidad que hay dentro de ella a nivel social y cultural. Así mismo, gracias a esta pluralidad construida por historias de conquista, de invasiones, de colonias, de migraciones y de globalización, existen múltiples maneras de abordar y vivenciar la noche las cuales escapan del imaginario convencional en el que

1 Considerando que son ciudades de más de diez millones de habitantes.

2 Los autores las diferencian de las «ciudades globales» las cuales definen como «ciudades más ordenadas, seguras y productivas que tienen disciplina urbanística, un proyecto de conectividad interna, interurbana e internacional muy claro y grandes infraestructuras como aeropuertos, sistemas modernos y masivos de transporte público; corresponden a las grandes aglomeraciones de América del Norte, Europa y Asia». (De Mattos e Iracheta, 2008: 102). 
la solemos pensar; es decir, no sólo se vive la noche de una ciudad con prácticas de entretenimiento en un espacio cerrado, con el trabajo nocturno, o con la delincuencia e ilegalidad.

Así pues, dentro de aquellas prácticas no-convencionales sobre la noche urbana, existen ciertas dinámicas que se encuentran en la noche de la Ciudad de México, y unas de ellas son las rodadas nocturnas que ejercen diferentes grupos de ciclistas urbanos, en particular, el pionero de todos: Ios Paseos Nocturnos de los Bicitekas. Este grupo se reúne todos los miércoles del año para realizar recorridos en bicicleta durante la noche, parten del Ángel de la Independencia (monumento importante y emblemático de la Ciudad de México) a las 9:45 p.m. y ruedan en el espacio urbano de la CDMX ${ }^{3}$, o incluso, en la zona metropolitana que es el Estado de México (uno de los estados fronterizos a la capital del país). Dicha práctica se ha realizado desde los últimos 21 años con una asistencia actual de aproximadamente 100 a 150 integrantes de distintas edades (jóvenes y adultos mayormente), diversas profesiones y clases sociales, con más de la mitad del género masculino.

El recorrido consta de dirigirse a un sitio al aire libre (normalmente parques públicos, estacionamientos o amplios camellones), descansar aproximadamente 40 minutos en él y regresar al punto de inicio. La distancia total varía entre 25 y 45 kilómetros por noche, y se dirigen hacia cualquier dirección de la ciudad ${ }^{4}$. Aquí podemos observar que esto ofrece posibilidades de conocer, vivenciar e incluso de habitar la urbe nocturna de una forma particular: mientras se rueda en bicicleta, es decir, en movimiento. El objetivo de nuestro documento es querer evidenciar una nueva manera de conocer una ciudad a través de la movilidad y el desplazamiento en bicicleta, considerando su relación con el espacio urbano a partir de las posibilidades geográficas que tiene un territorio específico. De esta forma, nos daremos cuenta cómo cierta dinámica despierta circunstancias y situaciones que, quizá de otro modo, no podrían percibirse o aparecer.

Esta investigación se encuentra en una fase de análisis teórico y empírico después de haber realizado seis meses de trabajo de campo durante el segundo semestre del 2019. Desde el planteamiento del proyecto se buscaba conocer la forma en la que los ciclistas viven la noche urbana, tanto desde un ámbito general como particular. Por lo que para la metodología del trabajo se utilizaron herramientas de la antropología social como lo son la observación participante y la realización de etnografías, en donde podía conocer no sólo cómo se organizaba la rodada, sino también cómo se vivía dentro de ella; y la elaboración de entrevistas a profundidad para conocer qué tipo de noción

3 Nomenclatura denominada para la Ciudad de México desde el 2016.

4 El destino se elige en una votación previa que los organizadores hacen días antes a la rodada. Hay muchas consideraciones a tomar para planear el punto de llegada, pero en este documento no especificaremos los detalles técnicos. 
tenían diversas personas que rodaban (jóvenes, grandes, mujeres, hombres, organizadores, participantes, etc.) sobre la dinámica urbana en la noche. Durante los recorridos fue importante conocer la magnitud de las distancias transitadas, así como la dimensión del grupo social que ejerce esta práctica, por ello se realizó un levantamiento fotográfico durante las rodadas y el registro de la ruta a través de una aplicación tecnológica. Gracias a todo lo obtenido, se han encontrado nuevas perspectivas, visiones y significados de una ciudad nocturna que, dentro de muchas cosas, puede ser extensamente transitada sin tener que planearse política y geográficamente para hacerlo. Es decir, sabemos que la ciudad está pensada con ciertos fines y de determinada manera, _como lo son las vialidades pensadas solamente para los automóviles-, pero la existencia de una práctica como ésta nos visibiliza la posibilidad de que la ciudad se puede pensar y habitar de una forma diferente a la que inicialmente se diseñó, particularmente en la noche. Por ello, en estos momentos de la investigación queremos remarcar y detallar los encuentros novedosos y los temas, un tanto desconocidos, sobre la urbe a partir de un nuevo acercamiento durante el tiempo nocturno, ya que se desmantela una parte de la identidad de la ciudad a través del escenario urbano y desconocido 5 .

\title{
2. INICIO Y CONSOLIDACIÓN DE LOS PASEOS NOCTURNOS DE LOS BICITEKAS
}

\author{
¿Cómo será el embotellamiento provocado \\ en las calles vacías por un automóvil solitario?
}

CARLOS MONSIVÁIS

En 1998 iniciaron las rodadas nocturnas de los ciclistas urbanos. En aquel tiempo la Ciudad de México no era lo que ahora es (2020). A pesar de que era una ciudad con una gran cantidad de población, en aquel entonces no había tanto interés por el uso de la bicicleta, de hecho, la idea era considerada extraña porque no se acostumbraba a usar cierto móvil para trasladarse en la ciudad, a excepción de la gente pobre ${ }^{6}$ (Pérez, 2013; Macías 2015); por lo tanto no se tenía el conocimiento de rodar en grupo, el respeto a los ciclistas y tampoco había vialidades disponibles para ellos. Sin embargo, la idea surgió de un interés por implementar el ciclismo para una ciudad «más humana y más amigable» (palabras de los Bicitekas fundadores), donde se tuviera el respeto social y el territorio urbano adecuado para los ciclistas.

5 Aunque ya existen muchos grupos de ciclistas nocturnos desde hace varios años en la Ciudad de México, mucha gente se sigue sorprendiendo por el hecho de que esta actividad sea posible.

6 «La bicicleta transmite una imagen estereotipada de su usuario: procedente de clase obrera y pobre, es aquel que no cuenta con los medios para comprarse un automóvil» (Pérez, 2013: 111). 
La persona que tuvo la idea de hacer los recorridos ciclistas durante la noche fue Tom Dieusaert, un hombre belga que en aquel entonces tenía 28 años y vivía provisionalmente en la Ciudad de México. En una entrevista realizada el pasado septiembre de 2019, Tom nos comentó que pensaba a la CDMX como una ciudad ideal para andar en bicicleta: «por ser plana, ya que no tiene muchas montañas, tiene clima seco y por lo tanto no sudas mucho»?. Esta idea nos hace ver que una ciudad en la que algunos hemos vivido gran parte de nuestras vidas puede ser vista de una forma que nunca se había pensado, como lo es recorrerla, habitarla y conocerla en bicicleta de noche como no se había hecho antes, al menos hasta ese entonces.

El plan de las rodadas fue creciendo gracias a la difusión de la actividad por medio de propagandas que hacían los organizadores para invitar a la gente, pero sobre todo a través de los rumores que se propagaban entre la comunidad ciclista, los jóvenes y muchos otros curiosos. Algunos no lo creían posible, otros decían que eso era "cosa de locos», pero por diversas inquietudes, intereses políticos sobre la movilidad, o incluso ganas de divertirse, fue que el grupo creció hasta llegar a tener, un año después, alrededor de cien asistentes. Por ello, podemos decir que al poco tiempo se fue convirtiendo en una especie de ritual urbano que se presentaba todos los miércoles de la noche en un punto de inicio específico: el Ángel de la Independencia ubicado en la avenida Reforma de la Ciudad de México (véase Figura 1).

Figura 1. Ángel de la Independencia de la Ciudad de México

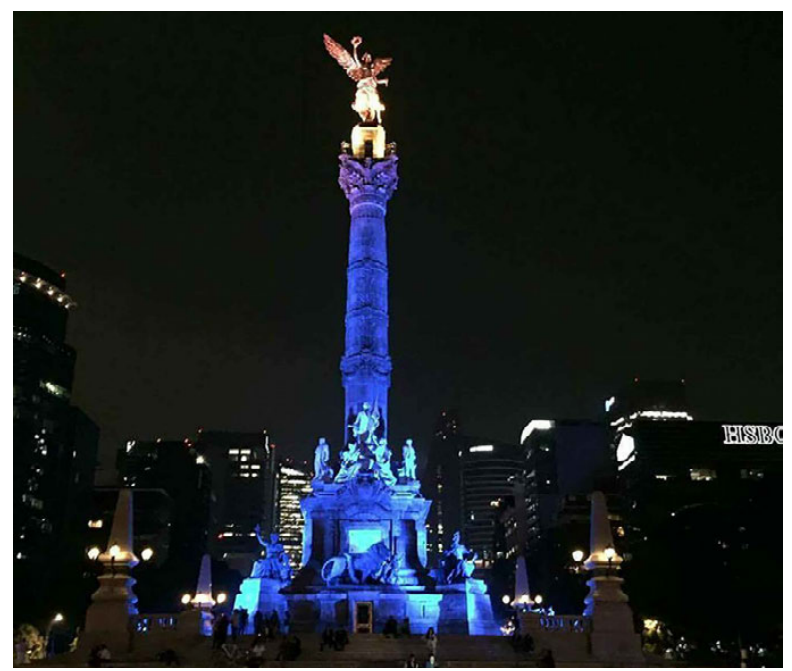

Fuente: Elaboración propia. 2019

7 Relato de entrevista realizada el 2 de septiembre de 2019. 
Nos referimos a la idea del ritual porque, aunque no es una práctica religiosa o sagrada, sí contiene propiedades que la llevan a ver como tal, por ejemplo: que la actividad se realiza en un tiempo y espacio específicos, que los participantes se encuentran para ejercer una dinámica particular no espontánea, que hay organizadores y guías que se encargan de llevar la caravana bajo control, que hay una dimensión colectiva como lo es la posibilidad de usar las calles para rodar y llegar a otros lugares; que hay emociones conjuntas dentro del grupo; por decir algunas de las propiedades ${ }^{8}$. Pero también, podemos mencionar que esta dinámica es un ritual porque, en términos de Randall Collins (2009) «los participantes desarrollan un foco de atención común y sus micro-ritmos corporales y emociones entran en consonancia recíproca» (71). Regresando a la conformación de las rodadas, el plan se programó sin tener que avisarse ni confirmarse por ningún medio, bien lo dice Tom de la siguiente manera:

\begin{abstract}
...lo mejor de todo esto es que no está organizado, es como una tradición, como festejar la Navidad, donde nadie tiene que decir 'oye, tenemos que festejar Navidad en tres días', ya se sabe que viene Navidad. Son cosas que (...) se autoorganizan, no hace falta que haya una cosa por Twitter, por Facebook, por Instagram (...) hay una dinámica, una inercia propia que se genera y se sigue autogenerando, el próximo miércoles otra vez y nadie lo cuestiona, es algo muy lindo y es mucho más fuerte a que alguien lo organice, y la misma tradición lo va justificando. Nadie en 2019 va a decir '¿por qué hacemos esto? ¿por qué nos juntamos lo miércoles acá?', bueno, porque siempre se hizo, porque de alguna forma funcionó. Porque algo que no funciona se deja de hacer. ${ }^{9}$
\end{abstract}

Así pues, con esta actividad podemos ver, primero que nada, cómo surge una experiencia urbana a partir de intereses comunes y de observar a la ciudad como un territorio con la posibilidad de recorrerse en bicicleta, tanto por sus características geográficas como climatológicas y urbanas, pero también sociales y culturales.

\title{
3. CONOCER LA CIUDAD DURANTE LA NOCHE
}

La ciudad está hecha para ser vista. MARC AUGÉ

8 Todas estas propiedades son extraídas del texto Archipiélagos del Ritual de Rodrigo Díaz Cruz (1998) Anthropos y UAM-I, México, pp. 225-227. A su vez, Díaz Cruz las retoma de otros autores, (Moore y Myerhoff, 1997; Rappaport, 1979; Lewis, 1980 y Grimes, 1990). Díaz indica que estas propiedades «permiten trazar un perfil o contorno de los rituales» (ídem)

9 Relato de entrevista realizada el 2 de septiembre de 2019. 
Hemos visto que la actividad nocturna que hemos estudiado para este proyecto nace de manera independiente, además, a través de los relatos de los fundadores y las fuentes de hace 21 años, encontramos que el grupo se presentaba con intenciones políticas y lúdicas, pero sobre todo, 'aprovechaba' la dimensión geográfica de una ciudad tan grande; por lo que nos arroja concepciones sobre la urbe que de otra forma no se percibirían.

Para empezar, una de las sensaciones que nos relata uno de los guías actuales de la rodada es que 'la ciudad se queda chica' con estos recorridos, ya que se puede transitar en tantos lugares de manera más rápida (que no quiere decir más veloz) a la que se suele imaginar. Para ver algunos ejemplos de los recorridos que se han hecho, observe los siguientes mapas de las rodadas (Figura 2 y Figura 3) en diferentes direcciones.

Figuras 2. Rodada a Central de Abastos y Figura 3. Rodada al pueblo de Culhuacán

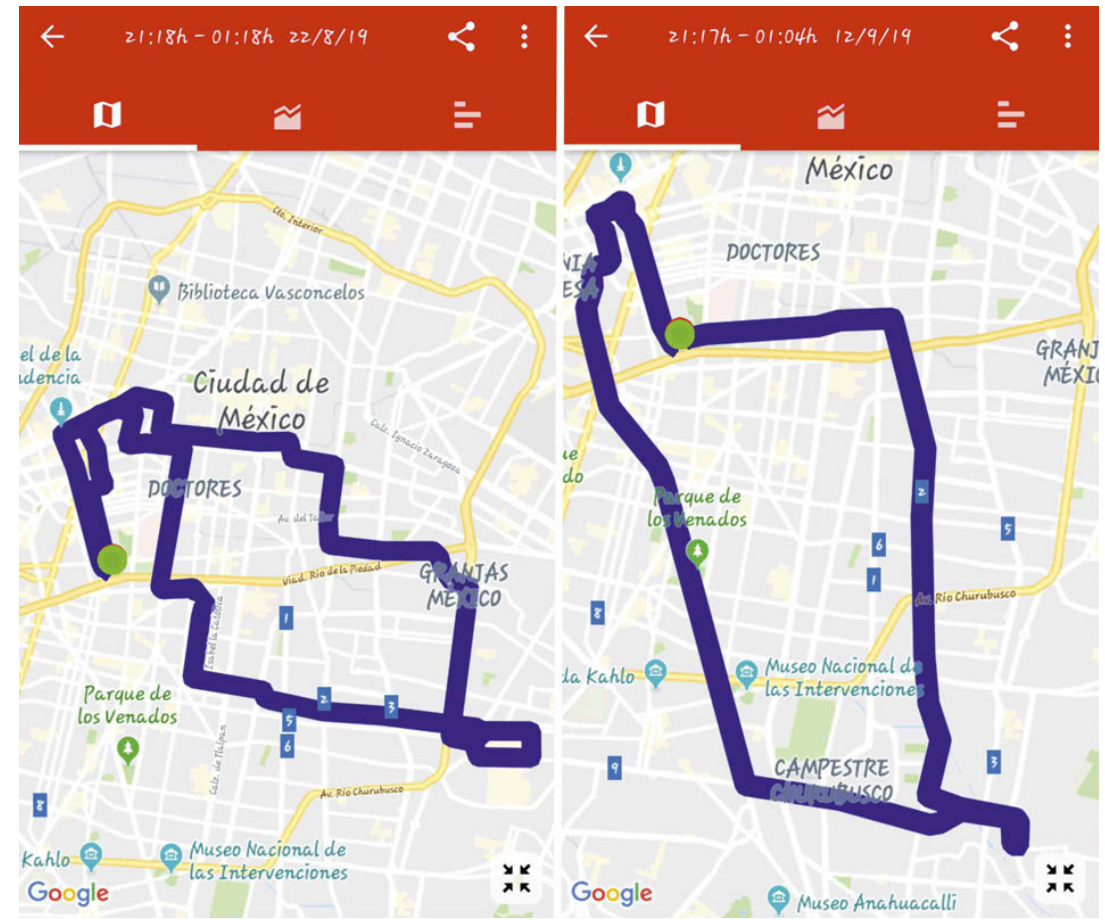

Figura 2: 21 de agosto de 2019. 36,33 km Figura 3: 11 de septiembre de 2019. 30,39 km

Los mapas fueron realizados con la aplicación Zeopoxa Ciclismo a través del teléfono inteligente de la autora. Se muestran de ejemplo dos rodadas hacia distintas direcciones de la ciudad. Los puntos verdes se refieren al hogar de la autora, _ el cual se encuentra a tres kilómetros del Ángel de la Independencia-. 
Con estos mapas podemos ver que existe una variedad de lugares por los que se pasa, así como de sitios a donde se llega, de manera que se recorren largas distancias y se perciben como «lugares lejanos» al punto de inicio. Respecto a la sensación de las distancias, Augé (2009) nos habla sobre la visita a tantos lugares de la ciudad de París mientras se rueda en bicicleta, así como la dimensión geográfica durante los traslados: «A quienes se arriesgan a utilizar la bicicleta por primera vez en la ciudad se les ofrece una experiencia inédita que les permite reevaluar las distancias» (ídem: 65-66), y aquí consideramos cambiar la frase por quienes se arriesgan a rodar en grupo durante la noche por primera vez en la ciudad, de manera que se genera, nuevamente, una experiencia urbana ${ }^{10}$.

Los ciclistas me han compartido durante el trabajo de campo sensaciones como la dimensión del tiempo y del espacio geográfico, en donde adquieren una noción completamente distinta a la habitual ya que, durante la rodada dentro del grupo, se va platicando, conviviendo, o incluso disfrutando el recorrido sin socializar. Así pues, la distancia se percibe muy diferente porque no se siente que se ha recorrido tanto kilometraje, ya que uno va sintiendo la rodada, la calle y la noche que los envuelve. Por esto, el tiempo de traslado también cobra otra dimensión al grado de que puede pasar una hora y media o dos y pareciera que ha pasado mucho menos. Uno rueda sin saber que se han atravesado dos o tres delegaciones ${ }^{11}$ con diversas colonias $^{12}$, sin embargo son evidente las diferencias que hay entre cada zona ya que todo sucede dentro de una ciudad con gran desigualdad social. De esta manera, lo que parece lejano ya no lo es en la práctica de la rodada, pues las distancias se acortan, los lugares se acercan, y por lo tanto las diferencias entre zonas se juntan mucho más de lo que podría pensarse.

Precisamente en estos traslados, la diversidad socioespacial de las zonas abunda en cada rodada, presentando una exposición a la heterogeneidad urbana $^{13}$, y nos hace percibir la variedad con la que está compuesta una ciudad como la CDMX, lo cual abre la posibilidad de «rodar en grupo donde te permite rodar en lugares donde normalmente no irías» ${ }^{14}$, y sobre todo nunca

10 De esta forma, Aguilar (2016) plantea la idea de experiencia urbana con el caminar en la ciudad, y lo que coincide aquí, —razón por la que tomamos su referencia-, es la actividad en movimiento y las posibilidades de sociabilidad durante la práctica.

11 Demarcaciones territoriales de la Ciudad de México.

12 «Una colonia es la denominación que se le da en México a un vecindario que no tiene autonomía jurisdiccional o representación. Usualmente las colonias reciben un código postal específico. A los desarrollos urbanos modernos como las comunidades en urbanización cerrada, llamadas barrios, fraccionamientos o vecindarios privados; se les denomina también colonias» Extraído de: https://es.wikipedia.org/wiki/Colonia_(M\%C3\%A9xico)

13 Como lo dice Aguilar (2016) respecto al caminar en la ciudad (32).

14 Relato de la entrevista realizada a Erick, uno de los guías actuales, antes de la rodada a Culhuacán, el día 4 de septiembre de 2019. 
se piensa visitar de noche; pues la noción de recorrer ciertas zonas en ciertos horarios construye una idea de peligro y riesgo. Al mismo tiempo, hay quienes provienen de zonas muy diferentes a las que se visitan, por lo tanto, se llega a lugares que no se conocerían de otra forma ni en otro momento dentro de esta geografía urbana tan diversa que tiene la Ciudad de México. Por eso podemos ver que se aprovecha la dimensión social y espacial de la ciudad a partir de la variedad de participantes y de lugares por recorrer y visitar. Cuando es de noche, el tiempo pasa de otra forma, y más porque las calles se vacían, pues pareciera que están sólo para los ciclistas. Ese vaciamiento y esa posibilidad de rodarla con tanta amplitud modifica la concepción del tiempo, del espacio y de la distancia que podemos recorrer. Incluso nos hace percibir desde nuestros sentidos, —el olfato y el oído, no sólo la vista—, una sensibilidad hacia la ciudad que con el bullicio del día no se pueden apreciar o reconocer; y justo ahí se encuentra una virtud de la noche: su apertura, su invitación a ver diferente, su distinción, e incluso su vacío de autos y sonidos que ofrece la posibilidad de escuchar y desplazarse de manera atípica. Si bien, la noche también es una alteridad del mundo que damos por establecido, ya que exhibe la posibilidad de la urbe nocturna como la forma de vivir una realidad aparte a partir de ofrecer una alternativa de vida (Arreola, 1990). Por ello, pareciera que la ciudad se transforma en otra, cambia y ya no se ve con esa enormidad que siempre vemos en nuestro imaginario.

Percibir el espacio urbano desde la bicicleta, da la posibilidad de estar más próximo y abierto a la naturaleza del entorno, por lo que hace notar la diferencia de cuando se está dentro de una burbuja aislada como lo es un automóvil o autobús, ya que cuando se anda en la bicicleta hay un contacto directo con las avenidas mientras se conoce una parte de la dimensión urbana dentro de una fiesta móvil, y por lo tanto eso cambia la manera de mirar el afuera, la ciudad que se recorre. Así pues, consideramos la idea de inmersión con la ciudad, donde se establece una relación con el entorno, la ciudad y sus espacios, transformando la experiencia y los recorridos realizados (Aguilar, 2016) a partir de las subjetividades, cercanías y conexiones con cada ruta, espacio y traslado.

Por otro lado, una consideración importante al conocer la urbe gracias a estos recorridos es que se va construyendo un mapa mental o mapa geográfico sobre la ciudad como una función valorativa del mundo (Signorelli, citada en Giglia, 2012, 15), sin necesidad de utilizar un mapa analógico o digital, es decir, después de varios trayectos con distancias extensas, se conocen las avenidas y las calles. Bien nos lo relata Fistix, uno de los participantes de la rodada: 
que ir a la Narvarte a tal lado y ya está y vámonos. Ya se me armó el mapa hasta mejor que el Waze. Acá rapidísimo todo.

Así mismo, nos comenta la misma Amalia Signorelli a partir de las interacciones establecidas con los lugares: «Cada sujeto es un efecto portador de un mapa mental del mundo que le permite orientarse en las relaciones con los lugares y con los otros sujetos y, a través de las representaciones, estar mentalmente en relación con otros lugares y sujetos distantes» (ídem, citada en Giglia, 2012, 15).

Finalmente, todo esto nos ofrece una nueva forma de conocer la ciudad nocturna, a través de las rodadas de noche conformadas por un grupo masivo que se reúne semanalmente. Así, la ciudad no se percibe como se miraba antes de conocer esta experiencia, sea de día o de noche, la imagen y dimensión de la ciudad ha cambiado después de una intervención social como lo son las rodadas nocturnas de los Bicitekas.

\section{HABITAR LA CIUDAD Y VIVENCIAR LA NOCHE URBANA}

Una vez que hemos conocido cómo se organizan las rodadas de los ciclistas nocturnos, podemos encontrar otra relación con la urbe la cual es habitar la ciudad. El concepto de habitar lo define Angela Giglia (2012) como la relación que se tiene con el espacio mediado por la cultura, en este caso podemos decir que es la cultura a través de la práctica de los ciclistas nocturnos. Hemos notado que esta dinámica se hace presente a partir de la intervención social de un gran conjunto de individuos sobre las avenidas de la ciudad. Por lo que se habita la ciudad en movimiento a partir de la presencia de los Bicitekas, donde estos adquieren significados de los lugares visitados y de las avenidas transitadas a través de su convivencia con estos sitios. Cuando sabemos que se recorren diferentes vialidades y se llegan a diferentes destinos, se adquiere un reconocimiento, interpretación y significado del espacio (ídem), ya que para algunos son lugares nuevos, desconocidos y lejanos a su zona habitacional, laboral o concurrida; pero para otros es llegar a zonas conocidas o familiares de la ciudad, que además, saben cómo se comportan esos lugares; es decir, son espacios domesticados (ídem), ya que por tener una frecuente asistencia, existe una familiaridad con los lugares. Cuando sucede esto, hay ocasiones que reviven memorias personales y sociales por los hechos marcados en la vida de cada uno, así como en la vida de estas zonas de la urbe. De la misma manera lo dice Aguilar (2016) respecto al caminar:

La evocación de este trayecto, (...) apunta la persistencia del desplazamiento en la memoria y su capacidad para trazar e identificar transformaciones en el entorno. La memoria del caminar, además de un ejercicio de nostalgia, es también la ubicación de huellas del pasado que se miran 
en el presente y permiten constatar persistencias y transformaciones, lo mismo que la creación de una sensación intensa de temporalidad (Aguilar, 2016, 28).

Por otro lado, la idea de rodar de noche inició por razones sociales que son importantes de marcar, tales como: la noche es el tiempo en el que mucha gente sale de trabajar y tiene tiempo libre para despejarse, hacer ejercicio y entretenerse; el tránsito vial disminuye y las calles comienzan a estar más accesibles para ser recorridas en bicicleta; hay una menor cantidad de autos, por lo tanto, el aire está más limpio; no hay sol que queme a los ciclistas, entre otras cosas. Pero una cuestión importante de considerar es que, de alguna forma, las dinámicas de la vida nocturna como lo son salir a beber, fumar y estar con los amigos, también se presentan en las rodadas nocturnas. Por ello, la intervención de la noche se mantiene, en este caso, en los espacios que han sido reglamentados de alguna manera, pero son intervenidos y habitados con una actividad distinta a la que se ha pensado sobre ellos: «el espacio lo ordenamos, pero el espacio también nos ordena» (Giglia, 2012, 16) de manera que, al suceder ambas cosas, la interacción y relación con un lugar se va determinando también desde su intervención junto con el orden impuesto. Es importante notar que, en los Paseos Nocturnos, los participantes no van sobre las ciclopistas instaladas en las vialidades, sino que, al ser tantos participantes, se presenta el cuerpo de una caravana ciclista sobre la calle. El grupo es mucho más grande que los automóviles, y esto los lleva a apropiarse de las avenidas, calles y callejones, así como de los lugares destino, por lo tanto, hay un habitar en movimiento del espacio público.

Figura 4. Rodada a Culhuacán

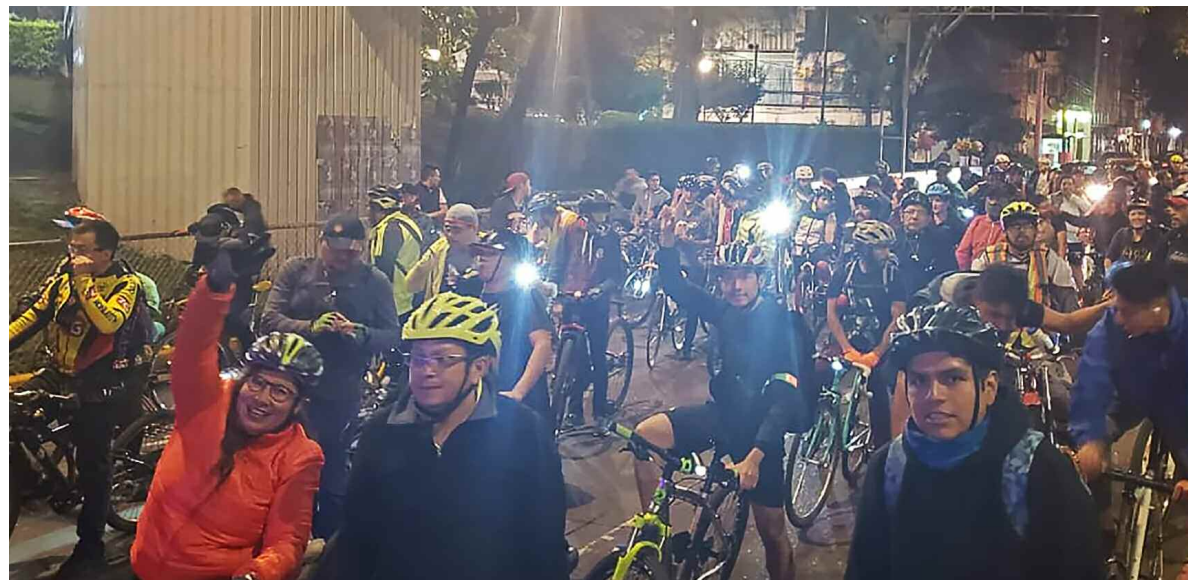

Fuente: Elaboración propia. 11 de septiembre de 2019 
La idea de vivenciar la noche desde una actividad nocturna no convencional nos hace encontrar aspectos de la ciudad de noche no convencionales, pero que también existen y muestran la ciudad que recorremos, habitamos y seguimos descubriendo a través del movimiento colectivo. Bien lo dice Marc Augé (2009) sobre el uso de la bicicleta en el espacio público, donde se trata de «socializar en las calles, reconstruir lugares de vida y soñar la ciudad» (19). Esto nos hace pensar que hay una intención de revivir la sensación del infante, desde la concepción de Augém, jugando en la calle con los amigos a partir de lo que permite el entorno o el ambiente socioterritorial.

\section{CONCLUSIONES}

Al conocer una actividad en movimiento que se realiza durante la noche dentro de la Ciudad de México, nos lanza una visión de la ciudad nocturna como un ágora, aquel espacio amplio que ofrece la oportunidad de estar y vivir en el afuera. Así pues, esta dinámica es una posibilidad distinta a las que recurrentemente suceden de noche en el espacio cerrado.

Lo que se ha visto en este periodo del proyecto de investigación, nos muestra no sólo la idea de otra ciudad distinta a la que conocemos, sino que también es una práctica donde cada día se escriben historias diferentes sobre las vialidades y las zonas de la Ciudad de México, para ser habitadas, significadas y socializadas de una manera distinta a la que conocemos. La mirada desde la antropología social nos muestra una ciudad dinámica durante la noche que se despierta una vez que se oculta el sol, y cuando se terminan las labores y actividades establecidas de muchos habitantes éstos pueden escapar de la vida cotidiana, al menos por un rato, y coincidir en el ritual urbano nocturno. Este trabajo nos ha hecho encontrar que la ciudad, aunque esté hecha de una forma preestablecida y diseñada con ciertos planes urbanos, cada habitante o visitante, así como cada grupo social, decide cómo vivirla, recorrerla y conocerla. Por esto mismo, los Paseos Nocturnos de los Bicitekas presentan una forma distinta de lo que se suele pensar sobre la noche urbana, y nos lanza una óptica de conocimiento sobre la Ciudad de México, de manera que se adquiere otro sentido y percepción de vida nocturna y de todo lo que puede haber en un territorio citadino que nunca se terminará de descubrir. Finalmente, estos recorridos nos hacen ver a una urbe como un laberinto inacabable que incita a ser conocido e intervenido, y en este caso se decide explorar con una multitud de ruedas que pintan de memorias las calles de una gran ciudad, como si fuera una gran pista deportiva. De esta manera, se marcan caminos únicos por una nómada urbana que, con el paso de los años, ha

15 «...muchas personas de cierta edad montan sus bicicletas, no diariamente y de manera solitaria, sino en grupo (...) En realidad juegan, pues su verdadera intención es, antes bien, recuperar los planes de la infancia y las complicidades de los niños» $(2009,43)$. 
mantenido la costumbre de rodar incansablemente sobre toda la extensión posible que la ciudad ofrece, o bien, en esa ciudad que se despierta bajo la oscuridad.

\section{BIBLIOGRAFÍA}

Aguilar, M. Á. (2016) El caminar urbano y la sociabilidad. Trazos desde la ciudad de México. Alteridades, vol. 26, núm. 52, julio-diciembre, México, 23-33.

Arreola Medina, A. (1990). La representación de la noche en la actual narrativa mexicana (1960-1990). México D. F.: Centro Virtual Cervantes.

Augé, M. (2009). Elogio de la bicicleta, Gedisa, España.

Collins, Randall (2009). Cadenas de rituales de interacción. Anthropos, Barcelona.

Díaz Cruz, R. (1998). Archipiélago de rituales. Anthropos y UAM Iztapalapa, México.

Giglia, A. (2012). «Capítulo 1: Habitar, orden cultural y tipos de hábitats». El habitar y la cultura: Perspectivas teóricas y de investigación, Anthropos, México, 9-23.

Lefebvre, H. (2013). La producción del espacio. Capitan Swing, Madrid.

Macías, P. (2015). Movilidad alternativa en la Ciudad de México: el caso de los grupos ciclistas del Distrito Federal. Tesis de licenciatura en Geografía Humana, UAM Iztapalapa, Ciudad de México.

Mattos, C. e Iracheta, A. (2008). «Globalización y territorio», Centro-h, núm. 2, diciembre, Organización Latinoamericana y del Caribe de Centros Históricos - OLACCHI, Quito, 99-110.

Pérez López, R. (2013). El sistema de bicicletas públicas «Ecobici»: del cambio modal al cambio social. Espacialidades. Revista de temas contemporáneos sobre lugares, política y cultura, vol. 3, núm. 2, julio-diciembre, UAM Cuajimalpa, Distrito Federal, México, 106-124.

\section{PÁGINAS WEB}

Colaboradores de Wikipedia (2020, 17 febrero). Colonia (México) - Wikipedia, la Enciclopedia Libre. Recuperado 18 de febrero, 2020, de: https://es.wikipedia.org/wiki/Colonia_(M\%C3\%A9xico) 




\title{
RECUPERACIÓN DEL PATRIMONIO INDUSTRIAL URBANO: LOS SILOS EN ESPAÑA \\ RECOVERY OF THE URBAN INDUSTRIAL HERITAGE: THE SILOS IN SPAIN \\ M. Carmen Cañizares Ruiz \\ Universidad de Castilla-La Mancha
}

\begin{abstract}
Resumen
Los silos destinados al almacenaje de cereales constituyen unas de las edificaciones más representativas del patrimonio industrial agroalimentario, tanto en áreas urbanas como en rurales. En España, la Red de Silos y Graneros organizada por el régimen franquista en la postguerra, integró más de 600 silos por todo el país dentro de la política intervencionista de la dictadura que estuvieron activos hasta la entrada de España en la Unión Europea. Hoy, una gran mayoría se encuentran abandonados y algunos se han rehabilitado para otros usos ya que sus valores (históricos, técnicos, arquitectónicos...) y sus potencialidades son evidentes. La valoración de la situación actual de los silos, así como las iniciativas de recuperación, relacionadas con factores como la ubicación y la posibilidad de albergar nuevos usos, se completa con la presentación del Proyecto Titanes en varios municipios de la provincia de Ciudad Real donde antiguos silos se han integrado en una ruta turística cuyo principal atractivo es el arte urbano.
\end{abstract}

Palabras clave: silos, patrimonio industrial agroalimentario, Red Nacional de Silos y Graneros, Proyecto Titanes.

\begin{abstract}
The silos destined to the storage of cereals constitute one of the most representative buildings of the industrial agrifood heritage, both in urban areas and in rural areas. In Spain, the Silos and Barns Network organized by the Franco regime in the postwar period, housed more than 600 silos throughout the country within the interventionist policy of the dictatorship that were active until Spain entered the European Union. Today, a large majority are abandoned and some have been rehabilitated for other uses since their values (historical, technical, architectural...) and their potential are evident. The assessment of the current situation of the silos as well as the recovery initiatives, related to factors such as the location and the possibility of housing new uses, is completed with the presentation of the Titanes Project in several municipalities of the province of Ciudad Real where old silos have been integrated into a tourist route whose main attraction is street art.
\end{abstract}

Keywords: silos, industrial agrifood heritage, National Network of Silos and Granaries, Titanes Project. 


\section{INTRODUCCIÓN: EL PROTAGONISMO DEL PATRIMONIO INDUSTRIAL}

La Carta de Nizhny Tagil sobre Patrimonio Industrial (2003), promovida por el TICCIH (Comité Internacional para la defensa y conservación del Patrimonio Industrial) e ICOMOS (Consejo Internacional de Monumentos y Sitios), afirma que este "se compone de los restos de la cultura industrial que poseen un valor histórico, tecnológico, social, arquitectónico o científico», es decir «edificios y maquinaria, talleres, molinos y fábricas, minas y sitios para procesar y refinar, almacenes y depósitos, lugares donde se genera, se transmite y se usa energía, medios de transporte y toda su infraestructura, así como los sitios donde se desarrollan las actividades sociales relacionadas con la industria» (ICOMOS, 2003, 2), para el período que se extiende desde la Revolución Industrial hasta la actualidad, preferentemente. Aboga por la importancia de la catalogación, el registro y la investigación, así como la necesidad de protección legal para todos sus elementos, considerados parte del patrimonio cultural de un territorio, junto con el mantenimiento y la conservación. Especialmente relevante, en este documento, es el lugar destinado a resaltar los valores de aquellos bienes, muchos de ellos hoy «recursos» al servicio de las estrategias de desarrollo territorial, que fueron fundamentales durante el proceso de industrialización de países, regiones y ciudades. Poseen un valor universal, a veces reconocido por la UNESCO en la Lista del Patrimonio Mundial; un valor social como parte del registro de vidas de hombres y mujeres corrientes, y como tal, proporciona un importante sentimiento de identidad; un valor tecnológico y científico en la historia de la producción, la ingeniería, la construcción; puede tener un valor estético por la calidad de su arquitectura, diseño o planificación. Además, estos valores son intrínsecos del mismo sitio, de su entramado, de sus componentes, de su maquinaria y de su funcionamiento, en el paisaje industrial, en la documentación escrita, y también en los recuerdos y las costumbres de las personas.

El enorme potencial de las «ruinas industriales» a partir de mediados de los años 70 del siglo pasado cuando se inicia la etapa postindustrial, junto con los valores citados, ha concedido a sus elementos materiales un gran protagonismo en el cambio de siglo por las posibilidades de incorporarlos a nuevos usos, muy importantes en las áreas urbanas (museos, viviendas, hoteles, etc.), así como a iniciativas de diferente tipología territorial (parques mineros, ecomuseos, etc.). Ello ha servido, en muchos casos, para conservar edificaciones, maquinaria, cuencas mineras o colonias fabriles que, despojadas de su función originaria, se «reinventan» para la sociedad actual y preservan la memoria del trabajo.

En España, desde el ámbito institucional, el Plan Nacional de Patrimonio Industrial, aprobado en 2001 y actualizado en 2011 por el Instituto del Patrimonio Cultural de España, destaca que el patrimonio industrial y sus huellas sobre el territorio se han convertido en nuevos bienes culturales y en un recurso activo para fomentar programas de desarrollo sostenible a escala local 
y regional. Estos bienes se insertan en un paisaje determinado, siendo cada vez más necesario interpretar el patrimonio no como elemento aislado, sino en su contexto territorial (Cañizares et al., 2019, 183).

Abordamos aquí, como objetivo principal, una breve revisión de la situación de los silos en España, claros exponentes del patrimonio industrial, concretamente en el grupo de «almacenes y depósitos» según la definición inicial, en base a la información documental y científica existente. Abandonados en muchos casos y rehabilitados en algunos, poseen valor histórico, tecnológico, social, arquitectónico o científico. Completaremos esta exposición con la presentación de un proyecto concreto de intervención, el Proyecto Titanes que se desarrolla en algunos municipios de la provincia de Ciudad Real (Castilla-La Mancha, España) y que busca sacarlos del olvido a través del arte dentro de un contexto en el que los espacios industriales abandonados, en algunos casos constituyen auténticas «escenografías que pueden ser potenciadas en los nuevos usos, además de servir de inspiración para el arte contemporáneo en disciplinas tan diversas como el cine, la fotografía, el teatro o la ópera» (Blanco y Río, 2015, 229).

\section{PATRIMONIO, ACTIVIDAD AGRARIA Y SILOS}

\subsection{EL PATRIMONIO INDUSTRIAL AGROALIMENTARIO}

El patrimonio industrial agroalimentario, también denominado patrimonio agroindustrial e incluso agrario, integra elementos (materiales e inmateriales), que son resultado de la acción del hombre en el medio para cultivar alimentos y transformarlos a través de procesos industriales bien se trate de cereales, vino, aceite, caña de azúcar, café, cacao, tabaco, etc. Engloba una de las tipologías patrimoniales que ha sido bastante olvidada y en la que existen ciertos «déficits en el campo de la investigación y de la historia industrial» (Álvarez, 2009, 9).

En España, la Carta de Baeza sobre el Patrimonio Agrario (2012) reconoce la importancia del «conjunto de bienes naturales y culturales, materiales e inmateriales, generados o aprovechados por la actividad agraria a lo largo de la historia» (Castillo, 2013, 32). Incluye, entre los elementos materiales, bienes muebles (utensilios, aperos o herramientas utilizados para la labranza, transporte, almacenaje y manufactura de los cultivos y el ganado, documentos y objetos bibliográficos, etc.); bienes inmuebles singulares (elementos constructivos: cortijos, huertas, centros de transformación agraria, graneros, etc.) y bienes inmuebles de conjunto o lineales (paisajes, asentamientos rurales, sistemas de riego, etc.); a los que se une el patrimonio inmaterial (lingüística, creencias, rituales y actos festivos, conocimientos, gastronomía y cultura culinaria, técnicas artesanales, etc.), así como el patrimonio natural y genético (variedades locales de cultivos, razas autóctonas de animales, semillas, suelos, vegetación y animales silvestres asociados, etc.). Sin duda, un patrimonio «que aún está poco considerado a pesar del importante papel que desempeñó en el desarrollo socio-cultural de nuestra historia reciente» (Bocanegra, 2016, 18). 
En este contexto los silos constituyen bienes inmuebles singulares, en origen destinados al aprovisionamiento agrícola de cereales que, en el contexto español, como en otros países, constituyen piezas clave de los «paisajes de granos del siglo XX» (Landi, 2019: 47), dada su vinculación con zonas rurales cerealísticas.

\subsection{LOS SILOS EN ESPAÑA}

Los silos y también los graneros son depósitos de gran entidad para el almacenaje del trigo y otros cereales, construidos de ladrillo u hormigón, preferentemente. Su grandiosidad, aun perdida su función, provoca que se les adjudique calificativos como las "catedrales olvidadas» (Azcárate, 2009) o «rascacielos rurales» (Vidigal, 2019), entre otras. Los más antiguos se comenzaron a construir en Estados Unidos, en la ciudad de Búfalo donde, en 1842, Joseph Dart ideó el primer «elevador de grano» (grain elevator) para el almacenamiento del cereal, a los que siguieron otros en Canadá y Argentina, mientras que, en Europa, los primeros se edificarían en Alemania y Suecia a comienzos del siglo XX (Azcárate, 2009, 59). Precisamente, estos primeros elevadores de grano, especialmente los americanos, «fueron un claro precedente del movimiento moderno europeo» (Sobrino, 1996, 205) y fascinaron a arquitectos como W. Gropius y Le Corbusier (Salamanca et al., 2012).

En España, un precedente lo encontramos en los silos cilíndricos de hormigón armado de la Panificadora de Vigo (1924) salvados del derribo gracias a la acción ciudadana local y la intervención del concello (Alonso, 2009, 141 y 145). Pero los silos, como hoy los conocemos, se construyen después de la Guerra Civil durante la dictadura franquista. Responden a una estrategia de regeneración de la agricultura nacional, sin materiales ni técnicas vanguardistas, resultado de un enorme esfuerzo realizado por unos ingenieros ajenos al debate arquitectónico nacional e internacional con «el único objetivo de establecer una Red Nacional de almacenaje de grano que fuera capaz de garantizar una regulación efectiva del comercio del cereal» (Azcárate, 2002, 55), siguiendo los principios de «utilidad, sencillez y economía».

Esta red comienza a organizarse en 1944, aprovechando los nudos de comunicaciones y las líneas de ferrocarril, básicas para el transporte de mercancías del momento, para localizar estas unidades de almacenamiento en el marco del Plan Nacional de Silos y Graneros (1945). Nace entonces la Red Nacional de Silos y Graneros, como herramienta reguladora (Vidigal, 2019, 35), vinculada al Servicio Nacional del Trigo' (1937) cuya finalidad fue posibilitar la compra de toda la cosecha de trigo a los agricultores, conservar una reserva nacional para garantizar el consumo con una materia básica, permitir la recepción en puerto

1 Posteriormente se vincularía con el Servicio Nacional de Cereales (SNC) y, más adelante, con el Servicio Nacional de Productos Agrarios (SENPA) con una intervención estatal cada vez menor. 
de trigo de importación y eventual exportación y una adecuada manipulación del grano y selección y tratamiento de semillas (Fernández Osuna, 2016, 206). En la distribución de unidades se tuvo en cuenta la territorialidad, con un mayor número de unidades en zonas cerealísticas; el rol, pues existieron silos y almacenes de recepción, silos de tránsito y reserva, y silos de puerto; y, finalmente, la individualidad, en función de las características propias de cada municipio (Salazar, 2015, 29-30). Se insertan en un contexto político en el que el régimen de Franco «en su afán por mostrar su carácter autoritario, pretende dignificar todos los edificios públicos agrarios mediante las directrices de arquitectura tradicional, neohistoricista y neovernácula» (Salamanca et al., 2012, 3).

Aunque el primer silo inaugurado oficialmente fue el de Córdoba en 1951, ya en 1949 se habían construido los de Valladolid, Villada (Palencia) y Alcalá de Henares (Madrid), llegando al final del período a contabilizar más de 950 unidades de almacenamiento. Un estudio reciente identifica 952, de ellas 670 verticales o silos y 282 horizontales o graneros (Fernández et al., 2017, 298), que en la última etapa se organizaron en dos redes, una red básica de almacenamiento, más densa en las comunidades autónomas con la mayor producción de granos y con edificaciones más grandes y modernas, y una red secundaria, con unidades más pequeñas y antiguas.

Su evolución estuvo directamente relacionada con las demandas del campo, las tecnologías constructivas disponibles, los avances en la maquinaria de transporte-elevación y los enclaves concretos (Azcárate, 2002, 59), hasta que la entrada de España en la Unión Europea y el fin del monopolio estatal les fue dejando sin uso y en situación de progresivo abandono, con continuos cambios de propiedad pública.

Desde el año 2004, el Grupo de Investigación Silos y Graneros (https://silosygraneros.es/) promueve la puesta en valor de la histórica Red Nacional mediante acciones para su documentación, valorización, conservación y difusión, considerando los contextos urbanos y rurales donde se insertan para promover proyectos de revitalización bajo nuevos usos adaptados a las demandas sociales actuales. Entre sus objetivos, también están: denunciar su abandono, destrucción o saqueo incontrolado de los bienes, edificaciones y maquinaria en ellos alojados, así como servir de plataforma de difusión científica. Sobresale su «inventario de libre consulta» con información actualizada y contrastada de las unidades que conformaron la Red respondiendo a 20 tipologías diferentes. Presenta 612 Silos de recepción; 279 Graneros; 27 Macrosilos (Tipo T); 13 Silos de selección de semilla; 10 Silos de tránsito (Tipo T), 4 Castillos (Tipo Z) y 2 Silos de puerto, es decir un total de 945 unidades, algunas ya desaparecidas. Significativa también es la iniciativa del Proyecto Silos en Andalucía, iniciado en 2013 por arquitectos y estudiantes para promover el debate sobre posibles nuevos usos. Su objetivo es también difundir, poner en valor, rehabilitar e investigar el patrimonio industrial agrario desatendido en el marco de un «espacio global de intercambio sobre silos que revierta positivamente en las comunidades rurales» (Bocanegra, 2016, 18). 
En resumen, destacamos dos hechos: en primer lugar, que muchos de ellos hoy se localizan en áreas urbanas e incluso en zonas urbanas que han ganado centralidad cuando en origen se edificaron en periferias como los de Córdoba, Jerez de la Frontera, Palencia, Soria, Mérida, Zaragoza, Albacete o Tarragona², entre otros. Y, en segundo lugar, que, aunque unos pocos se han destruido, lo cual «se puede considerar un despilfarro material y cultural» (Sobrino, 1996, 337), la mayoría se encuentran en precario estado de conservación y/o abandono, incluso sin protección legal, pues «la especialización les llevó a la muerte» (Garrido et al., 2017, 1). Un buen ejemplo es el complejo de silos (dos de recepción, uno de selección de semillas y edificaciones anexas) de Ciudad Real (Figura 1) para el que, en breve, se prevé una intervención de arte urbano.

Figura 1. Complejo de silos en Ciudad Real (España)

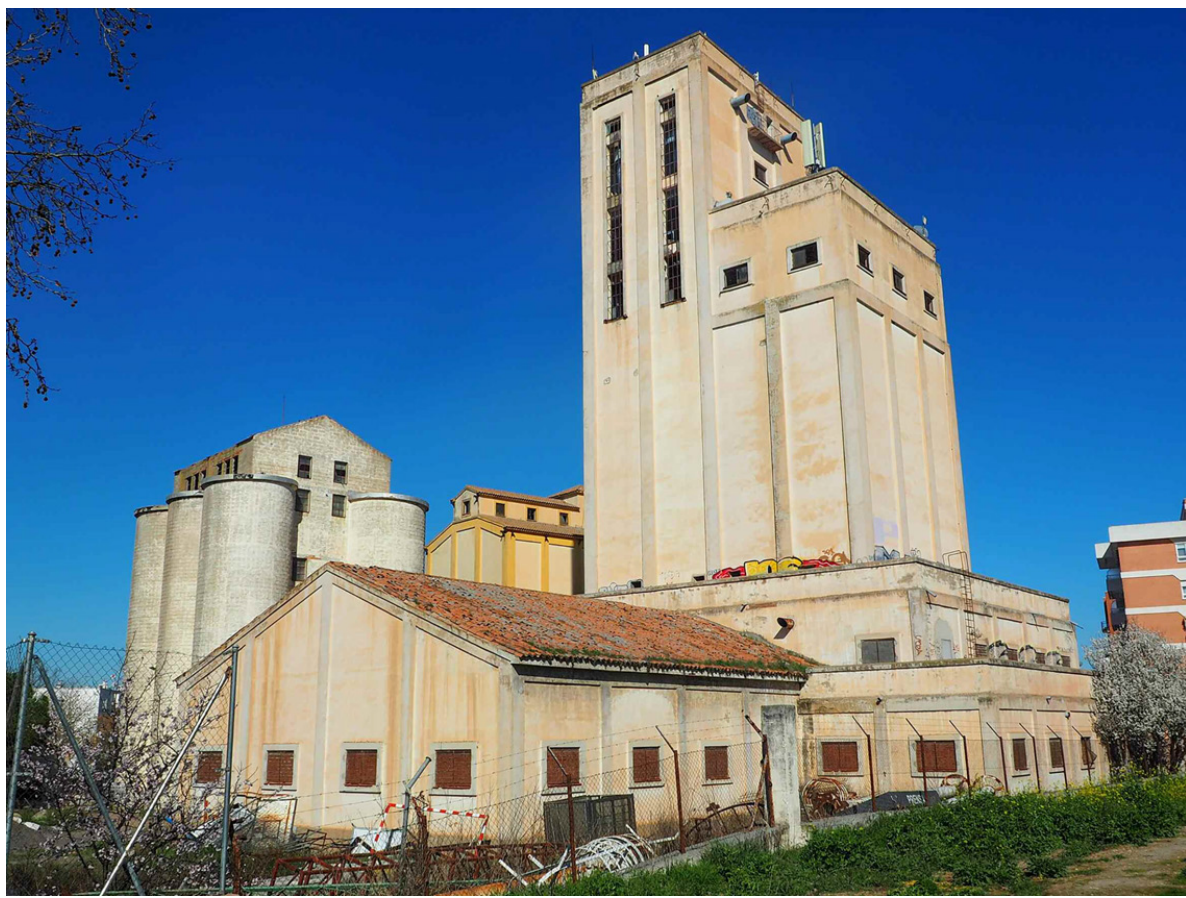

Fuente: Elaboración propia. 2020

En algunos casos se han tratado de «reinventar los edificios que aún permanecen en pie» (Salamanca et al., 2012, 7) a partir de usos culturales (teatros,

2 El silo de Málaga, uno de los más representativos en España, ha sido lamentablemente destruido en 2006, como también el de Nájera (La Rioja) en 2014, entre otros. 
centros de interpretación...), dotacionales (viviendas), institucionales (administración), etc. Su reutilización supone «en sí una estrategia sostenible ya que se consigue alargar el ciclo de vida de los materiales que lo constituyen y dar al edificio la posibilidad de ser rehabilitado para un nuevo uso» (Salazar, $2015,7)$. En España, excelentes ejemplos encontramos en el silo de Córdoba que, una vez rehabilitado, "se mantiene en buen estado tanto la maquinaria como el edificio en general y, lejos del abandono, destrucción o expolio que han sufrido otros ejemplares, su uso como depósito del Museo Arqueológico lo ha dotado nuevamente de utilidad, compatible con la conservación del silo como excepcional ejemplo de arquitectura industrial» (Jordano, 2012, 278). Y también, entre otros, en el silo de Fuentes de Andalucía (Sevilla), inaugurado en 2018 como complejo sociocultural integrando el edificio como centro de interpretación y las naves aledañas como centro juvenil o espacio joven (Fernández Osuna, 2016, 215).

No obstante, como se ha puesto de manifiesto en algunos eventos y publicaciones, los silos conforman una herencia extraña ya que marcan el paisaje en el que están inmersos, bien sea en ciudades, en campo abierto o en las orillas de los puertos, están cargados de una historia reciente visualmente fuerte y, sin embargo, «todavía no han movilizado a historiadores, geógrafos, economistas como cabría esperar» (Dorél-Ferré, 2014). Concretamente, en los espacios urbanos se han convertido en objeto de interés especulativo por el suelo que ocupan, cuyo valor ha ascendido en la mayor parte de los casos. Sin embargo, son muchas las dificultades para ofrecerles un nuevo uso, dadas las dimensiones de estas edificaciones y las enormes necesidades de financiación, principalmente. Cuestiones que han contribuido a que muchos se encuentren olvidados o, incluso, hayan desaparecido.

\section{EL «PROYECTO TITANES» (CIUDAD REAL, ESPAÑA)}

Como ocurre con otros elementos del patrimonio industrial, en el caso de los silos, «sus volúmenes, su materialidad y su escala convierten los vacíos urbanos y los restos de instalaciones e infraestructuras en un gran escenario sobre el que poder trabajar» (Blanco y Río, 2015, 229). Y esto es lo que ha sucedido en un conjunto de silos ubicados en distintos municipios de la provincia de Ciudad Real (Castilla-La Mancha, España) con la puesta en marcha del Proyecto Titanes (https://iamtitanes.com/). Uno de los más ambiciosos de las últimas décadas a la hora de combinar rehabilitación del patrimonio industrial agroalimentario y arte urbano. Un proyecto cultural e inclusivo cuya finalidad ha sido renovar la imagen de los silos de varias localidades, que se inició en abril de 2019 y aún no ha finalizado, pues de un total de 20 silos previstos, se ha intervenido en 10.

Surge bajo el auspicio institucional de la Diputación Provincial de Ciudad Real con una financiación inicial de $\mathbf{4 0 0} .000$ euros, promovido por el colectivo de 
artistas «Ink and Movement», al frente del cual se encuentra Okuda San Miguel (Óscar San Miguel Erice), comisario del proyecto y artista internacionalmente reconocido. Este grupo, que ya realizó hace 15 años el Urban Art Canarias como primer evento de arte público de gran formato, ha pretendido celebrarlo, en esta ocasión, con un proyecto artístico y social sobre las grandes paredes que ofrecen los silos. Los artistas que han participado, junto a Okuda San Miguel que ha transformado el Silo de Calzada de Calatrava y el interior del Silo de Villanueva de los Infantes, son Demsky y Smithe en el Silo de Corral de Calatrava, Fitan Magee en el de Herencia, Bicicleta Sem Feio en el de La Solana, Hell'o en el de Malagón, Equipo Plástico (Eltono, Nano4814, Nueria Mora y Sixe Paredes) en Manzanares I, así como Daniel Muñoz y Spok Brillor en Manzanares II, Nychos en el Silo de Porzuna y Ricardo Cavolo en el de Campo de Criptana, por el momento.

Como precedentes destacamos el éxito obtenido por Okuda San Miguel en la intervención realizada en 2018 sobre el mural de la piscina municipal de Puertollano (Ciudad Real) y, ese mismo año, la intervención en el silo de Almagro por el artista Antonio Laguna que sirvió de referencia para las celebraciones del 40 aniversario del Festival Internacional de Teatro Clásico. A partir de ahí comienza a fraguarse este proyecto con un título que identifica los silos con titanes que han resistido el paso del tiempo después de haber tenido un uso agrario muy intenso, además de servir como «homenaje a los orígenes como provincia vinculada al sector agrario, a la historia y las tradiciones» (Redacción Ciudad Real, 2020, 2).

Inicialmente se seleccionaron unidades de almacenamiento y se entró en contacto con los ayuntamientos que se encargaron de la regeneración (limpieza y mantenimiento) para poder ser intervenidos. A partir de ahí, cada artista generó un trabajo pensado para un silo concreto y hoy en cada uno de ellos se deja constancia no solo del autor, sino del significado conceptual de la obra a través de una placa informativa. Su elección se relaciona con el carácter de grandes infraestructuras que ofrecen, en mitad de espacios llanos con una visualización óptima desde la lejanía, la historia que tienen detrás, para lo que fueron creados y en lo que se han convertido (Ruiz de la Prada, 2020, 4-5).

Especial relevancia en este Proyecto tiene otro colectivo, «Laborvalía», asociación para la inclusión social de personas con discapacidad destinada a poner en marcha programas de inserción que demuestran cómo a través de las artes se puede mejorar la vida de personas con discapacidad y fomentar su integración social y laboral (http://laborvalia.es/). En este caso, en la transformación de los murales de los silos a través de la pintura, han colaborado más de 450 personas coordinadas por 50 monitores, lo cual demuestra que el arte puede ser una vía de inclusión. 
Tabla 1. Proyecto Titanes (Ciudad Real, España)

\begin{tabular}{|c|c|c|c|c|}
\hline Población & Hab. (2019) & Tipo de silo y año & Artista & Fecha \\
\hline $\begin{array}{c}\text { Calzada de } \\
\text { Calatrava }\end{array}$ & 3.719 & (D) Recepción 1983 & Okuda San Miguel & abril 2019 \\
\hline $\begin{array}{c}\text { Corral de } \\
\text { Calatrava }\end{array}$ & 1.123 & (E) Recepción 1983 & Demsky y Smithe & abril 2019 \\
\hline La Solana & 15.479 & (D) Recepción & Bicicleta Sem Feio & abril 2019 \\
\hline Manzanares & 17.997 & $\begin{array}{c}\text { (C) Recepción 1955 } \\
\text { (D) Recepción 1964 }\end{array}$ & $\begin{array}{c}\text { I. Equipo Plástico } \\
\text { II. Spok Brillor }\end{array}$ & abril 2019 \\
\hline Malagón & 7.998 & (D) Recepción 1955 & Hell'o & abril 2019 \\
\hline Herencia & 8.390 & (D) Recepción 1967 & Fitan Magee & mayo 2019 \\
\hline Porzuna & 3.532 & (E) Recepción 1970 & Nychos en & julio 2019 \\
\hline $\begin{array}{c}\text { Campo de } \\
\text { Criptana }\end{array}$ & 13.414 & (D) Recepción 1966 & Ricardo Cavolo & $\begin{array}{c}\text { octubre } \\
2019\end{array}$ \\
\hline $\begin{array}{c}\text { Villanueva de } \\
\text { los Infantes }\end{array}$ & 4.935 & (C) Recepción 1954 & Okuda San Miguel & $\begin{array}{c}\text { octubre } \\
2019\end{array}$ \\
\hline
\end{tabular}

Fuente: Elaboración propia. Marzo 2020 y https://sillosygraneros.es/

Como podemos observar en la Tabla 1, los núcleos de población en los que han sido intervenidos los silos son de diferente tamaño pues se reparten en el territorio provincial integrando espacios urbanos (señalados en cursiva) como Manzanares, La Solana o Campo de Criptana, a los que se unirá la capital, Ciudad Real (74.746 hab.). Junto con ellos, los otros se encuentran en núcleos semirurales como Herencia, Malagón, Villanueva de los Infantes, Calzada de Calatrava y Porzuna, e incluso rurales como Corral de Calatrava. En realidad, asentamientos de población, más allá de si estadísticamente son urbanos o rurales, que reflejan la conexión urbano-rural en este territorio donde el componente de ruralización es aún evidente.

Mayoritariamente las intervenciones son exteriores, es decir en las paredes o muros de los silos, lo cual permite que la obra se pueda ver incluso a cierta distancia. Sin embargo, en el silo de Villanueva de los Infantes, uno de los núcleos con mayor atracción turística de la provincia, la intervención por parte del santanderino Okuda San Miguel se realiza en el interior, uno de los pocos a escala mundial con estas características. Las obras de estos artistas se incluyen dentro del «arte urbano» (street art) cuyo su objetivo es interpretar y/o decorar el contexto (García Gayo, 2019, 154) a partir de una intervención, diferente a los graffiti.

Una de las intervenciones más relevantes es la realizada en el silo de Calzada de Calatrava por el propio comisario del proyecto (Figura 2). Con guiños a películas de Pedro Almodóvar, nacido aquí, como La mala educación y La flor de mi secreto, al Quijote y a la orden de los templarios, la obra de Okuda posiciona a este enclave como destino preferente del museo al aire libre que quiere ser Ciudad Real (Robles, 2019). 
Figura 2. Silo de Calzada de Calatrava (Ciudad Real, España

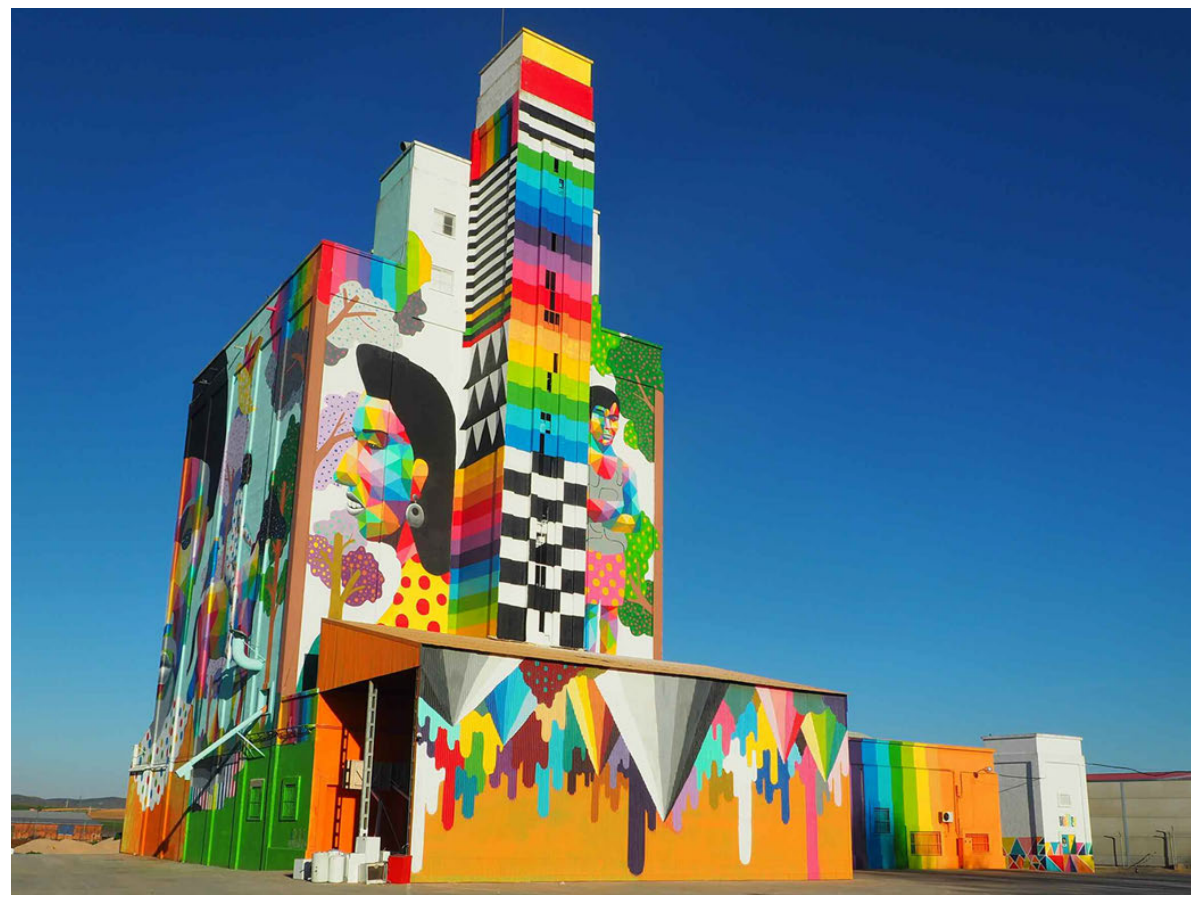

Fuente: Elaboración propia. 2020

Como en el caso de otros territorios, lo importante es «convertir estos elementos en motores del desarrollo local» (Bocanegra, 2016, 19), además de ser «aval de otros proyectos/iniciativas que promueven la defensa y salvaguarda de este patrimonio» (Bocanegra y Rodríguez, 2016, 230). De momento, su repercusión no es solo local o regional, sino también nacional e incluso internacional pues la web de viajes de National Geographic afirma que «algo surrealista está pasando en los silos manchegos» (Santos, 2019, 1). Visitas de artistas y expertos como Martha Cooper, publicaciones como la del diario británico The Guardian con el reportaje fotográfico Spain hosts world's largest open-air museum, afirmando que esta iniciativa «convierte a la tierra de Don Quijote en un proyecto de arte gigante» (García-Donas y Po, 2019, 1), o documentales como el de la cadena americana CNN dentro en su canal temático Great Big Story constituyen claros ejemplos. Añadimos la presentación de la «Ruta de los Silos» como producto turístico (Figura 3), por parte de la Diputación Provincial de Ciudad Real y los ayuntamientos implicados, en la última Feria Internacional de Turismo (FITUR), en enero de 2020, promocionando 20.000 kilómetros cuadrados de arte mural inclusivo (Yébenes, 2020, 1-2). 
Figura 3. Cartel anunciador de la Ruta de los Silos (Ciudad Real, España)

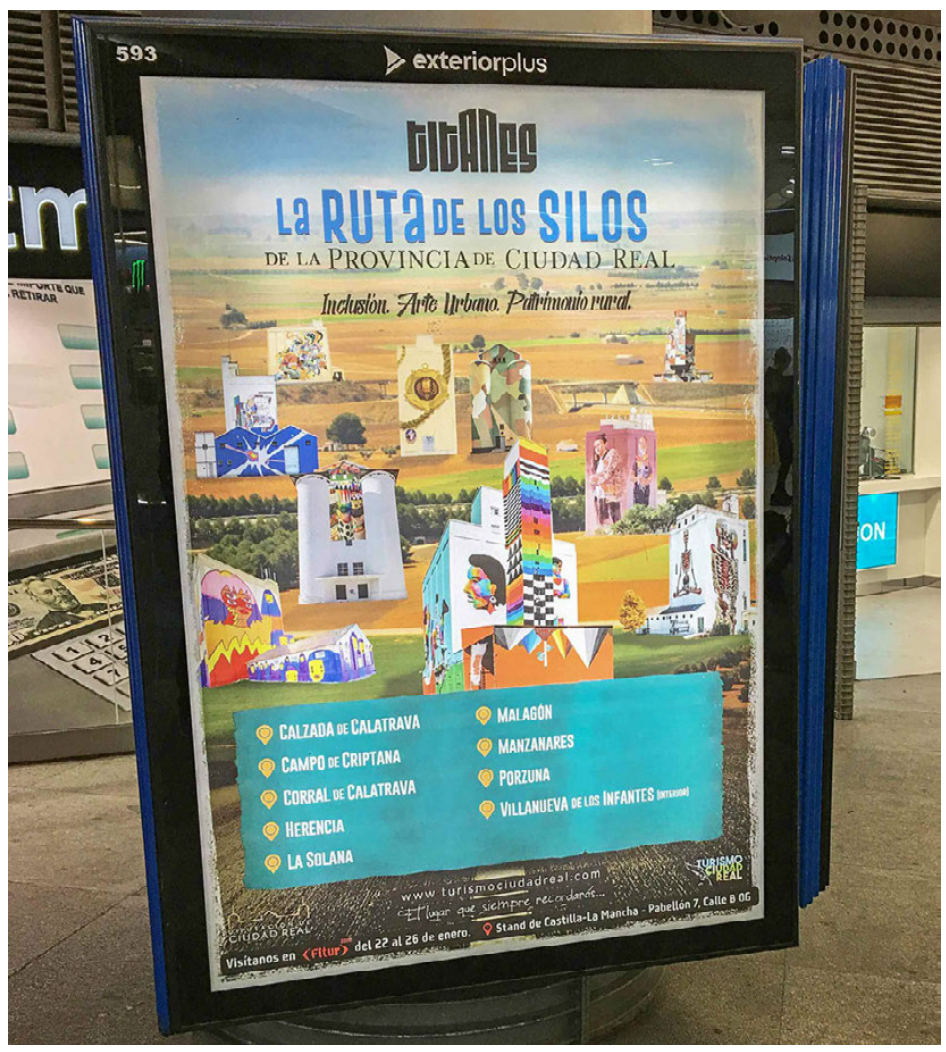

Fuente: Elaboración propia. 2020

\section{CONCLUSIONES}

Los valores acumulados a lo largo del tiempo por los silos y graneros en España, hacen de ellos unos de los bienes más significativos del patrimonio industrial agroalimentario, además de excelentes muestras de arquitectura industrial, paradójicamente realizada por ingenieros, asesorados por arquitectos. La existencia de más de 950 unidades, mayoritariamente abandonadas, ofrecen una enorme potencialidad para su valorización como ha quedado demostrado con algunos ejemplos de aquellos que se han reinventado con nuevos usos como museos, teatros, centros administrativos o espacios para jóvenes. Su distribución territorial, tanto en zonas urbanas, los menos, como rurales, realza su vinculación con el paisaje, aunque la desaparición de algunos de los más emblemáticos como el de Málaga destaca la escasa valoración que tienen a pesar de lo que representan. 
El Proyecto Titanes iniciado el año pasado con la intervención de 10 silos en 9 municipios de la provincia de Ciudad Real (Castilla-La Mancha, España) conforma un ejemplo de arte urbano inclusivo que puede reactivar el turismo de interior. Devuelve el protagonismo a estas unidades de almacenamiento que forman parte de la memoria de un territorio y asegura su conservación para las generaciones futuras. Adjudicarles un nuevo uso que permita rehabilitarlos completamente es algo aún complicado.

\section{BIBLIOGRAFÍA}

Alonso, J. R. (2009): El patrimonio industrial en Galicia en los albores del siglo XXI. LIÑO. Revista Anual de Historia del Arte, 15, 139-147.

Álvarez, M. A. (Ed.) (2009): Patrimonio Industrial Agroalimentario. Testimonios del diálogo intercultural. Gijón: CICEES.

Azcárate, C. A. (2002): Los silos de cereal en España. ¿Arquitectura? Industrial de la España Rural. En Coloquio Arquitectura, ciudad e ideología antiurbana. Pamplona: Universidad de Navarra, pp. 55-62. Recuperado de https://dadun.unav.edu/bitstream/10171/23587/1/2002\%206.pdf [Consulta: 24 de febrero de 2020].

Azcárate, C. A. (2009): Catedrales olvidadas: la red nacional de silos en España (1949-1990). Pamplona: T6 Ediciones.

Blanco, S. y Río, A. S. (2015): La fábrica como escenografía, la puesta en escena del patrimonio industrial. En M. A. Álvarez (Ed.), Espacios industriales abandonados, gestión del patrimonio y medio ambiente, pp. 229-235. Gijón: CICEES.

Bocanegra, A. (2016): Proyecto Silos: difusión y revalorización del patrimonio industrial abandonado. Revista PH, 89 (abril), 19-19.

Bocanegra, A. y Rodríguez, B. (2016): Proyecto Silos. Difusión y vías de conocimiento del patrimonio industrial a través de la cultura digital. En F. J. Sánchez (Coord.) (2016): Nuevas estrategias en la gestión del patrimonio industrial, pp. 223-233. Sevilla: Fundación Patrimonio Industrial de Andalucía y Universidad de Huelva.

Cañizares, M. C, Benito, P. y Pascual, H. (2019): Los límites del turismo industrial en áreas desfavorecidas. Experiencias singulares en España. Cuadernos Geográficos, 58 (1), 180-204. DOI: http://dx.doi.org/10.30827/cuadgeo.v58i1.6746.

Castillo, J. (Dir.) (2013): Carta de Baeza sobre patrimonio agrario. Sevilla: UNIA. Recuperado de https://digibug.ugr.es/handle/10481/36377 [Consulta: 24 de febrero de 2020].

Dorel-Ferré, G. (Coord.) (2014): Les silos, un patrimoine à inventer. Chambéry: Université de Savoie.

Fernández Fernández, V., Marcelo, V., Valenciano, J. V. y López-Díez, F. J. (2017): History, construction characteristics and possible reuse of Spain'snetwork 
of silos and granaries. Land Use Policy, 63, 298-311. http://dx.doi.org/10.1016/ j.landusepol.2017.01.017

Fernández Osuna, J. M. (2016): Silo Fuentes de Andalucía, mirador de la campiña. Gestión de un patrimonio singular. En F. J. Sánchez (Coord.) (2016): Nuevas estrategias en la gestión del patrimonio industrial. Sevilla: Fundación Patrimonio Industrial de Andalucía y Universidad de Huelva, pp. 205-220.

García-Donas, C. y Po, E. (2019): Spain hosts world's largest open-air museum. The Guardian (26/04/2019). Recuperado de

https://www.theguardian.com/travel/gallery/2019/apr/26/titanes-project-lamancha-spain-world-largest-open-air-at-museum-in-pictures [Consulta: 21 de febrero de 2020].

García Gayo, E. (2019): El espacio intermedio del arte urbano. Ge-conservación, 16 (diciembre), 154-165. Recuperado de https://ge-iic.com/ojs/index.php/revista/ article/view/704 [Consulta: 21 de febrero de 2020].

Garrido, M., Santiago, J. M. y Lafuente, F. J. (2017): Silos, Reused Machine-Buildings: A Proposal for Its Transformation. IOP Conference Series: Materials Science and Engineering, 245, pp. 1-10. doi:10.1088/1757-899X/245/8/082051.

Grupo de Investigación Silos y Graneros (2020): Red Nacional de Silos y Graneros de España. Recuperado de https://silosygraneros.es/ [Consulta: 10 de febrero de 2020].

ICOMOS (2003): Carta de Nizhny Tagil sobre Patrimonio Industrial. Recuperado de https://www.icomos.org/18thapril/2006/nizhny-tagil-charter-sp.pdf [Consulta: 18 de febrero de 2020].

Jordano, M.A. (2012): El silo de Córdoba, un ejemplo de arquitectura industrial. BSAA arte LXXVIII, pp. 261-278.

Landi, S. (2019): Rural landscapes of the 20th century: from knowledge to preservation. Architecture Civil Engineering Environment, 12(2), 47-56. Doi: 10.21307/ACEE-2019-022.

Lavorbalía (2020): Lavorbalía. Recuperado de http://laborvalia.es/ [Consulta: 21 de febrero de 2020].

Proyecto Titanes (2020): Proyecto Titanes. Recuperado de https://iamtitanes.com/_[Consulta: 21 de febrero de 2020].

Redacción Ciudad Real (2020): El proyecto de arte mural «Titanes» pone así de chulos varios silos de Ciudad Real. EnTomelloso.com. (22/04/2019). Recuperado de: https://entomelloso.com/noticias/sociedad/el-proyecto-de-artemural-titanes-pone-asi-de-chulos-varios-silos-de-ciudad-real/ [Consulta: 21 de febrero de 2020].

Robles, J. M. (2019): Arte urbano en la España vacía. Así quiere ser Ciudad Real un museo al aire libre. El Mundo (12/04/2019). Recuperado de https://mww.elmundo.es/cultura/2019/04/12/5caf788d21efaOd0078b45d1.html [Consulta: 21 de febrero de 2020].

Ruiz de la Prada. S. (2020): «Titanes», el proyecto de arte urbano que pone a Ciudad Real en el punto de mira. Harper's Bazaar (02/01/2020). Recuperado de: 
https://www.harpersbazaar.com/es/cultura/viajes-planes/a30121969/titanesproyecto-arte-urbano-ciudad-real-street-art-okuda/ [Consulta: 21 de febrero de 2020].

Salamanca, D. S., Ceballos, C. M. y Gordo, A. A. (2012): Ingeniería 20-Arquitectura 21. Los silos de cereal. En VV.AA. II Jornadas andaluzas de patrimonio industrial y de la obra pública. Sevilla: Fundación Patrimonio Industrial de Andalucía, pp. 1-8. Recuperado de:

https://dialnet.unirioja.es/servlet/articulo?codigo=4504166 [Consulta: 21 de febrero de 2020].

Salazar, A. (2015): Del trigo al hombre. Rehabilitar el silo. Tesis de Maestría. Barcelona: Universitat Politècnica de Catalunya. Recuperado de https://upcommons.upc.edu/handle/2117/84444 [Consulta: 21 de febrero de 2020].

Santos, N. (2019): Street Arte y costumbrismo. Algo surrealista está pasando en los silos manchegos. Nationalgeographic.com (30/06/2019). Recuperado de https://viajes.nationalgeographic.com.es/a/street-art-grafitis-silosciudad-real_14060 [Consulta: 21 de febrero de 2020].

Sobrino, J. (1996): Arquitectura industrial en España, 1830-1990. Madrid: Cátedra.

Vidigal, C. (2019): Rascacielos rurales: el silo de Olivenza. Análisis y puesta en valor del patrimonio agrícola. Escuela Técnica Superior de Arquitectura, Sevilla. Recuperado de:

https://idus.us.es/handle/11441/90834;jsessionid=C1955DC3CC2F17F9CD9044 B98F56E106 [Consulta: 16 de febrero de 2020]

Yébenes, J. (2020). Ciudad Real promociona 20.000 kilómetros cuadrados de arte mural inclusivo. Lanzadigital (25/01/2020). Recuperado de:

https://www.lanzadigital.com/provincia/ciudad-real-promociona-20-000kilometros-de-arte-mural-inclusivo/ [Consulta: 21 de febrero de 2020]. 


\title{
EL COLOR DEL PATRIMONIO URBANO EDIFICADO. APROXIMACIÓN A SU ESTUDIO
}

\author{
THE COLOUR OF URBAN BUILT HERITAGE. APPROACH TO ITS STUDY \\ Isolina Díaz-Ramos \\ Universidad de Las Palmas de Gran Canaria
}

\begin{abstract}
Resumen
Diferentes enfoques y procedimientos interdisciplinares han sido desarrollados en décadas recientes con el fin de promover la conservación de acabados arquitectónicos. Éstos han sido efectuados empleando una diversidad de métodos y técnicas como la Ciencia del Color, la Architectural Paint Research y Ciencia de la Conservación. Pese a que se han realizado una variedad de propuestas para definir los esquemas de color histórico en los edificios, no existe un marco estándar que aborde el problema de los acabados exteriores. Aún no se ha establecido una base de datos de acabados arquitectónicos históricos que sirva de guía en la toma de decisiones relativa a su conservación. Este artículo pretende mostrar una panorámica de los trabajos realizados dentro de este contexto a fin de contribuir a la unificación de criterios a emplear cuando se trata de recuperar los originales históricos.
\end{abstract}

Palabras clave: métodos y estudio del color, acabados arquitectónicos, paisaje urbano edificado, esquemas cromáticos.

\begin{abstract}
In recent decades, many different and interdisciplinary approaches have been developed to inform procedures in the conservation of architectural finishes. They have been accomplished using a variety of procedures from Colour Science, Architectural Paint Research, and Conservation Science. Despite the fact that many and varied procedures have been performed to define colour schemes in buildings, there's not a standard framework that addresses the problem of exterior façades. No underpinning database of historic architectural finishes has yet been established to guide decision-making in conservation of exterior historic renders. This paper aims to show an overview of works applied in this context in order to contribute to unify work criteria when trying to recover the historic originals.
\end{abstract}

Keywords: methods and colour studies, architectural finishes, built urban landscape, colour schemes. 


\section{INTRODUCCIÓN}

Un rango significativo de colores asociados a países y paisajes forman parte de la memoria colectiva: blancos y azules nos transportan a Grecia y al mediterráneo, rojizos y sienas a ciudades italianas, ocres y pigmentos terrosos a territorios del norte de África, y colores vivos y saturados a Méjico y muchas ciudades localizadas en América del Sur. El color posee, por lo tanto, importancia histórica y arquitectónica, y es esencial en el reconocimiento de un lugar.

Sin embargo, los exteriores polícromos han sido desatendidos en la mayoría de los trabajos de conservación y restauración del patrimonio construido, como si no se tratase un elemento sustancial del edificio. Por ello, la UNESCO (2016) ha identificado recientemente la falta de un sistema científico de principios y prácticas en la preservación del patrimonio urbano y su identidad. Junto al cambio climático, el rápido desarrollo urbano, así como la gentrificación, están generando un impacto negativo en centros históricos de valor excepcional.

Mientras se pasea por nuestros núcleos históricos, se puede apreciar cómo en muchos edificios vernáculos se están reemplazando los morteros de revestimiento y colores originales por cemento Portland, aditivos químicos de factura moderna, y colores acrílico-vinílicos (Aguilar, 2001). Estos nuevos productos son incompatibles con los acabados históricos, y producen la consecuente pérdida de un importante valor patrimonial, como es la autenticidad (International Council on Monuments and Sites, 1994). Retener este valor requiere de un marco de estudio basado en la evidencia y el registro de los acabados arquitectónicos que pueda ser empleado para impulsar prácticas de conservación sostenible y preservar el paisaje urbano original, a menudo obstaculizado por una falta de investigación que establezca la comprensión de la estética histórica.

En este sentido, Díaz-Ramos y Manzano (2019) se encuentran conformando en la actualidad un archivo matérico de revocos históricos pertenecientes a la ciudad de Las Palmas de Gran Canaria. Es esencial en la conservación de la policromía edilicia comprender que los morteros subyacentes, la superficie sobre la que el color se aplica, no puede nunca ser independiente del acabado (Mora y Mora, 1984).

El mayor objetivo de este artículo es mostrar la variedad de métodos y estudios de color aplicados en la superficie arquitectónica mediante una revisión histórica de trabajos de conservación del color de edificios y paisajes históricos urbanos, contribuyendo de esta manera a determinar las diferentes metodologías a aplicar en cada caso de estudio. 


\subsection{ESTRATOS DE SABIDURÍA}

La policromía original que un edificio presenta en el momento de su construcción forma parte de la historia intrínseca del bien y del paisaje histórico. Los morteros de revestimiento sobre los que se aplica la pintura, bien sea realizada al fresco o al seco, han sido aplicados tradicionalmente con el objetivo de proteger y embellecer tanto interiores como exteriores arquitectónicos. Realizados generalmente en una cuidadosa sucesión de pieles constituidas por un revoco grueso, superpuesto en diferentes capas a fin de dejar las superficies rectas y homogéneas; sobre él reposaba una segunda capa más fina, aplicada hasta tres veces. Encima, se llegaban a extender hasta tres manos de mortero de cal sobre el que se procedía a la aplicación final de los pigmentos, con una gama cromática que iba desde ocres, bermellones, azules y sus variantes (Vitruvio, 1987) (Figura 1).

Figura 1. Secuencia estratigráfica localizada en el Templete de Bramante, Roma.

Se aprecia la sucesión de capas de revoco (a y b), una capa de preparación de color blanca (c), y los diferentes estratos de color (1, 2, 3 y 4$)$

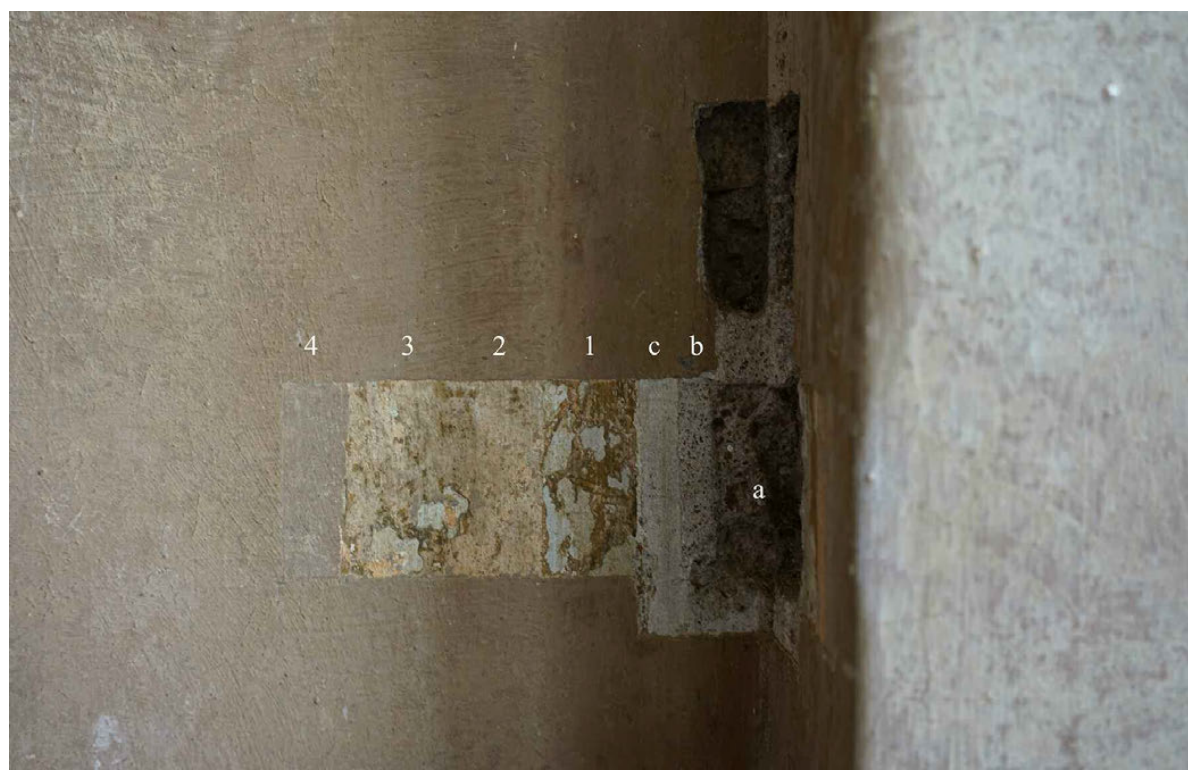

Fuente: Elaboración propia

Sin embargo, estas técnicas y materiales comprobados empíricamente a lo largo de siglos, comenzaron a ser sustituidos de manera paulatina por cementos de mayor dureza, hormigones y plásticos en las pinturas con la lle- 
gada de la Revolución Industrial, lo que propició la producción en masa y generó un cambio de gusto estético. Estos nuevos productos, creados para favorecer la rápida construcción edilicia, especialmente en el período de guerras, conformarán un nuevo tipo de arquitectura y modelo de vida, siendo los adoptados en la mayoría de los aspectos de la construcción y obras de arte modernas.

Esto es perceptible en la actualidad si comparamos los colores y texturas aún existentes en los edificios situados en centros históricos, originariamente pintados a la cal, con las superficies arquitectónicas de obra contemporánea, recubiertas con pinturas sintéticas. En estos últimos, la homogeneidad y regularidad de los muros son percibidos visualmente como «nuevo», a diferencia de la sensación de vejez y estropeado que suele atribuir el hombre moderno a lo heterogéneo de las superficies vernáculas.

De esta manera, los morteros y pinturas plásticas, así como el color de los objetos creados en serie que nos rodean, han generado en la percepción visual del hombre actual una homogeneidad cromática, una reducción tonal a la que nos hemos adaptado hoy en día, desaparecido de nuestro ámbito cotidiano los matices, texturas y variaciones tonales de antaño.

\begin{abstract}
(...), se guardiamo i palazzi delle periferie contemporanee, dipinti con vernici dai leganti sintetici, notiamo che col tempo si insudiciano e si screpolano ma il colore rimane compatto e plastico; al contrario i muri dei centri storici risentono delle condizioni atmosferiche e (...) cominciano a macularsi in modo fascinoso, rivelando un 'interazione dinamica tra la tempera e il ambiente. La differenza tra il disomogeneo del centro storico e lo «sporcato» delle periferie è la differenza che passa tra i concetti di «antico» e di «vecchio». II vecchio presuppone il nuovo, mentre l'antico si confronta solo con l'eternol (Falcinelli, 2017, 28).
\end{abstract}

\title{
2. CIENCIA DEL COLOR, ARCHITECTURAL PAINT RESEARCH Y CIENCIA DE LA CONSERVACIÓN
}

En décadas recientes, se ha realizado desde diversas disciplinas aproximaciones al estudio del color de superficies arquitectónicas a fin de resolver el

1 (...), si observamos los edificios de los suburbios contemporáneos, pintados con pinturas de aglutinantes sintéticos, observamos que con el tiempo se ensucian y se agrietan, pero el color permanece compacto y plástico; por el contrario, las paredes de los centros históricos se ven afectadas por las condiciones meteorológicas y (...) comienzan a mancharse de manera fascinante, revelando una interacción dinámica entre el temple y el medio ambiente. La diferencia entre el desnivel del centro histórico y lo «sucio» de los suburbios es la diferencia entre los conceptos de «viejo» y «antiguo» Lo viejo asume lo nuevo, mientras que lo viejo sólo se compara a lo eterno (traducción de la autora). 
problema de la conservación del color en monumentos, edificios singulares y centros históricos.

Éstos métodos han sido realizados empleando una variedad de procedimientos que van desde la Ciencia del Color (Borrelli, 2017), a la Architectural Paint Research (McDonnel, 2020), basada, al igual que la Ciencia de la Conservación, en la aplicación de métodos científicos de análisis (Matteini y Moles, 2009).

\subsection{LA CIENCIA DEL COLOR}

En este tipo de procedimiento se emplean generalmente instrumentos de medida y precisión del color que van desde colorímetros, que aportan lecturas directas sobre el muro y son traducidas a escalas de color tradicionales como CIELAB, Pantone, etc., hasta métodos visuales de especificación del color, utilizando herramientas como atlas o árboles de colores. La sistematización alfanumérica de un color ha sido realizada en varios países. Así, hoy en día disponemos del Sistema Munsell (americano), Natural Colour System (NCS), modelo sueco, DIN-Farbsystem 6164 (alemán), Optical Society of America Uniform Color Scales (OSA/UCS), y Coloroid System (Hungría). Cada uno de estos atlas de color contienen sus propias guías de uso (Figura 2).

Una gran variedad de trabajos prácticos efectuados con el apoyo en la Ciencia del Color ha sido realizada. En el contexto español, la combinación de investigación histórica junto a técnicas de registro basadas en la observación e interpretación visual ha constituido el método de trabajo aplicado en la inspección de acabados de las puertas de la ciudad amurallada de Córdoba. En este caso, la aplicación de la ciencia del color consistió esencialmente en la identificación y medida del color usando técnicas de raspado y comparación visual a través del uso de dibujos y muestras de referencia. De esta manera las diferentes secuencias estratigráficas fueron identificadas, analizadas y evaluadas (Bermúdez-Coronel y Ruiz, 2000). Similar metodología de trabajo ha sido empleada en la Carrera del Carro en la ciudad de Granada por Armenta (2014).

En el ámbito italiano, trabajos pioneros realizados en su mayoría en la década de los 80 del pasado siglo, han permitido poner en valor el elemento del color en numerosos centros históricos de Italia gracias al trabajo de Giovanni Brino, quien trajo a la luz la coloratura² de la región de la Liguria (1991), el Piemonte (1985), y ciudades como Torino (1987), llegando incluso a ciudades francesas como Marsella (2001).

2 Si bien el diccionario de la RAE define el término coloratura como «un adorno virtuosista en una melodía», este trabajo traslada la misma acepción a la terminología cromática, refiriéndose con este término a la variedad de tonos y matices que puede contener un color. No ha de olvidarse la comparación efectuada por teoría de la estética entre música y pintura. 
Figura 2. Proceso de trabajo de caracterización del color de muestras de mortero empleando el Atlas Munsell

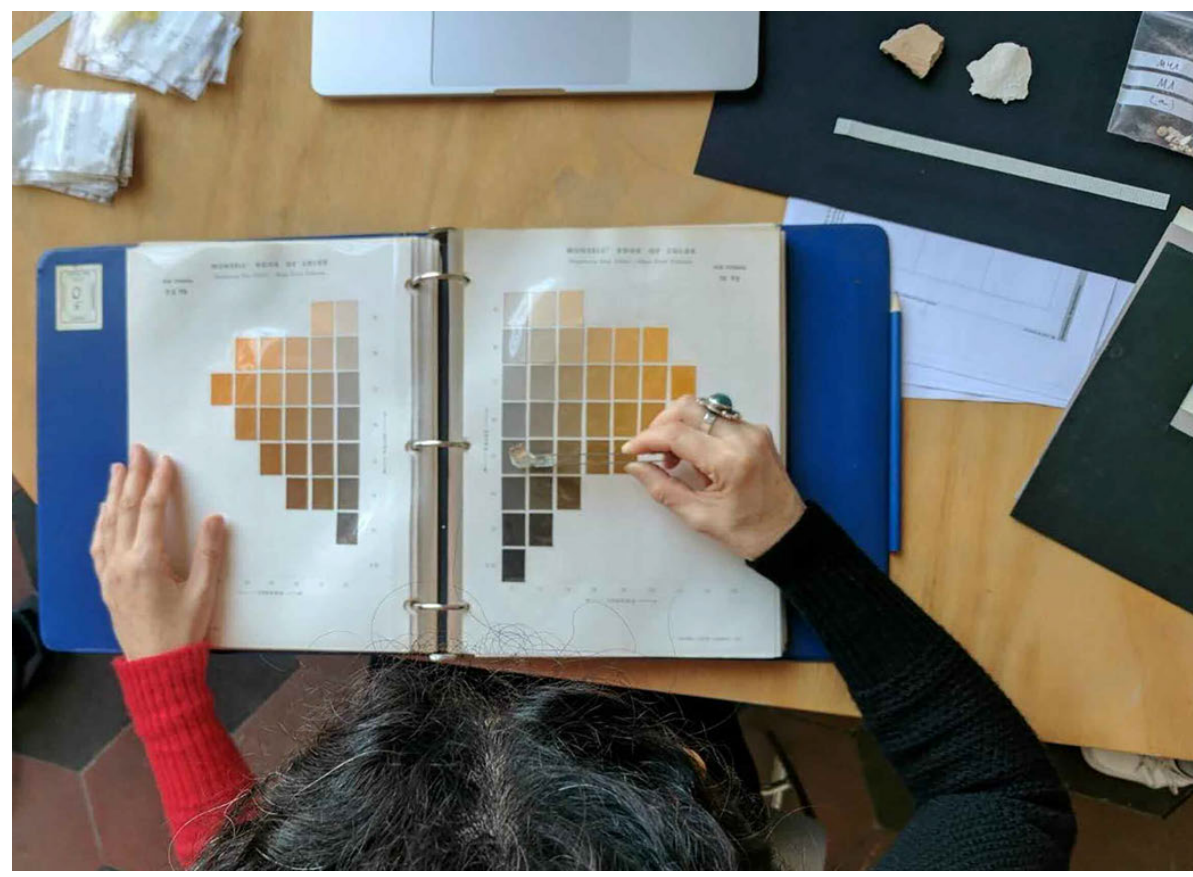

Fuente: Elaboración propia

Por otro lado, el uso de un calorímetro dentro del rango CIELAB ha sido empleado en trabajos de aproximación al color en el centro histórico de La Habana, Cuba, por Alfonso (2006).

A fin de descodificar el código alfanumérico ofrecido por la tabla Munsell y denominar a cada color de una manera determinada, salió a la luz el 'Diccionario del lenguaje universal del color', obra de Kelly \& Judd (1976). Este glosario define y da nombre a cada color de la nomenclatura Munsell.

\subsection{ARCHITECTURAL PAINT RESEARCH (APR)}

La investigación dentro de la Architectural Paint Research (APR), ciencia que desarrolla análisis sistemáticos de acabados arquitectónicos, tiene su foco en el estudio y conservación mayoritariamente de interiores arquitectónicos. Se apoya en el uso de métodos científicos de análisis.

Los escandinavos poseen una extensa experiencia en la investigación y práctica del estudio del color en edificios siguiendo la APR. El Instituto Noruego de Investigación en el Patrimonio Cultural (NIKU), una empresa privada si- 
tuada en Oslo, ha desarrollado numerosos estudios de esquemas cromáticos en edificios siguiendo la APR. Recientemente ha lanzado un software para implementar los datos obtenidos durante la toma de muestras y posteriores análisis, denominado KD Tool (Verweich y Edvarson, 2018). Mediante la realización de secciones transversales de muestras de los materiales que componen los acabados, la APR detecta tanto las capas de color como pigmentos y aglutinantes más significantes. Emplea para tal fin métodos de laboratorio, como la Microscopía Electrónica de Barrido (SEM) y la Microscopía Óptica (Figura 3). Siguiendo esta disciplina, Prime (2011) realiza un meticuloso análisis de secciones transversales con el objetivo de conocer los estratos de color originales de la arquitectura local realizada en madera de Guaymas, al sur de Puerto Rico. Para tal fin empleó, además, la Ciencia del Color, realizando raspados superficiales sobre el muro que permitían efectuar las lecturas visuales.

La APR ha contribuido también en la identificación del color original de la ciudad sueca de Visby. Laserna (2014) complementó en su trabajo, al igual que Prime, la Ciencia del Color junto con análisis de laboratorio.

Los trabajos realizados por estos autores se han limitado al conocimiento de los estratos originales que componen edificios históricos (Prime), y a determinar la edad de los pigmentos y su composición (Laserna), sin desarrollar entendimiento en los sustratos del mortero y/o capas de preparación.

Figura 3. Sección estratigráfica de muestra de revoco de vivienda de Las Palmas de Gran Canaria en la que se pueden apreciar, junto al mortero, hasta veintiún estratos de color

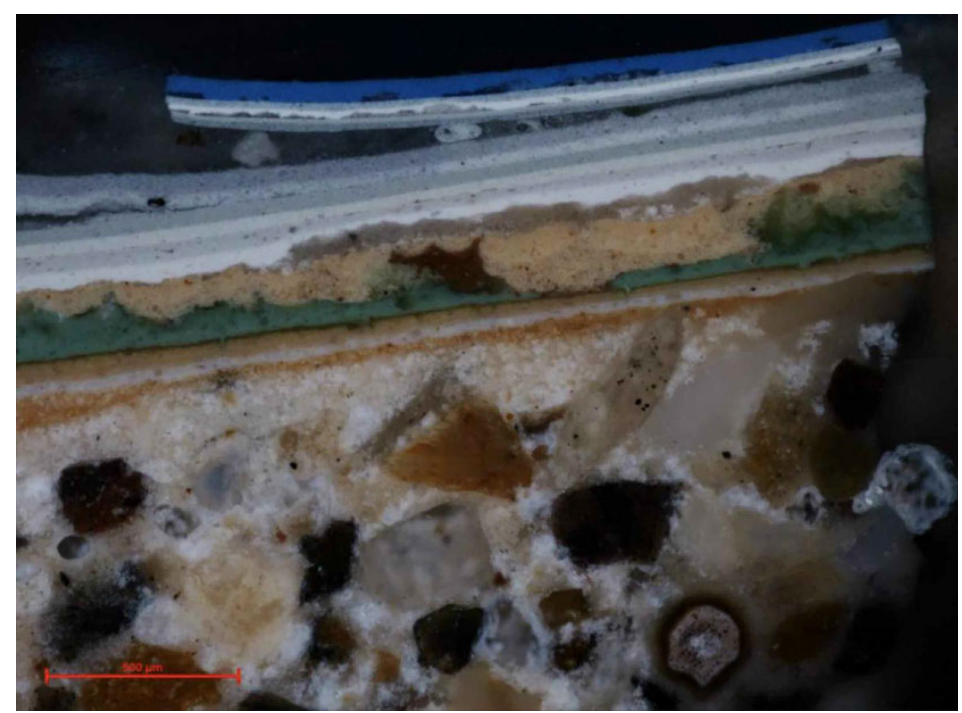

Fuente: Davide Melica (2019) 


\subsection{CIENCIA DE LA CONSERVACIÓN}

El campo de la restauración de la pintura mural ha contribuido a guiar hacia una metodología a aplicar en la conservación y restauración de superficies arquitectónicas (Mora, Mora y Philippot, 1984) (Figura 4).

Trabajos a destacar apoyados en la Ciencia de la Conservación han sido desarrollados en ciudades españolas como Ontiyent (García y Llopis, 2010) y Valencia (García, LLopis, Torres y Villaplana, 2012).

El Laboratorio Nacional de Ingeniería Civil (LNEN) de Portugal, sugiere un estudio integral de los acabados arquitectónicos, comprendiendo los revocos como una sola unidad compuesta por morteros, fijativos, aditivos y pigmentos (Veiga, Aguiar, Silva, y Carvalho, 2001). Proponen, por ello, incluir en los proyectos de investigación, la reproducción de la formulación de los morteros históricos y sus capas polícromas, siguiendo uno de los principios fundamentales de la restauración: el uso de materiales lo más similares al original.

Figura 4. Imagen SEM de mortero de revoco de edificio de Las Palmas de Gran Canaria que muestra el mapa de distribución del calcio (azul), silicio (rojo), aluminio (verde), potasio (celeste) y hierro (naranja)

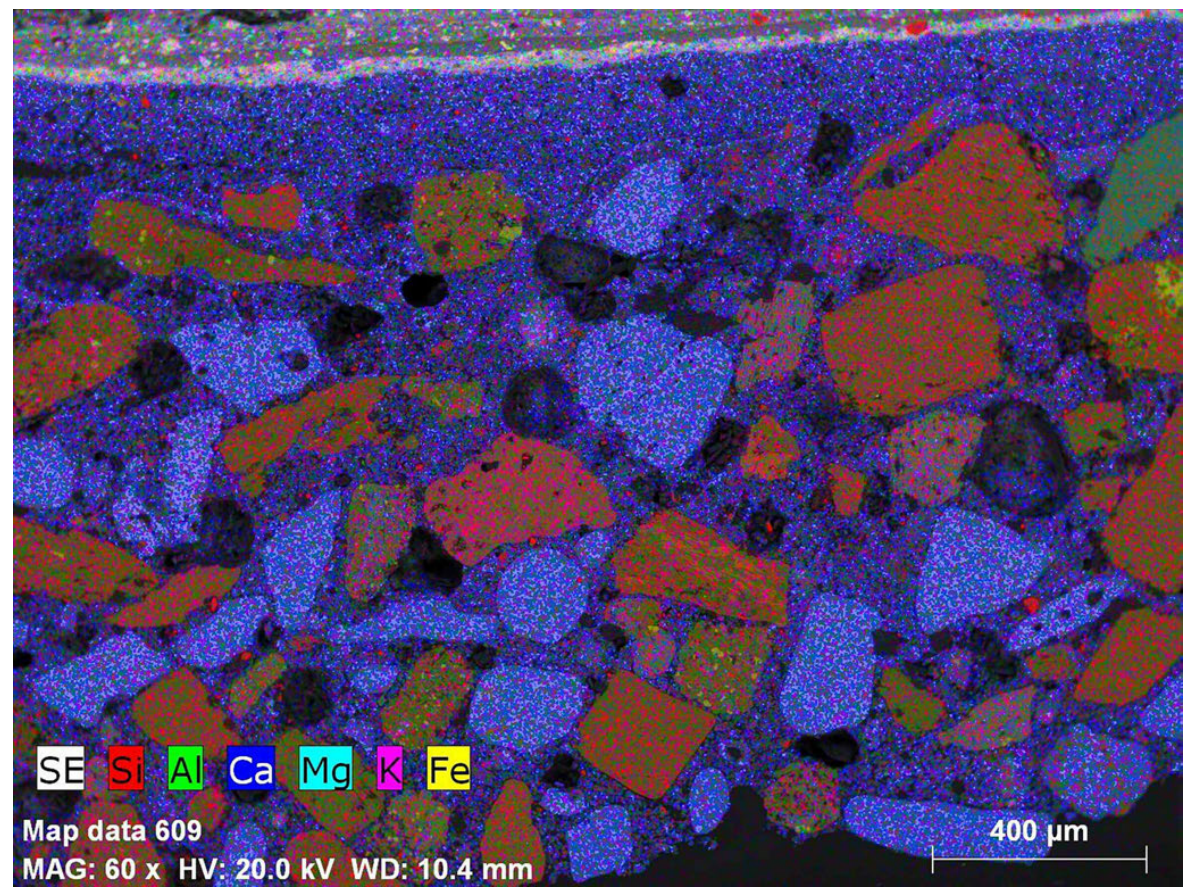

Fuente: Livio Ferrazza (2019) 
Siguiendo este precepto, Collado, Medina y García (2007) investigaron el color de la ciudad española de Granada siguiendo los métodos de análisis descritos en este artículo, pero realizan, además, las réplicas de los morteros y capas de pigmentación de sus resultados. Posteriormente sometieron las probetas realizadas a ensayos de envejecimiento. Se trata de un trabajo integrador de todos los procesos y métodos descritos en este texto.

\section{CONCLUSIONES}

Se ha pretendido en este documento mostrar un abanico de trabajos que han empleado metodologías diferentes para alcanzar un objetivo común: aportar conocimiento en el estudio del color original de edificios incluidos dentro de núcleos históricos que conforman, por ende, el paisaje urbano edificado.

Los métodos visuales de análisis, aquellos apoyados en la Ciencia del Color, contribuyen a la obtención in-situ de manera rápida de unos primeros resultados. Sin embargo, la percepción del color es un juicio totalmente subjetivo, y depende además del grado y tipo de luz que se proyecta sobre el objeto en el momento de realizar las lecturas. Por ello, este método debe concebirse como una primera aproximación al estudio de las capas de color, ya que no suele ofrecer resultados concluyentes.

Algo más compleja resulta la metodología de la Architectural Paint Research, dado que su objetivo primero es el de situar cada estrato de color en su momento histórico. Esto es muy enriquecedor cuando se aplica en el estudio de un edificio o monumento representativo de un lugar. Sin embargo, representa una ardua labor cuando se trabaja con conjuntos arquitectónicos y se pretende conocer el color de un determinado paisaje histórico.

Sin embargo, el empleo de la Ciencia de la Conservación, como las secciones estratigráficas o englobe de muestras en resina a las que se les practica una sección transversal para ser vistas a través de un microscopio óptico, ofrecen datos fehacientes acerca de las capas y estratos tanto del mortero como de la policromía original del bien de estudio.

Como conclusión, la autora considera que los métodos expuestos en el acercamiento al estudio del color son válidos según lo que se desee conocer: la aplicación de la Ciencia del Color resulta muy útil en una primera aproximación, dado que permite ofrecer una idea rápida y aproximada del número de capas y restos de mortero presentes en el bien. Por otro lado, si el estudio a realizar se refiere a un solo edificio histórico o monumento, resulta interesante aplicar la metodología de la Architectural Paint Research, y conocer el momento de aplicación de cada original histórico. Sin embargo, cuando el estudio a efectuar es global y pretende traer a la luz el color del paisaje histórico construido, lo más apropiado sería apoyarse en los métodos científicos de análisis apropiados para tal fin que ofrece la Ciencia de la Conservación. 
La réplica final de los resultados obtenidos contribuye a integrar las disciplinas mencionadas y a ofrecer una visión global del objeto de estudio.

\section{AGRADECIMIENTOS}

La autora desea expresar su agradecimiento a las instituciones que han permitido el inicio y desarrollo de la investigación del color de superficies arquitectónicas: la Real Academia de España en Roma y la Fundación Bogliasco en Génova, Italia. De igual modo, los químicos Livio Ferrazza (Instituto Valenciano de Conservación y Restauración de Bienes Culturales) y Davide Melica (Consulenza e Diagnostica per il Restauro e la Conservaczione in Matera, Italia) han contribuido en la realización de la sección estratigráfica y SEM presentadas en este artículo.

\section{BIBLIOGRAFÍA}

Aguilar, J. (2001). Urban image and historical buildings: Renders and paintings conservation, some theoretical and practical implications. En P. B. Lourenço y P. Roca (Eds.), 3rd International Seminar on Historical Constructions. Guimaraes: University of Minho, pp. 209 - 216.

Alfonso, A. (2006). Evolución de teorías y prácticas del color en la arquitectura. Centro de Estudios de la Oficina del Historiador de la Ciudad. La Habana: DeSoft.

Armenta, C. (2014). Estudio del color: Carrera del Darro de Granada. Granada: Universidad de Granada.

Bermúdez-Coronel, F. y Ruiz, M. (2000). Estudio estratigráfico de enlucidos. P H: Boletín del Instituto Andaluz del Patrimonio Histórico, 8 (33), 130 - 133.

Borrelli, E. (2017). La colorimetria: un codice numerico per una memoria del colore e un ausilio tecnico per il lavoro dei restauratori/conservatori. Bollettino ICR. Nuova Serie (34), 3 - 24.

Brino, G. (2001). Marseille et ses quartiers: Couleurs et traditions en architecture. Marseille: Atelier du patrimoine.

Brino, G. (1991). Colore di Liguria: introduzione ad una banca dati sulle facciate dipinte liguri. Genova: SAGEP Editrice.

Brino, G. (1987). Colore e città. I colori di Torino 1801-1863. Milano: Idea Books Edizioni.

Brino, G. (1985). I colori del Piemonte. Contributo alla formazione di una banca dei dati. Torino: Regione Piemonte.

Collado, F., Medina, V. y García, A. (2007). Metodología de estudio cromático de acabados arquitectónicos. Aplicación en la ciudad de Granada. Granada: Universidad de Granada.

Díaz-Ramos, I. y Manzano J. (2019). Sampling cathaloging methodology procedures for the conservation of historical colours in urban landscapes. En 
5th Historic Mortars Conference, pp. 555-564). RILEM's PRO 130. Paris: RILEM Publications S.A.R.L.

Falcinelli, R. (2017). Cromorama. Como il colore ha cambiato il nostro sguardo. Torino: Einaudi.

García, A. y Llopis, J. (2010). Estudio histórico del color del Centro Histórico de Ontiyent. Valencia: Ajuntament d'Ontiyent.

García, A., LLopis, J., Torres, A. y Villaplana, R. (2012). El color de Valencia. El centro histórico. Valencia: Excelentísimo Ayuntamiento de Valencia, Generalitat Valenciana.

International Council on Monuments and Sites (1994). The Nara Document on Authenticity. Nara: UNESCO, ICCROM and ICOMOS.

Kelly, K. y Judd, D. (1976). Color. Universal Language and dictionary of names. Washington: U.S Department of Commerce.

Laserna, M. (2014). Exterior colour schemes of dwellings in the historic centre of Visby 1860-1930: architectural paint research and the preservation of townscape. En L. Nilsen y K. Hinrichs (Eds.), 5th International Architectural Paint Research Conference. Stockholm, Sweden, pp. 58 - 66.

Matteini y Moles (2009). Ciencia y restauración. Donostia: Nerea.

McDonnel, P. (2020). Architectural Paint research and the archaeology of buildings. Archaeological Journal 177:1, 140 - 166.

DOI: 10.1080/00665983.2019.1615748

Mora, P. y Mora, L. (1984). Le superfici architettoniche, materiale e colore. Note ed esperienze per un approccio al problema del restauro. Bollettino d'Arte, Supl. 6, 17-32.

Mora, P. Mora, L. y Philippot, P. (1984). Conservation of wall paintings. London, Boston: Butterworths.

Prime, B. (2011). Exterior Architectural Finishes in Puerto Rico: The Painting traditions of Guayma's Vernacular Architecture. University of Pennsylvania, Philadelphia, PA. Recuperado de https://repository.upenn.edu/do/search/?q=author_Iname\%3A\%22Prime\%22\%20author_fname\%3A\%22Betty $\% 22 \&$ start=0\&context=19929\&facet $=$ [Consulta: 4 de julio de 2018].

United Nations Educational, Scientific and Cultural Organization (2016). Culture Urban Future Summary. France: UNESCO.

Veiga, M., Aguiar, J.; Silva, A. y Carvalho, F. (2001). Methodologies for characterisation and repair of mortars of ancient buildings. En P. B. Lourenço y P. Roca (Eds.), 3rd International Seminar on Historical Constructions. Guimaraes: University of Minho, pp. 353 - 362.

Verweich, E. y Edvarson, D. (2018). Investigating architectural finishes and surfaces: using an on line documentation tool to examine historical colour schemes. En M. Jablonski y K. Travers (Eds.), Macro to Micro: Examining Architectural Finishes. London: Archetype Publications, pp. 181 - 188.

Vitruvio, M. (1987). Los diez libros de la Arquitectura. Barcelona: Alta Fulla. 



\title{
MEMORIA HISTÓRICA, TERRITORIO Y PATRIMONIO. LA LECTURA DE LA LEY DE MEMORIA HISTÓRICA DE ANDALUCÍA EN EL MUNICIPIO DE SEVILLA \\ HISTORICAL MEMORY, TERRITORY AND HERITAGE. REGARDING THE HISTORICAL MEMORY LAW OF ANDALUSIA IN THE SEVILLE MUNICIPALITY \\ Víctor Fernández Salinas \\ Universidad de Sevilla \\ Rocío Silva Pérez \\ Universidad de Sevilla
}

Resumen

Esta comunicación analiza el rango patrimonial y la inserción territorial de nueve Lugares de Memoria Histórica y Democrática de Andalucía en Sevilla (declarados, incoados o propuestos). Para ello se determinarán los claroscuros desde la perspectiva geográfica de la forma con la que se han concebido estos lugares y su proyección espacial. El método del trabajo, extrapolable a otros territorios y ciudades, facilitará un campo de reflexión geográfica poco desarrollado hasta el momento y que puede servir de marco a reivindicaciones sociales urgentes sobre cómo gestionar una memoria que plantea aún graves disensiones políticas locales, autonómicas y nacionales en España.

Palabras clave: Sevilla, Andalucía, Lugares de Memoria Histórica, Lugares de Memoria Democrática, patrimonio.

\begin{abstract}
This paper analyses the heritage range and territorial insertion of nine Historical and Democratic Memory Places of Andalusia in Seville (declared, initiated or proposed). With this topic, lights and shadows will be determined from the geographical perspective about the way in which these places are conceived and their spatial projection. The method of work, extrapolated to other territories and cities, will facilitate a field of geographical reflection underdeveloped until today. It can serve as a framework for urgent social demands on how to manage a memory that still raises serious local, regional and national political dissensions in Spain.
\end{abstract}

Keywords: Seville, Andalusia, Historical Memory Places, Democratic Memory Places, heritage. 


\section{INTRODUCCIÓN}

\subsection{JUSTIFICACIÓN}

La memoria histórica ha sido objeto de creciente reflexión científica en España desde los últimos decenios del siglo xx (Andrés Sanz, 2008) y está muy ligada al espacio en el que se desarrollan los hechos que conmemora; sin embargo, los estudios geográficos para conceptualizar y analizar los lugares a los que hace referencia no son numerosos (García Álvarez, 2009). Esto es especialmente significativo, no solo porque en otros ámbitos ese esfuerzo lleva tiempo siendo objeto de la reflexión geográfica (Foote y Azaryahu, 2007; Hoelscher y Alderman, 2004; Till, 2003) o porque en España el interés por estos lugares lo llevan otros investigadores sociales (Colmeiro, 2005; Ruiz Torres, 2007; Romero García, 2009), sino porque se están desarrollando normativas que, al reivindicar esta memoria, lo hacen a través de la figura de lugares de la memoria histórica (o nombres equiparables) de claro interés geográfico. En este contexto, la aportación de conceptos y métodos con los que entender la inserción territorial de estos lugares y la identificación de las claves para su protección y gestión se entienden como la justificación básica de este artículo.

\subsection{OBJETIVOS, MÉTODO Y FUENTES}

\subsubsection{OBJETIVOS}

En consonancia con los planteamientos antes esbozados, los objetivos del trabajo son:

a) Reflexionar desde la perspectiva espacial y patrimonial sobre los conceptos y figuras relacionados con la memoria histórica.

b) Establecer una metodología básica para el análisis de los lugares de la memoria histórica.

c) Complementando el punto anterior, introducir el concepto de escenario de memoria histórica (en adelante escenario) como marco espacial de entendimiento de los citados lugares.

d) Centrar la reflexión en el caso del municipio de Sevilla.

\subsubsection{MÉTODO}

Para alcanzar los objetivos, se ha partido de una revisión teórica y conceptual de los términos relacionados con el objeto del trabajo (lugares y escenarios de memoria histórica, bienes patrimoniales memorialistas y espíritu de lugar). A continuación, se propone la aproximación al conocimiento del objeto de este trabajo (los lugares de la memoria histórica) en la escala del municipio de Sevilla. Para ello se determinará una mirada conjunta de todos los bienes 
reconocidos atendiendo a su origen, tipo (Tabla 1), contextualización, distribución y tipo de escenarios en los que se insertan (individuales o compartidos).

Tabla 1. Tipología de lugares de memoria histórica

\begin{tabular}{|l|l|}
\hline \multicolumn{2}{|c|}{ Espacios e infraestructuras públicos } \\
\hline Viario urbano & Calles, plazas, avenidas, etc. \\
\hline Dotacionales & Parques, cementerios, canales, etc. \\
\hline \multicolumn{2}{|c|}{ Edificios públicos } \\
\hline Institucionales & Ayuntamientos, diputaciones, gobiernos civiles, etc. \\
\hline Dotacionales genéricos & Hospitales, escuelas, juzgados, etc. \\
\hline Dotacionales de & $\begin{array}{l}\text { Fortalezas, cárceles, comisarías, refugios, cuarteles, fábricas } \\
\text { militares }\end{array}$ \\
\hline \multicolumn{2}{|c|}{ Espacios y edificios privados } \\
\hline Civiles & $\begin{array}{l}\text { Viviendas, sedes institucionales, periódicos, centros de ocio, } \\
\text { empresas, etc. }\end{array}$ \\
\hline Religiosos & Iglesias, residencias conventuales y monásticas, etc. \\
\hline \multicolumn{2}{|c|}{ Otros (cualquier otro escenario no encuadrable en los epígrafes anteriores) } \\
\hline
\end{tabular}

Fuente: Elaboración propia

\subsubsection{FUENTES}

Además de la bibliografía que se relaciona al final del trabajo, hay que citar dos textos legales: el Decreto 264/2001 sobre Creación y Regulación de los Lugares de Memoria Histórica de Andalucía y su Catálogo y la Ley 2/2017 sobre Memoria Histórica y Democrática de Andalucía. También ha sido de interés, entre otros documentos que también se citan al final, el «Informe de seguimiento de las actuaciones en materia de memoria democrática 20172018» de la Consejería de la Presidencia, Administración Local y Memoria Democrática de la Junta de Andalucía (2019). Por su parte, el trabajo de campo ha permitido reconocer in situ las circunstancias actuales por las que pasan los dos casos de estudio, para los que se han recogido materiales fotográficos y descriptivos.

\section{MEMORIA HISTÓRICA, PATRIMONIO Y ESPÍRITU DEL LUGAR}

\subsection{LA MEMORIA HISTÓRICA}

La memoria histórica, sobre todo desde finales del siglo xx, ha devenido un concepto global (Carretero, 2007; Halbwach y Lasén Díaz, 1995), avalado además por resoluciones muy directamente relacionadas con las más altas ins- 
tituciones de rango internacional (resoluciones de las Naciones Unidas sobre los derechos de víctimas de violaciones; sobre impunidad y sobre el derecho a la verdad). La memoria histórica es una reclamación de las bases sociales (asociaciones memorialistas, sindicatos, entidades locales, particulares) que reivindican una relectura de hechos históricos conflictivos sin resolver por el conjunto de la comunidad y que centra su discurso en la reparación y dignificación de las víctimas, normalmente los vencidos y agraviados por los hechos históricos de referencia. La memoria histórica no es, o no es solo, un hecho histórico delimitable en el tiempo y en el espacio, sino un proceso en el que las víctimas y sus familiares y allegados, articulan esa memoria para generar identidad y autoafirmación (Escudero Alday, 2018). Tampoco se puede decir que memoria histórica e historia, por cerca que se encuentren, sean lo mismo. La historia se refiere a hechos del pasado objetivamente probados a través de fuentes fiables; en cambio, la memoria histórica, aunque entronca con la anterior, tiene que ver más con los recuerdos, los sentimientos y las percepciones que con las objetividades científicas; sus bases son más subjetivas y cambiantes y, a diferencia de la historia, la memoria histórica siempre es presente. Ello la acerca más al mundo del patrimonio, tal como este se entiende hoy como proceso de asignación de valores (Manzini, 2011). Pierre Nora (1989) va más allá y entiende por historia una mirada parcial y conflictiva de lo que ya no es; memoria histórica sería un concepto mucho más rico, vivo, mutable y con ritmos alternantes de recuperación y olvido. La historia, con sus acuerdos y disensiones sociales, es de todos; la memoria es propia de un grupo, de sus reivindicaciones, afectos e identidades y, en el proceso de hacerla asertiva y universal, a menudo se vuelve difícil de gestionar ya que siempre comporta dosis de dolor propio y de incomprensión e ignorancia por parte de los que no empatizan con su mensaje.

\subsection{CONCEPTOS ESPACIALES CLAVE}

\subsubsection{LUGARES DE MEMORIA HISTÓRICA, LUGARES DE MEMORIA HISTÓRICA Y LUGARES DE MEMORIA DEMOCRÁTICA}

No es objeto de esta comunicación realizar una reflexión o aportación general sobre lo que ha significado la memoria histórica, cuestión que desbordaría su objeto, sino centrarse en la proyección espacial de esta memoria desde la perspectiva patrimonial y geográfica. Para ello, es importante definir algunos conceptos. Los lugares de memoria histórica son concebidos aquí como aquellos espacios connotados por un conflicto histórico que ha dejado huellas luctuosas en los habitantes (en todos o en una parte) de un territorio determinado (Icomos, 2017); en otras palabras, son la proyección espacial de dicha memoria. Para evitar confusiones, la expresión lugar de memoria histórica se escribe en minúscula en este trabajo cuando se hace referencia al 
concepto de forma genérica (concepto espacial y teórico) y se usará con mayúsculas iniciales cuando se trate de los Lugares de Memoria Histórica de Andalucía creados por el Decreto 264/2011 que les dio carta de naturaleza (concepto normativo).

Para mantener la coherencia con este criterio, también se escribirán con mayúscula los Lugares de Memoria Democrática cuyo inventario fue concebido por la Ley 2/2017 de Memoria Histórica y Democrática de Andalucía (por lo tanto, también concepto normativo).

\subsubsection{ESCENARIOS}

Los lugares de la memoria histórica se suelen identifican de forma segregada, de uno en uno, y, además, desligados de su entorno territorial. Para superar esto, en este trabajo se acuña el concepto de escenario con el objeto de, desde una perspectiva geográfica e integral, contextualizar los bienes memorialistas en el espacio y, en relación con ello, para determinar su tutela y gestión en este marco espacial. Se compone del elemento rememorativo de la memoria propiamente dicho (un inmueble, una pintada, una fosa, etc.) y el ámbito en que este se integra (una plaza, un cementerio, un cruce de caminos, etc.).

Los escenarios expresan la interrelación que existe entre elementos memorialistas y el marco espacial en el que se apoya la memoria. Ello da pie a diferenciar entre escenarios individuales, cuando se corresponden con un único lugar de memoria (por ejemplo, el lugar de apresamiento de activistas maquis en una cueva o una cárcel) o compartidos, cuando en un mismo ámbito coinciden dos lugares de memoria o más (por ejemplo, un área en la que estuvieran cercanos varios cuarteles, lugares utilizados como presidios o plazas en las que se desarrollaron actos violentos); se estaría en ese caso ante que precisarían un entendimiento más profundo, complejo y adecuado.

El escenario de la memoria histórica se acerca al concepto de entorno (como ámbito que protege un bien), pero en este caso adquiere sustancia y significado en sí mismo. Los entornos (al menos los de los bienes de interés cultural españoles; art. 18. de la Ley del Patrimonio Histórico Español, 1985), son inseparables de los bienes a los que protegen; el escenario (un área física, perceptiva y simbólica) completa, redefine y articula el mensaje y símbolo de un lugar de memoria histórica.

\subsection{EL NUEVO PARADIGMA PATRIMONIAL COMO REFERENTE DE LA MEMORIA HISTÓRICA}

Tal y como se ha señalado, a diferencia de la historia, la memoria histórica siempre es presente y ello la acerca a los conceptos de patrimonio y patrimonialización; que son entendidos actualmente como los elementos materiales e inmateriales a los que se les han asignados valores (patrimonio) y el 
proceso de esta asignación (patrimonialización). Los valores pueden ser de carácter identitario, de abajo arriba, e institucionales, de arriba abajo (Silva Pérez y Fernández Salinas, 2017). Pero en ese entendimiento actual del patrimonio la memoria histórica posee matices propios y distintivos por el peso que en ella tiene el abajo, la sociedad civil, contrariamente a lo que acontece en los reconocimientos patrimoniales convencionales, en los que el predominio recae en el arriba: las declaraciones institucionales. Ello dota a la memoria histórica de una especificidad en el mundo del patrimonio no exenta de contradicciones, ya que a menudo la patrimonialización de esta memoria, aunque el valor venga desde abajo, se reconoce (mediante leyes patrimoniales o similares) desde arriba.

La patrimonialización de la memoria histórica desde la sociedad civil está indisolublemente ligada a la manera variada y distinta con la que las distintas culturas entienden los duelos y la forma de superarlos y, dentro de una misma cultura, a la percepción diferenciada del hecho luctuoso por colectivos sociales y políticos. Esa condición poliédrica de la memoria histórica y de los procesos de patrimonialización que la promueven está siempre ligada, trátese de testimonios materiales o inmateriales, a espacios concretos; ello dota a esta memoria de una marcada espacialidad. El patrimonio como identidad compartida, y no solo el de la memoria histórica, cuando se crea desde abajo no siempre se concreta en objetos o símbolos tangibles, pero siempre se ancla a un espacio, fuera del cual es difícilmente comprensible. Hay un remedo de los sanfermines en Petersburg, Estados Unidos, pero nunca serán los sanfermines de Pamplona por mucho que imiten ritos y formas. Con la memoria histórica sucede algo similar, ya que también está amarrada a los sitios (cuarteles, tapias de cementerios, fosas, etc.) y a los hechos concretos que conmemoran (reclusiones, fusilamientos, torturas, etc.); pero los hechos rememorados (la memoria) se mantiene (se aspira a que se perpetúe) al tiempo que los espacios cambian. La relación espacio-tiempo en cuestión de memoria histórica es dialéctica y cambiante, particularmente en lo que tiene que ver con el espacio, en tanto que ente esencialmente dinámico y refractario a la fosilización.

El encadenamiento entre espacio e historia tiene ya una larga trayectoria en el mundo del patrimonio, pero desde ese campo no se ha acometido en toda su complejidad la dimensión espacial de los bienes patrimoniales, tampoco en el caso de los denominados sitios históricos (Hernando González, 2009). Existe una carta internacional, la de los Jardines [y Sitios Históricos] de Icomos (1981), pero en ella la relación entre memoria histórica y estos sitios no es objeto de referencias específicas. No obstante, la definición de sitio histórico de esta carta es bastante esclarecedora: «Un sitio histórico es un paisaje específico asociado a un hecho memorable como, por ejemplo, un suceso histórico importante, el origen de un mito famoso, de un combate épico o el motivo de un cuadro celebre» (art. . $^{\circ}$ ). Dejando al margen la idea de paisaje, que vendría a complicar de forma innecesaria en este punto la aclaración de la 
relación entre memoria y espacio, parece obvio que los hechos de la memoria histórica pueden ser conceptuados como sucesos históricos. Pero la memoria histórica entendida como bien patrimonial lleva implícita una peculiar espacialidad aún pendiente de definir en toda su especificidad y para la que el legado de la historia y la praxis del patrimonio se revelan insuficientes. La geografía tiene mucho que decir a este respecto.

\subsection{MEMORIA HISTÓRICA Y ESPÍRITU DEL LUGAR}

En una concepción cercana al proyecto de Pierre Nora (1997), la memoria histórica apila hechos y, en consecuencia, sus lugares de referencia. Estos, recordados $u$ olvidados por una sociedad y, a menudo, como heridas mal cicatrizadas, adquieren periódica o esporádicamente nuevos significados y crean no pocos conflictos en su entendimiento, aceptación y reposición. Los lugares de memoria histórica tienen, cuando poseen reconocimiento legal, un marchamo que trata de objetivar sus valores y condiciones de tutela, pero estos valores no son fáciles de proyectar en el espacio. El concepto de espíritu del lugar puede ayudar. Concretado en una declaración del Icomos (2008), esta figura aporta un enfoque que encaja con las claves de la memoria histórica, en las que los aspectos no tangibles asociados a hechos históricos que han dejado escasa huella en el espacio (aunque no siempre) son fundamentales para entender mejor unos hechos cuya memoria debe ser conservada con unas claves que no son las habituales en el resto del patrimonio.

Se entiende por espíritu del lugar: [...] el conjunto de los elementos materiales (sitios, paisajes, construcciones, objetos) e inmateriales (memorias, relatos, ritos, festivales, conocimientos), físicos y espirituales que dan sentido, valor, emoción y misterio al lugar (Icomos, 2008).

Tómese nota de que las dos primeras referencias que la declaración destaca entre los elementos inmateriales son las memorias y los relatos, dos aspectos que entroncan directamente con la memoria histórica y que complementan la mirada espiritual que proporciona sentido, valor y emoción a estos lugares. En el mundo del patrimonio, existen publicaciones que aplican este concepto aún joven a determinados bienes patrimoniales (Cahn, 2008; Tseng, Chen y Hsu, 2013), pero es prácticamente inexistente la producción que lo relaciona con lugares de memoria histórica (Montrusque-Bisso, 2016) y, cuando surge, es para alertar de su manipulación (Roigé, 2016), ya que el espíritu de los lugares de la memoria histórica precisa de escenarios, pero nunca de reconstrucciones temáticas.

\section{LA MEMORIA HISTÓRICA EN EL MUNICIPIO DE SEVILLA}

El reconocimiento oficial de la memoria histórica en Sevilla es corto en número de lugares, aunque complejo en su comprensión (Tabla 2). 
Tabla 2. Lugares de Memoria Histórica y Democrática de Sevilla

\begin{tabular}{|c|c|}
\hline Base legal o documental & Lugar \\
\hline \multirow{4}{*}{$\begin{array}{l}\text { Lugares de Memoria Histórica de } \\
\text { Andalucía (Decreto 264/2011) }\end{array}$} & Antigua Cárcel de Ranilla \\
\hline & Antigua Comisaria de Investigación y Vigilancia \\
\hline & Lugar del fusilamiento de Blas Infante \\
\hline & Canal de los Presos \\
\hline \multirow{3}{*}{$\begin{array}{l}\text { Lugares de Memoria Democrática de } \\
\text { Andalucía } \\
\text { (Ley 2/2017) }\end{array}$} & Jefatura Superior de Policía de la Gavidia (incoado) \\
\hline & Cuartel o Capitanía General de la Gavidia (incoado) \\
\hline & $\begin{array}{l}\text { Lugar del asesinato de Francisco Rodríguez } \\
\text { Ledesma (incoado) }\end{array}$ \\
\hline \multirow{2}{*}{$\begin{array}{l}\text { Lugares de Memoria Democrática de } \\
\text { Andalucía («Informe de Seguimiento } \\
\text { de las Actuaciones en Materia de } \\
\text { Memoria Histórica 2017-2018») }\end{array}$} & Fosas del cementerio de San Fernando (propuesto) \\
\hline & $\begin{array}{l}\text { Pintada del Movimiento Homosexual de Acción } \\
\text { Revolucionaria en los Juzgados del Prado de San } \\
\text { Sebastián (propuesto) }\end{array}$ \\
\hline
\end{tabular}

Fuente: Elaboración propia a partir de los documentos citados

Todos los lugares se proyectan en el espacio de manera puntual, con la excepción del caso particular de las fosas del cementerio de San Fernando, que es una pieza urbana de casi 28 ha; si bien las fosas ocupan una extensión mucho menor. Otra salvedad viene impuesta por el canal de los Presos, que más que un lugar es una sucesión de espacios articulados por el canal de irrigación construido por reclusos que, a cambio de su trabajo, redimían su condena. Posee una estructura lineal irregular que atraviesa el sector oriental y suroriental del municipio de Sevilla (aparte de otros del Bajo Guadalquivir). En cuanto a los hechos históricos con los que se relacionan estos nueve Lugares, una buena parte está vinculada al golpe militar o sus meses posteriores (cuatro); dos con el franquismo; dos con la transición y uno que abarca los períodos de la Guerra Civil y el franquismo.

Específicamente y diferenciando entre Lugares de Memoria Histórica, Lugares de Memoria Democrática y propuestas del «Informe de seguimiento de las actuaciones en materia de memoria histórica 2017-2018», los primeros (Decreto 264/2011) son cuatro y con gran dispersión (Figura 1): Comisaría de Investigación y Vigilancia (centro), lugar de fusilamiento de Blas Infante (periferia noroeste), cárcel de Ranilla (Nervión) y el canal de Los Presos (sector oriental y suroriental del municipio de Sevilla). 


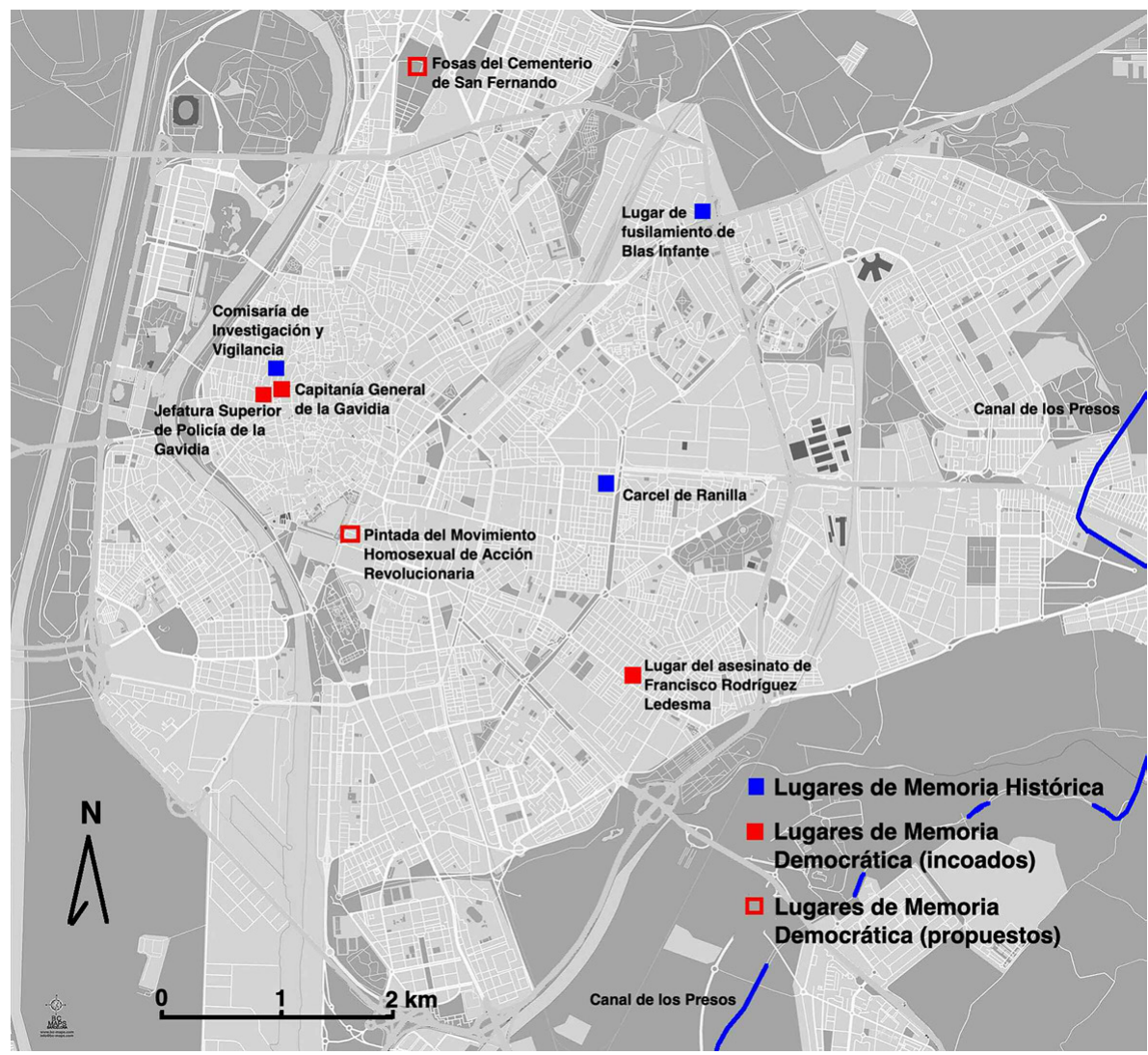

Fuente: Elaboración propia tomando como base los Mapas Ilustrator de España

Respecto de los Lugares de Memoria Democrática de Andalucía (Ley 2/2017), hay tres lugares incoados, solo uno de ellos ligado al propio levantamiento militar: Capitanía General (centro). Otro se relaciona con la represión franquista ya avanzada la dictadura: la Jefatura Superior de Policía de la Gavidia (en el centro también y muy próximo al anterior) y un tercero conectado con un hecho acaecido durante la transición: el sitio del atentado en el Cerro del Águila contra Francisco Rodríguez Ledesma (tiroteado en julio de 1977 y, como consecuencia de ello, fallecido en enero de 1988).

Existen otros dos lugares en el municipio de Sevilla que, sin haber sido incoados aún (y con la incertidumbre de que lleguen a serlo en un plazo medio) sí fueron incluidos en su día entre las 36 propuestas sociales para su declaración en el citado «Informe de seguimiento de las actuaciones en materia de 
memoria histórica 2017-2018». Se trata, por un lado, de una reivindicación de gran consenso entre las entidades memorialistas: las citadas fosas del cementerio de San Fernando, y, por otro, de una pintada realizada el 24 de junio de 1978, y conservada que es lo verdaderamente significativo, en los bajos de los Juzgados del Prado de San Sebastián por parte del Movimiento Homosexual de Acción Revolucionaria.

En cuanto a la determinación de los escenarios de estos lugares, puede señalarse, a la luz del reconocimiento oficial, que tres de ellos (Capitanía General, Comisaría de Investigación y Vigilancia y Jefatura Superior de Policía de la Gavidia) conforman entre sí un escenario compartido (entorno de las plazas de la Gavidia y del Duque de la Victoria) en el que habría que incluir, al menos, otros dos espacios sin reconocimiento alguno en la actualidad (el antiguo Teatro Variedades y la plaza del Duque de la Victoria; ver más adelante). Los otros seis Lugares, por su modo de insertarse en la ciudad y de interrelacionarse con otros lugares de la memoria, serían escenarios individuales, si bien las fosas del cementerio de San Fernando, por su número, distribución y amplitud de sus recintos requieren un análisis más complejo en este escenario. Tampoco debe pensarse que el antes aludido entorno de las plazas de la Gavidia y del Duque de la Victoria es el único en el municipio de Sevilla. Se ha dejado para publicaciones futuras la presentación y análisis más exhaustivos de estos escenarios compartidos. En todo caso, puede señalarse que, al menos, los entornos de la Plaza Nueva, Triana y las collaciones nororientales del antiguo sector intramuros (Ómnium Sanctórum, San Gil, San Marcos, etc.) conforman otros escenarios compuestos de notable significado memorialista (Ortiz Villalba, 1998).

\section{CONCLUSIONES}

\subsection{RESPECTO A LA RELACIÓN ENTRE MEMORIA HISTÓRICA, PATRIMONIO Y SU ADECUACIÓN AL MARCO LEGAL ANDALUZ}

En los últimos años se ha avanzado en la identificación global de los objetos de la memoria histórica, especialmente respecto a sus lugares. Sin embargo, la relación o puente entre memoria histórica y patrimonio dista de ser madura. Esta relación es todavía, a partir de las publicaciones científicas y ejemplos específicos de activación, difusa, incipiente y sin la profundidad que requeriría. No existen métodos, ni objetivos claros compartidos entre autores $y$, aunque es una reivindicación de las organizaciones memorialistas, aún falta un corpus teórico firme y una praxis exitosa que permitan afirmar que se está produciendo un entendimiento común entre la memoria histórica, incluyendo sus lugares, y el resto de los bienes patrimoniales. Se trata de un esfuerzo que ha de ser acometido de forma simultánea entre aquellos que proponen desde la base social los reconocimientos patrimoniales de esta me- 
moria y los responsables de la tutela patrimonial. Hasta ahora, en comunidades como Andalucía, puede decirse que el mundo de la memoria histórica ha desembarcado en el puerto del patrimonio, pero que también en este puerto no se sabe muy bien (ni tampoco se ha expresado la voluntad firme de hacerlo) cómo operar con estos bienes y convertirlos en bienes de provecho social. Al respecto, en este artículo se han esbozado algunas claves para la interiorización de la memoria histórica en el mundo del patrimonio a través de los procesos de patrimonializacion. También se ha podido profundizar sobre las oportunidades que ofrece el concepto de espíritu del lugar para el análisis y prospectivas de estos espacios. Ello ha permitido recalar en algunas contradicciones resultantes de la difícil conjugación entre patrimonialización de base social (propia de las asociaciones memorialistas) y patrimonialización institucional (inherente a las declaraciones llevadas a cabo por la Administración).

Estos reconocimientos, relativamente recientes en su trayectoria en Andalucía (ni siquiera un decenio), parten de un concepto relacionado con la conmemoración, pero sin tutela patrimonial: Ios Lugares de la Memoria Histórica de Andalucía del Decreto 264/2011; y terminan derivando hacia esa tutela con la creación de los Lugares de Memoria Democrática fruto de Ley de la Memoria Histórica y Democrática de Andalucía 2/2017. Esta deriva, que proviene del mundo de la memoria y no del patrimonio, genera dudas de todo tipo por cuanto que traslada a la administración cultural la responsabilidad de la tutela (aunque sea compartida con las instituciones locales) en unas condiciones lejos del buen entendimiento común entre los lenguajes memorialistas y los patrimonialistas. Más específicamente, sin haber reconvertido aún la cincuentena de Lugares de Memoria Histórica del Decreto 264/2011 y sin haber solucionado el panorama exiguo y desajustado de cuatro lugares de Memoria Democrática declarados, más nueve incoados y uno con la fase previa valorativa concluida. En otras palabras, un pequeño maremágnum que no sería tal si existiera voluntad política de avanzar en estas cuestiones; pero, a la luz del cambio de gobierno en Andalucía a principios de 2019 y de su difícil equilibrio interno, agravado por una actitud abiertamente hostil al desarrollo de la ley entre parte de los que sostienen dicho equilibrio, no parece que se vaya a subvertir esta situación de confusión y estancamiento.

\subsection{RESPECTO A LA METODOLOGÍA PROPUESTA PARA UN MEJOR ENTENDIMIENTO DE LOS LUGARES DE MEMORIA HISTÓRICA Y DEMOCRÁTICA EN SEVILLA}

El estudio de los Lugares de la Memoria Histórica y Democrática en Sevilla muestra de forma nítida las asimetrías en la identificación y asignación de valores a los lugares de la memoria histórica. El impulso que reciben desde abajo y con una visión parcial y simple del territorio (en parte ya adelantada antes), les hace perder el sentido global y unitario y esto no solo respecto a 
los lugares en sí (dispersos y sin conexiones), sino también con los tiempos a los que se refiere esa memoria. El golpe militar y los primeros meses de la rebelión son los que tienen más peso, pero otros períodos pierden consistencia, o ni siquiera existen (por ejemplo, el agitado período de la Sevilla republicana).

Las asimetrías y considerable confusión se corresponden en no poca medida con la responsabilidad de la propia Ley de Memoria Histórica y Democrática en materia de términos y definiciones, que acota las víctimas a aquellas personas que lucharon activamente por los derechos civiles de los andaluces. Quedan pues al margen, al menos sobre el papel, lugares en los que las víctimas no actuaron de esa forma proactiva o, sobre todo, pertenecían a sectores moderados o de derechas (que no siempre significó una actitud antirrepublicana, antidemocrática y, mucho menos, violenta). Los vencedores, que más bien se apropiaron y manipularon los hechos que acompañaron su sufrimiento, resarcieron su memoria en homenajes desde los momentos en los que ganaban los territorios, pero también debe recordarse que la grandeza de la memoria histórica es tratar por igual a quien igualmente sufrió. La injusticia es patentemente mayor en el lado de los vencidos, pero el mejor indicador de la calidad democrática de cualquier movimiento es la forma en que trata a las minorías.

Por otro lado, esta escala general ha permitido avanzar hacia el análisis reticular de estos lugares (lo que podría dar en denominarse red de Los Lugares de la Memoria Histórica y Democrática en Sevilla), a modo de subconjunto o parte integrante de la red más amplia de bienes patrimoniales de la ciudad. Al respecto, en este trabajo se han analizado conjuntamente la inserción territorial y el significado histórico de los nueve Lugares de Memoria Histórica o Democrática (declarados, incoados o en proceso) en el municipio de Sevilla. Su lectura conjunta ha sido un buen ejemplo de las aristas y asimetrías del reconocimiento de los lugares de la memoria histórica, que podría extrapolarse a toda Andalucía: no existe un programa que, ni histórica, ni espacialmente, dé claves para interpretar esta memoria y, menos aún, para tutelarla patrimonialmente de forma unitaria y coherente. Puede decirse de estos lugares que son todos los que están, pero que distan aún mucho ser estar todos los que son. El hecho de que los reconocimientos partan casi siempre de demandas sociales, a menudo de las asociaciones memorialistas, ha producido una mayor presencia ligadas a los sitios donde fueron vejadas, torturadas o asesinadas las víctimas del bando vencido (lugares de reclusión, de fusilamiento, fosas, etc.), pero no tanto donde, esas mismas víctimas, ejercieron su lucha activa para la defensa de sus derechos (ayuntamiento, gobierno civil, plaza de San Marcos, amplios sectores de los barrios de Triana y San Bernardo, etc.). 


\subsection{REFLEXIÓN CONCLUSIVA FINAL}

El reconocimiento patrimonial, como valor que le asigna la sociedad a un hecho o un bien, es una tarea pendiente en Andalucía y Sevilla respecto a su memoria histórica. Se han dado pasos, pero son aún, a pesar de contar con dos leyes (una nacional y otra autonómica), balbuceantes y poco consolidados como expresión de la ausencia de un consenso social mayoritario. En esta situación se impone la necesidad perentoria de identificar los hechos y traerlos al presente sin encono y como pieza clave de la realidad identitaria de un territorio. Se avanza, pero hasta el día en el que esta memoria no sea radicalmente respetada (como por ejemplo a la hora de dar nuevos usos a la Jefatura Superior de Policía de la Gavidia) o en la conformación de espacios que honren desde la dignidad la memoria que connotan (como el lugar del fusilamiento de Blas Infante), no se podrá decir, no solo que la sociedad española, andaluza y sevillana han madurado de forma adecuada, sino que por fin se han reconciliado con esa imagen que se reflejaba en el espejo de su carácter y espíritu que no terminaba de gustar y de ser aceptada por todos.

\section{REFERENCIAS}

Andrés Sanz, J. de (2008). Nacionalismo español y lugares de memoria. En C. Taibo Arias (Dir), Esencias, memorias e instituciones, pp. 291-306. Madrid: Los libros de La Catarata.

Cahn, A. L. (2008). El espíritu del lugar en las Cañadas Reales de la Corona de Castilla. Revista de Urbanismo, 19, 1-13 (en línea). Recuperado de: https://iamr.uchile.cl/index.php/RU/article/view/238/205 [Consulta el 23 de enero de 2020]

Carretero, M. (2007). La construcción de la memoria histórica en un mundo global. Buenos Aires: Paidós.

Colmeiro, J. F. (2005). Memoria histórica e identidad cultural: De la postguerra a la postmodernidad. Rubí (Barcelona): Anthoropos.

Consejería de la Presidencia, Administración Local y Memoria Democrática (2019). Informe de seguimiento de las actuaciones en materia de memoria histórica 2017-2018. Sevilla: Junta de Andalucía. Recuperado de:

https://www.juntadeandalucia.es/export/drupaljda/INFORME_SEGUIMIENTO_actuaciones_MD_2017-2018-.pdf [Consulta 22 de diciembre de 2019]

Escudero Alday, R. (2018). Memoria histórica e imperio de la ley: el poder judicial ante el derecho a la reparación de las víctimas del franquismo. Derechos y Libertades: Revista de Filosofía del Derecho y Derechos Humanos, 38, 73-105. Recuperado de https://doi.org/10.14679/1057

Foote, K. y Azaryahu, M. (2007). Toward a geography of memory: Geographical dimensions of public memory and commemoration. Journal of Political and Military Sociology, 35 (1), 125-144. 
García Álvarez, J. (2009). Lugares, paisajes y políticas de memoria histórica: Una lectura geográfica. Boletín de la Asociación de Geógrafos Españoles, 51, 175-202. Recuperado de http://age.ieg.csic.es/boletin/51/08-GARCIA.pdf [Consulta el 22 de diciembre de 2019]

Halbwachs, M. y Lasén Díaz, A. (1995). Memoria colectiva y memoria histórica. Reis. Revista Española de Investigaciones Sociológicas, 69, 209-219.

Hernando González, A. (2009). El patrimonio: Entre la memoria y la identidad de la Modernidad. Revista PH, 70, 88-97. Recuperado de:

https://doi.org/10.33349/2009.70.2753 [Consulta el 21 de marzo de 2019]

Hoelscher, S. y Alderman, D. (2004). Memory and place: Geographies of a critical relationship. Social and Cultural Geographies, 5 (83), 347-355.

Icomos (1981). Carta de los Jardines Históricos (Carta de Florencia). Florencia (Italia): Consejo Internacional de Monumentos y Sitios. Recuperada de: https://www.icomos.org/images/DOCUMENTS/Charters/gardens_sp.pdf [Consulta el 21 de diciembre de 2019]

Icomos (2008). Declaración de Quebec sobre el Espíritu del Lugar. Recuperado de https://icomos.es/wp-content/uploads/2020/01/13.DECLARACIÓNDE-QUEBEC.pdf [Consulta el 21 de noviembre de 2019]

Icomos (2017). Documento orientativo de Icomos acerca de la recuperación y recuperación post trauma para propiedades culturales del Patrimonio Mundial. París: Icomos. Recuperado de:

http://openarchive.icomos.org/1763/34/ICOMOS\%20Guidance\%20on\%20Post\% 20trauma\%20Recovery\%20-\%20Spanish\%20version.pdf [consulta: 13 de diciembre de 2019]

Manzini, L. (2011). El significado cultural del patrimonio. Estudios del patrimonio cultural, 6, 27-42. Recuperado de https://dialnet.unirioja.es/servlet/articulo?codigo=3737646 [Consulta: 22 de marzo de 2020]

Montestruque-Bisso, O. (2016). Memoria y lugar El recuerdo y olvido como forma de conservación de lo inmaterial. Limaq, 2, 143-158.

Nora, P. (1989). Between Memory and History. Les Lieux de Mémoire. Representations, 26, 7-25.

https://www.jstor.org/stable/2928520?seq=1\#page_scan_tab_contents [Consulta: 23 de diciembre de 2019]

Nora, P. (Dir.). (1997). Les lieux de mémoire [1984-1992]. París: Gallimard.

Ortiz Villalba, J. (1998). Sevilla 1936: del golpe militar a la Guerra Civil. Córdoba: Imprenta Vistalegre.

Roigé, X. (2016). De monumentos de piedra a patrimonio inmaterial. Estrategias políticas, museológicas y museográficas de presentación de la memoria. En I. Arrieta Urtizberea (Ed.), Lugares de memoria traumática, pp. 23-47. Bilbao: Universidad del País Vasco. Recuperado de http://www.academia.edu/download/52450124/UHPDF174313.pdf\#page=23 [Consulta: 22 de diciembre de 2019] 
Romero García, E. (2009). Lugares de memoria e itinerarios de la Guerra Civil española. Barcelona: Laertes.

Ruiz Torres, P. (2007). Los discursos de la memoria histórica en España. Hispania Nova: Revista de Historia Contemporánea, 7, 1-30. Recuperado de http://hispanianova.rediris.es/7/dossier/07d001.pdf [Consulta: 23 de enero de 2020]

Silva Pérez, R. y Fernández Salinas, V. (2017). El nuevo paradigma del patrimonio y su consideración con los paisajes: conceptos, métodos y prospectivas. Documents d'Anàlisi Geogràfica, 63 (1), 129-151. Recuperado de: https://doi.org/10.5565/rev/dag.344 [Consulta: 23 de enero de 2020]

Till, K. (2003). Places of memory. En J. Agnew, K. Mitchell y G. Toal (Eds.), A Companion to Political Geography, pp. 290-301. Londres: Blackwell.

Tseng, Y. K., Chen, H. K. y Hsu, P. Y. (2013). The use of digital images recording historical sites and «spirit of place»: A case study of Xuejia Tzu-chi Temple. International Journal of Humanities and Arts Computing, 7, 156-171. 



\title{
LA PRESENCIA DE LOS HORNOS DE CAL EN LA CONFIGURACIÓN DE LOS ESPACIOS URBANOS DE LAS CIUDADES DE CANARIAS
}

\section{THE PRESENCE OF LIME OVENS IN THE CONFIGURATION OF URBAN SPACES IN THE CITIES OF THE CANARY ISLANDS}

\author{
Jorge L. Manzano Cabrera \\ Universidad de Las Palmas de Gran Canaria \\ Francisco M. Mireles Betancor \\ FEDAC-Cabildo de Gran Canaria
}

Resumen

En la década de los años veinte, la iniciativa de inversión privada solicitaba permiso para construir hornos de grandes dimensiones en las ciudades de Canarias y quemar piedras de cal importadas. Áreas urbanas en expansión como Guanarteme, Chile o Las Arenas, tuvieron entre sus edificaciones un tipo de horno diferente, el de reverbero, de carácter industrial proyectados por técnicos como Laureano Arroyo o Cirilo Moreno.

Estos hornos de cal han sido destruidos progresivamente, o integrados, dentro de la trama urbana, en los procesos de expansión urbanística de finales del pasado siglo. De esta manera, los proyectos de arquitectos como Laureano Arroyo o Cirilo Moreno, fueron quedando camuflados y olvidados entre diversas viviendas y edificaciones, o enmarcados como elementos singulares dentro de espacios libres o a lo largo de paseos marítimos.

Esta aportación pretende analizar una tipología de hornos, conocidos como de reverbero, objeto de una fuerte presión urbanística por su entorno. Este patrimonio industrial, integrado dentro de la trama urbana de las ciudades canarias, será analizado mediante investigación histórica, documental y fotos aéreas o planimetrías anteriores y actuales.

Palabras clave: horno reverbero, cal, tejido urbano, presión urbanística, patrimonio industrial.

\section{Abstract}

In the 1920s, the private investment initiative requested permission to build large-scale kilns in the cities of the Canary Islands and burn imported lime stones. Expanding urban areas such as Guanarteme, Chile or Las Arenas, had among their buildings a different type of furnace, the reverberatory furnace which has an industrial character designed by technicians such as Laureano Arroyo or Cirilo Moreno.

These lime kilns have been progressively destroyed or integrated within the urban fabric in the processes of urban expansion in the end of the last century. 
In this way, the projects of architects such as Laureano Arroyo or Cirilo Moreno, were being camouflaged and forgotten among various homes and buildings or framed as singular elements within a free space or along a boardwalk. This study aims to analyse a typology of furnaces, known as reverberatory furnace, subject to strong urban pressure and environment surrounding them. This industrial heritage, integrated into the urban fabric of the Canarian cities, will be analysed through historical, documentary research and aerial photos or previous and current plans.

Keywords: reverberatory furnace, lime kilns, urban fabric, urban pressure, industrial heritage.

\section{INTRODUCCIÓN}

Durante la colonización de las islas y la construcción de las primeras viviendas, ejecutadas con materiales inflamables (Quintana, 2010), ante la necesidad urgente de abrigar a la nueva población, muchas de ellas fueron devastadas por incendios catastróficos, tal como sucedió en la Villa de Arriba de La Laguna (Lobo, 2004). Por ello, las autoridades obligaron a que todas las construcciones se ejecutasen con muros de piedra, barro y mortero (Lobo, 2004). La cal empieza a tener un papel trascendental en las islas, además de para el blanqueo de la azúcar producida en los ingenios, la potabilización del agua, favorecer la descomposición de los cadáveres, etc. (Mireles, 1996), como materia prima de los morteros en las construcciones, enjalbegar los paramentos (Quintana, 2015), por lo que se comienza construir hornos en casi todas las islas, siendo la isla oriental de Fuerteventura, por su producción y calidad, la materia prima de mayor calidad. La cal se elaboraba en caleras o hornos de cal en la propia obra si era de grandes proporciones, otros, próximos a la materia prima (madera o caleras), o a una zona de fácil conexión marítima o terrestre, por lo que, no es de extrañar que la mayoría de los hornos se documenten en la costa (Carta Etnográfica, 2002). Con el paulatino crecimiento de las ciudades, muchos hornos que se encontraban inicialmente en las afueras son invadidos por el crecimiento de la trama urbana, siendo en algunos casos absorbidos por la misma o derruidos hasta su total desaparición. Dentro de las ciudades se desarrollaron hornos de cal que por su tipología se justificaban a las normas municipales del momento', como son los hornos reverberos (V. punto 3.1.1).

Estas construcciones han marcado en muchos lugares de la geografía canaria, topónimos que resaltan la importancia que tuvieron en el desarrollo de las islas y que, en algunos casos, han formado parte del paisaje urbano.

1 ... reúne las circunstancias y detalles necesarios, visto contenido del art 372 de las ordenanzas municipales... (Palmas, agosto de 1900 — Resolución de licencia a favor de D. Pedro Trinidad Martín). 
Sin embargo, se desconoce la totalidad de hornos que hubo en el Archipiélago, y mucho menos sus tipologías, pues a lo largo de estos cinco siglos se han producido transformaciones, así como desapariciones de estructuras debidos al aumento del proceso de urbanización, según crecía la población que daban como resultado construcciones con diferentes características en cada isla.

Este artículo pretende mostrar la situación actual de este elemento patrimonial, su contribución en la construcción de la identidad de las zonas donde se enclavaron, dotándolas de personalidad propia. Analiza, además, el tejido urbano que se ha producido en su entorno a lo largo del tiempo que, en muchos casos, se produce a través de un proceso de fagocitación de la arquitectura de la cal.

\section{METODOLOGÍA}

Los antecedentes bibliográficos de la cal se han circunscrito a referencias históricas, al patrimonio industrial o a fuentes etnográficas (Suárez, 1994; Florido, 1999, 2000; Quintana, 2004; Mireles, 2019), o tipológicas (Manzano y Díaz, 2018). El estudio de los hornos dentro de la trama urbana se inicia a partir de la búsqueda en el Archivo Histórico Provincial de Las Palmas, consultando los documentos referentes a las solicitudes de obras de hornos de cal en la capital de Gran Canaria. En los expedientes consultados se han localizados tres tipologías, siendo los autores principales el arquitecto D. Laureano Arroyo y el ingeniero D. Julián Cirilo Moreno.

Dado el escaso número de elementos localizados en la ciudad de Las Palmas de Gran Canaria y la falta de presencia de los mismos en la actualidad, hemos querido ampliar el estudio de los hornos a través de planos y ortofotos a otras islas, como Tenerife, la Gomera y Fuerteventura, localizados los bienes de estudio usando el servicio de cartografía de Grafcan.

Las fotos aéreas de distintas fechas nos marcaban también el proceso y desarrollo urbanístico de las zonas estudiadas. Las más antiguas localizadas proceden de 1951-1957, donde se pudo hacer la comparativa y el proceso de incorporación de los hornos y su articulación, en algunos casos, en relación a la trama urbana.

Mediante la investigación histórica, documental y la búsqueda de fotos aéreas o planimetrías anteriores y actuales, se ha analizado el desarrollo urbanístico de los hornos de cal en el contexto de la ciudad y su vinculación con el entorno inmediato, así como su afección en el tejido urbano.

\section{HORNOS Y TIPOLOGÍAS}

La mayoría de los hornos del Archipiélago se sitúan aprovechando un promontorio en la orografía con cierto desnivel, generando un espacio en el que se inserta una estructura de forma troncocónica que se abomba en el centro. 
El desnivel asegura la base del horno y permite la subida a la boca de la cámara, en la parte superior, para Ilenarlo de cal y carbón. La falta de este desnivel se solventaba con la ejecución de rampas a base de la acumulación de tierras en sus laterales, modificando el entorno inmediato. La hornilla que da paso a la cámara de combustión se abría en la parte inferior (Manzano, J., Toño y Díaz-Ramos, 2018). Exteriormente los hornos se ejecutaban con muros de mampostería de piedra careada o con muros cajón de piedra y mortero de cal y, el interior, mediante piedra muerta (piedra de molino, tobas volcánicas, etc.). Se cubría con una capa de barro y arena, en unos casos y en otros mediante ladrillos refractarios (idem).

Los hornos se componen de dos elementos principales que son la cuba, generalmente de sección semioval, en su parte superior, donde se cargaba desde su boca las piedras a calcinar y, bajo la cuba, el hogar separado del anterior en algunos por un sistema de perfiles metálicos horizontales que conformaban una parrilla (Suárez, 2018).

\subsection{HORNOS EN GRAN CANARIA}

El desarrollo urbanístico que se produce a principios del siglo XX, genera una mayor demanda de cal que se traduce en la construcción de hornos y la ejecución de nuevos con mayores dimensiones, de planta cuadrangular al exterior, como los de la playa de Arinaga, t.m. Agüimes, con alturas que superan a veces los 10 metros de alto y de largo variable que oscila entre los 5 y 20 metros. El ancho de la boca en la parte superior variaba entre los 3 y 5 metros, y altura de 10 a 15 metros (Suárez, 1994:274). Estos hornos, con tolva de hierro, tenían una mayor producción y capacidad, habilitándose un acceso de tierra para que el camión pudiera cargar en la misma base, próximo a la hornilla. Al proceso expansivo de las nuevas urbanizaciones a finales del pasado siglo $X X$, se une la escasa relevancia y peso específico que ya tenía este sector en la economía canaria en esas fechas, que condujo a la destrucción progresiva de los hornos de cal, reflejada por el profesor Ramón Ojeda en su tesis doctoral, cuando dice que: las industrias tradicionales han sido durante la historia reciente de Gran Canaria actividades complementarias y de carácter minoritario que tenían su desarrollo, como norma general, amparadas en la agricultura y la ganadería (Ramón, 2002:187). Sin embargo, esta actividad tuvo relevancia en siglos pasados por el capital que puso en movimiento al tener un valor estratégico en el conjunto de las economías insulares al ser la base de la transformación del suelo agrícola para convertirlo en regadío. Quintana Andrés documenta que en el primer tercio del siglo XVII se han localizado 72 hornos de cal en la isla (...), destacando los construidos en las zonas de Hornos del Rey en Jinámar, (Telde), la montaña de San Francisco (Las Palmas), barranco de Guadalupe (Moya), los de las Cuevas de Torado, en el barranco de La Ballena, San Cristóbal o Vega de San Lázaro (Las Pal- 
mas de Gran Canaria), Tafira, Bañaderos (Arucas), Valle de Agaete o Barranco de Guía (Quintana, 2015:99).

Actualmente, el inventario patrimonial de FEDAC, Cabildo de Gran Canaria, recoge una totalidad de 41 hornos y 7 canteras de cal, o caleras, existentes en Gran Canaria a inicios del siglo XXI, donde la ubicación de los hornos viene determinada principalmente por:

- La situación de la mayoría de los terrenos calcáreos, que se encuentran en zonas próximas al mar, como sucede en los hornos de Aguadulce, Telde o en El Cabrón, en Agüimes (Ramón, 2002). Otro factor que se encuentra dentro de este punto es la disponibilidad de agua, necesaria para apagarla o matarla para su manipulación.

- La cercanía a las vías de comunicaciones, como a los caminos, para el transporte de la cal hasta los puntos de comercialización o caladeros desde donde se embarcaba a otras islas.

- En obras de gran envergadura, como fue el caso de algunas presas (González, 2020), donde sitúan los hornos próximos a los muros de contención. Como ejemplo está el horno de la presa de Paco Guerra, en el barranco de Los Dolores, en Firgas.

Los hornos que se levantaron en las proximidades de las grandes urbes, como en Las Palmas de Gran Canaria, abastecieron la demanda de la expansión de las ciudades a finales del siglo XIX y primeras décadas del XX, entrarían dentro de este grupo, frente al cuadrante oeste-noroeste de Gran Canaria, con un elevado número de hornos y caleras de extracción, debido a la escasa presión urbanística (Manzano y Mireles, 2017).

\subsubsection{HORNOS DE CAL REVERBERO EN LA CIUDAD DE LAS PALMAS DE GRAN CANARIA}

A principios del siglo XX, debido a la gran demanda dentro de la ciudad de Las Palmas de Gran Canaria, se ejecutaron nuevos hornos, que se situaron, en algunos casos, dentro de las mismas edificaciones y entorno, según se refleja en los expedientes analizados en el A. H. P. L. P. Muchos han desaparecido, otros se pueden encontrar dentro de la trama urbana en parcelas abandonadas con vientres rellenos de escombros, - los hornos del Pepe Conçalvez-, que se encuentra en suelo urbano, y que el P. G. O. U. de las Palmas de Gran Canaria lo contempla como norma de Viviendas en Régimen de Protección (Vp). La producción de cal se vio fuertemente estimulada por la ingente cantidad de obras públicas que se ejecutaban (Florido, 1999:331-332), propiciadas por la construcción del Puerto de Refugio (1883), y por el interés que la burguesía tenía en embellecer el aspecto general que presentaban las calles y barrios, ante el crecimiento urbanístico y poblacional experimentado por la urbe capitalina. El desarrollo de la ciudad se produjo de forma paralela a la inversión de dinero extranjero (Martín, 1995), principalmente inglés y, también a un despegue en las 
relaciones comerciales con otros puertos, donde se instalan hornos en sus proximidades, principalmente en los barrios de Los Arenales y La Isleta, (Florido, 1999), con mayor producción y tipología a los troncocónicos tradicionales.

Durante la Guerra Civil Española y la Segunda Guerra Mundial, un momento donde el país estuvo prácticamente cerrado al comercio internacional, en el periodo de la autarquía (1939-1959), la producción de cal en Canarias repuntó. Esta vez la demanda era interna y el comercio local consumía casi la totalidad de la producción estimulando la instalación de nuevos hornos y la puesta en marcha de los abandonados (Mireles, 2019).

Los que se construyeron dentro de la ciudad se justifica, como se recogen en la memoria de los proyectos de este tipo: menos molestia que una cocina económica, pues produce menos humos que esta y los gases de la combustión salen a bastante altura, la necesaria a impedir que sean aspiradas por los vecinos. El horno está dispuesto de manera que la materia que se quiera calcinar no esté en contacto con el combustible, sino con la llama y gases producidos por la combustión...2.

La siguiente tabla muestra algunas licencias otorgadas por las autoridades de la provincia de Las Palmas para la fundación de hornos de cal. Los procesos fueron acompañados por los dibujos respectivos y por una memoria descriptiva, elaborados por un arquitecto.

Tabla 1. Licencias para la construcción de hornos de cal en Las Palmas de Gran Canaria

\begin{tabular}{|l|l|l|l|l|}
\hline AÑO & $\begin{array}{l}\text { PROPIE- } \\
\text { TARIO }\end{array}$ & \multicolumn{1}{|c|}{ SITUACIÓN } & \multicolumn{1}{|c|}{ EXPEDIENTE } & $\begin{array}{l}\text { ARQUITECTO } \\
\text { / INGENIERO }\end{array}$ \\
\hline 1900 & $\begin{array}{l}\text { Pedro } \\
\text { Mrinidad }\end{array}$ & $\begin{array}{l}\text { Agua Dulce } \\
\text { (Los Arenales) }\end{array}$ & $\begin{array}{l}\text { Relativo a la instalación de un horno } \\
\text { reverbero para la calcinación de calizas } \\
\text { en el patio interior de la casa de D. } \\
\text { Manuel Miranda, sitas en el barrio de los } \\
\text { Arenales por D. Pedro Trinidad Martín. }\end{array}$ & L. Arroyo \\
\hline 1901 & $\begin{array}{l}\text { Bartolomé } \\
\text { Díaz Díaz }\end{array}$ & Camino de Chil & $\begin{array}{l}\text { Instruido a instancia de Don Bartolomé } \\
\text { Diaz y Diaz pidiendo autorización para } \\
\text { la rehabilitar é instalar de nuevo un } \\
\text { horno de cal en el margen izquierdo de } \\
\text { la carretera o camino de Chil. }\end{array}$ & \\
\hline
\end{tabular}

2 Extracto de la Memoria de la Solicitud de licencia Relativo a la instalación de un horno reverbero para la calcinación de calizas en el patio interior de las casas de D. Manuel Miranda, sitas en el barrio de los Arenales por D. Pedro Trinidad Martín AYUNTAMIENTO DE LAS PALMAS, SERIE EDIFICIOS INDUSTRIALES. AÑOS: 1869-1931. No INV:: 6 (Año 1900, Expdte.:91, p.2). 
Tabla 1 (Continuación). Licencias para la construcción de hornos de cal en Las Palmas de Gran Canaria

\begin{tabular}{|l|l|l|l|l|}
\hline AÑO & $\begin{array}{l}\text { PROPIE- } \\
\text { TARIO }\end{array}$ & \multicolumn{1}{|c|}{ SITUACIÓN } & \multicolumn{1}{|c|}{ EXPEDIENTE } & $\begin{array}{l}\text { ARQUITECTO } \\
\text { / INGENIERO }\end{array}$ \\
\hline 1901 & $\begin{array}{l}\text { Francisco } \\
\text { Sepúlveda }\end{array}$ & Venegas & $\begin{array}{l}\text { Sobre instalación de un horno reverbero } \\
\text { para calcinación de calizas, en un solar } \\
\text { en la calle de Venegas por D. Francisco } \\
\text { Sepúlveda. }\end{array}$ & L. Arroyo \\
\hline 1901 & $\begin{array}{l}\text { Pedro } \\
\text { Trinidad } \\
\text { Martín }\end{array}$ & $\begin{array}{l}\text { Prenas } \\
\text { (junto al mar) }\end{array}$ & $\begin{array}{l}\text { Relativo a la instalación de un horno de } \\
\text { reverbero para la calcinación de calizas } \\
\text { en un solar que linda con la playa de los } \\
\text { Arenales de esta ciudad, solicitada por } \\
\text { D. Pedro Trinidad Martin. }\end{array}$ & Lyo \\
\hline 1904 & $\begin{array}{l}\text { Pedro } \\
\text { Trinidad } \\
\text { Martín }\end{array}$ & $\begin{array}{l}\text { Pamochamoso } \\
\text { (Los Arenales) }\end{array}$ & $\begin{array}{l}\text { Relativo a la instalación de un horno de } \\
\text { reverbero para la calcinación de calizas } \\
\text { en un solar que linda con la playa de los } \\
\text { Arenales de esta ciudad, solicitada por } \\
\text { D. Pedro Trinidad Martin. }\end{array}$ & Moreno \\
\hline
\end{tabular}

\section{Fuente: Elaboración propia}

La Figura 1 representa los planos de dos tipos de hornos que se solicitaron licencia. Uno de 1901, situado en el margen izquierdo de la carretera de Chile, en la calle El Horno de Cal y, un segundo de 1904 de características diferentes, ubicado en la zona de los Arenales, entre las calles Pamochamoso y la antigua calle de la Marina, hoy calle de Luis Doreste Silva. En la ortofoto de 19511957 y los fotogramas aéreos de 1951-1957, se ha marcado en azul la situación de los distintos hornos constatados y como el de Pepe Conçalvez quedan vestigios en una parcela dentro del suelo urbano.

\subsubsection{LA AFECCIÓN EN EL TEJIDO URBANO}

La gran diferencia que se ha detectado entre los hornos de la ciudad de Las Palmas de Gran Canaria y el de la mayoría de los documentados en el resto de la Isla, estriba en que los hornos capitalinos quemaban piedras de cal importadas, eran de grandes dimensiones y respondían a la iniciativa de inversión privada, contando por lo general con proyecto y planos elaborados por un ingeniero o arquitecto, frente a los hornos troncocónicos que eran resultado de la experiencia y observación acumulada del aprovechamiento de la población local de un recurso explotado artesanalmente (Manzano y Mireles, 2017:129). 
Figura 1. Planos de los hornos diseñados por Laureano Arroyo y Cirilo, y fotogramas señalizándose la situación de los hornos en la ciudad de Las Palmas de Gran Canaria

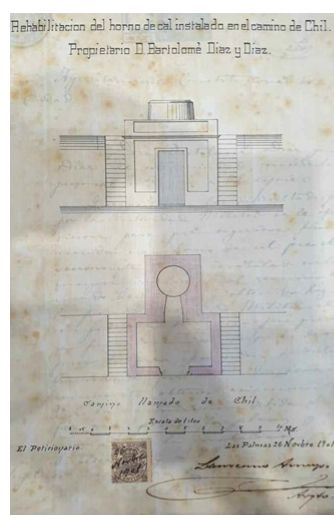

alzado y planta 1901

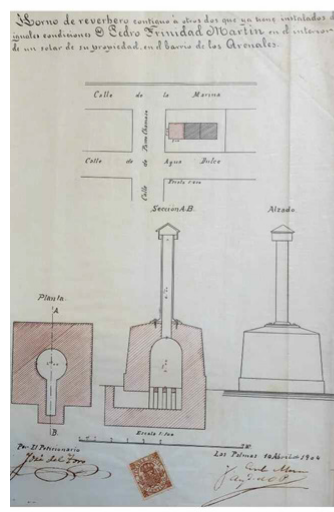

planta, sección y alzado 1904

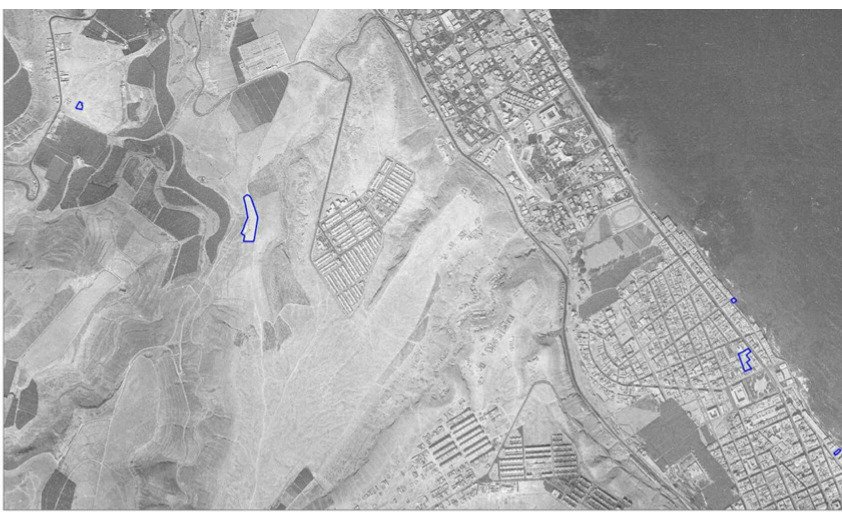

ortofoto $1951-1957$

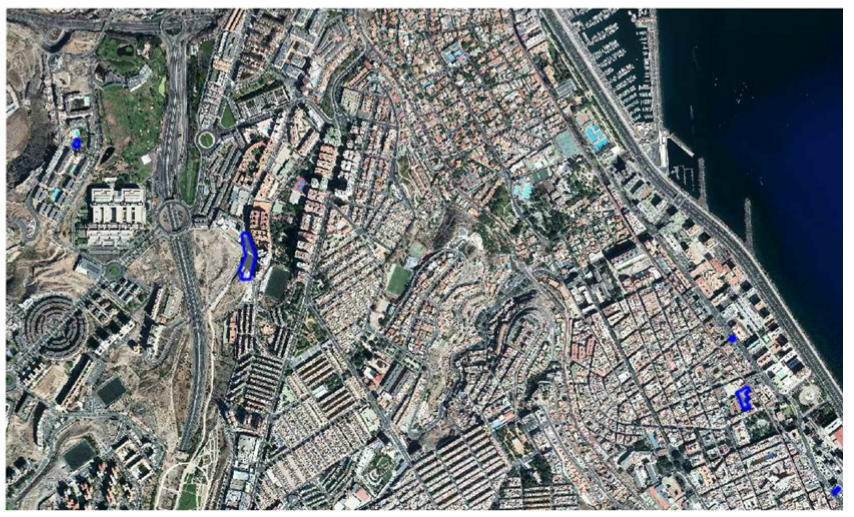

fotograma 2019

Fuente: Grafcan

Estos hornos formaban parte de la trama urbana (Figura 1), pues se diseñaron para estar integrados dentro o anexos a una edificación o vivienda, como se recoge en la memoria y planos de Laureano Arroyo o de Cirilo Moreno.

El horno, por su situación junto a la playa del mar y su especial disposición, en la forma descrita, no puede presentar ninguna de las malas condiciones de los establecimientos clasificados de insalubres, incómodos y peligrosos, porque funciona como una hornilla herméticamente cerrada, sin más comunicación con el exterior, que la chimenea de tiro que conduce los gases y humos a bastante altura y siempre hacia el mar, sea cualquiera el viento reinante... 3 .

3 Extracto de la memoria del proyecto de Laureano Arroyo, julio de 1900. 
La totalidad de estos hornos han desaparecido por la presión urbanística, quedando aún algunos restos como el referido del Pepe Conçalvez que se encuentra a la espera de la formalización las normas urbanísticas para su total destrucción.

\subsection{HORNOS DE CAL DEL PUERTO DE LA CRUZ. TENERIFE}

El conjunto industrial de cuatro hornos de cal e instalaciones anejas, construidos a finales del siglo XX por el maestro albañil Gregorio Barreto, se sitúan en la zona alta del casco urbano de Puerto de la Cruz, en el lugar conocido como Las Cabezas, Declarado B. I. C. en 2009, constituye una referencia histórica y popular reciente del Puerto de la Cruz. Estos hornos, tres mayores se utilizaron para la elaboración de la cal y, el cuarto, más pequeño, para la fabricación del yeso. Además, el conjunto se estructuraba con otros elementos auxiliares que servían de suplemento, tales como tanquillas donde se contenía el agua destinada al apagado de la cal viva; un cobertizo donde se guardaba el carbón para la cocción y otro para almacenar yeso.

Esta agrupación estructural de cuatro hornos, se encontraba completamente presionada por el desarrollo urbanístico de la zona, se ha transformado en un sitio histórico de interés para la población, sirviendo de lugar de esparcimiento, y en una oferta cultural y turística del municipio. La fragilidad de su presencia, estrangulado urbanísticamente por el nudo de tráfico y la construcción de un centro escolar cercano, cuyos escombros habían sepultado prácticamente parte de su superficie, devino en una situación de precariedad y la posibilidad de su desaparición. Con su restauración se ha conseguido recuperar los vestigios culturales de los caminos empedrados, las tanquillas y muros e, igualmente, se han rescatado, mediante anastilosis, los materiales originales. Dentro de la rehabilitación del conjunto se han realizado intervenciones urbanísticas como la creación de un puente peatonal para conectar con la calle Blanco y facilitar el acceso de los visitantes procedentes del centro de la ciudad, así como una empalizada que aísla y protege de la influencia del tráfico rodado en la zona. Contrariamente a lo que se pueda pensar, estos hornos de producción de cal no explotaban ningún yacimiento calcáreo cercano, sino que aprovecharon el auge del transporte marítimo que tuvo el norte de la isla de Tenerife en todos sus enclaves portuarios, donde la carga de lastre de aquellas embarcaciones se trataba de rentabilizar con piedras procedentes de caliches de otras islas, especialmente de Fuerteventura, rica en esta clase de yacimiento. Las piedras de caliche se descargaban en el puerto cuando volvían a cargar productos agrícolas de esta comarca, especialmente del Valle de La Orotava. Esta actividad se prolongaría hasta las primeras décadas del siglo XX, momento en que el cemento industrial se fue imponiendo, después de la Primera Guerra Mundial, como principal aglomerante constructivo, al tiempo que las nuevas embarcaciones dejaban de usar lastre para garantizar su navegabilidad. 

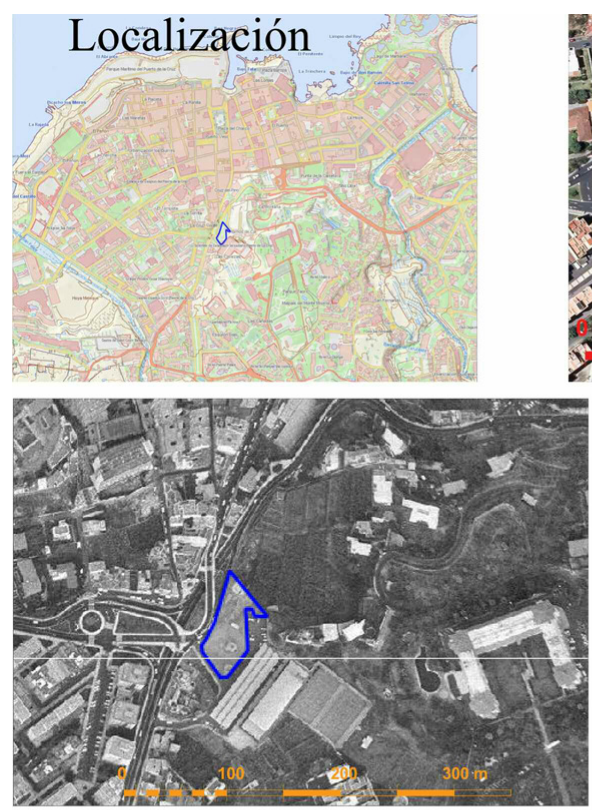

ortofoto año 1987

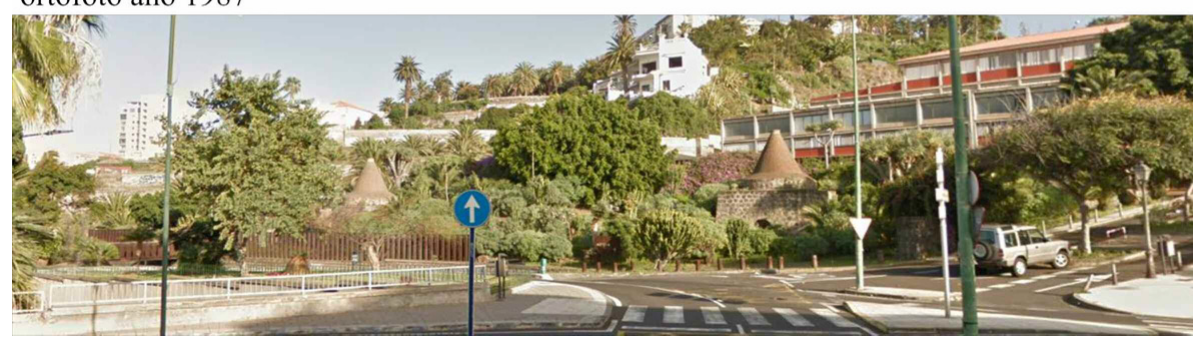

Fuente: Fotografía de los hornos. Grafcan

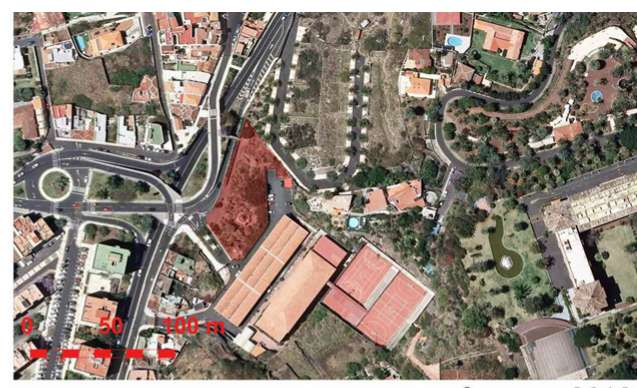

ortofoto año 2019

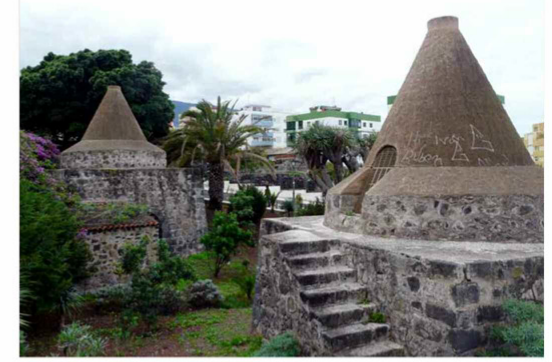

. 
En el año 2014, debido a su estado de deterioro y por los efectos de las lluvias torrenciales, se produjo el desmoronamiento de la esquina de la terraza inferior que da a la vía pública.

Figura 3. Ortofotos del horno de cal de San Sebastián de la Gomera
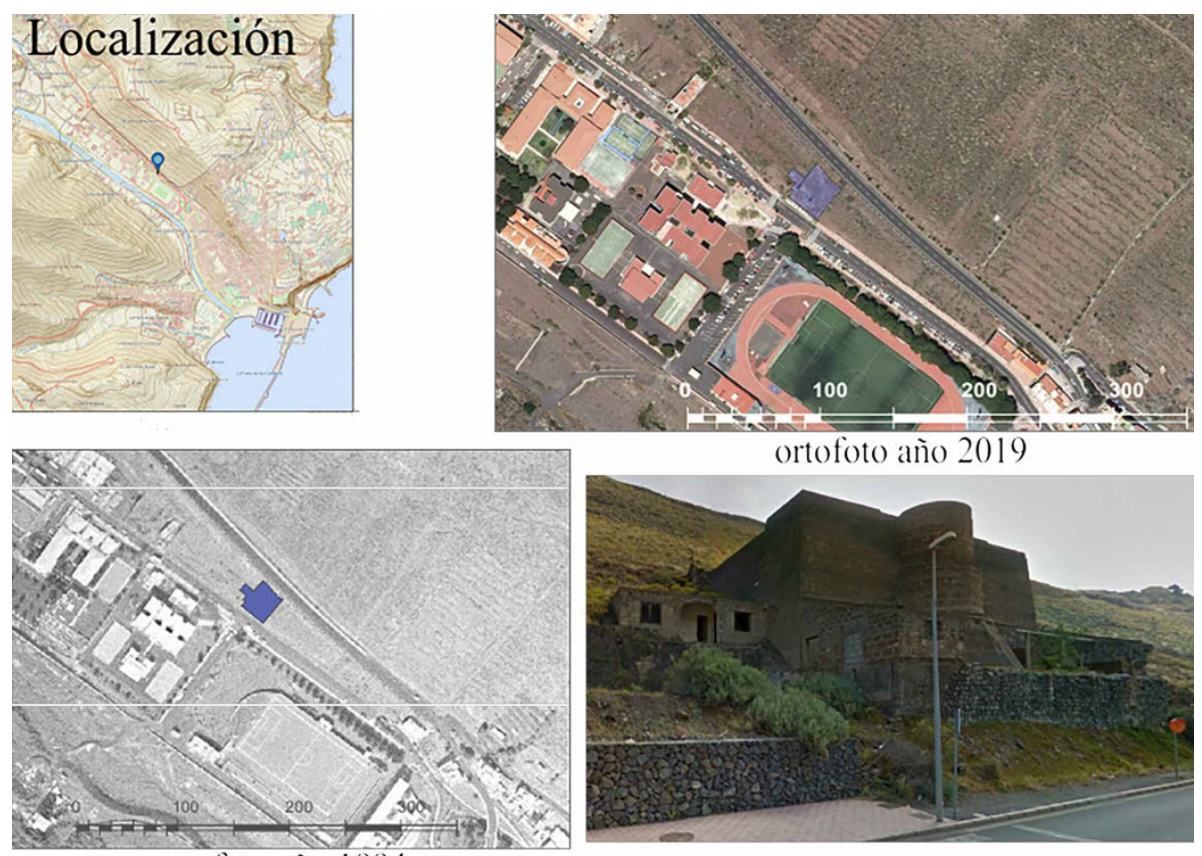

ortofoto ano 2019

ortofoto año 1994

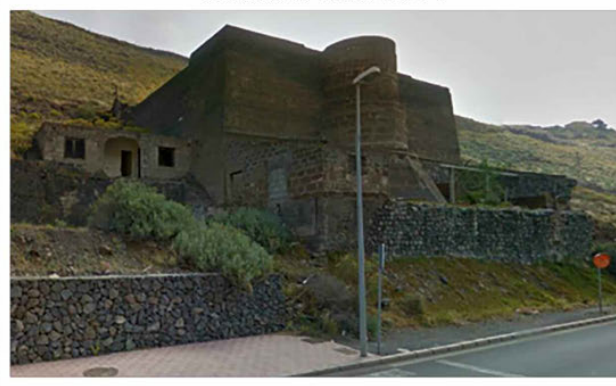

Fuente: Grafcan

Este horno tiene todos los elementos para poder ser un elemento del patrimonio industrial que puede integrarse dentro de la trama urbana, reacondicionando el espacio y poniendo en valor uno de los elementos etnográfico más significativos de la isla de la Gomera.

\subsection{LOS HORNOS DE CAL DE EL CHARCO. PUERTO DEL ROSARIO. FUERTEVENTURA}

Fuerteventura es una de las islas con mayor número de hornos. El inventario supera las 300 unidades, y es, junto con Tenerife, poseedora de un mayor patrimonio industrial asociado a la actividad económica de la cal. El conjunto de hornos de La Guirra, es una agrupación industrial compuesta por tres hornos, un almacén, una caseta-vivienda y un aljibe situado en el término municipal de Antigua, en la denominada Caleta de la Guirra, en la desembocadura del 
Barranco de Miraflor. Ha sido declarado en 1999, Bien de Interés Cultural con categoría de Monumento, así como la unidad de hornos de cal del Puerto del Tostón de El Cotillo, en el municipio de Antigua, también declarados Bien de Interés Cultural, con categoría de Sitio Etnológico, (BIC) en el año 2019. Otros conjuntos, como el del Charco en el municipio del Puerto del Rosario, ha sido objeto de una intervención urbanística, y en la actualidad, la zona recuperada se ha rehabilitado espacialmente, debido a su protección patrimonial, siendo un factor clave para la revitalización comercial, así como un modelo a seguir para revalorización de muchas de las edificaciones históricas existentes en el contexto (Figura 4).

Figura 4. Fotografías aéreas y vista de los hornos del Charco.

\section{Puerto del Rosario. Fuerteventura}

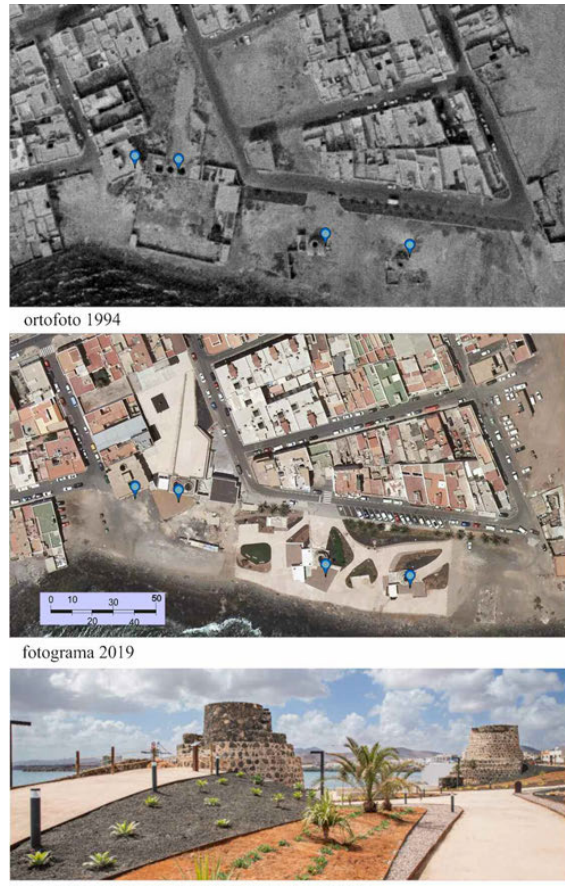

Vista de los hornos. Diario de Fuerteventura. 2019

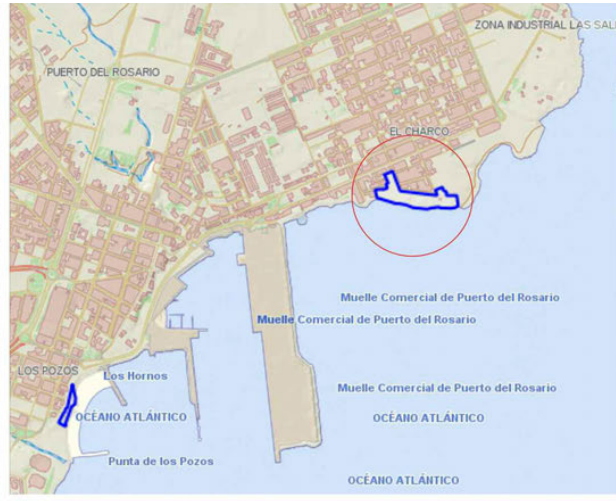

Localización - Puerto del Rosario

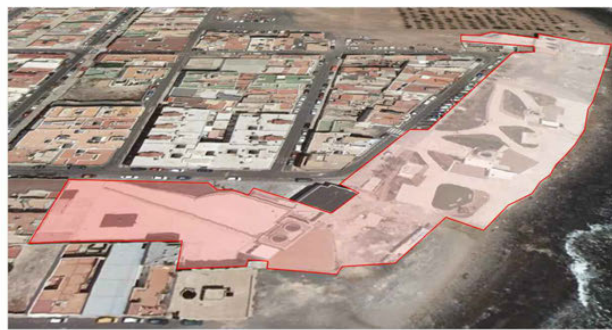

Vista aérea de los hornos. 2019

Fuente: Grafcan

\section{CONCLUSIONES}

El horno reverbero, a diferencia de los troncocónicos tradicionales, es una tipología que aún no ha sido suficientemente estudiada en profundidad, por 
lo que este artículo abre una nueva perspectiva para introducirnos en la vinculación que el patrimonio industrial puede ejercer como factor desencadenante de la recuperación del paisaje urbano en relación a la conformación y entramado urbanístico de las ciudades, así como de la impronta que sobre el tejido urbano puede ejercer en sus múltiples perspectivas.

La revalorización de los hornos, como factor cultural, y el interés que su protección provoca en el entorno poblacional, puede ser un factor coyuntural que genere una modificación sustancial de la trama estructural urbana en el contexto próximo, de tal manera que, estos espacios recuperados redundan en el uso del esparcimiento lúdico y cultural resultante de su restauración e integración paisajística del tejido urbano circundante y, la consiguiente, transformación de su contexto inmediato.

Los nuevos retos que impone la restauración de edificaciones históricas en general, y en el patrimonio industrial en particular, radica en que cada vez más se respetan los materiales y elementos originales en los proyectos de recuperación. Esta realidad obliga a profundizar en la investigación de las industrias que conformaron la base constructiva y, entre otros, de los morteros tradicionales que se emplearon en las edificaciones durante expansión urbanística de las ciudades canarias a finales del siglo XIX y primeras décadas del XX.

Finalmente, hacer hincapié en que la protección de estas industrias ha generado una articulación y tratamiento del entorno inmediato en los contextos urbanos en los que se han integrado a través de proyectos de rehabilitación, como se refleja en las actuaciones que se han realizado en los hornos de Las Cabezas, en Tenerife o en El Charco en la isla de Fuerteventura, o en la intervención del espacio púbico en el paseo de la avenida de Arinaga, Gran Canaria, resultado de una devolución social a través de la transformación en museo y en restaurante del conjunto de estructuras de la cal allí preexistentes.

El estudio de los hornos de cal reverberos (estructura, formación y evolución) abre una nueva vía de investigación en la incidencia social y económica, a través de la conformación del territorio inmediato a este tipo de industrias y su efecto en el urbanismo de algunas zonas de las principales capitales del Archipiélago.

\section{BIBLIOGRAFÍA}

Carta Etnográfica de Gran Canaria, FEDAC, Cabildo de Gran Canaria, (2002). https://cartaetnograficagc.org/.

Florido, A. (2000). El patrimonio arquitectónico industrial en la capital de Gran Canaria: un tesoro por valorar. En XIII Coloquio de Historia Canario-Americana (1998), pp. 2.901-2.910.

Florido, A. (1999). Arqueología industrial en Las Palmas de Gran Canaria. Ediciones del Cabildo de Gran Canaria. 
González, J. (2020). Obras hidráulicas de Gran Canaria. Una colección de poderosas construcciones. Las Palmas de Gran Canaria.

Lobo, M. (2004). Los comienzos de la industria de la cal en Canarias. En Homenaje a Francisco Navarro Artiles, p.p. 273-288. Academia Canaria de la Lengua.

Manzano, J., Toño y Díaz-Ramos, I. (2018). Tres hornos de cal en la isla de Gran Canaria. Tipologías y funcionamiento. En VI Jornadas FICAL, p. 249.

Manzano, J. y Mireles, F. (2017). Incidencias de la cal en el paisaje tradicional de Gran Canaria. EL PAJAR, Cuaderno de Etnografía Canaria, n 32, $121-$ 139.

Martín, J. (1995). Ingeniería en Canarias, 1850-1900: Juan de León y Castillo. En Boletín Millares Carló, n 14, p.p. 88-91. Las Palmas de Gran Canaria: Centro Asociado de la Uned.

Mireles, F. (2019). El ingeniero Juan de León y Castillo y el uso hidráulico de la cal. En IX Jornadas de Cultura del Agua. Casa Museo León y Castillo. Cabildo de Gran Canaria.

[https://jornadasdeculturadelagua.wordpress.com/2012/07/10/el-ingenierojuan-de-leon-y-castillo-y-el-uso-hidraulico-de-la-cal-por-francisco-mirelesbetancor/]

Mireles, F. (1996). En torno a la Cal. Guía Histórico Cultural de Telde, n 8, 43 44. Telde: Ayuntamiento Telde.

Quintana, P. (2015). El hábitat rural en Gran Canaria: una breve aproximación histórica. En Arquitectura y Paisaje. La Arquitectura tradicional en el medio rural de Canarias. Tomo III, pp. 8-293. Tenerife: Rincones del Atlántico, $n^{\circ} 9$.

Quintana, P. (2010). La casa cubierta vegetal en Canarias: tipologías constructivas, uso social y evolución histórica. El Pajar. Cuaderno de Etnografía Canaria, $\mathrm{n}^{\circ} 28,34-41$.

Quintana, P. (2004). La vivienda popular en Canarias durante el Antiguo Régimen. En Revista El Museo Canario, LIX. n 54, 319-315.

Ramón, A. (2002). Carta Etnográfica de Gran Canaria. Tesis doctoral Inédita. Las Palmas de Gran Canaria: Fedac / Cabildo de Gran Canaria.

Suárez, F. (1994). Ingenierías históricas de La Aldea. Las Palmas de Gran Canaria. Las Palmas de Gran Canaria: Cabildo Insular, Servicio Insular de Cultura.

Suárez, F. (2018). Arqueología Industrial en Canarias. Las Palmas de Gran Canaria. Las Palmas de Gran Canaria: Ediciones Cabildo Insular de Gran Canaria. 


\section{LOS MUSEOS COMO ELEMENTOS SOCIALES INTEGRADORES EN EL ENTRAMADO URBANO \\ MUSEUMS AS INTEGRATING SOCIAL ELEMENTS IN URBAN FABRICS \\ Héctor Moreno Mendoza \\ Universidad de Las Palmas de Gran Canaria}

Agustín Santana Talavera

Universidad de La Laguna

\section{Resumen}

Los ecomuseos tienen la función y misión de representar simbólicamente y contribuir a conservar físicamente el medio urbano y natural en el que se integran. Estas instituciones culturales, asumen un rol de actor principal en la implicación social en entramados urbanos, más o menos diseminados, con el objetivo de favorecer la cohesión territorial e identitaria. Se toma como caso de estudio el Proyecto Cultural de Desarrollo Comunitario de La Aldea (Gran Canaria, España), para analizar su grado de implicación en la cohesión intergeneracional, así como las sinergias entre el ecomuseo y diversos sectores económicos. Este trabajo ha tratado también de esclarecer los mecanismos de gestión y niveles de participación-reclutamiento. Metodológicamente, se realizó trabajo de campo con entrevistas, conversaciones informales y observación directa. Los resultados apuntan que partiendo de un modelo de gestión asambleario, se pretende crear una representación fiel (auto-reconocible y ligeramente idealizada) del pasado etnográfico cercano, atractivo para residentes y visitantes, con la visión de perdurar más allá de sus proponentes. Este modelo es tomado como ejemplo para otros lugares que desean incentivar la atracción a un territorio históricamente agrícola, en busca de un impulso económico y una cohesión urbana del territorio.

Palabras clave: ecomuseos, integración social, cohesión urbana, diseminación urbana, implicación social, beneficio socioeconómico.

\section{Abstract}

Ecomuseums have the function and mission of symbolically representing, contributing and physically conserving the urban and natural environment into which they are integrated. These cultural institutions assume a role as main actor in social involvement in urban fabrics, more or less scattered, with the aim of promoting territorial identity and cohesion. The Community Development Cultural Project in La Aldea (Gran Canaria, Spain) is taken as a case study to analyze the integration of citizens in the environment. The Project favors intergenerational cohesion, observing positive synergies between the 
ecomuseum and various economic sectors. This work has also tried to clarify the management mechanisms and levels of participation and recruitment. Methodologically, fieldwork was carried out with interviews, informal conversations and participant observation. The results point out that starting from an assembly management model, the aim is to create a faithful self-recognizable but slightly idealized representation of the near ethnographic past. This representation should be attractive to residents and visitors and give the vision of lasting beyond its proponents. This model is taken as an example for other places that want to exert attraction to a historically agricultural territory, in search of an economic boost and urban cohesion of the territory.

Keywords: ecomuseums, social integration, urban cohesion, urban dissemination, social involvement, socioeconomic benefit.

\section{INTRODUCCIÓN}

Los museos han sido instituciones dinamizadoras de la economía del espacio en el que se asientan, a la vez que han contribuido a la renovación urbana y a políticas de activación de acciones culturales en su entorno. Además, en los últimos años se ha incrementado la oferta cultural, así como la de ocio, existiendo una importante rivalidad entre atractivos para atraer a visitantes. Sin embargo, el interés de un museo no es únicamente para el turismo, sino que la comunidad local se beneficia de los impactos socioeconómicos y socioculturales que genera.

La relación entre museo y ciudad es de hecho un tema de interés general para la comunidad internacional que gestiona el patrimonio. Las ciudades ya no pueden considerarse, en un sentido restrictivo, como lugares donde las expresiones simbólicas de los poderes políticos pueden expandirse, siendo los museos solo una de estas expresiones culturales simbólicas (Vinson, 2006). Los museos juegan también un importante papel en los cambios tanto políticos, como sociales y económicos de las ciudades, de las comunidades de las que forman parte (Visser, 2016). Los museos tienen el potencial de conformar acciones de desarrollo socioeconómico en el entorno donde se asientan, independientemente que sea un hábitat concentrado o disperso. Se escoge como caso de estudio el Proyecto Cultural de Desarrollo Comunitario de La Aldea (Gran Canaria, España). El Proyecto realiza diversas actividades culturales, entre las que destaca la gestión de quince unidades museísticas distribuidas en el municipio. Ese conjunto de museos vivos, se consideran en su totalidad un ecomuseo ya que se orienta a la potenciación de la identidad del territorio, favorece participación de sus habitantes y fue creado para el desarrollo de la comunidad local.

Los ecomuseos son entendidos como un instrumento que el poder político y la población conciben, construyen y explotan conjuntamente; las instala- 
ciones y los recursos están a disposición de la población, según sus aspiraciones, conocimientos e idiosincrasia (Riviere, 1985). Siendo así, el beneficio económico-social de un ecomuseo (museo urbano) depende de la vertebración comunitaria del territorio. El propósito de este trabajo es determinar si existe una relación causal entre el grado de vertebración de la comunidad, el buen funcionamiento (éxito) y la perduración en el tiempo de los ecomuseos pertenecientes al Proyecto Comunitario de La Aldea. Además de ello, se han establecido dos objetivos específicos en el trabajo:

- Objetivo 1: Constatar la afirmación de que los museos son un elemento de dinamización en el espacio/entorno urbano de La Aldea de San Nicolás.

- Objetivo 2: Determinar hasta qué punto la actividad del ecomuseo responde a las necesidades (identitarias, económicas, etc.) de la población de La Aldea de San Nicolás, y ello se relaciona con el éxito percibido de los mismos.

\section{MARCO TEÓRICO}

El patrimonio local es el producto de la transformación histórica de un territorio determinado. Ese patrimonio es conservado y democratizado por los museos, que se han convertido en complejos centros culturales que dan acceso a los ciudadanos (Guitart, 2001). En un museo, es más importante la percepción del visitante sobre el lugar que el objeto en sí mismo. Todo lo que hay en un museo (edificio y contenido-escena) es recreado. El patrimonio es una construcción sociocultural continua, que en todo momento trata de adaptarse a las necesidades de la colectividad. Esa colectividad se asienta en un territorio, independientemente que sea ciudad o rural, pero tiene vinculaciones con el entramado urbano que la acoge.

\subsection{LOS MUSEOS EN EL ENTRAMADO Y COHESIÓN URBANA}

La conservación y promoción patrimonial tienen una lógica influencia en la ubicación de los espacios culturales en el tejido urbano. Además, los museos constituyen símbolos capaces de transformar imaginarios urbanos (Rosas, 2016). Esos imaginarios lo conforman la existencia de un patrimonio diverso y la implicación que los diferentes actores ejercen en la gestión del mismo. Existen nuevas conexiones (ya no sólo el edificio, exposición o programa), entre un museo y la ciudad. Esos vínculos establecen colaboraciones entre la planificación museística y la de la ciudad, haciendo que ésta progrese y generando relaciones creativas (Grewcok, 2012). Esas relaciones en ocasiones dependen de la apertura a la sociedad que tengan las instituciones culturales. Los museos pueden incluir partes de la historia o eventos actuales a menudo marginados, así como cuestionar las actitudes y acciones prevalecientes o existentes relacionadas con estos legados; este cambio es destinado a con- 
vertir el museo en un habilitador, proporcionando al público las herramientas necesarias para tratar los problemas que les afectan personalmente o a las comunidades en las que viven, ofreciendo vías de compromiso con temas complejos y activando políticas y debate social entre la población (Lanz y Montanari, 2014). Ese debate, así como la puesta en común de propuestas, tiene el objetivo de beneficiar a todas las partes interesadas en una mejora socioeconómica en el tejido urbano, participando actores tanto del ámbito público, como del privado, así como el no lucrativo.

\subsection{MUSEOS E IMPLICACIÓN SOCIAL DE LA COMUNIDAD}

El patrimonio no sólo tiene un gran potencial para contribuir al desarrollo de la identidad construida de los ciudadanos, sino que puede jugar un papel fundamental en el descubrimiento de las identidades recibidas de los diferentes colectivos que componen una comunidad (Sanz y Torruella, 2015). Ese patrimonio debe ser conservado y mostrado de un modo legible, además de fomentar acciones dinámicas orientadas a los ciudadanos, a través de la participación. Para ello, los museos tienen la tarea de realizar tales acciones, eliminando las tareas físicas o burocráticas entre el bien y el espectador.

Siempre hay una intervención sobre los bienes patrimoniales, que además son preparados para obtener una comprensión-satisfacción por el visitante. Para vincularlo al territorio debe darse un sentido de comunalidad / identidad de grupo, tanto en la construcción como en la representación. Esa vinculación pasa por la vertebración social, en la que los ciudadanos, independientemente de ideologías políticas o religiosas, se estructuran y organizan conjuntamente para promover cambios, en la búsqueda de un objetivo común.

El ICOM (Consejo Internacional de Museos) se esfuerza por llamar la atención sobre el papel de los museos, cultura y patrimonio cultural en la sociedad moderna ya que hoy en día hay comunidades que creen que pueden desarrollarse sin la conciencia de su patrimonio cultural y el papel de los museos en este proceso (Ognjević, 2017).Ese desarrollo debe ser sostenible, entendido como tal el que perdure en el tiempo, el que se sostenga con el objetivo de atender las necesidades actuales sin poner en peligro el de las generaciones futuras. Ese objetivo pasa tal vez por una gestión responsable de los museos.

\section{CASO DE ESTUdIO Y METODOLOGÍA}

\subsection{CASO DE ESTUDIO}

\subsubsection{EL PROYECTO CULTURAL DE DESARROLLO COMUNITARIO DE LA ALDEA}

EI PDCLA surge en La Aldea de San Nicolás, ubicada al oeste de la isla de Gran Canaria. La población es de 7.504 habitantes (2019). El cultivo del tomate es 
la principal actividad del municipio (Cabildo de Gran Canaria, 2018). El relieve erosionado y abrupto, los numerosos barrancos, un clima seco y un paisaje semiárido, han determinado la proliferación de pequeños núcleos diseminados a lo largo del municipio (López, 2003). Evidentemente la localización territorial ha sido el detonante de la creación del Proyecto Cultural Comunitario (ver Figura 1).

El Proyecto Cultural comienza en 1980 cuando dos maestros, José Pedro Suárez y Lidia Sánchez, deciden incorporar la cultura popular a las actividades del centro educativo en el que trabajaban (Sánchez, Suárez y Moya, 2002).

Esta experiencia didáctica y etnográfica ha sido reconocida por sus valores y por su preocupación por la recuperación y trasmisión del patrimonio inmaterial. La UNESCO (2011) considera patrimonio inmaterial las tradiciones que se transmiten oralmente o mediante gestos, y se modifican con el transcurso del tiempo a través de un proceso de recreación colectiva, siendo cada individuo el portador del patrimonio de su propia comunidad. El Proyecto responde a esta definición, por lo que ha sido considerado por el Comité Científico Internacional de Museos, como «el museo vivo más importante de Europa» (Sánchez y Suárez, 2006).

Son diversas actividades las que conforman el PDCLA: Museos Vivos (con la distribución de los museos en el núcleo del municipio), talleres de artesanía, deportes autóctonos, Jornadas de Folclore, participación en actos populares, etc. Desde su creación, el Proyecto ha ido generando numerosos museos vivos (Anderson, 1982; Naumova, 2015), en los que se puede disfrutar con las tradiciones (ordeñar, arar, trillar, amasar, conocer las tradiciones artesanales, visitar una escuela tradicional, un almacén de tomates acompañado por el capataz, etc).

Comenzaron con La Gañanía, una finca tradicional de principios del siglo XX con estancias originales donde se muestran las formas de vida de la cultura rural, y el Molino de Agua, una edificación de finales de siglo XIX que ha sido reconstruida. A continuación, se incorporaron otros museos con los oficios y actividades del pueblo en el siglo XX: La Tienda, Museo de la Música, Centro Locero, La Barbería, La Escuela, El Almacén de Tomates, La Zapatería, La Medicina Rural, La Carpintería, La Herrería y La Carnicería (Suárez y otros, 2005). Los dos últimos espacios incorporados al Proyecto son el Museo del Pastor (2014) y el Museo de la Vestimenta Tradicional (2016). Se pueden realizar tres visitas diferenciadas: una corta, una media y una larga, dependiendo del tiempo disponible de los visitantes y los espacios que quieran visitar (ver Figura 2). 
Figura 1. Mapa de localización del Proyecto Cultural de La Aldea

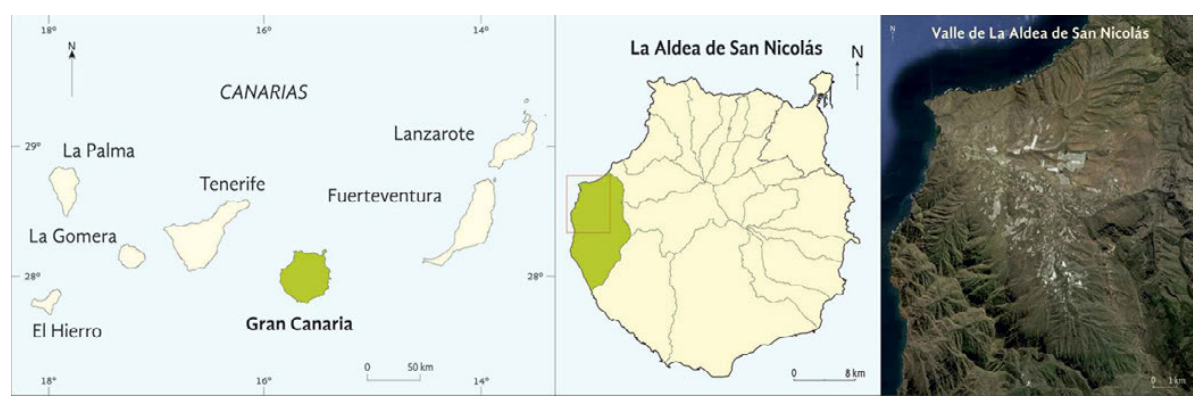

Fuente: Elaboración propia. Google Earth

\subsubsection{ASPECTOS DE GESTIÓN DEL PDCLA}

Los horarios de visita se tienen que concertar con el Proyecto y se programan para un mínimo de 10 personas. El precio de entrada es gratuito. El museo dispone de folletos, paneles, carteles y visitas guiadas. El Proyecto se conforma como una asociación sin ánimo de lucro, dirigido por una asamblea, en la que mediante votación se toman las decisiones. Los ingresos anuales $15.000 €$ (2019) proceden de una subvención de la FEDAC: Fundación para la Etnografía y Desarrollo de la Artesanía Canaria (perteneciente al Cabildo de Gran Canaria), con la que también hay un convenio para pagar alquileres y comida para los animales. En cuanto al personal, el número de implicados directos es de 45 voluntarios.

El Proyecto no dispone de cafetería o restaurante, ni de tienda de souvenirs, ni hay personal contratado. Como principios políticos del Proyecto, nunca se habla de la relación mantenida con los diferentes gobiernos. Se tiene un convenio de colaboración con la Consejería de Educación del Gobierno de Canarias. Con el ayuntamiento local no existe ningún convenio. No hay relación (para toma de decisiones o financiación) con empresas privadas. 
Figura 2. Mapa de localización de los museos del Proyecto

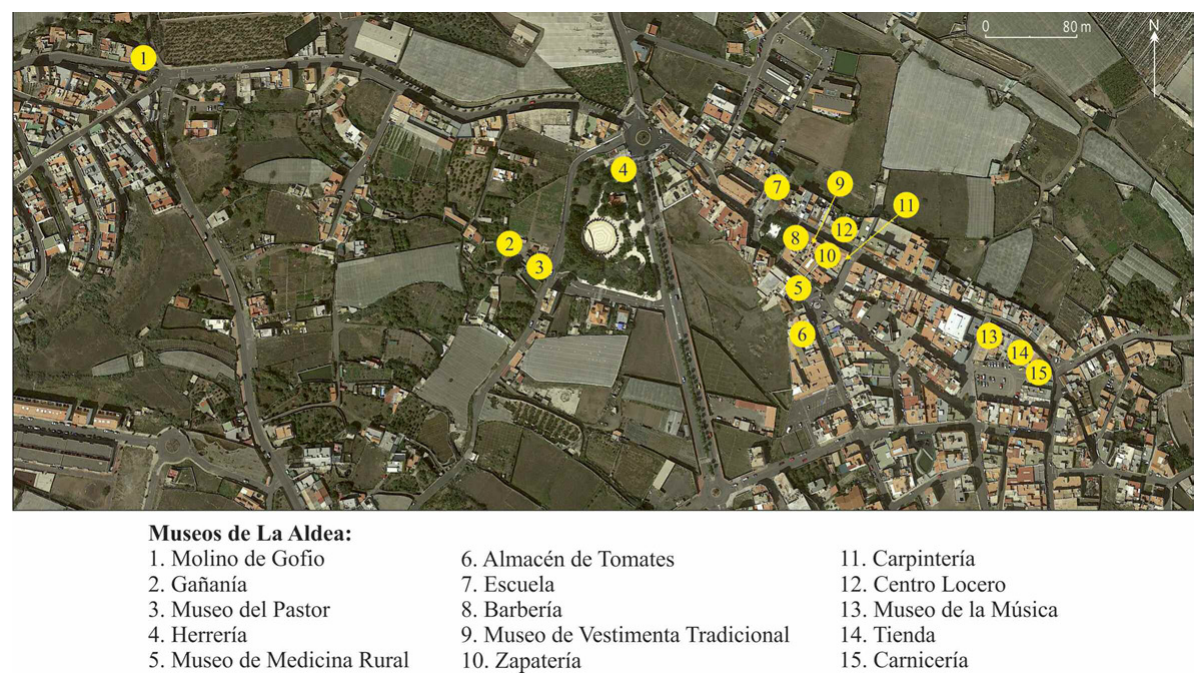

Fuente: Elaboración propia. Base Google Earth

\subsection{METODOLOGÍA}

El propósito de este trabajo es explorar la relación entre la comunidad, el funcionamiento de un museo y sus consecuencias en el entorno urbano. Se ha optado por una estrategia de investigación cualitativa centrada sobre el caso de estudio (Yacuzzi, 2005). Esta perspectiva se aplica mediante el análisis de las respuestas de entrevistas, y contrastando esa información con la obtenida a través de otras técnicas como conversaciones informales y observación directa (Creswell, 2007; Gray, 2014). Para realizar el análisis cualitativo y que este sea efectivo (Gibbs, 2012), la gestión de datos ha sido sistemática.

Partiendo de la afirmación planteada en la introducción de la investigación y los objetivos que la focalizan, se elaboraron tres modelos de entrevistas: un modelo para al director del Proyecto Comunitario (12 preguntas), otro para el cronista de La Aldea de San Nicolás (10 preguntas) y un tercero para varios directores de museos que conocen el Proyecto (8 preguntas), estableciendo una guía semiestructurada con preguntas de interés (función de los museos, cohesión de la comunidad, entorno urbano, acciones culturales, actividades de los ecomuseos, etc.). Las entrevistas tuvieron una duración aproximada preestablecida de 45 minutos. Se llevó a cabo la grabación digital de audio de cada una, para favorecer la interpretación (Yin, 2003).

Además, se llevaron a cabo conversaciones informales con responsables de diversos negocios en el entorno del Proyecto. Las dos cuestiones principales 
tratadas versaron sobre las relaciones que mantiene el Proyecto con el contexto urbano y sobre la sostenibilidad del Proyecto en el tiempo.

La interpretación de los resultados de las entrevistas se realizó mediante un CAQDAS, un software informático para análisis de información cualitativa. usando, concretamente, el programa Nvivo 10.

Se inició la tarea en Nvivo con la importación de la información, a través de elementos internos (entrevistas, notas de conversaciones y notas observacionales). A continuación, se realizó la codificación (reunir material por temas, tópico o caso) y creación de nodos (apartados que permiten recopilar información y buscar por patrones). Se ha codificado automáticamente la información mediante la «codificación automática basada en patrones», luego se vincularon activamente todos los nodos y documentos. A partir de esta tarea, se realizaron consultas para buscar y analizar palabras o frases en los recursos o nodos, enfatizando la frecuencia de aparición en los discursos tratados. Con esto fue posible iniciar la búsqueda de patrones basados en la clasificación, comprobando su congruencia y triangulando con lo observado en el trabajo de campo. Para finalizar, se exploraron los datos a partir de gráficas, modelos u otras técnicas de visualización. Esto sirvió para ayudar a explorar tendencias y probar teorías.

En esta comunicación sólo se presentarán algunos resultados generales obtenidos a partir del tratamiento sistemático de los datos.

\section{RESULTADOS}

\subsection{RELACIÓN ENTRE VERTEBRACIÓN SOCIAL Y PERDURACIÓN DE LOS MUSEOS}

En el caso del Proyecto Comunitario de la Aldea, los aspectos que determinan la cohesión de la comunidad con la perduración del Proyecto se basan en que los implicados colaboran de forma altruista en el mantenimiento de los museos, implicándose incluso familias enteras en el funcionamiento del Proyecto. Esa implicación se debe a diversas motivaciones, desde personales a comunales. Los integrantes del Proyecto miden el éxito del mismo en el ámbito social a través de los reconocimientos que se les ha concedido a todos los niveles, desde el local al internacional.

Los ecomuseos, como en cualquier otro espacio dedicado a la acción cultural, deben contar con la anuencia de la población que lo acoge, ya que se sustentan en la participación activa de esa población. Si no se logra una vertebración objetiva quedará como un relicto destinado a desaparecer con el tiempo. Es también importante la implicación de los visitantes en esos espacios (ver Figura 3).

Raussell Koster (Raussell, P. et al., 2007, 51) señala que el museo ejerce una función de vertebración simbólica del territorio y debe convertirse en protagonista de las políticas culturales de ese territorio y no estar constreñido a 
un mero recipiente o a un espectáculo. Un museo imbricado en un tejido social, transforma la sociedad. En el caso de La Aldea, la comunidad está abierta a sus integrantes, a sus problemas y necesidades, pueden ofertar alternativas y ofertas culturales con cierta continuidad. Esa transformación, en el caso de estudio seleccionado, se refleja en el considerable aumento y sostenimiento que han ocasionado las relaciones sociales en el entorno (cohesión social, encuentros vecinales, viajes comunitarios, actividades diversas, etc.).

Figura 3. Visitantes aprendiendo a descamisar en La Gañanía

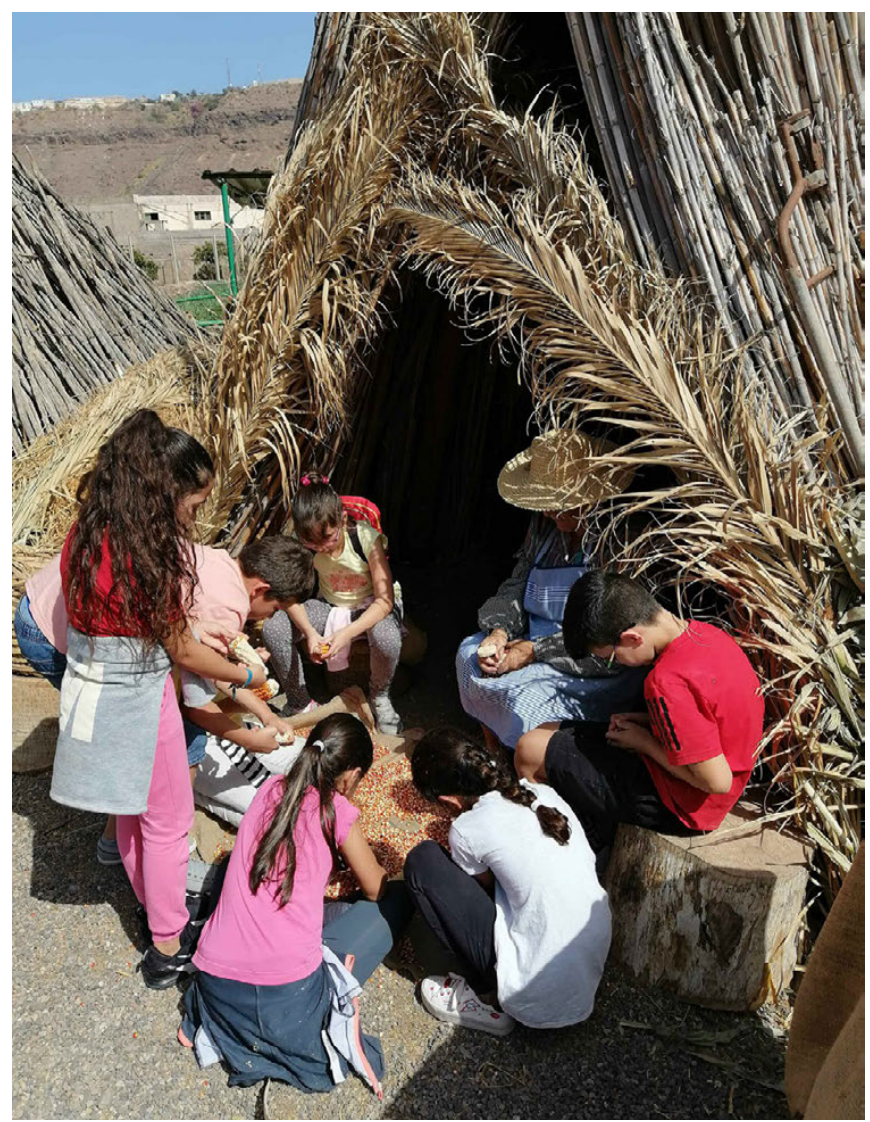

Fuente: Héctor Moreno. 2020

\subsection{MUSEOS ELEMENTOS DINAMIZADORES DE LA ECONOMÍA URBANA}

Los responsables y voluntarios del Proyecto Comunitario creen que se genera economía y visibilización del municipio porque los grupos que los visitan sue- 
len comer en los restaurantes del pueblo, compran productos locales y en ocasiones se quedan en el albergue municipal y en los hoteles del pueblo. Los museos se abren para el Mercadillo Municipal y para cualquier otro evento que solicite su colaboración.

Asimismo, entienden que la función que produce el Proyecto en el entramado urbano del municipio es que le aporta un aspecto extra desde el ámbito cultural.

La observación directa, junto con las conversaciones informales realizadas en el ámbito de estudio, determinan que cuando hay visitas a los museos vivos de La Aldea, se generan una serie de ingresos en el municipio, principalmente ligados a negocios de hostelería, transportes, comercio. Esos ingresos benefician a la agricultura e industria local, ya que muchos productos que consumen los visitantes son producidos en el propio municipio. Cuando hay ferias comerciales o artesanales, congresos, o eventos culturales, los beneficios se multiplican, e incluso los servicios de alojamientos incrementan considerablemente sus ingresos.

\subsection{ECOMUSEOS, NECESIDADES DE LA POBLACIÓN Y ÉXITO PERCIBIDO}

En el Proyecto Comunitario, se establece el éxito social en función de: la aceptación social cuando realizan actos culturales, en el hecho de mantener los museos abiertos sin cobrar nada, en el trabajo continuo a través del tiempo y en cómo la gente mayor del Proyecto acude a los museos como informantes (de algo que ellos años atrás fueron agentes activos). También se considera el trabajo de investigación y grabación de testimonios orales a mayores, en grabaciones de música popular etc.

Desde el Proyecto, consideran que el mismo responde a las necesidades identitarias y económicas de la población local, lo que repercute en el éxito percibido del mismo.

El Museo atiende las necesidades identitarias de la población debido a la vinculación de la memoria colectiva con las actividades expuestas en los museos (ver Figura 4). Muchos voluntarios del Proyecto trabajaron de forma directa en esas actividades. Por otro lado, atiende a necesidades económicas, ya que los voluntarios afirman que tener los museos abiertos genera una atracción constante, y conlleva una actividad económica de visitantes. La gente del pueblo se siente identificada con los museos, comprenden que deben luchar por un turismo cercano, cultural y sostenible donde la información se proporciona de primera mano a través de los mayores. 
Figura 4. Visitantes en el Museo del Pastor

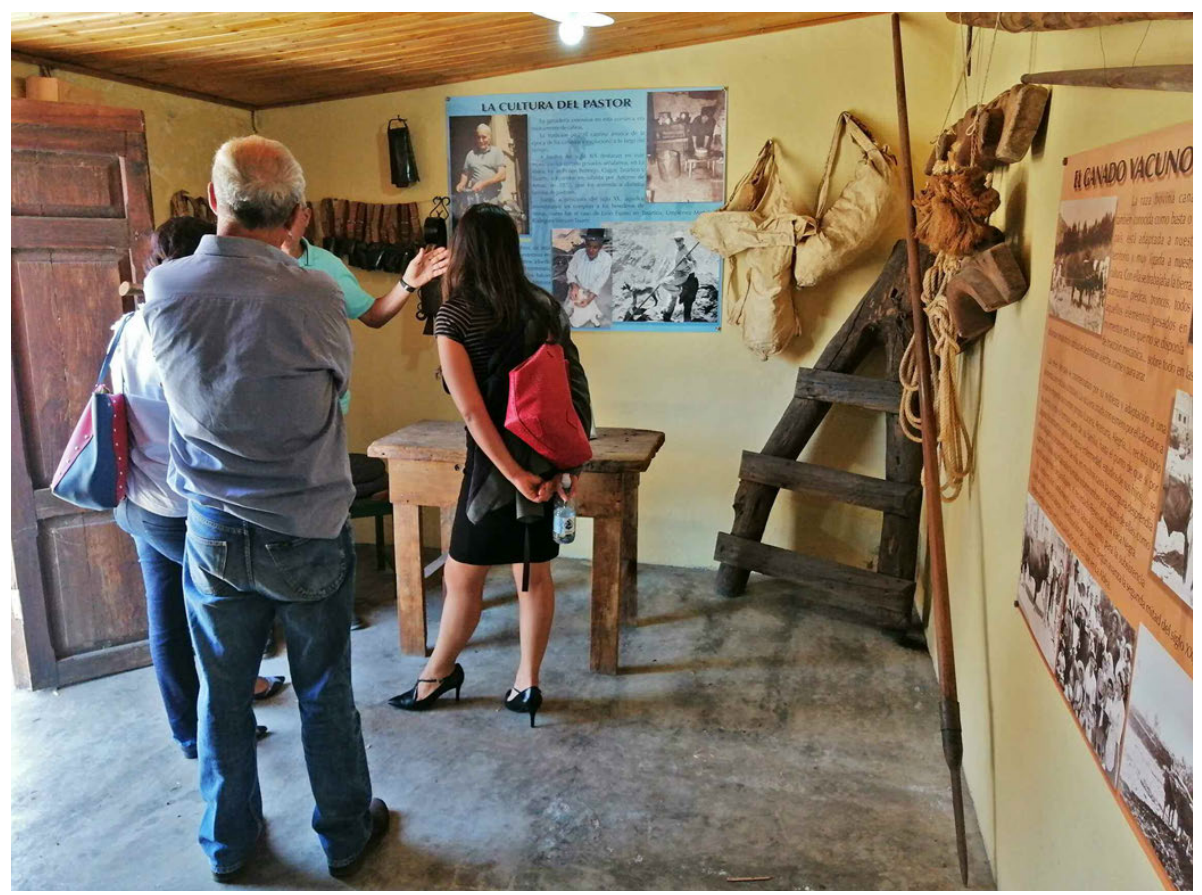

Fuente: Héctor Moreno. 2020

El ecomuseo de La Aldea es testigo de una identidad socio-cultural y por la misma razón sus funciones y actividades tienen mucho de positivo, no sólo en la perduración de formas del pasado, sino también en la creación de acciones para el futuro y para restantes generaciones.

\section{CONCLUSIONES}

Los museos son activos importantes no sólo como centros de difusión cultural y divulgación del patrimonio, sino también como un instrumento para la dinamización social y económica del entorno en el que se inserta.

Tras los resultados obtenidos con las entrevistas, observación directa y conversaciones informales, es posible aseverar el propósito de trabajo planteado al comienzo de esta investigación. Cabe resaltar el grado de éxito social que conlleva la vertebración de la participación ciudadana en la toma de decisiones de los ecomuseos, lo que genera una sinergia socioecónómica en el entramado urbano. Esa unión de acciones incrementa la posibilidad de perduración de un ecomuseo, ya que las diferentes generaciones se van implicando 
y turnando en las responsabilidades del mismo. La existencia de cohesión comunitaria aumenta el beneficio socioeconómico territorial sostenible generado por un museo urbano.

Los resultados de este estudio confirman la aseveración de Jamieson (2005), que considera que mostrar las colecciones en los museos puede tener repercusiones más amplias que un mero conocimiento por parte del público, pero también conlleva relaciones positivas con los descendientes directos de los creadores primigenios. Asimismo, se ratifica la afirmación de Sumadi (2020), que existe un efecto positivo entre las costumbres y tradiciones expuestas en el museo, con la actitud de los visitantes. En el caso de La Aldea, esos objetos no sólo se sacan de las colecciones, sino que las mismas colecciones, entendidas como espacios de trabajo, son reconvertidas en museos, y se establecen relaciones entre los creadores de esos espacios, objetos y saberes populares, con sus descendientes (hijos, nietos o bisnietos), que además son los nuevos encargados de transmitir los conocimientos de ese patrimonio, tanto tangible como intangible, a los visitantes actuales.

\section{AGRADECIMIENTOS}

Agradecemos a los voluntarios del Proyecto Cultural de Desarrollo Comunitario La Aldea por la facilidad y posibilidad que nos han dado para realizar este estudio, especialmente a su director. También al cronista de La Aldea de San Nicolás y a los directores de museos que han participado en la realización de las entrevistas.

\section{BIBLIOGRAFÍA}

Anderson, J. (1982). Living history: Simulating everyday life in living museums. American Quarterly, 34(3), 290-306.

Cabildo de Gran Canaria (2018). http://cabildo.grancanaria.com/la-aldea-desan-nicolas Acceso 8 de mayo de 2020.

Creswell, J. W. (2007). Qualitative Inquiry and Research Design: Choosing Among Five Approaches. California: Sage Publications, International Student Edition.

Gray, D. E. (2014). Doing Research in the Real World. 2nd Ed. London: Sage Publications.

Grewcok, D. (2012). Museums and the city: place, planning and possibilities. En Museum and design disciplines. En M. Ballarin y M. Della Mura (Eds.) Museum and Desing Disciplines, Proceedings of the conference series, pp. 21-32. Venecia: Universidad de Venecia.

Gibbs, G. (2012). El análisis de datos cualitativos en Investigación Cualitativa. Madrid: Ediciones Morata.

Guitart, C. V. (2001). Museos, patrimonio y territorio. Revista Barcelona, 29-31. Barcelona: Diputación de Barcelona. 
Jamieson, C. (2005). Colecciones y Comunidades. Boletín del Consejo Internacional de Museos, vol. 58, $\mathrm{n}^{\circ} 1,8$.

Lanz, F. y Montanari, E. (2014). A Reflection on Innovative Experiences in 21st Century European Museums. Advancing Museum Practices, 10-22. Turín: Allemandi y $\mathrm{C}$.

López, J. S. (Dir.) (2003). Norte de Gran Canaria. Guía de Patrimonio Cultural y Turismo Sostenible. Las Palmas de Gran Canaria: Mancomunidad de Ayuntamientos del Norte de Gran Canaria.

Naumova, A. (2015). «Touching» the Past: Investigating Lived Experiences of Heritage in Living History Museums. International Journal of the Inclusive Museum, 7.

Ognjević, T. (2017). Power of museums lies in diversity. The National Committee magazine, $n^{\circ}$ 7, 6-7. ICOM.

Rausell, P., Abeledo, R., Carrasco, S. y Martínez, J. (2007). Cultura: estrategia para el desarrollo local. Agencia Española de Cooperación Internacional al Desarrollo.

Riviere, G. H. (1985). Definición evolutiva del ecomuseo. Museum, XXXVII, 4, 182-184.

Rosas, M. A. L. (2016). The functions of museums in the construction of urban space: The Paseo del Prado in Madrid. Arte y Ciudad: Revista de Investigación, (10), 129-158.

Sánchez, L. y Suárez, J. P. (2006). Rescatar el Patrimonio intangible: el proyecto comunitario de La Aldea de San Nicolás. Boletín Patrimonio Histórico del Cabildo de Gran Canaria, n 3-4. Las Palmas de Gran Canaria: Cabildo de Gran Canaria.

Sánchez, L. G., Suárez J. P. y Moya, J. (2002). Proyecto comunitario de La Aldea: un compromiso con la cultura popular. Santa Cruz de Tenerife: Gobierno de Canarias.

Sanz, M. G. y Torruella, M. F. (2015). Educación patrimonial e identidad. El papel de los museos en la generación de cohesión social y de vínculos de pertenencia a una comunidad. Clío: History and History Teaching, (41), 15.

Suárez, F. y otros (2005): Guía del patrimonio etnográfico de Gran Canaria. Las Palmas de Gran Canaria: Cabildo de Gran Canaria.

Sumadi, S. (2020). Lifestyle, Religiosity and the Intention of Students in Visiting the Artifacts of Islamic Civilization. Museum. Journal of Environmental Management and Tourism, 11(2), 355-365.

Vinson, I. (2006): Urban life and museums. Museum International. Unesco. Vol. LVIII, n`3 /231, 8.

Visser, J. (2016): Museums in the city of the future. Strategy, thoughts about museums. https://themuseumofthefuture.com/2016/01/28/museums-inthe-city-of-the-future/ Acceso 9 de mayo de 2020.

Yacuzzi, E. (2005). El estudio de caso como metodología de investigación: teoría, mecanismos causales, validación. CEMA Working Papers: Serie Documentos de Trabajo, 296. Buenos Aires: Universidad del CEMA. 
Yin, R. K. (2003). Case study research: design and methods. $3^{\text {a }}$ ed. London: Sage Publications.

Unesco (2011). ¿Qué es el patrimonio cultural inmaterial?

https://ich.unesco.org/es/que-es-el-patrimonio-inmaterial-00003 Acceso 6 de mayo de 2020. 
Tras dos décadas convulsas para la ciudad en España, se están generando nuevos procesos de reconfiguración urbana en un contexto caracterizado, entre otros factores, por la desigualdad y los conflictos sociales, el envejecimiento de la población, las perspectivas de género, el aumento de la movilidad y las migraciones, la problemática ambiental y la despoblación. Un panorama tan dispar, que ahora se vuelve aún más complejo en la actual situación de pandemia, requiere de un análisis sosegado del modelo de ciudad.

En este contexto, el XV Coloquio de Geografía Urbana, celebrado en 2020 en plena crisis sanitaria, ha sido un escenario propicio para ahondar en la comprensión de la situación actual de la ciudad. En este libro se recogen 42 de las aportaciones presentadas en el coloquio procedentes de universidades y centros de investigación de varios países. Los trabajos, agrupados en seis temáticas generales en torno a dinámicas urbanas, cambios sociodemográficos, desigualdad y gentrificación, problemática de la vivienda y desposesión, planificación urbana, movilidad en la ciudad y patrimonio, revelan la complejidad del hecho urbano en España y en algunos países latinoamericanos y la necesidad de su continua interpretación a la luz de las tendencias y transformaciones que se han producido en los últimos años.
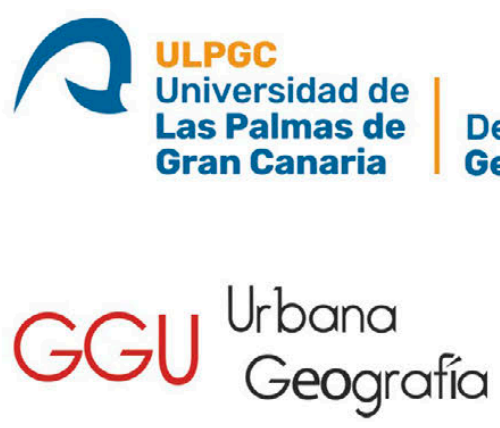

\section{GE URSA}

